\title{
ANAIS DO VI SIMPÓSIO INTERNACIONAL SOBRE GERENCIAMENTO DOS RESÍDUOS AGROPECUÁRIOS E AGROINDUSTRIAIS
}

07 a 09 de maio de 2019

Florianópolis, SC 
Sociedade Brasileira dos Especialistas em Resíduos das Produções Agropecuária e Agroindustrial - Sbera

Empresa Brasileira de Pesquisa Agropecuária

Embrapa Suínos e Aves

Ministério da Agricultura, Pecuária e Abastecimento

\section{Anais do VI Simpósio Internacional sobre Gerenciamento dos Resíduos Agropecuários e Agroindustriais}


Exemplares desta publicação podem ser acessados na:

\author{
Embrapa Suínos e Aves \\ BR 153, Km 110 \\ Caixa Postal 321 \\ CEP 89.700-991 Concórdia, SC \\ Fone: (49) 34410400 \\ Fax: (49) 34410497 \\ www.embrapa.br \\ www.embrapa.br/fale-conosco/sac
}

\section{Unidade responsável pela edição}

Sociedade Brasileira dos Especialistas em Resíduos

das Produções Agropecuária e Agroindustrial - Sbera e

Embrapa Suínos e Aves

\section{Comitê de Publicações}

Presidente: Marcelo Miele

Secretária: Tânia M.B. Celant

Membros: Airton Kunz

Monalisa Leal Pereira

Gustavo J.M.M. de Lima

Ana Paula A. Bastos

Gilberto S. Schmidt

Suplentes: Alexandre Matthiensen

Sabrina C. Duarte

Coordenação editorial: Tânia M. B. Celant

Editoração eletrônica: Vivian Fracasso

Normalização bibliográfica: Claúdia A. Arrieche

Foto da capa: Jairo Backes

\author{
Sociedade Brasileira dos Especialistas em Resíduos \\ das Produções Agropecuária e Agroindustrial - \\ Sbera \\ Concórdia, SC \\ contato@sbera.org.br \\ sigera@sbera.org.br \\ www.sbera.org.br
}

\section{Unidade responsável pelo conteúdo}

Sociedade Brasileira dos Especialistas em Resíduos das

Produções Agropecuária e Agroindustrial - Sbera

\section{Nota}

Os artigos publicados são de inteira responsabilidade de seus autores. As opiniões neles contidas não representam, necessariamente, a visão da Embrapa Suínos e Aves. A revisão ortográfica e gramatical dos artigos é de inteira responsabilidade dos respectivos autores.

\section{$1^{\text {a }}$ edição}

Publicação digitalizada (2019)

Todos os direitos reservados.

A reprodução não-autorizada desta publicação, no todo ou em parte, constitui violação dos direitos autorais (Lei nº 9.610).

\section{Dados Internacionais de Catalogação na Publicação (CIP)}

Embrapa Suínos e Aves

Simpósio Internacional sobre Gerenciamento dos Resíduos Agropecuários e

Agroindustriais (6. : 2019 : Florianópolis, SC).

Anais do VI Simpósio Internacional sobre Gerenciamento dos Resíduos Agropecuários e Agroindustriais, Florianópolis, 07 a 09 de maio de 2019.

Concórdia, SC : Sbera : Embrapa, 2019.

$556 \mathrm{p}$.

ISBN 978-85-93823-02-2

1. Energia. 2. Fertilizante. 3. Impacto ambiental. 4. Resíduos. 5. Tratamento. I. Título

CDD 628.7 (21. ed.) 


\title{
Comissão Organizadora
}

\author{
Presidente \\ Marcelo Bortoli
}

Universidade Tecnológica Federal do Paraná

Diretor Científico

Julio Cesar Pascale Palhares

Embrapa Pecuária Sudeste

Diretor Científico de Área (Agricultura)

Rodrigo da Silveira Nicoloso

Embrapa Suínos e Aves

Diretor Científico de Área (Agroindustrial)

Valéria Reginatto Spiller

Universidade de São Paulo

Diretor Científico de Área (Pecuária)

Airton Kunz

Embrapa Suínos e Aves

Secretária

Marina Celant De Prá

Universidade Tecnológica Federal do Paraná

Diretor Comercial

Ricardo Luis Radis Steinmetz

Embrapa Suínos e Aves

\section{Comissão Editorial}

\author{
Julio Cesar Pascale Palhares \\ Marcelo Bortoli \\ Ricardo Luis Radis Steinmetz \\ Tânia Maria Biavatti Celant \\ Vivian Fracasso
}




\section{Comissão Científica}

\begin{tabular}{|c|c|}
\hline Alejandra Herrero & Argentina \\
\hline Alexandre Mathienesen & Brasil \\
\hline Ana Carolina Amorim Orrico & Brasil \\
\hline Airton Kunz & Brasil \\
\hline Ariel Szogi & Estados Unidos da América \\
\hline Augusto H. Gameiro & Brasil \\
\hline Caio de Teves Inacio & Brasil \\
\hline Carlos Alberto Ceretta & Brasil \\
\hline Claudia Cordovil & Portugal \\
\hline Camila Michels & Brasil \\
\hline Cleverson Busso & Brasil \\
\hline Eder da Costa dos Santos & Brasil \\
\hline Edna Bertoncini & Brasil \\
\hline Francisco Salazar & Chile \\
\hline Gladys Vidal & Chile \\
\hline Hugo Moreira Soares & Brasil \\
\hline Jan Venglovsky & Eslováquia \\
\hline Leidiane Mariani & Brasil \\
\hline Liliana del Pilar Castro Molano & Brasil \\
\hline Luis Ferreira & Portugal \\
\hline Julio Cesar P. Palhares & Brasil \\
\hline Marcio Busi & Estados Unidos da América \\
\hline Marcelo Bortoli & Brasil \\
\hline Marcelo Godinho & Brasil \\
\hline Marcelo H. Otenio & Brasil \\
\hline Matias Vanotti & Estados Unidos da América \\
\hline Melissa Paola Mezzari & Estados Unidos da América \\
\hline Paulo Belli Filho & Brasil \\
\hline Paulo Cesar Cassol & Brasil \\
\hline Ricardo L. R. Steinmetz & Brasil \\
\hline Roberto Valencia & México \\
\hline Rodrigo Nicoloso & Brasil \\
\hline Saquib Mukhtar & Estados Unidos da América \\
\hline Suelen Paesi & Brasil \\
\hline Thalita Grauen & Brasil \\
\hline Thiago Edwiges & Brasil \\
\hline Tiago C. Severo & Brasil \\
\hline Vania Elisabete Schneider & Brasil \\
\hline Veronica Charlon & Argentina \\
\hline
\end{tabular}




\section{Apresentação}

O Brasil é um dos maiores produtores de produtos agropecuários e agroindustriais do mundo e tem nessas atividades um de seus pilares de desenvolvimento. Essa condição traz benefícios sociais e econômicos, mas também desafios ambientais, para que o desenvolvimento ocorra considerando a sustentabilidade dos sistemas agroindustriais.

A sustentabilidade insere o correto gerenciamento dos resíduos gerados por esses sistemas, baseando-se nos conhecimentos e tecnologias, o que garantirá produção de alimentos de reconhecido valor ambiental e a tomada de decisões nas dimensões ambiental, social e econômica.

A fim de apresentar, discutir e analisar a ciência presente e visualizar os desafios futuros a Sbera tem o prazer de realizar o VI Simpósio Internacional sobre Gerenciamento dos Resíduos Agropecuários e Agroindustriais - VI Sigera. Nesta edição o tema do evento será Biotecnologia aplicada ao tratamento e reuso dos resíduos.

No ano de 2019 o evento completa uma década de história. Pesquisadores, estudantes e profissionais nacionais e internacionais já tem o evento como parte de sua agenda. O Sigera é único evento com essa temática na América Latina e um dos maiores do mundo que tem como foco o gerenciamento dos resíduos agropecuários e agroindustriais.

Reuniões científicas são fundamentais para capilarização e partilha de conhecimentos, construção de parcerias de pesquisa e fomento a entrada de novos pesquisadores em temáticas de trabalho. Estas apresentam como resultado, não só o avanço da ciência e a internalização da importância desta para o desenvolvimento do país e para melhoria da qualidade de vida da sociedade, mas também, subsídios as políticas e ações de Estado e da iniciativa privada. 


\section{Sumário}

TECNOLOGIAS DE TRATAMENTO DE RESÍDUOS - AGROINDÚSTRIA

AVALIAÇÃO DO USO DE ULTRASSOM PARA A REMOÇÃO DE CROMO EM COURO WET BLUE: UMA ESTRATÉGIA INOVADORA PARA A REUTILIZAÇÃO DE RESÍDUOS DE CURTUME .

Bizzi, C.A.; Santos, D.; Giacobe, K.; Mello, P.A.; Zanatta, R.C.; Dallago, R.M.; Flores, E.M.M.

CINÉTICA DA DEGRADAÇÃO ANAERÓBIA DO EFLUENTE DE PROCESSAMENTO DA ACEROLA VERDE EM BATELADA

André, A.C.L.; Silva, K.C.D.; Silva, R.T.; Silva, P.T.S.; Silva, T.F.; Amorim, M.C.C.

DESASSOREAMENTO DE LAGOAS DE TRATAMENTO DE EFLUENTES VIA DESNITRIFICAÇÃO.. .25

Mutchamua, H.H.G.; Di Luccio, M.; Hollas, C.E.; Venturin, B.; Treichel, H.; Kunz, A.

PRODUÇÃO DE METANO FRENTE A VARIAÇÃO DO TEOR NUTRICIONAL DE UM REBANHO LEITEIRO..

Assunção, G.P.; Santos, A.M.; Barrado. C.M.; Figueiredo, A.T.

PRODUCTION AND CHARACTERIZATION OF AÇAÍ WASTE BIOCHAR THROUGH GASIFICATION PROCESS

Pessôa, T.S.; Nascimento, B.F.; Martins, L.; Fraga, T.J.M.; Silva, F.L.H.; da Motta Sobrinho, M.A.

PROPOSTA DE UM SISTEMA DE COGERAÇÃO DE ENERGIA UTILIZANDO TECNOLOGIA ACESSÍVEL E DE BAIXO CUSTO

Leite, S.A.F.; Leite, B.S.; D'Angelo, J.V. H.; Dell'Isola, A.T.P.

THE EMPLOYMENT OF AÇAI WASTE BIOCHAR AS AN ECOFRIENDLY ADSORBENT OF METHYLENE BLUE - KINETIC AND EQUILIBRIUM EVALUATION.

Pessôa, T.S.; da Silva, M.P.; Lima Ferreira, L.E.M.; Fraga, T.J.M.; Cavalcanti, J.V.; da Motta Sobrinho, M.A.

TRATAMENTO DE RESÍDUOS SÓLIDOS VIA VERMICOMPOSTAGEM VISANDO A OBTENÇÃO DE BIOPRODUTOS EMPREGADOS NA RECUPERAÇÃO DE SOLOS

Almeida, A.C.O. de; Furtado, I.F.S.P.C.; Vélez, A.M.

TREATMENT OF VITICULTURE WASTEWATER IN THE SÃO FRANCISCO VALLEY USING BIOCOAGULANTS .

Oliveira, A.F.G.; Nascimento, A.C.S.; Pereira, E.C.; Sá, J.I.F.; Barbosa, M.L.; Amorim, M.C.C.

ÁCIDOS CARBOXÍlICOS NA COMPOSTAGEM DE RESÍDUOS ORGÂNICOS DE AVES DE CORTE E GLICERINA BRUTA.

Aloisio, C.M.; Santos, F.T.; Fehmberger, C.; Bautitz, I.R.; Hermes, E.

ADSORÇÃO DE DICLOFENACO DE SÓDIO EM SOLUÇÃO AQUOSA EMPREGANDO BAGAÇO DE MALTE

Reis, M.A.; Diel, J.C.; Chiquim, M.S.; Bender, T.J.; Nunes, I. dos S.

AVALIAÇÃO DA HIDRÓLISE ÁCIDA DE CELULOSE ASSISTIDA POR ULTRASSOM PARA OBTENÇÃO

DE FURFURAL

Bizzi, C.A.; Santos, D.; Giacobe, K.; Contin, C.N.; Mello, P.A.; Flores, E.M.M.

AVALIAÇÃO DA SUBSTITUIÇÃO PARCIAL DA AREIA PELO RESÍDUO DO CAFÉ NA FABRICAÇÃO DE CONCRETO

Almeida, A.C.; Gonçalvez, J.V.C.; Freitas, B. F.; Carotta, M.S.L.M.; Faria, A.P.C.; Pereira, C.S.S. 
AVALIAÇÃO DO IODETO COMO CATALISADOR DA DECOMPOSIÇÃO RADICALAR DE PERÓXIDO DE HIDROGÊNIO PARA APLICAÇÃO NA DEGRADAÇÃO DO AZUL DE METILENO

Miotto, N.; Dallago, R.M.; Mignoni, M.L.; Venquiaruto, L.; Mores, R.; Zamadei, R.V.; Olkoski, L.; Michelon, W.

BAGAÇO DE UVA COMO ALTERNATIVA PARA ADSORÇÃO DE DICLOFENACO DE SÓDIO EM SOLUÇÃO AQUOSA

Reis, M.A.; Diel, J.C.; Chiquim, M.S.; Bender, T.J.; Cruz, W. de A.; Nunes, I. dos S.

BIOSSORÇÃO DE SELÊNIO EM MEIO AQUOSO POR BIOMASSA SECA E ÚMIDA DE EFLUENTE DE INDÚSTRIA CERVEJEIRA

Hackbarth, H.G.; Gonçalves, A.; Wisbeck, E.; Souza, O.

CARACTERIZAÇÃO FÍSICO-QUÍMICA DE COMPOSTO PRODUZIDO COM FARINHA DE ANIMAIS MORTOS

Guidoni, L.L.C.; Martins, G.A.; Sousa, A.R.; Oliveira, V.F.; Corrêa, L.B.; Corrêa, E.K.

COMPOSTAGEM AUTOMATIZADA DE RESÍDUOS DA AGROINDÚSTRIA FRIGORÍFICA

Cantú, R.R.; Schallenberger, E.; Morales, R.G.F.; Visconti, A.; Squerzzato, N.; Misfeld, A.G.

DEGRADAÇÃO DE PENAS DE FRANGOS DE CORTE POR QUERATINASES PRODUZIDAS A PARTIR DE UM FUNGO AUTÓCTONE ISOLADO NO SUL DO BRASIL

Preczeski, K.; Czapela, F.; Kubeneck, S.; Dalastra, C.; Fongaro, G.; Treichel, H.

DINÂMICA DOS COMPOSTOS DE ODOR EM SISTEMAS BASEADOS EM MICROALGAS

Vilas Boas, W.H.; Vieira, K.R.; Pinheiro, P.N.; Wagner, R.; Jacob-Lopes, E.; Zepka, L.Q.

EFEITO DE DIFERENTES PRÉ-TRATAMENTOS NA CINÉTICA DE PRODUÇÃO DE METANO DE CAMA DE FRANGO

Gaspareto, T.C.; Steinmetz, R.L.R.; Goldschmit, F.A.; Venturin, B.; Treichel, H.; Kunz, A.

EFEITO DO PH E DA RAZÃO CARBONO/NITROGÊNIO NO CULTIVO DE PHORMIDIUM AUTUMNALE EM VINHAÇA

Visentin, T.G.; Guimarães, B.M.; Bastos, R.G.

EFEITO DOS METAIS SOBRE OS PRODUTOS DE FERMENTAÇÃO DE GLICEROL

Barbosa, C.G.; Mermejo, B.C.; Fonseca, B.C.; Reginatto, V.

ELETROCOAGULAÇÃO DE VINHAÇA DE CANA-DE-AÇÚCAR: DESEMPENHO, CUSTO E SEDIMENTAÇÃO DO LODO GERADO.

Montaño, M.D.S.; Bastos, R.G.; Cardenas, V.O.C.

ESTUDO DA REMOÇÃO DO CORANTE VERMELHO REATIVO POR BIOSSORÇÃO COM SABUGO DE MILHO

Oliveira, A.P.; Hellmann, L.; Antoniolli, C.A.; Gressele, A.; Bernabé, B.A.; Gusmão, A.G.

ESTUDO DA REMOÇÃO DO FÁRMACO CLORIDRATO DE METFORMINA POR ADSORÇÃO UTILIZANDO CARVÃO ATIVADO DE CASCA DE COCO DE DENDÊ

Oliveira, A.P.; Hellmann, L.; Módenes, A.N.; Antoniolli, C.A.; Bernabé, B.A.; Gusmão, A.G.

ESTUDO DA UTILIZAÇÃO DE BAGAÇO DE CANA-DE-AÇÚCAR COMO ADSORVENTE DE VIOLETA CRISTAL

Reis, M.A.; Diel, J.C.; Chiquim, M.S.; Bender, T.J.; Fernandes, D.M.; Nunes, I. dos S.

ESTUDO SOBRE BISFENOL A - TRATAMENTO ENZIMÁTICO E REDUÇÃO DA TOXICIDADE 125

Costenaro, B.S.; Perassa, M.O.; Alano, C.G.; Rampinelli, J.R.; Bonatti-Chaves, M.; Furlan, S.A. 
EVALUATION OF THE PRETREATMENT OF CORN STALK USING AN ULTRASOUND SYSTEM

Venturin, B.; Mulinari, J.; Scapini, T.; Camargo, A.F.; Kunz, A.; Treichel, H.

FITOTOXICIDADE DE COMPOSTOS ORGÂNICOS OBTIDOS DE RESÍDUOS AVÍCOLAS ASSOCIADOS A GLICERINA BRUTA.

Santos, F.T.; Franciozi, S.A.; Fehmberger, C.; Aloisio, C.M.; Bautitz, I.R.; Hermes, E.

GLICEROL COMO SUBSTRATO PARA A PRODUÇÃO DE 1,3 PROPANODIOL POR CLOSTRIDIUM BEIJERINCKII

Mermejo, B.C.; Prata, G.P.; Fonseca, B.C.; Reginatto, V.

INFLUÊNCIA DO MEIO DE CULTIVO E DO PH NA PRODUÇÃO DE HIDROGÊNIO A PARTIR DE GLICEROL

Prata, P.G.; Mermejo, B.C.; Fonseca, B.C.; Reginatto, V.

POTENCIAL LIPOLÍTICO DE BACTÉRIAS ISOLADAS DE EFLUENTE DE ABATEDOURO BOVINO . .145

Haselroth, K.J.; Costa, I.M.D.; Wilke, P.; Hermes, E.

PRÉ-TRATAMENTO DE PELOS DE SUÍNO PARA APLICAÇÃO NO PROCESSO DE DESCOLORAÇÃO DE EFLUENTES TÊXTEIS

de Paris Junior, O.; Scapini, T.; Frumi Camargo, A.; Stefanski, F.S.; Fongaro, G.; Treichel, H.

PRODUÇÃO DE BIOCOMPÓSITOS FÚNGICOS A PARTIR DE BAGAÇO DE MALTE E PLEUROTUS SAJOR-CAJU

Deschamps, J.L.N.; Marschall, E.; Medeiros, N.V.; Riani, J.C.; Gern, R.M.M.; Wisbeck, E.

PRODUCTION OF MAYENITE $\left(\mathrm{Ca}_{12} \mathrm{Al}_{14} \mathrm{O}_{33}\right)$ USING EGGSHELL WASTE AS CALCIUM SOURCE.

Manera, C.; Perondi, D.; Didomenico, E.; Barcellos, T.; Godinho, M.

PRODUÇÃO DE SULFETO BIOGÊNICO PARA TRATAMENTO DE EFLUENTES RICOS EM METAIS 161

Rodrigues, M.H.R.; Mermejo, B.; dos Santos, D.V; Fonseca, B.C; Reginatto, V.

REMOÇÃO DE CARBONO E NITROGÊNIO DA VINHAÇA POR DESMODESMUS SUBSPICATUS IMOBILIZADAS EM PECTINA

Jesus, G.C.; Visentin, T.G.; Bastos, R.G.; Silva, M.A.

SÍNTESE VERDE DE NANOPARTÍCULAS DE PRATA A PARTIR DO EXTRATO DO BAGAÇO DE UVA BORDÔ.

Raota, C.S.; da Silva, T.B.; Giovanela, M.

UTILIZAÇÃO DE SERRAGEM DE PINUS ELLIOTTI DA INDÚSTRIA MOVELEIRA PARA O TRATAMENTO DE EFLUENTES TÊXTEIS.

Bortoluz, J.; Giovanela, M.

UTILIZAÇÃO DO BAGAÇO DE JABUTICABA (MYRCIARIA CAULIFLORA) PARA EXTRAÇÃO DE COMPOSTOS FENÓLICOS.

Liberalesso, L.O.; Leidens, N.

PHOSPHORUS PRECIPITATON ALTERNATIVES WHEN APPLYING ANAMMOX-BASED PROCESSES TO ANAEROBIC DIGESTER DEWATERING CENTRATES

Magrí, A.; Johansson, S.; Balaguer, M.D.; Ruscalleda, M.; Puig, S.; Colprim, J.

ESTUDO DO EFEITO DOS INIBIDORES EM ENSAIOS DE FERMENTAÇÃO COM CLOSTRIDIUM BEIJERINCKII

Fonseca, B.C.; Reginatto, V. 
TECNOLOGIAS DE TRATAMENTO DE RESÍDUOS - PECUÁRIA

WINDROW COMPOSTING AS STRATEGY TO RECYCLE ORGANIC WASTES FROM AQUACULTURE..191

Lopes, I.G.; Souza, L.F.; Cruz, M.C.P.; Vidotti, R.M.

EFFECT OF NITROGEN LOADING RATE ON DIGESTATE TREATMENT BY DEAMMONIFICATION PROCESS

Chini, A.; Hollas, C.E.; Bolsan, A.C.; Antes, F.G.; Treichel, H.; Kunz, A.

ESTUDO DA CORRELAÇÃO ENTRE TEMPERATURAS E A REMOÇÃO DA MATÉRIA ORGÂNICA EM BIODIGESTORES.

Sousa, I.P.; Rosa, A.P.; Souza, S.M.; Oliveira, N.S.; Magos, B.R.; Perez, R.

ESTUDO DAS CONDIÇÕES E VARIÁVEIS DE INFLUÊNCIA EM BIODIGESTORES MODELO CANADENSE.

Sousa, I.P.; Rosa, A.P.; Lopes, J.O.; Magos, B.R.; Perez, R.

EXPLORING THE BACTERIOSTATIC POTENTIAL OF MICROALGAE AGAINST PATHOGENIC MULTIDRUG RESISTANT BACTERIA.

Michelon, W.; Dinnebier, H.C.F.; Da Silva, M.L.B.; Matthiensen, A.; Soares, H.M.

EXTRACTION OF PHOSPHORUS AND AMINO ACIDS FROM MANURE AND ALGAE .210

Vanotti, M.B.; Szogi, A.A.

FORMATION AND STABILITY OF AEROBIC GRANULAR BIOMASS IN A CONTINUOUS-FLOW BIOREACTOR

Cofré, C.; Franchi, O.; Campos, J.L.; Valenzuela, D.; Pavissich, J.P.; Camus, N.; Belmont, M.; Pedrouso, A.; Carrera, P.;

Val del Río, A.; Mosquera-Corral, A.

MICROALGAE OBTAINED FROM SWINE WASTEWATER TREATMENT AS SOURCE OF AMINOACIDS AND OMEGA-3

Michelon, W.; Dinnebier, H.C.F.; Da Silva, M.L.B.; Matthiensen, A.; Soares, H.M.

QUICK START-UP OF DEAMMONIFICATION PROCESS USING NITRAMMOX ${ }^{\circledR}$ REACTOR. .222

Bonassa, G.B.; Prá, M.C.; Antes, F.G.; Bolsan, A.C.; Kunz, A.

RECOVERY OF PHOSPHATES FROM SWINE LAGOON SLUDGE USING QUICK WASH PROCESS AND GEOTEXTILE FILTRATION

Szogi, A.A.; Vanotti, M.B.; Shumaker, P.D.

RECUPERAÇÃO DE NUTRIENTES DO EFLUENTE DE UM BIODIGESTOR RURAL: ESTERCO BOVINO COMO ESTUDO DE CASO

Mantilla, L.; Jaimes-Estévez, J.; Castro, L., Escalante, H.

TRATAMIENTO DE AGUAS RESIDUALES DE GRANJAS PORCINAS BASADA EN EXPERIENCIAS DESARROLLADAS EN MÉXICO Y CHILE

Giácoman-Vallejos, G.; Ponce-Caballero, C.; Vidal, G.

A PERDA DE N DURANTE A COMPOSTAGEM EM PILHAS ESTÁTICAS É INFLUENCIADA PELA AERAÇÃO?

Orrico, A.C.A.; Vilela, R.N.S.; Santos, W.; Dias, A.M.D.F.; Macena, I.A.; Machado, J.F.

ALKALINITY CHANGING DURING NITROGEN REMOVAL IN A MLE REACTOR AT HIGH TSS CONCENTRATION .

Hollas, C.H.; Chini, A.; Bolsan, A.; Goldschmidt, F.A.; Kunz, A. 
ANAMMOX-BASED TREATMENT OF ANAEROBICALLY DIGESTED SEWAGE SLUDGE DEWATERING CENTRATE: FROM INOCULUM ENRICHMENT AND CULTURE TO PROCESS CONFIGURATIONS AND EMISSIONS

Magrí, A.; Connan, R.; Dabert, P.; Bridoux, G.; Béline, F.

CARACTERIZAÇÃO QUÍMICA DO DIGESTATO DE BOVINO EM DIFERENTES TEMPOS DE RETENÇÃO HIDRÁULICA..

Matos, C.F.; Silva, R.M.; Oliveira, R.S.; Pinheiro, E.F.M.; Leal, M.A.A.; Stafanato, J.B.

COMPOSTAGEM DE RESÍDUOS DA CADEIA AVÍCOLA: CONFORMIDADE COM PARÂMETROS DA IN $\mathrm{N}^{\circ} 25 / 2009 / \mathrm{MAPA}$

Santos, F.T.; Aloisio, C.M.; Fehmberger, C.; Zenatti, D.C.; Hermes, E.; Bautitz, I.R.

CORRELAÇÕES ENTRE PARÂMETROS DA CO-DIGESTÃO ANAERÓBIA DE GLICERINAS COM DEJETO DE GALINHAS POEDEIRAS.

Schwingel, A.W.; Orrico, A.C.A.; Leite, B.V.; Macena, I.A.; Dias, A.M.D.F.; Machado, J.F.

DESEMPENHO DA MARAVALHA E CARVÃO COMO FILTRO NO TRATAMENTO DE ÁGUAS RESIDUÁRIAS

Pires, C.S.; Oliveira, R.S.; Santos Junior, A.J.; Moraes, A.S.; Andrade, A.M.; Pinheiro, E.F.M.

DESIDRATAÇÃO DE RESÍDUOS DE PEIXES COMO FORMA DE AGREGAÇÃO DE VALOR E SUSTENTABILIDADE AMBIENTAL

Teodoro, J.C.; Krabbe, E.L.; Ávila, V.S.; Costa, A.P.G.C.; Bezerra, N.S.; Vinhaga, C.

DETERMINAÇÃO DE COMPOSTOS VOLÁTEIS MICROALGAIS COM POTENCIAL DE APLICAÇÃO INDUSTRIAL

Oliveira, A.S.; Vieira, K.R.; Pinheiro, P.N.; Wagner, R.; Jacob-Lopes, E.; Zepka, L.Q.

EFEITO DA TETRACICLINA SOBRE A ATIVIDADE DE BACTÉRIAS NITRIFICANTES

Langbehn, R.K.; Michels, C.; Soares, H.M.

REMOÇÃO DE COMPOSTOS ORGÂNICOS HIDROFÓBICOS DE ÁGUA RESIDUÁRIA UTILIZANDO A MICROALGA, PHORMIDIUM AUTUMNALE

Lasta, P.; Vieira, K.R.; Pinheiro, P.N.; Wagner, R.; Jacob-Lopes, E.; Zepka, L.Q.

VERMICOMPOSTING AS AN ALTERNATIVE WAS TO TREAT CATTLE MANURE AND CORN SILAGE WASTE

Tavares, A.; Minikowski, A.; Edwiges, T.

PRODUÇÃO DE ENERGIA A PARTIR DE RESÍDUOS

ANÁLISE ECONÔMICA PRELIMINAR DA PRODUÇÃO DE BIOETANOL DE RESÍDUOS VEGETAIS DA BANANICULTURA

Uchôa, P.Z.; Porto, R.C.T.; Marangoni, C.; Souza, O.

AVALIAÇÃO DA HIDRÓLISE ÁCIDA DE RESÍDUOS LIGNOCELULÓSICOS ASSISTIDA POR MICROONDAS PARA OBTENÇÃO DE PLATAFORMAS FURÂNICAS

Santos, D.; Bizzi, C.A.; Silva, C.M.; Wohlmann, W.; Mello, P.A.; Flores, E.M.M.

DESAFIOS E OPORTUNIDADES DA GERAÇÃO DISTRIBUÍDA A PARTIR DO BIOGÁS . 
ENRIQUECIMENTO DE CONSÓRCIO ELETROATIVO PARA UTILIZAÇÃO EM CÉLULAS A COMBUSTIIVEL MICROBIANAS .

Mancilio, L.B.K.; Silva, L.A.; Guazzaroni, M.E.; Santana, F.B.; De Andrade, A.R.; Reginatto, V.

FERMENTAÇÃO EM MICROAROBIOSE POR LEVEDURAS ISOLADAS DE BAGAÇO E PALHA DE MILHO ...

Baptista, C.W.; Milani, L.M.; Adorno, L.R.; Mibielli, G.M.; Müller, C.; Alves, S.L.Jr.

O QUE OCORREU COM OS PROJETOS DE MECANISMO DE DESENVOLVIMENTO LIMPO DA SUINOCULTURA NO BRASIL?

Mariani, L.; Mito, J.Y.L.; Stilpen, M.R.; Steinmetz, R.; Marques, F.S.; Cavaliero, C.K.N.

POTENCIAL BIOQUÍMICO DE METANO DE CAMA DE PERU

Cé, A.; Bortoli, M.; Steinmetz, R.L.R.; Venturin, B.; Tápparo, D.C.; Kunz, A.

PRÉ-TRATAMENTO DE BIOMASSA RESIDUAL DO PROCESSAMENTO DE AÇAÍ (EUTERPE OLERACEA) E SEU EFEITO NA PRODUÇÃO DE METANO .

Lima, A.C.P.; Gutarra, M.L.E.; Cammarota, M.C.

PRODUÇÃO BIOLÓGICA DE $\mathrm{H}_{2}$ UTILIZANDO VINHAÇA CÍTRICULA COMO SUBSTRATO

Pachiega, R.; Maintinguer, S.I.

PRODUZINDO BIOGÁS COM O SISTEMA ESPECIALIZADO OPUS.DIG

Cé, A.; Reinaldo, F.; Bortoli, M.; Staub, C.P.P.; Steinmetz, R.L.R.; Kunz, A.

USO DO PLASMA NÃO TÉRMICO PARA A DESLIGNIFICAÇÃO DO BAGAÇO DA CANA DE AÇÚCAR VISANDO À PRODUÇÃO DE BIOETANOL

Silva, B.M.; Sander, A.K.; Cubas, A.L.V.; Moecke, E.H.S.

ADIÇÃO FRACIONADA DE HIDROLISADO DE BAGAÇO DE MANDIOCA NA DIGESTÃO ANAERÓBIA

DA MANIPUEIRA

Da Silva, A.F.M.; Bautitz, I.R.; Aguiar, E.G.P.; Hermes, E.; Zenatti, D.C.

ANÁLISE DA TOLERÂNCIA DE UMA NOVA LINHAGEM DE CANDIDA PSEUDOINTERMEDIA A INIBIDORES DE FERMENTAÇÃO PRESENTES EM HIDROLISADOS LIGNOCELULÓSICOS

Giehl, A.; Deoti, L.; Lucaroni, A.C.; Baptista, C.W.; Treichel, H.; Alves, S.L. Jr.

AVALIAÇÃO DA ATIVIDADE METANOGÊNICA ESPECÍFICA DE LODOS ANAERÓBIOS DISTINTOS VISANDO A PRODUÇÃO DE BIOGÁS

Almeida, R.; Marana, K.B.B.; Toneli, J.T.C.

AVALIAÇÃO DO DIGESTATO RESULTANTE DA CODIGESTÃO DE EFLUENTES BOVINO E SUÍNO COM SORO DE LEITE

Thomas, N.; Marteres, T.J.; Somer, J.G.; Estevam, F.N.L.; Mito, J.Y.L.; Carvalho, E.L.

CARACTERIZAÇÃO DE DIFERENTES CASCAS DE FRUTAS (LARANJA, LIMA, LIMÃO E BERGAMOTA) PARA FINS ENERGÉTICOS.

Perondi, D.; Manera, C.; Bassanesi, G.R.; Zancanaro, D.A.; Godinho, M.; Zattera, A.J.

COMPARISON OF THE BIOCHEMICAL METHANE POTENTIAL OF DIFFERENT ORGANIC BIOMASS ..349

Tavares, A.; Ziglioli, E.; Remor, P.; Cavaler, J.; Alino, J.; Edwiges, T.

CONSTRUÇÃO DE UM BIODIGESTOR PARA A PRODUÇÃO DE BIOGÁS A PARTIR DE DEJETOS BOVINOS

Silva, L.F.S.; Leidens, N.; Nunes, I.S.; Neto, E.R. 
DETERMINAÇÃO DO PODER CALORÍFICO EXPERIMENTAL DO RESÍDUO DE DESPOLPAMENTO DA FRUTA MARACUJÁ

Souza, A.L.B.; Marana, K.B.B.; Rodrigues, D.S.; Colato, G.A.; Toneli, J.T.C.L.

DYNAMICS OF CARBON DIOXIDE CAPTURE AND EMISSION IN AN INTEGRATED BIOPROCESS ........361

Severo, I.A.; Lasta, P.; Pujol, S.B.; Bizello, R.S.; Zepka, L.Q.; Jacob-Lopes, E. …………………………………....361

ENSAIOS CINÉTICOS DE FERMENTAÇÃO DE XILOSE POR DIFERENTES CEPAS DE CLOSTRIDIUM....365

Fonseca, B.C.; Reginatto, V.

ESTUDO DO POTENCIAL ENERGÉTICO DO BIOGÁS EM SUINOCULTURAS NO VALE DO PIRANGA MG

Sousa, I.P.; Rosa, A.P.; Oliveira, N.S.; Lopes, J.O.; Ferreira. F.L.V., Perez, R.

IMPLANTAÇÃO DE UM BIODIGESTOR DE BAIXO CUSTO PARA PROCESSAR DEJETOS DE GADO LEITEIRO.

Pereira, G.S.; Paim, J.V.; Madruga, K.C.R.; Virmond, E.

OBTENÇÃO DE BIOPRODUTOS POR CEPAS DE CLOSTRIDIUM BEIJERINCKII A PARTIR DE GLICOSE

E XILOSE

Bortolucci, J.; Fonseca, B.C.; Reginatto, V.

PROCESS PERFOMANCE OF SWINE CARCASS AND MANURE CO-DIGESTION IN COMPARING OF MANURE MONO-DIGESTION: IMPACT OF ORGANIC LOADING RATE.

Tápparo, D.C.; Steinmetz, R.L.R.; Amaral, A.C.; Gasparetto, T.C.; Cé, A.; Kunz, A.

PRODUÇÃO BIOLÓGICA DE $\mathrm{H}_{2}$ UTILIZANDO RESÍDUO CITRÍCOLA

Silva, D. C.; Maintinguer, S.I.

PRODUÇÃO DE BIOETANOL DE RESÍDUOS DA BANANICULTURA POR MONO E COCULTURA MICROBIANA

Uchôa, P.Z.; Sellin, N.; Souza, O.

PRODUÇÃO DE BIOGÁS A PARTIR DE DEJETOS DE VACA LEITEIRA UTILIZANDO CINZA DE CASCA DE ARROZ COMO CATALISADOR

Batti, J.C.B.; Geremias, R.; Antônio, R.V.

PRODUÇÃO DE BIOGÁS DE EFLUENTE DE SUINOCULTURA E SORO DE LEITE EM CONDIÇÕES MESOFÍLICAS.

Lins, L.P.; Mito, J.Y.L.; Pinheiro, B.C.; Freddo, A.

PRODUÇÃO DE BIOGÁS E ENERGIA ELÉTRICA COM BIODIGESTOR DE LAGOA COBERTA E CSTR A PARTIR DE DEJETO SUÍNO

Amaral, A.C.; Candido, D.; Steinmetz, R.L.R.; Tapparo, D.C.; Kunz, A.

PRODUÇÃO DE BIOGÁS EM SISTEMAS DE PRODUÇÃO DE LEITE DE BOVINOS, COM E SEM SEPARAÇÃO DE SÓLIDOS NOS SUBSTRATOS EM BIODIGESTORES CONTINUOS

Isisanjos, I.S.; Toneli, J.C.L.; Sagula, A.L.; Lucas, J.

PRODUÇÃO DE ETANOL 2G POR MEYEROZYMA CARIBBICA EM HIDROLISADO DE CAULE E PALHA DE MILHO

Tadioto, V.; Barrilli, E.T.; Bohn, L.R.; Dresch, A.P.; Baptista, C.W.; Alves, S.L. Jr. 
PRODUÇÃO DE ETANOL UTILIZANDO HIDROLISADO DE BAGAÇO DE CANA-DE-AÇÚCAR EM BIORREATOR

Bonatto, C.; Venturin, B.; Alves, S.L. Jr.; Bazoti, S.F.; Treichel, H.

PRODUÇÃO DE METANO A PARTIR DA BIOMASSA RESIDUAL DO PROCESSAMENTO DE AÇAÍ (EUTERPE OLERACEA)

Lima, A.C.P.; Gutarra, M.L.E.; Cammarota, M.C.

USO DO NARIZ ELETRÔNICO PARA PRODUÇÃO DE BIODIESEL A PARTIR DE ÓLEO E GORDURA RESIDUAL (OGR)

Vidigal, I.G.; Batista, P.S.; Siqueira, A.F.; Giordani, D.S.; Ferreira, A.L.G.

USO DOS RESÍDUOS COMO FERTILIZANTE

AVALIAÇÃO DE PÓ DE ROCHA DE ARDÓSIA ASSOCIADO AO COMPOSTO DE RESÍDUDOS DA AGROINDUSTRIA FRIGORÍFICA NO CULTIVO DE ALFACE

Schallenberger, E.; Cantú, R.R.; Morales, R.G.F.; Visconti, A.; Vale, M.L.C.; Ceccon, A.P.

EFEITO DA APLICAÇÃO DE DEJETOS SUÍNOS NO ESTOQUE DE CARBONO ORGÂNICO DO SOLO .....429

Medeiros, S.F.; De Paiva Filho, S.V.; Ferreira, R.V.; De Oliveira, C.L.; Brunetta, R.F.; Tavares, R.L.

ÓXIDO DE MAGNÉSIO AUMENTA A DUREZA E EFICIÊNCIA AGRONÔMICA DE FERTILIZANTES FOSFATADOS

Nascimento, C.O.; Mattos, B.B.; Fialho, R.L.; Cabral-Albuquerque, E.C.M.; Benites, V.M.

TEOR DE CARBONO E DENSIDADE DE UM LATOSSOLO APÓS 15 ANOS DE FERTILIZAÇÃO COM DEJETO LÍQUIDO DE SUÍNO

Cassol, P.C.; Sacomori, W.; Erdmann, L.F.

AVALIAÇÃO DE FERTILIZANTES OBTIDOS EM COMPOSTAGEM AUTOMATIZADA DE RESÍDUOS DE FRIGORÍFICO E DE PORTO GRANELEIRO.

Cantú, R.R.; Schallenberger, E.; Morales, R.G.F.; Visconti, A.; Vale, M.L.C.; Ceccon, A.P.

AVALIAÇÃO DO COMPOSTO DE RESÍDUOS DA AGROINDUSTRIA FRIGORÍFICA NO CULTIVO DE TOMATE EM SISTEMA ORGÂNICO DE PRODUÇÃO

Schallenberger, E.; Cantú, R.R.; Morales, R.G.F.; Visconti, A.; Guimarães, G.G.F.; Padilha, P.R.

EVALUATION OF THE DIGESTATE FROM A REAL-SCALE ANAEROBIC REACTOR AS A BIOFERTILIZER

Ortega, A.; D’avila, L.; Bastos, J.A.; Schmoeller, L.; Somer, J.G.; Edwiges, T.

BIOFERTILIZANTES AERÓBIOS FORMULADOS COM RESIDUOS MARINHOS PROMOVEM O CRESCIMENTO DE PLANTAS DE ALFACE E REDUZEM A SEVERIDADE DE SCLEROTIUM ROLFSII.....452

Visconti, A.; Cantú, R.R.; Morales, R.G.F.; Schallenberger, E.

EFEITO DO COMPOSTO DE RESÍDUOS DA AGROINDÚSTRIA FRIGORÍFICA E DE PORTO GRANELEIRO NA PRODUÇÃO DE PIMENTÃO

Morales, R.G.F.; Cantú, R.R.; Schallenberger, E.; Visconti, A.; Ceccon, A.P.; Squerzzato, N.

EFEITO DO COMPOSTO DE RESÍDUOS DA AGROINDÚSTRIA FRIGORÍFICA NA PRODUÇÃO DE MUDAS DE RÚCULA.

Morales, R.G.F.; Palma, M.S.; Cantú, R.R.; Schallenberger, E.; Visconti, A.; Squerzzato, N. 
QUALIDADE FÍSICA DO SOLO EM ÁREA COM APLICAÇÃO DE DEJETOS SUÍNOS

Paiva Filho, S.V.;Medeiros, S.F.; Ferreira, R.V.; Oliveira, C.L.; Guimarães, A.G.; Tavares, R.L.M.

RESPOSTA INICIAL DO EUCALIPTO APÓS APLICAÇÃO DE DEJETOS LÍQUIDOS DE SUÍNOS NO OESTE DO PARANÁ.

Soares, M.T.S.; Maeda, S.; Bellote, A.F.J.; Andrade, G.C.; Gomes, J.B.V.; Fassina, S.H.

SUBSTRATOS ORGÂNICOS PROVENIENTES DE RESÍDUOS AGROINDUSTRIAIS: PRODUÇÃO DE MUDAS DE RÚCULA...

Poder, J.S.G.; Santos, F.T.; Hermes, E.; Bautitz, I.R.

USO DE BIOFERTILIZANTE COM RESÍDUO MARINHO NA PRODUÇÃO DE MUDAS DE RÚCULA..........476

Morales, R.G.F.; Visconti, A.; Onaka, K.A.; Cantú, R.R.; Schallenberger, E.; Palma, M.S.

VALOR AGRONÔMICO DO COMPOSTO DE RESÍDUOS DA AGROINDÚTRIA FRIGORÍFICA EM CULTIVOS SUCESSIVOS DE ALFACE

Cantú, R.R.; Schallenberger, E.; Morales, R.G.F.; Visconti, A.; Squerzzato, N.; Misfeld, A.G.

A ADUBAÇÃO ORGÂNICA É VIÁVEL PARA REDUZIR AS EMISSÕES DE $\mathrm{N}_{2} \mathrm{O}$ ? .484

Orrico Junior, M.A.P.; Reis, S.D.S.; Cardoso, A.S.; Orrico, A.C.A.; Cunha, S.S.

SISTEMAS DE GESTÃO DE RESÍDUOS

MANEJO DE EMBALAGENS DE AGROTÓXICOS: UMA ANÁLISE DOS RISCOS AOS AGRICULTORES

E AO AMBIENTE.

Stedile, N.L.R.; Schneider, V.E.S.; Carra, S.H.Z.; Peresin, D.

AQUACULTURE WASTE MANAGEMENT BY THE BLACK SOLDIER FLY LARVAE (HERMETIA ILLUCENS): PRELIMINARY RESULTS

Lopes, I.G.; Lalander, C.; Vinnerås, B.

AVALIAÇÃO ECONÔMICA DE TECNOLOGIAS PARA TRATAMENTO DOS RESÍDUOS LÍQUIDOS DA SUINOCULTURA E VALORAÇÃO DOS NUTRIENTES RECICLADOS

Souza, M.V.N. de; Barros, E.C.; Miranda, C.R. de; Sandi, A.J.

NUTRIENT BALANCES IN BEEF PRODUCTION SYSTEMS IN ARGENTINA AND URUGUAY .501

Gil, S.B.; Tieri, M.P.; LaManna, A.F.; Faverín, C.; Herrero, M.A.

NUTRIENT BALANCES IN MILK PRODUCTION SYSTEMS IN ARGENTINA..

Charlón, V.; Herrero, M.A.; Cuatrín, A.

CUSTO DO LICENCIAMENTO AMBIENTAL NA SUINOCULTURA

Pietramale, R.T.R.; Leite, B.K.V.; Castro, I.C.C.; Orrico, A.C.A.; Ruviaro, C.F.

DETERMINAÇÃO DA PRESSÃO AMBIENTAL EM BACIA HIDROGRÁFICA COM PRODUÇÃO INTENSIVA DE SUÍNOS POR MEIO DE FERRAMENTAS DE GEOPROCESSAMENTO

Bernardo, E.L.; Miranda, C.R.; Matthiensen, A.; Belli-Filho, P.

IMPACTO DA NUTRICÃO NO TEOR DE NUTRIENTES DE FEZES E URINA DE VACAS EM LACTAÇÃO

Novelli, T.I.; Morelli, M.; Palhares, J.C.P.

PEGADA HÍDRICA MENSAL DE UM SISTEMA LEITEIRO MISTO. .520

Fcamidu, B.V.; Giusti, G.; Novelli, T.I.; Palhares, J.C.P. 
UTILIZAÇÃO DE PRÁTICAS DE MANEJO DE RESÍDUOS EM PROPRIEDADES LEITEIRAS EM MINAS GERAIS

Palhares, J.C.P.; De Mori, C.; De Carmago, A.C.; Novo, A.L.M.

VALORAÇÃO ECONÔMICA DOS DEJETOS DA FASE DE CONFINAMENTO DE UM SISTEMA DE PRODUÇÃO DE LEITE

Silva, M.F.; Palhares, J.C.P.; Gameiro, A.H.

IMPACTOS DOS RESÍDUOS NOS SISTEMAS ÁGUA-SOLO-AR E PLANTA 532

ANÁLISE DA PRESENÇA DE AGROTÓXICOS EM UMA BACIA DE CAPTAÇÃO DE ÁGUA BRUTA .533

Schneider, V.E.; Menegat, D., Carra, S.H.Z., Peresin, D.

ARTROPODOFAUNA EM FLORESTAS IRRIGADAS COM EFLUENTE DE ABATEDOURO DE AVES .538

Vargas, R.J.; Araujo, I.R.C.; Morais, J.; Figueiredo, T.A.F.R.; Shutz, F.C.A.

BIOINDICADORES DE QUALIDADE DO SOLO EM REFLORESTAMENTO IRRIGADO COM EFLUENTE DE ABATEDOURO DE AVES

Vargas, R.J.; Araujo, I.R.C.; Morais, J.; Figueiredo, T.A.F.R.; Shutz, F.C.A.

CONTROLE ESTATÍSTICO DE QUALIDADE NO MONITORAMENTO BIOLÓGICO DO SOLO IRRIGADO COM EFLUENTE AGROINDUSTRIAL

Vargas, R.J.; Araujo, I.R.C.; Morais, J.; Figueiredo, T.A.F.R.; Shutz, F.C.A.

ESTIMATIVA DE NITROGÊNIO, FÓSFORO E POTÁSSIO EM DEJETO LÍQUIDO DE SUÍNOS VIA DENSIDADE E MATÉRIA SECA

Vedovato, M.; Soares, M.T.S.; Maeda, S.

REDUÇÃO DA EMISSÃO DE GEE ATRAVÉS DA COMPOSTAGEM EM UMA FÁBRICA DE PROCESSAMENTO MÍNIMO DE HORTALIÇAS...

Paiva, V.M.; Inácio, C.T. 


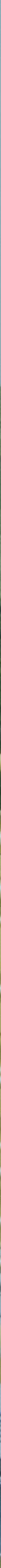

Foto: Luisa Letícia Biesus 


\title{
AVALIAÇÃO DO USO DE ULTRASSOM PARA A REMOÇÃO DE CROMO EM COURO WET BLUE: UMA ESTRATÉGIA INOVADORA PARA A REUTILIZAÇÃO DE RESÍDUOS DE CURTUME
}

\author{
Bizzi, C.A. ${ }^{* 1}$; Santos, D. ${ }^{1}$; Giacobe, K. ${ }^{1}$; Mello, P.A. ${ }^{1}$; Zanatta, R.C. ${ }^{2}$; Dallago, R.M. ${ }^{2}$; Flores, E.M.M. ${ }^{1}$ \\ ${ }^{1}$ Universidade Federal de Santa Maria, Departamento de Química, Santa Maria, RS, Brasil \\ ${ }^{2}$ Universidade Regional Integrada do Alto Uruguai e das Missões, Departamento de Ciências Agrárias, Erechim, RS, Brasil \\ *c_bizzi@yahoo.com.br
}

\begin{abstract}
RESUMO: No presente estudo foi investigada a utilização do ultrassom na remoção de cromo de resíduos sólidos de curtume. Foram avaliados diversos sistemas de ultrassom (banhos, sondas e cup horns), com diferentes frequências $(20 \mathrm{a} 130 \mathrm{kHz})$ e potências nominais $(100$ a $750 \mathrm{~W})$. Após a escolha do sistema de US mais adequado, foram investigados parâmetros de processo, tais como: solução de extração $\left(\mathrm{HCl}, \mathrm{HNO}_{3}\right.$, $\mathrm{H}_{2} \mathrm{SO}_{4}, \mathrm{CH}_{2} \mathrm{O}_{2}$ e $\left.\mathrm{C}_{2} \mathrm{H}_{2} \mathrm{O}_{4}\right)$, temperatura $\left(10\right.$ a $90{ }^{\circ} \mathrm{C}$ ), tempo de sonicação (1 a $\left.40 \mathrm{~min}\right)$, amplitude de ultrassom (10 a 90\%), quantidade de matéria-prima $(50 \mathrm{a} 450 \mathrm{mg})$ e concentração de solução extratora $(0,1 \mathrm{a} 4,0$ mol L' ${ }^{1}$ ). Para comparação dos resultados foram feitas extrações utilizando agitação mecânica (100 a 500 rpm) nas mesmas condições de tempo, temperatura e concentração de ácido previamente otimizadas. Para comprovar a aplicabilidade do processo proposto, experimentos de aumento de escala foram feitos em um reator ultrassônico operando com frequencia de $37 \mathrm{kHz}$ e potencia nominal de $330 \mathrm{~W}$. Após a otimização dos parâmetros de processo $\left(150 \mathrm{mg}\right.$ de matéria-prima, $\mathrm{HNO}_{3} 3 \mathrm{~mol} \mathrm{~L}{ }^{-1}, 30{ }^{\circ} \mathrm{C}, 90 \%$ de amplitude e 30 min de ultrassom) foram obtidas remoções de cromo superiores a 92\%. Quando comparado com métodos convencionais, o tempo de extração foi reduzido de 36 horas para $30 \mathrm{~min}$. O processo proposto permitiu a remoção de cromo de resíduos de curtume em condições brandas de temperatura, utilizando ácidos diluídos e sob pressão atmosférica, sendo uma alternativa promissora para a reutilização de couro curtido.
\end{abstract}

Palavras-chave: cromo, ultrassom, resíduo de curtume, extração.

\section{ULTRASOUND-ASSISTED EXTRACTION OF CHROMIUM FROM RESIDUAL TANNED LEATHER: AN INNOVATIVE STRATEGY TO WASTE REUSE IN TANNERY INDUSTRY}

\begin{abstract}
In this work, the ultrasound energy was investigated for chromium removal from residual tanned leather. The ultrasound-assisted extraction experiments were carried out in several systems such as ultrasonic baths, probes and cup horns. After chosen the most appropriate ultrasonic system, the following parameters were evaluated: extraction solution $\left(\mathrm{HCl}, \mathrm{HNO}_{3}, \mathrm{H}_{2} \mathrm{SO}_{4}, \mathrm{CH}_{2} \mathrm{O}_{2}\right.$ and $\mathrm{C}_{2} \mathrm{H}_{2} \mathrm{O}_{4}$ ), temperature (10 to $90{ }^{\circ} \mathrm{C}$ ), sonication time (1 to $40 \mathrm{~min}$ ), ultrasound amplitude (10 to $90 \%$ ), feedstock amount (50 to $450 \mathrm{mg}$ ) and concentration of extraction solution $\left(0.1\right.$ to $\left.4 \mathrm{~mol} \mathrm{~L}^{-1}\right)$. For the comparison of the obtained results, the chromium extraction was also performed by using mechanical stirring (100 to $500 \mathrm{rpm}$ ) at same conditions of time, temperature and acid concentration previously optimized. To prove the applicability of the proposed process for scaling up, an ultrasonic reactor operating at $37 \mathrm{kHz}$ and $330 \mathrm{~W}$ was evaluated. After process optimization using $150 \mathrm{mg}$ of feedstock, $3 \mathrm{~mol} \mathrm{~L}^{-1} \mathrm{HNO}_{3}$, at $30{ }^{\circ} \mathrm{C}, 90 \%$ of amplitude and $30 \mathrm{~min}$ of sonication it was achieved a $\mathrm{Cr}$ removal with efficiency of $92 \%$. When the ultrasound-assisted extraction was compared with conventional procedures, the extraction time was reduced from 36 hours to $30 \mathrm{~min}$. Using the proposed process chromium was efficiently removed at room temperature, atmospheric pressure and using diluted extraction solution, being a promise alternative for residual tanned leather reuse.
\end{abstract}

Keywords: chromium, ultrasound energy, residual tanned leather, extraction.

\section{INTRODUÇÃO}

Os resíduos industriais são considerados um problema para o meio ambiente e saúde humana (Tarr, 2003). Os subprodutos das indústrias têxteis e de curtimento de couro podem conter contaminantes ambientais, tais como, metais potencialmente tóxicos e moléculas cancerígenas (Tchounwou et al., 2012). Entre os metais potencialmente tóxicos, o cromo é utilizado para a estabilização de peles animais e no curtimento de couro. Nesses casos, o cromo (III) é coordenado a grupamentos carboxílicos das estruturas proteicas e são formadas 
ainda pontes com grupamentos hidroxilas aumentando a estabilidade da estrutura do couro (Heidemann, 1994; Poulopoulou et al., 1998). A inércia do cromo e a capacidade de formar espécies estáveis tornam esse elemento único para o tratamento de peles animais (Mengistie et al., 2012).

O processo de curtimento de couro gera quantidades substanciais de resíduos. Cerca de $40 \%$ das peles e/ou couros são perdidos como aparas e resíduos de corte gerando mais de 600000 toneladas de resíduos sólidos por ano em todo o mundo (Ferreira et al., 2010). Além disso, o processo de curtimento utiliza grandes quantidades de água, descarregando no meio ambiente, aproximadamente, 200 litros de água residual para cada quilograma de couro produzido (Puntener, 1995). Contudo, os resíduos de curtume são classificados como perigosos e exigem tratamento e disposição em aterro industrial (Poulopoulou et al., 1998)

Alguns tratamentos têm sido propostos para a remoção de cromo em resíduos de curtume, tais como, a extração ácida, extração alcalina e hidrólise enzimática (Brow et al., 1986; Cabeza et al., 1998; Mu, 2003; Ferreira et al., 2010). O processo de extração em meio ácido e/ou alcalino requer o uso de reagentes concentrados, inúmeras etapas e longos tempos de extração (Brow et al., 1986; Cabeza et al., 1998). No caso da hidrólise enzimática, a formação de produtos inibitórios e o elevado custo de aquisição de enzimas puras dificultam a utilização em escala industrial (Mu, 2003). Nesse sentido, o desenvolvimento de processos alternativos para a remoção de cromo em resíduos de curtume é uma importante linha de pesquisa.

Entre as tecnologias que contribuem para a intensificação de processos, o ultrassom tem sido considerado uma alternativa promissora em processos de extração, desemulsificação e purificação (Castro e Capote, 2007). Quando o ultrassom se propaga em meios líquidos, são gerados ciclos de compressão e rarefação (Ashokkumar et al., 2016). Se a onda ultrassônica possuir energia suficiente, em determinado ciclo de rarefação, microbolhas ou cavidades são formadas devido aos vapores e gases dissolvidos no meio (Ashokkumar et al., 2016). Isso resulta em uma rápida penetração dos vapores e gases para o interior das cavidades (bolhas de cavitação), que crescem ao longo dos sucessivos ciclos de compressão e rarefação. Ao atingirem um tamanho instável, as bolhas implodem liberando uma enorme quantidade de energia na forma de temperatura e pressão (Mason e Lorimer, 2002). Devido ao colapso implosivo dessas bolhas, pode ser gerado um ambiente adequado para a penetração da solução de extração no material sólido, bem como a formação de espécies radicalares que auxiliam nos processos de extração (Mason e Lorimer, 2002). Apesar das inúmeras vantagens do uso de energia de ultrassom em protocolos de extração, sua aplicação na remoção de cromo em resíduos sólidos de indústrias de curtumes é pouco descrita na literatura.

Diante disso, no presente estudo foi investigada a remoção de cromo de couro curtido resídual utilizando a energia ultrassom. Foram avaliados parametros operacionais de processo, tais como, potencia dissipada, frequência e amplitude de ultrassom. Adicionalmente, foram feitas otimizações de solução extratora, temperatura, tempo e quantidade de matéria-prima. Foram feitos ainda, experimentos com agitação mecânica a fim de comprovar os efeitos do ultrassom no processo de extração, bem como foi avaliada a utilização de reatores e até $9 \mathrm{~L}$ para aplicação do processo proposto.

\section{MATERIAIS E MÉTODOS}

Para os experimentos de extração assistida por ultrassom foram utilizados sistemas de ultrassom do tipo sonda, cup horn e banho, de frequências e potências variadas. Para os sistemas de ultrassom do tipo sonda, foram utilizados equipamentos com frequência de $20 \mathrm{kHz}$ e potência de $130 \mathrm{~W}$ ou $750 \mathrm{~W}$ (Sonics and Materials Inc., EUA), ambas equipados com sonda de liga de titânio. Também foram utilizados dois sistemas de ultrassom do tipo cup horn (Sonics and Materials Inc., EUA) acoplados a processadores de $20 \mathrm{kHz}$ e $130 \mathrm{~W}$ ou $750 \mathrm{~W}$, ambos com cuba de vidro. Além desses equipamentos, foram utilizados quatro banhos de ultrassom (Elma GmbH \& Co, Singen, Alemanha), os quais foram nomeados de 1 a 4, conforme mostrado na Tabela 1.

Experimentos de aumento de escala foram feitos utilizando um reator ultrassônico de $37 \mathrm{kHz}$ com $250 \mathrm{~mm}$ de comprimento, $300 \mathrm{~mm}$ de largura e $200 \mathrm{~mm}$ de altura. Para comparação de resultados, a remoção de Cr foi feita utilizando agitação mecânica (AREX-F20500413, Velp Scientifica srl, Usmate, Itália). Para todos os experimentos, a remoção de $\mathrm{Cr}$ foi determinada por espectrometria de absorção atômica com chama (AAS Vario 6, Analytik Jena, Alemanha) utilizando chama ar/acetileno.

Experimentos preliminares foram feitos utilizando solução ácida a $30{ }^{\circ} \mathrm{C}, 30 \mathrm{~min}$ e $5 \%$ dos seguintes ácidos: $\mathrm{HCl}, \mathrm{HNO}_{3}, \mathrm{H}_{2} \mathrm{SO}_{4}, \mathrm{CH}_{2} \mathrm{O}_{2} \mathrm{e} \mathrm{C}_{2} \mathrm{H}_{2} \mathrm{O}_{4}$, em todos os sistemas de ultrassom descritos anteriormente, com amplitude de $70 \%$. A relação entre massa inicial $(\mathrm{mg})$ : volume $(\mathrm{mL})$ foi arbitrariamente selecionada para 150: 20 . 
Após a escolha do sistema de ultrassom e solução ácida mais eficiente, avaliações adicionais foram feitas utilizando um banho de ultrassom e solução de $\mathrm{HNO}_{3}$. Para melhor avaliar a influência da energia ultrassônica sobre a eficiência da extração, foi aplicada uma metodologia de superfície de resposta. As relações entre a resposta e as variáveis do processo foram estabelecidas de acordo com um desenho composto central (CCD). Foram avaliados cinco fatores independentes: temperatura, tempo, amplitude de US, quantidade de matéria-prima e concentração de $\mathrm{HNO}_{3}$ com a eficiência de remoção de $\mathrm{Cr}$ como resposta.

As condições mais eficientes de remoção de $\mathrm{Cr}$, obtidas com o processo de extração assistida por ultrassom foram comparadas com aquelas obtidas por extração convencional em condições de silêncio (sem o uso de ultrassom). Neste caso particular, foi utilizada a agitação mecânica (100 a 500 rpm) para comparação. Para provar a aplicabilidade do processo proposto, um reator ultrassônico foi selecionado para aumentar a escala. Os parâmetros de ultrassom foram previstos para várias cargas do reator $(1,3,5,7$ ou 9 L).

\section{RESULTADOS E DISCUSSÃO}

Quando as sondas de ultrassom e cup horns foram avaliados, a maior remoção de Cr foi obtida, mas o couro residual foi praticamente dissolvido e poucos restos de couro sólido permaneceram após o processo, inviabilizando o reuso do couro tratado. É importante ressaltar que, quando comparada a solução de extração ácida, $\mathrm{HNO}_{3}$ e $\mathrm{H}_{2} \mathrm{SO}_{4}$ aumentam a remoção de $\mathrm{Cr}$ em todos os experimentos. Para sistemas de cup horn, a densidade acústica foi de 65 e $120 \mathrm{~W} \mathrm{dm}^{-3}$ para os geradores operando a 130 e $750 \mathrm{~W}$ (potência nominal), respectivamente. Em relação às sondas, a densidade acústica foi de cerca de 210 e $950 \mathrm{~W} \mathrm{dm}^{-3}$ para sondas ultrassônicas operando com geradores operando a 130 e $750 \mathrm{~W}$ (potência nominal), respectivamente.

Para os sistemas de banho ultrassônico, a densidade acústica determinada pela calorimetria variou de 20 a $95 \mathrm{~W} \mathrm{dm}^{-3}$. Utilizando um intervalo de 25 a $37 \mathrm{kHz}$, observou-se um aumento da eficiência de extração. É importante enfatizar que, utilizando banhos de ultrassom, a degradação do couro residual foi menor que $10 \%$ em todos os experimentos, permitindo a reutilização dos resíduos de couro em outros processos. Apesar da relativa baixa eficiência de remoção de $\mathrm{Cr}$, como essa foi a única condição onde o produto da extração assistido por US poderia ser reutilizado, a solução diluída de $\mathrm{HNO}_{3}$ e o banho de ultrassom operando a $37 \mathrm{kHz} / 95 \mathrm{~W}$ $\mathrm{dm}^{-3}$ foram escolhidos para os experimentos subsequentes.

$\mathrm{Na}$ avaliação dos resultados obtidos pelo CCD, observou-se que os efeitos mais influentes foram os termos lineares com $p$-values menores que 0,05. O modelo estatístico provou que a remoção de $\mathrm{Cr}$ aumenta com a amplitude da US e a temperatura de extração. É importante enfatizar que a concentração de $\mathrm{HNO}_{3}$ exerceu um efeito positivo muito significativo. A remoção de $\mathrm{Cr}$ aumentou com os níveis de amplitude e atingiu a intensidade máxima quando a amplitude foi de $90 \%$. Considerando a remoção de Cr e a condição de compromisso entre a extração e a qualidade do couro residual após o processo, a condição otimizada foi selecionada como: $150 \mathrm{mg}$ de matéria-prima, $3 \mathrm{~mol} \mathrm{~L}-1$ de $\mathrm{HNO}_{3}$, a $30{ }^{\circ} \mathrm{C}, 90 \%$ de amplitude e 30 minutos de sonicação para alcançar uma remoção de Cr maior que $92 \%$.

Quando comparado com agitação mecânica, uma menor eficiência de extração foi obtida usando agitação de 100 a 500 rpm (inferior a 60\%). Estes resultados demonstram a importância do uso de energia ultrassônica e seus efeitos químicos e físicos para a remoção de $\mathrm{Cr}$ de couro residual. A menor remoção de $\mathrm{Cr}$ pode ser associada à baixa energia fornecida à mistura de extração quando esta foi mecanicamente agitada. Quando a calorimetria foi aplicada no banho ultrassônico $(37 \mathrm{kHz})$, a densidade acústica foi de cerca de $95 \mathrm{~W}$ $\mathrm{dm}^{-3}$. Por outro lado, a densidade acústica para agitação mecânica em várias rotações foi menor que $17 \mathrm{~W}$ dm ${ }^{3}$, justificando a diferença de eficiência de extração observadas entre o procedimento assistido por US e procedimento com agitação mecânica.

Nos experimentos de aumento de escala observou-se que, para 1, 3 e 5 L de carga do reator, a remoção de $\mathrm{Cr}$ (superior a 87\%) foi bastante semelhante àquela obtida na extração proposta em menor escala $(20 \mathrm{~mL})$. Quando avaliados 7 e $9 \mathrm{~L}$, a remoção de Cr foi menor que 76\%. Tal redução na eficiência de remoção de Cr pode ser associada à grande distância da solução da superfície do banho (onde os transdutores US estão posicionados), bem como a redução na densidade de energia acústica liberada. Neste sentido, até $5 \mathrm{~L}$ de carga de reator pode ser usado com eficiência de $87 \%$ de remoção de $\mathrm{Cr}$. Isso representando o tratamento de $1,8 \mathrm{~kg}$ $\mathrm{dia}^{-1}$ de couro curtido residual. 


\section{CONCLUSÃO}

Com base nos resultados obtidos no presente estudo, o processo proposto foi considerado uma alternativa promissora para a remoção de $\mathrm{Cr}$ de couro curtido residual. Observou-se que o banho de ultrassom $(37 \mathrm{kHz})$ apresentou eficiência de extração melhor que a obtida quando se utilizou agitação mecânica (100 a $500 \mathrm{rpm})$. Nas condições otimizadas, a eficiência obtida com o uso de energia ultrassônica foi pelo menos $24 \%$ maior que a obtida com o uso de agitação mecânica. O processo proposto foi eficiente para a remoção de $\mathrm{Cr}$ sem prejudicar a estrutura do couro, permitindo seu uso posterior. O processo de extração assistida por ultrassom mostrou-se simples e de baixo consumo de tempo quando comparado aos processos convencionais de tratamento.

\section{AGRADECIMENTOS}

Os autores agradecem ao Conselho Nacional de Desenvolvimento Científico e Tecnológico (CNPq), a Coordenação de Aperfeiçoamento de Pessoal de Nível Superior (CAPES) e a Fundação de Amparo à Pesquisa do Estado do Rio Grande do Sul (FAPERGS) por apoiar este estudo.

\section{REFERÊNCIAS}

ASHOKKUMAR, M. et al. Handbook of Ultrasonics and sonochemistry, first ed., Springer, Berlim, 2016. BROWN, D.A. et al. Investigation of carboxylic acids for the extraction of chromium (iii) from leather waste and the possible reuse of the extracted chromium in the tanning industry. Environmental Technology 7, 289298, 1986.

CABEZA, L.F. et al. Processing of leather waste: pilot scale studies on chrome shavings: isolation of potentially valuable protein products and chromium. Waste Management 18, 211-218, 1998.

CASTRO, M.D.L. et al. Analytical Applications of Ultrasound, first ed., Elsevier, Boston, 2007.

FERREIRA, M.J. et al. Finished leather waste chromium acid extraction and anaerobic biodegradation of the products. Waste Management 30, 1091-1100, 2010.

HEIDEMANN E., Eine erweiterte Theorie der Kochfesten Gerbung, Lokalisation im Kollagen. Das Leder. 45, 2-12, 1994.

Mason, T.J. et al. Applied Sonochemistry: The Uses of Power Ultrasound in Chemistry and Processing, first ed., Wiley Online Library, Weinheim, 2002

MENGESTIE, E., et al. Ultrasound assisted chrome tanning: towards a clean leather production technology. Ultrasonics. Sonochemistry 32, 204-2012, 2016.

MU, C. et al. Towards zero discharge of chromium-containing leather waste through improved alkali hydrolysis. Waste Management 23, 835-843, 2003.

POULOPOULOU, V.G. et al. A method for the removal of chromium from tanned leather wastes. Journal of Air Waste Management Association 48, 846-852, 1998.

PUNTNER, A., The ecological challenge of producing leather. Journal of American Leather Chemistry Association 6, 126-134, 1995.

TARR, M.A Chemical degradation methods for wastes and pollutants: environmental and industrial applications. CRC Press, New York, 2003.

TCHOUNWON, P.B et al. Heavy metal toxicity and the environment in molecular, clinical and environmental toxicology. Springer, Switzerland, 2013.

Tabela 1. Especificações dos banhos de ultrassom utilizados em UAAH.

\begin{tabular}{ccccc}
\hline Banho & Potência nominal, W & Frequência, kHz & Volume do banho, L & Modelo \\
\hline 1 & 200 & 35 ou 130 & 8,6 & TI-H-10 \\
2 & 100 & 25 ou 45 & 3,5 & TI-H-5 \\
3 & 330 & 37 ou 80 & 12,9 & P120H \\
4 & 330 & 37 ou 80 & 9 & P120H \\
\hline
\end{tabular}




\title{
CINÉTICA DA DEGRADAÇÃo ANAERÓBIA DO EFLUENTE DE PROCESSAMENTO DA ACEROLA VERDE EM BATELADA
}

\author{
André, A.C.L. ${ }^{1}$; Silva, K.C.D. ${ }^{1}$; Silva, R. T. ${ }^{\text {; }}$ Silva, P.T.S. ${ }^{2}$; Silva, T.F. ${ }^{3}$; Amorim, M.C.C. ${ }^{* 4}$ \\ ${ }^{1}$ Graduandos em Eng.Agrícola e Ambiental, Bolsista PET Saneamento Ambiental, UNIVASF, Juazeiro-BA. \\ andreza_carlalopes@hotmail.com; kessia155@hotmail.com;rodxtorres@hotmail.com \\ ${ }^{2}$ Pesquisadora da Embrapa Semiárido, Petrolina-PE. paula.silva@embrapa.br; \\ ${ }^{3}$ Analista Ambiental, Niagro, Petrolina, PE.tsilva@niagro.com.br \\ ${ }^{4}$ Professora Tutora PET Saneamento Ambiental, UNIVASF, Juazeiro-BA. miriam.cleide@univasf.edu.br
}

\begin{abstract}
RESUMO: O trabalho objetivou avaliar a cinética de degradação anaeróbia do efluente da ultrafiltração do processamento da acerola verde em três diferentes cargas de matéria orgânica aplicadas $\left(\mathrm{T}_{1}=0,85 \mathrm{~g} \mathrm{DQO}_{\mathrm{Apl}}\right.$ $\mathrm{L}^{-1}$ Reator, $\mathrm{T}_{2}=1,5 \mathrm{~g} \mathrm{DQO}_{\mathrm{Apl}} \mathrm{L}^{-1}$ Reator $\mathrm{e}_{3}=2,0 \mathrm{~g} \mathrm{DQO}_{\mathrm{Apl}} \mathrm{L}^{-1}$ Reator). O efluente foi obtido da NIAGRO, em Petrolina, $\mathrm{PE}$, e submetido a degradação em frascos reatores em batelada em triplicata repetições inoculados com lodo anaeróbio, incubados a $30^{\circ} \mathrm{C}$ por oito dias. As características avaliadas foram: $\mathrm{pH}$, demanda química de oxigênio e produção de metano medidas a cada 48 horas, determinando-se a eficiência (Ef) de remoção da massa de DQO, a constante de velocidade de decaimento da DQO $\left(\mathrm{K}_{\mathrm{d}}\right)$ como parâmetro cinético, fazendo-se o balanço de DQO em termos de DQO convertida em metano $\left(\mathrm{DQO}_{\mathrm{CH} 4}\right)$, DQO utilizada para formação de novas células (biomassa) ( $\mathrm{DQO}_{\text {Biom }}$ ) e $\mathrm{DQO}$ presente no efluente em forma de ácidos graxos voláteis $\left(\mathrm{DQO}_{\mathrm{AGV}}\right)$. Como parâmetro cinético foi determinada a constante de velocidade $\mathrm{K}_{\mathrm{d}}$ para reação de primeira ordem. Foram observadas remoções máximas de massa de DQO de $89 \%$. O $\mathrm{T}_{1}$ apresentou a maior taxa de produção de metano $\left(0,102 \mathrm{~L} \mathrm{CH}_{4} \mathrm{~g}^{-1} \mathrm{DQO}\right.$ Removida), maior valor de $\mathrm{K}_{\mathrm{d}}\left(0,328 \mathrm{~d}^{-1}\right)$ com $\mathrm{R}^{2}=0,955$ após ajuste da equação adaptada de cinética de primeira ordem, evidenciando assim o potencial para a bioconversão em energia. Já o $\mathrm{T}_{3}$ mostrou-se não adequado à cinética adotada, com valores de $\mathrm{R}^{2}$ inferiores aos demais tratamentos.
\end{abstract}

Palavras-chave: carga orgânica, DQO, metano, ultrafiltração.

\section{KINETICS OF DEGRADATION ANAEROBIA OF THE WASTEWATER OF GREEN ACEROLA IN BATCH}

\begin{abstract}
The objective of this study was to evaluate the anaerobic degradation kinetics of the ultrafiltration effluent from the processing of green acerola in three different organic matter loads $\left(\mathrm{T}_{1}=0.85\right.$ $\mathrm{g} \mathrm{COD}_{\text {Apl }} \mathrm{L}^{-1}$ Recator, $\mathrm{T}_{2}=1.5 \mathrm{~g} \mathrm{COD}_{\text {Apl }} \mathrm{L}^{-1}$ Reactor and $\mathrm{T}_{3}=2.0 \mathrm{~g} \mathrm{COD}_{\mathrm{Apl}} \mathrm{L}^{-1}$ Recator). The effluent was obtained from NIAGRO, in Petrolina, PE, and submitted to degradation in batch reactor flasks in three replicates inoculated with anaerobic sludge, incubated at $30{ }^{\circ} \mathrm{C}$ for eight days. The evaluated characteristics were: $\mathrm{pH}$, chemical oxygen demand and methane production measured every $48 \mathrm{~h}$, determining the efficiency (Ef) of removal of the COD mass, the COD decay rate constant $\left(\mathrm{K}_{\mathrm{d}}\right)$ as the kinetic parameter, COD of the biomass, COD of the methane and COD present in the effluent in the form of volatile fatty acids $\left(\mathrm{COD}_{\mathrm{VFA}}\right)$ were used to calculate the balance of the COD. As a kinetic parameter the velocity constant $\mathrm{K}_{\mathrm{d}}$ was determined for first order reaction. Maximum mass removals of $89 \%$ were observed. The $T_{1}$ highest value of $K_{d}\left(0,328 \mathrm{~d}^{-1}\right)$ with $\mathrm{R}^{2}=0.955$ was obtained after adjusting the first-order kinetic equation, thus evidencing the potential for the production of methane (0.102 $\mathrm{L} \mathrm{CH}_{4} \mathrm{~g}^{-1} \mathrm{DQO}_{\text {Removed }}$ ) and the bioconversion in energy. Already $\mathrm{T}_{3}$ was not suitable for the adopted kinetics, with $\mathrm{R}^{2}$ values lower than the other treatments.
\end{abstract}

Keywords: COD, methane, organic load, ultrafiltration.

\section{INTRODUÇÃO}

O Brasil é um dos maiores produtores de acerola (Malpighia emarginata DC.) do mundo, contando com uma área plantada de 7.200 ha, destes, 1.339 ha encontram-se plantados no perímetro irrigado Senador Nilo Coelho (Calgaro; Braga, 2012), localizado no Vale do São Francisco, Petrolina, PE. O mercado de processamento da acerola encontra-se em expansão, devido ao alto teor de ácido ascórbico presente na fruta, que por tratar-se de uma espécie climatérica apresenta dois estádios de maturação passíveis de colheita e industrialização: madura e verde (Correa et al., 2017). Essa diferença na maturação faz com que haja dois ciclos distintos de processo de beneficiamento, gerando efluentes diversificados, sendo a etapa de ultrafiltração a responsável pelo efluente com maior teor de matéria orgânica em termos de demanda química de oxigênio 
(DQO) e, consequentemente de difícil degradação e, portanto, dotado de elevado potencial poluidor quando disposto no meio ambiente sem tratamento prévio. Em virtude disso, de acordo com González-Sánchez et al. (2015), a aplicação de um tratamento biológico anaeróbio pode ser uma alternativa viável e eficaz, proporcionando também um reaproveitamento energético para este tipo de efluente.

A digestão anaeróbia é uma alternativa eficaz de bioconversão de diferentes resíduos recalcitrantes, em biogás e produtos de menor impacto ao ambiente, sendo esta influenciada por fatores como $\mathrm{pH}$, alcalinidade do meio, ácidos graxos voláteis e a própria carga de matéria orgânica do resíduo a qual, inflencia no tempo de bioestabilização ou na velocidade de decomposção do material (Metcalf e Eddy, 2003; Leiva et al., 2014).

Pesquisas têm sido realizadas a fỉm de otimizar a taxa de bioestabilização da matéria orgânica, porém estudos com efluentes da agroindústria da fruticultura da região do Vale do São Francisco ainda são escassos, principalmente no que tange os da acerola, seja esta verde ou madura. Portanto, o presente estudo teve como propósito avaliar a cinética de remoção da matéria orgânica em termos demanda química de oxigênio do efluente resultante da etapa da ultrafiltração do processamento da acerola verde, em reatores de batelada com diferentes cargas orgânicas aplicadas.

\section{MATERIAL E MÉTODOS}

O efluente foi proveniente da ultrafiltração no processamento da acerola verde da NIAGRO (Nichirei do Brasil Agrícola Ltda.) localizada no Distrito Industrial de Petrolina-PE. Para a determinação da cinética de degradação utilizou-se como parâmetro de avaliação a remoção da carga orgânica em termos de DQO aplicada por Litro de Reator $\left(\mathrm{DQO}_{\mathrm{Apl}} \mathrm{L}_{\mathrm{R}}^{-1}\right)$. Para tanto se realizaram ensaios em batelada, conduzidos conforme metodologia dos frascos sacrifício de Amorim et al. (2013) que consiste em sacrificar um conjunto de frascos reatores triplicatas para análises do efluente no decorrer do tempo de degradação.

Foram avaliadas três cargas de DQO $\left(\mathrm{T}_{1}=0,85 \mathrm{~g} \mathrm{DQO}_{\mathrm{Apl}} \mathrm{LR}_{\mathrm{R}}^{-1}, \mathrm{~T}_{2}=1,5 \mathrm{~g} \mathrm{DQO}_{\mathrm{Apl}} \mathrm{L}_{\mathrm{R}}{ }^{-1}\right.$ e $\mathrm{T}_{3}=2,0 \mathrm{~g} \mathrm{DQO}_{\mathrm{Apl}}$ $\mathrm{L}_{\mathrm{R}}{ }^{-1}$ ), determinando-se a eficiência de remoção (Ef) da massa de DQO (DQO $\mathrm{Rem}$ ), a constante de velocidade de decaimento da DQO $\left(\mathrm{K}_{\mathrm{d}}\right)$ como parâmetro cinético, e o balanço de DQO em termos de DQO efetivamente transformada em metano $\left(\mathrm{DQO}_{\mathrm{CH} 4}\right)$ e DQO utilizada para formação de novas células (biomassa) (DQO $\left.\mathrm{Biom}\right)$ conforme Metcalf e Eddy (2003). A DQO presente no efluente em forma de ácidos graxos voláteis (DQO $\left.{ }_{\mathrm{AGV}}\right)$ não convertidos em metano foi calculada pela diferença do somatório das duas últimas ( $\left.\mathrm{DQO}_{\mathrm{CH} 4} \mathrm{e} \mathrm{DQO}_{\mathrm{Biom}}\right)$. A constante $\mathrm{K}_{\mathrm{d}}$ foi determinada considerando que em um reator de batelada a taxa de mudança de concentração do reagente é proporcional à concentração deste reagente num dado instante, admitindo-se, portanto, uma reação de primeira ordem (Eq. 1) (Metcalf e Eddy, 2003):

$$
(-r)=-\frac{d S}{d t}=k_{d} S
$$

Onde r é a velocidade de reação ( $\mathrm{g} \mathrm{L}^{-1}$ dias), $\mathrm{S}$ a concentração do reagente limitante (DQO) ( $\mathrm{g} \mathrm{L}^{-1}$ ), $\mathrm{T} \mathrm{o} \mathrm{Tempo}^{-1}$ de detenção hidráulica (dias) e $\mathrm{K}_{\mathrm{d}}$ a constante de velocidade para reação de primeira ordem (ou d $\left.{ }^{-1}\right)$.

O inóculo utilizado foi o lodo anaeróbio de reator UASB (Upflow Anaerobic Sludge Blanket) tratando esgotos domésticos na Companhia Pernambucana de Saneamento em Petrolina-PE. A concentração do lodo foi de $5 \mathrm{~g} \mathrm{~L}^{-1}$ (Bertolino et al., 2007) e a suplementação nutricional foi feita de acordo com Florêncio (1994). Os ensaios tiveram um tempo de degradação de $192 \mathrm{~h}$ (oito dias), com os três tratamentos em triplicata onde eram sacrificadas para análises de DQO (APHA, 2012) e pH, uma triplicata a cada $48 \mathrm{~h}$, totalizando com o branco 75 frascos reatores com volume útil de $0,118 \mathrm{~L}$ e headspace de $0,026 \mathrm{~L}$ conforme recomendado por Aquino et al. (2007). O pH foi aferido no momento da montagem dos frascos reatores (dia zero)para verificar a neutralidade do meio. Em seguida os frascos foram vedados com tampas de borracha butírica e lacres de alumínio com o auxílio de um alicate recravador, sendo conectadas nas borrachas septos seringas cirúrgicas de $10 \mathrm{~mL}$ para acúmulo do biogás produzido. Os frascos foram incubados em estufa a $30^{\circ} \mathrm{C}$, temperatura ideal para as bactérias constituintes do lodo (Metcalf e Eddy, 2003).

O biogás medido e coletado nas seringas a cada 48 h foi inserido em frascos coletores de gás, e posteriormente enviados ao Laboratório de Química Ambiental da Embrapa Semiárido, para análise da composição por meio de um cromatógrafo gasoso, modelo 7890A com detector do tipo FID equipado com metanador. A coluna utilizada foi a agilent Hayesep Q80/100, como gás de arraste foi utilizado o $\mathrm{N}_{2}$ num fluxo de $25 \mathrm{~mL} \mathrm{~min}^{-1}$, o tempo de corrida foi de 11 minutos e a temperatura do detector e do forno foram $300^{\circ} \mathrm{C}$ e $60^{\circ} \mathrm{C}$, respectivamente. Para os cálculos das concentrações de dióxido de carbono e metano foram construídas duas curvas de calibração, uma para o $\mathrm{CO}_{2}\left(250,500\right.$ e 1000 ppm) e outra para o $\mathrm{CH}_{4}(0,5,1$ e 3 $\mathrm{ppm}$ ). Em seguida calculou-se o volume de metano produzido e a taxa de produção de metano por $\mathrm{g}_{\mathrm{DQO}} \mathrm{O}_{\mathrm{Rem}}$ ( $\mathrm{L} \mathrm{CH}_{4} \mathrm{~g}^{-1} \mathrm{DQO}_{\mathrm{Rem}}$ ). 


\section{RESULTADOS E DISCUSSÃO}

A Tabela 1 dispõe os resultados da biodegradação, os percentuais de remoção da massa de matéria orgânica (DQO) após os oito dias de degradação, em relação ao dia zero e os parâmetros cinéticos $\left(\mathrm{K}_{\mathrm{d}} \mathrm{e} \mathrm{R}^{2}\right)$ obtidos a partir do ajuste do modelo de primeira ordem conforme curvas de decaimento da DQO ao longo do tempo de degradação da Figura 1.

De acordo com os dados nota-se que a cinética para as cargas aplicadas nos $\mathrm{T}_{1} \mathrm{e} \mathrm{T}_{2}$, foram semelhantes com ambos os tratamentos apresentando redução progressiva da DQO até 192 h, com 89\% de remoção de massa de DQO ao final do tempo de degradação e mantendo $\mathrm{pH}$ na faixa de 6,0. Embora esses tratamentos tenham apresentado os mesmos percentuais de DQO convertidos em metano e em novas células a taxa de produção de metano por $\mathrm{g} \mathrm{DQO}_{\mathrm{Rem}}\left(\mathrm{L} \mathrm{CH}_{4} \mathrm{~g}^{-1} \mathrm{DQO}_{\mathrm{Rem}}\right)$ diferiram, com o tratamento de menor carga de $\mathrm{DQO}_{\mathrm{Apl}}$ apresentando a maior taxa. Este fato pode estar associado a substâncias não solúveis mensuradas pela DQO que, por não serem biodegradáveis não são convertidas em metano. $\mathrm{O}$ tratamento com maior carga de $\mathrm{DQO}$ Apl apresentou a menor remoção de matéria orgânica e também o menor valor de pH final $(4,89)$ valor inferior ao ideal (6,8 a 7,5) conforme Metcalf e Eddy (2003).

A taxa de produção de metano de $0,102 \mathrm{~L} \mathrm{~g}^{-1} \mathrm{DQO}_{\mathrm{Rem}}$ no $\mathrm{T}_{1}$ foi a maior taxa obtida entre os tratamentos e assemelhou-se aos resultados de Cremonez et al. (2016) de 0,161 $\mathrm{L} \mathrm{CH}_{4} \mathrm{~g}^{-1} \mathrm{DQO}_{\mathrm{Rem}}$, tratando efluentes de fecularia, o qual possui características de matéria orgânica e acidez semelhantes ao efluente da acerola. Esta taxa de produção de metano demonstra que o efluente estudado é uma fonte potencial de bioenergia, como afirmam Khan et al. (2015) citando que os resíduos da agroindústria de frutas cítricas apresentam-se promissores para geração de bioenergia.

No ajuste da equação da cinética de primeira ordem para remoção da matéria orgânica (Figura 1) foram obtidos valores de $\mathrm{K}_{\mathrm{d}}$ para os $\mathrm{T}_{1}, \mathrm{~T}_{2}$ e $\mathrm{T}_{3}$ de $0,328,0,309$ e $0,209 \mathrm{~d}^{-1}$ respectivamente. $\mathrm{O}$ tratamento com menor $\mathrm{DQO}_{\text {Apl }}$ foi o que apresentou a maior velocidade de reação bem como o melhor ajuste à curva $\left(\mathrm{R}^{2}=0,955\right)$ demonstrando ajuste adequado do modelo. O que não ocorreu com o $\mathrm{T}_{3}$ de maior $\mathrm{DQO}_{\mathrm{Apl}}\left(\mathrm{R}^{2}=0,677\right)$, fato que atribui-se à menor disponibilidade de matéria orgânica biodegradável no efluente com maior carga aplicada bem como maior acidez visto que apresentou $\mathrm{pH}$ ácido. Os coeficientes de decaimento do material orgânico obtidos nos três tratamentos avaliados são considerados baixos quando comparados aos apresentados na literatura para águas residuárias da suinocultura $\left(\mathrm{k}=1,52 \mathrm{~d}^{-1}\right)$ (Matos et al., 2010) e para esgotos domésticos $\left(\mathrm{K}_{\mathrm{d}}\right.$ de 1,62 $\left.\mathrm{d}^{-1}\right)$ (Brasil et al., 2007). No entanto, estão de acordo com Zerrouk et al. (2015) que modelaram a digestão anaeróbia de águas residuais do processamento de frutas, concluindo que os mesmos são de menor biodegradabilidade e conversão de metano quando comparados com outros estudos apresentados na literatura, porém com potencial biodegradável anaerobiamente.

\section{CONCLUSÃO}

Para todos os tratamentos avaliados as remoções máximas de massa de DQO ocorreram após as $48 \mathrm{~h}$ apresentando resultados satisfatórios com valores acima de $73 \%$, indicando que o tempo de detenção hidráulica de dois dias pode ser adotado para sistemas em bateladas tratando efluente da ultrafiltração de processamento da acerola verde com carga entre 0,85 e $1,5 \mathrm{~g} \mathrm{DQO} \mathrm{L}_{\mathrm{R}}{ }^{-1}$.

A cinética da degradação mostrou que os maiores valores de $\mathrm{K}_{\mathrm{d}}$ ocorreram para os tratamentos com as menores massas de DQO aplicada evidenciando, assim, a influência da carga orgânica. Todos os $\mathrm{K}_{\mathrm{d}}$ foram menores que os coeficientes de degradação de esgotos sanitários, associa-se isto ao fato de que o efluente de processamento da acerola verde apresenta compostos de menor biodegradabilidade orgânica, ou seja, em sua maioria na forma particulada. Porém as remoções de DQO e a taxa de produção de metano evidenciam potencial para otimização da digestão anaeróbia, por meio de estudos que propiciem condições ambientais ainda mais adequadas para os microrganismos metanogênicos.

\section{REFERÊNCIAS}

APHA, WPCF. Standard Methods for the Examination of Water and Wastewater, 23th ed., American Public Health Association, Washington, DC, USA, 2012.

AMORIM, S.M; KATO, M.T; FLORENCIO, L.; GAVAZZA, S. Influence of Redox Mediators and Electron Donors on the Anaerobic Removal of Color and Chemical Oxygen Demand from Textile Effluent. Clean - Soil, air, water, v.41, p. 928-933, 2013.

AQUINO, S.; CHERNICHARO, C. A. L.; FORESTI, E.; SANTOS, M. L. F.; MONTEGGIA, L. O. Metodologias para determinação da Atividade Metanogênica Específica (AME) em lodos anaeróbios. Revista de Engenharia Sanitária e Ambiental, v. 12, n. 2, p.192-201, 2007.

BERTOLINO S.M.; CARVALHO, C.F.; AQUINO, S.F. Caracterização e Biodegradabilidade aeróbia e anaeróbia dos esgotos produzidos em campus universitário. Engenharia Sanitária e Ambiental, vol. 13, nº 3, 271-277, 2008. 


\section{VISIGER

BRASIL, M. S.; MATOS, A. T.; SOARES, A. A. Plantio e desempenho fenológico da taboa (Thypha sp.) utilizada no tratamento de esgoto doméstico em sistema alagado construído. Revista Engenharia Sanitária e Ambiental, v.12, p.266272, 2007.

CAlGaro, M.; BRAGA, M. B. Coleção Plantar: A cultura da acerola. 3 Ed. Brasília: Embrapa, 2012.150 p.

CREMONEZ, P. A.; TELEKEN, J. G.; FEIDEN, A.; ROSSI, E.; SOUZA, S. M.; TELEKEN, J.; DIETER, J.; ANTONELLI, J. Biodigestão anaeróbia de polímero orgânico de fécula de mandioca. Revista de Ciências Agrárias, v. 39, n. 1, p. 122-133, 2016.

CORRÊA, C. V.; GOUVEIA, A. M. DE S.; MARTINS, B.N.M.; JORGE, L.G.; LANNA, N. DE B. L.; TAVARES, A. N. B.; MENDONÇA, V. Z.; EVANGELISTA, R. M. Influence of ripening stages on physicochemical characteristics of acerola fruits. Revista de Ciências Agrárias, v. 40, n. 4, p. 808-813, 2017.

EMBRAPA - Empresa Brasileira de Pesquisa Agropecuária, ministério da agricultura e do abastecimento. A Cultura da Acerola. Brasília, DF - $3^{\text {a }}$ edição rev. Ampl., 2012.

FLORÊNCIO, L. 1994. The fate of metanol in anaerobic bioreactors. PhD thesis, Wageningen Agricultural University, Wageningen, The Netherlands.

GONZÁLEZ-SÁNCHEZ, M. E.; FABIEL, S. P.; VILARREAL, A. W.; MENDOZA, R. B.; OCAMPO, G. Y. Residuos agroindustriales com potencial para la produccion de metano mediante La digestion anaerobia. Revista Argentina de Microbiología, v. 47, n. 3, p. 229-235, 2015.

LEIVA, M.B.; HOSSEINI KOUPAIE, E.; ESKICIOGLU, C. Anaerobic co-digestion of wine/fruit-juice production waste with landfill leachate diluted municipal sludge cake under semi-continuous flow operation. Waste Management, n. 34, p. 1860-1870, 2014.

MATOS, A. T.; FREITAS, W. S.; BORGES, A. C. Dinâmica da remoção de matéria orgânica de águas residuárias da suinocultura em sistemas alagados construídos cultivados com diferentes espécies vegetais. In: Congresso Brasileiro de Engenharia Agrícola, 39, 2010c, Vitória. Anais...Jaboticabal: SBEA,2010c. CD Rom.

METCALF E EDDY. Wastewater engineering: treatment, disposal and reuse. 4 ed. New York: McGraw-Hill Book, p. 1771, 2003.

KHAN, N.; ROES-HILL, M.; WELZ, P. J.; GRANDIN, K. A.; KUDANGA, T.; DYK, J. S. V.; OHLHOFF, C.; ZYL, W. H. E.; PLETSCHKE, B. I. Fruit waste streams in South Africa and their potential role in developing a bio-economy. South Africa Journal of Science, v. 111, n. 5/6, p. 1-11, 2015.

ZERROUKI, S.; RIHANI, R.; BENTAHAR, F.; BELKACEMI, K. Anaerobic digestion of wastewater from the fruit juice industry: experiments and modeling. Water Science \& Technology, v.72, n. 1, p.123-134, 2015.

Tabela 1. Parâmetros cinéticos e resultados da biodegradação da matéria orgânica (DQO).

\begin{tabular}{|c|c|c|c|c|c|c|c|c|c|}
\hline $\begin{array}{c}\text { Tra } \\
\text { t }\end{array}$ & $\mathrm{g} \mathrm{DQO}_{1} \mathrm{Apl} \mathrm{LR}_{\mathrm{R}^{-}}$ & $\underset{1}{g \text { DQm }} \mathbf{L}_{R^{-}}$ & $\begin{array}{c}\% \mathrm{E} \\
\mathrm{f}\end{array}$ & $\begin{array}{c}\% \mathrm{DQO}_{\mathrm{CH}} \\
4 \\
\end{array}$ & $\begin{array}{c}\text { \%DQO } \\
\text { m }\end{array}$ & $\begin{array}{c}\% \mathrm{DQO}_{\mathrm{AG}} \\
\mathrm{v}\end{array}$ & $\begin{array}{l}\mathrm{CH}_{4} \mathrm{~g}^{-} \\
{ }^{1} \mathrm{DQO}_{\text {Rem }}\end{array}$ & $K_{d}\left(d^{-1}\right)$ & $\mathbf{R}^{2}$ \\
\hline $\mathrm{T}_{1}$ & $0,85 \pm 0,06$ & $0,76 \pm 0,06$ & 89 & 73 & 16 & 11 & 0,102 & 0,328 & $\begin{array}{l}0,9 \\
55\end{array}$ \\
\hline $\mathrm{T}_{2}$ & $1,50 \pm 0,21$ & $1,24 \pm 0,22$ & 89 & 74 & 16 & 10 & 0,070 & 0,309 & $\begin{array}{l}0,9 \\
49\end{array}$ \\
\hline $\mathrm{T}_{3}$ & $2,00 \pm 0,13$ & $1,45 \pm 0,13$ & 73 & 60 & 13 & 27 & 0,045 & 0,209 & $\begin{array}{l}0,6 \\
77\end{array}$ \\
\hline
\end{tabular}

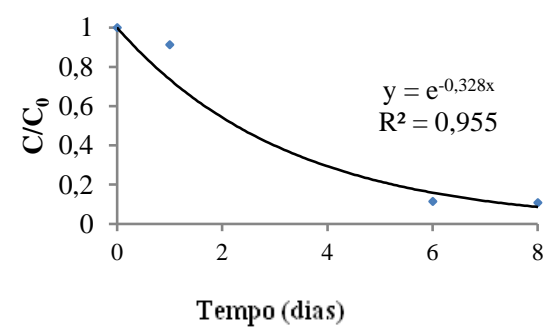

(A)

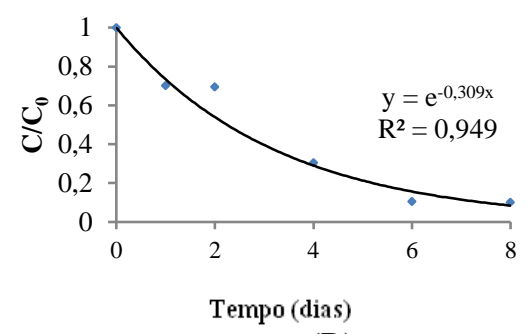

(B)

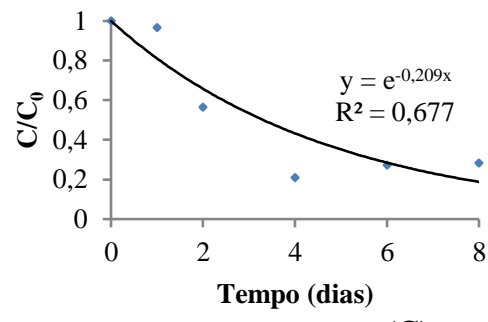

$(\mathrm{C})$

Figura 1. Curvas de decaimento da DQO na degradação do efluente da acerola verde: (A) DQO $\mathrm{Apl}_{\mathrm{d}}$ de $0,85 \mathrm{~g}$; (B) $\mathrm{DQO}_{\mathrm{Apl}}$ de $1,50 \mathrm{~g} ;(\mathrm{C}) \mathrm{DQO}_{\mathrm{Apl}}$ de $2,00 \mathrm{~g}$ ajustadas ao modelo de primeira ordem. 


\title{
DESASSOREAMENTO DE LAGOAS DE TRATAMENTO DE EFLUENTES VIA DESNITRIFICAÇÃO
}

\author{
Mutchamua, H.H.G. ${ }^{1}$; Di Luccio, M. ${ }^{2}$; Hollas, C.E. ${ }^{3}$; Venturin, B. ${ }^{* 3}$; Treichel, H. ${ }^{4}$; Kunz, A. ${ }^{5}$ \\ ${ }^{1}$ Mestrando em Engenharia de Alimentos-Universidade Federal de Santa Catarina, Florianópolis, SC-Brasil \\ ${ }^{2}$ Professor da Universidade Federal de Santa Catarina, Florianópolis, SC-Brasil \\ ${ }^{3}$ Doutorando em Engenharia Agrícola- Universidade Estadual do Oeste do Paraná, Campus Cascavel, PR-Brasil, \\ ${ }^{4}$ Professora da Universidade Federal da Fronteira Sul-Campus Erechim, RS-Brasil \\ ${ }^{5}$ Pesquisador da Embrapa Suínos e Aves, Concórdia, SC - Brasil
}

\begin{abstract}
RESUMO: A desnitrificação é um processo biológico caracterizado pelo consumo de nitrato, em que os agentes do processo são batérias heterotróficas, que necessitam na sua atividade de uma fonte de carbono biodisponível/teor de carbono. Sendo assim, pode-se utilizar este processo para reduzir a matéria orgânica em lagoas de tratamento (ou armazenamento) que apresentam alta deposiçao de lodo geralmente já desativadas. Nesse âmbito realizou-se um estudo com o objetivo de avaliar a influência da homogeneização e biodisponibilidade/teor de carbono nas taxas de desnitrificação. O experimento foi realizado durante 45 dias em escala laboratorial em batelada, com lodos com teores de carbono orgânico total (COT) de $2504 \mathrm{mg} \mathrm{L}^{-}$ ${ }^{1}$ (alto), 524,20 $\mathrm{mg} \mathrm{L}^{-1}$ (médio) e 260,20 $\mathrm{mg} \mathrm{L}^{-1}$ (baixo) em que foram misturados a uma solução de nitrato a 300 mgN-NO ${ }_{3}{ }^{-1} \mathrm{~L}^{-1}$ e colocados em bequeres de $4 \mathrm{~L}$, numa proporção de $75 \%$ solução e $25 \%$ de lodo, em que foram homegeneizados manualmente com uma espátula numa frequência de 10 vezes de um a dois periodos por dia, de acordo com o delineamento experimental estabelecido. As taxas de desnitrificação para os lodos alto, médio e baixo, com nenhuma homogeneização foram $122,40 \mathrm{mgN}^{-N_{0}}{ }_{3}{ }^{-} \mathrm{L}^{-1} \mathrm{~d}^{-1}, 24,81 \mathrm{mgN}-\mathrm{NO}_{3}{ }^{-} \mathrm{L}^{-1} \mathrm{~d}^{-1}$ e $13,79 \mathrm{mgN}-$ $\mathrm{NO}_{3}{ }^{-} \mathrm{L}^{-1} \mathrm{~d}^{-1}$ respectivamente. Conclui-se que a taxa de desnitrificação é afetada fundamentalmente pelo teor de carbono orgânico total/biodisponibilidade presente no lodo, e não pela homogeneização.
\end{abstract}

Palavras-chave: carbono, desnitrificação, homogeneização.

\section{DESILTING OF TREATMENT EFFLUENTS LAGOONS BY DENITRIFICATION}

\begin{abstract}
Denitrification is a biological process characterized by the consumption of nitrate, where in the process agents are heterotrophic bacteria, which require in their activity a bioavailable carbon source / carbon content. Therefore, it is possible to use this process to reduce the organic matter in treatment lagoons (or storage) that present high deposition of sludge usually already deactivated. In this scope a study was carried out with the objective of evaluating the influence of the homogenization and bioavailability / carbon content in denitrification rates. The experiment was carried out for 45 days in a batch laboratory scale with sludges with total organic carbon contents of $2504 \mathrm{mg} \mathrm{L}^{-1}$ (high), $524.20 \mathrm{mg} \mathrm{L}^{-1}$ (medium) and $260.20 \mathrm{mg} \mathrm{L}^{-1}$ (low) in which they were mixed to a solution of nitrate at $300 \mathrm{mgN}^{-N}{ }_{3}{ }^{-} \mathrm{L}^{-1}$ and placed in $4 \mathrm{~L}$ beakers in a proportion of $75 \%$ solution and $25 \%$ of sludge, where they were manually homogenized with a spatula at a frequency of 10 times and in one to two periods per day, according to the established experimental design. The mean denitrification rates for high, medium and low sludge were $122,40 \mathrm{mgN}-\mathrm{NO}_{3}{ }^{-} \mathrm{L}^{-1} \mathrm{~d}^{-1}, 24,06 \mathrm{mgN}-\mathrm{NO}_{3}{ }^{-} \mathrm{L}^{-1} \mathrm{~d}^{-1}$

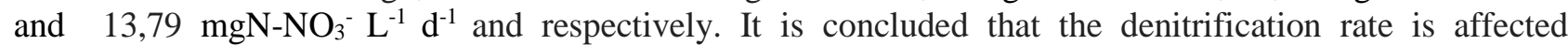
fundamentally by the total organic carbon content / bioavailability present in the sludge, and not by the homogenization.
\end{abstract}

Keywords: carbon, denitrification, homogenization. 


\section{INTRODUÇÃO}

Segundo Sant'Anna Junior (2010), a taxa da desnitrificação não tem sido tão investigada quanto à da nitrificação, havendo na literatura, registros de trabalhos conduzidos com sistemas reacionais distintos e concentrações diferentes das espécies de interesse (nitrato e carbono).

A reação da desnitrificação ocorre utilizando nitrogênio inorgânico como aceptor final de elétrons e uma ampla variedade de compostos orgânicos como doadores de elétrons, como exemplo metanol, acetato, glicose e etanol (Rodrigues, 2016).

Segundo Bueno (2011), a eficiência da desnitrificação depende acentuadamente da disponibilidade do material carbono orgânico para redução do nitrato ou nitrito, e da temperatura que influência na velocidade do processo.

A gestão de passivos ambientais (lodos e outros) originados pelos sistemas de tratamento de efluentes constitui um dos escopos das agroindústrias no que concerne aos resíduos pelos impactos negativos para saúde pública. Com isso, surge a necessidade de encontrar tecnologias econômicas que possam contribuir para o gerenciamento destes passivos. A desnitrificação sendo uma técnica que consome matéria orgânica pode-se apresentar como uma alternativa de solução ao assoreamento de lagoas (acumulo de sedimento), haja vista que é um processo heterotrófico podendo assim contribuir para o consumo do carbono ainda disponível nestas lagoas.

Sendo assim, o trabalho teve como objetivo avaliar a influência da homogeneização e biodisponibilidade/teor carbono nas taxas de desnitrificação de lodos de diferentes origens.

\section{MATERIAL E MÉTODOS}

Para realização do experimento, foram coletadas três amostras de lodos com diferentes teores de carbono, sendo provenientes de uma lagoa assoreada e de biodigestor de lagoa coberta (BLC), ambos de uma unidade produtora de leitões (UPL) localizada em Videiras, e do flotodecantador da estação de tratamento de dejetos suínos da Embrapa Suínos e Aves, Concórdia. Foi feita uma amostragem simples, na lagoa assoreada com uma área de 20 x 40m em três pontos nas larguras, distanciados em $6 \mathrm{~m}$ e três pontos nos comprimentos distanciados a 10m,todos pontos foram coletados numa profundidade de $1 \mathrm{~m}$, após coleta foram homogeneizados e colocados recipientes de $5 \mathrm{~L}$, quanto as amostras do biodigestor de lagoa coberta e flotodecantador ambas foram coletadas nos pontos de saída de lodo em recipientes de $5 \mathrm{~L}$, todas amostras posteriormente preservadas numa temperatura de $4^{\circ} \mathrm{C}$.

Realizou-se a caracterização dos lodos através das análises de $\mathrm{pH}$, COT, nitrogênio amoniacal total $\left(\mathrm{N}-\mathrm{NH}_{3}\right.$ ), alcalinidade, densidade e demanda bioquímica de oxigênio (DBO), de acordo (APHA, 2012).

Foram preparadas soluções de nitrato a partir do nitrato de sódio $\left(\mathrm{NaNO}_{3}\right)$, para uma concentração de $300 \mathrm{mgN}-\mathrm{NO}_{3} \mathrm{~L}^{-1}$.

O experimento foi realizado no Laboratório de Experimentação e Analise Ambientais da Embrapa Suínos e Aves-Concordia, utilizando-se béqueres de 4 L como espaço reacional, em que foi colocada uma

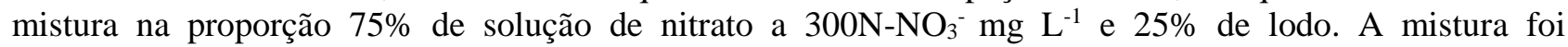
homogeneizada diariamente com uma espátula numa frequência de 10 vezes de um a dois períodos por dia, segundo estabelecido pelo delineamento experimental (Tabela 1).

O estudo deu-se por meio de planejamento estatístico, utilizando-se delineamento composto central (DCC). O delineamento proposto foi um $2^{2}$, tendo como variáveis independentes os diferentes tipos de lodos (teor de carbono) e a necessidade ou não, de homogeneização, e como variável resposta, as taxas de consumo de nitrato (Tabela 1).

A análise estatística foi feita utilizando-se o software statistica v. 12 trial, com nível de confiança de $95 \%(\mathrm{p}<0,05)$.

\section{RESULTADOS E DISCUSSÃO}

A Tabela 2 contém os valores das diferentes características físico-químicas, que foram consideradas para tipificação dos lodos, principalmente os valores do COT e DBO. 
Utilizando-se a metodologia de planejamento experimental, foi possível identificar que a variável concentração de carbono orgânico total foi a única significativa para a resposta taxa de consumo de nitrato de $122,40 \mathrm{mgN}-\mathrm{NO}_{3}{ }^{-} \mathrm{L}^{-1} \mathrm{~d}^{-1}$ (lodo alto), $24,81 \mathrm{mgN}^{-\mathrm{NO}_{3}}{ }^{-} \mathrm{L}^{-1} \mathrm{~d}^{-1}$ (lodo médio) e $13,79 \mathrm{mgN}^{-\mathrm{NO}_{3}}{ }^{-} \mathrm{L}^{-1} \mathrm{~d}^{-1}$ (lodo baixo), com $95 \%$ de confiança. A variável homogeneização não foi significativa, como pode ser visto no gráfico de pareto da figura 1. Sperling (1996) afirma que o consumo da matéria carbonácea é alta em lodos com frações do tipo rapidamente biodegradável, que é o caso do lodo alto com DBO $15725 \mathrm{mg} \mathrm{L}^{-1}$, para os lodos médio e baixo, apresentam o que autor considera como lentamente biodegradável, o que pode explicar a insignificância do efeito homogeneização. Conforme Golçaves (1999), existe uma relação direta entre DBO e carbono orgânico total nas taxas desnitrificação. Becarri et. al (1983) testando em sistema agitado, concluíram que as taxas de desnitrificação dos reatores não diferem dos sistema sem agitação, se a fonte de carbono se apresentar biodisponível.

Também a partir dos resultados do planejamento de experimentos, foi possível propor modelos empíricos matemáticos, em que pode-se verificar a taxa de consumo de nitrato durante o processo de desnitrificação em diferentes tipos de lodos.

O modelo matemático da Equação 1, (níveis codificadas), foi validado através de análise de variância (ANOVA), apresentando um coeficiente de correlação $\left(\mathrm{r}^{2}\right)$ de 0,97.

$$
T C N=29,14+4,33 H+10,35 *[C O T]-0,67 * H *[C O T]
$$

Onde:

TCN- Taxa de Consumo de Nitrato $\left(\mathrm{mgN}-\mathrm{NO}_{3}{ }^{-} \mathrm{L}^{-1} \mathrm{~d}^{-1}\right)$

H-Homogeneização

[COT] - Carbono Orgânico Total

A superfície de resposta foi gerada utilizando a interação das duas variáveis independentes. O efeito das variáveis para a resposta taxa de consumo de nitrato pode ser visto na figura 2.

\section{CONCLUSÃO}

As taxas de desnitrificação foram influenciadas basicamente pelo teor de carbono/biodisponibilidade, isto é, o lodo alto apresentou consumo de nitrato diário superior ao médio e o baixo. Quanto a homogeneização observou-se que não constitui um fator determinante para a taxa de desnitrificação, independentemente do tipo de lodo.

\section{AGRADECIMENTOS}

$\checkmark$ Ministério da Ciência e Tecnologia, Ensino Superior e Técnico Profissional, Moçambique.

$\checkmark$ Conselho Nacional de Desenvolvimento Científico e Tecnológico, Brasil.

$\checkmark$ A Empresa Brasileira de Pesquisa Agropecuária-Suínos e aves, Concórdia, SC, Brasil.

$\checkmark$ SISTRATES-BNDES (Projeto No 23.17.00.023.00.00).

\section{REFERÊNCIAS}

AMERICAN PUBLIC HEALTH ASSOCIATION (APHA). Standard Methods for the examination of water and wastewater. $20^{\mathrm{a}}$ ed., WASHINGTON, D.C.: APHA, AWWA, WEF, 1157 p, 1998.

APHA - American Public Health Association. Standard Methods for the Examination of Water and Wastewater. 22 ed. Washington, DC: American Public Health Association, 2012.

BECARRI, M.; PASSINO, R.; RAMADOORI, R.; TANDOI, V. Cinets of dissimilatory nitrate and nitrite reduction in suspended growth culture, 1983.

BUENO, R.F., Nitrificação e desnitrificação simultânea em reator com biomassa em suspensão e fluxo continuo de esgoto. Dissertação (Mestrado em Saúde púbica) - Universidade de São paulo,32-35pp 2010.

GOÇALVES.R. F. Gerenciamento do lodo de lagoas de estabilização não mecanizadas. Espírito Santo. 1999. RODRIGUES, M.I., IEMMA, A.F., Planejamento de experimentos \& otimização de processos, $3^{\circ}$ ed. cárita. 2014. 


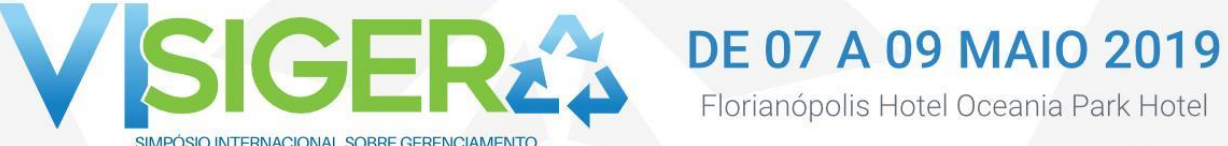

RODRIGUES,V.A.J.,Influência do sedimento no processo de remoção de nitrogênio por nitrificação/desnitrificação em lagoas de polimento, Belo Horizonte, 2016.

SANT'ANNA JR., G. L. Tratamento biológico de efluentes: Fundamentos e aplicações. Rio de Janeiro: 2010. SPERLING, M.V., Princípios básicos do tratamento de esgotos .2 ${ }^{\text {ed }}$.Belo Horizonte, 1996.

Tabela 1. Níveis codificados no planejamento experimental.

\begin{tabular}{ccc}
\hline Experimento & Homogeneização & Teor de Carbono \\
\hline $\mathbf{1}$ & -1 (sem homogeneização) & 8,86 (Alto - Flotodecantador) \\
$\mathbf{2}$ & 1 (dois períodos/dia) & 8,86 (Alto - Flotodecantador) \\
$\mathbf{3}$ & -1 (sem homogeneização) & -1 (Baixo - Lagoa) \\
$\mathbf{4}$ & 1 (dois períodos/dia) & -1 (Baixo - Lagoa) \\
$\mathbf{5}$ & 0 (um período/dia) & 0 (Médio - BLC) \\
$\mathbf{6}$ & 0 (um período/dia) & 0 (Médio - BLC) \\
$\mathbf{7}$ & 0 (um período/dia) & 0 (Médio - BLC) \\
\hline
\end{tabular}

Tabela 2. Caracterização físico-química dos diferentes lodos

\begin{tabular}{|c|c|c|c|c|c|c|c|c|c|c|c|}
\hline \begin{tabular}{|c|} 
Tipo de \\
Lodo \\
\end{tabular} & $\begin{array}{c}\text { Densidade } \\
\left(\mathrm{g} \mathrm{L}^{-1}\right)\end{array}$ & $\begin{array}{c}\text { DBO } \\
\left(\mathbf{m g ~ L}^{-1}\right) \\
\end{array}$ & pH & $\begin{array}{c}\text { COT } \\
\left(\mathrm{mg} \mathrm{L}^{-1}\right)\end{array}$ & $\begin{array}{l}\text { N-total } \\
\left(\mathrm{mg} \mathrm{L}^{-1}\right)\end{array}$ & $\begin{array}{c}\mathrm{N}-\mathrm{NH}_{3} \\
\left(\mathrm{mg} \mathrm{L}^{-1}\right) \\
\end{array}$ & $\begin{array}{c}\text { Alcalinidade } \\
\left(\mathrm{CaCO}_{3} \mathrm{mg} \mathrm{L}^{-1}\right)\end{array}$ & $\begin{array}{c}\mathbf{S T} \\
\left(\mathrm{g} \mathrm{kg}^{-1}\right)\end{array}$ & $\begin{array}{c}\mathbf{S F} \\
\left(\mathrm{g} \mathrm{kg}^{-1}\right)\end{array}$ & $\begin{array}{c}\mathbf{S V} \\
\left(\mathrm{g} \mathrm{kg}^{-1}\right)\end{array}$ & $\begin{array}{c}\text { SV/ST } \\
(\%)\end{array}$ \\
\hline Alto & 1,02 & 15725 & 7,32 & 2504 & 1733,28 & 1289,80 & 5283,63 & 64,90 & 18,20 & 46,70 & 71,90 \\
\hline Médio & 1,02 & 11642 & 6,95 & 542,60 & 1833,20 & 1321,40 & 4189,50 & 29,40 & 10,40 & 19,00 & 64,60 \\
\hline Baixo & 1,04 & 7760 & 7,35 & 260,02 & 958,80 & 783,28 & 4233,33 & 122,70 & 65,90 & 56,80 & 46,30 \\
\hline
\end{tabular}

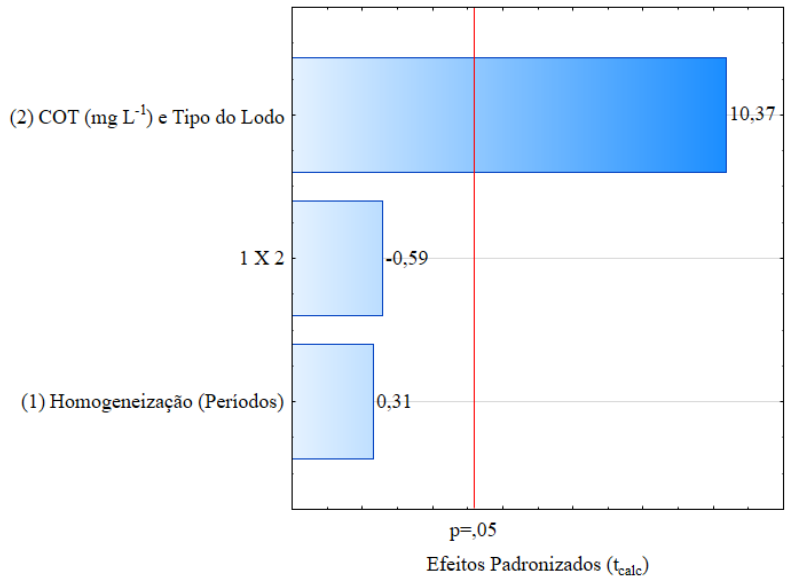

Figura 1. Relação entre o teor de carbono e homogeneização.

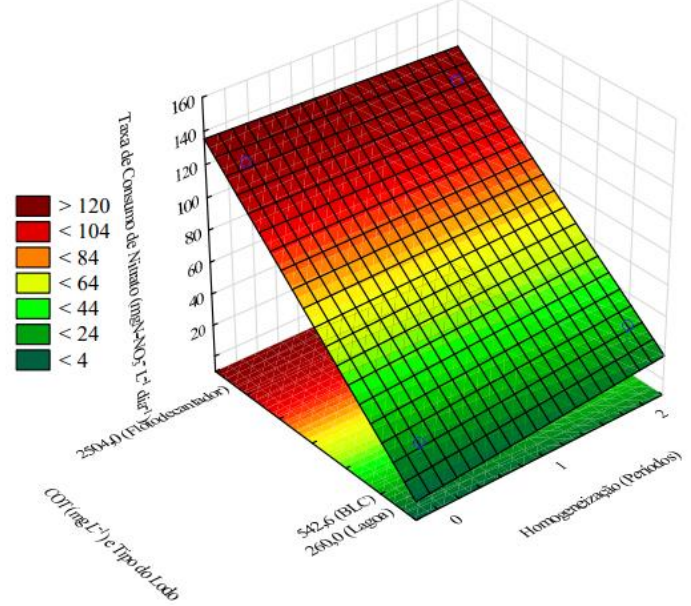

Figura 2. Superfície de resposta das taxas de desnitrificação dos diferentes tipos de lodos. 


\title{
PRODUÇÃO DE METANO FRENTE A VARIAÇÃO DO TEOR NUTRICIONAL DE UM REBANHO LEITEIRO
}

\author{
Assunção, G.P. ${ }^{1}$; Santos, A.M.*1,2 ${ }^{*}$ Barrado. C.M. ${ }^{1}$; Figueiredo, A.T. ${ }^{1}$ \\ ${ }^{1}$ Universidade Federal de Goiás, Catalão-GO-Brasil \\ ${ }^{2}$ Fundação Getulio Vargas / Energia, Rio de Janeiro-RJ-Brasil \\ "email: angelica.santos@.fgv.br
}

\begin{abstract}
RESUMO: A biodigestão anaeróbia tem sido aplicado com sucesso no tratamento de águas residuais da agroindústria cujos despejos contém elevadas concentrações de matéria orgânica. Nesta pesquisa, a biodigestão foi avaliada de acordo com o potencial de produção de metano, a partir de dejetos gerados por diferentes grupos de rebanho leiteiro. Esses grupos são diferenciados pelo período de lactação, que acarreta uma variação no teor nutricional da alimentação. A alimentação em si consiste da mesma composição (silagem de milho, milho puro, farelo de soja e concentrado vitamínico), contudo apresenta um aumento de 4 a $10 \%$ na quantidade desses componentes. Os grupos foram divididos em três categorias, sendo: grupo 1 (mais de dois períodos de lactação), grupo 2 (segunda lactação) e grupo 3 (primeiro período de lactação). Os biodigestores utilizados foram alimentados de forma individual com os dejetos referentes a esses grupos e diluídos na proporção 1:2 (dejeto/água). O sistema de biodigestão foi montado em batelada utilizando incubadora shaker orbital com temperatura controlada de $36^{\circ} \mathrm{C}$ e agitação de $150 \mathrm{rpm}$. O metano gerado foi monitorado a partir da medição direta do volume deslocado de solução de hidróxido de sódio. Os parâmetros cinéticos foram obtidos através do modelo matemático modificado de Gompertz. Os resultados demonstram que uma maior suplementação influenciou no menor tempo de adaptação dos microorganismos (de 19 para 4 dias), maior taxa de produção de metano (33\% superior) e tempo de retenção hidráulica menor (de 66 para 33 dias).
\end{abstract}

Palavras-chave: metano, biodigestão anaeróbia, rebanho leiteiro.

\begin{abstract}
Anaerobic digestion has been successfully applied in the treatment of agroindustrial wastewater whose evictions contain high concentrations of organic matter. In this research, the biodigestion was evaluated according to the potential of methane production, from waste generated by different groups of dairy herd. These groups are differentiated by the lactation period, which results in a variation in the nutritional content of the diet. The diet itself consists of the same composition (corn silage, pure corn, soybean meal and vitamin concentrate), but it has an increase of 4 to $10 \%$ in the quantity of these components. The groups were divided into three categories: Group 1 (more than two lactation periods), Group 2 (second lactation) and Group 3 (first lactation period). The biodigesters used were fed individually with the manure related to these groups and diluted in the proportion 1:2 (slurry/water). The biodigestion system was assembled in batch using an orbital shaker incubator with controlled temperature of $36^{\circ} \mathrm{C}$ and agitation of $150 \mathrm{rpm}$. The methane generated was monitored from the direct measurement of the displaced volume of sodium hydroxide solution. The kinetic parameters were obtained using the modified Gompertz mathematical model. The results show that greater supplementation influenced the shorter adaptation time of microorganisms (from 19 to 4 days), higher methane production rate (33\% higher) and a lower hydraulic retention time (from 66 to 33 days).
\end{abstract}

Keywords: methane, anaerobic digestion, dairy herd.

\section{INTRODUÇÃO}

No Brasil, a produção de leite é uma das principais atividades agropecuárias e teve aumento nos últimos anos (IBGE, 2017). Porém, a intensificação desse sistema de produção resulta em grandes concentrações de dejetos, gerando impactos ambientais.

A utilização de resíduos agrícolas através da digestão anaeróbia é uma estratégia para redução dos gases de efeito estufa (GEE), uma vez que melhora o sistema de manejo do solo e permite reduzir o uso de combustíveis fósseis. Esta estratégia também melhora o tratamento de resíduos orgânicos e seu uso como fertilizante, podendo fornecer uma fonte de energia renovável local. 
O biogás é uma mistura gasosa combustível composta principalmente de metano $\left(\mathrm{CH}_{4}\right)$ e gás carbônico $\left(\mathrm{CO}_{2}\right)$, derivada da atividade biológica durante a decomposição de resíduos orgânicos em meio anaeróbio. A composição do biogás varia de acordo com o substrato a ser degradado e com as condições físicas e químicas que influenciam no processo da biodigestão anaeróbia.

A intensidade da emissão de metano originária da fermentação ruminal de bovinos depende de alguns fatores, tais como, o tipo de animal, consumo de alimentos, e ainda digestibilidade da dieta (Mallmann, 2013). O estudo da influência da dieta do rebanho leiteiro está diretamente relacionado com a qualidade dos resíduos, o que influência diretamente na melhoria dos produtos obtidos pelo processo de biodigestão anaeróbia.

Portanto, o estudo cinético se mostra de extrema importância para poder correlacionar os nutrientes, juntamente com os microorganismos presentes, para melhor produtividade de biometano. Dessa forma, o objetivo geral foi analisar o processo de biodigestão anaeróbia de dejetos de rebanho leiteiro alimentados com quantidades diferentes de nutrientes. O uso do modelo matemático permite definir o tempo de adaptação dos microrganismos (fase lag) e taxa de produção de metano $\left(\mu_{\mathbf{m}}\right)$.

\section{MATERIAL E MÉTODOS}

A pesquisa foi realizada no Laboratório de Pesquisa em Soluções Energéticas e Ambientais (LPSEA) localizado na Universidade Federal de Goiás, regional Catalão (UFG/RC).

Os dejetos foram obtidos de rebanho leiteiro do sistema de confinamento (Compost Barn) da Fazenda Ribeirão, Km 06 Catalão - GO, coordenadas $18,09^{\circ} \mathrm{S}, 47,91^{\circ} \mathrm{W}$. O sistema de confinamento é dividido em grupos, seguindo os períodos de lactação e a taxa produtora de leite. Utilizou três tipos de dejetos dos seguintes grupos: grupo 1 - vacas com mais de dois períodos de lactação; grupo 2 - segunda lactação e grupo 3 - novilha, primeiro período de lactação (primeira cria). A Tabela 1, apresenta a alimentação de cada grupo.

Foram montados três biodigestores em batelada em frascos de vidro borossilicato com capacidade total de 1,0 L. A cada biodigestor foi adicionado $500 \mathrm{~mL}$ de meio reacional composto por água e dejeto bovino. As análises físico-químicas da entrada do biodigestor de $\mathrm{pH}$, sólidos totais (ST) e sólidos totais voláteis (STV), foram realizadas de acordo com as metodologias descritas em Standard Methods for the Examination of Water and Wastewater (Apha, et al., 2012).

Os substratos (dejetos) foram diluídos em proporção de 1:2 (dejetos/água) e filtrados em uma peneira de $1,0 \mathrm{~mm}$. O sistema de biodigestão foi montado em uma incubadora Shaker Orbital com temperatura controlada de $36^{\circ} \mathrm{C}$ e agitação de $150 \mathrm{rpm}$. O biogás gerado foi monitorado a partir da medição direta do volume deslocado de solução de hidróxido de sódio. A produção de metano foi monitorada diariamente em períodos de $24 \mathrm{~h}$.

Os dados da produção de biogás foram submetidos a análise de produtividade utilizando o método matemático modificado de Gompertz, que pode ser observado pela equação 1, onde é possível analisar de maneira clara todos os parâmetros $\left(\lambda, \mu_{m}, A\right)$ sendo eles: $(\lambda)$ fase lag, $\left(\mu_{m}\right)$ taxa máxima de produção de biogás e (A) produção máxima de biogás (Zwietering et al., 1990).

$$
y=A \exp \left\{-\exp \left[\frac{\mu_{m} \cdot e}{A}(\lambda-t)+1\right]\right\}
$$

\section{RESULTADOS E DISCUSSÃO}

As características físico-química dos afluentes, mostraram valores próximos de $\mathrm{pH}(5,5$ - 6,2), sólidos totais voláteis $(1,7 \%-2,0 \%)$ e sólidos totais $(2,0-2,45 \%)$, porém as performances dos biodigestores foram diferentes. De acordo com Angelidaki et al. (2003) a população de microorganismos se estabelece conforme o substrato, sendo que a eficácia da conversão dos compostos em biogás depende da disponibilidade e da biodegradabilidade do substrato. Desse modo, o substrato exerce influência na velocidade de crescimento microbiano, consequentemente na produção de biogás.

Os dados experimentais foram modelados a partir da aplicação do Modelo de Gompertz modificado, que propiciou os cálculos dos parâmetros cinéticos dos diferentes substratos (dejetos) para produção de metano, os quais são apresentados na Tabela 2. O dejeto do rebanho leiteiro do grupo 3, alimentados com uma dieta mais rica em nutrientes, apresentou os melhores resultados da taxa máxima de produção de metano $\left(\mu_{m}=\right.$ $\left.101,81 \mathrm{~mL} d^{-1}\right)$ e fase lag $(\boldsymbol{\lambda}=4 d)$, indicando que tal dejeto apresentou maior biodegradabilidade anaeróbia em relação aos demais dejetos estudados. A fase lag de crescimento microbiano representa o período inicial, 
que precede a fase de crescimento exponencial, e, nessa fase, os micro-organismos se encontram em um estado de latência (Prats et al., 2008).

Os dejetos do grupo 2 obteve taxa máxima de produção de metano $\left(\mu_{m}=66,63 \mathrm{~mL} \mathrm{~d}^{-1}\right)$ similar ao dejeto do grupo $1\left(\mu_{m}=67,06 \mathrm{~mL} d^{-1}\right)$, a fase lag foram iguais com tempo de 19 dias. $\mathrm{O}$ grupo 1 foi o rebanho que recebeu a menor dieta nutricional, sendo o rebanho do grupo $2 \mathrm{com} 4 \%$ a mais de nutrientes e os rebanhos do grupo 3 com 10\%. Observa-se que a suplementação alimentar de $4 \%$ não influenciou nos parâmetros cinéticos $\left(\mu_{\mathrm{m}}\right.$ e fase $\lambda$ ), mas com $10 \%$ de suplementação na dieta alimentar do rebanho (grupo 3) aumentou 33\% na taxa máxima de produção de biogás e diminuiu de 19 dias para 4 dias a fase de adaptação dos microorganismos. Dessa forma, o período de adaptação da comunidade microbiana do grupo 1 e 2 apresentaram piores performance, possivelmente por causa da deficiência nutricional no meio reacional submetido.

A Figura 1, representa as curvas de produção de metano ao longo do tempo, observa-se que o gráfico do grupo 3 apresentou o menor tempo de retenção hidráulica (TRH) com 33 dias, já os biodigestores com dejetos do grupo 1 e 2 , apresentaram estabilidade para produção acumulada de metano com dobro do tempo, 66 dias.

Em relação ao ajuste do modelo aos dados experimentais, o coeficiente de determinação $\left(\mathrm{R}^{2}\right)$ é uma medida que representa o ajuste de um modelo em relação aos valores experimentais observados. Ele varia entre 0 e 1 e assinala o quanto o modelo consegue explicar os valores observados. Portanto, é possível notar que o modelo foi capaz de reproduzir a produtividade de metano com bons ajustes, com $\mathrm{R}^{2}>0,995$.

\section{CONCLUSÃO}

A avaliação da biodigestão anaeróbia de substratos cujos dejetos são produzidos por animais que receberam diferentes dietas se fez interessante, pois demonstraram através dos dados que uma maior suplementação alimentar influenciou na qualidade dos dejetos em produzir metano, gerando dejetos mais ricos em energia e nutrientes para biodigestão anaeróbia, obtendo menor tempo de adaptação dos microrganismos (fase lag), maior taxa de produção de metano $\left(\mu_{m}\right)$ e menor tempo de retenção hidráulica (TRH).

\section{AGRADECIMENTOS}

Os autores agradecem o apoio financeiro da Concessionária Serra do Facão - SEFAC da Fundação Getulio Vargas - FGV e da Agência Nacional de Energia Elétrica - ANEEL no âmbito do projeto de P\&D (P\&D 06899-2612/2016) que viabilizou a realização deste trabalho a Universidade Federal de Goiás- Regional Catalão e o ao Curso de Pós-Graduação em Química.

\section{REFERÊNCIAS}

ANGELIDAKI, I.; ELLEGAARD, L.; AHRING, B. K. Applications of the anaerobic digestion process. Advances in biochemical engineering/biotechnology, v. 82, p. 1-33, 2003.

APHA. 2012 Standard Methods for the Examination of Water and Wastewater. American Public Health Association, Washington, DC.

IBGE - Instituto Brasileiro de Geografia e estatística. Estatística da Produção Pecuária, 2017. Disponível em: ftp://ftp.ibge.gov.br/Producao_Pecuaria/Fasciculo_Indicadores_IBGE/abate-leite-couro-

ovos_201701caderno.pdf. Arquivo consultado em 23 de novembro de 2018.

MALLMANN, Larissa Schmatz. Potential of methane production from cattle based on addition of wet brewery residue to diet. 2013. 89 f. Tese (Doutorado em Engenharia) - Universidade Estadual do Oeste do Paraná, Cascavel, 2013.

PRATS, Clara et al. Analysis and IbM simulation of the stages in bacterial lag phase: Basis for an updated definition. Journal of Theoretical Biology, v. 252, n. 1, p.56-68, 2008.

ZWIETERING, M.H., JONGENBURGER, I., ROMBOUTS, F.M., van't Riet, K. Modeling of the bacterial growth curve. Applied and Environmental Microbiology, v. 56, n. 6, p. 1875-188, 1990. 
Tabela 1. Classificação da dieta de confinamento do rebanho em diferentes períodos de lactação.

\begin{tabular}{cccc}
\hline Dados Gerais & Grupo 1 & Grupo 2 & Grupo 3 \\
\hline $\mathrm{N}^{\text {o de Vacas (unid) }}$ & 40 & 42 & 40 \\
Silagem de milho $(\mathrm{kg})$ & 31,68 & 33 & 35,31 \\
Milho puro $(\mathrm{kg})$ & 6,72 & 7 & 7,49 \\
Farelo de soja $(\mathrm{kg})$ & 4,32 & 4,5 & 4,82 \\
Concentrado vitamínico $(\mathrm{kg})$ & 0,48 & 0,5 & 0,54 \\
\hline
\end{tabular}

Tabela 2. Parâmetros do modelo de Gompertz calculados para as três condições experimentais utilizados.

\begin{tabular}{ccccc}
\hline Substrato & $\begin{array}{c}\text { Produção } \\
\text { acumulada de } \\
\text { metano } \\
\boldsymbol{A}(\mathbf{m l})\end{array}$ & $\begin{array}{c}\text { Taxa máxima de } \\
\text { produção de metano } \\
\mu_{\boldsymbol{m}}\left(\mathbf{m l ~ d} \mathbf{~ d}^{-1}\right)\end{array}$ & $\begin{array}{c}\text { Fase lag } \\
\boldsymbol{\lambda}(\mathbf{d})\end{array}$ & $\begin{array}{c}\text { Coeficiente de } \\
\text { correlação } \boldsymbol{R}^{\mathbf{2}}\end{array}$ \\
\hline Dejeto do Grupo 1 & 2127,73 & 66,63 & 19 & 0,997 \\
Dejeto do Grupo 2 & 2307,65 & 67,06 & 19 & 0,997 \\
Dejeto do Grupo 3 & 1976,78 & 101,81 & 4 & 0,995 \\
\hline
\end{tabular}

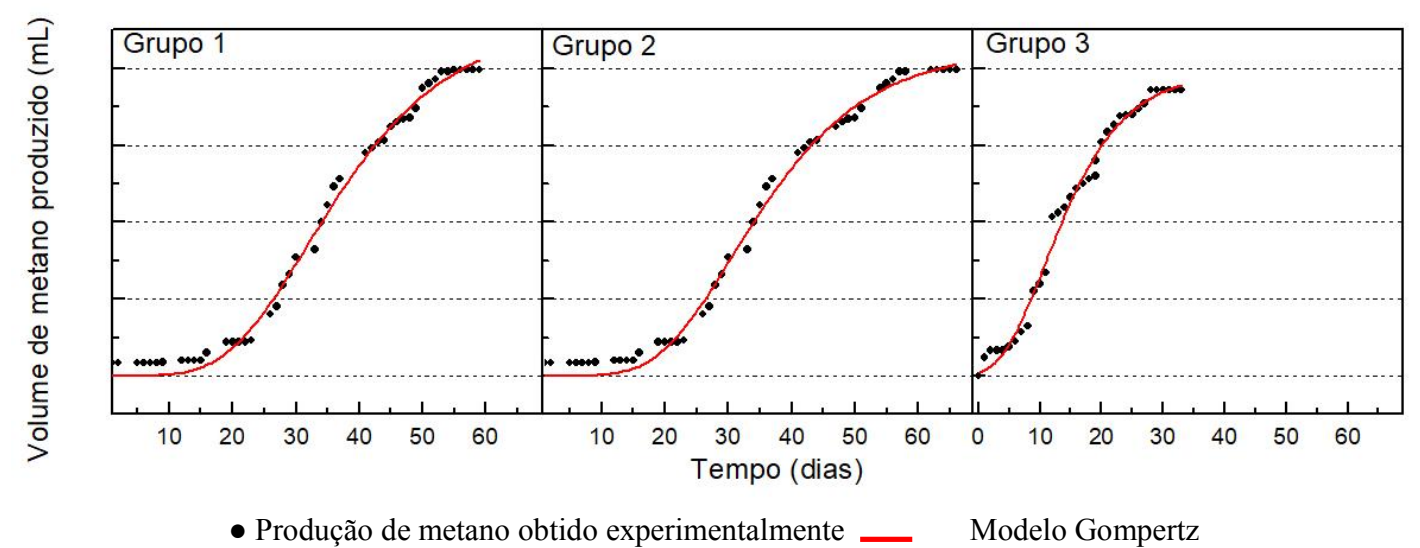

Figura 1. Volume produzido de metano pelos diferentes dejetos. 


\title{
PRODUCTION AND CHARACTERIZATION OF AÇAÍ WASTE BIOCHAR THROUGH GASIFICATION PROCESS
}

\author{
Pessôa, T.S.*1; Nascimento, B.F. ${ }^{2}$; Martins, L. ${ }^{3}$; Fraga, T.J.M. ${ }^{2}$; Silva, F.L.H. ${ }^{4}$;a Motta Sobrinho, \\ M.A. ${ }^{2}$ \\ ${ }^{1}$ Professor of Federal Institute of Education, Science and Technology of Pernambuco (IFPE) -PE 60 Highway, W/N, Ipojuca-PE; \\ ${ }^{2}$ Researchers of Department of Chemical Engineering, Federal University of Pernambuco (UFPE) - Arthur de Sá Street, W/N, \\ Recife-PE \\ ${ }^{3}$ Master's Degree student of Post-Graduation Program in Environmental Engineering, Federal Rural University of Pernambuco \\ (UFRPE)-Dom Manoel de Medeiros Street, W/N, Recife-PE \\ ${ }^{4}$ Researcher of Department of Chemical Engineering, Federal University of Paraíba (UFPB) - Campus Universitário I, João \\ Pessoa-Paraíba - CEP: 58051-900 \\ *thiagosabino22@gmail.com
}

\begin{abstract}
As the main residue of the açaí processing industry, the fruit core is an oleaginous seed, formed by a small solid endosperm attached to a tegument, which at maturity is rich in cellulose, hemicellulose and lignin. This biomass possesses a wide potential of application in the environmental and sanitary technology. Aiming to add value to the waste from açaí processing industry, it was used as biomass for energy production. The energy produced from gasification of the biomass was quantified and can reach up to $26 \mathrm{kWe}$. Moreover, the charcoal resulting from this process was then activated and characterized in order to apply it as biosorbent of textile dyes and other applications. Specific Surface Area and Pore Distribution (BET), Thermogravimetric analysis (TGA), Scanning Electron Microscopy (SEM), Fourrier Transfer-Infrared Spectroscopy (FTIR) and $\mathrm{X}$-ray Diffraction (XRD) techniques were employed to characterize açaí biochar. It was observed significant modifications on biochar surface morphology after its activation with $\mathrm{NaOH}$ A.P. 99\%; furthermore, the anionic activation increased its specific surface area from 1.94 to $491.90 \mathrm{~m}^{2} \mathrm{~g}^{-1}$ and leaded to an expressive increase in its maximum adsorption capacity of Methylene Blue from 33.73 to $93.23 \mathrm{mg} \mathrm{g}^{-1}$. Moreover, the equilibrium isotherm applied to fit the experimental data was the combined Langmuir-Freundlich model.
\end{abstract}

Keywords: açaí waste, biochar, gasification process, agricultural residue processing, characterization.

\section{INTRODUCTION}

In Brazil, the production of açaí has a great relevance in the economic scenario, especially in the North and Northeast of the country, since the commercialization of pulp generates jobs, moves the economy, provides food and, consequently, income for the population. As the main residue of the açaí processing industry, the core is an oleaginous seed, formed by a small solid endosperm attached to a tegument, which at maturity is rich in cellulose, hemicellulose and lignin, and this by-product corresponds to approximately $85 \%$ of the fruit. Because they do not have a proper disposal and use these tons of these wastes are randomly disposed of in the streets and can cause environmental damage. Carbons, charcoal and biochar is applied in several purposes worldwide, since soil remediation to wastewater treatment. Among their several applications, it can be remarked: effluent treatment by adsorption (Garcia et al., 2017; Cazetta et al., 2016), pasture herbicide healer (Singh et al., 2019), catalysis and chemical reducing agent (Liu and Astruck, 2018). Additionally, it is reported in the literature that the world demand for activated carbons can be expected to dramatically increase (rising 8.1\% per year to 2.1 million metric tons in 2018) (Maneerung et al., 2016). The "processing of a waste to treat another waste" is one of the key points inside the concept of Industrial Circular Economy (ICE), which delivers the philosophy of add value to residues and effluent of industrial processes, which would be discharged causing degradation to environment and increasing costs (Fraga et al., 2018; Clark et al., 2016).

In this work, residue from the açaí processing industry was used as biomass in a gasifier to produce energy and the biochar produced in this process was then benefited, characterized and then used in the adsorption of Methylene Blue.

\section{Açaí biochar production}

\section{MATERIALS AND METHODS}

The biomass used in the experiment was obtained from the açaí stone in a natural gas gasifier, installed in the Activated Charcoal Laboratory of the UFPB (João Pessoa-PB). The açaí waste was collected in the city of Belém-PA. They were dried and exposed to the sun for four days to remove moisture. Then, the dry material 
was fed to the fixed bed gasifier imported from the Indian Institute of Science/Combustion Gas Propulsion Laboratory, IISc/CGPL. The gasifier is equiped with an "open top" gas lighter and downflow air inlet that has a thermal capacity of $4 \mathrm{~kW}$ and electric capacity of $1 \mathrm{~kW}$.The material fell by gravity as it was being gassed. A successful employment of biomass from mix wood waste in this gasifier leaded to a maximum energy generation of $26 \mathrm{kWe}$ (Rumão et al., 2014). For a biomass consumption of $10 \mathrm{~kg} / \mathrm{h}$, there is the generation of approximately $10 \mathrm{kWe}$ and a production of $1 \mathrm{~kg}$ of charcoal. Moreover, the charcoal derived from gasification can be destined to adsorption of water pollutants as an alternative to commercial activated carbon. The biochar was then sieved in 100 Mesh $(0.149 \mathrm{~mm})$. For the activation, the sample was contacted with the activating agent $\mathrm{NaOH}$ A.P. $97.0 \%$ in a muffle under heating of $400^{\circ} \mathrm{C}$ and, subsequently, $700^{\circ} \mathrm{C}$ for $2 \mathrm{~h}$.

\section{Characterization of açaí biochar}

All açaí biochar characterization analyses were performed at the Laboratory of Activated Carbon and at the Laboratory of Analytic Chemistry of Federal University of Paraíba (UFPB). Specific Surface area and Pores Distribution (BET) were performed under Brunauer-Emett-Teller method of adsorption-desorption of $\mathrm{N}_{2}$ flow in a microporosimeter Micrometrics, model ASAP 2020. Scanning Electron Microscopy (SEM) was performed through an electronic microscope MEO, Model 1430. The TGA analyzes were performed in the Thermic analyzer Shimadzu, model TGA Q 50, using a heating ramp of $10^{\circ} \mathrm{C}$ per minute under a dynamic atmosphere of air, using a nitrogen gas flow of $25 \mathrm{~mL} \mathrm{~min}^{-1}$, raising the ambient temperature up to $900^{\circ} \mathrm{C}$. Infrared spectroscopy (FTIR) was performed on the IR spectrophotometer Shimadzu, model IRPrestige-21. Xray diffraction technique were realized through a X-ray diffractometer Bruker, model D2 PHASER, equipped with $\mathrm{Cu}-\mathrm{K} \alpha$ radiation, with a scanning range of $5^{\circ}$ to $85^{\circ}$ with a pitch of $0.02^{\circ} \mathrm{min}^{-1}$.

\section{Adsorption of Methylene Blue in batch}

Aliquots of $25 \mathrm{~mL}$ of $\mathrm{MB}$ dye solution were transferred to flasks of $125 \mathrm{~mL}$. All dye adsorption experiments were carried out with constant stirring $(300 \mathrm{rpm})$, under environmental conditions $\left(25^{\circ} \mathrm{C} ; 1 \mathrm{~atm}\right)$ and $\mathrm{pH}$ 5.5. Standard solutions of $\mathrm{NaOH}$ and $\mathrm{HCl}$ of 6.0 and $0.1 \mathrm{M}$ were used to adjust the $\mathrm{pH}$ of the $\mathrm{MB}$ solution. After the adsorption, the adsorbent and adsorbate were separated by filtration and the residual concentration of dyes samples in the solution were measured by an UV-Vis spectrophotometer in a maximum absorbance peak for MB $\left(\lambda_{\max } 659 \mathrm{~nm}\right)$. All the experiments had been performed in duplicate, in which C was calculated by the arithmetic media between the two measurements. Using the final concentration data, the adsorption capacity (q) was finally calculated (Equation 1).

$$
q=\frac{\left(C_{0}-C\right) \cdot V}{m}
$$

where $\mathrm{q}$ is the adsorption capacity in equilibrium $\left(\mathrm{mg} \mathrm{g}^{-1}\right) ; \mathrm{C}_{0}$ and $\mathrm{C}$ are the initial and equilibrium concentration, respectively $\left(\mathrm{L}^{-1}\right) ; \mathrm{V}$ is the solution's volume $(\mathrm{L}) ; \mathrm{m}$ is the adsorbent mass $(\mathrm{g})$.

Equilibrium experiments were realized to define significant parameters, such as maximum adsorption capacity $\left(\mathrm{q}_{\mathrm{m}}\right)$ and the equilibrium constant $\left(\mathrm{K}_{\mathrm{LF}}\right)$. These parameters were obtained through the fitting of Langmuir-Freundlich model (L-F), described in the Equation 2, by the tool "non-linear curve fit" of Origin $9.0^{\mathrm{TM}}$ software.

$$
\frac{q}{q_{m}}=\frac{K_{L F} C^{n}}{1+K_{L F} C^{n}}
$$

where $\mathrm{q}$ is the adsorption capacity in equilibrium $\left(\mathrm{mg} \mathrm{g}^{-1}\right) ; \mathrm{C}$ is the adsorbate concentration at equilibrium (mg $\left.\mathrm{L}^{-1}\right) ; \mathrm{q}_{\mathrm{m}}$ is the maximum adsorption capacity $\left(\mathrm{mg} \mathrm{g}^{-1}\right) ; \mathrm{n}$ is the heterogeneity factor (dimensionless); and finally, $\mathrm{K}_{\mathrm{LF}}$ is the Langmuir-Freundlich model equilibrium constant $\left(\left(\mathrm{L} \mathrm{mg}^{-1}\right)^{\mathrm{n}}\right)$.

\section{Characterization analysis}

\section{RESULTS AND DISCUSSION}

Through the SEM images at 3000x magnification (Figure 1a) of the samples it was possible to observe a meso and macroporous structure, with formation of aggregates on the larger surfaces. After $\mathrm{NaOH}$ activation of the biochar, the presence of pores can be clearly observed (Figure 1b). According to IUPAC recommendation, pores with diameter lesser than $20 \AA$ are called micropores; and those with diameter higher than $500 \AA$ are called macropores; between both measurements, it is considered mesoporous structure 
(Thommes et al., 2015). BET analysis showed a significant increase in açaí biochar after its anionic activation: from 1.94 to $491.90 \mathrm{~m}^{2} \mathrm{~g}^{-1}$. Moreover, $\mathrm{N}_{2}$ adsorption-desorption exhibited the characteristic hysteresis and a type IV isotherm behavior (Figure 1c), evidencing its mesoporous morphology (Thomes et al., 2015). TGA analysis (Figure 1d) showed a loss of mass between $50^{\circ} \mathrm{C}$ and $100^{\circ} \mathrm{C}$ and it was due to loss of water from the material. Between $100^{\circ} \mathrm{C}$ and $250^{\circ} \mathrm{C}$ the mass loss becomes linear and the biochar presented a relative thermal stability. From $250^{\circ} \mathrm{C}$ the second mass loss is registered, corresponding to the degradation and volatilization of the components of the carbonaceous materials. FTIR spectra for $\mathrm{NaOH}$-activated biochar exhibited a wide band at $3483 \mathrm{~cm}^{-1}$, attributed to the stretching vibration of $\mathrm{OH}$ group. Such band is not seen in non-activated biochar (Figure 1e). Moreover, the presence of $\mathrm{OH}$ moieties favors the adsorption of cationic dyes, such Methylene Blue, by the increasing of electron donor-receptor interactions, which was observed in the increase of maximum adsorption capacity. XRD diffractograms (Figure 1f) showed that after the activation process there was a marked reduction in the d-spacing and intensity of the same, probably due to the $\mathrm{NaOH}$ chemical attack to some crystalline structures of biochar that occurred during the activation. In the activated charcoal diffractogram it is also possible to observe the formation of some more acute peaks, which can be attributed to traces of the Na from the activation agent which were not completely removed. Moreover, both XRD patterns exhibited characteristics of amorphous carbon.

\section{Adsorption of textile dyes - a comparative study}

Açaí biochar exhibited a high adsorption capacity of Methylene Blue in comparison to other biosorbents reported in the literature (Table 1). The effect of chemical activation is reported as one factor of enhancing biosorbent surface, once there is an increase of its specific surface area, and consequently, a multiplicity of its active sites (Cazetta et al., 2016). Another remarked advantage of açaí $\mathrm{NaOH}$-activated biochar is its fast adsorption in comparison to all other summarized biosorbents. Additionally it showed much higher adsorption velocity when compared with carbons derived from palm kernell husks and wood shavings: 14 and 5 times faster, respectively (Table 1).

\section{CONCLUSIONS}

The work aimed the application of açaí waste as biomass for the gasifing process, its potential for energy generation and further application as biosorbent of toxic dyes from wastewaters. Despite its elevated potential, it is necessary expand the adsorption towards other type of dyes, especially those consumed in textile industry, which are discharged in water bodies from laundries and washers. Characterization analyses evidenced that the anionic activation process can enhance biochar surface properties, provoking a substantive increase in its maximum adsorption capacity.

\section{ACKNOWLEDGMENTS}

The authors kindly thank the financial support provided by the agencies Conselho Nacional de Desenvolvimento Científico e Tecnológico - CNPq (grant 311133/2015-0) and Fundação de Amparo à Ciência e Tecnologia do Estado de Pernambuco - FACEPE (grants IBPG-1917-3.06/16 and APQ-1086-3.06/15).

\section{REFERENCES}

Cazetta, A. L.; Pezoti, O.; Bedin, K. C.; Silva, T. L.; Paesano Junior, A.; Asefa, T.; Almeida, V. C. Magnetic Activated Carbon Derived from Biomass Waste by Concurrent Synthesis: Efficient Adsorbent for Toxic Dyes. ACS Sustainable Chemistry and Engineering, v. 4(3), p. 1058-1068, 2016.

Clark, J. H.; Farmer, T. J.; Herrero-Davila, L.; Sherwood, J. Circular economy design considerations for research and process development in the chemical sciences. Green Chemistry, v. 18, 3914-3934, 2016.

El-Sayded, G. O.; Yehia, M. M.; Asaad, A. A. Assessment of activated carbon prepared from corncob by chemical activation with phosphoric acid. Water Resources and Industry, v.7-8, p. 66-75, 2014.

Fraga, T. J. M.; Fraga, D. M. S. M.; da Silva, T. C.; Carvalho, M. N.; da Motta Sobrinho, M. A. Adsorption of reactive dyes onto thermally treated waste from aluminum lamination. Water Practice and Technology, v. 13(3), p. 629-641, 2018.

Garcia, J. R.; Sedran, U.; Zaini, M. A. A.; Zakaria, Z. A. Preparation, characterization, and dye removal study of activated carbon prepared from palm kernel shell. Environmental Science and Pollution Research, v. 25(6), p. 5076-5085, 2018. 
Islam, M.A., Ahmed, M.J., Khanday, W.A., Asif, M., Hameed, B.H. Mesoporous actived carbon prepared from $\mathrm{NaOH}$ activation of rattan (Lacosperma secundiflorum) hydrochar for methylene blue removal. Ecotoxicology and Environmental Safety, v. 138, p. 279-285, 2017.

Liu, X.; Astruc, D. Development of the applications of palladium on charcoal in organic synthesis. Advanced Synthesis and Catalysis, v. 360(18), p. 3426-3459, 2018.

Maneerung, T.; Liew, J.; Dai, Y.; Kawi, S.; Chong, C.; Wang, C.-H. Activated carbon derived from carbon residue from biomass gasification and its application for dye adsorption: kinetics, isotherms and thermodynamic studies. Biorresource Technology, v. 200, p. 350-359, 2016.

Rumão, A. S.; Jaguaribe, E. F.; Bezerra, A. F.; Oliveira, B. L. N.; Queiroga, B. L. C. Electricity generation from biomass gasification. Engenharia Térmica (Thermal Engineering), v. 13(1), p. 28-31, 2014.

Singh, V.; Masabni, J.; Baumann, P.; Isakeit, T.; Matocha, M.; Provin, T.; Liu, R.; Carson, K.; Bagavathiannan, M. Activated charcoal reduces pasture herbicide injury in vegetable crops. Crop Protection, v. 117, p. 1-6, 2019.

Spagnoli, A. A.; Giannakoudakis, D. A.; Bashkova, S. Adsorption of methylene blue on cashew nut Shell based carbons activated with zinc chloride: The role of surface and structural parameters. Journal of Molecular Liquids, v. 229, p. 465-471, 2016.

Thommes, M.; Kaneko, K.; Neimark, A. V.; Olivier, J. P.; Rodriguez-Reinoso, F.; Rouquerol, J.; Sing, K. S. W. Physisorption of gases, with special reference to the evaluation of surface area and pore size distribution (IUPAC Technical Report). Pure and Applied Chemistry, v. 87(9-10), p. 1051-1069, 2015.
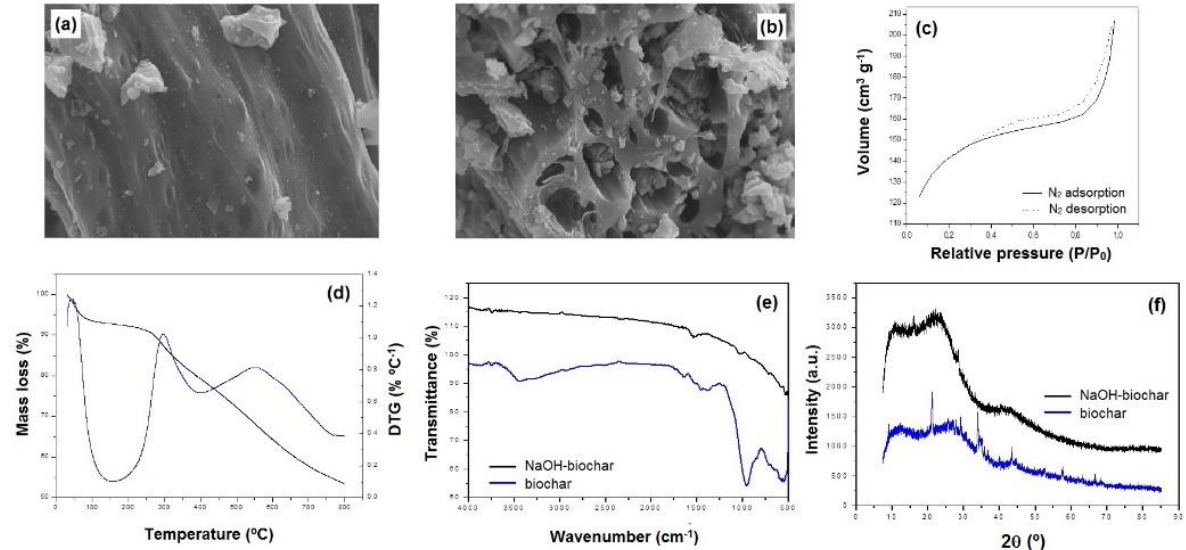

Figure 1. SEM photos for non-activated biochar (a); NaOH-activated biochar (b); $\mathrm{N}_{2}$ BET isotherm for $\mathrm{NaOH}$-biochar (c); thermograms for non-activated biochar (d); FTIR spectra for non-activated biochar and $\mathrm{NaOH}$-biochar (e); XRD patterns for non-activated biochar and $\mathrm{NaOH}$-biochar (f).

Table 1. Comparative evaluation of the adsorption of a cationic dye by açaí biochar and the adsorption of other types of dyes by some modified biomass charcoals reported in the literature

\begin{tabular}{|c|c|c|c|c|c|}
\hline Raw material & $\begin{array}{c}\text { Activating } \\
\text { agent }\end{array}$ & $\begin{array}{c}\text { SBET } \\
\left(\mathbf{m}^{2} \mathbf{g}^{-1}\right) \\
\end{array}$ & $\begin{array}{c}\mathbf{q m} \\
\left(\mathbf{m g ~ g}^{-1}\right) \\
\end{array}$ & $t_{\text {eq }}(\min )$ & Reference \\
\hline Coconut shells charcoal & $\mathrm{FeCl}_{3} 6 \mathrm{H}_{2} \mathrm{O}$ & 238 & 22.30 & 25 & Cazetta et al. (2016) \\
\hline Palm kernell husks & $\mathrm{ZnCl}_{2}$ & 857 & 183.00 & 360 & Garcia et al. (2017) \\
\hline Corncob & $\mathrm{H}_{3} \mathrm{PO}_{4}$ & 633 & 17,57 & 45 & El-Asyed et al. (2014) \\
\hline Wood shavings & $\mathrm{NaOH}$ & 1135 & 359.00 & 120 & Islam et al. (2017) \\
\hline Cashew nutshells & $\mathrm{ZnCl}_{2}$ & 875 & 215.00 & 60 & Spagnoli et al. (2017) \\
\hline Endocarp of açaí & $\mathrm{NaOH}$ & 492 & 93.23 & 40 & Present work \\
\hline
\end{tabular}




\title{
PROPOSTA DE UM SISTEMA DE COGERAÇÃO DE ENERGIA UTILIZANDO TECNOLOGIA ACESSÍVEL E DE BAIXO CUSTO
}

\author{
Leite, S.A.F.*1,2; Leite, B.S. ${ }^{1}$; D'Angelo, J.V. H. ${ }^{2}$; Dell'Isola, A.T.P. ${ }^{1}$ \\ ${ }^{1}$ Universiadde Federal de Viçosa- Campus Florestal, MG - Brasil \\ sibeleaugusta@ufv.br \\ ${ }^{2}$ Universidade Estadual de Campinas, SP-Brasil
}

\begin{abstract}
RESUMO: Os biodigestores já são uma realidade para projetos sociais e implantação em pequenas propriedades rurais. Entretanto eles precisam ser melhorados e adaptados às necessidades regionais e também às condições ambientais locais, para operação e uso mais eficientes. Neste contexto, este trabalho teve como objetivo realizar um estudo de viabilidade econômica de um sistema de biodigestão em conjunto com um sistema para geração de energia elétrica, para atendimento às demandas de uma pequena propriedade rural. Este estudo contemplou melhorias em biodigestores de baixo custo, mediante a inserção de um sistema de aquecimento e controle de temperatura, bem como um sistema para recirculação e agitação do efluente. A partir da análise de custo realizada, observou-se que estas melhorias aumentaram o custo inicial do projeto em $15 \%$. O tempo de retorno aumento de 5 para 6 anos, entretanto estas melhorais podem garantir o bom desempenho do processo e consequentemente o retorno do investimento no tempo previsto.
\end{abstract}

Palavras-chave: biogás, biodigestão, motogerador.

\section{PROPOSAL FOR AN ENERGY COGENERATION SYSTEM USING ACCESSIBLE AND LOW COST TECHNOLOGY}

\begin{abstract}
The biodigestors are already a reality for social projects and implantation in small rural properties. However, they need to be improved and adapted to regional needs as well as to local environmental conditions for more efficient operation and use. In this context, the objective of this work was to carry out an economic feasibility study of a biodigestion system together with a system to generate electricity to meet the demands of a small rural property. This study contemplated improvements in low cost biodigesters, through the insertion of a heating and temperature control system, as well as a system for recirculation of the effluent. From the cost analysis, it was observed that these improvements increased the initial cost of the project by $15 \%$. The time of return increases from 5 to 6 years, however these improvements can guarantee the good performance of the process and consequently the return of the investment in the provided time.
\end{abstract}

Keywords: biogas, biodigestion, motor generator.

\section{INTRODUÇÃO}

Os biodigestores mais comuns, em atividades agropecuárias são: o tipo Canadense, o tipo Indiano e o tipo Chinês. Em geral, eles podem ser considerados de baixo nível tecnológico e adequados à aplicação para resíduos rurais. Desta forma, possuem como vantagem o baixo custo e a facilidade de construção e operação. Entretanto, não possuem controle de variáveis operacionais, tais como temperatura e $\mathrm{pH}$ e devem ser operados com teor de sólidos em torno de 6 a $8 \%$ m/v (CORTEZ; LORA; GÓMEZ, 2008). O biodigestor modelo Canadense é o mais utilizado no Brasil. Ele é um modelo tipo horizontal, que apresenta uma caixa de carga em alvenaria e uma cúpula inflável, feita de uma manta plástica maleável (MINISTÉRIO DA AGRICULTURA, PECUÁRIA E ABASTECIMENTO, 2016). Os biodigestores Indiano e Chinês são feitos enterrados ao solo. A grande diferença entre eles é que a cúpula do biodigestor indiano é feita por um gasômetro móvel, que se movimenta para cima e para baixo de acordo com a maior ou menor produção de biogás. $\mathrm{O}$ modelo indiano apresenta uma cúpula fixa e por isso trabalha à pressão variável, o que pode ser um risco devido à produção de biogás (CORTEZ; LORA; GÓMEZ, 2008).

Em especial, os modelos Indiano e Chinês podem ser construídos utilizando tecnologia e materiais de fácil acesso aos produtores rurais. Por exemplo, o biodigestor tipo modelo indiano, construído em alvenaria, conforme proposto pela cartilha: 12 Passos para construir um Biodigestor (Figura 1), foi alvo do projeto 
"Biodigestores: Uma Tecnologia Social no Programa Nacional de Habitação Rural" (DIACONIA, 2012?). Ressalta-se que, em geral, os modelos propostos por programas sociais são muito simples e podem comprometer a eficiência do processo de biodigestão. A aparente simplicidade dos sistemas de biodigestão esconde sua complexidade dos processos físico-químicos e biológicos existentes no mesmo. A biodigestão é dependente de variáveis ambientais como $\mathrm{pH}$, manutenção da temperatura, carga orgânica, acidez / alcalinidade e concentração de amônia (CHERNICHARO, 2007; KOTHARI et al., 2014).

Portanto, os biodigestores voltados para tecnologias sociais podem ser melhorados, a fim de garantir o bom desempenho do processo. A inserção do controle de temperatura e de um sistema de agitação são alternativas para melhorar estas tecnologias. Tais ações são importantes, principalmente, nas regiões do Sul e do sudeste brasileiro, os quais podem ter variações bruscas de temperatura no outono e no inverno, o que pode comprometer todo o processo de biodigestão e consequentemente, o planejamento financeiro advindo da implantação deste sistema. Diante do exposto, este trabalho tem como objetivo realizar um estudo de viabilidade econômica do sistema de biodigestão em conjunto com um sistema para geração de energia elétrica, para atendimento às demandas de uma suinocultura de pequeno porte ou de uma pequena propriedade rural. Este estudo contemplou melhorias em biodigestores de baixo custo, mediante a inserção de um sistema de aquecimento e controle de temperatura, bem como um sistema para recirculação e agitação do efluente.

\section{MATERIAL E MÉTODOS}

Para o levantamento dos custos referentes à construção do sistema de biodigestão/cogeração de energia elétrica, foram realizadas pesquisas na internet em sites como www.americanas.com.br ou www.mercadolivre.com.br. Quando necessário, foi realizada uma pesquisa de mercado na cidade de Florestal/MG ou mesmo cotações com fornecedores específicos.

Foi realizada uma busca de alternativas de biodigestão/cogeração de energia disponíveis no mercado, direcionado a baixas potências de instalação. A busca pelas alternativas tecnológicas considerou a aquisição do motogerador (pesquisa de mercado) e o tipo de biodigestor. Para a construção do sistema de biodigestão também foram pesquisadas tecnologias para controle de temperatura e para a agitação e as barreiras de umidade e ácido sulfídrico. Ressalta-se que a escolha das tecnologias adotadas foi orientada preferencialmente pela simplicidade, baixo custo, fácil aplicabilidade, buscando as bases da Tecnologia Social, que prevê a inclusão social e a melhoria da qualidade de vida.

A análise de viabilidade econômica foi realizada pelo Tempo de Retorno do investimento. Ele foi calculado considerando o valor total dos investimentos realizados e a estimativa anual dos retornos previstos (BHATTACHARYYA; BANERJEE, 2007). Os custos dos investimentos foram calculados considerando a aquisição do motogerador e a construção de cada biodigestor completo (com aquecimento e agitação) e ainda a inclusão de ao menos um kit filtro /compressor de gás. Os retornos foram calculados considerando a quantidade de energia elétrica produzida. $\mathrm{O}$ preço da energia foi calculado a partir do preço atual da energia elétrica adquirida pela concessionária de Minas Gerais.

\section{RESULTADOS E DISCUSSÃO}

A partir da pesquisa realizada no mercado brasileiro, pelos autores do trabalho, observou-se que a disponibilidade de motores de combustão para biogás, para baixas potências instaladas, estão em torno de 25 a $35 \mathrm{~kW}$. Estes possuem custo elevado (Modelo 25kW, Biogás Motores Estacionários (www.biogasmotores.com.br): R \$ 80.000,00; Modelo CHP60, 35kW (www.chpbrasil.com.br): $\mathrm{R} \$ 150.000,00$. Valores desconsiderando frete e instalação), em torno de $\$ 1.000,00$ (mil dólares) por kW de potência instalada. Devido aos custos e ao grande potencial de geração de energia dos mesmos (demandando um grande empreendimento e grande geração de biogás), os mesmo se tornam inapropriados para aplicação em Tecnologias Sociais, para pequenos produtores rurais. Uma opção seria a importação de motogeradores com potência menor que 5kW. Entretanto, os custos com importação (considerando 70 \% do valor bruto, somente com tributos) e a burocracia do processo, também podem inviabilizar a implantação dos mesmos pelos pequenos produtores.

No mercado nacional brasileiro, foi identificado motogeradores com potência menor que $5 \mathrm{~kW}$, oferecidos pela empresa Shanghai Amazonas (www.shanghaiamazonas.com). O custo do motogerador nacional é $50 \%$ inferior ao importado (em torno de $\mathrm{R} \$ 1000,00$ por $\mathrm{kW}$ instalado), demonstrando um potencial promissor do uso do mesmo em Tecnologias Sociais. Entretanto, ressalta-se que, segundo os fabricantes, os 
motogeradores são apropriados para Gás Liquefeito de Petróleo (GLP) e Gás Natural Veicular (GNV), precisando de testes e regulação para utilização de biogás.

Para a construção do biodigestor, foi escolhido o modelo tipo indiano, construído em alvenaria, conforme proposto pela cartilha: 12 Passos para construir um Biodigestor (Figura 1), realizado pela Diaconia e produto do projeto "Biodigestores: Uma Tecnologia Social no Programa Nacional de Habitação Rural" (DIACONIA, 2012?). Considerou-se a construção de biodigestores com capacidade aproximada de $9000 \mathrm{~L}$, que é maior ao sugerido pelo projeto, porém a partir da instalação de duas unidades, os biodigestores podem fornecer a quantidade de biogás necessária ao funcionamento do conjunto motogerador de $2 \mathrm{~kW}$ (menor potência disponível). O custo dos materiais para a construção de uma unidade destes biodigestores pode ser estimado em $R \$ 2.300,00$, sendo $R \$ 1.000,00$ para materiais de construção e $R \$ 1.300,00$ para a caixa d'água utilizada como gasômetro. Tais valores desconsideram o valor de mão-de-obra, o qual pode variar de acordo com a região e com o envolvimento do pequeno produtor na implantação dos biodigestores.

Considerando que existem perdas de calor do biodigestor para o meio, por irradiação da superfície e por condução pelo solo, foi sugerido a instalação de uma resistência elétrica com potência de $1 \mathrm{~kW}$. Para esta potência, as resistências elétricas, de uso submerso, podem ser adquiridas a um valor médio de $R \$ 150,00$. O conjunto termostato/sensor, para atuar no controle de temperatura, tem preços variando de $\mathrm{R} \$ 100,00$ a 200,00 dependendo de fatores como fabricante e tipo (exemplo: analógico ou digital).

$\mathrm{O}$ filtro purificador de biogás e o compressor para injetar o gás no conjunto motogerador foram cotados por empresa especializada em projeto de biodigestores (Cotação obtida pela BGS Equipamentos para Biogás: www.bgsequipamentos.com.br).

Considerando que a agitação deve ser dimensionada pensando na recirculação do efluente, para homogeneização, em regime laminar (evitando a turbulência) do sistema, foi proposto a instalação de bombas profissionais com potência entre $1 / 10$ e $1 / 3 \mathrm{cv}$ ( 75 e $250 \mathrm{~W}$, respectivamente), ao custo médio de $\mathrm{R} \$ 400,00$ e temporizadores, para controlar o tempo de agitação, ao custo de $\mathrm{R} \$ 50,00$.

A Tabela 1 apresenta o custo estimado para a implantação do sistema de biodigestão, para o fornecimento de $300 \mathrm{kwh}$, por mês. O investimento total foi calculado como R $\$ 10.590,00$. Considerando que, o custo da energia rural no estado de Minas Gerais, incluindo os impostos, pode chegar a 0,50 centavos por $\mathrm{kWh}$ (https://www.cemig.com.br/pt-br/atendimento/Paginas/valores_de_tarifa_e_servicos.aspx), a conta de energia do produtor pode ser diminuída em $\mathrm{R} \$ 150,00$ mensalmente. Isto equivale a $\mathrm{R} \$ 1.800,00$ por ano e a um tempo de retorno de aproximadamente 6 anos.

Ressalta-se que, os retornos em função da implantação da biodigestão vão além do que foi calculado. Eles podem ser considerados por itens não mensuráveis, tais como a adequação à legislação ambiental, melhoria das condições sanitárias e melhorias das condições ambientais, como a redução do odor. Além disso, existe a produção do biofertilizante, que pode ser usado na própria unidade rural e nos arredores, como complementação aos fertilizantes minerais inorgânicos.

\section{CONCLUSÃO}

A partir do estudo realizado pode-se concluir que é possível implementar um sistema de biodigestão/cogeração de energia, utilizando tecnologias acessíveis, para atender ao público de pequenos produtores rurais. Estas melhorias nos biodigestores aumentam o custo inicial do projeto em torno de $15 \%$ e o tempo de retorno de 5 para 6 anos. Entretanto o controle da temperatura e a homogeneização do sistema são importantes para ajudar no desempenho do processo e garantir o fornecimento de energia elétrica esperado.

\section{AGRADECIMENTOS}

Universidade Federal de Viçosa; Universidade Estadual de Campinas, FAPEMIG, CNPq (Processo 141923/2017-2).

\section{REFERÊNCIAS}

BHATTACHARYYA, B.C., BANERJEE, R., Environmental Biotechnology. Oxford University, 2007. CHERNICHARO, C. A. DE L. Reatores Anaeróbios. 2 ed ed. Belo Horizonte: Departamento de Engenharia Sanitária e Ambiental-UFMG, 2007. 
CORTEZ, L. A. B.; LORA, E. E. S.; GÓMEZ, E. O. Biomassa para energia. Campinas: Editora da UNICAMP, 2008. Disponível em: <https://www.legifrance.gouv.fr/affichTexte.do?cidTexte=JORFTEXT000025414042 $\&$ dateTexte $=\&$ categorieLien $=\mathrm{id}>$.

DIACONIA. 12 Passos para construir um biodigestor. Pernambuco, Brasil. (2012?). Disponível em: http://tecnologiasocial.fbb.org.br/tecnologiasocial/banco-de-tecnologias-sociais/pesquisartecnologias/detalhar-tecnologia-327.htm. Acesso em Ago. 2018 KOTHARI, R. et al. Different aspects of dry anaerobic digestion for bio-energy: An overview. Renewable and Sustainable Energy Reviews, v. 39, p. 174-195, 2014. Disponível em: <http://dx.doi.org/10.1016/j.rser.

2014.07.011>.

MINISTÉRIO DA AGRICULTURA PECUÁRIA E ABASTECIMENTO. Suinocultura de baixa emissão de carbono. Brasília: [s.n.], 2016.

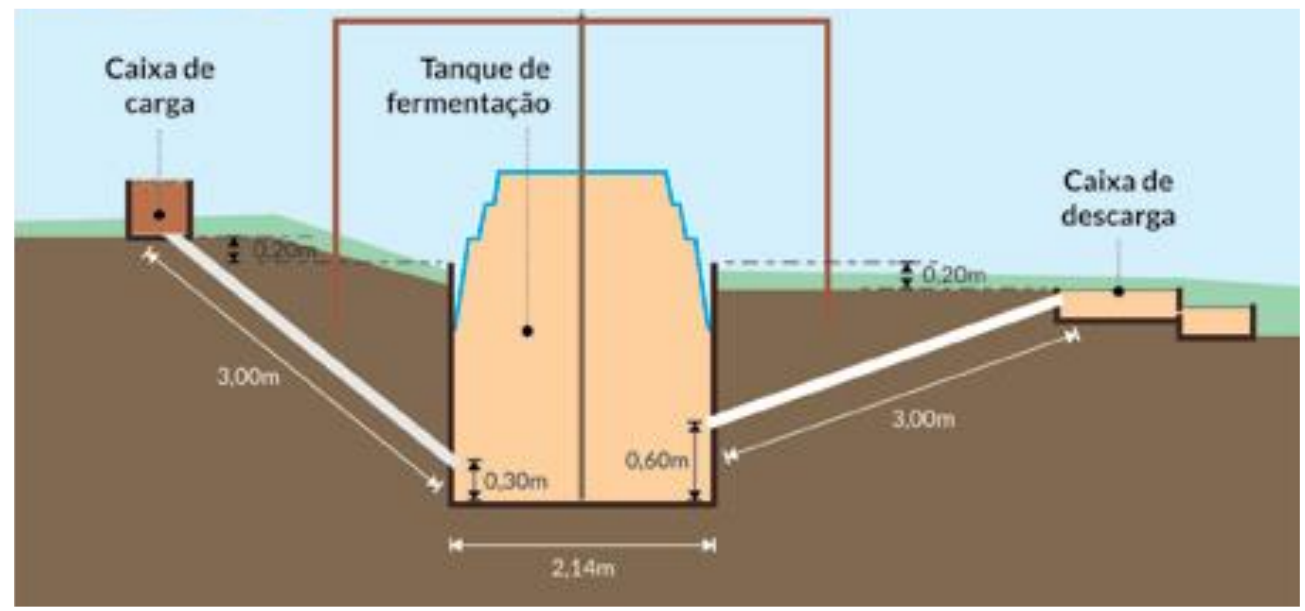

Figura 1. Biodigestor tipo modelo indiano, conforme proposto pela cartilha: 12 Passos para construir um Biodigestor. (DIACONIA, 2012?).

Tabela 1. Custo estimado para a implantação do sistema de biodigestão/cogeração de energia elétrica, para o fornecimento de $300 \mathrm{kwh}$, por mês.

\begin{tabular}{lccc}
\hline Tipo & Quantidade & Valor Unitário & Valor total \\
\hline $\begin{array}{l}\text { Material para Construção dos Biodigestores } \\
\text { (volume 9 } \mathrm{m}^{3} \text { ) }\end{array}$ & 02 unidades & $\mathrm{R} \$ 1.000,00$ & $\mathrm{R} \$ 2.000,00$ \\
Gasômetro (caixa d'água 3000 L) & 02 unidades & $\mathrm{R} \$ 1.300,00$ & $\mathrm{R} \$ 2.600,00$ \\
$\begin{array}{l}\text { Mão-de-Obra } \\
\text { Conjunto Motogerador }\end{array}$ & 05 diárias & $\mathrm{R} \$ 200,00$ & $\mathrm{R} \$ 1.000,00$ \\
$\begin{array}{l}\text { Sistema de Aquecimento (resistência e controlador } \\
\text { de temperatura) }\end{array}$ & 02 unidades & $\mathrm{R} \$ 2.800,00$ & $\mathrm{R} \$ 2.800,00$ \\
$\begin{array}{l}\text { Sistema de Agitação (Bomba de recírculo e } \\
\text { temporizador) }\end{array}$ & 02 unidades & $\mathrm{R} \$ 450,00$ & $\mathrm{R} \$ 600,00$ \\
$\begin{array}{l}\text { Compressor de Biogás } \\
\text { Filtro purificador de biogás (R\$) }\end{array}$ & 01 unidade & $\mathrm{R} \$ 400$ & $\mathrm{R} \$ 900,00$ \\
Valor Total & 01 unidade & $\mathrm{R} \$ 290,00$ & $\mathrm{R} \$ 400,00$ \\
Custo da Energia Elétrica consumida (R\$mês) & & & $\mathrm{R} \$ 290,00$ \\
Tempo de Retorno (anos) & & & $\mathrm{R} \$ 10.590,00$ \\
\hline
\end{tabular}




\title{
THE EMPLOYMENT OF AÇAI WASTE BIOCHAR AS AN ECOFRIENDLY ADSORBENT OF METHYLENE BLUE - KINETIC AND EQUILIBRIUM EVALUATION
}

\author{
Pessôa, T.S.*1; da Silva, M.P.; Lima Ferreira, L.E.M.²; Fraga, T.J.M. ${ }^{2}$; Cavalcanti, J.V.²; da Motta \\ Sobrinho, M.A. ${ }^{2}$ \\ ${ }^{1}$ Professor of Federal Institute of Education, Science and Technology of Pernambuco (IFPE) -PE 60 Highway, W/N, Ipojuca-PE; \\ ${ }^{2}$ Researchers of Department of Chemical Engineering, Federal University of Pernambuco (UFPE)-Arthur de Sá Street, W/N, \\ Recife-PE; \\ thiagosabino22@gmail.com
}

\begin{abstract}
In order to develop a suitable adsorbent for textile dyes, a new biochar of acai residues was evaluated for the removal of methylene blue (MB) from aqueous solution. After washing, the açai powder was dried and calcined for $2 \mathrm{~h}$ in order to remove volatile materials and increase the carbon content in the charcoal. Finally, the sample was activated with $1.0 \mathrm{~mol} \mathrm{~L}^{-1} \mathrm{NaOH}$. Experiments were performed to evaluate the fit of pseudo-first-order (PFO) and pseudo-second order (PSO) models and their parameters. The adsorption kinetics showed that the adsorption capacity at equilibrium state and the second order kinetic constant of $42.79 \mathrm{mg} \mathrm{g}^{-1}$ and $0.997 \mathrm{~g} \mathrm{mg}^{-1} \mathrm{~min}^{-1}$, respectively. In addition, the PSO model fitted better the kinetic experimental data with high coefficient of determination $\left(\mathrm{R}^{2} 0.996\right)$. Equilibrium studies were performed to obtain the maximum adsorption capacity and the equilibrium constant. In addition, the Langmuir-Freundlich (L-F) model was applied to fit experimental data. From this study, it was observed that the L-F model fitted the experimental data with satisfactory $\mathrm{R}^{2}, 0.998$. The maximum adsorption capacity in monolayer $\left(\mathrm{q}_{\mathrm{m}}\right)$ and equilibrium constant $\left(\mathrm{K}_{\mathrm{LF}}\right)$, evaluated by the L-F model, were $93.23 \mathrm{mg} \mathrm{g}^{-1}$ and $0.00589\left(\mathrm{~L} \mathrm{mg}^{-1}\right)^{\mathrm{n}}$, respectively. This adsorption capacity was increased by $173 \%$ in comparison to the non-activated acai biochar. These results showed that açaí has excellent perspectives of large scale application as a biosorbent of textile dyes.
\end{abstract}

Keywords: açaí waste, agricultural residue processing, biochar, adsorption, textile wastewater

\section{INTRODUCTION}

As one of the most polluting industrial segments of water bodies, textile industry processes consume high amounts of water, which are then converted into wastewaters. These effluents are characterized by high concentrations of organic matter associated with high toxicity, caused by the presence of dyes, surfactants, suspended solids and organochlorine compounds (Cisneros et al., 2002). Among the several harms caused by dyestuffs in the human health it can be cited: eye burns, dysfunction of kidney, tachycardia, cyanosis, dyspnea and irritation to the skin (Yu et al., 2018). Furthermore, the most dangerous threat to human health is dyes carcinogenic potential, caused by an elevated medium and long term exposition to their molecules. Aiming to mitigate the destructible potential of dyes from textile effluents discharged in the aquatic environment, many researchers have studied several materials as adsorbent. Moreover, many profitable adsorbents for textile dyes reported in the literature are derived from biomass; among them, it can be highlighted: yellow mombin fruit carbon (Brito et al., 2018), sugar beet pulp charcoal (Dursun et al., 2013), grand nutt shells charcoal (Kaur et al., 2013), coconut residual fiber (Rani et al., 2017), eucalyptus bark (Tahir et al., 2016), and several others.

Due to açaí wide availability in Brazil Northern region, it consists in a low cost raw material for juice and food industry as well as for gastronomic centers in many regions of the country. As the main residue of the açaí processing industry, the core is an oleaginous seed, formed by a small solid endosperm attached to a tegument, which at maturity is rich in cellulose, hemicellulose and lignin, and this by-product corresponds to approximately $85 \%$ of the fruit. By not having a proper disposal and use, tons of this waste are randomly disposed of in the streets and can cause environmental damage.

It should be noted that, unprecedentedly, in the gasifier that has the objective of producing combustible gases, the production of activated carbon has as its by-product. For a consumption of $10 \mathrm{kh} / \mathrm{h}$, there is the generation of approximately $10 \mathrm{~kW}$ and a production of $1 \mathrm{~kg}$ of coal 
The objective of this work is to evaluate the removal efficiency, adsorption capacity and other parameters of the charcoal derived from açaí waste calcination, employed as adsorbent of Methylene Blue (MB). Additionally, this research paper authors are strongly motivated by the lack of reported works which uses açaí biochar in wastewater treatments in the literature.

\section{Açaí biochar production}

\section{MATERIALS AND METHODS}

The biomass used in the experiment was obtained from the açaí stone in a natural gas gasifier, installed in the Activated Charcoal Laboratory of the UFPB (João Pessoa-PB). The açaí waste was collected in the city of Belém-PA. They were dried and exposed to the sun for four days to remove moisture. Then, the dry material was fed to the fixed bed gasifier (Figure 1) with "open top" gas lighter and downflow air inlet that has a thermal capacity of $4 \mathrm{~kW}$ and electric capacity of $1 \mathrm{~kW}$ (Silva, 2017). The material fell by gravity as it was being gassed. The biochar was then sieved in $100 \mathrm{Mesh}(0.149 \mathrm{~mm})$. For the activation, the sample was contacted with the activating agent $\mathrm{NaOH}$ A.P. $97.0 \%$ in a muffle under heating of $400^{\circ} \mathrm{C}$ and, subsequently, $700^{\circ} \mathrm{C}$ for $2 \mathrm{~h}$.

\section{Adsorption experiments in batch mode}

Aliquots of $25 \mathrm{~mL}$ of $\mathrm{MB}$ dye solution were transferred to flasks of $125 \mathrm{~mL}$. All dye adsorption experiments were carried out with constant stirring $(300 \mathrm{rpm})$, under environmental conditions $\left(25^{\circ} \mathrm{C} ; 1 \mathrm{~atm}\right)$ and $\mathrm{pH}$ 5.5. Standard solutions of $\mathrm{NaOH}$ and $\mathrm{HCl}$ of 6.0 and $0.1 \mathrm{M}$ were used to adjust the $\mathrm{pH}$ of the $\mathrm{MB}$ solution. After the adsorption, the adsorbent and adsorbate were separated by filtration and the residual concentration of dyes samples in the solution were measured by an UV-Vis spectrophotometer in a maximum absorbance peak for MB $\left(\lambda_{\max } 659 \mathrm{~nm}\right)$. All the experiments had been performed in duplicate, in which C was calculated by the arithmetic media between the two measurements. Using the final concentration data, the adsorption capacity (q) was finally calculated (Equation 1).

$$
q=\frac{\left(C_{0}-C\right) \cdot V}{m}
$$

where $\mathrm{q}$ is the adsorption capacity in equilibrium $\left(\mathrm{mg} \mathrm{g}^{-1}\right) ; \mathrm{C}_{0}$ and $\mathrm{C}$ are the initial and equilibrium concentration, respectively $\left(\mathrm{L}^{-1}\right) ; \mathrm{V}$ is the solution's volume $(\mathrm{L}) ; \mathrm{m}$ is the adsorbent mass $(\mathrm{g})$.

\section{Equilibrium studies and Langmuir-Freundlich model}

To obtain the Langmuir-Freundlich isotherm (L-F), the Freundlich "n-power" isotherm was combined to the Langmuir isotherm. Langmuir model describes the adsorption of certain species onto homogeneous sites of the adsorbent. Freundlich model, on the other hand, is related to a high degree of heterogeneity of the adsorption, which assumes an exponential distribution of active sites and energies (Paiva et al., 2018; Carvalho et al., 2012). L-F model is given by Equation 2.

$$
\frac{q}{q_{m}}=\frac{K_{L F} C^{n}}{1+K_{L F} C^{n}}
$$

where $\mathrm{q}$ is the adsorption capacity in equilibrium $\left(\mathrm{mg} \mathrm{g}^{-1}\right) ; \mathrm{C}$ is the adsorbate concentration at equilibrium ( $\mathrm{mg}$ $\left.\mathrm{L}^{-1}\right) ; \mathrm{q}_{\mathrm{m}}$ is the maximum adsorption capacity $\left(\mathrm{mg} \mathrm{g}^{-1}\right) ; \mathrm{n}$ is the heterogeneity factor (dimensionless); and finally, $\mathrm{K}_{\mathrm{LF}}$ is the Langmuir-Freundlich model equilibrium constant $\left(\left(\mathrm{L} \mathrm{mg}^{-1}\right)^{\mathrm{n}}\right)$.

\section{Kinetic experiments and modeling}

Adsorption kinetics describes the rate at which the adsorbate molecules are adsorbed by the adsorbent. The experiments were performed under environmental conditions $\left(25^{\circ} \mathrm{C}\right)$ and $\mathrm{MB}$ initial concentration ranged from 5, 15, 25, 50, $75 \mathrm{e} 100 \mathrm{mg} \mathrm{L}^{-1}$. Contact time between sorbent and sorbate varied from 0 to $120 \mathrm{~min}$. The most used mathematical models for adsorption kinetics are those of pseudo-first-order (PFO) and pseudosecond-order (PSO), given by Equations 3 and 4, respectively:

$$
\begin{aligned}
& q_{t}=q_{e}\left(1-e^{-k_{F} t}\right) \\
& q_{t}=\frac{k_{S} q_{e}^{2} t}{\left(1+k_{S} q_{e} t\right)}
\end{aligned}
$$


All models were fitted to their respective experimental data through the tool "non-linear curve fit" of Origin $9.0^{\mathrm{TM}}$ software.

\section{Equilibrium and kinetics of $\mathrm{MB}$ adsorption}

Figure 1a shows the kinetics using the activated and non-activated carbon, respectively; where it was found that the kinetics was quick in the first $5 \mathrm{~min}$ for the activated carbon, and after 40 min the equilibrium state was observed (Figure 2a). For non-activated charcoal, on the other hand, kinetic state was reached after $20 \mathrm{~min}$ (Figure 2b). Calculated adsorption capacity in the equilibrium state were $42.41 \mathrm{mg} \mathrm{g}^{-1}$ and $42.99 \mathrm{mg} \mathrm{g}^{-}$ ${ }^{1}$ for PFO and PSO models respectively. The kinetic and equilibrium parameters are summarized in Table 1. Equilibrium isotherms exhibited a favorable behavior for both $\mathrm{NaOH}$-activated and non-activated biochar, as depicted in Figure 2 (c and d). L-F isotherm fitting to equilibrium data allowed obtaining the parameters for MB removal onto $\mathrm{NaOH}$-activate biochar: $\mathrm{q}_{\mathrm{m}}$ and $\mathrm{K}_{\mathrm{LF}}$ were $93.23 \mathrm{mg} \mathrm{g}^{-1}$ and $0.0059 \mathrm{~L} \mathrm{~g}^{-1}$ respectively. Moreover, for non-activated biochar, the same equilibrium parameters were $33.73 \mathrm{mg} \mathrm{g}^{-1}$ and $0.0070 \mathrm{~L} \mathrm{~g} \mathrm{~g}^{-1}$. These results indicated that the activation played an important role in MB removal, and can be attributed to an increasing in açaí biochar active sites distribution over its pores and surface.

\section{CONCLUSIONS}

Açaí waste was calcined by biomass gaseifier and applied as biosorbent of MB dye. Satisfactory adsorption capacity was reached by Langmuir-freundlich equilibrium isotherm. $\mathrm{NaOH}$ activation enhanced biochar adsorptive properties, since maximum adsorprion capacity increased $173 \%$ in comparison to nonactivated açaí biochar.

\section{ACKNOWLEDGMENTS}

The authors kindly thank the financial support provided by the agencies Conselho Nacional de Desenvolvimento Científico e Tecnológico - CNPq (grant 311133/2015-0) and Fundação de Amparo à Ciência e Tecnologia do Estado de Pernambuco - FACEPE (grants IBPG-1917-3.06/16 and APQ-1086-3.06/15).

\section{REFERENCES}

Brito, M. J. P.; Veloso, C. M.; Santos, L. S.; Bonomo, R. C. F.; Fontan, R. C. I. Adsorption of the textile dye Dianix $^{\circledR}$ royal blue CC onto carbons obtained from yellow mombin fruit stones and activated with $\mathrm{KOH}$ and $\mathrm{H}_{3} \mathrm{PO}_{4}$ : Kinetics, adsorption equilibrium and thermodynamic studies. Powder Technology, v. 339, p. 334-343, 2018

Carvalho, M. N.; Abreu, C. A. M.; Benachour, M.; Sales, D. C. S.; Baraúna, O. S.; da Motta Sobrinho, M. A. Applying combined Langmuir-Freundlich model to the multi-component adsorption of BTEX and phenol on smectite clay. Adsorption Science and Technology, v. 30(8-9), p. 691-699, 2012.

Cisneros, R. L.; Espinoza, A. G.; Litter, M. I., Photodegradation of an azo dye oh the textile industry. Chemosphere, v. 48(4), p.393-399, 2002.

Dursun, A. Y.; Tepe, O.; Uslu, G.; Dursun, G.; Saatci, Y. Kinetics of Remazol Black B adsorption onto carbon prepared from sugar beet pulp. Environmental Science and Pollution Research, v. 20, p. 2472-2483, 2013.

Kaur, S.; Rani, S.; Mahajan, R. K. Adsorption kinetics for removal of the hazardous dye Congo Red by biowaste materials as adsorbents. Journal of Chemistry, v. 2013, n. 628582, 2013.

Paiva, T. M. N.; Fraga, T. J. M.; Sales, D. C. S.; Carvalho, M. N.; da Motta Sobrinho, M. A. Anomalocardia brasiliana shellfish shells as a novel and ecofriendly adsorbent of acid Nylosan Brilliant Blue. Water Science and Technology, v. 78 (7), p. 1576-1586, 2018.

Rani, K. C.; Naik, A.; Chaurasiya, R. S.; Raghavarao, K. S. M. S. Removal of toxic Congo red dye from water employing low-cost coconut residual fiber. Water Science and Technology, v. 75 (9), p. 2225-2236, 2017.

Silva, F.S. Efeito dos tamanhos padronizados de retalhos de madeira na melhoria do funcionamento de um gaseificador de biomassa (in Portuguese). Master degree dissertation. Post-graduation program in Mechanical Engineering of Federal University of Paraíba (UFPB). João Pessoa-PB. 54f. 2017.

Tahir, M. A.; Bhatti, H. N.; Iqbal, M. Solar Red and Brittle Blue direct dyes adsorption onto Eucalyptus angophoroides bark: Equilibrium, kinetics and thermodynamic studies. Journal of Environmental Chemical Engineering, v. 4, p. 2431-2439, 2016. 
Yu, H.; Wang, T.; Dai, W.; Yu, L.; Ma, N. Competitive adsorption of dye species onto biomass nanoporous carbon in single and bicomponent systems. Brazilian Journal of Chemical Engineering, v. 35(1), p. 253-264, 2018.
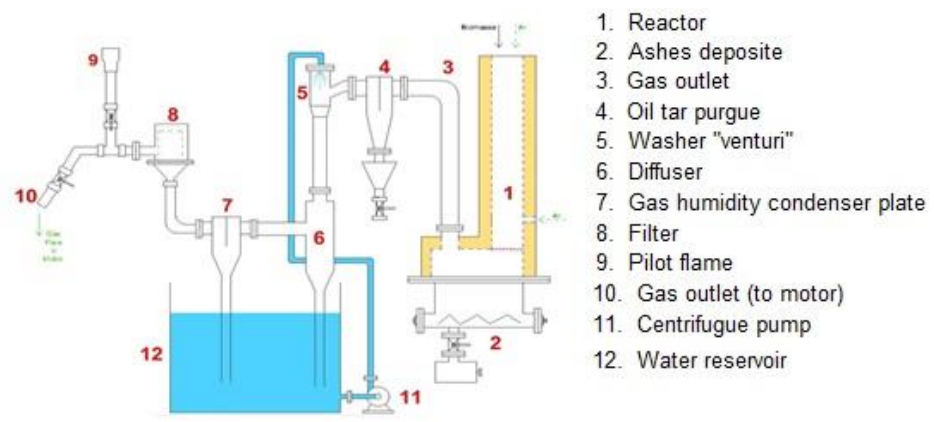

Figure 1. Scheme of biomass gasefier. Source: Silva (2017).
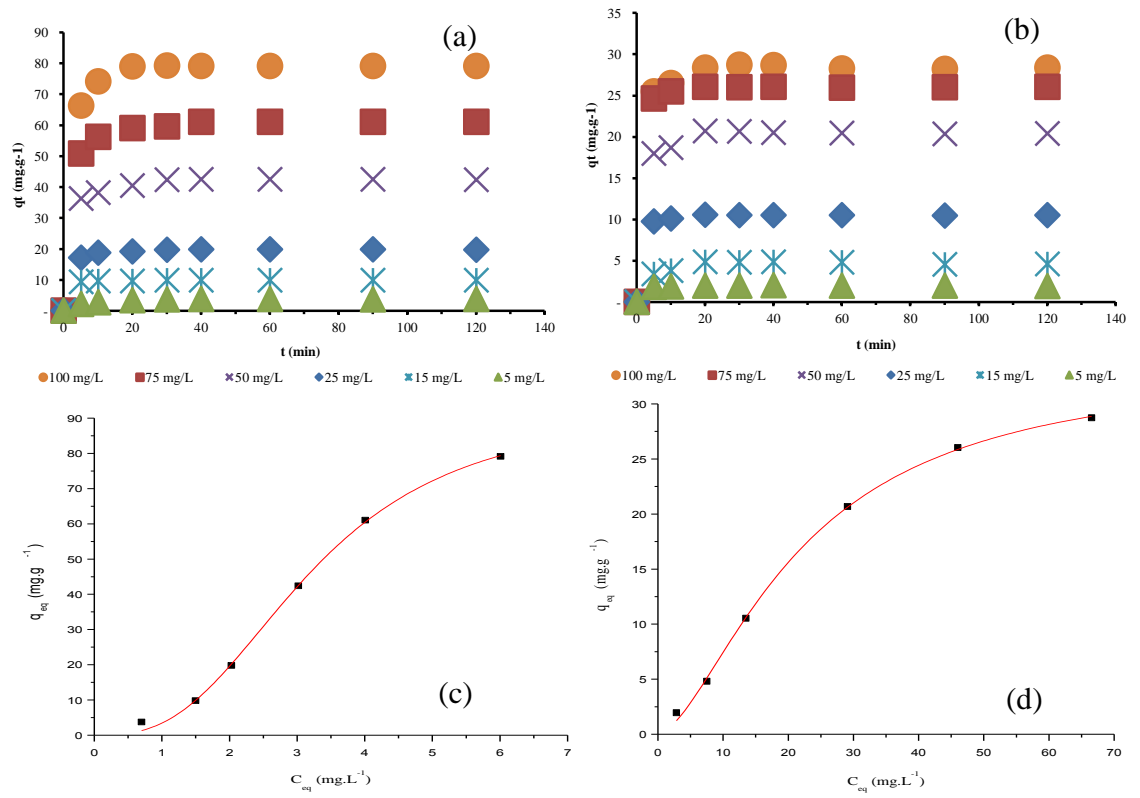

Figure 2. kinetic curves for $\mathrm{MB}$ adsorption onto $\mathrm{NaOH}$-activated açaí biochar (a); and non-activated açaí biochar (b); L-F equilibrium isotherm obtained for $\mathrm{NaOH}$-activated açaí biochar (c); non-activated açaí biochar (d).

Table 1. kinetic and equilibrium parameters for MB removal by non-activated and $\mathrm{NaOH}$-activated açaí biochar.

\begin{tabular}{|c|c|c|c|c|c|c|c|}
\hline \multicolumn{8}{|c|}{ Kinetic parameters } \\
\hline & & \multicolumn{3}{|c|}{ PFO } & \multicolumn{3}{|c|}{ PSO } \\
\hline $\begin{array}{c}\mathrm{C}_{0} \\
\left(\mathrm{mg} \mathrm{L}^{-1}\right)\end{array}$ & $\begin{array}{c}\mathrm{q}_{\mathrm{e} \exp } \\
\left(\mathrm{mg} \mathrm{g}^{-1}\right)\end{array}$ & $\begin{array}{c}\mathrm{q}_{\mathrm{e}} \\
\left(\mathrm{mg} \mathrm{g}^{-1}\right)\end{array}$ & $\mathrm{k}_{1}\left(\min ^{-1}\right)$ & $\mathrm{R}^{2}$ & $\begin{array}{c}\mathrm{q}_{\mathrm{e}} \\
\left(\mathrm{mg} \mathrm{g}^{-1}\right)\end{array}$ & $\begin{array}{c}\mathrm{k}_{2} \\
\left(\mathrm{~g} \mathrm{mg}^{-1} \min ^{-1}\right)\end{array}$ & $\mathrm{R}^{2}$ \\
\hline 50.00 & 42.41 & 41.75 & 0.3786 & 0.992 & 42.99 & 0.9967 & 0.998 \\
\hline \multicolumn{8}{|c|}{ L-F equiibrium parameters } \\
\hline \multicolumn{4}{|c|}{ non-activated biochar } & \multicolumn{4}{|c|}{ NaOH-activated biochar } \\
\hline $\mathrm{q}_{\mathrm{m}}\left(\mathrm{mg} \mathrm{g}^{-1}\right)$ & $\begin{array}{c}\mathrm{k}_{\mathrm{LF}} \\
\left(\mathrm{L} \mathrm{mg}^{-1}\right)^{\mathrm{n}}\end{array}$ & $\mathrm{n}$ & $\mathrm{R}^{2}$ & $\frac{\mathrm{q}_{\mathrm{m}}}{\left(\mathrm{mg} \mathrm{g}^{-1}\right)}$ & $\begin{array}{c}\mathrm{k}_{\mathrm{LF}} \\
\left(\mathrm{L} \mathrm{mg}^{-1}\right)^{\mathrm{n}}\end{array}$ & $\mathrm{n}$ & $\mathrm{R}^{2}$ \\
\hline 33.73 & 0.0070 & 1.607 & 0.998 & 93.23 & 0.0059 & 2.79 & 0.998 \\
\hline
\end{tabular}




\title{
TRATAMENTO DE RESÍDUOS SÓLIDOS VIA VERMICOMPOSTAGEM VISANDO A OBTENÇÃO DE BIOPRODUTOS EMPREGADOS NA RECUPERAÇÃO DE SOLOS
}

\author{
Almeida, A.C.O. de ${ }^{1}$; Furtado, I.F.S.P.C. ${ }^{1}$; Vélez, A.M. ${ }^{2}$ \\ ${ }^{1}$ Graduandas do Curso de Engenharia de Bioprocessos e Biotecnologia, UTFPR campus Toledo, Toledo,PR-Brasil \\ ${ }^{2}$ Professora do Curso de Engenharia de Bioprocessos e Biotecnologia, UTFPR campus Toledo, Toledo,PR-Brasil \\ anaescallon@utfpr.edu.br
}

\begin{abstract}
RESUMO: O processo de vermicompostagem é uma alternativa para destinação dos resíduos orgânicos sólidos gerados pela população, visando sua biotransformação por minhocas a fim de obter húmus e biofertilizante que podem ser empregados na agricultura para recuperação de solos. Este trabalho tem por objetivo realizar a caracterização dos bioprodutos obtidos pela vermicompostagem com minhocas vermelhas da califórnia (Eisenia foetida). Para tal, realizou-se análises de $\mathrm{pH}$, teor de umidade, temperatura, teste de cinzas e relação C:N. Obteve-se resultados satisfatórios a partir do tratamento de $10 \mathrm{~kg}$ de resíduos sólidos, de modo a reduzir a relação C:N de 19 para 11,6 e alcançar uma população de minhocas 10 vezes maior.
\end{abstract}

Palavras-chave: agricultura, minhoca, resíduos orgânicos.

\section{TREATMENT OF SOLID WASTE THROUGH VERMICOMPOSTAGING TO OBTAIN BIOPRODUCTS EMPLOYED IN SOIL RECOVERY}

\begin{abstract}
The vermicompost process is an alternative for the disposal of the solid organic waste generated by the population, aiming its biotransformation by earthworms in order to obtain humus and biofertilizer that can be used in agriculture to recover soils. This work aims to characterize the bioproducts obtained by vermicomposting with California red worms (Eisenia foetida). Analyzes of $\mathrm{pH}$, moisture content, temperature, ash test and C: $\mathrm{N}$ ratio were carried out. Satisfactory results were obtained, managing $10 \mathrm{~kg}$ of solid waste, a decrease of $\mathrm{C}: \mathrm{N}$ ratio from 19 to 11,6 and a increase of an earthworm population of more than 10 times.
\end{abstract}

Keywords: agriculture, earthworm, organic waste.

\section{INTRODUÇÃO}

O crescimento da população e a industrialização vem aumentando a quantidade de resíduos sólidos gerados pelo homem. Essa problemática torna-se mais crítica na medida em que as áreas disponíveis para acomodação dos rejeitos diminuem, além de existir um risco potencial de contaminação do meio ambiente dependendo da disposição final desses resíduos (VERAS \& POVINELLI, 2004).

No Brasil, a lei $\mathrm{n}^{\circ}$ 12305/2010 instituiu a Política Nacional de Resíduos Sólidos que possui diretrizes sobre a gestão integrada e o gerenciamento de resíduos sólidos. A ideologia da lei é não produzir ou reduzir a produção de rejeitos sólidos, reutilizar, reciclar e compostar. E apenas os rejeitos que não foram aproveitados nas etapas anteriores serão encaminhados a aterros sanitários (BRASIL, 2010).

A partir desse contexto, desenvolveu-se novas tecnologias e procedimentos para reutilização dos resíduos sólidos, dando ênfase a matérias orgânicas. Com isso, a técnica de vermicompostagem, que consiste na digestão da matéria orgânica pela microflora de minhocas, se disseminou, pois ela dá origem a dois bioprodutos (húmus e biofertilizate) que possuem capacidade de regeneração de solo.

Portanto, o objetivo do presente trabalho foi realizar a caracterização húmus e do biofertilizante produzidos durante a vermicompostagem com minhocas vermelha da Califórnia (Eisenia foetida) num período de aproximadamente 3 meses. 


\section{MATERIAL E MÉTODOS}

Para a fase de montagem da vermicomposteira, necessitou-se de 3 baldes de $15 \mathrm{~kg}$ cada, onde o primeiro seria a caixa coletora, e os outros dois os digestores. Como o ar é de extrema importância para o processo, visto que as minhocas fazem trocas gasosas pela sua pele, realizou-se furos nas extremidades das caixas, bem como em suas tampas e nas laterais.

Montou-se então, na caixa digestora uma "cama" de minhocas, a qual foi coberta com uma fina camada de húmus e posteriormente adicionou-se 54 minhocas. Em seguida, acrescentou-se os resíduos orgânicos a serem utilizados e cobriu-se os mesmos com grama. Colocou-se semanalmente cascas de banana, morango, maçã, mamão, pêssego, goiaba, além de pedaços de alface, borra de café e erva de chimarrão até que se atingisse $3 / 4$ da capacidade da caixa.

\section{Metodologia analítica}

Analisou-se o $\mathrm{pH}$, teor de umidade e temperatura, a fim da elaboração da figura 1, que representa o comportamento desses parâmetros ao longo do tempo. No início e no final do processo realizou-se o teste de cinzas e relação C:N do húmus. Após a obtenção dos bioprodutos empregou-se metodologia para verificação da presença/ausência de coliformes.

Para o pH do composto adaptou-se a metodologia do Adolfo Lutz (2008). Assim, pesou-se $10 \mathrm{~g} \mathrm{de}$ húmus e diluiu-se em $100 \mathrm{~mL}$ de água destilada. Agitou-se em agitador magnético por 30 minutos e deixouse em repouso por 10 minutos. Após, filtrou-se em papel pregueado e aferiu-se o $\mathrm{pH}$ com o $\mathrm{pHmetro} \mathrm{Lucadema}$ 210, este parâmetro foi analisado semanalmente.

Ademais, para a temperatura empregou-se termômetro, do tipo pistola, de infravermelho GM300 BENETEC. O teste de umidade foi realizado em balança de infravermelho i-Thermo 163M, já na técnica do teor de cinzas, realizando-se uma calcinação a $550^{\circ} \mathrm{C}$ por 4 horas, estas metodologias foram adaptadas do Adolfo Lutz (2008). A relação C:N inicialmente tende a ser alta, no entanto, ao final do processo deve ser reduzida. O teste foi realizado pela GERPEL/UNIOESTE.

Para a análise de coliformes, primeiramente pesou-se $10 \mathrm{~g}$ de húmus em um erlenmeyer, adicionou-se $90 \mathrm{~mL}$ de solução salina esterilizada $(0,85 \%$ de $\mathrm{NaCl})$, e incubou-se por $30 \mathrm{~min}$ a $200 \mathrm{rpm}$. O mesmo foi feito para o biofertilizante, no entanto utilizou-se $10 \mathrm{~mL}$. Depois, fez-se diluição seriada $\left(10^{-1}\right.$ a $\left.10^{-4}\right)$ em tubos contendo $9 \mathrm{~mL}$ de solução salina esterilizada $(0,85 \%$ de $\mathrm{NaCl})$. Plaqueou-se $100 \mu \mathrm{L}$, em placa contendo meio MacConkey, das diluições $10^{-2}$ e $10^{-4}$ e incubou-se em estufa a $35^{\circ} \mathrm{C}$ por $18-24$ horas.

\section{RESULTADOS E DISCUSSÃO}

Os primeiros resultados obtidos estão dispostos na figura 1, correspondente ao gráfico de $\mathrm{pH}$, temperatura e umidade referentes ao processo de vermicompostagem. Percebe-se que nenhum dos parâmetros apresentaram variações prejudiciais. Ademais, a umidade e o $\mathrm{pH}$ variaram em decorrência da atividade minhocária, de modo que ao final do processo notou-se estabilização desses parâmetros.

A tabela 1 demostra os resultados de temperatura, $\mathrm{pH}$ do húmus e do biofertilizante, relação $\mathrm{C}: \mathrm{N} \mathrm{e}$ umidade em comparação com a literatura, podendo-se observar que os valores estão em concordância com a mesma mostrando a reprodutibilidade do processo.

O teor de cinzas obtido inicialmente foi de $2 \%$ e no final $22 \%$, evidenciando que o húmus obtido estava rico em micro e macronutrientes com capacidade para usos posteriores, principalmente na agricultura de maneira a melhorar a qualidade do solo.

Para a análise microbiológica do húmus, visualizou-se crescimento bacteriano nas diluições de $10^{-2} \mathrm{e}$ $10^{-3}$, com $13 \times 10^{2}$ e $3 \times 10^{3} \mathrm{UFC} / \mathrm{g}$, respectivamente. Gonçalves e Reque (2013) também avaliaram a presença de coliformes no húmus, obtendo como resultado $2,2 \times 10^{5} \mathrm{NPM} / \mathrm{g}$, o que mostra que o composto obtido no presente trabalho apresenta baixa quantidade de coliformes. Já no biofertilizante não houve crescimento bacteriano.

Por fim, a quantidade de minhocas obtida ao final do processo é outro parâmetro satisfatório, tendo em vista que se obteve mais de 600 minhocas ao final da vermicompostagem, tratando $10 \mathrm{~kg}$ de residuos sólidos e demostrando que as condições proporcionadas foram ideais para sua reprodução e formação dos bioprodutos. A figura 2 faz um comparativo entre o início e final do processo de vermicompostagem, assim como apresenta os bioprodutos obtidos. 


\section{CONCLUSÃO}

A partir deste trabalho, compreende-se que a vermicompostagem é uma alternativa para o tratamento de resíduos sólidos, ao invés de enviá-los para aterros sanitários, direcionando assim sua transformação a um produto de qualidade que acarreta em benefícios ao meio ambiente e pode ser fonte de renda para famílias, sendo que foi possível tratar $10 \mathrm{~kg}$ de resíduos, obtendo húmus e biofertilizante com boas condições para serem comercializados. Ademais, sugere-se estudos posteriores acerca da composição do biofertilizante, bem como comparações dos bioprodutos com produtos comerciais.

\section{AGRADECIMENTOS}

A UTFPR campus Toledo pela infraestrutura disponibilizada e ao George L. B. Corrêa que prestou consultoria durante o processo.

\section{REFERÊNCIAS}

BRASIL. Lei No 12.305, DE 02 DE AGOSTO DE 2010. Política Nacional de Resíduos Sólidos, Brasília, DF, ago 2010. Disponível em: <http://www.planalto.gov.br/ccivil_03/_Ato2007-2010/2010/Lei/ L12305.htm>. Acesso em: 03 out. 2018.

BRASIL. Ministério da agricultura, pecuária e abastecimento secretaria de defesa agropecuária. Instrução normativa sda $n^{\circ}$ 25: normas sobre as especificações e as garantias, as tolerâncias, o registro, a embalagem e a rotulagem dos fertilizantes orgânicos simples, mistos, compostos, organominerais e biofertilizantes destinados à agricultura. 2009. Disponível em: <http://www.agricultura.gov.br/assuntos/ insumos-agropecuarios/insumos-agricolas/fertilizantes/legislacao/in-25-de-23-7-2009-fertilizantesorganicos.pdf $>$. Acesso em: 11 nov 2018.

GARCIA, F. R. M.; ZIDKO, A. Criação de minhocas: As operárias do húmus, 2006.

GONÇALVES, L.; REQUE, R. Incorporação de meios de cultivo microbiológico em compostagem. 2013. 58p. Trabalho de Conclusão de Curso. Universidade Tecnológica Federal do Paraná, Curitiba.

INSTITUTO ADOLFO LUTZ [2008]. Métodos físico-químicos para análise de alimentos. São Paulo: Intituto Adolfo Lutz, 2008. 1020p. Disponível em: <http://www.ial.sp.gov.br/resources/editorinplace/ial/ 2016_3_19/analisedealimentosial_2008.pdf>. Acesso em: 08 out 2018.

MORSELLI, T. B. G. A. Minhocultura. Pelotas: Editora e Gráfica Universitária da NAIR, J. ; SEKIOZOIC, M. Effectof pre-composting on vermicomposting of kiche waste. Bioresources Technology, v. 16, p. 20912095, 2006.

SCHIEDECK, G.; GONÇALVES, M. de M.; SCHWENGBER, J. E. Minhocultura : produção de húmus. ABC da agricultura familiar: Embrapa. 2. ed., 56p, Brasília-DF, 2014.

TURRUELLA, E.P.;RAMÍREZ, M.C.; MARTÍNEZ, F.; NODALS, A.R.; CONCEPCIÓN, N.C. Manual para la producción de abonos orgánicos em la agricultura urbana. Ciudad de La Habana: INIFAT/PNUD, 2002. $102 \mathrm{p}$.

VERAS, L. R. V.; POVINELLI, J. A vermicompostagem do lodo de lagoas de tratamento de efluentes industriais consorciada com composto de lixo urbano. Revista de Engenharia Sanitária e Ambiental, São Paulo, v. 9, n.3, p.218-224, 2004.

Tabela 1. Comparação dos resultados obtidos durante o processo de vermicompostagem com a literatura.

\begin{tabular}{ccc}
\hline Análises & Autores & Literatura \\
\hline Temperatura $\left({ }^{\circ} \mathrm{C}\right)$ & $14-30$ & $15-30$ (MORSELLI, 2009). \\
pH & $4-9,35$ & $5-9$ (GARCIA e ZIDKO, 2006). \\
C:N (início-fim) & $19: 1-11,6: 1$ & $15: 1-11: 1$ (SCHIEDECK et al.,2014) \\
Umidade $(\%)$ & $70-89$ & $70-90 \%$ (TURRUELLA et al., 2002). \\
$\mathrm{pH}$ - biofertilizante & 9 & Mínimo 6 (Brasil, 2009). \\
\hline
\end{tabular}




\section{VISIGER_心

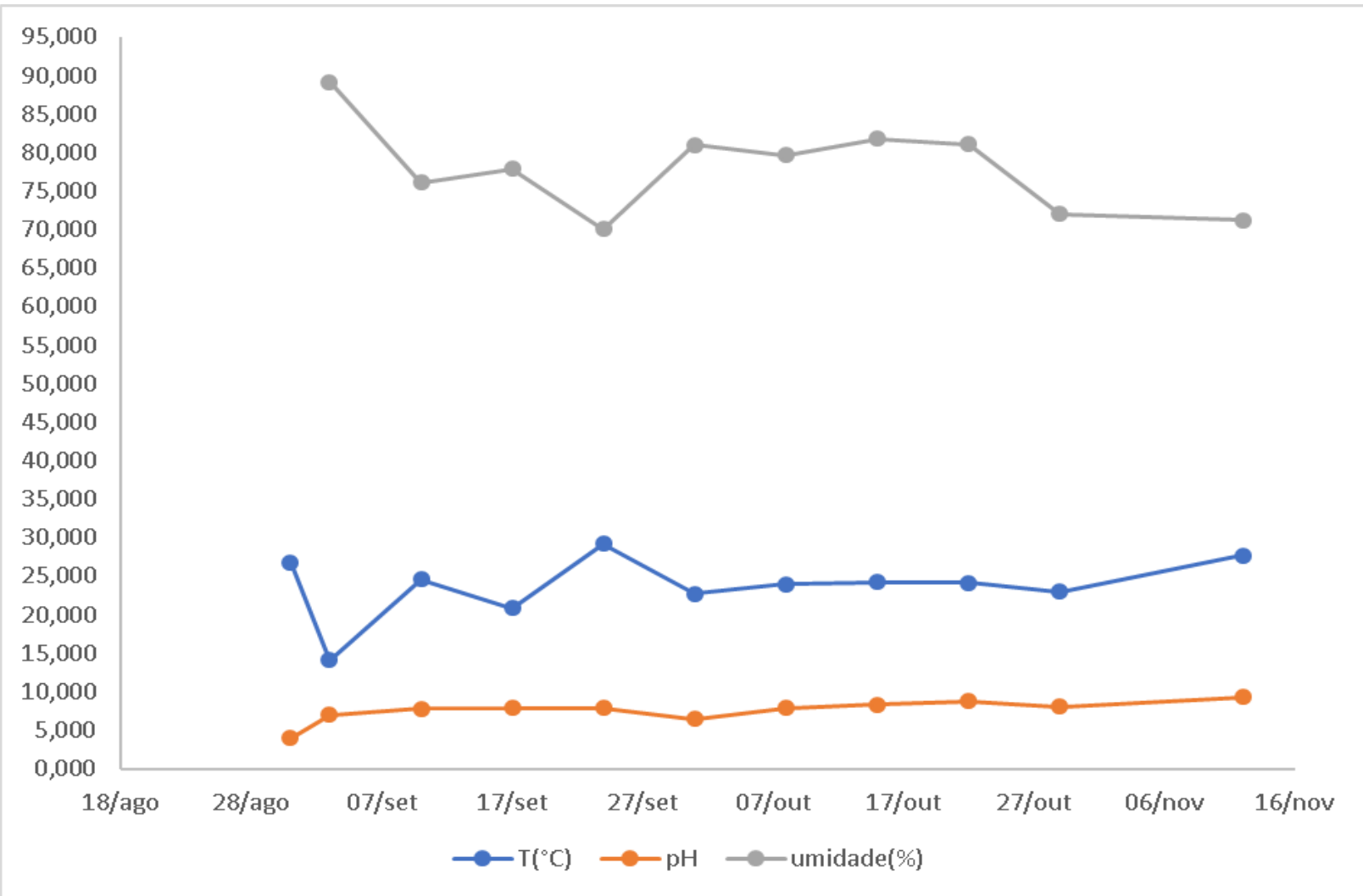

Figura 1. Gráfico referente aos parâmetros de $\mathrm{pH}$ do húmus, temperatura e umidade, analisados durante o processo de vermicompostagem.

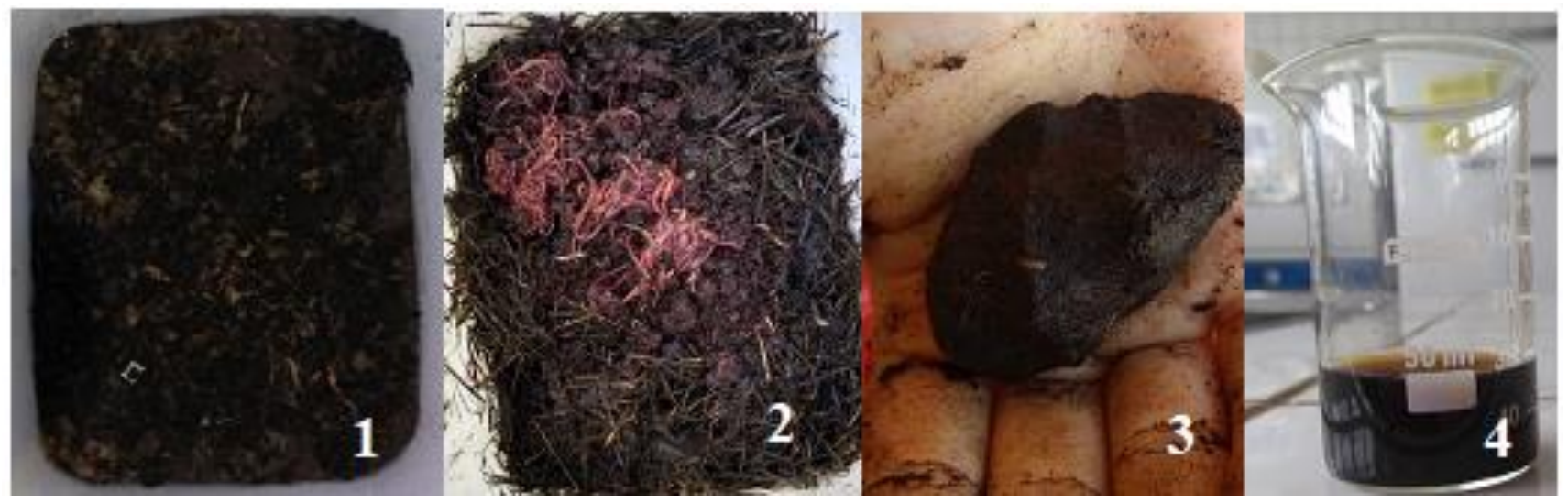

Figura 2. Comparação do húmus de minhoca inicial (1) e final (2) e seus respectivos bioprodutos, húmus (3) e biofertilizante (4). 


\title{
TREATMENT OF VITICULTURE WASTEWATER IN THE SÃO FRANCISCO VALLEY USING BIOCOAGULANTS
}

\author{
Oliveira, A.F.G. ${ }^{1}$; Nascimento, A.C.S. ${ }^{1}$; Pereira, E.C. ${ }^{1}$; Sá, J.I.F. ${ }^{2}$; Barbosa, M.L. ${ }^{2}$; Amorim, M.C.C.*3 \\ ${ }^{I}$ Graduandos em Eng. Agrícola e Ambiental, Bolsistas PET, Univasf, Juazeiro, BA - Brasil. alden441@ hotmail.com; \\ amandacaroline.sn@hotmail.com; elionaide.pereira@hotmail.com; ${ }^{2}$ Graduandos Eng. Civil, Bolsista BIA, Univasf, Juazeiro, BA- \\ Brasil.itamarjosesa@gmail.com; Bolsista PET, Univasf, Juazeiro,BA-Brasil maisa-lb@hotmail.com; \\ ${ }^{3}$ Professora Tutora PET Saneamento Ambiental, Univasf, Juazeiro, BA-Brasil.miriam.cleide@ univasf.edu.br
}

\begin{abstract}
Viticulture situated in the São Francisco Valley currently represents the second largest producer region of fine wines in Brazil. The winery processes generate wastewaters which need treatments, aiming the mitigation of environmental problems. The aim of this work was to evaluate the performance of biocoagulants (Moringa Oleifera and Opuntiaficus-indica) compared to the potassium alum (double sulfate of aluminum and potassium) and to the aluminum sulfate, with and without filtration after the clarification. The results showed that the seeds of Moringa Oleifera and the potassium alum presented the best efficiencies in the removal of turbidity and organic matter.
\end{abstract}

Keywords: clarification, drumstick tree, grape washing, opuntia, potassium alum.

\section{INTRODUCTION}

Brazil is considered the fifth largest wine producer in the southern hemisphere, with about 1,1 thousand wineries distributed throughout the country. The viticulture of the states of Pernambuco and Bahia, situated in the São Francisco Valley, currently represents the second largest producer region of fine wines in Brazil, representing $15 \%$ of the national market, the only vineyard in the world with two annual harvests (Roloff, 2013).

The water use is intense in the wineries, and according to Vlyssides et al. (2005) the productions of wastewater in viticulture processes are of the order of 0.7 to 1.2 times the wine production, and specific studies (Ros et al., 2017) demonstrate that for each liter of produced wine, 2 to $6 \mathrm{~L}$ of wastewater are generated. Specifically, in the São Francisco Valley, data by Birolo e Zanela (2017) point that 4 million liter/year are produced, thus indicating a considerable generation of wastewaters with potential for environmental impacts, due to the high load of organic matter (sugars and organic acids). Physical-chemical treatments of these waters through biocoagulants or natural coagulants were proposed by Martins et al. (2009) and in practical essays of Oliveira et al. (2018), being among the coagulants the seed of Moringa oleifera Lam (drumstick tree) and cacti species. Lo Monaco et al. (2010) emphasize that the natural coagulants/flocculant shave demonstrated advantages in relation to those of chemical origin, specifically regarding biodegradability, low toxicity and low production index of residual sludge, when compared with the aluminum sulfate chemical coagulant.

In this manner, the aim of this work was to evaluate the efficacy of biocoagulants in the physicalchemical treatment of the grape-washing wastewater, by testing seeds of Moringa oleifera Lam and the cactus Opuntiaficus-indica, compared to the potassium alum (double sulfate of aluminum and potassium) and to the aluminum sulfate, through the determination of color, turbidity and organic matter removals.

\section{MATERIAL AND METHODS}

The wastewater was originated from the grape-washing processes performed in the Quintas São Braz winery, located in the Estrada da Tapera, Petrolina - PE. $100 \mathrm{~L}$ of the water were collected with a previously sanitized container, being characterized in 14 hours according to the parameters of color and turbidity (Tur), $\mathrm{pH}$, electrical conductivity (EC), total solids (TS), total fixed solids (TFS) and total volatile solids (TVS), chemical oxygen demand (COD) and biochemical oxygen demand (BOD), alkalinity (Al), total hardness (TH), total nitrogen $(\mathrm{N})$, ammoniacal nitrogen $\left(\mathrm{NH}_{3}\right)$ and total phosphorus $(\mathrm{P})$. Two biocoagulants were tested: seeds of Moringa oleifera Lam (drumstick tree) and the cactus Opuntia fícus-indica, compared with the aluminum sulfate chemical coagulant and the potassium alum. The drumstick seeds and the cactus were daily collected, directly from the drumstick trees and plants in the riparian zone of the Univasf in Juazeiro, BA. The seeds were peeled and crushed with mortar and pestle until obtaining a homogenous powder, preparing a stock 
solution of $20 \mathrm{~g} \mathrm{~L}^{-1}$ in a magnetic stirrer for 15 minutes (Franco et al., 2017). The proceeding for the preparing of the cactus stock solution followed the methodology of Ostrowsk (2014), by washing and removing the peel and thorns, being the viscous part transferred to themortar, macerated, and by adding $\mathrm{NaCl}$ extractive solution at $1 \%$ (following the proportion of $1 \mathrm{~g}$ of sample for $3 \mathrm{~mL}$ of solution), stirring in a magnetic stirrer for 30 minutes. The extract was filtered in filter paper, thus obtaining the stock solution. The preparing of the potassium alum (commercially obtained in powder) solution $\left(20 \mathrm{~g} \mathrm{~L}^{-1}\right)$ consisted of the addition of $10 \mathrm{~g}$ of the commercially obtained powder in $0,5 \mathrm{~L}$ was distilled water, homogenizing the solution in magnetic stirrer for 15 minutes. For each biocoagulant, two dosages were tested: $1 \mathrm{~g} \mathrm{~L}^{-1}$ and $1.5 \mathrm{~g} \mathrm{~L}^{-1}$ for the drumstick seeds; 0.5 $\mathrm{g} \mathrm{L}^{-1}$ and $1 \mathrm{~g} \mathrm{~L}^{-1}$ for the cactus; $0.5 \mathrm{~g} \mathrm{~L}^{-1}$ and $1 \mathrm{~g} \mathrm{~L}^{-1}$ for the potassium alumand $0.05 \mathrm{~g} \mathrm{~L}^{-1}$ and $0.08 \mathrm{~g} \mathrm{~L}^{-1}$ for the aluminum sulfate. The treatment process was composed of correction of the wastewater $\mathrm{pH}$ with sodium bicarbonate, clarification (coagulation/flocculation/sedimentation), followed by slow filtering in filter (0.16 $\mathrm{mm}$ ). The clarification was performed in a Jar-test JT303 Milan, with fast mixing speed of $95 \mathrm{rpm}$ for 2 minutes, and slow mixing speed of $35 \mathrm{rpm}$ for 30 minutes and sedimentation time of one hour (Stroher et al., 2012). All essays were performed in triplicate, being the data analyzed in the software SISVAR 5.6, in order to evaluate the interaction within coagulants, dosages and filtration, according with Tukey's test at $95 \%$.

\section{RESULTS AND DISCUSSION}

It might be observed, in Table 1, that the wastewater presented elevated values of color, turbidity, and EC. Turbidity appeared well above the values found by Heredia et al. (2005), of 115 NTU. The pH was acid, with a very close value to those of Ortigara et al. (2009) (4.0) and Ioannou et al. (2015) (5.3). The solids were elevated, according with the value Heredia et al. (2005), who found 9,100 $\mathrm{mg}$ of TS L ${ }^{-1}$. The elevated COD value corroborates with Antunes (2016), whose effluent, generated in grape washing, presented COD in the range of 1,200 to $17,900 \mathrm{mg} \mathrm{L}^{-1}$. The relation $\mathrm{BOD}_{5} / \mathrm{COD}$ of 0.31 points that most of the organic matter present in the wastewater does not present a biodegradable character, such as the value of 0,49 obtained by Vlyssides et al. (2005). The Al, N and P values were low when compared with those of Ortigara et al. (2005) of $60 \mathrm{mg}$ $\mathrm{L}^{-1}, 38 \mathrm{mg} \mathrm{L}^{-1}$ and $25 \mathrm{mg} \mathrm{L}^{-1}$ respectively.

None of the biocoagulants nor the aluminum sulfate promoted color removal, being the potassium alum the least efficient in this regard, and according with Lucas \& Perez (2011) the use of aluminum sulfate in the clarification treatment of winery effluents is not efficient in consequence of the nature of the compounds responsible for the color: totally soluble and resistant to degradation. Table 2 presents the data of turbidity and COD removal for essays with and without water filtration after the sedimentation time. It might be verified that the drumstick provided higher turbidity removals, varying from $90 \%$ to $93 \%$ after filtration. However, according with Tukey's test at 95\%, there was no significant difference for the drumstick with $1.5 \mathrm{~g} \mathrm{~L}^{-1}$, the potassium alum with $1 \mathrm{~g} \mathrm{~L}^{-1}$ and the aluminum sulfate with $0.05 \mathrm{~g} \mathrm{~L}^{-1}$, which presented removals of $93 \%, 93 \%$ and 95\%, respectively. Braz et al. (2010), working with wastewaters from red and white wine producer wineries, observed that the process of coagulation/flocculation with the use of aluminum sulfate allowed a removal of $92 \%$ of turbidity, although obtaining small COD removals. Rizzo et al. (2010), on the other hand, obtained $73 \%$ of COD removal with the use of the chitosan natural coagulant, and $92 \%$ turbidity removal in winery wastewaters. Regarding the removal of organic matter, it could be verified, for the present work, that the removals were low. It is worth noting that without the filtering process the drumstick presented the highest removal $(27 \%)$, and after filtration the potassium alum provided the highest removal (26\%). The aluminum sulfate was the coagulant that obtained organic matter removal in all stages, although with low results.

There was an increase in alkalinity in all clarification treatments; for the cactus, the variation ranged from $49 \mathrm{mg} \mathrm{L}^{-1}$ to $53 \mathrm{mg} \mathrm{L}^{-1}$, and in the remaining from $393 \mathrm{mg} \mathrm{L}^{-1}$ to $970 \mathrm{mg} \mathrm{L}^{-1}$. Regarding hardness, the drumstick and the cactus did not provide significant variation concerning the initial wastewater, within 122 $\mathrm{mg} \mathrm{L}^{-1}$ and $146 \mathrm{mg} \mathrm{L}^{-1}$; as for the potassium alum, the increase was significant, varying from $1750 \mathrm{mg} \mathrm{L}^{-1}$ to $1950 \mathrm{mg} \mathrm{L}^{-1}$. In contrast, the aluminum sulfate obtained the best results with values varying from $7 \mathrm{mg} \mathrm{L}^{-1}$ to $12 \mathrm{mg} \mathrm{L}^{-1}$. 


\section{CONCLUSION}

The wastewater presented acid character, with elevated turbidity and high concentration of nonbiodegradable organic matter, with average $\mathrm{BOD}_{5} / \mathrm{COD}$ relation. Among the biocoagulants in comparison with the aluminum sulfate, the Moringa Oleifera (drumstick tree) and the potassium alum revealed to be the most promising coagulating agents for turbidity and COD removal. Regarding the color, none of the biocoagulants nor the aluminum sulfate provided any removals.

\section{ACKNOWLEDGMENTS}

To the Programa de Educação Tutorial (PET) - Conexões de Saberes: Saneamento Ambiental da Universidade Federal do Vale do São Francisco and to Capes/FNDE for the concession of the scholarships.

\section{REFERENCES}

ANTUNES, M. R. O.; CARVALHO, L. A. de; CARVALHO, G. L de. Produção do Vinho e o Tratamento de Seus Efluentes. Revista Científica Semana Acadêmica, Fortaleza, v. 1, n. 98, 2016.

BIROLO, F.; ZANELA, V. Vinhos Tropicais: um desafio à tradição. Revista XXI Ciência para a Vida, v.16, MAI-AGO, 2017.

BRAZ, R.; PIRRA, A.; LUCAS, M. S.; PERES, J. A. Combination of long term aerated storage and chemical coagulation/flocculation to winery wastewater treatment. Desalination, v. 263, n. 1, p. 226-232, 2010.

FRANCO, C. S.; BATISTA, M. D. A.; OLIVEIRA, L. F. C. de; KOHN, G. P.; FIA, R. Coagulação com Semente de Moringa Oleífera Preparada por Diferentes Métodos em Águas com Turbidez de 20 a 100 UNT. Engenharia Sanitária e Ambiental, v.22 n.4, p. 781-788, jul/ago, 2017.

HEREDIA, J.B de; TORREGROSA, J.; DOMINGUEZ, J.; PARTIDO, E. Degradation of wine distillery wastewaters by the combination of aerobic biological treatmentwith chemical oxidation by Fenton's reagent, Water Sci. Technol. v. 51, n. 1, p. 167-174, 2005.

IOANNOU, L. A.; LI PUMA, G.; FATTA-KASSINOS, D. Treatment of winery wastewater by physicochemical, biological and advanced processes: A review. Journal of Hazardous Materials, v. 286, p. 343-368, 9 abr. 2015.

LO MONACO, P. A. V.; MATOS, A. T.; RIBEIRO, I. C. A.; NASCIMENTO, F. S.; SARMENTO, A. P. Utilização de extrato de sementes de moringa como agente coagulante no tratamento de água para abastecimento e águas residuárias. Ambi-Agua, Taubaté, v. 5, n. 3, p. 222-231, 2010.

LUCAS, M. S.; PERES, J. A. Processos de Tratamento de Efluentes Vinícolas: Breve perspectiva. Quinta de Prados: Centro de Química de Vila Real - Departamento de Química Universidade de Trás - dos - Montes e Alto Douro. Boletim da Sociedade Portuguesa de Química, p. 41 - 47, 2011.

MARTINS, R.C.; ABEGAO, F.J.; SILVA, A.M.; QUINTA-FERREIRA, R.M. Integrated Strategy for treatment of winery wastewaters using flocculation, ozonation and Fenton's oxidation, J. Adv. Oxid.Technol. v. 12, n.2, p. 255-264, 2009.

OLIVEIRA, N. T.; NASCIMENTO, K. P.; GONÇALVES, B. de O.; LIMA, F. C. de; COSTA, A. L. N. da. Tratamento De Água Com Moringa Oleífera Como Coagulante/Floculante Natural. Revista Científica Faema, v. 9, n. 1, p.373-382, 2018.

ORTIGARA, A.R.C.; SEZERINO, P.H.; BENTO, A.P. and SCARATTI, D. Quali-quantitative characterization and wastewater treatment of a winery located in the mid-west of Santa Catarina state, South of Brazil. Water Science \& Technology, v. 60, n. 4, p. 1025-1031, 2009.

OSTROWSKI, J. Utilização de Extrato de Cacto Cereus Jamacaru como Coagulantes Auxiliares para a Diminuição de Turbidez da Água de Turbidez Sintética. 2014. 45 f. Trabalho de Conclusão de Curso (Graduação em Tecnologia Em Processos Químicos) - Universidade Tecnológica Federal Do Paraná, Toledo, 2014.

RIZZO, L.; LOFRANO, G.; BELGIORNO, V. Olive mill and winery wastewaters pre-treatment by coagulation with chitosan. Sep. Sci. TechnoL., v. 45, n. 16, p. 2447-2452, 2010.

ROLOFF, M.; CAUS, M. Avaliação setorial de 2013. IBRAVIN- Instituto Brasileiro do Vinho. Disponível em <www.ibravin.org.br/downloads/1380742265.pdf>. Acesso em 2 nov. 2017. 
ROS, C.; CAVINATO, C.; BOLZONELLA, D.; PAVAN, P. Renewable energy from thermophilic anaerobic digestion of winery residue: Preliminary evidence from batch and continuous lab-scale trials. Biomass and Bioenergy, v. 91, p. 150-159, 2017.

STRÖHER, A. P.; JUNIOR, O. M. C; MENEZES, M. L. de; BERGAMASCO, R.; PEREIRA, N. C. Aplicação de Moringa oleífera Lam no tratamento de efluente proveniente da lavagem de jeans. Editora UniBH, Revista e-Xacta, Belo Horizonte, v. 5, n. 1, p. 61-66, 2012.

VLYSSIDES, A. G.; BARAMPOUTI E. M.; MAI, S. Wastewater characteristics from Greek wineries and distilleries. Water Sci Technol, v. 51, n. 1, p. 53-60, 2005.

Tabel 1. Characterization of the residual water from the grape washing.

\begin{tabular}{cccccccccccccc} 
Color & Tur & pH & EC & TS & TFS & TVS & COD & BOD & Al & TH & N & NH $_{3}$ & P \\
\hline UC & NTU & & $\mu \mathrm{C} / \mathrm{cm}$ & & & & & $\mathrm{mg} \mathrm{L}^{-1}$ & & & & & \\
\hline 235 & 716 & 3.9 & 666.7 & 10.083 & 575 & 9,508 & 11,170 & 3,500 & 9.67 & 144 & 23 & 22 & 13 \\
\hline
\end{tabular}

Tabel 2. Removal (\%) of turbidity and COD of residual water after sedimentation without and with filtration.

\begin{tabular}{cccccc}
\hline Coagulants & Dosages $\left(\mathbf{g ~ L}^{-\mathbf{1}}\right)$ & \multicolumn{2}{c}{ Removal (\%) without filtration } & \multicolumn{2}{c}{ Removal (\%) with filtration } \\
\hline \multirow{2}{*}{ Cactus } & & Turbidity & COD & Turbidity & COD \\
\cline { 2 - 5 } & 0.5 & $47 \mathrm{a}$ & $*$ & $73 \mathrm{c}$ & 13 \\
Potassium alum & 1 & $48 \mathrm{a}$ & 14 & $77 \mathrm{~cd}$ & 23 \\
Seeds of Moringa & 0.5 & $78 \mathrm{~b}$ & $*$ & $89 \mathrm{df}$ & $*$ \\
oleifera & 1 & $77 \mathrm{~b}$ & $*$ & $93 \mathrm{f}$ & 26 \\
Aluminum sulfate & 1.5 & $89 \mathrm{bg}$ & 27 & $90 \mathrm{dfg}$ & 13 \\
& 0.05 & $87 \mathrm{bg}$ & $*$ & $93 \mathrm{fg}$ & 16 \\
& 0.08 & $78 \mathrm{~b}$ & 5 & $95 \mathrm{f}$ & 22 \\
\hline
\end{tabular}

- Removals (\%) without / with turbidity filtration containing at least one equal letter does not present significant difference according to the Tukey test at $95 \%$.

- (*) There was an increase in COD. 


\title{
ÁCIDOS CARBOXÍLICOS NA COMPOSTAGEM DE RESÍDUOS ORGÂNICOS DE AVES DE CORTE E GLICERINA BRUTA
}

\author{
Aloisio, C.M. ${ }^{1}$; Santos, F.T. ${ }^{1}$; Fehmberger, C. ${ }^{1}$; Bautitz, I.R. ${ }^{1}$; Hermes, E. ${ }^{* 1}$ \\ ${ }^{1}$ Programa de Pós-Graduação em Tecnologias de Bioprodutos Agroindustriais, Universidade Federal do Paraná (UFPR), Palotina, \\ PR - Brasil \\ elianehermes@yahoo.com.br
}

\begin{abstract}
RESUMO: Durante o processo de humificação, são produzidos diferentes grupos funcionais aumentando o grau de oxidação da matéria orgânica e elevando a capacidade de troca catiônica, sendo portanto utilizados para avaliar a maturidade do composto orgânico. Diante disso, o objetivo deste estudo foi avaliar a concentração dos ácidos fórmico, acético, propiônico e butírico no decorrer do tempo da compostagem de resíduos orgânicos da cadeia de aves associados a glicerina bruta. As concentrações de glicerina bruta em relação a massa seca dos resíduos foram de 0,$0 ; 1,5 ; 3,0 ; 4,5$ e 6,0\% (cinco tratamentos) e os paramêtros de monitoramento adotados foram: temperatura, umidade e revolvimentos semanais em todo o processo de compostagem. A quantificação dos ácidos orgânicos voláteis (acético, butírico e propiônico) e do ácido fórmico foi realizada por cromatografia líquida de alta eficiência, sendo as análises realizadas quinzenalmente $(7,22,37,52$ e 67 dias de compostagem). Em todos os tratamentos, aos sete dias de compostagem, os ácidos fórmico e propiônico foram encontrados em maiores quantidades quando comparados aos ácidos butírico e acético. Ao longo do período de compostagem, houve redução para todos os ácidos analisados, chegando muito próximo a zero, independente do tratamento. A presença do ácido propiônico no processo de compostagem indica a intensa atividade dos microrganismos na degradação da matéria orgânica.
\end{abstract}

Palavras-chave: adubo orgânico, grupos funcionais, matéria orgânica.

\section{CARBOXYLIC ACIDS IN THE COMPOSITION OF ORGANIC WASTE FROM POULTRY AND CRUDE GLYCERINE}

\begin{abstract}
During the humification process, different functional groups are produced increasing the oxidation degree of the organic matter and increasing the cation exchange capacity, being therefore used to evaluate the maturity of the organic compound. Therefore, the objective of this study was to evaluate the concentration of formic, acetic, propionic and butyric acids during the composting time of organic residues from poultry chain associated with crude glycerin. The concentrations of crude glycerin in relation to the dry mass of the residues were $0.0 ; 1.5 ; 3.0 ; 4.5$ and $6.0 \%$ (five treatments) and the monitoring parameters adopted were: temperature, humidity and weekly revolves throughout the composting process. The quantification of volatile organic acids (acetic, butyric and propionic) and formic acid was carried out by high performance liquid chromatography. The analyzes were carried out biweekly (7, 22, 37, 52 and 67 days of composting). In all treatments, at seven days of composting, formic and propionic acids were found in higher amounts when compared to butyric and acetic acids. During the composting period, there was reduction for all acids analyzed, reaching very close to zero, regardless of the treatment. The presence of propionic acid in the composting process indicates the intense activity of the microorganisms in the degradation of organic matter.
\end{abstract}

Keywords: organic fertilizer, functional groups, organic matter.

\section{INTRODUÇÃO}

Durante o processo de maturação dos resíduos a matéria orgânica é humificada e ocorre intensa produção de grupos funcionais carboxílicos e fenólicos, ocasionando aumento da capacidade de troca de cátions devido à oxidação da matéria orgânica (BUTLER et al., 2001; BERNAL; ALBUQUERQUE; MORAL, 2009). Os compostos orgânicos resultantes do processo de compostagem, são formados por diferentes grupos funcionais (ALBUQUERQUE e MORAL, 2009), dentre eles estão os aromáticos, carboxílicos, fenólicos e carbonilas (VEGA, 2005). 
Os grupos funcionais, são funções importantes presentes nas substâncias húmicas, pois determinam propriedades de suas atividades junto a íons metálicos e minerais de solos, sedimentos, e teor de umidade. A dissociação dos grupos funcionais ácidos origina cargas negativas nas substâncias húmicas e refletem na capacidade de troca catiônica (ALLEN et al., 2001). Durante o processo de humificação, são produzidos diferentes grupos funcionais aumentando o grau de oxidação da matéria orgânica e elevando a capacidade de troca catiônica, sendo, portanto, utilizados para avaliar a maturidade do composto orgânico (BERNAL et al., 1998).

A análise dos grupos funcionais permite avaliar a reatividade das substâncias húmicas (SANTOS, 2016). Dessa forma, os diferentes grupos funcionais, determinam a complexa estrutura das substâncias húmicas e são modificadas em função de diferentes fatores (CANELLAS et al., 2005). Com isso, o tempo de compostagem, as características dos materiais a serem compostados, o grau de humificação e o teor de carbono presente nos materiais, assim como, a matéria orgânica total pode variar de um substrato para outro, influenciando na estrutura das substâncias húmicas (WU; MA, 2002). A diversidade de grupos funcionais e a flexibilidade estrutural que compõem as substâncias húmicas, indicam a reatividade e o seu comportamento em faixas de reações (CANELLAS et al., 2005).

Diante disso, o objetivo deste estudo foi avaliar a concentração dos ácidos fórmico, acético, propiônico e butírico no decorrer do tempo da compostagem de resíduos orgânicos da cadeia de aves associados a glicerina bruta.

\section{MATERIAL E MÉTODOS}

O experimento foi realizado na Universidade Federal do Paraná (UFPR) - Setor Palotina, que possui as seguintes coordenadas geográficas: $24^{\circ} 17^{\prime}$ latitude sul e $53^{\circ} 50^{\prime}$ longitude oeste. A compostagem dos resíduos orgânicos foi conduzida em composteiras construídas com paletes, contendo 4 divisórias dentro de cada composteira, de modo que houvesse 4 repetições de cada tratamento, revestidas com tela permeável. As composteiras foram confeccionadas manualmente e dispostas sobre lona para impermeabilização no pátio e com cobertura para proteção da incidência solar direta e das chuvas.

Para o processo de compostagem foram utilizados diferentes resíduos como fontes de carbono: poda de árvores urbanas, bagaço de cana e glicerina bruta. A glicerina bruta foi adquirida de uma usina de biodiesel da região, a poda de árvore foi obtida junto a prefeitura da cidade e o bagaço de cana em uma garapeira da região e carvão remanescente da queima em caldeiras de frigorífico.

Os resíduos aplicados como fontes de nitrogênio foram cedidos por uma cooperativa de abate de aves e produtores de engorda de frango da região, sendo estes: resíduo de incubatório, a cama de frango, o lodo de flotador.

Os tratamentos foram constituídos dos resíduos orgânicos de uma indústria de beneficiamento de aves, bem como diferentes concentrações de glicerina bruta na massa natural do material compostado $(0,1,5 ; 3,0$; 4,5 e 6\%) denominados de T0,0; T1,5; T3,0; T4,5 e T6,0\%. As misturas foram definidas em função da composição de carbono e nitrogênio dos resíduos, fixando a relação C:N de aproximadamente 26/1 para todos os tratamentos

A temperatura da leira foi monitorada a cada 3 dias, com auxílio de termômetro digital, a uma profundidade de aproximadamente $30 \mathrm{~cm}$. Por ocasião das medidas de temperatura das leiras, a temperatura ambiente foi monitorada, pois quando a temperatura do interior das leiras estava semelhante a temperatura ambiente, considerou-se o final do processo de compostagem. A umidade das leiras foi controlada semanalmente após cada revolvimento e ajustada com adição da quantidade de água necessária, para se obter aproximadamente $60 \%$ de umidade.

A quantificação dos ácidos orgânicos voláteis (acético, butírico e propiônico) e do ácido fórmico foi realizada por cromatografia líquida de alta eficiência (CLAE) em sistema Shimadzu® equipado com Coluna Aminex ${ }^{\circledR}$ HP-87H (300 mmx 7,8 mm Bio-Rad), forno CTO20A a temperatura de $64{ }^{\circ} \mathrm{C}$, controlador CBM$20^{\mathrm{a}}$, detector UV com arranjo de diodos SPD20A em comprimento de onda de $208 \mathrm{~nm}$ e bomba LC-20AT. A fase móvel foi composta por água ultrapura Milli-Q (Millipore®) acidificada com $\mathrm{H}_{2} \mathrm{SO}_{4} 0,005 \mathrm{M}$ em fluxo de $0,5 \mathrm{ml} \mathrm{min}^{-1}$ e volume de injeção de $20 \mu \mathrm{L}$ (LAZARO et al., 2012; PENTEADO et al., 2013). As análises foram realizadas quinzenalmente $(7,22,37,52$ e 67 dias de compostagem), no Laboratório de Recursos Hídricos e Saneamento Ambiental (RHESA) da Universidade Estadual do Oeste do Paraná (UNIOESTE) Campus Cascavel. 


\section{RESULTADOS E DISCUSSÃO}

Os ácidos carboxílicos de cadeia curta como o fórmico, acético, propiônico e o butírico são encontrados com maior frequência nas primeiras semanas do processo de compostagem, com uma maior ocorrência do ácido acético em relação aos demais (AQUINO e SANTIAGO-SILVA, 2006). As concentrações dos ácidos fórmico, acético, propiônico e butírico no decorrer da compostagem, estão apresentadas na Figura 1.

Em todos os tratamentos, aos sete dias de compostagem, os ácidos fórmico e propiônico eram encontrados em maiores quantidades quando comparados aos ácidos butírico e acético. Ao longo do período de compostagem, houve redução para todos os ácidos analisados, chegando muito próximo do valor 0 , independente do tratamento.

O ácido fórmico foi encontrado em maior volume para o tratamento T3 no $7^{\circ}$ dia e sua redução ocorreu rapidamente a partir do $22^{\circ}$ dia. Pinheiro et al. (2013), apontam que o ácido fórmico é produzido durante a descarboxilação do ácido oxálico por bactérias que o utilizam como fonte de carbono durante o processo de decomposição da matéria orgânica e permanecem por um curto período de tempo misturado ao composto em degradação, pois são rapidamente consumidos e utilizados por bactérias e fungos.

$\mathrm{O}$ ácido acético é frequentemente encontrado em quantidades significativas, normalmente são produzidos a partir de resíduos florestais. Jonis et al. (2006) afirmam que este ácido faz parte do ciclo do carbono e é fonte de energia para os microrganismos.

Os tratamentos T0 e T1 apresentaram os maiores níveis de ácido propiônico aos sete dias de compostagem. Em contrapartida, os tratamentos T3 e T6 obtiveram aumento na quantidade do ácido propiônico no $22^{\circ}$ dia, diferindo dos tratamentos T0, T1,5 e T4,5. A presença do ácido propiônico indica a intensa atividade dos microrganismos na degradação da matéria orgânica que apresenta por característica a insolubilidade em água (SUZESK et al., 2007).

O ácido butírico assim como o ácido propiônico está diretamente relacionado ao excesso de gordura presente nos materiais orgânicos. Quando comparado aos valores dos ácidos acético, fórmico e propiônico, o ácido butírico apresentou as menores quantidades em todos os tratamentos do estudo, porém, ao final da compostagem, a presença desse ácido, mesmo sendo próxima do valor zero, ainda pode ser notada. Segundo Oliveira et al. (2008), a granulometria e a qualidade dos materiais a serem degradados, podem contribuir na liberação do ácido butírico e dessa forma, influenciar no retardamento da compostagem e na qualidade final do composto.

\section{CONCLUSÃO}

Aos sete dias de compostagem, os ácidos fórmico e propiônico foram encontrados em maiores quantidades quando comparados aos ácidos butírico e acético em todos os tratamentos. Ao longo do período de compostagem, houve redução para todos os ácidos analisados, chegando muito próximo a zero.

\section{AGRADECIMENTOS}

O presente trabalho foi realizado com apoio da Coordenação de Aperfeiçoamento de Pessoal de Nível Superior - Brasil (CAPES) - Código de Financiamento 001.

\section{REFERÊNCIAS}

ALBURQUERQUE, J. A.; MORAL, R. Composting of animal manures and chemical criteria for compost maturity assessment. a review. Bioresource Technology, v. 100, p. 5444-5453, 2009.

ALLEN D. D.; SMITH Q. R.; ASCHNER M. Characterization of the blood-brain barrier choline transporter using the in situ rat brain perfusion technique. J. Neurochem, v. 76, p. 1032-1041, 2001.

BERNAL, M. P.; NAVARRO, A. F.; ROIG, A.; CEGARRA, J.; GARCÍA, D. Carbon and nitrogen transformation during composting of sweet sorghum bagasse. Biology and Fertility of Soils, v. 22, p. 141-148, 1998.

BERNAL, M. P; ALBURQUERQUE, J. A; MORAL, R. Composting of animal manures and chemical criteria for compost maturity assessment. A review. Bioresource Tecnology, v. 100, p. 5444-5453, 2009.

BUTLER, T. A.; SIKORA, L. J.; STEINHILBER, P. M.; DOUGLASS, L. W. Compost age and sample storage effects on maturity indicators of biosolids compost. Journal of Environmental Quality, v. 30, p. 2141-2148, 2001. 
CANELLAS, L. P.; RUMJANEK, V. M. Distribuição da matéria orgânica e características de ácidos húmicos em solos com adições de resíduos de origem urbana. Pesquisa Agropecuária Brasileira, v. 36, p. 1529-1538, 2005.

JONIS, J. E.; BAEYENS, J.; GARY, D. Impact of mineralisation of C and $\mathrm{N}$ from soil and willow litter and its relationship with microbial community biomass and structure bending. Biology and Fertility of Soils. v. 50, p. 695-702, 2006.

LAZARO, C. Z.; VICH, D. V.; HIRASAWA, J. S.; VARESCHE, M. B. A. Hydrogen production and consumption of organic acids by a phototropic microbial consortium. International Journal of Hydrogen Energy, v. 37, p. 11691-11700, 2012.

OliVeIRA, E. C. A.; SARTORI, R. H.; GARCEZ, T. B. Compostagem. Universidade de São Paulo. Piracicaba, 2008.

PENTEADO, E. D.; LAZARO, C. Z.; SAKAMOTO, I. K.; ZAIAT, M. Influence of seed sludge and pretreatment method on hydrogen production in packed-bed anaerobic reactors. International Journal of Hydrogen Energy, v. 38, p. 6137-6145, 2013.

PINHEIRO, L. G; SILVA, C. A.; LIMA, J. M.; COSTA, A. L. Ácidos orgânicos de baixa massa molar em solos e materiais orgânicos. Quimica Nova, v. 36, p. 413-418, 2013.

SUZESK, M.; SAMPAIO, S. C.; MALLMANN, L. S. Aspectos físicos e químicos do vermicomposto produzido a partir do esterco bovino e compostos de resíduos verdes urbanos. Engenharia na Agricultura, v. 15, p. 39-44, 2007.

VEGA, M. R. G. Fundamentos da Química Orgânica. In: CABELLAS, L. P.; SANTOS, G. A. Humosfera: Tratado preliminar sobre a química das substâncias húmicas. Campos dos Gaoytacazes, 2005. 309p.

WU, L.; MA, Q. C. Relationship between compost stability and extractable organic carbon. Journal of Environmental Quality, v. 31, p. 1323-1328, 2002.
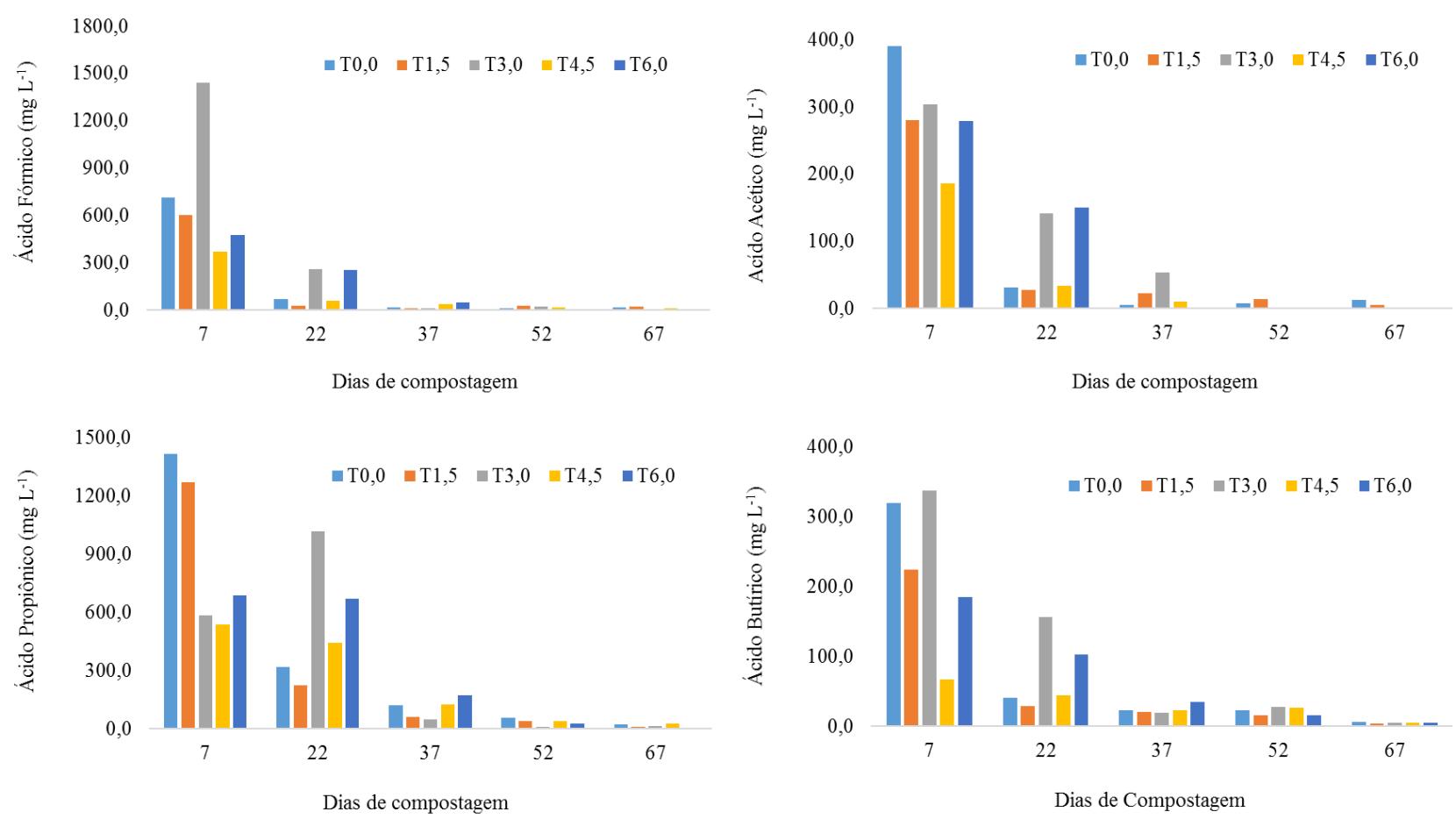

Figura 1. Concentração de ácido fórmico, ácido acético, ácido propiônico e ácido butírico nos tratamentos durante o processo de compostagem. 


\title{
ADSORÇÃO DE DICLOFENACO DE SÓDIO EM SOLUÇÃO AQUOSA EMPREGANDO BAGAÇO DE MALTE
}

\author{
Reis, M.A.*11; Diel, J.C. ${ }^{1}$; Chiquim, M.S. ${ }^{1}$; Bender, T.J. ${ }^{\text {; }}$ Nunes, I. dos S. ${ }^{1}$ \\ ${ }^{1}$ Pesquisadores da Universidade Regional Integrada do Alto Uruguai e das Missões, Santo Ângelo, RS - Brasil. \\ isaac.eq@san.uri.br
}

\begin{abstract}
RESUMO: O bagaço de malte é o principal subproduto do processo de fabricação de cerveja e grandes quantidades deste resíduo são geradas diante da demanda de produção da bebida. Em vista disso, este trabalho objetivou aproveitar o bagaço de malte como material adsorvente na remoção de diclofenaco de sódio (DCF) por adsorção, como alternativa para minimizar os impactos ambientais decorrentes de seu descarte inadequado e, ao mesmo tempo, promovendo o tratamento de efluentes industriais contaminados pelo fármaco. A partir das cinéticas de adsorção, avaliou-se a remoção de DCF na concentração fixa de $50 \mathrm{mg} \mathrm{L}^{-1}$, variando-se as dosagens de adsorvente nos patamares de 0,$025 ; 0,050$ e $0,075 \mathrm{~g}$, ajustando-se as soluções ao pH 4 . A condição mais atrativa foi a massa de $0,025 \mathrm{~g}$, alcançando uma remoção de $65,03 \%$ para uma capacidade adsortiva de $65,03 \mathrm{mg} \mathrm{g}^{-1}$, decorridos 75 min de contato. Para os modelos cinéticos testados, o modelo de PPO apresentou melhor ajuste aos dados experimentais. Tais resultados revelam a potencialidade do bagaço de malte como biomassa alternativa no tratamento de efluentes contendo o fármaco DCF.
\end{abstract}

Palavras-chave: Bagaço de malte, resíduo, adsorção, diclofenaco de sódio.

\section{ADSORTION OF SODIUM DICLOFENAC IN AQUEOUS SOLUTION EMPLOYING MALT MARC}

\begin{abstract}
Malt marc is the main by-product of the brewing process and large quantities of this residue are generated in response to the production demand of the beverage. The aim of this work was to exploit malt marc as an adsorbent in the removal of sodium diclofenac by adsorption, as an alternative to minimize environmental impacts resulting from its inadequate disposal and, at the same time, to promote the treatment of industrial effluents contaminated by drug. From the adsorption kinetics, the determination of DCF at the fixed concentration of $50 \mathrm{mg} \mathrm{L}^{-1}$ was evaluated, the adsorbent dosages being varied at the levels of 0,025 ; 0,050 and $0,075 \mathrm{~g}$, adjusting the solutions to $\mathrm{pH} 4$. The most attractive condition was the mass of $0,025 \mathrm{~g}$, achieving a $65.03 \%$ removal for an adsorptive capacity of $65,03 \mathrm{mg} \mathrm{g}^{-1}$, after $75 \mathrm{~min}$ of contact. For the kinetic models tested, the PPO model presented better fit to the experimental data. These results reveal the potential of malt marc as an alternative biomass in the treatment of effluents containing the drug DCF.
\end{abstract}

Keywords: Malt marc, residue, adsorption, sodium diclofenac.

\section{INTRODUÇÃO}

À medida que aumentam as atividades industriais, há também um aumento de resíduos gerados e descartados no meio ambiente. Muitas vezes, esses resíduos são lançados em corpos d'água utilizados como fonte de abastecimento público, sendo um dos fatores mais preocupantes quanto aos problemas relacionados aos recursos hídricos (NOWACKI et al., 2014).

Neste cenário, de acordo com Nascimento et al. (2015), surgem os contaminantes emergentes, que são grupos de substâncias ainda sem monitoramento ou sem relatórios sanitários indicando a sua presença nos esgotos ou na água de consumo. Dentre esses contaminantes encontram-se diversos fármacos, como o diclofenaco de sódio (DCF).

$\mathrm{O}$ avanço da agroindústria também tem acarretado problemas quanto ao descarte de resíduos provenientes de seus processos. Como é o caso do bagaço de malte (BM), um subproduto gerado durante o processo cervejeiro após a etapa de mostura (preparo do mosto), na qual todos os compostos solúveis de interesse já foram extraídos por processos enzimáticos (CARVALHO et al., 2016).

Diante disso, surge a necessidade de promover o tratamento dos efluentes gerados, bem como o reaproveitamento de subprodutos agroindustriais. Como alternativa, tem-se a adsorção, uma operação unitária que consiste em separar os materiais de uma mistura por meio de sua afinidade por alguns dos componentes da mesma. Neste sentido, este trabalho visa avaliar o potencial do bagaço de malte (BM) como um adsorvente na remoção de diclofenaco de sódio (DCF) em solução aquosa, estudando o efeito da massa de adsorvente 
$(0,025 ; 0,050 ; 0,075$ e $0,01 \mathrm{~g})$, a concentração do corante em solução $\left(10\right.$ e $\left.50 \mathrm{mg} \mathrm{L}^{-1}\right)$ e o tempo de contato, ajustando os dados experimentais a modelos cinéticos.

\section{MATERIAL E MÉTODOS}

$\mathrm{O}$ adsorvente utilizado foi o bagaço de malte proveniente de indústria cervejeira da cidade de Cerro Largo, RS. A biomassa foi seca durante $24 \mathrm{~h} \mathrm{em} 105^{\circ} \mathrm{C}$, moída em moinho de facas tipo Willey, e posteriormente peneirada em série de peneiras.

A biomassa foi submetida à medida do $\mathrm{pH}$ no ponto de carga zero ( $\mathrm{pH}$ PZC), empregando-se o "Método dos 11 pontos". O procedimento consistiu na adição de $0,02 \mathrm{~g}$ de material adsorvente e $20 \mathrm{~mL}$ de solução aquosa de $\mathrm{NaCl} 0,1 \mathrm{~mol} \mathrm{~L}^{-1}$ em erlenmeyers de $125 \mathrm{~mL}$, sob 11 diferentes condições de $\mathrm{pH}$ inicial $(1,2,3,4$, $5,6,7,8,9,10,11)$, ajustados com soluções de $\mathrm{HCl}$ ou de $\mathrm{NaOH}$. Apontou-se o $\mathrm{pH}$ final das soluções decorridas 24 h de equilíbrio, sob agitação de 120 rpm, em mesa agitadora orbital (CT-145, Cientec).

Para a realização dos experimentos, foram preparadas soluções a partir da dissolução de DCF em água destilada, na concentração inicial de $100 \mathrm{mg} \mathrm{L}^{-1}$. Todas as soluções foram ajustadas ao valor de $\mathrm{pH}$ PZC determinado, realizando-se a correção necessária com soluções de $\mathrm{NaOH}$ e $\mathrm{HCl}$. Inicialmente, realizaram-se testes de dosagem de adsorvente e de concentração inicial do fármaco em solução, objetivando-se determinar as melhores condições para executar os ensaios cinéticos. As massas testadas foram 0,$025 ; 0,050 ; 0,075$ e 0,10 $\mathrm{g}$ de BM, e as concentrações de DCF 10 e $50 \mathrm{mg} \mathrm{L}^{-1}$.

Os ensaios de adsorção foram realizados variando-se massas adsorventes de 0,$025 ; 0,050 ;$ e $0,075 \mathrm{~g} \mathrm{em}$ $50 \mathrm{~mL}$ de solução de fármaco, na concentração de estudo de $50 \mathrm{mg} \mathrm{L}^{-1}$. As amostras foram agitadas em temperatura ambiente, a $160 \mathrm{rpm}$, em mesa agitadora orbital. Realizou-se a quantificação em espectrofotômetro (UV-2600, Shimadzu), no comprimento de onda de $275 \mathrm{~nm}$, em intervalos de tempo regulares (a cada $10 \mathrm{~min}$, até $60 \mathrm{~min}$; após a cada 15 até $120 \mathrm{~min}$; e de $30 \mathrm{em} 30$ até $180 \mathrm{~min}$ ), até atingir-se o ponto de equilíbrio do adsorvato/adsorvente. As alíquotas foram coletadas com auxílio de uma seringa, a qual continha uma ponteira com filtro.

O processo adsortivo foi analisado por meio das Equações 1 e 2, que representam a capacidade de adsorção da biomassa $(q t)$ e a eficiência de remoção $(\eta)$ do fármaco, respectivamente:

$$
\begin{aligned}
& \boldsymbol{q}_{t}=\frac{V\left(c_{0}-c_{t}\right)}{m} \\
& \eta=\frac{\left(c_{0}-C_{t, f}\right)}{c_{0}} \times 100
\end{aligned}
$$

sendo $C_{0}$ a concentração inicial de fármaco, em $\mathrm{mg} \mathrm{L}^{-1} ; C_{t}$ a concentração medida no intervalo de tempo, em $\mathrm{mg} \mathrm{L}^{-1} ; m$ a massa de adsorvente utilizada no processo de adsorção, em $\mathrm{g} ; V$ volume de solução que contém o fármaco, em $\mathrm{L}$; e $C_{t, f}$ a concentração no tempo final do processo, em $\mathrm{mg} \mathrm{L}^{-1}$.

Utilizou-se o pacote computacional MatLab® para a construção dos perfis cinéticos de adsorção e determinação dos parâmetros cinéticos dos modelos testados pseudo-primeira ordem (PPO) e pseudo-segunda ordem (PSO), apresentados pelas Equações 3 e 4, respectivamente:

$$
\begin{aligned}
& q_{t}=q_{e}\left(1-e^{-k_{1} t}\right) \\
& q_{t}=\frac{t}{\left(\frac{1}{k_{2} q_{e}^{2}}\right)+\left(\frac{t}{q_{e}}\right)}
\end{aligned}
$$

sendo $k_{l}$ a constante adimensional da taxa de adsorção de PPO; $k_{2}$ a constante adimensional da taxa de adsorção de PSO; $t$ o tempo de adsorção, em min; e $q_{e}$ a capacidade de adsorção no equilíbrio (máxima capacidade adsortiva), em $\mathrm{mg} \mathrm{g}^{-1}$.

O coeficiente de correlação linear $\left(\mathrm{R}^{2}\right)$ e o erro relativo médio (ERM) foram os parâmetros analisados para verificação do melhor ajuste do modelo, considerando-se os melhores ajustes aqueles que apresentaram os maiores valores para o $\mathrm{R}^{2}$ e menores valores da ERM.

\section{RESULTADOS E DISCUSSÃO}

No processo de adsorção, conforme afirma Graebin (2014), o pH da solução apresenta-se como um fator que pode influenciar as condições de operação, uma vez que a variação pode aumentar ou diminuir significativamente a capacidade adsortiva dos materiais, ativando ou desativando sítios ativos presentes. Por 
este motivo, é importante determinar o $\mathrm{pH}_{\mathrm{PZC}}$ dos adsorventes utilizados no processo, visando-se encontrar o pH ideal para realização dos ensaios cinéticos. Neste sentido, determinou-se o pH PZC do BM utilizado no presente trabalho, encontrando-se o valor de 4.

$\mathrm{Na}$ remoção de fármacos, o pKa do adsorbato é um fator de influencia diretamente no processo adsortivo, aliado as condições operacionais de pH. De acordo com Luna et al. (2017), para que o processo de adsorção seja favorável, é essencial a interação eletrostática entre o adsorvato e o adsorvente. Segundo Hasan et al. (2016), o pKa do DCF está em torno de 4, o que significa que, em $\mathrm{pH}<4$ a solução apresenta carga positiva, e em $\mathrm{pH}>4$ a é carga negativa. Já em relação ao $\mathrm{pH}$ PZC do adsorvente, soluções com $\mathrm{pH}>\mathrm{PZC}$ apresentam carga positiva, e soluções com pH < PZC apresentam carga negativa. Sendo assim, o ideal é trabalhar com soluções considerando-se o pH da solução entre o pKa do DCF e o pH no PZC do BM. Por isso, todas as soluções de DCF utilizadas no processo adsortivo com BM foram ajustadas ao $\mathrm{pH} 4$.

Os testes de dosagem de adsorvente e de concentração inicial do fármaco em solução foram utilizados para que as melhores condições para realização dos ensaios cinéticos fossem definidas. As massas que apresentaram maior eficiência na remoção de DCF foram as de 0,025; 0,050 e 0,075 g de BM em solução de $50 \mathrm{mg} \mathrm{L}^{-1}$ do fármaco. O comportamento observado vai de encontro as condições apresentadas na literatura, uma vez que as menores massas e a maior concentração apresentam as melhores condições para realização dos ensaios cinéticos. Como comprovado por Diel et al. (2018), que obtiveram resultados mais satisfatórios com maiores quantidades de adsorvente, tornando o contato entre as fases mais efetivo, acelerando o processo de transferência de massa. Já no que diz respeito à concentração inicial do adsorvato em solução, Peters et al. (2015) afirmam que o aumento da concentração promove a redução da eficiência de remoção, devido à rapidez com que o processo atinge o equilíbrio, uma vez que o fármaco migra muito rapidamente para a superfície do adsorvente.

A Figura 1 apresenta os resultados dos ensaios de adsorção e os modelos ajustados aos parâmetros experimentais para a concentração inicial de $50 \mathrm{mg} \mathrm{L}^{-1}$ de DCF com massas 0,025 ; 0,050; e 0,075 g de BM. Com base nos dados apresentados pela Figura 1, pode-se analisar que quando se empregou 0,025 g de BM, alcançou-se uma capacidade de adsorção igual a $65,03 \mathrm{mg} \mathrm{g}^{-1}$, o que remete a uma eficiência de remoção de $65,03 \%$. A eficiência do processo, como citado anteriormente, diminui para as demais condições, obtendo-se para a massa de $0,050 \mathrm{~g}$, uma capacidade adsortiva de $26,27 \mathrm{mg} \mathrm{g}^{-1}$, o que compreende uma remoção de 52,54\% do DCF. Já quando utilizados $0,075 \mathrm{~g}$ de BM, encontrou-se uma capacidade adsortiva de $15,24 \mathrm{mg} \mathrm{g}^{-1}$ e uma remoção de $45,73 \%$. Em todas as condições testadas, o equilíbrio foi atingido aos 75 min de contato entre adsorvato e adsorvente.

Considerando-se as eficiências de remoção apresentadas, pode-se definir como a melhor condição a quantidade de $0,025 \mathrm{~g}$ de BM, apresentando a maior remoção dentre as massas testadas, equivalente a 65,03\%. Comparando-se com as bibliografias consultadas em relação ao emprego do BM como material adsorvente, pode-se afirmar que a remoção promovida para adsorção do DCF foi satisfatória. Com o mesmo adsorvente, Dupont et al. (2018) removeram 28,1\% do corante vermelho do congo em 20 min de contato, e Steffen et al. (2018) adsorveram 62,3\% do corante violeta cristal com BM in natura, e 87,23\% com o mesmo BM modificado, em 210 min de contato. Tais resultados apontam que o BM é uma biomassa alternativa na remoção de diferentes contaminantes dos corpos hídricos, sendo que as condições operacionais influindo diretamente nos resultados.

A Tabela 1 elucida os parâmetros dos modelos cinéticos utilizados para ajustar os dados experimentais obtidos no processo adsortivo empregando 0,025; 0,050 e 0,075 g de BM em solução aquosa de DCF na concentração de $50 \mathrm{mg} \mathrm{L}^{-1}$. Por meio destes dados, verifica-se que a adsorção apresentou melhor ajuste ao modelo PPO para as três massas testadas.

\section{CONCLUSÃO}

Em vista dos dados apresentados, constata-se que o resíduo proveniente da mosturação da indústria cervejeira (bagaço de malte), é promissor para a remoção de poluentes emergentes de corpos d'água. No que tange ao processo adsortivo, verificou-se que a condição de melhor eficiência de processo corresponde a massa de $0,025 \mathrm{~g}$ do resíduo, frente a $50 \mathrm{mg} \mathrm{L}^{-1}$ do contaminante, obtendo-se remoção de $65,03 \%$ do mesmo. Os dados encontrados foram analisados quanto aos modelos cinéticos, podendo-se inferir que o modelo que melhor se ajusta aos experimentos realizados foi o de PPO. Ademais, observa-se que a adsorção utilizando o resíduo agroindustrial é uma alternativa eficaz de reutilização do mesmo, auxiliando ainda na descontaminação hídrica. 


\section{VISIGER

\section{REFERÊNCIAS}

CARVALHO, G.P.; et al.. Aproveitamento biotecnológico de resíduos cervejeiros. Anais do XXI Congresso Brasileiro de Engenharia Química, Fortaleza, 2016.

DIEL, J. C.; et al.. Avaliação da capacidade de adsorção de violeta cristal empregando casca de bergamota in natura. In: $12^{\circ}$ Congresso Brasileiro sobre Adsorção, Gramado, 2018.

DUPONT, G K.; et al.. Avaliação da adsorção do corante vermelho do congo empregando resíduo de bagaço de malte. In: $12^{\circ}$ Congresso Brasileiro sobre Adsorção, Gramado, 2018.

GRAEBIN, G. O.. Secagem do bagaço de cana-de-açúcar e estudo da sua aplicação na remoção de metal pesado. 133 f. Dissertação - Universidade Estadual do Oeste do Paraná, Toledo, 2014.

HASAN, Z; et al. Adsorptive removal of diclofenac sodium from water with Zr-based metal-organic frameworks. Chemical Engineering Journal, n. 284, p. 1406-1413, 2016.

LUNA, M. D. G.; et al. Removal of sodium diclofenac from aqueous solution by adsorbents derived from cocoa pod husks. Journal of Environmental Chemical Engineering, n. 5, p. 1465-1474, 2017.

NASCIMENTO, L. X; et al.. Contaminantes orgánicos emergentes: impactos y soluciones para la salud humana y el medio ambiente. Recyt, n. 24, p. 28-34. 2015.

NOWACKI, C. de C. B.; et al.. Química Ambiental: conceitos, processos, e estudo dos impactos ao meio ambiente. $1^{a}$ ed. São Paulo: Érica, 2014.

PETERS, V.; et al.. Adsorção de azul de metileno em partículas de endocarpos de butiás. In: XXXVII Congresso Brasileiro de Sistemas Particulados.

STEFFEN, A. C.; et al.. Avaliação da capacidade de adsorção de violeta cristal utilizando bagaço de malte in natura e modificado. In: $12^{\circ}$ Congresso Brasileiro sobre Adsorção, Gramado, 2018.

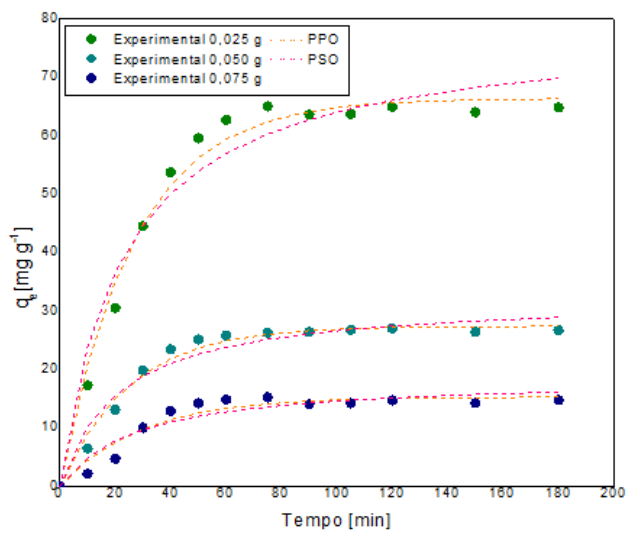

Figura 1. Perfis cinéticos com modelos ajustados ao processo de adsorção de DCF utilizando BM em diferentes dosagens adsorventes.

Tabela 1. Dados cinéticos obtidos a partir dos modelos testados para adsorção de DCF.

\begin{tabular}{cccc}
\hline \multirow{2}{*}{ Modelos } & \multicolumn{3}{c}{ Massa de adsorvente $[\mathbf{g}]$} \\
\cline { 2 - 4 } & $\mathbf{0 , 0 2 5}$ & $\mathbf{0 , 0 5 0}$ & $\mathbf{0 , 0 7 5}$ \\
\hline $\boldsymbol{q}_{\boldsymbol{e}}\left[\mathrm{mg} \mathrm{g}^{-1}\right]$ & Pseudo-primeira ordem (PPO) & \\
$\boldsymbol{k}_{\mathbf{1}}\left[\mathrm{min}^{-1}\right]$ & 66,38 & 27,41 & 15,3 \\
$\mathrm{R}^{2}$ & 0,03756 & 0,03976 & 0,0342 \\
$\mathrm{ERM}[\%]^{\mathbf{0 , 9 8 5}}$ & $\mathbf{0 , 9 7 9 9}$ & $\mathbf{0 , 9 2 4 6}$ \\
$\boldsymbol{q}_{\boldsymbol{e}}\left[\mathrm{mg} \mathrm{g}^{-1}\right]$ & 2,621 & 1,26 & 1,469 \\
$\boldsymbol{k}_{\mathbf{2}}\left[\mathrm{g} \mathrm{mg} \mathrm{min}^{-1}\right]$ & Pseudo-segunda ordem (PSO) & & \\
$\mathrm{R}^{2}$ & 78,7 & 32,33 & 18,63 \\
$\left.\mathrm{ERM}^{2}\right]$ & 0,0005539 & 0,001443 & 0,001937 \\
& 0,9547 & 0,946 & 0,8816 \\
& 4,551 & 2,066 & 1,816 \\
\hline
\end{tabular}




\title{
AVALIAÇÃo DA HIDRÓliSE ÁCIDA DE CELULOSE ASSISTIDA POR ULTRASSOM PARA OBTENÇÃO DE FURFURAL
}

\author{
Bizzi, C.A.. ${ }^{\text {}}$; Santos, D. ${ }^{1}$; Giacobe, K. ${ }^{1}$; Contin, C.N. ${ }^{1}$; Mello, P.A. ${ }^{1}$; Flores, E.M.M. ${ }^{1}$ \\ ${ }^{1}$ Universidade Federal de Santa Maria, Departamento de Química, Santa Maria, RS, Brasil \\ c_bizzi@yahoo.com.br
}

\begin{abstract}
RESUMO: A conversão de biomassa a produtos químicos possibilita a obtenção de polímeros, solventes e combustíveis, a partir de fontes renováveis de carbono. O presente estudo avaliou o uso do ultrassom na intensificação da conversão de celulose para obtenção de furfural. Foram avaliados diferentes sistemas de aplicação de ultrassom (banhos, sondas e cup horns) com experimentos comparativos sob agitação mecânica e estudo da potência liberada em cada caso. Os seguintes parâmetros foram avaliados: amplitude (30 a 70\%), temperatura de sonicação $\left(30\right.$ a $\left.70{ }^{\circ} \mathrm{C}\right)$ e concentração de $\mathrm{HNO}_{3}\left(4\right.$ a 8 mol L $\left.\mathrm{L}^{-1}\right)$. Os produtos foram quantificados por cromatografia a líquido de alta eficiência acoplada a espectrometria de massa por tempo-devôo (UPLC-ToF-MS) e a pureza foi confirmada por ressonância magnética nuclear (NMR, de ${ }^{13} \mathrm{C} \mathrm{e}{ }^{1} \mathrm{H}$ ). $\mathrm{O}$ resíduo de celulose após hidrólise foi avaliado por microscopia eletrônica de varredura (SEM). No sistema cup horn, com amplitude de 50\%, temperatura de $30{ }^{\circ} \mathrm{C}$ e 60 minutos de sonicação, utilizando $\mathrm{HNO}_{3}$ $4 \mathrm{~mol} \mathrm{~L}^{-1}$ foram obtidos os maiores rendimentos reacionais, chegando a $23 \%$ de conversão a furfural, sem que nenhuma etapa adicional de deslignificação fosse necessária. A utilização de um ácido diluído volátil associado à temperatura amena de reação representam vantagens significativas ao processo assistido por ultrassom.
\end{abstract}

Palavras-chave: furfural, ultrassom, celulose, hidrólise.

\section{ULTRASOUND-ASSISTED ACID HYDROLYSIS OF CELLULOSE TO FURANIC PLATFORMS SYNTHESIS}

\begin{abstract}
In this work, the use of ultrasound energy for the production of furanic platforms from cellulose was investigated and the synthesis of furfural was demonstrated. Several ultrasonic systems were evaluated, as ultrasound bath, cup horn and probe, in order to investigate hydrolysis of cellulose and its conversion to furfural. The influence of the following parameters in the ultrasound-assisted acid hydrolysis (UAAH) were studied: ultrasound amplitude (30 to $70 \%$ ), sonication temperature $\left(30\right.$ to $70{ }^{\circ} \mathrm{C}$ ) and $\mathrm{HNO}_{3}$ solution $(4$ to 8 mol $\left.\mathrm{L}^{-1}\right)$. For each evaluated condition, the products were identified by ultra-performance liquid chromatography with high-resolution time-of-flight mass spectrometry (UPLC-ToF-MS), which provide accurate information regarding the products obtained from biomass conversion. The furfural structure was confirmed by nuclear magnetic resonance spectroscopy $\left({ }^{1} \mathrm{H}\right.$ and ${ }^{13} \mathrm{C}$ NMR). In addition, cellulosic residues from hydrolysis reaction were characterized using scanning electron microscopy (SEM), which contributed for a better understanding of physical-chemical effects caused by ultrasound. After process optimization, a $4 \mathrm{~mol} \mathrm{~L}^{-1} \mathrm{HNO}_{3}$ solution, sonicated for $60 \mathrm{~min}$ at $30{ }^{\circ} \mathrm{C}$ in a cup horn system at $50 \%$ of ultrasound amplitude, lead to $23 \%$ of conversion to furfural. It is worth note that no additional step of delignification was required. This mild temperature condition combined to the use of a diluted acid solution represents an important contribution for the selective production of chemical building blocks using ultrasound energy.
\end{abstract}

Keywords: furfural, ultrasound, cellulose, hydrolysis.

\section{INTRODUÇÃO}

A busca por matérias-primas alternativas para processos industriais tem sido alvo de diversos estudos. A utilização de fontes renováveis de carbono reduz a dependência de fontes fósseis para obtenção de produtos de química fina (Silveira, 2008). De acordo com a literatura, a disponibilidade de recursos fósseis tende a reduzir nos próximos anos, em função das dificuldades de extração e dos impactos negativos causados pelo seu uso em larga escala (Mothé e Miranda, 2010).

Dentre as potenciais fontes alternativas ao petróleo, a biomassa surge como um expoente em pesquisas tecnológicas. De maneira geral, a biomassa é formada por carboidratos, lignina, proteínas, gorduras e, numa menor extensão, por várias outras substâncias, tais como vitaminas, terpenos, carotenóides, alcalóides, 
pigmentos e flavorizantes (Rodrigues, 2011). Essa vasta composição proporciona a diversificação da matriz industrial, impulsionando a descentralização dos meios produtores de matérias-primas e locais de geração de energia, podendo resultar em um modelo industrial mais sustentável.

O furfural é um importante produto químico usado na síntese de vários compostos sintéticos de alto valor agregado (álcool furfurílico, tetra-hidrofurano, ácido levulínico). Industrialmente, é produzido por processos de desidratação de açúcares, através de um complexo mecanismo reacional que envolve longos tempos reacionais, elevadas temperaturas e pressões (Rocha, 2015). As principais fontes de matéria-prima utilizadas nesses processos são plantas com alto teor de celulose, um biopolímero formado pela união de moléculas de glicose por ligações glicosídicas $\beta-1,4$. Esta é a maior fonte de carbono disponível na natureza, além de ser uma das mais abundantes fontes de energia renovável, permitindo a síntese de vários produtos em escala industrial (Barbosa, 2008).

Nos últimos anos, estudos relatam a utilização de energias alternativas para a conversão seletiva de biomassa, tais como micro-ondas e ultrassom. Lacerda et al. (2015) avaliou a conversão de materiais lignocelulósicos em plataformas furânicas utilizando líquidos iônicos e dióxido de titânio assistida por microondas em temperaturas inferiores a $200{ }^{\circ} \mathrm{C}$. Cravotto et al. (2009) uniu as energias micro-ondas e ultrassom, aumentando a transferência de massa e reduzindo o tempo para extrações de óleos em plantas. Tabasso et al. (2013) propôs a conversão de biomassa a ácido levulínico assistida por micro-ondas, com redução drástica do tempo reacional e com alta seletividade, obtendo até $95 \%$ de conversão.

Considerando a ausência de estudos utilizando ultrassom como fonte primária de energia na conversão de biomassa, aliada às condições extremas necessárias nas reações de hidrólise ácida, esse estudo teve como objetivo avaliar a eficiência do ultrassom para conversão de celulose em uma única etapa. Buscou-se um processo que proporcione rotas reacionais seletivas para a síntese de compostos furânicos e condições reacionais mais brandas, com ácidos diluídos e temperaturas mais amenas.

\section{MATERIAL E MÉTODOS}

Para os experimentos de hidrólise ácida assistida por ultrassom (UAAH), foram utilizados sistemas de ultrassom do tipo sonda, cup horn e banho, de frequências e potências variadas. Para os sistemas de ultrassom do tipo sonda, foram utilizados equipamentos com frequência de $20 \mathrm{kHz}$ e potência de $130 \mathrm{~W}$ ou $750 \mathrm{~W}$ (Sonics and Materials Inc., EUA), ambas equipados com sonda de liga de titânio. Também foram utilizados dois sistemas de ultrassom do tipo cup horn (Sonics and Materials Inc., EUA) acoplados a processadores de $20 \mathrm{kHz}$ e $130 \mathrm{~W}$ ou $750 \mathrm{~W}$, ambos com cuba de vidro. Além desses equipamentos, foram utilizados quatro banhos de ultrassom (Elma GmbH \& Co, Singen, Alemanha), os quais foram nomeados de 1 a 4, conforme mostrado na Tabela 1.

As reações de hidrólise foram feitas em provetas de vidro com fundo plano, com $12 \mathrm{~cm}$ de altura, $6 \mathrm{~cm}$ de diâmetro externo e $5 \mathrm{~cm}$ de diâmetro interno. A avaliação/caracterização da seletividade das reações foi feita por cromatografia a líquido de alta eficiência acoplada a espectrometria de massa por tempo de vôo (UPLC-ToF-MS, Xevo G2 Q-Tof, Waters, EUA). Os resíduos de hidrólise foram caracterizados por microscopia eletrônica de varredura (SEM, Sigma 300 VP Carl Zeiss, Inglaterra) e a pureza do produto foi avaliada por ressonância magnética nuclear (NMR, Bruken DPX 400, EUA). Os ensaios sob agitação mecânica (condição de silêncio, na ausência do ultrassom) foram feitos utilizando agitador mecânico (Polytron, Suíça).

Para as reações de hidrólise os seguintes reagentes foram utilizados: ácido nítrico (65\%) (Merck, Alemanha), celulose microcristalina (Sigma-Aldrich, Alemanha) e água purificada pelo sistema Milli-Q® (Ultrapure Water Purification Systems, EUA). Nitrogênio e argônio (White Martins, Brasil), foram utilizados para SEM e como gás de colisão para fonte de ionização em UPLC-Tof-MS. Acetonitrila (Fluka, Steinheim, Alemanha) e metanol (Phillipsburg, EUA) foram utilizados para solubilização e diluição das amostras. Para quantificação foi utilizado um padrão de furfural (99\%, Sigma-Aldrich, Steinheim, Alemanha).

Os experimentos foram feitos conforme Santos (2017). Celulose microcristalina $(0,5 \mathrm{~g})$ foi transferida para o reator e foram adicionados $20 \mathrm{~mL}$ de solução ácida, diluída à $10 \%$. A mistura foi submetida a aplicação do ultrassom durante $60 \mathrm{~min}$, com a temperatura de $50^{\circ} \mathrm{C}$, em todos os sistemas de ultrassom avaliados. Após os experimentos preliminares, com os resultados satisfatórios obtidos e com auxílio de um estudo da potência liberada por calorimetria, o sistema cup horn foi selecionado para continuação do estudo. Em seguida, os parâmetros avaliados foram: concentração de ácido $\left(4,6\right.$ e 8 mol L $\left.{ }^{-1} \mathrm{HNO}_{3}\right)$, temperatura da reação $(30,50$ e $70{ }^{\circ} \mathrm{C}$ ) e amplitude do ultrassom (30, 50 e 70\%). Paralelamente, a eficiência de conversão foi comparada com a obtida para o processo sob agitação mecânica $\left(100 \mathrm{rpm}, 50^{\circ} \mathrm{C}\right.$ e $\left.60 \mathrm{~min}\right)$. Após a reação, os extratos foram 
filtrados e diluídos com metanol (1:10) para posterior determinação por UPLC-ToF-MS e a pureza do produto foi avaliada por NMR de ${ }^{1} \mathrm{He} \mathrm{e}^{13} \mathrm{C}$. O resíduo de celulose obtido após UAAH foi seco e caracterizado por SEM.

\section{RESULTADOS E DISCUSSÃO}

Neste estudo, a intensidade de potência foi avaliada pelo método calorimétrico (Kimura et al., 1996), baseado na variação da temperatura durante a aplicação do ultrassom, na massa de celulose e no calor específico da solução. A intensidade de potência observada nos banhos de ultrassom foi na faixa de 1 a $2,5 \mathrm{~W}$ $\mathrm{dm}^{-3}$ e para os sistemas cup horn e sonda foi de 3 e $14 \mathrm{~W} \mathrm{dm}^{-3}$, respectivamente. Para a reação feita sob agitação mecânica, a potência liberada foi significativamente menor (cerca de $1 \mathrm{~W} \mathrm{dm}^{-3}$ ).

Apesar da sonda fornecer a maior intensidade de potência dentre os sistemas avaliados, não foi constatada a presença de furfural nos extratos provenientes deste sistema. É possível que um incremento na intensidade de potência liberada favoreça a formação de radicais que interferem no curso e na seletividade da reação, além da maior energia liberada. A presença de furfural também não foi detectada para os experimentos utilizando os banhos de ultrassom ou sob agitação mecânica. Para esses casos, da mesma forma para os experimentos utilizando a sonda, apenas fragmentos de monômeros de carboidratos foram identificados. Por outro lado, no sistema cup horn a formação de furfural foi detectada e esse sistema foi selecionado para os experimentos seguintes. Além disso, cabe ressaltar que em todos os experimentos, restou um resíduo de celulose microcristalina parcialmente degradada ao final da UAAH.

Em seguida, foi feita a avaliação da concentração da solução ácida para hidrólise. Foi observado um decréscimo na conversão de furfural com aumento da concentração ácida, o que pode ser justificado pela oxidação do produto formado, levando a formação de compostos furânicos de menor peso molecular. A concentração de $\mathrm{HNO}_{3}$ escolhida para a continuação dos experimentos foi de $4 \mathrm{~mol} \mathrm{~L}^{-1}$.

Em relação à influência da temperatura na conversão de celulose, foram feitos experimentos com temperaturas de 30 a $70{ }^{\circ} \mathrm{C}$, sendo obtida a maior seletividade na temperatura de $30{ }^{\circ} \mathrm{C}$. Em temperaturas superiores, foi observada a degradação da celulose, porém sem seletividade para produção de compostos furânicos.

Uma vez otimizada a concentração ácida $\left(4 \mathrm{~mol} \mathrm{~L}^{-1}\right)$ e a temperatura reacional $\left(30{ }^{\circ} \mathrm{C}\right)$, foram feitos experimentos avaliando diferentes amplitudes de ultrassom (30 a 70\%). Nos ensaios com amplitude de 50 e $70 \%$, foi observado que a concentração de furfural não foi modificada com o incremento da amplitude. Devido ao custo energético, a amplitude de $50 \%$ foi escolhida para otimização do processo. Assim, a condição de UAAH otimizada foi de: $0,5 \mathrm{~g}$ de celulose e $20 \mathrm{~mL}$ de $\mathrm{HNO}_{3} 4 \mathrm{~mol} \mathrm{~L}^{-1} \mathrm{em}$ sistema cup horn, operando por 60 minutos, com amplitude de $50 \%$ e temperatura de $30{ }^{\circ} \mathrm{C}$.

\section{CONCLUSÃO}

Neste estudo foi investigada a conversão de celulose em furfural, um importante produto químico, através do uso do ultrassom como fonte de energia alternativa. Foram obtidos rendimentos de $23 \%$ de conversão à furfural a partir de celulose, empregando temperaturas amenas $\left(30^{\circ} \mathrm{C}\right)$ e soluções ácidas diluídas $\left(\mathrm{HNO}_{3} 4 \mathrm{~mol} \mathrm{~L}^{-1}\right)$, em tempos relativamente curtos $(60 \mathrm{~min})$ com uso de ultrassom em sistema do tipo cup horn (operando sob pressão atmosférica). A hidrólise ácida assistida por ultrassom (UAAH) se mostrou útil para a conversão de celulose, com tempos e temperaturas de reação inferiores, sem a necessidade de uma etapa prévia de deslignificação, promovendo ganhos de energia.

\section{AGRADECIMENTOS}

Os autores agradecem ao Conselho Nacional de Desenvolvimento Científico e Tecnológico (CNPq), a Coordenação de Aperfeiçoamento de Pessoal de Nível Superior (CAPES) e a Fundação de Amparo à Pesquisa do Estado do Rio Grande do Sul (FAPERGS) por apoiar este estudo.

\section{REFERÊNCIAS}

BARBOSA, C. Biomassa para energia. UNICAMP, 2008.

CRAVOTTO, G.; BOFFA, L.; MANTEGNA, S.; PEREGO, P.; AVOGADRO, M.; CINTAS, P. Improved extraction of vegetable oils under high-intensity ultrasound and/or microwaves, Ultrasonics. Sonochemistry., v. 15 , p. 898-902, 2008. 
KIMURA T. et al. Standardization of ultrasonic power for sonochemical reaction, Ultrasonic. Sonochem., v. 3, p. 157-161, 1996.

LACERDA, V.S. et al. A kinetic study on microwave-assisted conversion of cellulose and lignocellulosic waste into hydroxymethylfurfuralfurfural. Bioresource Tecnology, v. 180, p. 88-96, 2015.

MOTHÉ, C.G.; MIRANDA I.C. Aproveitamento energético e caracterização de resíduos de biomassa. Publit, 2010.

ROCHA, M.H. Avaliação técnica de biorrefinarias para a produção de biocombustíveis líquidos $e$ eletricidade através da gaseificação de biomassa. Tese de Doutorado. Programa de Pós-graduação em Engenharia Mecânica. Universidade Federal de Itajuba, Itajubá, 2015.

RODRIGUES, J.A.R. Do engenho a biorrefinaria: a usina de açucar como empreendimento industrial para a geração de produtos bioquímicos e combustiveis. Quimica Nova, v. 34, p.1242-1254, 2011.

SANTOS, D. Hidrólise ácida de biomassa assistida por ultrassom para obtenção de furfural. Dissertação de mestrado. PPGEQ. Universidade Federal de Santa Maria, Santa Maria, 2017.

SILVEIRA, M.S. Aproveitamento de cascas de coco verde para a produção de briquete em Salvador-BA. Dissertação de Mestrado. PPGTAPP. Universidade Federal da Bahia, Salvador, 2008.

TABASSO S. et al. Microwave-assisted flash conversion of non-edible polysaccharides and post-harvest tomato plant waste to levulinic acid. Green Chemistry, v. 16, p. 73-76, 2014.

Tabela 1. Especificações dos banhos de ultrassom utilizados em UAAH.

\begin{tabular}{ccccc}
\hline Banho & Potência nominal, $\mathbf{W}$ & Frequência, $\mathbf{k H z}$ & Volume do banho, $\mathbf{L}$ & Modelo \\
\hline 1 & 200 & 35 ou 130 & 8,6 & TI-H-10 \\
2 & 100 & 25 ou 45 & 3,5 & TI-H-5 \\
3 & 330 & 37 ou 80 & 12,9 & P120H \\
4 & 330 & 37 ou 80 & 9 & P120H \\
\hline
\end{tabular}




\title{
AVALIAÇÃo da SUBSTITUIÇÃO PARCIAL DA AREIA PELO RESÍDUO DO CAFÉ NA FABRICAÇÃO DE CONCRETO
}

\author{
Almeida, A.C.*¹; Gonçalvez, J.V.C. ${ }^{1}$; Freitas, B.F. ${ }^{1}$; Carotta, M.S.L.M. ${ }^{1}$; Faria, A.P.C. ${ }^{1}$; Pereira, \\ C.S.S. ${ }^{1}$ \\ ${ }^{1}$ Universidade de Vassouras, Vassouras, RJ - Brasil. \\ alanalmeida.eq@hotmail.com,www.universidadedevassouras.edu.br
}

\begin{abstract}
RESUMO: A produção de resíduos no ramo industrial gera impactos ambientais. Com isso, é necessária a busca por meios que reduzam e reutilizem esses resíduos. O Brasil é o maior produtor e exportador de café mundial, sendo um dos principais produtos no mercado consumidor e tendo uma produção de 30 milhões de sacas por ano. A produção de café gera uma grande quantidade de subprodutos como sua própria casca. Desta maneira, a reutilização deste resíduo é uma boa alternativa para o seu descarte. Diante deste fato, foi avaliada a substituição parcial da areia pela casca do café na produção de concreto, de forma a reduzir a utilização da areia na fabricação do mesmo. Para a produção dos corpos de prova, os traços foram formulados substituindose a areia pela casca do café em 5\% na sua composição. Para a confecção dos corpos de prova considerou-se a proporção 0,5:0,5:1:0,5 (brita: areia: cimento: água) respectivamente. Para avaliação da resistência mecânica à compressão foram realizados ensaios após 7,14, 21 e 28 dias, utilizando prensa hidráulica com capacidade de $80 \mathrm{MPa}$. Considerou-se satisfatória a substituição parcial da areia pelo resíduo do café, obtendo-se uma resistência à compressão de $\pm 20 \mathrm{MPa}$, valor superior a resistência obtida com o concreto produzido sem a substituição da areia. A reutilização da casca do café, não comprometeu a resistência do material.
\end{abstract}

Palavras-chave: café, concreto, resíduo agroindustrial.

\section{EVALUATION OF THE PARTIAL REPLACEMENT OF THE SAND BY THE COFFEE WASTE IN CONCRETE PRODUCTION}

\begin{abstract}
The production of waste in the industrial sector generates environmental impacts. Thus, it is necessary to search for means that reduce and reuse these residues. Brazil is the largest worldwide producer and exporter of coffee, being one of the main products in the consumer market and having a production of 30 million sacks per year. Coffee production generates a large quantity of by-products as its own bark. In this way, the reuse of this residue is a good alternative for its disposal. In view of this fact, it was evaluated the partial substitution of the sand by the coffee peel in the production of concrete, in order to reduce the use of sand in the fabrication of the same. For the production of the specimens, the traits were formulated by replacing the sand by the coffee peel by $5 \%$ in its composition. For the preparation of the specimens, the proportion was considered 0.5:0.5:1: 0.5 (gravel: Sand: Cement: Water) respectively. To evaluate the mechanical compressive strength, assays were performed after 7.14, 21 and 28 days, using a hydraulic press with a capacity of $80 \mathrm{MPa}$. It was considered satisfactory the partial substitution of the sand by the coffee residue, obtaining a compressive strength of $\pm 20 \mathrm{MPa}$, higher value of the resistance obtained with the concrete produced without replacing the sand. The reuse of the coffee peel did not compromise the resistance of the material.
\end{abstract}

Keywords: coffee, concrete, agrobusiness waste.

\section{INTRODUÇÃO}

Com o avanço da industrialização, os resíduos transformaram-se em graves problemas urbanos. Uma das formas de solução para os problemas gerados é a reciclagem de resíduos, em que a construção civil tem um grande potencial de utilização, uma vez que ela chega a consumir até $75 \%$ de recursos naturais. (Ângulo et al.). 
O estudo do reaproveitamento de resíduos pela indústria da construção civil vem se consolidando como uma prática importante para a sustentabilidade devido à mesma possuir a vantagem de poder incorporar em seus materiais os resíduos sólidos gerados em atividades dos mais diversos segmentos de produção. A procura de novos materiais, técnicas construtivas e a inserção de resíduos e de matérias renováveis, tem sido de suma importância (Silva, 2017a).

O concreto é um dos materiais de construção mais utilizados e é definido como um material composto, constituído por cimento, água, agregado miúdo (areia), agregado graúdo (pedra ou brita) e ar. Pode também conter adições (pozolanas, sílica ativa, etc.) e aditivos químicos com a finalidade de melhorar ou modificar suas propriedades básicas (Silva, 2017b).

O processamento do café gera grandes quantidades de resíduo sólido (casca ou polpa, dependendo do processo). Segundo Vale et al. (2007), a partir do processamento de duas toneladas de café, são gerados uma tonelada de grãos e uma tonelada de resíduo. A casca do café é utilizada tradicionalmente como adubo, alimento para animais e como combustível utilizado no processo de secagem do próprio café (Silva, 2012).

Com isso, o presente trabalho teve como objetivo a adição da casca do café triturada a uma mistura de areia, concreto e brita, de forma a minimizar o consumo de areia como matéria-prima do concreto e a avaliação de como o mesmo se comporta aos testes de compressão.

\section{Materiais}

\section{MATERIAL E MÉTODOS}

O resíduo do café (Figura 1) foi gentilmente cedido pela Fazenda Serra da Garcia, localizada no município de Liberdade/MG. A casca do café e a areia foram peneiradas e para a produção do concreto considerou-se as frações retidas na peneira de $1,18 \mathrm{~mm}$, seguindo a norma NBR 7225/93, a qual preconiza que, areia é um material natural, de propriedades adequadas, de dimensão nominal máxima inferior a 2,0 mm e de dimensão nominal mínima igual ou superior a $0,075 \mathrm{~mm}$. Utilizou-se o cimento Portland de alto-forno (CP III-40 RS) constituído por silicatos e aluminatos que na presença de água hidratam-se formando um material de elevada resistência mecânica. A utilização desse tipo de concreto é utilizada em obras pesadas como, por exemplo, barragens (NBR5735/91). A brita foi peneirada e utilizaram-se as frações retidas na peneira de 9,5 mm. De acordo com a NBR 7225/93 este tipo de brita é denominado brita do tipo 1 .

\section{Traço do concreto dos corpos-de-prova}

Foram elaborados traços sem adição do resíduo e traços com a adição de 5\% do resíduo do café (cascas) em substituição a areia na proporção de 1:0,5:0,5:0,5 considerando brita: areia: cimento: água, respectivamente. $\mathrm{O}$ resíduo foi substituído nas mesmas proporções que a quantidade de areia dita. A mistura destas matérias primas foi realizada em uma betoneira (capacidade de $120 \mathrm{~L}$ ) e a água foi adicionada aos poucos até a homogeneização.

\section{Corpos de prova para ensaio de resistência mecânica à compressão}

$\mathrm{O}$ procedimento para moldagem e cura de corpos de prova do concreto para o ensaio resistência mecânica à compressão, seguiu-se de acordo com a NBR 5738/2015. Realizou-se o ensaio de adensamento do concreto (Slump Test) de acordo com a norma NBR NM 67. O ensaio foi realizado com o preenchimento de uma forma tronco-cônica em três etapas de adensamento iguais com 12 golpes, retirando-se a forma lentamente e medindo a diferença entre o concreto e o molde usado. Foram preenchidos 12 corpos de prova adotando-se as dimensões de $20 \mathrm{~cm}$ de altura e $10 \mathrm{~cm}$ de diâmetro. Os corpos de prova foram preenchidos gradualmente com o auxílio de uma barra de ferro para realizar o adensamento, evitando formação de poros no concreto. Após a confecção, os corpos de prova foram colocados sobre uma superfície horizontal e armazenados por um período de 28 dias. Após o tempo mínimo de cura do concreto (sete dias), foram realizados os ensaios de compressão axial em uma prensa hidráulica (capacidade $80 \mathrm{MPa}$ ) conforme a norma NBR 5739/07. Os testes foram realizados em triplicata nos dias 14, 21 e 28 dias. 


\section{RESULTADOS E DISCUSSÃO}

Os resultados dos ensaios de resistência à compressão são descritos na Tabela 1 e a Figura 2 ilustra o resultado do ensaio de compressão após o tempo de cura de 28 dias. Os resultados foram gerados pelo software Pavitest concreto 1.3.0.24 de acordo com a norma para ensaio de compressão de corpos cilíndricos (NBR 5739/2007). A resistência (expressa em MPa) foi obtida pela relação entre a força aplicada e a área da seção transversal do corpo de prova. De acordo com Batista et.al., (2018) o concreto contém microfissuras antes mesmo de ser submetido a tensões externas, portanto, a resistência é relacionada com a tensão requerida para causar a fratura e é sinônimo do grau de ruptura no qual a tensão aplicada alcança seu valor máximo.

O concreto produzido com a adição de $5 \%$ de resíduo apresentou resultados satisfatórios, apresentando resistência mecânica $(19,30 \pm 1,00)$ maior que o concreto produzido sem a adição de resíduo, que apresentou uma resistência de $12,2 \pm 1,95 \mathrm{MPa}$.

A resistência à compressão alcançada representa 57\% do valor para cargas de veículos leves, onde o critério estabelecido para a resistência à compressão fck (Feature Compression Know) aplicado para este fim é de $35 \mathrm{MPa}$. Por outro lado, a resistência obtida supera o valor para aplicação de artefatos (bloquetes) para intertravamento de passeio de pessoas em que a norma ABNT NBR 9781/2013 indica o valor de 15Mpa. Essa superação da resistência do concreto pode ser atribuída à palha da casca de café, que em sua composição, existem agentes com propriedades pozolanas. (Oliveira e Souza, 2017).

\section{CONCLUSÃO}

Através dos resultados preliminares obtidos, a substituição parcial da areia pelo resíduo do café na produção de concreto foi considerada tecnicamente viável, apresentando resultados de resistência à compressão de $\pm 20 \mathrm{MPa}$. O concreto proposto contribui para minimizar o uso da areia, uma matéria prima não renovável, visando diminuir o impacto ambiental, aumentando desta forma as propostas para produção de concretos mais sustentáveis. Novos estudos deverão ser realizados.

\section{REFERÊNCIAS}

ÂNGULO, S. C.; Zordan, S. E.; John, V. M. Desenvolvimento sustentável e a reciclagem de resíduos na construção civil. São Paulo: SP, 2001.

Associação Brasileira de Normas Técnicas - ABNT. NBR 5735 - Cimento Portland de alto-forno. Rio de Janeiro, RJ, 1991.

Associação Brasileira de Normas Técnicas - ABNT. NBR 5738 Concreto - Procedimento para moldagem e cura de corpos de prova. Rio de Janeiro, RJ, 2015.

Associação Brasileira de Normas Técnicas - ABNT. NBR 5739 Concreto - Ensaio de compressão de corposde- prova cilíndricos. Rio de Janeiro, RJ, 2007.

Associação Brasileira de Normas Técnicas - ABNT. NBR 7225 Concreto - Materiais de pedra e agregados naturais. Rio de Janeiro, RJ, 1993.

Associação Brasileira de Normas Técnicas - ABNT. NBR 9778 Argamassa e concreto endurecido Determinação de absorção de água por imersão - Índice de vazio e massa específica. Rio de Janeiro, RJ, 1987. Associação Brasileira de Normas Técnicas - ABNT. NBR 9781 Peças de concreto para pavimentação Especificação e métodos de ensaio. Rio de Janeiro, RJ, 2013.

Associação Brasileira de Normas Técnicas - ABNT. NBR NM 67 Concreto - Determinação da consistência pelo abatimento do tronco cone. Rio de Janeiro, RJ, 2007.

BATISTA, A. B. et al. Estudo da utilização do PVC como constituinte de concreto reciclado. Revista Eletrônica TECCEN, Vassouras, RJ, 11(1), 39-46, 2018.

OLIVEIRA, D. C., Souza, R. E. Produção de bloquetes em concreto verde com adição de palha de café. Pensar Acadêmico, Manhuaçu, MG, v. 15, n. 1, p.109-119, janeiro-junho, 2017.

SILVA, J. P. Da., Caracterização da casca de café (coffee arábica, 1) in natura, e de seus produtos obtidos pelo processo de pirólise em reator mecanicamente agitado. Campinas, SP, 2012.

SILVA J. A. et al. Avaliação da produção de concreto utilizando resíduo do processamento industrial da azeitona. Rio de Janeiro, RJ, 2017 (a,b). 


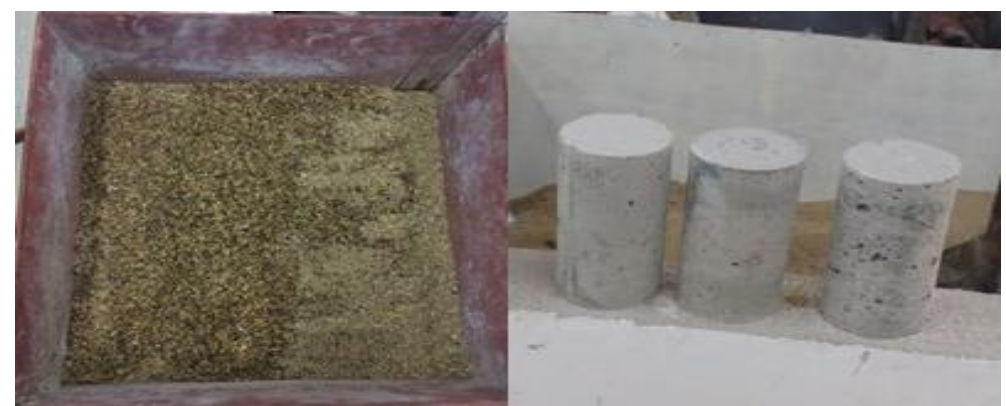

Figura 1. Resíduo do café (casca triturada) e corpos de prova do concreto produzido.

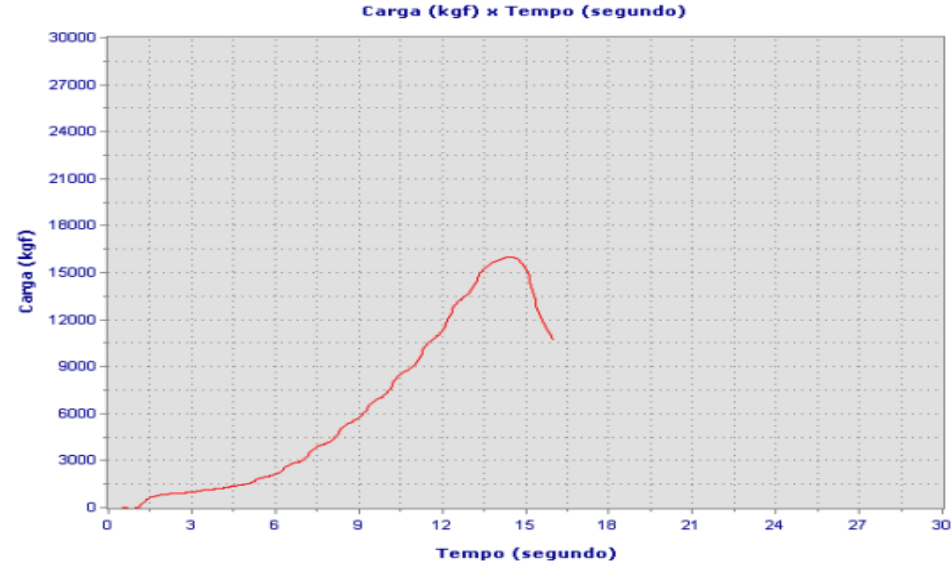

Figura 2. Resultado da resistência a compressão após 28 dias com a adição de 5\% de resíduo (Software Pavistest concreto 1.3.0.24).

Tabela 1. Dados da análise de compressão axial.

\begin{tabular}{cc}
\hline $\begin{array}{c}\text { Tempo de cura } \\
\text { (dias) }\end{array}$ & $\begin{array}{c}\text { Resistência à compressão } \\
\text { (Mpa) }\end{array}$ \\
\hline 7 & $12,33 \pm 0,69$ \\
14 & $17,07 \pm 1,38$ \\
21 & $20,97 \pm 1,44$ \\
28 & $19,30 \pm 1,00$ \\
\hline
\end{tabular}




\title{
AVALIAÇÃO DO IODETO COMO CATALISADOR DA DECOMPOSIÇÃO RADICALAR DE PERÓXIDO DE HIDROGÊNIO PARA APLICAÇÃO NA DEGRADAÇÃO DO AZUL DE METILENO
}

\author{
Miotto, N. ${ }^{12^{*}}$; Dallago, R.M. ${ }^{2}$; Mignoni, M.L. ${ }^{2}$; Venquiaruto, L. ${ }^{2}$; Mores, R. ${ }^{3,4}$; Zamadei, R.V. ${ }^{1}$; \\ Olkoski, L. ${ }^{2}$; Michelon, W. ${ }^{5}$ \\ ${ }^{1} U R I$ - Erechim, Erechim, RS - Brasil \\ ${ }^{2} I F-$ Sertão, Sertão, $R S-$ Brasil \\ ${ }^{3} U n C$ - Concórdia, Concórdia SC - Brasil \\ ${ }^{4}$ FACC - Concórdia, Concórdia SC-Brasil \\ ${ }^{5}$ Universidade Federal de Santa Catarina, Florianopolis, SC-Brasil \\ dallago@uricer.edu.br
}

\begin{abstract}
RESUMO: A presença de compostos não biodegradáveis em efluentes líquidos é um dos principais problemas nas estações de tratamento de efluentes. Entre as principais alternativas para a remoção destes compostos estão os processos oxidativos avançados (POA's), que se baseiam na formação de radicais hidroxila $(* \mathrm{OH})$, os quais são agentes altamente oxidantes. Estes radicais podem reagir com uma grande variedade de classes de compostos, promovendo sua mineralização. Um sistema empregado para geração do * $\mathrm{OH}$ é o processo fenton. Porém, o emprego do ferro como catalisador torna necessário uma etapa de tratamento adicional para remoção deste metal ao final do processo, fator que tem despertado o interesse na investigação de novos catalisadores que possam minimizar este inconveniente. Neste contexto, o presente estudo teve como objetivo avaliar o iodeto como precursor catalítico para decomposição radicalar do peróxido de hidrogênio $\left(\mathrm{H}_{2} \mathrm{O}_{2}\right)$, visando a geração de radicais hidroxila. A metodologia para avaliação da atividade catalítica radicalar do precursor iodeto foi baseada na técnica de gasometria, conduzida em ensaios com água e também na presença de uma solução do corante azul de metileno (AM). Os resultados da atividade catalítica mostraram que o iodeto é um potencial catalisador do mecanismo radicalar de decomposição do $\mathrm{H}_{2} \mathrm{O}_{2}$.
\end{abstract}

Palavras-chave: processos oxidativos avançados, fenton, radical $* \mathrm{OH}$.

\section{EVALUATION OF IODIDE AS A CATALYST FOR THE RADICALAR DECOMPOSITION OF HYDROGEN PEROXIDE FOR APPLICATION IN THE DEGRADATION OF METHYLENE BLUE}

\begin{abstract}
The presence of non-biodegradable compounds in wastewater is one of the main problems in wastewater treatment plants. Among the main alternatives for the removal of these compounds are the advanced oxidative processes (AOPs), which are based on the formation of hydroxyl radicals $(* \mathrm{OH})$, which are highly oxidizing agents. These radicals can react with a wide variety of classes of compounds, promoting their mineralization. A system used to generate $* \mathrm{OH}$ is the fenton. However, the iron catalyst job as additional treatment step is necessary to remove one of the metal at the end of the process, a factor which has raised interest in the investigation of new catalysts that can minimize this inconvenience. In this context, the present study aimed to evaluate the iodate catalytic precursors for the radical decomposition using of hydrogen peroxide $\left(\mathrm{H}_{2} \mathrm{O}_{2}\right)$, aiming the generation of hydroxyl radicals. The methodology for the evaluation of the radical catalytic activity of the precursors under study was based on the technique of gasometry, conducted in water tests and also in the presence of a methylene blue. The results of the catalytic activity showed that only the iodide was characterized as a potential catalyst of the radical decomposition mechanism of $\mathrm{H}_{2} \mathrm{O}_{2}$.
\end{abstract}

Keywords: advanced oxidative processes, fenton, hydroxyl radicals.

\section{INTRODUÇÃO}

Os processos oxidativos avançados (POA's) têm sido extensivamente estudados e usados como métodos de tratamento eficazes para degradar contaminantes orgânicos recalcitrantes e tóxicos em águas residuárias. Esses processos usam o radical hidroxila, um poderoso agente oxidante, que é capaz de promover a mineralização de poluentes orgânicos (LEE; LEE; LEE, 2014). Destaca-se entre os POA's o processo Fenton, que envolve as reações catalíticas de íons ferrosos $\left(\mathrm{Fe}^{2+}\right)$ na decomposição de peróxido de hidrogênio $\left(\mathrm{H}_{2} \mathrm{O}_{2}\right)$ em radical hidroxila $(* \mathrm{OH})$. Este processo já tem sido empregado em escala real para degradar contaminantes 
orgânicos em unidades de tratamento de águas e efluentes industriais (MIKLOS et al, 2018).

$\mathrm{O}$ sucesso deste processo pode ser atribuído, em parte, à facilidade de operação e flexibilidade para implementação, inclusive em unidades de tratamento já existentes, além da alta eficiência na mineralização dos poluentes (BOKARE; CHOI, 2014). Por outro lado, o emprego de grandes quantidades de íons ferrosos, torna necessário uma etapa de pós-tratamento do efluente para remoção do ferro, aumentando o custo do processo pela adição de produtos químicos (MIRZAEI et al., 2017). Considerando a viabilidade comprovada de implantação e eficiência do processo Fenton, bem como a desvantagem no uso do ferro, muitas pesquisas têm se concentrado em explorar novos catalisadores para substituir o mesmo (WANG et al., 2016).

Visto que a reação Fenton consiste basicamente em uma reação redox, torna-se essencial avaliar o potencial padrão de redução $\left(\mathrm{E}^{\circ}\right)$ das espécies químicas envolvidas no processo. Pois para que a reação ocorra espontaneamente e o $\mathrm{H}_{2} \mathrm{O}_{2}\left(\mathrm{E}^{\mathrm{o}}=1,77 \mathrm{~V}\right)$ sofra redução e se decomponha em $* \mathrm{OH}$, é necessário que o precursor catalítico apresente um valor de $\mathrm{E}^{\mathrm{o}}$ inferior ao $\mathrm{E}^{\mathrm{o}}$ do $\mathrm{H}_{2} \mathrm{O}_{2}$.

Examinando os valores de $\mathrm{E}^{\mathrm{o}}$ para diversos elementos, verificou-se que o íon iodeto $\left(\mathrm{I}^{-}\right)$é um potencial precursor catalítico na decomposição via radicalar do peróxido de hidrogênio, visto que atende ao critério eletroquímico ( $\mathrm{E}^{\mathbf{o}}$ catalisador $\left.<\mathrm{E}^{\mathbf{o}} \mathrm{H}_{2} \mathrm{O}_{2}\right)$, com valor de $\mathrm{E}^{\mathrm{o}}\left(\mathrm{I}_{2} / \mathrm{I}^{-}\right)=0,53 \mathrm{~V}$. Outra característica importante que contribuiu para sua escolha está relacionada com o produto formado na reação de oxidação do iodeto, que é o iodo $\left(\mathrm{I}_{2}\right)$, que, além de ser insolúvel em água, é um agente oxidante e pode contribuir na degradação oxidativa de compostos orgânicos, potencializando assim o processo oxidativo (KHALED et al., 2011). Além disso, o $\mathrm{I}_{2}$ formado cristaliza na forma de escamas pretas que apresentam um brilho metálico, isto porque o $\mathrm{I}_{2}$ é um composto com baixa solubilidade em meio aquoso $\left(0,0013\right.$ mol. $\left.\mathrm{L}^{-1}\right)$ (LEE, 1999). Desta forma o iodo pode ser facilmente removido ao final da reação por um processo de sedimentação ou filtração, possibilitando o seu reuso após uma etapa de redução.

Neste contexto, o objetivo geral deste estudo foi demonstrar, experimentalmente, que o potencial padrão de redução do iodo é inferior ao do peróxido de hidrogênio e que este pode atuar na decomposição radicalar do peróxido de hidrogênio.

\section{MATERIAL E MÉTODOS}

$\mathrm{O}$ potencial da atividade catalítica do iodeto em relação à decomposição do $\mathrm{H}_{2} \mathrm{O}_{2}$ foi avaliado pela técnica de gasometria monitorando o volume de gás oxigênio $\left(\mathrm{O}_{2}\right)$ gerado na reação. $\mathrm{O}$ volume de $\mathrm{O}_{2}$ formado na reação entre o $\mathrm{H}_{2} \mathrm{O}_{2}$ e o catalisador foi medido pelo deslocamento da coluna de água em uma bureta invertida.

As condições experimentais estabelecidas basearam-se no estudo realizado por Moretto (2011). Para os ensaios de atividade catalítica adicionou-se: $9,5 \mathrm{~mL}$ de água deionizada, $0,2 \mathrm{~mL}$ de $\mathrm{H}_{2} \mathrm{O}_{2}$ e $1 \mathrm{~mL}$ da solução de catalisador (KI 0,5 mol.L $\mathrm{L}^{-1}$ ). Antes de adicionar o catalisador e $\mathrm{o}_{2} \mathrm{O}_{2}, \mathrm{o} \mathrm{pH}$ do meio reacional foi ajustado em 3,0, com uma solução de $\mathrm{H}_{2} \mathrm{SO}_{4}(5 \%)$, o qual, como ocorre no processo Fenton, é considerado ideal para a decomposição catalítica do $\mathrm{H}_{2} \mathrm{O}_{2}$ (WANG et al., 2016). Após a adição dos reagentes, o frasco foi fechado e a reação foi acompanhada pela medida volumétrica do oxigênio $\left(\mathrm{O}_{2}\right)$ gerado em função do tempo reacional, verificando-se temporalmente a quantidade de gás produzido. De forma paralela, foi realizado um ensaio em branco, somente com água deionizada e peróxido de hidrogênio.

Na segunda etapa, os ensaios foram realizados empregando uma solução de azul de metileno (AM) em substituição a água. O AM foi usado como molécula modelo de um contaminante para comprovar o mecanismo radicalar a partir do efeito do composto orgânico no volume de $\mathrm{O}_{2}$ gerado. Nestes ensaios, foram adicionados $9,5 \mathrm{~mL}$ da solução de azul de metileno $\left(20 \mathrm{mg} \cdot \mathrm{L}^{-1}\right)$ no frasco de vidro, em sequência o pH da solução foi ajustado em 3,0 e adicionado $0,2 \mathrm{~mL}$ de $\mathrm{H}_{2} \mathrm{O}_{2}(30 \% \mathrm{v} / \mathrm{v})$ e $1 \mathrm{~mL}$ da solução de catalisador KI 0,5 mol.L $\mathrm{L}^{-1}$.

\section{RESULTADOS E DISCUSSÃO}

A quantidade de $\mathrm{O}_{2}$ gerada em função do tempo reacional para reação de decomposição catalítica do peróxido de hidrogênio na presença de diferentes quantidades de íons iodeto $\left(\mathrm{I}^{-}\right)$é apresentada na Figura 1A.

Observa-se que no ensaio realizado com presença de iodeto a geração de oxigênio molecular $\left(\mathrm{O}_{2}\right)$ ocorreu já nos minutos iniciais, aumentando gradativamente a geração de $\mathrm{O}_{2}$ durante 45 minutos reacionais, totalizando 9,2 $\mathrm{ml}$ de gás gerado ao final do ensaio. $\mathrm{O}$ ensaio em branco (água e $\mathrm{H}_{2} \mathrm{O}_{2}$ ) não gerou $\mathrm{O}_{2}$ no tempo reacional observado, evidenciando que o iodeto atuou como catalisador da decomposição do peróxido de hidrogênio. 
Buscando comprovar se o processo de decomposição do peróxido de hidrogênio, principalmente observado para o íon iodeto, está ocorrendo de forma radicalar, com geração radical *OH ou não, paralelamente foram conduzidos ensaios na presença de um contaminante orgânico, o azul de metileno. A evolução do volume de $\mathrm{O}_{2}$ gerado na reação de decomposição catalítica do peróxido de hidrogênio por íons iodeto, na presença do azul de metileno, estão apresentados na Figura 1B.

Para a reação conduzida na presença do contaminante orgânico, ou seja, do azul de metileno, observase uma redução na produção de $\mathrm{O}_{2}$ em relação ao ensaio conduzido somente com água e $\mathrm{H}_{2} \mathrm{O}_{2}$. Esta tendência é característica de mecanismo radicalar para a decomposição catalítica do peróxido de hidrogênio (OLIVEIRA et al., 2008). Oliveira et al. (2009) relatam que quando o mecanismo de decomposição do $\mathrm{H}_{2} \mathrm{O}_{2}$ é via radicais livres, nos ensaios conduzidos na presença de um composto orgânico, se pode observar um efeito competidor pelos radicais *OH entre as reações de decomposição do $\mathrm{H}_{2} \mathrm{O}_{2}$ e de oxidação do poluente orgânico (AM).

Corrobora com esta hipótese duas situações distintas observadas para o sistema reacional em análise, uma de caráter experimental e outra de caráter teórico:

i) experimentalmente o ensaio proporcionou, além da menor produção de $\mathrm{O}_{2}$, a remoção da coloração azul do meio reacional (Figura 2) o qual é um indicativo do caráter oxidativo do meio, que mediante reações de oxidação, proporcionadas pelos radicais hidroxila, conduz a um rearranjo estrutural na molécula do azul de metileno a qual, agora oxidada e com menor número de ligações em ressonância (duplas conjugadas), perde sua capacidade de absorção de radiação na região visível do espectro;

ii) teoricamente ou conceitualmente o sistema reacional proposto gera uma força eletromotriz (f.e.m.= $\Delta \mathrm{E}^{\circ}$ ) positiva para a reação de oxidação-redução entre o peróxido de hidrogênio e o iodeto, indicando que a reação redox ocorre espontaneamente, ou seja, se comporta como uma pilha galvânica, conforme as reações a seguir (equações 1 a 3).

$$
\begin{array}{ll}
\mathrm{H} 2 \mathrm{O} 2+2 \mathrm{e}-\rightarrow * \mathrm{OH}+\mathrm{OH}- & \text { semi-reação do cátodo/ } \mathrm{E}^{\circ}=1,77 \mathrm{v} \\
\mathrm{I} 2+2 \mathrm{e}-\rightarrow \mathrm{I}- & \text { semi-reação do ânodo/ } \mathrm{E}^{\circ}=0,53 \mathrm{v} \\
\mathrm{H} 2 \mathrm{O} 2+2 \mathrm{I}-\rightarrow \mathrm{I} 2+* \mathrm{OH}+\mathrm{OH}- & \Delta \mathrm{E}^{\circ}=\mathrm{E}^{\circ} \text { cátodo }-\mathrm{E}^{\mathrm{o}} \text { ânodo=1,24 v }
\end{array}
$$

Sendo assim, tanto teoricamente quanto experimentalmente, os resultados comprovam que os íons iodeto atuam como catalisadores da decomposição radicalar do $\mathrm{H}_{2} \mathrm{O}_{2}$. Outra vantagem observada para este sistema está relacionada a um dos produtos da reação, mais especificamente ao iodo $\left(\mathrm{I}_{2}\right)$ formado (Figura 2) que por ser uma molécula apolar com baixa solubilidade em água $\left(0,0013\right.$ mol. $\left.\mathrm{l}^{-1}\right)$, apresenta-se na foram de um precipitado (LEE, 1999). Neste contexto, após a reação, o iodo poderá ser facilmente removido/recuperado do sistema reacional, por um processo físico de sedimentação ou filtração, tornando o processo cíclico.

\section{CONCLUSÃO}

Os resultados dos ensaios realizados evidenciaram que o iodeto, em $\mathrm{pH}$ ácido, pode atuar como catalisador do mecanismo radicalar de decomposição do $\mathrm{H}_{2} \mathrm{O}_{2}$. O mecanismo radicalar observado experimentalmente está de acordo com os dados teóricos da reação redox entre o peróxido de hidrogênio e iodeto, em que o iodeto atua como agente redutor do $\mathrm{H}_{2} \mathrm{O}_{2}$, conduzindo a um processo redox espontâneo, ou seja, gerando uma pilha galvânica ( $\Delta \mathrm{E}^{\circ}$ positivo).

\section{AGRADECIMENTOS}

\section{URI - Campus de Erechim, CAPES, FAPERGS, CNPq e IFRS-Campus Sertão.}

\section{REFERÊNCIAS}

BOKARE, A. D.; CHOI, W. Review of iron-free Fenton-like systems for activating $\mathrm{H}_{2} \mathrm{O}_{2}$ in advanced oxidation processes. Journal of Hazardous Materials, v. 275, p. 121-135, 2014.

KHALED, E.; EL-RIESB, M. A.; ZIDANEC, F. I.; IBRAHIMB, S. A.; ABD-ELMONEMB, M. S. Kinetic catalytic determination of trace levels of iodide based on the oxidation of basic dyes with hydrogen peroxide monitored potentiometrically using simple PVC.electrodes. Talanta, v. 83, p. 1538-1543, 2011.

LEE, H. J.; LEE, H. S.; LEE, C.H. Degradation of diclofenac and carbamazepine by the copper (II)-catalyzed dark and photo-assisted Fenton-like systems. Chemical Engineering Journal, v. 245, p. 258-264, 2014. 
LEE, J. D. Química inorgânica não tão concisa. 5a ed. São Paulo: Edgard Blücher, 1999.

MIKLOS, D. B.; REMY, C.; JEKEL, M.; LINDEN, K. G.; DREWES, J. E.; HÜBNER, U. Evaluation of advanced oxidation processes for water and wastewater treatment - A critical review. Water Research, v. 139, p. 118-131, 2018. MIRZAEI, A.; CHEN, Z.; HAGHIGHAT, F.; YERUSHALMI, L. Removal of harmaceuticals from water by homo/heterogonous Fenton-type processes - A review. Chemosphere, v. 174, p. 665-688, 2017.

MORETTO, D. Avaliação da remoção de pigmentação de calda de indústria de balas utilizando peróxido de hidrogênio promovido com íon hidroxila. 2011. Dissertação (Mestrado em Engenharia de Alimentos) - Universidade Regional Integrada do Alto Uruguai e das Missões, Erechim, 2011.

OLIVEIRA, L.C.A.; RAMALHO, T.C.; SOUZA, E.F., GONÇALVES, M.; OLIVEIRA, D.Q.L.; PEREIRA, M.C.; FABRIS. J.D. Catalytic properties of goethite prepared in the presence of $\mathrm{Nb}$ on oxidation reactions in water: Computational and experimental studies. Applied Catalysis B: Environmental, v. 83, p. 169-176, 2008.

OLIVEIRA, L.C.A.; SILVA, A.C.; OLIVEIRA, D.Q.L.; ANASTACIO, A.L.; RAMALHO, T.C.; LOPES, J.H.; CARVALHO, H.W.P.; RODRIGUEZ TORRES, C.E. Nb-containing Hematites Fe2_xNbxO3: The role of Nb5+ on the reactivity in presence of the H2O2 or ultraviolet light. Applied Catalysis A: General, v. 357, p. 79-84, 2009.

WANG, N.; ZHENG, T.; ZHANG, G.; WANG, P. A review on Fenton-like processes for organic wastewater treatment. Journal of Environmental Chemical Engineering, v. 4, p. 762-787, 2016.

A

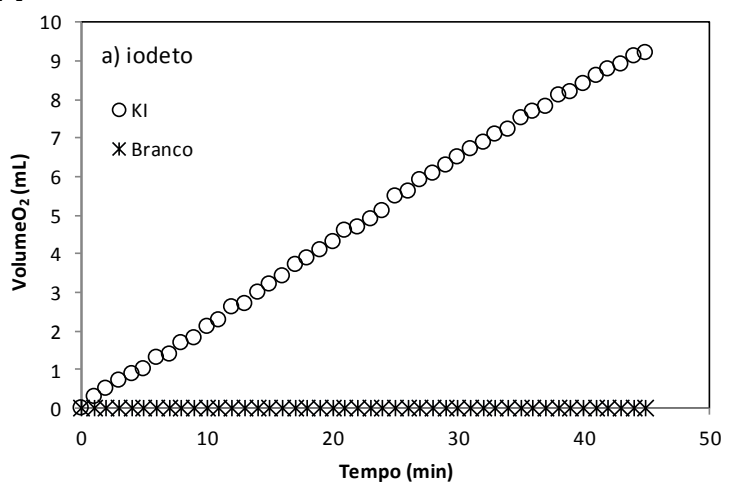

B

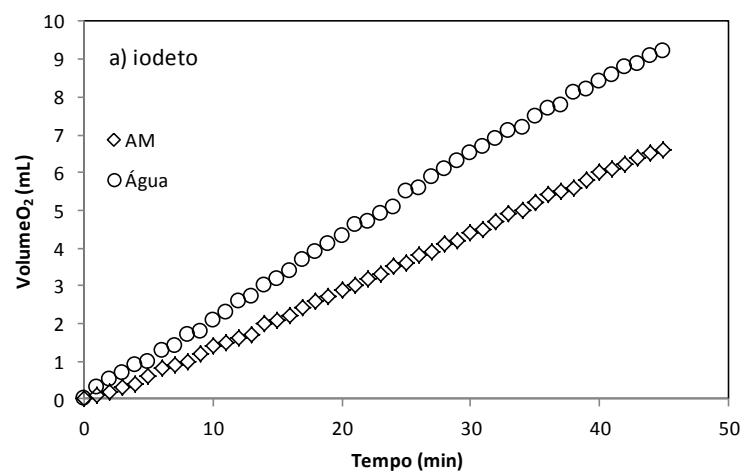

Figura 1. A) Volume de $\mathrm{O}_{2}$ gerado na decomposição catalítica do $\mathrm{H}_{2} \mathrm{O}_{2}$, na ausência de azul de metileno, empregando como catalisador o iodeto; B)Volume de $\mathrm{O}_{2}$ gerado na decomposição catalítica do $\mathrm{H}_{2} \mathrm{O}_{2}$, na presença de azul de metileno (AM), empregando o iodeto como catalisador.
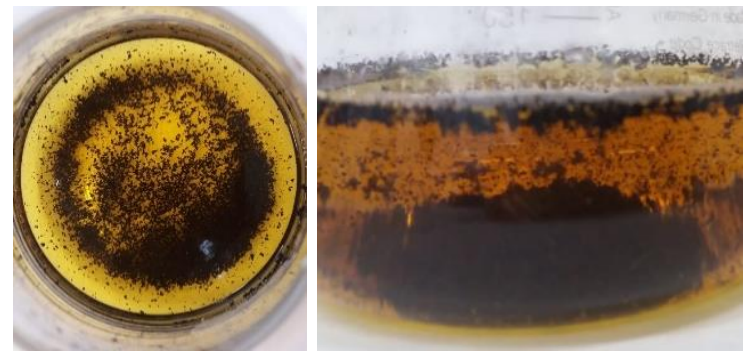

Figura 2. Sistema reacional após ensaio de decomposição catalítica do peróxido de hidrogênio por íons iodeto, na presença de azul de metileno. 


\title{
BAGAÇO DE UVA COMO ALTERNATIVA PARA ADSORÇÃO DE DICLOFENACO DE SÓDIO EM SOLUÇÃO AQUOSẢ
}

\author{
Reis, M.A. ${ }^{* 1}$; Diel, J.C. ${ }^{1}$; Chiquim, M.S. ${ }^{1}$; Bender, T.J. ${ }^{1}$; Cruz, W. de A.; Nunes, I. dos S. ${ }^{1}$ \\ ${ }^{1}$ Pesquisadores da Universidade Regional Integrada do Alto Uruguai e das Missões, Santo Ângelo, RS - Brasil \\ isaac.eq@san.uri.br
}

\begin{abstract}
RESUMO: O presente trabalho objetiva em um todo a sustentabilidade, visando aplicar o resíduo agroindustrial vinícola no tratamento de corpos hídricos contendo contaminantes como o fármaco diclofenaco de sódio (DCF), por meio da operação unitária de adsorção. Neste contexto, a partir das cinéticas de adsorção, avaliou-se a remoção de DCF na concentração fixa de $50 \mathrm{mg} \mathrm{L}^{-1}$, variando-se as dosagens de adsorvente nos patamares de 0,$025 ; 0,050$ e $0,075 \mathrm{~g}$, ajustando-se as soluções ao $\mathrm{pH}$ entre 4 e 5,3 . Verificou-se que a condição mais atrativa foi a massa de $0,025 \mathrm{~g}$ de BU, apresentando uma eficiência de remoção de 90,83\%, para a capacidade adsortiva de $90,83 \mathrm{mg} \mathrm{g}^{-1}$, admitindo-se o tempo de equilíbrio de $75 \mathrm{~min}$, sendo que o modelo de PPO apresentou o melhor ajuste cinético a estes dados. Tais resultados revelam a grande potencialidade do bagaço de uva no tratamento de efluentes contendo DCF, em um curto período de tempo e apresentando grande eficiência de remoção.
\end{abstract}

Palavras-chave: Adsorção, resíduo, bagaço de uva, diclofenaco de sódio.

\section{GRAPE MARC AS ALTERNATIVE FOR ADSORPTION OF SODIUM DICLOFENAC IN AQUEOUS SOLUTION}

ABSTRACT: The objective of this study is to evaluate sustainability in order to apply agroindustrial residues in the treatment of water bodies containing contaminants such as diclofenac sodium (DCF) using adsorption. In this context, from the adsorption kinetics, the determination of DCF at the fixed concentration of $50 \mathrm{mg} \mathrm{L}^{-}$ ${ }^{1}$ was evaluated, the adsorbent dosages being varied at the levels of $0.025 ; 0.050$ and $0.075 \mathrm{~g}$, the solutions being adjusted to $\mathrm{pH}$ between 4 and 5.3. It was found that the most attractive condition was the mass of 0.025 $\mathrm{g}$ of BU, exhibiting a removal efficiency of $90.83 \%$, for the adsorptive capacity of $90.83 \mathrm{mg} \mathrm{g}^{-1}$, assuming the equilibrium time of $75 \mathrm{~min}$, and the PPO model presented the best kinetic adjustment to these data. These results reveal the great potential of grape bagasse in the treatment of effluents containing DCF, in a short period of time and presenting great removal efficiency.

Keywords: Adsorption, residue, grape bagasse, sodium diclofenac.

\section{INTRODUÇÃO}

A comunidade científica vem constatando que a água contaminada ocasiona risco potencial à saúde e ao ambiente, o que se deve à presença de pequenas concentrações de contaminantes orgânicos, também conhecidos como emergentes (SILVA et al., 2016). Como é o caso do diclofenaco de sódio (DCF), apontado por Müller et al. (2014) como um anti-inflamatório não hormonal derivado do ácido fenilacético.

Atualmente, além da preocupação com a poluição dos corpos hídricos, ocasionada por contaminantes como o DCF, Gallon et al. (2014) constata a necessidade de destinar corretamente os resíduos produzidos pelos sistemas agroindustriais, como o bagaço residual do processamento da uva pela indústria vinícola, cujo descarte gera um enorme passivo ambiental. Isso porque, segundo dados da Embrapa (2014), estima-se que o bagaço corresponda a 16\% da uva processada, o que equivale à geração de 210 mil toneladas por ano.

De acordo com Lima et al. (2015), diversas pesquisas são desenvolvidas para promover a aplicação das mais variadas espécies de biomassas vegetais objetivando a descontaminação de águas por substâncias orgânicas por meio da adsorção, uma operação unitária de transferência de massa que está relacionada à habilidade de certos sólidos em concentrar na sua superfície determinadas substâncias existentes em fluidos, possibilitando a separação destes componentes.

Neste sentido, o presente trabalho buscou avaliar a capacidade adsortiva de bagaço de uva (BU) empregando diferentes massas do biossorvente $(0,025 ; 0,050 ; 0,075$ e $0,01 \mathrm{~g})$ frente a uma solução de diclofenaco de sódio (DCF) na concentração de $50 \mathrm{mg} \mathrm{L}^{-1}$. 


\section{MATERIAL E MÉTODOS}

A matéria-prima utilizada como adsorvente foi o bagaço de uva (pertencente à variedade Vitis Labrusca, cultivar Isabel), proveniente de fermentação vinícola artesanal, realizada no município de Santo Cristo, referente à safra 2017/2018. O preparo da biomassa adsorvente englobou a secagem em estufa com recirculação de ar a $60^{\circ} \mathrm{C}$ por $24 \mathrm{~h}$, e a moagem em moinho de facas tipo Willey.

A biomassa foi submetida à medida do $\mathrm{pH}$ no ponto de carga zero ( $\mathrm{pH}$ PCZ), empregando-se o "Método dos 11 pontos". O procedimento consistiu na adição de $0,02 \mathrm{~g}$ de material adsorvente e $20 \mathrm{~mL}$ de solução aquosa de $\mathrm{NaCl} 0,1 \mathrm{~mol} \mathrm{~L}^{-1}$ em erlenmeyers de $125 \mathrm{~mL}$, sob 11 diferentes condições de $\mathrm{pH}$ inicial $(1,2,3,4$, $5,6,7,8,9,10,11)$, ajustados com soluções de $\mathrm{HCl}$ ou de $\mathrm{NaOH}$. Apontou-se o $\mathrm{pH}$ final das soluções decorridas $24 \mathrm{~h}$, sob agitação de $120 \mathrm{rpm}$, em mesa agitadora orbital (CT-145, Cientec). Todas as soluções, preparadas a partir da dissolução de DCF em água destilada, foram ajustadas ao valor de pHPCZ determinado, com correções a partir de soluções de $\mathrm{NaOH}$ e $\mathrm{HCl}$.

Inicialmente, realizaram-se testes de dosagem de adsorvente e de concentração inicial do fármaco em solução, objetivando-se determinar as melhores condições para executar os ensaios cinéticos. As massas testadas foram 0,$025 ; 0,050 ; 0,075$ e $0,10 \mathrm{~g}$ de BU, em $50 \mathrm{mg} \mathrm{L}^{-1}$ de DCF.

Os ensaios de adsorção foram realizados variando-se massas adsorventes de 0,$025 ; 0,050$; e $0,075 \mathrm{~g}$ em $50 \mathrm{~mL}$ de solução de fármaco, na concentração de estudo de $50 \mathrm{mg} \mathrm{L}^{-1}$.

As amostras foram agitadas em temperatura ambiente, a $160 \mathrm{rpm}$, em mesa agitadora orbital. Realizouse a quantificação em espectrofotômetro (UV-2600, Shimadzu), no comprimento de onda de $275 \mathrm{~nm}$, em intervalos de tempo regulares (a cada $10 \mathrm{~min}$, até $60 \mathrm{~min}$; a cada $15 \mathrm{~min}$ até $120 \mathrm{~min}$; e após, a cada $30 \mathrm{~min}$ ), até atingir-se o ponto de equilíbrio do adsorvato/adsorvente.

O processo adsortivo foi analisado por meio das Equações 1 e 2, que representam a capacidade de adsorção da biomassa $(q t)$ e a eficiência de remoção $(\eta)$ do fármaco, respectivamente:

$$
\begin{gathered}
q_{t}=\frac{V\left(C_{0}-C_{t}\right)}{m} \\
\eta=\frac{\left(C_{0}-C_{t, f}\right)}{C_{0}} \times \mathbf{1 0 0}
\end{gathered}
$$

sendo $C_{0}$ a concentração inicial de fármaco, em $\mathrm{mg} \mathrm{L}^{-1} ; C_{t}$ a concentração medida no intervalo de tempo, em $\mathrm{mg} \mathrm{L}^{-1} ; m$ a massa de adsorvente utilizada no processo de adsorção, em g; $V$ volume de solução que contém o fármaco, em L; e $C_{t, f}$ a concentração no tempo final do processo, em $\mathrm{mg} \mathrm{L}^{-1}$.

Utilizou-se o pacote computacional MatLab® para a construção dos perfis cinéticos de adsorção e determinação dos parâmetros cinéticos dos modelos testados pseudo-primeira ordem (PPO) e pseudo-segunda ordem (PSO), apresentados pelas Equações 3 e 4, respectivamente:

$$
\begin{aligned}
q_{t} & =q_{e}\left(1-e^{-k_{1} t}\right) \\
q_{t} & =\frac{t}{\left(\frac{1}{k_{2} q_{\rho}^{2}}\right)+\left(\frac{t}{q_{e}}\right)}
\end{aligned}
$$

sendo $k_{l}$ a constante adimensional da taxa de adsorção de PPO; $k_{2}$ a constante adimensional da taxa de adsorção de PSO; $t$ o tempo de adsorção, em min; e $q_{e}$ a capacidade de adsorção no equilíbrio (máxima capacidade adsortiva), em $\mathrm{mg} \mathrm{g}^{-1}$.

O coeficiente de correlação linear $\left(\mathrm{R}^{2}\right)$ e o erro relativo médio (ERM) foram os parâmetros analisados para verificação do melhor ajuste do modelo, considerando-se os melhores ajustes aqueles que apresentaram os maiores valores para o $\mathrm{R}^{2}$ e menores valores da ERM.

\section{RESULTADOS E DISCUSSÃO}

No processo de adsorção, conforme afirma Graebin (2014), o pH da solução apresenta-se como um fator que pode influenciar as condições de operação, uma vez que a variação pode aumentar ou diminuir significativamente a capacidade adsortiva dos materiais, ativando ou desativando sítios ativos presentes. Por este motivo, é importante determinar o $\mathrm{pH}_{\mathrm{PCZ}}$ dos adsorventes utilizados no processo, visando-se encontrar o pH ideal para realização dos ensaios cinéticos. Neste sentido, determinou-se o pHPCZ do BU utilizado no 
presente trabalho, encontrando-se o valor de 5,3.

Aliado ao pH da solução, trabalhando-se com a remoção de fármacos, outro importante fator que influencia diretamente na eficiência do processo é o pKa do fármaco. De acordo com Hasan et al. (2016), o pKa do DCF está em torno de 4, o que significa que, em pH abaixo de 4 a solução apresenta carga positiva, e acima de 4, carga negativa. Para que o processo de adsorção seja favorável, segundo Luna et al. (2017), é necessária a interação eletrostática entre o adsorvato e o adsorvente. Desta forma, se a solução de DCF apresenta carga negativa acima do $\mathrm{pH} 4$, é necessário trabalhar com um adsorvente na sua forma positiva. Por isso, todas as soluções de DCF utilizadas no processo adsortivo com BU foram ajustadas ao pH entre 4 e 5,3.

Por meio dos testes de dosagem de adsorvente, determinou-se que as melhores condições para realização dos ensaios cinéticos, considerando-se a eficiência de remoção de DCF, foram as massas de 0,025; 0,050 e $0,075 \mathrm{~g}$ de BU. No entanto, tais condições diferem da bibliografia consultada, uma vez que as menores massas apresentam as melhores condições para realização dos ensaios cinéticos. Em conformidade com Chiquim et al. (2018), com maiores quantidades de adsorvente o contato entre as fases torna-se mais efetivo, acelerando o processo de transferência de massa.

Na Figura 1 constam os perfis cinéticos de adsorção com os dados experimentais ajustados aos modelos PPO e PSO para os ensaios de DCF na concentração de $50 \mathrm{mg} \mathrm{L}^{-1}$ com 0,025; 0,050; e 0,075 g de BU. Por meio da Figura 1 verifica-se que, empregando-se $0,025 \mathrm{~g}$ de BU, alcançou-se uma eficiência de remoção de $90,83 \%$, com uma capacidade adsortiva de $90,83 \mathrm{mg} \mathrm{g}^{-1}$, admitindo-se o tempo de equilíbrio de 75 min. Para $0,05 \mathrm{~g}$ de BU, o tempo de equilíbrio foi atingido aos $60 \mathrm{~min}$, apresentando remoção de 86,29\% e capacidade de $43,14 \mathrm{mg} \mathrm{g}^{-1}$. Já se utilizando $0,075 \mathrm{~g}$, com uma capacidade adsortiva de $26,03 \mathrm{mg} \mathrm{g}^{-1}$, o equilíbrio da operação foi atingido aos 50 min, removendo 78,09\% de DCF.

Em relação ao tempo de equilíbrio, Silva et al. (2015) apontam que a remoção rápida do adsorvato e o alcance do equilíbrio em um curto período de tempo pode ser uma das indicações que o adsorvente é eficaz e pode se tornar uma alternativa promissora. Franco et al. (2018), empregando 0,15 g de carvão ativado granulado removeram cerca de $80 \%$ de DCF na concentração de $20 \mathrm{mg} \mathrm{L}^{-1}$, admitindo o tempo de equilíbrio de $150 \mathrm{~min}$. No presente trabalho, o equilíbrio foi alcançado em tempos menores (de 50 a $75 \mathrm{~min}$ ), com remoções maiores ou equivalentes.

Com base dos dados de eficiência de remoção apresentados, pode-se afirmar que as três dosagens testadas de BU foram eficientes na remoção do DCF em solução aquosa, podendo-se definir como a melhor condição do processo adsortivo a quantidade de $0,025 \mathrm{~g}$ de BU, apresentando a maior remoção dentre as massas testadas, equivalente a $90,83 \%$.

A Tabela 1 apresenta os parâmetros dos modelos cinéticos utilizados para ajustar os dados experimentais obtidos na adsorção de DCF na concentração de $50 \mathrm{mg} \mathrm{L}^{-1}$ empregando 0,$025 ; 0,050$ e $0,075 \mathrm{~g}$ de BU. Por meio dos dados dispostos na Tabela 1 , levando em consideração os maiores valores obtidos para $\mathrm{R}^{2} \mathrm{e}$ menores valores para ERM, observa-se que o processo adsortivo apresentou melhor ajuste ao modelo PPO para as massas de 0,025 e $0,050 \mathrm{~g}$, enquanto o modelo PSO melhor ajustou-se a massa de $0,075 \mathrm{~g}$ de BU, apresentando coeficientes de correlação $\left(\mathrm{R}^{2}\right)$ satisfatórios.

\section{CONCLUSÃO}

Considerando-se o passivo ambiental ocasionado pelo descarte de resíduos da indústria vinícola e o grande volume de corpos hídricos contaminados por compostos orgânicos, o presente trabalho avaliou a capacidade adsortiva de bagaço de uva na remoção de diclofenaco de sódio em solução aquosa. Por meio de ensaios cinéticos, determinou-se que a massa de $0,025 \mathrm{~g}$ em solução de $50 \mathrm{mg} \mathrm{L}^{-1}$ de DCF foi a mais atrativa, removendo $90,83 \%$ do fármaco em 75 min de contato. A análise conjunta dos resultados permitiu concluir que o BU pode ser utilizado como adsorvente efetivo na remoção de DCF, sendo uma alternativa promissora para minimizar os impactos ambientais decorrentes do descarte inadequado de resíduos agroindustriais e da poluição dos corpos hídricos.

\section{AGRADECIMENTOS}

Os autores gostariam de agradecer à Universidade Regional Integrada do Alto Uruguai e das Missões pela bolsa concedida, financiada via PIIC-URI e ao Grupo de Pesquisa e Desenvolvimento em Engenharia de Processos. 


\section{REFERÊNCIAS}

CHIQUIM, M. S.; et al. Estudo da capacidade de adsorção de azul de metileno utilizando resíduo de bagaço de malte. In: $12^{\circ}$ Congresso Brasileiro sobre adsorção, Gramado, 2018.

EMBRAPA (Brasília). Bagaço de uva vira alimentos funcionais. 2014. Disponível em: <https://www.embrapa.br/busca-de-noticias/-/noticia/2235712/bagaco-de-uva-vira-alimentos-funcionais>.

Acesso em: 19 nov. 2018.

FRANCO, M. A.; et al. Adsorção de diclofenaco sódico em carvão ativado granulado. In: $6^{\circ}$ Congresso Internacional de Tecnologias para o Meio Ambiente, Bento Gonçalves, 2018.

GALLON, I.; et al. Destino e análise do uso alternativo do resíduo bagaço de uva na cadeia do agronegócio. In: Simpósio Internacional de Inovação em Cadeias Produtivas do Agronegócio, 2014.

GRAEBIN, G. O.. Secagem do bagaço de cana-de-açúcar e estudo da sua aplicação na remoção de metal pesado. 133 f. Dissertação - Universidade Estadual do Oeste do Paraná, Toledo, 2014.

HASAN, Z; et al. Adsorptive removal of diclofenac sodium from water with Zr-based metal-organic frameworks. Chemical Engineering Journal, n. 284, p. 1406-1413, 2016.

LIMA, J. P.; et al. Farinha de entrecasca de melancia em biscoitos sem glúten. Ciência rural, v. 45, n. 9 , p.1688-1694, 17 jul. 2015.

LUNA, M. D. G.; et al. Removal of sodium diclofenac from aqueous solution by adsorbents derived from cocoa pod husks. Journal of Environmental Chemical Engineering, n. 5, p. 1465-1474, 2017.

MÜLLER, S. S.; et al. Análise clínica e biomecânica do efeito do diclofenaco sódico na consolidação da fratura da tíbia no rato. Acta Ortop Bras, São Paulo, v. 12, n. 4, p.1-8, dez. 2018.

SILVA, L. M.; et al. Remoção de corante catiônico de meio aquoso usando resíduo da agroindústria de alimentos como adsorvente. In: XXXVII Congresso Brasileiro de Sistemas Particulados, 2015.

SILVA, R. F.; et al. Identificação e quantificação de contaminantes emergentes em estações de tratamento de esgoto. Revista Virtual de Química, Recife, v. 8, n. 3, p.702-715, 18 abr. 2016.

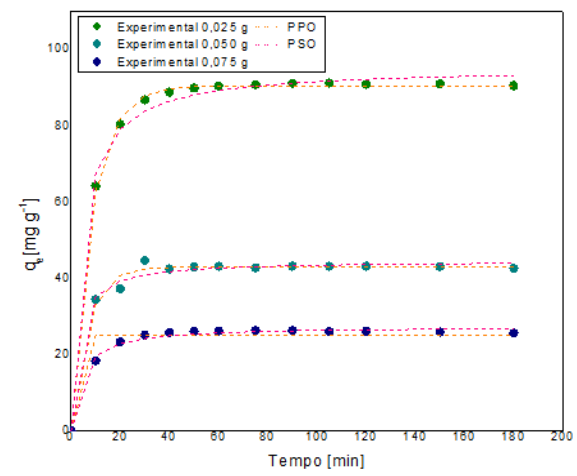

Figura 1. Perfis cinéticos com modelos ajustados ao processo de adsorção de DCF utilizando BU em diferentes dosagens adsorventes.

Tabela 1. Dados cinéticos obtidos a partir dos modelos testados para adsorção de DCF.

\begin{tabular}{|c|c|c|c|}
\hline \multirow{2}{*}{ Modelos } & \multicolumn{3}{|c|}{ Massa de adsorvente [g] } \\
\hline & 0,025 & $\mathbf{0 , 0 5 0}$ & $\mathbf{0 , 0 7 5}$ \\
\hline \multicolumn{4}{|c|}{ Pseudo-primeira Ordem (PPO) } \\
\hline$q_{e}\left[\mathrm{mg} \mathrm{g}^{-1}\right]$ & 90,47 & 42,95 & 25,07 \\
\hline$k_{1}\left[\min ^{-1}\right]$ & 0,1183 & 0,1483 & 3,644 \\
\hline $\mathrm{R}^{2}$ & 0,9988* & 0,988* & 0,9035 \\
\hline ERM [\%] & 0,8614 & 1,312 & 2,262 \\
\hline \multicolumn{4}{|c|}{ Pseudo-segunda Ordem (PSO) } \\
\hline$q_{e}\left[\mathrm{mg} \mathrm{g}^{-1}\right]$ & 95,35 & 44,55 & 27,34 \\
\hline$k_{2}[\mathrm{~g} \mathrm{mg} \mathrm{min}-1]$ & 0,002558 & 0,008363 & 0,00932 \\
\hline $\mathrm{R}^{2}$ & 0,9936 & 0,9858 & $0,9891 *$ \\
\hline ERM [\%] & 2,018 & 1,427 & 0,7599 \\
\hline
\end{tabular}

*Modelo cinético de melhor ajuste. 


\title{
BIOSSORÇÃO DE SELÊNIO EM MEIO AQUOSO POR BIOMASSA SECA E ÚMIDA DE EFLUENTE DE INDÚSTRIA CERVEJEIRA
}

\author{
Hackbarth, H. G. ${ }^{1}$; Gonçalves, A. ${ }^{2}$; Wisbeck, E. ${ }^{2}$; Souza, O. ${ }^{2 *}$ \\ ${ }^{1}$ Departamento de Engenharia Química, Universidade da Região de Joinville (UNIVILLE), SC - Brasil; \\ ${ }^{3}$ Programa de Mestrado em Engenharia de Processos, Universidade da Região de Joinville (UNIVILLE), SC - Brasil; \\ ozair.souza@univille.br
}

RESUMO: As particularidades da levedura Saccharomyces cerevisiae, como elevada geração de biomassa residual nas indústrias de etanol combustível e cerveja, bem como capacidade de absorção de metais, a tornam um biossorvente de destaque. Neste trabalho, avaliou-se a potencialidade da biossorção de selênio (sorbato (A)), contaminante comum em águas residuais de indústrias químicas, dissolvido em meio aquoso proveniente de biomassa microbiana (biossorvente (B)) descartada por uma indústria cervejeira da região de Joinville. Foram realizados nove ensaios de biossorção utilizando $S$. cerevisiae na sua forma inativa, na condição de biomassa úmida (BU) e seca (BS), conduzidos à $30^{\circ} \mathrm{C}$, com velocidade de agitação de $120 \mathrm{~min}^{-1}$ e tempo reacional de 48 horas. Diferentes concentrações iniciais de A $\left(7,5 ; 22,5\right.$ e $\left.30,0 \mathrm{mg} \mathrm{L}^{-1}\right)$ e de B $(2,0 ; 17,5 ; 24,0$ e 52,5 $\mathrm{g} \mathrm{L}^{-1}$ ) foram testadas. Para reduzir maiores concentrações de Se, ao se utilizar o biossorvente seco, podese optar pelo experimento com 22,5 mg. $\mathrm{L}^{-1}$ de A e 17,5 g.L. $\mathrm{L}^{-1}$ de $\mathrm{B}$ e ao se utilizar o biossorvente úmido, o ensaio com $30 \mathrm{mg} . \mathrm{L}^{-1}$ de A e 24 g.L $\mathrm{L}^{-1}$ de B se torna mais apropriado, pois os dois casos removem maiores concentrações de Se utilizando menor concentração de biossorvente. Todos os ensaios apresentaram redução na concentração inicial de Se na solução.

Palavras-chave: biossorção de metais, biotratamento, Saccharomyces cerevisiae, selênio.

\section{BIOSORPTION OF SELENIUM IN AQUEOUS MEDIA BY DRY AND WET BIOMASS OF BEER INDUSTRIA EFFLUENT}

\begin{abstract}
The particularities of the yeast Saccharomyces cerevisiae, such as high residual biomass generation in the fuel ethanol and beer industries, as well as the absorption capacity of metals, make it a prominent biosorbent. In this work, the potential of selenium biosorption (sorbate, A), common contaminant in wastewater of chemical industries, dissolved in aqueous medium by microbial biomass (biosorbent, B), discarded by a brewery industry of Joinville region. Nine biosorption assays were carried out using $S$. cerevisiae in its inactive form, in humid biomass (BU) and dry biomass (BS) conditions, conducted at $30^{\circ} \mathrm{C}$, with a stirring speed of $120 \mathrm{rpm}$ and a reaction time of 48 hours. Different initial concentrations of A (7,5;

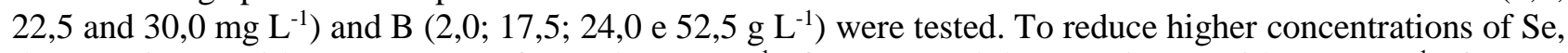
the experiment with $22.5 \mathrm{mg} . \mathrm{L}-1$ of $\mathrm{A}$ and $17.5 \mathrm{~g} \mathrm{~L}^{-1}$ of B (BS) and the experiment with $30 \mathrm{mg} \mathrm{L}^{-1}$ of A and $24 \mathrm{~g} \mathrm{~L}^{-1}$ of $\mathrm{B}$ (BU) can be utilized, because the two cases remove higher concentrations with lower concentration of biomass. All the tests showed a reduction in the initial concentration of Se in the solution.
\end{abstract}

Palavras-chave: Biotreatment, Metal biosorption, Saccharomyces cerevisiae, selenium.

\section{INTRODUÇÃO}

As diferentes formas de oxidação e capacidade de bioacumulação tornam o selênio (Se) um elemento perigoso quando presente em altas concentrações, desenvolvendo a doença selenose que afeta os tecidos corporais e sistema nervoso (Tan, 2003). Águas residuais de indústrias químicas que utilizam o Se como matéria-prima em atividades como combustão de carvão, refino de petróleo e metais nobres, fundição, fabricação de cerâmica e de vidro são propícias a tê-lo como contaminante. Nesse contexto, tecnologias eficazes na remoção de Se devem ser utilizadas devido à preocupação ambiental e a necessidade do atendimento aos limites legais estabelecidos para cada região (Tan, 2003; Twidwell e Beam, 2002).

O uso de adsorventes alternativos provenientes de resíduos industriais torna a biossorção um método de tratamento vantajoso na remoção de metais, que está associado a baixo custo operacional, grande disponibilidade, seletividade e não geração de resíduos secundários. O Brasil conta com uma elevada produção de bebidas e combustíveis via fermentação alcoólica, ocupando a terceira posição em produção de cerveja, 
sendo as leveduras o segundo maior constituinte do resíduo gerado nesse segmento (Cervieri Júnior et al., 2017).

O levedo cervejeiro quando esgotado no processo fermentativo apresenta potencial em diversas áreas, como na produção de ração animal devido ao seu elevado teor proteico, na indústria biotecnológica para a produção de celulose, na indústria farmacêutica e até mesmo para fins mais nobres, como na biossorção de metais (Cervieri Júnior et al., 2017; Lin et al., 2013). Diante do exposto, este trabalho propôs avaliar a potencialidade da biossorção de Se (selenito de sódio) dissolvido em meio aquoso proveniente de biomassa microbiana descartada por uma indústria cervejeira da região de Joinville.

\section{Coleta e caracterização do biossorvente}

\section{MATERIAL E MÉTODOS}

A biomassa microbiana contida em efluente de indústria cervejeira foi disponibilizada por indústria da região de Joinville, SC. Durante um mês de produção, foram estimados os volumes de efluentes gerados para cada tipo de cerveja e quantificada a biomassa microbiana presente no efluente da cerveja de maior produção. $\mathrm{O}$ fermento residual escolhido como objeto de estudo foi o correspondente a cerveja de maior geração de efluente. A determinação da concentração microbiana (em massa seca) no efluente da cerveja selecionada foi determinada por gravimetria com base na norma ASTM E871-82 (ASTM, 2013).

\section{Preparo do biossorvente úmido}

$\mathrm{O}$ efluente da cerveja selecionada foi filtrado à vácuo e lavado com água deionizada. O retido foi transferido para frasco Duran graduado, adicionado de água deionizada até 1L e armazenado sob refrigeração para uso por posterior. A concentração de biomassa da suspensão em base seca foi determinada, de acordo com ASTM E871-82 (ASTM, 2013) e a partir do seu valor, estimou-se o volume da suspensão a ser utilizada em cada um dos ensaios de biossorção para atingir a concentração planejada.

\section{Preparo do biossorvente seco}

A biomassa retida no papel filtro foi tratada com etanol $70 \%$ e acondicionada, sob refrigeração à $6^{\circ} \mathrm{C}$, durante $24 \mathrm{~h}$. Em seguida, a mistura foi novamente filtrada e lavada para remoção de todo o etanol. A biomassa retida foi seca em estufa à $50{ }^{\circ} \mathrm{C}$ durante $48 \mathrm{~h}$ com posterior trituração, o farelo obtido foi mantido refrigerado até o uso. Após este tratamento, a biomassa microbiana apresentava um teor de umidade em torno de $15 \%$ (determinada em base úmida, conforme norma ASTM E871-82).

\section{Preparo da solução-estoque de selênio}

Três diferentes concentrações de Se (sorbato) no meio reacional foram planejadas para os ensaios de biossorção: 7,5, 22,5 e $30 \mathrm{mg} \mathrm{L}^{-1}$. Essas concentrações foram obtidas a partir da diluição de alíquotas de uma solução-estoque aquosa de selenito de sódio $\left(\mathrm{Na}_{2} \mathrm{SeO}_{3}\right)$ no meio reacional contendo o biossorvente. A soluçãoestoque foi preparada a partir da diluição de $1000 \mathrm{mg}$ de $\mathrm{Na}_{2} \mathrm{SeO}_{3} 98 \%$ (produto comercial Incasa, lote 112033/17) em $1000 \mathrm{~mL}$ de água deionizada.

\section{Ensaios de biossorção}

Os ensaios foram realizados em duplicata, a $120 \mathrm{~min}^{-1} \mathrm{em}$ agitador orbital a $30{ }^{\circ} \mathrm{C}$ durante $48 \mathrm{~h}$. Foram realizados doze ensaios de biossorção, cada qual contendo nove frascos Erlenmeyer de $500 \mathrm{~mL}$ com $200 \mathrm{~mL}$ de meio reacional (solução de $\mathrm{Na}_{2} \mathrm{SeO}_{3}+$ biossorvente + água). Os ensaios realizados estão mostrados na Tabela 1. Todas as concentrações de BS e BU foram expressas em base de massa seca. As concentrações utilizadas de A e B dos ensaios seguiram os valores propostos nos estudos de Zator (2017) e Khakpour et al. (2014). Após o preparo do meio reacional mostrado na Tabela 1, o pH da mistura A+B, foi ajustado para 4,5 com ácido clorídrico $1 \mathrm{M}$ antes de ser acondicionado no agitador para reação.

\section{Análise estatística}

Os resultados referentes à eficiência $(R)$ e capacidade microbiana de biossorção $(Y)$ foram analisados pelo teste F para p $<0,05$ empregando o programa computacional Excel ${ }^{\circledR}$ (2010). Quando p-valor for menor que o nível de significância escolhido, assumiu-se a desigualdade das variâncias, caso contrário, foi considerada que as variâncias são constantes ou homogêneas. 


\section{RESULTADOS E DISCUSSÃO}

A partir do levantamento feito nos registros internos da empresa que forneceu a biomassa microbiana empregada como biossorvente, estimou-se uma geração de $0,0685 \mathrm{~L}$ de efluente por L de cerveja Pilsen produzida. A caracterização desse resíduo indicou um $\mathrm{pH}$ médio de 5,5 $\pm 0,2$ com uma concentração média da biomassa microbiana (em massa seca) de $97,3 \pm 4,9 \mathrm{~g} \mathrm{~L}^{-1}$, sendo possível estimar uma disponibilidade anual de biomassa residual para aproveitamento como biossorvente de cerca de 17,5 t. A biomassa após a secagem apresentou configuração rígida caramelizada devido a açúcares remanescentes da fermentação, com formação de aglomerados irregulares e pontiagudos (Figura 1a), com a trituração o biossorvente se tornou mais homogêneo com formato circular de, aproximadamente, $1 \mathrm{~mm}$ de diâmetro (Figura 1b).

Observa-se na Figura 2 que todos os ensaios apresentaram redução na concentração inicial de Se na solução. Utilizando o biossorvente seco observa-se que os melhores resultados em eficiência de biossorção de Se (R\%) foram obtidos em ES1 $(88,37 \%)$ e ES2 $(65,11 \%)$. Já, ao utilizar biossorvente úmido 96,16\% de eficiência foram obtidos em ES7, 94,26\% em ES11 e 97,52\% em ES12. Para reduzir maiores concentrações de Se, ao se utilizar o biossorvente seco, pode-se optar pelo experimento ES2 e ao se utilizar o biossorvente úmido, o ensaio ES11 se torna mais apropriado, pois os dois casos removem maiores concentrações de Se utilizando menor concentração de biossorvente (Tabela 1).

Para Gadd (2013) quando a quantidade de A a ser removido é aumentada em relação à massa de B, maior a eficiência. No presente estudo, não foi possível observar esta afirmação, pois na maior proporção da concentração entre A e B (ES4 e ES10) não se alcançou os melhores resultados. Khakpour et al. (2014) comprovaram esta interdependência propondo como modelo uma equação de pseudo-segunda ordem onde $\mathrm{A}$ e B foram considerados os responsáveis pelo mecanismo predominante da reação (interação entre A e B) e a condição para a quimissorção do selênio nas células foi indicada como a etapa limitadora que controla a taxa de biossorção do processo. As melhores eficiências de biossorção (R) foram obtidas nos ensaios de maior concentração de biossorvente, devido a maior disponibilidade de sítios ativos para a interação.

O comportamento do biossorvente seco na concentração de $2,0 \mathrm{~g} \mathrm{~L}^{-1}$ foi bem diferente daquele evidenciado por Khakpour et al. (2014). Para os autores, essa quantidade de biomassa foi suficiente para absorver até $88 \%$ do selênio inicial $\left(\mathrm{Se}_{0}=50 \mathrm{mg} \mathrm{L}^{-1}\right)$. Essa discrepância pode ter ocorrido pelo fato dos autores terem utilizado fermento comercial recém cultivado como biossorvente e não biomassa microbiana residual de indústria cervejeira como a utilizada neste trabalho.

\section{CONCLUSÃO}

A biomassa microbiana residual gerada por indústria cervejeira apresentou potencial para uso como biossorvente de selênio, podendo ser utilizada como coadjuvante no tratamento de efluente de indústria química da região de Joinville que possui um residual de selênio em torno de $30 \mathrm{mg} \mathrm{L}^{-1}$.

Comparando os melhores resultados, verificou-se que a utilização do fermento residual de cervejas na forma úmida (sem pré-tratamento químico e secagem) possibilitou eficiência na biossorção de Se assim como o mesmo tipo de biossorvente previamente tratado e seco. Para reduzir maiores concentrações de Se, ao se utilizar o biossorvente seco, pode-se optar pelo experimento com 22,5 mg.L.-1 de A (Se) e 17,5 g.L $\mathrm{L}^{-1}$ de B ( $S$. cerevisiae) e ao utilizar o biossorvente úmido, o ensaio ES11 (30 mg. $\mathrm{L}^{-1}$ de A e 24 g.L $\mathrm{L}^{-1} \mathrm{de}$ B) se torna mais apropriado maiores concentrações de Se são removidas utilizando-se menor concentração de biossorvente.

O fermento residual de cervejas pode ser utilizado, então, como um tratamento primário, que anteceda algum outro método convencional de remoção de metais, reduzindo custos e aumentando sua eficiência.

\section{REFERÊNCIAS}

AMERICAN SOCIETY FOR TESTING AND MATERIALS. ASTM E871-82: Standard Test Method for Moisture Analysis of Particulate Wood Fuels, West Conshokocken, PA, 2013.

CERVIERI JÚNIOR, Osmar. Panoramas setoriais 2030: bebidas. In: Panoramas setoriais 2030: desafios e oportunidades para o Brasil. Rio de Janeiro: Banco Nacional de Desenvolvimento Econômico e Social, 2017. p.69-78.

KHAKPOUR, H., YOUNESI, H., MOHAMMADHOSSEINI, H., Two-stage biosorption of selenium from aqueous solution using dried biomass of the baker's yeast Saccharomuyces cerevisae. Journal of Environmental Chemical Engineering, v. 2, p. 532-542, 2014. 
LIN, D.; SANCHEZ, P. L.; LI, R.; LI, Z. Production of bacterial cellulose by Gluconacetobacter hansenii CGMCC 3917 using only waste beer yeast as nutrient source. Bioresource Technology, v. 151, p. 113-119, 2013.

SANTA CATARINA (ESTADO). Decreto $\mathbf{n}^{\mathbf{0}}$ 14.250, de 5 de junho de 1981. Disponível em: <http://www.pge.sc.gov.br/index.php/legislacao-estadual-pge>. Acesso em: 14 jun de 2018.

TAN, J.; ZHU, W.; WANG, W.; LI, R.; HOU, S.; WANG, D.; YANG, L. Selenium in soil and endemic diseases in China.The Science of the Total Environment, China, v. 284, p. 227-235, 2002.

TWIDWELL, L. G; BEAM, C. W. Potencial Technologies for Removing Thallium from Mine and Process Wastewater: An Abbreviated Annotation of the Literature. The European Journal of Mineral Processing and Environmental Protection, vol. 2, n. 1, p. 1-10, 2002.

ZATOR, F. Avaliação da potencialidade de biossorção inativa de selênio por biomassa microbiana descartada de indústria cervejeira. 20f. Trabalho de conclusão de curso (Bacharel em Engenharia Química) - Universidade da Região de Joinville, Joinville, 2017.

Tabela 1. Ensaios realizados com diferentes concentrações de selênio (sorbato (A)) e de biomassa microbiana (em massa seca) proveniente de indústria cervejeira (biossorvente (B)) conduzidos a $30^{\circ} \mathrm{C}$ e $\mathrm{pH}$ 4,5 com biomassa na forma de biossorvente seco (BS) e biossorvente úmido (BU)

\begin{tabular}{lcc}
\hline Ensaio & A & B \\
\hline ES1 BS e ES7 BU & 7,5 & 52,5 \\
ES2 BS e ES8 BU & 22,5 & 17,5 \\
ES3 BS e ES9 BU & 22,5 & 2,0 \\
ES4 BS e ES10 BU & 30,0 & 2,0 \\
ES5 BS e ES11 BU & 30,0 & 24,0 \\
ES6 BS e ES12 BU & 30,0 & 52,5 \\
\hline
\end{tabular}
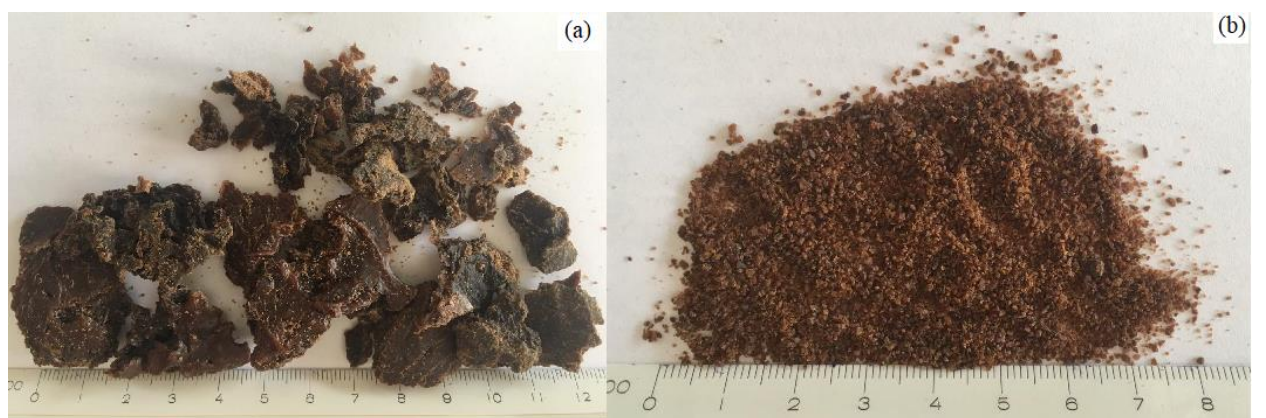

Figura 1. Biomassa microbiana de Saccharomyces cerevisiae após a secagem (a) e trituração (b).

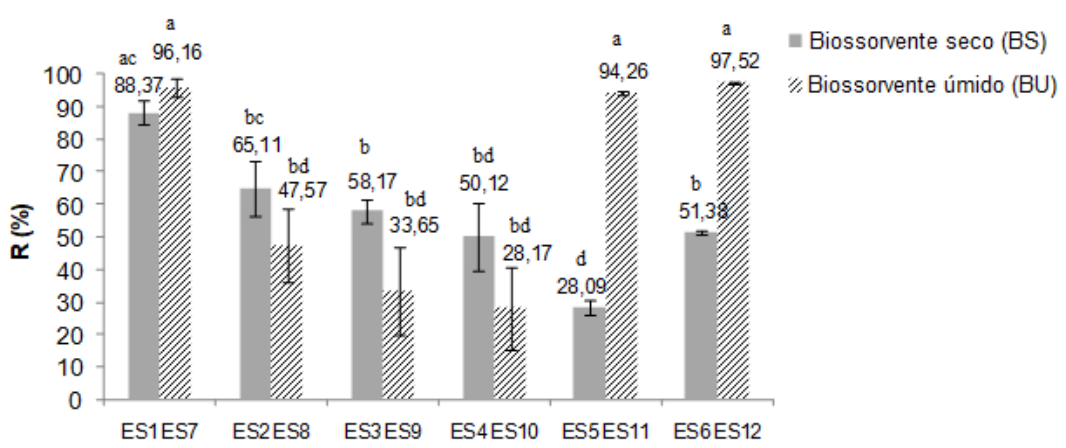

Figura 2. Valores médios \pm desvio padrão de eficiência (R) de biossorção de selênio com biossorvente seco (Ensaios ES1 a ES6) e com biossorvente úmido (Ensaios ES6, ES7 e ES9). Letras iguais representam médias sem diferença significativa pelo teste $F(p<0,05)$. 


\title{
CARACTERIZAÇÃO FÍSICO-QUÍMICA DE COMPOSTO PRODUZIDO COM FARINHA DE ANIMAIS MORTOS
}

\author{
Guidoni, L.L.C.* ${ }^{1}$; Martins, G.A. ${ }^{1}$; Sousa, A.R. ${ }^{1}$; Oliveira, V.F. ${ }^{1}$; Corrêa, L.B. ${ }^{1}$; Corrêa, E.K. ${ }^{1}$ \\ ${ }^{I}$ Núcleo de Ensino, Pesquisa e Extensão em Resíduos e Sustentabilidade. Universidade Federal de Pelotas, RS - Brasil. \\ lucaslcg@gmail.com
}

\begin{abstract}
RESUMO: O Brasil é um dos maiores consumidores e exportadores de carne suína no mundo. Como consequência o volume de resíduos e concentração de animais mortos demanda avançõs nas práticas de gerenciamento e destinação. Entre as alternativas e limitações dos sistemas utilizados atualmente, a reciclagem do cadáver animal por digestor, seguido de secagem e moagem, resulta em uma farinha inócuo do ponto de vista sanitário, para posterior destinação, como a produção de fertilizantes orgânicos através da compostagem. O objetivo desse trabalho foi avaliar a caracterização físico-química de fertilizante orgânico produzido através da compostagem com farinha de animais mortos. Uma mistura com farinha e composto imaturo, foi testada em duas pilha de compostagem de $20 \mathrm{~m}^{3}$, monitorada durante 120 dias com registro diário de temperatura. A mistura inicial e o produto final do processo foram analisados quanto ao teor de umidade, matéria orgânica, carbono orgânico, nitrogênio, fósforo, $\mathrm{pH}$ e condutividade elétrica. Como resultado, o composto final apresentou alto teor nutricional e caracteristicas de fertilizante organomineral. No entando, analises complementares são fundamentias para confirmar o grau de maturação do composto.
\end{abstract}

Palavras-chave: destinação de animais mortos, graxaria, compostagem, valorização de resíduos.

\section{PHYSICAL-CHEMICAL CHARACTERIZATION OF COMPOST PRODUCED WITH DEAD ANIMAL MEAL}

\begin{abstract}
Brazil is one of the largest consumers and exporters of swine meat in the world. As consequence, the waste volume and concentration of dead animals demand improvements in the management and destination practices. As an alternative to the limitations of the systems currently applied, rendering dead animal by digester, followed by drying and milling, results in a sanitary innocuous flour, for later destination, as production of organic fertilizers through composting. The objective of this work was to evaluate the physical-chemical characterization of organic fertilizer produced by composting with dead animal meal. It was prepared a mixture with meal and immature compost, in duplicate composting piles with $20 \mathrm{~m}^{3}$, monitored for 120 days by daily temperature record. The initial mixture and the final product of composting process were analyzed to moisture content, organic matter, organic carbon, nitrogen, phosphorus, $\mathrm{pH}$ and electrical conductivity. As a result, the final compound presented high nutritional content and characteristics of organomineral fertilizer. However, complementary analyzes are essential to confirm the degree of compost maturity.
\end{abstract}

Keywords: dead animals destination, rendering, composting, waste valorization.

\section{INTRODUÇÃO}

O Brasil atualmente abate 43 milhões de cabeça de suínos por ano, sendo o quinto maior consumidor e com perspectivas de suprir 44\% do mercado mundial de até 2020 (Lima et al, 2017). Por outro lado, nas etapas de produção ocorrem mortes dos animais devido a problemas ou causas naturais, que alcançam volume superior a 110.000 ton de carcaças de suíno/ano, dos quais aproximadamente $50 \%$ estão concentradas na região sul do país (Krabbe e Wilbert, 2016).

A produção intensiva de animais resulta em altas concentrações de animais em pequenas áreas, produzindo grandes quantidades de resíduos que levam a limitação da aplicação de práticas de destinação ou disposição usuais, devido ao risco a saúde humana e animal, emissões de atmosféricas, contaminação microbiana de solo e água e poluição de cursos d'água (Hidalgo et al, 2018).

Nesse contexto, iniciou em 2015 na Empresa Brasileira de Pesquisa Agropecuária (EMBRAPA) o projeto Tecnologias para destinação de animais mortos (TEC-DAM), que inclui nos planos de ação rotas que consideram a produção de farinhas de animais para posterior avaliação de alternativas, como a biodigestção 
anaeróbia, incineração, desidratação, compostagem, hidrólise e produção de fertilizantes organominerais (Krabbe e Wilbert, 2016).

Cabe salientar, diante da notória vocação agrícola do nosso país, a ampla possibilidade para reciclagem desses resíduos e posterior produção de fertilizante orgânico com alto teor de nutrientes, em busca da diminuição da forte dependência da agricultura nacional com a importação de fertilizantes inorgânicos industriais (Cruz et al, 2017).

Nesse cenário, mais investigações que confirmem a compostagem como alternativa viável e segura para valorização da farinha de animais mortos e seu potencial para produção de compostos orgânicos com alto teor de nutrientes devem ser conduzidas. O objetivo desse trabalho foi avaliar a caracterização físico-química de fertilizante orgânico produzido através da compostagem com farinha de animais mortos.

\section{MATERIAL E MÉTODOS}

O experimento foi conduzido na região sul do Brasil, em pátio de compostagem coberto e com piso impermeável. Foram utilizados farinha de animais mortos (FAM), proveniente de unidade piloto especifica de reciclagem (esterilização com temperatura e pressão, secagem e moagem) de cadáveres de suíno misturado com composto orgânico imaturo (COI). Esse composto foi produzido em processo prévio de compostagem, a partir de serragem de eucalipto com lodo adensado, proveniente de flotador de estação de tratamento de efluente de unidade de processamento de subproduto de proteína animal.

A proporção da mistura FAM:COI em volume foi 12:8 $\left(\mathrm{m}^{3}\right)$. As pilhas de $20 \mathrm{~m}^{3}$ cada, foram montadas com auxílio de pá carregadeira, com 1,6 m de altura e revolvimento semanal. O experimento foi conduzido com duas repetições, com duração de 120 dias (de agosto a novembro).

As amostras foram do tipo compostas, com 3 subamostras retiradas da parte centrais de cada pilha de compostagem ou monte de matéria prima, homogeneizadas, lacradas e encaminhadas para análise laboratorial. Os parâmetros físico-químicos foram analisados para matéria prima, para o material em compostagem no início do processo e para o fertilizante produzido ao final do período. As temperaturas das leiras e do ambiente foram registradas com termômetro digital durante todo o período do estudo.

Foram determinados fósforo total $(\mathrm{P})$ por espectrofotometria em UV-Visível $(660 \mathrm{~nm})$, teor de nitrogênio total (NTK) por micro-Kjeldhal, carbono orgânico total pelo método Walkley-Black com aquecimento e para o índice $\mathrm{pH}$ e condutividade elétrica (CE) foram utilizados equipamentos de bancada (Tedesco et al., 1995). O teor de umidade foi determinado por gravimetria em estufa à $105^{\circ} \mathrm{C}$ por $24 \mathrm{~h}$, e em seguida a secagem, as amostras passaram por combustão em forno mufla por $4 \mathrm{~h}$ a $550^{\circ} \mathrm{C}$, para determinação da matéria orgânica pelo inverso da matéria mineral (AOAC, 1995). Todas as análises foram realizadas em triplicata.

A normalidade dos dados foi verificada pelo teste de Shapiro-Wilk. Em caso de distribuição normal, foi realizado teste T para amostras dependentes (pareadas) em relação ao fator "tempo", com 95\% de intervalo de confiança, considerando a diferença entre as médias no início (dia 1) e no final do processo de compostagem (dia 120) significativa quando $\mathrm{p}<0,05$.

\section{RESULTADOS E DISCUSSÃO}

Na caracterização apresentada na Tabela 1, foi confirmado o potencial da FAM como matéria-prima de altos teores de NTK e P. O COI apresentou umidade de 50\%, considerada acima do limite para compostos estabilizados, funcionando no presente experimento principalmente para ajuste da umidade e agente estruturante da mistura.

A baixa relação $\mathrm{C} / \mathrm{N}$ de ambos os materiais e da mistura inicial, apresentada na Tabela 1, indicam que em caso de umidade elevada a emissão de amônia poderia ser um desafio ao longo do processo de compostagem. Normalmente, nos processos de compostagem de carcaças de animais são indicados relação C/N entorno de 25-30/1 para início do processo, em busca de um melhor desenvolvimento da microbiota e redução do tempo de decomposição (Won et al, 2016).

Apesar disso, a evolução da temperatura mostrada na Figura 1, evidencia fase termofílica com duração superior a 50 dias, o que indica bom desenvolvimento microbiano, eliminação de patógenos, controle de odores e de vetores.

Conforme Tabela 2, o teor de umidade no início da compostagem foi baixo e decaiu ao fim dos 120 dias $(\mathrm{p}<0,05)$, o que sugere baixa possibilidade de geração de lixiviado e redução da volatização de nitrogênio na forma de amônia. Isso pode ser reforçado pelo teor NTK, que apresentou valores superiores para o composto 
final produzido em relação a mistura inicial $(\mathrm{p}<0,05)$.

No dia 120, os teores de NTK e P somados foram superior a 10\%, o que confirma um composto orgânico com alto valor nutricional, podendo vir a ser equivalente a fertilizante organomineral, conforme Instrução Normativa 25 (Brasil, 2009). Por outro lado, a mineralização ao longo do processo de compostagem elevou os valores de $\mathrm{CE}(\mathrm{p}<0,05)$, o que pode ser limitante para aplicação no solo e uso em determinadas culturas vegetais, conforme destacado por Onwosi et al (2017).

Nesse sentido, para avaliação completa da qualidade final do composto devem ser conduzidos outros ensaios, para em conjunto dos parâmetros físico-químicos, indicar com maior exatidão o grau de maturação do fertilizante produzido (Qian et al, 2014).

\section{CONCLUSÃO}

O composto com farinha de animais mortos apresentou características de material estabilizado e teores de nitrogênio e fósforo correspondentes a um fertilizante organomineral.

A relação de nutrientes encaminhadas inicialmente a compostagem apresentou-se fora do ideal considerada para início do processo, porém o uso de farinha de animais mortos não comprometeu o desenvolvimento de microrganismos termofílicos e favoreceu os teores finais de nitrogênio.

No entanto, em conjunto com a caracterização físico-química, outros parâmetros devem ser determinados para poder afirmar o grau de maturação do fertilizante a ser aplicado ao solo.

\section{AGRADECIMENTOS}

O presente trabalho foi realizado com apoio da Coordenação de Aperfeiçoamento de Pessoal de Nível Superior - Brasil (CAPES).

\section{REFERÊNCIAS}

AOAC, OFFICIAL METHODS OF ANALYSIS OF AOAC INTERNACIONAL. 1995. v. 2, 17. ed. Gaithersburg - EUA: AOAC.

BRASIL. Ministério da Agricultura, Pecuária e Abastecimento. 2009. Instrução Normativa n²5, 23 de julho de 2009.

CRUZ, A. C.; PEREIRA, F. S.; FIGUEIREDO, V. S. 2017. Fertilizantes organominerais de resíduos do agronegócio: avaliação do potencial econômico brasileiro. Indústria química. BNDS Setorial, pp. 137-187. HIDALGO, D.; MARTÍN-MARROQUÍN, J.M.; CORONA, F. 2018. The effect of feed composition on anaerobic co-digestion of animal-processing by-products. Journal of Environmental Management, v. 216, pp.105-110.

KRABBE, E. L. E WILBERT, C. A. 2016. Os passivos das cadeias de produção de proteína animal - animais mortos. Avicultura Industrial, Estudos da Embrapa. $\mathrm{N}^{\circ} 01$, ed 1251.

LIMA, G. J. M. M.; NOCOLOSO, R. S.; KRABBE, E. L. 2017. Uso de animais mortos na fabricaçao de farinhas de origem animal: vale a pena correr riscos? Revista Reciclagem Animal, Graxaria Brasileira. Ed 56.

QIAN, X.; SHEN, G.; WANG Z.; GUO, C.; LIU, Y.; LEI, Z.; ZHANG, Z. 2014. Co-composting of livestock manure with rice straw: Characterization and establishment of maturity evaluation system. Waste Management, v. 34, n. 2, pp. 530-535.

TEDESCO, J.M.; GIANELLO, C.; BOHNEM, H.; VOLKWEISS, S.J. 1995. Análises de solo, plantas e outros materiais. Faculdade de Agronomia Universidade Federal do RS, 2ed.

ONWOSI, C. O., IGBOKWE, V. C., ODIMBA, J. N., EKE, I. E., NWANKWOALA, M. O., IROH, I. N., EZEOGU, L. I. 2017. Composting technology in waste stabilization: On the methods, challenges and future prospects. J. Environ. Manage. v.190, pp. 140-157.

WON, S. G.; PARK, J. Y.; RAHMAN, M. M.; PARK, K. Y.; RA, C. S. 2016. Co-composting of swine mortalities with swine manure and sawdust. Compost Science \& Utilization, v. 24:1, pp.42-53. 
Tabela 1. Parâmetros físico-químicos da matéria prima encaminhada para processo de compostagem.

\begin{tabular}{lcc}
\multicolumn{1}{c}{ Parâmetro } & Composto imaturo & Farinha de animais mortos \\
\hline Teor de umidade $(\%)$ & $49,66 \pm 4,14$ & $7,45 \pm 0,46$ \\
Nitrogênio total kjeldahl* $(\%)$ & $2,56 \pm 0,02$ & $8,86 \pm 0,39$ \\
Relação Carbono:Nitrogênio & 16,9 & 4,3 \\
pH & $6,77 \pm 0$ & $6,65 \pm 0,06$ \\
Condutividade elétrica $\left(\mu \mathrm{S} \mathrm{cm}^{-1}\right)$ & $3.493,3 \pm 98,65$ & $2.900,0 \pm 17,32$ \\
Fósforo total* $(\%)$ & $1,94 \pm 0,11$ & $3,64 \pm 0,60$ \\
\hline
\end{tabular}

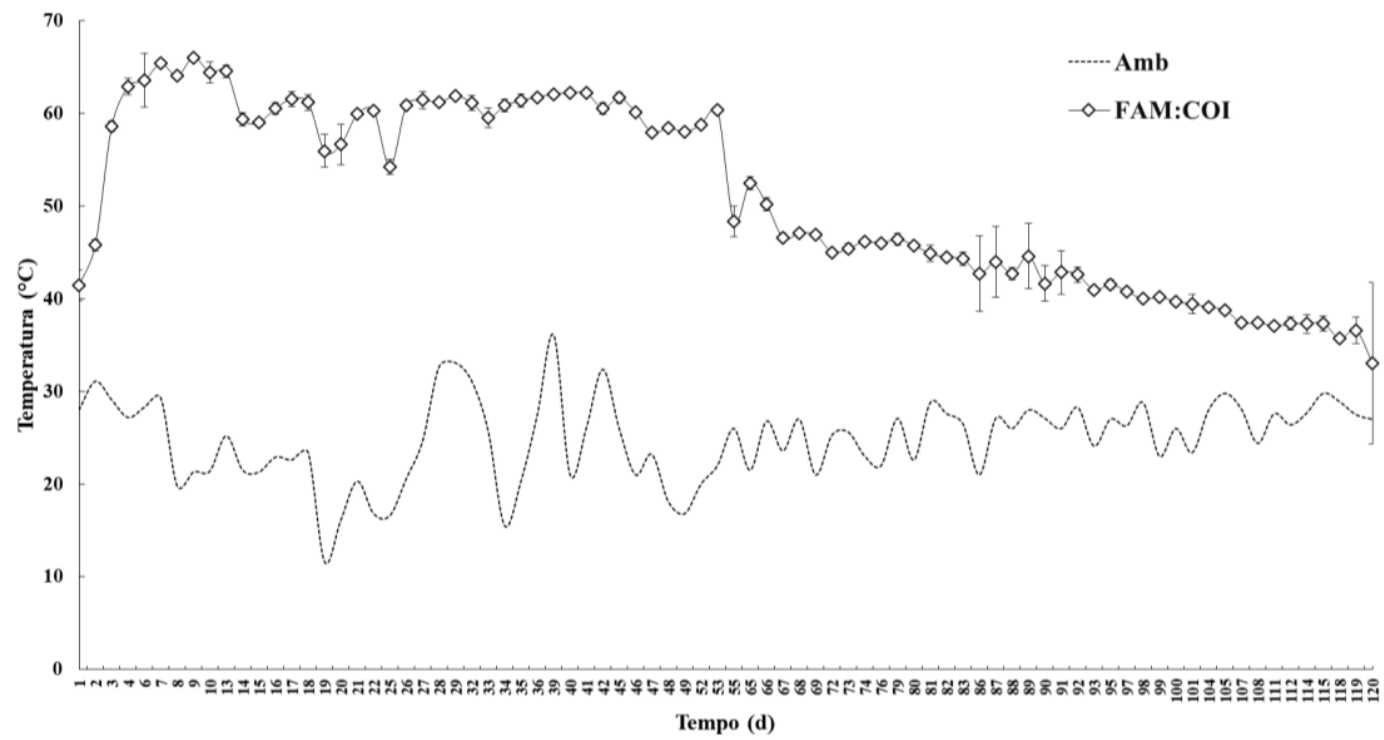

Figura 1. Evolução da temperatura das pilhas de compostagem com farinha de animais mortos (FAM) e composto imaturo (COI).

Tabela 2. Caracterização físico-química da mistura inicial da compostagem e do composto final.

\begin{tabular}{|c|c|c|}
\hline Parâmetro & Mistura inicial (Dia 1) & Composto final (Dia 120) \\
\hline Teor de umidade $(\%)$ & $38,60 \pm 0,08 \mathrm{a}$ & $22,92 \pm 0,21 b$ \\
\hline Matéria orgânica* (\%) & $90,57 \pm 2,26 \mathrm{~ns}$ & $86,49 \pm 2,17$ \\
\hline Carbono orgânico total* $(\%)$ & $49,25 \pm 0,16 a$ & $39,55 \pm 0,6 b$ \\
\hline Nitrogênio total kjeldahl* (\%) & $5,37 \pm 0,83 \mathrm{~b}$ & $6,86 \pm 0,03 \mathrm{a}$ \\
\hline Relação Carbono:Nitrogênio & $8,97 \pm 1,09 \mathrm{a}$ & $5,73 \pm 0,35 b$ \\
\hline $\mathrm{pH}$ & $7,50 \pm 0,09 \mathrm{~ns}$ & $7,50 \pm 0,06$ \\
\hline Condutividade elétrica $\left(\mu \mathrm{S} \mathrm{cm}^{-1}\right)$ & $3.367 \pm 207 b$ & $4.950 \pm 318 \mathrm{a}$ \\
\hline Fósforo total* $(\%)$ & $3,87 \pm 0,07 \mathrm{a}$ & $3,19 \pm 0,09 \mathrm{~b}$ \\
\hline
\end{tabular}

Médias seguidas por letras $(a, b)$ diferentes na mesma linha apresentaram diferença significativa entre elas $(\mathrm{p}<0,05)$. ns - não houve diferença significativa. *Base seca 


\title{
COMPOSTAGEM AUTOMATIZADA DE RESÍDUOS DA AGROINDÚSTRIA FRIGORÍFICA
}

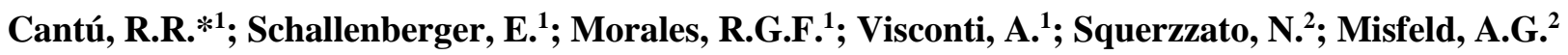

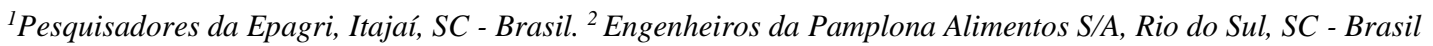 \\ rrcantu@epagri.sc.gov.br
}

\begin{abstract}
RESUMO: Os setor agroindustrial de Santa Catarina, possui elevada importância socioeconômica. Apesar disso, geram elevados volumes de resíduos, que quando não tratados, ocasionam sérios problemas ambientais. Esses materiais podem ser transformados em fertilizantes para uso em cultivos agrícolas. A compostagem automatizada pode viabilizar o manejo de grandes volumes de resíduos com elevados teores de umidade, como os gerados por frigoríficos. Assim, o objetivo do trabalho foi avaliar a viabilidade da compostagem automatizada desses materiais, com diferentes misturas. Os materiais eram, resíduo do frigorífico (RF), da criação de suínos (RS), ração (RA) e cinzas (RC) e pó de rocha (RP). Os tratamentos foram: T1- 49\% de RS+ $49 \%$ de RF $+1 \%$ de RA/RC; T2- 39,5\% de RS + 59,5\% de RF + $1 \%$ de RA/RC; $\mathrm{T} 3-38,5 \%$ de RS + 58,5\% de $\mathrm{RF}+1 \%$ de RA/RC + 2,5\% de RP; $\mathrm{T} 4-36 \%$ de $\mathrm{RS}+56 \%$ de RF $+1 \%$ de RA/RC + 5\% de RP; T5- 33,5\% de $\mathrm{RS}+53,5 \%$ de $\mathrm{RF}+1 \%$ de RA/RC $+10 \%$ de RP. Os resíduos foram distribuídos em leiras por caminhões e tratores, e manejados com uma máquina automatizada. Foram avaliadas as temperaturas das misturas durante a compostagem e a composição química do composto produzido. A temperatura atingiu em todo as misturas patamares desejáveis $\left(70^{\circ} \mathrm{C}\right)$ à um bom processo e as composições químicas dos compostos, atendem as exigências do MAPA. A compostagem automatizada dos resíduos de frigoríficos é viável, produzindo um fertilizante com características adequadas para o uso.
\end{abstract}

Palavras-chave: composto orgânico, fertilizante, temperatura

\section{AUTOMATED COMPOSTING OF AGROINDUSTRIAL WASTE}

\begin{abstract}
The agroindustrial sectors of Santa Catarina are of high socioeconomic importance. Nevertheless, they generate high volumes of waste, which when left untreated can cause serious environmental problems. These materials can be transformed into fertilizers for use in agricultural crops. Automated composting can enable the management of large volumes of waste with high moisture content, such as those generated by agroindustrial. Thus, the objective of the work was to evaluate the viability of the automated composting of these materials, with different mixtures. The materials were: agroindustrial residue (RF), pig rearing (RS), ration (RA) and ash (RC) and rock dust (RP). The treatments were: $\mathrm{T} 1-49 \%$ de $\mathrm{RS}+49 \%$ de RF $+1 \%$ de RA/RC; T2- 39,5\% de RS + 59,5\% de RF + $1 \%$ de RA/RC; T3- $38,5 \%$ de RS + 58,5\% de RF + $1 \%$ de RA/RC + 2,5\% de RP; T4- 36\% de RS + 56\% de RF + $1 \%$ de RA/RC + 5\% de RP; $\mathrm{T} 5-33,5 \%$ de RS + $53,5 \%$ de $\mathrm{RF}+1 \%$ de RA/RC $+10 \%$ de RP.. The residues were distributed in lines by trucks and tractors, and handled with an automated machine. The temperatures of mixtures during composting and the chemical composition of compost produced were evaluated. The temperature reached throughout the mixtures desirable levels $\left(70^{\circ} \mathrm{C}\right)$ to a good process and the chemical compositions of the compost, meet the requirements of MAPA. The automated composting of agroindustrial waste is feasible, producing a fertilizer with characteristics suitable for use.
\end{abstract}

Keywords: organic compost, fertilizer, temperature

\section{INTRODUÇÃO}

Santa Catarina se destaca pela forte presença dos setores agropecuário e agroindustrial, que possuem elevada importância socioeconômica, sendo responsável por aproximadamente $60 \%$ das exportações do Estado e envolvendo mais de 400 mil famílias. Apesar da relevância, os setores geram elevados volumes de resíduos, que quando não tratados, podem ocasionar sérios problemas ambientais. Esses materiais podem ser transformados em fertilizantes de elevada qualidade para cultivos como os de hortaliças, que possuem grande relevância para a agricultura de SC (Cantú et al. 2016; Santos et al. 2016). 
A Região do Vale do Itajaí - SC tem tradição na agroindústria frigorífica, possuindo diversos empreendimentos (Santos et al. 2016). Somente de um desses empreendimentos geram um volume em torno de $350 \mathrm{Mg}$ mês $^{-1}$ de resíduos, provenientes de frigoríficos localizados nos municípios de Rio do Sul e Presidente Getúlio e da criação de suínos. Esses resíduos eram destinados na maioria a aterros sanitários e o restante aplicados áreas de pastagens e reflorestamento, após um período de estabilização em sistemas de decantação a céu aberto. Considerando os custos de destino desses resíduos e a preocupação com sustentabilidade ambiental, foi firmado no ano de 2017 uma parceria entre a Epagri e uma Agroindústria Frigorífica, para viabilizar o tratamento dos materiais por meio da compostagem automatizada.

A compostagem automatizada possui inúmeras vantagens por viabilizar o manejo de grandes volumes de resíduos com elevados teores de umidade. A automação do processo, promove a decomposição aeróbica, que além de ser mais eficiente na transformação dos materiais orgânicos em substâncias húmicas, eleva a temperatura eliminando contaminantes microbiológicos, reduz a emissão de gases de efeito estufa e o mal cheiro (Bernal et al. 2009; Cantú et al. 2016; Cantú et al. 2017).

Considerando os aspectos aqui abordados, o objetivo do trabalho foi realizar um estudo sobre formulações de misturas de resíduos de frigorífico, para avaliar a viabilidade da compostagem automatizada desses materiais.

\section{MATERIAL E MÉTODOS}

O trabalho foi desenvolvido na unidade de compostagem automatizada Lauro Pamplona localizada no município de Trombudo Central - SC, localidade de Pouso da Caixa, no período de 30 de outubro de 2017 a 30 de janeiro de 2018. Os resíduos foram provenientes dos frigoríficos, localizados em Rio do Sul e Presidente Getúlio, das criações de suínos de granjas localizadas em Ituporanga e Rio do Sul e da fábrica de rações localizada em Agronômica, todos pertencentes ao mesmo empreendimento agroindustrial.

Os resíduos dos frigoríficos (RF) eram principalmente material dos aparelhos digestivos do abate de suínos e também bovinos, entre outros rejeitos provenientes desse processo. Os resíduos das granjas de criação de suínos (RS) eram dejetos líquidos suínos misturados a um leito de serragem e maravalha. Outros resíduos em menor proporção eram das fábricas de ração (RA), e cinzas de caldeira (RC) provenientes da queima de madeira utilizadas na geração de energia para os frigoríficos. Foi avaliado também a mistura de resíduo (pó) de mineradoras de ardósia (RP), abundante na região.

Foram avaliadas cinco misturas de resíduos em diferentes proporções entre os materiais (Tabela 1), constituindo os seguintes tratamentos: $\mathrm{T} 1-49,5 \%$ de $\mathrm{RS}+49,5 \%$ de RF + 0,5\% de RA+ 0,5\% de RC; $\mathrm{T} 2-$ $39,5 \%$ de $\mathrm{RS}+59,5 \%$ de $\mathrm{RF}+0,5 \%$ de $\mathrm{RA}+0,5 \%$ de $\mathrm{RC} ; \mathrm{T} 3-38,5 \%$ de $\mathrm{RS}+58,5 \%$ de $\mathrm{RF}+0,5 \%$ de $\mathrm{RA}+$ $0,5 \%$ de $\mathrm{RC}+2,5 \%$ de RP; $\mathrm{T} 4-36 \%$ de $\mathrm{RS}+56 \%$ de $\mathrm{RF}+0,5 \%$ de $\mathrm{RA}+0,5 \%$ de $\mathrm{RC}+5 \%$ de $\mathrm{RP} ; \mathrm{T} 5-33,5 \%$ de $\mathrm{RS}+53,5 \%$ de $\mathrm{RF}+0,5 \%$ de RA $+0,5 \%$ de RC $+10 \%$ de RP. A tomada de decisão para a elaboração das misturas foi uma razão da proporção que os RF eram gerados, com a disponibilidade dos RS, RA e RC, considerando a relação $\mathrm{C} / \mathrm{N}$ dos materiais e seus os teores de umidade. $\mathrm{O}$ RP foi adicionado em proporções crescentes para verificar o efeito na compostagem.

Os resíduos foram distribuídos e misturados com caminhões e trator com concha, em compartimentos (duas paredes paralelas de alvenaria) de 1,5 m de altura por 4,0 m de largura e $95 \mathrm{~m}$ de comprimento. A leira de compostagem (mistura de materiais) foi montada de uma extremidade à outra, avançando 25 m por semana, sendo que em 25 dias ocupava todo o compartimento. A leira era continuadamente revolvida desde seu início por uma máquina autopropulsionada que revolve a mistura com helicoides, se deslocando sobre a pilha da compostagem. A máquina se movimentava sobre as paredes laterais dos compartimentos, diariamente até a montagem completa da leira $(95 \mathrm{~m})$ e após, três vezes por semana até o final do processo automatizado.

Após três meses do início da compostagem, quando a temperatura começou a declinar o material compostado foi retirado do compartimento automatizado e depositado no compartimento para depósito. Nesse local, não houve revolvimento do material, e após mais dois meses, o composto foi considerado pronto para o uso. A tomada de decisão para finalização do processo foi devido às características do composto relacionadas a relação $\mathrm{C} / \mathrm{N}$, igual ou abaixo de 15 (Tabela 2), além da temperatura do fertilizante declinar próxima à do ambiente, que indicam a estabilidade do material. 
Foram avaliados a composição química inicial da mistura de resíduos e a composição final do composto produzido. Além disso, foram avaliados a temperatura das pilhas de compostagem durante o período com revolvimento automatizado (três meses) com termômetros digitais. Os resultados das características químicas foram submetidos a análise de variância e ao teste de separação de médias (Sisvar 5.6) e as temperaturas foram submetidas a análises de regressão.

\section{RESULTADOS E DISCUSSÃO}

Considerando a evolução da temperatura no decorrer das compostagens (Figura 1) é possível inferir que ocorreu um processo adequado de transformação microbiológica dos resíduos em todos os tratamentos. Isso porque, quando as condições estão ideais é possível notar um aumento gradual da temperatura logo no início do processo, atingindo a fase termofílica (acima de $45^{\circ} \mathrm{C}$ ), logo após os 10 primeiros dias e ultrapassando os $60{ }^{\circ} \mathrm{C}$ após 30 dias (Bernal et al., 2009; Cantú et al., 2016). Em todos os tratamentos, as dinâmicas das temperaturas foram bastante semelhantes, indicando que todas as misturas podem ser compostadas adequadamente, conforme discutido por Bernal et al., (2009).

A fase termofílica se estendeu por um longo período, atingindo o pico próximo aos 50 dias (Figura 1). Essa duração está dentro do esperado, que varia conforme a composição dos materiais utilizados (Bernal et al., 2009; Cantú et al., 2016). Após aproximadamente os 50 dias do início do processo, a temperatura começa a declinar, sendo isso atribuído à diminuição da atividade microbiológica (Cantú et al., 2016). Esse aspecto se deve possivelmente, pelo do esgotamento do carbono mais lábil utilizado pelos microrganismos (Bernal et al., 2009; Cantú et al., 2016). Ao final do processo automatizado, as temperaturas declinaram para abaixo de 50 ${ }^{\circ} \mathrm{C}$. Após esse processo e mais dois meses de armazenamento, os compostos atingiram temperatura mais próxima à do ambiente, com $38^{\circ} \mathrm{C}$ em média.

Observando as composições químicas dos compostos produzidos (Tabela 2), é possível observar que todos os tratamentos atenderam as exigências do Ministério da Agricultura e Pecuária - MAPA / IN SDA no 72016. Os compostos para serem registrado no referido órgão, devem apresentar $\mathrm{pH}$ acima de 6 , teores de $\mathrm{N}$ acima de $0,5 \%$, relação $\mathrm{C} / \mathrm{N}$ abaixo de 20 e umidade abaixo de $50 \%$. Apenas o $\mathrm{T} 5$ proporcionou um composto com $\mathrm{pH}$ 5,9 , estando muito próximo ao limite.

A redução do pH observada no T4 e T5 deve estar relacionado a crescente adição do RP nesses tratamentos, considerando que esse aspecto foi a única diferença entre as composições de T2, T3, T4 e T5. Por outro lado, a adição das doses crescentes de RP proporcionou aumento nos teores de $\mathrm{K}$ e Ca no composto final. Esse aspecto, conforme Alves et al. (2013), deve estar aos elevados teores desses elementos no RP (Tabela 2), que embora refratários, tiveram a sua solubilização possivelmente potencializada pelo processo de compostagem com elevada atividade microbiológica.

Apesar da compostagem dos resíduos provenientes da agroindústria frigorífica e da criação de suínos ter se desenvolvido adequadamente, é importante para cada situação identificar os materiais e testar misturas para os casos específicos. Isso porque, conforme Bernal et al. (2009), diferentes resíduos proporcionam mudanças no desenvolvimento da atividade microbiológica durante a compostagem e assim, manejos como proporções de misturas, revolvimento, adição de umidade, devem ser estudados em cada caso. Em relação a adição de pó de ardósia na compostagem, embora tenha havido incremento de nutrientes como $\mathrm{K} \mathrm{e} \mathrm{Ca}$, mais estudos devem ser realizados.

\section{CONCLUSÃO}

A compostagem automatizada de resíduos da agroindústria frigorífica e da criação de suínos, atinge os critérios de um sistema considerado eficiente, produzindo o composto orgânico com características promissoras de um fertilizante de elevada qualidade para o uso em cultivos, estando de acordo com as normas exigidas pelo MAPA.

\section{REFERÊNCIAS}

ALVES, J.M; SOUZA, F.W.S; SANTOS, C.C; SILVA, M.H; SANTANA, A.P. Produção de fertilizante organomineral a partir de resíduos agroindustriais e rejeitos minerais. Anais II Congresso Brasileiro de Rochagem, Poços de Caldas, 2013. 339 p.

BERNAL, M.P.; ALBURQUERQUE, J.A.; MORAL, R. Composting of animal manures and chemical criteria for compost maturity assessment. A review. Bioresource Technology, v. 100, p. 5444-5453, 2009. 


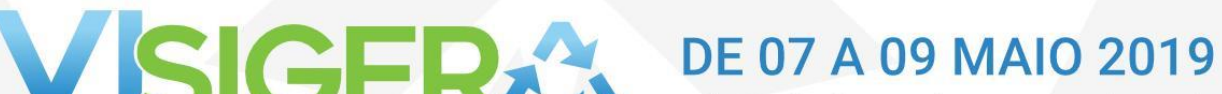

CANTU, R.R. et al Dinamica da temperatura na compostagem de residuos da industria do palmito, Revista Brasileira de Agroecologia: In: Cadernos de agroecologia, 2016.

CANTÚ, R.R; AITA, C; DONEDA, A, GIACOMINI, D.A; DESSBESELL, A; ARENHARDT, M; BASTIANI, G.G; PUJOL, S.B; ROCHETE, F; CHANTIGNY, M.H; GIACOMINI, S. 2017. Alternatives to regular urea for abating $\mathrm{N}$ losses in lettuce production under sub-tropical climate. Biology and Fertility of Soils. 53: 589-599.

SANTOS, A.A.; FELICIANO, A.M.; PADRAO, G.A. In: Feliciano, A.M. (Coord.). Números da Agropecuaria Catarinense. Florianopolis: Epagri/Cepa, 2016. 69 p.

Tabela 1. Principais características dos resíduos utilizados na compostagem automatizada.

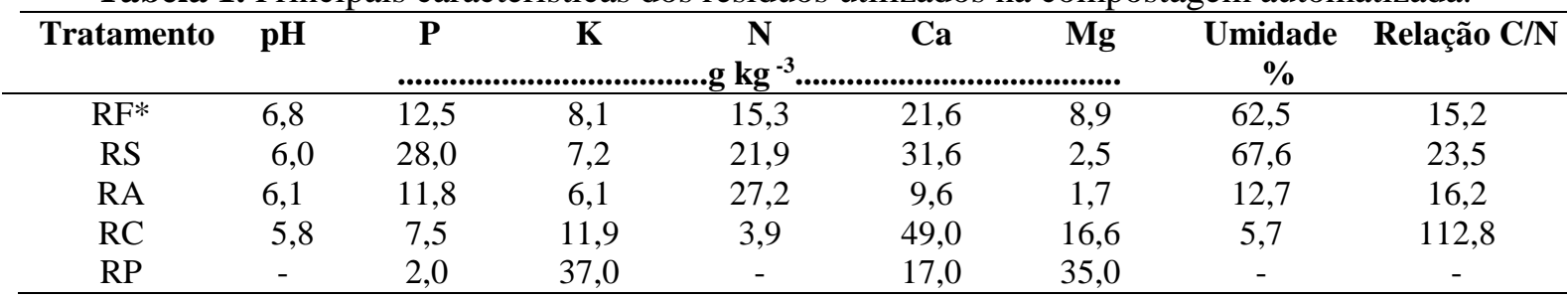

* os tratamentos são compostos obtidos com diferentes proporções de resíduos de frigorífico e da criação de suínos.

Tabela 2. Principais características dos compostos obtidos com diferentes proporções de resíduos.

\begin{tabular}{|c|c|c|c|c|c|c|c|c|}
\hline Tratamento & $\mathbf{p H}$ & $\begin{array}{c}\mathbf{P} \\
\ldots \ldots \ldots . . . . \\
\end{array}$ & $\mathbf{K}$ & $\begin{array}{c}\mathrm{N} \\
\mathrm{g} \mathrm{kg}^{-3} . .\end{array}$ & Ca & $\begin{array}{c}\text { Mg } \\
\ldots \ldots \ldots . . . .\end{array}$ & $\begin{array}{c}\text { Umidade } \\
\%\end{array}$ & Relação C/N \\
\hline $\mathrm{T} 1 *$ & $7,1 \mathrm{a}$ & $20,0 \mathrm{a}$ & $7,5 \mathrm{~b}$ & $23,0 \mathrm{a}$ & $22,0 \mathrm{a}$ & $7,0 \mathrm{a}$ & $25,1 \mathrm{a}$ & $14,0 \mathrm{a}$ \\
\hline $\mathrm{T} 2$ & $6,8 \mathrm{ab}$ & $20,0 \mathrm{a}$ & $7,0 \mathrm{~b}$ & $22,0 \mathrm{a}$ & $16,0 \mathrm{c}$ & $6,0 \mathrm{a}$ & $23,3 \mathrm{a}$ & $14,5 \mathrm{a}$ \\
\hline T3 & $7,0 \mathrm{a}$ & $19,0 \mathrm{a}$ & $7,8 \mathrm{ab}$ & $22,5 \mathrm{a}$ & $18,0 \mathrm{bc}$ & $7,0 \mathrm{a}$ & $24,0 \mathrm{a}$ & $14,5 \mathrm{a}$ \\
\hline $\mathrm{T} 4$ & $6,3 \mathrm{bc}$ & $18,0 \mathrm{a}$ & $7,8 \mathrm{ab}$ & $20,0 \mathrm{a}$ & $21,0 \mathrm{ab}$ & $7,0 \mathrm{a}$ & 27,9 a & $15,0 \mathrm{a}$ \\
\hline T5 & $5,9 \mathrm{c}$ & $20,0 \mathrm{a}$ & $9,4 \mathrm{a}$ & $21,0 \mathrm{a}$ & $23,0 \mathrm{a}$ & $7,0 \mathrm{a}$ & $25,0 \mathrm{a}$ & $15,1 \mathrm{a}$ \\
\hline
\end{tabular}

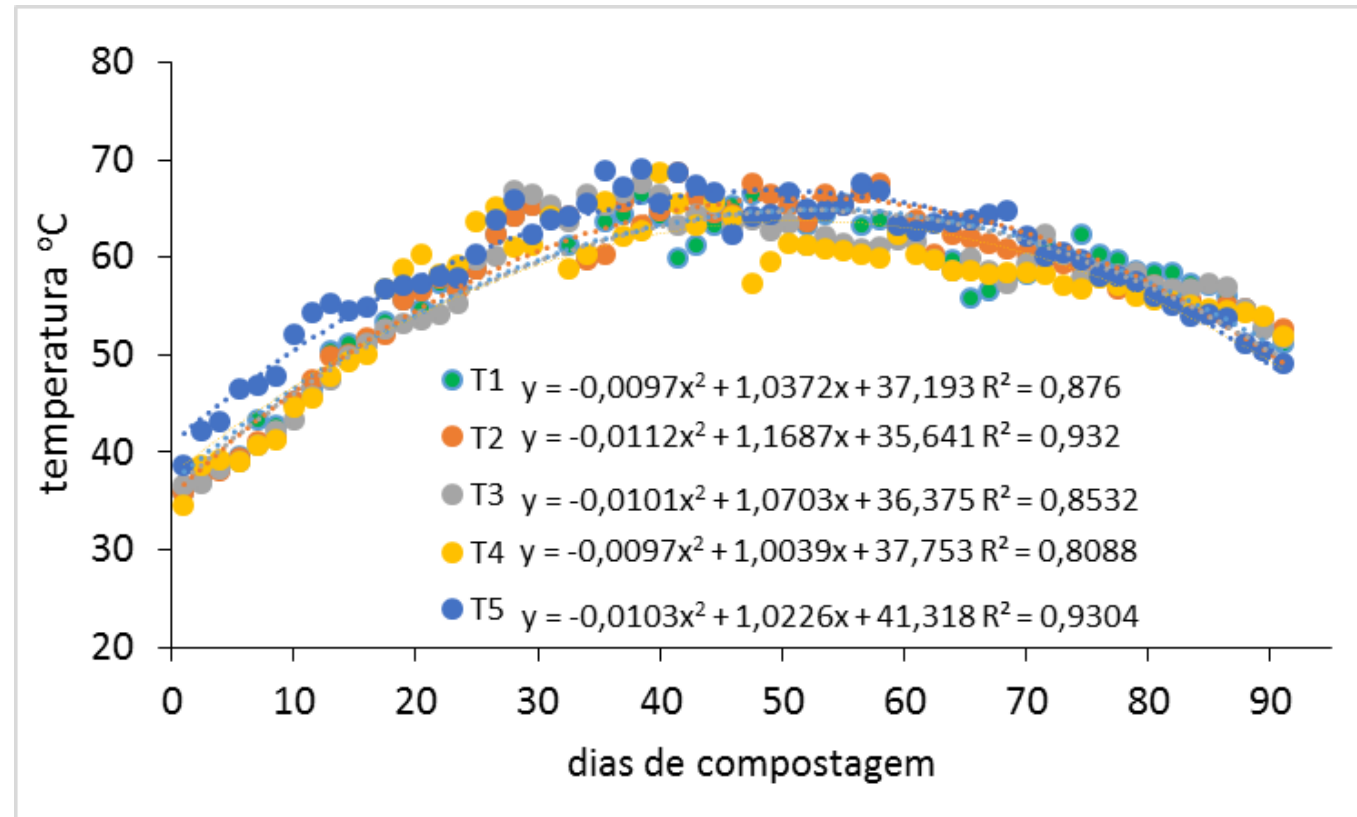

Figura 1. Temperatura das pilhas de compostagem de diferentes proporções de resíduos de frigorífico e da criação de suínos, com adição de pó de rocha (ardósia). 


\title{
DEGRADAÇÃO DE PENAS DE FRANGOS DE CORTE POR QUERATINASES PRODUZIDAS A PARTIR DE UM FUNGO AUTÓCTONE ISOLADO NO SUL DO BRASIL
}

\author{
Preczeski, K. ${ }^{1}$; Czapela, F. ${ }^{1}$; Kubeneck, S. ${ }^{1}$; Dalastra, C. ${ }^{1}$; Fongaro, G. ${ }^{1}$; Treichel, H. ${ }^{1}$ \\ 1Laboratório de Microbiologia e Bioprocessos, Universidade Federal da Fronteira Sul, Erechim, RS - Brasil. \\ helentreichel@gmail.com
}

RESUMO: Resíduos queratinosos como penas, pelos, cascos, bicos e chifres de animais, são gerados em função da intensa atividade pecuária no Brasil. Dessa forma têm-se buscado aplicar estes resíduos em processos biotecnológicos por meio da ação de microrganismos produtores de queratinases. As queratinases são capazes de hidrolisar compostos que contêm queratina em sua composição, sendo tais enzimas amplamente utilizadas nas indústrias de alimentos, fertilizantes, farmacêutica, cosméticos e têxtil, além de possuir grande importância na área biotecnológica para conversão de resíduos queratinosos em produtos de alto valor. Com isso, o objetivo deste estudo foi verificar o potencial de produção de queratinases a partir de fungos promissores isolados de um local de disposição de penas no Sul do Brasil, onde a avicultura é uma das principais atividades econômicas. Para isso, inicialmente analisou-se a degradação de penas a partir de cinco fungos isolados, em que um deles (1B) foi selecionado para realizar fermentação submersa utilizando penas de frangos de corte como substrato sob condições de temperatura e agitação de $28^{\circ} \mathrm{C}$ e $150 \mathrm{rpm}$, respectivamente. Após 6 dias de fermentação a maior atividade queratinolítica foi obtida na fração sólida do meio fermentativo, apresentando 258,5 U/mL de queratinase mensurada em pena. Nesse mesmo período obteve-se a maior degradação do substrato de queratina (47\%). Os resultados obtidos são promissores frente à prospecção de isolados fúngicos autóctones capazes de deteriorar compostos queratinosos para fins de tratamento de resíduos pecuários, como da avicultura, buscando ainda a produção de queratinases que poderão ser purificadas e amplamente utilizadas para fins biotecnológicos.

Palavras-chave: compostos queratinosos, enzimas queratinolíticas, degradação.

\section{FEATHER DEGRADATION FROM KERATINASES PRODUCED BY ISOLATE INDIGENOUS FUNGUS FROM SOUTHERN BRAZIL}

\begin{abstract}
Keratinous residues such as feathers, hairs, hooves, beaks and horns of animals, are generated due to intense livestock activity in Brazil. In this way we have tried to apply these residues in biotechnological processes through the action of microorganisms producing keratinases. Keratinases are capable of hydrolyzing compounds containing keratin in their composition, being such enzymes widely used in the food, fertilizer, pharmaceutical, cosmetic and textile industries, besides being of great importance in the biotechnological area for the conversion of keratinous residues to high value products. Therefore, the objective of this study was to verify the potential of keratinases production from promising fungi isolated from a feather disposal site in southern Brazil, where poultry farming is one of the main economic activities. For this, initially the degradation of feathers from five isolated fungi, one of them (1B) was selected to perform submerged fermentation using feathers of broiler chickens as substrate under conditions of temperature and agitation of $28^{\circ} \mathrm{C}$ and $150 \mathrm{rpm}$, respectively. After 6 days of fermentation the highest keratinolytic activity was obtained in the solid fraction of the fermentative medium, presenting $258.5 \mathrm{U} / \mathrm{mL}$ of keratinase measured in feather. In this same period, the highest degradation of the keratin substrate $(47 \%)$ was obtained. The results obtained are promising for the prospection of indigenous fungal isolates capable of deteriorating keratinous compounds for the purpose of treatment of livestock residues, such as poultry, also seeking the production of keratinases that can be purified and widely used for biotechnological purposes.
\end{abstract}

Keywords: keratinous compounds, keratinolytic enzymes, degradation. 


\section{INTRODUÇÃO}

Resíduos queratinosos como penas, pelos, cascos, bicos e chifres de animais são gerados em abundância devido a intensa atividade pecuária no Brasil, possuindo aplicação limitada pelo fato de serem difíceis de degradar. Por outro lado, apresentam características que os tornam materiais com alto valor agregado se tratados corretamente. Microrganismos produtores de queratinases são uma alternativa promissora para melhorar a degradabilidade e elevar a valoração destes materiais queratinosos (KIM; LIM; SUH, 2001).

Dessa forma, tem se buscado estudar a produção de queratinases capazes de degradar e valorar materiais queratinosos, sendo estas enzimas uma classe de proteases com potencial de hidrolisar queratina, (BRANDELLI; DAROIT; RIFFEL, 2010; GEGECKAS et al., 2018), destacando-se em diversas áreas, tais como, de alimentos, de fertilizantes, de cosméticos, têxteis, farmacêuticas (BRANDELLI; DAROIT; RIFFEL, 2010) e também na degradação de materiais queratinosos provenientes de diversas atividades pecuárias (OKOROMA et al., 2012; MAZOTTO et al., 2013; DAROIT; BRANDELLI, 2014; BRANDELLI; SALA; KALIL, 2015).

Estas enzimas podem ser obtidas comercialmente ou a partir de processos fermentativos em estado sólido (FES) ou em estado submerso (FS) por intermédio de microrganismos autóctones capazes de produzir tais enzimas (MAZOTTO et al., 2013; DEMIR et al., 2015).

Dentre os microrganismos envolvidos na degradação de materiais queratinosos estão os fungos, considerados promissores produtores de queratinases, pois grande parte dos fungos queratinolíticos isolados e identificados encontram-se em ambientes com presença de resíduos de queratina, estando ambientados à presença desses compostos queratinosos (ANBU et al., 2008; GANAIE et al., 2010; ISMAIL et al., 2012; KACHUEI et al., 2012).

Neste contexto, o objetivo deste estudo foi verificar o potencial de produção de queratinases a partir de fungos promissores isolados de resíduos de penas dispostos no solo na região sul do Brasil.

\section{MATERIAL E MÉTODOS}

Primeiramente foi realizado o isolamento de fungos com potencial de degradação de compostos queratinosos. Esses microrganismos foram obtidos de um local de disposição de penas localizado no Sul do Brasil. De posse das culturas puras, cinco microrganismos foram submetidos a um processo de indução à produção de queratinases utilizando penas de frango (10g/L em meio sólido).

As penas foram devidamente lavadas com álcool etílico 70\%, permanecendo submersas por $8 \mathrm{~h}$ e, após, secas em estufa a $68^{\circ} \mathrm{C}$ por $16 \mathrm{~h}$ para fins de esterilização. Após a indução, esses fungos foram submetidos ao processo fermentativo em estado submerso utilizando penas de frango de corte como substrato e, dentre estes, dois apresentaram maior potencial de degradação das penas, mas somente um deles foi selecionado para continuidade dos testes.

Foi realizada uma nova fermentação com o microrganismo selecionado, em que cada erlenmeyer era composto por $10 \mathrm{~g} / \mathrm{L}$ de penas brancas inteiras, $100 \mathrm{~mL}$ de tampão Tris $\mathrm{HCl} \mathrm{pH} 8,550 \mathrm{mM}$ e $10^{4}$ esporos por $\mathrm{mL}$ do microrganismo $1 \mathrm{~B}$, sendo incubados a $28^{\circ} \mathrm{C}$ e $150 \mathrm{rpm}$ (Adaptado de MAZOTTO et al., 2013). Foi preparada também uma amostra controle, em que não foi adicionado o inóculo fúngico. Foram realizadas quantificações em duplicata de medida de atividade de queratinase nas frações sólida e líquida da fermentação em diferentes tempos de incubação, bem como a avaliação da degradação do substrato. A atividade queratinolítica foi determinada a partir de azoqueratina (SIGMA-K8500) e a degradação das penas a partir da perda de massa. As amostras analisadas foram destrutivas.

\section{RESULTADOS E DISCUSSÃO}

Foram obtidos cinco fungos morfologicamente distintos, os quais foram avaliados quanto à sua capacidade de degradabilidade de penas de frangos de corte por meio da produção de queratinases.

Dos fungos estudados, dois isolados (1B e 3B) foram capazes de degradar as penas usadas como substrato de queratina. $\mathrm{O}$ isolado $1 \mathrm{~B}$ foi selecionado para dar continuidade aos ensaios, pois na indução foi observada elevada deterioração das penas.

Os resultados da fermentação realizada a partir do isolado 1B apontaram a produção de queratinases em apenas três (3) dias de fermentação, considerando a degradação visual das penas utilizadas. O controle da fermentação não apresentou degradação do substrato, mostrando que não houve contaminação por outros microrganismos (Figura 1). 
A Tabela 1 apresenta a quantificação da atividade queratinolítica tanto na fase líquida quanto na sólida do processo fermentativo frente aos substratos queratinosos (pena e azoqueratina). Destaca-se que na fração sólida da fermentação obteve-se a partir de 3 até 6 dias, 45,16 U/mL e 62,67 U/mL de queratinase, respectivamente. Ainda, no sexto dia de fermentação a atividade queratinolítica atingiu seu ponto máximo, sendo obtidas $258,51 \mathrm{U} / \mathrm{mL}$ de queratinase utilizando pena como substrato de medida de atividade.

$\mathrm{O}$ aumento na atividade demonstra o potencial fúngico para produção de queratinases ativas e para a degradação de resíduos queratinosos, visto que a degradação do substrato chegou próximo à 50\% da massa inicial, sendo este o ponto de máxima atividade queratinolítica. A maior atividade na porção sólida demonstra possível atração entre a enzima e seu substrato, direcionando estudos que visem produzir e extrair queratinases a partir da superfície da pena, sendo uma inovação esta área de estudo.

\section{CONCLUSÃO}

Diante do exposto, pode-se verificar o potencial de produção de queratinases atrelado à degradação de resíduos queratinosos, visto que o maior valor de atividade queratinolítica foi obtido juntamente com a maior degradação do substrato fermentativo. Ressalta-se que o êxito obtido no presente estudo muito se deve ao isolamento de fungos autóctones, proveniente de locais onde há descarte contínuo de penas, podendo estimular a adaptação fúngica e a consequente produção de queratinases.

O processo aqui apresentado demonstra potencial biotecnológico, já que apresenta uma alternativa promissora para a degradação de resíduos queratinosos ao passo que desse obtêm-se enzimas com alto valor agregado, sendo relevante a continuidade da investigação da atividade queratinolítica presente na fração sólida da fermentação.

\section{AGRADECIMENTOS}

Os autores agradecem à Fundação de Amparo à Pesquisa do Estado do Rio Grande do Sul - FAPERGS, à Coordenação de Aperfeiçoamento de Pessoal de Nível Superior - CAPES, ao Conselho Nacional de Desenvolvimento Científico e Tecnológico - CNPq e ao grupo de pesquisa do Laboratório de Microbiologia e Bioprocessos - LAMIBI da UFFS campus Erechim.

\section{REFERÊNCIAS}

ANBU, Periasamy et al. Extracellular keratinase from Trichophyton sp. HA-2 isolated from feather dumping soil. International Biodeterioration and Biodegradation, v. 62, n. 3, p. 287-292, 2008.

BRANDELLI, Adriano; DAROIT, Daniel J.; RIFFEL, Alessandro. Biochemical features of microbial keratinases and their production and applications. Applied Microbiology and Biotechnology, v. 85, n. 6, p.1735-1750, 2010.

BRANDELLI, Adriano; SALA, Luisa; KALIL, Susana Juliano. Microbial enzymes for bioconversion of poultry waste into added-value products. Food Research International, v. 73, p.3-12, 2015.

DAROIT, Daniel Joner; BRANDELLI, Adriano. A current assessment on the production of bacterial keratinases. Critical Reviews in Biotechnology, v. 34, n. 4, p.372-384, 2014.

DEMIR, Tuğçe et al. An optimization approach to scale up keratinase production by Streptomyces sp. 2M21 by utilizing chicken feather. International Biodeterioration \& Biodegradation, v. 103, p.134-140, 2015.

GANAIE, M.A. et al. Isolation and Identification of Keratinophilic Fungi from Different Soil Samples in Jhansi City (India). Plant Pathology Journal, v. 9, n. 4, p.194-197, 2010.

GEGECKAS, Audrius et al. Characterization and application of keratinolytic paptidases from Bacillus spp. International Journal Of Biological Macromolecules, v. 113, p.1206-1213, 2018.

ISMAIL, Abdel-mohsen S. et al. Novel keratinase from Trichoderma harzianum MH-20 exhibiting remarkable dehairing capabilities. International Biodeterioration \& Biodegradation, v. 70, p.14-19, 2012.

KACHUEI, Reza et al. Isolation of keratinophilic fungi from soil in Isfahan province, Iran. Journal de Mycologie Médicale, v. 22, n. 1, p.8-13, 2012.

KIM, J.M; LIM, W.J; SUH, H.J. Feather-degrading Bacillus species from poultry waste. Process Biochemistry, v. 37, n. 3, p.287-291, 2001.

MAZOTTO, Ana Maria et al. Degradation of feather waste by Aspergillus niger keratinases: Comparison of submerged and solid-state fermentation. International Biodeterioration \& Biodegradation, v. 85, p.189-195, 2013. 
OKOROMA, Emeka A. et al. Identification and characterisation of a Bacillus licheniformis strain with profound keratinase activity for degradation of melanised feather. International Biodeterioration \& Biodegradation, v. 74, p.54-60, 2012.
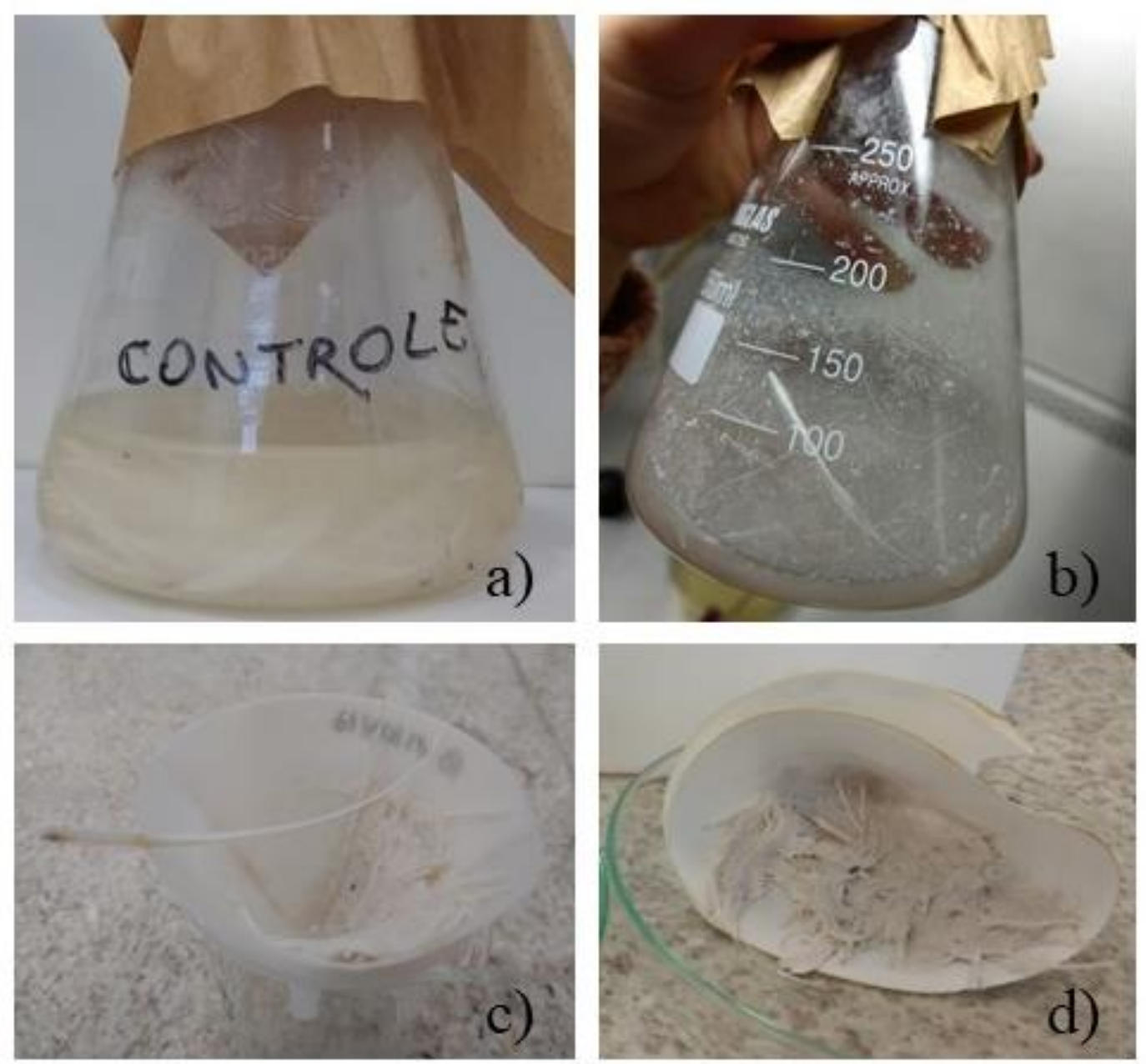

Figura 1. Controle da fermentação submersa (a), meio fermentativo (b), meio filtrado (c) e massa seca (d) após 3 dias de fermentação com o microrganismo1B.

Tabela 1. Resultados de medida de atividade queratinolítica e de degradação de substrato queratinoso em diferentes tempos de fermentação nas frações líquida e sólida (Azoqueratina e Penas).

\begin{tabular}{ccccc}
$\begin{array}{c}\text { Fermentação } \\
\text { (dias) }\end{array}$ & $\begin{array}{c}\text { Atividade em azoqueratina } \\
(\mathbf{U} / \mathbf{m L})\end{array}$ & $\begin{array}{c}\text { Degradação } \\
(\mathbf{\%})\end{array}$ & $\begin{array}{c}\text { Atividade em penas } \\
(\mathbf{U} / \mathbf{m L})\end{array}$ \\
\hline \multirow{2}{*}{3} & Fração Líquida & 13,50 & 27,53 & - \\
& Fração Sólida & 45,16 & & - \\
\multirow{2}{*}{6} & Fração Líquida & 2,40 & \multirow{2}{*}{47,78} & 0,00 \\
\cline { 2 - 3 } & Fração Sólida & 62,67 & & 258,51 \\
\hline
\end{tabular}




\title{
DINÂMICA DOS COMPOSTOS DE ODOR EM SISTEMAS BASEADOS EM MICROALGAS
}

\author{
Vilas Boas, W.H.*1; Vieira, K.R. ${ }^{1}$; Pinheiro, P.N. ${ }^{1}$; Wagner ${ }^{1}$, R.; Jacob-Lopes, E. ${ }^{1}$; Zepka, L.Q. ${ }^{1}$ \\ ${ }^{1}$ Universidade Federal de Santa Maria, Departamento de Ciência e Tecnologia em Alimentos \\ E-mail para contato: lqz@pq.cnpq.br
}

\begin{abstract}
RESUMO: O objetivo do estudo foi avaliar a dinâmica dos compostos de odor em sistemas baseados em microalgas. Os experimentos foram realizados em biorreator descontínuo com aeração contínua e ausência de luminosidade, contendo $2 \mathrm{~L}$ de água residuária proveniente do abate e processamento de aves e suínos, inoculado com a microalga Phormidium autumnale. Os compostos orgânicos voláteis foram isolados por microextração em fase sólida no headspace (FIBRA DVB/Car/PDMS) e analisados por cromatografia gasosa acoplada a um detector de massas (SPME-GCMS). A amostragem foi realizada a cada 24 horas durante o de tempo de residência celular. Um total de 11 compostos de odor intenso foram detectados por GC-MS, destes, 9 compostos foram totalmente removidos durante o período de 72 horas. O dimetil dissulfeto e o indol foram os compostos mais recalcitrantes, com eficiências de remoção na ordem de 69,0 e 95,9\%, respectivamente.
\end{abstract}

Palavras-chave: Phormidium autumnale, cultivo heterotrófico, água residuária.

\section{MICROALGAE-BASED SYSTEMS IN THE DYNAMICS OF THE ODOROUS COMPOUNDS}

ABSTRACT: The objective of this work was to evaluate the microalgae-based systems in the dynamics of the odorous compounds. The experiments were carried out in a discontinuous bioreactor with continuous aeration and absence of light, containing $2 \mathrm{~L}$ of wastewater from the slaughter and processing of poultry and pigs inoculated with the microalga phormidium autumnale. The volatile organic compounds were isolated by solid phase microextraction in the headspace (DVB/Car/PDMS FIBER) and analyzed by gas chromatography coupled to a mass detector (SPME-GCMS). Sampling was performed every 24 hours over cell residence time. A total of 11 compounds of odor intense were detected by gc-ms, of these, 9 compounds were completely removed during the 72 hours period. Dimethyl disulfide and indole were the more recalcitrant compounds, with removal efficiencies in order of 69.0 and $95.9 \%$, respectively.

Keywords: Phormidium autumnale, heterotrophic cultivation, wastewater.

\section{INTRODUÇÃO}

As emissões de odor provenientes de estações de tratamento de águas residuárias (ETARs) causam impacto nas comunidades locais e são cada vez mais a causa de reclamações (Lebrero et al., 2013). Uma gama diversificada de compostos orgânicos voláteis (COVs) é emitida a partir do tratamento de águas residuárias. Sabe-se que uma variedade destes compostos contribui para os maus odores, dentre eles estão as aminas, cetonas, uma variedade de compostos aromáticos incluindo indol, escatol, $\rho$-cresol e tolueno (Wang et al., 2012).

O controle de odor em estações de tratamento é um dos pontos mais importantes, e também mais desafiadores do processo de tratamento de efluentes (Talaiekhozani, et al., 2016). As microalgas são consideradas uma fonte potencialmente nova e valiosa de compostos biologicamente ativos para aplicações em vários setores de biotecnologia (Lauritano et al., 2018). Além disso, o uso de microalgas desempenha um papel vital na conversão de resíduos para produtos diversos, como biocombustíveis, nutracêuticos, polímeros, pigmentos e uma variedade de produtos químicos. As algas têm inerentemente potencial para transformar gases de efeito estufa industriais, bem como águas residuais, em 64 produtos úteis, servindo como uma plataforma eficaz de captura e uso de carbono (Wang et al., 2017).

Em face disso, o objetivo deste trabalho foi avaliar a dinâmica dos compostos de odor na indústria de processamento de carne a partir de processos baseados em microalgas. 


\section{MATERIAL E MÉTODOS}

A microalga utilizada foi a Phormidium autumnale, isolada do Deserto Cuatro Sienegas no México $\left(26^{\circ} 59^{\prime} \mathrm{N} 102^{\circ} 03 \mathrm{~W}\right)$. As culturas reservas foram mantidas e propagadas em agar-agar solidificado $\left(20 \mathrm{~g} \mathrm{~L}^{-1}\right)$ com meio sintético BG11 (Rippka et al., 1979). As condições de manutenção usadas foram $25^{\circ} \mathrm{C}$ e intensidade luminosa constante de 1klux.

Os experimentos foram realizados em um reator de coluna de bolhas. O sistema foi construído de vidro de borosilicato com diâmetro externo de $12,5 \mathrm{~cm}$ e altura de $16 \mathrm{~cm}$, com razão altura/diâmetro proporção igual a 1,28 e um volume nominal de 2,0 L. O sistema de dispersão do reator consistiu em um difusor de ar com 2.5 centímetros de diâmetro localizado no interior do biorreator. O fluxo de ar controlado pelo medidor de fluxo (Kl-Key Instruments®, Trevose, PA, EUA) e a entrada de ar e a saída de gases foram filtrados com unidades filtrantes constituídas de membrana de polipropileno, com um diâmetro de poro de $0,22 \mu \mathrm{m}$ e o diâmetro total de $50 \mathrm{~mm}$ (Millex FG ${ }^{\circledR}$, Billerica, MA, EUA). O biorreator, incluindo unidades filtrantes foram esterilizados em autoclave a $121^{\circ} \mathrm{C}$ durante 20 minutos. Os experimentos foram realizados em biorreatores em regime de batelada, alimentado com 2,0 L de água residuária, oriundas do abate e processamento de aves e suínos (Concórdia, SC). As condições experimentais foram as seguintes: concentração inicial do inóculo de $100 \mathrm{mg}$ $\mathrm{L}^{-1}$, a temperatura de $25^{\circ} \mathrm{C}$, o $\mathrm{pH}$ ajustado para 7,6, aeração de $1 \mathrm{VVM}$ (volume de ar por volume de meio por minuto), ausência de luz e relação C/N (Carbono/Nitrogênio) de 30.

Os compostos voláteis formados no bioprocesso foram isolados pela técnica de microextração em fase sólida aplicada em headspace (HS-SPME). A amostragem realizada no tempo zero e a cada $24 \mathrm{~h}$ durante o crescimento celular. A fibra de SPME de revestimento misto empregada foi a DVB/Car/PDMS $(50 / 30 \mu \mathrm{m} \times$ $20 \mathrm{~mm}$, Supelco Bellefonte, PA, USA), pré-condicionada conforme as recomendações fornecidas pelo fabricante. A temperatura de extração de $40^{\circ} \mathrm{C}$, com um tempo de equilíbrio de 5 minutos, após exposição da fibra por 45 minutos. A análise dos compostos voláteis foi realizada em um cromatógrafo a gás acoplado a um espectrômetro de massas (GC/MS Shimadzu QP-2010 Plus). As separações cromatográficas em coluna Chrompack WAX 52-CB $(60 \mathrm{~m} \times 0,25 \mathrm{~mm}$ d.i. $\times 0,25 \mu \mathrm{m}$ de diâmetro de fase estacionária). $\mathrm{O}$ gás de arraste utilizado foi o hélio com vazão constante de $1,6 \mathrm{~mL} \mathrm{~min}^{-1}$. A temperatura inicial da coluna de $35^{\circ} \mathrm{C}$, permanecendo por 5 minutos, após elevada até $220^{\circ} \mathrm{C}$ com gradiente de temperatura de $5^{\circ} \mathrm{C} \mathrm{min}^{-1}$, mantendose isotermicamente por 5 minutos. A interface GC/MS e da fonte de ionização foram mantidos a $250^{\circ} \mathrm{C}$. $\mathrm{O}$ detector de massas foi operado no modo de ionização por elétrons, com feixe de elétrons a $+70 \mathrm{eV}$. O analisador de massas do tipo quadrupolos foi utilizado no modo de varredura na faixa de 35 a $350 \mathrm{~m} / \mathrm{z}$. Os compostos foram identificados primeiramente por comparação dos seus espectros de massa com os do banco de dados espectral da própria biblioteca do GC-MS (NIST MS Search 2.0). A identificação foi confirmada por comparação dos Îndices de Retenção Linear calculados.

\section{RESULTADOS E DISCUSSÃO}

O estudo centrou-se na desodorização de odores a partir de efluentes brutos de uma indústria alimentícia de abate e processamento de aves e suínos utilizando a microalga Phormidium autumnale. Desta forma, a análise dos dados apresentada na Tabela 1 mostra o perfil volátil, a intensidade de odor e a descrição do odor da água residuária.

Um total de 11 diferentes compostos de odor foram detectados nas águas residuárias, nos quais apresentam descritor de odor desagradável. Observa-se que houve uma mudança clara no perfil volátil do biorreator heterotrófico microalgal. No período de 24 horas, 04 compostos de odor foram removidos. De 24 a 48 horas, mais 02 compostos desapareceram. E no período de 72 horas mais 03 compostos deixaram de aparecer. O perfil de remoção fica mais bem representado pela Figura 1, em que mostra o cromatograma do processo.

Após 72 horas de tempo de residência, o bioprocesso demonstrou uma eficiência de remoção de 100\% em nove compostos de odor. Apenas os compostos dimetil dissulfeto e o indol obtiveram eficiência de remoção de $69 \%$ e $95,9 \%$, respectivamente. No entanto, o composto indol representa uma dificuldade no processo de desodorização. O problema tecnológico para remover indol consiste na presença simultânea de componentes estruturais hidrofóbicos e hidrofílicos, anéis de benzeno e pirrol, juntamente com ligações de $\mathrm{CH}$, que são uma superfície hidrofóbica e o centro hidrofílico é o heteroátomo N (Matias et al., 2015). Já a continuidade da presença do composto dimetil dissulfeto deve ao fato deste composto fazer parte do metabolismo da microalga. Crê-se que o catabolismo microbiano do dimetilsulfonopropionato (DMSP) é o principal processo biológico que gera o composto volátil (Carrión et al., 2015). 


\section{VISIGER

\section{CONCLUSÃO}

As águas residuais do processamento de aves e suínos apresentam um total de 11 compostos odoríferos, sendo que biorreator heterotrófico de microalgal apresentou capacidade em remover um total de 09 compostos em 72 horas de tempo de residência. $\mathrm{O}$ dimetil dissulfeto e o indol foram os compostos mais recalcitrantes, com eficiências de remoção na ordem de 69,0 e 95,9\%, respectivamente.

\section{AGRADECIMENTOS}

Coordenação de Aperfeiçoamento de Pessoal de Nível Superior (CAPES); Fundação de Amparo à Pesquisa do Estado do Rio Grande do Sul (FAPERGS); Conselho Nacional de Pesquisa (CNPq) e Universidade Federal de Santa Maria (UFSM).

\section{REFERÊNCIAS}

CARRIÓN, O., CURSON, A. R. J., KUMARESAN, D., FU, Y., LANG, A. S., MERCADÉ, E., TODD, J. D.(). A novel pathway producing dimethylsulphide in bacteria is widespread in soil environments. Nat Commun, 2015; 6: 6579.

LAURITANO, C., MARTIN, J., CRUZ, M., REYES, F., ROMANO, G., LANORA, A. First identification of marine diatoms with anti-tuberculosis activity. Scientific Reports, 2018; 8, 1-10.

LEBRERO, R., RANGEL, M. G. L., \& MUÑOZ, R. Characterization and biofiltration of a real odorous emission from wastewater treatment plant sludge. Journal of Environmental Management, 2013; 116, 50-57.

MATIAS, T., MARQUES, J., QUINA, M. J., GANDO-FERREIRA, L., VALENTE, A. J. M., PORTUGAL, A., \& DURÃES, L. Silica-based aerogels as adsorbents for phenol-derivative compounds. Colloids and Surfaces A: Physicochemical and Engineering Aspects, 2015; 480, 260-269.

RIPPKA, R., DERUELleS, J., WATERBURY, J. B., HERDMAN, M., \& STANIER, R. Y. Generic assignments strain histories and properties of pure cultures of cyanobacteria. Journal of General Microbiology, $1979 ; 111,1-61$.

TALAIEKHOZANI, A., BAGHERI, M., GOLI, A., \& KHOOZANI, M. R. T. An overview of principles of odor production, emission, and control methods in wastewater collection and treatment systems. Journal of Environmental Management, 2016; 170, 186-206.

WANG, B., SIVRET, E.C., PARCSI, G., WANG, X., STUETZ, R.M. Characterising volatile organic compounds from sewer emissions by thermal desorption coupled with gas-chromatography-mass spectrometry Chem. Eng. Trans., 2012; 30, 73-78

WANG, X., BAO, K., CAO, W., ZHAO, Y., \& HU, W. C. Screening of microalgae for integral biogas slurry nutrient removal and biogas upgrading by different microalgae cultivation technology. Scientific Reports, $2017 ; 7,1-12$.

Tabela 1. Eficiência de remoção de odor no biorreator heterotrófico de microalgal

\begin{tabular}{|c|c|c|c|c|c|c|c|c|c|}
\hline \multirow[b]{2}{*}{ Pico } & \multirow[b]{2}{*}{ Composto } & \multirow[b]{2}{*}{$\begin{array}{c}\text { Limiar de } \\
\text { percepção } \\
\left(\mu \mathrm{g} \cdot \mathbf{m}^{-3}\right)\end{array}$} & \multirow{2}{*}{$\begin{array}{l}\text { LRI } \\
\text { DB- } \\
\text { Wax }\end{array}$} & \multicolumn{4}{|c|}{ Tempo de Residência } & \multirow{2}{*}{$\begin{array}{c}\text { Eficiência de } \\
\text { Remoção }(\%)\end{array}$} & \multirow[b]{2}{*}{$\begin{array}{c}\text { Descritor de } \\
\text { odor }\end{array}$} \\
\hline & & & & $\mathbf{0 ~ h}$ & $24 \mathrm{~h}$ & $48 \mathrm{~h}$ & $72 \mathrm{~h}$ & & \\
\hline 1 & dissulfeto de carbono & 300 & 762 & $1,1 \pm 0,1$ & $1,1 \pm 0,1$ & $1,1 \pm 0,1$ & $\mathrm{nd}^{c}$ & 100 & desagradável \\
\hline 2 & dimetil sulfeto & 20000 & 771 & $0,4 \pm 0,1$ & nd & nd & nd & 100 & $\begin{array}{l}\text { repolho } \\
\text { deteriorado }\end{array}$ \\
\hline 3 & dimetil dissulfeto (dmds) & 3500 & 1080 & $5,8 \pm 0,1$ & $2,3 \pm 0,4$ & $1,9 \pm 0,2$ & $1,8 \pm 0,4$ & 69,0 & putrefação \\
\hline 4 & hexanal & 200 & 1092 & $15,7 \pm 0,1$ & nd & nd & nd & 100 & grama, gordura \\
\hline 5 & dimetil trissulfeto & 100 & 1363 & $1,2 \pm 0,2$ & $0,9 \pm 0,2$ & nd & nd & 100 & repolho, vegetais \\
\hline 6 & benzaldeído & 10 & 1545 & $55,4 \pm 0,1$ & nd & nd & nd & 100 & queimado, doce \\
\hline 7 & o-cresol & 20 & 1909 & $0,8 \pm 0,1$ & $0,3 \pm 0,1$ & $0,2 \pm 0,4$ & nd & 100 & medicinal \\
\hline 8 & fenol & 20000 & 1915 & $3,0 \pm 0,3$ & $0,6 \pm 0,9$ & $0,6 \pm 0,7$ & nd & 100 & borracha plástica \\
\hline 9 & $\rho$-cresol & 20 & 1991 & $90,0 \pm 0,7$ & $47,3 \pm 1,0$ & nd & nd & 100 & fecal \\
\hline 10 & índol & 0.3 & 2390 & $7,3 \pm 1,2$ & $3,0 \pm 0,9$ & $1,0 \pm 0,7$ & $0,3 \pm 0,5$ & 95,9 & estrume, fecal \\
\hline 11 & escatol & 0.00056 & 2437 & $1,2 \pm 0,6$ & nd & nd & nd & 100 & fecal, nauseante \\
\hline
\end{tabular}



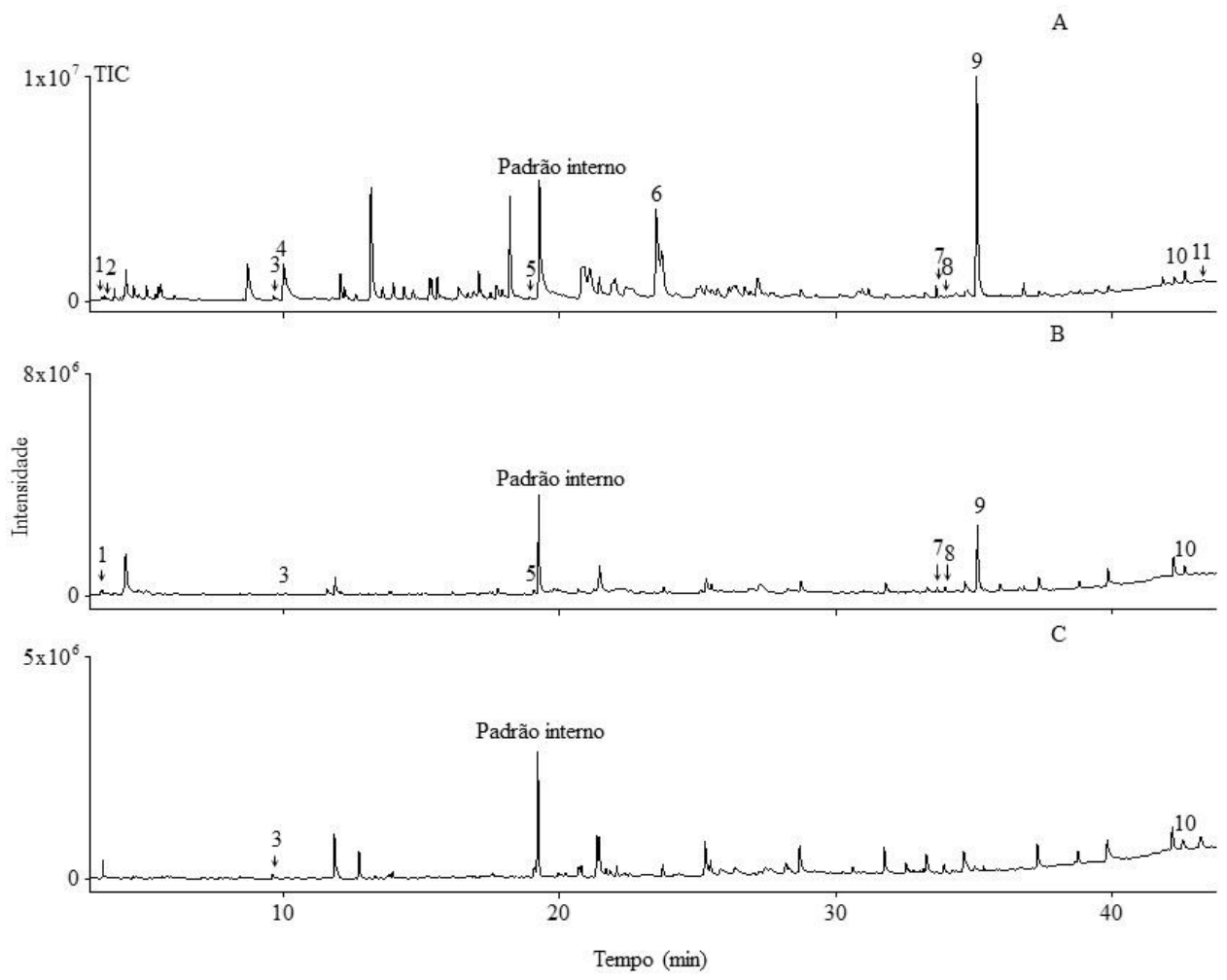

Figura 1. Cromatograma (corrente iônica total) dos compostos orgânicos voláteis do biorreator heterotrófico microalgal. As letras correspondem aos tempos de residência com os quais os cromatogramas foram obtidos: $\mathrm{A}=0 \mathrm{~h}, \mathrm{~B}=24 \mathrm{~h}, \mathrm{C}=72 \mathrm{~h}$. 


\title{
EFEITO DE DIFERENTES PRÉ-TRATAMENTOS NA CINÉTICA DE PRODUÇÃO DE METANO DE CAMA DE FRANGO
}

\author{
Gaspareto, T.C.*1'; Steinmetz, R.L.R. ${ }^{2}$; Goldschmit, F.A. ${ }^{2}$; Venturin, B. ${ }^{3}$; Treichel, H. ${ }^{1}$; Kunz, A. ${ }^{1,2,3}$ \\ ${ }^{1}$ Universidade Federal da Fronteira Sul, Pós-Graduação em Ciência e Tecnologia Ambiental, campus Erechim, RS. \\ ${ }^{2}$ Embrapa Suínos e Aves, Concórdia, SC - Brasil. \\ ${ }^{3}$ Universidade Estadual do Oeste do Paraná, campus Cascavel, PR; \\ taisgaspareto@hotmail.com
}

\begin{abstract}
RESUMO: Devido ao sistema intensivo de produção de frango de corte são geradas elevadas quantidades de resíduos como a cama de frango. A digestão anaeróbia é uma tecnologia de interesse para o tratamento de resíduos provenientes da agroindústria brasileira. No entanto, quando aplicada a cama de frango apresenta limitações devido as características recalcitrantes da mesma, sendo recomendada a aplicação de prétratamentos para aumento da velocidade de hidrólise, redução no tempo de retenção hidráulico e maior produção de biogás/metano. No presente estudo objetivou-se avaliar a influência dos pré-tratamentos com peróxido de hidrogênio $\left(\mathrm{H}_{2} \mathrm{O}_{2}\right)$ e ultrassom (US) nos parâmetros cinéticos de produção de metano a partir da cama de frango. O equipamento AMPTS II foi utilizado para Testes de Potencial Bioquímico de Metano (PBM) foram conduzidos automaticamente (AMPTS II, Bioprocess Control) de acordo com a normaVDI 4630. O modelo de Gompertz modificado foi aplicado para melhor entendimento da cinética do processo após os pré-tratamentos. Foram testadas três condições de pré-tratamento com $\mathrm{H}_{2} \mathrm{O}_{2}$ a $0,14 \%$ v.v ${ }^{-1}$ e US a $700 \mathrm{~W}$ durante 3 minutos. Na primeira condição de ensaio a amostra foi pré-tratada somente com US, na segunda condição foi pré-tratada com peróxido de hidrogênio e na terceira condição foi pré-tratada com $\mathrm{H}_{2} \mathrm{O}_{2}$ seguido de ultrassom. Embora a produção máxima de metano não tenha apresentado diferença significativa $(\mathrm{p} \leq 0.05)$ entre os pré-tratamentos, a amostra pré-tratada com ultrassom apresentou redução na fase lag do processo de digestão anaeróbia da cama de frango.
\end{abstract}

Palavras-chave: hidrólise, avicultura, Modelo de Gompertz.

\section{EFFECT OF DIFFERENTS PRETREATMENTS ON METHANE PRODUCTION KINETICS OF POULTRY LITTER}

\begin{abstract}
Due to the intensive system of broilers production, high amounts of residues with polluting potential such as poultry litter are generated. Anaerobic digestion is an interesting technology for the treatment of residues from the Brazilian agroindustry. However, when applied to poultry litter, it has limitations because of its recalcitrant characteristics. In this way, it is recomended to apply pretreatments to improve the hydrolysis rate, reduction of hydraulic retention time and higher production of biogas/methane. The present study aimed to evaluate the influence of the pretreatments with hydrogen peroxide $\left(\mathrm{H}_{2} \mathrm{O}_{2}\right)$ and ultrasound (US) on the kinetic parameters of methane production from poultry litter. Biochemical Methane Potential (BMP) were performed using an automatic apparatus device (AMPTS II, Bioprocess Control), following the international standard VDI 4630 test.Modified Gompertz model was applied for a better understanding the kinetics of the process after the pretreatments. Three pretreatment conditions were tested with $0.14 \% \mathrm{v} \cdot \mathrm{v}^{-1} \mathrm{H}_{2} \mathrm{O}_{2}$ and $700 \mathrm{~W}$ US for 3 minutes. In the first test condition the sample was pretreated only with ultrasound, in the second condition it was pretreated with hydrogen peroxide and in the third condition it was pretreated with peroxide followed by ultrasound. Although the maximum methane production did not present a significant difference $(\mathrm{p} \leq 0.05)$ between the pre-treatments, the pre-treated sample with ultrasound showed a reduction in the lag phase of the anaerobic digestion process of the poultry litter.
\end{abstract}

Keywords: hydrolysis, poultry farming, Gompertz model. 


\section{INTRODUÇÃO}

A crescente demanda por carne de frango e seus derivados faz da atividade avícola uma das indústrias que mais cresce em todo o mundo (POLESEK-KARCZEWSKA et al., 2018). No entanto, a produção em desenvolvimento intensivo leva ao aumento na geração de resíduos como a cama de frango (BURRA et al., 2016). A cama de frango corresponde a soma do material utilizado como cama (ex: maravalha, palha, etc) juntamente com as fezes, penas e descamações epiteliais das aves, restos de comida e água. (DALÓLIO et al, 2017; KELLEHER et al, 2002; LYNCH et al, 2013; MANTE; AGBLEVOR, 2010). A digestão anaeróbia é um processo biológico destinado a degradação de substratos orgânicos e é realizada por comunidades microbianas robustas e de cultura mista na ausência de oxigênio tendo como produto final o biogás (KHANAL, 2008) e um digestato rico em nutrientes que podem agregar valor a atividade (RICO-CONTRERAS et al, 2017). No entanto, a rota anaeróbia aplicada a cama de frango é caracterizada por algumas limitações, tais como, baixa velocidade de hidrólise na cama seca e degradação pouco eficiente (SHEN; ZHU, 2018). A indústria avícola busca constantemente oportunidades para tornar o setor ainda mais rentável (RICOCONTRERAS et al, 2017). Pré-tratamentos aliadas a digestão anaeróbia tornam-se alternativas interessantes à redução do tempo de retenção hidráulico do processo e ao incremento na produção de biogás. O presente estudo teve como principal objetivo avaliar a influência de diferentes pré-tratamentos com peróxido de hidrogênio $\left(\mathrm{H}_{2} \mathrm{O}_{2}\right)$ e ultrassom (US) nos parâmetros cinéticos de produção de metano a partir da digestão anaeróbia de cama de frango.

\section{MATERIAL E MÉTODOS}

A amostra de cama de frango utilizada no estudo foi coletada em uma granja comercial localizada na cidade de Jaborá - SC (-27 $10^{\prime} 33^{\prime \prime}$ latitude e $-51^{\circ} 44^{\prime} 01^{\prime}$ ' longitude) após 12 lotes de de produção de frangos de corte tendo maravalha como material inicial. Devido a heterogeneidade da cama de frango, a amostra coletada (5 kg) foi homogeneizada (homogeneizador em Y) e quarteada (Marca Humboldt, modelo H-3980) a fim de se obter frações semelhantes.

Para a caracterização da amostra bruta foram realizadas determinações da série de sólidos (sólidos totais, fixos e voláteis), nitrogênio total Kejedhal, fósforo total, potássio e carbono orgânico total, como mostra a Tabela 1, de acordo com APHA (2012).

O experimento foi conduzido no Laboratório de Estudos em Biogás, da Embrapa Suínos e Aves, aplicando-se a combinação de três ensaios com diferentes condições de pré-tratamento com peroxido de hidrogênio $\left(0,14 \%\right.$ v. $\left.\mathrm{v}^{-1}\right)$ e ultrassom ( $700 \mathrm{~W}$ durante 3 minutos). Em cada ensaio foram utilizados $6,79 \mathrm{~g}$ de amostra em $68 \mathrm{~mL}$ de água (correspondente a $10 \%$ de matéria seca). Como condição controle foi utilizada somente a amostra suspensa em água. Na primeira condição de ensaio a amostra suspensa em água foi prétratada somente com ultrassom, na segunda condição foi pré-tratada com peróxido de hidrogênio e na terceira condição foi pré-tratada com peróxido seguido de ultrassom. Os testes foram conduzidos em triplicata e diretamente nos frascos reatores $(500 \mathrm{~mL})$ utilizados durante os ensaios de produção de metano.

A produção de metano foi mensurada por meio do sistema automático para testes de Potencial Bioquímico de Metano (AMPTS II, Bioprocess Control, Suécia), em condições mesofílicas $\left(37 \pm 1{ }^{\circ} \mathrm{C}\right)$. Aos reatores contendo as amostras pré-tratadas, como descrito anteriormente, foram adicionados $400 \mathrm{~g}$ de inóculo aclimatado em condições mesofílicas $\left(37 \pm 1^{\circ} \mathrm{C}\right)$, preparado conforme descrito por Steinmetz et al. (2016). A contribuição do gás proveniente do inóculo foi avaliada em ensaio paralelo (sem adição de substrato), o qual foi subtraído da fração de inóculo adicionado em cada teste. Como controle positivo para o ensaio de digestão anaeróbia utilizou-se celulose microcristalina de alta pureza. A concentração de sólidos voláteis em cada reator foi fixada em $10 \%\left(\mathrm{~m} \cdot \mathrm{v}^{-1}\right)$ e os testes foram considerados finalizados quando a produção diária de metano foi inferior a $1 \%$ do montante produzido (VDI 4630, 2006).

efeito dos pré-tratamentos foi avaliado através do cálculo dos parâmetros; potencial máximo de produção de metano, velocidade máxima de produção de metano e tempo de duração da fase laG, aplicando-se o modelo não linear de Gompertz (equação 1) (WARE; POWER, 2017). A comparação dos parâmetros do modelo de regressão não linear (A, rm, $\lambda$ ), foi realizada com o auxílio do Software Statistic 12.

$$
M(t)=A * \exp \left(-\exp \left(\left(\frac{r m}{A}\right) *(\lambda-t) * e^{1}+1\right)\right)
$$


Onde $A$ é o potencial máximo de produção de $\mathrm{CH}_{4}\left(\mathrm{~mL}_{\mathrm{NCH} 4} \cdot \mathrm{gSv}^{-1}\right.$.adic $), r_{m}$ é a velocidade máxima de produção de $\mathrm{CH}_{4}\left(\mathrm{~mL}_{\mathrm{NCH} 4} \cdot \mathrm{gSv}^{-1} \cdot\right.$ adc $)$; $\lambda$ : fase lag $(\mathrm{d})$.

\section{RESULTADOS E DISCUSSÃO}

A caracterização da cama de frango utilizada é apresentada na Tabela 1 . O modelo não linear de Gompertz foi ajustado às cinéticas de produção de metano em cada tratamento, conforme mostra a Tabela 2. Nota-se valores de coeficiente de determinação $\left(R^{2}\right)$ superiores a 0,99 em todos os tratamentos. A avaliação da produção máxima de metano não apresentou diferença significativa $(\mathrm{p} \leq 0.05)$ entre os pré-tratamentos, tendo resultados entre $58,7 \pm 8,6$ e 70,9 $\pm 3,3 \mathrm{~mL}_{\mathrm{NCH}} \cdot \mathrm{gsv}^{-1}$.adic.

$\mathrm{Na}$ velocidade máxima de produção de metano $(\mathrm{r} m)$ nenhum dos pré-tratamentos diferiram estatisticamente do controle $\left(17,6 \pm 2,8 \mathrm{~mL}_{\mathrm{NCH}} \cdot \mathrm{gsv}^{-1}\right.$.adc), porem observa-se que numericamente as condições com ultrassom tanto na ausência $\left(\mathrm{mL}_{\mathrm{NCH}} \cdot \mathrm{gSv}^{-1} \cdot \mathrm{adc}^{-1}\right)$ quanto na presença de peróxido de hidrogênio $(18,9 \pm 0,6$ $\mathrm{mL}_{\mathrm{NCH}} \cdot \mathrm{gsv}^{-1}$.adc) proporcionaram médias levemente superiores.

Os pré-tratamentos com ultrassom apresentaram diferença significativa $(\mathrm{p} \leq 0.05)$ na redução da fase adaptativa (lag- $\lambda$ ), refletindo na redução de tempo da ocorrência das velocidades máximas de produção de

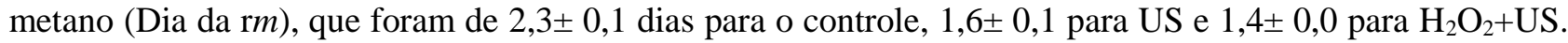
Possivelmente o ultrassom proporcionou a quebra estrutural de compostos complexos, redução da dimensão das partículas e aumento da área biodisponível da cama de frango, favorecendo a aclimatação e desenvolvimento dos microrganismos no meio (CHU et al., 2001; ZOU et al, 2016).

No pré-tratamento com peróxido de hidrogênio, não foi observada influência na cinética, possivelmente devido a baixa concentração usada nos testes. Venturin et al (2018), obtiveram aumento de $22 \%$ no potencial

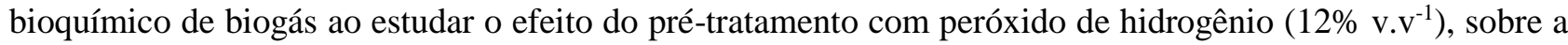
fração lignocelulósica do caule de milho. Assim, uma alternativa para incremento na produção de biogás de cama de frango, seria a solubilização $\left(e \mathrm{e}_{2} \mathrm{O}\right)$, seguido por um processo de separação da fração lignocelulósica e solúvel, com aplicação de $\mathrm{H}_{2} \mathrm{O}_{2}$ na fração fibrosa.

\section{CONCLUSÃO}

A aplicação da modelagem matemática possibilitou melhor avaliação e interpretação do comportamento do substrato durante o processo de digestão anaeróbia. Embora os pré-tratamentos estudados não tenham ocasionado mudanças no potencial bioquímico de metano da amostra, o processo de ultrassom mostrou-se promissor, pois promove redução do tempo de duração da fase lag, tornando a cama de frango um substrato mais propicio para o processo de digestão anaeróbia.

\section{AGRADECIMENTOS}

À Coordenação de Aperfeiçoamento de Pessoal de Nível Superior (CAPES), CNPq e projeto BiogasfertTT (Embrapa).

\section{REFERÊNCIAS}

APHA; AWWA; WEF. Standard methods for the examination of water and wastewater. 22th ed. Washington: APHA, 2012.

BURRA, K. G., HUSSEIN, M.S., AMANO, R.S., GUPTA, A.K., Syngas evolutionary behavior during chicken manure pyrolysis and air gasification. Applied Energy, v. 181, p. 408 415, 2016.

CHU, C. P., CHANG, B., LIAO, G.S., JEAN, D.S., LEE, D.J., Observations on changes in ultrasonically treated waste-activated sludge. Water Research, v. 35, n. 4, p. 1038-1046, 2001.

DALÓLIO, F.S., SILVA, J.N., OLIVEIRA, A.C., TINÔCO, I.F., BARBOSA, R.C., RESENDE, M.O., ALBINO, L.F., COELHO, S.T., Poultry litter as biomass energy: a review and future perspectives. Renewable and Sustainable Energy Reviews. v. 76, p.941-949. 2017.

KHANAL, S. K. Anaerobic biotechnology for bioenergy production: Principles and Applications. p. 308, 2008.

KELLEHER, B. P., LEAHY, J.J., HENIHAN, A.M., O’DWYER, T.F., SUTTON, D., LEAHY, M.J., Advances in poultry litter disposal technology - A review. Bioresource Technology, v. 83, n. 1, p. 27-36, 2002. 
LYNCH, D., HENIHAN, A.M., BOWENB ET AL., B., LYNCH, D., MCDONNELL, K., KWAPINSKI, W., LEAHY, J.J., Utilisation of poultry litter as an energy feedstock. Biomass and Bioenergy, v. 49, n. 0, p. $197-$ 204, 2013.

MANTE, O. D.; AGBLEVOR, F. A., Influence of pine wood shavings on the pyrolysis of poultry litter. Waste Management, v. 30, n. 12, p. 2537-2547, 2010.

POLESEK-KARCZEWSKA, S., TURZYŃSKI, T., KARDAŚ, D., HEDA, L., Front velocity in the combustion of blends of poultry litter with straw. Fuel Processing Technology, v. 176, n. april, p. 307315,2018 .

RICO-CONTRERAS, J.O., AGUILAR-LASSERRE ,A.A., MENDEZ-CONTRERAS, J.M., LOPEZANDRES, J.J., CID-CHAMA, G., Moisture content prediction in poultry litter using artificial intelligence techniques and monte carlo simulation to determine the economic yield from energy use. Journal of Environmental Management, v. 202, p. 254-267, 2017.

SHEN, J.; ZHU, J. Kinetics of poultry litter in a leach bed reactor with agitation based on two mechanisms: enzymatic hydrolysis and direct solubilization. Biochemical Engineering Journal, v. 135, p. 115-122, 2018.

STEINMETZ, R. L. R., MEZZARI, P.M., SILVA, M.L.B., KUNZ, A., AMARAL, A.C., TÁPPARO, D.C., SOARES, H.M., Enrichment and acclimation of an anaerobic mesophilic microorganism's inoculum for standardization of bmp assays. Bioresource Technology, v. 219, p. 21-28, 2016

SIQUEIRA, D.P., COLLA, L.M., ALVES, S.L., BENDER, J.P., STEINMETZ, R.L.R., KUNZ, A., GONGARO, G., TREICHEL, H., Effect of pretreatments on corn stalk chemical properties for biogas production purposes. Bioresource Technology, v. 266, p. 116-124, 2018.

VDI 4630. Fermentation of organic materials - characterization of the substrate, sampling, collection of material data, fermentation tests. The Association of German Engineers, Düsseldorf, Germany. 2006.

ZOU, S., WANG, X., CHEN, Y., WAN, H., FENG, Y., Enhancement of biogas production in anaerobic codigestion by ultrasonic pretreatment. Energy Conversion and Management, v. 112, p. 226-235, 2016. WARE, A.; POWER, N. Modelling methane production kinetics of complex poultry slaughterhouse wastes using sigmoidal growth functions. Renewable Energy, v. 104, p. 50-59, 2017.

Tabela 1. Características físicas e químicas da cama de frango com 12 lotes de produção.

\begin{tabular}{lc}
\hline \multicolumn{1}{c}{ Parâmetro } & Cama de frango 12 lotes \\
\hline Sólidos Totais $\left(\%, \mathrm{~m} \mathrm{~m}^{-1}\right)$ & 76,88 \\
Sólidos Fixos $\left(\%, \mathrm{~m} \mathrm{~m}^{-1}\right)$ & 37,7 \\
Sólidos voláteis $\left(\%, \mathrm{~m} \mathrm{~m}^{-1}\right)$ & 39,17 \\
Relação C/N & 7,73 \\
$\mathrm{~N}_{\text {Total }}\left(\%, \mathrm{~m} \mathrm{~m}^{-1}\right)$ & 2,68 \\
$\mathrm{C}_{\text {Total }}\left(\%, \mathrm{~m} \mathrm{~m}^{-1}\right)$ & 20,71 \\
$\mathrm{P}_{\text {Total }}\left(\%, \mathrm{~m} \mathrm{~m}^{-1}\right)$ & 1,45 \\
$\mathrm{~K}_{\text {Total }}\left(\%, \mathrm{~m} \mathrm{~m}^{-1}\right)$ & 2,95 \\
\hline
\end{tabular}

Tabela 2. Descrição das cinéticas obtidas com o Modelo de Gompertz para os parâmetros de potencial máximo de produção de $\mathrm{CH}_{4}(\mathrm{~A})$, velocidade máxima de produção de $\mathrm{CH}_{4}(\mathrm{r} m)$, dia de ocorrência da

\begin{tabular}{|c|c|c|c|c|c|}
\hline Pré-Tratamento & $\begin{array}{c}\mathrm{A} \\
\left(\mathrm{NmLCH}_{4} \mathrm{~g} \mathrm{SV}^{-1}\right)\end{array}$ & $\begin{array}{c}\mathrm{r}_{m} \\
\left(\mathrm{NmLCH}_{4} \mathrm{~g} \mathrm{SV}^{-1} \mathbf{d}^{-1}\right)\end{array}$ & $\begin{array}{l}\text { Dia da } \mathbf{r}_{m} \\
\text { (d) }\end{array}$ & $\begin{array}{c}\lambda \\
(d)\end{array}$ & $\mathbf{R}^{2}$ \\
\hline Controle & $70,9 \pm 3,3^{\mathrm{a}}$ & $17,6 \pm 2,8^{b c}$ & $2,3 \pm 0,1^{\mathrm{d}}$ & $0,9 \pm 0,1^{\mathrm{f}}$ & $0,9965 \pm 0,0028$ \\
\hline US & $69,8 \pm 3,1^{\mathrm{a}}$ & $20,4 \pm 3,3^{\mathrm{c}}$ & $1,6 \pm 0,1^{\mathrm{e}}$ & $0,3 \pm 0,1^{\mathrm{g}}$ & $0,9905 \pm 0,0056$ \\
\hline $\mathrm{H}_{2} \mathrm{O}_{2}$ & $58,7 \pm 8,6^{\mathrm{a}}$ & $15,5 \pm 2,6^{\mathrm{b}}$ & $2,1 \pm 0,2^{\mathrm{d}}$ & $0,6 \pm 0,2^{\mathrm{f}}$ & $0,9922 \pm 0,0114$ \\
\hline $\mathrm{H}_{2} \mathrm{O}_{2}+\mathrm{US}$ & $64,7 \pm 2,2^{\mathrm{a}}$ & $18,9 \pm 0,6^{\mathrm{bc}}$ & $1,4 \pm 0,0^{\mathrm{e}}$ & $0,1 \pm 0,0^{\mathrm{g}}$ & $0,9972 \pm 0,0002$ \\
\hline
\end{tabular}

velocidade máxima de produção de $\mathrm{CH}_{4}$ (Dia da $\mathrm{r} m$ ), fase lag $(\lambda)$ e coeficiente de determinação $\left(\mathrm{R}^{2}\right)$

Onde: $\mathrm{CF}=$ Cama de Frango, US= Ultrassom, $\mathrm{H}_{2} \mathrm{O}_{2}=$ Peróxido de Hidrogênio.

*Médias seguidas pelas mesmas letras não apresentam diferença significativa entre elas $p \leq 0.05$. 


\title{
EFEITO DO PH E DA RAZÃO CARBONO/NITROGÊNIO NO CULTIVO DE PHORMIDIUM AUTUMNALE EM VINHAÇA
}

\author{
Visentin, T.G.*1'; Guimarães, B.M. ${ }^{\text {; }}$ Bastos, R.G. $^{1}$ \\ ${ }^{1}$ Universidade Federal de São Carlos, Araras, SP - Brasil \\ taisnevisentin@gmail.com
}

\begin{abstract}
RESUMO: Processos utilizando microalgas vinculadas ao tratamento de efluentes agroindustriais têm se tornado atrativos devido à obtenção de biomassa com valor comercial associado à eficiente de remoção de alguns poluentes. Entretanto, a separação das células continua sendo um dos maiores desafios desta tecnologia, sendo estudadas linhagens filamentosas com facilitada decantação da fase líquida. Sendo assim, o objetivo da pesquisa foi avaliar a produção de biomassa e remoção de carbono (TOC), nitrogênio (TN) e fósforo (P) no cultivo heterotrófico da cianobactéria filamentosa Phormidium autumnale em vinhaça de cana-de-açúcar em diferentes condições de $\mathrm{pH}$ inicial e razão $\mathrm{C} / \mathrm{N}$. Os experimentos foram conduzidos em frascos Erlenmeyers na ausência de luz a partir de vinhaça previamente esterilizada e centrifugada com inóculo de $1 \mathrm{~g} \mathrm{~L}^{-1} \mathrm{de}$ biomassa microalgal em diferentes razões $\mathrm{C} / \mathrm{N}(9$ a 28$)$ e $\mathrm{pH}$ iniciais $(6,6$ a 8,4) por 24 horas. Os resultados indicaram maiores produtividades $\left(127 \mathrm{mg} \mathrm{L}^{-1} \mathrm{~h}^{-1}\right)$ para $\mathrm{pH}$ inicial 8,4 e C/N 23, porém, a maior remoção de carbono da vinhaça ocorreu para $\mathrm{C} / \mathrm{N}$ inicial de 9, ou seja, mais limitada pela disponibilidade de carbono. A

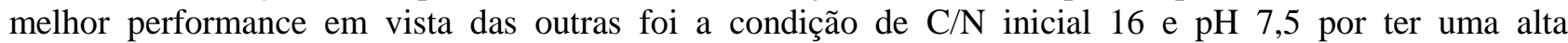
produtividade de biomassa, boa remoção de $\mathrm{TOC}$, $\mathrm{TN}$ e $\mathrm{P}$, sendo em razão $\mathrm{C} / \mathrm{N}$ própria da vinhaça, sem necessidade de correção. Diante disso, os ensaios indicam a viabilidade do cultivo desta cianobactéria na faixa de $\mathrm{pH}$ e $\mathrm{C} / \mathrm{N}$ iniciais avaliadas.
\end{abstract}

Palavras-chave: águas residuárias, biomassa, cultivo heterotrófico, microalga.

\section{EFFECT OF THE PH AND THE CARBON/NITROGEN RATIO BY PHORMIDIUM AUTUMNALE CULTIVATION IN VINASSE}

\begin{abstract}
Processes using microalgae with wastewater treatment has been attractive due to the obtaining of biomass with commercial value associated to the efficient removal of some pollutants. However, cell separation remains one of the major challenges of this technology, with filamentous strains being studied with easy decantation of the liquid phase. Thus, the aim of this research was to evaluate the biomass and carbon (TOC), nitrogen (TN) and phosphorus (P) production in the heterotrophic culture of filamentous cyanobacteria Phormidium autumnale in sugarcane vinasse under different conditions of initial $\mathrm{pH}$ and $\mathrm{C} / \mathrm{N}$ ratio. The experiments were conducted in Erlenmeyer flasks without light source from previously sterilized vinasse and centrifuged with $1 \mathrm{~g} \mathrm{~L}^{-1}$ inoculum of microalgal biomass at different $\mathrm{C} / \mathrm{N}$ (9 to 28) and initial $\mathrm{pH}$ ratios (6.6 to 8.4) for 24 hours. The results indicated higher yields $\left(127 \mathrm{mg} \mathrm{L}^{-1} \mathrm{~h}^{-1}\right)$ at initial $\mathrm{pH} 8.4$ and $\mathrm{C} / \mathrm{N} 23$, however, the higher carbon removal of the vinasse occurred at the initial $\mathrm{C} / \mathrm{N}$ of 9 , that is, more limited by availability of carbon. The best performance in view of the others was the initial $\mathrm{C} / \mathrm{N}$ condition 16 and $\mathrm{pH} 7.5$ because it had a high biomass productivity, good removal of TOC, TN, and $\mathrm{P}$, being $\mathrm{C} / \mathrm{N}$ own vinasse, without the necessity of correction. Faced with this, the assays indicate the viability of the cultivation of this cyanobacterium in the initial $\mathrm{pH}$ and $\mathrm{C} / \mathrm{N}$ range evaluated.
\end{abstract}

Keywords: wastewater, biomass, heterotrophic growth, microalgae.

\section{INTRODUÇÃO}

Existem cerca de 400 usinas de açúcar e álcool no Brasil, sendo responsáveis pelo processamento de aproximadamente 660 bilhões de toneladas de cana-de-açúcar, com a geração de 28 bilhões de litros de etanol e 38 bilhões de toneladas de açúcar (Brasil, Silva e Siqueira, 2016). A principal água residuária proveniente da fabricação do etanol é a vinhaça, sendo gerada em grandes volumes, alcançando de 10 litros a 15 litros a cada 1 litro de etanol produzido. Além disso, a vinhaça possui odor e coloração escura, tendo um potencial poluidor alto devido às grandes concentrações de matéria orgânica, nutrientes e ph ácidos presentes (Silva et al., 2016). Um método de aproveitamento dessa água residuária vem ganhando destaque, sendo o cultivo com 
microalgas, pois elas são capazes de obter alta produtividade de biomassa atrelado ao alto acúmulo de biomoléculas de interesse econômico e industrial (Brasil, Silva e Siqueira, 2016).

Neste sentido, a integração da produção de microalgas com o setor sucroenergético parece promissor, pois diversas espécies de microalgas são conhecidas por habitarem em ambientes extremos, como locais poluídos, solos desérticos, sugerindo por este motivo as baixas exigências nutricionais (Francisco et al., 2014). Uma microalga que vem demonstrando notoriedade é a Phormidium autumnale, uma cianobactéria filamentosa, não ramificada, que possuiu filamentos de 3 a $4 \mu \mathrm{m}$ de diâmetro. Pesquisas tem evidenciado o potencial desse micro-organismo na utilização em processos de biorremediação (Maroneze et al., 2014; Francisco et al., 2014; Neves et al., 2016).

Por outro lado, o cultivo de microalgas em efluentes pode apresentar limitações devido à elevada cor $\mathrm{e}$ turbidez de alguns efluentes, limitando a penetração da luz, o que pode dificultar o crescimento desses microorganismos. Entretanto, espécies heterotróficas se sobressaem, pois utilizam a matéria orgânica presente na ausência de luminosidade para a produção de energia (Bastos et al., 2015). Além de algumas cianobactérias atuarem no aproveitamento de carbono, nitrogênio e fósforo presentes no meio a partir de efluentes agroindustriais, realizam a ciclagem desses nutrientes em biomassa, surgindo uma tecnologia promissora pelo equilíbrio de vetores sustentáveis com o aproveitamento de compostos poluentes (Santos et al., 2016). Diante disso, o objetivo desse trabalho foi estudar o cultivo heterotrófico de Phormidium autumnale em vinhaça de cana-de-açúcar nas diferentes condições iniciais de $\mathrm{pH}$ e razão $\mathrm{C} / \mathrm{N}$ avaliando a produção de biomassa e remoção de carbono (TC), nitrogênio $(\mathrm{TN})$ e fósforo $(\mathrm{P})$.

\section{Inóculo e meio de cultura}

\section{MATERIAL E MÉTODOS}

A cianobactéria Phormidium autumnale, isolada do Deserto Cuatro Cienegas no México $\left(26^{\circ} 59^{\prime} \mathrm{N}\right.$ $102^{\circ} 03 \mathrm{~W}$ ), foi mantida e propagada em meio BG 11 (Rippka et al., 1979) previamente esterilizado e com pH ajustado em 7,5 no Laboratório de Microbiologia Aplicada e Controle (LABMAC/CCA/UFSCar) do Centro de Ciências Agrárias da Universidade Federal de São Carlos (CCA/UFSCar), Campus Araras/SP. As culturas foram mantidas em balões de cultivo de $6 \mathrm{~L}$, em aeração constante de $1 \mathrm{VVM}$ e fotoperíodo de $12 \mathrm{~h}$ até a concentração celular atingir cerca de $1 \mathrm{~g} \mathrm{~L}^{-1}$ para posteriormente serem utilizadas nos cultivos.

\section{Efluente para o cultivo}

A vinhaça foi coletada em uma usina sucroalcooleira da região de Araras/SP, acondicionada em recipientes fechados e mantidos sobre refrigeração a $4^{\circ} \mathrm{C}$ até a sua utilização no LABMAC/CCA/UFSCar. A vinhaça foi caracterizada de acordo com a metodologia proposta por Apha (2012). Os parâmetros analisados antes dos cultivos foram $\mathrm{pH}$, turbidez (NTU), sólidos suspensos (SS), carbono orgânico total (TOC), nitrogênio total (TN), fósforo inorgânico (P), sendo calculada a razão C/N.

\section{Cultivo heterotrófico e obtenção de dados}

Os ensaios foram conduzidos em agitador orbital a $100 \mathrm{rpm}$ a partir de frascos erlenmeyers cobertos com papel alumínio para evitar incidência luminosa, de volume igual a $100 \mathrm{ml}$, contendo $25 \mathrm{ml}$ de vinhaça previamente esterilizada a $121^{\circ} \mathrm{C}$ por $00 \mathrm{~h} 20$ e centrifugada por $00 \mathrm{~h} 10$ à $3500 \mathrm{rpm}$, contendo inóculo de $1 \mathrm{~g} \mathrm{~L}^{-1}$ de biomassa microalgal.

As diferentes razões $\mathrm{C} / \mathrm{N}$ e $\mathrm{pH}$ foram estabelecidas de acordo com o delineamento composto central rotacional, sendo essas as variáveis independentes, e como respostas obteve-se a concentração celular e a remoção de carbono orgânico, fósforo e nitrogênio da vinhaça, cada condição foi realizada em triplicata, os ensaios foram: 1: C/N 9 e pH 6,6; 2: C/N 23 e pH 6,6; 3: C/N 9 e pH 8,4; 4: C/N 23 e pH 8,4; 5: C/N 16 e pH 7,5; 6: C/N 28 e pH 7,5. A razão $\mathrm{C} / \mathrm{N}$ da vinhaça foi calculada pela relação entre TOC e TN e ajustada com quantidades conhecidas de nitrato de sódio ou glicose, e o $\mathrm{pH}$ foi ajustado por potenciometria. O cultivo teve duração de 24h00, após foram coletadas amostras para a análise da concentração celular, TOC, TN e P.

\section{Forma de análise dos resultados}

As análises para a caracterização da vinhaça foram realizadas em triplicata, verificando os valores médios e respectivos desvios padrões. Os resultados da concentração celular foram determinados por gravimentria pela filtração de $5 \mathrm{ml}$ em filtro de $0,45 \mu \mathrm{m}$ de diâmetro. No final do cultivo foram avaliados TOC 
e TN em Analisador TOC-LCPN SIMADZUß, e fósforo inorgânico através de kit reagente colorimétrico LABORLAB $^{\circledR}$. A concentração de TOC, TN e $\mathrm{P}$ foi utilizada para calcular a eficiência de remoção $\left(\mathrm{RE}=\mathrm{S}_{0^{-}}\right.$ $\left.\mathrm{S} / \mathrm{S}_{0}\right)$, em que $\mathrm{S}_{0}$ é a concentração inicial de TOC, TN e $\mathrm{P}\left(\mathrm{mg} \mathrm{L}^{-1}\right)$ e $\mathrm{S}$ é a concentração final de TOC, TN e $\mathrm{P}$ $\left(\mathrm{mg} \mathrm{L}^{-1}\right)$. A produtividade de biomassa $\left(\mathrm{P}=\mathrm{X}-\mathrm{X}_{\mathrm{o}} / \mathrm{t}\right)$ foi calculada nas diferentes condições de cultivo, em que $\mathrm{X}$ é a biomassa final $\left(\mathrm{mg} \mathrm{L}^{-1}\right), \mathrm{X}_{0}$ é a biomassa inicial $\left(\mathrm{mg} \mathrm{L}^{-1}\right)$ e t é o tempo.

\section{RESULTADOS E DISCUSSÃO}

A vinhaça é gerada em grandes quantidades pelas indústrias sucroalcooleiras e apresenta em sua composição altas concentrações de matéria orgânica e nutrientes, sendo capaz de suportar o cultivo heterotrófico de cianobactérias (De Matos e Bastos, 2015). Diante disso, a Tabela1 descreve a caracterização da vinhaça utilizada neste trabalho e se observa que as concentrações de TOC, TN e P foram de $7854 \mathrm{mg} \mathrm{L}^{-1}$, 499,2 $\mathrm{mg} \mathrm{L}^{-1}$ e $35,5 \mathrm{mg} \mathrm{L}^{-1}$ respectivamente, e a razão $\mathrm{C} / \mathrm{N}$ calculada foi de 16 , sendo um valor um pouco abaixo do ótimo para cultivo de micro-organismos $(\mathrm{C} / \mathrm{N}=20)$ de acordo com Queiros et al. (2007) e o pH é ácido, sendo de 4,3.

Visto isso, foram realizados ensaios com diferentes razões $\mathrm{C} / \mathrm{N}$ e pH para verificar em qual condição a cianobactéria produziria maior quantidade de biomassa e melhor remoção de TOC, TN e P, nesse sentido, a TABELA 2 apresenta os parâmetros cinéticos de produção de biomassa e remoção de TOC, TN e P nas diferentes condições. No que se refere à produção de biomassa, as condições de 1 a 5 se sobressaíram, obtendo um significativo aumento em $24 \mathrm{~h} 00$ triplicando a concentração de biomassa, destacando a produtividade das condições 4 e 5 de 127,22 $\mathrm{mg} \mathrm{L}^{-1} \mathrm{~h}^{-1}$ e $99,44 \mathrm{mg} \mathrm{L}^{-1} \mathrm{~h}^{-1}$, respectivamente. Para a remoção de TOC as condições 3 e 5 ficaram em destaque com remoção de $49 \%$ e $48 \%$ nessa mesma ordem. Já para a remoção de TN e P os cultivos em evidência são o 2 e o 5 removendo $48 \%$ e $46 \%$ de TN e $33 \%$ e $26 \%$ de P respectivamente.

Nessas condições experimentais, se verifica que a maior produtividade $\left(127,22 \mathrm{mg} \mathrm{L}^{-1} \mathrm{~h}^{-1}\right)$ foi obtida para $\mathrm{pH}$ inicial 8,4 e C/N 23, visto que maiores concentrações celulares ocorrem em pH mais próximos da neutralidade e básico vinculados com condições $\mathrm{C} / \mathrm{N}$ mais elevadas (Francisco et al., 2015). Obteve-se maior remoção de carbono da vinhaça para $\mathrm{C} / \mathrm{N}$ inicial de 9 e pH 8,4, ou seja, na condição mais limitada pela disponibilidade de carbono, além disso, a condição que obteve melhor performance em vista das outras foi a de $\mathrm{C} / \mathrm{N}$ inicial 16 e pH 7,5 por ter uma alta produtividade de biomassa, boa remoção de TOC, TN e P, sendo em razão C/N própria da vinhaça, sem necessidade de correção.

\section{CONCLUSÃO}

Observando as características do efluente utilizado, como a alta concentração de matéria orgânica e nutrientes, se torna possível o cultivo de Phormidium autumnale e ainda se verifica altas concentrações de biomassa final, além de boas remoções de TOC, TN e P. Diante disso, os ensaios propostos indicam a viabilidade do cultivo desta cianobactéria em todas as faixa de $\mathrm{pH}$ e $\mathrm{C} / \mathrm{N}$ iniciais avaliadas.

\section{AGRADECIMENTOS}

Ao CNPq e ao Programa de Pós-graduação em Agricultura e Ambiente (PPGAA/CCA/UFSCar).

\section{REFERÊNCIAS}

APHA. Standard methods for the examination of water and wastewater. 22th. ed. Washington, DC, New York: American Public Health Association, 2012.

BASTOS, R. G.; BONINI, M. A.; ZEPKA, L. Q.; JACOB-LOPES, E.; QUEIROZ, M. I. Treatment of rice parboiling wastewater by cyanobacterium Aphanothece microscopica Nägeli with potential for biomass products. Desalination and Water Treatment, v.56, n.3, p.608-614, 2015.

BRASIL, B.S.A.F.; SILVA, F.G.; SIQUEIRA, F.G. Microalgae biorefineries: The Brazilian scenario in perspective. New Biotechnology, v. 39, p. 90-98, 2016.

DE MATTOS, L. F. A.; BASTOS, R. G. COD and nitrogen removal from sugarcane vinasse by heterotrophic green algae Desmodesmus sp. Desalination and Water Treatment, v. 57, p. 9465-9473, 2015.

FRANCISCO, E. C.; FRANCO, T. T.; JACOB-LOPES, E. Assessment of different carbohydrates as exogenous carbon source in cultivation of cyanobacteria. Bioprocess and Biosystems Engineering, v. 37, n. 8, p. 1497-1505, 2014. 
FRANCISCO, E. C.; FRANCO, T. T.; ZEPKA, L. Q.; JACOB-LOPES, E. From wast-to-energy: the process integration and intensification fo bulk oil and biodiesel production by microalgae. Journal of environmental and chemical engineering, v.3, p. 482-487, 2015.

MARONEZE, M. M.; MENEZES, C. R.; BARIN, J.S.; QUEIROZ, M. I.; ZEPKA, L.Q.; JACOB-LOPES, E. Treatment of cattle-slaughterhouse wastewater and the reuse of sludge for biodiesel production by microalgal bioreactors. Scientia Agricola (USP Impresso), v. 1, p. 53, 2014.

NEVES, C.; MARONEZE, M. M; TEIXEIRA, G. J. G.; ZEPKA, L. Q.; JACOB-LOPES, E. Produção de biodiesel 3G por Phormidium autumnale a partir de resíduos agroindustriais. Congresso Brasileiro de Engenharia Química em Iniciação Científica, 2016.

QUEIROZ, M.I.; LOPES, E.J.; ZEPKA, L.Q.; BASTOS, R.G.; GOLDBECK, R. The kinetics of the removal of nitrogen and organic matter from parboiled rice effluent by cyanobacteria in a stirred batch reactor, Bioresour. Technol, v.98, p.2163-2169, 2007.

RIPPKA, R.; DERUELES, J.; WATERBURY, J.B.; HERDMAN, M.; STANIER, R.Y. Generic assignments strain histories and properties of pure cultures of cyanobacteria. J. Gen Microbiol, v.111, p.1-61, 1979.

SANTOS, A. M.; SANTOS, A. M.; SEVERO, I. A.; QUEIROZ, M. I.; ZEPKA, L. Q.; JACOB-LOPES, E. Nutrient Cycling in Wastewater Treatment Plants by Microalgae-Based Processes. In: Industrial Waste: Management, Assessment and Environmental Issues. Nova Science Publishers, Inc., Chapter 2 p. 41-64, 2016.

SILVA, M. A.; BARBOSA, G. H.; CODATO, C. B.; MATTOS, L. F. BASTOS, R. G.; KIECKBUSCH, T. G. Heterotrophic growth of green microalgae Desmodesmus subspicatus in ethanol distillation wastewater (vinasse) and lipid extraction with supercritical $\mathrm{CO}_{2}$. Journal of Chemical Technology and Biotechnology, v. 92, n.3, p.573-579, 2016.

Tabela1. Caracterização da vinhaça de cana-de-açúcar utilizada nos ensaios.

\begin{tabular}{cc}
\hline Parâmetros & Valores médios \\
\hline $\mathrm{pH}$ & 4,3 \\
Turbidez $(\mathrm{NTU})$ & 142 \\
Sólidos suspensos $\left(\mathrm{mg} \mathrm{L}^{-1}\right)$ & 1120 \\
$\mathrm{TOC}\left(\mathrm{mg} \mathrm{L}^{-1}\right)$ & 7854 \\
$\mathrm{TN}\left(\mathrm{mg} \mathrm{L}^{-1}\right)$ & 499,2 \\
$\mathrm{P}\left(\mathrm{mg} \mathrm{L}^{-1}\right)$ & 34,5 \\
Razão C/N & 16 \\
\hline
\end{tabular}

TOC: carbono orgânico total, TN: nitrogênio total, P: fósforo inorgânico, Razão C/N: razão carbono/nitrogênio.

Tabela 2. Parâmetros cinéticos obtidos variando a razão $\mathrm{C} / \mathrm{N}$ e o pH.

\begin{tabular}{cccccccc}
\hline Condição & $\mathbf{p H}$ & $\mathbf{C} / \mathbf{N}$ & $\begin{array}{c}\text { Biomassa final } \\
\left(\mathbf{m g ~ L}^{-1}\right)\end{array}$ & $\begin{array}{c}\text { RE TOC } \\
(\boldsymbol{\%})\end{array}$ & $\begin{array}{c}\text { RE TN } \\
(\boldsymbol{\%})\end{array}$ & $\begin{array}{c}\text { RE P } \\
(\boldsymbol{\%})\end{array}$ & $\begin{array}{c}\text { Produtividade } \\
\left(\mathbf{m g ~ L}^{-\mathbf{1}} \mathbf{h}^{-1}\right)\end{array}$ \\
\hline 1 & 6,6 & 9 & 3067 & 45 & 24 & 25 & 86,11 \\
2 & 6,6 & 23 & 3187 & 31 & 48 & 33 & 91,11 \\
3 & 8,4 & 9 & 3073 & 49 & 34 & 24 & 86,39 \\
4 & 8,4 & 23 & 4053 & 28 & 39 & 14 & 127,22 \\
5 & 7,5 & 16 & 3387 & 48 & 46 & 26 & 99,44 \\
6 & 7,5 & 28 & 2613 & 33 & 41 & 24 & 67,22 \\
\hline
\end{tabular}

C/N: razão carbono/nitrogênio, RE TOC (\%): eficiência de remoção de carbono orgânico total, RE TN (\%): eficiência de remoção de nitrogênio total, RE P (\%): eficiência de remoção de fósforo inorgânico. 


\title{
EFEITO DOS METAIS SOBRE OS PRODUTOS DE FERMENTAÇÃO DE GLICEROL
}

\author{
Barbosa, C.G. ${ }^{1}$; Mermejo, B.C. ${ }^{* 1}$; Fonseca, B.C. ${ }^{1}$; Reginatto, V. ${ }^{1}$ \\ ${ }^{1}$ Faculdade de Filosofia, Ciências e Letras de Ribeirão Preto - Universidade de São Paulo, 14040-901 - Ribeirão Preto - SP, Brasil \\ valeriars@ffclrp.usp.br
}

\begin{abstract}
RESUMO: Embora o etanol seja o principal biocombustível produzido e comercializado pelo Brasil, o biodiesel vem ocupando espaço neste mercado. Cerca de $10 \%$ da produção de biodiesel corresponde ao glicerol. Uma alternativa para este glicerol residual é sua conversão em produtos de interesse industrial. Neste sentido, tem-se sua utilização do glicerol para geração de gás hidrogênio $\left(\mathrm{H}_{2}\right)$ que, quando obtido de fontes renováveis é considerado fonte de energia renovável e limpa. O gênero mais eficiente no processo fermentativo de produção de $\mathrm{H}_{2}$ é o Clostridium. Sabe-se que existem metais que podem contribuir para o aumento da produção de $\mathrm{H}_{2}$ como, por exemplo, ferro e cobre em baixas quantidades. Portanto, este trabalho teve por objetivo avaliar o processo fermentativo do glicerol pelo Clostridium beijerinckii $\mathrm{Br} 21$ utilizando na presença de $\mathrm{Fe}$ e $\mathrm{Cu}$. Ensaios fermentativos foram conduzidos utilizando o glicerol como fonte de carbono e os metais $\mathrm{Fe}$ e $\mathrm{Cu}$ ambos na concentração de $0,01 \mathrm{mmol} \mathrm{L}^{-1} \mathrm{e}$ a mistura dos metais. $\mathrm{O}$ ensaio contendo a mistura dos metais gerou $14,09 \mathrm{mmol} \mathrm{L}^{-1}$ de $\mathrm{H}_{2}$ com maior consumo de substrato, 27,95 $\mathrm{mmol} \mathrm{L}^{-1}$. Portanto, na presença de ferro e cobre é possível aumentar a produção do gás hidrogênio com maior consumo de glicerol. O $C$. beijerinckii $\mathrm{Br} 21$ se mostrou efetivo na conversão do glicerol em $\mathrm{H}_{2}$ uma vez que o glicerol era a única fonte de carbono.
\end{abstract}

Palavras-chaves: biodiesel, resíduo, ferro, cobre, 1,3-propanodiol, Clostridium beijerinckii Br21.

\section{EFFECT OF METALS ON THE GLYCEROL FERMENTATION PRODUCTS}

\begin{abstract}
Although ethanol is the main biofuel produced and marketed by Brazil, biodiesel has been occupying space in this market. About $10 \%$ of biodiesel production corresponds to glycerol. An alternative to this residual glycerol is its conversion into products of industrial interest. In this sense, there is the use of glycerol for the generation of hydrogen gas $\left(\mathrm{H}_{2}\right)$, which, when obtained from renewable sources, is considered a source of renewable and clean energy. The most efficient genus in the fermentation process of $\mathrm{H}_{2}$ production is Clostridium. It is known that metals can contribute to increased $\mathrm{H}_{2}$ production, such as iron and copper in low quantities. Therefore, the objective of this work was to evaluate the fermentative process of glycerol by Clostridium beijerinckii $\mathrm{Br} 21$ using in the presence of $\mathrm{Fe}$ and $\mathrm{Cu}$. Fermentation assays were conducted using glycerol as the carbon source and $\mathrm{Fe}$ and $\mathrm{Cu}$ metals both at the concentration of $0.01 \mathrm{mmol} \mathrm{L}-1$ and the metals blend. The test containing the mixture of metals generated $14.09 \mathrm{mmol} \mathrm{L}-1 \mathrm{of} \mathrm{H}_{2}$ with higher substrate consumption, $27.95 \mathrm{mmol} \mathrm{L}-1$. Therefore, in the presence of iron and copper it is possible to increase the production of the hydrogen gas with greater consumption of glycerol. C. beijerinckii $\mathrm{Br} 21$ proved effective in converting glycerol to $\mathrm{H}_{2}$ since glycerol was the only source of carbon.
\end{abstract}

Keywords: biodiesel, residue, iron, copper, 1,3-propanediol, Clostridium beijerinckii $\mathrm{Br} 21$.

\section{INTRODUÇÃO}

Atualmente o etanol ainda é o principal biocombustível produzido e comercializado no Brasil, entretanto, o biodiesel vem ocupando considerável espaço neste mercado devido ao aumento de seu consumo. A produção do biodiesel tem como subproduto o glicerol (glicerina), onde cerca de $10 \%$ da produção corresponde a quantidade de glicerol obtida. Por exemplo, em 2015 no Brasil cerca de 3,9 milhões de $\mathrm{m}^{3}$ de biodiesel foi produzido, gerando 346,8 mil $\mathrm{m}^{3}$ de glicerol (ANP, 2016). A produção do biodiesel é decorrente da reação de transesterificação partindo de um triacilglicerol e álcool na presença de um catalisador gerando também o glicerol. Uma alternativa para o glicerol residual seria sua bioconversão em produtos de interesse industrial. Neste sentido, tem-se a utilização do glicerol para gerar gás hidrogênio $\left(\mathrm{H}_{2}\right)$ por fermentação (Trchounian et al., 2017).

Quando obtido de fontes renováveis, por exemplo, através dos processos bioquímicos, o gás hidrogênio é considerado uma fonte de energia renovável e limpa, pois sua combustão gera apenas água. Além disso, o $\mathrm{H}_{2}$ possui um alto valor energético, sendo $122 \mathrm{KJ} \mathrm{g}^{-1}$. Portanto, não colabora para o efeito estufa e serve como 
uma alternativa aos combustíveis fósseis (Lay et al.,1999; Mathews e Wang, 2009). Existem diversas formas de obtenção de $\mathrm{H}_{2}$, entre elas a fermentação, que consiste na conversão de carboidratos, como fonte de substrato, em gás carbônico e gás hidrogênio, através de microrganismos anaeróbios estritos ou facultativos (Amorim, 2007). Esse processo apresenta vantagens como alta velocidade de reação e tecnologia simples. O gênero que apresenta eficácia na fermentação para produção de $\mathrm{H}_{2}$ é o Clostridium (Fonseca et al., 2016). A espécie Clostridium beijerinckii é capaz de metabolizar diversos substratos, podendo transformar resíduos agroindustriais e biomassa em biocombustíveis. Trata-se de uma bactéria mesófila, gram-positiva, anaeróbia e formadora de endósporos (Wiegel et al.,2006). O C. beijerinckii possui metabolismo bifásico, possui uma fase acidogênica, que ocorre durante sua fase de crescimento exponencial, onde $\mathrm{o} \mathrm{h}_{2}$ e os ácidos acético e butírico são produzidos. A outra fase é a solvetogênica, na qual acetona, etanol e butanol são produzidos (Chen e Blaschek, 1999). De acordo com Sarma et al. (2012) o rendimento teórico máximo de $\mathrm{H}_{2}$ pela fermentação do glicerol é obtido quando somente ácido acético é obtido concomitantemente.

$$
\mathrm{C}_{3} \mathrm{H}_{8} \mathrm{O}_{3}+\mathrm{H}_{2} \mathrm{O} \rightarrow \mathrm{CH}_{3} \mathrm{COOH}+\mathrm{CO}_{2}+3 \mathrm{H}_{2} \quad \text { [Equação 1] }
$$

$\mathrm{O}$ metabolismo de glicerol possui duas vias, a oxidativa e a redutiva. Na via oxidativa o glicerol é convertido em dihidroxiacetona, catalisada pela enzima glicerol desidrogenase gerando equivalentes redutores, o $\mathrm{NADH}_{2}$. Em seguida a dihidroxiacetona é fosforilada gerando piruvato produto final da glicólise, e dependendo do microrganismo pode ser transformado em diversos produtos como ácido lático, etanol, ácido acético, ácido butírico, entre outros. Na via redutiva ocorre a conversão do glicerol em 3-hidroxipropionaldeído através da catálise pela enzima glicerol desidratase, que tem como cofator a coenzima $\mathrm{B}_{12}$. Em seguida, o 3hidroxipropionaldeído sofre redução produzindo 1,3 propanodiol (1,3-PDO) e o $\mathrm{NADH}_{2}$ é regenerado a NAD (Rodrigues, 2016). A equação 2 proposta por Tong et al. (1991) é a que descreve o maior rendimento de 1,3PDO, mediante a formação de ácido acético:

$$
4 \mathrm{C}_{3} \mathrm{H}_{8} \mathrm{O}_{3} \rightarrow 3 \mathrm{C}_{3} \mathrm{H}_{8} \mathrm{O}_{2}+\mathrm{H}_{3} \mathrm{CCOOH}+\mathrm{CO}_{2}+2 \mathrm{H}_{2} \mathrm{O} \quad \text { [Equação 2] }
$$

Sabe-se que os metais podem contribuir para o aumento da produção de $\mathrm{H}_{2}$ como no caso do $\mathrm{Fe}$ (II), em quantidades de traço, pois quantidades maiores geram inibição do microrganismo produtor de $\mathrm{H}_{2}$. A presença do íon Fe (II) é importante para a fermentação, uma vez que é cofator da enzima hidrogenase, responsável pela redução de prótons em $\mathrm{H}_{2}$ (Calusinska et al., 2010). Outro metal que pode contribuir é o cobre em baixas quantidades, aproximadamente $50-100 \mathrm{mg} \mathrm{L}^{-1}$, porém quantidades maiores que essas geram uma inibição do processo (Chiu-Yue e Shi-Heu, 2008). Entretanto, não existem trabalhos que relacionem a concentração dos metais ferro (II) e cobre para a produção de $\mathrm{H}_{2}$ a partir da fermentação do glicerol, que foi o objeto de estudo do seguinte trabalho.

\section{Ensaios de fermentação em batelada}

\section{MATERIAL E MÉTODOS}

Utilizou-se cepa de C. beijerinckii Br21 isolada e identificada pelo laboratório de biotecnologia ambiental e energias renováveis (LABIORE) (Fonseca et al., 2016). Os ensaios de fermentação foram realizados utilizando meio de cultura descrito por Trchounian (2017) coma seguinte composição: $\mathrm{K}_{2} \mathrm{HPO}_{4} 1,5$ $\mathrm{g} \mathrm{L}^{-1}, \mathrm{KH}_{2} \mathrm{PO}_{4} 1,5 \mathrm{~g} \mathrm{~L}^{-1}, \mathrm{MgSO}_{4} .7 \mathrm{H}_{2} \mathrm{O}$ 0,492 $\mathrm{g} \mathrm{L}^{-1}$, L-Cisteína 0,5 g L $\mathrm{g}^{-1}, \mathrm{MnSO}_{4} \cdot \mathrm{H}_{2} \mathrm{O} 0,015 \mathrm{~g} \mathrm{~L}^{-1}, \mathrm{FeSO}_{4} \mathrm{X}$ $7 \mathrm{H}_{2} \mathrm{O} 0,02 \mathrm{~g} \mathrm{~L}^{-1}$, extrato de levedura $0,5 \mathrm{~g} \mathrm{~L}^{-1}$, ácido aminobenzoico $0,002 \mathrm{~g} \mathrm{~L}^{-1}$, tiamina $0,002 \mathrm{~g} \mathrm{~L}^{-1} \mathrm{e}$ biotina $0,0004 \mathrm{~g} \mathrm{~L}^{-1}$. O pH do meio foi de 6,9. Foram preparadas soluções dos metais $\mathrm{Fe}^{2+} \mathrm{e} \mathrm{Cu}^{2+}$ ambos $0,01 \mathrm{mmol} \mathrm{L}^{-}$ ${ }^{1}$. O pré-inóculo foi preparado com meio contendo glicerol $110 \mathrm{mmol} \mathrm{L}^{-1}$. Os ensaios foram realizados com 35 $\mathrm{mL}$ meio, $2 \mathrm{~mL}$ de glicerol e $1 \mathrm{~mL}$ de solução de vitaminas, as soluções dos metais ferro e cobre $1 \mathrm{~mL}$ e $2 \mathrm{~mL}$ do microrganismo a partir do pré-inóculo. Os ensaios foram realizados em triplicata para cada condição: ferro, cobre e mistura de ferro e cobre, e sem a solução de metais (controle). Todos foram colocados em agitação por 60 horas a $35^{\circ} \mathrm{C}$.

\section{Concentração dos substratos e produtos}

Foram retiradas amostras no tempo inicial e final da fermentação, para análise de $\mathrm{pH}$, densidade óptica (D.O) e análise dos produtos solúveis do metabolismo. A análise e determinação do gás hidrogênio produzido foi realizada ao final da fermentação (60 horas). Os produtos formados e o substrato consumido nos ensaios de fermentação foram quantificados através da análise por cromatografia líquida de alta eficiência. Já para a determinação do gás hidrogênio $\left(\mathrm{H}_{2}\right)$ produzido durante os ensaios realizou-se no cromatógrafo a gás uma 
curva padrão, na qual volumes conhecidos do gás foram injetados obtendo suas respectivas áreas e relacionados com a porcentagem correspondente ao volume injetado. Dessa forma, foi possível obter uma relação e uma equação da reta $(\mathrm{y}=43.831,68 \mathrm{x}-325.957,30)$, com $\mathrm{R}^{2}=0,99$, que foi utilizada para os cálculos da porcentagem de $\mathrm{H}_{2}$ contidos no headspace, que é a parte gasosa presente nos frascos das amostras dos ensaios de fermentação.

\section{RESULTADOS E DISCUSSÃO}

Através dos ensaios de fermentação tendo glicerol como substrato suplementado com as soluções dos metais ferro e cobre, foi possível verificar que os valores de $\mathrm{pH}$ tanto no tempo zero como no tempo final (60 horas) foram próximos para as diferentes condições. Contudo, houve leve aumento no valor do $\mathrm{pH}$, principalmente no ensaio com adição de ferro em comparação com o controle (sem soluções de metais). Foi observado aumento na D.O, como esperado, no tempo final, isso porque as células se reproduziram, onde variação da D.O nos ensaios controle (sem adição dos metais), no ensaio com Fe, no ensaio com Cu e no ensaio $\mathrm{Fe}$ e $\mathrm{Cu}$ foi de 0,246 0,436, 0,334 e 0,250, respectivamente. Contudo foi possível observar que a adição da solução somente de ferro ao meio gerou maior crescimento celular em relação ao controle e aos outros metais. Verificou-se que a maior produção do gás hidrogênio se deu com a adição da solução de mistura de cobre e ferro ao meio de cultura, 14,09 $\mathrm{mmol} \mathrm{L}^{-1}$, sendo 13,34 $\mathrm{mmol} \mathrm{L}^{-1}$ (controle), 12,34 $\mathrm{mmol} \mathrm{L}^{-1}$ (cobre), 10,46 $\mathrm{mmol} \mathrm{L}^{-1}$ (ferro) Figura 1 (A). As análises em cromatografia líquida de alta eficiência permitiram determinar a quantidade do glicerol consumido durante o ensaio de fermentação, Figura 1 (B), e os produtos solúveis do metabolismo do C. beijerinckii $\mathrm{Br} 21$, Figura 1 (C). A concentração inicial de glicerol foi $110 \mathrm{mmol} \mathrm{L}^{-1}$ e o ensaio com maior consumo de substrato foi com cobre e ferro, pois, 27,95 $\mathrm{mmol} \mathrm{L}^{-1}$, seguido de $24,17 \mathrm{mmol}$ $\mathrm{L}^{-1}$ (controle), 21,29 $\mathrm{mmol} \mathrm{L}^{-1}$ (ferro), 19,83 $\mathrm{mmol} \mathrm{L}^{-1}$ (cobre). Os rendimentos de $\mathrm{H}_{2}$ por glicerol consumido foram de $62 \%$ (cobre), $55 \%$ (controle), $50 \%$ (cobre e ferro) e $49 \%$ (ferro), comparando-se com o teórico apresentado na Equação 1. O principal produto solúvel da fermentação do glicerol foi o 1,3-PDO com maior formação no ensaio com cobre $14,12 \mathrm{mmol} \mathrm{L}^{-1}$ com rendimento de $71 \%$. No entanto, neste mesmo ensaio não foi o que observada a maior produção de gás hidrogênio. Para o ensaio de ferro foi obtido $13,77 \mathrm{mmol} \mathrm{L}^{-1}$ de 1,3-PDO, rendimento de $65 \%$, seguido de $9,59 \mathrm{mmol} \mathrm{L}^{-1}$ para o controle, rendimento de $40 \%$ e $7,01 \mathrm{mmol} \mathrm{L}^{-}$ ${ }^{1}$ para o ensaio contendo ferro+cobre com rendimento de $25 \%$. Assim, a interferência dos metais ferro, cobre e a combinação desses metais foram estudadas e mostradas nos diferentes aspectos de consumo de glicerol, formação de $\mathrm{H}_{2}$ como produto da fase gasosa e 1,3-PDO como produto solúvel no meio de cultura, liberado pelo metabolismo do glicerol através do C. beijerinckii $\mathrm{Br} 21$.

\section{CONCLUSÃO}

Através do uso do glicerol como fonte de carbono, considerado um subproduto da reação de formação do biodiesel, utilizando o metabolismo do C. beijerinckii $\mathrm{Br} 21$ é possível converter o glicerol em gás hidrogênio e 1,3-PDO. Essa conversão é realizada de maneira não agressiva ao meio ambiente, sendo uma alternativa aos combustíveis fósseis para fonte de energia. Dessa forma, adicionando ao meio de cultura soluções de metais (ferro (II) e cobre (II)) é possível aumentar a produção do gás hidrogênio, levando também a um consumo maior de glicerol e formação de outros produtos solúveis no meio, como o 1,3 propanodiol. O C. beijerinckii $\mathrm{Br} 21$ é um microrganismo que se mostrou efetivo na conversão do glicerol em $\mathrm{H}_{2}$, pois conseguiu crescer e se multiplicar usando apenas essa fonte de carbono.

\section{AGRADECIMENTOS}

O presente trabalho foi realizado com apoio da Coordenação de Aperfeiçoamento de Pessoal de Nível Superior - Brasil (CAPES) - Código de Financiamento 001.

\section{REFERÊNCIAS}

AMORIM, E.L.C. Desempenho de reator anaeróbio de leito fluidificado operado sob condições de aumento progressivo da carga orgânica no tratamento de fenol. Dissertação de Mestrado - USP, São Carlos, p. 145, 2007.

Agência Nacional do Petróleo, Gás Natural e Biocombustíveis. Consulta do anuário estatístico 2016, disponível em: http://www.anp.gov.br/images/publicacoes/Anuario_Estatistico_ANP_2016.pdf

Calusinska, M. The Surprising Diversity of Clostridial Hydrogenases: a comparative genomic perspective. MICROBIOLOGY, 156, 1575-1588, 2010. 
CHEN, C.K.; BLASCHEK, H.P. Examination of Physiological and Molecular Factors Involved in Enhanced Solvent Production by Clostridium beijerinckii BA101. Applied and Environmental Microbiology, v. 65(5): 2269-2271, 1999.

Chiu-Yue, L., Shi-Heu, S. Heavy metal effects on fermentative hydrogen production using natural mixed microflora. International journal of hydrogen energy 33, 587- 593, 2008.

FONSECA, B.C. et al. Fermentative production of $\mathrm{H}_{2}$ from different concentrations of galactose by the new isolate Clostridium beijerinckii Br21. International journal of hydrogen energy v. 41, p. 21109- 21120, 2016.

HALLENBECK, P.C. Fundamentals of the fermentative production of hydrogen. Water Science Technologies, v. 52 (1-2): 21-29, 2005.

LAY, J.J. et al. Feasibility of biological hydrogen production from organic fraction of municipal solid waste. Water Res. 33:2576-2586, 1999.

MATHEWS, S.G.; WANG, G. Metabolic pathway engineering for enhanced biohydrogen production. International Journal of Hydrogen Energy, v.34: 7404, 2009.

NTAIKOU, I. et al. Biohydrogen Production from Biomass and Wastes via Dark Fermentation: a Review. Waste Biomass Valorization, v. 1: 21-39, 2010.

RODRIGUES, C.V. Produção biotecnológica de hidrogênio partir do glicerol, bioproduto da produção do biodiesel. Dissertação de Mestrado - UNESP, Araraquara, 151 f, 2016.

SARMA S.J. et al. Microbial hydrogen production by bioconversion of crude glycerol: a review.

International Journal of Hydrogen Energy, v. 37, p. 6473-6490, 2012.

TONG, I.T. et al. 1,3-propanediol production by Escherichia coli expressing genes from the Klebsiella pneumoniae dha regulon. Applied and environmental microbiology, v.57, p. 3541-3546, 1991.

TRCHOUNIAN, Karen et al. Glycerol and mixture of carbon sources conversion to hydrogen by Clostridium beijerinckii DSM791 and effects of various heavy metals on hydrogenase activity. International journal of hydrogen energy v.42, p. 7875- 7882, 2017.

WEIGEL, J. et al. Prokaryote. New York Springer, v.3: 654-678, 2006.

A
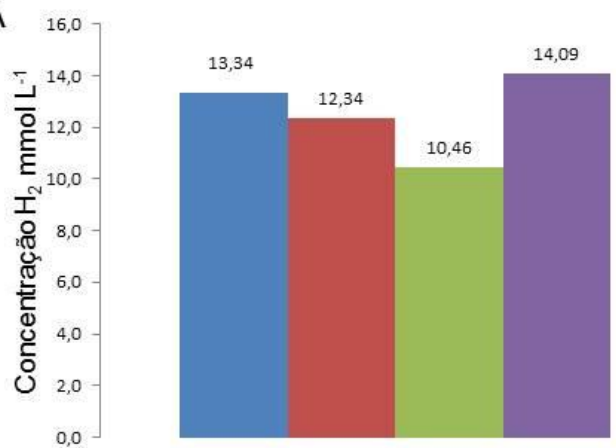

$\mathrm{H}_{2}$

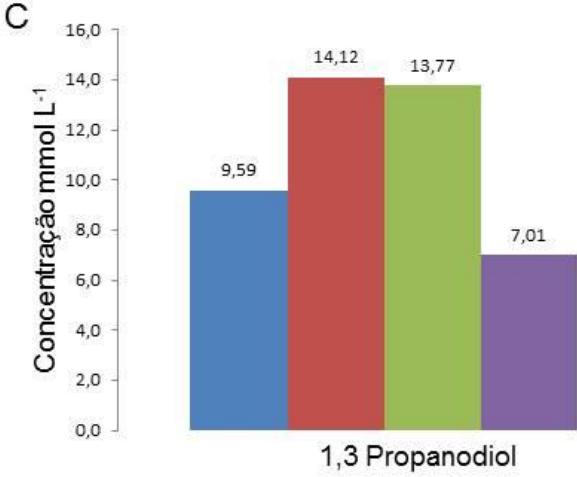

B
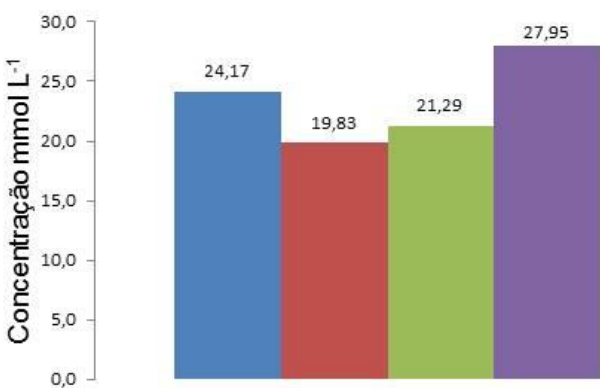

Glicerol consumido

를 Cobre

- Ferro

E Ferro + Cobre

Figura 1. Ensaio fermentativo de glicerol $110 \mathrm{mmol} \mathrm{L}^{-1}$ por $C$. beijerinckii $\mathrm{Br} 21$ utilizando meio de cultura descrito por Trchounian (2017). A- Gás hidrogênio produzido $\left(\mathrm{H}_{2}\right), \mathrm{mmol} \mathrm{L}^{-1}$. B- Glicerol consumido, mmol $\mathrm{L}^{-1}$. C- 1,3-Propanodiol produzido, $\mathrm{mmol} \mathrm{L}^{-1}$. 


\title{
ELETROCOAGULAÇÃO DE VINHAÇA DE CANA-DE-AÇÚCAR: DESEMPENHO, CUSTO E SEDIMENTAÇÃO DO LODO GERADO
}

\author{
Montaño, M.D.S. ${ }^{* 1}$; Bastos, R.G. ${ }^{1}$; Cardenas, V.O.C. ${ }^{2}$ \\ ${ }^{1}$ Universidade Federal de São Carlos (UFSCar), Centro de Ciências Agrárias, SP - Brasil. \\ ${ }^{2}$ Universidade Federal de São Paulo (UNIFESP), Departamento de Engenharia Química, SP - Brasil. \\ reinaldo.bastos@ufscar.br
}

\begin{abstract}
RESUMO: A agroindústria de produção de etanol combustível gera grandes quantidades de vinhaça como principal água residuária do processo. Embora a legislação permita seu uso como fertirrigação, tal volume é restrito e dependente das características do solo a ser aplicado, sendo que o restante deve receber um tratamento adequado para sua posterior descarga ao ambiente ou reuso. Nesse sentido, o presente trabalho teve como objetivo avaliar o processo de eletrocoagulação como alternativa para o tratamento da vinhaça de cana-deaçúcar. Para tal fim usou-se um reator eletrolítico de batelada com eletrodos de alumínio espaçados $3 \mathrm{~cm}$. A corrente elétrica e agitação foi fixada em 6 A e 450 rpm, respectivamente. Após três horas de eletrocoagulação, observou-se uma clara separação entre fases sólido-líquido da vinhaça e após cinco horas de eletrólise e posterior sedimentação por gravidade $(24 \mathrm{~h})$, obteve-se um efluente altamente clarificado (remoção de $99 \%$ da turbidez) e com pH 7,8. Além de neutralizar o efluente inicialmente ácido $(4,3)$, o tratamento também removeu quantidades consideráveis de sólidos dissolvidos, cor e carga orgânica, consumindo $3,6 \mathrm{~kg} \mathrm{~m}^{-3} \mathrm{de}^{\mathrm{a}}$ alumínio metálico e $46,10 \mathrm{kWh} \mathrm{m}^{-3}$ de energia elétrica, com custo aproximado de $\mathrm{R} \$ 47,50 \mathrm{~m}^{-3}$. O lodo gerado após eletrocoagulação apresentou uma baixa velocidade de sedimentação por gravidade $\left(0,12 \mathrm{~cm} \mathrm{~min}^{-1}\right)$ e um elevado volume final após 24 h (40\%), pelo que se sugere o estudo de outros métodos de separação do lodo.
\end{abstract}

Palavras-chave: clarificação, destilaria, efluente, eletroquímica, turbidez.

\section{SUGARCANE VINASSE ELECTROCOAGULATION: PROCESS PERFORMANCE, TREATMENT COST AND SLUDGE SETTLING}

\begin{abstract}
Ethanol biofuel productive process generates large amounts of vinasse, the effluent from the production process. Although the legislation allows its use as fertigation, such volume is restricted. Thus, the remaining effluent must receive a suitable treatment for its subsequent discharge into the environment or reuse. By this way, the present work objective is to evaluate the process of electrocoagulation as an alternative for the treatment of sugar cane vinasse. For this purpose was used a batch electrolytic reactor with $3 \mathrm{~cm}$ gap aluminum electrodes. The electric current and stirring was set at $6 \mathrm{~A}$ and $450 \mathrm{rpm}$, respectively, during the electrolysis. After three hours of electrocoagulation, a clear separation of solid-liquid phases was observed and after five hours of electrolysis and subsequent sedimentation by gravity $(24 \mathrm{~h})$ a highly clarified effluent was obtained (turbidity removal of $99 \%$ ) and $\mathrm{pH}$ 7.8. In addition to initially acidic effluent neutralization (initial $\mathrm{pH}$ of vinasse $=4.3$ ), the treatment also removed considerable amounts of dissolved solids, color and organic matter, consuming $3.6 \mathrm{~kg} \mathrm{~m}^{-3}$ of metallic aluminum and $46.10 \mathrm{kWh} \mathrm{m}^{-3}$ of electrical energy. The approximate cost of the process calculated from the previous mentioned values was $47.50 \mathrm{R} \$ \mathrm{~m}^{-3}$. The sludge generated after electrocoagulation showed a low sedimentation velocity by gravity $(0.12 \mathrm{~cm} \mathrm{~min}-1)$ and a high final volume after $24 \mathrm{~h}(40 \%)$, suggesting the study of other methods of sludge separation.
\end{abstract}

Keywords: clarification, distillery, effluent, electrochemistry, turbidity.

\section{INTRODUÇÃO}

No Brasil, a produção anual de etanol combustível a partir de cana-de-açúcar atinge mais de 27 bilhões de litros, sendo a atividade agroindustrial mais importante para a economia do país (IBGE, 2015). Estima-se que, com os processos produtivos atuais, cada litro de etanol gera entre 10 a 14 litros de vinhaça, a principal água residuária do processo. Atualmente, a legislação permite a disposição da vinhaça no solo em forma de fertirrigação (CETESB, 2006). No entanto, o volume é restrito segundo a demanda de nutrientes da cultura e as caraterísticas do solo, sendo que o efluente restante deve ser adequadamente tratado antes de sua descarga no ambiente. 
Nos últimos anos, diversos pesquisadores têm procurado métodos de tratamento deste efluente. Devido a que suas caraterísticas físico-químicas podem limitar a aplicação dos tratamentos biológicos convencionais (España-Gamboa et al., 2011), entre as alternativas pode se encontrar a eletrocoagulação. Este método eletroquímico baseia-se na geração in situ simultânea de espécies químicas coagulantes (íons $\mathrm{Al}^{+3} \mathrm{ou} \mathrm{Fe}^{+2}$, segundo o material anódico utilizado), hidrogênio gasoso $\left(\mathrm{H}_{2}\right)$ e íons hidroxilo $\left(\mathrm{OH}^{-}\right)$pela corrosão eletrolítica de um ânodo de sacrifício e pela decomposição da água na superfície do cátodo, desencadeada pela passagem de uma corrente elétrica entre eletrodos (Garcia-Segura et al., 2017). Após a geração de uma determinada quantidade de coagulante, ocorre a desestabilização e agregação do material suspenso e coloidal, sendo que a mistura bifásica gerada deve ser separada mediante filtração, centrifugação ou sedimentação. No último caso, as partículas agregadas se separam pela ação da gravidade, formando o lodo como no caso da coagulação química convencional (Mollah et al., 2001).

Nesse sentido, o presente trabalho teve como objetivo avaliar o processo de eletrocoagulação da vinhaça de cana-de-açúcar, apresentando o custo aproximado do tratamento e as características de sedimentabilidade do lodo gerado.

\section{MATERIAL E MÉTODOS}

A vinhaça utilizada no estudo foi coletada o mês de setembro 2017 diretamente da saída das colunas de destilação de uma usina sucroalcooleira de Araras, São Paulo em recipientes plásticos de $20 \mathrm{~L}$, sendo conduzida para o Laboratório de Microbiologia Aplicada e Controle (LABMAC) da Universidade Federal de São Carlos (UFSCar), Campus Araras. No local, as amostras foram fracionadas e congeladas até seu uso.

Para a eletrocoagulação, usou-se um reator eletrolítico de bancada tipo batelada sem controle de temperatura nem $\mathrm{pH}$, composto por: fonte elétrica de corrente contínua (0-12 V; 0-50 A); cuba eletrolítica de material plástico de $15 \times 15 \times 15 \mathrm{~cm}$, contendo $2,8 \mathrm{~L}$ de vinhaça; eletrodos de alumínio em arranjo paralelo, 2 cátodos e 2 ânodos, com uma área anódica total de $300 \mathrm{~cm}^{2}$ (relação área anódica: volume $=0,107 \mathrm{~cm}^{-1}$ ) e distância cátodo-ânodo de $3 \mathrm{~cm}$; agitador magnético na base da cuba $(450 \mathrm{rpm})$. A eletrocoagulação foi feita em triplicata, por cinco horas, corrente constante de $6 \mathrm{~A}$ (densidade de corrente $=20 \mathrm{~mA} \mathrm{~cm}{ }^{-2}$ ) e inversão de polaridade automática em intervalos de $15 \mathrm{~min}$, para evitar a polarização dos eletrodos.

A coleta de amostras ocorreu nos tempos de três a cinco horas, em intervalos de 30 minutos, para posterior sedimentação por 24 horas em tubos de ensaio e caraterização físico-química do sobrenadante, segundo a metodologia da APHA (2005). Após cinco horas de eletrocoagulação, realizou-se o teste de sedimentação do lodo em uma coluna de vidro de $37 \mathrm{~cm}$ de altura e $5,8 \mathrm{~cm}$ de diâmetro. Calculou-se o custo do tratamento segundo Güçlï (2014), levando em consideração o consumo de energia elétrica do processo e o consumo teórico de eletrodos calculado segundo a lei de Faraday. Os resultados são apresentados como o valor médio \pm erro padrão.

\section{RESULTADOS E DISCUSSÃO}

A caraterização físico-química da vinhaça bruta e após cinco horas de eletrocoagulação é apresentada na Tabela 1. Entre os parâmetros do efluente bruto destacam-se o pH ácido, a elevada turbidez e matéria orgânica. Do ponto de vista eletroquímico, a elevada condutividade elétrica da vinhaça favorece a passagem de corrente elétrica entre eletrodos, o que permite realizar o tratamento usando um baixo voltagem $(4,3 \pm 0,4 \mathrm{~V})$ e sem adição de sais ou eletrólitos suporte, necessários para a eletrocoagulação de efluentes com condutividades elétricas menores (Garcia-Segura et al., 2017).

Observou-se alcalinização do efluente com remoção de sólidos dissolvidos. Esta é uma característica da eletrocoagulação e se constitui numa das principais vantagens do processo quando comparado à coagulação química, a qual tende a diminuir o $\mathrm{pH}$ após tratamento e além adicionar espécies químicas contaminantes como $\mathrm{Na}^{+}, \mathrm{Cl}^{-1}$ ou $\mathrm{SO}_{4}^{-2}$ (Cañizares et al., 2009). Nesse sentido, a correição de $\mathrm{pH}$ sem adição de reagentes químicos pode ser de grande interesse um pós-tratamento por métodos biológicos e subsequente reuso do efluente (Fuess et al., 2018).

A eletrocoagulação atingiu uma remoção de $65 \%$ da cor do efluente. Sabe-se que a cor marrom escura caraterística da vinhaça é devida ao seu elevado teor de taninos, ácidos húmicos, caramelos e melanoidinas, compostos produzidos a partir da reação de Maillard entre açúcares e proteínas quando submetidas a elevadas temperaturas comuns em algumas etapas do processo de produção de açúcar e etanol (España-Gamboa et al., 2011). Levando em conta que esses compostos têm caraterísticas recalcitrantes e antimicrobianas que podem 
dificultar o tratamento biológico deste efluente (Arimi et al., 2014), pode se sugerir a eletrocoagulação como uma etapa prévia a esses bioprocessos.

$\mathrm{Na}$ Figura 1 se apresentam os valores percentuais de turbidez remanescente segundo o tempo de eletrocoagulação a partir de $3 \mathrm{~h}$, tempo desde o qual conseguiu-se uma nítida separação de fases sólido-líquido na sedimentação da vinhaça eletrocoagulada. Atinge-se um elevado grau de clarificação da vinhaça após o tratamento, diminuindo consequentemente uma parte considerável da matéria orgânica presente no efluente. Tal resultado é similar ao obtido por Kannan et al. (2006) e confirma a eficiência do processo para a desestabilização do material suspenso e coloidal da vinhaça, que origina sua elevada turbidez inicial.

O custo estimado do processo mostra um comportamento lineal conforme o tempo (Figura 1), atingindo $\mathrm{R} \$ 47,50$ por $\mathrm{m}^{3}$ após cinco horas. Analisando os componentes do custo total, após cinco horas de eletrólise

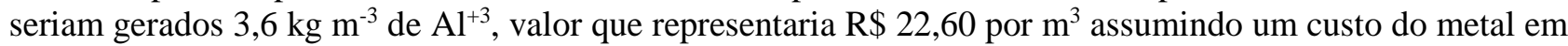
forma sólida (placas de alumínio) de $\mathrm{R} \$ 6,28$ por $\mathrm{kg}$ (Demirbas e Kobya, 2017). Por outro lado, o consumo de energia elétrica após esse tempo atingiu $46,10 \mathrm{kWh} \mathrm{m}^{-3}$, valor que representa um custo de $\mathrm{R} \$ 24,90$ por $\mathrm{m}^{3}$ considerando o preço médio da eletricidade no Brasil de $\mathrm{R} \$ 0,54$ por $\mathrm{kWh}$ (ANEEL, 2018).

Além da eficiência do processo, é também importante avaliar a sedimentabilidade do lodo gerado, devido a que a facilidade na separação sólido-líquido é fundamental para escolher ou não a eletrocoagulação como tecnologia de tratamento. Na Figura 2 observa-se que o lodo gerado sedimenta seguindo o modelo proposto por Kynch (1952). Pode-se distinguir uma fase de decréscimo constante da interfase sólido-líquido após 10-15 minutos se sedimentação, atingindo a velocidade média de $0,12 \mathrm{~cm} \mathrm{~min}^{-1}$ no período de até $2 \mathrm{~h}$. Após esse tempo, começa a fase de compressão do lodo, até atingir o volume final de $40 \%$ após 24 horas. A velocidade de sedimentação do lodo é menor ao respeito de valores encontrados em trabalhos similares, na ordem de 0,5 a $4 \mathrm{~cm} \mathrm{~min}^{-1}$ (Zodi et al., 2010). Tal diferença pode ser atribuída a uma possível menor densidade do floco gerado após eletrocoagulação da vinhaça ou ao elevado teor de sólidos suspensos do efluente, o que dificultaria o processo de sedimentação por gravidade.

\section{CONCLUSÃO}

A eletrocoagulação da vinhaça de cana-de-açúcar mostrou-se como um método eficiente para a clarificação e neutralização do efluente bruto, removendo além quantidades consideráveis de sólidos dissolvidos, cor e carga orgânica. O custo do processo após cinco horas de eletrólise foi calculado como $\mathrm{R} \$ 47,50$ por $\mathrm{m}^{3}$, considerando a massa de eletrodos consumida e a demanda de energia elétrica do processo. O lodo gerado apresentou uma baixa velocidade de sedimentação $\left(0,12 \mathrm{~cm} \mathrm{~min}^{-1}\right)$ e um elevado volume final (40\%) no teste de sedimentação por gravidade, pelo que se sugere testar outros métodos de separação do lodo.

\section{AGRADECIMENTOS}

Os autores agradecem à Fundação de Amparo à Pesquisa do Estado de São Paulo (FAPESP) pelo suporte financeiro (Processo: 17/21617-7).

\section{REFERÊNCIAS}

ANEEL. Ranking das tarifas, 2018. Disponível em: < http://www.aneel.gov.br/ranking-das-tarifas>. Acesso em: 9 abr. 2018.

APHA - American Public Health Association. Standard Methods for the Examination of Water and Wastewater, 21 ed. Washington, D.C. 2005.

ARIMI, M. M. et al. Antimicrobial colorants in molasses distillery wastewater and their removal technologies.

International Biodeterioration \& Biodegradation. v. 87, p. 34-43. 2014.

CAÑIZARES, P. et al. The $\mathrm{pH}$ as a key parameter in the choice between coagulation and electrocoagulation for the treatment of wastewaters. Journal of Hazardous Materials. v. 163, p. 158-164. 2009.

CETESB, 2005. Norma Técnica P4.231 - Vinhaça: Critérios e Procedimentos para Aplicação no Solo Agrícola. Disponível em: <http://www.cetesb.sp.gov.br/Tecnologia//P4_231.pdf>. Acesso em: 30 ago. 2018.

DEMIRBAS, E.; KOBYA, M. Operating cost and treatment of metalworking fluid wastewater by chemical coagulation and electrocoagulation processes. Process Safety and Environmental Protection. v. 105, p. 7990. 2017.

ESPAÑA-GAMBOA, E. et al. Vinasses: characterization and treatments. Waste Management \& Research. v. 29, n. 12, p. 1235-1250. 2011. 


\section{VISIGERÄ DEF7 A09 MA0 2019

FUESS, L. T.; GARCIA, M. L.; ZAIAT, M. Seasonal characterization of sugarcane vinasse: Assessing environmental impacts from fertirrigation and the bioenergy recovery potential through biodigestion. Science of The Total Environment. v. 634, p. 29-40, 2018.

GARCIA-SEGURA, S. et al. Electrocoagulation and advanced electrocoagulation processes: A general review about the fundamentals, emerging applications and its association with other technologies. Journal of Electroanalytical Chemistry. v. 801, p. 267-299, 2017.

GÜÇLÜ, D. Optimization of electrocoagulation of pistachio processing wastewaters using the response surface methodology. Desalination and Water Treatment. v. 54, n. 12, p. 3338-3347. 2015.

IBGE. Pesquisa Industrial - Produto, 2015. Disponível em: <http://www.ibge.gov.br/home/estatistica/ economia/industria/pia/produtos/produto2015/defaultproduto.shtm>. Acesso em: 30 ago. 2018.

KANNAN, N.; KARTHIKEYAN, G.; TAMILSELVAN, N. Comparison of treatment potential of electrocoagulation of distillery effluent with and without activated Areca catechu nut carbon. Journal of Hazardous Materials. v. B137, p. 1803-1809. 2006.

KYNCH, G. J. A theory of sedimentation. Transactions of the Faraday Society. v. 48, p. 166-176. 1952. MOLLAH, M. Y. A. et al. Electrocoagulation (EC) - science and applications. Journal of Hazardous Materials. v. B84, p. 29-41. 2001.

ZODI, S. et al. Treatment of the industrial wastewaters by electrocoagulation: Optimization of coupled electrochemical and sedimentation processes. Desalination. v. 261, n. 1-2, p. 186-190. 2010.

Tabela 1. Caracterização físico-química da vinhaça bruta e após cinco horas de eletrocoagulação.

\begin{tabular}{lccc}
\hline \multicolumn{1}{c}{ Parâmetro } & Vinhaça bruta & Vinhaça tratada & Remoção \\
\hline Turbidez (NTU) & $2.440 \pm 400$ & $15 \pm 2$ & $99 \%$ \\
pH & $4,3 \pm 0,1$ & $7,8 \pm 0,1$ & - \\
Cor verdadeira (Abs $475 \mathrm{~nm})$ & $0,38 \pm 0,07$ & $0,13 \pm 0,01$ & $65 \%$ \\
Sólidos dissolvidos totais $\left(\mathrm{mg} \mathrm{L}^{-1}\right)$ & $7.410 \pm 820$ & $5.980 \pm 780$ & $19 \%$ \\
Carbono orgânico total $\left(\mathrm{mg} \mathrm{L}^{-1}\right)$ & $10.030 \pm 450$ & $5.805 \pm 210$ & $42 \%$ \\
Condutividade elétrica $\left(\mathrm{mS} \mathrm{cm}^{-1}\right)$ & $14,8 \pm 1,6$ & $12,0 \pm 1,6$ & $19 \%$ \\
\hline
\end{tabular}

Valor médio \pm desvio padrão $(n=3)$.

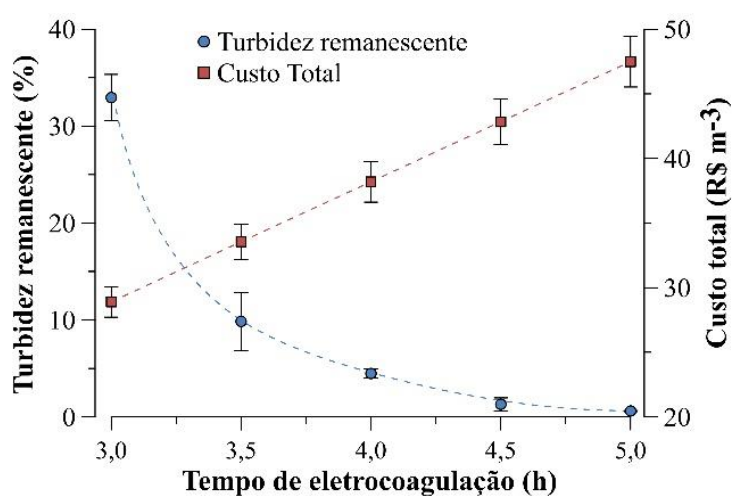

Figura 1. Turbidez remanescente e custo total da eletrocoagulação segundo o tempo do processo.

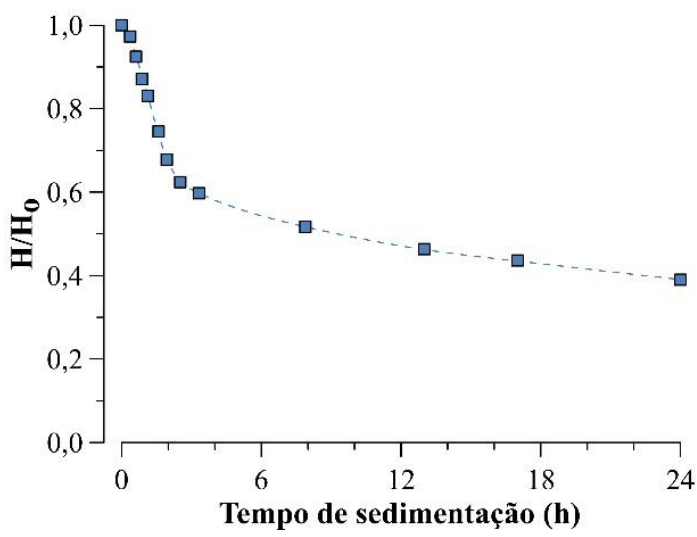

Figura 2. Curva de sedimentação da vinhaça eletrocoagulada por cinco horas: altura da interfase sólido-líquido conforme o tempo de sedimentação. 


\title{
ESTUDO DA REMOÇÃO DO CORANTE VERMELHO REATIVO POR BIOSSORÇÃO COM SABUGO DE MILHO
}

\author{
Oliveira, A.P.*1' Hellmann, L. $^{2}$; Antoniolli, C.A. ${ }^{1}$; Gressele, A. ${ }^{1}$; Bernabé, B.A. ${ }^{1}$; Gusmão, A.G. ${ }^{1}$; \\ ${ }^{I}$ Departamento de Engenharia Química - Universidade Tecnológica Federal do Paraná(UTFPR), Francisco Beltrão, PR - Brasil; \\ ${ }^{2}$ Programa de Pós-Graduação em Engenharia Química - Universidade Estadual do Oeste de Paraná, Toledo, PR - Brasil \\ anapoliveira@utfpr.edu.br
}

\begin{abstract}
RESUMO: Este trabalho teve como finalidade avaliar a aplicação do resíduo agroindustrial de sabugo de milho na biossorção do corante vermelho reativo. Neste processo, ocorre a transferência do poluente da fase líquida (adsorbato) para o material sólido (adsorvente), no qual o mesmo fica retido. O estudo de adsorção em batelada para a remoção do corante foi realizado a partir de testes preliminares, determinando-se condições operacionais como $\mathrm{pH}$, temperatura e granulometria, bem como estudo cinético e de equilíbrio. Foram determinadas como condições ideais de operação $\mathrm{pH}$ inicial igual a 2,0 , temperatura de $25^{\circ} \mathrm{C}$ e mistura granulométrica, sob agitação de $90 \mathrm{rpm}$. Ao analisar os dados cinéticos, verificou-se que o tempo de equilíbrio ocorre em torno de 16 horas, sendo que o modelo cinético Elovich descreveu adequadamente o processo. No estudo de equilíbrio, a isoterma de Freundlich foi a que se ajustou melhor aos dados, com coeficiente de determinação de $\mathrm{R}^{2}=0,9919$. Os resultados obtidos demonstram a potencialidade de emprego do sabugo de milho como biossorvente em sistemas de tratamento de efluentes contendo o corante vermelho reativo.
\end{abstract}

Palavras-chave: adsorção, resíduos agroindustriais, tratamento de efluentes.

\section{REACTIVE RED DYE REMOVAL STUDY BY BIOSORPTION WITH CORN COB}

ABSTRACT: The objective of this work was the evaluation of the application of the agroindustrial residue corn cob on the adsorption of the reactive red dye. In this process, it is possible to transfer the pollutant from the liquid phase (adsorbate) to the solid material (adsorbent), in which it is retained. The batch adsorption study for dye removal was performed from preliminary tests, determining operating conditions such as $\mathrm{pH}$, temperature and granulometry, as well as the kinetic and equilibrium study. The ideal operational conditions were determined as $\mathrm{pH} 2,0,25^{\circ} \mathrm{C}$ temperature and granulometric mix, under $90 \mathrm{rpm}$ agitation. When analysing the kinetic study, it was verified that the balance time occurs in about 16 hours, and that the Elovich kinetic model properly described the process. In the equilibrium study, Freundlich isotherm was the one that best fit the data, with a coefficient of determination of $\mathrm{R}^{2}=0,9919$. The results obtained demonstrate the potential of using corn cob as a biosorbent in effluent treatment cointaining reactive red dye.

Keywords: adsorption, agroindustrial residues, effluent treatment.

\section{INTRODUÇÃO}

A indústria têxtil destaca-se como uma fonte significativa de contaminação de ambientes aquáticos, produzindo efluentes com grandes quantidades de corantes (Mokhtar et al., 2017; Temesgen et al., 2018). As moléculas de corante são complexas e estáveis, caracterizando águas residuais com alta coloração, de baixa biodegradabilidade, prejudicial às atividades fotossintéticas e tóxicas para os organismos que entram em contato com corpos d'água (Ribeiro et al., 2015).

Os métodos de tratamento de efluentes contendo corantes sintéticos utilizados nas indústrias apresentam limitações técnicas e econômicas, portanto, o processo de biossorção tem recebido destaque decorrente da viabilidade econômica em termos de custos reduzidos de implantação da técnica e do material adsorvente, simplicidade de projeto e facilidade de operação (Garg et al., 2004; Bouras et al., 2017).

As características econômicas da região Sudoeste do Paraná indicam o grande desenvolvimento agrícola e da pecuária regional, o que aponta a potencialidade de geração de resíduos como o sabugo de milho, que geralmente é destinado a alimentação animal. Desta forma, este projeto avaliou a utilização do resíduo agrícola de sabugo de milho como adsorvente alternativo para o processo de remoção do corante têxtil Vermelho Reativo em meio aquoso. 


\section{MATERIAL E MÉTODOS}

O preparo do sabugo de milho foi realizado a partir da lavagem com água corrente, secagem à $45^{\circ} \mathrm{C}$, trituração mecânica e separação em frações granulométricas entre 0,04 à $1 \mathrm{~mm}$.

Para a determinação do valor de $\mathrm{pH}$ onde a carga superficial do biossorvente é nula (pHpcz), seguiu-se a metodologia descrita por Davranche et al. (2003). Utilizaram-se dois erlenmeyers contendo uma suspensão com $5 \mathrm{~g}$ de adsorvente e $100 \mathrm{~mL}$ de $\mathrm{NaNO}_{3}\left(0,1 \mathrm{~mol} \mathrm{~L}^{-1}\right)$, titulando-se um dos frascos com uma solução de $\mathrm{HNO}_{3}\left(0,1 \mathrm{~mol} \mathrm{~L}^{-1}\right)$ e o outro com NaOH $\left(0,1 \mathrm{~mol} \mathrm{~L}^{-1}\right)$, na faixa de $\mathrm{pH}$ entre 2 e 12 , respectivamente.

Para o preparo da solução do corante vermelho, secou-se o corante a $100{ }^{\circ} \mathrm{C}$ em estufa por 2 horas, pesou-se $100 \mathrm{mg}$ do corante seco e preparou-se uma solução estoque de concentração $100 \mathrm{mg} \mathrm{L}^{-1}$, sendo ajustado o pH com NaOH $\left(1 \mathrm{~mol} \mathrm{~L}^{-1}\right)$ e $\mathrm{HCl}\left(1 \mathrm{~mol} \mathrm{~L}^{-1}\right)$. Na determinação da concentração do corante antes e após o processo de adsorção, utilizou-se a técnica de espectrofotometria UV-Vis. Inicialmente foi realizada a varredura entre 300 e $700 \mathrm{~nm}$ para determinação do comprimento de onda de maior absorção do corante no espectrofotômetro UV - Vis. Para a construção da curva de calibração, preparam-se soluções de corante em diferentes concentrações na faixa de 0 à $100 \mathrm{mg} \mathrm{L}^{-1}$, sendo estas analisadas no comprimento de onda de maior absorção do corante (518 nm).

Os testes preliminares foram operados em sistema batelada e em duplicata. Em frascos erlenmeyers de $125 \mathrm{~mL}$, adicionaram-se $0,25 \mathrm{~g}$ de adsorvente e $50 \mathrm{~mL}$ de solução de corante $\left(100 \mathrm{mg} \mathrm{L}^{-1}\right)$, sendo a mistura mantida sob agitação constante $(90 \mathrm{rpm})$ em mesa agitadora orbital, com variação dos parâmetros temperatura $\left(20,25\right.$ e $\left.45^{\circ} \mathrm{C}\right), \mathrm{pH}(1-10)$ e tamanho de partícula (9-400 mesh). A fase líquida foi separada do biossorvente, após $24 \mathrm{~h}$ de contato, por centrifugação (3000 rpm durante $10 \mathrm{~min}$ ), e a análise da concentração residual do corante feita por espectrofotometria UV-Vis no comprimento de onda de $518 \mathrm{~nm}$. A capacidade de remoção do corante (q) foi determinada pelo balanço de massa com base nas concentrações da fase líquida inicial $\left(\mathrm{C}_{0}\right)$ e no equilíbrio $(\mathrm{C})$, volume de adsorbato $(\mathrm{V})$ e massa de adsorvente $(\mathrm{m})$, conforme apresentado na Equação (1).

$$
\mathrm{q}=\frac{\left(\mathrm{C}-\mathrm{C}_{0}\right) \mathrm{V}}{\mathrm{m}}
$$

O estudo cinético foi realizado nas melhores condições apontadas pelos testes preliminares. Assim, a cinética de adsorção foi avaliada adicionando-se $0,25 \mathrm{~g}$ de adsorvente em $50 \mathrm{~mL}$ da solução de corante (100 $\mathrm{mg} \mathrm{L}{ }^{-1}$ ) em pH 2,0, mantendo-se a temperatura e velocidade de agitação controlados em $25{ }^{\circ} \mathrm{C}$ e $90 \mathrm{rpm}$, respectivamente. Foram coletadas alíquotas da solução em intervalos previamente estipulados, entre 5 min e $72 \mathrm{~h}$. As amostras coletadas foram centrifugadas e em seguida determinou-se a concentração residual de corante em solução por espectrofotometria UV-Vis $(518 \mathrm{~nm})$. A avaliação da cinética de adsorção do corante pelo sabugo de milho foi realizada pelo cálculo da capacidade de remoção do corante, e pelos modelos de pseudoprimeira ordem, pseudossegunda ordem e Elovich.

Para a obtenção dos dados de equilíbrio, utilizou-se $0,25 \mathrm{~g}$ de adsorvente para $50 \mathrm{~mL}$ de solução de corante, sob agitação em $90 \mathrm{rpm}$ e temperatura de $25^{\circ} \mathrm{C}$. A concentração inicial da solução foi avaliada de 10 a $1000 \mathrm{mg} \mathrm{L}^{-1}$. Após $24 \mathrm{~h}$ de contato, a solução foi separada do biossorvente por centrifugação, e determinada a concentração residual do corante por espectrofotometria UV-Vis $(518 \mathrm{~nm})$. Os dados de equilíbrio foram modelados pelas isotermas de Langmuir, Freundlich, Temkin, Dubinin-Radushkevich e BET.

\section{RESULTADOS E DISCUSSÃO}

O ponto de carga zero para o sabugo de milho foi identificado em $\mathrm{pH}$ 5,5, e a carga da superfície do sabugo de milho apresentou caráter predominantemente positivo para valores de $\mathrm{pH}$ inferiores a 5,5, e consequentemente carga líquida negativa valores de $\mathrm{pH}$ superiores a 5,5.

$\mathrm{Na}$ avaliação da influência do $\mathrm{pH}$ no processo de sorção do corante pelo sabugo de milho, verificou-se que a melhor capacidade de remoção foi observada para pH 2,0 (12,3 $\left.\mathrm{mg} \mathrm{g}^{-1}\right)$, com uma taxa de remoção de $62,5 \%$. Dessa maneira, o pH inicial da solução para os demais testes de adsorção foi padronizado em 2,0. Este comportamento está relacionado com o pHpcz do sabugo de milho, dessa forma, observa-se maior remoção dos corantes em condições de $\mathrm{pH}$ em que a carga superficial líquida do biossorvente apresenta-se predominantemente positiva, o que indica um caráter aniônico do corante.

$\mathrm{Na}$ avaliação da influência do diâmetro de partícula, foi observado que para a fração de granulometria entre 0,04-0,4 mm, foram obtidos os melhores resultados em termos de capacidade de remoção $(15,1 \pm 0,3 \mathrm{mg}$ $\mathrm{g}^{-1}$ ), decorrente da maior área de contato das partículas de adsorvente em função do seu tamanho reduzido. 
Resultados similares foram alcançados empregando-se a fração de tamanhos intermediários de partículas (0,04-1 mm), indicando a utilização desta, visto que possibilitam boa capacidade de remoção $(13,5 \pm 0,35 \mathrm{mg}$ $\left.\mathrm{g}^{-1}\right)$, sem a necessidade de moagem excessiva e o melhor aproveitamento do biomaterial.

$\mathrm{Na}$ análise da influência da temperatura no processo, não houve variação significativa na capacidade de remoção para as três temperaturas avaliadas $\left(11,4 \pm 0,4 \mathrm{mg} \mathrm{g}^{-1}\right)$, de modo a ser utilizada a temperatura ambiente $\left(25^{\circ} \mathrm{C}\right)$ nos demais ensaios.

A cinética de adsorção do corante vermelho empregando o sabugo de milho como biossorvente foi avaliada a fim ser determinado o tempo de equilíbrio do processo. O comportamento cinético, observado na Figura 1, apresentou elevadas taxas de remoção no início do processo, com pequena variação na capacidade de remoção para tempos superiores a 16 horas, sendo este um indicativo do estabelecimento do equilíbrio nesta região. Porém, para que fosse assegurado que o equilíbrio fosse alcançado, todos os testes do estudo foram realizados com um tempo de contato de 24 horas. Conforme apresentado na Figura 1(a), dentre os modelos avaliados, verifica-se que o modelo de Elovich foi o que melhor se ajustou os dados experimentais $\left(\mathrm{R}^{2}=0,9876\right)$, sugerindo que ocorra o fenômeno de quimiossorção no processo. Os parâmetros dos modelos ajustados são apresentados na Tabela 1 .

Com relação ao estudo de equilíbrio, observa-se na Figura 1(b) que a capacidade de adsorção aumenta em função da concentração do corante, sendo a capacidade de adsorção no equilíbrio de aproximadamente 11 $\mathrm{mg} \mathrm{g}^{-1}$. A isoterma de Freundlich foi a que melhor representou o processo $\left(\mathrm{R}^{2}=0,9919\right)$, na qual a intensidade de adsorção (n) obtida foi de 3,6, e está na faixa de 2-10, o que representa boas características de adsorção (TEMESGEN et al., 2018). Dessa maneira, sugere-se que a adsorção do corante ocorre em multicamada, com superfície heterogênea. $\mathrm{O}$ modelo matemático de Freundlich relaciona a capacidade de adsorção máxima do corante $\mathrm{q}_{\mathrm{eq}}\left(\mathrm{mg} \mathrm{g}^{-1}\right)$, a concentração de equilíbrio $\mathrm{C}_{\mathrm{eq}}\left(\mathrm{mg} \mathrm{L}^{-1}\right)$, a constante de Freundlich $\mathrm{k}_{\mathrm{F}}\left(\mathrm{L}^{-1}\right)$ e uma constante $\mathrm{n}$ que caracteriza a intensidade de adsorção. Os valores ajustados para os modelos avaliados são apresentados na Tabela 2.

\section{CONCLUSÃO}

De forma geral, conclui-se que o resíduo agrícola de sabugo de milho apresentou potencial de aplicação como biossorvente em sistemas de tratamento de resíduos industriais contendo corantes, principalmente pelo baixo custo na aquisição do material e facilidade de operação do sistema. Porém, neste estudo foi obtida uma baixa taxa de remoção do corante pelo material avaliado, sendo possível o aumento da eficiência do processo por tratamentos químicos do sabugo de milho, bem como a implantação de um processo de tratamento contínuo, estudos a serem realizados em trabalhos futuros.

\section{REFERÊNCIAS}

BOURAS, H.D.; YEDDOU, A.R.; BOURAS, N.; HELLEL, D.; HOLTZ, M.D.; SABAOU, N.; CHERGUI, A.; NADJEMI, B. Biosorption of Congo red dye by Aspergillus carbonarius M333 and Penicillium glabrum Pg1: Kinetics, equilibrium and thermodynamic Studies; Journal of the Taiwan Institute of Chemical Engineers; p. $915-923 ; 2017$.

DAVRANCHE, M., LACOUR, S., BORDAS, F., BOLLINGER, J.C.; An easy determination of the surface chemical properties of simple and natural solids. Journal of Chemical Education, v. 80; p. 76-78; 2003.

GARG, V.K; KUMAR, RAKESH; GUPTA, RENUKA. Removal of malachite green dye from aqueous solution by adsorption using agro-industry waste: a case study of Prosopis cineraria. Dyes and Pigments, v. 62, p. 1-10, 2004.

MOKHTAR, N.; AZIZ, E. A.; ARIS, A.; ISHAK, W.F.W.; ALI, N. S. M.; Biosorption of azo-dye using marine macro-alga of Euchema Spinosum; Journal of Environmental Chemical Engineering; v. 5, n. 6, p. 5721-5731; 2017.

RIBEIRO, C.; SCHEUFELE F. B.; ESPINOZA-QUINONES, F. R.; MÓDENES, A. N.; SILVA, G. C. M.; VIEIRA, M. G. A.; BORBA, C. E.; Characterization of Oreochromis niloticus fish scales and assessment of their potential on the adsorption of reactive blue 5G dye. Colloids and Surfaces A: Physicochemical and Engineering Aspects. v. 482, p. 693-701, 2015.

TEMESGEN, F.; GABBIYE, N.; SAHU, O.; Biosorption of reactive red dye (RRD) on activated surface of banana and orange peels: Economical alternative for textile effluent; Surfaces and Interfaces; v. 12; p. 151$159 ; 2018$. 

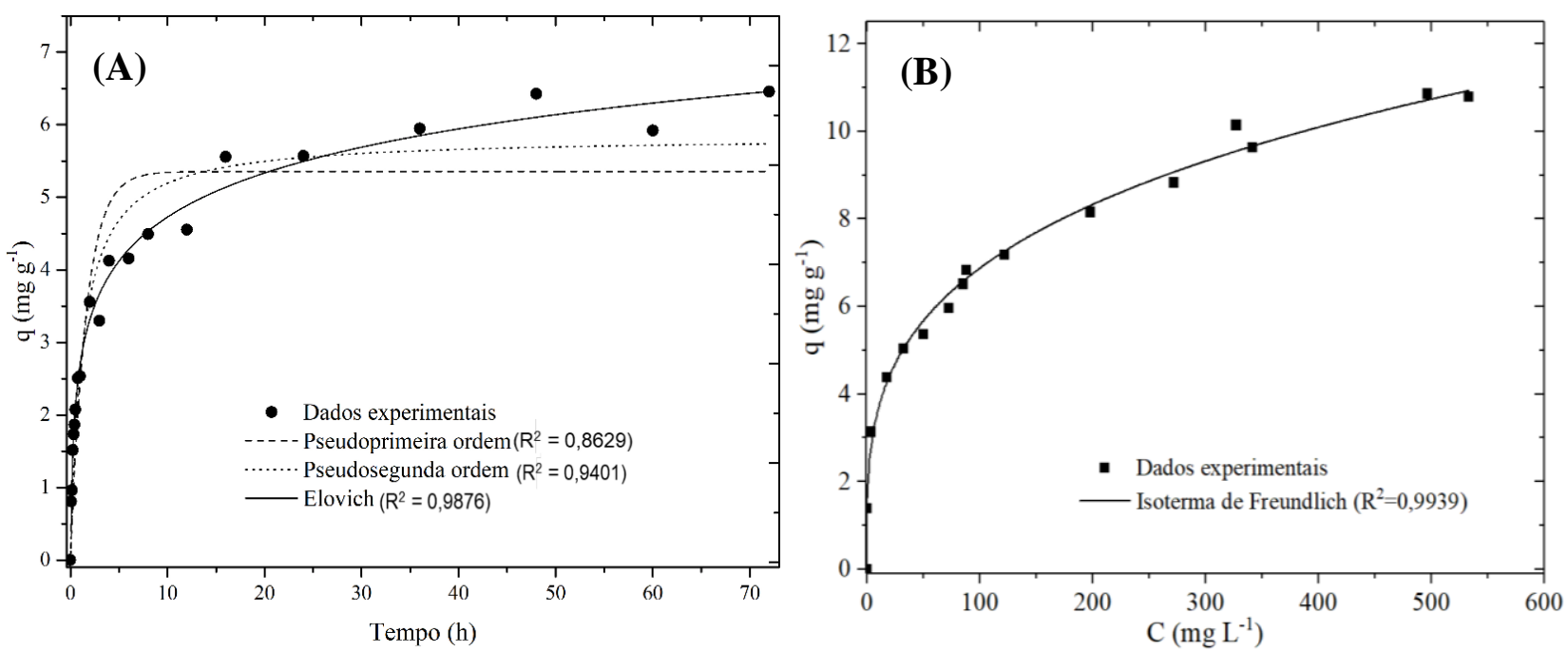

Figura 1. (a) Dados cinéticos e (b) Dados de equilíbrio da adsorção do corante vermelho pelo sabugo de milho.

Tabela 1. Valores dos parâmetros ajustados dos modelos cinéticos de adsorção.

\begin{tabular}{cccc}
\hline Modelo Cinético & \multicolumn{2}{c}{ Parâmetros ajustados } & $\mathbf{R}^{\mathbf{2}}$ \\
\hline Pseudoprimeira ordem & $\mathrm{q}_{\mathrm{eq}}\left(\mathrm{mg} \mathrm{g}^{-1}\right)$ & $5,35 \pm 0,25$ & 0,8629 \\
$\mathrm{k}_{1}\left(\mathrm{~h}^{-1}\right)$ & $0,62 \pm 0,13$ & \\
$\mathrm{q}(\mathrm{t})=\mathrm{q}_{\mathrm{eq}}\left(1-\mathrm{e}^{-\mathrm{k}_{1} \mathrm{t}}\right)$ & $\mathrm{q}_{\mathrm{eq}}\left(\mathrm{mg} \mathrm{g}^{-1}\right)$ & $5,8 \pm 0,2$ & 0,9401 \\
Pseudossegunda ordem & $\mathrm{k}_{2}\left(\mathrm{~g} \mathrm{mg}^{-1} \mathrm{~h}^{-1}\right)$ & $0,14 \pm 0,03$ & \\
$\mathrm{q}(\mathrm{t})=\frac{\mathrm{q}_{\mathrm{eq}}^{2} \mathrm{k}_{2} \mathrm{t}}{1+\mathrm{q}_{\mathrm{eq}} \mathrm{k}_{2} \mathrm{t}}$ & $\alpha\left(\mathrm{mg} \mathrm{g}^{-1} \mathrm{~h}^{-1}\right)$ & $19,22 \pm 2,03$ & 0,9876 \\
Elovich & $\beta\left(\mathrm{g} \mathrm{mg}^{-1}\right)$ & $1,14 \pm 0,03$ & \\
$\mathrm{q}(\mathrm{t})=\frac{1}{\beta} \ln (\alpha \beta)+\frac{1}{\beta} \ln (\mathrm{t})$ & &
\end{tabular}

*q(t) e qeq são a capacidade de remoção de corante no tempo t e no equilíbrio, respectivamente, $\mathrm{k}_{1}$ e $\mathrm{k}_{2}$ são constantes de velocidade, $\alpha$ é a taxa de adsorção e $\beta$ parâmetro relacionado a energia de ativação.

Tabela 2. Valores dos parâmetros ajustados dos modelos de isotermas de adsorção avaliadas.

\begin{tabular}{|c|c|c|c|}
\hline Isotermas & \multicolumn{2}{|c|}{ Parâmetros ajustados } & $\mathbf{R}^{2}$ \\
\hline $\begin{array}{c}\text { Langmuir } \\
\mathrm{q}_{\mathrm{eq}}=\frac{\mathrm{q}_{\mathrm{max}} \mathrm{b} \mathrm{C}_{\mathrm{eq}}}{1+\mathrm{b} \mathrm{C}_{\mathrm{eq}}}\end{array}$ & $\begin{array}{l}\mathrm{q}_{\max }\left(\mathrm{mg} \mathrm{g}^{-1}\right) \\
\mathrm{b}\left(\mathrm{L} \mathrm{mg}^{-1}\right)\end{array}$ & $\begin{array}{c}10,97 \pm 0,67 \\
0,021 \pm 0,005\end{array}$ & 0,9095 \\
\hline $\begin{array}{c}\text { Freundlich } \\
\mathrm{q}_{\mathrm{eq}}=\mathrm{k}_{\mathrm{F}}\left(\mathrm{C}_{\mathrm{eq}}\right)^{1 / \mathrm{n}}\end{array}$ & $\begin{array}{c}\mathrm{k}\left(\mathrm{L}^{-1}\right) \\
\mathrm{n}\end{array}$ & $\begin{array}{c}1,91 \pm 0,09 \\
3,6 \pm 0,1\end{array}$ & 0,9939 \\
\hline $\mathrm{q}=\frac{\mathrm{BET}}{\left(\mathrm{C}_{\mathrm{s}}-\mathrm{C}_{\mathrm{eq}}\right)\left[1+(\mathrm{b}-1)\left(\frac{\mathrm{C}_{\mathrm{eq}}}{\mathrm{C}_{\mathrm{s}}}\right)\right]}$ & $\begin{array}{c}\mathrm{q}_{\max }\left(\mathrm{mg} \mathrm{g}^{-1}\right) \\
\mathrm{b} \\
\mathrm{C}_{\mathrm{S}}\left(\mathrm{mg} \mathrm{L}^{-1}\right)\end{array}$ & $\begin{array}{c}7,00 \pm 0,45 \\
138,6 \pm 41,9 \\
1356,2 \pm 186,8\end{array}$ & 0,9541 \\
\hline $\mathrm{q}=\mathrm{B} \ln \left(\mathrm{k}_{\mathrm{t}}\right)+\mathrm{B} \ln \left(\mathrm{C}_{\mathrm{eq}}\right)$ & $\begin{array}{c}\mathrm{b} \\
\mathrm{k}_{\mathrm{T}}\left(\mathrm{L} \mathrm{mg}^{-1}\right)\end{array}$ & $\begin{array}{c}1,30 \pm 0,13 \\
3,1 \pm 1,7\end{array}$ & 0,9134 \\
\hline $\begin{array}{c}\text { Dubinin-Radushkevich } \\
\mathrm{q}_{\mathrm{eq}}=\mathbf{q}_{\text {maxD }} \mathrm{e}^{\left((-\beta)\left(\mathrm{RT} \ln \left(1+\frac{1}{\mathrm{C}_{\mathrm{eq}}}\right)\right)^{2}\right)}\end{array}$ & $\begin{array}{l}\mathrm{q}_{\max }\left(\mathrm{mg} \mathrm{g} \mathrm{g}^{-1}\right) \\
\beta\left(\operatorname{mol} 2 \mathrm{~kJ}^{-2}\right)\end{array}$ & $\begin{array}{c}8,6 \pm 0,6 \\
74,7 \pm 34,8\end{array}$ & 0,7030 \\
\hline
\end{tabular}




\title{
ESTUDO DA REMOÇÃO DO FÁRMACO CLORIDRATO DE METFORMINA POR ADSORÇÃO UTILIZÂNDO CARVÃO ATIVADO DE CASCA DE COCO DE DENDÊ
}

\author{
Oliveira, A.P.*1; Hellmann, L. ${ }^{2}$; Módenes, A.N. ${ }^{2}$; Antoniolli, C.A. ${ }^{1}$; Bernabé, B.A. ${ }^{1}$; Gusmão, A.G. ${ }^{1}$; \\ ${ }^{1}$ Departamento de Engenharia Química - Universidade Tecnológica Federal do Paraná (UTFPR), Francisco Beltrão, PR - Brasil; \\ ${ }^{2}$ Programa de Pós-Graduação em Engenharia Química - Universidade Estadual do Oeste de Paraná, Toledo, PR - Brasil \\ anapoliveira@utfpr.edu.br
}

RESUMO: O presente estudo tem como objetivo analisar a adsorção do fármaco de cloridrato de metformina utilizando o carvão ativado de casca de coco de dendê como adsorvente. Os ensaios experimentais foram realizados em sistema batelada com $0,25 \mathrm{~g}$ de adsorvente e $50 \mathrm{~mL}$ de solução do fármaco, sendo a mistura mantida sob agitação $(100 \mathrm{rpm})$ e temperatura controladas. Foram realizados estudos preliminares para avaliação das condições experimentais adequadas para os parâmetros $\mathrm{pH}$ e temperatura, testes cinético e de equilíbrio. Os testes preliminares indicaram que as condições operacionais de $\mathrm{pH} 7,0$ e temperatura de $25^{\circ} \mathrm{C}$, favorecem o processo de adsorção do fármaco, sendo estas condições utilizadas para obtenção dos dados cinéticos e de equilíbrio de adsorção. O tempo de equilíbrio determinado foi de aproximadamente $12 \mathrm{~h}$, sendo o modelo cinético de pseudossegunda ordem o que melhor representou os dados experimentais. A partir dos dados de equilíbrio sugere-se um processo de adsorção em superfície heterogênea, seguindo o modelo de Toth, com capacidade máxima de adsorção de $17,86 \pm 2,87 \mathrm{mg} \mathrm{g}^{-1}$. Com base nos resultados obtidos, verificou-se que o carvão ativado de casca de coco de dendê apresenta potencial de utilização como biossorvente em sistemas de tratamento de águas contendo o fármaco em estudo.

Palavras-chave: adsorção, cloridrato de metformina, carvão ativado.

\section{STUDY OF THE REMOVAL OF THE METFORMIN CHLORIDRATE DRUG BY ADSORPTION USING ACTIVATED CHARCOAL OF DENDE COCONUT SHELL}

\begin{abstract}
The present study aims to analyze the adsorption of the drug metformin hydrochloride using the activated charcoal of dende coconut shell as an adsorbent. The experimental tests were carried out in a batch system with $0,25 \mathrm{~g}$ of adsorbent and $50 \mathrm{~mL}$ of the drug solution, with the mixture being kept under controlled agitation $(100 \mathrm{rpm})$ and temperature. Preliminary studies were carried out to evaluate the experimental conditions suitable for ph, temperature, kinetic and equilibrium parameters. Preliminary tests indicated that the operating conditions of ph 7,0 and temperature of $25^{\circ} \mathrm{C}$ favor the adsorption process of the drug, and these conditions have been used to obtain kinetic data and adsorption equilibrium. The determined equilibrium time was approximately $12 \mathrm{~h}$, with the kinetic model of pseudosecond order representing the best experimental data. From the equilibrium data it is suggested an adsorption process on a heterogeneous surface, following the toth model, with a maximum adsorption capacity of $17.86 \pm 2.87 \mathrm{mg} \mathrm{g}^{-1}$. Based on the results obtained, it was verified the that activated charcoal of dende coconut shell presents potential for use as a biosorbent in water treatment systems containing the drug under study.
\end{abstract}

Keywords: adsorption, metformin hydrochloride, activated charcoal.

\section{INTRODUÇÃO}

Com os avanços na medicina e nas indústrias farmacêuticas, aliado ao crescente índice de doenças nos seres humanos, tem-se verificado um aumento significativo no consumo de fármacos e, consequente incremento nas concentrações dessas substâncias no meio ambiente, principalmente nos recursos hídricos (Niemuth et al., 2015; Oosterhuis et al., 2013). A contaminação pelo descarte incorreto deste tipo de substância pode se dar pela disposição de comprimidos na forma sólida em aterros, excreção na urina e ainda pela lixiviação pela água da chuva em solos contaminados ou chorume.

Dentre os fármacos que recebem destaque pelo consumo em larga escala, podemos citar o cloridrato de metformina, sendo este amplamente prescrito para o tratamento da diabetes II e minoritariamente para o emagrecimento e tratamento de câncer (Sahra et al., 2010). Dentre os efeitos colaterais de superdosagem deste 
medicamento podemos citar irritação gastrintestinal, acidose metabólica, hipovolemia, acidose láctica, convulsões, depressão respiratória e hipoglicemia com sintomas que incluem perda de força física, confusão mental, palpitações, transpiração e vômitos.

Tendo em vista que as estações de tratamento de esgoto doméstico convencionais não contemplam tratamentos específicos para a remoção de substâncias como o fármaco cloridrato de metformina, estes compostos estão sendo dispostos nos recursos hídricos e expondo os seres humanos ao consumo excessivo dos mesmos (Pereira et al., 2016). Dessa forma, métodos alternativos para a remoção de fármacos têm sido avaliados, sendo a adsorção um processo adequado visto que se apresenta de fácil operação, baixo custo e seletivo a substâncias específicas como o cloridrato de metformina. Acrescenta-se ainda que, devido a grande disponibilidade de resíduos de origem vegetal, o Brasil destaca-se como potencial produtor de adsorventes, como é o caso do emprego da casca de coco de dendê, que é um resíduo da produção do óleo, podendo ser utilizada como matéria prima para a produção de carvão ativado (Ferreira et al., 2015). Nesse sentido, o objetivo desse estudo foi avaliar a eficiência de adsorção do cloridrato de metformina utilizando o carvão ativado de casca de coco de dendê.

\section{MATERIAL E MÉTODOS}

O adsorvente utilizado foi o carvão ativado de casca de coco de dendê comercial. Para o preparo da solução de fármaco a ser tratada, inicialmente realizou a secagem do mesmo à $100^{\circ} \mathrm{C}$ por 2 horas. Em seguida, fez a dissolução do fármaco em água destilada resultando na concentração de $100 \mathrm{mg} \mathrm{L}^{-1}$. Para determinação da concentração do fármaco em solução, foi empregada a técnica de espectrofotometria UV-Vis (Shimadzu, Modelo UV 1800), sendo feita a varredura para determinação do comprimento de onda de maior absorção do composto, sendo este $233 \mathrm{~nm}$. Além disso, foi feita uma curva de calibração com concentrações de fármaco de 2 a $20 \mathrm{mg} \mathrm{L}^{-1}\left(\mathrm{R}^{2}=0,999\right)$, visando correlacionar a concentração conhecida com a absorbância medida no espectrofotômetro UV-Vis no comprimento de onda de $233 \mathrm{~nm}$.

Foram realizados testes preliminares baseados na investigação de parâmetros operacionais como o $\mathrm{pH}$ inicial da solução (4 a 10) e temperatura de sorção $\left(25,35\right.$ e $\left.45^{\circ} \mathrm{C}\right)$. Os ensaios de adsorção em batelada foram realizados em erlenmeyers de $125 \mathrm{~mL}$, contendo $0,25 \mathrm{~g}$ de adsorvente e $50 \mathrm{~mL}$ de solução a ser tratada com concentração inicial de $100 \mathrm{mg} \mathrm{L}^{-1}$. A mistura foi mantida sob agitação constante (100 rpm) em uma mesa agitadora orbital com temperatura controlada por $24 \mathrm{~h}$. Após esse período de contato, parte da solução foi separada do adsorvente por centrifugação a $3000 \mathrm{rpm}$ durante $10 \mathrm{~min}$. A análise da concentração final do fármaco presente na solução foi realizada por Espectrofotometria UV-Vis $(233 \mathrm{~nm})$.

A quantidade de fármaco adsorvida foi calculada pelo balanço de massa descrito na Equação (1).

$$
q=\frac{\left(C_{o}-C\right) V}{m}
$$

sendo q $\left(\mathrm{mg} \mathrm{g}^{-1}\right)$ a quantidade de fármaco adsorvido, $\mathrm{C}_{\mathrm{e}}$ e $\mathrm{C}\left(\mathrm{mg} \mathrm{L}^{-1}\right)$ concentrações iniciais e finais de fármaco em solução, respectivamente, $\mathrm{V}(\mathrm{L})$ o volume da solução e $\mathrm{m}(\mathrm{g})$ a massa de adsorvente.

Com base nos ensaios preliminares, foram determinadas as condições operacionais do estudo cinético e de equilíbrio. Sob tais condições de sorção, preparou-se uma solução de concentração inicial de $100 \mathrm{mg} \mathrm{L}^{-1}$ sendo ajustados o pH desta para 7,0 e posteriormente adicionados a 1 litro de solução 5 g do carvão ativado de casca de coco de dendê e mantida sob agitação de 100 rpm. Retirou-se amostras com tempos entre 1 e 1440 minutos, sendo estas subsequentemente diluídas (10 vezes) e sua concentração medida por espectrofotometria UV-vis a $233 \mathrm{~nm}$. Os dados obtidos, foram avaliados por modelos cinéticos amplamente aplicado neste tipo de análises, tais como: pseudoprimeira ordem, pseudosegunda ordem e Elovich.

Para a obtenção dos dados de equilíbrio, utilizou-se a proporção de $0,25 \mathrm{~g}$ de adsorvente para $50 \mathrm{~mL}$ de solução de fármaco, nas condições de $\mathrm{pH} 7,0$, temperatura de $25^{\circ} \mathrm{C}$ e velocidade de agitação de $100 \mathrm{rpm}$. No estudo do equilíbrio, a concentração inicial da solução variou de 5 a $800 \mathrm{mgL}^{-1}$. Após 24 h de contato, a solução foi separada do biossorvente e centrifugada $(3000 \mathrm{rpm})$, para posterior determinação da concentração residual do fármaco por espectrofotometria UV-Vis $(233 \mathrm{~nm})$. Os resultados de equilíbrio foram modelados de acordo com as isotermas de Langmuir, Freundlich, Redlich Peterson, Temkin, Dubinin-Radushkevich e Toth. 


\section{RESULTADOS E DISCUSSÃO}

No estudo preliminar em que se avaliou a influência do $\mathrm{pH}$ no processo de adsorção do fármaco pelo carvão ativado de casca de coco de dendê, verificou-se que a melhor capacidade de remoção foi para pH inicial $7,0\left(8,3 \pm 0,4 \mathrm{mg} \mathrm{g}^{-1}\right)$, sendo este empregado nos demais testes realizados. Outro parâmetro avaliado nos ensaios preliminares foi a temperatura do processo, sendo que a variação deste parâmetro não indicou alterações significativas na eficiência de remoção do fármaco $\left(9,4 \pm 0,6 \mathrm{mg} \mathrm{g}^{-1}\right)$, assim utilizou-se a temperatura de $25^{\circ} \mathrm{C}$ (ambiente) nos demais ensaios.

Os resultados obtidos para o teste cinético, são apresentados na Figura 1(a), na qual observa-se que o equilíbrio é estabelecido em torno de $21 \mathrm{~h}$ de contato, sendo estes avaliados pelos modelos de pseudoprimeira ordem, pseudosegunda ordem e Elovich. Os parâmetros ajustados para os modelos cinéticos avaliados, apresentados na Tabela 1, indicam que o modelo de pseudossegunda ordem foi o que melhor ajustou os dados experimentais $\left(\mathrm{R}^{2}=0,9829\right)$, indicando que possa ocorrer adsorção química do fármaco.

O comportamento dos dados de equilíbrio para adsorção do fármaco de Cloridrato de Metformina juntamente com o ajuste das isotermas, podem ser visualizados da Figura 1(b). Como pode ser observado na Figura 1(b), juntamente com os parâmetros ajustados dos modelos de isotermas apresentados na Tabela 2, o modelo que melhor descreveu os dados experimentais foi a isoterma de Toth $\left(\mathrm{R}^{2}=0,9826\right)$, com capacidade máxima de adsorção $\left(\mathrm{q}_{\operatorname{maxT}}\right)$ de $17,86 \pm 2,87 \mathrm{mg} \mathrm{g}^{-1}$, sendo $\mathrm{b}_{\mathrm{T}}\left(1,003 \pm 0,910 \mathrm{~L} \mathrm{mg}^{-1}\right)$ e $\mathrm{n}_{\mathrm{T}}(0,328 \pm 0,074)$ parâmetros do modelo que representam a constante de Toth e heterogeneidade da superfície, respectivamente. Dessa maneira, sugere-se que a adsorção do fármaco ocorre em superfície heterogênea, visto que este modelo considera que a energia de adsorção na grande maioria dos sítios ativos é inferior a energia máxima de adsorção (Allen et al., 2003).

\section{CONCLUSÃO}

Com base nos resultados obtidos nos testes preliminares, pode-se concluir que o parâmetro $\mathrm{pH}$ exerce influência no processo, sendo a adsorção foi favorecida em $\mathrm{pH} \mathrm{7,0.} \mathrm{Por} \mathrm{outro} \mathrm{lado,} \mathrm{verificou-se} \mathrm{que} \mathrm{a}$ temperatura do meio não influencia significativamente na capacidade de adsorção do fármaco, sendo dessa forma utilizada a temperatura de $25{ }^{\circ} \mathrm{C}$. Na avaliação da cinética de adsorção, observou-se que o tempo de equilíbrio foi de aproximadamente $21 \mathrm{~h}$, seguindo o modelo de pseudossegunda ordem. No estudo do equilíbrio, o ajuste dos modelos avaliados aos dados experimentais mostrou que a isoterma de Toth foi a que melhor representou o processo, indicando adsorção em superfície heterogênea, com capacidade máxima de adsorção indicada pelo modelo de $17,86 \pm 2,87 \mathrm{mg} \mathrm{g}^{-1}$. De forma geral, o carvão de casca de coco de dendê apresentou potencial de aplicação como biossorvente no tratamento de água contendo fármaco de cloridrato de metformina.

\section{AGRADECIMENTOS}

À PRATI DONADUZZI por fornecer o fármaco de cloridrato de metformina utilizado nesse estudo.

\section{REFERÊNCIAS}

ALLEN, S.J.; GAN, Q.; MATTHEWS, R.; JOHNSON, P.A.; Comparison of optimised isotherm models for basic dye adsorption by kudzu; Bioresource Technology; v. 88; p. 143-152; 2003.

SAHRA, B. S.; Marchand-Bruste, L. M. B. Y.; TANTI, J. F.; BOST, F. Metformin in cancer therapy: A new perspective for an old antidiabetic drug? Mol Cancer Ther, v.9; p.1092-1099; 2010.

FERREIRA, R.C.; DE LIMA, H.H.C.; CÂNDIDO, A.A.; COUTO JUNIOR, O.M.; ARROYO, P.A.; DE CARVALHO, K.Q.; GAUZE, G.F.; BARROS, M.A.S.D.; Adsorption of Paracetamol Using Activated Carbon of Dende and Babassu Coconut Mesocarp; International Journal of Biotechnology and Bioengineering; v.9; $\mathrm{n}$. 7; 2015.

NIEMUTH, J. N.; JORDAN, R.; CRACO, J.; BLANKSMA, C.; JONHSON, R.; KLAPER, R. D. Metformin exposure at environmentally relevant concentrations causes potential endocrine disruption in adult male fish. Environmental toxicology and chemistry, v. 34, p. 291-296; 2015.

OOSTERHUIS M.; SACHER F.; TER LAAK T. L.; Prediction of concentration levels of metformin and other high consumption pharmaceuticals in wastewater and regional surface water based on sales data; Sci. Total Environ., v. 442, p. 380-388; 2013. 
PEREIRA, C. D.; MARANHO, L. A.; CORTEZ, F. S.; PUSCEDDU, F. H.; SANTOS, A. R.; RIBEIRO, D. A.; CESAR, A.; GUIMARÃES, L. L. Occurrence of pharmaceuticals and cocaine in a brazilian coastal zone; Sci. Toal Environ., V. 548-549, P. 148-154; 2016.
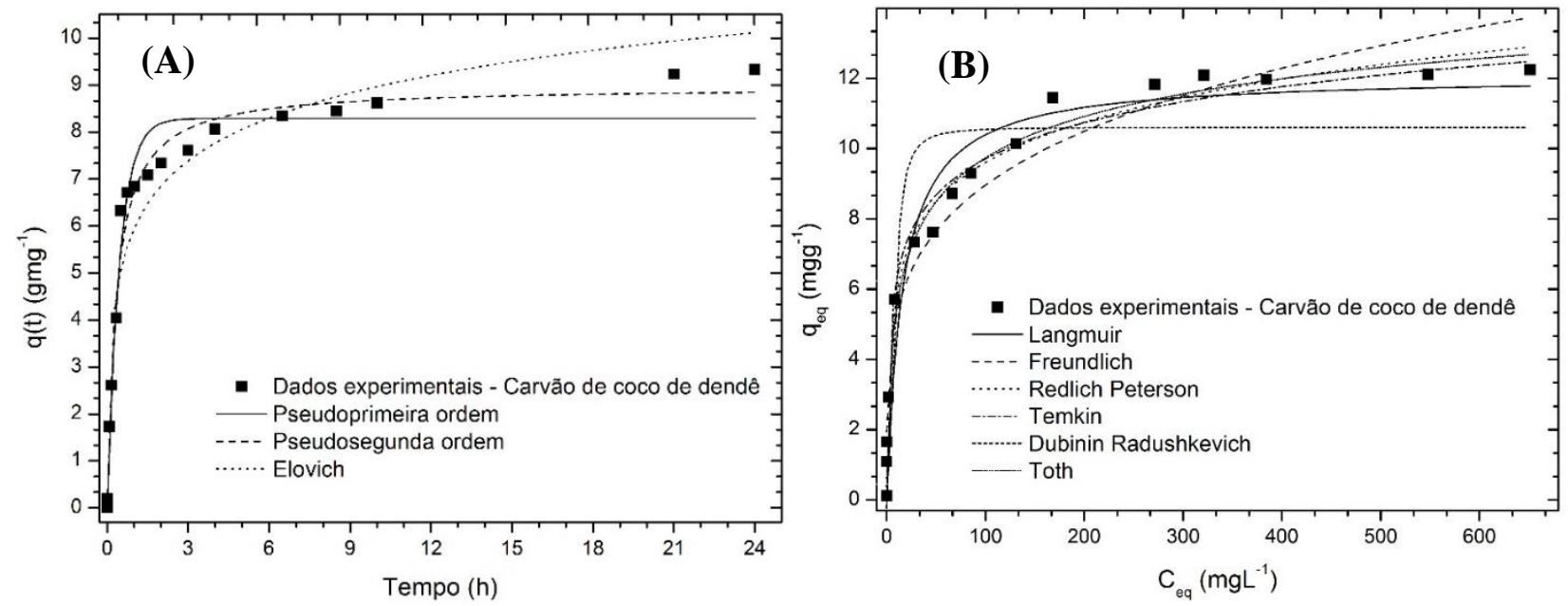

Figura 1. (a) Dados cinéticos e (b) Dados de equilíbrio da adsorção do fármaco de cloridrato de Metformina pelo carvão ativado de casca de coco de dendê.

Tabela 1. Valores dos parâmetros ajustados dos modelos cinéticos de adsorção.

\begin{tabular}{|c|c|c|c|}
\hline \multirow{2}{*}{$\begin{array}{c}\text { Modelo Cinético } \\
\text { Pseudoprimeira ordem } \\
\mathrm{q}(\mathrm{t})=\mathrm{q}_{\mathrm{eq}}\left(1-\mathrm{e}^{-\mathrm{k}_{1} \mathrm{t}}\right)\end{array}$} & \multicolumn{2}{|c|}{ Parâmetros ajustados } & $\mathbf{R}^{2}$ \\
\hline & $\begin{array}{l}\mathrm{q}_{\mathrm{eq}}\left(\mathrm{mg} \mathrm{g}^{-1}\right) \\
\mathrm{k}_{1}\left(\mathrm{~h}^{-1}\right)\end{array}$ & $\begin{array}{l}8,290 \pm 0,202 \\
2,189 \pm 0,247\end{array}$ & 0,9637 \\
\hline $\begin{array}{l}\text { Pseudossegunda ordem } \\
\qquad \mathrm{q}(\mathrm{t})=\frac{\mathrm{q}_{\mathrm{eq}}^{2} \mathrm{k}_{2} \mathrm{t}}{1+\mathrm{q}_{\mathrm{eq}} \mathrm{k}_{2} \mathrm{t}}\end{array}$ & $\begin{array}{c}\mathrm{q}_{\mathrm{eq}}\left(\mathrm{mg} \mathrm{g}^{-1}\right) \\
\mathrm{k}_{2}\left(\mathrm{~g} \mathrm{mg}^{-1} \mathrm{~h}^{-1}\right)\end{array}$ & $\begin{array}{c}8,966 \pm 0,174 \\
0,335 \pm 0,039\end{array}$ & 0,9829 \\
\hline $\mathrm{q}(\mathrm{t})=\frac{1}{\beta} \ln (\alpha \beta)+\frac{1}{\beta} \ln (\mathrm{t})$ & $\begin{array}{c}\alpha\left(\mathrm{mg} \mathrm{g}^{-1} \mathrm{~h}^{-1}\right) \\
\beta\left(\mathrm{g} \mathrm{mg}^{-1}\right)\end{array}$ & $\begin{array}{c}70,486 \pm \\
31,088 \\
1,312 \pm 0,093\end{array}$ & 0,9439 \\
\hline
\end{tabular}

Tabela 2. Valores dos parâmetros ajustados dos modelos de isotermas de adsorção avaliadas.

\begin{tabular}{|c|c|c|c|}
\hline Isotermas & \multicolumn{2}{|c|}{ Parâmetros ajustados } & $\mathbf{R}^{2}$ \\
\hline Langmuir & & $12,069 \pm 0,477$ & \\
\hline $\mathrm{q}_{\mathrm{eq}}=\frac{\mathrm{q}_{\mathrm{max}} \mathrm{b} \mathrm{C}_{\mathrm{eq}}}{1+\mathrm{b} \mathrm{C}_{\mathrm{eq}}}$ & $\begin{array}{c}\mathrm{q}_{\max }\left(\mathrm{mg} \mathrm{g}^{-1}\right) \\
\mathrm{b}\left(\mathrm{L} \mathrm{mg}^{-1}\right)\end{array}$ & $0,062 \pm 0,016$ & 0,9460 \\
\hline Freundlich & $\mathrm{k}_{\mathrm{F}}\left(\mathrm{L}^{-1}\right)$ & $3,142 \pm 0,371$ & \\
\hline $\mathrm{q}_{\mathrm{eq}}=\mathrm{k}_{\mathrm{F}}\left(\mathrm{C}_{\mathrm{eq}}\right)^{1 / \mathrm{n}}$ & $\mathrm{n}$ & $4,394 \pm 0,425$ & 0,9436 \\
\hline $\begin{array}{l}\text { Redlich-Peterson } \\
\mathrm{q}_{\mathrm{eq}}=\frac{\mathrm{k}_{\mathrm{rp}} \mathrm{C}_{\mathrm{eq}}}{1+\mathrm{a}_{\mathrm{rp}} \mathrm{C}_{\mathrm{eq}}^{\beta}}\end{array}$ & $\begin{array}{l}\operatorname{kRP}\left(\mathrm{Lg}^{-1}\right) \\
\operatorname{aRP}\left(\mathrm{L} \mathrm{mg}^{-1}\right)\end{array}$ & $\begin{array}{l}3,515 \pm 1,384 \\
0,696 \pm 0,342\end{array}$ & 0,95792 \\
\hline $\mathrm{q}_{\mathrm{eq}}=\frac{\mathrm{q}_{\max \mathrm{T}} \mathrm{b}_{\mathrm{T}} \mathrm{C}_{\mathrm{eq}}}{\left[1+\left(\mathrm{b}_{\mathrm{T}} \mathrm{C}_{\mathrm{eq}}\right)^{\mathrm{n}_{\mathrm{T}}}\right]^{1 / \mathrm{n}_{\mathrm{T}}}}$ & $\begin{array}{c}\mathrm{q}_{\operatorname{maxT}}\left(\mathrm{mg} \mathrm{g}^{-1}\right) \\
\mathrm{b}_{\mathrm{T}}\left(\mathrm{L} \mathrm{mg}^{-1}\right) \\
\mathrm{n}_{\mathrm{T}}\end{array}$ & $\begin{array}{c}17,86 \pm 2,87 \\
1,003 \pm 0,9103 \\
0,328 \pm 0,074\end{array}$ & 0,9826 \\
\hline $\mathrm{q}_{\mathrm{eq}}=\mathrm{B} \ln \left(\mathrm{k}_{\mathrm{T}}\right)+\mathrm{B} \ln \left(\mathrm{C}_{\mathrm{eq}}\right)$ & $\begin{array}{c}\mathrm{B} \\
\mathrm{k}_{\mathrm{t}}\left(\mathrm{L} \mathrm{mg}^{-1}\right)\end{array}$ & $\begin{array}{l}1,479 \pm 0,068 \\
7,071 \pm 1,978\end{array}$ & 0,9687 \\
\hline $\begin{array}{c}\mathrm{q}_{\mathrm{eq}}=\mathbf{q}_{\operatorname{maxD}} \mathrm{e}^{\left((-\beta)\left(\mathrm{RT} \ln \left(1+\frac{1}{\mathrm{C}_{\mathrm{eq}}}\right)\right)^{2}\right)} \\
\end{array}$ & $\begin{array}{c}\mathrm{q}_{\operatorname{maxD}}\left(\mathrm{mg} \mathrm{g}^{-1}\right) \\
\beta\left(\mathrm{mol}^{2} \mathrm{~kJ}^{-2}\right)\end{array}$ & $\begin{array}{l}10,600 \pm 0,6371 \\
0,595 \pm 976,69\end{array}$ & 0,8236 \\
\hline
\end{tabular}




\title{
ESTUDO DA UTILIZAÇÃO DE BAGAÇO DE CANA-DE-AÇÚCAR COMO ADSORVENTE DE VIOLETA CRISTAL
}

\author{
Reis, M.A. ${ }^{* 1}$; Diel, J.C. ${ }^{1}$; Chiquim, M.S. ${ }^{1}$; Bender, T.J. ${ }^{1}$; Fernandes, D.M.; Nunes, I. dos S. ${ }^{1}$

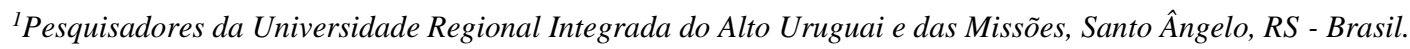 \\ isaac.eq@san.uri.br
}

\begin{abstract}
RESUMO: O presente trabalho objetiva a sustentabilidade, aplicando o resíduo agroindustrial da industrialização do açúcar no tratamento de efluentes contendo contaminantes como corante violeta cristal (CVC), por meio da operação unitária de transferência de massa sólido-fluido, a adsorção. Neste contexto, a partir das cinéticas de adsorção, avaliou-se a remoção de CVC na concentração de $100 \mathrm{mg} \mathrm{L}^{-1}$, variando-se as dosagens de adsorvente de 0,$05 ; 0,10$ e $0,15 \mathrm{~g}$. Verificou-se que a condição mais atrativa foi a massa de 0,15 $\mathrm{g}$ de BC, apresentando uma eficiência de remoção de 97,08\%, para a capacidade adsortiva de 32,36 $\mathrm{mg} \mathrm{g}^{-1}$, admitindo-se o tempo de equilíbrio de $90 \mathrm{~min}$, sendo que ambos modelos, PPO e PSO, apresentam bons ajustes cinéticos a estes dados, onde PSO se destacou mais. Tais resultados revelam o potencial do bagaço de canade-açúcar no tratamento de efluentes contendo CVC e apresentando grande eficiência de remoção.
\end{abstract}

Palavras-chave: Adsorção, resíduo, bagaço de cana-de-açúcar, corante violeta cristal.

\section{STUDY OF THE USE OF SUGAR CANE BAGASSE AS AN ADSORVENT FOR VIOLET CRYSTAL DYE}

\begin{abstract}
The present work aims at sustainability, applying the agroindustrial residue of the sugar industrialization in the treatment of effluents containing contaminants as crystal violet dye (CVC), through the unitary operation of solid-fluid mass transfer, adsorption. In this context, from the adsorption kinetics, the removal of CVC at the concentration of $100 \mathrm{mg} \mathrm{L}-1$ was evaluated, the adsorbent dosages being varied from $0.05 ; 0.10$ and $0.15 \mathrm{~g}$. It was verified that the most attractive condition was the mass of $0.15 \mathrm{~g}$ of $\mathrm{BC}$, presenting a removal efficiency of $97.08 \%$, for the adsorptive capacity of $32.36 \mathrm{mg} \mathrm{g}-1$, assuming the equilibrium time of 90 min, and both models, PPO and PSO, present good kinetic adjustments to these data, where PSO stood out more. These results reveal the potential of the sugarcane bagasse in the treatment of effluents containing $\mathrm{CVC}$ and presenting great removal efficiency.
\end{abstract}

Keywords: Adsorption, waste, sugar cane bagasse, violet crystal dye.

\section{INTRODUÇÃO}

$\mathrm{O}$ crescimento industrial tem acarretado aumento de poluentes em águas naturais, afetando as espécies existentes no ecossistema aquático e, consequentemente, as populações que necessitam destas águas. Entre os vários contaminantes aquosos, os corantes são considerados um dos mais perigosos devido à sua dificuldade de remoção, por apresentarem estabilidade e natureza não biodegradável. Os corantes são amplamente utilizados em muitas indústrias, como as de cosméticos, couro, papel, alimentos e têxtil. Caso não tratados de forma adequada podem acarretar problemas ambientais e ser indutor de câncer em seres humanos (GOSWAMI; PHUKAN, 2017).

Há operações unitárias eficazes em tratamento de efluentes. A mais econômica e de menor consumo energético é a adsorção, que consiste na transferência de componentes de uma fase fluida líquida ou gasosa para a superfície de uma fase sólida. O componente adsorvido é chamado de adsorbato, enquanto a superfície sólida que retém tal componente é chamada de adsorvente (GOMIDE, 1988).

Diversos materiais de baixo custo já foram utilizados como adsorventes de corantes de modo a tornar o processo de adsorção mais viável economicamente (ZIMMERMANN et al., 2016). A cana-de-açúcar está entre as principais culturas da economia brasileira. O seu bagaço tem despertado o interesse dos pesquisadores por ser uma biomassa abundante e de baixo custo, além de possuir grupos funcionais como hidroxilas, carbonilas, carboxilas, metoxilas, etc., os quais podem constituir sítios ativos tornando-o um promissor adsorvente para vários solutos (FREITAS et al., 2018). 
O violeta cristal (VC) é um corante catiônico muito usado como agente de coloração, que além de causar sérias doenças em seres humanos, pode levar ao esgotamento de recursos d'água quando em altas concentrações (O’NEILL et al., 1999). Assim sendo, a remoção deste contaminante de corpos d'água é de extrema importância e necessita de grande atenção (GOPI et al., 2016).

Desta forma, o objetivo deste trabalho é determinar o potencial de adsorção do bagaço de cana-de-açúcar (BC) na remoção do corante catiônico violeta cristal (CVC), avaliando os perfis cinéticos com diferentes dosagens de adsorventes.

\section{MATERIAL E MÉTODOS}

O bagaço de cana de açúcar (BC) foi utilizado como bioadsorvente. Seu preparo englobou a secagem em estufa a $60{ }^{\circ} \mathrm{C}$ por $24 \mathrm{~h}$, a moagem em moinho de facas tipo Willey, a lavagem com água corrente para retirar o excesso de açúcar, e secagem em estufa nas condições iniciais.

Os ensaios de adsorção foram realizados variando-se massas adsorventes de 0,$05 ; 0,10$; e $0,15 \mathrm{~g}$ em 50 $\mathrm{mL}$ de solução de corante, com o pH da solução, na concentração de estudo de $100 \mathrm{mg} \mathrm{L}^{-1}$.

As amostras foram agitadas em temperatura ambiente, a $160 \mathrm{rpm}$, em mesa agitadora orbital. Realizouse a quantificação em espectrofotômetro (UV-2600, Shimadzu), no comprimento de onda de $492 \mathrm{~nm}$, em intervalos de tempo regulares (a cada $5 \mathrm{~min}$, até $30 \mathrm{~min}$; a cada $15 \mathrm{~min}$ até $60 \mathrm{~min}$; e após, a cada $30 \mathrm{~min}$ ), até atingir-se o ponto de equilíbrio do adsorvato/adsorvente.

O processo adsortivo foi analisado por meio das Equações 1 e 2, que representam a capacidade de adsorção da biomassa $(q t)$ e a eficiência de remoção $(\eta)$ do corante, respectivamente:

$$
\begin{gathered}
q_{t}=\frac{V\left(C_{0}-C_{t}\right)}{m} \\
\eta=\frac{\left(C_{0}-C_{t, f}\right)}{C_{0}} \times 100
\end{gathered}
$$

sendo $C_{0}$ a concentração inicial de corante, em $\mathrm{mg} \mathrm{L}^{-1} ; C_{t}$ a concentração medida no intervalo de tempo, em $\mathrm{mg} \mathrm{L}^{-1} ; m$ a massa de adsorvente utilizada no processo de adsorção, em g; $V$ volume de solução que contém o corante, em L; e $C_{t, f}$ a concentração no tempo final do processo, em $\mathrm{mg} \mathrm{L}^{-1}$.

Utilizou-se o pacote computacional MatLab ${ }^{\circledR}$ para a construção dos perfis cinéticos de adsorção e determinação dos parâmetros cinéticos dos modelos testados pseudo-primeira ordem (PPO) e pseudo-segunda ordem (PSO), apresentados pelas Equações 3 e 4, respectivamente:

$$
\begin{aligned}
q_{t} & =q_{e}\left(1-e^{-k_{1} t}\right) \\
q_{t} & =\frac{t}{\left(\frac{1}{k_{2} q_{e}^{2}}\right)+\left(\frac{t}{q_{e}}\right)}
\end{aligned}
$$

sendo $k_{l}$ a constante adimensional da taxa de adsorção de PPO; $k_{2}$ a constante adimensional da taxa de adsorção de PSO; $t$ o tempo de adsorção, em min; e $q_{e}$ a capacidade de adsorção no equilíbrio (máxima capacidade adsortiva), em $\mathrm{mg} \mathrm{g}^{-1}$.

O coeficiente de correlação linear $\left(\mathrm{R}^{2}\right)$ e a soma quadrática dos erros (SQE) foram os parâmetros analisados para verificação do melhor ajuste do modelo, considerando-se os melhores ajustes aqueles que apresentaram os maiores valores para o $\mathrm{R}^{2}$ e menores valores da SQE.

\section{RESULTADOS E DISCUSSÃO}

A Figura 1 representa os perfis cinéticos de adsorção com os dados experimentais ajustados aos modelos PPO e PSO para os ensaios com $50 \mathrm{~mL}$ de CVC na concentração de $100 \mathrm{mg} \mathrm{L}^{-1}$ com 0,05; 0,10; e $0,15 \mathrm{~g}$ de $\mathrm{BC}$.

Através da Figura 1 verifica-se que, empregando-se $0,05 \mathrm{~g}$ de $\mathrm{BC}$, alcançou-se uma eficiência de remoção de 90,49\%, com uma capacidade adsortiva de $90,49 \mathrm{mg} \mathrm{g}^{-1}$, admitindo-se o tempo de equilíbrio de 90 min. Para 0,10 g de BC, o tempo de equilíbrio foi atingido aos $60 \mathrm{~min}$, apresentando remoção de 90,35\% e capacidade de $45,17 \mathrm{mg} \mathrm{g}^{-1}$. Já se utilizando $0,15 \mathrm{~g}$, com uma capacidade adsortiva de $32,36 \mathrm{mg} \mathrm{g}^{-1}$, o 
equilíbrio da operação foi atingido aos $90 \mathrm{~min}$, removendo 97,08 \% de CVC.

De acordo com Diel et al. (2018) que fez adsorção do CVC na concentração de $100 \mathrm{mg} \mathrm{L}^{-1}$ utilizando casca de bergamota como adsorvente, resultou em uma remoção de $82,3 \%$ de corante, no tempo de equilíbrio de 70 min. Embora que neste trabalho levou mais tempo para se obter o equilíbrio, conseguiu-se uma remoção mais eficiente, constatando assim o valor da BC.

Em relação a cinética feita em diferentes dosagens de adsorvente nota-se que a maior massa teve melhor rendimento em relação as demais, devido sua superior área superficial, ou seja, maior contato entre adsorvente e adsorbato. Segundo Ofomaja (2008), em grande parte dos casos a remoção aumenta com o aumento de massa de adsorvente, ocorrendo assim o aumento do número de sítios de adsorção na superfície do adsorvente, confirmando os valores obtidos deste trabalho.

Nota-se pela Figura 1 que a curva se eleva rapidamente nos tempos iniciais, devido ao potencial da BC na remoção do $\mathrm{CVC}$, abrindo oportunidade para mais experimentos com coletas em tempos menores, ou também, fazer ensaios com adsorvente tratado em meio básico ou ácido.

A Tabela 1 apresenta os parâmetros dos modelos cinéticos utilizados para ajustar os dados experimentais obtidos na adsorção de CVC na concentração de $100 \mathrm{mg} \mathrm{L}^{-1}$ empregando 0,05; 0,10; e 0,15 g de BC. Mediante aos dados dispostos na Tabela 1, observa-se que o processo adsortivo apresentou melhor ajuste foi do modelo PSO, tanto para coeficiente de correlação linear como para SQR, em todas as dosagens testadas. No entanto, o modelo PPO também apresentou ajuste bom, pois os valores de $\mathrm{R}^{2}$ também foram satisfatórios, acima de 0,99 .

\section{CONCLUSÃO}

Tendo em vista os efeitos negativos causados por efluentes contaminados por compostos orgânicos, o presente trabalho avaliou a capacidade de adsorção do resíduo agroindústrias, a cana-de-açúcar, na remoção de corante catiônico violeta cristal em solução aquosa. Através de ensaios cinéticos com diferentes dosagens de adsorvente, determinou-se que a massa de $0,15 \mathrm{~g}$ em solução de CVC na concentração de $100 \mathrm{mg} \mathrm{L}^{-1}$ removeu cerca de $97,08 \%$ de corante em 90 min de contato. A análise de modelos PPO e PSO indicou bons ajustes cinéticos, com valores altos de $\mathrm{R}^{2}$ e baixos de SQE. Constatando assim, que a utilização de bagaço de cana-de-açúcar é uma alternativa viável em diminuir concentração de efluentes industriais contaminados, minimizando os impactos ambientais.

\section{AGRADECIMENTOS}

Os autores gostariam de agradecer à Universidade Regional Integrada do Alto Uruguai e das Missões pela bolsa concedida, financiada via PIIC-URI e ao Grupo de Pesquisa e Desenvolvimento em Engenharia de Processos.

\section{REFERÊNCIAS}

DIEL, J.C.; SALLET, K.T.; CHIQUIM, M.S.; MAURER, E.; COLOVINI, B.G.; NUNES, I. Dos S. Avaliação da capacidade de adsorção de violeta cristal empregando casca de bergamota in natura. $\mathbf{1 2}^{\circ}$ Encontro Brasileiro sobre Adsorção - EBA. Gramado/RS, 2018.

FREITAS, A.P.; WATANABE, E.O.; ROMANIELO, L.L. Avaliação do potencial adsortivo do bagaço de cana na adsorção de proteínas do leite. In: $12^{\circ}$ Congresso Brasileiro sobre adsorção, Gramado, 2018.

GOMIDE, R. Operações unitárias: Operações de Transferência de Massa, V.4. São Paulo: R. Gomide, 1988. GOPI, S.; PIUS, A.; THOMAS, S. Enhanced adsorption of Crystal violet by synthesized and characterized chitin nano whiskers from shrimp shell. J. of Water Process Engineering, v.14, p.1-8, 2016.

GOSWAMI, M.; PHUKAN, P. Enhanced adsorption of cationic dyes using acid modified activated carbon. J. Environ. Chem. Eng., v. 5, n. 4, p. 3508-3517, 2017.

O’NEILL, C.; HAWKES, F. R.; HAWKES, D. L.; LOURENÇO, N. D.; PINHEIRO, H. M.; DELÉE, W. Colour in textille effluents - sources, measurement, discharge consentsand simulation: a review. J. Chem. Technol. Biot., v. 74, p. 1009-1018, 1999.

OFOMAJA, Augustine E.; Ho, Yuh-Shan. Effect of temperatures and $\mathrm{pH}$ on methyl violet biosorption by mansonia wood sawdust. Bioresource technology, v. 99, n. 13, p. 5411-5417, 2008. 
ZIMMERMANN, B.M.; DOTTO, G.L.; KUHN, R.C.; MAZUTTI M.A.; TREICHEL H.; FOLETTO E.L. Adsorption of hazardous dye Rodhamine B onto Brazilian natural bentonite. J. Environ. Tech. Manage., v 19, p. 1-15, 2016.

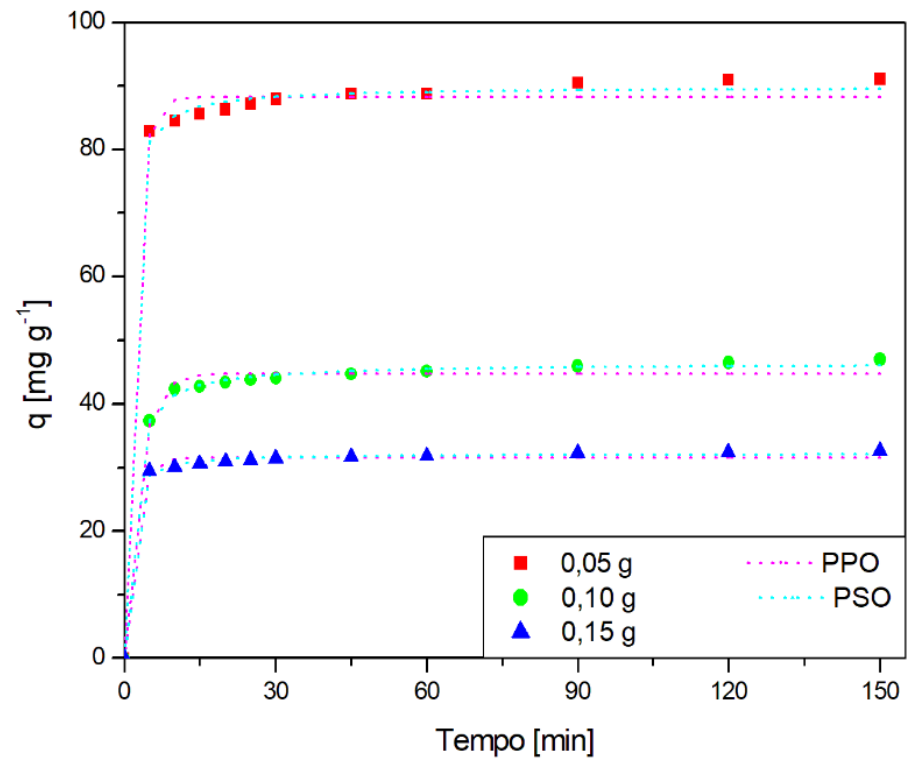

Figura 1. Perfis cinéticos com modelos ajustados ao processo de adsorção de CVC utilizando BC em diferentes dosagens adsorventes.

Tabela 1. Dados cinéticos obtidos a partir dos modelos testados para adsorção de CVC.

\begin{tabular}{|c|c|c|c|}
\hline \multirow{2}{*}{ Modelos Cinéticos } & \multicolumn{3}{|c|}{ Massa de adsorvente [g] } \\
\hline & $\mathbf{0 , 0 5}$ & $\mathbf{0 , 1 0}$ & $\mathbf{0 , 1 5}$ \\
\hline \multicolumn{4}{|c|}{ Pseudo-primeira Ordem (PPO) } \\
\hline$q_{e}\left[\mathrm{mg} \mathrm{g}^{-1}\right]$ & 88,26 & 44,83 & 31,58 \\
\hline$k_{1}\left[\min ^{-1}\right]$ & 0,5404 & 0,344 & 0,5264 \\
\hline $\mathrm{R}^{2}$ & 0,9937 & 0,9911 & 0,9936 \\
\hline SQE [\%] & 2,114 & 1,283 & 0,7624 \\
\hline \multicolumn{4}{|c|}{ Pseudo-segunda Ordem (PSO) } \\
\hline$q_{e}\left[\mathrm{mg} \mathrm{g}^{-1}\right]$ & 89,98 & 46,46 & 32,23 \\
\hline$k_{2}\left[\mathrm{~g} \mathrm{mg} \mathrm{min}^{-1}\right]$ & 0,02078 & 0,01788 & 0,05506 \\
\hline $\mathrm{R}^{2}$ & $0,9982 *$ & $0,9984 *$ & $0,9984 *$ \\
\hline SQE [\%] & 1,143 & 0,5497 & 0,384 \\
\hline
\end{tabular}

*Modelo cinético de melhor ajuste. 


\title{
ESTUDO SOBRE BISFENOL A - TRATAMENTO ENZIMÁTICO E REDUÇÃO DA TOXICIDADE
}

\author{
Costenaro, B.S. ${ }^{1}$; Perassa, M.O. ${ }^{2}$; Alano, C.G. ${ }^{3}$; Rampinelli, J.R.*33 Bonatti-Chaves, M. ${ }^{1,3}$; Furlan, \\ S.A. ${ }^{3}$ \\ ${ }^{1}$ Departamento de Farmácia, Universidade da Região de Joinville - UNIVILLE, Joinville, SC - Brasil \\ ${ }^{2}$ Departamento de Biologia, Universidade da Região de Joinville - UNIVILLE, Joinville, SC - Brasil \\ ${ }^{3}$ Departamento de Engenharia Química, Universidade da Região de Joinville - UNIVILLE, Joinville, SC - \\ Brasil \\ jamilerampinelli@univille.br
}

\begin{abstract}
RESUMO: O bisfenol A (BPA) é classificado como um composto desregulador endócrino, ou seja, é um composto capaz de alterar as funções do sistema endócrino e, consequentemente, causar efeitos adversos à saúde. Assim, sua presença no meio ambiente faz-se preocupante e diversos modos de remoção deste composto são sugeridos como degradação fotocatalítica, processos oxidativos avançados, dentre outros. A remoção do BPA por fungos lignocelulolíticos vem chamando a atenção de pesquisadores nos últimos anos devido a este mostrar-se um método menos custoso, mais seguro e, segundo definições da Química Verde, ambientalmente correto. Assim sendo, o objetivo deste trabalho foi avaliar a toxicidade de uma solução de BPA antes e após tratamento com caldo enzimático bruto de Pleurotus sajor-caju (condições de reação: concentração da solução de BPA 30 ppm, tempo de reação 10 horas, caldo enzimático bruto diluído (1:1), pH 5,0 e temperatura ambiente). Observou-se ao final do tempo de reação diminuição da toxicidade da solução de BPA, tanto nos testes utilizando-se o microcrustáceo Daphnia magna (toxicidade aguda: diminuição de 5 vezes utilizando-se diluição de 12,5\%) quanto nos testes com semente de rúcula, Eruca sativa, (diminuição de 320 e 28 vezes na toxicidade para raiz e para a planta, respectivamente). Desta forma, a utilização do caldo enzimático bruto de Pleurotus sajor-caju mostra-se um método promissor para a resolução de problemas ambientais no futuro, como a remoção de compostos desreguladores endócrinos como o BPA.
\end{abstract}

Palavras-chave: caldo enzimático bruto, desregulador endócrino, Pleurotus sajor-caju, toxicidade ambiental.

\section{STUDY ON BISPHENOL A - ENZYMATIC TREATMENT AND REDUCTION OF TOXICITY}

\begin{abstract}
Bisphenol-A (BPA) is classified as an endocrine disrupting compound, i.e., and as such is capable of altering the functions of the endocrine system and, consequently, causing adverse health effects. Thus, its presence in the environment is a matter of concern and several ways of removal of this compound are suggested such as photocatalytic degradation, advanced oxidative processes, among others. The removal of BPA by lignocellulolytic fungi has been attracting the attention of researchers in recent years due to proving less costly, safer and, according to Green Chemistry definitions, environmentally correct. Therefore, the objective of this work was to evaluate the toxicity of a BPA solution before and after treatment with Pleurotus sajor-caju crude enzyme broth (reaction conditions: concentration of BPA solution $30 \mathrm{ppm}$, reaction time 10 h, diluted crude enzyme broth (1:1), pH 5.0 and room temperature). The reduction on the toxicity of the BPA solution was observed at the end of the reaction time, both in the tests using the Daphnia magna (acute toxicity: 5 -fold reduction in toxicity using $12.5 \%$ dilution) and in relation to tests with rocket see, Eruca sativa (there was a reduction of 320 and 28 times in root and plant toxicity, respectively). Thus, the use of Pleurotus sajorcaju crude enzyme broth of is very promising for the future resolution of environmental problems, such as the removal of endocrine disrupting compounds such as BPA.
\end{abstract}

Key words: crude enzyme broth, endocrine disrupter, Pleurotus sajor-caju, environmental toxicity. 


\section{INTRODUÇÃO}

O bisfenol-A (BPA) é classificado como um composto desregulador endócrino, os quais são suspeitos de alterar as funções do sistema endócrino e, consequentemente, causar efeitos adversos à saúde dos seres vivos (Chang e Chang, 2014). Por conta disso, os efeitos do BPA sobre a saúde humana tem sido muito discutido nas últimas décadas, assim como, tem-se discutido o efeito do BPA sobre o meio ambiente, devido a migração deste para o solo e/ou para o meio aquático, por conta, por exemplo, do descarte inadequado de materiais plásticos, materiais de construção, eliminação de efluentes de estações de tratamento municipais, lixiviação de aterros etc. (Michalowicz, 2014; Bernardo et al., 2015). Existem diferentes formas e/ou metodologias para se remover/degradar o BPA de efluentes. Entretanto, um método bastante promissor tem sido a utilização de enzimas oxidativas, especialmente as lacases, produzidas por diferentes fungos, para a degradação desta classe de poluentes. Fungos do gênero Pleurotus são reconhecidamente bons produtores de lacases e donos de um complexo enzimático único. Assim sendo, este trabalho teve como objetivo avaliar a toxicidade de uma solução de BPA antes e após tratamento de remoção com o caldo enzimático bruto de Pleurotus sajor-caju (condições de reação: concentração da solução de BPA 30 ppm, tempo de reação 10 h, caldo enzimático bruto diluído (1:1), pH 5,0 e temperatura ambiente).

\section{Microrganismo e meio de manutenção}

\section{MATERIAL E MÉTODOS}

Utilizou-se a espécie Pleurotus sajor-caju obtida da Coleção de Culturas de Basidiomicetos do Instituto de Botânica (São Paulo/SP), sob código CCB 019, mantida em meio sólido TDA (Furlan et al., 1997), sob refrigeração $\left(4^{\circ} \mathrm{C}\right)$ e repiques feitos a cada três meses.

\section{Produção do caldo enzimático bruto}

Os inóculos foram preparados em frascos Duran de $2 \mathrm{~L}$ contendo $400 \mathrm{~mL}$ (ou seja, 10\% do volume útil do biorreator) de meio de cultivo OXI45 (Rampinelli, 2016), descrito abaixo, sem sulfato de cobre e pó de cascas de banana. Os frascos foram inoculados com micélio de 7 dias, contido em uma placa de Petri. Em seguida, incubados a $30^{\circ} \mathrm{C}$ com agitação recíproca de $110 \mathrm{~min}^{-1}$, por sete dias (Furlan et al., 2008). Em seguida, realizou-se o cultivo em biorreator de mistura completa B. Braun, Biostat $\mathrm{B}$, a $30^{\circ} \mathrm{C}$, velocidade de agitação fixada em $350 \mathrm{rpm}$, a aeração em $0,37 \mathrm{vvm}$. O pH inicial foi ajustado em 6,0. O tempo de cultivo foi de quatro dias, tempo em que a atividade de lacase é máxima, conforme Rampinelli (2016). Como meio de cultivo utilizou-se o meio OXI45 composto por: água de imersão de palha de bananeira adicionado de $45 \mathrm{~g} \mathrm{~L}^{-1}$ de pó de cascas de banana, $150 \mu \mathrm{M}$ de sulfato de cobre, $5,4 \mathrm{mM}$ de tartarato de amônio e $10 \mathrm{~g} \mathrm{~L}^{-1}$ de glicose. Após o período de quatro dias o caldo enzimático bruto foi centrifugado a $5000 \mathrm{~g}$ por cinco minutos para separação da biomassa, e partículas sólidas maiores, e congelado até início dos experimentos.

\section{Remoção do bisfenol A pelo caldo enzimático bruto de Pleurotus sajor-caju}

Utilizou-se a seguinte mistura na proporção $1: 1: 1(\mathrm{v} / \mathrm{v} / \mathrm{v})$ para a realização dos experimentos: solução BPA $30 \mathrm{ppm}$, solução tampão citrato $\left(20 \mathrm{mM}-\mathrm{pH}\right.$ 5) e caldo enzimático bruto (em torno de $50 \mathrm{U} \mathrm{L}^{-1}$, considerando a diluição que ocorre no momento da mistura dos três componentes, caldo + solução tampão + solução BPA). Incubou-se a temperatura ambiente por $10 \mathrm{~h}$ (Kuss et al., 2018). Um experimento controle (caldo enzimático inativado por fervura) foi conduzido concomitantemente. Todos os experimentos foram realizados em triplicata.

\section{Avaliação da toxicidade antes e após tratamento enzimático}

Nos tempos 0 e $10 \mathrm{~h}$ mediu-se atividade de lacase e concentração de BPA. Assim como, testes ecotoxicológicos foram realizados (toxicidade aguda com Daphnia magna e testes com sementes de rúcula, Eruca sativa). Uma porção da mistura inicial (caldo enzimático + solução tampão + solução BPA) foi inativada por fervura e os mesmos testes foram realizados (atividade enzimática, concentração de BPA e testes ecotoxicológicos). 


\section{Métodos análiticos}

A concentração de BPA foi determinada por meio de extração utilizando-se éter etílico. $\mathrm{O}$ sobrenadante foi analisado por cromatografia gasosa acoplada a espectrometria de massa. A coluna HP-5 (5\% phenylmethylsiloxane), foi mantida a $290^{\circ} \mathrm{C}$ durante a injeção e depois programada para aquecimento de 140 ${ }^{\circ} \mathrm{C} \min ^{-1}$ a $310{ }^{\circ} \mathrm{C}$, por $10 \mathrm{~min}$, para realizar a análise quantitativa. O BPA foi identificado mediante seu tempo de retenção característico, e as concentrações do composto calculadas com base na curva de calibração estabelecida com padrão externo de BPA. Os testes de toxicidade aguda com Daphnia magna seguiram metodologia descrita pela Cetesb (2007). Além dos testes com Daphnia magna, realizou-se também testes de fitotoxicidade com a Eruca sativa, popularmente conhecida como rúcula. Nos quais foram avaliados os seguintes parâmetros: germinação das sementes, o crescimento das radículas e o índice de germinação (Costa, 2010 apud Correia, 2015).

\section{Análise estatística}

O Teste Q de Dixon, com nível de confiança de 95\%, foi utilizado para avaliar a rejeição de valores desviantes (Rorabacher, 1991) e o Teste Tukey para avaliar a existência de diferenças estatisticamente significativas entre as médias dos resultados, com nível de confiança de 95\%.

\section{RESULTADOS E DISCUSSÃO}

Observou-se ao final do tempo de $10 \mathrm{~h}$ manutenção da atividade enzimática, em torno de $80 \%$, assim como diminuição na concentração de BPA. Com relação aos testes ecotoxicológicos utilizando-se o microcrustáceo Daphnia magna, observa-se, de acordo com a Figura 1, diminuição da toxicidade após o tratamento enzimático quando se utiliza a diluição de 12,5\%. Calculando-se o percentual de inibição observase percentual de inibição de $25 \%$ para o tempo 0 e de $5 \%$ para o tempo $10 \mathrm{~h}$, na diluição de $12,5 \%$, ou seja, diminuição de cinco vezes na toxicidade. Foram realizados experimentos utilizando-se as seguintes diluições $100 \%, 75 \%, 50 \%, 25 \%, 12,5 \%, 6,25 \%, 3,12 \%, 1,56 \%$ e $0,78 \%$. A partir da diluição $6,25 \%$, e inferiores, não observou-se morte/imobilização de nenhum organismo, em nenhuma das soluções testadas, ou seja, antes e após tratamento enzimático. Assim como, observou-se morte/imobilização de todos os organismos nas diluições $100 \%$ a $25 \%$, antes e após tratamento enzimático.

Com relação aos testes utilizando-se sementes de rúcula (E. sativa), observa-se por meio da Figura 2 maior comprimento tanto da raiz quanto da planta nos testes após o tratamento enzimático. Mais especificamente, observa-se aumento de 320 e 28 vezes no crescimento da raiz e da planta, respectivamente. Nos testes utilizando-se as diluições $50 \%$ e $25 \%$ não observou-se diferença estatisticamente significativa entre os comprimentos da raiz e da planta.

De acordo com os resultados apresentados, sugere-se grande potencial de aplicação do caldo enzimático bruto de Pleurotus sajor-caju para resolução de problemas ambientais, como por exemplo, no caso deste estudo, para a remoção de compostos interferentes endócrinos como o BPA. Obviamente, estudos adicionais são necessários até a obtenção de um formulado enzimático que possa ser comercializado e utilizado na área ambiental.

\section{CONCLUSÃO}

Observou-se ao longo do tempo de reação manutenção da atividade enzimática, assim como redução da concentração de BPA e da sua toxicidade após o tratamento enzimático, tanto nos testes com Daphnia magna (diminuição de 5 vezes na toxicidade utilizando-se diluição de 12,5\%) quanto nos testes com semente de rúcula (diminuição de 320 e 28 na toxicidade para raiz e para a planta). A utilização do caldo enzimático bruto de Pleurotus sajor-caju mostra-se bastante promissora para resolução futura de problemas ambientais, como a remoção do composto interferente endócrino bisfenol-A (BPA).

\section{REFERÊNCIAS}

BERNARDO, P.E.M.; NAVAS, S.A.; MURATA, L.T.F.; ALCÂNTARA, M.R.S. Bisfenol A: o uso em embalagens para alimentos, exposição e toxicidade - Uma Revisão. Revista Instituto Adolfo Lutz, 74(1):1-11, 2015. 
CETESB L5.018. São Paulo. Métodos de avaliação da toxicidade de poluentes a organismos aquáticos, 2007. CHANG, B.; CHANG, Y. Biodegradation of toxic chemicals by Pleurotus eryngii in submerged fermentation and solid-state fermentation. Journal of Microbiology, Immunology and Infection, Article in press, p. 1-7, 2014.

CORREIA, C. H. G. Reuso de resíduo de areia descartada de fundição (ADF) - uma avaliação técnica e toxicológica do processo de produção de fritas cerâmicas em escala laboratorial. Joinville, Univille. 2015.

FURLAN S.A., VIRMOND L.J., MIERS D., BONATTI M., GERN R.M.M., JONAS R. Mushroom strains able to grow at high temperatures and low $\mathrm{pH}$ values. World Journal of Microbiology and Biotechnology, 13: 689-692, 1997.

FURLAN. S. A.; GERN, R. M. M.; WISBECK, E.; BONATTI, M.; SILVEIRA, M. L. L.; SILVA, H. H. Possibilities of Pleurotus applications in food, health and environmental technologies. In: KOUTINAS, A.; PANDEY, A.; LARROCHE, C. Current topics on Bioprocesses in Food Industry. Nova Delhi: Asiatech, p. 482-495, 2008.

K. KUSS, C.G. ALANO, A. ARBIGAUS, J.R. RAMPINELLI, M.L.L. SILVEIRA, M. BONATTI-CHAVES, S.A. FURLAN. Study of the removal of bisphenol-a by Pleurotus sajor-caju crude enzyme broth. Academia Mexicana de Investigación y Docencia en Ingeniería Química A.C, v. 17, n. 3, p. 989-998, 2018.

MICHALOWICZ, J. Bisphenol A - Sources, toxicity and biotransformation. Environmental Toxicology and Pharmacology, v. 37, p. 738-758, 2014.

RAMPINELLI, J. R. Utilização de casca de banana para a produção de lacase por Pleurotus sajor-caju CCB 019. Tese (doutorado em Engenharia Química). Universidade Federal de Santa Catarina. Florianópolis. 2016. RORABACHER, D. B. Statistical treatment for rejection of deviant values: critical values of Dixon's "Q" parameter and related subrange ratios at the $95 \%$ confidence level. Anal. Chem., v. 63, p. 139-146, 1991.

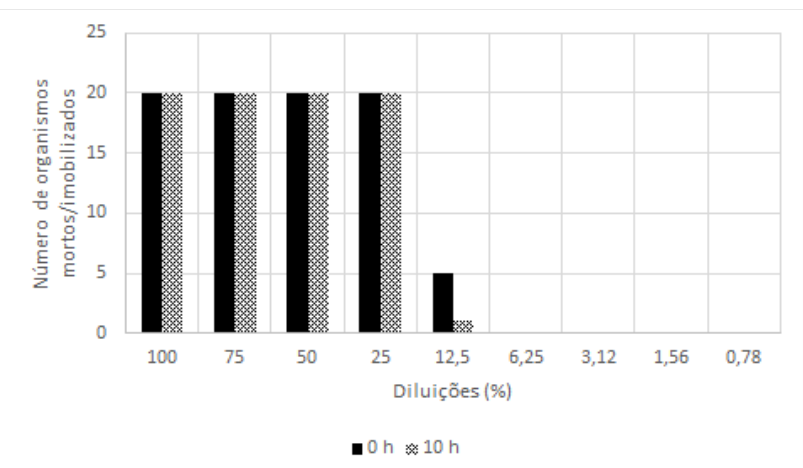

Figura 1. Teste ecotoxicológico com Daphnia magna antes e após tratamento enzimático.

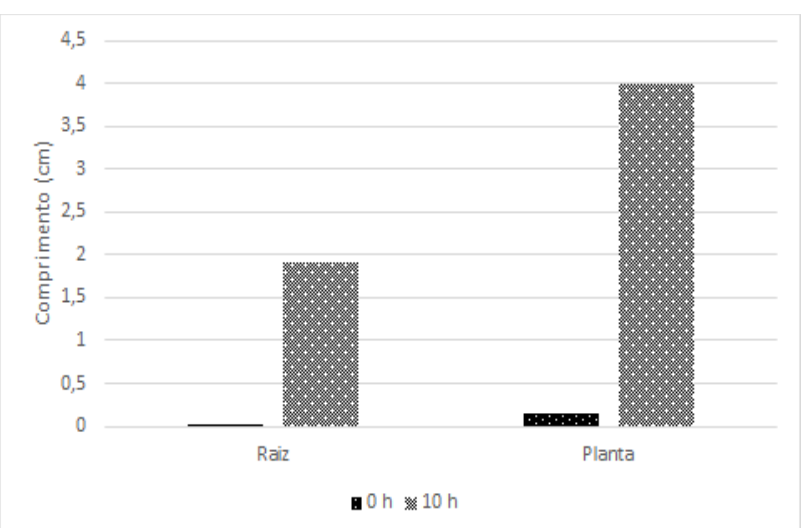

Figura 2. Teste ecotoxicológico utilizando-se sementes de rúcula, antes e após tratamento enzimático da solução de bisfenol-A (BPA). 


\title{
EVALUATION OF THE PRETREATMENT OF CORN STALK USING AN ULTRASOUND SYSTEM
}

\author{
Venturin, B.*11; Mulinari, J. ${ }^{2}$; Scapini, T. ${ }^{3}$ Camargo, A.F. ${ }^{3}$; Kunz, A. ${ }^{4}$; Treichel, H. ${ }^{5}$ \\ ${ }^{I}$ PhD student in Agricultural Engineering - Western Paraná State University, Campus Cascavel, PR - Brazil, \\ ${ }^{2} P h D$ student in Chemical Engineering - Federal University of Santa Catarina, Florianópolis, SC - Brazil, \\ ${ }^{3}$ Mater's student in Environmental Science and Technology - Federal University of Fronteira Sul, Campus Erechim, RS - Brazil, \\ ${ }^{4}$ Researcher at Embrapa Suínos e Aves, Concórdia, SC - Brazil, \\ ${ }^{5}$ Professor at Federal University of Fronteira Sul, Campus Erechim, RS - Brazil.
}

\begin{abstract}
The growing demand for biofuels shows the need to significantly increase its production with high efficiency and in a sustainable way. This increase can be achieved with the full use of corn stalks and other biomasses. The lignocellulosic biomass has a high content of cellulose, which can be converted to different biocompounds. The great obstacle of this conversion is its complex chemical structure. So, the pretreatment of this material is a decisive step in the breakdown of its structure. This study evaluated the pretreatment through ultrasonic waves at the frequency of $40 \mathrm{kHz}$ on corn stalk bran (Zea mays), using the experimental design methodology. The factors studied were liquid/solid ratio $\left(3,5,7 \mathrm{~g}\right.$ in $100 \mathrm{~mL}$ of $\left.\mathrm{H}_{2} \mathrm{O}\right)$, exposure time $(22.5,40,57.5 \mathrm{~min})$, temperature of the reaction medium $\left(20,50,80{ }^{\circ} \mathrm{C}\right)$ and ultrasonic bath power $(20,50,80 \%$ of $132 \mathrm{~W})$. After being submitted to the pretreatment, the biomass was analyzed through high performance liquid chromatography. The concentrations of glucose, xylose, cellobiose, arabinose, acetic acid, furfural and hydroxymethylfurfural were determined in order to calculate the structural composition (cellulose, hemicellulose and lignin) of the material after the pretreatment. The statistical analysis of the experimental matrix showed that there were no significant changes in the composition of the pretreated biomass in the studied tracks. As the levels tested were very mild, the next step is to look for experimental conditions with higher irradiation energies of ultrasound waves, as well as higher exposure time and temperature of the reaction medium.
\end{abstract}

Keywords: biofuels, structural composition, chromatographic analysis.

\section{INTRODUCTION}

The issue of sustainable development has been widely discussed, with the highlight being the search for the expansion of the energy matrix. Thus, the need to replace the large-scale use of oil reserves by the use of biofuels is becoming increasingly clear. In this sense, lignocellulosic materials, which basically have cellulose, hemicellulose and lignin in their structure, are a promising alternative (Dagnino et al., 2013; Lizasoain et al., 2017).

This type of raw material has a high carbohydrate content, which are in polymer chains and can be saccharified and digested. The main obstacles to this conversion are to disassemble the resistant structure of the lignocellulosic biomass, effectively release the sugars susceptible to co-digestion and make its use economically viable (Paudel et al., 2017; Santos et al., 2012).

The pretreatment has a decisive role in the de-structuring of the complex chemical structures that forms the different lignocellulosic materials in order to facilitating the subsequent hydrolysis process, since after treated the material will present higher digestibility (Dinuccio et al., 2010; Zheng et al., 2014). The ideal pretreatment produces an easily digestible solid, does not degrade sugars, significantly removes lignin, does not inhibit the subsequent digestion step, produces waste without wasting the solid material, has a high degree of simplicity and is effective (Mosier et al., 2005; Pienkos and Zhang, 2009; Zhao et al., 2018).

In this context, the objective of this work was to investigate the pretreatment in an ultrasonic system of a lignocellulosic raw material, the corn stalk (Zea mays), using experimental design methodology. 


\section{MATERIAL AND METHODS}

An amount of dry mass of crushed and sifted corn stalk (CSCS) was weighed into $250 \mathrm{~mL}$ erlenmeyers using an analytical balance (SHIMADZU AUY220, Philippines). The variables studied were dry mass (3, 5 and $7 \mathrm{~g}$ in $100 \mathrm{~mL}$ of $\mathrm{H}_{2} \mathrm{O}$ ), exposure time $(22.5,40$ and $57.5 \mathrm{~min}$ ), temperature of the reaction medium (20, 50 and $\left.80^{\circ} \mathrm{C}\right)$ and ultrasonic bath power $(20,50$ and $80 \%$ of $132 \mathrm{~W})$. Considering the water from the intrinsic moisture of the CSCS, a final volume of $100 \mathrm{~mL}$ of $\mathrm{H}_{2} \mathrm{O}$ was adjusted. The evaluated responses for this design were the structural composition of the crushed corn stalk after pretreatment in ultrasound system.

All experiments were carried out using the same volume of liquid $(100 \mathrm{~mL})$, therefore the interference of the liquid/solid ratio $\left(\mathrm{m} . \mathrm{v}^{-1}\right)$ in the pretreatment performance could be evaluated. These $100 \mathrm{~mL}$ were placed in erlenmeyers containing the biomass, which were capped and taken to the ultrasonic bath (UNIQUE INC., USC- $1800^{\mathrm{a}}$, operating frequency of $40 \mathrm{kHz}$ and maximum power of $132 \mathrm{~W}-0.42 \mathrm{~W} . \mathrm{cm}^{-2}$ ) (Nakashima et al., 2016; Nikolic et al., 2010). After the experiment time, the samples were removed from the ultrasound system, cooled to room temperature $\left(25^{\circ} \mathrm{C}\right)$ and filtered through a $100 \mu \mathrm{m}$ nylon filter, the supernatant was discarded. The pretreated biomass was then washed with $1.5 \mathrm{~L}$ of distilled water until it reached $\mathrm{pH} 7$.

The biomass retained in the nylon filter was dried until constant mass at $105^{\circ} \mathrm{C}$ in an oven (SOLAB SL100, Brazil). After that, the samples were weighed in an analytical balance, stored in plastic bottles and frozen in a freezer at $-4{ }^{\circ} \mathrm{C}$ for later analysis of its structural composition according to the methodology described by Venturin et al. (2018).

\section{RESULTS AND DISCUSSION}

The composition of the sieved biomass after pretreatment in ultrasound system can be observed in Table 1. It can be observed that, practically, none of the experimental conditions tested changed the structural composition of the biomass. In results reported by Nakashima et al. (2016) and Nikolic et al. (2010), the ultrasound system proved to be effective to destabilize the lignocellulosic structure. However, different from this study, the authors used ultrasonic radiation with power up to $600 \mathrm{~W}$ and association with other solvents.

When all the results of cellulose, hemicellulose and lignin content were used, three mean values and their respective standard errors could be calculated, all of them in percentage $\left(\mathrm{m} \cdot \mathrm{m}^{-1}\right)$. They were $30.7 \pm 0.4 \%$ for cellulose, $22.8 \pm 0.3 \%$ for hemicellulose and $20.5 \pm 0.4 \%$ for lignin. These values are very close to those obtained for the untreated CSCS, $29.7 \pm 0.8 \%$ for cellulose, $23.3 \pm 0.3 \%$ for hemicellulose and $21.8 \pm 2.4 \%$ for lignin, which served as a parameter to verify the initial contents in the biomass composition.

By evaluating the effects of the variables for the three responses studied (cellulose, hemicellulose and lignin), it was observed that with $95 \%$ certainty none of the variables tested had a significant effect. Nakashima et al. (2016) studied the effect of isolated ultrasound in the biomass structure (stalk straw and corn leaves) and then analyzed the changes in the fiber through infrared spectroscopy using Fourier transform, with no change in composition. This result corroborates the ones presented in this paper.

The unsatisfactory results obtained can be attributed mainly to the very mild experimental conditions employed. Soft temperature values of the ultrasound system, associated with low ultrasound powers, were not able to disassemble the rigid lignocellulosic structure. The ultrasonic waves and the cavitation effect caused by them did not have a significant effect on the studied ranges. Probably by using higher ultrasonic powers, above $132 \mathrm{~W}$ (maximum provided by the equipment used for these tests), and other solvents, promising results can be obtained in the alteration of the lignocellulosic material composition (Mood et al., 2013; Sasmal and Mohanty, 2018). Ultrasound can be considered a clean energy, since no toxic chemicals are required and, when used in combination with solvents, it can reduce the amount of solvent needed in comparison to the conventional technique. These characteristics encourage the exploration of ultrasound for corn stalk pretreatment in order to use this biomass for the production of biofuels in future works.

\section{CONCLUSIONS}

Ultrasound pretreatment (UNIQUE INC., USC-1800, operating frequency of $40 \mathrm{kHz}$ and maximum power of $132 \mathrm{~W}-0.42 \mathrm{~W} . \mathrm{cm}^{-2}$ ) did not show significant changes in the structural composition of the corn stalk. So, its use in the experimental conditions studied is not recommended. However, it is expected that by using higher ultrasound power it will be possible to have significant effects on the lignocellulosic structure. 


\section{ACKNOWLEDGMENTS}

This study was financed in part by the Coordenação de Aperfeiçoamento de Pessoal de Nível Superior - Brazil (CAPES) and by the Conselho Nacional de Desenvolvimento Científico e Tecnológico - Brazil (CNPq). The authors would like to thank CAPES and CNPq for the financial support.

\section{REFERENCES}

Dagnino, E.P., Chamorro, E.R., Romano, S.D., Felissia, F.E., Area, M.C., 2013. Optimization of the acid pretreatment of rice hulls to obtain fermentable sugars for bioethanol production. Ind. Crops Prod. 42, 363368

Dinuccio, E., Balsari, P., Gioelli, F., Menardo, S., 2010. Evaluation of the biogas productivity potential of some italian agro-industrial biomasses. Bioresour. Technol. 101, 3780-3783.

Lizasoain, J., Trulea, A., Gittinger, J., Kral, I., Piringer, G., Schedl, A., Nilsen, P.J., Potthast, A., Gronauer, A., Bauer, A., 2017. Corn stover for biogas production: effect of steam explosion pretreatment on the gas yields and on the biodegradation kinetics of the primary structural compounds. Bioresour. Technol. 244, 949956.

Mood, S.H., Golfeshan, A.H., Tabatabei, M., Jouzani, G.S., Najafi, G.H., Gholami, M.,Ardjmand, M., 2013. Lignocellulosic biomass to bioethanol, a comprehensiva review with a focua on pretreatment. Renew. Sustain. Energy Rev. 27, 77-93.

Mosier, N., Wyman, C., Dale, B., Elander, R., Lee, Y.Y., Holtzapple, M., Ladisch, M., 2005. Features of promising technologies for pretreatment of lignocellulosic biomass. Bioresour. Technol. 96, 673-686.

Nakashima, K., Ebi, Y., Kubo, M., Shibasaki-Kitakawa, N., Yonemoto, T., 2016. Pretreatment combining ultrasound and sodium percarbonate under mild conditions for efficient degradation of corn stover. Ultrason. Sonochem. 29, 455-460.

Nikolic, S., Mojovic, L., Rakin, M., Pejin, D., Pejin, J., 2010. Ultrasound-assisted production of bioethanol by simultaneous saccharification and fermentation of corn meal. Food Chem. 122, 216-222.

Paudel, S.R., Banjara, S.P., Choi, O.K., Park, K.Y., Kim, Y.M., Lee, J.W., 2017. Pretreatment of agricultural biomass for anaerobic digestion: current state and challenges. Bioresour. Technol. 245, 1194-1205.

Pienkos, P.T., Zhang, M., 2009. Role of pretreatment and conditioning processes on toxicity of lignocellulosic biomass hydrolysates. Cellulose 16, 743-762.

Santos, F. A, Queiróz, J.H. De, Colodette, J.L., Fernandes, S. A, Guimarães, V.M., 2012. Potencial da palha de cana-de-aucar para produção de etanol. Quim. Nova 35, 1004-1010.

Sasmal, S., Mohanty, K., 2018. Pretreatment of lignocellulosic biomass toward biofuel production. 203-221. Venturin, B., Camargo, A.F., Scapini, T., Mulinari, J., Bonatto, C., Bazoti, S., Siqueira, D.P., Colla, L.M., Alves Jr, S.L., Bender, J.P., Steinmetz, R.L.R., Kunz, A., Fongaro, G., Treichel, H., 2018. Effect of pretreatments on corn stalk chemical properties for biogas production purposes. Bioresour. Technol. 266, $116-124$.

Zhao, X., Luo, K., Zhang, Y., Zheng, Z., Cai, Y., Wen, B., Cui, Z., Wang, X., 2018. Improving the methane yield of maize straw: focus on the effects of pretreatment with fungi and their secreted enzymes combined with sodium hydroxide. Bioresour. Technol. 250, 204-213.

Zheng, Y., Zhao, J., Xu, F., Li, Y., 2014. Pretreatment of lignocellulosic biomass for enhanced biogas production. Prog. Energy Combust. Sci. 42. 
Table 1. Structural composition of crushed and sieved corn stalk after pretreatment in ultrasound system, coded and real values.

\begin{tabular}{cccccccc}
\hline Assay & $\begin{array}{c}\text { Time } \\
(\mathbf{m i n})\end{array}$ & $\begin{array}{c}\text { Temperature } \\
(\mathbf{(} \mathbf{C})\end{array}$ & $\begin{array}{c}\text { Power } \\
(\boldsymbol{\%})\end{array}$ & $\begin{array}{c}\text { Dry mass } \\
(\mathbf{g})\end{array}$ & $\begin{array}{c}\text { Cellulose } \\
\left(\mathbf{\%} \mathbf{~ m . m}^{-1}\right)\end{array}$ & $\begin{array}{c}\text { Hemicellulose } \\
\left(\boldsymbol{\%} \mathbf{~ m . m}^{-1}\right)\end{array}$ & $\begin{array}{c}\text { Lignin } \\
\left(\boldsymbol{\%} \mathbf{~ m . m}^{-1} \mathbf{)}\right.\end{array}$ \\
\hline 1 & $-1(22.5)$ & $-1(42.5)$ & $-1(20)$ & $-1(3)$ & 29.4 & 21.3 & 27.2 \\
2 & $-1(22.5)$ & $-1(42.5)$ & $-1(20)$ & $1(7)$ & 30.2 & 22.4 & 17.8 \\
3 & $-1(22.5)$ & $-1(42.5)$ & $1(80)$ & $-1(3)$ & 31.4 & 21 & 17.2 \\
4 & $-1(22.5)$ & $-1(42.5)$ & $1(80)$ & $1(7)$ & 31.2 & 23.1 & 12.8 \\
5 & $-1(22.5)$ & $1(67.5)$ & $-1(20)$ & $-1(3)$ & 31.3 & 23.5 & 19.4 \\
6 & $-1(22.5)$ & $1(67.5)$ & $-1(20)$ & $1(7)$ & 29.7 & 22.2 & 22.5 \\
7 & $-1(22.5)$ & $1(67.5)$ & $1(80)$ & $-1(3)$ & 32 & 23.4 & 18.8 \\
8 & $-1(22.5)$ & $1(67.5)$ & $1(80)$ & $1(7)$ & 29.2 & 21.7 & 32 \\
9 & $1(57.5)$ & $-1(42.5)$ & $-1(20)$ & $-1(3)$ & 30.7 & 22.9 & 17.6 \\
10 & $1(57.5)$ & $-1(42.5)$ & $-1(20)$ & $1(7)$ & 31.3 & 23.3 & 21.3 \\
11 & $1(57.5)$ & $-1(42.5)$ & $1(80)$ & $-1(3)$ & 31.1 & 23.5 & 20.7 \\
12 & $1(57.5)$ & $-1(42.5)$ & $1(80)$ & $1(7)$ & 29.9 & 22.5 & 23.4 \\
13 & $1(57.5)$ & $1(67.5)$ & $-1(20)$ & $-1(3)$ & 32.9 & 24.6 & 22.6 \\
14 & $1(57.5)$ & $1(67.5)$ & $-1(20)$ & $1(7)$ & 33 & 24.7 & 25 \\
15 & $1(57.5)$ & $1(67.5)$ & $1(80)$ & $-1(3)$ & 30.7 & 23 & 11.3 \\
16 & $1(57.5)$ & $1(67.5)$ & $1(80)$ & $1(7)$ & 31.2 & 23.8 & 20.2 \\
$17(\mathrm{C})$ & $0(40)$ & $0(55)$ & $0(50)$ & $0(5)$ & 33.1 & 24.6 & 18.7 \\
$18(\mathrm{C})$ & $0(40)$ & $0(55)$ & $0(50)$ & $0(5)$ & 25 & 18.9 & 23 \\
$19(\mathrm{C})$ & $0(40)$ & $0(55)$ & $0(50)$ & $0(5)$ & 29.4 & 22.4 & 17.1 \\
\hline
\end{tabular}




\title{
FITOTOXICIDADE DE COMPOSTOS ORGÂNICOS OBTIDOS DE RESÍDUOS AVÍCOLAS ASSOCIADOS A GLICERINA BRUTA
}

\author{
Santos, F.T. ${ }^{1}$; Franciozi, S.A. ${ }^{1}$; Fehmberger, C. ${ }^{1}$; Aloisio, C.M. ${ }^{1}$; Bautitz, I.R. ${ }^{1}$; Hermes, E. ${ }^{* 1}$ \\ IPrograma de Pós-Graduação em Tecnologias de Bioprodutos Agroindustriais, Universidade Federal do Paraná (UFPR), Palotina, \\ PR - Brasil. \\ elianehermes@yahoo.com.br
}

\begin{abstract}
RESUMO: A cadeia produtiva de aves gera uma variedade e quantidade considerável de resíduos orgânicos com as mais distintas características (fonte de nitrogênio). No mesmo panorama, a produção de biodiesel gera como subproduto a glicerina bruta (GB) (fonte de carbono). Nos resíduos orgânicos de cadeias agroindustriais, o processo de compostagem vem sendo empregado como forma de tratamento. Diante disso, o objetivo deste estudo foi avaliar a fitotoxicidade de compostos orgânicos provenientes de resíduos orgânicos da cadeia de aves associados a glicerina bruta. As concentrações de GB em relação a massa seca dos resíduos foram de 0,0; 1,$5 ; 3,0 ; 4,5$ e $6,0 \%$ (cinco tratamentos) e os paramêtros de monitoramento adotados foram: temperatura, umidade e revolvimentos semanais em todo o processo de compostagem. Realizou-se a determinação do índice de germinação (IG) (fitotoxicidade) no início e final do processo. Os resultados para o IG no início da compostagem foram de 53,36; 48,97; 58,41; 48,81 e 51,14\% e ao final do processo foram de 146,51; 146,45; 133,$21 ; 144,02$ e $132,47 \%$ para o T0,0; T1,5; T3,0; T4,5 e T6,0\%, respectivamente e condutividade elétrica abaixo de $3 \mathrm{mS} \mathrm{cm}^{-1}$. Dessa forma, os compostos orgânicos obtidos apresentaram-se livres de compostos fitotóxicos e com condutividade elétrica indicada para produção de mudas.
\end{abstract}

Palavras-chave: índice de germinação, resíduos orgânicos, valor agronômico.

\section{PHYTO-TOXICITY OF ORGANIC COMPOUNDS OBTAINED FROM POULTRY WASTE ASSOCIATED WITH CRUDE GLYCERINE}

\begin{abstract}
The production chain of poultry generates a considerable variety of organic waste with the most different characteristics (nitrogen source). In the same scenario, biodiesel production generates crude glycerin (GB) as a byproduct. In the organic residues of agroindustrial chains, the composting process has been used as a form of treatment. Therefore, the objective of this study was to evaluate the phytotoxicity of organic compounds from organic residues of the poultry chain associated with crude glycerin. The concentrations of GB in relation to the dry mass of the residues were $0.0 ; 1.5 ; 3.0 ; 4.5$ and $6.0 \%$ (five treatments) and the monitoring parameters adopted were: temperature, humidity and weekly revolves throughout the composting process. The germination index (GI) (phytotoxicity) was determined at the beginning and end of the process. The results for the GI at the beginning of composting were 53.36; 48.97; 58.41; 48.81 and $51.14 \%$ and at the end of the process were $146.51 ; 146,45 ; 133.21 ; 144.02$ and $132.47 \%$ for T0.0; T1,5; T3.0; T4.5 and T6.0\%, respectively, and electrical conductivity below $3 \mathrm{mS} \mathrm{cm}^{-1}$. Thus, the organic compounds obtained were free of phytotoxic compounds and with electrical conductivity indicated for the production of seedlings.
\end{abstract}

Keywords: germination index, organic waste, agronomic value.

\section{INTRODUÇÃO}

Com o desenvolvimento do setor avícola, existe a produção de uma quantidade significativa de resíduos ao longo de toda a cadeia, principalmente matrizeiro, incubatório (carcaças e cama de frango) e frigorífico (COSTA et al., 2017). Apesar dos resíduos agroindustriais possuírem elevado potencial poluente, não podem ser considerados como rejeito, pois possuem valor econômico agregado e podem ser tratados e aproveitados no próprio setor (MATOS, 2014).

Os resíduos sólidos mais representativos produzidos pela cadeia da avicultura de corte compreendem os resíduos de incubatório, cama de frango, lodo de flotador e biochar/carvão residual remanescente da queima nas caldeiras (CARNEIRO, 2012). Na produção de biodiesel, mesmo diante dos ganhos econômicos e 
ambientais, existe a preocupação no que se refere à geração de resíduos, pois neste processo tem-se um subproduto conhecido como glicerina bruta com alto potencial poluidor (CUBAS et al., 2010).

Diante dos custos para a purificação da glicerina bruta, esta apresenta-se como uma fonte de carbono para o processo de compostagem que converte resíduos orgânicos em adubos orgânicos. Denomina-se como composto orgânico a matéria orgânica resultante da decomposição microbiológica de resíduos e restos vegetais, sendo este bioestabilizado, homogêneo, sem exalação de cheiro desagradável, de pigmentação escurecida e livre de microrganismos patogênicos (KIEHL, 2010). Devido ao conteúdo de nutrientes presente nos resíduos se concentrar ao final do processo de compostagem pelas perdas de carbono, o composto orgânico pode apresentar-se tóxico e o excesso de sais concentrados eleva a condutividade elétrica que interfere na absorção dos nutrientes pela raiz das plantas (TAKANE et al., 2012; SANTOS et al., 2016).

Dessa forma, o índice de toxicidade do composto pode inferir quanto da sua fitotoxicidade sobre as plantas. Sendo assim, o objetivo do estudo foi avaliar a fitotoxicidade de compostos orgânicos provenientes de resíduos orgânicos da cadeia de aves associados a glicerina bruta.

\section{MATERIAL E MÉTODOS}

O experimento foi conduzido na Universidade Federal do Paraná (UFPR) - Setor Palotina, a qual possui as seguintes coordenadas geográficas: $24^{\circ} 17^{\prime}$ latitude sul e $53^{\circ} 50^{\prime}$ longitude oeste. O processo de compostagem dos resíduos orgânicos agroindustriais foi conduzido em composteiras construídas com paletes, contendo 4 divisórias dentro de cada composteira, de modo que houvesse 4 repetições de cada tratamento, revestidas com tela permeável, denominadas de células de compostagem. As composteiras foram confeccionadas manualmente e dispostas sobre lona para impermeabilização no pátio e com cobertura para proteção da incidência solar direta e das chuvas.

Utilizou-se no processo de compostagem diferentes resíduos como fontes de carbono, tais como poda de árvores urbanas, bagaço de cana e glicerina bruta. A glicerina bruta foi adquirida de uma usina de biodiesel da região, a poda de árvore foi obtida junto a prefeitura da cidade e o bagaço de cana em uma garapeira da região e carvão remanescente da queima em caldeiras de frigorífico.

Os resíduos utilizados neste experimento como fontes de nitrogênio foram fornecidos por uma cooperativa de abate de aves e produtores de engorda de frango da região, sendo estes: resíduo de incubatório, a cama de frango, o lodo de flotador.

Os tratamentos foram constituídos de diferentes proporções dos resíduos orgânicos provenientes de uma indústria de beneficiamento de aves, bem como diferentes concentrações de glicerina bruta na massa natural do material compostado $(0,1,5 ; 3,0 ; 4,5$ e $6 \%)$ denominados de T0,0; T1,5; T3,0; T4,5 e T6,0\%. As misturas foram definidas em função da composição de carbono e nitrogênio dos resíduos, fixando a relação C:N de aproximadamente $26 / 1$ para todos os tratamentos

A temperatura da leira foi monitorada a cada 3 dias, com auxílio de termômetro digital, a uma profundidade de aproximadamente $30 \mathrm{~cm}$. Por ocasião das medidas de temperatura das leiras, a temperatura ambiente foi monitorada, pois quando a temperatura do interior das leiras estava semelhante a temperatura ambiente, considerou-se o final do processo de compostagem. A umidade das leiras foi controlada semanalmente após cada revolvimento e ajustada com adição da quantidade de água necessária, para se obter aproximadamente $60 \%$ de umidade. A condutividade elétrica foi realizada de acordo com a metodologia proposta por Brasil (2007) ao final do processo de compostagem.

Realizou-se a determinação do índice de germinação (IG) (fitotoxicidade) no início e final do processo. Para isso, preparou-se extratos na proporção de 1:10 (m/v) de massa seca de composto, diluídos em água destilada e estes permaneceram em agitação por 24 h a 160 RPM. Adicionaram-se 3 mL dos extratos em cada placa de Petri contendo papel de filtro esterilizado duplo e dez sementes de Lipidium sativum (agrião de jardim), em duplicata. As placas de Petri contendo as sementes foram incubadas a $25^{\circ} \mathrm{C}$ com ausência de luz por $48 \mathrm{~h}$ em uma câmara de germinação e o tratamento controle foi realizado apenas com água destilada. O IG foi calculado de acordo com a fórmula da equação 01, com a metodologia adaptada de Zucconi et al. (1981) e Silva e Vilas Bôas (2007).

$$
\mathrm{IG}(\%)=\frac{\text { NGEXT }^{*} \text { LREXT }}{\text { NGCONT }^{*} \text { LRCONT }} * 100
$$


Em que: NGext $=$ número de sementes germinadas no extrato; NGcont $=$ número de sementes germinadas no controle; LRext $=$ comprimento médio das radículas do extrato; LRcont - comprimento médio das radículas do controle.

Inicialmente foram verificadas as pressuposições do modelo, posteriormente havendo influência de algum tratamento na variável resposta utilizou-se o teste de Tukey $(\mathrm{p}<0,05)$ para comparação das médias. Os dados foram analisados utilizando o software estatístico STATISTIC 8.0.

\section{RESULTADOS E DISCUSSÃO}

Segundo Bernal et al. (2009) o composto que apresenta IG acima de $80 \%$ está livre de compostos fitotóxicos. No entanto, para Silva e Vilas Bôas (2007) para investigar a toxicidade de um biofertilizante, é necessário atender a alguns requisitos, sendo que um dos testes incluídos no Canadian C. Enviroment Ministerial (CCME) (1996) preconiza que "a germinação de sementes indicadoras em extratos aquosos de compostos orgânicos deve atingir valores acima de $90 \%$ de germinação em relação ao controle". O IG de sementes representa uma condição química-orgânica que indica a presença ou ausência de compostos orgânicos que podem causar toxicidade. O IG do composto orgânico início e final do processo de compostagem, provenientes de resíduos orgânicos da cadeia de aves associados a GB, está apresentado na Tabela 1.

Os IG no início do processo de compostagem foram abaixo de $60 \%$ para todos os tratamentos, enquanto que, os valores obtidos no composto final para o IG foram superiores a $130 \%$, classificando os compostos finais como fitoestimulantes na germinação e crescimento da raiz das plantas. O composto final pode ser classificado de acordo com Bernal et al. (2009) como muito maturado por apresentar IG acima de 100\%. Não foi constatada diferença significativa entre os tratamentos tanto nos valores iniciais quanto finais.

A condutividade elétrica alta pode refletir a toxicidade dos compostos orgânicos, pois a toxidez é uma propriedade que demostra o potencial de uma substância em causar um efeito danoso a um organismo vivo. A condutividade elétrica é a concentração de substâncias químicas, como sais, que interferem na absorção da água pelas raízes causando, assim, a desidratação da plântula (RAND, 2000; COSTA et al., 2008). A salinidade elevada prejudica as plantas por meio do estresse hídrico e a toxicidade causada por íons acarreta no desequilíbrio nutricional (MORAES et al., 2018). Segundo Gávilan (2004), valores abaixo de $0,74 \mathrm{mS} \mathrm{cm}^{-1}$ são considerados muito abaixo do ideal para nutrição de mudas, entre 0,75 e $3,0 \mathrm{mS} \mathrm{cm}^{-1}$ são considerados valores adequados para a produção de mudas de hortaliças. Já valores acima de $5 \mathrm{mS} \mathrm{cm}^{-1}$ podem causar redução de crescimento pela salinidade, ocasionado a queimadura das raízes e provocando a murcha das mudas.

Para a condutividade elétrica final dos compostos orgânicos (Tabela 1), constatou-se que não houve diferença estatística entre os tratamentos com adição de GB ao processo de compostagem. Todos os tratamentos apresentam-se com valores dentro do estipulado por Gávilan (2004), ou seja, não causa efeito deletério as plantas mais sensíveis, como por exemplo hortaliças.

\section{CONCLUSÃO}

Os compostos orgânicos obtidos da compostagem de resíduos agroindustriais apresentaram-se sem a presença de agentes fitotóxicos e com condutividade elétrica indicada para a produção de mudas.

\section{A CAPES pela concessão de bolsa de estudos.}

\section{AGRADECIMENTOS}

\section{REFERÊNCIAS}

BERNAL, M. P; ALBURQUERQUE, J. A; MORAL, R. Composting of animal manures and chemical criteria for compost maturity assessment. A review. Bioresource Tecnology, v. 100, p. 5444-5453, 2009.

BRASIL. Ministério da Agricultura, Pecuária e Abastecimento - MAPA. Secretaria de Defesa Agropecuária. Instrução Normativa $\mathbf{N}^{\circ}$ 17, de 21 de maio de 2007. Aprova os Métodos Analíticos Oficiais para Análise de Substratos e Condicionadores de Solos, na forma do Anexo à presente Instrução Normativa. Diário Oficial da República Federativa do Brasil, Brasília, DF, 24 maio 2007. Seção 1, p. 8. 


\section{VISIGERRA

CARNEIRO, L. J. Compostagem de resíduos agroindustriais: revolvimento, inoculação e condições ambientais. 64 f. Dissertação. (Mestrado em Engenharia Agrícola) Universidade Estadual do Oeste do Paraná, Cascavel, 2012.

CCME. Canadian C. Enviroment Ministerial. Guidelines for compost quality. CCME 106 E. Toronto, 1996. COSTA, C. R.; OLIVI, P.; BOTTA, C. M. R.; ESPINDOLA, E. L. G. A toxicidade em ambientes aquáticos: discussão e métodos de avaliação. Revista Química Nova, v. 31, n. 7, p. 1820-1830, 2008. COSTA, M. S. S. M.; BERNARDI, F. H.; COSTA, L. A. M.; PEREIRA, D. C.; LORIN, H. E. F.; ROZATTI, M. A. T.; CARNEIRO, L. J. Composting as a cleaner strategy to broiler agro-industrial wastes: Selecting carbono source to optimize the process and improve the quality of the final compost. Journal of Cleaner Production, v. 142, p. 2084-2092, 2017.

CUBAS, J. L.; ADÃO, D. C; FERREIRA, F. A. F; DELFINO, L. D.; ZAGONEL, G. F; SILVA, P. R.; MAIA, M.; ADAD, L. B.; VECHIATTO, W. W. D.; SUCHEK, E. M.; COSTA. B. J. Neutralização da glicerina bruta obtida pela transesterificação dos óleos de crambe, cárcamo e soja. In: Congresso Brasileiro de Plantas Oleaginosas, Óleos, Gorduras e Biodiesel, 7., 2010, Belo Horizonte. Anais... Belo Horizonte: UFLA, 2010.

GÁVILAN, M. U. Tratado de cultivo sin suelo. 3. ed. Almería, ES: S.A. Mundi-pensa. 2004.

KIEHL, E. J. Fertilizantes Orgânicos. São Paulo: Agronômica Ceres LTDA, 2010. 248 p.

MATOS, A. T. Tratamento e Aproveitamento Agrícola de Resíduos Sólidos. Viçosa: UFV, 2014, 146$167 \mathrm{p}$.

MORAES, P. L. D.; DIAS, N. S.; OLIVEIRA, A. M.; SOUSA NETO, O. N.; SARMENTO, J. D. A.; GONZAGA, M. I. S. Effects of nutrient solution salinity on the physiological performance of melon cultivated in coconut fiber. Revista Caatinga, v. 31, n. 3, 2018.

RAND, G. M. Fundamentals of aquatic toxicology: effects, environmental fate, and risk assessment. 2 ed., Washington: Taylor \& Francis. 2000.

SANTOS, F. T.; LUDWIG, F.; COSTA, L. A. M.; COSTA, M. S. S. de M.; REMOR, M. B.; SILVA, P. E. R. Growth analysis of potted gerbera conducted with mineral fertilization and organic fertigation. Ciencia e Investigación Agraria, v. 43, p. 111-120, 2016.

SILVA, F. A. M.; VILLAS BÔAS, R. L. Teste de germinação como indicador de manutenção em composto orgânico. Revista Energia na Agricultura, v. 22, n. 3, p. 63-73, 2007.

TAKANE, R. J.; SIQUEIRA, P. T. V.; KAMPF, A. N. Técnica de preparo de substratos para aplicação em hortaliças. 2. ed. Brasília: LK Editora, 2012. 100 p.

ZUCCONI F., PERA A., FORTE M., De BERTOLDI M. Evaluating toxicity of immature compost. BioCycle, v. 22 , n. 2 , p. $54-57,1981$.

Tabela 1. Índice de germinação e condutividade elétrica no processo de compostagem.

\begin{tabular}{cccc}
\hline Tratamento & $\begin{array}{c}\text { Índice de germinação } \\
\text { inicial }\end{array}$ & $\begin{array}{c}\text { Índice de germinação } \\
\text { final }\end{array}$ & $\begin{array}{c}\text { Condutividade elétrica } \\
\left(\mathbf{m S ~ c m}^{-1}\right)\end{array}$ \\
\hline $\mathrm{T} 0,0$ & $53,36 \mathrm{a}$ & $146,51 \mathrm{a}$ & $2,22 \mathrm{a}$ \\
$\mathrm{T} 1,5$ & $48,97 \mathrm{a}$ & $146,45 \mathrm{a}$ & $2,58 \mathrm{a}$ \\
$\mathrm{T} 3,0$ & $58,41 \mathrm{a}$ & $133,21 \mathrm{a}$ & $2,05 \mathrm{a}$ \\
$\mathrm{T} 4,5$ & $48,81 \mathrm{a}$ & $144,02 \mathrm{a}$ & $2,53 \mathrm{a}$ \\
$\mathrm{T} 6,0$ & $51,14 \mathrm{a}$ & $132,47 \mathrm{a}$ & $2,86 \mathrm{a}$ \\
\hline
\end{tabular}

*Letras diferentes na mesma coluna representam médias estatisticamente diferentes a 5\% de significância. 


\title{
GLICEROL COMO SUBSTRATO PARA A PRODUÇÃO DE 1,3 PROPANODIOL POR CLOSTRIDIUM BEIJERINCKII
}

\author{
Mermejo, B.C*11; Prata, G.P. ${ }^{1}$; Fonseca, B.C. ${ }^{1}$; Reginatto, V. ${ }^{1}$ \\ ${ }^{1}$ Faculdade de Filosofia, Ciências e Letras de Ribeirão Preto - Universidade de São Paulo, 14040-901 - Ribeirão Preto - SP, Brasil \\ valeriars@ffclrp.usp.br
}

RESUMO: A produção de biodiesel tem levado a busca de uma destinação adequada para o glicerol resultante do processo. O glicerol pode servir como fonte de carbono para algumas espécies do gênero Clostridium. Um dos principais subprodutos que pode ser gerado a partir da fermentação do glicerol pelo Clostridium é o 1,3propanodiol (1,3-PDO) que é utilizado industrialmente na obtenção de polímeros. A fermentação do glicerol pelo Clostridium pode ocorrer por duas vias, a redutiva e a oxidativa. É na via redutiva que o 1,3-PDO é obtido. Neste trabalho foram realizados ensaios cinéticos de fermentação com o Clostridium beijerinckii $\mathrm{Br} 21 \mathrm{em}$ diferentes concentrações de glicerol. Constatou-se que a concentração de $40 \mathrm{~g} \mathrm{~L}^{-1}$ de glicerol favorece a formação de 1,3-PDO. O meio Reinforced Clostridium Medium - RCM, rico em fontes complexas de nitrogênio, não promoveu a formação do 1,3 PDO. Ao contrário no meio $\mathrm{CH}$, mais pobre em nutrientes, foi observada a formação de 1,3 PDO.

Palavras-chave: biodiesel, glicerol, composição do meio.

\section{GLYCEROL AS A SUBSTRATE FOR THE PRODUCTION OF 1,3 PROPANODIOL BY CLOSTRIDIUM BEIJERINCKII}

\begin{abstract}
The high biodiesel production has led to the search for a suitable destination for the glycerol resulting from the process. Glycerol can serve as a carbon source for some species of the genus Clostridium. One of the main by-products that can be generated from the fermentation of glycerol by Clostridium is 1,3propanediol (1,3-PDO) which has industrial importance as polymer monomer. The fermentation of glycerol by Clostridium can occur by two routes, the reductive and the oxidative. It is in the reductive pathway that 1,3PDO is obtained. In this work, fermentation kinetics assays with different concentrations of glycerol were carried out by Clostridium beijerinckii $\mathrm{Br} 21$. The concentration of $40 \mathrm{~g} \mathrm{~L}^{-1}$ of glycerol favors the formation of 1,3-PDO. Reinforced Clostridium Medium - RCM, rich in complex nitrogen sources, did not promote the formation of 1,3 PDO. On the other hand, $\mathrm{CH}$ medium, which is poor in nutrients, promotes the formation of 1,3 PDO by $C$. beijerinckii $\mathrm{Br} 21$.
\end{abstract}

Keywords: biodiesel, glycerol, medium composition.

\section{INTRODUÇÃO}

Na produção do biodiesel cerca de 10\% de glicerol é formado como subproduto (Yazdani e Gonzalez, 2007). Segundo a ANP no ano de 2017, cerca de $374,5 \mathrm{mil} \mathrm{m}^{3}$ de glicerol foram obtidos em decorrência da produção de biodiesel, sendo esse valor $9 \%$ maior do que em 2016, estes dados referem-se à produção bruta de glicerol. Dessa forma, devido à quantidade gerada deste resíduo industrial têm-se buscado alternativas para seu uso, a fim de reduzir os custos da produção de biodiesel. $\mathrm{O}$ glicerol pode ser convertido em: hidrogênio, 1,3-propanodiol (1,3-PDO), dihidroxiacetona, ácido succínico, ácido propionico, etanol, ácido cítrico entre outros (Silva et al. 2009). Um dos principais produtos que pode ser gerado a partir do glicerol é o 1,3-PDO devido a sua importância industrial na obtenção de polímeros, cosméticos, alimentos, etc. (Jun et al., 2010). Este produto pode ser obtido por fermentação utilizando microrganismo do gênero Clostridium (Biebl, 2001). Existem fatores podem afetar a eficiência da fermentação do glicerol, tais como os nutrientes, o pH do meio (Yazdani e Gonzalez, 2007) e a concentração do substrato (Papanikolaou et al., 2000).

A fermentação do glicerol pode ocorrer por duas vias, a redutiva e a oxidativa. Na via oxidativa, o glicerol é destinado à via glicolítica (Papanikolaou et al., 2000; Yazdani e Gonzalez, 2007), pela qual é possível obter etanol, butanol, acetona, acetato, butirato e lactato (Silva et al., 2009). A via redutiva ocorre em duas etapas, a primeira onde o glicerol sofre uma desidratação sendo convertido a 3-hidroxipropionaldeído (3- 
HPA), catalisada pela glicerol desidratase, que via de regra é dependente de vitamina $\mathrm{B}_{12}$. Na segunda etapa, o 3-HPA é reduzido a 1,3-PDO pela 1,3-PDO desidrogenase que é dependente de equivalente redutor, $\mathrm{NADH}_{2}$. Um aumento significativo no rendimento de 1,3-PDO pode ser obtido pela interação das vias redutiva e oxidativa, devido à formação de $\mathrm{NADH}_{2}$, na via glicolítica que pode ser consumido na via redutiva. Na via oxidativa que favorece a conversão de glicerol em 1,3-PDO somente acetato é produzido como subproduto (TONG, et al. 1991), Equação 1:

$$
4 \mathrm{C}_{3} \mathrm{H}_{8} \mathrm{O}_{3} \rightarrow 3 \mathrm{C}_{3} \mathrm{H}_{8} \mathrm{O}_{2}+\mathrm{H}_{3} \mathrm{CCOOH}+\mathrm{CO}_{2}+2 \mathrm{H}_{2} \mathrm{O}
$$

Neste trabalho foi verificada a influência da concentração de glicerol e do meio de cultura na obtenção de 1,3 PDO pelo Clostridium beijerinckii $\mathrm{Br} 21$.

\section{MATERIAL E MÉTODOS}

O microrganismo utilizado nos ensaios $C$. beijerinckii $\mathrm{Br} 21$ isolado por Fonseca et al. (2016). Ensaios cinéticos de fermentação com diferentes concentrações de glicerol foram realizados nas concentrações de 10, 20, 40, 60 e $100 \mathrm{~g} \mathrm{~L}^{-1}$. Para realização do ensaio o meio de cultura utilizado foi o $\mathrm{CH}$ (Chen et al. 2005), onde o glicerol foi a única fonte de carbono. Posteriormente, a influência da composição do meio de cultura na obtenção de 1,3-PDO foi comparada utilizando o meio $\mathrm{CH}$ (Chen et al. 2005) e o meio RCM modificado (Wischral et al. 2015).

\section{Composição dos meios de cultura}

Meio CH (Chen et al. 2005): glicerol 10-100 g L ${ }^{-1}, \mathrm{NaCl} 1,0 \mathrm{~g} \mathrm{~L}^{-1}$, extrato de levedura $1,0 \mathrm{~g} \mathrm{~L}^{-1}, \mathrm{Na}_{2} \mathrm{HPO}_{4}$ $5,0 \mathrm{~g} \mathrm{~L}^{-1}, \mathrm{KH}_{2} \mathrm{PO}_{4} 1,0 \mathrm{~g} \mathrm{~L}^{-1}, \mathrm{MgSO}_{4} .7 \mathrm{H}_{2} \mathrm{O} 0,1 \mathrm{~g} \mathrm{~L}^{-1}, \mathrm{FeSO}_{4} .7 \mathrm{H}_{2} \mathrm{O} 0,045 \mathrm{~g} \mathrm{~L}^{-1}, 2 \mathrm{~mL}$ solução de oligoelementos $\left(\mathrm{H}_{3} \mathrm{BO}_{3} 2,85 \mathrm{~g} \mathrm{~L}^{-1}, \mathrm{MnSO}_{4} \cdot 4 \mathrm{H}_{2} \mathrm{O} 2,03 \mathrm{~g} \mathrm{~L}^{-1}, \mathrm{FeCl}_{3} \cdot 6 \mathrm{H}_{2} \mathrm{O} 0,167 \mathrm{~g} \mathrm{~L}^{-1}\right)$.

Meio RCM modificado (Wischral et al. 2015): glicerol 40,0 $\mathrm{g} \mathrm{L}^{-1}$, cisteína $0,5 \mathrm{~g} \mathrm{~L}^{-1}, \mathrm{D}(+)$-glicose $5,0 \mathrm{~g}$ $\mathrm{L}^{-1}$, extrato de carne 10,0 $\mathrm{g} \mathrm{L}^{-1}$, peptona $10,0 \mathrm{~g} \mathrm{~L}^{-1}, \mathrm{CH}_{3} \mathrm{COONa} 0,005 \mathrm{~g} \mathrm{~L}^{-1}, \mathrm{NaCl} 3,0 \mathrm{~g} \mathrm{~L}^{-1}$, amido $1,0 \mathrm{~g} \mathrm{~L}^{-1}$, extrato de levedura $0,5 \mathrm{~g} \mathrm{~L}^{-1}, \mathrm{~K}_{2} \mathrm{HPO}_{4} 5,0 \mathrm{~g} \mathrm{~L}^{-1}$.

\section{RESULTADOS E DISCUSSÃO}

É importante investigar se o substrato glicerol causa alguma inibição ao crescimento celular do Clostridium. Assim, observou-se que em concentrações de 10 a $40 \mathrm{~g} \mathrm{~L}^{-1}$ foram obtidas as maiores velocidades específicas de crescimento (dados não apresentados). Dessa maneira, constatou-se que as concentrações onde houve maior produção de 1,3-PDO foram em $40 \mathrm{~g} \mathrm{~L}^{-1}\left(434 \mathrm{mmol} \mathrm{L}^{-1}\right)$ e $60 \mathrm{~g} \mathrm{~L}^{-1}\left(652 \mathrm{mmol} \mathrm{L}^{-1}\right)$, sendo 117,8 $\pm 17,7$ e $128,9 \pm 2,0 \mathrm{mmol} \mathrm{L}^{-1}$, respectivamente. Os metabólitos obtidos pela fermentação de diferentes concentrações de glicerol por $C$. beijerinckii estão descritos na Tabela 1, assim como os rendimentos.

Dessa maneira, para a concentração de glicerol de $40 \mathrm{~g} \mathrm{~L}^{-1}\left(434 \mathrm{mmol} \mathrm{L}^{-1}\right)$ foi possível analisar o crescimento da cepa de $C$. beijerinckii $\mathrm{Br} 21$ no meio de cultura RCM modificado e compará-la com o ensaio na mesma concentração em meio $\mathrm{CH}$. O crescimento celular (Figura 1) e a velocidade específica (dados não apresentados) atingiram, para o meio RCM, maiores valores em menor intervalo de tempo. Entretanto, foi observado que para este meio houve maior queda de $\mathrm{pH}$, indicando a possível formação de ácidos como subprodutos (Figura 1).

No meio RCM modificado não houve a conversão de glicerol em 1,3-PDO. Praticamente toda a glicose presente neste meio foi consumida $\left(71,60 \pm 058 \mathrm{mmol} \mathrm{L}^{-1}\right)$, enquanto menos de $10 \%\left(33,30 \pm 7,80 \mathrm{mmol} \mathrm{L}^{-1}\right)$ de glicerol foi consumido, Tabela 2. Como subproduto foi obtido ácido butírico, $28,01 \pm 1,79 \mathrm{mmol} \mathrm{L}^{-1}$ para o ensaio com o meio RCM modificado, e apenas traços de ácico acético e lático, dados apresentados na Tabela 2, indicando que a glicose e o glicerol foram direcionados para a via oxidativa e não a redutiva. Como o crescimento celular para o ensaio com o meio RCM foi consideravelmente maior que o observado para o meio $\mathrm{CH}$, supõe-se que o metabolismo foi destinado para a produção de biomassa e ácido butírico.

Apesar do meio RCM modificado ser fico em nutrientes e que embora a glicose no meio RCM, descrito por Wischral et al (2015) vise o aumento do poder redutor no meio, este efeito não foi observado. E, comparando os dados apresentados na Tabela 2, dentre os dois meios de culturas utilizados para os ensaios, o $\mathrm{CH}$ é mais apropriado para a produção de 1,3-PDO. 
Segundo Biel (1999) o rendimento de 1,3-PDO pode ser maior quando se inibe a produção de $\mathrm{H}_{2}$, contudo, como no decorrer dos ensaios não foi determinado este parâmetro, não foi possível levar essa informação em consideração. Além disso, para favorecer uma das vias metabólicas do glicerol deve-se atentar qual nutriente é limitante no processo. Por exemplo, estudos constataram que uma vez que a fonte de carbono é o fator limitante a tendência é que a via destinada para produção de ácido butírico e etanol - via na qual a produção de energia (ATP) é maior - e não segue, portanto, para a via destinada a 1,3-PDO e do ácido acético. Outro fator que pode interferir no rendimento da fermentação do glicerol visando 1,3-PDO, além dos já mencionados, é a variação do $\mathrm{pH}$. Estudos da influência do $\mathrm{pH}$ na fermentação do glicerol visando a obtenção de 1,3-PDO demonstraram que em baixo valor de pH os elétrons são deslocados em função da produção de 2,3butanodiol, e concluíram que pH em torno de 7,0 favorece a produção de 1,3-PDO.

\section{CONCLUSÃO}

Dessa forma, concluiu-se que a composição do meio de cultura exerce grande influência sobre a formação de 1,3 PDO pelo C. beijerinckii $\mathrm{Br} 21$, sendo o meio mais pobre em nutrientes o mais apropriado. A concentração de glicerol de $40 \mathrm{~g} \mathrm{~L}^{-1}$ forneceu o maior rendimento de 1,3 PDO.

\section{AGRADECIMENTOS}

O presente trabalho foi realizado com apoio da Coordenação de Aperfeiçoamento de Pessoal de Nível Superior - Brasil (CAPES) - Código de Financiamento 001.

\section{REFERÊNCIAS}

Agência Nacional do Petróleo, Gás Natural e Biocombustíveis, consulta do anuário estatístico 2018.

BIEBL, H. Fermentation of glycerol by clostridium pasteurianum batch and continuous culture studies. $\mathbf{J}$ ind microbiol biotechnol, 2001, 27: 18-26.

BIEBL, H. et al. Microbial production of 1,3-propanodiol. Applied microbiology and biotechnology, v. 52 p. 289-297, 1999.

CHEN, W.M et al. Fermentative hydrogen production with clostridium butyricum CGS5 isolated from anaerobicsewage sludge. International journal of hydrogen energy, v. 30: 1063-1070, 2005.

FONSECA, B.C. et al. Fermentative production of $\mathrm{H}_{2}$ from different concentrations of galactose by the new isolate Clostridium beijerinckii Br21. International journal of hydrogen energy v. 41, p. 21109- 21120, 2016.

JUN, S.A. et al. Microbial fed-batch production of 1,3-propanediol using raw glycerol with suspended and immobilized Klebsiella pneumoniae. Appl biochem biotech, 2010, 161 (1-8): 491-501.

PAPANIKOLAOU, S. et al. High production of 1,3-propanediol from industrial glycerol by a newly isolated Clostridium butyricum strain. Journal of biotechnology 77 (2000) 191-208.

SILVA, G.P. et al. Glycerol: a promising and abundant carbon source for industrial microbiology. Biotechnol advances 27 2009, 30-9.

TONG, I.T. et al. 1,3-propanediol production by Escherichia coli expressing genes from the Klebsiella pneumoniae dha regulon. Applied and environmental microbiology, v.57, p. 3541-3546, 1991.

WISCHRAL, C. et al. 1,3-propanediol: statistical optimization of medium to improve production by Clostridium beijerinckii DSM 791. Journal: journal of advances in biotechnology. vol .5, no. 2. 2015. 614623. ISSN 2348-6201.

YAZDANI, S.S., Gonzalez, R. Anaerobic fermentation of glycerol: a path to economic viability for the biofuels industry. Current opinion in biotechnology, 2007, 18:213-219. 
Tabela 1. Metabólitos formados pela fermentação do glicerol em diferentes concentrações por C. beijerinckii $\mathrm{Br} 21$ utilizando o meio $\mathrm{CH}$.

\begin{tabular}{|c|c|c|c|c|c|c|}
\hline $\begin{array}{c}\text { Glicerol } \\
\left(\mathrm{mmol} \mathrm{L}^{-1}\right)\end{array}$ & $\begin{array}{c}\text { Glicerol } \\
\text { Consumido } \\
\left(\mathbf{m m o l ~ L} \mathbf{L}^{-1}\right)\end{array}$ & $\begin{array}{c}\text { 1,3-PDO } \\
\left.(\mathbf{m m o l ~ L})^{-1}\right)\end{array}$ & $\begin{array}{c}\text { Yp/s 1,3- } \\
\text { PDO (mmol } \\
\text { mmol-1 }^{-1}\end{array}$ & $\begin{array}{c}\text { Ácido } \\
\text { acético } \\
\left(\mathbf{m m o l ~ L}^{-1}\right)\end{array}$ & $\begin{array}{c}\text { Etanol } \\
\left(\mathbf{m m o l} \mathbf{L}^{-1}\right)\end{array}$ & $\begin{array}{c}\text { Ácido } \\
\text { Lático } \\
\left.(\mathbf{m m o l ~ L})^{-1}\right)\end{array}$ \\
\hline 109,0 & $75,0 \pm 4,3$ & $41,8 \pm 2,2$ & $0,53 \pm 0,06$ & $1,29 \pm 0,09$ & $18,3 \pm 2,52$ & $4,57 \pm 0,64$ \\
\hline 217,0 & $130,4 \pm 6,9$ & $55,1 \pm 2,1$ & $0,60 \pm 0,32$ & $353 \pm 1,16$ & $17,7 \pm 1,54$ & - \\
\hline 434,0 & $149,9 \pm 11,1$ & $117,8 \pm 17,7$ & $0,78 \pm 0,06$ & - & - & - \\
\hline 652,0 & $172,9 \pm 4,8$ & $128,9 \pm 2,0$ & $0,76 \pm 0,03$ & - & $15,4 \pm 2,22$ & - \\
\hline 1086,0 & $86,8 \pm 28,9$ & $4,3 \pm 0,8$ & $0,09 \pm 0,03$ & $2771,5 \pm 0$ & - & - \\
\hline
\end{tabular}

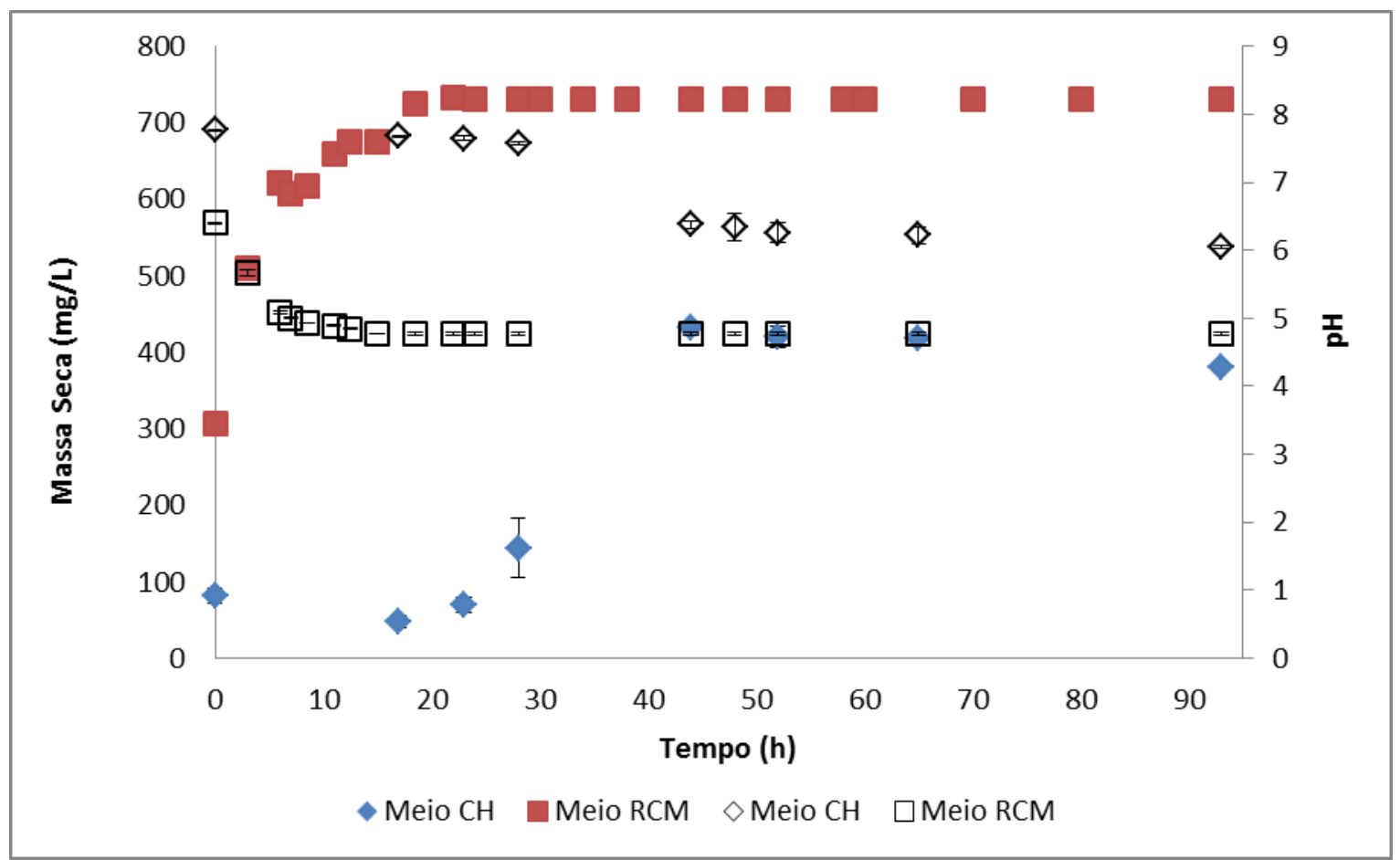

Figura 1. Concentração em massa seca de C. beijerinckii $\mathrm{Br} 21 \mathrm{e} \mathrm{pH}$ em função do tempo de fermentação utilizando glicerol na concentração inicial $40 \mathrm{~g} \mathrm{~L}^{-1}\left(434 \mathrm{mmol} \mathrm{L}^{-1}\right)$ nos meios $\mathrm{CH}$ e RCM modificado, respectivamente.

Tabela 2. Metabólitos formados pela fermentação do glicerol $40 \mathrm{~g} \mathrm{~L}^{-1}\left(434 \mathrm{mmol} \mathrm{L}^{-1}\right)$ por C. beijerinckii Br21 utilizando os meios CH e RCM modificado, descritos por Chen et al. 2005 e por Wischral et al. 2015, respectivamente.

\begin{tabular}{|c|c|c|c|c|c|c|c|}
\hline Meio & $\begin{array}{c}\text { Glicerol } \\
\text { inicial } \\
\left(\mathbf{m m o l ~ L}^{-1}\right)\end{array}$ & $\begin{array}{c}\text { Glicerol } \\
\text { consumido } \\
\left(\text { mmol L L-1) }^{-1}\right)\end{array}$ & $\begin{array}{c}\text { 1,3-PDO } \\
\left(\mathrm{mmol} \mathrm{L}^{-1}\right)\end{array}$ & $\begin{array}{c}\text { Ácido } \\
\text { butírico } \\
\left(\mathbf{m m o l ~ L} \mathbf{L}^{-1}\right)\end{array}$ & $\begin{array}{c}\text { Ácido } \\
\text { Acético } \\
\left(\mathbf{m m o l ~ L} \mathbf{L}^{-1}\right)\end{array}$ & $\underset{(\mathbf{m m o l ~ L}}{\text { Etanol }})$ & $\begin{array}{c}\text { Ácido } \\
\text { Lático } \\
\left(\left(\mathbf{m m o l ~ L} \mathbf{L}^{-1}\right)\right.\end{array}$ \\
\hline $\mathbf{C H}$ & & $\begin{array}{c}149,9 \pm \\
11,1\end{array}$ & $\begin{array}{c}117,8 \pm \\
17,7\end{array}$ & - & $0,78 \pm 0,1$ & - & - \\
\hline $\begin{array}{c}\text { RCM } \\
\text { modificado }\end{array}$ & 434,0 & $33,3 \pm 7,8$ & - & $28,0 \pm 1,8$ & $0,1 \pm 0,0$ & - & $0,20 \pm 0,0$ \\
\hline
\end{tabular}




\title{
INFLUÊNCIA DO MEIO DE CULTIVO E DO PH NA PRODUÇÃO DE HIDROGÊNIO A PARTIR DE GLICEROL
}

\author{
Prata, P.G ${ }^{1}$; Mermejo, B.C.*1; Fonseca, B.C ${ }^{1}$; Reginatto, V. ${ }^{1}$ \\ ${ }^{1}$ Faculdade de Filosofia, Ciências e Letras de Ribeirão Preto - Universidade de São Paulo, 14040-901 - Ribeirão Preto - SP, Brasil \\ valeriars@ffclrp.usp.br
}

RESUMO: No Brasil a produção de biodiesel é expressiva, sendo que cerca de $10 \%$ da produção da produção de biodiesel resulta em glicerol. . Nesse contexto, tem se buscado alternativas para tratamento e/ou utilização do glicerol residual. Alguns trabalhos têm estudado o glicerol como fonte de carbono em processos biotecnológicos. Alguns microrganismos apresentam metabolismo capaz de utilizar o glicerol para a produção fermentativa de $\mathrm{H}_{2}$, bicombustível limpo e renovável. Um dos microrganismos mais estudados para esta finalidade é o Clostridium. Dessa forma, este trabalho analisou o crescimento celular do Clostridium beijerinckii $\mathrm{Br} 21$ em diferentes concentrações de glicerol e, a influencia do $\mathrm{pH}$ inicial do meio na produção de biohidrogênio. A concentração de gçlicerol que apresentou maior crescimento celular foi a de $10 \mathrm{~g} \mathrm{~L}^{-1}$, portanto, esta foi a concentração escolhida para os demais ensaios. Dois meios de cultivo distintos apresentaram pH inicial 'timo de 6,5 e pH 7,5 para o cultivo do Clostridium. Dessa maneira, pode-se concluir que para cada meio utilizado, determinado $\mathrm{pH}$ inicial apresentou maior influência na produção de biohidrogênio.

Palavras-chave: Clostridium beijerinckii; biohidrogênio; $\mathrm{pH}$ inicial.

\section{INFLUENCE OF THE HYDROGEN PRODUCTION AND THE PH IN THE PRODUCTION OF HYDROGEN FROM GLYCEROL}

\begin{abstract}
In Brazil the production of biodiesel is expressive, and about 10\% of the production of biodiesel production results in glycerol. . In this context, alternatives have been sought for treatment and / or use of residual glycerol. Some studies have studied glycerol as a carbon source in biotechnological processes. Some microorganisms have metabolism capable of using glycerol for the fermentative production of $\mathrm{H}_{2}$, clean and renewable biofuel. One of the most studied microorganisms for this purpose is Clostridium. Thus, this work analyzed the cellular growth of Clostridium beijerinckii $\mathrm{Br} 21$ in different concentrations of glycerol and the influence of the initial $\mathrm{pH}$ of the medium on the production of biohydrogen. The concentration of gligerol that presented the highest cell growth was $10 \mathrm{~g} \mathrm{~L}^{-1}$, therefore, this was the concentration chosen for the other tests. Two distinct culture media had an initial $\mathrm{pH}$ of 6.5 and $\mathrm{pH} 7.5$ for the culture of Clostridium. Thus, it can be concluded that for each medium used, the initial $\mathrm{pH}$ had a greater influence on the production of biohydrogen.
\end{abstract}

Keywords: Clostridium beijerinckii; biohydrogen; initial $\mathrm{pH}$.

\section{INTRODUÇÃO}

O aumento da população e o crescimento exacerbado de indústrias no mundo todo, incentivados pela política de globalização acarretaram na crescente necessidade energética. Devido essa inevitável necessidade de produção de energia e principalmente o esgotamento das reservas energéticas existentes, vindas dos combustíveis fósseis, tem se buscado o desenvolvimento de tecnologias para a geração de energias limpas e renováveis. Essa busca por novas fontes de energias é corroborada pela necessidade de diminuir os problemas ambientais atualmente enfrentados, advindos do uso, por longo tempo, dessas matrizes fósseis energéticas (Skonieczny; Yargeau, 2009).

A produção de biodiesel, biocombustível renovável produzido a partir de óleos vegetais e/ou gordura animal pelo processo de transesterificação dessas matérias-primas, tem atualmente aumentado no Brasil, colocando o país numa posição de destaques (Patil et al., 2017). No processo de transesterificação, é produzido majoritariamente o biodiesel, mas também há a produção do glicerol, um coproduto desse processo (Peiter $e t$ al., 2016). Com a alta produção de biodisel, o mercado atual evidencia um excesso de glicerina, onde $10 \%$ da massa de biodiesel corresponde a glicerol, fator este preocupante para as indústrias envolvidas com a produção 
(Pérez, 2014). O glicerol $\left(\mathrm{C}_{3} \mathrm{H}_{8} \mathrm{O}_{3}\right)$, também conhecido como 1,2,3-propanotriol, trata-se de um álcool com densidade maior que a água, altamente viscoso, inodoro e líquido a $25^{\circ} \mathrm{C}$ (Peiter et al., 2016). A glicerina, como é popularmente conhecida, trata-se do glicerol purificado que é utilizado em grande parte pelas indústrias alimentícias e de cosméticos. Porém, mesmo com essa utilização, grande parte do glicerol residual permanece em excesso, levando a constante busca por alternativas de seu uso. Nesse contexto, alguns trabalhos têm estudado e evidenciado a utilização do glicerol como fonte de carbono em processos biotecnológicos Sabe-se que alguns microrganismos apresentam metabolismo capaz de utilizar o glicerol para a produção fermentativa de $\mathrm{H}_{2}$, bicombustível limpo e renovável (Trchounian et al., 2017).

$\mathrm{O} \mathrm{H}_{2}$ apresenta alto poder calorífico $\left(141,86 \mathrm{KJ} \mathrm{g}^{-1}\right)$ quando comparado com a densidade energética de outros combustíveis, comumente utilizados, como a gasolina $\left(47,5 \mathrm{KJ} \mathrm{g}^{-1}\right)$ e o gás metano $\left(55,53 \mathrm{KJ} \mathrm{g}^{-1}\right)$ e sua combustão libera apenas água para a atmosfera (Fonseca, 2016). É notório que dessa maneira, a utilização do biohidrogênio como combustível apresenta vantagem tanto quimicamente, como biologicamente. Um dos microrganismos mais estudados e referenciados para a produção de $\mathrm{H}_{2}$ por meio de fermentação é o Clostridium (Fonseca, 2016). Uma das rotas metabólicas deste microrganismo possibilita o consumo de glicerol como fonte de carbono para a produção de $\mathrm{H}_{2}$. Diversos outros produtos, de valor agregado tambémpodem ser obtidos atraves da fermentação de glicerol pelo Clostridium, como por exemplo, a conversão de glicerol a 1,3-propanodiol, substância que pode ser utilizada em diversos tipos de indústrias.

Ensaios de fermentação utilizando cepas de Clostridium descritos na literatura, buscam analisar quais as caracteristicas de meio que permitem a maior produção de $\mathrm{H}_{2}$ a partir de glicerol (Kraemer e Bagley, 2007). Os fatores que influemciam na obtenção final de hidrogênio é a concentração de glicerol, o pH inicial, a quantidade de inóculo, o meio de cultura, a temperatura de incubação, entre outros fatores. Dessa forma, este trabalho analisou o crescimento celular do C. beijerinckii $\mathrm{Br} 21$ utilizando diferentes concentrações de glicerol. Além desses parâmetro, também foi analisada a influencia da composição do meio de cultivo e do pH inicial na produção de biohidrogênio e outros produtos de interesse comercial.

\section{MATERIAL E MÉTODOS}

A cepa de C. beijerinckii $\mathrm{Br} 21$ foi isolada por (Fonseca et al. 2016) no laboratório de biotecnologia ambiental e energias renováveis. Os ensaios para a análise da influência da concentração de glicerol foram realizados em batelada com o meio $\mathrm{CH}$, descrito por Chen et al. (2005), que apresenta: $\mathrm{NaHPO}_{4} 5,0 \mathrm{~g} \mathrm{~L}^{-1}$, extrato de levedura $1,0 \mathrm{~g} \mathrm{~L}^{-1}, \mathrm{NaCl} \mathrm{1,0} \mathrm{g} \mathrm{L}{ }^{-1}, \mathrm{KH}_{2} \mathrm{PO}_{4} 1,0 \mathrm{~g} \mathrm{~L}^{-1}, \mathrm{MgSO}_{4} .7 \mathrm{H}_{2} \mathrm{O} 0,10 \mathrm{~g} \mathrm{~L}^{-1}, \mathrm{FeSO}_{4} .7 \mathrm{H}_{2} \mathrm{O} 0,045 \mathrm{~g}$ $\mathrm{L}^{-1}$ e 2,0 mL da solução de oligoelementos $\left(\mathrm{H}_{3} \mathrm{BO}_{3} 2,86 \mathrm{~g} \mathrm{~L}^{-1}, \mathrm{MnSO}_{4} \cdot 4 \mathrm{H}_{2} \mathrm{O} 2,03 \mathrm{~g} \mathrm{~L}^{-1}\right.$ e FeCl $3.6 \mathrm{H}_{2} \mathrm{O} 0,167 \mathrm{~g}$ $\mathrm{L}^{-1}$. O meio foi preparado com diferentes concentrações de glicerol 10, 40, 50, 60, 100, $200 \mathrm{e} 300 \mathrm{~g} \mathrm{~L}^{-1}$. Foram realizadas etapas de pré-inóculo para diminuir a fase lag do microrganismo. Os frascos foram incubados sob agitação a $105 \mathrm{rpm}$ a $35^{\circ} \mathrm{C}$. Alíquotas foram coletadas em tempos específicos, foi medida a D.O da solução para compor uma curva de crescimento e também o pH da solução. Nos ensaios de fermentação para verificar a influência da composição do meio de cultivo e do pH inicial na produção de biohidrogênio foram analisadas apenas amostras retiradas no tempo inicial e no tempo final (62 horas). Os meios utilizados foram o meio $\mathrm{CH}$ descritos por Chen (2005), descrito anteriormente, e o meio descrito por Trchounian et al, 2017, com a composição: $\mathrm{K}_{2} \mathrm{HPO}_{4} 1,5 \mathrm{~g} \mathrm{~L}^{-1}, \mathrm{KH}_{2} \mathrm{PO}_{4} 1,5 \mathrm{~g} \mathrm{~L}^{-1}, \mathrm{MgSO}_{4} .7 \mathrm{H}_{2} \mathrm{O}$ 0,492 g L${ }^{-1}$, L-Cisteína 0,5 g L ${ }^{-1}, \mathrm{MnSO}_{4} \cdot \mathrm{H}_{2} \mathrm{O}$ $0,015 \mathrm{~g} \mathrm{~L}^{-1}, \mathrm{FeSO}_{4} \times 7 \mathrm{H}_{2} \mathrm{O} 0,02 \mathrm{~g} \mathrm{~L}^{-1}$, extrato de levedura $0,5 \mathrm{~g} \mathrm{~L}^{-1}$, ácido aminobenzoico $0,002 \mathrm{~g} \mathrm{~L}^{-1}$, tiamina $0,002 \mathrm{~g} \mathrm{~L}^{-1}$ e biotina $0,0004 \mathrm{~g} \mathrm{~L}^{-1}$. O pH inicial dos meios foram ajustados em 5,5, 6,5 e 7,5. Ao final do teste foi medida a pressão no interior do frasco. A pressão foi esgotada, e uma alíquota do conteúdo do head-space foi coletada e injetada no cromatográfo a gás. Através da pressão no interior do frasco e do conteúdo do headspace foi determinada a quantidade de $\mathrm{H}_{2}$. Foi medida a D.O e o pH final da fermentação. Todas as amostras foram centrifugadas e filtradas e submetidas a determinação dos produtos solúveis através da cromatografia líquida de alta eficiência.

\section{RESULTADOS E DISCUSSÃO}

Dentre as concentrações de glicerol testadas a menor de $10 \mathrm{~g} \mathrm{~L}^{-1}$ foi a que apresentou maior crescimento celular (Figura $1 \mathrm{~A}$ ). Nas demais concentrações de glicerol houve aumento da fase lag, ou seja, de adaptação do microrganismo, que foi de $10 \mathrm{~h}$ a $10 \mathrm{~g} \mathrm{~L}^{-1}$ a $27 \mathrm{~h} \mathrm{em} 60 \mathrm{~g} \mathrm{~L}^{-1}$ de glicerol. Os ensaios para as concentrações de $200 \mathrm{~g} \mathrm{~L}^{-1}$ e $300 \mathrm{~g} \mathrm{~L}^{-1}$ de glicerol não apresentaram crescimento celular (resultado não apresentado). Da mesma forma as velocidades específicas de crescimento do C. beijerinckii $\mathrm{Br} 21$ (dados não 
apresentados) acompanharam as mesmas tendências das curvas de crescimento, na qual o maior crescimento celular e que atingiu a velocidade específica máxima em menor tempo, ou seja, $10 \mathrm{~g} \mathrm{~L}^{-1}$. A variação do $\mathrm{pH}$ nos ensaios com 10, 20, 40, 60 e $100 \mathrm{~g} \mathrm{~L}^{-1}$ estão apresentados na Figura 1 (B). Pode-se observar que a fermentação em que ficou evidenciado a maior queda de $\mathrm{pH}$, corresponde ao ensaio com a concentração de glicerol em 10 $\mathrm{g} \mathrm{L}^{-1}$. Geralmente, o pH durante uma fermentação nos revela o crescimento dos microrganismos, uma vez que durante o crescimento há produção de diversos compostos capazes de provocar alterações no potencial hidrogeniônico do meio de cultura, tais como ácidos orgânicos. Tendo em vista que as menores concentrações de glicerol promoveram os maiores crescimentos da cultura do C. beijerinckii (Figura 1A), esta faixa de concentração foi utilizada nos ensaios seguintes.

Nos ensaios para a produção de hidrogênio foi verificado que o pH 6,5 inicial propiciou o maior crescimento celular e consequentemente de produção de $\mathrm{H}_{2}$ Tabela 1. Não foi observada produção de $\mathrm{H}_{2} \mathrm{em}$ pH inicial de 5,5. É possível, então, relacionar que a produção de biohidrogenio está diretamente atrelada ao crescimento celular. Diferente do observado para o meio $\mathrm{CH}$, quando o meio descrito por Trchounian et al. (2017) foi utilizado o crescimento celular foi considerável em todos os valores de $\mathrm{pH}$ inicial, Tabela 1, o que também contribuiu para a produção de hidrogênio. $\mathrm{O}$ pH que apresentou o maior crescimento celular, também foi o responsável pela maior produção de hidrogênio pelo microrganismo, neste caso, o pH de 7,5. Dessa maneira, pode-se concluir que para cada meio de cultura utilizado, o $\mathrm{pH}$ inicial mais apropriado foi. Amostras do início e do final dos ensaios de crescimento foram analisadas quanto a concentração de glicerol e dos produtos e metabólitos formados. O segundo destino do glicerol consumido foi diferente para as condições, entretanto em pH 5,5 no meio Trchounian et al. (2017) favoreceu a formação de $\mathrm{H}_{2}$. O 1,3-propanodiol também foi um dos principais produtos encontrados independentemente da condição estudada. Este resultado incentiva a perspectivas futuras de pesquisa e obtenção de 1,3-PDO por via biotecnológica, uma vez que se trata de uma substância de bastante interesse industrial.

\section{CONCLUSÃO}

Foi possível inferir que o microrganismo Clostridium beijerinckii $\mathrm{Br} 21$ apresenta a capacidade de metabolizar o glicerol, como única fonte de carbono, produzindo hidrogênio e demais produtos de valor agregado, durante a fermentação. Além disso, foi possível concluir com os dados apresentados, que o pH inicial influencia no crescimento celular e consequentemente na produção de hidrogênio e no perfil de metabólitos.

Apesar dos resultados apresentados não enfatizarem a produção de biohidrogênio, o trabalho exibe dados interessantes sobre a produção de outros compostos durante a fermentação. Á vista disso, este presente trabalho evidencia e incentiva a obtenção de diversos produtos de interesse comercial e industrial por via biotecnológica, tais como o 1,3-propanodiol.

\section{AGRADECIMENTOS}

O presente trabalho foi realizado com apoio da Coordenação de Aperfeiçoamento de Pessoal de Nível Superior - Brasil (CAPES) - Código de Financiamento 001.

\section{REFERÊNCIAS}

CHEN, W.M. et al. Fermentative hydrogen production with clostridium butyricum cgs5 isolated from anaerobicsewage sludge. International journal of hydrogen energy, v. 30: 1063-1070, 2005.

FONSECA, B.C. et al. Fermentative production of $\mathrm{H}_{2}$ from different concentrations of galactose by the new isolate Clostridium beijerinckii Br21. International journal of hydrogen energy v. 41, p. 21109- 21120, 2016.

JIANG, W et al. Key enzymes catalyzing glycerol to 1,3-propanediol. Biotechnology for biofuels, v. 9, n. 1, p. 1-19, 2016.

KRAEMER, J.T. BAGLEY D.M. improving the yield from fermentative hydrogen production. Biotechnol lett. 29:685-695, 2007.

PATIL, Y. et al. Fermentation of glycerol by anaerobium acetethylicum and its potential use in biofuel production. Microbial biotechnology, v. 10, n. 1, p. 203-217, 2017.

PEITER, G. C. et al. Alternativas para o uso do glicerol produzido a partir do biodiesel. Revista brasileira de energias renováveis, v. 5, n. 4, p. 519-537, 2016. 
PÉREZ, R. S.. Produção de hidrogênio a partir da reforma em fase líquida do glicerol: avaliação econômica e logística. 166 f. 2014.

RODRIGUES, C. V. Produção biotecnológica de hidrogênio a partir do glicerol, bioproduto da produção do biodiesel. 151 f. 2016.

SKONIECZNY, M. T.; Yargeau, V. Biohydrogen production from wastewater by Clostridium beijerinckii: effect of ph and substrate concentration. International journal of hydrogen energy, v. 34, n. 8, p. 32883294, 2009.

TRCHOUNIAN, K. et al. Glycerol and mixture of carbon sources conversion to hydrogen by clostridium beijerinckii dsm791 and effects of various heavy metals on hydrogenase activity. International journal of hydrogen energy, v. 42, n. 12, p. 7875-7882, 2017.
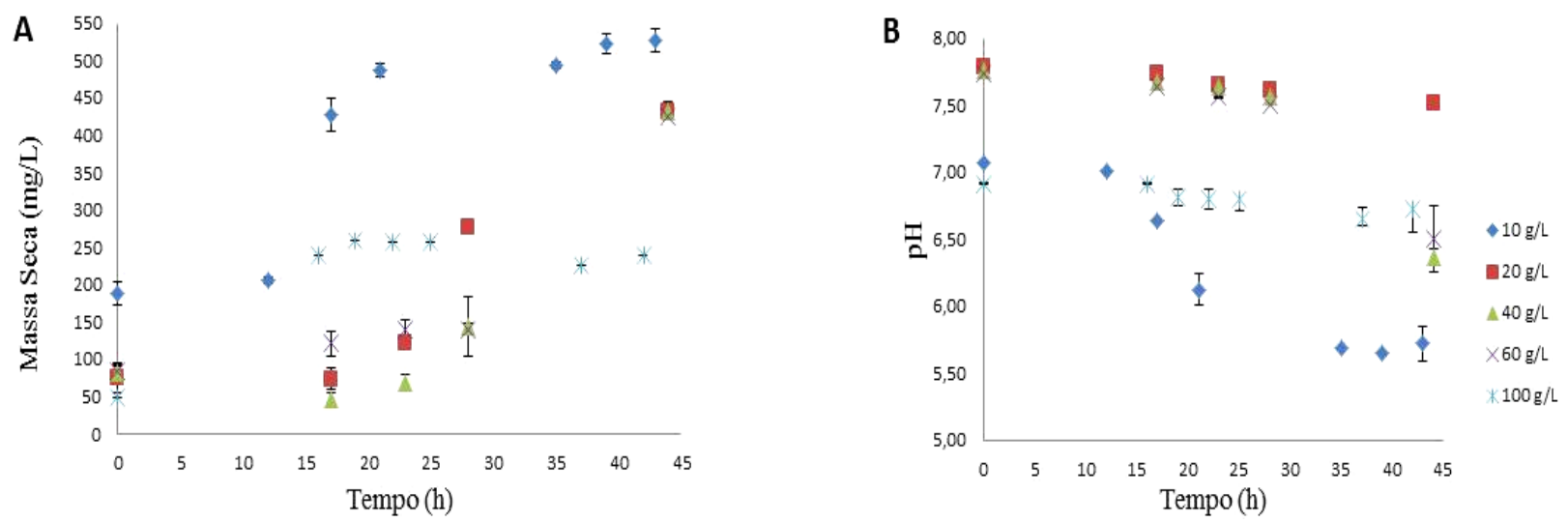

Figura 1. A- concentração em massa seca de C. beijerinckii $\mathrm{Br} 21\left(\mathrm{mg} \mathrm{L}^{-1}\right)$. B- $\mathrm{pH}$ em função do tempo de fermentação (h) utilizando glicerol nas concentrações iniciais de 10, 20, 40, $60 \mathrm{e} 100 \mathrm{~g} \mathrm{~L}^{-1} \mathrm{em}$ meio CH.

Tabela 1. Produtos obtidos através da fermentação de glicerol por C. beijerinckii em diferentes meios de cultura e $\mathrm{pH}$. 


\title{
POTENCIAL LIPOLÍTICO DE BACTÉRIAS ISOLADAS DE EFLUENTE DE ABATEDOURO BOVINO
}

\author{
Haselroth, K.J. ${ }^{1}$; Costa, I.M.D. ${ }^{2}$; Wilke, P. ${ }^{2}$; Hermes, E. ${ }^{* 1}$ \\ ${ }^{1}$ Programa de Pós-Graduação em Tecnologias de Bioprodutos Agroindustriais, Universidade Federal do Paraná (UFPR), Palotina, \\ $P R$ - Brasil. \\ ${ }^{2}$ Graduação em Engenharia de Bioprocessos e Biotecnologia, Universidade Federal do Paraná (UFPR), Palotina, PR - Brasil. \\ elianehermes@yahoo.com.br
}

\begin{abstract}
RESUMO: As lipases são enzimas que apresentam grande potencial biotecnológico, principalmente devido as diversas aplicações que apresentam, como por exemplo, seu uso como auxiliar no tratamento de resíduos lipídicos. Estas podem ser produzidas tanto por microrganismos, como por organismos vegetais e animais, porém atualmente as de origem microbiana são as mais utilizadas principalmente devido às facilidades de controle. Diante disso, o presente estudo teve como objetivo selecionar, isolar e cultivar microrganismos produtores de lipase a partir de efluente de abatedouro bovino. Inicialmente foi realizada uma caracterização físico-química do efluente. Para a seleção dos microrganismos foi utilizado um meio de cultura contendo ( $\mathrm{g} \mathrm{L}^{-}$ $\left.{ }^{1}\right)$ : peptona 10,0, $\mathrm{NaCl} 5,0, \mathrm{CaCl}_{2} 2 \mathrm{H}_{2} \mathrm{O} 0,1$, ágar 18,0 e Tween $20(1 \%(\mathrm{v} / \mathrm{v})$, e as bactérias que apresentaram halo de degradação foram isoladas utilizando o método Streak-plate em ágar nutriente a $30^{\circ} \mathrm{C}$. Através do crescimento da colônia e do halo de degradação foi estimado o índice enzimático. Foi preparado o extrato bruto para determinação da dosagem proteica e atividade lipolítica. O efluente em estudo apresentou $\mathrm{pH}$ de 6,48 , demanda química de oxigênio (DQO) de $8.914,44 \pm 69,38 \mathrm{mg} \mathrm{L}^{-1}$ e óleos e graxas de $2.333,33 \pm 0,00 \mathrm{mg}$ $\mathrm{L}^{-1}$. Os maiores resultados de índice enzimático, atividade lipolítica e dosagem proteica foram obtidos para a bactéria 1, sendo respectivamente de 3,46;2,46 $\mathrm{U} \mathrm{mL}^{-1}$ e 13,12 $\mathrm{mg} \mathrm{mL}^{-1}$. Foi possível concluir que o efluente de abatedouro bovino é uma excelente fonte para a obtenção de microrganismos produtores de lipase.
\end{abstract}

Palavras-chave: índice enzimático, lipase, resíduos lipídicos.

\section{LIPOLITICAL POTENTIAL OF ISOLATED BACTERIA OF EFFLUENT OF CATTLE SLAUGHTERHOUSE}

\begin{abstract}
Lipases are enzymes that present great biotechnological potential, mainly due to the diverse applications they present, such as their use as an aid in the treatment of lipid residues. They can be produced both by microorganisms, plant and animal organisms, but currently, those of microbial origin are the most used mainly due to the control facilities. Therefore, the present study aimed to select, isolate and cultivate lipaseproducing microorganisms from cattle slaughterhouse effluent. Initially, a physical-chemical characterization of the effluent was carried out. For the selection of the microorganisms, a culture medium containing $\left(\mathrm{g} \mathrm{L}^{-1}\right)$ : peptone 10.0, NaCl 5.0, $\mathrm{CaCl}_{2} 2 \mathrm{H}_{2} \mathrm{O} 0.1$, agar 18.0 and Tween $20(1 \%(\mathrm{v} / \mathrm{v})$, and the bacteria presenting degradation halo were isolated using the streak-plate method on nutrient agar at $30^{\circ} \mathrm{C}$. Through the growth of the colony and the halo of degradation, the enzymatic index was estimated. The crude extract was prepared to determine the protein dosage and lipolytic activity. The effluent under study had $\mathrm{pH}$ of 6.48 , chemical oxygen demand (COD) of $8914.44 \pm 69.38 \mathrm{mg} \mathrm{L}^{-1}$ and oils and greases of $2333.33 \pm 0,00 \mathrm{mg} \mathrm{L}^{-1}$. The highest results of the enzymatic index, lipolytic activity, and protein dosage were obtained for bacterium 1, being respectively 3.46; $2.46 \mathrm{U} \mathrm{mL}^{-1}$ and $13.12 \mathrm{mg} \mathrm{mL}^{-1}$. It was possible to conclude that the slaughterhouse effluent is an excellent source for obtaining microorganisms that produce lipase.
\end{abstract}

Keywords: enzymatic index, lipase, lipid residues.

\section{INTRODUÇÃO}

De acordo com o Ministério da Agricultura, Pecuária e Abastecimentoda agricultura (MAPA), a expectativa é que até 2020 a produção brasileira de carnes suprirá $45 \%$ do mercado mundial (BRASIL, 2017). Essa grande produção gera quantidades cada vez maiores de aguas residuárias oriundos dos processos utilizados em abatedouros.

Os efluentes provenientes dessas agroindústrias possuem excessiva quantidade de óleo e gordura, acarretando alguns problemas, tais como: a redução da taxa de transferência de fase de células-aquosa, sedimentação devido ao desenvolvimento de microrganismos filamentosos, desenvolvimento e flotação de 
lamas com fraca atividade, entupimento e o aparecimento de odores desagradáveis. Assim, a aplicação de lipases como pré-tratamento para hidrolisar e dissolver os lipídeos pode melhorar a degradação biológica de águas residuais, de forma a acelerar e otimizar a eficiência do processo (CAMMAROTA e FREIRE, 2006).

As lipases (triacilglicerol acil hidrolases, E.C.3.1.1.3) incluem um grupo de enzimas hidrolíticas que atuam na interface orgânico-aquosa, catalisando a hidrólise de ligações éster-carboxílicas, presentes em acilgliceróis (SAXENA et al., 2003). A produção e aplicação de lipases de origem microbiana têm sido a mais empregada no meio biotecnológico, principalmente devido às facilidades de controle e o aumento da capacidade produtiva (SILVA; BISPO; PAGANO, 2016). Além disso, são biocatalisadores que possuem características significativas, como ação em condições suaves, estabilidade em solventes orgânicos e elevada especificidade de substrato (SNELLMAN; SULLIVAN; COLWELL, 2002).

No entanto, apesar da sua potencialidade, uma barreira no uso das lipases comerciais é o elevado custo, o que justifica a necessidade de pesquisas que tenham como propósito o isolamento de novas fontes microbianas, com potencial lipolítico de forma economicamente viável (GRIEBELER et al., 2011; SINGH e MUKHOPADHYAY, 2012).

Diante disso, o presente estudo teve como objetivo selecionar, isolar e cultivar microrganismos produtores de lipase a partir de efluente de abatedouro bovino.

\section{Caracterização do efluente}

\section{MATERIAL E MÉTODOS}

Os procedimentos experimentais foram realizados no Laboratório de Química Analítica e Análises Ambientais da Universidade Federal do Paraná (UFPR) - Setor Palotina. Foi utilizado efluente de abatedouro bovino oriundo da caixa de gordura de uma agroindústria localizada na região Noroeste do Paraná. As análises para caracterização físico-química do efluente foram $\mathrm{pH}$, demanda química de oxigênio (DQO), sólidos totais, fixos e voláteis conforme APHA (2005) e óleos e graxas de acordo com a metodologia proposta por Suehara et al. (2005).

\section{Seleção e isolamento de bactérias lipolíticas}

A seleção das bactérias foi realizada inoculando-se a água residuária nas diluições de $10^{-4}$ a $10^{-6} \mathrm{em}$ placas de petri com o meio de cultura contendo $\left(\mathrm{g} \mathrm{L}^{-1}\right)$ : peptona 10,0, $\mathrm{NaCl} 5,0, \mathrm{CaCl}_{2} 2 \mathrm{H}_{2} \mathrm{O} 0,1$, ágar 18,0. Após a esterilização do meio de cultura, foi adicionado Tween 20 (previamente esterilizado) numa concentração final de $1 \%(\mathrm{v} / \mathrm{v})$, e as placas foram incubadas por $48 \mathrm{~h}$ a $30{ }^{\circ} \mathrm{C}$ para o crescimento dos microrganismos (VIEIRA et al., 2006). As bactérias que apresentaram halo de degradação, o qual representa atividade lipolítica, foram isoladas em placas contendo ágar nutriente através do método Streak-Plate e mantidas em BOD a $30^{\circ} \mathrm{C}$ (SUEHARA et al., 2005). Após o isolamento as bactérias foram mensuradas quanto ao diâmetro médio do halo de degradação e diâmetro médio da colônia para obtenção do índice enzimático pelo método de Hankin e Anagnostakis (1975):

em que,

$$
\mathbf{I E}=\mathbf{D}^{\mathrm{H}} / \mathbf{D}^{\mathrm{C}}
$$

IE = Índice enzimático

$\mathrm{D}^{\mathrm{h}}=$ Diâmetro médio do halo de degradação

$\mathrm{D}^{\mathrm{c}}=$ Diâmetro médio da colônia

\section{Identificação}

As seis bactérias isoladas foram submetidas ao teste de gram e identificação morfológica.

\section{Processo fermentativo}

Os três microrganismos que apresentaram o maior índice enzimático foram cultivados em frascos de $250 \mathrm{ml}$ em agitador-incubador a $150 \mathrm{rpm}$ e $37^{\circ} \mathrm{C}$ por $24 \mathrm{~h}$ contendo $50 \mathrm{ml}$ do meio de cultura proposto por Bueno et al. (2014) com modificações: extrato de levedura $\left(2 \mathrm{~g} \mathrm{~L}^{-1}\right)$, peptona $\left(5 \mathrm{~g} \mathrm{~L}^{-1}\right), \mathrm{KH}_{2} \mathrm{PO}_{4}\left(3,0 \mathrm{~g} \mathrm{~L}^{-1}\right)$, $\mathrm{MgSO}_{4} .7 \mathrm{H}_{2} \mathrm{O}\left(0,2 \mathrm{~g} \mathrm{~L}^{-1}\right)$ e $1 \%$ (v/v) de óleo de soja. A suspensão de células obtida foi padronizada em 1.0 de absorbância em espectrofotômetro Femto 600S no comprimento de onda de $600 \mathrm{~nm}$ e inoculada $5 \mathrm{ml}$ da suspensão padronizada em outro erlenmeyer de $250 \mathrm{~mL}$, contendo $50 \mathrm{~mL}$ do meio descrito anteriormente e nas mesmas condições da anterior. O cultivo foi interrompido por centrifugação (15 min a $3000 \mathrm{rpm}$ ), o sobrenadante foi usado para análise da atividade lipolítica e dosagem proteica. 


\section{Atividade lipolítica e dosagem proteica}

A determinação da atividade lipolítica foi realizada pelo método titulométrico segundo Dellamora-Ortiz et al. (1997) com modificações, onde utilizou $5 \mathrm{~mL}$ de emulsão de óleo de oliva $20 \%$ (v/v) em goma arábica $5 \%(\mathrm{p} / \mathrm{v})$ e dois $\mathrm{mL}$ de tampão fosfato de sódio $0,1 \mathrm{M}, \mathrm{pH}$ 7,0. O ensaio foi realizado em shaker com agitação de $180 \mathrm{rpm}$, a $37^{\circ} \mathrm{C}$, sendo iniciado pela adição de três $\mathrm{mL}$ da preparação enzimática e após 20 min de incubação, a reação foi paralisada pela adição de $10 \mathrm{~mL}$ de uma mistura etanol e acetona (1:1). Os ácidos graxos formados pela hidrólise dos triacilgliceróis presentes na emulsão foram quantificados pela titulação com NaOH 0,05 N, aplicando-se fenolftaleína como indicador. Também foi utilizado um branco, contendo três $\mathrm{mL}$ do tampão fosfato de sódio em vez do preparo enzimático. A atividade lipásica foi expressa em micromoles de ácidos graxos liberados, por minuto de reação, por mililitro de amostra. A dosagem de proteínas totais foi realizada de acordo com o método de Bradford (1976) utilizando-se uma solução estoque de soro de albumina bovina numa concentração de $1 \mathrm{mg} \mathrm{mL}^{-1}$ para elaboração da curva-padrão.

\section{RESULTADOS E DISCUSSÃO}

Os valores obtidos na caracterização do resíduo foram de 6,48 para o $\mathrm{pH}, 2333,33 \pm 0,00 \mathrm{mg} \mathrm{L}^{-1}$ para

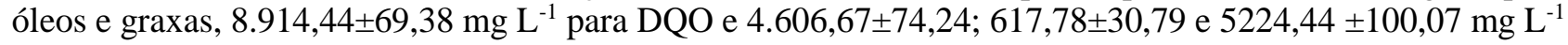
para sólidos totais voláteis, sólidos totais fixos e sólidos totais, respectivamente. Como o efluente em estudo possui elevada quantidade de lipídeos, já era esperado que o mesmo se apresentasse como uma fonte promissora para o isolamento de bactérias lipolíticas.

Analisando-se os valores, apenas o $\mathrm{pH}$ atende aos parâmetros estabelecidos pela Resolução CONAMA 430/2011, para lançamento de efluentes em corpor d'água, enquanto que os demais parâmetros apresentam valores elevados, necessitando de tratamento prévio ao seu descarte no ambiente. Como por exemplo, o valor de óleos e graxas que precisa ficar abaixo de $50 \mathrm{mg} \mathrm{L}^{-1}$, sendo que a degradação desses óleos por meio de lipases produzidas por bactérias isoladas do próprio efluente faz-se uma opção promissora.

Por meio da observação dos halos de degradação formados ao redor das colônias (indicativo de produção de lipase), foi possível selecionar e isolar seis bactérias morfologicamente distintas. Rocha et al. (2013), ao isolar microrganismos da água residuária de purificação do biodiesel, 12 culturas foram obtidas, dais quais sete eram linhagens de levedura, dois fungos filamentosos e três bactérias.

Com relação ao teste de Gram, todas as bactérias apresentaram-se como Gram-negativa. Corroborando com a literatura que sugere que a maioria das bactérias lipolíticas encontradas na natureza são Gram-negativas KANWAR e GOSWAMI, 2002). Carvalho (2012) obteve resultado semelhante, onde no meio com Rodamina $\mathrm{B}$, das 25 linhagens que apresentaram atividade lipolítica, $80 \%$ foi caracterizada como Gram-negativa e apenas $20 \%$ como Gram-positivas.

Quanto a morfologia todos os isolados apresentaram aspecto cremoso e em relação a cor, as colônias um a cinco apresentaram-se como brancas e a bactéria seis amarela. Já para a borda das bactérias, as colônias um e seis apresentaram borda bem definida, enquanto que o restante das colônias não apresentou borda definida.

Ao mensurar os diâmetros médios dos halos de degradação e os diâmetros médios das colônias isoladas foi possível calcular o índice enzimático de três bactéria, já que estas apresentaram os maiores halos. O maior valor $(3,46)$ obtido foi referente a bactéria 1 (Tabela 1). Silva et al. (2016), realizaram o estudo de isolamento de bactérias lipolíticas de efluente de planta piloto de biodiesel, e observaram indice enzimático de 1,03 a 2,37.

Com relação a atividade enzimática e a dosagem proteica, também constatou-se que os maiores valores foram para a bactéria 1 , sendo respectivamente de $2,46 \mathrm{U} \mathrm{mL}^{-1}$ e $13,12 \mathrm{mg} \mathrm{mL}^{-1}$. Posteriormente as bactérias serão encaminhadas para identificação molecular através de sequenciamento.

\section{CONCLUSÃO}

As águas residuárias de abatedouro bovino são uma fonte de estudo promissora para prospecção de bactérias lipolíticas. Além disso, os resultados deste estudo reforçam a ideia de que microrganismos provenientes de ambientes com uma alta carga lipídica, mostram-se como verdadeiros produtores de lipase.

\section{AGRADECIMENTOS}

O presente trabalho foi realizado com apoio da Coordenação de Aperfeiçoamento de Pessoal de Nível Superior - Brasil (CAPES) - Código de Financiamento 001. 


\section{REFERÊNCIAS \\ APHA; AWWA; WEF. Standard methods for the examination of water and wastewater. 21 ed. Washington, p. $1268,2005$.}

BECKER, J. M.; CALDWELL, G. A.; ZACHGO, E. A. Exercise 1 - aseptic technique and establishing pure cultures: the streak plate and culture transfer. In:. Biotechnology: a laboratory course. 2.ed. Academic press, 1996. P. 9-16.

BRADFORD, M. M. A rapid and sensitive method for the quantitation of microgram quantities of protein utilizing the principle of protein-dye binding. Anal. Biochem., v. 72, p. 248, 1976.

BRASIL. Conselho Nacional do Meio Ambiente. Resolução no 430, de 13 de maio de 2011. Dispõe sobre as condições e padrões de lançamento de efluentes. Diário Oficial da União, Brasília, DF, nº 92, 16 mai. 2011 , Seção 3, p. 6.

BRASIL. Ministério da Agricultura. Exportação. Brasília, DF, 2017. Disponível em: < http://www.agricultura.gov.br/assuntos/sanidade-animal-e-vegetal/saude-animal/exportacao> . Acesso em: 08 de novembro de 2018

BUENO, P. R. M.; OLIVEIRA, T. F.; CALIARI, M.; CASTIGLIONI, G. L.; JUNIOR, M. S. S. Selection and optimization of extracellular lipase production using agro-industrial waste. African Journal of Biotechnology, v. 13, n. 4, p. 566-573, 2014.

CAMMAROTA, M. C.; FREIRE, D. M. G. A review on hydrolytic enzymes in the treatment of wastewater with high oil and grease content. Bioresource Technology. v.97, n.17, p. 2195-2210, 2006.

CARVALHO, L. C. T. Produção de lipases e biossurfactantes por bactérias isoladas de um solo contaminado com óleo vegetal residual. Dissertação (Mestrado). João Pessoa. Centro de Ciências Exatas e da Natureza, Universidade Federal da Paraíba. 2012.

DELlAMORA-ORTIZ, G. M.; MARTINS, R. C.; ROCHA, W. L.; DIAS, A. P. Activity and stability of a Rzizomucor miehei lipase in hydrophonic media. Biotechnology Applied Biochemistry, Indianapolis, v. 26, p.111116, 1997.

GRIEBELER, N.; POLLONI, A. E.; REMONATTO, D.; ARBTER, F.; VARDANEGA, R.; CECHET, J. L.; DI LUCCIO, M.; OLIVEIRA, D.; TREICHEL, H.; CANSIAN, R. L.; RIGO, E.; NINOW, J. Isolation and screening of lipase-producing fungi with hydrolytic activity. Food and Bioprocess Technology, v. 4, n. 4, p. 578-586, 2011. HANKIN, L.; ANAGNOSTAKIS, S. L. The use of solid media for detection of enzyme production by fungi. Mycologia, v. 67, p. 597-607, 1975.

KANWAR L.; GOSWAMI, P. Isolation of a pseudomonas lipase produced in pure hydrocarbon substrate and its application in the synthesis of isoamyl acetate using membrane-immobilised lipase. Enzyme and Microbial Technology, v. 31, p 727- 735, 2002.

PACHECO, J. W.; YAMANAKA, H. T. Guia técnico ambiental de abates (bovino e suínos) - Série (P+L). São Paulo, CETESB, 96 p., 2006.

ROCHA, D. C. D.; GOMES, B. M.; D GOMES, S.; SENE, L.; ZENATTI, D. C. Selection of microorganisms producer of lipase for fat removal from biodiesel purification water. Engenharia Agrícola, v. 33, n. 2, p. 332-340, 2013.

SAXENA, R. K.; SHEORAN, A.; GIRI, B.; DAVIDSON, W. S. Purification strategies for microbial. Journal of Microbiological Methods, v. 52, p.1-18, 2003.

SILVA, M. O. M. B.; BISPO, D. F.; PAGANO, R. L.; SILVA, A. S.; SANTOS, E. J.; SILVA, C. F. Isolamento de microrganismos e estudo da produção de lipase utilizando resíduos agroindustriais. Scientia Plena, Sergipe, v. 12 , n. 5, p. 1-9, 2016.

SNELLMAN, E. A.; SULLIVAN, E. R.; COLWELL, R. R. Purification and properties of the extracellular lipase, lipa, of acinetobacter sp. Rag-1. Biochemical Engineering Journal, v. 11, n.2, p. 269-274, 2002.

SUEHARA, K.; KAWAMOTO, Y.; FUJII, E.; KOHDA, J.; NAKANO, Y.; YANO., T. Biological Treatment of Wastewater Discharged from Biodiesel Fuel Production Plant with Alkali-Catalyzed Transesterification. Journal of Bioscience and Bioengineering, v. 100, n.4, p. 437-442, 2005.

VIEIRA, T. M.; SILVA, E. P.; FILHO, N. R. A.; VIEIRA, J. D. G. Determinação e quantificação da degradação bacteriana de biodiesel de óleo de palma. In: Congresso da rede brasileira de tecnologia de biodiesel, BRASÍLIA, DF, 2006. ANAIS... BRASÍLIA, DF: PROSSIGA/IBICT, 2006. p. 218-223.

Tabela 1. Índice enzimático, atividade lipolítica e dosagem proteica das bactérias selecionadas.

\begin{tabular}{cccc}
\hline Bactérias & Índice enzimático & Atividade lipolítica $\left(\mathbf{U} \mathbf{~ m L}^{-\mathbf{1}}\right)$ & Dosagem proteica $\left(\mathbf{m g ~ m L}^{-\mathbf{1}}\right)$ \\
\hline 1 & 3,46 & $2,46 \pm 0,12$ & $13,12 \pm 0,00$ \\
2 & 3,08 & $1,58 \pm 0,00$ & $10,70 \pm 0,01$ \\
3 & 2,11 & $2.10 \pm 0,03$ & $6,30 \pm 0,00$ \\
\hline
\end{tabular}




\title{
PRÉ-TRATAMENTO DE PELOS DE SUÍNO PARA APLICAÇ̃̃o NO PROCESSO DE DESCOLORAÇÃO DE EFLUENTES TÊXTEIS
}

\author{
de Paris Junior, O. ${ }^{1}$; Scapini, T. ${ }^{1}$; Frumi Camargo, A. ${ }^{1}$; Stefanski, F.S. ${ }^{1}$; Fongaro, G. $^{1}$; Treichel, H. $^{1}$ \\ ${ }^{I}$ Laboratório de Microbiologia e Bioprocessos, Universidade Federal da Fronteira Sul, Erechim, RS - Brasil \\ helentreichel@gmail.com
}

\begin{abstract}
RESUMO: A produção brasileira de carne suína é constituída em sistemas modernos e de alto rendimento. Com avanço da tecnologia para a produção de proteína animal houve um aumento da geração de resíduos no setor, alguns destes considerados de alto potencial poluidor. Geralmente a destinação destes resíduos são aterros sanitários, fertilizantes e ração animal, porém inúmeros apresentam potencial para serem valorados em outros processos com alto valor agregado. Um dos subprodutos gerados durante o processo de abate e que não tem seu potencial explorado é o pelo suíno, visto o alto percentual de queratina que torna a estrutura deste material extremamente complexa, necessitando de estudos de técnicas para remoção desta camada superficial e posterior aplicação em processos de interesse. Nesse sentido, este estudo propôs uma avaliação do prétratamento de pelos de suíno para posterior aplicação do biomaterial na remoção da coloração de efluentes têxteis. O pré-tratamento foi realizado em cinco diferentes sistemas reacionais, apresentando resultados satisfatórios para a técnica utilizando peróxido de hidrogênio em meio alcalino. A exposição dos pelos de suíno pré-tratados em efluente têxtil mostrou-se relevante, apresentando remoção de $89 \%$ e $45 \%$, para o corante azul e vermelho, respectivamente. Por fim, o desenvolvimento de novos métodos de valoração de resíduos que sejam viáveis economicamente e ecologicamente adequados vem sendo explorados a nível mundial. Com caráter inovador e aplicação de um resíduo pouco explorado, este trabalho apresenta um estudo promissor da valoração dos pelos de suíno para aplicação na remoção de cor de efluente têxtil.
\end{abstract}

Palavras-chave: Valoração de resíduos, Biomaterial, Peróxido de hidrogênio.

\section{PRE-TREATMENT OF PIG HAIRS FOR APPLICATION IN THE PROCESS OF DECORATION OF TEXTILE EFFLUENTS}

\begin{abstract}
The Brazilian production of pork is made up of modern and high yielding systems. With advances in technology for the production of animal protein, there was an increase in the generation of waste from the sector, some of these considered as high potential polluters. Usually the destination of these wastes are sanitary landfills, fertilizers and animal feed, but many have the potential to be valued in other processes with high added value. One of the byproducts generated during the slaughtering process, which does not have its potential exploited is pig hairs, since the high percentage of keratin that makes the structure of this material extremely complex, necessitating techniques studies to remove this superficial layer and subsequent application in processes of interest. In this sense, this study proposed an evaluation of the pre-treatment of pig hairs for later application of the biomaterial in the removal of the coloration of textile effluents. Pretreatment was performed in five different reaction systems, presenting satisfactory results for the technique using hydrogen peroxide in alkaline medium. Exposure of pre-treated pig hairs in textile effluent was relevant, with removal of $88.5 \%$ and $44.7 \%$ for blue and red dye, respectively. Finally, the development of new waste valuation methods that are economically viable and environmentally suitable sound are being explored worldwide. With an innovative character and application of a residue little explored until the present date, this work presents a promising study of the evaluation of pig hairs for application in the color removal of textile effluent.
\end{abstract}

Keywords: Residues valuation, Biomaterial, Hydrogen peroxide.

\section{INTRODUÇÃO}

O processamento da carne suína, desde as agroindústrias até o produto final apresentam grande importância nos setores econômico e social brasileiro, e isso se dá principalmente pelo fato do Brasil ser o quarto maior produtor e exportador de carne suína no cenário mundial (ALI et al., 2017; USDA, 2015). Com o aumento da produção de carne suína, a geração de resíduos deste setor também aumenta gradativamente e são considerados de alto potencial poluidor. A destinação ambientalmente adequada da maior parte dos resíduos gerados durante o abate de suínos é o aterro sanitário ou industrial, ração animal e fertilizante, 
entretanto um dos subprodutos gerados durante o processo de abate e que não tem seu potencial explorado é o pelo suíno, possivelmente pelo fato de seu tempo de degradação ser prolongado, por conta da estrutura complexa formada por ligações queratinosas presentes em sua superfície (MABROUK, 2008). Por apresentar uma estrutura complexa o pelo é um subproduto que necessita de pré-tratamento para que seu potencial possa ser investigado. Existem uma série de pré-tratamentos que podem ser aplicados, como físicos, químicos ou até a combinação de técnicas (CAI; ZHENG, 2009).

Neste sentido, o objetivo deste estudo foi avaliar diferentes pré-tratamentos de pelo suíno bruto residual da indústria frigorífica visando posterior aplicação na descoloração de corantes têxteis.

\section{MATERIAL E MÉTODOS}

Avaliação de diferentes pré-tratamentos do pelo de suíno

Com intuito de pré-tratar as amostras de pelo de suíno, foram realizados ensaios com diferentes técnicas utilizando peróxido de hidrogênio $\left(\mathrm{H}_{2} \mathrm{O}_{2}\right)$, ácido sulfúrico $\left(\mathrm{H}_{2} \mathrm{SO}_{4}\right)$, hidróxido de sódio $(\mathrm{NaOH})$ e vapor úmido em autoclave.

Os ensaios de pré-tratamento utilizando $\mathrm{H}_{2} \mathrm{O}_{2}$ foram conduzidos utilizando uma solução de $12 \%\left(\mathrm{v} \mathrm{v}^{-1}\right)$ de $\mathrm{H}_{2} \mathrm{O}_{2}$, com volume final de $100 \mathrm{~mL}$ e pH ajustado em 11,5 (SUN et al., 2015). Após adição da biomassa os erlenmeyers permaneceram em agitador orbital a $28^{\circ} \mathrm{C}, 150 \mathrm{rpm}$ durante 3 horas (adaptado de RABELO et al., 2008).

O experimento conduzido em autoclave foi realizado com volume final de $100 \mathrm{~mL}$ e as amostras foram submetidas a condições de 30 minutos, pressão de 1 bar e $120^{\circ} \mathrm{C}$.

Para a técnica de pré-tratamento utilizando $\mathrm{H}_{2} \mathrm{SO}_{4}$ combinado ao vapor úmido em autoclave foram preparadas $100 \mathrm{~mL}$ de uma solução $1 \%\left(\mathrm{v} \mathrm{v}^{-1}\right)$ de $\mathrm{H}_{2} \mathrm{SO}_{4}$. Os erlenmeyers contendo as amostras foram submetidos a autoclave por 30 minutos, pressão de 1 atm e $120^{\circ} \mathrm{C}$.

Nos ensaios em meio alcalino utilizou-se $\mathrm{NaOH}$ e as amostras preparadas em concentração final de 0,025 M (adaptado de CHEONG et al., 2018). A técnica de pré-tratamento em meio alcalino foi conduzida em dois sistemas reacionais: agitador orbital $\left(150 \mathrm{rpm}, 28^{\circ} \mathrm{C}, 3\right.$ horas) e vapor úmido em autoclave (1 bar, 120 ${ }^{\circ} \mathrm{C}, 30$ minutos). O resíduo foi adicionado aos meios reacionais com relação de $5 \%$ ( $\mathrm{m} \mathrm{v}^{-1}$ ) de pelos de suíno, considerando massa seca. Os experimentos foram realizados em triplicata, e ao final de cada processo as amostras foram filtradas, secas em estufa e pesadas para determinação da perda de massa e o percentual de degradação (REDDY et al., 2017).

\section{Avaliação do resíduo pré-tratado para descoloração de corante têxtil}

A partir dos resultados promissores obtidos no processo de pré-tratamento, os pelos de suíno foram aplicados na descoloração de efluente têxtil azul e vermelho. Para tanto, $0,1 \%$ de pelo de suíno bruto e prétratado foram adicionados a soluções de $50 \mathrm{~mL}$ de efluentes contendo os corantes, com pH 7,0. As amostras foram mantidas em agitador orbital, durante 1 hora a $25{ }^{\circ} \mathrm{C}$. Os resultados foram avaliados em espectrofotômetro UV-VIS a $515 \mathrm{~nm}$ e $618 \mathrm{~nm}$ para o corante vermelho e azul, respectivamente. Posteriormente, com os pelos de suínos pré-tratados foram realizados ensaios para avaliação da remoção da coloração em uma ampla faixa de pH, variando de 1,0 a 8,0, nas mesmas condições do ensaio anterior.

\section{RESULTADOS E DISCUSSÃO}

A avaliação de diferentes técnicas de pré-tratamento em pelo de suíno foi realizada em cinco diferentes sistemas reacionais e os resultados foram avaliados com base na degradação do material. A Figura 1 apresenta os resultados obtidos nos experimentos. Ao observar os resultados nas diferentes técnicas de pré-tratamento, é possível constatar que os sistemas reacionais com $\mathrm{H}_{2} \mathrm{O}_{2}$ em meio alcalino e com $\mathrm{NaOH}$ combinado ao vapor úmido em autoclave foram mais efetivos em relação ao percentual de degradação, sendo, respectivamente, 49 $\%$ e $46 \%$ (média \pm erro padrão). Ainda assim, tratando-se do resultado observado para a técnica com $\mathrm{NaOH}$ combinado ao vapor úmido em autoclave, é possível perceber que a degradação é resultante da combinação de dois sistemas reacionais. Isso pode ser afirmado com base na degradação obtida isoladamente nos dois sistemas, de $10 \%$ para o pré-tratamento em autoclave e $29 \%$ para o pré-tratamento com $\mathrm{NaOH}$ em agitador orbital.

Quanto aos resultados observados na reação envolvendo $\mathrm{H}_{2} \mathrm{SO}_{4}$ combinado ao vapor úmido em autoclave, obteve-se um percentual de degradação de $22 \%$. Apesar de ter demonstrado potencial de degradação, não apresentou maior efetividade que os demais pré-tratamentos, então o pré-tratamento com $\mathrm{H}_{2} \mathrm{O}_{2}$ em meio alcalino mostrou maior potencial na degradação de pelo de suíno, sendo esta técnica utilizada para os experimentos seguintes. 
Sendo assim, os pelos de suínos bruto e pré-tratado foram expostos a efluentes com corante de industriais têxteis, visando a remoção da coloração. Neste contexto, a Tabela 1 apresenta os resultados, demonstrando a necessidade do pré-tratamento no resíduo para que a remoção dos corantes fosse efetiva, visto que a remoção do corante utilizando o resíduo pré-tratado foi de maior efetividade do que quando aplicado o material bruto. A hipótese para tal comportamento pode estar relacionada a maior instabilidade estrutural dos fios do pelo de suíno após o processo com $\mathrm{H}_{2} \mathrm{O}_{2}$, tornando o fio mais susceptível a ligações químicas com os corantes.

Com intuito de aumentar a eficiência do processo, experimentos foram realizados em uma ampla faixa de $\mathrm{pH}$, conforme exposto na Tabela 2. Os resultados de maior eficiência foram obtidos em $\mathrm{pH} 3,0 \mathrm{com} 89 \%$ de remoção para o corante azul e pH 4,0 com $45 \%$ de remoção para o corante vermelho. Marques et al. (2017) aplicou enzima peroxidase extraída de farelo de arroz para remoção de coloração de efluente têxtil vermelho, e obteve resultados de $45 \%$ de remoção da coloração, o mesmo obtido neste estudo para o mesmo corante. Ainda, os autores não observaram remoção de coloração para o corante azul quando exposto a peroxidase, diferente do obtido neste trabalho, onde o corante azul teve afinidade maior que o corante vermelho com o resíduo pré-tratado, apresentando o dobro do percentual de remoção. Demonstra-se assim o grande potencial da aplicação dos pelos de suíno pré-tratados para remoção da coloração de efluentes da indústria têxtil, com perspectivas futuras de ampliação de escala do processo.

\section{CONCLUSÃO}

O avanço do setor de produção e exportação de suínos no mundo traz à tona uma grave problemática ambiental, a geração de resíduos do setor produtivo de proteína animal. Este problema aumenta paralelamente ao avanço econômico do setor e estudos de valoração de dejetos suínos estão ganhando espaço na pesquisa mundial, muitas vezes destinados a geração de energia e fertilizantes, porém há uma escassez de resultados voltados a valoração dos pelos de suínos.

Neste contexto, este estudo apresentou uma proposta de pré-tratamento de pelos de suíno, onde após exposto a cinco sistemas reacionais observou-se a maior degradação na técnica utilizando $\mathrm{H}_{2} \mathrm{O}_{2}$ em meio alcalino, onde obteve-se $49 \%$ de degradação. Com resultado promissor, os pelos de suíno pré-tratados foram expostos a efluentes têxteis de coloração azul e vermelha, onde foi possível uma remoção de aproximadamente $88 \%$ em pH 3,0 e $45 \%$ em pH 4,0, para o corante azul e vermelho, respectivamente. É importante salientar que até a presente data não há relatos literários de remoção de cor de efluente têxtil utilizando pelo de suíno. Por fim, o estudo apresentou resultados satisfatórios, mostrando-se promissor para posteriores processos de otimização e ampliação de escala.

\section{AGRADECIMENTOS}

Os autores agradecem a CAPES, CNPq, FAPERGS e UFFS.

\section{REFERÊNCIAS}

ALI, B. A., VAN ZATEN, H. H. E., BERENTSEN, P., BASTIAANSEN, J. W. M., BIKKER, P., LANSINK, A. O. Environmental and economic impacts of using co-products in the diets of finishing pigs in Brazil. Journal of Cleaner Production, v. 162, p. 247-259, 2017.

CAI, C.; ZHENG, X. Medium optimization for keratinase production in hair substrate by anew Bacillus subtilis KD-N2using response surface methodology. Journal of Industrial Microbiology \& Biotechnology, v.36, p. 875-883, 2009.

MABROUK, M. E. M. Feather degradation by a new keratinolytic Streptomyces sp MS-2. Journal of Microbiology and Biotechnology, v. 24, p. 2331-2338, 2008.

MARQUES, C.T.; GOLUNSKI, S. M.; VENTURIN, B.; CAMARGO, A. F.; SCAPINI, T.;

BALDISSARELLI, D.; MODKOVSKI, T. A.; PRECZESKI, K. P.; DALLA ROSA, C.; VARGAS, G. D. P.; BUFFON, J. G.; ROSIN, C. K.; ARENZON, A.; MOSSI, A. J.; TREICHEL, H. Removal of a red dye using noncommercial peroxidase extracted from rice bran. Environmental Quality Management, v. 27, p. 25-31, 2017.

RABELO, S. C.; FILHO, R. M.; COSTA, A. C. Lime pretreatment of sugarcane bagasse for bioethanol production. Applied Biochemistry and Biotechnology, v. 153, p. 139-150, 2008

REDDY, M. R.; REDDY, K. S.; CHOUHAN, Y. R.; BEE, H.; REDDY, G. Effective feather degradation and keratinase production by Bacillus pumilus GRK for its application as bio-detergent additive. Bioresource Technology, v. 243, p. 254-263, 2017. 


\section{VISIGER A DE 07 A 09 MA10 2019

SUN, C.; LIU, R.; CAO, W.; YIN, R.; MEI, Y.; ZHANG, L. Impacts of Alkaline Hydrogen Peroxide Pretreatment on Chemical Composition and Biochemical Methane Potential of Agricultural Crop Stalks. Energy and Fuels, v. 29, p. 4966-4975, 2015.

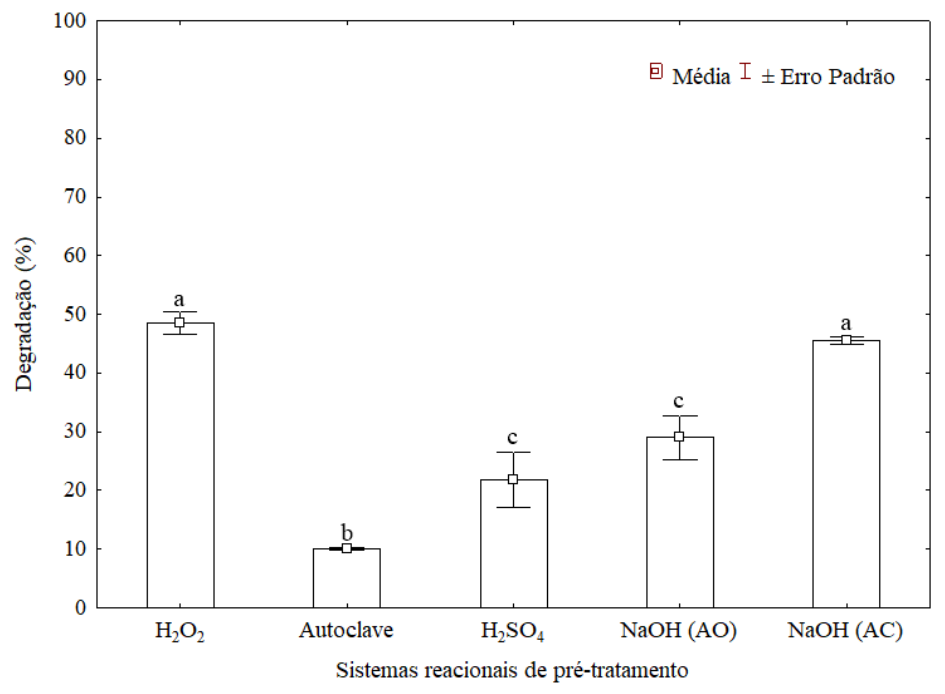

Figura 1. Resultados obtidos referentes aos ensaios preliminares com diferentes técnicas de pré-tratamento do pelo de suíno, sendo respectivamente: Peróxido de Hidrogênio em meio alcalino $\left(\mathrm{H}_{2} \mathrm{O}_{2}\right)$; Vapor úmido em autoclave (Autoclave); Ácido sulfúrico combinado ao vapor úmido em autoclave $\left(\mathrm{H}_{2} \mathrm{SO}_{4}\right)$; Hidróxido de sódio em agitador orbital (NaOH-AO); Hidróxido de sódio combinado ao vapor úmido em autoclave (NaOH-AC). *letras minúsculas iguais não diferem entre si com 95\% de confiança pelo teste de Tukey.

Tabela 1. Resultados obtidos para exposição dos pelos de suíno bruto e após o pré-tratamento com $\mathrm{H}_{2} \mathrm{O}_{2}$ para redução da coloração em efluentes têxteis azul e vermelho. Sendo condições de $25^{\circ} \mathrm{C}, \mathrm{pH} 7,0$, tempo de contato de 1 hora e $150 \mathrm{rpm}$.

\begin{tabular}{lcc}
\hline & \multicolumn{2}{c}{ Redução da coloração (\%) } \\
\cline { 2 - 3 } & Corante azul & Corante vermelho \\
\hline Pelos de suíno bruto & 3 & 6 \\
Pelos de suíno pré-tratado & 5 & 14 \\
\hline
\end{tabular}

Tabela 2. Resultados obtidos para avaliação de diferentes $\mathrm{pH}$ na exposição dos pelos de suíno pré-tratados com $\mathrm{H}_{2} \mathrm{O}_{2}$ para redução da coloração em efluentes têxteis azul e vermelho.

\begin{tabular}{ccc}
\hline \multirow{2}{*}{$\mathbf{p H}$} & \multicolumn{2}{c}{ Redução da coloração (\%) } \\
\cline { 2 - 3 } & Corante Azul & Corante Vermelho \\
\hline 1,0 & 8 & 24 \\
2,0 & 14 & 20 \\
\hline 3,0 & 89 & 44 \\
4,0 & 35 & 45 \\
\hline 5,0 & 5 & 16 \\
6,0 & 0 & 11 \\
7,0 & 9 & 8 \\
8,0 & 0 & 0 \\
\hline
\end{tabular}




\title{
PRODUÇÃO DE BIOCOMPÓSITOS FÚNGICOS A PARTIR DE BAGAÇO DE MALTE E PLEUROTUS SAJOR-CAJU
}

\author{
Deschamps, J.L.N.*1; Marschall, E. ${ }^{1}$; Medeiros, N.V. ${ }^{1}$; Riani, J.C. ${ }^{1}$; Gern, R.M.M. ${ }^{1}$; Wisbeck, E. ${ }^{1}$ \\ ${ }^{1}$ Pesquisadores da Universidade da Região de Joinville - UNIVILLE, Joinville, SC - Brasil \\ *joara.champs@gmail.com
}

\begin{abstract}
RESUMO: No Brasil são produzidos, aproximadamente, 14 bilhões de litros de cerveja por ano, o que resulta em uma grande geração de resíduos, sendo o bagaço de malte o resíduo gerado em maior quantidade, cerca de 3,5 bilhões de kg por ano. Resíduos orgânicos tal qual o bagaço de malte, podem ser utilizados como material nutriente na fabricação de compósitos produzidos por meio do crescimento fúngico. Estes materiais podem ser mais eficientes e rentáveis do que muitos processos sintéticos e podem substituir embalagens plásticas, de madeiras, espumas e isopor. Com o intuito de agregar valor ao bagaço de malte e considerando que o mesmo possui potencial para o cultivo de Pleurotus sajor-caju, desenvolveu-se biocompósitos a partir do bagaço de malte in natura, adicionado de folhas de bananeira (1:1). Estes substratos foram inoculados em frações de 10, 20 e $30 \%$, incubados a $30^{\circ} \mathrm{C}$, triturados e colocados em moldeiras. Após o preenchimento total do micélio fúngico, os corpos de prova foram secos a 40 ou $60{ }^{\circ} \mathrm{C}$ e submetidos a análises de tempo de crescimento micelial, resistência à compressão e absorção de umidade do ar. A condição que utilizou $30 \%$ de inóculo e secagem a $60{ }^{\circ} \mathrm{C}$ apresentou um menor tempo global de processo (18 dias) e também uma menor absorção de umidade. Esta condição foi definida como a melhor condição para a produção destes biocompósitos.
\end{abstract}

Palavras-chave: Biocompósitos, bagaço de malte, Pleurotus, resíduos.

\section{PRODUCTION OF FUNGAL COMPOSITES FROM MALT BAGASSE AND Pleurotus sajor-caju}

ABSTRACT: At Brazil around 14 billion liters of beer are produced per year, which results in a large waste generation, the malt bagasse is the main amount of waste, about 3,5 billion kg per year. Organic waste such as malt bagasse can be used as nutrient material in the manufacture of composites produced through the growth of fungus. These materials can be more efficient and profitable than many synthetic processes, and could substitute materials as plastic package, wood, foam and polystyrene. With the intention of adding value to the malt bagasse and considering that it has potential for the cultivation of Pleurotus sajor-caju, this research has developed composite materials formed by malt bagasse in natura added of banana tree leaves (1:1). These substrates were inoculated in fractions of 10,20 and $30 \%$, incubated at $30{ }^{\circ} \mathrm{C}$, triturated and placed in moulds. After the total completion of the mycelia cells, the proof bodies were dry at 40 and $60{ }^{\circ} \mathrm{C}$ and submitted to analyses of compression, absorption of water and humidity. The condition using $30 \%$ of inoculum and drying at $60^{\circ} \mathrm{C}$ presented a lower global process time (18 days), and also a lower humidity absorption, and was defined as the ideal condition of the process.

Keywords: Biocomposite materials, malt bagasse, Pleurotus, waste.

\section{INTRODUÇÃO}

A indústria cervejeira no Brasil é muito expressiva, produzindo, aproximadamente, 14 bilhões de litros de cerveja por ano (CERVBRASIL,2016). No entanto, como resultado dessa produção de cerveja, tem-se uma grande geração de resíduos e subprodutos tais como o bagaço de malte, que é o subproduto do processo cervejeiro gerado em maior quantidade, onde para cada $100 \mathrm{~L}$ de cerveja produzidos, são obtidos entre 20 a $30 \mathrm{Kg}$ de bagaço de malte (BONATO, 2016).

Devido ao alto valor nutricional do bagaço de malte, sua vasta disponibilidade durante o ano e seu baixo custo, existem diversos estudos cujo intuito é o aproveitamento deste resíduo. Em sua maior parte, as pesquisas são direcionadas à alimentação animal. Como exemplo Mendonça em 2012 utilizou o resíduo úmido de cervejaria na alimentação de cabras anglo nubiana no final da lactação. Entretanto, alguns problemas com a utilização deste resíduo para alimentação animal já foram relatados, como enfermidades em bovinos associadas ao consumo de resíduos de cervejaria (BRUST et al., 2015). 
Schulz (2016) produziu cogumelos comestíveis do gênero Pleurotus sajor-caju utilizando o resíduo úmido de cervejaria adicionado de folhas de bananeira, pois o fungo não foi capaz de frutificar somente no bagaço de malte, devido à alta compactação deste substrato. O cultivo de bananeira também é representativo no Brasil, sendo que Santa Catarina é o terceiro maior estado produtor de banana (EPAGRI, 2015). Essa produção significativa também gera um resíduo biodegradável: as folhas de bananeira. De acordo com Souza et al. (2010) para cada tonelada de banana industrializada são gerados $780 \mathrm{~kg}$ de folhas de bananeira, as quais são amplamente utilizadas no cultivo de cogumelos (STURION, 1994).

Materiais compósitos derivados de recursos naturais renováveis têm recebido um grande interesse nestes últimos anos, pois são uma alternativa sustentável ao uso de materiais fósseis e derivados de petróleo. Biocompósitos produzidos por meio do crescimento fúngico podem ser mais eficientes e rentáveis do que muitos processos sintéticos e orgânicos em virtude do rápido crescimento dos fungos, do seu alto nível de bioeficiência, e da sua capacidade de utilizar múltiplos nutrientes e fontes de recursos (BAYER et al., 2008).

Considerando que o bagaço de malte possui potencial para o cultivo de Pleurotus sajor-caju e que o micélio fúngico pode agir como ligante das partículas do resíduo foram desenvolvidos biocompósitos a partir do resíduo úmido de cervejaria (bagaço de malte), visando ampliar o aproveitamento e agregar valor aos resíduos da indústria cervejeira.

\section{Microrganismo e inóculo}

\section{MATERIAL E MÉTODOS}

A espécie de microrganismo utilizada foi Pleurotus sajor-caju, obtida da coleção de culturas de basidiomicetos do instituto de botânica (São Paulo/SP) sob o código ccb 019. O inóculo consiste em grãos de trigo colonizados com micélio de $P$. sajor-caju, $e$ foram produzidos conforme o método descrito por Bonatti et al. (2004).

\section{Preparo e inoculação dos substratos}

O substrato é composto pelo bagaço de malte in natura misturado com folhas de bananeira (1:1) previamente cortadas em forrageiro, secas em estufa a $60^{\circ} \mathrm{C}$ por $24 \mathrm{~h}$ e embaladas, separadamente, em saco de ráfia que foi imerso em água por $12 \mathrm{~h}$ e escorrido por, aproximadamente, $2 \mathrm{~h}$. Esta mistura foi adicionada de $5 \%$ de farelo de arroz em relação à massa seca, como fonte de nitrogênio, embalada na proporção $100 \mathrm{~g}$ de substrato (em relação à massa de substrato seco) por pacote de polipropileno $(28 \mathrm{x} 40 \mathrm{~cm})$ e esterilizados a 121 ${ }^{\circ} \mathrm{C}$ por $2 \mathrm{~h}$. A inoculação foi feita em câmara de fluxo laminar usando-se 10, 20 ou 30\% de inóculo de Pleurotus sajor-caju em relação à massa de substrato seco. Os pacotes foram incubados a $30^{\circ} \mathrm{C}$, na ausência de luz, até a completa colonização do substrato pelo micélio fúngico. Os substratos colonizados foram triturados em processador de alimentos até obter uma mistura homogênea. Em moldeiras plásticas cilíndricas $(6 \mathrm{~cm} \varnothing)$ os substratos processados foram introduzidos e compactados, assepticamente, até atingir $2,5 \mathrm{~cm}$ de altura para obter-se os corpos de prova (ABNT, 2016). Este procedimento foi realizado em câmara de fluxo laminar. As moldeiras foram fechadas e incubadas na ausência de luz, a $30^{\circ} \mathrm{C}$, até a completa colonização do substrato pelo micélio fúngico. Os corpos de provas foram pesados e secos em estufa com circulação forçada de ar, a temperatura de 40 ou $60^{\circ} \mathrm{C}$ até massa constante. A cada $24 \mathrm{~h}$, aproximadamente, foi realizada a pesagem dos corpos de prova para o acompanhamento da cinética de secagem e cálculo da velocidade de secagem para cada fração de inoculo em cada temperatura.

\section{Análises}

O teste de compressão foi realizado em equipamento EMIC de acordo com a NBR 8082 (ABNT, 2016). Os corpos de prova também foram submetidos à análise de absorção de umidade do ar, onde foram mantidos em temperatura ambiente com a umidade relativa do ar monitorada, durante 60 dias, com o intuito de verificar a contaminação visual por outros microrganismos. Os resultados obtidos foram analisados pelo teste estatístico para rejeição de valores desviantes (teste q de Dixon), sendo aceitos ou não (RORABACHER, 1991). Serão também submetidos à análise de variância dos valores médios das amostras, através do teste Tukey com nível de significância de $5 \%$ (ANOVA).

\section{RESULTADOS E DISCUSSÃO}

Os tempos de crescimento micelial e o tempo total de processo envolvido na produção dos corpos de prova do material biocompósito estão apresentados na Figura 1. O tempo de crescimento micelial, ou seja, o tempo necessário para a completa colonização dos pacotes foi 30, 28 e 12 dias para os percentuais de 10,20 e $30 \%$ de 
inóculo, respectivamente. Após o resíduo colonizado pelo micélio fúngico ter sido triturado e distribuído nos moldes, o tempo de colonização para restabelecimento das hifas no biocompósito variou de acordo com o percentual de inóculo, sendo o tempo total de crescimento 38, 34 e 16 dias para os percentuais de 10, 20 e $30 \%$ respectivamente.

A condição de $30 \%$ mostrou-se mais favorável em relação ao tempo de crescimento micelial e total dos corpos de prova, apresentando o menor tempo em relação às condições de 10 e $20 \%$ de inóculo.

Na Tabela 1 observa-se os teores de umidade dos corpos de prova antes da secagem e verifica-se que, na fração de inóculo de $30 \%$ o teor de umidade inicial foi maior, em torno de $66 \%$, em comparação com as outras frações analisadas. No entanto, este maior teor de umidade inicial não influenciou a velocidade inicial de secagem, que foi a mesma, cerca de $26 \mathrm{~g} /$ dia a $60{ }^{\circ} \mathrm{C}$ e em torno de $18 \mathrm{~g} /$ dia a $40{ }^{\circ} \mathrm{C}$, tanto para inóculo de $30 \%$ quanto para 20 e $10 \%$. Verifica-se, então, que os corpos de prova secos a $60^{\circ} \mathrm{C}$ obtiveram maior velocidade inicial de secagem, em relação aos corpos de prova secos a $40^{\circ} \mathrm{C}$. Uma maior velocidade de secagem é um parâmetro do processo que garante um menor tempo de secagem e consequentemente um menor tempo total de processo. Os corpos de prova secos a $60{ }^{\circ} \mathrm{C}$ levaram 2 dias para secarem enquanto que os corpos de prova secos a $40^{\circ} \mathrm{C}, 4$ dias.

Analisando-se os tempos de produção dos corpos de prova (Figura 1) e os tempos de secagem (Tabela 1) observa-se que a condição que utilizou $30 \%$ de inóculo e secagem a $60{ }^{\circ} \mathrm{C}$, apresentou um menor tempo total de produção dos corpos de prova (16 dias) e também um menor tempo de secagem ( 2 dias), resultando no menor tempo global de processo (18 dias).

Quando se analisou as tensões de compressão verificou-se que não houve diferença significativa entre as frações de inóculo utilizadas e entre as temperaturas de secagem, ficando este valor em torno de 0,016 MPa. Rocha (2018) ao avaliar os resíduos de guaraná e erva mate in natura na produção de biocompósitos observou uma resistência á compressão de 0,094 Mpa. Porém, quando a autora utilizou guaraná e erva mate residual, da produção de cogumelos, este valor foi superior (0,140 MPa).

Em relação a absorção da umidade do ar (\%) observou-se que em 60 dias de exposição todos os biocompósitos aumentaram o percentual de absorção e não houve nenhuma contaminação microbiana neste período. Verificou-se que os biocompósitos com $30 \%$ de inóculo, secos a 40 ou $60{ }^{\circ} \mathrm{C}$ foram os que menos absorveram umidade do ar. No entanto, ressalta-se que os biocompósitos produzidos com $30 \%$ de inóculo, por absorverem menor umidade, devem ter preferência na definição das condições de preparo destes biocompósitos.

\section{CONCLUSÃO}

Os biocompósitos com $30 \%$ de inóculo e secos a $60{ }^{\circ} \mathrm{C}$ foram os que apresentaram maior velocidade inicial de secagem levando a um menor tempo global de processo (18 dias), sendo definido então como a melhor condição para a produção de biocompósitos com substrato in natura de bagaço de malte e folhas de bananeira. Para trabalhos futuros serão testados outros substratos, como o bagaço de malte in natura sem adição de folhas de bananeira, e o substrato residual da produção de cogumelos em bagaço de malte in natura adicionado de folha de bananeira.

\section{AGRADECIMENTOS}

Os autores agradecem ao apoio financeiro dado pela CAPES e pela UNIVILLE. Agradecem também à empresa Opa Bier, pelo apoio para realização do trabalho.

\section{REFERÊNCIAS}

ABNT - Associação Brasileira de Normas Técnicas. NBR 8082: Espuma rígida de poliuretano para fins de isolação térmica - Determinação da resistência a compressão. Rio de Janeiro, 2016.

ASTM - American Society for Testing and Materials. D570-95: Standard Test Method for Water Absorption of Plastics. New York, 1998.

BAYER, E., MCLNTYRE, G., SWERSEY, B.L. Method for producing grown materials and products made thereby. In: World Intellectual Property Organization, WO 2008/073489 A2, 2008.

BONATO, S.V. Método para gestão de resíduos na cadeia cervejeira do Rio Grande do Sul. Tese de Doutorado do Programa de Pós-Graduação em Engenharia de Produção, na Universidade Federal do Rio Grande do Sul, p. 66, 2016.

BONATTI, M., KARNOPP, P., SOARES, H.M., FURLAN, S.A. Evaluation of Pleurotus ostreatus and Pleurotus sajor-caju nutritional characteridtics when cultivated in different lignocellulosic wastes. Food Chemistry, v. 88, p. 425-428, 2004. 
BRUST, L.A.C., ARAGÃO, A.P., BEZERRA JR, P.S., GALVÃO, A., FRANÇA, T.N., GRAÇA, F.A.S., PEIXOTO, P.V. Enfermidades em bovinos associados ao consumo de resíduos de cervejaria. Pesquisa Veterinária Brasil, v. 35, n.12, p. 956-964, dez, 2015.

CERVBRASIL. Associação Brasileira da indústria da cerveja. Anuário 2016. Disponível em: <http://www.cervbrasil.org.br>. Acesso em jun. 2018

EPAGRI. Empresa de Pesquisa Agropecuária e Extensão Rural de Santa Catarina - Epagri, 2015. Disponível em: <http://www.epagri.sc.gov.br/?page_id=1349>. Acesso em Mar. 2018.

MENDONÇA, L.M. Utilização do resíduo úmido de cervejaria na alimentação de cabras anglo nubiana em final de lactação. Dissertação de mestrado do Programa de Pós-Graduação e Estudos em recursos naturais, na Universidade Federal do Sergipe, p. 26, 2012.

ROCHA, M.I. Produção de biocompósitos de Pleurotus sajor-caju utilizando resíduos de erva-mate e guaraná. Disssertação de Mestrado do Programa de Pós-graduação em Engenharia de Processos, na Universidade da Região de Joinville - UNIVILLE, 86 p., 2018.

RORABACHER, D.B. Statistical treatment for rejection of deviant values: critical values of Dixon's "Q" parameter and related subrange rations at the 95\% confidence level. Analytical Chemistry, v.63, n.2, p.139146, 1991.

SCHULZ, J.G. Estudo da produção de Pleurotus sajor-caju em resíduo de cervejaria (bagaço de malte). Disssertação de Mestrado do Programa de Pós-Graduação em Engenharia de Processos, na Universidade da Região de Joinville - UNIVILLE, 76 p., 2016.

SOUZA, O.; FEDERIZZI, M.; COELHO, B.; WAGNER, T. M.; WISBECK, E. Biodegradação de resíduos lignocelulósicos gerados na bananicultura e sua valorização para a produção de biogás. Revista Brasileira de Engenharia Agrícola e Ambiental, v.14, p.438-443., 2010

STURION, G.L. (1994). Utilização da folha de bananeira como substrato para o cultivo de cogumelos comestiveis (Pleurotus spp.). Dissertação (Mestrado em Ciência dos Alimentos) - Universidade de São Paulo, Piracicaba, $147 \mathrm{p}$.

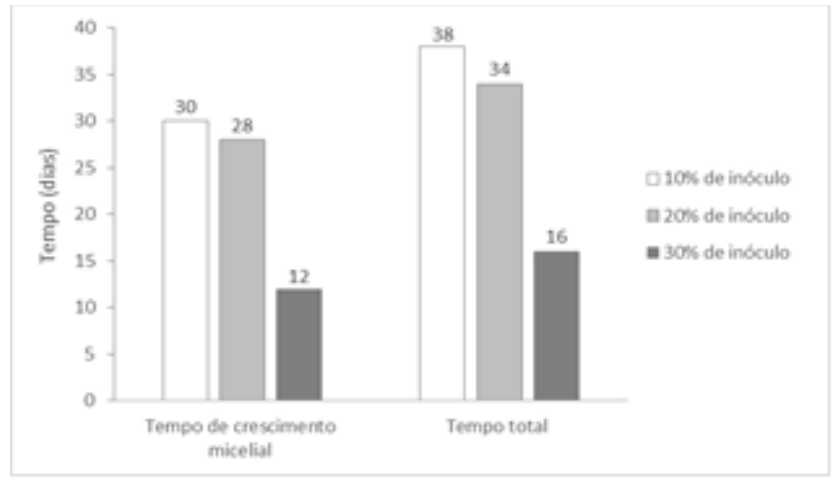

Figura 1. Tempo de crescimento micelial e tempo total do processo de produção dos corpos de prova do material biocompósito no substrato in natura com 10, 20 ou $30 \%$ de inóculo.

Tabela 1. Valores médios de teor de umidade inicial $\pm \mathrm{dp}(\%)$, velocidade inicial de secagem $\pm \mathrm{dp}(\mathrm{g} / \mathrm{dia})$ e tempo de secagem (dias) dos corpos de prova produzidos com 10, 20 e 30\% de inóculo no substrato in natura e secos a 40 e $60^{\circ} \mathrm{C}$. Letras iguais nas colunas, significam médias sem diferença significativa pelo teste de Tukey com nível de confiança de $95 \%$.

\begin{tabular}{ccccc}
\hline $\begin{array}{c}\text { Teor de inóculo } \\
(\boldsymbol{\%})\end{array}$ & $\begin{array}{c}\text { Temperatura de } \\
\text { secagem }\left(\mathbf{(}^{\mathbf{C}}\right)\end{array}$ & $\begin{array}{c}\text { Teor de umidade } \\
\text { inicial }(\boldsymbol{\%})\end{array}$ & $\begin{array}{c}\text { Velocidade inicial de } \\
\text { secagem }(\mathbf{g} / \mathbf{d i a})\end{array}$ & $\begin{array}{c}\text { Tempo de } \\
\text { secagem }(\mathbf{d i a s})\end{array}$ \\
\hline 10 & 40 & $59,88 \pm 1,34 a$ & $18,11 \pm 0,99 c$ & 4 \\
10 & 60 & $59,66 \pm 2,56 a$ & $25,99 \pm 1,59 d$ & 2 \\
20 & 40 & $58,27 \pm 2,30 a$ & $17,56 \pm 2,43 c$ & 4 \\
20 & 60 & $57,93 \pm 2,57 a$ & $24,44 \pm 2,49 d$ & 2 \\
30 & 40 & $66,54 \pm 0,67 b$ & $19,15 \pm 1,17 c$ & 4 \\
30 & 60 & $66,61 \pm 1,06 b$ & $26,68 \pm 1,25 d$ & 2 \\
\hline
\end{tabular}




\title{
PRODUCTION OF MAYENITE (Ca12Al $\left.{ }_{14} \mathrm{O}_{33}\right)$ USING EGGSHELL WASTE AS CALCIUM SOURCE
}

\author{
Manera, C.*1; Perondi, D. ${ }^{1}$; Didomenico, E. ${ }^{1}$; Barcellos, T. ${ }^{2}$; Godinho, M. ${ }^{1}$ \\ ${ }^{1}$ University of Caxias do Sul, Graduate Program in Engineering Processes and Technologies, Caxias do Sul, RS - Brasil \\ ${ }^{2}$ University of Caxias do Sul, Graduate Program in Biotechnology, Caxias do Sul, RS - Brasil \\ *cmaneral@ucs.br
}

\begin{abstract}
In recent studies, mayenite was found to have a superior performance for catalyst support for tar reforming when compared with the supports commonly used. The objective of this work was to evaluate the use of eggshell as calcium source for mayenite production by means of its textural properties and phase identification. Mayenite was produced by solid-state reaction with partial and total substitution of the calcium by calcined eggshells. Mayenite was also produced using eggshells without calcination. The results showed that mayenite was successfully synthesized by ultrasound method using calcined eggshell as calcium source and no noticeable change in the XRD pattern and textural properties was observed in relation to the mayenite produced with commercial $\mathrm{Ca}(\mathrm{OH})_{2}$. Eggshells without calcination were not suitable due to the low conversion to mayenite. The use of eggshells as a raw material for mayenite synthesis can be considered as an alternative to increase the value of eggshell waste.
\end{abstract}

Keywords: solid-state reaction, calcium aluminates, catalyst support, waste management.

\section{INTRODUCTION}

The use of biomass as a renewable energy is getting increased attention due to its abundance and low cost (LI; HIRABAYASHI; SUZUKI, 2009a). Among the possible processes using biomass as an energy source, gasification has attracted special attention because it allows to produce a gas utilizable for different applications (SAVUTO et al., 2017). However, gas from gasification processes usually has unacceptable levels of tars, which can cause operational problems in downstream processes (LI; HIRABAYASHI; SUZUKI, 2009b).

As the catalytic cracking of tar has proven to be the best alternative, the research should be focused on finding an effective catalyst for tar reforming (SAVUTO et al., 2017). Compared to the most common materials, mayenite $\left(\mathrm{Ca}_{12} \mathrm{Al}_{14} \mathrm{O}_{33}\right)$ as a catalyst support was found to have a better performance due to its special free oxygen restored property (LI; HIRABAYASHI; SUZUKI, 2009a), and thus showing an excellent resistance against coke formation and sulfur poisoning.

According to the Brazilian Animal Protein Association (ABPA) (2018), Brazil had a production of 39,9 billion of eggs in 2017 and 99,7\% of the total production was used to attain the internal demand of the country. Besides a major ingredient in products such as cakes, pasta and fast foods (WITOON, 2011), eggs represent an important source of calcium. Eggshells are composed of $96 \% \mathrm{CaCO}_{3}, 1 \% \mathrm{MgCO}_{3}, 1 \% \mathrm{Ca}_{3}\left(\mathrm{PO}_{4}\right)_{2}$, organic substances and water (OLIVEIRA; BENELLI; AMANTE, 2013). According to Stadelman (2003), eggshell represents $10 \%$ of the total mass of hen egg, that weighs about $60 \mathrm{~g}$. Thus, in Brazil for example, about 240.000 tonnes of eggshell waste were generated in 2017. Therefore, the application of eggshell as a raw material for value-added products has become the object of several studies (WEI; XU; LI, 2009).

The objective of this work was to evaluate the partial and total substitution of the calcium used for mayenite production by eggshell. Evaluation of the materials was carried out by means of its textural properties and phase identification.

\section{MATERIAL AND METHODS}

The hen eggs were obtained at a local market in Caxias do Sul. Analytical grade reagents $\mathrm{Ca}(\mathrm{OH})_{2}$ (purity > 95\%) and $\mathrm{Al}(\mathrm{OH})_{3}$ (purest) were bought from Cinética Reagents \& Solutions.

Firstly, eggshells were washed in tap water to remove impurities. Eggshells were kept in acetone for 15 min, washed again and dried overnight at $120^{\circ} \mathrm{C}$. Calcination was performed in a muffle furnace at $900{ }^{\circ} \mathrm{C}$ for $4 \mathrm{~h}$ under static air atmosphere. The calcination product was a CaO-rich solid. 
The reagents were mixed in stoichiometric $\mathrm{Ca} / \mathrm{Al}$ molar ratio (6/7) to a total mass of $20 \mathrm{~g}$. Mayenite was produced with calcium from eggshell in the molar proportion of 0 (only commercial $\left.\mathrm{Ca}(\mathrm{OH})_{2}\right), 25,50,75$ and $100 \%$ (only calcined eggshells). Samples were named M-CES000, M-CES025, M-CES050, M-CES075 and M-CES100, respectively. Mayenite was also produced using only eggshell without calcination as calcium source. This sample was named M-ES100.

The mixture of reagents was added to $200 \mathrm{~mL}$ of Mili-Q water in a beaker and the suspension was treated using an ultrasound probe (Sonics, VCX500 model) with power of $200 \mathrm{~W}$ during $10 \mathrm{~min}$. The obtained solids were vacuum filtered and dried at $120^{\circ} \mathrm{C}$ overnight. After the procedure, samples were calcined at 1000 ${ }^{\circ} \mathrm{C}$ in air for $4 \mathrm{~h}$. Final temperature was reached with a heating rate of $30{ }^{\circ} \mathrm{C} \mathrm{min}^{-1}$.

\section{Characterization}

Samples were characterized by phase identification and textural properties. Samples were investigated by X-ray powder diffraction (XRD) analysis (Shimadzu X-ray diffractometer, XRD 6000) using CuK $\alpha$ radiation in the $2 \theta$ range of $5-75^{\circ}$, resolution of $0,05^{\circ}$ and integration time of $3 \mathrm{~s}$. Phase identification was performed by comparison with COD (Crystallography Open Database) files. Specific surface area, total pore volume and average pore size of the materials were evaluated by $\mathrm{N}_{2}$ adsorption at $77 \mathrm{~K}$ in a Surface Area and Pore Size Analyzer (Quantachrome, Nova 1200). Prior to analysis, samples were outgassed under vacuum at $380{ }^{\circ} \mathrm{C}$ for $20 \mathrm{~h}$. Specific surface area was calculated by 11-points BET method.

\section{RESULTS AND DISCUSSION}

X-ray diffraction patterns in Figure 1 show effectiveness of ultrasound method in the production of mayenite. Regarding the samples produced with calcined eggshells, no noticeable change in the XRD pattern was observed in relation to the mayenite produced with commercial $\mathrm{Ca}(\mathrm{OH})_{2}$, not even with the total replacement of calcium source by the calcined eggshells. Therefore, the other compounds present in the eggshell in smaller quantities had no effects in the formation of calcium aluminate phases, including mayenite. Besides mayenite, traces of other calcium aluminate phases were observed in the diffractogram. $\mathrm{Ca}_{3} \mathrm{Al}_{2} \mathrm{O}_{6}$ and $\mathrm{CaAl}_{2} \mathrm{O}_{4}$ are neighboring phases of the mayenite according to the phase diagram of $\mathrm{CaO}-\mathrm{Al}_{2} \mathrm{O}_{3}$ system. $\mathrm{Ca}_{3} \mathrm{Al}_{2} \mathrm{O}_{6}$ is in equilibrium with mayenite for a $\mathrm{Ca} / \mathrm{Al}$ molar ratio between $3 / 2$ and $6 / 7(\mathrm{Ca} / \mathrm{Al}$ ratio of mayenite) and $\mathrm{CaAl}_{2} \mathrm{O}_{4}$ is in equilibrium with mayenite for a Ca/Al molar ratio between $6 / 7$ and $1 / 2$. Furthermore, these phases are also intermediate in the formation of the mayenite according to the reaction represented by Equation 1.

$$
5 \mathrm{Ca}_{3} \mathrm{Al}_{2} \mathrm{O}_{6}+9 \mathrm{CaAl}_{2} \mathrm{O}_{4} \leftrightharpoons 2 \mathrm{Ca}_{12} \mathrm{Al}_{14} \mathrm{O}_{33} \quad \text { (Equation 1) }
$$

$\mathrm{Ca}_{3} \mathrm{Al}_{2} \mathrm{O}_{6}$ and $\mathrm{CaAl}_{2} \mathrm{O}_{4}$ were also found as spurious phases in mayenite produced by sol-gel method (CUCCINIELLO et al., 2013), hydrothermal method (CUCCINIELLO et al., 2017) and co-precipitation method (WILLIAMSON; GLASSER, 1962).

Mayenite production was also observed in the sample with the substitution of the calcium hydroxide by eggshells without calcination. Calcium carbonate present in eggshells was completely decomposed thermally in the synthesis, since its peaks were not present in the synthesized material. However, the small intensity of the peaks related to the mayenite suggests a lower content of mayenite in the sample. Furthermore, in addition to the impurities previously observed, another two phases were also observed (i.e. $\mathrm{CaAl}_{4} \mathrm{O}_{7}$ and $\mathrm{CaO}$ ). Therefore, eggshells without calcination are not suitable for the production of mayenite by the proposed method.

Textural properties of mayenite samples are presented in Table 1. Mayenite samples synthesized with calcined eggshells presented similar textural properties to the mayenite synthesized with commercial $\mathrm{Ca}(\mathrm{OH})_{2}$. The slightly lower surface area obtained should be associated to the slightly lower porosity of the material observed by the lower total pore volume. The higher pore volume presented by the sample produced from eggshell without thermal treatment (M-ES100) can be associated with the release of $\mathrm{CO}_{2}$ during the synthesis. The porosity may have hampered the formation of mayenite by solid-state reaction, and thus several other phases were observed as impurities. 


\section{CONCLUSION}

Mayenite $\left(\mathrm{C}_{12} \mathrm{Al}_{14} \mathrm{O}_{33}\right)$ was successfully synthesized by ultrasound method using eggshell as calcium source. Besides the formation of mayenite, other phases (i.e. $\mathrm{CaO}, \mathrm{CaAl}_{4} \mathrm{O}_{7}$ ) were present in the synthesized sample. No differences were found between mayenite samples produced from calcined eggshells and commercial calcium hydroxide. Use of eggshells without previous thermal treatment was not suitable for the production of mayenite. Finally, the use of eggshells as a raw material for mayenite synthesis can be considered as an alternative to increase the value of eggshells waste.

\section{ACKNOWLEDGMENTS}

The authors would like to thank the Higher Education Personnel Improvement Coordination (CAPES) [147439/2017] for financial support.

\section{REFERENCES}

ASSOCIAÇÃO BRASILEIRA DE PROTEÍNA ANIMAL. Relatório Anual 2017. Available in: <http://www.abpa-br.com.br/storage/files/relatorio-anual-2018.pdf>. Access in: 10 november 2018. CUCCINIELLO, R.; INTISO, A.; CASTIGLIONE, S.; GENGA, A.; PROTO, A.; ROSSI, F. Total oxidation of trichloroethylene over mayenite $\left(\mathrm{Ca}_{12} \mathrm{Al}_{14} \mathrm{O}_{33}\right)$ catalyst. Applied Catalysis B: Environmental, v. 204, p. 167-172, 2017.

CUCCINIELLO, R.; PROTO, A.; ROSSI, F.; MOTTA, O. Mayenite based supports for atmospheric NOx sampling. Atmospheric Environment, v. 79, p. 666-671, 2013.

LI, C.; HIRABAYASHI, D.; SUZUKI, K. A crucial role of $\mathrm{O}_{2}{ }^{-}$and $\mathrm{O}_{2}{ }^{2-}$ on mayenite structure for biomass tar steam reforming over $\mathrm{Ni} / \mathrm{Ca}_{12} \mathrm{Al}_{14} \mathrm{O}_{33}$. Applied Catalysis B: Environmental, v. 88, n. 3-4, p. 351-360, 2009a.

. Development of new nickel based catalyst for biomass tar steam reforming producing $\mathrm{H}_{2}$-rich syngas. Fuel Processing Technology, v. 90, n. 6, p. 790-796, 2009b.

OLIVEIRA, D. A.; BENELLI, P.; AMANTE, E. R. A literature review on adding value to solid residues: eggshells. Journal of Cleaner Production, v. 46, p. 42-47, 2013.

SAVUTO, E.; DI CARLO, A.; GALLUCCI, K.; NATALI, S.; BOCCI, E. Characterization and performance analysis of an innovative Ni/Mayenite catalyst for the steam reforming of raw syngas. Fuel, v. 194, p. 348356, 2017.

STADELMAN, W. J. Eggs - Structure and Composition. Encyclopedia of Food Sciences and Nutrition. 2. ed. Oxford: Academic Press, 2003. p. 2005-2009.

WEI, Z.; XU, C.; LI, B. Application of waste eggshell as low-cost solid catalyst for biodiesel production. Bioresource Technology, v. 100, n. 11, p. 2883-2885, 2009.

WILLIAMSON, J.; GLASSER, F. P. Reactions in heated lime-alumina mixtures. Journal of Applied Chemistry, v. 12, n. 12, p. 535-538, 1962.

WITOON, T. Characterization of calcium oxide derived from waste eggshell and its application as $\mathrm{CO}_{2}$ sorbent. Ceramics International, v. 37, n. 8, p. 3291-3298, 2011.

Table 1. Textural properties of mayenite produced with eggshell.

\begin{tabular}{lcccccc}
\hline Sample & $\begin{array}{c}\text { M- } \\
\text { CES000 }\end{array}$ & $\begin{array}{c}\text { M- } \\
\text { CES100 }\end{array}$ & $\begin{array}{c}\text { M- } \\
\text { CES075 }\end{array}$ & $\begin{array}{c}\text { M- } \\
\text { CES050 }\end{array}$ & $\begin{array}{c}\text { M- } \\
\text { CES025 }\end{array}$ & M-ES100 \\
\hline Surface area BET $\left(\mathrm{m}^{2} \mathrm{~g}^{-1}\right)$ & 2,76 & 1,74 & 1,74 & 1,59 & 1,84 & 2,15 \\
Total pore volume $\left(\mathrm{cm}^{3} \mathrm{~g}^{-1}\right)$ & 0,0039 & 0,0027 & 0,0027 & 0,0025 & 0,0026 & 0,0068 \\
Average pore size $(\mathrm{nm})$ & 5,59 & 6,09 & 6,31 & 6,30 & 5,54 & 12,59 \\
\hline
\end{tabular}




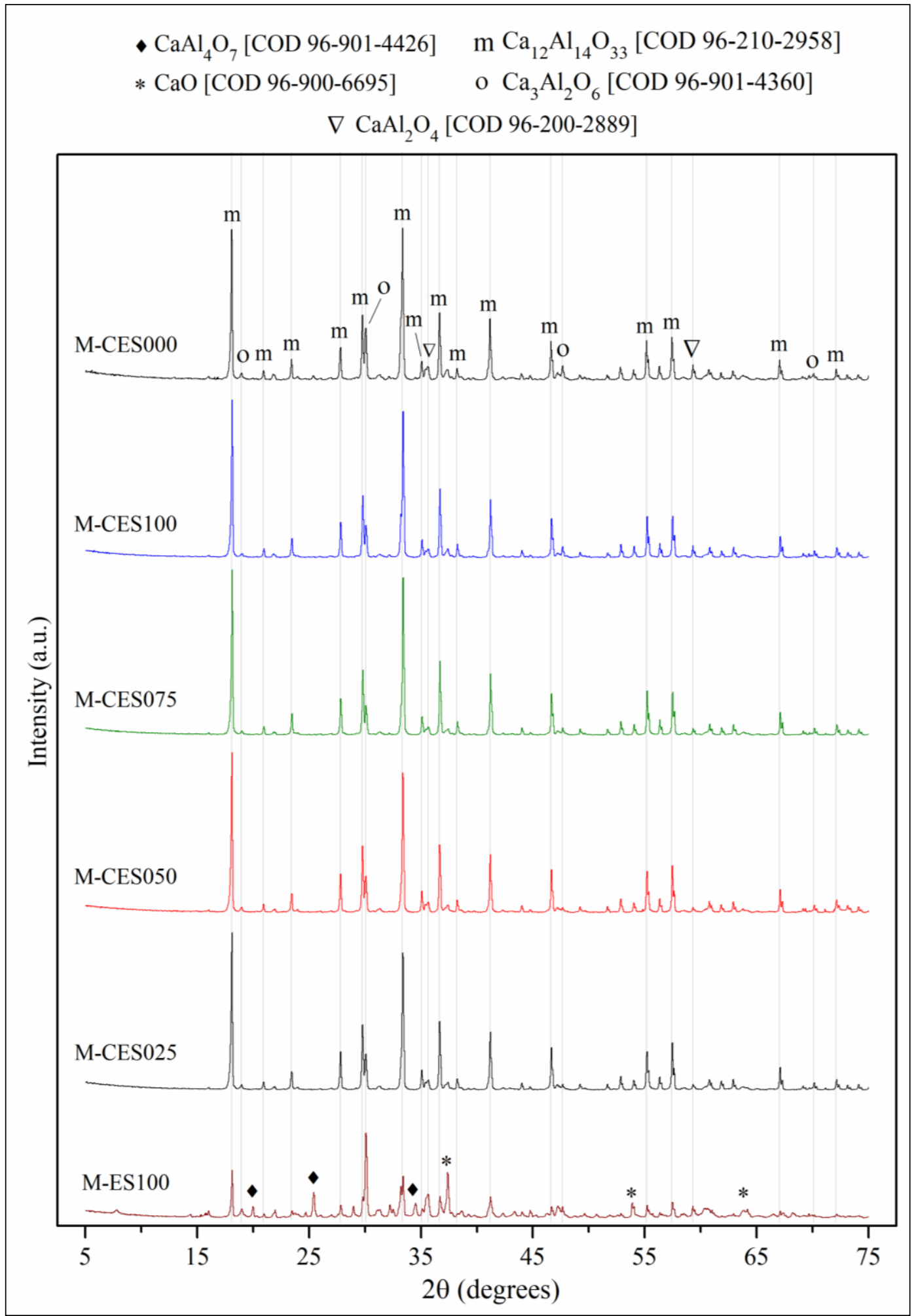

Figure 1. XRD patterns of mayenite produced with eggshell. 


\title{
PRODUÇÃO DE SULFETO BIOGÊNICO PARA TRATAMENTO DE EFLUENTES RICOS EM METAIS
}

\author{
Rodrigues, M.H.R. ${ }^{1}$; Mermejo, B.; dos Santos, D.V; Fonseca, B.C; Reginatto, V. \\ ${ }^{1}$ Faculdade de Filosofia, Ciências e Letras de Ribeirão Preto - Universidade de São Paulo, 14040-901 - Ribeirão Preto - SP, Brasil \\ valeriars@ffclrp.usp.br
}

RESUMO: $\mathrm{O}$ sulfato $\left(\mathrm{SO}_{4}{ }^{2-}\right)$ é um dos íons mais comumente encontrados nos resíduos industriais. Existem processos químicos e biológicos que podem ser utilizados para tratar resíduos ricos em sulfato e assim diminuir os impactos que esses compostos podem causar no meio ambiente. As bactérias redutoras de sulfato (BRS) removem os íons $\mathrm{SO}_{4}{ }^{2-}$ do meio convertendo-os em sulfeto $\left(\mathrm{S}^{2-}\right)$, principalmente, o sulfeto de hidrogênio $\left(\mathrm{H}_{2} \mathrm{~S}\right)$. O sulfeto de hidrogênio gerado pode ser utilizado para reduzir alguns metais que são tóxicos e precipitá-los. Dessa maneira, este trabalho teve por finalidade avaliar a redução de sulfato por BRS presentes em uma cultura mista coletada de um reator anaeróbio utilizado no tratamento de vinhaça. Um biorreator de 1,0 L de volume útil foi alimentado diariamente com meio sintético contendo sulfato, lactato e minerais com tempo de detenção hidráulica (TDH) de 2,2 dias. A redução de sulfato foi em torno de $55 \%$. Este efluente rico em sulfetos será utilizado na precipitação de metais presentes em efluentes gerados em laboratório de ensino de química.

Palavras-chave: bactérias redutoras de sulfato, BRS, sulfeto de hidrogênio, metais.

\section{BIOGENIC SULPHIDE PRODUCTION FOR THE TREATMENT OF METALS RICH EFFLUENTS}

\begin{abstract}
Sulphate $\left(\mathrm{SO}_{4}{ }^{2-}\right)$ is one of the most commonly ions found in industrial wastewaters. There are chemical and biological processes that can be used to treat sulfur-rich wastewater and thus reduce the impact of this compound to the environment. Sulphate reducing bacteria (SRB) reduce $\mathrm{SO}_{4}{ }^{2-}$ ions by converting them to sulphide $\left(\mathrm{S}^{2-}\right)$, mainly as hydrogen sulphide $\left(\mathrm{H}_{2} \mathrm{~S}\right)$. The hydrogen sulfide can be further employed to reduce some metals that are toxic. The objective of this work was to evaluate the sulfide production by sulfate reducing bacteria (BRS) present in mixed culture collected from an anaerobic reactor used in the treatment of vinasse. A 1.0 L bioreactor of useful volume was fed daily with synthetic medium containing sulfate and lactate and minerals with hydraulic detention time (TDH) of 2.2 days. The sulphate reduction was around $55 \%$. This sulphide rich effluent will be used in the precipitation of metals present in chemical laboratory effluents.
\end{abstract}

Keywords: sulfate reducing bacteria, BRS, hydrogen sulphide, lactate, residues.

\section{INTRODUÇÃO}

Os íons sulfato $\left(\mathrm{SO}_{4}{ }^{2-}\right)$ são comumente encontrados em resíduos industriais, como por exemplo, da indústria de refino do petróleo. Um dos problemas ambientais é devido a associação de $\mathrm{SO}_{4}{ }^{2-}$ com metais pesados que são provenientes, por exemplo, das drenagens ácidas de mina (Groudev et al., 2008). Existem processos químicos e biológicos que podem ser utilizados para tratar esses resíduos e assim diminuir os impactos que esses compostos podem causar no meio ambiente. Um desses tratamentos é baseado na utilização de bactérias redutoras de sulfato (BRS) que removem os íons $\mathrm{SO}_{4}{ }^{2-}$ do meio convertendo-os em sulfeto $\left(\mathrm{S}^{2-}\right)$, principalmente, como sulfeto de hidrogênio $\left(\mathrm{H}_{2} \mathrm{~S}\right)$ (Berner, 1974). As BRS são facilmente identificadas pela presença de precipitado preto, que é decorrente da formação de sulfeto de ferro, e também devido ao cheiro característico devido ao $\mathrm{H}_{2} \mathrm{~S}$ (Postgate et al., 1984). Vários estudos baseados nesse princípio foram realizados e esta técnica é considerada uma alternativa eficiente e economicamente viável. Em função do metabolismo das BRS, durante a respiração anaeróbia, o sulfato irá atuar como receptor final de elétrons - agente oxidante, sendo, portanto, reduzido enquanto a matéria orgânica presente no meio será oxidada (Postgate, 1984). 
As melhores condições para ação das BRS são pH próximo ao neutro (moderadamente alcalino) e temperatura na faixa de $28-38{ }^{\circ} \mathrm{C}$, além do ambiente redutor (Madigan et al., 2004). Existem compostos que são adicionados ao meio reacional para que o potencial necessário de oxi-redução do ambiente seja atingido, como por exemplo, o tioglicolato de sódio. Entretanto, o próprio sulfeto de hidrogênio produzido pelo metabolismo das BRS é capaz de fazer com que esse valor seja atingido. Outra vantagem das BRS é que estas são capazes utilizar vários substratos como doador de elétrons, por exemplo, lactato, metanol, piruvato, demonstrando o seu potencial também no tratamento de resíduos com material orgânico (Gibson, 1990). A importância ambiental e biotecnológica deste tipo de tratamento para resíduos ricos em sulfatos é que o sulfeto de hidrogênio gerado pode ser utilizado para reduzir alguns metais que são tóxicos de forma controlada (Kiran et al. 2017). Dessa maneira, este trabalho teve por finalidade avaliar a produção de sulfeto biogênico por bactérias redutoras de sulfato (BRS) provenientes de cultura mista, em reator anaeróbio.

\section{MATERIAL E MÉTODOS}

O biorreator possui 2 litros de capacidade, no qual foi adicionado $1000 \mathrm{~mL}$ de lodo proveniente de tratamento anaeróbio de vinhaça de cana de açúcar, contendo $1,0417 \mathrm{~g} / \mathrm{L}$ de sólidos totais (ST). Ao biorreator foi adicionado meio Postgate (1984) modificado de modo que o volume útil foi de 1 litro. O meio é composto por $\mathrm{K}_{2} \mathrm{HPO} 40,5 \mathrm{~g} \mathrm{~L}^{-1}, \mathrm{NH}_{4} \mathrm{CL} 1,0 \mathrm{~g} \mathrm{~L}^{-1}, \mathrm{Na}_{2} \mathrm{SO}_{4} 1,0 \mathrm{~g} \mathrm{~L}^{-1}, \mathrm{CaCl}_{2} .2 \mathrm{H}_{2} \mathrm{O} 0,1 \mathrm{~g} \mathrm{~L}^{-1}, \mathrm{MgSO}_{4} .7 \mathrm{H}_{2} \mathrm{O} 2,0 \mathrm{~g} \mathrm{~L}^{-1}$, NaDL-lactato $2,0 \mathrm{~g} \mathrm{~L}^{-1}$, extrato de levedura $1,0 \mathrm{~g} \mathrm{~L}^{-1}$, Na-resazurina $(0,1 \% \mathrm{~m} / \mathrm{v})$ 0,5 mL, $\mathrm{FeSO}_{4} .7 \mathrm{H}_{2} \mathrm{O} 0,5 \mathrm{~g} \mathrm{~L}^{-1}$. A modificação do meio foi a ausência de tioglicolato de sódio e ácido ascórbico $\mathrm{O}$ reator foi montado com uma camisa externa de modo que a temperatura de $34^{\circ} \mathrm{C}$ foi controlada por banho térmico. A saída do reator estava submersa para evitar a entrada de oxigênio. $O$ sistema foi mantido sob agitação constante exceto na retirada de alíquotas para análise e na alimentação do mesmo. Diariamente foi retirado $450 \mathrm{~mL}$ do meio do reator para a determinação de $\mathrm{pH}$ e de sulfato, sendo imediatamente alimentado com o mesmo volume de meio. Para avaliação do consumo de sulfato pelas BRS, foi realizada a quantificação de sulfato através de análise turbidimétrica com realização prévia da curva de padrão de $\mathrm{Na}_{2} \mathrm{SO}_{4}$ nas mesmas condições de análise, porém, com concentrações conhecidas de $\mathrm{SO}_{4}{ }^{2-}$. Nesta análise fez-se uso do reagente gelatina $\mathrm{BaCl}_{2}$ de forma que em solução aquosa e na presença dos íons $\mathrm{SO}_{4}{ }^{2-}$ forma-se o precipitado sulfato de bário $\left(\mathrm{BaSO}_{4}\right)$ que é insolúvel tornando turva a solução mediante a agitação. Portanto, as partículas de sulfato de bário presentes no meio reacional das amostras estariam suspensas e, como sua formação é dependente diretamente da concentração de íons $\mathrm{SO}_{4}{ }^{2-}$ presentes, pode-se quantificar as amostras. Dessa forma, a reação que descreve a formação deste precipitado é dada por:

$$
\mathrm{SO}_{4}{ }^{2-}{ }_{(\mathrm{aq})}+\mathrm{BA}^{2+}{ }_{(\mathrm{aq})} \rightarrow \mathrm{BASO}_{4(\mathrm{~s})}
$$

[Equação 1]

\section{RESULTADOS E DISCUSSÃO}

Após 11 dias de alimentação diária do biorreator foi iniciado o monitoramento do $\mathrm{pH}$ e do consumo de sulfato. Em relação à variação de $\mathrm{pH}$, as amostras do meio de cultura adicionado ao reator apresentaram pequena oscilação $\left(\mathrm{pH}_{\text {MÍ́NIMO }}=6,81\right.$ e $\left.\mathrm{pH}_{\text {MÁXIMO }}=7,04\right)$, que pode ser atribuída ao próprio preparo do meio de cultura. Em relação aos valores de $\mathrm{pH}$ determinados nas amostras de sobrenadante do meio de cultivo houve também pequena oscilação $\left(\mathrm{pH}_{\text {MíNIMO }}=7,99\right.$ e $\left.\mathrm{pH}_{\text {MÁXIMO }}=8,16\right)$. Comparando os valores do meio de cultura com os do sobrendante é possível propor que o pequeno aumento de $\mathrm{pH}$ deve-se a presença de bicarbonato que pode ser gerado devido a degradação do lactato. Dessa forma, de acordo com Gibson (1990) o lactato pode seguir as seguintes vias de oxidação:

$$
\begin{aligned}
2 \mathrm{CH}_{3} \mathrm{CHOHCOO}^{-}+\mathrm{SO}_{4}{ }^{2-} \rightarrow 2 \mathrm{CH}_{3} \mathrm{CHOO}^{-}+2 \mathrm{HCO}_{3}+\mathrm{HS}^{-}+\mathrm{H}^{+} & \\
\Delta \mathrm{G}^{0 \prime} & =-160 \mathrm{~kJ} \mathrm{~mol}^{-1} \text { sulfato } \\
2 \mathrm{CH}_{3} \mathrm{CHOHCOO}^{-}+3 \mathrm{SO}_{4}{ }^{2-} \rightarrow 6 \mathrm{HCO}_{3}+3 \mathrm{HS}^{-}+\mathrm{H}^{+} & \\
\Delta \mathrm{G}^{0 \prime} & =-85 \mathrm{~kJ} \mathrm{~mol}^{-1} \text { sulfato }
\end{aligned}
$$


Decorridos 28 dias de funcionamento do sistema, foi realizada a quantificação de sulfato. A quantidade de sulfato determinada nas amostras do meio de cultura foi $1,9 \mathrm{~g} \mathrm{~L}^{-1}( \pm 0,02)$. A essa variação em relação à quantidade teórica de sulfato que deveria estar presente no meio de cultura, atribui-se a preparação do meio de cultura que era realizada semanalmente (Figura 1).

Para as amostras do efluente, foi possível observar que na primeira amostra coletada o consumo de sulfato foi menor que nas demais (Figura 2). Este fato pode ser explicado devido ao período de adaptação das BRS ao meio. Nas demais alíquotas analisadas o consumo foi aumentando chegando em torno de $1,2 \mathrm{~g} \mathrm{~L}^{-1} \mathrm{de}$ sulfato. Posteriormente, o consumo do sulfato permaneceu constante e cerca de 1,0 $\mathrm{g} \mathrm{L}^{-1}$. Em média, $55 \%$ $\left(1,05 \pm 0,09 \mathrm{~g} \mathrm{~L}^{-1}\right)$ do sulfato foi consumido pelas BRS com base nas coletas realizadas até o momento.

\section{CONCLUSÃO}

A cultura mista utilizada no reator são capazes de reduzir o sulfato presente no meio reacional utilizando lactato na proporção de 1:2,5 sulfato:lactato. Em decorrência dos resultados obtidos, pretende-se para as próximas análises dobrar a quantidade de lactato presente no meio de cultura para aumentar a concentração de sulfeto no efluente e utilizá-lo no tratamento de águas residuárias contendo metais.

\section{AGRADECIMENTOS}

O presente trabalho foi realizado com apoio da Coordenação de Aperfeiçoamento de Pessoal de Nível Superior - Brasil (CAPES) - Código de Financiamento 001. Rodrigues M.H.R recebeu bolsa do Programa Unificado de bolsas - PUB da Pró-Reitoria de Graduação da Universidade de São Paulo - USP.

\section{REFERÊNCIAS}

BERNER, R.A. Kinetic models for the early diagenesis of nitrogen, sulfur, phosphorus and silicon in anoxic marine sediments. The Sea-ldeas and Observations on the Progress in the Study of Seas ed. Goldberg, e.d. Pp. 427-450. New York: interscience, 1974.

GIBSON, G. R. Physiology and ecology of the sulfate-reducing bacteria. Journal of Applied Bacteriology, v. 69 , n. 6, p. 769-797, 1990.

GROUDEV, S. et al. Bioremediation of acid mine drainage in a uranium deposit. Hydrometallurgy, v. 94, p.93-99, 2008.

KIRAN, G.M. An overview of sulfidogenic biological reactors for the simultaneous treatment of sulfate and heavy metal rich wastewater. Chemical engineering science 158 (2017) 606-620.

MADIGAN, M.T. et al. Microbiologia de brock. São Paulo, Prentice hall, 2004.

POSTGATE, J.R. et al. The genomes of Desulfovibrio gigas and Desulfovibrio vulgaris. Journal of general microbiology, v. 130, p. 1597-1601, 1984.

POSTGATE, J.R. The sulphate reducing bacteria 2nd. Edition. Cambridge university press, 1984. 


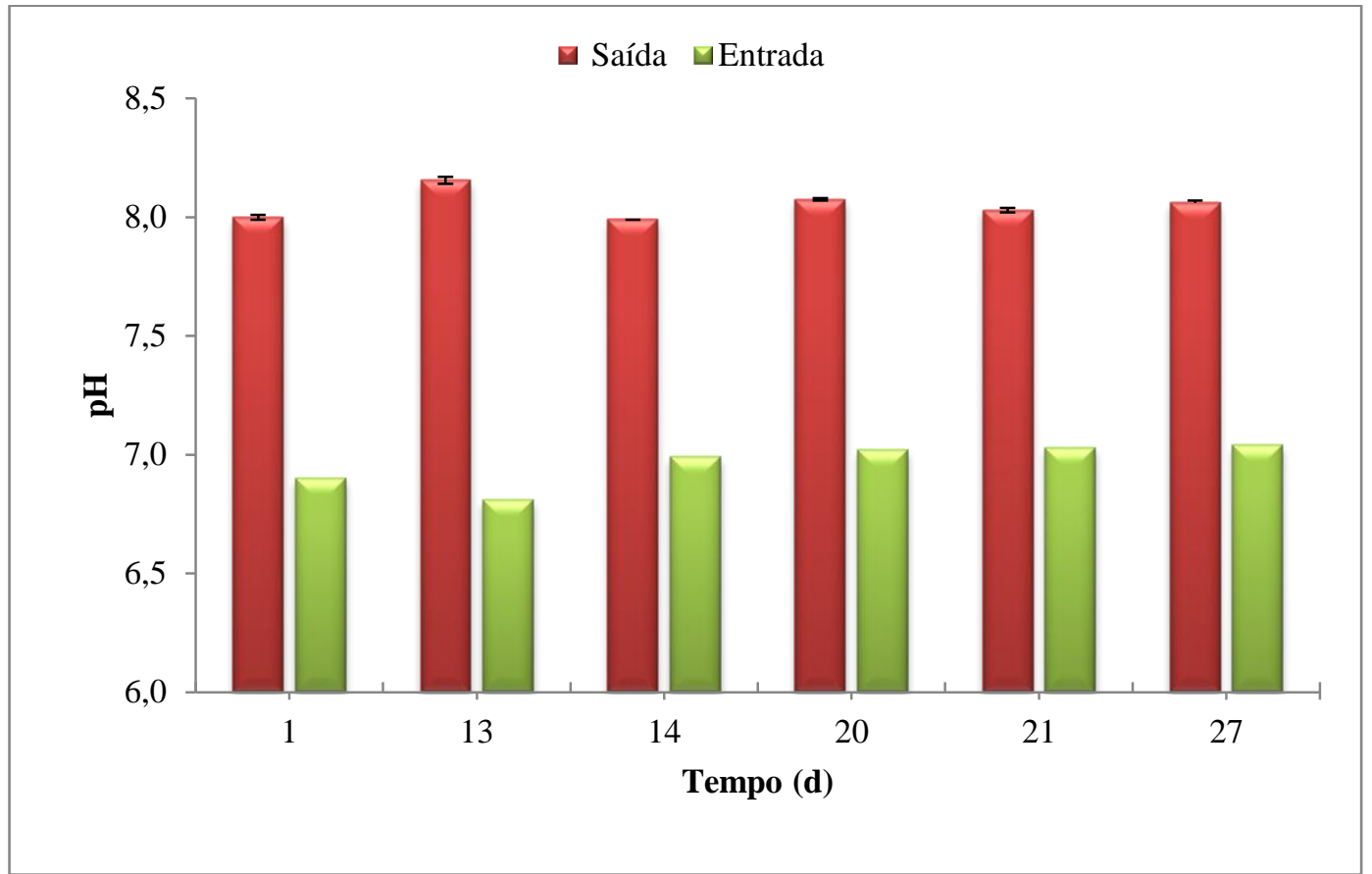

Figura 1. pH na saída (efluente) e na entrada (meio de cultura) do biorreator ao longo do tempo (d).

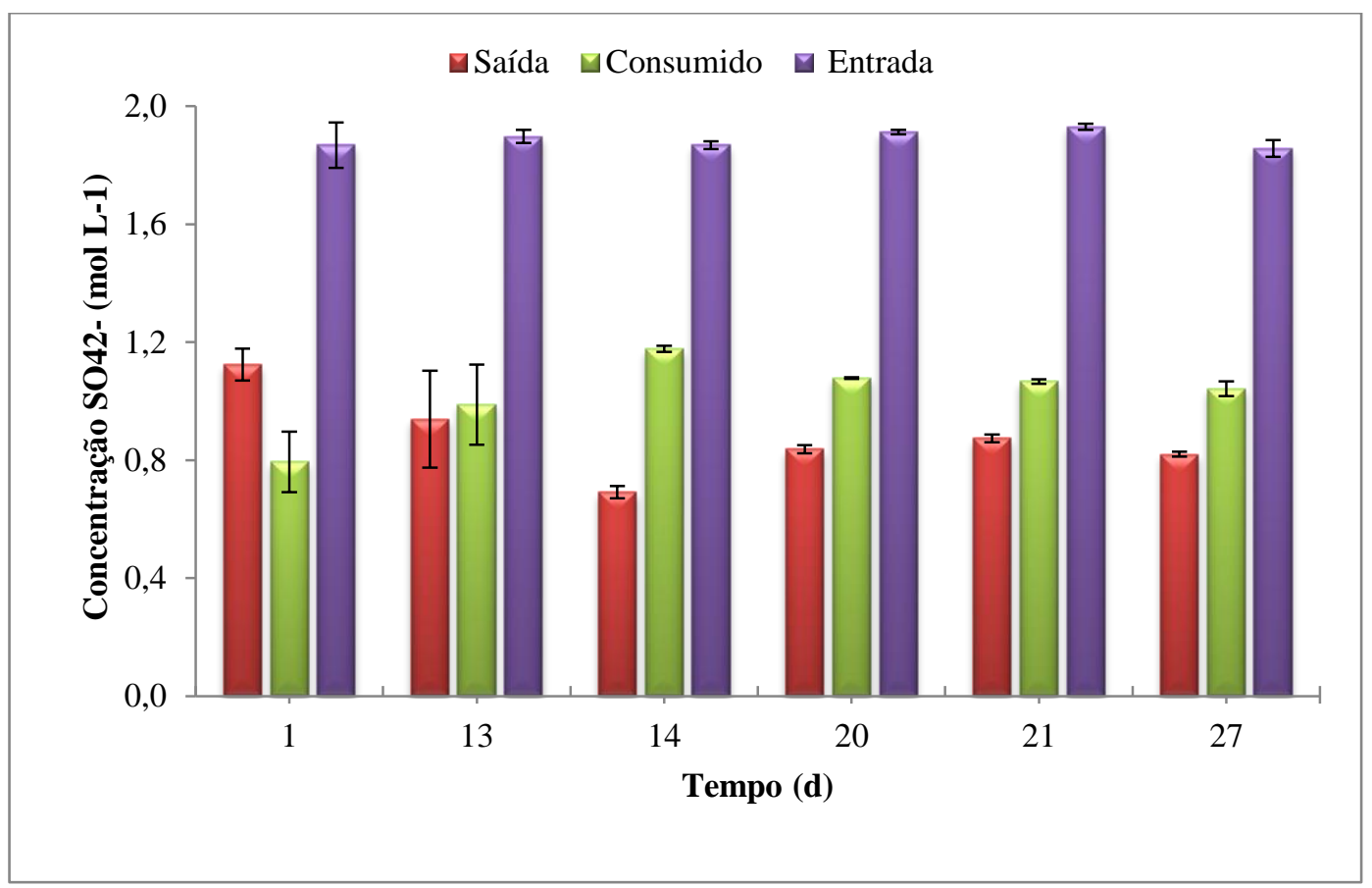

Figura 2. Concentração de sulfato $\left(\mathrm{mol} \mathrm{L}^{-1}\right)$ na saída (efluente), na entrada (meio de cultura) e consumida ao longo do tempo de operação do biorreator. 


\title{
REMOÇÃO DE CARBONO E NITROGÊNIO DA VINHAÇA POR DESMODESMUS SUBSPICATUS IMOBILIZADAS EM PECTINA
}

\author{
Jesus, G.C. ${ }^{\text {; }}$ Visentin, T.G. ${ }^{1}$; Bastos, R.G. ${ }^{1}$, Silva, M.A.*1 \\ ${ }^{1}$ Universidade Federal de São Carlos, Araras, SP - Brasil. \\ mariana.alt@ufscar.br
}

\begin{abstract}
RESUMO: A vinhaça é a principal água residuária do processo de produção do etanol, sendo que o seu destino mais comum é a fertirrigação de cana-de-açúcar. No entanto, o seu uso deve ser cauteloso, uma vez que em excesso pode acarretar em problemas ambientais. Estudos recentes vêm propondo a remoção de carbono e nitrogênio de águas residuárias agroindustriais por microalgas imobilizadas em matrizes de biopolímeros. Neste contexto, o objetivo deste trabalho foi o desenvolvimento de esferas de pectina para a imobilização da microalga Desmodesmus subspicatus, assim como a avaliação do seu potencial para remoção de carbono e nitrogênio da vinhaça. As esferas foram produzidas pela técnica de gotejamento em solução de reticulante $\left(\mathrm{Cacl}_{2}\right)$. A microalga imobilizada apresentou velocidade específica de crescimento de $0,002 \mathrm{~h}^{-1}$, com remoções de carbono (em torno de $40 \%$ ) e nitrogênio (34\%). Os resultados demonstraram a viabilidade do cultivo desta microalga imobilizada em pectina, assim como a capacidade de remoção de potássio da vinhaça.
\end{abstract}

Palavras-chave: águas residuárias, cultivo heterotrófico, microalgas imobilizadas.

\section{CARBON AND NITROGEN REMOVAL FROM VINASSE BY DESMODESMUS SUBSPICATUS IMOBILIZED IN PECTIN}

\begin{abstract}
Vinasse is the main wastewater in the ethanol production process, and its most common destination is the fertigation of sugarcane. However, its use must be cautious, since too much can lead to environmental problems. Recent studies have proposed the removal of carbon and nitrogen from agroindustrial wastewater by microalgae immobilized in biopolymer matrices. In this context, the objective of this work was the development of pectin beads for the immobilization of the microalga Desmodesmus subspicatus, as well as, the evaluation of its potential for the removal of carbon and nitrogen from vinasse. The beads were produced by the cross-linking solution $\left(\mathrm{CaCl}_{2}\right)$ drip technique. The immobilized microalga presented a specific growth rate of $0.002 \mathrm{~h}^{-1}$, with removals of carbon (around $40 \%$ ) and nitrogen (34\%). The results demonstrated the viability of the cultivation of this microalga immobilized on pectin, as well as the capacity to remove potassium from vinasse.
\end{abstract}

Keywords: heterotrophic growth, microalgae immobilization, wastewater.

\section{INTRODUÇÃO}

A vinhaça é a principal água residuária da produção de etanol, caracterizada pelo seu odor forte, coloração escura, $\mathrm{pH}$ ácido, alto teor de potássio e potencial poluente devido à alta carga de matéria orgânica. As tecnologias de produção atuais geram cerca de $10 \mathrm{~L}$ de vinhaça por litro de etanol produzido. O principal destino da vinhaça é na fertirrigação, no entanto, quando aplicada em altas doses, pode acarretar em salinização do solo e poluição de lençóis freáticos (Silva et al., 2007a). Diversas pesquisas têm buscado alternativas para uso e tratamento da vinhaça, como o reuso na fermentação, evaporação, produção de leveduras e geração de energia via biogás (Christofoletti et al., 2013).

A tecnologia de imobilização de microalgas em diversas matrizes tem sido estudada para produção de biomassa e outros metabólitos, além da biorremediação de águas residuárias, especificamente para remoção de nutrientes e metais pesados. Comparativamente às células livres, as principais vantagens da imobilização são a facilidade de remoção da biomassa, aumento da tolerância das células em condições desfavoráveis (temperaturas extremas, acidez e inibidores) e a possibilidade de condução de cultivos contínuos (de-Bashan \& Bashan, 2010). O sistema de imobilização de microalgas em matrizes de macromoléculas, tais como alginato e pectina, vem despertando interesse devido às suas características de biodegradabilidade, biocompatibilidade e não toxicidade, alta retenção celular, resistência mecânica difusividade de substratos e produtos (Yu et al., 
2011). A microalga Chlorophyceae Desmodesmus subspicatus tem sido cultivada tanto livre como imobilizada em diversos efluentes industriais e domésticos, com elevada viabilidade celular elevada, tolerância a variações de $\mathrm{pH}$ e temperatura, além de velocidades específicas de crescimento semelhantes em ambas condições (Silva et al., 2017b). Neste contexto, o objetivo do presente trabalho foi desenvolver matrizes de pectina para imobilização da microalga Desmodesmus subspicatus e avaliar o seu potencial de remoção de carbono e nitrogênio da vinhaça.

\section{MATERIAL E MÉTODOS}

Pectina cítrica de baixo teor de metoxilação Genu ${ }^{\circledR} 8002$ (CP Kelco, Brasil) foi utilizada no preparo das partículas. A vinhaça foi coletada em indústria sucroalcooleira da região de araras, sp. aproximadamente 500 $\mathrm{ml}$ da suspensão da microalga Desmodesmus subspicatus $\left(1,8 \mathrm{~g} \mathrm{~L}^{-1}\right)$ foi centrifugada a $3000 \mathrm{rpm}$ por $20 \mathrm{~min}$. $\mathrm{O}$ concentrado foi ressuspendido em $50 \mathrm{~mL}$ de água deionizada e adicionado a $350 \mathrm{~mL}$ de solução de pectina, resultando em $400 \mathrm{~mL}$ de solução de pectina na concentração desejada. Alíquotas desta solução (12,5 mL) foram gotejadas em $50 \mathrm{~mL}$ de solução reticulante levemente agitada $\left(\mathrm{CaCl}_{2}\right)$ através de uma bomba peristáltica com uma agulha (1,2 mm de diâmetro médio) acoplada à mangueira. As esferas foram mantidas no reticulante a $4^{\circ} \mathrm{c}$ por $3 \mathrm{~h}$ para estabilização, coletada por filtração e lavadas com água deionizada. A eficiência de imobilização pode ser verificada pela contagem de células viáveis em câmara de Neubauer na solução de pectina-microalga e na solução de $\mathrm{CaCl}_{2}$ após a reticulação. Para a definição dos parâmetros do processo de produção das esferas, esferas controle e com microalgas foram preparadas em diferentes concentrações de pectina $(5,7$ e $10 \% \mathrm{~m} / \mathrm{v})$ e diferentes concentrações de reticulante $\left(\mathrm{CaCl}_{2} 2,5\right.$ e $\left.10 \% \mathrm{~m} / \mathrm{v}\right)$.

A vinhaça teve seu $\mathrm{pH}$ ajustado para 7,6 e foi centrifugada $\left(1844 \mathrm{~g} ; 20 \mathrm{~min}, 20^{\circ} \mathrm{C}\right)$ previamente a cada experimento. Uma quantidade definida de células imobilizadas foi adicionada em Erlenmeyers de $125 \mathrm{ml}$ contendo $25 \mathrm{~mL}$ de vinhaça, mantidas em agitador orbital $\left(100 \mathrm{rpm}, 25^{\circ} \mathrm{C}\right)$, com monitoramento de contagem celular para estimativa da velocidade específica de crescimento $\left(\mu_{m a ́ x}\right)$ pelas curvas semi-logarítmas da contagem celular $(\mathrm{N})$, além do teor de carbono e nitrogênio do meio em analisador TOC-LCPN SHIMADZU ${ }^{\circledR}$.

\section{RESULTADOS E DISCUSSÃO}

A Figura 1 apresenta o crescimento celular dentro das esferas de microalgas imobilizadas com pectina $7 \%$ em diferentes concentrações de $\mathrm{CaCl}_{2}$. O pico em 6 horas pode ser explicado pela maior porosidade da matriz, resultando em um melhor posicionamento das células e maior difusão de nutrientes pela esfera biopolimérica. A velocidade específica de crescimento $\left(\mu_{\text {máx }}\right)$ na vinhaça centrifugada para as esferas de pectina $7 \%$ foi da ordem de $0,001 \mathrm{~h}^{-1}\left(\mathrm{t}_{\mathrm{g}}=693\right.$ horas) para 2 e $10 \%$ de cloreto de cálcio, e $0,002 \mathrm{~h}^{-1}\left(\mathrm{t}_{\mathrm{g}}=346\right.$ horas $) 5 \%$ de cloreto de cálcio.

Em relação aos perfis de carbono e nitrogênio na vinhaça ao longo do cultivo (Figura 2), pode-se verificar que estes foram similares para os experimentos com as diferentes concentrações de reticulante usadas para a produção das matrizes de pectina. Conforme previsto, as concentrações foram reduzidas (em torno de 32,39 e $41 \%$ de carbono e 11, 24 e 34\% de nitrogênio, para 2, 5 e $10 \%$ de cloreto de cálcio, respectivamente) ao longo dos cultivos, ou seja, houve consumo destes compostos pela microalga, evidenciado pela semelhança das curvas. Vale ressaltar que no ensaio realizado com esferas reticuladas com cloreto de cálcio $2 \%$, apresentou uma redução máxima de nitrogênio de aproximadamente $21 \%$, em 12 horas de cultivo. Apesar do crescimento

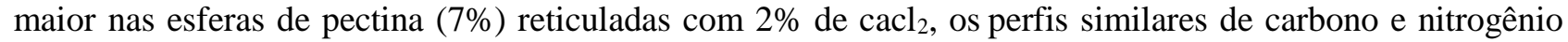
sugerem que, além do desenvolvimento microbiano, parte dos substratos podem ter sido incorporados às esferas, sem necessariamente a geração de biomassa. Nesse sentido, os resultados indicam a viabilidade do cultivo destas microalgas imobilizadas em efluentes com remoção de parte dos poluentes para o interior das partículas.

\section{CONCLUSÃO}

Nas condições experimentais, foi possível concluir que é viável cultivo da microalga Desmodesmus subspicatus imobilizada em pectina, uma vez que apresentou velocidade específica de crescimento de $0,002 \mathrm{~h}^{-}$ ${ }^{1}$, com remoções de carbono e nitrogênio da vinhaça em torno de $40 \%$. 


\section{AGRADECIMENTOS}

À CAPES e ao Programa de Pós-Graduação em Produção Vegetal e Bioprocessos Associados (PPGPVBA/CCA/UFSCar).

\section{REFERÊNCIAS}

CHRISTOFOLETTI, C.A.; ESCHER, J.P.; CORREIA, J.E.; MARINHO, J.F.U.; FONTANETTI, C.S. Sugarcane vinasse: environmental implications of its use. Waste Manag, v. 33, p. 2752-2761, 2013. de-BASHAN, L.E.; BASHAN, Y. Immobilized microalgae for removing pollutants: review of practical aspects. Bioresour. Technol, v. 101, p. 1611-1627, 2010.

SILVA, M.A.S.; GRIEBELER, N.P.; BORGES, L.C. Uso de vinhaça e impactos nas propriedades do solo e lençol freático. Rev. Bras. Eng. Agríc. Ambient, v. 11, n. 1, p. 108-114, 2007a.

SILVA, M.A.; BARBOSA, G.H.; CODATO, C.B.; MATTOS, L.F.A.; BASTOS, R.G.; KIECKBUSCH, T. G.Heterotrophic growth of green microalgae Desmodesmus subspicatus in ethanol distillation wastewater (vinasse) and lipid extraction with supercritical $\mathrm{CO}_{2}$. J. Chem. technol. biotechnol, v. 92, n. 3, p.573-579, $2017 \mathrm{~b}$.

YU, W.; SONG, H.; ZHENG, G.; LIU, X.; ZHANG, Y.; MA, X. Study on membrane characteristics of alginate- chitosan microcapsule with cell growth. J. Membr. Sci, v. 377, p. 214-220, 2011.

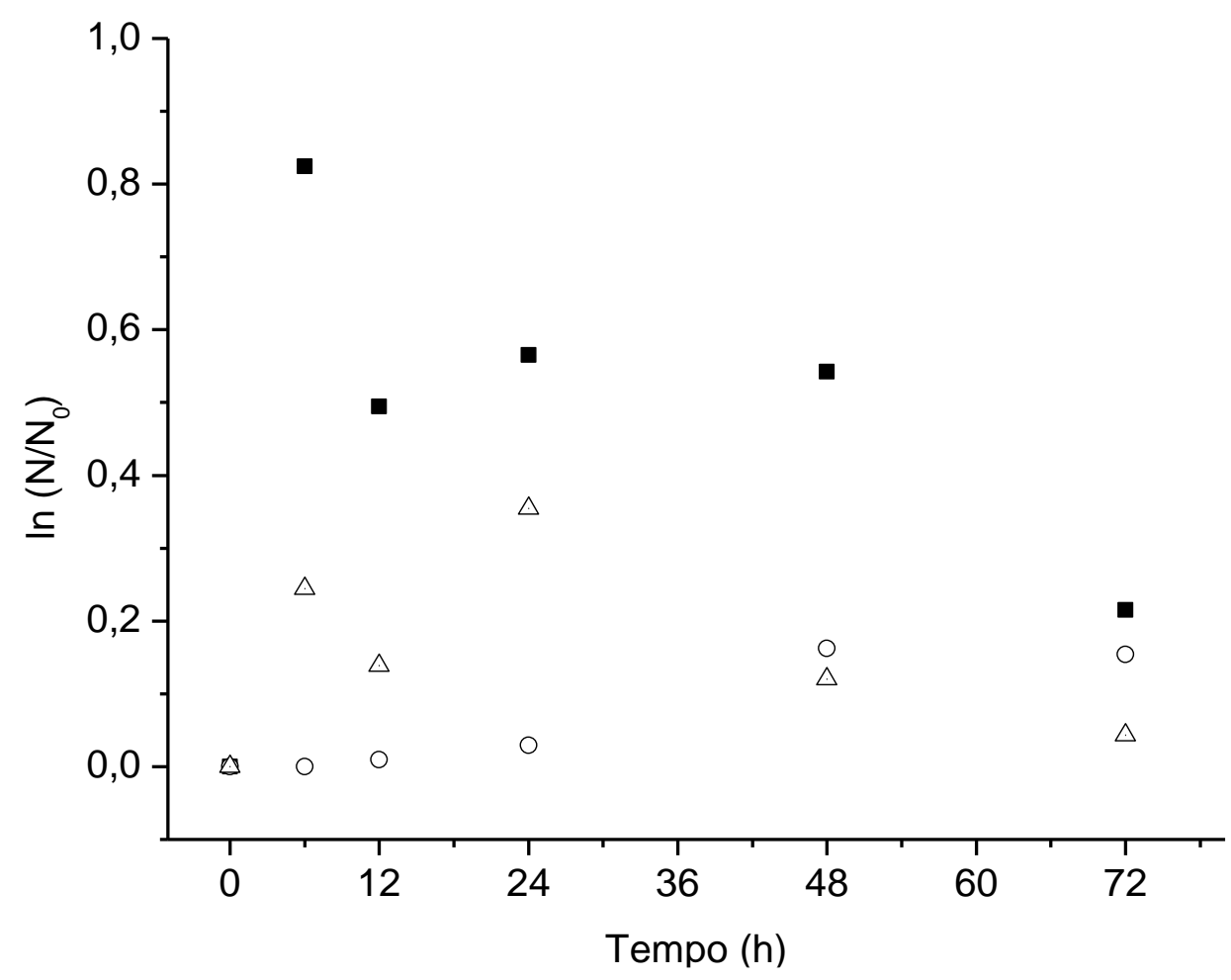

Figura 1. Perfis do crescimento da microalga D. subspicatus imobilizada em esferas de pectina (7\%) reticuladas com $2 \%$ de $\mathrm{CaCl}_{2}(\mathbf{\bullet}), 5 \%$ de $\mathrm{CaCl}_{2}(\mathrm{O})$ e $10 \%$ de $\mathrm{CaCl}_{2}(\Delta)$ em vinhaça centrifugada. 

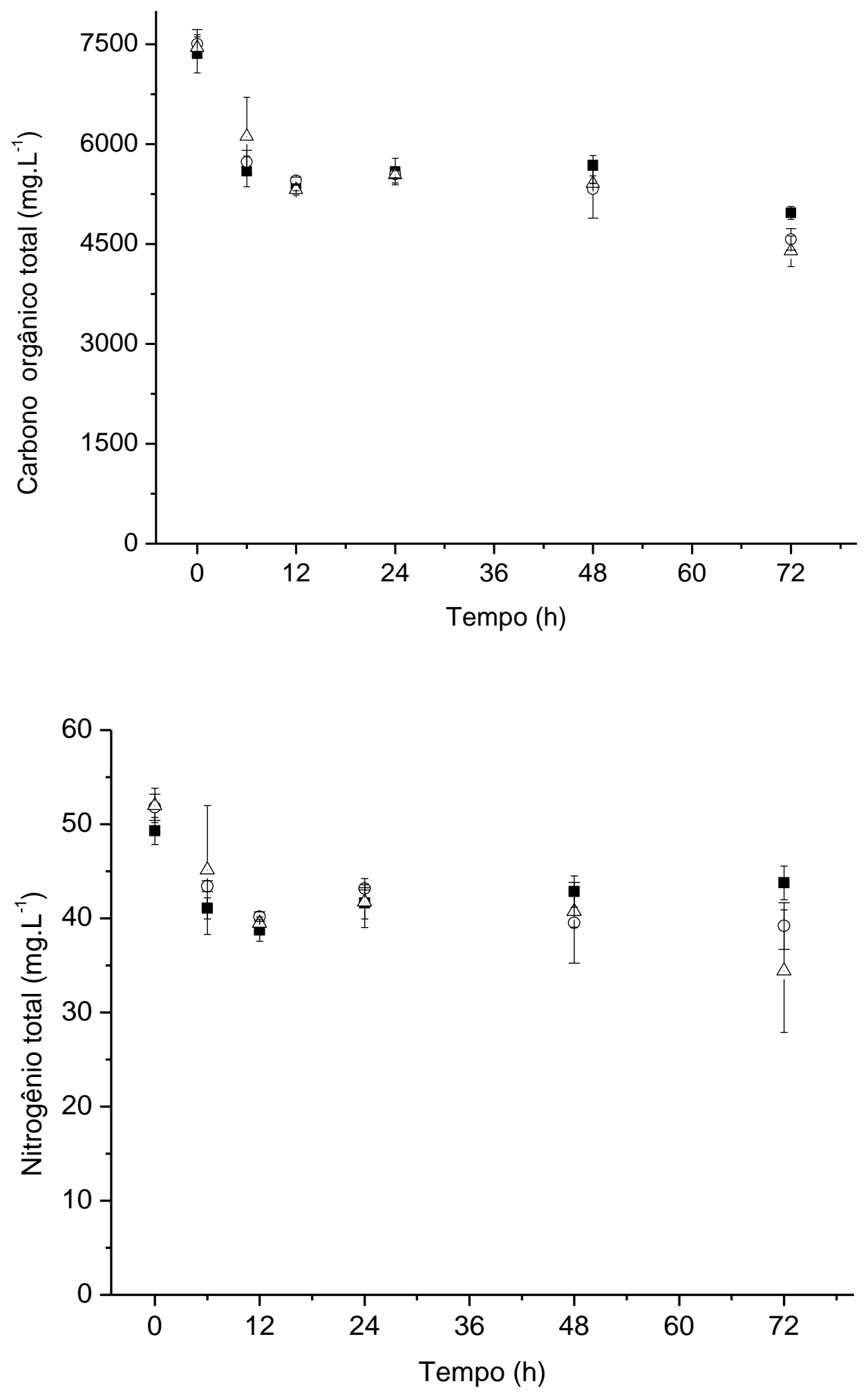

Figura 2. Perfis de Carbono Orgânico Total (a) e Nitrogênio Total (b) durante o cultivo da microalga $D$. subspicatus imobilizada em esferas de pectina (7\%) reticuladas com $2 \% \mathrm{de}^{\mathrm{CaCl}} \mathrm{Cl}_{2}(\mathbf{\bullet}), 5 \%$ de $\mathrm{CaCl}_{2}(\mathrm{O})$ e $10 \%$ de $\mathrm{CaCl}_{2}(\Delta)$ em vinhaça centrifugada. 


\title{
SÍNTESE VERDE DE NANOPARTÍCULAS DE PRATA A PARTIR DO EXTRATO DO BAGAÇO DE UVA BORDÔ
}

\author{
Raota, C.S. ${ }^{* 1}$; da Silva, T.B. ${ }^{1}$; Giovanela, M. $^{1}$ \\ ${ }^{I}$ Universidade de Caxias do Sul, Caxias do Sul, RS - Brasil. \\ csraota@ucs.br
}

\begin{abstract}
RESUMO: As metodologias tradicionais para a síntese de nanopartículas metálicas compreendem a utilização de reagentes tóxicos que podem causar impactos negativos, tanto ao meio ambiente como à saúde humana. Assim, uma alternativa mais segura para a produção desses nanomateriais baseia-se nos conceitos da Química Verde, no qual são utilizados reagentes menos nocivos e de fontes renováveis. Nesse contexto, o presente trabalho teve por objetivo a síntese verde de nanopartículas de prata (AgNPs), a partir do extrato do bagaço de uva bordô, sua caracterização, bem como a aplicação no tratamento terciário de efluentes industriais. Para tanto, os parâmetros de extração dos compostos bioativos do bagaço foram previamente otimizados, e o sistema com o melhor desempenho utilizou uma solução hidroalcoólica a $50 \%$ (v/v) assistida por um misturador do tipo hélice. $\mathrm{O} \mathrm{pH}$ da síntese verde foi igualmente aprimorado e, em $\mathrm{pH}=10,0$, as $\mathrm{AgNPs}$ apresentaram um diâmetro médio de 2,9 nm e estabilidade em solução. A atividade bactericida das AgNPs foi comprovada pela determinação da atividade mínima inibitória e pela formação dos halos de inibição frente a bactérias Grampositivas e Gram-negativas. Por fim, os resultados obtidos na etapa de desinfecção revelaram que os pellets de quitosana-AgNPs são eficazes na remoção de bactérias, sendo que, após $1 \mathrm{~h}$ de contato, foram capazes de reduzir a contagem das bactérias $E$. coli, possibilitando a sua aplicação no tratamento terciário de efluentes industriais.
\end{abstract}

Palavras-chave: química verde, nanopartículas de prata, vitivinicultura, tratamento terciário, efluentes

\section{GREEN SYNTHESIS OF SILVER NANOPARTICLES USING THE EXTRACT OF BORDÔ GRAPE POMACE}

\begin{abstract}
Traditional methodologies for the synthesis of metallic nanoparticles include the use of toxic chemicals that can have negative impacts on the environment and human health. Thus, a safer alternative to the production of these nanomaterials is based on the concepts of Green Chemistry, which uses less harmful reagents and from renewable sources. In this context, the goals of the present work were the green synthesis of silver nanoparticles (AgNPs) using the extract of Bordô grape pomace, their characterization, and its subsequent application in the tertiary industrial wastewater treatment. The extraction conditions of bioactive compounds of grape pomace were previously optimized and the system which achieved the best performance was extraction with a hydroalcoholic solution at $50 \%(\mathrm{v} / \mathrm{v})$, assisted by a propeller. The $\mathrm{pH}$ of the synthesis was equally refined and the synthesized AgNPs at $\mathrm{pH}=10.0$, presented an average diameter of $2.9 \mathrm{~nm}$ and stability in solution. Bacterial activity of AgNPs was verified by determination of inhibitory minimum activity and by the formation of an inhibition halo in the bacteria grown by superficial diffusion test, against Grampositive and Gram-negative bacteria. In conclusion, the results obtained at the disinfection step revealed that chitosan-AgNPs pellets were effective in bacterial removal. After $1 \mathrm{~h}$ of contact, they reduced the bacterial count of $E$. coli bacteria, thus enabling their application in tertiary industrial wastewater treatment.
\end{abstract}

Keywords: green chemistry, silver nanoparticles, viticulture, tertiary treatment, wastewaters.

\section{INTRODUÇÃO}

A sustentabilidade é a capacidade de conservação de um processo ou sistema, referindo-se às ações realizadas para satisfazer as necessidades humanas sem, no entanto, comprometer as demandas futuras. Uma importante linha de pesquisas nessa área está relacionada ao beneficiamento, à incorporação e ao reaproveitamento de resíduos, visando a um destino mais nobre e apropriado desses materiais. $\mathrm{O}$ polo vitivinícola do Rio Grande do Sul, por exemplo, gera uma quantidade expressiva de bagaço de uva, que é considerado um passivo ambiental devido às altas quantidades geradas. Somente no ano de 2017, cerca de 54 milhões de quilogramas de bagaço de uva foram produzidos, sendo comumente destinados à alimentação animal, à incorporação em adubos, à produção de etanol ou simplesmente ao descarte no meio ambiente. 
Embora seja um resíduo de baixo valor agregado, o bagaço de uva é rico em compostos bioativos, visto que cerca de $70 \%$ dos compostos fenólicos permanecem no bagaço mesmo após o processamento.

Frente a essa característica e sua disponibilidade, diversos estudos têm sido realizados visando a um destino mais nobre para esse resíduo, como a utilização na indústria de alimentos, na indústria farmacêutica, ou como fonte de compostos antioxidantes nos mais diversos processos, como por exemplo, na síntese verde de nanopartículas metálicas. Além de ser mais segura e menos nociva que os métodos tradicionais, a síntese verde tem a vantagem de ser um processo ambientalmente correto e de baixo custo. As nanopartículas de prata (AgNPs), por exemplo, são normalmente sintetizadas em meio aquoso, utilizando um precursor metálico, na presença de agentes redutores como o boroidreto de sódio e a hidrazina, e de estabilizadores como o citrato de sódio, além de surfactantes como polivinilpirrolidona (PVP). No entanto, esses reagentes podem ser substituídos por substâncias de origem natural, tais como os compostos fenólicos provenientes do bagaço de uva. Essas nanopartículas possuem elevada atividade bactericida, e podem ser utilizadas em produtos têxteis, em embalagens de produtos alimentícios, na produção de tintas, no tratamento de águas e efluentes, em produtos hospitalares, entre outros.

Nesse contexto, esse trabalho teve por objetivo avaliar a possiblidade de utilização de compostos bioativos do bagaço de uva Bordô na síntese de AgNPs, com a perspectiva de uma melhor utilização, em termos tecnológicos, desses resíduos provenientes da indústria vinícola. Aliado a esse propósito, as AgNPs sintetizadas foram incorporadas em uma matriz polimérica biodegradável de quitosana, visando sua posterior aplicação na desinfecção de um efluente industrial.

\section{MATERIAIS E MÉTODOS}

O nitrato de prata $\left(\mathrm{AgNO}_{3}\right)(\geq 99,0 \%)$, o glutaraldeído (50\% v/v em água), e o ácido acético (ACS), foram obtidos da Merck. O etanol (95\%) e a quitosana, por sua vez, foram adquiridos da Vetec Química Fina Ltda e da Sigma Aldrich, respectivamente. O bagaço de uva Bordô, variedade Vitis labrusca (cultivar Ives), foi coletado no dia 13 de fevereiro de 2017 na Vinícola Waldemar Milani Ltda (Caxias do Sul, RS), sendo armazenado em um freezer a $-20^{\circ} \mathrm{C}$ até o momento das análises. O efluente foi coletado no dia 5 de maio de 2018 na estação de tratamento de efluentes de uma indústria de artigos de cutelaria (Farroupilha, RS).

\section{Obtenção e caracterização do extrato do bagaço de uva Bordô}

A influência da concentração de etanol na solução extratora foi avaliada nas proporções de 50,30 e $20 \%$ (v/v), e o $\mathrm{pH}$ da solução extratora foi variado de 2,5 a 12,0. Os processos físicos de extração avaliados foram: (a) extração assistida por sonda de ultrassom, com amplitude de $30 \%$, por $10 \mathrm{~min}$ em modo intermitente (Sonics, modelo Vibra-cell) (BURIN et al., 2014); (b) agitação magnética simples, por 30 min a $200 \mathrm{rpm}$ (Ika, modelo HS 7); (c) agitação manual vigorosa durante 2 min, e (d) agitação com misturador tipo hélice por 5 min a $300 \mathrm{rpm}$ (Fisatom, modelo 713D). Ao término de todos esses experimentos, a mistura foi centrifugada durante $5 \mathrm{~min}$ a $5000 \mathrm{rpm}$ (Novatecnica, modelo NT820), seguido de uma filtração por gravidade em papel Whatman $(\mathrm{GF} / \mathrm{F}, 0,7 \mu \mathrm{m})$. Os ensaios foram avaliados pela quantificação de fenólicos totais pelo método de Folin-Ciocalteu (ROESLER et al., 2007).

\section{Síntese e caracterização das nanopartículas de prata}

A síntese das AgNPs foi realizada à temperatura ambiente, combinando-se volumes iguais da solução aquosa de $\mathrm{AgNO}_{3}$ e do extrato de bagaço de uva. A influência do $\mathrm{pH}$ do extrato na síntese foi avaliada de 2,6 a 12,7. As AgNPs foram analisadas por espectroscopia de absorção molecular na região do UV-Vis, no intervalo de 300 a $650 \mathrm{~nm}$. O tamanho e morfologia das nanopartículas foram avaliados por microscopia eletrônica de transmissão (MET), sendo que as soluções foram previamente diluídas em água destilada (1:10, v/v) e depositadas sobre um grid de cobre, para então serem analisadas em um microscópio JEM, modelo 1200 EXIl, com uma tensão de $80 \mathrm{kV}$. A determinação da estabilidade pelo ensaio do potencial zeta (Stabino, modelo Particle Metrix) foi realizada com tempo de leitura de $100 \mathrm{~s}$ e intervalo de $5 \mathrm{~s}$.

\section{Síntese, caracterização e aplicação dos pellets de quitosana-AgNPs}

A síntese dos pellets de quitosana-AgNPs foi realizada pela mistura de $90,0 \mu \mathrm{L}$ de glutaraldeído $(25 \%$ v/v, em água), 2,0 $\mathrm{mL}$ da solução de AgNPs e de $8,0 \mathrm{~g}$ da solução de quitosana $\left(1,5 \% \mathrm{~m} / \mathrm{v}\right.$ em $0,2 \mathrm{~mol} \mathrm{~L}^{-1}$ de ácido acético). A mistura foi gotejada em uma solução de $\mathrm{NaOH} 1,5 \mathrm{~mol} \mathrm{~L}^{-1}$, e os pellets foram deixados em repouso por cerca de $30 \mathrm{~min}$, e depois lavados com água ultrapura tipo I (LOVATEL et al., 2015).

O teste de inibição do crescimento bacteriano por difusão em superfície foi realizado em placas de Petri com meio de cultura BHI ágar, onde foram inoculadas as bactérias Gram-positivas Staphylococcus aureus e 
Enterococcus faecalis, e as Gram-negativas Escherichia coli e Pseudomonas aeruginosa. Após a secagem, colocou-se em cada placa três pellets de quitosana-AgNPs, e estas foram incubadas a $37^{\circ} \mathrm{C}$ por $24 \mathrm{~h}$. A avaliação foi realizada com base no diâmetro do halo de inibição formado.

$\mathrm{O}$ tratamento terciário do efluente industrial foi realizado adicionando-se 25 pellets de quitosana-AgNPs em $250,0 \mathrm{~mL}$ da amostra, sendo o sistema homogeneizado a $150 \mathrm{rpm}$ em uma incubadora shaker (Novatecnica, modelo 715D), variando os tempos de agitação de 30 a 120 min. A determinação quantitativa de coliformes totais, antes (efluente bruto) e depois do tratamento, foi realizada por meio da técnica de contagem em profundidade, utilizando placas Petrifilm da 3M (AOAC, 2016).

\section{Obtenção e caracterização do extrato de uva Bordô}

A extração dos compostos fenólicos está diretamente relacionada à composição da solução extratora, sendo o melhor desempenho obtido pela solução a $50 \%$ v/v. Esse comportamento também foi observado por Rockenbach et al. (2008), que avaliaram uvas das variedades Vitis vinifera (Ancelota e Tannat). A extração assistida por ultrassom apresentou os melhores resultados dentre todos os sistemas avaliados, visto que as ondas de ultrassom promovem o rompimento das estruturas do bagaço, possibilitando uma maior transferência dos compostos fenólicos para a solução hidroalcoólica (BURIN et al., 2014).

$\mathrm{O}$ perfil de concentração de fenólicos totais em função do $\mathrm{pH}$ do extrato assemelha-se ao encontrado por Bordignon Junior et. al (2009), no qual os valores de pH ácido apresentaram uma maior eficiência de extração em relação aos de $\mathrm{pH}$ básico, com uma discreta acentuação em pH neutro. Segundo Lopes et al. (2007), esse comportamento é explicado pelas reações de equilíbrio que ocorrem com o cátion flavílio das antocianinas, no qual o pH ácido promove a sua solubilidade. A quantificação de fenólicos totais foi de 327,35 $\mu \mathrm{g}$ equivalentes de ácido gálico por mililitro de extrato, ou 17,89 mg EAG por grama de bagaço. Na literatura, os resultados encontrados dependem da variedade de uva, da safra e do método de extração.

\section{Síntese e caracterização das AgNPs}

As soluções dos extratos dos pHs 4,0 a 12,7 apresentaram banda característica na região de $400-450 \mathrm{~nm}$, enquanto nas soluções de $\mathrm{pH}$ 2,6 e 3,0 não houve formação de AgNPs. $\mathrm{O}$ aumento do $\mathrm{pH}$ provoca um estreitamento gradual da banda plasmônica das AgNPs, com aumento de sua intensidade. Segundo Velgosová et al. (2016), esse comportamento corresponde à redução de tamanho, uniformidade e homogeneidade das partículas. De acordo com Mesquita (2016), os grupos hidroxila presentes nos compostos orgânicos da solução extrato são responsáveis pela redução dos íons $\mathrm{Ag}^{+} \mathrm{a} \mathrm{Ag}^{0}$, e a sua disponibilidade é diretamente afetada pelo $\mathrm{pH}$ do meio reacional.

As AgNPs das amostras apresentaram comportamentos distintos, conforme ilustra a Figura 1. As nanopartículas possuem formato circular e poliédrico, apresentando-se agregadas em $\mathrm{pH} 7,0$ e 12,0, enquanto as demais estão dispersas. Os diâmetros médios das AgNPs variaram de 2,9 $(\mathrm{pH}=10,0)$ a $55,3 \mathrm{~nm}(\mathrm{pH}=8,0)$. Segundo Melo (2015), o pH ácido favorece a agregação das nanopartículas, enquanto valores de pH mais altos favorecem a nucleação.

Os resultados da análise de potencial zeta mostraram que todas as AgNPs, com exceção daquelas que foram sintetizadas em $\mathrm{pH}=12,7$, são estáveis em solução, ou seja, a carga sobre as partículas promove a repulsão entre elas, impedindo a sua agregação e precipitação (CASANOVA, 2010). Segundo Křížová e Wiener (2013), os taninos e carboidratos presentes em extratos de derivados de uvas apresentam alto potencial de estabilização de nanopartículas de prata coloidal.

\section{Tratamento terciário de um efluente industrial}

No ensaio de inibição do crescimento bacteriano por difusão em superfície, os pellets formaram halos de inibição em todas as bactérias avaliadas. $\mathrm{O}$ desempenho ligeiramente superior contra $E$. coli está em conformidade com o resultado observado por Senthil et al. (2017).

Quanto ao tratamento terciário de um efluente industrial, o efluente bruto apresentou uma contaminação por E. coli de cerca de $40 \mathrm{UFC} \mathrm{mL}^{-1}$. Após $1 \mathrm{~h}$ de contato, os pellets de quitosana-AgNPs apresentaram atividade bactericida, alcançando o valor de $21 \mathrm{UFC} \mathrm{mL}^{-1}$ após 120 min de tratamento. 


\section{CONCLUSÕES}

O extrato do bagaço de uva Bordô extraído por uma solução hidroalcoólica teve sua atividade antioxidante comprovada, sendo capaz de realizar a síntese verde das AgNPs e proporcionar estabilidade à solução. Os pellets de quitosana-AgNPs formaram halos de inibição contra bactérias Gram-positivas e Gramnegativas, comprovando o efeito bactericida. $\mathrm{O}$ tratamento terciário de um efluente industrial reduziu a quantidade de bactérias $E$. coli, indicando que os pellets de quitosana-AgNPs possuem atividade bactericida suficiente para tratar um efluente industrial. Por fim, conclui-se que é possível realizar um processo ambientalmente correto para a síntese de AgNPs utilizando o extrato de um resíduo do setor vitivinícola, e aplicar satisfatoriamente os pellets de quitosana-AgNPs na desinfecção de efluentes industriais.

\section{REFERÊNCIAS}

AOAC. Método 991.14: Determinação Quantitativa de Escherichia coli pela técnica de contagem em profundidade. 20a ed. 2016.

BORDIGNON JUNIOR, Celso Luiz et al. Influência do pH da solução extrativa no teor de antocianinas em frutos de morango. Ciência e Tecnologia de Alimentos, V. 29, n. 1, p. 183-188, mar. 2009. FapUNIFESP (SciELO).

BURIN, Vívian Maria et al. Bioactive compounds and antioxidant activity of Vitis vinifera and Vitis labrusca grapes: Evaluation of different extraction methods. Microchemical Journal, v. 114, p. 155-163, maio 2014. Elsevier BV.

CASANOVA, Monise Cristina Ribeiro. Síntese, caracterização e estudo da estabilidade de nanopartículas metálicas estabilizadas com polieletrólitos e tióis. 87 f. Dissertação (Mestrado) - Curso de Mestrado em Ciências, Universidade de São Paulo, São Carlos, 2010.

LOPES, T. et al. Antocianinas: Uma breve revisão das características estruturais e da estabilidade. Revista Brasileira de Agrociência, v. 13, n. 3, p. 291-297, 2007.

LOVATEL, R.H. et al. Disinfection of biologically treated industrial wastewater using montmorillonite/alginate/nanosilver hybrids. Journal of Water Process Engineering, v. 7, p. 273-279, set. 2015. Elsevier BV.

MELO, Grasieli Beloni de. Síntese Verde e Caracterização de Nanopartículas de Prata Usando Extrato Aquoso de Erva Mate (Ilex paraguariensis). 39 f. TCC (Graduação) - Curso de Engenharia de Alimentos, Universidade Tecnológica Federal do Paraná, Campo Mourão, 2015.

MESQUITA, Ricardy Leonam Pontes. Síntese de Nanopartículas de Prata através de Ultrassom utilizando Galactomanana. 95 f. Dissertação (Mestrado) - Curso de Mestrado em Química, Universidade Federal do Ceará, Fortaleza, 2016.

ROCKENBACH, Ismael Ivan et al. Influência do solvente no conteúdo total de polifenóis, antocianinas e atividade antioxidante de extratos de bagaço de uva (Vitis vinifera) variedades Tannat e Ancelota. Ciência e Tecnologia de Alimentos, v. 28, p. 238-244, dez. 2008. FapUNIFESP (SciELO).

ROESLER, Roberta et al. Atividade antioxidante de frutas do cerrado. Ciência e Tecnologia de Alimentos, v. 27, n. 1, p. 53-60, mar. 2007. FapUNIFESP (SciELO).

SENTHIL, B. et al. Non-cytotoxic effect of green synthesized silver nanoparticles and its antibacterial activity. Journal of Photochemistry and Photobiology B: Biology, v. 177, p.1-7, dez. 2017. Elsevier BV.

VELGOSOVÁ, Oksana et. al. Influence of pH on green synthesis of Ag nanoparticles. Materials Letters, v. 180, p. 336339, out. 2016. Elsevier BV.

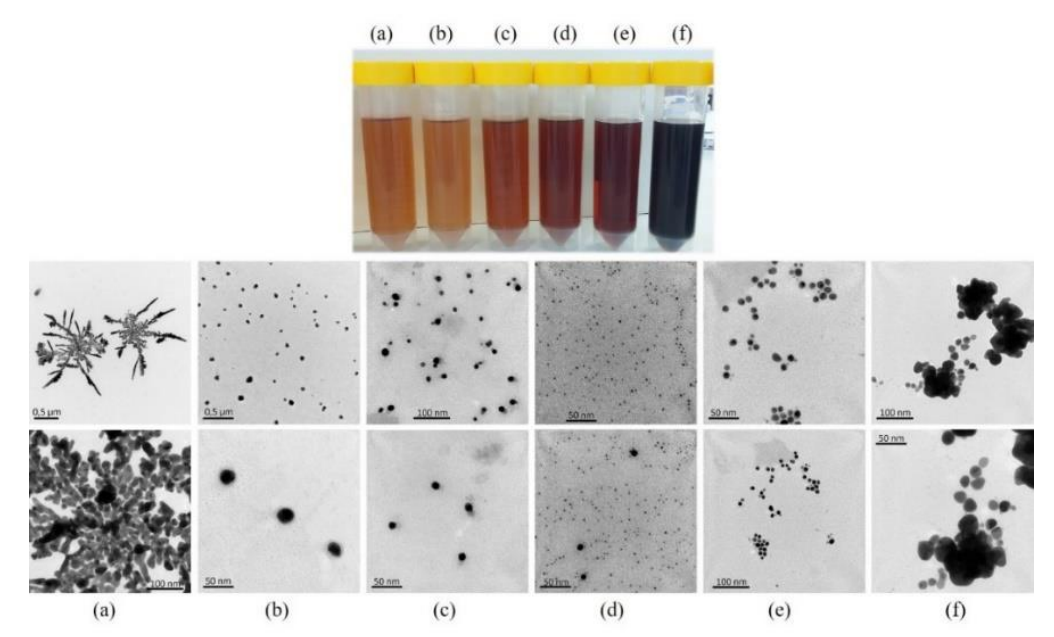

Figura 1. Imagens de MET das AgNPs em função do pH do meio: (a) 7,0; (b) 8,0; (c) 9,0; (d) 10,0; (e) 11,0; (f) 12,0 . 


\title{
UTILIZAÇÃO DE SERRAGEM DE PINUS ELLIOTTI DA INDÚSTRIA MOVELEIRA PARA O TRATAMENTO DE EFLUENTES TÊXTEIS
}

\author{
Bortoluz, J. *1; Giovanela, M. ${ }^{1}$ \\ ${ }^{1}$ Universidade de Caxias do Sul, Caxias do Sul, RS - Brasil. \\ jbortoluz@ucs.br
}

\begin{abstract}
RESUMO: Resíduos da indústria moveleira possuem um grande potencial para serem utilizados como adsorventes no tratamento de efluentes têxteis. Além de apresentarem baixo custo, possuem em sua estrutura química, componentes ricos em grupos funcionais oxigenados que são capazes de interagir com as moléculas de corante. A utilização desses materiais como adsorventes pode contribuir para a redução da disposição incorreta desses resíduos no meio ambiente, proporcionando um destino mais nobre para os mesmos. Nesse contexto, o presente trabalho teve por objetivo tratar a serragem de Pinus elliottii, por meio da remoção dos extrativos da madeira, visando sua posterior aplicação na remoção do corante azul de metileno (AM) de soluções aquosas por meio da técnica de adsorção. A serragem passou por um tratamento em Sohxlet, utilizando benzeno, etanol e água. Depois de seco, o material foi caracterizado e utilizado para avaliar a influência de parâmetros experimentais no processo adsortivo. Em geral, a serragem de Pinus elliotii tratada atingiu remoções de $95 \%$ do AM, e a taxa de remoção do AM seguiu o modelo de pseudossegunda ordem. O conjunto de resultados evidenciou que a serragem de Pinus elliottii tratada é uma alternativa promissora para a remoção de corantes catiônicos de efluentes industriais têxteis.
\end{abstract}

Palavras-chave: serragem, Pinus elliotti, azul de metileno, adsorção, efluentes têxteis.

\section{USE OF PINUS ELLIOTTI SAWDUST FOR THE TREATMENT OF TEXTILE WASTEWATERS}

ABSTRACT: Waste from the furniture industry has great potential to be used as adsorbents in the treatment of textile wastewaters. In addition to presenting low cost, they have in their chemical structure, components rich in oxygenated functional groups that are capable of interacting with dye molecules. The use of these materials as adsorbents can contribute to the reduction of the incorrect disposition in the environment, providing a nobler destination. In this context, the objective of the present work was to treat the Pinus elliottii sawdust by removal of wood extractives, aiming its later application in the removal of the methylene blue (MB) of aqueous solutions by adsorption technique. Sawdust underwent a Sohxlet treatment using benzene, ethanol and water. After drying, the material was characterized and used to evaluate the influence of experimental parameters on the adsorptive process. In general, the treated Pinus elliotii sawdust reached 95\% removal percentages of AM, and the removal rate followed the pseudo-second order model. The set of results showed that treated Pinus elliottii sawdust is a promising alternative for the removal of cationic dyes from industrial textile wastewaters.

Keywords: sawdust, Pinus elliottii, methylene blue, adsorption, textile wastewaters.

\section{INTRODUÇÃO}

De acordo com Kunz et al. (2002), os efluentes têxteis se caracterizam por serem demasiadamente coloridos, devido à presença de corantes que não se fixam à fibra durante o processo de tingimento. Corantes básicos como o azul de metileno (AM), por exemplo, possuem alta intensidade de cor e são visíveis até mesmo em baixas concentrações (menos de 1,0 $\mathrm{mg} \mathrm{L}^{-1}$ ) (Rafatullah et al., 2010; Yagub et al., 2014). Além disso, esses compostos são quimicamente estáveis e de difícil degradação (Yagub et al., 2014). Desse modo, o descarte inadequado de corantes nos corpos receptores, pode ocasionar sérios problemas ambientais.

Atualmente, existem muitos métodos físicos, químicos e biológicos que podem ser empregados para o tratamento desse tipo de efluente, tais como adsorção, coagulação/flotação, destruição eletroquímica, filtração por membranas, ozonização, degradação microbiana, entre outros (Yagub et al., 2014).

Dentre as várias tecnologias de tratamento de água disponíveis, a adsorção tem se mostrado uma técnica bastante conveniente, principalmente pela simplicidade de operação, baixo custo e elevadas taxas de remoção. 
Além disso, por não ser um método destrutivo, possibilita a recuperação do corante sem a perda de sua identidade química (Rafatullah et al., 2010).

Segundo Dallago et al. (2005), o carvão ativado é o material que apresenta a maior capacidade de adsorção. No entanto, embora esse material seja utilizado frequentemente como adsorvente para remover corantes de águas residuais, seu alto custo representa um problema (Rafatulla et al., 2010).

Desse modo, nos últimos anos, tem-se introduzido novos adsorventes em processos de adsorção. Diversos estudos mostram a possibilidade de aplicação de materiais residuais para remover corantes da água. No Estado do Rio Grande do Sul, a indústria moveleira tem uma expressiva participação na economia, principalmente na região da Serra Gaúcha, e isso significa que há uma grande geração de resíduos de madeira provenientes dessa cadeia produtiva. Embora muitas vezes sejam aproveitados para alguns fins específicos, esses resíduos podem se constituir em um problema de gestão ambiental das empresas (Hilling et al., 2009). Assim, a aplicação dos mesmos em processos de adsorção para a remoção de corantes de efluentes da indústria têxtil pode ser uma boa alternativa para evitar que esses resíduos sejam dispostos em aterros. Singh et al. (2015) utilizaram serragem de madeira proveniente de diferentes serrarias para remover AM da água. Esses autores constataram que a serragem disponível naquela região pode ser aplicada como um adsorvente de baixo custo bastante efetivo, atingindo remoções de até $99 \%$ da concentração inicial de corante. Outros autores como Chen et al. (2018) e Alidadi et al. (2018), mostraram que a modificação da serragem com uma mistura de hidróxido de sódio e trietanolamina, e cloreto de ferro (III), respectivamente, podem melhorar significativamente as capacidades adsortivas do material.

Dentro desse contexto, o objetivo do presente trabalho foi tratar a serragem de Pinus elliottii, através da remoção dos extrativos da madeira pela norma TAPPI T204cm-97, para sua posterior aplicação na remoção do corante AM de soluções aquosas por meio da adsorção.

\section{MATERIAL E MÉTODOS}

Para a remoção dos extrativos da madeira, a serragem foi submetida a três extrações consecutivas: uma com a mistura de etanol/benzeno (1:2, v/v), uma com etanol e uma com água destilada. O tempo de extração para cada solvente foi de $04 \mathrm{~h} 00$ e começou a ser contado após o primeiro ciclo de extração. Para isso, o material foi previamente acondicionado em um cartucho de celulose e, em seguida, em um Soxhlet munido de um condensador. Essas extrações foram realizadas a quente, com o auxílio de uma manta de aquecimento. Para evitar a perda dos solventes por evaporação, o sistema foi conectado a um banho de água termostatizado a 15 ${ }^{\circ} \mathrm{C}$, que manteve o sistema refrigerado durante todo o procedimento experimental.

$\mathrm{O} \mathrm{pH}$ no ponto de carga zero ( $\mathrm{pH}_{\mathrm{PCZ}}$ ) da serragem de Pinus elliottii tratada foi igualmente verificado com base no método proposto por Smičiklas et al. (2000).

Os ensaios de adsorção foram realizados, utilizando-se uma incubadora shaker refrigerada de bancada, da marca Nova Técnica. O tempo de contato foi escolhido após a realização de um primeiro ensaio preliminar, no qual foi verificado que o sistema contendo AM e a serragem de Pinus elliottii tratada entra em equilíbrio em $240 \mathrm{~min}$, sendo este o tempo utilizado para os demais ensaios. As concentrações das soluções AM, ao término dos experimentos, foram determinadas por espectroscopia UV-vis. Para os ensaios que avaliaram a influência dos parâmetros experimentais foram utilizados Erlenmeyers contendo $50 \mathrm{~mL}$ de solução de AM a $100 \mathrm{mg} \mathrm{L}^{-1}$. No ensaio que definiu o melhor $\mathrm{pH}$ inicial para o meio, utilizaram-se Erlenmeyers com soluções de AM ajustadas de $\mathrm{pH} \mathrm{3,0} \mathrm{a} \mathrm{10,0.} \mathrm{A} \mathrm{melhor} \mathrm{quantidade} \mathrm{de} \mathrm{massa} \mathrm{de} \mathrm{adsorvente,} \mathrm{por} \mathrm{sua} \mathrm{vez,} \mathrm{foi} \mathrm{otimizada,}$ variando-se a quantidade de serragem por Erlenmeyer de 50 a $250 \mathrm{mg}$. Para o ajuste dos dados experimentais cinéticos, foram utilizados os modelos reacionais pseudoprimeira e pseudossegunda ordem. Neste último ensaio, foi realizado o teste de Fisher para comparar a diferença estatística entre os dois modelos.

\section{RESULTADOS E DISCUSSÃO}

O ensaio para a determinação do $\mathrm{pH}$ no ponto de carga zero $\left(\mathrm{pH}_{\mathrm{PCZ}}\right)$ mostrou que a serragem de Pinus elliottii tratada possui um $\mathrm{pH}_{\mathrm{PCZ}}$ igual a 5,13. Dessa forma, para espécies como o AM (corante catiônico), a adsorção será favorecida em valores de $\mathrm{pH}>5,13$.

A Figura 1 mostra os resultados que avaliaram o efeito dos parâmetros experimentais do processo de adsorção do corante AM pela serragem de Pinus elliottii tratada. A Figura 1(a) mostra que ao se elevar o pH de 3,0 para 10,0, a capacidade de adsorção $\left(\mathrm{q}_{\mathrm{t}}\right)$ da serragem de Pinus elliotti tratada aumenta consideravelmente, mostrando que o processo em questão é favorecido em pHs mais alcalinos. Esse fenômeno 
pode ser explicado pelo resultado do ensaio de $\mathrm{pH}_{\mathrm{pcz}}$ da serragem, onde se verificou que em $\mathrm{pH}>5,13$, a carga superficial do adsorvente é negativa, o que proporciona uma interação eletrostática mais efetiva com o corante

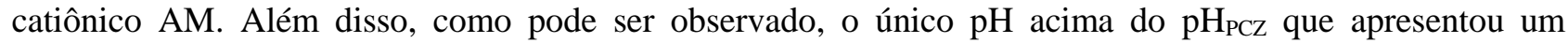
comportamento diferente dos demais, foi o pH 6,0. Essa tendência pode ser explicada pelo fato de que nessa faixa de $\mathrm{pH}$ ainda existem espécies $\mathrm{H}^{+}$, as quais competem com as moléculas de AM pela acomodação nos sítios ativos, e dificultam a interação adsorvente-adsorvato (Zhang et al., 2015). Em pHs igual ou superior a 7,0, a curva exibe um comportamento constante. Desse modo, qualquer pH que fosse escolhido dentro dessa faixa poderia ser favorável ao processo de adsorção. No entanto, neste trabalho, optou-se utilizar o pH 10,0, a fim de aproximar a solução sintética de AM a efluentes reais da indústria têxtil, os quais saem das operações com caráter extremamente alcalino.

Os resultados referentes à otimização da quantidade de massa de adsorvente se encontram na Figura 1(b). Como pode ser observado, quanto maior a massa de serragem de Pinus elliotti tratada disponível no meio, maior o percentual de remoção $(\% R)$ do corante AM. Todorciuc et al. (2015) explicam que isso ocorre devido a maior disponibilidade de sítios ativos para que ocorram as interações entre o adsorvente e o adsorvato. Em contrapartida, os valores de $\mathrm{q}_{\mathrm{t}}$ apresentaram um comportamento contrário ao \%R. De acordo com Deniz e Karabulut (2017), esse decréscimo pode estar relacionado a sítios ativos remanescentes, que não foram ocupados durante o processo de adsorção. Além disso, a agregação de partículas do adsorvente pode ocorrer em processos, onde a quantidade de massa é maior, resultando em uma diminuição da área superficial efetiva. Desse modo, a escolha da melhor quantidade de serragem de Pinus elliottii tratada foi baseada nos resultados de $\% R$. Nesse sentido, a massa escolhida foi a de 0,200 g, visto que quantidades maiores de adsorvente implicariam em uma maior geração de resíduos, sem ganhos expressivos em termos de remoção.

Os parâmetros cinéticos obtidos por meio dos modelos de pseudoprimeira e pseudossegunda ordem encontram-se na Tabela 1. Através dos resultados encontrados, é possível perceber que ambos os modelos se ajustam bem aos dados experimentais, visto que os coeficientes de determinação $\left(\mathrm{R}^{2}\right)$ estão muito próximos de 1,0. Para as concentrações de 120 e $150 \mathrm{mg} \mathrm{L}^{-1}$, o teste $\mathrm{F}$ mostrou que os modelos são estatisticamente idênticos, quando se utiliza um nível de confiança de $95 \%$. No entanto, em concentrações menores, o teste $\mathrm{F}$ revela que os modelos são estatisticamente diferentes, sendo o modelo cinético de pseudossegunda ordem, $\mathrm{o}$ mais adequado para descrever o processo em questão. Outros estudos que também avaliaram o processo de adsorção do corante AM em serragem, encontraram resultados semelhantes, e concluíram que o modelo de pseudossegunda ordem descreve melhor o processo de adsorção (Singh et al., 2015; Zhang et al., 2015). Por fim, esses dados revelam que $q_{t}$ e a concentração de AM aumentam concomitantemente, mostrando que o adsorvente se comporta de modo satisfatório mesmo em concentrações mais elevadas.

\section{CONCLUSÃO}

A serragem de Pinus elliottii tratada mostrou ser uma alternativa viável para a remoção de AM de soluções aquosas, atingindo remoções de $95 \%$ do corante em condições otimizadas. Além ser um material residual, que pode ser utilizado em processos de adsorção, a serragem possui ainda um menor custo que o carvão ativado. Vale ressaltar que a sua utilização como adsorvente minimiza a quantidade de resíduos de madeira da indústria moveleira descartados no meio ambiente, e consequentemente, os impactos causados à natureza.

\section{AGRADECIMENTOS}

Os autores agradecem à CAPES, ao CNPq e à FAPERGS pelo apoio financeiro.

\section{REFERÊNCIAS}

Alidadi, H. et al. Enhanced removal of tetracycline using modified sawdust: optimization, isotherm, kinetics, and regeneration studies. Process Safety and Environmental Protection, [S.I.], v. 117, p. 51-60, 2018. Chen, X. et al. Natural adsorbent based on sawdust for removing impurities in waste lubricants. Journal of Hazardous Materials, [S.I.], v. 350, p. 38-45, 2018.

Dallago, R. M.; Smaniotto, A.; Oliveira, L. C. A. Resíduos sólidos de curtumes como adsorventes para a remoção de corantes em meio aquoso. Quimica Nova, [S.I.], v. 28, n. 3, p. 433-437, 2005. 


\section{VISIGER

Deniz, F.; Karabulut, A. Biosorption of heavy metal ions by chemically modified biomass of coastal seaweed community: studies on phycoremediation system modeling and design. Ecological Engineering, [S.I.], v. 106, p. 101-108, 2017.

Hilling, E.; Schneider, V. E.; Pavoni, E. T. Geração de resíduos de madeira e derivados da industria moveleira em função das variáveis de produção. Produção, [S.I.] v. 19, n. 2, p. 292-303, 2009.

Kunz, A. et al. Novas tendências no tratamento de efluentes têxteis. Quimica Nova, [S.I.], v. 25, n. 1, p. 7882, 2002.

Rafatullah, M. et al. Adsorption of methylene blue on low-cost adsorbents: a review. Journal of Hazardous Materials, [S.I.], v. 177, n. 1-3, p. 70-80, 2010.

Singh, A. et al. Adsorptive capacity of sawdust for the adsorption of mb dye and designing of two-stage batch adsorber. Cogent Environmental Science, [S.I.], v. 1, n. 1, p. 1-16, 2015.

Smičiklas, I. D. et al. The point of zero charge and sorption of cadmium (II) and strontium (II) ions on synthetic hydroxyapatite. Separation and Purification Technology, [S.I.] v. 18, n. 3, p. 185-194, 2000.

Todorciuc, T.; Bulgariu, L.; Popa, V. I. Adsorption of cu (II) from aqueous solution on wheat straw lignin: equilibrium and kinetic studies. Cellulose Chemistry and Technology, [S.I.], v. 49, n. 2, p. 439-447, 2015.

Yagub, M. T. et al.. Dye and its removal from aqueous solution by adsorption: a review. Advances in Colloid and Interface Science, [S.I.], v. 209, p. 172-184, 2014.

Zhang, R. et al. Competitive adsorption of methylene blue and $\mathrm{Cu}^{2+}$ onto citric acid modified pine sawdust.

Clean - Soil, Air, Water, [S.I.], v. 43, n. 1, p. 96-103, 2015.
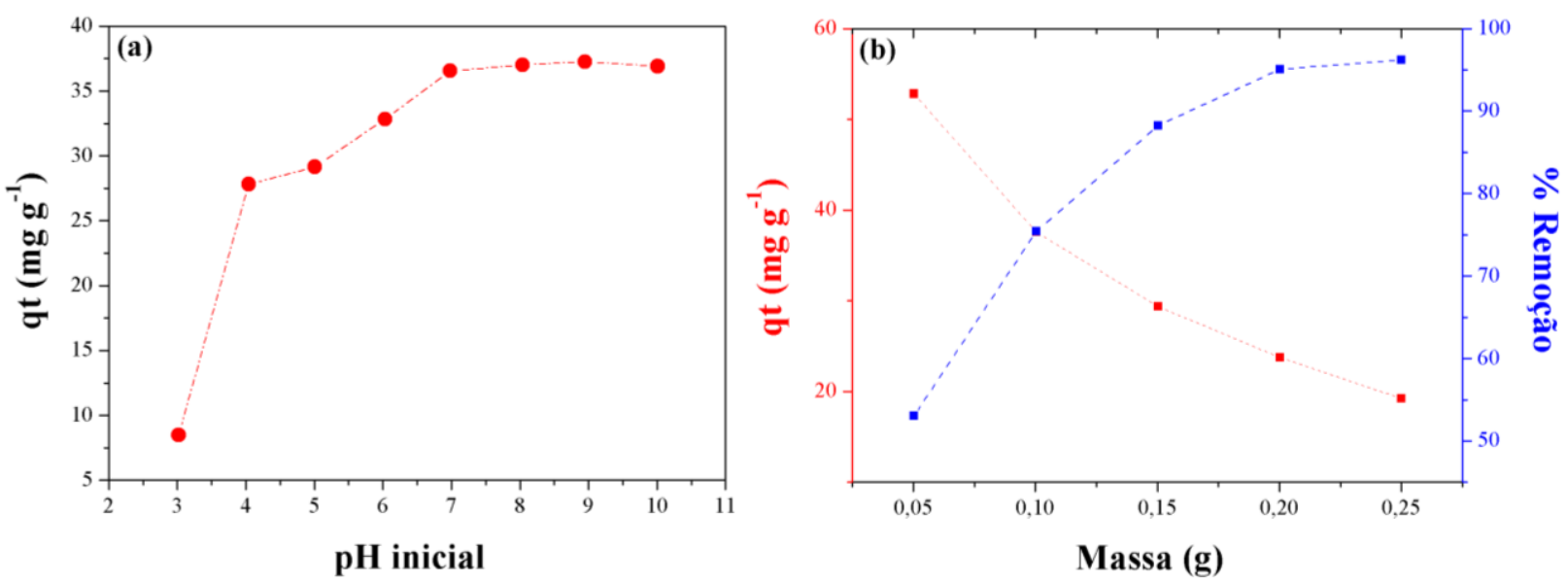

Figura 1. Ensaios de otimização dos parâmetros experimentais: (a) pH inicial do meio; (b) quantidade de massa de adsorvente.

Tabela 1. Parâmetros cinéticos para os modelos de pseudoprimeira e pseudossegunda ordem.

\begin{tabular}{|c|c|c|c|c|c|}
\hline Concentração de AM $\left(\mathrm{mg} \mathrm{L}^{-1}\right)$ & 60 & 80 & 100 & 120 & 150 \\
\hline \multicolumn{6}{|c|}{ Pseudoprimeira ordem } \\
\hline $\mathrm{q}_{\mathrm{t}}\left(\mathrm{mg} \mathrm{g}^{-1}\right)$ & 14,08 & 18,21 & 21,56 & 23,18 & 24,70 \\
\hline $\mathrm{k}_{1} \times 10^{-3}\left(\mathrm{~min}^{-1}\right)$ & 0,63 & 0,46 & 0,43 & 0,46 & 0,40 \\
\hline $\mathrm{R}^{2}$ & 0,9762 & 0,9652 & 0,9380 & 0,9208 & 0,8838 \\
\hline \multicolumn{6}{|c|}{ Pseudossegunda ordem } \\
\hline $\mathrm{q}_{\mathrm{t}}\left(\mathrm{mg} \mathrm{g}^{-1}\right)$ & 14,54 & 19,01 & 22,64 & 24,39 & 26,25 \\
\hline $\mathrm{k}_{2} \times 10^{-3}\left(\mathrm{~g} \mathrm{mg}^{-1} \mathrm{~min}^{-1}\right)$ & 0,082 & 0,04 & 0,03 & 0,03 & 0,02 \\
\hline $\mathrm{R}^{2}$ & 0,9971 & 0,9959 & 0,9846 & 0,9738 & 0,9567 \\
\hline \multicolumn{6}{|c|}{ Teste de Fisher } \\
\hline$F$, sendo $F_{\text {sup }}=0,2690$ e $F_{\text {inf }}=3,7168$ & 8,2989 & 8,7073 & 4,0679 & 3,0327 & 2,6876 \\
\hline
\end{tabular}




\title{
UTILIZAÇÃO DO BAGAÇO DE JABUTICABA (MYRCIARIA CAULIFLORA) PARA EXTRAÇÃO DE COMPOSTOS FENÓLICOS
}

\author{
Liberalesso, L.O.*1; ${ }^{*}$ Leidens, N. $^{1}$ \\ ${ }^{1}$ Universidade Regional Integrada do Alto Uruguai e das Missões (URI), Santo Ângelo - RS, Brasil \\ larissaliberalesso@aluno.santoangelo.uri.br
}

RESUMO: A jabuticaba é uma fruta nativa brasileira rica em compostos bioativos. O seu processamento em produtos como polpas e geleias gera o bagaço, que possui uma grande quantidade de compostos fenólicos. O objetivo deste trabalho foi reaproveitar o bagaço de jabuticaba para extrair e quantificar os compostos fenólicos a partir de uma solução hidroetanólica. Desta forma, quatro experimentos foram realizados, onde foram avaliadas as mudanças do percentual de etanol da solução e a relação entre a quantidade de soluto e solvente. A concentração de compostos fenólicos totais foi determinada a partir do método espectrofotométrico de FolinCiocalteau, expressa em termos de ácido gálico. Os teores de fenólicos extraídos variaram entre 245,7 e $288,4 \mathrm{mgGAE} / \mathrm{L}$. Os resultados mostraram que quanto maior o volume de etanol presente na solução e quanto menor a relação soluto/solvente, maior será a quantidade de compostos fenólicos extraídos do bagaço de jabuticaba.

Palavras-chave: compostos fenólicos, bagaço de jabuticaba, reaproveitamento.

\section{UTILIZATION OF JABUTICABA BAGASSE (Myrciaria cauliflora) FOR PHENOLIC COMPOUNDS EXTRACTION}

\begin{abstract}
Jabuticaba is a Brazilian native fruit rich in bioactive compounds. Its processing into products as pulps and jellies generates bagasse, which has a large amount of phenolic compounds. The objective of this work was to reuse the residue to extract and quantify phenolic compounds of jabuticaba bagasse using a hydroethanolic solution. Four experiments were conducted where the changes of ethanol percentage of the solution and the relation between the amount of solute and solvent were evaluated. The concentration of total phenolic compounds was determined with the Folin-Ciocalteau spectrophotometric method, expressed in terms of gallic acid. The extracted phenolic contents ranged from 245.7 to $288.4 \mathrm{mgGAE} / \mathrm{L}$. The results showed that the higher the volume of ethanol presents in the solution and the lower the solute/solvent ratio, the greater is the amount of phenolic compounds extracted from the jabuticaba bagasse.
\end{abstract}

Keywords: phenolic compounds, jabuticaba bagasse, reuse.

\section{INTRODUÇÃO}

A fruticultura é um dos setores de grande destaque do agronegócio brasileiro. Através de uma grande variedade de culturas, produzidas em todo o país e em diferentes climas, a fruticultura conquista resultados expressivos e assim gerando oportunidades para os pequenos negócios brasileiros. O Brasil é o terceiro maior produtor de frutas no mundo, ficando atrás apenas da china e índia, o que mostra a relevância do setor para a economia brasileira (Sebrae, 2015).

A jabuticabeira é uma árvore frutífera pertencente à família Myrtaceae, de ocorrência espontânea em grande parte do Brasil. Seus frutos são do tipo baga globosa de até três $\mathrm{cm}$ de diâmetro, com casca avermelhada quase preta, polpa esbranquiçada mucilaginosa, agridoce, e apresenta comumente uma única semente. A jabuticaba é consumida in natura ou na forma de diversos produtos, como licores, sucos, polpas, iogurtes, sorvetes e geleias, e apresenta diversas classes de compostos fenólicos. (Lima et al., 2011). O processamento da jabuticaba produz o bagaço, que representa cerca de 50\% do total da fruta, em massa. (Morales et al., 2016).

Como o bagaço de frutas é gerado em grandes quantidades e é rico em compostos fenólicos, percebe-se a sua potencial aplicação para a extração destes compostos, que podem ser utilizados em diversos ramos da indústria farmacêutica e de alimentos, substituindo produtos sintéticos, como corantes, aditivos alimentícios e substâncias antioxidantes (Angelo e Jorge, 2007; Morales et al., 2016). 
O objetivo deste trabalho foi reaproveitar o bagaço de jabuticaba para extrair e quantificar os compostos fenólicos, utilizando uma solução hidroetanólica como solvente de extração. Nos processos de extração foram avaliadas duas condições experimentais, percentual de etanol na solução e relação entre a quantidade de soluto e solvente.

\section{Bagaço de jabuticaba}

\section{MATERIAL E MÉTODOS}

O bagaço de jabuticaba foi adquirido através de agroindústrias locais da região das missões, no rio grande do sul. O bagaço foi submetido ao processo de secagem em estufa, em temperatura de aproximadamente $50{ }^{\circ} \mathrm{C}$. Depois de seco, o bagaço foi triturado em um moinho de facas, com o intuito de homogeneizar a granulometria dos sólidos.

\section{Extração dos compostos fenólicos}

A extração dos compostos fenólicos foi realizada com $15 \mathrm{~g}$ de bagaço de jabuticaba seco e triturado e uma solução aquosa de solvente orgânico (etanol) em um recipiente com agitação, a temperatura ambiente, durante uma hora. $\mathrm{O}$ pH da solução foi ajustado em quatro com ácido cítrico.

Nos experimentos de extração, foram avaliadas as relações entre soluto e solvente com alterações nos parâmetros percentual de etanol, sendo 70 e $30 \%$ de álcool. Os experimentos foram realizados em triplicata. Após cada experimento, os extratos foram filtrados com o auxílio de funil e papel filtro. A Tabela 1 apresenta os quatro experimentos realizados, com as respectivas quantidades de etanol e água da solução.

\section{Quantificação dos compostos fenólicos}

A análise dos compostos fenólicos totais foi realizada através do método espectrofotométrico de FolinCiocalteau, com leituras a $765 \mathrm{~nm}$, expresso em equivalente em ácido gálico, em mgGAE/l (Singleton et al., 1999).

\section{RESULTADOS E DISCUSSÃO}

A Figura 1 apresenta o bagaço de jabuticaba seco e triturado e o extrato do bagaço de jabuticaba obtido em um dos experimentos.

Os teores de fenólicos totais extraídos variaram entre 245,7 e 288,4 mgGAE/L, mostrando, desta forma, que o bagaço de jabuticaba representa uma importante fonte destes compostos. Os valores encontrados neste trabalho para o bagaço de jabuticaba são superiores aos teores de compostos fenólicos do bagaço de uva Isabel e de uva branca descritos por Melo et al. (2011), que também utilizaram etanol e água como solvente de extração.

O melhor resultado obtido foi no experimento dois, onde foi utilizada a maior quantidade de etanol em solução e a menor relação soluto/solvente. Já a menor quantidade de fenólicos extraídos foi no experimento três, que foi realizado com o menor percentual de etanol e a maior relação entre a quantidade de sólido e solução. Os resultados dos quatro experimentos podem ser observados na Tabela 2.

A partir da Tabela 2, pode-se observar que, a quantidade de etanol na solução hidroetanólica e a relação soluto/solvente influenciam na extração dos compostos fenólicos do bagaço de jabuticaba. A extração de fenólicos diminui com o aumento da relação soluto/solvente, ou seja, quanto maior a quantidade de solução hidroetanólica em relação à quantidade de bagaço, menor a quantidade de compostos fenólicos extraídos. Em relação ao percentual de etanol, quanto maior a quantidade de etanol em relação à quantidade de água presente na solução, mais eficiente será a extração dos compostos fenólicos. Estes resultados estão de acordo com Gruz et al. (2013), que encontraram esta mesma relação ao extrair compostos fenólicos do bagaço de uva.

A partir da Tabela 2, pode-se observar que, a quantidade de etanol na solução hidroetanólica e a relação soluto/solvente influenciam na extração dos compostos fenólicos do bagaço de jabuticaba. A extração de fenólicos diminui com o aumento da relação soluto/solvente, ou seja, quanto maior a quantidade de solução hidroetanólica em relação à quantidade de bagaço, menor a quantidade de compostos fenólicos extraídos. Em relação ao percentual de etanol, quanto maior a quantidade de etanol em relação à quantidade de água presente na solução, mais eficiente será a extração dos compostos fenólicos. Estes resultados estão de acordo com Gruz et al. (2013), que encontraram esta mesma relação ao extrair compostos fenólicos do bagaço de uva. 


\section{CONCLUSÃO}

Visando o aproveitamento de resíduos agroindustriais, este trabalho buscou extrair os compostos fenólicos presentes no bagaço de jabuticaba, já que estes compostos apresentam importantes propriedades nutricionais e funcionais e podem ser aplicados em outros produtos, entre eles, nas indústrias alimentícia e farmacêutica. Nos quatro experimentos realizados, foram extraídas quantidades de compostos fenólicos entre 245,7 e 288,4 mgGAE/L. O melhor resultado foi obtido na condição de menor relação soluto/solvente e maior percentual de etanol.

\section{AGRADECIMENTOS}

A URI pelo financiamento deste projeto para ser realizado e ao Grupo de Pesquisa e Desenvolvimento em Engenharia de Processos (GDEP).

\section{REFERÊNCIAS}

ANGELO PM, JORGE N. Compostos fenólicos em alimentos - uma breve revisão. Rev. Inst. Adolfo Lutz. São Paulo, v. 66, n. 1, 2007.

GRUZ APG, SOUSA CGS, TORRES AG, FREITAS SP, CABRAL LMC, Recuperação de compostos bioativos a partir do bagaço de uva. Revista Brasileira de Fruticultura, v. 35, n. 4, p. 1147-1157, 2013.

LIMA AJB, CORRÊA AD, SACZK AA, MARTINS PM, CASTILHO RO, Anthocyanins, pigment stability and antioxidant activity in jabuticaba [Myrciaria cauliflora (Mart.) O. Berg]. Revista Brasileira de Fruticultura, v. 33, n. 3, p. 877-887, 2011.

MELO PS, BERGAMASCHI KB, TIVERON AP, MASSARIOLI AP, OLDONI TLC, ZANUS MC, PEREIRA GE, ALENCAR SM, Composição fenólica e atividade antioxidante de resíduos agroindustriais. Ciência Rural, v. 41, n. 6, p. 1088-1093, 2011.

MORALES P, BARROS L, DIAS MI, SANTOS-BUELGA C, FERREIRA IC, RAMIREZ AE, BERRIOS JJ, Non-fermented and fermented jabuticaba (Myrciaria cauliflora Mart.) pomaces as valuable sources of functional ingredients. Food Chemistry, v. 208, p. 220-227, 2016.

SEBRAE, Agronegócio - Fruticultura. Boletim de Inteligência, 2015. Disponível em: http://www.bibliotecas.sebrae.com.br/chronus/ARQUIVOS_CHRONUS/bds/bds.nsf/64ab878c176e5103877 bfd3f92a2a68f/\$file/5791.pdf. Acesso em: 27/11/2017.

SINGLETON VL, ORTHOFER R, LAMUELA-RAVENTÓS RM, Analysis of total phenols and other oxidation substrates and antioxidants by means of Folin-Ciocalteau reagent. Methods of Enzymology, v. 299, p. $152-178,1999$.

Tabela 1. Experimentos de extração dos compostos fenólicos do bagaço de jabuticaba.

\begin{tabular}{cccccc}
\hline Experimento & $\begin{array}{c}\text { Soluto/solvente } \\
(\mathbf{m} / \mathbf{v})\end{array}$ & $\begin{array}{c}\text { Volume de } \\
\text { solvente } \\
(\mathbf{m L})\end{array}$ & $\begin{array}{c}\text { \% Etanol } \\
(\mathbf{v} / \mathbf{v})\end{array}$ & $\begin{array}{c}\text { Volume de } \\
\text { etanol }(\mathbf{m L})\end{array}$ & $\begin{array}{c}\text { Volume de } \\
\text { água }(\mathbf{m L})\end{array}$ \\
\hline 1 & $1: 9$ & 135 & 70 & 94,5 & 40,5 \\
2 & $1: 3$ & 45 & 70 & 31,5 & 13,5 \\
3 & $1: 9$ & 135 & 30 & 40,5 & 94,5 \\
4 & $1: 3$ & 45 & 30 & 13,5 & 31,5 \\
\hline
\end{tabular}

Tabela 2. Resultados dos experimentos de extração dos compostos fenólicos do bagaço de jabuticaba.

\begin{tabular}{cccc} 
Experimento & Soluto/Solvente $(\mathbf{m} / \mathbf{v})$ & \% Etanol $(\mathbf{v} / \mathbf{v})$ & Fenólicos totais $(\mathbf{m g G A E} / \mathbf{L})$ \\
\hline 1 & $1: 9$ & 70 & $254,4 \pm 13,1$ \\
2 & $1: 3$ & 70 & $288,4 \pm 19,7$ \\
3 & $1: 9$ & 30 & $245,7 \pm 5,1$ \\
4 & $1: 3$ & 30 & $271,9 \pm 11,1$ \\
\hline
\end{tabular}




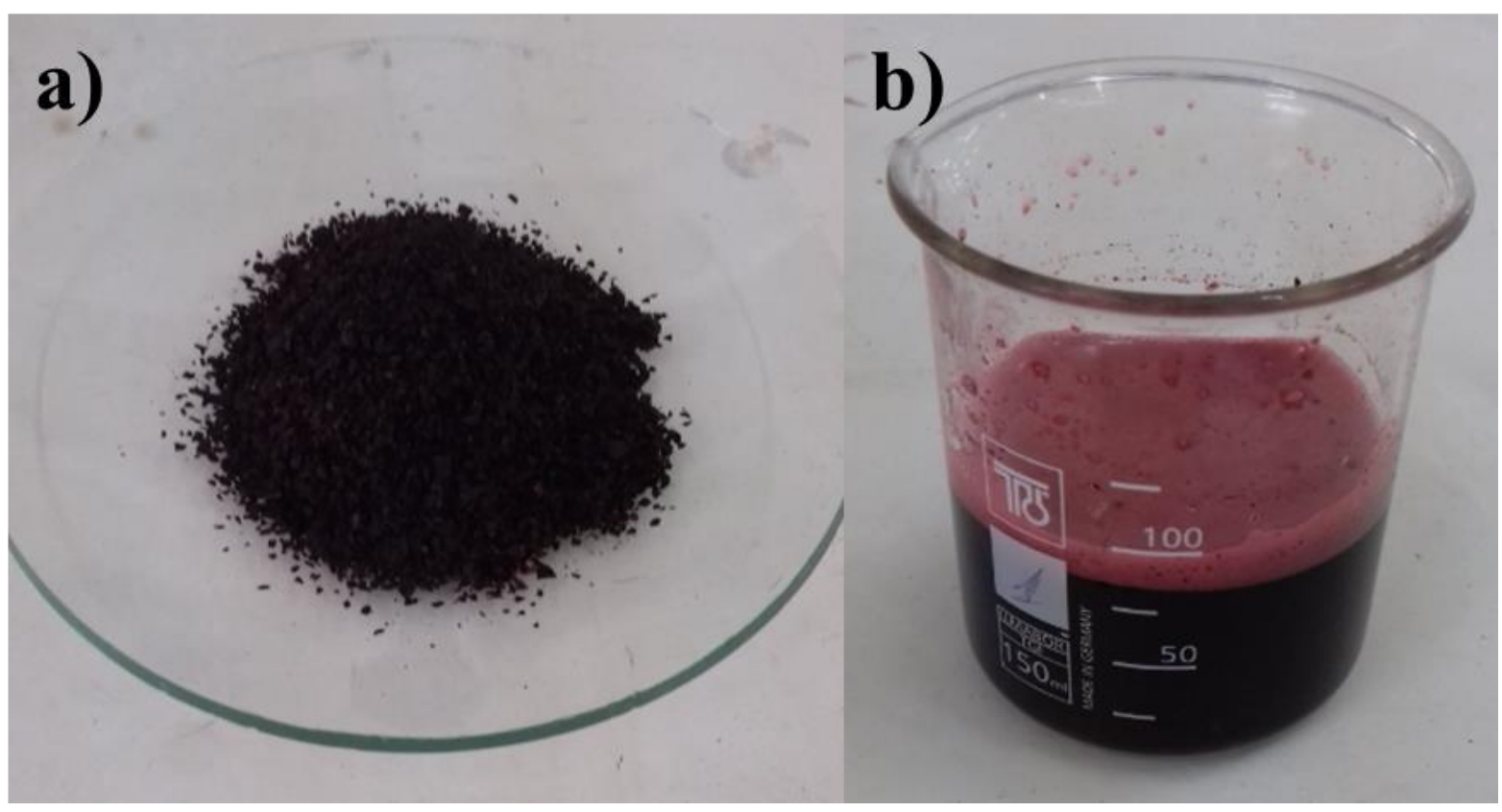

Figura 1. a) bagaço de jabuticaba seco e triturado; b) extrato hidroetanólico do bagaço de jabuticaba. 


\title{
PHOSPHORUS PRECIPITATON ALTERNATIVES WHEN APPLYING ANAMMOX- BASED PROCESSES TO ANAEROBIC DIGESTER DEWATERING CENTRATES
}

\author{
Magrí, A.. ${ }^{\text {11}}$; Johansson, S. ${ }^{1}$; Balaguer, M.D. ${ }^{1}$; Ruscalleda, M. ${ }^{1}$; Puig, S. ${ }^{1}$; Colprim, J. ${ }^{1}$ \\ ${ }^{1}$ LEQUIA, University of Girona $(U d G)$, Girona, Spain \\ *albert.magri@lequia.udg.cat
}

\begin{abstract}
Treatment of anaerobic digester dewatering centrates through autotrophic nitrogen (N)-removal based on anaerobic ammonium oxidation (anammox) is increasingly applied as an energy-efficient alternative. Phosphorus $(\mathrm{P})$ usually is also abundant in centrates, so that there is potential for integrating partial nitritationanammox (PNA) and P-precipitation aiming at macro-nutrient recovery. This contribution presents some experiences regarding the precipitation of phosphate from anaerobic centrates as a: (i) conditioning pretreatment, (ii) co-occurring biologically induced process, and (iii) refining post-treatment, in relation to PNA. Overall such integration of processes is interesting since it allows reducing the treatment cost and recovering valuable products (e.g. struvite, apatite) in the context of the circular economy.
\end{abstract}

Keywords: anaerobic ammonium oxidation, phosphate precipitation, resource recovery.

\section{INTRODUCTION}

Organic waste streams such as sewage sludge and livestock manure are commonly digested anaerobically to produce biogas as a renewable energy source. The effluent coming out of the biodigester (i.e. digestate) is frequently dewatered using mechanical devices like centrifuges. The separated liquid phase -also known as centrate- retains a significant fraction of the nutrients originally present in the processed stream (van Loosdrecht and Salem, 2006; Marchi et al., 2015; Pintucci et al., 2017), containing more N than P. Thus, centrate management and treatment according to an optimized strategy will foster energy-efficiency, costeffectiveness and sustainability (Abma et al., 2010).

The biological treatment of centrates through partial nitritation (PN) coupled with anammox is increasingly attracting attention for the innovation and development in the water industry as an economical option for N-removal. Some encouraging reasons are the low energy demand for aeration linked to ammonium $\left(\mathrm{NH}_{4}{ }^{+}\right)$oxidation and no need for an external organic carbon source during denitrification. The number of new PNA facilities operating worldwide is increasing fast (Lackner et al., 2014), and this fact leads to new opportunities for the integration of PNA bioprocesses with $\mathrm{P}$ and potassium $(\mathrm{K})$ recovery strategies. The orthophosphate $\left(\mathrm{PO}_{4}{ }^{3-}\right)$ available in the centrate can be separated before biological treatment. Indeed, high $\mathrm{PO}_{4}{ }^{3-}$ levels are inhibitory for the anammox sludge and must be prevented (Zhang et al., 2016; Connan et al., 2018). Otherwise, the PNA process implies some compositional changes in the centrate that can favor $\mathrm{PO}_{4}{ }^{3-}$ and $\mathrm{K}^{+}$ recovery scenarios.

Phosphorus is a scarce resource used in agri-food production. Nowadays, this nutrient is mostly obtained from mined phosphate rock to produce fertilizers (Cordell et al., 2009). Alternatively, several technologies are already available for the recovery of $\mathrm{P}$ from wastewater. Most commonly implemented strategies are based on the precipitation of $\mathrm{PO}_{4}{ }^{3-}$ to form different salts with low water solubility (Egle et al., 2015). Thus, magnesium $\left(\mathrm{Mg}^{2+}\right)$-phosphates are mostly precipitated as magnesium-ammonium-phosphate (struvite, MAP). Otherwise, $\mathrm{K}^{+}$can replace $\mathrm{NH}_{4}{ }^{+}$leading to the formation of K-struvite (MPP), but the simultaneous availability of $\mathrm{NH}_{4}{ }^{+}$ and $\mathrm{K}^{+}$constrains the precipitation of $\mathrm{K}$-struvite (Taylor et al., 1963). In the case of calcium $\left(\mathrm{Ca}^{2+}\right)$-phosphates, the range of possible compounds is wider depending on the $\mathrm{pH}$ and bulk liquid composition. Typical forms are hydroxyapatite (HAP), dicalcium phosphate dihydrate (brushite, DCPC), octacalcium phosphate (OCP), tricalcium phosphate (TCP), and amorphous calcium phosphate (ACP). Phosphate precipitation can be applied before, together with, and after the PNA process; this is as a conditioning pretreatment, induced inside the bioreactor, and as a refining post-treatment (Figure 1). In this contribution, some research experiences conducted in this framework at LEQUIA laboratory are presented, all them aiming to the recovery of $\mathrm{P}$ from waste streams (leading to products easily usable in the industry and as green fertilizers). 


\section{Conditioning pretreatment (precipitation of MAP)}

Precipitation tests were conducted in a continuous air-lift crystallizer (precipitator) treating simulated digested pig and cow manure dewatering centrate, and before applying biological N-removal (Pintucci et al., 2017). Such crystallizer was designed according to three characteristic zones from the bottom to the top: $(i)$ collector, where biggest particles settled; (ii) riser, where air was injected to promote fluidization and chemicals were added to promote nucleation and crystal growth; and (iii) clarifier, where the up-flow velocity was kept constantly low to prevent loss of crystals. Different up-flow velocities were tested in experiments lasting $1 \mathrm{~h}$ to assess the influence on MAP particle size. The up-flow velocity was adjusted by modifying the air-flow rate (1-10 $\left.\mathrm{L} \mathrm{min}^{-1}\right)$ in the range from 13.3 to $26.3 \mathrm{~m} \mathrm{~h}^{-1}$. Composition of the influent wastewater was $0.72 \mathrm{~kg} \mathrm{NH}_{4}^{+}-$ $\mathrm{N} \mathrm{m}^{-3}$ and $0.12 \mathrm{~kg} \mathrm{PO}_{4}{ }^{3-}-\mathrm{P} \mathrm{m}^{-3}$. $\mathrm{A} \mathrm{Mg}^{2+}$ source was added to adjust the $\mathrm{Mg}^{2+} / \mathrm{PO}_{4}{ }^{3-}$ molar ratio to $2.5 / 1$. The $\mathrm{pH}$ in the riser was controlled at 8.5 (using $\mathrm{NaOH} 1 \mathrm{M}$ ). Temperature of the feeding was adjusted to $30^{\circ} \mathrm{C}$. The minimum theoretical equivalent diameter that could be retained in the riser was estimated according to the upflow velocity (= critical settling velocity). MAP particles settled in the collector were recovered at the end of the experiment while the treated effluent was continuously discharged by overflow. Finally, the effect of increasing the particle residence time $(139 \mathrm{~h})$ on the particle size distribution was tested once the up-flow velocity was fixed at $22.6 \mathrm{~m} \mathrm{~h}^{-1}$. Laser diffraction and optical counting were used to measure crystal size distributions (Tarragó et al., 2016).

\section{Biologically induced precipitation (HAP)}

The PNA process was operated in a single-stage sequencing batch reactor (SBR) treating digested sewage sludge dewatering centrate, and running at a low aeration intensity and $25^{\circ} \mathrm{C}$ during 200 days. A stepfeed strategy was used in cycles lasting $6 \mathrm{~h}$, and each cycle included 10 identical sequences of feeding and reaction. The average $\mathrm{N}$-loading rate was progressively increased from 0.09 to $0.31 \mathrm{~kg} \mathrm{NH}_{4}{ }^{+}-\mathrm{N} \mathrm{m}^{-3} \mathrm{~d}^{-1}$ according to the centrate feeding time. Other considerations regarding the operation of the SBR were the absence of sludge purging, chemicals addition, or $\mathrm{pH}$ control throughout the experimental period. Initially, total and volatile suspended solids contents in the reactor were $0.86 \mathrm{~kg} \mathrm{TSS} \mathrm{m}^{-3}$ and $0.79 \mathrm{~kg} \mathrm{VSS} \mathrm{m}^{-3}$ (VSS/TSS ratio $=0.92$ ). The centrate used was collected in a municipal wastewater treatment plant with chemical Premoval in the main-stream. Its composition was $4.4 \mathrm{~kg} \mathrm{CaCO}_{3} \mathrm{~m}^{-3}$ (alkalinity), $0.97 \mathrm{~kg} \mathrm{NH}_{4}{ }^{+}-\mathrm{N} \mathrm{m}^{-3}, 0.06 \mathrm{~kg}$ $\mathrm{PO}_{4}{ }^{3-}-\mathrm{P} \mathrm{m}^{-3}, 0.28 \mathrm{~kg} \mathrm{~K}^{+} \mathrm{m}^{-3}, 0.08 \mathrm{~kg} \mathrm{Ca}^{2+} \mathrm{m}^{-3}$ and $0.01 \mathrm{~kg} \mathrm{Mg}^{2+} \mathrm{m}^{-3}$ (pH 8.1). Advanced analytical techniques based on scanning electron microscopy (SEM), X-ray diffraction (XRD), and inductively coupled plasma applications (i.e., ICP-MS and ICP-OES) were used to characterize the granules. More details are given elsewhere (Johansson et al., 2017).

\section{Refining post-treatment (co-precipitation of MAP and MPP)}

The PNA process was run using the same reactor setup and similar centrate than previously described for the research focused on biologically induced P-precipitation. In this case, the initial solids content within the reactor was fixed at $2.0 \mathrm{~kg} \mathrm{VSS} \mathrm{m}{ }^{-3}$. The average $\mathrm{N}$-loading rate was $0.27 \mathrm{~kg} \mathrm{NH}_{4}{ }^{+}-\mathrm{N} \mathrm{m}^{-3} \mathrm{~d}^{-1}$. Three factors affecting precipitation were tested in batch experiments (in beakers) using the PNA-SBR effluent: $\mathrm{Mg}^{2+} / \mathrm{PO}_{4}{ }^{3-}$ molar ratio (from $0.75 / 1$ to $1.75 / 1$ at $\mathrm{pH} 10$ and $25^{\circ} \mathrm{C}$ ), $\mathrm{pH}$ (from 8 to 12 at a $\mathrm{Mg}^{2+} / \mathrm{PO}_{4}{ }^{3-}$ ratio of $1.25 / 1$ and $25^{\circ} \mathrm{C}$ ) and temperature (from $20^{\circ} \mathrm{C}$ to $40^{\circ} \mathrm{C}$ at a $\mathrm{Mg}^{2+} / \mathrm{PO}_{4}{ }^{3-}$ ratio of $1.25 / 1$ and $\mathrm{pH} 10$ ). Magnesium chloride in powder and $\mathrm{NaOH} 1 \mathrm{M}$ were used to adjust the $\mathrm{Mg}^{2+} / \mathrm{PO}_{4}{ }^{3-}$ ratio and $\mathrm{pH}$, respectively. Temperature was controlled fitting water jackets to the beakers. Testing parameters were adjusted before mixing the solutions for $1 \mathrm{~h}$. Solids were allowed to settle for $30 \mathrm{~min}$ and captured. More details are given by Johansson et al. (2019).

\section{RESULTS AND DISCUSSION}

\section{Conditioning pretreatment (precipitation of MAP)}

The size of the particles recovered from the crystallizer directly correlated with the up-flow velocity applied, and evolved in accordance with the minimum theoretical equivalent diameter numerically estimated (although values obtained experimentally were somewhat greater than estimates). Thus, by increasing the upflow velocity from 13.3 to $26.3 \mathrm{~m} \mathrm{~h}^{-1}$, the mean diameter of the recovered crystals increased from 113 to 243 $\mu \mathrm{m}$ (46\% increase). Furthermore, by increasing the particle residence time (up-flow velocity of $22.6 \mathrm{~m} \mathrm{~h}^{-1}$ ), a 
progressive increase of the mean size from 201 to $314 \mu \mathrm{m}$ was achieved, and particles of up to $800-1000 \mu \mathrm{m}$ were recovered. The up-flow velocity control did not affect the $\mathrm{PO}_{4}{ }^{3-}$ recovery efficiency (>90\% in all cases). Exclusively MAP crystals were identified by XRD. Particle size plays a significant role in fertilizers affecting nutrient availability, plant uptake, blending, storage, handling and application properties (UNIDO and IFDC, 1998; Ahmed et al., 2016). Thus, interest in a methodology to control particle size when recovering MAP from centrates is high. Feasibility of MAP recovery from centrates with high solids content (1-3 kg TSS m $\mathrm{k}^{-3}$ was also demonstrated in another study -such high TSS content favored heterogeneous nucleation- (Tarragó et al., 2018).

\section{Biologically induced precipitation (HAP)}

The average $\mathrm{N}$ removal efficiency in the PNA-SBR ranged from $60 \%$ to $74 \%$, and the specific $\mathrm{N}$ removal rate reached $0.18 \mathrm{~g} \mathrm{NH}_{4}{ }^{-}-\mathrm{N} \mathrm{g}^{-1} \mathrm{VSS} \mathrm{d}^{-1}$. The average solids content in the reactor increased up to 1.45 $\mathrm{kg} \mathrm{VSS} \mathrm{m}^{-3}$ by the end of the experimental period but the corresponding VSS/TSS ratio decreased sharply to 0.62 -which is indicative of a high degree of mineralization-. No precipitation or scaling was detected in the bulk liquid or on the walls of the bioreactor. A stratification of the biomass was clearly evidenced under regular operation of the SBR, with reddish colored granules at the top and dark-brown granules with hard core at the bottom. Hence, granules with a high inorganic content settled easily, which allowed for an easy recovery. The organic content of the granules collected at the bottom of the reactor was $<30 \mathrm{wt} \%$ (in dry weight basis). The SEM analysis confirmed the porous beehive-like structure of the granules, which is indicative that mineralization was biologically induced. The main elemental constituents of these granules were $\mathrm{Ca}$ and $\mathrm{P}$, representing $34 \mathrm{wt} \%$ and $16 \mathrm{wt} \%\left(36 \mathrm{wt} \%\right.$ as $\left.\mathrm{P}_{2} \mathrm{O}_{5}\right)$, respectively. This composition leads to a Ca ${ }^{2+} / \mathrm{PO}_{4}{ }^{3-}$ molar ratio of 1.64, which is close to the theoretical value of 1.67 for HAP. The XRD analysis confirmed the presence of HAP although probably coexisting with ACP. The metals content in the recovered product complied with the proposed EU limits for P fertilizers (EC, 2016). The recovered granules could either be spread directly on croplands as a $\mathrm{P}$ source, or alternatively, be incorporated as a secondary feedstock in the production of fertilizers. In this last scenario, the removal of the small organic matter fraction remaining in the granules may be needed.

\section{Refining post-treatment (co-precipitation of MAP and MPP)}

The average N-removal efficiency in the PNA-SBR was 79\%. Consequently, the concentration of $\mathrm{NH}_{4}{ }^{+}$ and alkalinity in the reactor effluent decreased by more than $85 \%$, whereas the concentration of $\mathrm{PO}_{4}{ }^{3-}$ and $\mathrm{K}^{+}$ remained mostly unchanged. Composition of the effluent was about $0.37 \mathrm{~kg} \mathrm{CaCO}_{3} \mathrm{~m}^{-3}$ (alkalinity), $0.13 \mathrm{~kg}$ $\mathrm{NH}_{4}{ }^{+}-\mathrm{N} \mathrm{m}^{-3}, 0.06 \mathrm{~kg} \mathrm{PO}_{4}{ }^{3-}-\mathrm{P} \mathrm{m}^{-3}, 0.27 \mathrm{~kg} \mathrm{~K}^{+} \mathrm{m}^{-3}, 0.04 \mathrm{~kg} \mathrm{Ca}^{2+} \mathrm{m}^{-3}$ and $0.01 \mathrm{~kg} \mathrm{Mg}^{2+} \mathrm{m}^{-3}$ (pH 7.7). Thus, the $\mathrm{N} / \mathrm{P} / \mathrm{K}$ molar ratio in the effluent was 5.2/1.0/3.9, with both $\mathrm{N}$ and $\mathrm{K}$ in excess over $\mathrm{P}$. Under these conditions, the precipitation of MPP becomes feasible depending on the availability of $\mathrm{Mg}^{2+}$, and even though the solubility product for MPP is higher than for MAP (Taylor et al., 1963). The high alkalinity removal strongly reduces the need for chemical and energy inputs regarding $\mathrm{pH}$-control, as similarly reported elsewhere (Szogi and Vanotti, 2009). The $\mathrm{PO}_{4}{ }^{3-}$ and $\mathrm{NH}_{4}{ }^{+}$removal increased with the $\mathrm{Mg}^{2+} / \mathrm{PO}_{4}{ }^{3-}$ ratio, with a $\mathrm{P}$ removal efficiency above $90 \%$ when the ratio was 1.25 , and reaching a maximum of $96 \%$ when such ratio was fixed at 1.75. Since the PNA effluent had an excess of $\mathrm{K}^{+}$and $\mathrm{NH}_{4}{ }^{+}$over $\mathrm{PO}_{4}{ }^{3-}$, only part of these two cations were removed through struvite precipitation. Best results regarding $\mathrm{P}$ removal were obtained at $\mathrm{pH} 10-11(94 \%$ $\mathrm{PO}_{4}{ }^{3-}, 7 \% \mathrm{~K}^{+}$and $44 \% \mathrm{NH}_{4}{ }^{+}$). When the $\mathrm{pH}$ was raised to 12 , a sharp drop in nutrient removal was observed, probably because of the formation of alternative $\mathrm{Mg}^{2+}$ compounds. The $\mathrm{PO}_{4}{ }^{3-}$ and $\mathrm{K}^{+}$removal decreased with temperature while the $\mathrm{NH}_{4}{ }^{+}$removal increased. In this regard, the $\mathrm{PO}_{4}{ }^{3-}$ removal decreased steadily from $94 \%$ to $81 \%$ while the temperature was moved up from $20^{\circ} \mathrm{C}$ to $40^{\circ} \mathrm{C}$. No $\mathrm{K}^{+}$removal was observed above $35^{\circ} \mathrm{C}$. $\mathrm{NH}_{4}{ }^{+}$removal was higher than the corresponding $\mathrm{PO}_{4}{ }^{3-}$ removal on a molar basis particularly when $\mathrm{pH}>9$, or as far as the temperature increased, indicating that part of the $\mathrm{NH}_{4}{ }^{+}$can be stripped out of the system as ammonia $\left(\mathrm{NH}_{3}\right)$. Recovered MPP represents also an interesting alternative to conventional K-sources obtained by mining potash ores (Ciceri et al., 2015; Tarragó et al., 2018). 


\section{CONCLUSIONS}

Several alternatives are feasible in order to combine PNA and P-recovery based on phosphate precipitation when dealing with treatment of anaerobic digester dewatering centrates. Thus, $\mathrm{P}$ precipitation can be applied before, during, or after the PNA process. Potential targets for such approach are lowering the consumption of energy and chemical reagents, lowering the treatment cost, minimizing the risk of toxicity for the microorganisms involved in PNA, or recovering new valuable and marketable high-quality products in the framework of the circular economy.

\section{ACKNOWLEDGEMENT}

This contribution was written in the framework of the research project DigesTake (COMRDI16-1-0061) funded by ACCIÓ-Generalitat de Catalunya. LEQUIA (http://www.lequia.udg.edu/) is recognized as a consolidated research group by the Catalan Government (code 2017-SGR-1552).

\section{REFERENCES}

Abma W. R., Driessen W., Haarhuis R. and van Loosdrecht, M. C. M. 2010. Upgrading of sewage treatment plant by sustainable and cost-effective separate treatment of industrial wastewater. Water Sci. Technol., 61, $1715-1722$.

Ahmed S., Klassen T. N., Keyes S., Daly M., Jones D. L., Mavrogordato M., Sinclair I. and Roose T. 2016. Imaging the interaction of roots and phosphate fertiliser granules using 4D X-ray tomography. Plant Soil, 401, 125-134.

Ciceri D., Manning D. A. C. and Allanore A. 2015. Historical and technical developments of potassium resources. Sci. Total Environ., 502, 590-601.

Connan R., Dabert P., Moya-Espinosa M., Bridoux G., Béline F. and Magrí A. 2018. Coupling of partial nitritation and anammox in two- and one-stage systems: Process operation, $\mathrm{N}_{2} \mathrm{O}$ emission and microbial community. J. Clean. Prod., 203, 559-573.

Cordell D., Drangert J. -O. and White S. 2009. The story of phosphorus: Global food security and food for thought. Global Environ. Chang., 19, 292-305.

EC (European Commission). 2016. Proposal for a Regulation of the European Parliament and of the Council, Laying Down Rules on the Making Available on the Market of CE Marked Fertilizing Products and Amending Regulations (EC) No 1069/2009 and (EC) No 1107/2009.

Egle L., Rechberger H. and Zessner M. 2015. Overview and description of technologies for recovering phosphorus from municipal wastewater. Resour. Conserv. Recycl., 105, 325-346.

Johansson S., Ruscalleda M. and Colprim J. 2017. Phosphorus recovery through biologically induced precipitation by partial nitritation-anammox granular biomass. Chem. Eng. J., 327, 881-888.

Johansson S., Ruscalleda M., Saerens B. and Colprim J. 2019. Potassium recovery from centrate: taking advantage of autotrophic nitrogen removal for multi-nutrient recovery. J. Chem. Technol. Biotechnol. doi: 10.1002/jctb.5828. (in press)

Lackner S., Gilbert E. M., Vlaeminck S. E., Joss A., Horn H. and van Loosdrecht M. C. M. 2014. Full-scale partial nitritation/anammox experiences - An application survey. Water Res., 55, 292-303.

Marchi A., Geerts S., Weemaes M., Wim S. and Christine V. 2015. Full-scale phosphorus recovery from digested waste water sludge in Belgium - part I: technical achievements and challenges. Water Sci. Technol., 71, 487-494.

Pintucci C., Carballa M., Varga S., Sarli J., Peng L., Bousek J., Pedizzi C., Ruscalleda M., Tarrago E., Prat D., Colica G., Picavet M., Colsen J., Benito O., Balaguer M., Puig S., Lema J. M., Colprim J., Fuchs W. and Vlaeminck S. E. 2017. The ManureEcoMine pilot installation: advanced integration of technologies for the management of organics and nutrients in livestock waste. Water Sci. Technol., 75, 1281-1293.

Szogi A. A. and Vanotti M. B. 2009. Removal of phosphorus from livestock effluents. J. Environ. Qual., 38, 576-586.

Tarragó E., Puig S., Ruscalleda M., Balaguer M. D. and Colprim J. 2016. Controlling struvite particles' size using the up-flow velocity. Chem. Eng. J., 302, 819-827.

Tarragó E., Ruscalleda M., Colprim J., Balaguer M. D. and Puig S. 2018. Towards a methodology for recovering K-struvite from manure. J. Chem. Technol. Biotechnol., 93, 1558-1562. 
Tarragó E., Sciarria T. P., Ruscalleda M., Colprim J., Balaguer M. D., Adani F. and Puig S. 2018. Effect of suspended solids and its role on struvite formation from digested manure. J. Chem. Technol. Biotechnol., 93, 2758-2765.

Taylor A. W., Frazier A. W. and Gurney E. L. 1963. Solubility products of magnesium ammonium and magnesium potassium phosphates. Trans. Faraday Soc., 59, 1580-1584.

UNIDO and IFDC (United Nations Industrial Development Organization and International Fertilizer Development Center). 1998. Fertilizer Manual. Kluwer Academic Publishers, Dordrecht, The Netherlands.

van Loosdrecht M. C. M. and Salem S. 2006. Biological treatment of sludge digester liquids. Water Sci. Technol., 53, 11-20.

Zhang Z. -Z., Xu J. -J., Hu H. -Y., Shi Z. -J., Ji Z. -Q., Deng R., Shi M. -L. and Jin R. -C. 2016. Insight into the short- and long-term effects of inorganic phosphate on anammox granule property. Bioresour. Technol., 208, 161-169.

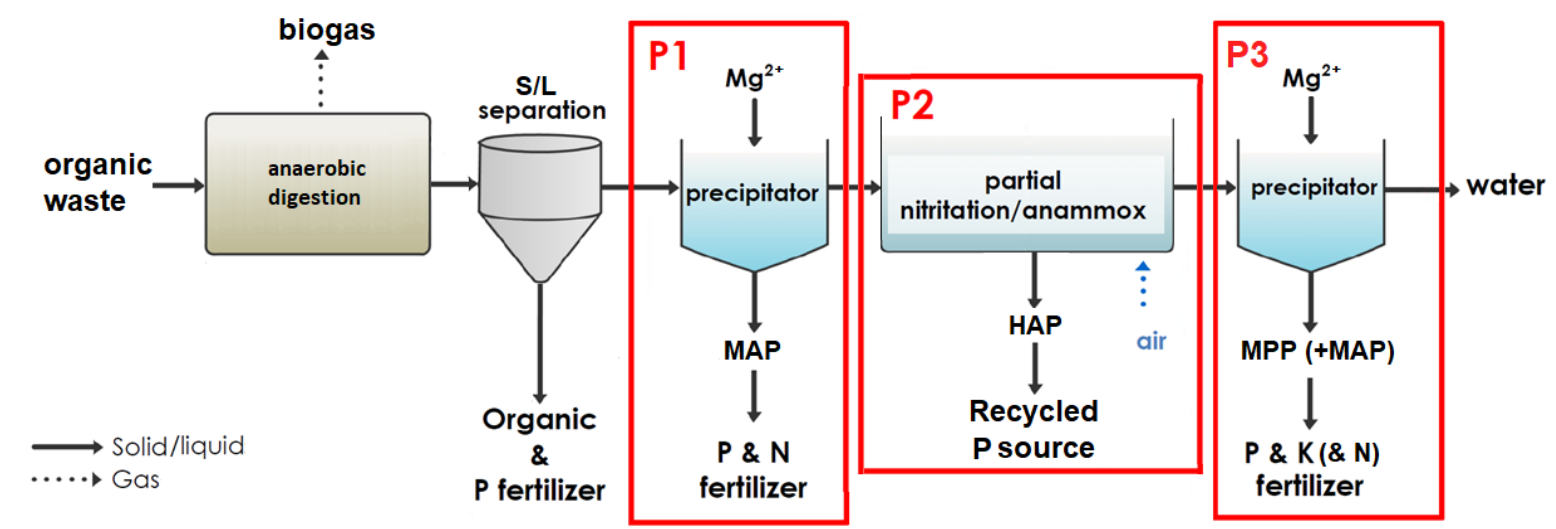

Figure 1. Phosphorus precipitation alternatives before (P1), during (P2) and after (P3) the PNA bioprocess. 


\title{
ESTUDO DO EFEITO DOS INIBIDORES EM ENSAIOS DE FERMENTAÇÃO COM CLOSTRIDIUM BEIJERINCKII
}

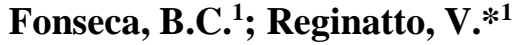 \\ ${ }^{1}$ Universidade de São Paulo, Faculdade de Filosofia Ciências e Letras de Ribeirão Preto, SP, Departamento de Química \\ LABIORE - Laboratório de Biotecnologia Ambiental e Energias Renováveis \\ valeriars@ffclrp.usp.br
}

\begin{abstract}
RESUMO: Os biocombustíveis, como o $\mathrm{H}_{2}$, estão avançando rapidamente como fontes alternativas de energia renovável devido às suas características não poluentes e à competitividade de custo em comparação com os combustíveis fósseis. Portanto, dentre os vários desafios para o desenvolvimento de biocombustíveis obtidos por bioprocessos a partir de materiais lignocelulósicos está o aproveitamento integral por parte dos microrganismos dos carboidratos que compõe a biomassa lignocelulósica, além da superação do efeito inibitório que os demais derivados da sacarificação podem causar nos microrganismos fermentativos. Além da dificuldade da assimilação da xilose em presença da glicose, outro fator que influencia na bioconversão eficiente de açúcares derivados dos pré-tratamentos e da hidrólise da biomassa lignocelulósica em biocombustíveis e outros produtos químicos de interesse industrial, é a geração de compostos inibidores do crescimento microbiano derivados da lignina presente na biomassa. Para entender melhor o consumo do hidrolisado da biomassa lignocelulósica, testes foram realizados contendo xilose na presença de glicose e presença de potenciais inibidores de fermentação resultantes dos métodos de hidrólise desses materiais lignocelulósicos, tais como o 5-hidroximetilfurfural (5-HMF), o siringaldeído e a vanilina. Nesta etapa do trabalho, foi testada a concentração de $1 \mathrm{~g} / \mathrm{L}$ destes três inibidores para o Clostridium beijerinckii $\mathrm{Br} 21$, visando a produção de $\mathrm{H}_{2}$ utilizando como fontes de carbono a mistura de glicose e xilose $(15 \mathrm{~g}$ de xilose $+15 \mathrm{~g}$ de glicose /L). Nos três ensaios podemos observar que a glicose foi consumida preferencialmente. E o efeito inibitório foi observado em relação a produção de ácido butírico, sendo que a vanilina causou maior inibição, seguida do siringaldeído e do HMF, nesta ordem.
\end{abstract}

Palavras-chave: Clostridium, glicose, xilose, biohidrogênio, inibidores.

\section{STUDY OF THE EFFECT OF INHIBITORS IN FERMENTATION ASSAYS WITH CLOSTRIDIUM BEIJERINCKII}

\begin{abstract}
Biofuels, such as $\mathrm{H}_{2}$, are fast advancing as alternative sources of renewable energy because of their non-polluting characteristics and cost competitiveness compared to fossil fuels. Therefore, among the various challenges for the development of biofuels obtained by bioprocesses from lignocellulosic materials is the integral use by microorganisms of the carbohydrates that make up the lignocellulosic biomass, in addition to overcoming the inhibitory effect that the other saccharification derivatives can cause in fermenting microorganisms. In addition to the difficulty of assimilating xylose in the presence of glucose, another factor that influences the efficient bioconversion of sugars derived from pre-treatments and the hydrolysis of lignocellulosic biomass in biofuels and other industrial chemicals is the generation of growth inhibitory compounds microbial biomass derived from lignin present in biomass. To better understand the hydrolyzate consumption of the lignocellulosic biomass, tests were carried out containing xylose in the presence of glucose and the presence of potential fermentation inhibitors resulting from the hydrolysis methods of these lignocellulosic materials, such as 5-hydroxymethylfurfural (5-HMF), syringaldehyde and vanillin. The concentration of $1 \mathrm{~g} / \mathrm{L}$ of these three inhibitors for Clostridium beijerinckii $\mathrm{Br} 21$ was tested for $\mathrm{H}_{2}$ production using the glucose and xylose mixture ( $15 \mathrm{~g} / \mathrm{L}$ of xylose $+15 \mathrm{~g} / \mathrm{L}$ of glucose) as carbon sources. In the three trials we can observe that glucose was consumed preferentially. And the inhibitory effect was observed in relation to butyric acid production, with vanillin causing greater inhibition, followed by seringaldehyde and $\mathrm{HMF}$, in that order.
\end{abstract}

Keywords: Clostridium, glucose, xylose, biohydrogen, inhibitors. 


\section{INTRODUÇÃO}

Os combustíveis oriundos de biomassa vegetal são denominados biocombustíveis e representam uma estratégia para obtenção de energia a partir de matéria orgânica renovável (PETROBRÁS, 2007). Uma das limitações mais importantes em relação à produção de biocombustíveis é o alto custo das matérias-primas. Por essa razão, as tendências recentes no desenvolvimento de processos biotecnológicos têm se concentrado no uso de resíduos lignocelulósicos para a obtenção de biocombustíveis (ANGENENT et al., 2004). O Brasil é o maior produtor mundial de cana-de-açúcar, seguido pela Índia e pela China. Além do açúcar e do etanol, o bagaço e a palha estão se tornando produtos de destaque nessa agroindústria, pois constituem importantes matérias-primas para a geração de energia (SALLES, 2015).

Em geral, os materiais lignocelulósicos devem ser pré-tratados e depois hidrolisados antes de serem usados como fonte de carbono em um processo de fermentação. O pré-tratamento é um passo importante, pois envolve a decomposição da parede celular e a deslignificação do complexo celulose-hemicelulose-lignina (ANDRADE et al., 2017).

Além da mistura de açúcares gerada após hidrólise, também são formados compostos de degradação destes açúcares, como o 5-hidroximetilfurfural (HMF), ácidos orgânicos e polifenóis derivados da lignina, estes são inibidores dos microrganismos fermentativos (JÖNSSON; MARTíN, 2016).

Compostos tóxicos/inibidores de crescimento são gerados dependendo do tipo de tratamento que a biomassa lignocelulósica é submetida. O tipo e a quantidade de inibidores gerados dependem da biomassa, uma vez que é a lignina a principal fonte destes inibidores(IBRAHEEM; NDIMBA, 2013).

Neste trabalho, avaliamos o efeito do HMF, do siringaldeído e da vanilina como inibidores derivado da hidrólise de materiais lignocelulósicos sobre a assimilação de xilose e de glicose pela cepa de C. beijerinckii $\operatorname{Br} 21$.

\section{MATERIAL E MÉTODOS}

O microrganismo utilizado foi o C. beijerinckii $\mathrm{Br} 21$ isolado em nosso laboratório (Fonseca et al., 2016), cultivado em frascos de penicilina de $100 \mathrm{~mL}$ contendo $60 \mathrm{~mL}$ de meio RCM líquido, com pH ajustado para 7 , contendo glicose $(15 \mathrm{~g} / \mathrm{L})$ e xilose $(15 \mathrm{~g} / \mathrm{L})$ como fontes de carbono, gás nitrogênio foi borbulhado para assegurar a anaerobiose do sistema o ensaio foi submetido a temperatura de $35{ }^{\circ} \mathrm{C}$ para crescimento. Foi realizado um ensaio controle, sem a presença de inibidores, um ensaio contendo $1 \mathrm{~g} / \mathrm{L}$ de HMF como inibidor, outro ensaio contendo $1 \mathrm{~g} / \mathrm{L}$ de siringaldeído e outro com $1 \mathrm{~g} / \mathrm{L}$ de vanilina. Amostras foram coletadas periódicamente para medida da concentração celular, $\mathrm{pH}$, e para análises dos metabólitos finais.

O crescimento celular foi determinado pela densidade ótica (DO) em $600 \mathrm{~nm}$ utilizando espectrofotômetro UV/Vis (BEL Engineering - UV - M51) e transformando-se este valor em concentração de massa celular seca representado em $\mathrm{mg} / \mathrm{L}$. O pH no decorrer dos ensaios foi medido utilizando pHmetro MS TECHNOPON®.

A quantificação da concentração de açúcares (glicose e xilose) durante os ensaios de fermentação, assim como a concentração de metabólitos formada foi realizada utilizando Cromatografia Líquida de Alta Eficiência - CLAE, com uso da coluna Aminex HPX-87H $(7,8 \mathrm{~mm}$ x $300 \mathrm{~mm})$ com temperatura controlada em $60^{\circ} \mathrm{C}$, sob condições isocráticas. A fase móvel utilizada foi de $\mathrm{H} 2 \mathrm{SO} 45 \mathrm{mmol} / \mathrm{L}$ com o fluxo de $0,4 \mathrm{~mL} / \mathrm{min}$. O detector utilizado foi o RID (índice de refração) e a aquisição e o tratamento dos dados foram realizados pelo software LabSolutions.

A composição do gás do head space dos frascos durante os ensaios foi determinada utilizando cromatógrafo a gás (CG 2014, Shimadzu, Japão) equipado com detector de condutividade térmica (DCT). Para as análises, utilizou uma coluna empacotada de peneira molecular $5 \mathrm{~A}(2,0 \mathrm{~m}$ x 4,7 mm), com gás argônio como gás arraste com vazão de $30 \mathrm{~mL} / \mathrm{min}$. As temperaturas do injetor, da coluna e do detector foram de $80,50 \mathrm{e}$ $100^{\circ} \mathrm{C}$, respectivamente.

Alíquotas retiradas no início e no final de cada ensaio de fermentação foram analisadas para verificar o consumo de xilose e os metabólitos solúveis formados.

Todos os experimentos foram realizados em triplicatas de forma independente, e os resultados apresentados como a média e seus desvios médios. A curva de crescimento celular, após conversão da densidade ótica (DO) em concentração de massa celular seca (mg/L) assim como a variação do pH no ensaio, foram obtidas para os diferentes inibidores em função do tempo. A equação de Boltzmann (sigmóide) foi o modelo estatístico ajustado aos dados experimentais (KANURIĆ et al., 2018; LONCAR et al., 2014). 


\section{RESULTADOS E DISCUSSÃO}

Os resultados de crescimento celular e $\mathrm{pH}$ do C.beijerincki $\mathrm{Br} 21$ durante os ensaios cinéticos com diferentes inibidores estão expressos na Figura 1. Os resultados mostraram que a cepa de Clostridium analisada foi capaz de crescer em todos os inibidores testados, com fase lag crescente para o HMF, siringaldeído e vanilina, respectivamente. As maiores concentrações celulares foram observadas no ensaio contendo HMF, indicando dessa forma uma menor inibição em relação aos demais.

Quanto ao $\mathrm{pH}$, um decaimento maior foi observado para maiores concentrações celulares, indicando maior formação dos ácidos orgânicos. Os valores de variação do $\mathrm{pH}$ foram maiores para o inibidor com menor efeito na fermentação, o HMF, seguido do siringaldeído e da vanilina, nesta ordem.

Os dados de consumo de substratos e produção de $\mathrm{H} 2$ e ácido butírico estão expressos na Figura 2 A, B, $\mathrm{C}$ e $\mathrm{D}$ para o controle (sem inibidor), o HMF, o siringaldeído e a vanilina, respectivamente. Quanto à produção de $\mathrm{H}_{2}$, a cepa apresentou produção máxima de 5,32 $\pm 0,14,6,15 \pm 0,12$ e e 4,02 $\pm 0,32 \mathrm{mmol} / \mathrm{L}$ de $\mathrm{H}_{2}$ para HMF, siringaldeído e vanilina, respectivamente.

Em relação aos metabólitos solúveis formados nos ensaios, a cepa $\mathrm{Br} 21$ produziu, como único metabólito, o ácido butírico, na concentração máxima de 68,70 \pm 0,83, 23,40 $\pm 2,98$ e 4,13 $\pm 0,35 \mathrm{mmol} / \mathrm{L}$, para $\mathrm{HMF}$, siringaldeído e vanilina, respectivamente.

As maiores concentrações foram observadas principalmente para o HMF, corroborando mais uma vez que esta cepa é mais resistente a esse inibidor nesta concentração.

\section{CONCLUSÃO}

Os resultados mostraram que a cepa é capaz de fermentar um meio contendo os três inibidores explorados. Nos três ensaios pudemos observar um maior consumo da glicose comparado ao consumo da xilose, confirmando a preferência desse monossacarídeo pelo metabolismo da cepa estudada. Nota-se que o $C$. beijerinckii $\mathrm{Br} 21$ produziu a maior quantidade de ácido butírico com o HMF. A capacidade de fermentar em presença de inibidores produzidos pela hidrólise de biomassa lignocelulósica para produção de $\mathrm{H}_{2}$ e ácido butírico justifica o interesse em estudar essa cepa.

\section{AGRADECIMENTOS \\ Este trabalho foi apoiado pelo Processo FAPESP 2018/00789-7 e pela CAPES.}

\section{REFERÊNCIAS}

ANDRADE, L. P. et al. Influence of sugarcane bagasse variability on sugar recovery for cellulosic ethanol production. Bioresource Technology, V. 241, P. 75-81, out. 2017.

ANGENENT, L. T. et al. Production of bioenergy and biochemicals from industrial and agricultural wastewater. Trends in Biotechnology, V. 22, N. 9, P. 477-485, set. 2004.

IBRAHEEM, O.; NDIMBA, B. K. Molecular adaptation mechanisms employed by ethanologenic bacteria in response to lignocellulose-derived inhibitory compounds. International Journal of Biological Sciences, V. 9, N. 6, P. 598-612, 2013.

JÖNSSON, L. J.; MARTÍN, C. Pretreatment of lignocellulose: formation of inhibitory by-products and strategies for minimizing their effects. Bioresource Technology, V. 199, P. 103-112, 1 jan. 2016.

KANURIĆ, K. G. et al. Kinetics of lactose fermentation in milk with kombucha starter. Journal of food and drug analysis, V. 26, N. 4, P. 1229-1234, 1 out. 2018.

LONCAR, E. et al. Kinetics of saccharose fermentation by kombucha. Chemical Industry and Chemical Engineering Quarterly, V. 20, N. 3, P. 345-352, 2014.

PETROBRÁS. Biocombustíveis 50 perguntas e respostas sobre este novo mercado. Ministério das Minas e Energia. [S.L: S.N.]. Disponível em: <https://www.agencia.cnptia.embrapa.br/repositorio/matprima1_ 000g7pcetcc02wx5ok0wtedt32e6jis7.pdf>. acesso em: 14 dez. 2018.

SALLES, S. Futuros do bioetanol: o Brasil na liderança? - GEOPI. [S.L: S.N.]. 


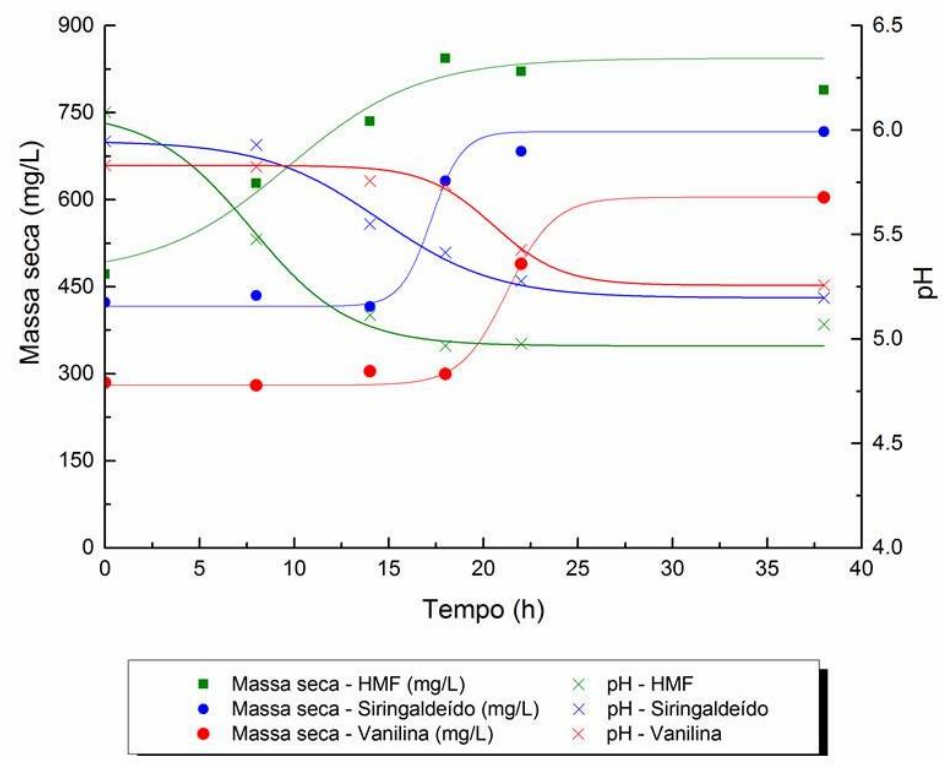

Figura 1. Concentração de massa celular seca $(\mathrm{mg} / \mathrm{L})$ e valores de $\mathrm{pH}$ em função do tempo (h) dos ensaios de fermentação realizados com adição de $1 \mathrm{~g} / \mathrm{L}$ de 5-HMF, siringaldeído e vanilina com a cepa de $C$. beijerinckii $\mathrm{Br} 21$.
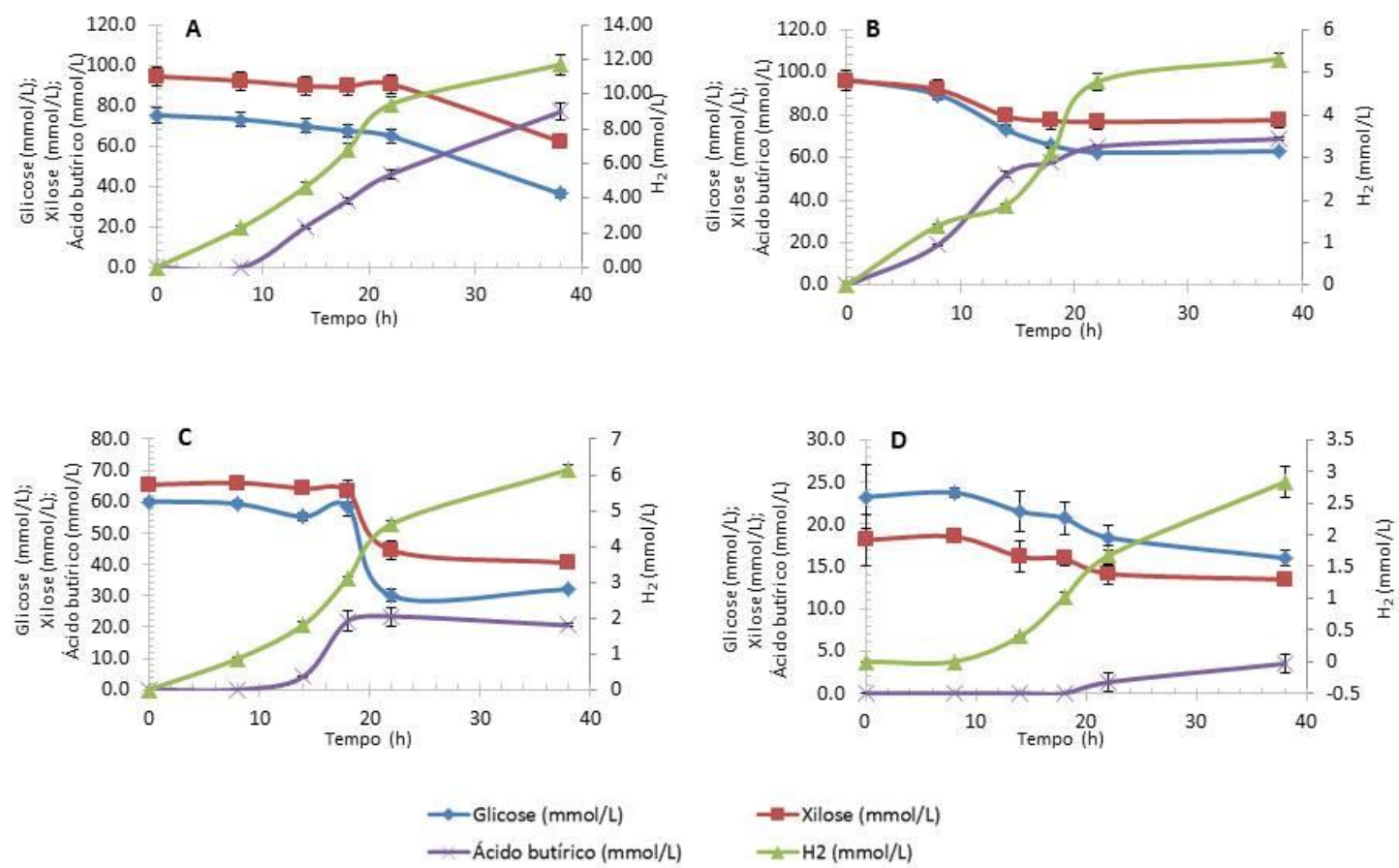

$$
\begin{aligned}
& -\mathrm{m}-\mathrm{Xilose}(\mathrm{mmol} / \mathrm{L}) \\
& =\mathrm{H} 2(\mathrm{mmol} / \mathrm{L})
\end{aligned}
$$

Figura 2. Concentração de glicose e xilose consumidas ( $\mathrm{mmol} / \mathrm{L}$ ); produção de $\mathrm{H}_{2}(\mathrm{mmol} / \mathrm{L})$ e produção de ácido butírico (mmol/L) em função do tempo (h) do ensaio da fermentação da cepa de C. beijerinckii $\mathrm{Br} 21$, sem adição de inibidores (A), com adição de $1 \mathrm{~g} / \mathrm{L}$ de 5 -HMF (B), $1 \mathrm{~g} / \mathrm{L}$ de siringaldeído (C) e $1 \mathrm{~g} / \mathrm{L}$ de vanilina $(\mathrm{D})$. 


\title{
WINDROW COMPOSTING AS STRATEGY TO RECYCLE ORGANIC WASTES FROM AQUACULTURE
}

\author{
Lopes, I.G. '; Souza, L.F. ${ }^{1}$; Cruz, M.C.P.'; Vidotti, R.M. ${ }^{1,3}$ \\ ${ }^{1}$ Centro de Aquicultura da UNESP. Via de Acesso Prof. Paulo Donato Castellane, s/n. CEP 14884-900 - Jaboticabal, SP, Brazil \\ +5511999474752*Corresponding Author - ivanguid@gmail.com \\ ${ }^{2}$ Faculdade de Ciências Agrárias e Veterinárias da Unesp, Departamento de Solos e Adubos. Via de Acesso Prof. Paulo Donato \\ Castellane, s/n. CEP 14884-900 - Jaboticabal, SP, Brazil \\ ${ }^{3}$ Agência Paulista de Tecnologia dos Agronegócios. Rodovia Washington Luiz, Km 372. Caixa Postal 24 - CEP 15830-000 - \\ Pindorama, SP, Brazil
}

\begin{abstract}
Aquaculture production is rapidly increasing worldwide and consequently, waste generation is growing. The aim of this study was to evaluate different methods of windrow composting and to access compost quality for agricultural use. By means of a $2 \times 2 \times 4$ factorial scheme testing two methods (with and without recharges of animal waste), two substrates (wood shavings and peanut shells) and four replicates, we assembled 16 compost piles and evaluated composting time, organic matter content, nitrogen and carbon concentrations and $\mathrm{pH}$ of the compost. Additionally, a seed germination test was performed to assess compost phytotoxicity. Composting time was 37 days for PS (peanut shells without recharges), 47 for PSR (peanut shell with recharges), 53 days for WS and WSR (wood shavings without and with recharges, respectively). All piles showed temperatures above $55{ }^{\circ} \mathrm{C}$ for at least 15 days due to periodic turnings, thus ensuring pathogen reduction, and the composts' total nitrogen concentration ranged from 22 to $33 \mathrm{~g} \mathrm{~kg}^{-1}$, whilst inorganic nitrogen represented from $7.0 \%$ (PS) to $17.7 \%$ (WS) of this total. The average humid yield of treatments without recharges (WS and PS) was 61.6\% and for PSR and WSR was 50.6\%. Finally, the seed germination test revealed no phytotoxicity in the produced composts. It was concluded that windrow composting is an adequate method to manage aquaculture waste, transforming the materials into a stable high-quality product for agricultural use and for degraded soils' recovery.
\end{abstract}

Keywords: fish carcass, fish farm, circle economy, biotechnology, thermophilic.

\section{INTRODUCTION}

Aquaculture is one of the fastest growing food sectors annually and according to FAO (2016), fish production exceeded 167 million tons in $2014,44 \%$ of which is represented by continental and marine aquaculture. The activity's growth brings with it a significant increase in organic waste generation and in general, rural enterprises do not have precious planning to deal with this waste and in consonance, the producers are not prepared technically to deal with these materials. Similarly, other sectors of aquaculture, such as research centers, are sometimes not prepared to manage such waste.

The solid fraction of waste generated in aquaculture enterprises (e.g. naturally dead animals or carcasses from processing) have rich organic loads and can contribute negatively to environmental problems when ignored or inadequately disposed. The exploitation of this waste is of great interest, seen that from different technologies it is possible to reduce volumes and recycle nutrients, increasing the possibility of income generation from waste (Lalander et al., 2017). Among several possibilities of waste management, windrow composting stands out as a method of low initial investment and simple maintenance (Lopes et al., 2017), as well as being used to manage wastes that cannot be used for another purpose, such as decomposing carcasses (Vidotti et al., 2016).

Besides reducing significantly the initial waste biomass (Lopes et al., 2017), the composting process results in the production of nutrient rich organic fertilizers, which can be directly applied with the aim of increasing soil fertility and the fertilization of crops (Mantovani et al., 2005). Carcasses of aquatic animals are rich in essential nutrients for plants (e.g. nitrogen $\mathrm{N}$, phosphorus $\mathrm{P}$ and calcium $\mathrm{Ca}$ ), increasing the potential of using organic composts produced with it. Thus, the aim of this study was to evaluate windrow composting by means of two distinct methods and the final nutritional quality of the produced composts.

\section{MATERIAL AND METHODS}

The experiment was conducted in the Composting Sector of the Aquaculture Center of Unesp (Caunesp), Jaboticabal/SP, Brazil, between February and December 2017. The used wastes were whole fish, shellfish and 
frog carcasses, minced carcasses, viscera and others, which summed up to $3900 \mathrm{~kg}$ throughout collection period, being part of this waste used in this study. The plant substrates used as carbon sources and aeration materials were wood shavings and peanut shells, characterized in Table 1.

Four treatments were performed in a $2 \times 2 \times 4$ factorial scheme, using two plant substrates, two methods (with and without the recharge of animal wastes) and four replicates, defined as WS (wood shavings without recharges), PS (peanut shells without recharges), WSR and PSR (wood shavings and peanut shells with recharges, respectively. The proportions between plant substrate and aquaculture wastes resulting from the different methods were 0.8:1.0 (w/w) and 0.5:1.0 (w/w) in treatments without and with recharges, respectively. Windrows were assembled using the minimum of substrate possible, in order to maintain the shape of the piles with good internal aeration, as demonstrated in Figure 1.

The need for management of the windrows was defined based on two variables, temperature and moisture, so that when one of these variables was not within the adequate limits foreseen in the literature (Eggen e Vethe, 2001; Richard et al., 2002), a complete turning of the material was performed manually (which occurred in average every 7 days), with water addition. At the end of the experiment, the produced composts were homogenized and three samples collected per windrow. Samples were dried $\left(65^{\circ} \mathrm{C}\right)$ for 16 hours, grinded and sieved $(1 \mathrm{~mm})$, and analyzed for $\mathrm{pH}$, organic matter content $(\mathrm{OM})$, total organic carbon $\left(\mathrm{C}_{\mathrm{T}}\right)$, total nitrogen $\left(\mathrm{N}_{\mathrm{T}}\right)$, inorganic nitrogen $\left(\mathrm{N}_{-} \mathrm{NH}_{4}{ }^{+} \mathrm{e} \mathrm{N}-\mathrm{NO}_{3}{ }^{-}\right)$and final $\mathrm{C} / \mathrm{N}$ ratio. Additionally, the composts were kept for 60 and 100 days in an aerated place for curing and later analysis. The same procedures and analysis were performed in the composts after the periods mentioned.

A seed germination test proposed by Zucconi et al. (1981) was performed to evaluate possible phytotoxic effects on the produced composts. Liquid extracts were prepared and both lettuce (Lactuca sativa) and cress seeds (Nasturtium officinale) were disposed in germination boxes for 120 hours with 12/12 photoperiod. A control treatment was defined with deionized water. The percentage of germination, roots and aerial part length were measured. All data were analyzed for errors normality (Cramér-von-Mises) and homoscedasticity of variances (Box-Cox). Considering the randomized factorial scheme of $2 \times 2 \times 4$, the variables were submmited to a variance analysis (one-way ANOVA) followed by the multiple comparison test of Tukey (5\% 0. Differently, seed germination data were analyzed by a one-way ANOVA followed by the Dunnett's test (5\%). All statistical tests were performed with the aid of the software R.

\section{RESULTS AND DISCUSSION}

Composting time varied from 37 (PS), 47 (PSR) and 53 days (WS and WSR), being defined by the drop of the temperature without returning to the thermophilic range $\left(40-70{ }^{\circ} \mathrm{C}\right)$, even after turning and adding water to the materials, staying equal to ambient temperature. The humid yield was $58.5 \pm 1.7 \%$ in WS, $64.7 \pm 6.4 \%$ in PS, $49.3 \pm 1.3 \%$ in WSR and $54.3 \pm 3.2 \%$ in PSR. Moisture was kept within 40-60\% and temperature increased to higher values then $55^{\circ} \mathrm{C}$ in all windrows, assuring maximum pathogen reduction (Andreev et al., 2017). The final $\mathrm{pH}$ of the composts was kept above 6.0 (Table 2), considered as adequate for its application in the soil without risks of acidification (US Composting Council, 2001).

The $\mathrm{N}_{\mathrm{T}}$ contents were satisfactory in all produced composts. However, the recharge of animal wastes in pre-existing windrows favored the accumulation of this nutrient in WSR and PSR. The concentrations of N$\mathrm{NH}_{4}{ }^{+}$and $\mathrm{N}-\mathrm{NO}_{3}{ }^{-}$represented $17.7 \%$ of $\mathrm{N}_{\mathrm{T}}$ in WS, 7.04\% in PS, 8.64\% in WSR and $14.9 \%$ in PSR. In addition to the low $\mathrm{C} / \mathrm{N}$ ratios observed, it is possible to assume that the composts had adequate characteristics for agricultural use, by being able to rapidly provide large amounts of $\mathrm{N}$ to crops, avoiding possible immobilizations of the soil $\mathrm{N}$ (Abera et al., 2012).

After 60 and 100 days passed the composting process, the cured composts presented the same characteristics $(\mathrm{P}>0.05)$ in comparison to the initial analysis, which was performed exactly after the end of decomposition. Facing this fact, it is possible to rise two hypothesis: $i$ ) the adopted handling was efficient and the final physico-chemical characteristics of the composts would not be altered throughout time, i.e. the composts were ready to be applied to the soil; ii) water addition and turnings could be done even in curing composts, aiming to improve its characteristics. However, adopting this method in curing composts implies in increased costs with labor, energy and land use, facts that should be taken into account to evaluate the benefits of this possibility.

Seed germination was satisfactory, reaching more than $50 \%$ of seeds germinated for both lettuce and cress (Table 3), proposed as the minimum percentage for stable composts free of phytotoxicity (Zucconi et al., 1981). Immature composts may present high concentrations of salts and phytotoxic substances, such as 
polyphenols, which may inhibit germination and the initial development of seedlings (Gavilanes-Terán et al., 2016). The height of seedlings did not differ among treatments, however cress's root length of seeds exposed to composts extracts was differential in relation to the control treatment (with deionized water), a fact that was attributed to the lack of available nutrients which leads to root elongation, as plants search for better conditions to develop (Forde and Lorenzo, 2001).

\section{CONCLUSIONS}

Composting organic aquaculture wastes in windrows with periodic turnings allows the production of high quality composts in short periods. Using peanut shells as substrate and carbon source yielded composts with higher yields in comparison to wood shavings, and for both plant substrates, the final products proved stable and free of phytotoxicity. Curing composts for 100 days does not alter physico-chemical characteristics of the composts, when no handlings are used.

\section{REFERENCES}

Abera G, Wolde-Meskel E, Bakken LR (2012) Carbon and nitrogen mineralization dynamics in different soils of the tropics amended with legume residues and contrasting soil moisture contents. Biology and Fertility of Soils 48: 51-66. https://doi.org/10.1007/s00374-011-0607-8.

Andreev N, Ronteltap M, Boincean B, Lens PNL (2017) Treatment of source-separated human feces via lactic acid fermentation combined with thermophilic composting. Compost Science and Utilization 25: 220-230. https://doi.org/10.1080/1065657X.2016.1277809.

Egen T, Vethe $\varnothing$ (2001) Stability indices for different composts. Compost Science and Utilization 9: 19-26. https://doi.org/10.1080/1065657X.2001.10702013.

FAO (2016) The State of World Fisheries and Aquaculture 2016. Contributing to food security and nutrition for all. Rome. 200 pp.

Forde B, Lorenzo H (2001) The nutritional control of root development. Plant and Soil 232: 51-68. https://doi.org/10.1023/A:1010329902165.

Lalander C, Nordberg A, Vinnerås B (2017) A comparison in product-value potential in four treatment strategies for food waste and faeces - assessing composting, fly larvae composting and anaerobic digestion. Global Change Biology Bioenergy 10: 84-91. https://doi.org/10.1111/gcbb.12470.

Lopes IG, Vidotti RM, Martins ALM (2017) Compostagem orgânica: método eficiente para a gestão de resíduos de animais da aquicultura. Pesquisa \& Tecnologia 14 (1), 1-6.

Mantovani, JR.; Ferreira, M.E.; Cruz, MCP; Barbosa, J.C (2005). Alterações nos atributos de fertilidade em solo adubado com composto de lixo urbano. Revista Brasileira de Ciência do Solo 29: 817-824.

Richard TL, Hamelers HVM, Veeken A, Silva T (2002) Moisture relationships in composting processes. Compost Science and Utilization 10: 286-302. https://doi.org/10.1080/1065657X.2002.10702093.

US Composting Council. Field guide to compost use (2001). http://compostingcouncil.org/admin/wpcontent/plugins/wp-pdfupload/pdf/1330/Field_Guide_to_Compost_Use.pdf (accessed October 29, 2018).

Vidotti RM, Lopes IG (2016) Resíduos orgânicos gerados na piscicultura. Pesquisa \& Tecnologia 13: 1-6.

Zucconi F, Pera A, Forte M, de Bertoldi M (1981) Evaluating toxicity of immature compost. Biocycle 22, 5457.

Table 1. Chemical characterization of wood shavings $(n=3)$, peanut shells $(n=3)$ and aquatic animal carcasses $(\mathrm{n}=10)$.

\begin{tabular}{llll}
\hline & Wood Shavings & Peanut Shells & Animal Carcasses \\
\hline $\mathrm{C}\left(\mathrm{g} \mathrm{kg}^{-1}\right)$ & $489.4 \pm 11.1$ & $485.7 \pm 9.6$ & $533.0 \pm 10.1$ \\
$\mathrm{~N}\left(\mathrm{~g} \mathrm{~kg}^{-1}\right)$ & $1.9 \pm 0.1$ & $12.6 \pm 0.2$ & $80.1 \pm 2.3$ \\
$\mathrm{C} / \mathrm{N}$ & $257.9 \pm 9.24$ & $38.4 \pm 2.11$ & $5.73 \pm 0.07$ \\
Cellulose $(\%)$ & $44.62 \pm 0.7$ & $32.93 \pm 0.6$ & $\mathrm{ND}$ \\
Hemicellulose (\%) & $14.89 \pm 0.3$ & $14.50 \pm 0.5$ & $\mathrm{ND}$ \\
Lignin (\%) & $24.32 \pm 0.6$ & $32.65 \pm 0.4$ & $\mathrm{ND}$ \\
$\mathrm{OM}(\%)$ & $87.4 \pm 1.0$ & $80.5 \pm 0.7$ & $63.3 \pm 0.3$ \\
$\mathrm{MM}(\%)$ & $0.11 \pm 0.0$ & $4.09 \pm 0.2$ & $11.4 \pm 0.1$ \\
\hline
\end{tabular}

Values presented as mean \pm standard deviation. $\mathbf{C}$ : organic carbon; $\mathbf{N}$ : total nitrogen; $\mathbf{C}$ : $\mathbf{N}$ : carbon: nitrogen ratio; OM: organic matter; MM: mineral matter; ND: not determined. 
Table 2. Physico-chemical characterization of produced composts $(n=4)$ with animal and plant wastes, at the end of the experiments.

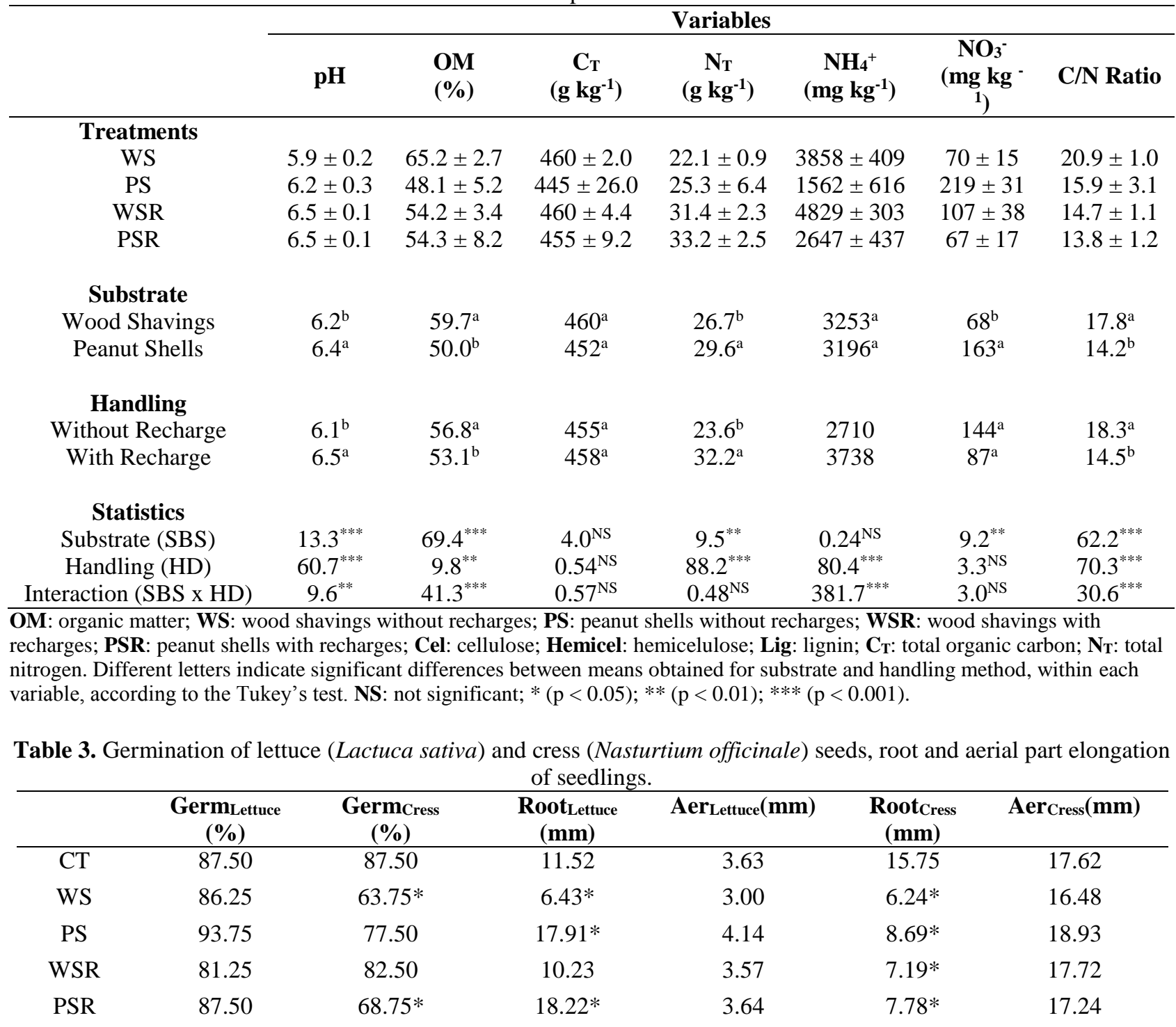

Values presented as means \pm standard deviation $(\mathrm{n}=4)$. WS: wood shavings without recharges; PS: peanut shells without recharges; WSR: wood shavings with recharges; PSR: peanut shells with recharges; Germ: germination; Aer: seedlings aerial part. Asterisks indicate significant differences of the variable with its control in the same column, according to the Dunnett's test $(\mathrm{p}<0.05)$.
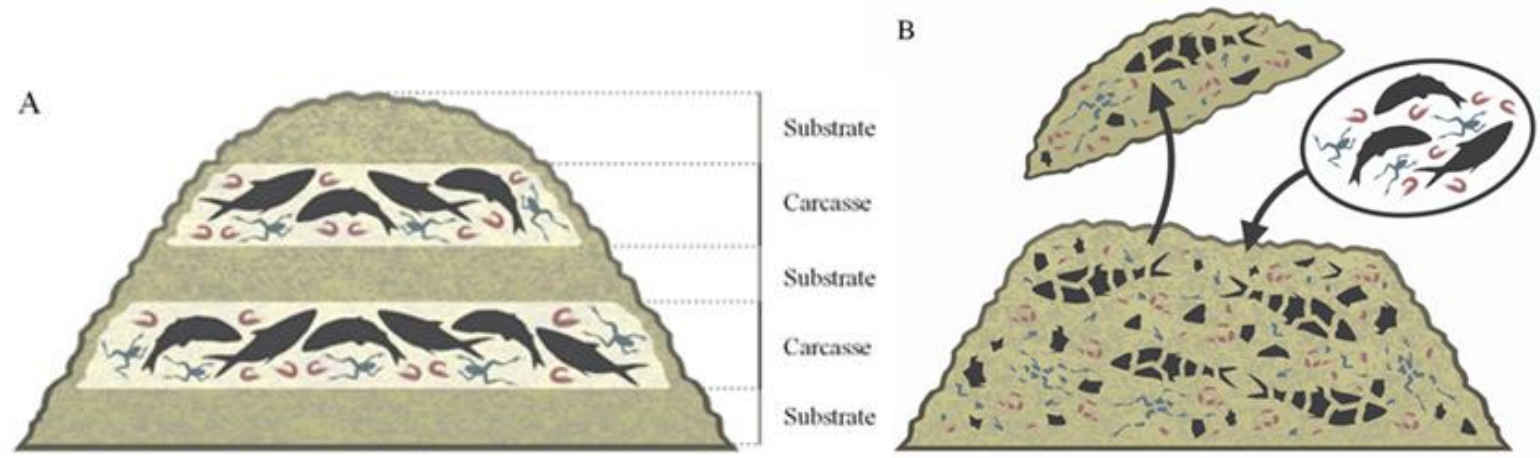

Figure 1. Schematic representation of the initial assembly of a composting windrow in layers (a); and of a recharge event with carcasses of aquatic animals in a pre-existing windrow, evidencing the homogenization of decomposing materials with the substrate (b). 


\title{
EFFECT OF NITROGEN LOADING RATE ON DIGESTATE TREATMENT BY DEAMMONIFICATION PROCESS
}

\author{
Chini, A. ${ }^{1}$; Hollas, C.E. ${ }^{1}$; Bolsan, A.C. ${ }^{2}$; Antes, F.G. ${ }^{3 *}$; Treichel, H. ${ }^{4}$; Kunz, A. ${ }^{1,3,4}$ \\ ${ }^{1}$ Department of Agricultural Engineering, PGEAGRI-UNIOESTE, Cascavel, PR, Brazil - angechini@gmail.com \\ ${ }^{2}$ University of Western of Santa Catarina, Joaçaba, SC, Brazil \\ ${ }^{3}$ Embrapa Suínos e Aves, Concórdia, SC, Brazil \\ ${ }^{4}$ Department of Environmental Science and Technology, UFFS, Erechim, RS, Brazil
}

\begin{abstract}
Deammonification is being studied as an alternative for digestate treatment to remove ammoniacal nitrogen. In this process, the ammonia is partially oxidized to nitrite, and both species, $\mathrm{NO}_{2}{ }^{-}-\mathrm{N}$ and $\mathrm{NH}_{4}{ }^{+}-\mathrm{N}$, are substrate to anammox process, under autotrophic conditions. The concentration of ammoniacal nitrogen in effluents is an important key to be controlled in this process to avoid overloading that could be deleterious to anammox bacteria. The present study aimed to test the effect of nitrogen loading rate (NLR) over the deammonification process in an EGSB reactor. It could be concluded that digestate treatment by deammonification process is feasible with nitrogen removal efficiency higher than $80 \%$ for a NLR of 2.5 $\mathrm{kg} \mathrm{m}^{-3} \mathrm{~d}^{-1}$.
\end{abstract}

Keywords: anammox; partial nitration; ammoniacal nitrogen; wastewater treatment.

\section{INTRODUCTION}

Swine farming stands out as a productive chain of great economic and social importance, especially in the southern region of Brazil. Thus, in order to increase productivity and to have greater sanitary control, subsistence model goes to larger concentrated animal feeding operations (CAFOs) in small territorial areas. However, this production model generates high effluent volumes (Kunz, Miele e Steinmetz, 2009). Thus, swine manure has high concentration of nitrogen, organic matter and other pollutants which exceeds land assimilation capacity arising the need to reduce the negative impacts over the environment.

The organic matter can be considerably reduced by anaerobic digestion (AD) process (Amaral et al., 2016). However, the nitrogen is not removed in this process and an additional treatment is required to reduce this nutrient in digestate (AD effluent). An alternative to treat the nitrogen is the deammonification process (Chini et al., 2016). Deammonification is a consortium of anammox and nitrifying bacteria. Initially, occurs the partial nitritation, where the ammoniacal nitrogen is partially converted to nitrite, thus providing the stoichiometric conditions required by anammox process.

According to the literature, the nitrogen loading rate (NLR) usually employed vary from $0.06 \mathrm{~kg} \mathrm{~m}^{-3} \mathrm{~d}^{-}$ ${ }^{1}$ (Xu et al., 2018) to $0.7 \mathrm{~kg} \mathrm{~m}^{-3} \mathrm{~d}^{-1}$ (Pichel et al., 2018) on the deammonification process for digestate treatment. Considering the relatively high concentration of ammoniacal nitrogen in digestate, the objective of this work was to evaluate the effect of higher NLR, compared to those usually reported in literature.

\section{MATERIAL AND METHODS}

The study was carried out at the Laboratory of Experimentation and Environmental Analysis (LEEA) of Embrapa Suínos e Aves - Concórdia/SC. The deammonification process was established in an EGSB, singlestage (working volume of $1 \mathrm{~L}$ ). Feeding was carried out with a digestate from a continuous stirred tank reactor (CSTR), which operates with high solids concentration $\left(20 \%, \mathrm{v} \mathrm{v}^{-1}\right)$ under mesophilic conditions treating swine manure. The main parameters evaluated were: $\mathrm{pH}$, dissolved oxygen (DO), temperature, $\mathrm{NH}_{4}{ }^{+}-\mathrm{N}, \mathrm{NO}_{2}{ }^{-}$ $-\mathrm{N}, \mathrm{NO}_{3}^{-}-\mathrm{N}$ and total organic carbon (TOC) (Rice et al., 2017). The reactor was monitored for 178 days and was divided into six phases according to the NLR applied during this period that ranged from 1.2 to $3.2 \mathrm{~kg} \mathrm{~m}^{-}$ ${ }^{3} \mathrm{~d}^{-1}$ (Table 01).

\section{RESULTS AND DISCUSSION}

The work involved the reactor monitoring to evaluate how much the increase of NLR affects the efficiency of nitrogen removal. The system started (phase 1) to be fed with digestate at a NLR of $1.22 \pm 0.06$ $\mathrm{kg} \mathrm{m}^{-3} \mathrm{~d}^{-1}$ and the average efficiency of total nitrogen removal (TNR) during this phase was $70 \pm 0.07 \%$ (Figure 
01). It was higher than observed by Pichel et al. (2018), that reached a NLR of $0.3 \mathrm{~kg} \mathrm{~m}^{-3} \mathrm{~d}^{-1}$. In phase 2, NLR was increased to $1.67 \pm 0.21 \mathrm{~kg} \mathrm{~m}^{-3} \mathrm{~d}^{-1}$ and the TNR efficiency was $66 \pm 11 \%$. In the beginning of this phase the efficiency decreased, but from the 52 operational day the TNR efficiency increased to $66 \pm 5.15 \%$ and remained stable until the end of the phase. From $3^{\text {rd }}$ until $5^{\text {th }}$ phase the behavior of TNR efficiency was similar as can be seen at Figure 01, remaining around $78 \pm 7.4 \%$. In the phase 6, when the NLR was $3.15 \pm 0.02 \mathrm{Kg}$ $\mathrm{m}^{-3} \mathrm{~d}^{-1}$ the TNR efficiency raised to $81 \pm 5.9 \%$.

In order to prove the presence of ammonia oxidizing bacteria (anammox), the stoichiometric coefficients for chemical species involved in anammox process were calculated. These values are shown in Figure 02 in comparison to the theoretical coefficients (Buha et al., 2015). The $\mathrm{N}_{2}$ coefficient remained very close to the theoretical value, which corroborates with the assumption that deammonification process is responsible for the ammonia removal.

Additionally, it was observed that the $\mathrm{NO}_{3}{ }^{-} \mathrm{N}$ coefficient remained below the value established by literature and, therefore, it is assumed that another process occurred along with the deammonification, as for example denitrification. However, the nitrogen removal through denitrification probably was almost negligible because the consumption of TOC during treatment was of about $17 \pm 11.5 \%$. As known, organic carbon is the electron acceptor during heterotrophic denitrification. It is important to highlight that the ammonia load used in this work is about 9.3 times higher than normally applied in this type of process (CAO et al., 2017), which shows the robustness of the reactor used in this work.

\section{CONCLUSIONS}

The deammonification process is a promising technology in the wastewater treatment with high concentrations of ammoniacal nitrogen as digestate, mainly because the anammox process has a relatively low operational cost in relation to other nitrogen removal processes usually used.

\section{ACKNOWLEDGMENT}

The authors gratefully acknowledge the support provided by the project SISTRATES FUNTECBNDES, CNPq and CAPES.

\section{REFERENCES}

Amaral, a. C. Do et al. Influence of solid-liquid separation strategy on biogas yield from a stratified swine production system. Journal of environmental management, v. 168, p. 229-235, 2016.

Buha, d. M. Et al. Review on wastewater treatment technologies for nitrogen removal. Global journal of multidisciplinary studies, v. 4, n. 6, p. 299-318, 2015.

Cao, s. Et al. Nitrite production from partial-denitrification process fed with low carbon/nitrogen (c/n) domestic wastewater: performance, kinetics and microbial community. Chemical engineering journal, $v$. 326, p. 1186-1196, 2017.

Chini, a. Et al. Recirculation and aeration effects on deammonification activity. Water, air, and soil pollution, v. 227, n. 2, 2016.

Kunz, a.; miele, m.; steinmetz, r. L. R. Advanced swine manure treatment and utilization in brazil. Bioresource technology, v. 100, n. 22, p. 5485-5489, 2009.

Pichel, a. Et al. How to cope with nob activity and pig manure inhibition in a partial nitritation-anammox process? Separation and purification technology, 2018.

Rice, e. W. Et al. Standard methods for the examination of water and wastewater. 23. Ed. Washington: american public health association, 2017.

$\mathrm{Xu}$, x. Et al. Start-up of a full-scale snad-mbbr process for treating sludge digester liquor. Chemical engineering journal, v. 343, p. 477-483, 2018. 
Table 1. Distribution in phases of experimental days according to the nitrogen loading rate (NLR).

\begin{tabular}{ccc}
\hline Phase & Operational days & NLR $\left(\mathbf{k g ~ m}^{\mathbf{- 3}} \mathbf{d}^{\mathbf{- 1}}\right)$ \\
\hline 1 & $1-32$ & $1.22 \pm 0.06$ \\
2 & $33-74$ & $1.67 \pm 0.21$ \\
3 & $75-103$ & $2.01 \pm 0.04$ \\
4 & $104-132$ & $2.44 \pm 0.09$ \\
5 & $133-170$ & $2.88 \pm 0.08$ \\
6 & $171-178$ & $3.15 \pm 0.02$ \\
\hline
\end{tabular}

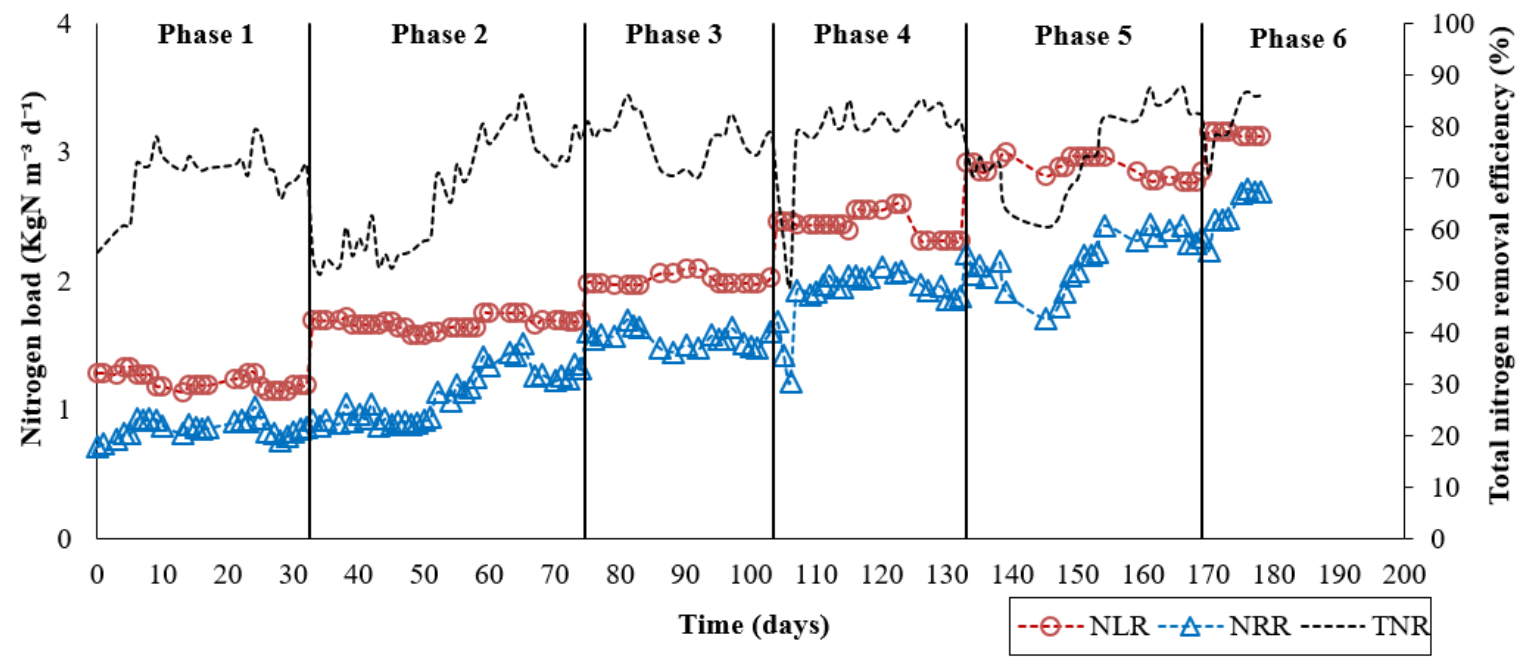

Figure 1. Nitrogen loading rate (NLR), nitrogen removal rate (NRR) and total nitrogen removal (TNR) efficiency of EGSB reactor during the experimental phases.

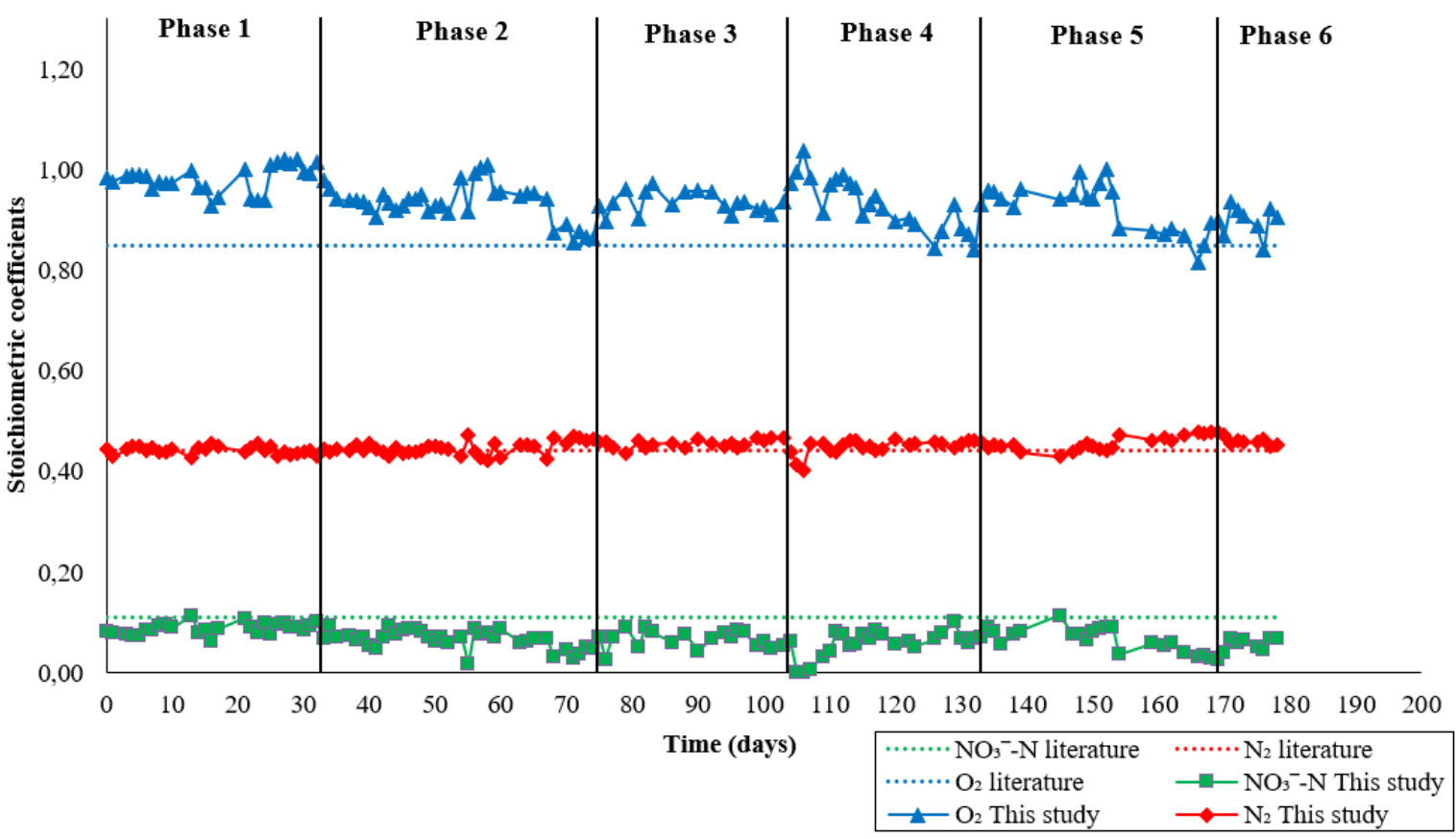

Figure 2. Stoichiometric coefficients calculated from results obtained at this work and at the literature. 


\title{
ESTUDO DA CORRELAÇÃO ENTRE TEMPERATURAS E A REMOÇÃO DA MATÉRIA ORGÂNICA EM BIODIGESTORES
}

\author{
Sousa, I.P.* ${ }^{1}$; Rosa, A.P. ${ }^{1}$; Souza, S.M. ${ }^{1}$; Oliveira, N.S. ${ }^{1}$; Magos, B.R. ${ }^{1}$; Perez, R. ${ }^{1}$; \\ ${ }^{1}$ Universidade Federal de Viçosa, Viçosa, $M G$ - Brasil \\ *izabelle.sousa@ufv.br
}

\begin{abstract}
RESUMO: O objetivo do estudo foi avaliar a correlação entre as temperaturas externas (ambiente, efluente e solo) e interna (biogás e substrato) do biodigestor, sendo que estas foram ainda correlacionadas com a eficiência de remoção da demanda química de oxigênio (DQO). O estudo foi desenvolvido em uma suinocultura localizada no município de Teixeira - MG. O monitoramento das temperaturas foi realizado por sensores de temperatura instalados no biodigestor para aferir as temperaturas do biogás e do substrato e na área próxima ao biodigestor para aferir a temperatura do solo, ambiente e do efluente. As coletas do efluente (entrada e saída) foram realizadas semanalmente determinando-se a DQO. Observou-se que todas as temperaturas monitoradas se correlacionam linearmente, apresentando r acima de 0,9 . As temperaturas do meio ambiente e a do substrato apresentaram melhor associação com a temperatura do solo, assim como a temperatura do biogás foi melhor associada com a temperatura ambiente. E por fim, a remoção de DQO apresentou melhor correlação linear com a temperatura do biogás $(r=0,89)$, seguida do substrato $(r=0,85)$, solo $(\mathrm{r}=0,85)$ e por último ambiente $(\mathrm{r}=0,82)$. Conclui-se que o monitoramento da temperatura do solo apresenta grande influência nos sistemas de biodigestores modelo Canadense. Em adição, a eficiência de remoção de DQO foi melhor correlacionada pela temperatura do biogás.
\end{abstract}

Palavras-chave: biodigestor, água residuária, suinocultura, correlação, temperatura.

\section{STUDY OF THE CORRELATION BETWEEN TEMPERATURES AND REMOVAL OF ORGANIC MATTER IN BIODIGESTORS}

ABSTRACT: This study aimed at evaluating the correlation between external temperatures (environmental, effluent and soil) and internal temperatures (biogas and substrate) in a biodigestor as well as the COD (Chemical Oxygen Demand). The experiment was carried out at a pig farm in Teixeiras, Minas Gerais. Temperature sensors were installed to measure the internal and external temperatures of the biodigester. The data were collected from January to September 2018. The sampling campaigns for COD characterization were performed weekly. It was observed that all monitored temperatures presented a linear correlation (r) above 0.9. Environmental and substrate temperatures showed better association with soil temperature and the biogas was better correlated with the environment temperature. Finally, the removal of COD had a better linear correlation with the biogas temperature $(\mathrm{r}=0,89)$, followed by the substrate $(\mathrm{r}=0,85)$, soil $(\mathrm{r}=0,85)$ and environment $(0,82)$. In addition the soil temperature presented a greater influence on the Canadense model biodigester, and the COD removal efficiency was better correlated by the biogas temperature.

Keywords: biodigestor, wastewater, pig farming, correlation, temperature.

\section{INTRODUÇÃO}

A suinocultura nos últimos anos se expandiu de forma significativa no Brasil, atingindo uma produção de 3,75 milhões de toneladas de carne suína no ano de 2017 (ABPA, 2018). Em virtude da elevada produção de suinos e do grande aporte de dejetos gerados, identifica-se o alto potencial poluidor da atividade. Os biodigestores atuam como solucionadores dos problemas para o tratamento desses dejetos, sendo atrativo não apenas para o controle dos impactos ambientais, mas também para o aproveitamento energetico do biogás, subproduto gerado no processo anaeróbio.

A tecnologia de biodigestão anaerobia é conhecida há anos, porém ainda é pouco difundida entre os produtores, muitas vezes por falta de suporte técnico ou conhecimento para intervenção no processo, em especial no sentido de potencializar as eficiência de remoção de matéria orgânica e produção do biogás (FERNANDES FILHO, et al. 2018). 
Dentre os modelos de biodigestores disponíveis no mercado, o biodigestor modelo canadense se destaca pelo menor custo de construção e operação (CALZAR et al. 2015). Todavia, a tecnificação desse sistema é um grande desafio, devido a eficiência do processo de biodigestão anaeróbia ser facilmente afetado por vários fatores, principalmente pela temperatura (LIN et al. 2016).

Apesar de alguns estudos afirmarem que o controle da temperatura é primordial para que o sistema atinja uma ótima eficiência no processo, ainda existem lacunas sobre como as temperaturas podem afetar a eficiência de remoção da biomassa em biodigestores modelo canadense em escala plena.

Dessa forma, objetivou-se avaliar a correlação entre as temperaturas do meio ambiente, solo e interna do biodigestor sendo eles, do biogás e do lodo (substrato). Além de correlacioná-las com a eficiência de remoção da DQO.

\section{MATERIAL E MÉTODOS}

O monitoramento foi realizado em uma suinocultura localizada no município de Teixeiras- MG. A granja possui sistema produtivo em ciclo completo com 946 matrizes e seu sistema de tratamento é composto por dois biodigestores modelo Canadense em paralelo, com dimensões externas de 13,4 m de largura e 37,5 m de comprimento e dimensões interna (parte enterrada no solo) 10 e 34,0 m de largura e comprimento, respectivamente, e $2,5 \mathrm{~m}$ de profundidade.

No sistema de tratamento foram instalados sensores de temperatura, conforme observado na Figura 1. Os dados de temperatura foram enviados e armazenados em intervalos de 30 segundos, via internet, para um banco de dados monitorado de forma remota no centro de conhecimento em Bioenergia, situado na Universidade Federal de Viçosa (UFV), Viçosa- MG. Os dados foram tratados de forma que se obteve as médias diárias, seguidas de médias mensais e desvio padrão (DP).

Em adição, o monitoramento da qualidade do efluente (entrada e saída) nos biodigestores em termos de DQO foi realizado semanalmente, seguindo metodologia indicada por APHA (2017). Os dados do monitoramento das temperaturas e da qualidade do efluente foram avaliados no período de janeiro a setembro de 2018. A partir dos dados tratados, permitiu-se analisar as tendências das temperaturas mensais em relação à eficiência de remoção de DQO. O estudo da influência entre as temperaturas e as eficiências de remoção de DQO foi realizado a partir da análise do coeficiente de correlação de Pearson (r) com nível de $5 \%$ de significância $(\alpha)$ pelo teste de Student (teste“"t") calculados pelo software ${ }^{\circledR}$ 3.5.0.

\section{RESULTADOS E DISCUSSÃO}

As eficiências de remoção de DQO nos meses de janeiro a setembro variaram entre 73 a $22 \%$ (Tabela 1), o que está de acordo com o reportado por Campos et al., (2004) e Souza et al., (2014) os quais indicaram eficiências para a remoção de DQO em biodigestores modelo Canadense de $58 \%$ e $72 \%$, respectivamente. Foi observado que o efluente do sistema de tratamento não atende ao padrão de lançamentos de efluentes em corpos hídricos. A normativa COMPAM/CERH-MG n ${ }^{\circ} 1 / 08$ determina uma redução mínima de $70 \%$ da carga orgânica quantificado por DQO ou $75 \%$ em média anual, tendência já reportada como característica dos sistemas anaeróbios, os quais requerem pós-tratamento (MINAS GERAIS, 2008). Tal condição foi somente atendida no mês de março.

Segundo Chen et al., (2008) variações de temperatura no processo anaeróbio de até $5^{\circ} \mathrm{C}$ podem afetar a ação microbiológica no processo e consequentemente, reduzir a produção de biogás, mas com o passar do tempo retorna ao padrão de produção de biogás, para o sistema monitorado a amplitude de variação do substrato foi de $5,3^{\circ} \mathrm{C}$ comparando-se o mês mais quente com o mês mais frio. No entanto, as alterações na temperatura do substrato aconteceram de forma gradual não ultrapassando $1,5^{\circ} \mathrm{C}$ de um mês para o outro, com exceção ao intervalo de agosto para setembro que apresentou um aumento de $2,5^{\circ} \mathrm{C}$ (Tabela 1 ). Desta forma, as alterações de temperatura do substrato observadas nesse estudo estão dentro do citado por esse autor não causando dados irreversíveis processo.

De forma geral, as temperaturas dos pontos avaliados apresentaram elevada correlação e se diferiram estatisticamente, visto que estes valores foram comprovados a partir do p-valor (Tabela 2), indicando que estes foram menores que o $\alpha$ a 5\%. Os valores obtidos entre as variáveis denotam a relação positiva entre elas. Assim, entre as temperaturas do substrato e do solo foi obtido $r$ de 0,96 (Tabela 2). E observou-se que a temperatura do substrato foi maior do que a do solo em quase todos os meses monitorados o que corroborou com o encontrado por Perrigault et al., (2012). Esses mesmo autores, descreveram a importância do 
monitoramento das temperaturas, uma vez que, foi observado uma transferência de calor entre eles, de forma que o substrato por estar mais quente tenderá a perder calor para o solo (meio mais frio) o que pode afetar o processo de biodigestão anaeróbia.

A temperatura do solo também apresentou elevada correlação com a temperatura ambiente, apresentando $\mathrm{r}$ de 0,98 (Tabela 2). Essa associação entres as temperaturas também foi observado Xing et al., (2018) o qual obteve $\mathrm{r}$ de 0,91 . Foi observado que maiores temperaturas do ambiente ocasionaram maiores temperaturas do solo e que a temperatura do solo no período monitorado foi sempre superior ao do ambiente.

Já a temperatura do biogás apresentou maior correlação linear com a temperatura do ambiente (r 0,96). Está maior associação pode ter sido influenciada pela maior exposição do biogás a esta temperatura, visto que o armazenamento do subproduto gasoso é dado na parte superior do biodigestor (PERRIGAULT et al., 2012).

Em termos de DQO, os valores de remoção da matéria orgânica apresentaram melhor correlação com a temperatura do biogás $(r=0,89)$, seguida do substrato $(r=0,85)$, solo $(r=0,85)$ e por último ambiente $(r=0,82)$. A melhor correlação da eficiência de remoção de DQO e da temperatura do biogás podem ser explicadas em termos de balanço de massa, visto que parte da DQO afluente (50 a 70\%) é transferida para a composição gasosa, condição típica da digestão anaeróbia (CHERNICHARO, 2007).

\section{CONCLUSÃO}

A partir do estudo realizado foi possível verificar uma correlação entre a temperatura ambiente e o solo, que por sua vez influência a temperatura do substrato. Em contrapartida, a temperatura do biogás sofre significativa influência da temperatura ambiente.

Em termos da relação da eficiência de remoção de DQO, as temperaturas que mais influenciaram foram do biogás seguida da temperatura do substrato e do solo. No entanto, supõem-se que todas as temperaturas apresentam papel importante no processo de biodigestão anaeróbia utilizando biodigestor Canadense.

\section{AGRADECIMENTOS}

O presente trabalho foi realizado com o apoio da Cnpq (Conselho Nacional de Desenvolvimento Científico e Tecnológico), FAPEMIG (Fundação de Amparo à Pesquisa do Estado de Minas Gerais) e da Coordenação de Aperfeiçoamento de Pessoal de Nível Superior - Brasil (CAPES) - Código de Financiamento 001 .

\section{REFERÊNCIAS}

ABPA. Associação Brasileira de Proteína Animal. Relatório Anual 2018. São Paulo, 2017. Disponível em: http://abpa-br.com.br/storage/files/relatorio-anual-2018.pdf Aceso em: 25/11/2018.

APHA. American Public Health Association, \& American Water Works Association. Standard methods for the examination of water and wastewater. American public health association. 2017.

CALZAR, L. F.; LIMA, C. B. L.; NOGUEIRA, C. E. C.; SIQUEIRA, J. A. C.; SANTOS, R. F. Avaliação Dos Custos De Implantação De Biodigestores E Da Energia Produzida Pelo Biogás. Journal of the Brazilian Association of Agricultural Engineering. Eng. Agríc, v.35, N.6 Jaboticabal nov./dez, 2015.

CAMPOS, A. T., CAMPOS, A. T. D., \& SANTOS, E. P. D. Análise energética de biodigestores tubulares usando dejetos de suínos. In: Encontro de Energia no Meio Rural, v.5, Campinas-SP, 2004.

CHEN, K. J. JANG, A.; YIM, S. K.; KIM, I. S. The effects of digestion temperature and temperature shock on the biogas yields from the mesophilic anaerobic digestion of swine manure. Bioresource Technology, v. 99, N. 1, pp. 1-6, 2008.

CHERNICHARO, C. A. L. Reatores anaeróbios. 2. ed. Belo Horizonte: Departamento de Engenharia Sanitária e Ambiental. Universidade Federal de Minas Gerais. 380 p. (Princípios do tratamento biológico de águas residuárias, v.5), 2007.

FERNANDES FILHO, A. C., SANTANA, C. O. S., \& GATTAMORTA, M. A. Utilização De Biodigestores Para Geração De Energia Elétrica A Partir De Dejetos De Suínos No Brasil. Inovae-Journal Of Engineering, Architecture And Technology Innovation, Issn 2357-7797, v.6, N.1, pp.67-84, 2018.

MINAS GERAIS. Deliberação normativa conjunta COPAM/CERH-MG no 01, de 05 de maio de 2008. Dispõe sobre a classificação dos corpos de água e diretrizes ambientais para o seu enquadramento, bem como estabelece as condições e padrões de lançamento de efluentes, e dá outras providências. 


\section{VISIGERÃ DEF7A9 MAMA 2019

LIN, Q.; VRIEZE, J.; HE, G.; LI, X.; LI, J. Temperature regulates methane production through the function centralization of microbial community in anaerobic digestion. Bioresource Technology, v.99, pp.1-6, 2016. PERRIGAULT, T.; WEATHERFORD, V.; MARTÍ-HERRERO, J.; POGGIO, D. Towards thermal design optimization of tubular digesters in cold climates: A heat transfer model. Bioresource Technology, v.124, pp.259-268, November, 2012.

SOUSA, F. A., CAMPOS, A. T., DE BARRos SILVA, E., GANDINI, A. M. M., CORRÊA, J. M., \& GRAZZIOTTI, P. H. Redução do potencial poluidor de dejetos de suínos em lagoas de estabilização em série. Bioscience Journal, v.30, N.1, 2014.

XING, L.; LI, L.; GONG, J.; REN, C.; LIU, J.; CHEN, H. Daily soil temperatures predictions for various climates in United States using data-driven model. Energy, v.160, pp.430-440, October, 2018.

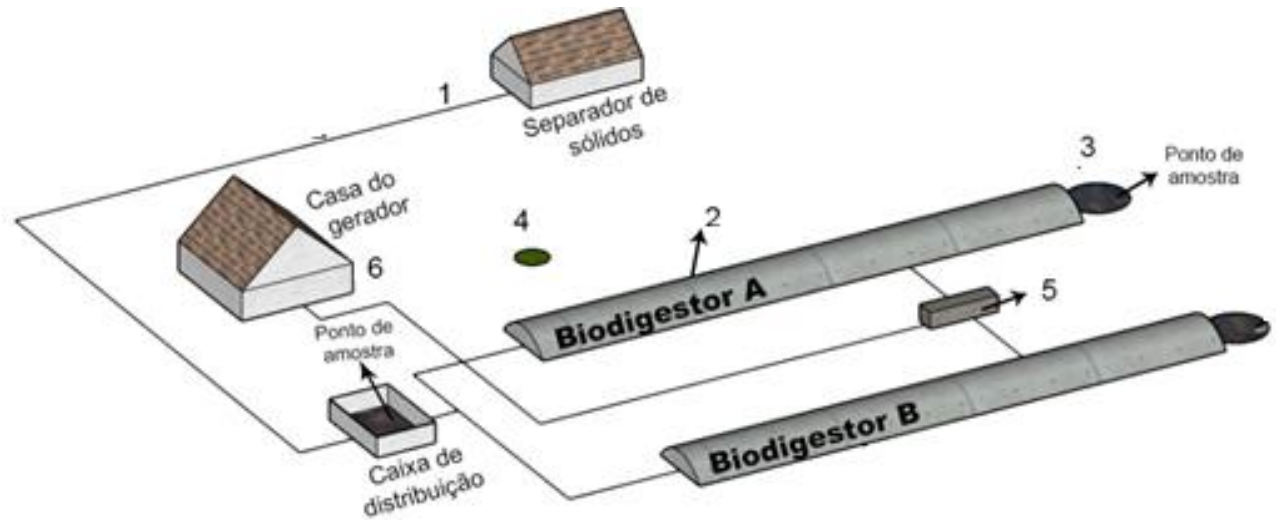

Legenda: Sensores de Temperatura: 1- Afluente, 2- Interno do biodigestor (substrato), 3- Efluente, 4- solo (1 m de profundidade), 5 biogás (1 m de profundidade), 6- ambiente.

Figura 1. Croqui ilustrativo dos locais de instalação dos sensores de temperatura.

Tabela 1. Médias mensais dos parâmetros analisados.

\begin{tabular}{ccccccc}
\hline MÊS & Ambiente $\left({ }^{\circ} \mathbf{C}\right)$ & Solo $\left({ }^{\circ} \mathbf{C}\right)$ & Biogás $\left({ }^{\circ} \mathbf{C}\right)$ & Substrato $\left({ }^{\circ} \mathbf{C}\right)$ & $\begin{array}{c}\text { Efluente } \\
\left({ }^{\circ} \mathbf{C}\right)\end{array}$ & DQO $(\%)$ \\
\hline Janeiro & $25,5 \pm 1,3$ & $27,9 \pm 1,2$ & $27,9 \pm 2,7$ & $26,3 \pm 0,2$ & $27,0 \pm 0,3$ & $68,2 \pm 23,9$ \\
Fevereiro & $24,0 \pm 1,6$ & $26,5 \pm 0,9$ & $25,8 \pm 2,7$ & $25,8 \pm 0,2$ & $25,9 \pm 0,5$ & $61,3 \pm 23,6$ \\
Março & $24,6 \pm 1,3$ & $26,1 \pm 0,2$ & $28,4 \pm 2,7$ & $26,3 \pm 0,2$ & $26,6 \pm 0,3$ & 73,10 \\
Abril & $21,5 \pm 1,2$ & $24,2 \pm 0,5$ & $26,0 \pm 2,2$ & $25,0 \pm 0,5$ & $25,0 \pm 0,5$ & $64,4 \pm 17,5$ \\
Maio & $19,5 \pm 2,1$ & $22,4 \pm 0,6$ & $20,6 \pm 4,5$ & $23,2 \pm 0,6$ & $23,1 \pm 0,7$ & $59,6 \pm 20,1$ \\
Junho & $19,0 \pm 1,2$ & $21,1 \pm 0,2$ & $18,9 \pm 1,4$ & $21,8 \pm 0,2$ & $21,7 \pm 0,1$ & $42,9 \pm 5,8$ \\
Julho & $17,8 \pm 1,2$ & $19,8 \pm 0,4$ & $17,8 \pm 1,6$ & $21,0 \pm 0,3$ & $20,6 \pm 0,4$ & $21,62 \pm 11,1$ \\
Agosto & $19,2 \pm 1,3$ & $20,2 \pm 0,3$ & $19,4 \pm 1,5$ & $19,7 \pm 2,3$ & $21,0 \pm 0,3$ & $42,78 \pm 23,0$ \\
Setembro & $20,3 \pm 1,8$ & $21,8 \pm 0,3$ & $20,6 \pm 2,8$ & $22,2 \pm 0,4$ & $22,4 \pm 0,5$ & $34,96 \pm 11,0$ \\
\hline
\end{tabular}

Tabela 2. Apresentação das correlações entre as variáveis monitoradas

\begin{tabular}{ccccc}
\hline Variável & DOO & Biogás & Solo & Ambiente \\
\hline Biogás & 0,89 & & & \\
& $(0,002)$ & & & \\
Solo & 0,85 & 0,95 & & \\
& $(0,004)$ & $(0,00007)$ & 0,98 & \\
Ambiente & 0,82 & 0,96 & $(0,000005)$ & \\
& $(0,007)$ & $(0,00006)$ & 0,91 \\
Substrato & 0,85 & 0,94 & 0,96 & $0,91)$ \\
\hline
\end{tabular}




\title{
ESTUDO DAS CONDIÇÕES E VARIÁVEIS DE INFLUÊNCIA EM BIODIGESTORES MODELO CANADENSE
}

\author{
Sousa, I.P. ${ }^{* 1}$; Rosa, A.P. ${ }^{1}$, Lopes, J.O. ${ }^{1}$; Magos, B.R. ${ }^{1}$; Perez, R. ${ }^{1}$ \\ ${ }^{1}$ Universidade Federal de Viçosa, Viçosa, $M G$ - Brasil. \\ izabelle.sousa@ufv.br
}

RESUMO: O objetivo do estudo foi avaliar as influências das temperaturas externas e internas no processo de tratamento de água residuária de suinocultura em um biodigestor modelo canadense. $\mathrm{O}$ experimento foi realizado em uma granja na cidade de Teixeiras (Minas Gerais). Para tanto, foram instalados sensores de temperatura para aferir temperaturas internas do biodigestor: substrato, afluente, efluente, biogás; e externas: ambiente e solo. Os dados foram coletados no período de janeiro a julho de 2018 e avaliados em termos de comportamento a partir dos dados médios diários a partir da leitura dos dados em intervalos de 15 minutos. Esses sensores aferiram as variações térmicas de forma contínua por um período de seis meses. A partir dos dados obtidos, observou-se um padrão semelhante entre a temperatura do substrato e do solo, e uma maior variação térmica na temperatura ambiente e do biogás. Em adição, a temperatura do afluente foi mais influenciada pela temperatura ambiente e a do efluente pela temperatura do substrato. De posse do conjunto de dados avaliado, sugere-se que dentre as várias temperaturas avaliadas, a temperatura do solo apresenta maior influência no processo de biodigestão anaeróbia por influenciar mais diretamente a temperatura do substrato.

Palavras-chave: águas residuárias, monitoramento, suinocultura, temperatura.

\section{DETERMINING THE CONDITIONS AND VARIABLES THAT INFLUENCE ANAEROBIC DIGESTION IN THE CANADENSE BIODIGESTORS MODEL}

\begin{abstract}
This study aimed at evaluating the influence of external and internal temperatures on the swine wastewater treatment in a Canadense biodigester model. The experiment was carried out at a pig farm in Teixeiras (Minas Gerais). Temperature sensors were installed to measure internal temperatures of the biodigester (substrate, affluent, effluent, biogas) and external (environment and soil). The data were collected from January to July 2018 and were evaluated in terms of daily average data collected every 15 minutes. These sensors measured the thermal variations continuously over a period of six months. According to the findings a similar pattern was observed between the temperature of the substrate and the soil, and a greater thermal variation in the environment temperature and the biogas. In addition, the temperature of the affluent was more influenced by the environment whereas the effluent was more influenced by the substrate. It has been suggested that among the various temperatures evaluated, soil temperature has a greater influence on the anaerobic biodigestion process because it influences the substrate temperature more directly.
\end{abstract}

Keywords: wastewater, monitoring, pig farming, temperature.

\section{INTRODUÇÃO}

O setor de suinocultura representa uma atividade relevante na economia brasileira, ocupando o quarto lugar no ranking de produção e exportação de carne suína (ABPA, 2018). No entanto, o confinamento de suínos resulta na geração de grande volume de dejetos com alto potencial poluidor, mas quando tratados por biodigestão anaeróbia, podem ter valor agregado pelo aproveitamento energético de biogás e recuperação de nutrientes.

Um dos métodos mais indicados para o tratamento de dejetos suínos no Brasil são os biodigestores modelo Canadense (CALZAR et al., 2015). Segundo Perrigault et al., (2012) esta configuração se destaca pelo menor custo de construção e operação, entretanto apesar dos benefícios apresentados, o emprego desta configuração de biodigestores é associada ao não conhecimento das condições operacionais ideias. $\mathrm{O}$ tratamento do efluente pode ser empregado para contribuir para a sustentabilidade energética das granjas a partir da potencialização da produção do biogás. 
De acordo com Kinyua et al., (2016), a eficiência do tratamento e a produção do biogás estão associados diretamente com a temperatura, pela manutenção e estabilidade das bactérias anaeróbias.

Chernicharo (2007) sugere que a temperatura ótima do processo anaeróbio esteja em torno dos $35^{\circ} \mathrm{C}$. Tavares et al., (2016) relatam que se a temperatura estiver entre as faixas mesofílicas $\left(20\right.$ a $\left.45^{\circ} \mathrm{C}\right)$ ou termofílicas (> 45) os sistemas operam de forma otimizada em termos de eficiência. Todavia, apesar da evidente influência da temperatura na produção de biogás e na eficiência do tratamento são escassos os estudos que avaliem a interferência das temperaturas externas (ambiente, solo e afluente) no processo de biodigestão anaeróbia em escala plena, assim como o estudo de tendências e variações sazonais das temperaturas, seja ao longo do dia ou ao longo das estações do ano. O melhor entendimento do comportamento das temperaturas e suas relações favorecerá a creditação da tecnologia de tratamento, o aprimoramento dos projetos dos biodigestores e a otimização das condições operacionais para o tratamento anaeróbio. Este trabalho objetivou avaliar as tendências e o comportamento de temperaturas internas e externas a biodigestores modelo Canadense escala plena instalados em uma granja ao longo do ciclo diário de operação.

\section{MATERIAL E MÉTODOS}

O experimento foi conduzido em uma suinocultura localizada no município de Teixeiras - MG. A granja possui dois biodigestores modelo Canadense, com capacidade volumétrica de $1.250 \mathrm{~m}^{3}$. Os biodigestores apresentam formato trapezoidal, com dimensões externas de 13,4 m x 37,5 m e dimensões internas (parte enterrada no solo) de $10 \mathrm{~m}$ e 34,0 m de largura e comprimento, respectivamente, e 2,5 m de profundidade. Para o monitoramento das temperaturas foi realizado a instalação de sensores de temperatura distribuídos na área de estudo conforme expecificado na Figura 1. Os dados dos sensores de temperatura foram aferidos de forma contínua no período de 10 de janeiro a 30 de julho de 2018 .

Os dados das temperaturas foram enviados via internet para um banco de dados localizado em uma central de controle no Centro de Conhecimento em Bioenergia, situado na Universidade Federal de Viçosa (UFV), Viçosa-MG. Para a avaliação das tendências das variações térmicas no processo de biodigestão anaeróbia foram selecionados dados de temperatura a cada 15 minutos. Em sequência, realizou-se médias dos dias monitorados. Já para avaliar o comportamento das temperaturas no ciclo diário, as temperaturas foram obtidas a partir de médias históricas para o período ao longo do dia. Estes dados foram descritos por inferência estatística.

\section{RESULTADOS E DISCUSSÃO}

No período de monitoramento foi possível observar que a temperatura do biogás, seguida do ambiente apresentaram maior variação, apresentando para o período estudado temperatura mínima e máxima de 5,8 e $53,5{ }^{\circ} \mathrm{C}$ para o biogás e 6,8 e $35,4{ }^{\circ} \mathrm{C}$ para a temperatura ambiente. A temperatura do afluente apresentou variação máxima de $31,9{ }^{\circ} \mathrm{C}$ e mínima de $20,1{ }^{\circ} \mathrm{C}$. Já a temperatura interna do biodigestor (substrato) apresentou a menor variação, $\left(20,1^{\circ} \mathrm{C}\right.$ a $\left.26,9^{\circ} \mathrm{C}\right)$. E por fim, as temperaturas do solo e do efluente tiveram amplitude de 18,3 e $9,7^{\circ} \mathrm{C}$, respectivamente, para o período monitorado (Figura 2).

Para o período avaliado foi possível verificar que as variações da temperatura ambiente tiveram forte influência no comportamento das temperaturas monitoradas, e que a temperatura do substrato apresentou uma queda de $6,8^{\circ} \mathrm{C}$ comparando-se os meses de janeiro e julho. Mesmo com essa alteração, o biodigestor operou em condições mesofilícas, condições esperadas para região de clima tropical (GARFÍ et al., 2016). A temperatura do substrato medida à $1 \mathrm{~m}$ de profundidade apresentou média de $24,3{ }^{\circ} \mathrm{C}$, este resultado foi similar aos estudos de Perrigault et al. (2012), o qual estudou o comportamento das temperaturas do substrato em diferentes profundidades em biodigestores tubulares de baixo custo com médias de $24,5{ }^{\circ} \mathrm{C}$ e $24,0{ }^{\circ} \mathrm{C}$, a profundidades de 30 e $60 \mathrm{~cm}$, respectivamente.

A verificação dos valores médios da temperatura ambiente $\left(21,8^{\circ} \mathrm{C}\right)$ inferiores à do substrato $\left(24,3^{\circ} \mathrm{C}\right)$ também foi apontada por outros autores (PERRIGAULT et al. 2012; MARTÍ-HERRERO et al. 2014). Em relação a temperatura do solo, foi possível verificar que sua média $\left(24,5^{\circ} \mathrm{C}\right)$ se aproxima da temperatura do substrato $\left(24,3^{\circ} \mathrm{C}\right)$, o que justifica a afirmação feita por Terradas-Ill et al., (2014), sobre utilizar essa temperatura para prever a temperatura interna do biodigestor em função de uma boa correlação $\left(R^{2} 0,90\right)$ encontrada em seu estudo. No entanto, segundo Kumar e Bai (2008) essa tendência acontece em biodigestores construídos abaixo da superfície do solo. As temperaturas do biogás e do efluente apresentaram valores médios de 23,9 e $23,7^{\circ} \mathrm{C}$, respectivamente. 
No monitoramento do ciclo diário (Figura 3), observou-se que a temperatura ambiente seguiu um padrão relatado por Oliveira et al. (2017) de forma que apresentou a menor temperatura após o nascer do sol, próximo a 6 horas e a máxima temperatura após 2 a 3 horas do pico da radiação solar, ocorrendo entre 14 e 15 horas. A temperatura do biogás foi a mais influenciada por essa temperatura, apresentando comportamento semelhante. Uma explicação para essa tendência é a maior transferência de calor causada por fenômenos de radiação e convecção sobre a parte superior do biodigestor, onde se concentra o biogás produzido no processo anaeróbio (PERRIGAULT et al. 2012). Outra fonte de aquecimento do biogás segundo esse mesmo autor é decorrente da atividade metanogênica, uma vez que, esta atividade produz energia na forma de calor.

O processo de biodigestão anaeróbia é sensível a variações de temperatura (GARFÍ et al., 2016), mas como pode ser observado durante o comportamento diário a temperatura do substrato não sofreu variações bruscas permanecendo em um padrão constante. As temperaturas do solo obtiveram um ligeiro aumento no intervalo entre 7 horas e 17 horas. Dentre as temperaturas externas monitoradas, a temperatura do solo foi a que mais se aproximou da temperatura do substrato. Essa aproximação segundo alguns autores é justificada pela transferência de calor por condução entre as superfícies do solo e do biodigestor. Em adição, pôde-se verificar que o padrão de temperatura do efluente apresentou semelhança com o do substrato.

\section{CONCLUSÃO}

Dentre os pontos avaliados, conclui-se que a temperatura ambiente e do biogás apresentaram maior variação térmica no período estudado e que obtiveram esse mesmo comportamento no ciclo diário. A temperatura do substrato se aproximou da temperatura do solo e do efluente. Assim, esses resultados apontam a importância do monitoramento das temperaturas externas e internas do biodigestor para adequação de métodos de estimativa de produção de biogás, que muitas vezes considera somente a temperatura ambiente. Em adição, foi observado que a temperatura do solo é associada mais diretamente ao padrão e comportamento da temperatura do substrato, e por isso, de grande relevância no processo de biodigestão anaeróbia para a configuração de modelo canadense.

\section{AGRADECIMENTOS}

O presente trabalho foi realizado com o apoio da Cnpq (Conselho Nacional de Desenvolvimento Científico e Tecnológico), FAPEMIG (Fundação de Amparo à Pesquisa do Estado de Minas Gerais) e da Coordenação de Aperfeiçoamento de Pessoal de Nível Superior - Brasil (CAPES) - Código de Financiamento 001.

\section{REFERÊNCIAS}

ABPA. Associação Brasileira de Proteína Animal. Relatório Anual 2018. São Paulo, 2017. Disponível em: http://abpa-br.com.br/storage/files/relatorio-anual-2018.pdf Aceso em: 25/11/2018.

CALZA, L. F.; LIMA, C. B. L.; NOGUEIRA, C. E. C.; SIQUEIRA, J. A. C.; SANTOS, R. F. Avaliação Dos Custos De Implantação De Biodigestores E Da Energia Produzida Pelo Biogás. Journal of the Brazilian Association of Agricultural Engineering. Eng. Agríc, v.35, N.6 Jaboticabal nov./dez. 2015.

CHERNICHARO, C. A. L. Reatores anaeróbios. 2. ed. Belo Horizonte: Departamento de Engenharia Sanitária e Ambiental. Universidade Federal de Minas Gerais. 380 p. (Princípios do tratamento biológico de águas residuárias, v.5), 2007.

GARFÍ, M.; MARTÍ-HERRERO, J.; GARWOOD, A.; FERRER, I. Household anaerobic digesters for biogas production in Latin America: A review. Renewable and Sustainable Energy Reviews, v. 60, pp. 599-614, July, 2016.

KINYUAL, M. N.; ROWSE, A. E.; ERGAS, S. J. Review of small-scale tubular anaerobic digesters treating livestock waste in the developing world. Renewable and Sustainable. Energy Reviews, v. 58, pp. 896-910, 2016.

KUMAR, K. V.; BAI, R, K. Solar greenhouse assisted biogas plant in hilly region - A field study. Solar Energy, v. 82, Issue 10, pp. 911-917, October, 2008.

MARTÍ-HERRERO, J.; ALVAREZ, R.; ROJAS, M. R.; ALIAGA, L.; CÉSPEDES, R.; CARBONELL, J. Improvement through low cost biofilm carrier in anaerobic tubular digestion in cold climate regions.

Bioresource Technology, v 167, pp. 87-93, September, 2014 


\section{VISIGERA DE 07 A 09 MA10 2019

PERRIGAULT, T.; WEATHERFORD, V.; MARTÍ-HERRERO, J.; POGGIO, D. Towards thermal design optimization of tubular digesters in cold climates: A heat transfer model. Bioresource Technology. v 124, pp. 259-268, November, 2012.

OLIVEIRA, M. J.; CARNEIRO, C. D. R.; VECCHIA, F. A. S.; BAPTISTA, G. M. M. Ciclos climáticos e causas naturais das mudanças do clima. Terræ didatica, v.13, N. 3, pp. 149-184, 2017.

TAVARES, S. G.; FEIDEN, A.; CORREIA, A. F.; SOARES, C. M. T.; GREGOLIN, M. R. P. Influência Das Variações Térmicas E Climáticas Na Produção De Biogás. Nativa, Sinop, v.4, N.5, pp.287-295, Set./Out, 2016.

TERRADAS-ILL, G.; CUONG, H.; PHAM, C. H.; TRIOLO, J. M.; MARTÍ-HERRERO, J.; SOMMER, S. G. Thermic model to predict biogas production in unheated fixed-dome digesters buried in the ground. Environ Sci Technol, v. 48, pp. 3253-3262, 2014.

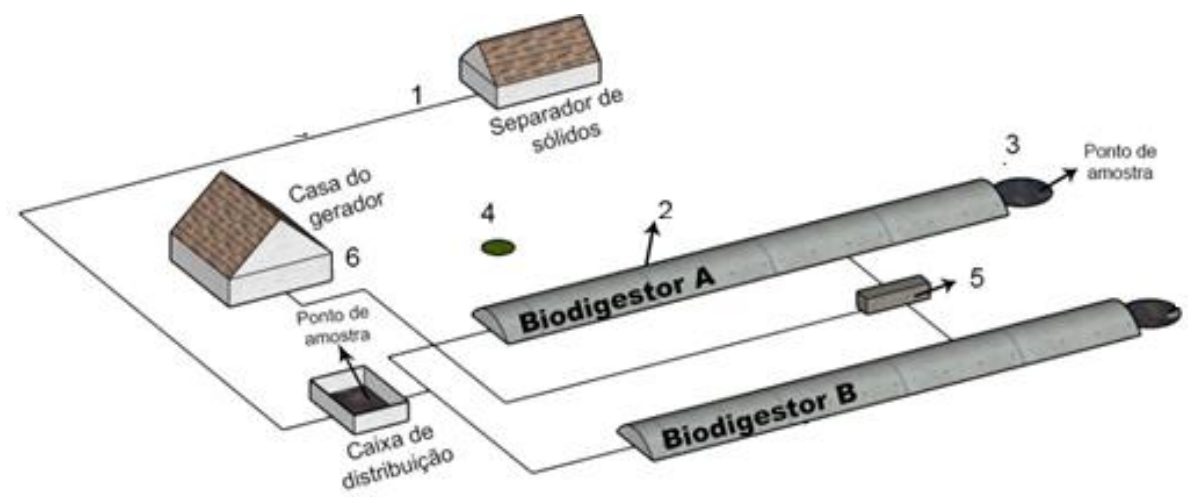

Legenda: Sensores de Temperatura: 1- Afluente, 2- Interno do biodigestor (substrato), 3- Efluente, 4- solo, 5- biogás, 6- ambiente.

Figura 1. Croqui ilustrativo dos locais de instalação dos sensores de temperatura.

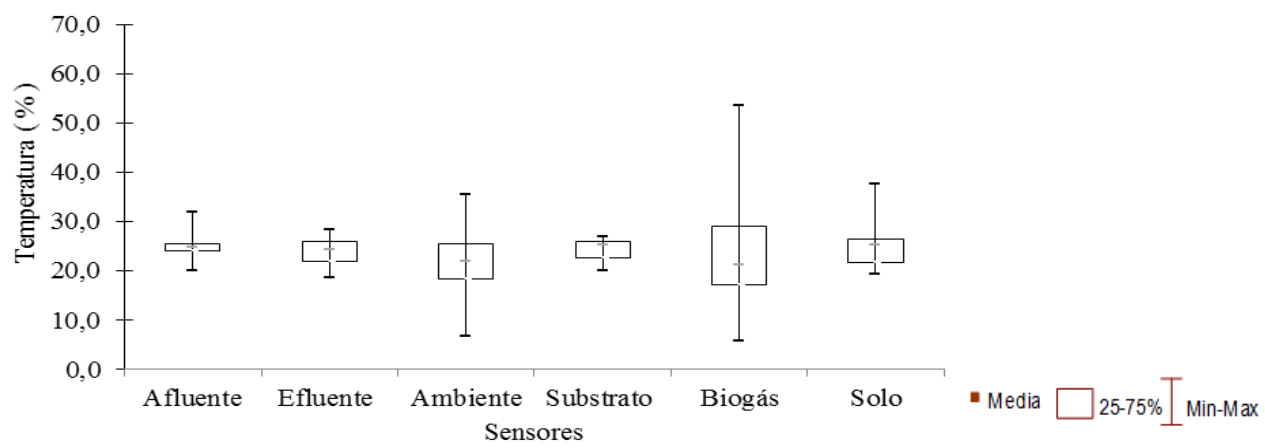

Figura 2. Variações das temperaturas internas e externas ao biodigestor para o período monitorado.

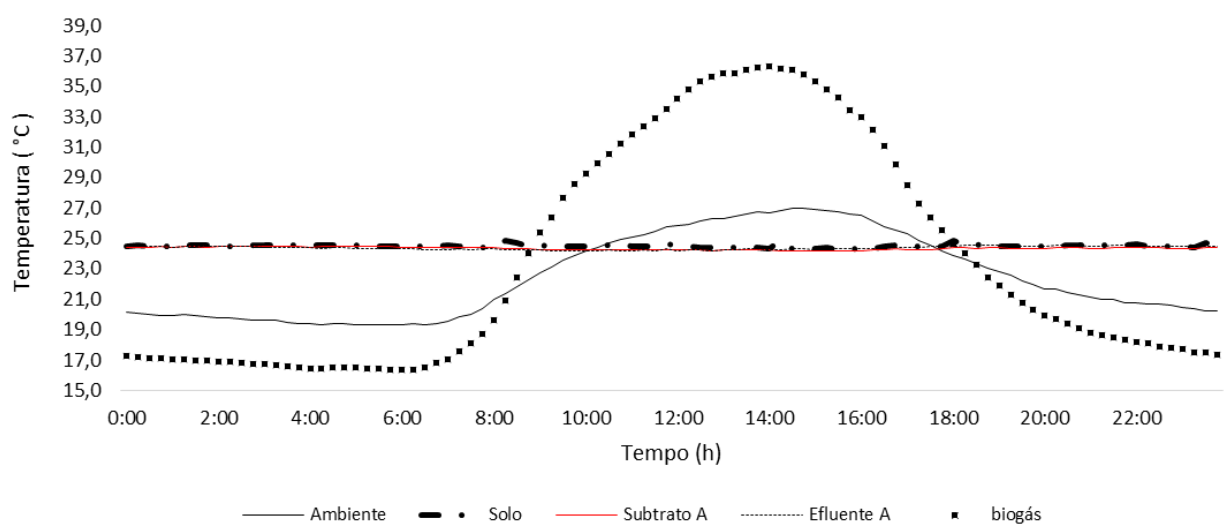

Figura 3. Ciclo médio diário das temperaturas internas e externas ao biodigestor para o período monitorado. 


\title{
EXPLORING THE BACTERIOSTATIC POTENTIAL OF MICROALGAE AGAINST PATHOGENIC MULTI-DRUG RESISTANT BACTERIA
}

\author{
Michelon, W.*1; Dinnebier, H.C.F. ${ }^{2}$; Da Silva, M.L.B. ${ }^{3}$; Matthiensen, A. ${ }^{4}$; Soares, H.M. ${ }^{1}$ \\ ${ }^{1}$ Federal University of Santa Catarina, Florianopolis, SC - Brazil \\ william@unc.br; soares@enq.ufsc.br \\ ${ }^{2}$ Federal University of Fronteira Sul, Erechim, RS - Brazil \\ ${ }^{3}$ Rice University, Houston, Texas - USA, silva@ rice.edu \\ ${ }^{4}$ Embrapa Suínos e Aves, Concórdia, SC-Brazil \\ alexandre.matthiensen@embrapa.br
}

\begin{abstract}
Microalgae are rich in metabolic compounds with recognized antibiotic properties. In this study, the potential use of the microalgae Chlorella spp on the inhibition of several pathogenic antibiotic resistant bacteria was investigated. Microalgae biomass was obtained from a pilot scale reactor simulating phycoremediation of swine wastewater treatment. Microalgae extracts were obtained with solvent extraction using hexane, dichloromethane or methanol. Different concentrations of extracts were tested against the following model pathogenic bacteria known to cause disease in swine, i.e., Streptococcus suis (BRMSA 1410), Enterococcus faecalis (ATCC 29212), and Staphylococcus hyicus (CEDISA 634/15). Results indicated that microalgae extracts obtained with dichloromethane were most efficient to inhibit the growth of Streptococcus suis, Enterococcus faecalis and Staphylococcus hyicus when tested at $0.390 \mathrm{mg} \mathrm{mL}^{-1}$. The microalgae extracts obtained with hexane or methanol showed bactericidal activity against Enterococcus faecalis and Streptococcus suis at minimum inhibitory concentration of 0.390 and $0.195 \mathrm{mg} \mathrm{mL}^{-1}$, respectively. Overall, the results support the notion that microalgae biomass obtained from swine wastewater treatment holds great promise as raw material for extraction of bacteriostatic compounds. This is of paramount importance nowadays considering the consequences of antibiotic misuse and abuse and its implications on the spread of multi-drug resistant superbug.
\end{abstract}

Keywords: antimicrobial, solvent extraction, multi-drug resistant bacteria, microalgae

\section{INTRODUCTION}

There are several pathogenic bacteria that pose a serious economic threat to animal farming and associated industries. For instance, Staphylococcus hyicus can cause exudative epidermis in swine (ANDRESEN, 1998), cutaneous lesions in cattle (HAZARIKA et al., 1991), and conjunctivitis in chickens and turkeys (CHEVILLE et al., 1988). Streptococcus suis is another important pathogen that is associated with septicemia (ZHANG, 2017) and meningitis (FOWLER et al., 2013). This same pathogen is also of concern as an emerging zoonotic agent in humans (GOYETTE-DESJARDINS et al., 2014). Enterococcus faecalis, an opportunistic pathogen causes nosocomial, urinary, and neonatal infections (ANDERSON et al., 2016). To avoid or minimize the dissemination of infection diseases, antibiotics are broadly utiized. Nonetheless, it is necessary to explore alternative solutions to antibiotics because over the years the misuse and/ or abuse of these drugs resulted in the selection and widespread of several resistant bacteria (BAQUERO et al., 2008). In this regard the antimicrobial and antiviral properties of microalgae extracts (PLAZA et al., 2010) could be an option and as such should be further explored as potential agent against the proliferation of pathogenic bacteria. Interestingly and conveniently, the source of microalgae biomass could be obtained directly from swine wastewater effluents undergoing treatment (i.e., phycoremediation). The strategy to use microalgae to treat different types of wastewaters is not novel with over 75 years of development (ARBIB, 2013). The use of phycoremediation as a tertiary treatment step can yield large amount of microalgae biomass that can be harvested and processed to obtain a wide range of valuable metabolites (YAMAGUCHI, 1997). Therefore, this study aimed to investigate whether the extracts of the microalgae Chorella spp. obtained from phycoremediation of swine wastewaters could be effective to inhibit the growth of several model pathogenic bacteria that are known to pose a risk to animal health. 


\section{MATERIAL AND METHODS}

Microalgae consortia were obtained from a facultative pond at EMBRAPA Swine and Poultry, Concórdia, Brazil. The inoculum was composed by microalgae consortium dominated by Chlorella spp. Experiments were conducted in 12-L glass photobioreactors (PBR) filled with non-sterile $6 \% \mathrm{v} \mathrm{v}^{-1}$ UASB digestate effluent diluted in water. PBRs were inoculated with $70 \mathrm{mg}$ dry weight microalgae $\mathrm{L}^{-1}$ (or $30 \% \mathrm{v} \mathrm{v}^{-}$ ${ }^{1}$ of inoculum). PBRs were maintained at room temperature $\left(23^{\circ} \mathrm{C}\right)$ under mixotrophic conditions $(44.8 \mu \mathrm{mol}$ $\mathrm{m}^{-2} \mathrm{~s}^{-1}$ ) and continuous agitation. Experiments were also conducted using a pilot scale 500-L reactor placed

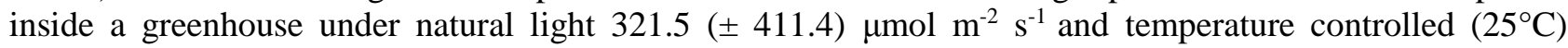
conditions. The medium was kept under continuous agitation using a submersible aquarium pump. After 11 days following inoculation, the growth medium containing the microalgae biomass was harvested via centrifugation (EVODOS, T10, Netherlands). The harvested biomass was immediately frozen $\left(-40{ }^{\circ} \mathrm{C}\right)$ and lyophilized (Model 030-JJ LJI Scientific) for further analyses. The dried microalgae powder $(20 \mathrm{~g})$ was subjected to hexane, dichloromethane or methanol extraction at concentration ratio of 5:1. Using a rotary evaporator the extracts were kept under vacuum at $50{ }^{\circ} \mathrm{C}$ to eliminate any residual concentrations of solvents. The extracts were then resuspended in dimethyl sulphoxide (DMSO) at a concentration of $100 \mathrm{mg} \mathrm{mL}^{-1}$ for further investigation. The effects of the extracts with antibacterial activity were evaluated by the Kirby Bauer disc diffusion method (LENNETTE et al., 1985). The following bacteria were used as model organisms: Streptococcus suis (BRMSA 1410), Enterococcus faecalis (ATCC 29212) and Staphylococcus hyicus (CEDISA 634/15). Filter-paper disc $(6.0 \mathrm{~mm})$ were saturated with 20 and $50 \mu \mathrm{L}$ of the extract solution. To determine the sensitivity of each extract was performed using the Mueller Hinton agar plates (for $S$. suis it was used sheep blood). Plates were incubated at $\left(37^{\circ} \mathrm{C}\right)$ for a period of $18-24 \mathrm{~h}$ in dark. Florfenicol $\left(30 \mu \mathrm{g} \mathrm{mL} \mathrm{L}^{-1}\right)$ was used as positive controls. The minimum inhibitory concentration (MIC) of microalgae extract was determined by micro-dilution. For determination of the minimal bacterial concentration (MBC), plates made with trypticase soy agar (TSA) were used. A $25 \mu \mathrm{L}$ aliquot of diluted extracts was inserted in each well and the plates incubated at $37^{\circ} \mathrm{C}$ for $18-24 \mathrm{~h}$.

\section{RESULTS AND DISCUSSION}

Previous studies reported the use of different microalgae compounds including terpenoids, polyphenols, phenolic acids, phycobiline, hydroxycinnamic acid derivatives, flavonoids and steroids (PINA-PÉREZ et al., 2017) on bacteria inhibition. These compounds previously identified as antimicrobial are fatty acids, halogenated compounds, terpenes and sulphur contain heterocyclic compounds (PRADHAN et al., 2014). Here, the antimicrobial activity of Chlorella spp extracts was evaluated against the growth of multi-resistant bacteria (i.e resistant to amoxicillin, ampicillin, ciprofloxacin, enrofloxacin, lincomycin, lincomycin plus spectinomycin, norfloxacin, and penicillin) that causes several diseases in swine. All extracts tested showed antimicrobial activity (Figure 1). Extracts obtained with hexane showed an inhibition halo of $13 \mathrm{~mm}$ for Enterococcus faecalis and $10 \mathrm{~mm}$ for Streptococcus suis (Table 1). Extracts obtained with methanol showed an inhibition zone of $16 \mathrm{~mm}$ for Enterococcus faecalis and $9 \mathrm{~mm}$ for Streptococcus suis (Table 1). However, only the extract obtained with dichloromethane extraction was efficient to inhibit all the bacteria tested. The zone of inhibition (halo diameter $\mathrm{mm}$ ) was $15 \mathrm{~mm}$ for Staphylococcus hyicus, $18 \mathrm{~mm}$ for Streptococcus faecalis, and $12 \mathrm{~mm}$ for Enteroccoccus sui (Table 1). The extracts obtained with dichloromethane showed the best antibacterial effect with MIC of $0.390,0.390$ and $0.195\left(\mathrm{mg} \mathrm{mL}^{-1}\right)$ for Staphylococcus hyicus, Enteroccoccus faecalis and Streptococcus suis, respectively (Table 2). The effects of the extracts were also tested for its capacity as bacteriostatic (i.e., bacteria are kept alive but the growth inhibited) or bactericidal (i.e., bacteria are killed). The results suggested that dichloromethane-extracted compounds were effective as bacteriostatic at concentrations higher than $0.39 \mathrm{mg} \mathrm{mL}^{-1}$ for the gram-positive Staphylococcus hyicus and Enteroccoccus faecalis and $0.195 \mathrm{mg} \mathrm{mL}^{-1}$ for Streptococcus suis (Table 3). Most (if not all) antibiotics used today for gram-positive bacteria are also based on similar bacteriostatic effects (PANKEY and SABATH, 2004). 


\section{CONCLUSIONS}

The extracts obtained from Chlorella spp biomass collected from swine wastewater phycoremediation showed antimicrobial activity against several multi-drugs resistant bacteria. Depending on the chemical characteristics of the solvent used, different compounds are selectively extracted. The extracts obtained using hexane, dichloromethane and methanol showed antimicrobial activity with a zone of inhibition (halo) $>10 \mathrm{~mm}$. The use of broth dilution method as a quantitative method to estimate the minimum inhibitory bacteriostatic concentration indicated values of $0.390 \mathrm{mg} \mathrm{mL}^{-1}$ for Staphylococcus hyicus and Enteroccoccus faecalis, and $0.195 \mathrm{mg} \mathrm{mL}^{-1}$ for Streptococcus suis. Overall, extracts of microalgae Chlorella spp. were effective as a bacteriostatic agent against the proliferation of pathogenic multi-drug resistant bacteria known to threaten animal health and are thus of great concern in the animal industry.

\section{ACKNOWLEDGEMENTS}

The authors gratefully acknowledge the support provide by CAPES Foundation, Ministry of Education of Brazil and SISTRATES-BNDES (Project No 23.17.00.023.00.00).

\section{REFERÊNCIAS}

ANDERSON, Annette C. et al. Enterococcus Faecalis from food, clinical specimens, and oral sites: prevalence of virulence factors in association with biofilm formation. Frontiers In Microbiology, v. 6, p. 1534, 2016. ANDRESEN, Lars Ole. Differentiation and distribution of three types of exfoliative toxin produced by Staphylococcus hyicus from pigs with exudative epidermitis. FEMS Immunology and Medical Microbiology, v. 20, n. 4, p. 301-310, 1998.

ARBIB, Zouhayr et al. Long term outdoor operation of a tubular airlift pilot photobioreactor and a high rate algal pond as tertiary treatment of urban wastewater. Ecological engineering, v. 52, p. 143-153, 2013.

BAQUERO, Fernando; MARTÍNEZ, José-Luis; CANTÓN, Rafael. Antibiotics and antibiotic resistance in water environments. Current opinion in biotechnology, v. 19, n. 3, p. 260-265, 2008.

CHEVILLE, N. F. et al. Acute fibrinopurulent blepharitis and conjunctivitis associated with Staphylococcus hyicus, Escherichia coli, and Streptococcus sp. in chickens and turkeys. Veterinary pathology, v. 25, n. 5, p. 369-375, 1988.

FOWLER, Heather et al. Streptococcus suis meningitis in swine worker, Minnesota, USA. Emerging infect diseases, v.19, n 2, 330-1, 2013.

GOYETTE-DESJARDINS, Guillaume et al. Streptococcus suis, an important pig pathogen and emerging zoonotic agent - an update on the worldwide distribution based on serotyping and sequence typing. Emerging microbes and infections, v. 3, n. 6, p. e45, 2014.

HAZARIKA, R. A. et al. Cutaneous infection associated with Staphylococcus hyicus in cattle. Research in veterinary science, v. 50, n. 3, p. 374-375, 1991.

LENNETTE, E.H.; Ballows, A.; Hausler, W.J. et al. Manual of clinical microbiology. 4. ed. Washington: ASM. 1985

PANKEY, G. A.; SABATH, L. D. Clinical relevance of bacteriostatic versus bactericidal mechanisms of action in the treatment of Gram-positive bacterial infections. Clinical infectious diseases, v. 38, n. 6, p. 864870, 2004.

PINA-PÉREZ, M. Consuelo et al. Antimicrobial potential of macro and microalgae against pathogenic and spoilage microorganisms in food. Food chemistry, v. 235, p. 34-44, 2017.

PLAZA, Merichel et al. Screening for bioactive compounds from algae. Journal of pharmaceutical and biomedical analysis, v. 51, n. 2, p. 450-455, 2010.

PRADHAN, Jyotirmayee; DAS, Sachidananda; DAS, Basanta Kumar. Antibacterial activity of freshwater microalgae: A review. African Journal of Pharmacy and Pharmacology, v. 8, n. 32, p. 809-818, 2014.

YAMAGUCHI, Katsumi. Recent advances in microalgal bioscience in Japan, with special reference to utilization of biomass and metabolites: a review. Journal of applied phycology, v. 8, n. 6, p. 487-502, 1996. ZHANG, Qiang et al. hP1330 contributes to Streptococcus suis Virulence by inducing Toll-like receptor 2and erK1/2-Dependent Pro-inflammatory responses and influencing In Vivo S. suis loads. Frontiers in immunology, v. 8, p. 869, 2017. 

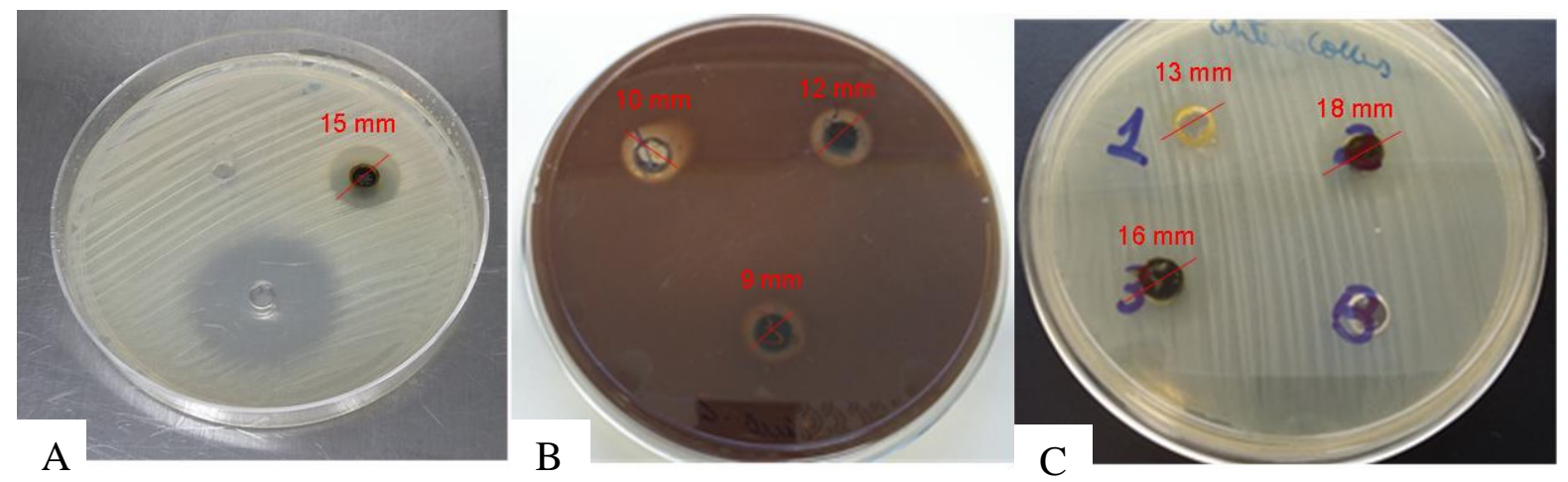

Figure 1. Effects of Chlorella spp. extracts on the inhibition of Staphylococcus hyicus (A), Streptococcus suis (B) and Enteroccoccus faecalis (C). The larger the diameter (i.e., inhibition halo) surrounding the wells containing the extracts, the higher is the bacteriostatic effect.

Table 1. Antimicrobial activity of microalgae extracts against pathogenic bacteria.

\begin{tabular}{|c|c|c|c|c|c|}
\hline \multirow[b]{2}{*}{ Test organism } & \multicolumn{4}{|c|}{ Mean diameter of inhibition zone $(\mathrm{mm})$} & \multirow{2}{*}{$\begin{array}{l}\text { Concentration } \\
\left(100 \mathrm{mg} \mathrm{mL}^{-1}\right)\end{array}$} \\
\hline & $\begin{array}{c}\text { Florfenicol } \\
\left(30 \mu \mathrm{g} \mathrm{mL} L^{-1}\right)\end{array}$ & Hexane & Dichloromethane & Methanol & \\
\hline \multirow{2}{*}{ Staphylococcus hyicus } & \multirow[t]{2}{*}{$x_{0}$} & - & 15 & - & $50 \mu \mathrm{L}$ \\
\hline & & - & 12 & - & $20 \mu \mathrm{L}$ \\
\hline \multirow{2}{*}{ Enteroccoccus faecalis } & \multirow{2}{*}{26} & 13 & 18 & 16 & $50 \mu \mathrm{L}$ \\
\hline & & - & 10 & 9 & $20 \mu \mathrm{L}$ \\
\hline \multirow{2}{*}{ Streptococcus suis } & \multirow{2}{*}{20} & 10 & 12 & 9 & $50 \mu \mathrm{L}$ \\
\hline & & 7 & 9 & 7 & $20 \mu \mathrm{L}$ \\
\hline
\end{tabular}

Table 2. The minimum inhibitory concentration (MIC) of dichloromethane extract.

\begin{tabular}{cc}
\hline \multirow{2}{*}{ Test organism } & $\begin{array}{c}\text { Minimum Inhibitory Concentration } \\
\left(\mathbf{m g ~ m} \mathbf{L}^{-1}\right)\end{array}$ \\
\cline { 2 - 2 } & Dichloromethane \\
\hline Staphylococcus hyicus & 0.390 \\
Enteroccoccus faecalis & 0.390 \\
Streptococcus suis & 0.195 \\
\hline
\end{tabular}

Table 3. Effect of dichloromethane-extracted compounds from Chlorella spp. as bacteriostatic or bactericidal.

\begin{tabular}{ccc}
\hline Test organism & Bacteriostatic & Bactericidal \\
\hline Staphylococcus hyicus & + & - \\
Enteroccoccus faecalis & + & - \\
Streptococcus suis & + & - \\
\hline
\end{tabular}




\title{
EXTRACTION OF PHOSPHORUS AND AMINO ACIDS FROM MANURE AND ALGAE
}

\author{
Vanotti, M.B.*1; Szogi, A.A. ${ }^{1}$ \\ ${ }^{I}$ USDA, Agricultural Research Service, Florence, SC - USA \\ matias.vanotti@usda.gov
}

\begin{abstract}
A new method for simultaneous extraction of amino acids and phosphorus from biological materials has been developed and is presented. The experiments used swine manure solids fraction after solidsliquid separation. The simultaneous extraction produced two streams: a phosphorus charged stream and a protein charged stream. The proteins were further concentrated with ultrafiltration (UF) and flocculation. On a dry-weight basis, it was found that the separated manure solids contained 15.2-17.4 percent (\%) proteins and $3.0 \%$ phosphorus. Quantitative extraction of phosphorus and proteins from manures was possible with this new system. The recovered phosphorus solids had $20.4 \%$ phosphates. UF of 5 and 10 Kilodalton (kDa) captured all the proteins. The protein solids were converted into amino-acids using acid hydrolysis. Further, the system was proved effective to extract phosphorus and proteins from other biological materials, such as algae or crops. The recovered proteins could be used for production of amino acids and the recovered phosphorus could be used as a recycled material that replaces commercial phosphate fertilizers. The simultaneous extraction of amino acids and phosphorus could be a potential new revenue stream from wastes.
\end{abstract}

Keywords: nutrient recovery, amino acids, phosphate minerals, separated manure solids.

\section{INTRODUCTION}

The recovery of phosphorus and proteins from manure could be advantageous to offset treatment and storage costs and to lessen the environmental impacts of land application. Phosphorous in manure can contaminate rivers, lakes, and bays through runoff, if applied onto a cropland excessively. Thus, recovering phosphorous from manure can not only help reduce such contamination, but also reduces the use of commercial fertilizer based on phosphate rock. The phosphorus mine has limited reserves and cannot be replaced by other means as fertilizer. Protein is a natural resource used in a wide range of commercial applications from pharmaceuticals to dietary supplements, foods, feeds, and industrial applications.

\section{MATERIAL AND METHODS}

A new process for simultaneous extraction of proteins and phosphorus from biological materials has been developed and investigated (Figure 1). The new process received US Patent (Vanotti and Szogi, 2018). The experiments used swine manure solids fraction after solids-liquid separation. From raw manure, wet solids are dissolved in acidic solution and then treated with a basic solution so phosphorus will precipitate and be reclaimed. The proteins in the washed solids can be extracted and concentrated with ultrafiltration and flocculation.

\section{RESULTS AND DISCUSSION}

On a dry-weight basis, the separated manure solids contained high amounts of proteins $(15.2 \%-17.4 \%)$ and phosphorus (3.0\%). Quantitative extraction of phosphorus and proteins from manures was possible with this new system. The phosphorus was first separated from the solids in a soluble extract, then the proteins were separated from the solids and solubilized with an alkali solvent (figure 2). Phosphorus and protein recovery were enhanced by $19 \%$ and $22 \%$ with the inclusion of a rinse after the washing, respectively. The recovered phosphorus solids had $20.4 \%$ phosphates $\left(\mathrm{P}_{2} \mathrm{O}_{5}\right)$. The protein content in the extract was determined with the Bradford method (figure 3). The protein extract was concentrated using ultrafiltration (UF) and lyophilization to obtain a solid protein concentrate. UF of 5 and $10 \mathrm{kDa}$ captured all the proteins, but $30 \mathrm{kDa}$ resulted in $22 \%$ loss. The protein solids were converted into amino-acids using acid hydrolysis. Furthermore, the system was effective to extract phosphorus and proteins from other biological materials, such as algae or crops. The recovered proteins could be used for production of amino acids and the recovered phosphorus could be used as a recycled material that replaces commercial phosphate fertilizers. The process can be combined with other 
processes in a total system that could recover ammonia, phosphorus, amino acids, organic compost, and clean water from raw manure (Figure 4). This could be a potential new revenue stream from wastes.

\section{CONCLUSIONS}

A system and method for separating nutrients, such as phosphorus and protein, from biological materials has been developed. Biological material, for example in the form of wet solids from raw manure, may first be separated out by a solid-liquid separator. The wet solids were dissolved in an acidic solution. The resulting supernatant from the acidic treatment was diverted and phosphorus reclaimed therefrom. The resulting precipitate from the acidic treatment was separated from the supernatant and treated with a basic solution. The resulting supernatant following the basic treatment was diverted and protein reclaimed therefrom. The system can be used to extract phosphorus and proteins from other biological materials, such as algae or crops.

\section{ACKNOWLEDGEMENT}

This research is part of USDA-ARS Project 6082-12630-001-00D "Improvement of Soil Management Practices and Manure Treatment/Handling Systems of the Southern Coastal Plains." We acknowledge the field and laboratory assistance of William Brigman and Chris Brown, USDA-ARS, Florence, SC. Support by The Kaiteki Institute, Mitsubishi Chemical Holdings Group through ARS Cooperative Agreement 58-6082-5006-F is acknowledged.

\section{REFERENCES}

Vanotti, M.B. and Szogi, A.A. (2018). Extraction of amino acids and phosphorus from biological materials. US Patent No.: 10,150,711 B2, Dec. 11. 2018. United States Patent \& Trademark Office.

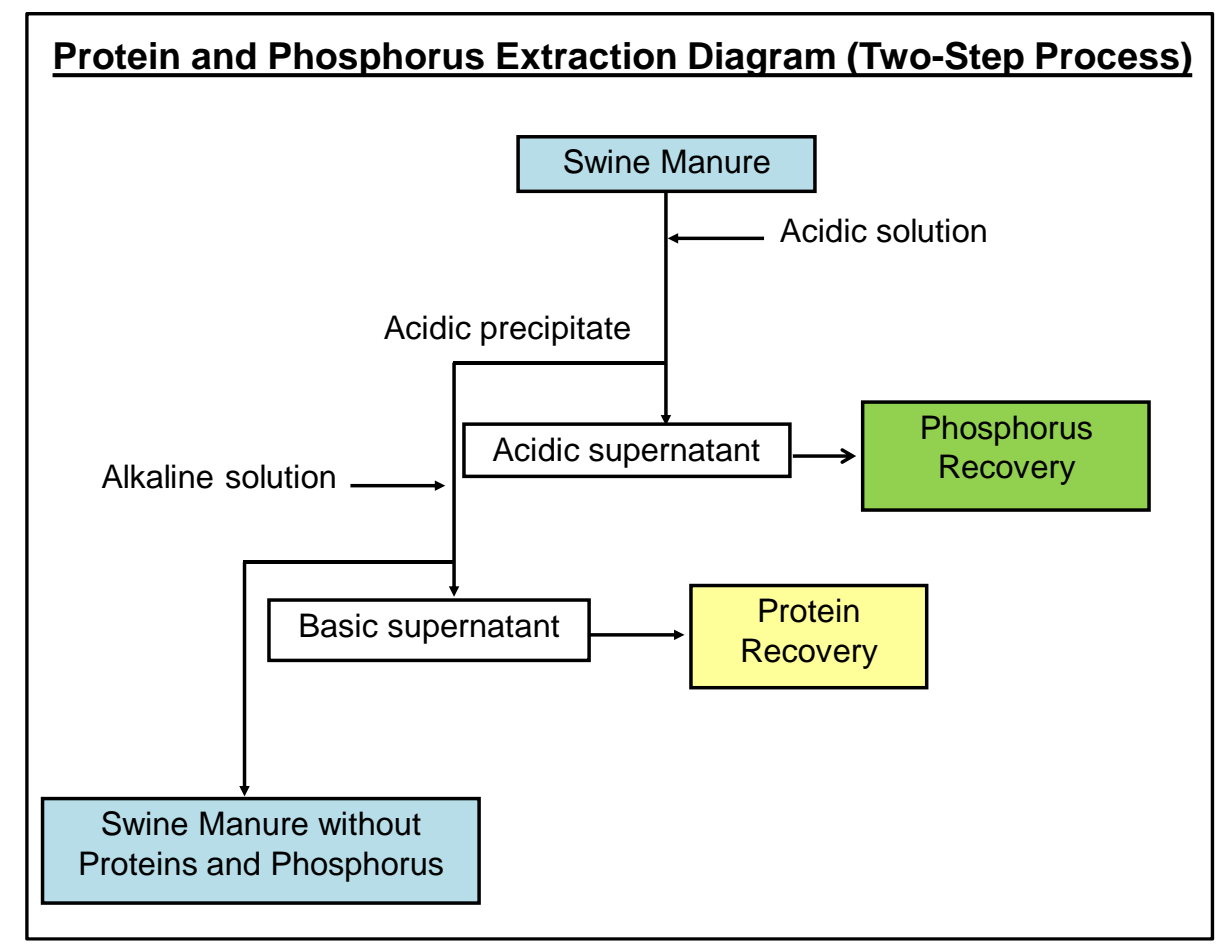

Figure 1. Diagram of process for simultaneous extraction of phosphorus and proteins from manure. 


\section{VISIGERL'

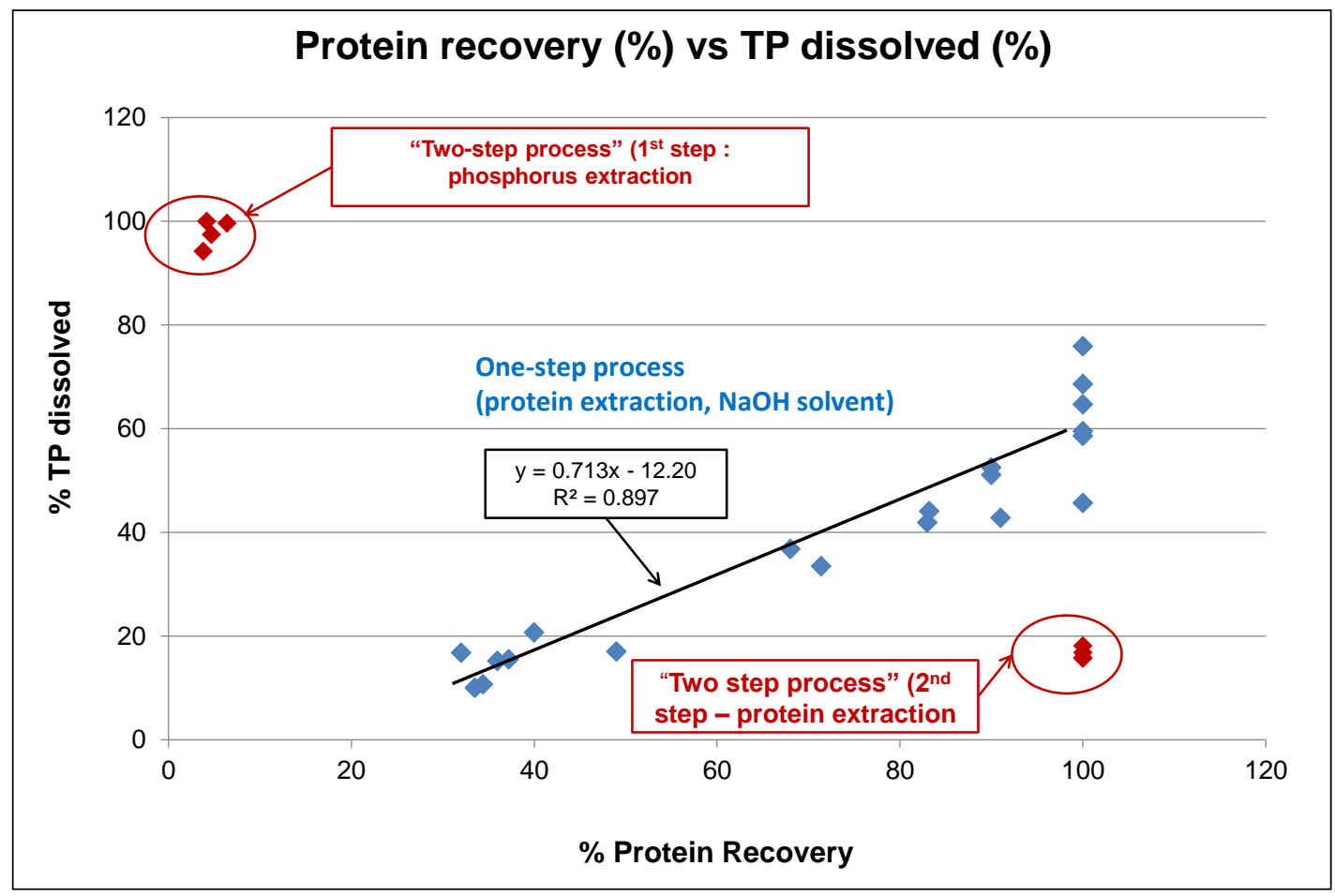

Figure 2. A two-step process was effective to reclaim both proteins and phosphorus.

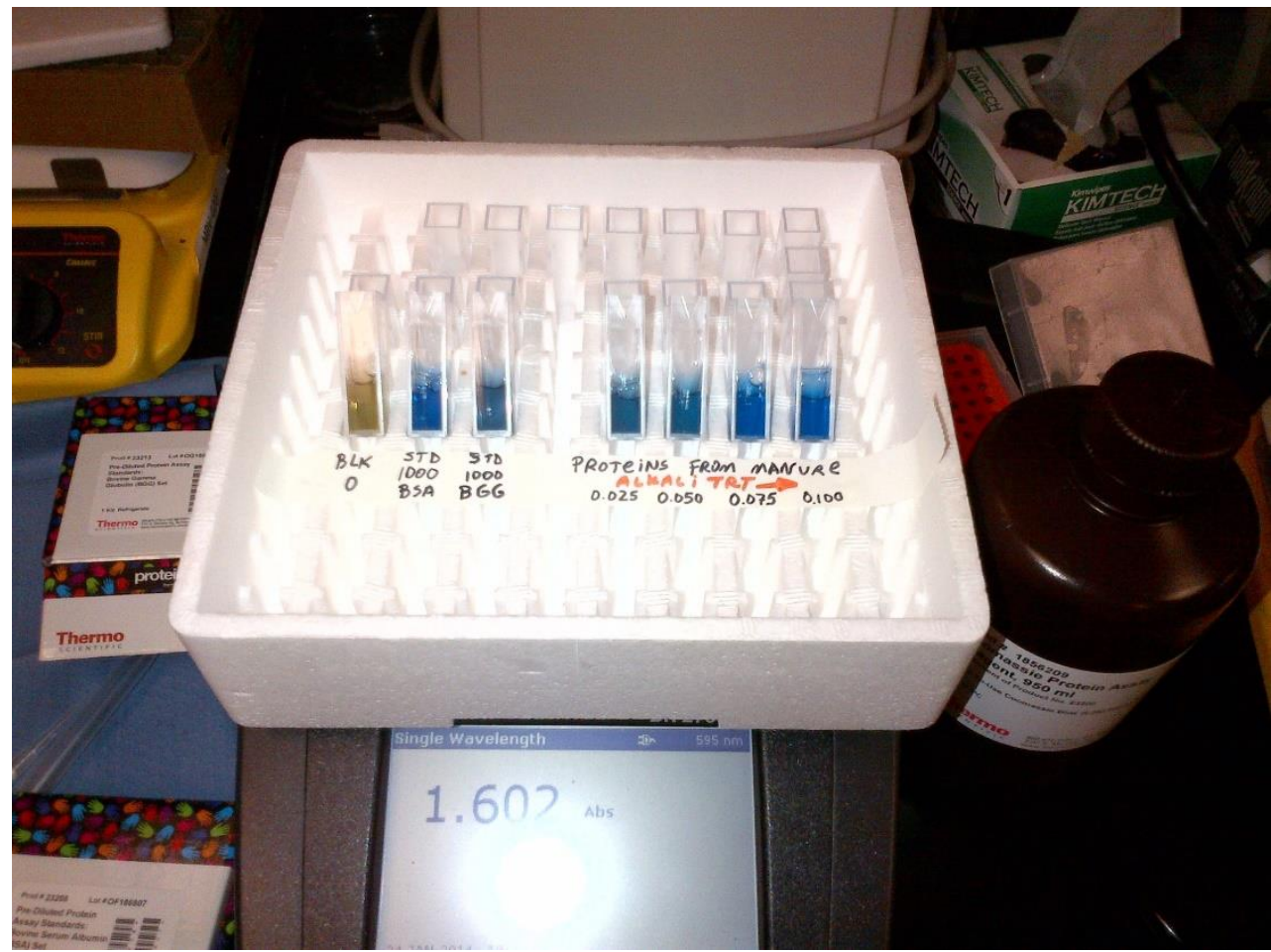

Figure 3. Extraction of proteins from manure and protein determination using Bradford method. 


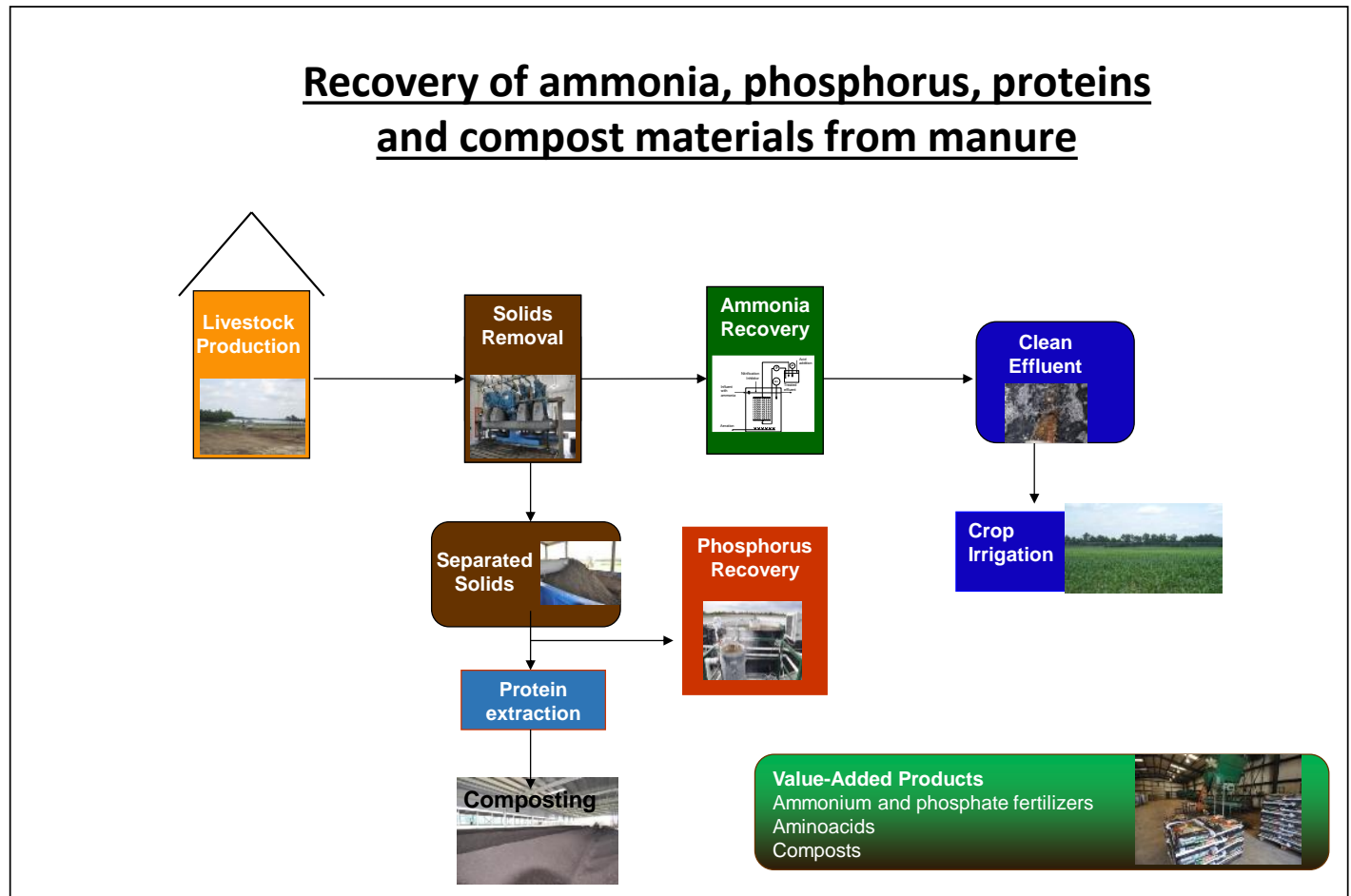

Figure 4. Recovery of ammonia, phosphorus, amino acids, organic compost and clean water from raw manure. 


\title{
FORMATION AND STABILITY OF AEROBIC GRANULAR BIOMASS IN A CONTINUOUS-FLOW BIOREACTOR
}

\author{
Cofré, C. ${ }^{1}$; Franchi, O. ${ }^{2}$; Campos, J.L.*2; Valenzuela, D. ${ }^{2}$; Pavissich, J.P.'; Camus, N. ${ }^{2}$; Belmont, M. ${ }^{3}$; \\ Pedrouso, A. ${ }^{4}$; Carrera, P. ${ }^{4}$; Val del Río, A. ${ }^{4}$; Mosquera-Corral, A. ${ }^{4}$ \\ ${ }^{1}$ Chemical and Environmental Engineering Department, Technical University Federico Santa María, Chile, Ave. España 1680, \\ Valparaíso, Chile (constanza.cofre@alumnos.usm.cl) \\ ${ }^{2}$ Facultad de Ingeniería y Ciencias, Universidad Adolfo Ibáñez, Avda. Padre Hurtado 750, Viña del Mar, Chile \\ (os.franchi@gmail.com; jluis.campos@uai.cl; daniel.valenzuela@uai.cl; juan.pavissich@uai.cl; ncamus@alumnos.uai.cl) \\ ${ }^{3}$ Department of Environment, Faculty of Engineering, University of Playa Ancha, Avenida Leopoldo Carvallo 270, 2340000 \\ Valparaíso, Chile (marisol.belmonte@upla.cl) \\ ${ }^{4}$ Department of Chemical Engineering, Institute of Technology, Universidade de Santiago de Compostela, E-15705 Santiago de \\ Compostela, Spain(alba.pedrouso@usc.es; paula.carrera@usc.es; mangeles.val@usc.es; anuska.mosquera@usc.es)
}

\begin{abstract}
A continuous flow system with "flat geometry" composed by two completely mixed aerobic tanks in series and a settler was used to promote the formation of aerobic granular sludge. Making similarities of this system with a typical sequencing batch reactor (SBR), for aerobic granules cultivation, the value of the tank 1/tank 2 volume ratio would correspond with the feast/famine length ratio while the settler upflow liquid velocity imposed would be related to the settling time. From the three experiments performed the best results were obtained when the tank $1 / \operatorname{tank} 2$ volume ratio was of 0.28 and the settler upflow velocity of $2.5 \mathrm{~m} \mathrm{~h}^{-1}$. At these conditions the aggregates had settling velocities between $29-113 \mathrm{~m} \mathrm{~h}^{-1}$, sludge volume index at 10 minutes $\left(\mathrm{SVI}_{10}\right)$ of $70 \mathrm{~mL} \mathrm{~g} \mathrm{TSS}{ }^{-1}$ and diameters between 1.0-5.0 mm. In order to maintaining the physical stability of the granules, a continuous purge of biomass was necessary. A second experiment operated under such operating conditions but without biomass purge shows that food to microorganisms ratio (F/M) in the first tank should be around 5-6 g COD g VSS${ }^{-1} \mathrm{~d}^{-1}$ to maintain the integrity of the granular biomass.
\end{abstract}

Keywords: Continuous flow; feast/famine length ratio; granular biomass.

\section{INTRODUCTION}

In the last years, research focused on obtaining stable aerobic granular sludge under continuous flow conditions is gaining attention. This is due to the fact that existing WWTPs operate normally in continuous mode and as a consequence up-gradings based on aerobic granular biomass are easily applicable if are based on continuous systems too. Most of the attempts carried out to develop granular biomass or maintaining its stability under a continuous flow regime were done using airlift reactors or type columns reactors (Li et al., 2016). These reactors are characterized by a height to diameter ratio (H/D) greater than 6-8, which helps to maximize the hydraulic shear forces. Nevertheless, until now, only few works are reported to achieve aerobic granulation using systems with "flat geometries" $(H / D \approx 1)$, similar to those of conventional activated sludge (Morales et al., 2012).

Already, "accidental granulation" has been reported in continuous flow activated sludge systems but the operational conditions which promote granulation phenomena are still unknown (Bruce et al., 2014). As a first step to understand accidental granulation, a recent survey was conducted in North America, to help to identify full-scale facilities achieving very low sludge volume index values, which may indicate the formation of granules or potential for granulation (Martin et al., 2016). On basis of these observations, the aim of the present work is to define the operating conditions that successfully promote granulation using a continuous flow system with "flat geometry".

\section{MATERIAL AND METHODS}

In order to obtain the formation of aerobic granular sludge a continuous flow system composed of two completely stirred tanks in series, with an overall height/width/length ratio of 1/0.8/1, was used (Figure 1 ). The purpose of the first tank (tank 1, useful volume of $0.6 \mathrm{~L}$ ) was to allow the contact between biomass and substrate during a short period of time to promote its conversion into intracellular storage compounds (feast period) while, in the second tank (tank 2), substrate concentration should be almost zero (famine period). Therefore, the tank 1/tank 2 volume ratio served to determine the feast/famine ratio of the configuration 
proposed. This ratio was changed during the experiment to achieve a suitable feast/famine length ratio by changing the useful volume of tank 2 from 4.0 to $2.1 \mathrm{~L}$ (Table 1). To retain the biomass, a settler operated at an upflow liquid velocity higher than $1 \mathrm{~m} \mathrm{~h}^{-1}$ (values assayed 1.4 and $2.5 \mathrm{~m} \mathrm{~h}^{-1}$ ) was used to carry out the washout of biomass that did not have suitable sedimentation properties. The settled biomass was recirculated to the first tank by means of a peristaltic pump with a large diameter tubing to minimize the possible disintegration of the granules. This peristaltic pump was activated 15 minutes each hour and the biomass recycling ratio was of 0.25 . The passage of the biomass present in tank 1 to the tank 2 occurred only during the periods in which the recirculation pump was activated, due to the increase in the flowrate that tank 1 receives. In this way, the recycling rate of biomass serves to control the time it takes for the total biomass to suffer an alternation between conditions of feast and famine.

The system was fed with a synthetic medium simulating the composition of domestic wastewater containing 0.55-0.65 $\mathrm{g} \mathrm{COD} \mathrm{L}^{-1}$. The first experiment was divided in three stages according to the different conditions assayed (Table 1). At the beginning of each operational stage, the system was inoculated with flocculent biomass taken from the municipal wastewater treatment plant of Curacaví (Chile) characterized by a sludge volume index at $30 \mathrm{~min}\left(\mathrm{SVI}_{30}\right)$ of $200 \mathrm{~mL} \mathrm{~g} \mathrm{TSS}^{-1}$. The system operated at $20{ }^{\circ} \mathrm{C}$ and without $\mathrm{pH}$ control ( $\mathrm{pH}$ value was between 8.1 and 8.3). The dissolved oxygen concentration in the aerobic tanks was around $7.8 \mathrm{mg} \mathrm{O}_{2} \mathrm{~L}^{-1}$ during the operational period. A second experiment was carried under similar operating conditions of Stage III of the first experiment but without purge of biomass.

\section{RESULTS AND DISCUSSION}

During Stages I and II of the first experiment the tank $1 / \operatorname{tank} 2$ volume ratio was of 0.15 and the upflow velocity imposed in the settler of $1.4 \mathrm{~m} \mathrm{~h}^{-1}$. In the first stage the tank 1 was operated under anoxic conditions and although filamentous biomass and small flocs were predominant, on day 56, some granule-like particles appeared. As the organic matter removal efficiency in tank 1 was low (around 36\%) and the most part was removed in the tank 2 , the feast/famine regime being not fulfilled.

Therefore, in Stage II the tank 1 mode was changed to aerobic conditions (Table 2). In this way, its organic matter removal efficiency increased up to $70 \%$, achieving the approximation to a feast period in tank 1. On day 10 of Stage II, the formation of granule-like particles was observed but, in few days, these particles were covered by filamentous biomass. Later, on 29 day of Stage II, rounded aggregates, whose surface was still covered with filaments, started to predominate. However, these aggregates were unstable and broke within a week of their formation. During the rest of Stage II several episodes of formation and break-up of this type of aggregates were observed. The appearance of filaments on the surface of the aggregates and their break-up would indicate substrate limitation conditions (Mosquera-Corral et al., 2005). Since dissolved oxygen concentration in both tanks was around $7.8 \mathrm{mg} \mathrm{O}_{2} \mathrm{~L}^{-1}$, the possible substrate limitation could be attributed to the low presence of organic matter.

In Stage III of the first experiment, to avoid the substrate limitation, the volume of the second tank was reduced in order to decrease the period where biomass was exposed to a very low organic matter concentration (famine) and, therefore, to achieve a proper feast/famine balance (Corsino et al., 2017). Furthermore, the imposed upflow liquid velocity in the settler was increased from 1.4 to $2.5 \mathrm{~m} \mathrm{~h}^{-1}$. Under these operating conditions, initial formation of aggregates with settling velocities between $29-113 \mathrm{~m} \mathrm{~h}^{-1}, \mathrm{SVI}_{10}$ of $70 \mathrm{~mL} \mathrm{~g}$ $\mathrm{TSS}^{-1}$ and diameters between 1.0-5.0 mm was observed (Figure 2). The formation of the aggregates was associated with the appearance of translucent structures (similar to alginate spheres) that turned compact over the time of operation. During this stage, biomass purges were carry out in order to prevent the appearance of filamentous biomass. During the second experiment, the physical stability of granules was tested using the same operational conditions as in Stage III of the first experiment but without applying biomass purges. During the first eleven days of operation, the F/M ratio of tank 1 was around 5-6 g COD g VSS${ }^{-1} \mathrm{~d}^{-1}$ which promoted the formation of compact granules of $\sim 0.3 \mathrm{~mm}$ of diameter (Figure 2). These granules were stable until day 18, after that the emergence of a mixture of filamentous biomass and fluffy-filamentous granules with 0.7-2.0 $\mathrm{mm}$ of diameter was observed. At day 22, filamentous biomass became dominant and a progressive decrease in COD removal was observed. At day 38, there was a mixture of granules with $\sim 2 \mathrm{~mm}$ of diameter and filamentous biomass, but the COD removal was still poor. The granules instability could be caused by the loss of $\mathrm{F} / \mathrm{M}$ ratio differences between $\mathrm{R} 1$ and $\mathrm{R} 2$ that started at day 14 and induced a progressive filamentous biomass growth. From day 38 on, a similar proportion between filamentous and granular biomass was 
observed, probably due to the recovery of the F/M ratio differences between R1 and R2 that induced a new biomass granulation period. It is known that the F/M ratio is a relevant variable to biomass granulation and a $\mathrm{COD}$ concentration gradient promotes the growth of granule forming biomass due to the famine-feast feeding condition (Wu et al., 2018).

In terms of COD removal the system performed better in Stage III when the treated OLR was up to 4.4 $\mathrm{g} \mathrm{COD} \mathrm{L}^{-1} \mathrm{~d}^{-1}$ with an overall removal efficiency of $95 \%$ (Table 2). In the three stages, the ammonia removal efficiency was between $15-30 \%$. This removal can be totally attributed to biomass assimilation since nitrification did not take place (nitrite or nitrate was never detected) due to the low sludge retention time (SRT) achieved (between 0.4 and 2.7 days, Table 2). These low SRT values are attributed to the washout in the effluent of small granules, embedded in the fraction of flocculent and/or filamentous biomass, that presented unsuitable settling velocities to be retained inside the system. Although, this washout diminished from Stage I to Stage III, decreasing the solids concentration in the effluent and increasing the SRT values (Table 2). As it was observed, short SRT values limit nitrogen removal efficiency but have not a negative effect on the granulation process (Li et al., 2008).

\section{CONCLUSIONS}

It is possible to form aerobic aggregates $\left(\mathrm{SVI}_{10}\right.$ of $70 \mathrm{~mL} \mathrm{~g} \mathrm{TSS}^{-1}$ and settling velocities of $29-113 \mathrm{~m} \mathrm{~h}^{-}$ ${ }^{1}$ ), for organic matter removal in continuous flow systems, operating under hydrodynamic conditions that simulate those obtained in a discontinuous reactor. Control of F/M in the first tank is necessary in order to maintain the physical stability of the granular biomass.

\section{ACKNOWLEDGEMENT}

This work was funded by the Chilean Government through the project FONDECYT 1180650, CORFO/14ENI2-26865 and CONICYT/FONDAP/15130015 and by the Spanish Government through TREASURE (CTQ2017-83225-C2-1-R) and GRANDSEA (CTM2014-55397-JIN) projects. J.L. Campos belongs to Center UAI Earth and the authors from the USC belong to CRETUS (AGRUP2015/02) and the Galician Competitive Research Group (GRC ED431C 2017/29). All these programs are co-funded by FEDER.

\section{REFERENCES}

Bruce, S.C.R., Downing, L., Young, M., Nerenberg, R., 2014. Floc or granule? Evidence of granulation in a continuous flow system. Proceedings of Water Environment Federation, 2889-2897.

Corsino, S.F., di Biase, A., Devlin, T.R., Munz, G., Torregrossa, M., Oleszkiewicz, J.A. 2017. Effect of extended famine conditions on aerobic granular sludge stability in the treatment of brewery wastewater. Bioresour. Technol., 226, 150-157.

Li, Y., Liu, Y., Xu, H.L., 2008. Is sludge retention time a decisive factor for aerobic granulation in SBR? Bioresour. Technol. 99, 7672-7677.

Li, D., Lv, Y., Zeng, H., Zhang, J., 2016. Enhanced biological phosphorus removal using granules in continuous-flow reactor. Chem. Eng. J., 298, 107-116.

Martin, K., Shaw, A., de Clippeleir, H., Sturm, B., 2016. Accidental Granular Sludge?: Understanding process design and operational conditions that lead to low SVI-30 values through a survey of full scale facilities in North America. Proceedings of Water Environment Federation, 3385-3394.

Morales, N., Figueroa, M., Mosquera-Corral, A., Campos, J.L., Méndez, R., 2012. Aerobic granular-type biomass development in a continuous stirred tank reactor. Sep. Purif. Technol., 89, 199-205.

Mosquera-Corral, A., de Kreuk, M.K., Heijnen, J.J., van Loosdrecht, M.C.M., 2005. Effects of oxygen concentration on N-removal in an aerobic granular sludge reactor. Wat. Res., 39, 2676-2686.

Wu, D., Zhang, Z., Yua Z., Zhu, L. (2018). Optimization of F/M ratio for stability of aerobic granular process via quantitative sludge discharge. Bioresour. Technol. 252, 150-156. 
A

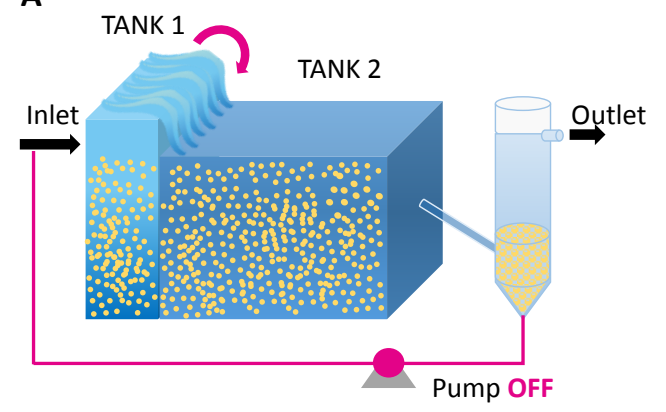

B

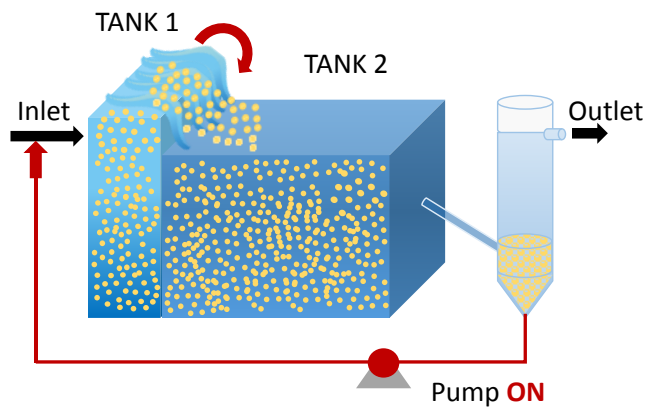

Figure 1. Schematic system performance: A) recirculation pump stopped: biomass does not pass from tank 1 to tank 2, only liquid does; B) recirculation pump in operation: biomass passes from tank 1 to tank 2 .

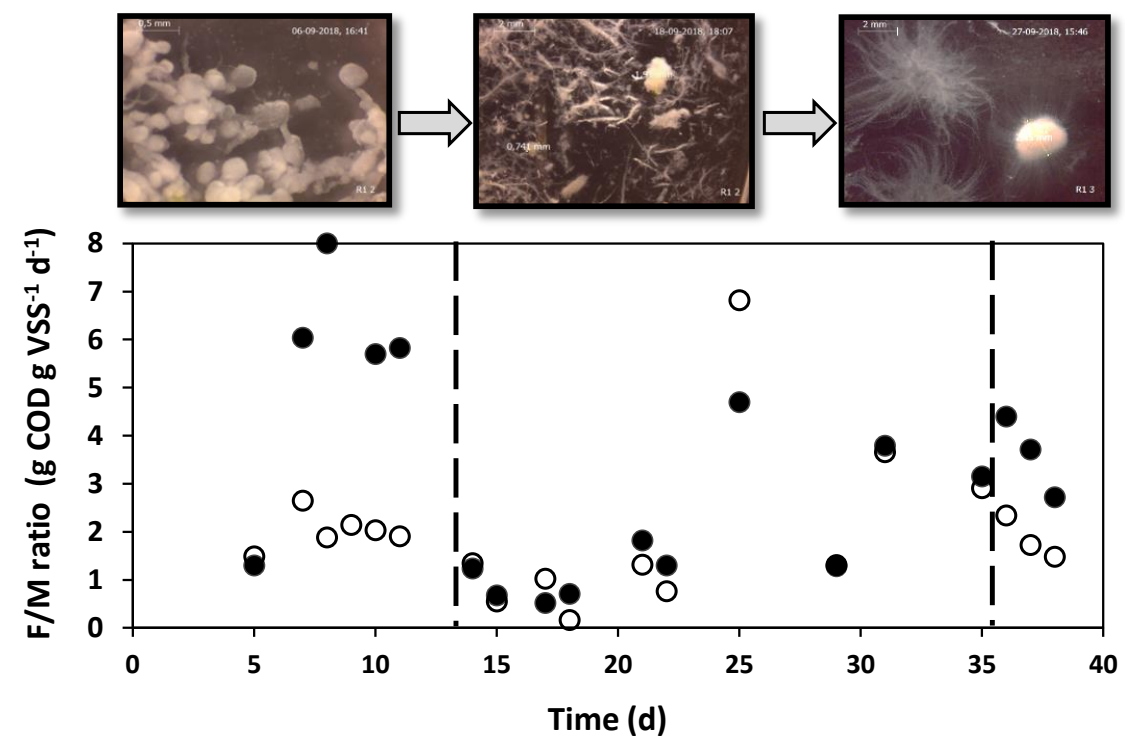

Figure 2. Biomass structure (A) during different F/M ratios phases (IIIA, IIIB and IIIC) of R1 (empty circles) and R2 (filled circles) during continuous operation.

Table 1. Operational conditions and configurations of the system during the different stages of the experiment.

\begin{tabular}{lccc}
\hline & Stage I & Stage II & Stage III \\
\hline Operational period (d) & 60 & 40 & 30 \\
Useful volume of tank 2 & 4.6 & 4.6 & 2.3 \\
HRT of the whole system $(\mathrm{h})$ & 6 & 6 & 3 \\
OLR of the whole system $\left(\mathrm{g} \mathrm{COD} \mathrm{g} \mathrm{L}^{-1} \mathrm{~d}^{-1}\right)$ & 2 & 2 & 4 \\
Tank 1 & Anoxic & Aerobic & Aerobic \\
Upflow velocity in the settler $\left(\mathrm{m} \mathrm{h}^{-1}\right)$ & 1.4 & 1.4 & 2.5 \\
\hline
\end{tabular}

Table 2. Main operational results obtained throughout the different stages of the experiment.

\begin{tabular}{lccc}
\hline & Stage I & Stage II & Stage III \\
\hline Organic matter removal efficiency of Tank 1 (\%) & 36 & 70 & 80 \\
Overall organic matter removal efficiency (\%) & 85 & 93 & 95 \\
Overall biomass concentration $\left(\mathrm{g} \mathrm{VSS} \mathrm{L}^{-1}\right)$ & 0.26 & 0.43 & 2.05 \\
Overall F/M ratio $\left(\mathrm{g} \mathrm{COD} \mathrm{g} \mathrm{VSS}^{-1} \mathrm{~d}^{-1}\right)$ & 8.3 & 5.1 & 2.1 \\
Diameter of the biomass particles $\left.(\mathrm{mm})_{\mathrm{SVI}_{10}\left(\mathrm{~mL} \mathrm{~g} \mathrm{TSS}^{-1}\right)}\right)$ & $0.8-3.0$ & $0.5-10.0$ & $1.0-5.0$ \\
$\mathrm{SRT}(\mathrm{d})$ & -- & 110 & 70 \\
\hline
\end{tabular}




\title{
MICROALGAE OBTAINED FROM SWINE WASTEWATER TREATMENT AS SOURCE OF AMINOACIDS AND OMEGA-3
}

\author{
Michelon, W.*1; Dinnebier, H.C.F. ${ }^{2}$; Da Silva, M.L.B. ${ }^{3}$; Matthiensen, A. ${ }^{4}$; Soares, H.M. ${ }^{1}$ \\ ${ }^{1}$ Federal University of Santa Catarina, Florianopolis, SC - Brazil-william@unc.br; soares@enq.ufsc.br \\ ${ }^{2}$ Federal University of Fronteira Sul, Erechim, RS - Brazil - eng.helgadinnebier@gmail.com \\ ${ }^{3}$ Rice University, Houston, Texas - USA silva@ rice.edu \\ ${ }^{4}$ Embrapa Suínos e Aves, Concórdia, SC-Brazil - alexandre.matthiensen@embrapa.br
}

\begin{abstract}
The use of microalgae to remove nutrients from swine wastewater effluents (i.e. phycoremediation) has been extensively reported as effective tertiary treatment or polishing treatment to remove nutrients. One of the greatest advantages of this biological treatment is in the production of valuable microalgae biomass that can be considered as food supplement for animal nutrition. In this work, two different swine wastewater effluents [i.e., digestate from an Anaerobic Upflow Sludge Blanket (UASB), and effluent from an air-sparged nitrification-denitrification reactor] were tested for the growth of microalgae and the produced biomass compared for its protein, aminoacids and fatty acids contents. The biomass from both effluents tested had high amino acids content: arginine (2.6\%), isoleucine $(2.1 \%)$, histidine $(1 \%)$, leucine $(4.1 \%)$, lysine $(2.5 \%)$, methionine $(0.8 \%)$, phenylalanine $(2.6 \%)$, threonine $(2.4 \%)$, tryptophan $(0.5 \%)$, valine (2.8\%). Stress-induced conditions such as limiting the concentration of nutrients in microalgae culture medium contributed to the production of lipids and polyunsaturated fatty acids (5.3\%, mainly omega-3) and unsaturated fatty acids $(10 \%)$. Overall, the results suggest that microalgae biomass obtained from the phycoremediation of swine wastewater that are rich in nutrients lead to production of a low cost microalgae biomass rich in aminoacids and fatty acids which are of paramount importance as supplemental diet for the maintenance of healthy animal growth.
\end{abstract}

Keywords: microalgae, wastewater, aminoacids, fatty acids, animal nutrition.

\section{INTRODUCTION}

The swine farming in Brazil plays an important role in the country's economy (ABPA, 2017). To warrant the growth of healthy animals, careful attention is constantly being placed on the right formulation of the animal diets offering adequate nutritional balance. Protein sources are usually expensive and its costs continue to increase considerably over the years. Therefore, it is wise to consider new alternative sources of proteins that are cheaper, abundant, and compatible with animal feed formulations. Microalgae are known to accumulate considerable quantities of proteins, lipids (SUN et al., 2014) and associated essential amino acids and omegas (LUM et al., 2013). Studies have shown that the use of microalgae in animal feed can replace up to $50 \%$ of protein in existing diets (HARUN, et al., 2010) and help to improve animal's immune system, intestinal function, appetite with weight gain (SATHASIVAM, et al., 2017). Microalgae biomass could be cheaply and promptly obtained from different types of reactors, including the ones built to treat wastewater effluents. Therefore, we hypothesize that it may be possible to combine the production of microalgae biomass rich in protein and lipids with swine wastewaters treatment (i.e., phycoremediation) (PRANDINI, et al, 2016). It is worth mentioning that variations in nutrient concentration present in different types of wastewater can affect the biochemical composition of the biomass (MICHELON, et al., 2015). Thus, associating the composition of wastewater with amino acids and or fatty acids contents in microalgae can guide us in the production of biomasses that better suit our expectations regarding to the minimum amount of protein or lipid contents from the biomass. Therefore, the objective of this study was to compare the amino acids and fatty acid concentrations in microalgae grown in two different types of swine wastewater effluents, i.e., digestate from anaerobic digester and effluent from a nitrification-denitrification reactor, as well as under nitrogen and phosphorus limited conditions

\section{MATERIAL AND METHODS}

Microalgae consortia were obtained from a facultative pond at EMBRAPA Swine and Poultry, Concórdia, Brazil. The inoculum was composed by microalgae consortium dominated by Chlorella spp. Experiments were conducted in 12-L glass photobioreactors (PBR) filled with non-sterile $6 \% \mathrm{v} \mathrm{v}^{-1}$ UASB digestate effluent diluted in water. PBRs were inoculated with $70 \mathrm{mg}$ dry weight microalgae $\mathrm{L}^{-1}$ (or $30 \% \mathrm{v} \mathrm{v}^{-}$ ${ }^{1}$ of inoculum). PBRs were maintained at room temperature $\left(23^{\circ} \mathrm{C}\right)$ under mixotrophic conditions $(44.8 \mu \mathrm{mol}$ 
$\mathrm{m}^{-2} \mathrm{~s}^{-1}$ ) and continuous agitation. Experiments were also conducted using a pilot scale 500-L reactor placed inside a greenhouse under natural light $321.5( \pm 411.4) \mu \mathrm{mol} \mathrm{m}^{-2} \mathrm{~s}^{-1}$ and temperature controled $25^{\circ} \mathrm{C}$ conditions Culture medium in the reactor was kept under continuous agitation using a submersible aquarium pump. After 11 days following inoculation, the growth medium containing the microalgae biomass was harvested via centrifugation (EVODOS, T10, Netherlands). The harvested biomass was immediately frozen $\left(-40{ }^{\circ} \mathrm{C}\right)$ and lyophilized (Model 030-JJ LJI Scientific) for further analyses. For evaluating the effects of nitrogen and phosphorus starvation, briefly, microalgae biomass was harvested, after cells were resuspended in fresh 500$\mathrm{L}$ nutrient-free water. To verify the influence of phosphorus depletion, nutrient-free water was artificially amended with either $50 \mathrm{mg} \mathrm{N}-\mathrm{NO}_{3} \mathrm{~L}^{-1}$. To avoid nutrient exacerbation during the tests, $\mathrm{N}$ was continuously monitored and replenished accordingly. The concentration of amino acid was determined according to Hagen et al. (1989) and White et al. (1986) using a HPLC (Shimadzu, LC-20A). The concentration of tryptophan was obtained according to Lucas and Sotelo (1980) using a spectrophotometer (Femto, 700 Plus). Lipids were analyzed as esters using a FID-equipped gas chromatography (Varian, CP-3800) as previously described (AOCS, 2013).

\section{RESULTS AND DISCUSSION}

The effects of two different wastewater effluents on the concentration of amino acids and fatty acids contents in microalgae were compared (Table 1). The obtained amino acids concentrations were compared to current amino acid concentrations required to feed swine at different stages of animal growth. The use of nutrient-rich digestate effluent led to proliferation of microalgae with the following concentrations of amino acids (as \% of total protein content) arginine (2.6), isoleucine (2.1), histidine (1), leucine (4.1), lysine (2.5), methionine (0.8), phenylalanine (2.6), threonine (2.4), tryptophan (0.5), valine (2.8). The concentration of amino acids obtained surpassed the concentrations of amino acids typically utilized in the animal diet (NRC, 1998; ROSTAGNO, 2017). Among these amino acids, lysine deserves special attention considering its importance in pig nutrition where it can serve as building block for the production of proteins, peptides and non-peptide molecules. A deficiency in lysine impairs the immunity system and increase the susceptibility of infectious diseases in animals (MORALES et al., 2015). After lysine, threonine is the second most important amino acids to be considered. This latter amino acid is involved in the adequate function of digestive and immune systems (WANG et al., 2006). Microalgae grown in the digestate (effluent of UASB) also showed high concentrations of tryptophan $(0.5 \%$, Table 1$)$, an amino acid that plays a major role in the synthesis of proteins, in the weight gain and in feed efficiency (PASTUSZEWSKA et al., 2007). A noticeable higher concentration of threonine $(2.4 \%)$ was observed in microalgae grown in wastewater under limited concentration of phosphorus as nutrient for microalgae (Table 1).

The lipid and fatty acid contents increased in microalgae grown in $\mathrm{N}$ and $\mathrm{P}$ limited conditions (Table 5). The increase in lipid content was mainly associated with the accumulation of monounsaturated fatty acids (MUFAs, by up to $4.7 \%$ ), polyunsaturated (PUFAs, by up to $5.2 \%$ ) and unsaturated fatty acid (UFAs, by up to $10 \%$ ). Among all fatty acids studied here, the omega-3 polyunsaturated deserves especial attention since its use in animal feed was reported to decrease serum levels of triglycerides during swine gestation, improving piglet birth weights (POSSER et al., 2018).

\section{CONCLUSIONS}

The importance of this research is three fold. First, phycoremediation, which is recognized as an efficient polishing step for swine wastewater treatment, can generate high yields of valuable microalgae biomass. Second, the produced microalgae is attractive as a feedstock rich in amino acids and fatty acids that can be utilized as supplement in animals diets. Third, the concentrations of amino acids and/or fatty acids in the biomass can be adjusted during microalgae growth by controlling nitrogen and phosphorus present in the wastewater as culturing medium. Therefore, we have total flexibility to produce a biomass that provides protein or lipid contents that best suit the nutritional demands. Overall, these results served to improve our current understanding of microalgae biochemical changes as a functional of the growth conditions and how these changes ultimately affect the production of amino acids and fatty acids that can be further explored for supplementation of animal diets. 
ACKNOWLEDGEMENTS

The authors gratefully acknowledge the support provide by CAPES Foundation, Ministry of Education of Brazil and SISTRATES-BNDES (Project No 23.17.00.023.00.00).

\section{REFERÊNCIAS}

ABPA - Associação Brasileira de Proteína Animal - Relatório anual (2017) São Paulo: Disposable at: http://abpa-br.com.br/stora ge/ files /3678c _final_abpa_relat orio_anual _2016_portu gues_web_reduz ido.pdf. Accessed 06 nov 2018

AOCS, 2013. Official Methods and Recommended Practices of the AOCS, $\left(6^{\text {th }}\right.$ Ed.). Firestone, Champaign IL: American Oil Chemists' Society.

HAGEN, S. R.; FROST, B.; AUGUSTIN, J. Precolumn phenylisothiocyanate derivatization and liquid chromatography of amino acids in food. Journal-Association of Official Analytical Chemists, v. 72, n. 6, p. 912-916, 1989.

HARUN, R. et al. Bioprocess engineering of microalgae to produce a variety of consumer products. Renewable and Sustainable Energy Reviews, v. 14, n. 3, p. 1037-1047, 2010.

LUCAS, B. and SOTELO, A. Effect of different alkalies, temperature, and hydrolysis times on tryptophan determination of pure proteins and of foods. Analytical Biochemistry, v. 109, n. 1, p. 192-197, 1980.

LUM, K. K.; KIM, J. and LEI, X. G. Dual potential of microalgae as a sustainable biofuel feedstock and animal feed. Journal of Animal Science and Biotechnology, v. 4, n. 1, p. 53, 2013.

MICHELON, W. et al. Effects of nitrogen and phosphorus on biochemical composition of microalgae polyculture harvested from phycoremediation of piggery wastewater digestate. Applied Biochemistry and Biotechnology, v. 178, n. 7, p. 1407-1419, 2016.

MORALES, A. et al. Effect of L-lysine on expression of selected genes, serum concentration of amino acids, muscle growth and performance of growing pigs. Journal of animal physiology and animal nutrition, v. 99, n. 4, p. 701-709, 2015.

N.R.C., 1998. Nutrient requirements of swine. National Academies Press.

PASTUSZEWSKA, B. et al. Effects of supplementing pig diets with tryptophan and acidifier on protein digestion and deposition, and on brain serotonin concentration in young pigs. Animal feed science and technology, v. 132, n. 1-2, p. 49-65, 2007.

POSSER, C. J. M. et al. Supplementation of diets with omega-3 fatty acids from microalgae: Effects on sow reproductive performance and metabolic parameters. Livestock Science, v. 207, p. 59-62, 2018.

PRANDINI, Jean Michel et al. Enhancement of nutrient removal from swine wastewater digestate coupled to biogas purification by microalgae Scenedesmus spp. Bioresource technology, v. 202, p. 67-75, 2016.

ROSTAGNO, Horacio Santiago. Tabelas brasileiras para aves e suínos: composição de alimentos e exigências nutricionais. $4^{\text {th }}$ ed.Universidade Federal de Viçosa. Departamento de Zootecnica, 2017.

SATHASIVAM, R. et al. Microalgae metabolites: A rich source for food and medicine. Saudi Journal of Biological Sciences, 2017.

SUN, X. et al. Effect of nitrogen-starvation, light intensity and iron on triacylglyceride/carbohydrate production and fatty acid profile of Neochloris oleoabundans HK-129 by a two-stage process. Bioresource Technology, v. 155, p. 204-212, 2014.

WANG, X. et al. Effects of graded levels of true ileal digestible threonine on performance, serum parameters and immune function of 10-25 kg pigs. Animal feed science and technology, v. 129, n. 3-4, p. 264-278, 2006. WHITE, J. A.; HART, R. J.; FRY, J. C. An evaluation of the Waters Pico-Tag system for the amino-acid analysis of food materials. Journal of Analytical Methods in Chemistry, v. 8, n. 4, p. 170-177, 1986. 
Table 1. Amino acids concentration profile present in the microalgae biomass. Data shown as percentage of the total protein content.

\begin{tabular}{cccccccc}
\hline Amino Acids (\%) & UASB & NR & $\begin{array}{c}\mathbf{P} \\
\text { Limited }\end{array}$ & $\begin{array}{c}\text { N and P } \\
\text { limited }\end{array}$ & [Starting & Growing & Finishing]* \\
\hline Aspartic acid & 4.71 & 3.02 & 4.01 & 1.52 & - & - & - \\
Glutamic acid & 5.01 & 3.24 & 4.91 & 1.99 & - & - & - \\
Serine & 1.88 & 1.36 & 2.07 & 0.83 & - & - & - \\
Glycine & 2.73 & 2.10 & 2.87 & 1.10 & - & - & - \\
Histidine & 0.99 & 0.60 & 0.57 & 0.27 & 0.47 & 0.38 & 0.27 \\
Arginine & 2.58 & 1.96 & 2.59 & 0.97 & 0.64 & 0.47 & 0.32 \\
Threonine & 1.99 & 1.53 & 2.37 & 1.04 & 0.99 & 0.80 & 0.58 \\
Alanine & 3.28 & 2.59 & 4.00 & 1.69 & - & - & - \\
Prolina & 1.85 & 1.40 & 2.42 & 0.96 & - & - & - \\
Tyrosine & 1.42 & 1.04 & 1.30 & 0.56 & - & - & - \\
Valine & 2.66 & 1.85 & 2.82 & 1.07 & 1.02 & 0.82 & 0.59 \\
Methionine & 0.82 & 0.43 & 0.67 & 0.31 & 0.41 & 0.34 & 0.26 \\
Cysteine & 0.70 & 0.37 & 0.68 & 0.27 & - & - & - \\
Isoleucine & 1.73 & 1.41 & 2.06 & 0.80 & 0.80 & 0.65 & 0.47 \\
Leucine & 3.51 & 2.55 & 4.15 & 1.68 & 1.41 & 1.14 & 0.82 \\
Phenylalanine & 2.12 & 1.48 & 2.57 & 0.90 & 0.71 & 0.58 & 0.42 \\
Lysine & 2.52 & 1.29 & 2.29 & 0.92 & 1.46 & 1.17 & 0.85 \\
Tryptophan & 0.49 & 0.23 & 0.33 & 0.21 & 0.28 & 0.24 & 0.17 \\
\hline
\end{tabular}

* Nutritional requirements of whole male swine of high genetic potential (NRC, 1998; Rostagno, 2017).

Table 2. Fatty acids concentration profile present in the microalgae biomass. Data shown as percentage of the total

\begin{tabular}{|c|c|c|c|c|}
\hline Fatty acids (\%) & UASB & NR & $\mathbf{P}$ limited & $\mathbf{N}$ and $\mathbf{P}$ limited \\
\hline Myristic Acid (C14:0) & 0.01 & 0.01 & 0.02 & 0.09 \\
\hline Myristoyl Acid (C14:1) & 0.04 & 0.02 & 0 & 0.01 \\
\hline Pentadecanoic Acid (C15:0) & 0.01 & 0.01 & 0.01 & 0.02 \\
\hline Palmitic Acid (C16:0) & 0.23 & 0.33 & 0.84 & 5.27 \\
\hline Palmitoleic Acid (C16:1n7) & 0.16 & 0.04 & 0.01 & 0.04 \\
\hline Margaric Acid (C17:0) & 0.01 & 0.01 & 0.02 & 0.05 \\
\hline Estearic Acid (C18:0) & 0.03 & 0.05 & 0.03 & 0.44 \\
\hline Oleic Acid (C18:1n9c) & 0.08 & 0.14 & 0.2 & 4.63 \\
\hline Linoleic Acid (C18:2n6c) & 0.13 & 0.2 & 0.16 & 1.32 \\
\hline Linolenic Acid (C18:3n6) & 0.01 & 0.02 & 0.02 & 0.05 \\
\hline Linolenic Acid (C18:3n3) & 0.47 & 0.48 & 1.03 & 3.87 \\
\hline Arachic acid (C20:0) & - & - & - & 0.02 \\
\hline Eicosatrienoic acid (20:3) & - & - & 0.01 & 0.02 \\
\hline Behenic Acid (C22:0) & - & 0.01 & 0.01 & 0.04 \\
\hline Erucic Acid (C22:1n9) & - & - & - & 0.01 \\
\hline Eicosapentaenoic acid (C20:5n3) & - & - & - & 0.01 \\
\hline Lignoceric Acid (C24:0) & - & - & 0.01 & 0.01 \\
\hline$\Sigma$ MUFAs & 0.29 & 0.2 & 0.23 & 4.75 \\
\hline$\Sigma$ PUFAs & 0.63 & 0.71 & 1.22 & 5.27 \\
\hline$\Sigma$ UFAs & 0.92 & 0.91 & 1.45 & 10.03 \\
\hline$\Sigma$ SFAs & 0.31 & 0.42 & 0.95 & 5.96 \\
\hline$\Sigma \omega-3$ & 0.48 & 0.49 & 1.04 & 3.9 \\
\hline$\Sigma \omega-6$ & 0.15 & 0.22 & 0.18 & 1.37 \\
\hline$\Sigma \omega-9$ & 0.09 & 0.14 & 0.21 & 4.7 \\
\hline
\end{tabular}

Monounsaturated (MUFAs), polyunsaturated (PUFAs), unsaturated (UFAs) and saturated (SFA) fatty acid. 


\title{
QUICK START-UP OF DEAMMONIFICATION PROCESS USING NITRAMMOX ${ }^{\circledR}$ REACTOR
}

\author{
Bonassa, G.B.*1; Prá, M.C. ${ }^{2}$; Antes, F.G. ${ }^{3}$; Bolsan, A.C. ${ }^{4}$; Kunz, A. ${ }^{1,3}$ \\ ${ }^{1}$ Department of Agricultural Engineering, PGEAGRI/CCET-Unioeste-Cascavel-PR-Brazil \\ gabrielabonassa@gmail.com \\ ${ }^{2}$ Federal Technological University of Paraná, UTFPR, Dois Vizinhos-PR-Brazil \\ ${ }^{3}$ Embrapa Suínos e Aves, Concórdia-SC-Brazil \\ University of Western of Santa Catarina, Joaçaba-SC-Brazil
}

\begin{abstract}
Among the processes for autotrophic nitrogen removal, the deammonification process stands out for achieving high efficiency in the treatment of effluents with low $\mathrm{C} / \mathrm{N}$ ratio, such as swine digestate. Although several studies have been developed in recent years, there are still some challenges related to the start-up of the deammonification process using digestates instead of synthetic wastewaters. The aim of this work was to evaluate the start-up of a single process of deammonification using digestate from a covered lagoon biodigester (CLB) in the NITRAMMOX ${ }^{\circledR}$ reactor. This reactor was designed to work in continuous flow, and is of airlift type with concentric tubes, agitated and mixed pneumatically. Additionally, the reactor is designed to itself geometry of dimensioning with conical bottom to favor the two groups of deammonification bacterias: the ammonia oxidizing bacteria (AOB) and the Anammox bacteria. After inoculation, the NITRAMMOX ${ }^{\circledR}$ reactor achieved the start-up close to the tenth day with nitrogen removal average up to $70 \%$ in the first 30 days of operation. In addition, it was also noted that NITRAMMOX ${ }^{\circledR}$ can be used as a reactor for the deammonification process using digestate from a CLB as a substrate, contributing in this way with the management of the wastes generated in the swine chain, which refer to large volumes of significant pollutant potential.
\end{abstract}

Keywords: swine digestates, biological nitrogen removal, ammonium wastewater treatment.

\section{INTRODUCTION}

The current way of swine production, termed concentrated animal feeding operations (CAFOs), brings with it some problems to the environmental and public health due to some characteristics of the effluents generated in that, related to the high concentration of organic matter, nutrient, pathogens and antibiotics. The application of these effluents as soil fertilizer had a measurable effect on surface and groundwater quality, and promotes higher concentrations of total nitrogen when compared to control watersheds (CHRISTENSON; SERRE, 2017). The anaerobic digestion (AD) is the common way applied to treat the swine manure, where the organic matter present in the effluent is stabilized by decomposition in the absence of molecular oxygen. However, this kind of treatment do not allow for nutrients removal, like ammoniacal nitrogen, that remains in the liquid fraction resulted from the treatment (AMINI et al., 2017).

Due to the high amount of nitrogen, the digestate must be treated aiming to reduce the pollutant potential and to comply the guidelines and agro-environmental rules. Among the types of treatment that can be applied for nitrogen removal the combination of partial nitritation with the anaerobic ammonium oxidation (Anammox) process (PN/A), that is also known as deammonification, have brought some advantages compared to other available technologies. PN/A do not require an external source of organic carbon and promote reduction in energy costs and sludge production (NAWI; STUCKEY, 2018). The PN/A process includes the oxidation of approximately half of the ammonium present in digestates to nitrite, by the ammonium oxidizing bacteria (AOB), followed by the conversion of the remaining ammonium and nitrite to $\mathrm{N}_{2}$, by the Anammox bacteria (MIAO et al., 2018).

Considering the unstable characteristics of the swine manure and different seasonal conditions during the operation of reactors, the efficiency $\mathrm{AD}$ in covered lagoons biodigesters (CLB) can change and consequently the digestate composition, mainly concencentrations of organic carbon and ammoniacal nitrogen will be different. This variation in digestate composition represents one of the major challenges to the practical application of PN/A process to this kind of wastewater, due to the high sensitivity of anammox bacteria to different environmental conditions and its very low growth rates (around 11 days). Therefore the start-up 
period of this kind of process usually could take more time than other biological processes (WANG et al., 2017).

To overcome the challenges coupled with the effluents treatment for nitrogen removal, recently a different reactor was developed (EMBRAPA, 2018). The NITRAMMOX ${ }^{\circledR}$ reactor is a new proposal of pneumatic reactor with intrinsic features projected to remove nitrogen from effluents with low $\mathrm{C} / \mathrm{N}$ ratio, like swine digestates. Therefore, the purpose of this study was to evaluate the start-up and stable operation of the PN/A process in a single reactor called NITRAMMOX ${ }^{\circledR}$, operating with digestate coming from a CLB.

\section{MATERIAL AND METHODS}

This study was developed in Laboratory of Studies and Environmental Analysis (LEEA) of Embrapa Suínos e Aves located in Concórdia, SC.

The NITRAMMOX ${ }^{\circledR}$ reactor was developed to operate in a single phase and based in the concept of airlift reactor coupled to a three-phase separator used in UASB reactors. This reactor has a total net volume of $8 \mathrm{~L}$ and operates with continuous feed, recirculation and pneumatic homogenization. Inside the reactor there is a concentric tube to favor both microbial groups with aerobic and anaerobic zones, wherein the digestate is moved from bottom-up (riser) by the displacement of air bubbles that are fed in the base of the reactor (this phenomenon favors the AOB). The fluid returns from up-bottom in a different region than the rise (downcomer) (which favors the anammox bacteria). The experimental system is shown in Figure 1.

The anammox biomass used to inoculate the NITRAMMOX $^{\circledR}$ reactor was deposited under the provisions of the Collection of Microorganisms of Interest for Swine and Poultry (CMISEA) at Concórdia (accession number: BRMSA 00323). The biomass was previously acclimated in a continued flow reactor with synthetic wastewater containing $100 \mathrm{mg} \mathrm{NH}_{3}-\mathrm{N} \mathrm{L}^{-1}$ e $100 \mathrm{mg} \mathrm{NO}_{2}^{-}-\mathrm{N} \mathrm{L}^{-1}$. In case of the $\mathrm{AOB}$, they were also maintained at Embrapa and were harvesting from a sequencing batch reactor fed with synthetic wastewater containing $300 \mathrm{mg} \mathrm{NH}_{4}-\mathrm{N} \mathrm{L}^{-1}$ (VIANCELLI et al., 2011; DE PRÁ et al., 2016). The total cellular concentration of $\mathrm{AOB}+$ Anammox used to inoculate the reactor was $2.38 \mathrm{gVSS} \mathrm{L}^{-1}$, obtained by the ratio of wet biomass of 0.3:1 L AOB:ANAMMOX in $8 \mathrm{~L}$ of reactor.

The initial characteristics of the CLB digestate used to fed the reactor was $1192 \mathrm{mg} \mathrm{L}^{-1}$ of NH$_{3}-\mathrm{N}$ and $176 \mathrm{mg} \mathrm{L}^{-1}$ of total organic carbon (TOC), which provides a $\mathrm{C} / \mathrm{N}$ ratio of approximately 0.15 . For the start-up of the reactor, the digestate was diluted to a concentration of $100 \mathrm{mg} \mathrm{L}^{-1} \mathrm{NH}_{3}-\mathrm{N}$ and according to the hydrodynamic characterization of the NITRAMMOX ${ }^{\circledR}$ obtained by De Prá (2017) the nitrogen loading rate (NLR) was maintained in $0.5 \mathrm{~kg}-\mathrm{N} \mathrm{m}^{-3} \mathrm{~d}^{-1}$, flow rate of $32 \mathrm{~L} \mathrm{~d}^{-1}$ and recirculation flow of $64 \mathrm{~L} \mathrm{~d}^{-1}$. The Hydraulic Retention Time (HRT) was fixed at $6 \mathrm{~h}$ and temperature between 26 and $35^{\circ} \mathrm{C}$. The system was also maintained with continuous aeration regulated according to the stoichiometric coefficients obtained.

Samples were collected daily from the reactor influent and effluent to follow-up the start-up process inside the NITRAMMOX ${ }^{\circledR}$. Determinations of $\mathrm{NH}_{3}-\mathrm{N} \mathrm{NO}_{2}{ }^{-}-\mathrm{N}$ and $\mathrm{NO}_{3}{ }^{-}-\mathrm{N}$ were performed by specific flow injection analysis methods for each parameter, adapted from Standard Methods (APHA, 2012). Dissolved oxygen (DO) and $\mathrm{pH}$ were analyzed using pHmeter and DOmeter, respectively.

\section{RESULTS AND DISCUSSION}

The enrichment of anammox and AOB sludge previously in the lab-scale reactors is a good strategy for fast start-up of the single-stage deammonification system, as observed by Casagrande et al. (2013).

Both sludges were enriched before the NITRAMMOX ${ }^{\circledR}$ reactor inoculation, and the start-up was monitored for 30 days, as shown in Figure 2(a), during which the influent ammoniacal nitrogen concentration was kept stable in approximately $100 \mathrm{mg} \mathrm{L}^{-1}$ and the airflow varied according to the concentration of nitrite in the effluent to enable PN. To start-up the deammonification process it is primordial to keep low DO concentration, once this is helpful for the activation of anammox bacteria that present higher doubling time than AOB. It also helps to reduce the possibility of nitrite inhibition due to the maintenance of the aerated environment (YANG et al., 2019).

Figure 2(a) shows the concentration of the nitrogen forms in the influent and effluent, where it is possible to see that during the start-up of the NITRAMMOX ${ }^{\circledast}$ milder nitrogen concentration conditions was applied and NLR of approximately $0.5 \mathrm{~kg}-\mathrm{N} \mathrm{m}^{-3} \mathrm{~d}^{-1}$ to promote the activity of microorganisms of interest. These conditions where based on those previously applied by de Prá et al. (2013), and it is possible to note that after 10 days the stoichiometric coefficients obtained get approximated to the theoretical values (Figure 2(b)) and 
the nitrogen removal efficiency was about $60 \%$ (Figure 2(a)). This period was the same to the obtained by Yang et al. (2019) to start-up the deammonification, which also applied NLR of approximately $0.5 \mathrm{~kg}^{-\mathrm{N} \mathrm{m}} \mathrm{m}^{-3}$ $\mathrm{d}^{-1}$ initially, and similar to the obtained by De Prá (2017) using the NITRAMMOX ${ }^{\circledR}$ fed with swine digestate coming from a UASB reactor (12 days).

It was possible to observe that after a period of biomass adaptation of approximately 8 days, the concentration of $\mathrm{NH}_{3}-\mathrm{N}, \mathrm{NO}_{2}^{-}-\mathrm{N}$ and $\mathrm{NO}_{3}{ }^{-} \mathrm{N}$ were significantly reduced at reactor effluent, demonstrating the gradual interaction and increased activity of the bacteria responsible for the deammonification process. After the $13^{\text {th }}$ operation day the air flow supplied was increased aiming to get higher nitrogen removal efficiency due to increasing partial nitration and consequently nitrite and ammonia supply to anammox bacteria. However, as can be observed at Figure 2(a), at this moment the efficiency was reduced and get inconstant, probably due to the relatively long doubling time of the Anammox bacteria. However, although the observed fall in efficiency, after a few days the process was reestablished, with the increasing of nitrogen removal efficiency. This information indicate the restoration of the bacterial activity to the air flow, and by the $25^{\text {th }}$ day the process of deamonification get stable again giving rise to a future increase in the concentration of ammoniacal nitrogen fed to the NITRAMMOX ${ }^{\circledR}$.

\section{CONCLUSION}

The NITRAMMOX® reactor proved to be a promising technology for the nitrogen removal of swine digestate, with start-up around 10 days and robust for the applicability of the deamonification process, supporting a wide operational variability and adapting well to varied situations.

With controlled conditions of temperature (between 26 and $35^{\circ} \mathrm{C}$ ), HRT (6 hours) and initial ammonia concentration around $100 \mathrm{mg} \mathrm{L}^{-1}$ in the CLB digestate, the NITRAMMOX ${ }^{\circledR}$ reached $70 \%$ of nitrogen removal efficiency in 30 days.

\section{ACKNOWLEDGEMENT}

The authors gratefully acknowledge the support provide by CAPES Foundation, Ministry of Education of Brazil and SISTRATES-BNDES (Project No 23.17.00.023.00.00).

\section{REFERENCES}

AMINI, A. et al. Cost-effective treatment of swine wastes through recovery of energy and nutrients. Waste Management, v. 69, p. 508-517, 2017.

APHA - American Public Health Association. Standard methods for the examination of water and wastewater. 22 ed. Washington, DC: American Public Health Association. 2012.

CASAGRANDE et al. High nitrogen removal rate using ANAMMOX process at short hydraulic retention time. Water science \& Technology, v. 67, n. 5, p. 968-975, 2013.

$\mathrm{CHOI}$ et al. Key operating parameters affecting nitrogen removal rate in single-stage deammonification. Chemosphere, v. 207, p. 357-364, 2018.

CHRISTENSON, E. C.; SERRE, M. L. Integrating remote sensing with nutrient management plans to calculate nitrogen parameters for swine CAFOs at the sprayfield and sub-watershed scales. Science of The Total Environment, v. 580, p. 865-872, 2017.

DE PRÁ, M. C. Desenvolvimento e validação de protótipo de reator para aplicação do processo de desamonificação utilizando digestato da suinocultura. 2017. Tese (Doutorado em Engenharia Química), UFSC, Universidade Estadual de Santa Catarina, Florianópolis, 2017.

DE PRÁ, M. C. et al. Kinetic models for nitrogen inhibition in ANAMMOX and nitrification process on deammonification system at room temperature. Bioresource Technology, v. 202, p. 33-41, 2016.

DE PRÁ, M. C. et al. Influência da concentração de nitrogênio em reatores com atividade anammox durante o start-up do sistema. III Simpósio Internacional sobre Gerenciamento de Resíduos Agropecuários e Agroindustriais, n. 2, p. 12-15, 2013.

Empresa Brasileira De Pesquisa Agropecuária. EMBRAPA. No. processo: 913209929. Title: NITRAMMOX. KHAN et al. Long-term efficient deammonification operation with PVA/alginate carrier modified by foaming agente. International Biodeterioration \& Biodegradation, v. 129, p. 148-155, 2018.

MIAO, Y. et al. Partial nitrification-anammox (PNA) treating sewage with intermittent aeration mode: Effect of influent C/N ratios. Chemical Engineering Journal, v. 334, p. 664-672, 2018. 
NAWI, M. N. M.; STUCKEY, D. C. Pre-oxidation of ammonium using nanofiltration membranes for partial nitrification preceding Anammox. Chemical Engineering Journal, v. 353, p. 218-224, 2018.

VIANCELLI, A. et al. Bacterial biodiversity from an anaerobic up flow bioreactor with ANAMMOX activity inoculated with swine sludge. Brazilian Archives of Biology and Technology, v. 54, n. 5, p. 1035-1041, 2011.

WANG, G. et al. A pilot-scale study on the start-up of partial nitrification-anammox process for anaerobic sludge digester liquor treatment. Bioresource Technology, v. 241, p. 181-189, 2017.

YANG et al. Quick start-up and stable operation of a one-stage deammonification reactor with a low quantity of AOB and ANAMMOX biomass. Science of The Total Environment, v. 654, p. 933-941, 2019.

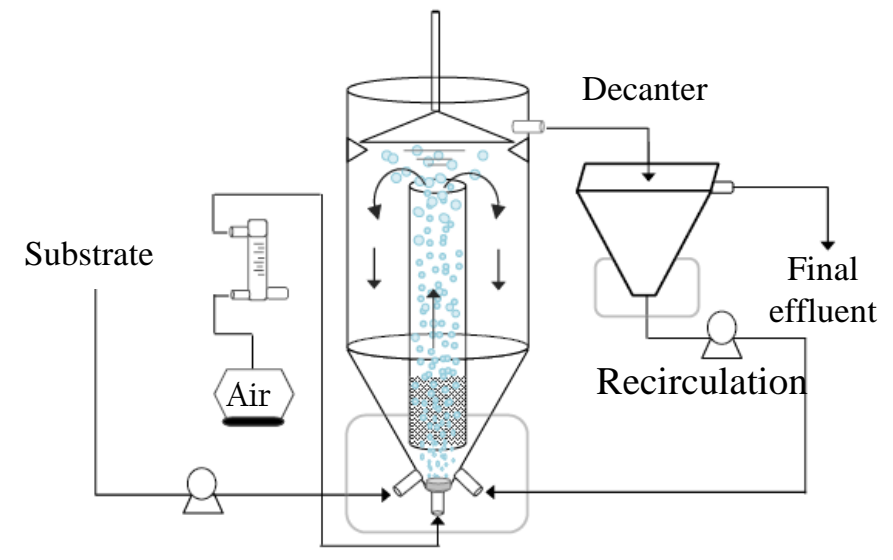

Figure 1. Schematic representation of the experimental system of the NITRAMMOX $^{\circledR}$ reactor (DE PRÁ, 2017).

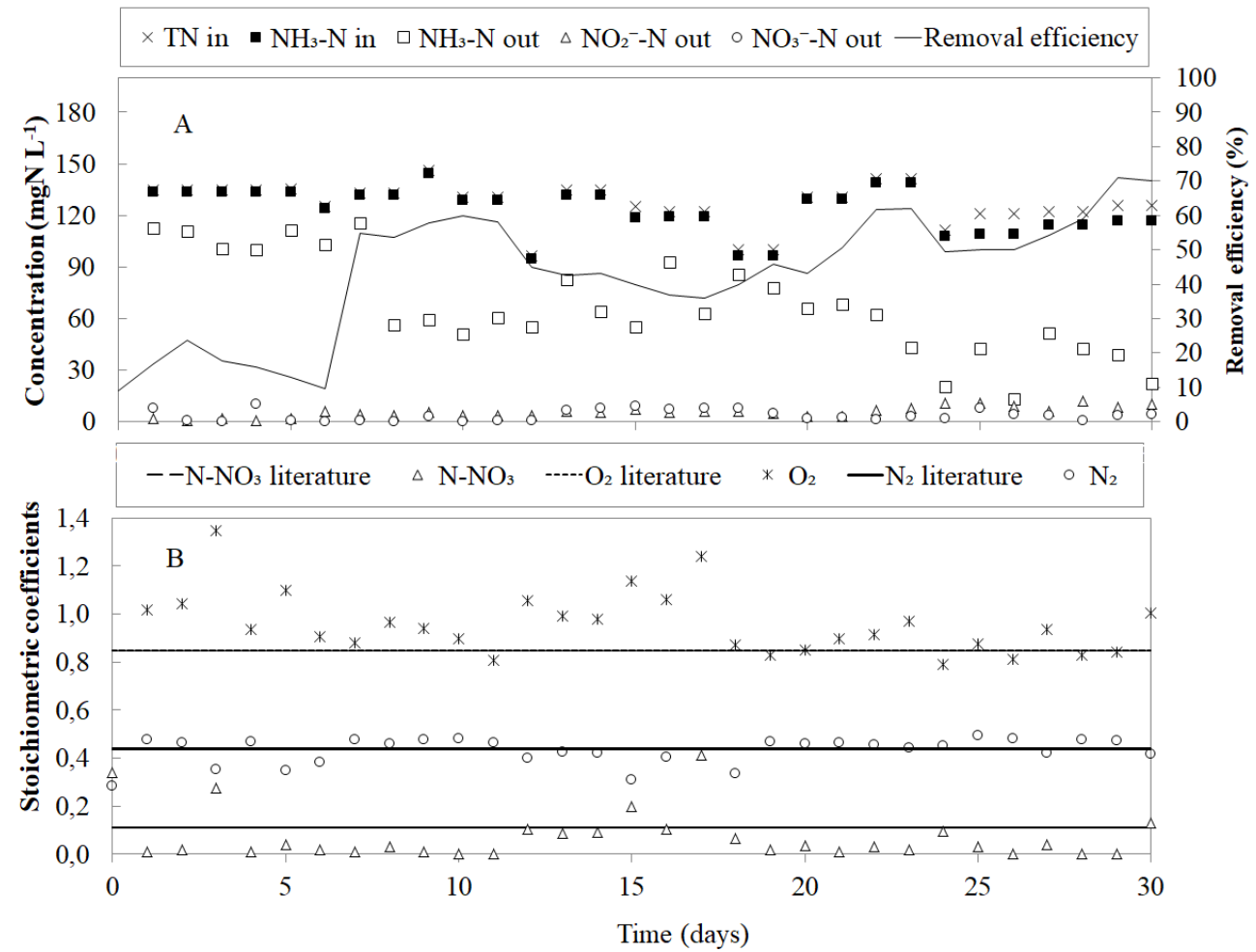

Figure 2. Performance of the NITRAMMOX ${ }^{\circledR}$ reactor: A - Monitoring of concentrations of nitrogen species and $\mathrm{B}-$ Monitoring of the stoichiometric coefficients. 


\title{
RECOVERY OF PHOSPHATES FROM SWINE LAGOON SLUDGE USING QUICK WASH PROCESS AND GEOTEXTILE FILTRATION
}

\author{
Szogi, A.A. *; Vanotti, M.B.; Shumaker, P.D. \\ USDA-ARS, Coastal Plains Soil, Water, and Plant Research Center, Florence, SC, USA \\ ariel.szogi@ars.usda.gov
}

\begin{abstract}
A widespread, low-cost method of dewatering anaerobic swine lagoon sludge in U.S. farms is the use of geotextile bag filtration. Because of typically high phosphorus $(\mathrm{P})$ contents in lagoon sludge, the dewatered sludge is eventually hauled to distant fields to reduce the environmental risk of excess $\mathrm{P}$ in land nearby the lagoon. The inclusion of a P recovery approach, called "Quick Wash" (QW), along with the geotextile bags could eliminate or reduce hauling costs of dewatered sludge and produce a nitrogen-rich organic soil amendment and a valuable recovered P product for use as fertilizer. The QW process uses a novel combination of acid, base, and organic polyelectrolytes to selectively extract and recover $\mathrm{P}$ from manure solids. The objective of this study was to evaluate the potential advantage and technical feasibility of combining the QW process and geotextile dewatering in a system to extract and recover $\mathrm{P}$ from lagoon sludge.
\end{abstract}

Keywords: phosphorus, nutrient recovery, solids dewatering.

\section{INTRODUCTION}

In North Carolina, the second largest swine (Sus scrofa L.) producer in the United States with a total inventory of 8.9 million heads, swine manure is stored and treated in anaerobic lagoons. As part of the lagoon management, excess lagoon sludge is removed by pumping after mechanical agitation or dredging. The sludge is then dewatered once it is removed from the lagoon. A low-cost and widespread method of dewatering lagoon sludge is the use of geotextile bag filtration with injection of a flocculant polymer. The polymer is added to increase retention of the small particulate solids by the dewatering bag. The dewatered sludge collected in the geotextile bags is land applied at agronomic rates according to its nutrient content. However, nutrient management plans may limit $\mathrm{P}$ application to crop or pastureland near the lagoon because lagoon sludge usually has a high phosphorus $(\mathrm{P})$ content. The inclusion of a $\mathrm{P}$ recovery approach along with the geotextile bag technology could: 1) eliminate or reduce hauling costs of dewatered sludge, and 2) produce a valuable concentrated $\mathrm{P}$ product for use as fertilizer.

A number of technologies for $\mathrm{P}$ recovery are already operational at full-scale in industrial, municipal, and agricultural treatment systems (Karunanithi et al., 2015). Among them, a novel chemical P recovery process using a combination of acid, base, and organic polyelectrolytes called "Quick Wash" (QW) was used to selectively extract and recover P from both raw poultry litter and fresh swine manure solids (Szogi et al., 2008, 2015a,b). The QW is a patented treatment process (U.S. Patent 8,673,046; first filed Feb. 5, 2008) developed for rapid acid wet extraction of $\mathrm{P}$ from solid manure and $\mathrm{P}$ recovery in a solid concentrated form (Szogi et al., 2014). The inclusion of the QW process in a lagoon sludge management plan offers an opportunity to recover $\mathrm{P}$ as a valuable fertilizer byproduct. The objective of this study was to evaluate the potential advantage and technical feasibility of combining the QW process with a geotextile dewatering technology to extract and recover $\mathrm{P}$ from lagoon sludge. In order to provide process data to operate a field scale system, laboratory experiments were performed to determine: 1) acid rates for optimal release of soluble P from swine lagoon sludge; 2) mesh size for effective dewatering of acidified sludge with geotextile bags; and 3) P recovery efficiency. In addition, the study included elemental composition of the products (washed sludge solids and recovered phosphate) and a mass flow balance.

\section{MATERIALS AND METHODS}

Figure 1 show first the individual technologies: basic QW process (Figure 1A) and geotextile bag dewatering (Fig. 1B), and their combination in one single system, hereafter called "QW retrofit" (Figure 1C). The basic QW process includes three steps (Szogi et al., 2014): (1) selective P extraction, (2) P recovery, and (3) P recovery enhancement (Figure 1A). In the first step, manure solids or slurry are mixed with an acidic solution (sulfuric acid) to form a washed solid organic residue and a liquid P extract. In step 2, P is precipitated under alkaline conditions by adding hydrated lime to the liquid extract, and in the final step (step 3) the addition 
of an organic anionic polymer, polyacrylamide (PAM), enhances the formation and recovery of a P-rich precipitate. In the geotextile bag filtration system alone (Figure 1B), polymer (cationic PAM) is injected to enhance filtration and dewatering of solids retained in the geotextile bag, producing an effluent low in solids. In the QW retrofit (Figure 1C), the sludge is first acidified and then cationic PAM is injected to flocculate and retain solids in the geotextile bag (QW step 1). The acidic liquid flowing out of the geotextile bag is then collected in a settling tank to recover the $\mathrm{P}$ precipitate after reaction with hydrated lime and anionic PAM (QW steps 2 and 3). The $\mathrm{P}$ is recovered as a precipitate from the bottom of the settling tank and further dewatered. The effluent from the settling tank, low in solids and $\mathrm{P}$, is then sent to the lagoon or eventually recycled as dilution water. Sludge analyses and effluents from the QW process were performed according to Standard Methods for Examination of Water and Wastewater (APHA, 1998).

\section{RESULTS AND DISCUSSION}

This study showed that the amount of recoverable $\mathrm{P}$ from lagoon sludge depended on the acidic $\mathrm{pH}$ obtained after sulfuric acid application. The highest release of TP in solution was $83 \%$ of total P, was obtained when the lagoon sludge was acidified to $\mathrm{pH}$ 3.0. The $\mathrm{P}$ released in the acidic extract was recovered as a calcium phosphate product using hydrated lime. The mass of $\mathrm{P}$ recovered at $\mathrm{pH} 10$ was about $80 \%$ of the initial total $\mathrm{P}$. The extremely low concentrations of $\mathrm{P}$ in the effluent $\left(2-3 \mathrm{mg} \mathrm{L}^{-1}\right)$ and a mass flow balance confirmed that about $20 \%$ of the initial TP persisted in the dewatered sludge solids. The recovered calcium phosphate product was identified as amorphous calcium phosphate (ACP) which had higher $\mathrm{P}$ grades $\left(33.2\right.$ to $35.5 \% \mathrm{P}_{2} \mathrm{O}_{5}$ ) than rock phosphate and low heavy metal content. Results of this study support the technical feasibility of using the QW process combined with geotextile bag filtration for recovery of $\mathrm{P}$ from anaerobic swine lagoons.

\section{CONCLUSIONS}

The Quick Wash process, developed by USDA-ARS, for extraction and recovery of $\mathrm{P}$ from animal manure solids was tested for recovery of $\mathrm{P}$ from anaerobic swine lagoon sludge. With the QW process, $\mathrm{P}$ was extracted in solution from dredged sludge by mixing the sludge with sulfuric acid prior to dewatering using polymer enhanced mechanical solid-liquid separation. Following, $\mathrm{P}$ was recovered by addition of liquid lime and an anionic flocculent to the separated liquid extract to form a calcium-containing P precipitate. The QW process generates two solid products: 1) sludge solids low in $\mathrm{P}$ that can be used as a nitrogen-rich organic soil amendment; and 2) a concentrated P material for use as a fertilizer. While most of the nitrogen and carbon was left in the washed sludge solids, the QW process extracted and recovered as much as $90 \%$ of the P from sludge. The $\mathrm{P}$ grade of the recovered phosphate was in the range of $33.2-35.5 \% \mathrm{P}_{2} \mathrm{O}_{5}$. The inclusion of this process in a lagoon sludge management plan offers producers an opportunity to locally land-apply the low-P sludge as a nitrogen-rich organic soil amendment and recycling recovered $P$ as a valuable product.

\section{ACKNOWLEDGMENTS}

This work is part of USDA-ARS National Program 212; ARS Project 6082-12630-001-00D "Improvement of Soil Management Practices and Manure Treatment/Handling Systems of the Southern Coastal Plain."

\section{REFERNCES}

APHA (1998). Standard Methods for Examination of Water and Wastewater, 20th ed. Washington, DC: American Public Health Association.

Karunanithi, R., Szogi, A.A., Bolan, N., Naidu, R., Loganathan, P., Hunt, P.G., Vanotti, M.B., Saint, C.P., Ok, Y.S., and Krishnamoorthy, S. (2015). Phosphorus recovery and reuse from waste streams. Adv. Agron. 131, 173-250.

Szogi, A. A., Vanotti, M.B., and Hunt, P.G. (2008). Phosphorus recovery from poultry litter. Trans. ASABE 51, 1727-1734.

Szogi, A.A., Vanotti, M.B., Hunt, P.G., (2014). Process for removing and recovering phosphorus from animal waste. U.S. Patent No. 8,673,046. Washington, DC: U.S. Patent and Trademark Office.

Szogi, A.A., Vanotti, M.B., and Hunt, P.G. (2015a). Phosphorus recovery from pig manure prior to land application. J. Environ. Manage. 157, 1-7.

Szogi, A.A., Vanotti, M.B., Ro, K.S. (2015b). Methods for treatment of animal manures to reduce nutrient pollution prior to soil application. Curr. Pollution Rep. 1, 47-56. 
A.
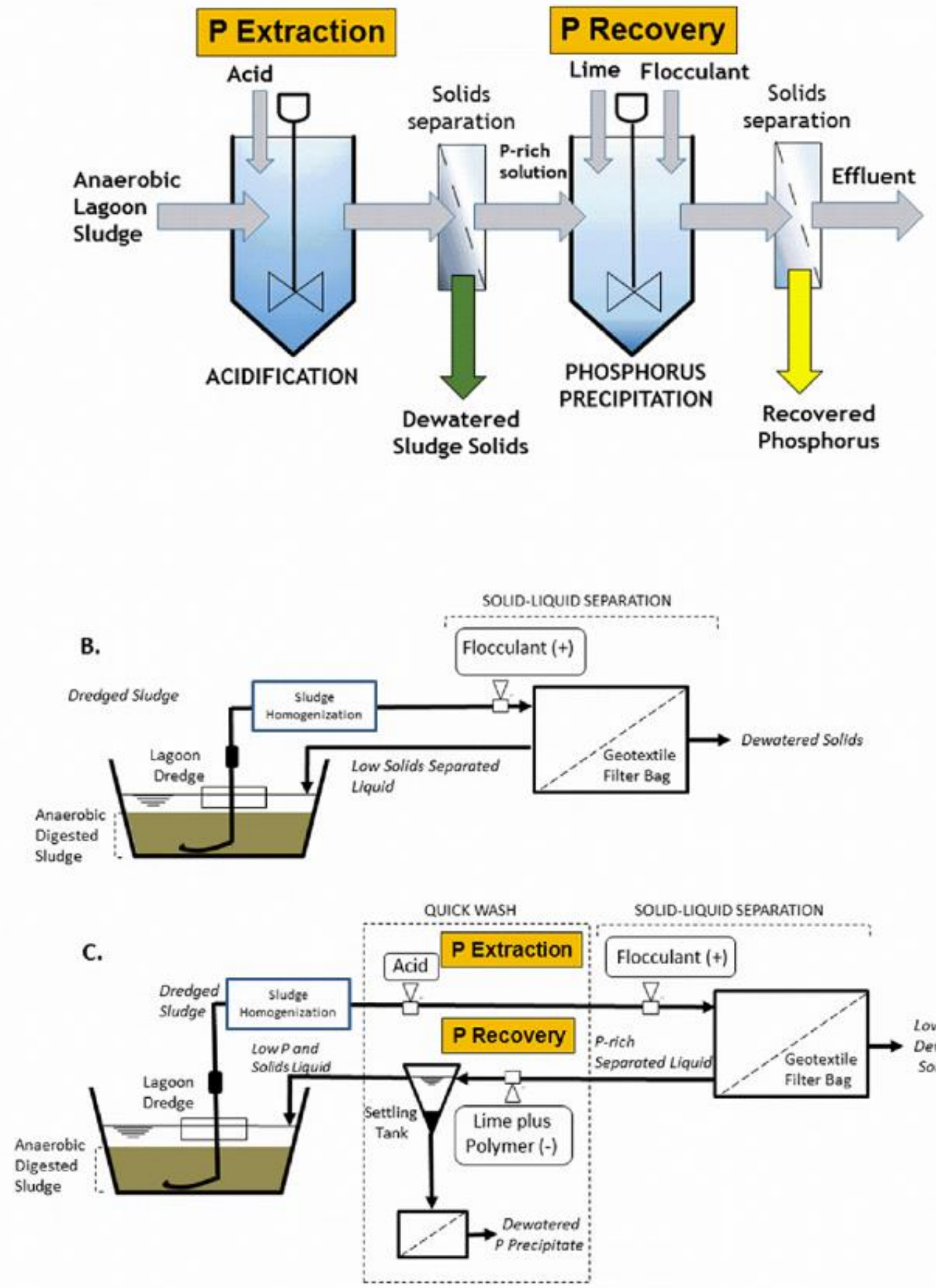

Figure 1. Schematic diagrams of the basic Quick Wash process (A), the geotextile bag filtration for dewatering of sludge (B), and the combination of the Quick Wash process and the geotextile bag filtration into one system for $\mathrm{P}$ recovery from sludge $(\mathrm{C})$. 


\title{
RECUPERAÇÃO DE NUTRIENTES DO EFLUENTE DE UM BIODIGESTOR RURAL: ESTERCO BOVINO COMO ESTUDO DE CASO
}

\author{
Mantilla, L. ${ }^{1}$; Jaimes-Estévez, J. ${ }^{1}$; Castro, L. ${ }^{* 1}$, Escalante, H. ${ }^{1}$ \\ ${ }^{1}$ Grupo de Investigación INTERFASE, Escuela de Ingeniería Química, Universidad Industrial de Santander, Carrera 27, Calle 9, \\ Bucaramanga, Colombia \\ *licasmol@uis.edu.co
}

\begin{abstract}
RESUMO: O intuito desta investigação foi obter estruvita partindo do digerido de um digestor rural, alimentado com esterco bovino. A fim de determinar as variáveis de operação para recuperar a estruvita (íons $\mathrm{PO}_{4}{ }^{3-}$ e $\mathrm{NH}_{4}{ }^{+}$), foi desenvolvido um delineamento experimental, no qual foi avaliado o efeito combinado da razão molar de $\mathrm{Mg}_{2}{ }^{+}: \mathrm{PO}_{4}{ }^{3-}$ (1.5:1, 2.5:1 e 3.5: 1), tempo de reação (10, 50 e $\left.90 \mathrm{~min}\right)$ e a velocidade de agitação $(100,450$ e 800 rpm). Adicionalmente, uma análise econômica foi desenvolvida. A combinação de condições determinadas como favoráveis foram: relação molar de 1.5 , tempo de reação de 50 minutos e velocidade de agitação de $450 \mathrm{rpm}$. Estes resultados indicam que a maior recuperação de fosfato é obtida com a concentração de magnésio $(153 \mathrm{mg} / \mathrm{l})$ contida no esterco bovino digerido. As porcentagens de recuperação obtidas foram de

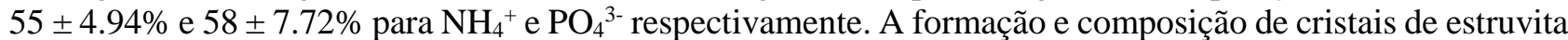
foram confirmadas por meio de microscopia de petrografia, microscopia eletrônica de varredura (SEM) e radiação infravermelha. O rendimento da estruvita obtida foi de $295.75 \mathrm{mg} / \mathrm{L}$ de digerido utilizado. Este digerido pode ser usado para precipitar a estruvita, que representa uma economia de fertilização em torno de US \$ 94 / mês (custos de compra e transporte).
\end{abstract}

Palavras-chave: digestor; esterco bovino; estruvita; matéria digerida.

\section{NUTRIENTS RECOVERY FROM A RURAL DIGESTER EFFLUENT: CATTLE MANURE AS STUDY CASE}

\begin{abstract}
The aim of this research was recovery nutrients $\left(\mathrm{PO}_{4}{ }^{3-}\right.$ and $\mathrm{NH}_{4}{ }^{+}$ions) in form of struvite, used cattle manure digestate from low cost anaerobic digester. In order to determinate operating variables $\left(\mathrm{Mg}_{2}{ }^{+}\right.$: $\mathrm{po}_{4}{ }^{3-}$ molar ratio, reaction time and stirring speed) an experimental design and an economic analysis were developed. Struvite crystal was identified by mean of petrographic microscopy and infrared radiation. The highest recovery rates of $55 \pm 4.94 \%$ and $58 \pm 7.72 \%$ for $\mathrm{NH}_{4}{ }^{+}$and $\mathrm{PO}_{4}{ }^{3-}$, respectively was achieved at 1.5 molar ratio, 50 minutes reaction time and $450 \mathrm{rpm}$ stirring speed. Struvite yield was $295.75 \mathrm{mg} / \mathrm{l}$. These results show that the highest phosphate recovery is achieved with the magnesium concentration $(153 \mathrm{mg} / \mathrm{l})$ contained in the cattle manure digestate. This digestate could be used to precipitate struvite which represents fertilizing saving around USD \$ 94/month (purchasing and transporting costs).
\end{abstract}

Keywords: cattle manure, digestate; household digester; struvite.

\section{INTRODUCTION}

Low-cost digesters are part of an attractive technology for anaerobic waste treatments in developing countries. In the last decades, AD is energy focused with low attention on nutrient recovery. The small-scale decentralised operations are emerging technologies to nutrients recovery, such as developments to precipitate struvite from source-separated urine from household digester in Sweden (Ganrot et al., 2009) and Nepal (Neset \& Cordell, 2010). Regarding to household biogas digesters in Latin America, knowledge about nutrient recovery through struvite precipitation from low cost digestate is limited. According to the scenario described above, it is necessary to adapt a nutrient recycling technology that can be implemented in rural zones to manage and valorise the digestate produced in rural digesters. The aim of this research was to determine the operating conditions to recover nutrients from a real digestate obtained in a household digester. 


\section{MATERIAL AND METHODS}

This study was conducted at a farm located in Colombia with a $692-\mathrm{mm} / \mathrm{m}^{2}$ of average precipitation and a $23 \pm 5^{\circ} \mathrm{C}$. The farm has a tubular low-cost digester that uses cattle manure as substrate. Table 1 summarizes the design parameters of the digester. Aiming to evaluate the effect of the variables that influence nutrients recovery, the study used a $2^{3}$ factorial design with a central point. Three variables were co-related: reaction time (10; $90 \mathrm{~min})$, stirring speed $(100 ; 800 \mathrm{rpm})$ and a $\mathrm{Mg}^{2+}: \mathrm{PO}_{4}{ }^{3-}$ molar ratio $(1.5: 1 ; 3.5: 1) . \mathrm{MgCl}_{2}$ was used as a source of $\mathrm{Mg}^{2+}$. Based on the experimental results and theoretical yields of struvite precipitation reached in this study, an economic analysis was performed. The cost of equipment for capital expenditures (CAPEX) calculation was considered based on the Colombian market for 2018 (personal communication). The other assumptions for operating expenses (OPEX) calculation were based on the data reported by Yetilmezsoy et al., (2017) and Tao et al., (2016). Economic aspects included the biogas supply for cooking food.

\section{RESULTS AND DISCUSSION}

The effects of the operating variables are observed in Figure 1. The most influential variable in $\mathrm{PO}_{4}{ }^{3-}$ recovery was a $\mathrm{Mg}^{2+}: \mathrm{PO}_{4}{ }^{3-}$ ratio (1.5) with a reliability of $95 \%$. These results show that the highest phosphate recovery is achieved with the magnesium concentration $(153 \mathrm{mg} / \mathrm{L})$ contained in the cattle manure digestate. Stirring speed of $450 \mathrm{rpm}$, and reaction time of $50 \mathrm{~min}$, reached $\mathrm{PO}_{4}{ }^{3-}$ and a $\mathrm{NH}_{4}{ }^{+}$recoveries around $55 \pm 4.94$ and $58 \pm 7.72 \%$, respectively. Table 2 compares the spontaneous and assisted nutrient recovery. A way to recover nutrients faster is using stirring. It is possible to obtain similar yields, but without energy supplies increasing the reaction time. Petrographic microscopic analysis evidenced struvite formation (Figure 2) and some impurities. Figure 3 shows an infrared spectrum of solids obtained under the favorable operating conditions, compared to a struvite pattern (Stefov et al., 2005). The spectrum shows the absorption bands corresponding to the different elements or components found in the sample.

The infrared spectrum can be compared with the absorptions obtained for precipitation studies based on human urine (Muryanto et al., 2016). In addition, the solid precipitated was analyzed quantitatively. Struvite potential in this research was $297.75 \mathrm{mg}$ struvite/L from the digestate used. Results confirm that cattle manure digestate has high nutritional potential for struvite precipitation thanks to its high nutrient content $\left(\mathrm{PO}_{4}{ }^{3-}\right.$ and $\mathrm{NH}_{4}^{+}$). Traditionally, cattle manure disposal is on-farm cropland. This research shows that nutrients recovery and anaerobic digestion can be coupled, presenting and integrative solution to cattle manure management.

With the results previously obtained, it is possible to recycle nutrients $\left(\mathrm{Mg}^{2+}, \mathrm{PO}_{4}{ }^{3-}\right.$ and $\left.\mathrm{NH}_{4}{ }^{+}\right)$available in cattle manure digested matter, so that it may be profitable and suitable for biogas digester users, providing energy and fertilizer savings. The household digester provides both biogas and digestate. The net present value (NPV) was USD \$ 40/year. In this case, biogas is used for cooking with propane saving around USD $\$ 75 /$ month (purchasing and transporting costs). Concerning to digestate, it could be used to precipitate struvite which represents fertilizing saving around USD \$94/month (purchasing and transporting costs).

\section{CONCLUSIONS}

The optimal operation conditions to nutrients recovery from real digestate via struvite precipitation were determined by a composed central design. A statistical analysis revealed that the maximum phosphate recovery was obtained at a $\mathrm{Mg}^{2+}: \mathrm{PO}_{4}{ }^{3-}$ molar ratio of 1.5 (this ratio don't require external source of $\mathrm{Mg}^{2+}$ ), with a 450 rpm stirring speed and a 50 minute reaction time. The results are quite promising, due to $\mathrm{Mg}^{2+}$ content in cattle digestate is favorable for phosphate recovery through struvite precipitation at the optimal settings. Under these conditions, the study reached a recovery of $55 \pm 4.94$ and $58 \pm 7.72 \%$ of $\mathrm{PO}_{4}{ }^{3-}$ and $\mathrm{NH}_{4}{ }^{+}$respectively. The petrography and infrared spectrum analyses confirmed that the precipitate formed was struvite with some impurities. In agreement with the present research, household digester presents an integrative solution to cattle manure management. In this case, the low cost digester was fed with $50 \mathrm{~kg} / \mathrm{d}$ of cattle manure to produced renewable energy in form of biogas $\left(0.85 \mathrm{Nm}^{3}\right.$ biogas/d with $65.6 \%$ methane), and to recycle nutrients as struvite, providing energy and fertilizer savings of $76 \%$ and $80 \%$ (using all digestate volume for crop irrigation), respectively. 


\section{VISIGER

\section{REFERENCES}

Barbosa, S. G., Peixoto, L., Meulman, B., Alves, M. M., \& Pereira, M. A. (2016). A design of experiments to assess phosphorous removal and crystal properties in struvite precipitation of source separated urine using different Mg sources. Chemical Engineering Journal, 298 , 146-153.

Escalante, H., Castro, L., Amaya, M., Jaimes, L., \& Jaimes-Estévez, J. (2018). Anaerobic digestion of cheese whey: Energetic and nutritional potential for the dairy sector in developing countries. Waste Management, 711-718.

Ganrot, Z., Broberg, J., \& Bydén, S. (2009). Energy efficient nutrient recovery from household wastewater using struvite precipitation and zeolite adsorption techniques: A pilot plant study in Sweden. London, UK: IWA Publishing.

Jaffer, Y., Clark, T., Pearce, P., \& Parsons, S. (2002). Potential phosphorus recovery by struvite formation. Water Research, 36, 1834-1842.

Muryanto, S., Sutanti, S., \& Kasmiyatun, M. (2016). Inhibition of struvite crystal growth in the presence of herbal extract orthosiphon aristatus BL.MIQ. MATEC Web of Conferences, 18, 1-5.

Neset, T., \& Cordell, D. (2010). Phosphorus and global food security: a synthesis. Linköping University Electronic Press.

Stefov, V., Šoptrajanov, B., Kuzmanovski, I., Lutz, H. D., \& Engelen, B. (2005). Infrared and Raman spectra of magnesium ammonium phosphate hexahydrate (struvite) and its isomorphous analogues. III. Spectra of protiated and partially deuterated magnesium ammonium phosphate hexahydrate. Journal of Molecular Structure, 752(1-3), 60-67.

Zhao, Q., Zhang, T., Frear, C., Bowers, K., Harrison, J., \& Chen, S. (2010). Phosphorous recovery technology in conjunction with dairy anaerobic digestion. Climate Friendly Farming, 1, 1-34.

Table 1. Design and operation parameters of the low-cost digester.

\begin{tabular}{lc}
\hline Parameters & Value \\
\hline Location & Andean region \\
Altitude (m.a.s.l.) & 959 \\
Digester design & Plastic tubular digester \\
Average ambient $\mathrm{T}\left({ }^{\circ} \mathrm{C}\right)$ & 23 \\
Liquor $\mathrm{T}\left({ }^{\circ} \mathrm{C}\right)$ & 25 (psychrophilic \\
$\mathrm{V}_{\text {useful }}\left(\mathrm{m}^{3}\right)$ & conditions) \\
$\mathrm{HRT}($ day) & 7.5 \\
Feedstock $($ type - amount in $\mathrm{kg} /$ day $)$ & 35 \\
$\mathrm{OLR}\left(\mathrm{kg} \mathrm{VS} / \mathrm{m}^{3}{ }_{\text {digester }}\right.$ day) & Cattle manure -50 \\
$\mathrm{BPR}\left(\mathrm{m}^{3}{ }_{\text {biogas }} / \mathrm{m}^{3}\right.$ digester day) & 0.7 \\
$\mathrm{SBP}\left(\mathrm{m}^{3}{ }_{\text {biogas }} / \mathrm{kg} \mathrm{VS}\right)$ & 0.11 \\
Methane content $(\%)$ & 0.15 \\
Digestate $\mathrm{N}_{-} \mathrm{NH}_{4}$ content $(\mathrm{mg} / \mathrm{L})$ & 65 \\
Digestate $\mathrm{P}-\mathrm{P}_{2} \mathrm{O}_{5}$ content $(\mathrm{mg} / \mathrm{L})$ & 95 \\
\hline
\end{tabular}

Note: T: temperature; V: volume; HRT: hydraulic retention time; OLR: organic loading rate; BPR: biogas production rate; SBP: specific biogas production.

Table 2. Spontaneous and assisted nutrient recovery from digestate.

\begin{tabular}{ccc}
\hline \multirow{2}{*}{ Variable } & \multicolumn{2}{c}{ Method to nutrient recovery } \\
\cline { 2 - 3 } & Spontaneous & Assisted \\
\hline $\mathrm{PO}_{4}{ }^{3-}$ Recovery (\%) & $26 \pm 3.8$ & $55 \pm 4.94$ \\
$\mathrm{Mg}^{+}$addition (mmol) & 0 & 0 \\
stirring required (rpm) & 0 & 450 \\
Reaction time (h) & 24 & 0.85 \\
\hline
\end{tabular}




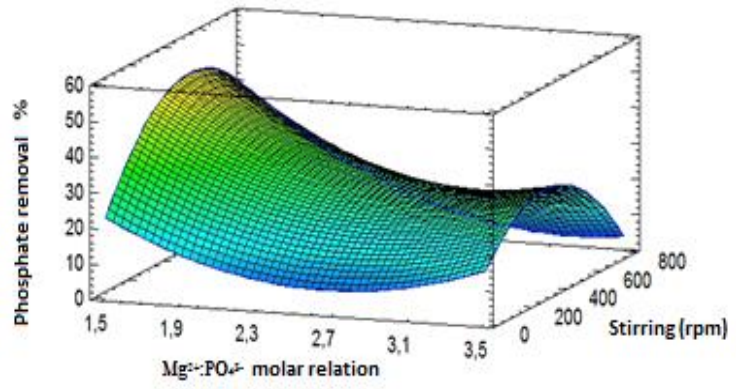

Figure 1. Surface response of the $\mathrm{PO}_{4}{ }^{3-}$ recovery design.

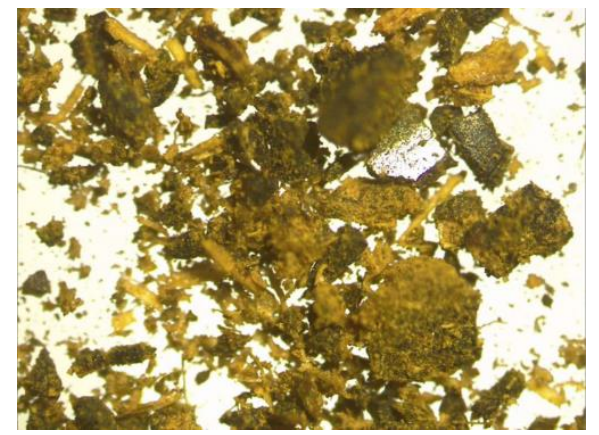

Figure 2. Micrographs of precipitate obtained from optimal conditions assay.

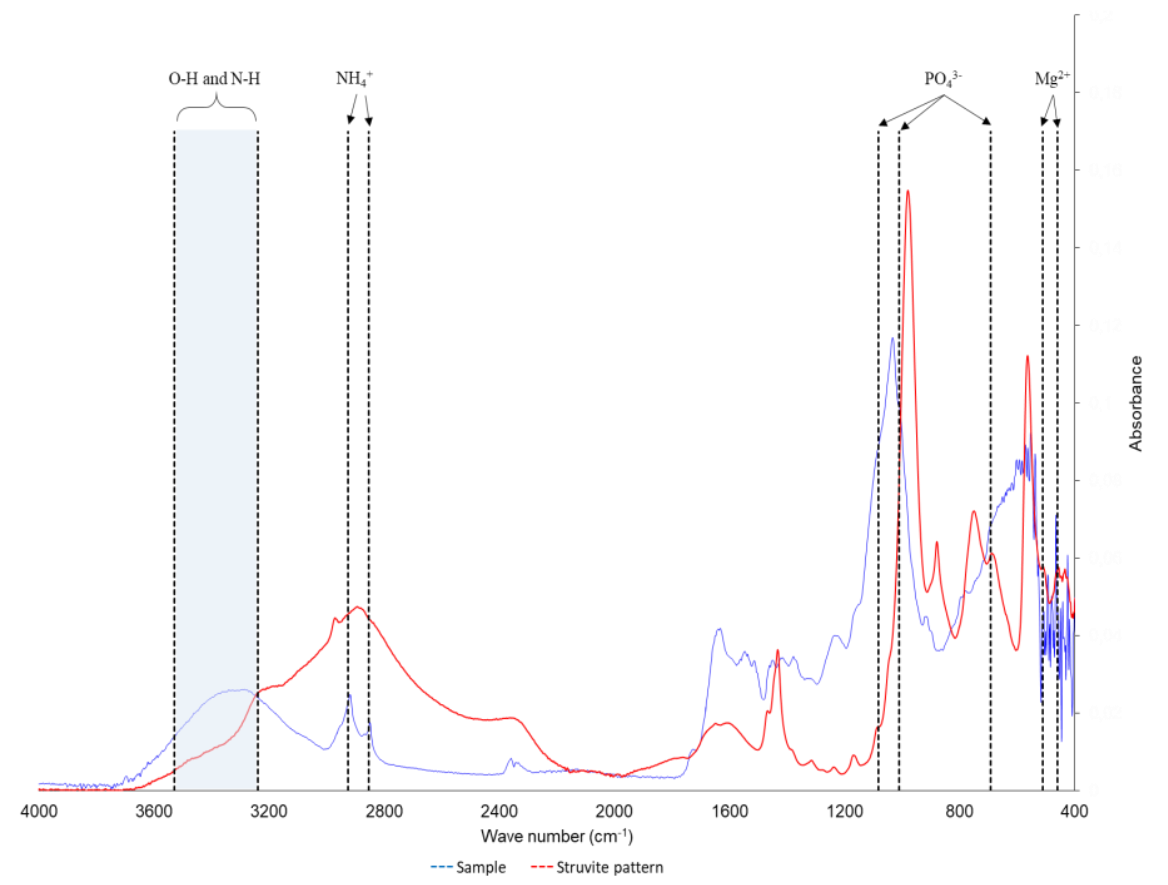

Figure 3. Infrared Radiation Spectra of precipitate obtained from the assisted assay. 


\title{
TRATAMIENTO DE AGUAS RESIDUALES DE GRANJAS PORCINAS BASADA EN EXPERIENCIAS DESARROLLADAS EN MÉXICO Y CHILE
}

\author{
Giácoman-Vallejos, G. ${ }^{1}$; Ponce-Caballero, C. ${ }^{1}$; Vidal, G. ${ }^{2}$ \\ ${ }^{1}$ Facultad de Ingeniería, Universidad Autónoma de Yucatán. Av. Industrias no contaminantes por anillo periférico Norte s/n. \\ Mérida, Yucatán México.Email: giacoman@uady.mx. \\ ${ }^{2}$ Grupo de Ingeniería y Biotecnología Ambiental GIBA-UDEC), Facultad de Ciencias Ambientales y Centro EULA-Chile. \\ Universidad de Concepción - Chile,email: glvidal@udec.cl
}

\begin{abstract}
The agricultural and livestock sector in Mexico and Chile has become a fundamental productive activity in economic, social and environmental terms. However, the environmental impact of the sector is explained through the large generation of wastewater. The biological treatment of the effluents is not enough to comply with the regulations for discharges to surface ecosystems. So, wastewater treated by anaerobic systems contains short and long chain fatty acids; mainly long chain acids recalcitrant to the biological process. Moreover, the long chain fatty acids, such as oleic and stearic acid are inhibitors in biological processes in concentration higher than $1.0 \mathrm{~g} / \mathrm{L}$. This paper shows results of advanced oxidation process (ozone and UV$\mathrm{H}_{2} \mathrm{O}_{2}$ ), using different doses of $\mathrm{H}_{2} \mathrm{O}_{2}$ at different $\mathrm{UV}$ exposure times or dealing with different ozone flow and exposure times. The removal of fatty acids through the application of the two short advanced oxidation processes proposed were $80-94 \%$, resulting both, efficient processes for use in swine wastewater.
\end{abstract}

Keywords: Advanced oxidation process, fatty acid, ozone, swine wastewater, UV- $\mathrm{H}_{2} \mathrm{O}_{2}$

\section{INTRODUCCIÓN}

El garantizar que todas las personas tengan acceso en todo momento a alimentos suficientes, seguros y nutritivos para cubrir sus necesidades nutricionales y las preferencias culturales para una vida sana y activa (FAO, 2011) obliga a las naciones a implementar políticas publicas con miras a incrementar la producción, abastecimiento y distribución de alimentos. Así, el sector agropecuario en México y Chile se ha convertido en una actividad productiva fundamental en términos económicos, sociales y ambientales. Así, la ganadería y la agricultura desempeñan un papel relevante en la producción de alimentos, la generación de insumos para diversas cadenas de producción y porque usa de manera intensiva el suelo y el agua.

La mayor cantidad de carne que se producía en el mundo en el año 2013 (Errecart et al., 2013) fue la de porcino con 109.45 millones de toneladas, seguida de la de ave con 84.07 y la de bovino con 58.62. Varios países, entre ellos México y Chile han impulsado la producción de cerdos. Así, México ocupa la posición número 9 a nivel mundial con 1.45 millones de toneladas generadas en 2016, y el segundo productor latinoamericano después de Brasil (FIRA, 2017; Hernández, 2014). En Chile la producción anual es de aproximadamente 500 mil toneladas, correspondiendo al 8\% de la producción latinoamericana (Vidal et al., 2012). Este crecimiento productivo a ocasionando que se genere una mayor cantidad de desechos fecales líquidos, que constituyen un problema serio de contaminación, la cual ha originado la necesidad de desarrollar un manejo adecuado o un tratamiento completo de los desechos (BID, 2011). La calidad de los efluentes de granjas porcinas y de tratamientos anaerobios, no es suficiente y adecuada para ser descargado en cuerpos de agua, ni para ser reutilizado en riego agrícola, por lo que se requiere un sistema que continúe el tratamiento y que remueva principalmente nutrientes, SST, CF y DQO, para lo cual se recomienda sistemas combinados Anaerobio - Aerobio - Humedal (Garzon-Zuñiga y Buelna, 2014, Vidal et al., 2012) y también se recomienda el uso de procesos de Oxidación avanzada de corta duración (Giacoman et al., 2014).

El agua residual porcina contiene ácidos grasos de cadena corta y larga, principalmente los ácidos grasos de cadena larga que son difíciles de degradar por medios biológicos. Los ácidos grasos de cadena larga, como el ácido oleico y esteárico, presentes en el alimento son inhibidores en el tratamiento anaerobio, en concentraciones de $1.0 \mathrm{~g} / \mathrm{L}$. Por esta razón, es necesario contar con un sistema de tratamiento adecuado, para la eliminación de la materia orgánica biodegradable, así como para la fracción de materia no biodegradable presente en los efluentes porcinos. Por ello, se estudio la aplicación corta de dos procesos de oxidación avanzada para aumentar la biodegradabilidad (IB) de dichos residuos. 


\section{Reactor para el tratamiento con ozono}

\section{METODOLOGÍA}

Se utilizó un reactor de acrílico de $1.25 \mathrm{~L}$ equipado con un difusor de burbuja fina en la parte inferior. El sistema se acondicionó con tres trampas de ozono. El generador de ozono empleado fue de marca "Ozore residual 48 LPM", y alimentado con oxígeno ultra puro (Figura 1, (a)). El volumen de operación fue de 750 $\mathrm{mL}$ y los flujos de ozono estudiados fueron $0.5,0.75$ y 1 LPM, manteniendo una presión de 10 psi; y tiempos de 5,10 y 15 min.

\section{Reactor para el tratamiento $\mathrm{UV}-\mathrm{H}_{2} \mathrm{O}_{2}$}

Se empleó un reactor tubular acoplado de forma concéntrica con una lámpara de radiación UV $(\lambda=254$ $\mathrm{nm}$ ). El reactor fue operado en forma discontinua (Batch) con tiempos de exposición a la radiación de 15, 30, 45 y 60 minutos y concentraciones de $\mathrm{H}_{2} \mathrm{O}_{2}$ de $0.01 \%, 0.05 \%$ y $0.1 \%$ (Figura 1 , (b)).

\section{Análisis de las muestras}

El agua porcina, tomada del efluente de un reactor anaerobio, se fortificó con $60 \mathrm{mg} / \mathrm{L}$ de ácido heptanoico (ácido graso de cadena corta) y $120 \mathrm{mg} / \mathrm{L}$ de ácido oleico (ácido graso de cadena larga). A la entrada y salida del reactor se determinaron las concentraciones de DQO (Método Estándar*, método reflujo cerrado, 5220), los ácidos grasos se cuantificaron por cromatografía de gases (GC) con detector de ionización de flama (FID), de la marca Thermo Scientific modelo TRACE GC ULTRA.

\section{RESULTADOS Y DISCUSIÓN}

De los resultados obtenidos se observó que el mejor flujo de ozono aplicado fue de 0.75 LPM, dado que a dicho flujo se presentó la mayor absorción de ozono en la fase gas-líquido, y además el pH de la muestra se mantenía en estado neutro. Los análisis de ácido oleico y heptanoico hacen ver que existe una degradación de las cadenas largas a cadenas más cortas. Las evaluaciones cuantitativas evidencian una remoción de los dos ácidos mencionados, sin embargo en las determinaciones de la materia orgánica expresada como DQO, las remoción es baja, demostrando así que no se da una mineralización de la materia orgánica por la aplicación del proceso de oxidación avanzada, sino solo la ruptura de las moléculas largas a estructuras más sencillas. La Figura 2 permite observar, una importante degradación del ácido oleico a los 10 minutos de tratamiento para los diferentes flujos de ozono. Con respecto al ácido heptanoico (Tabla 1) se puede apreciar que a los $30 \mathrm{~min}$ y con un flujo de 0.75 LPM se logra una remoción del 93.61\% y para el ácido oleico la remoción fue del $89.19 \%$. De la aplicación corta de ozono a las aguas resuduales porcinas, que ya pasaron un proceso biológico anaerobio y que no logran cumplir con las normas en materia de descarga, se puede señalar que con este proceso se logra una fraccmentación de las cadenas largas que tienen poca degradabilidad biologica transformandolas a cadenas más corta, incrementando así el indice de biodegradabilidad (IB) y haciendo de esa forma factible su degradación biológica (Tabla 1).

De igual manera con la aplicación de la fotocatalisis a través de la exposición de la muestra de agua residual procina a una fuente de luz ultravioleta se demuestra que también se puede lograr una fraccmentación de las cadenas largas a cadenas más cortas haciendo vialbe su degradación biológica posterior. En la Figura 3, se observa que a los 30 minutos de tiempo de exposición a la lámpara UV se remueve el $82.19 \%$ del ácido heptanóico con una dosis de $0.05 \%$ de $\mathrm{H}_{2} \mathrm{O}_{2}$, el $49.51 \%$ con una dosis de $0.1 \%$ de $\mathrm{H}_{2} \mathrm{O}_{2}$ y $25.39 \%$ con la dosis menor de $0.01 \%$. A los 45 minutos con la dosis de $0.1 \% \mathrm{H}_{2} \mathrm{O}_{2}$ se alcanza el $85.73 \%$ de remoción, $78.58 \%$ con $0.05 \%$ de $\mathrm{H}_{2} \mathrm{O}_{2}$ y el $49.77 \%$ con $0.01 \%$ de $\mathrm{H}_{2} \mathrm{O}_{2}$. En la Figura 3 , se puede observar que se degrada el $82.17 \%$ del ácido oleico con una dosis de $0.01 \%$ de $\mathrm{H}_{2} \mathrm{O}_{2}$, el $81.95 \%$ de remoción con $0.05 \%$ de $\mathrm{H}_{2} \mathrm{O}_{2}$ y el $65.1 \%$ con $0.1 \%$ de $\mathrm{H}_{2} \mathrm{O}_{2}$ a los 30 min de exposición. En un tiempo de exposición de 45 min se alcanza una remoción del $91.78 \%$ con una $0.01 \% \mathrm{H}_{2} \mathrm{O}_{2}$, el $94.52 \%$ con $0.05 \% \mathrm{H}_{2} \mathrm{O}_{2}$ y $83.3 \%$ con una dosis de $0.1 \%$ $\mathrm{H}_{2} \mathrm{O}_{2}$. Por lo tanto, la dosis óptima de $\mathrm{H}_{2} \mathrm{O}_{2}$ es $0.05 \%$ en un tiempo de exposición de 45 minutos, para logar la mayor remoción del ácido oleico.

\section{CONCLUSIONES}

Los procesos de oxidación avanzada aplicados en este trabajo resultaron ser efectivos para la remoción de los ácidos grasos de cadena larga y cadena corta, mejorando la biodegradabilidad ( $\mathrm{IB}=0.62)$ en las aguas residuales porcinas. Así, los resultados óptimos logrados de la aplicación de ozono, son el 93.61\% de remoción 
del ácido heptanoico y el 89.19\% para el ácido oleico, a los 30 min y con un flujo de 0.75 LPM. En la aplicación de UV- $\mathrm{H}_{2} \mathrm{O}_{2}$, la dosis óptima fue de $0.05 \%$ de $\mathrm{H}_{2} \mathrm{O}_{2}$ y un tiempo de exposición de 30 minutos para obtener una remoción del $82.19 \%$ para el ácido heptanóico, y para el ácido oleico, la dosis óptima fue de $0.05 \%$ de $\mathrm{H}_{2} \mathrm{O}_{2}$ en 45 minutos para obtener un $94.52 \%$ de degradación. Se requieren mayores tiempos de exposición de lámpara UV para lograr la remoción de ácidos de cadena larga (ácido oleico), en comparación con los ácidos de cadena corta (ácido heptanóico).

\section{AGRADECIMENTOS}

G. Giácoman agradece a CONICYT/FONDAP/15130015 por el soporte entregado para su estadía de investigación en la Universidad de Concepción.

\section{REFERENCIAS}

FAO. (2011). Publicado por el Programa CE-FAO « La Seguridad Alimentaria: Información para la toma de decisiones ». Ddisponible en línea en: http://www.fao.org/docrep/014/al936s/al936s00.pdf.

BID (2011). Tratamiento de aguas residuales y excretas animales: Análisis de la experiencia de América Latina y el Caribe con proyectos del mecanismo de desarrollo limpio. Banco Interamericano de Desarrollo.

Errecart V., Lucero M., Sosa M.A. (2013) Analisis del mercado mundial de carnes. Centro de economía regional (CERE). Universidad Nacional de San Martín. Argentina.

Fira (2017). Fideicomisos Instituidos el relación con la agricultura (FIRA), México. Documento elaborado con información disponible a marzo de 2017: diees@fira.gob.mx

Garzon-Zuñiga M. A.; Buelna G. (2014). Caracterización de aguas residuales porcinas y su tratamiento por diferentes procesos en México. Rev. Int. Contam. Ambie. 30 (1) 65-79.

Giácoman G., Hernández E., Ponce C., Hernández A., Ruiz E. J., Barceló I. D. (2014). Aplicación corta de un proceso de oxidación avanzada para incrementar la biodegradabilidad de aguas residuales porcícolas. XXXIV Congreso Interamericano de Ingeniería Sanitaria y Ambiental (organizado por AIDIS, México). 2-6 Noviembre de 2014. Monterrey. México.

Hernández. G. R. (2014). Manejo de excretas porcinas - Sistemas convencionales y alternativos. Departamento de Producción Animal: Cerdos. Facultad de Medicina Veterinaria y Zootecnia -UNAM. http://www.engormix.com/MA-porcicultura/manejo/articulos/manejo-excretas-porcinas-sistemas-t375/124p0.htm.

Vidal G., Pozo G. y Arumi J.L. (2012). Aportes a la gestión y optimización de la tecnología ambiental del sector porcino. Ediciones Universidad de Concepción. ISBN: 978-956-227-367-1.
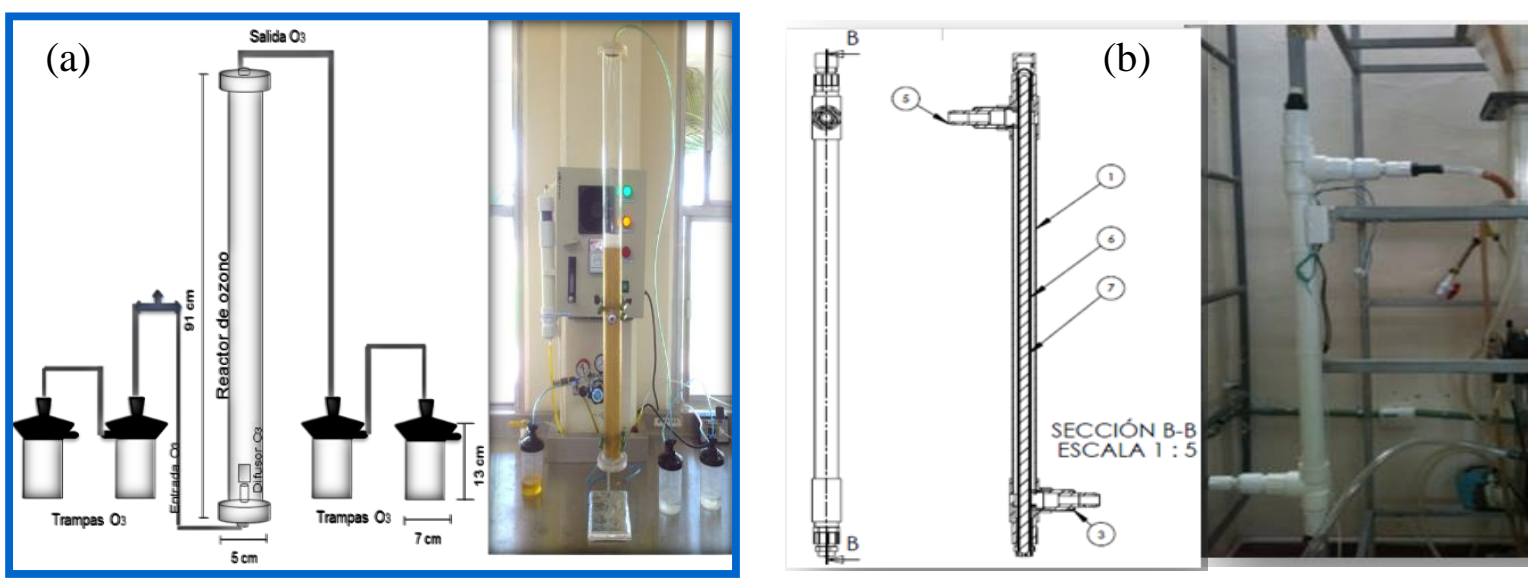

Figura 1. Esquema del (a) reactor de ozonación y (b) del reactor para $\mathrm{UV}-\mathrm{H}_{2} \mathrm{O}_{2}$ para el tratamiento del agua residual porcina. 


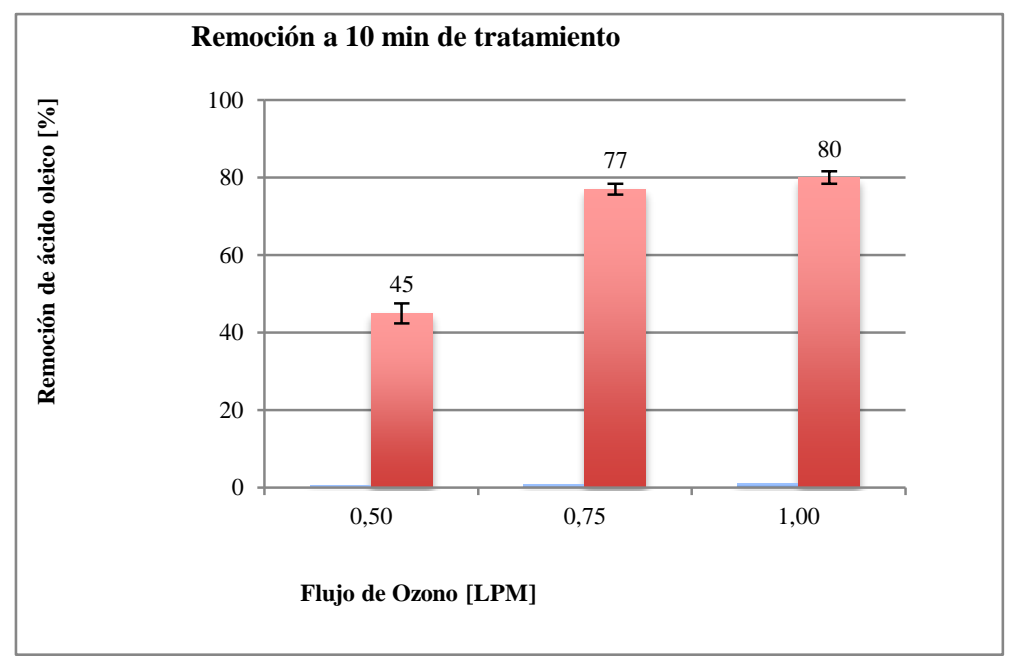

Figura 2. Remoción de ácido oleico.
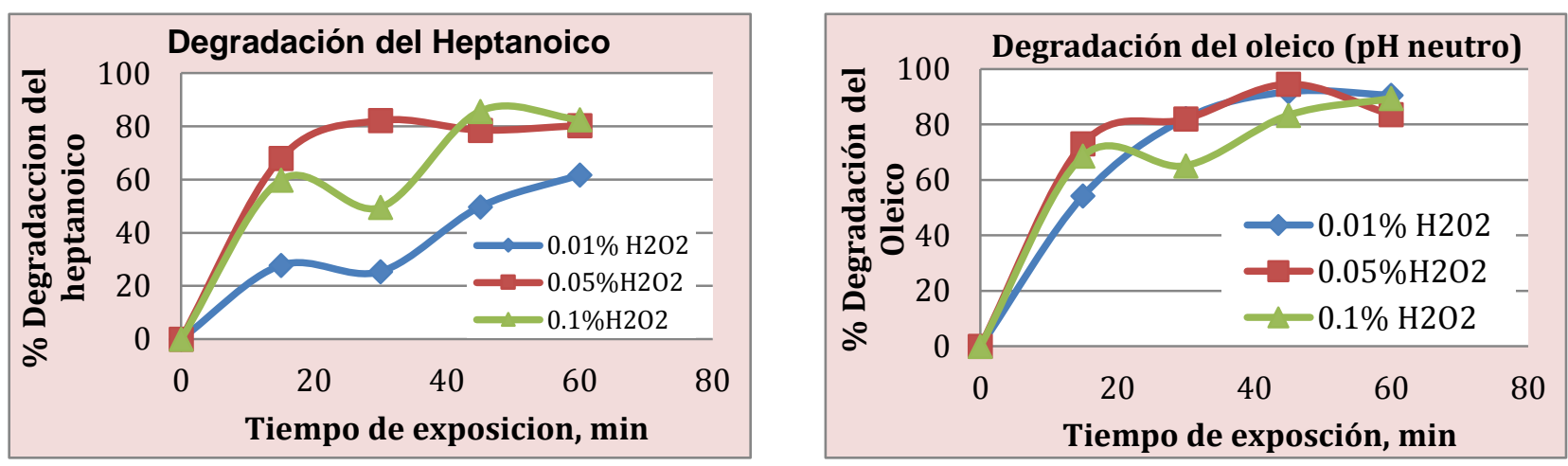

Figura 3. Porcentaje de remoción del ácido heptanóico y oleico.

Tabla 1. Proceso de ozonización del agua residual porcina.

\begin{tabular}{ccccc}
\hline Parámetros & Unidades & $\begin{array}{c}\text { Muestra entrada agua } \\
\text { residual más C7 y C18 }\end{array}$ & $\begin{array}{c}\text { Efluente proceso de } \\
\text { ozonización 30 min } \\
\text { 0.75 LPM }\end{array}$ & $\begin{array}{c}\text { Remoción } \\
\%\end{array}$ \\
\hline $\mathrm{pH}$ & --- & 7.92 & 8.3 & --- \\
$\mathrm{DBO}_{5}$ & $\mathrm{mg} / \mathrm{L}$ & 1,045 & 3,200 & --- \\
$\mathrm{DQO}_{\mathrm{T}}$ & $\mathrm{mg} / \mathrm{L}$ & 6,310 & 5,164 & 18.16 \\
$\mathrm{COT}$ & $\mathrm{mg} / \mathrm{L}$ & 2,094 & 2,036 & 2.77 \\
$\mathrm{IB}$ & --- & 0.17 & 0.62 & --- \\
$\mathrm{AVGs}$ & $\mathrm{mg} / \mathrm{L}$ & 98.6 & 6.3 & 93.61 \\
Oleico & $\mathrm{mg} / \mathrm{L}$ & 141.5 & 15.3 & 89.19 \\
\hline
\end{tabular}




\title{
A PERDA DE N DURANTE A COMPOSTAGEM EM PILHAS ESTÁTICAS É INFLUENCIADA PELA AERAÇÃO?
}

\author{
Orrico, A.C.A.*1; ${ }^{*}$ Vilela, R.N.S. ${ }^{2}$; Santos, W. ${ }^{3}$; Dias, A.M.D.F. ${ }^{3}$; Macena, I.A. ${ }^{3}$; Machado, J.F. ${ }^{3}$ \\ ${ }^{1}$ Docente do Curso de Zootecnia da Universidade Federal da Grande Dourados, MS - Brasil \\ ${ }^{2}$ Aluna do Programa de Pós-Graduação em Zootecnia da Universidade Federal da Grande Dourados, MS - Brasil \\ ${ }^{3}$ Aluno do Curso de Zootecnia da Universidade Federal da Grande Dourados, MS - Brasil \\ anacarolamorim@hotmail.com
}

\begin{abstract}
RESUMO: As perdas de $\mathrm{N}$ durante a compostagem podem alcançar valores elevados, reduzindo assim a eficiência da reciclagem de nutrientes durante o processo. O objetivo deste trabalho foi avaliar a influência da aeração nas quantidades de $\mathrm{N}$ perdidas em leiras formadas com quatro resíduos orgânicos (descartes de abatedouro bovino, restos de incubatório, resíduos da filetagem de peixes e restos alimentares de restaurante universitário) compostados em pilhas estáticas, recebendo ou não aeração. As leiras foram formadas com os resíduos descritos e material volumoso na proporção de 3:1, e mantidas em compostagem por 90 dias, sendo revolvidas aos 50 e 75 dias. No início e final do processo foram mensurados os teores de $\mathrm{N}$, além das concentrações de $\mathrm{C}$ e medida do $\mathrm{pH}$ nos substratos iniciais. As perdas de $\mathrm{N}$ foram influenciadas $(\mathrm{p}<0,05)$ pela aeração em pilhas estáticas, sendo favorecidas na condição com aeração, com valores médios de 83 e $81 \%$ de perdas de $\mathrm{N}$ para a leiras aeradas e não aeradas, respectivamente. $\mathrm{O} \mathrm{pH}$ inicial dos substratos iniciais foi: 6,92; 7,52; 7,18 e 4,42, enquanto as relações C:N foram de 14,1;10,7;12,1 e 14,3 para os resíduos de abatedouro, incubatório, peixes e restaurante, respectivamente. A aeração forçada em pilhas estáticas aumenta as perdas de $\mathrm{N}$ durante a compostagem dos resíduos de abatedouro bovino, filetagem de peixes, incubatório de ovos e restaurante universitário.
\end{abstract}

Palavras-chave: fertilizante orgânico, leira, volatilização.

\section{IS N LOSS DURING COMPOSTING IN STATIC PILES INFLUENCED BY THE AERATION?}

\begin{abstract}
N}$ losses during composting can reach high values, thus reducing the efficiency of nutrient recycling during the process. The objective of this work was to evaluate the influence of aeration on the amounts of $\mathrm{N}$ lost in piles formed with four organic residues (bovine slaughtering waste, hatchery remains, fish filleting residues and food rests from a university restaurant) composted in static cells, receiving or no aeration. The piles were formed with the described residues and bulk material in the proportion of 3:1, and kept in compost for 90 days, being revolved at 50 and 75 days. At the beginning and the end of the process the $\mathrm{N}$ contents were measured, as well as the $\mathrm{C}$ concentrations and $\mathrm{pH}$ measurements on the initial substrates. $\mathrm{N}$ losses were influenced $(\mathrm{p}<0.05)$ by aeration in static piles, being favored in the aeration condition, with average values of 83 and $81 \%$ of $\mathrm{N}$ losses for aerated and non-aerated piles, respectively. The initial $\mathrm{pH}$ of the starting substrates was: $6.92 ; 7.52 ; 7.18$ and 4.42 , while the $\mathrm{C}$ : $\mathrm{N}$ ratios were $14.1 ; 10.7 ; 12.1$ and 14.3 for slaughterhouse, hatchery, fish and restaurant waste, respectively. Forced aeration in static piles increases $\mathrm{N}$ losses during composting of cattle slaughter residues, fish filleting, egg hatchery and university restaurant.
\end{abstract}

Keywords: organic fertilizer, pile, volatilization.

\section{INTRODUÇÃO}

Comumente a compostagem é empregada para os dejetos de animais e muitos trabalhos científicos já foram conduzidos a partir destes substratos (Moller et al. (2004), Gu et al. (2017)). Já os resíduos originados com o processamento de animais (restos abate, filetagem e carcaças), a incubação de ovos, ou mesmo restos alimentares dos refeitórios universitários, possuem em sua composição constituintes como gorduras, carnes, ossos e sangue, que, se direcionados corretamente em sistemas de compostagem poderão resultar em produtos (compostos) de excelente qualidade. Estes resíduos possuem condições desejáveis para a proliferação acelerada de microrganismos patogênicos, além da formação de elevadas quantidades de gases tóxicos no início do processo de degradação, sendo assim inviabilizado o revolvimento das pilhas de compostagem 
contendo este material. Além disso, a presença de sangue e tecidos musculares podem retardar o desenvolvimento do processo de compostagem, já que elevam a proporção de nitrogênio nas leiras, causando desbalanço da relação C:N.

De acordo com Chen et al. (2015), perdas de $\mathrm{N}$ ocorrem, principalmente, por meio da volatilização de alguns compostos orgânicos durante o período de compostagem. Os diferentes métodos de aeração das leiras são indicados em função da origem e das características dos substratos, custo de investimento e de operações, tempo para alcançar a maturação das leiras e disponibilidade de área, no entanto, esta escolha pode afetar diretamente a retenção ou perda de $\mathrm{N}$ no processo (Rasapoor et al., 2016).

Em decorrência da permanência das leiras por períodos longos com elevadas temperaturas, ocorrem perdas de $\mathrm{N}$ pelo processo de desnitrificação e a presença de $\mathrm{N}$ tanto na forma de nitrato quanto no amônio é desejada no composto para otimizar seu uso agrícola, já que as plantas conseguem assimilar mais facilmente esses componentes através do sistema radicular (Rasapoor et al., 2016). Na pesquisa realizada por Rasapoor et al. (2016), o maior tempo que as leiras de ventilação natural e revolvimento mecânico mantiveram-se na fase termofílica influenciou na ação das bactérias que transformam amônio em nitrito, os autores explicam que estes microrganismos atuam após as temperaturas tornarem-se menores que $40^{\circ} \mathrm{C}$ e com condições de aeração favoráveis, pois sem oxigênio as bactérias usam o nitrato como aceitador de elétrons, causando o processo indesejado de desnitrificação.

O objetivo deste trabalho foi avaliar a influência da aeração nas quantidades perdidas de $\mathrm{N}$ em leiras formadas com quatro diferentes resíduos orgânicos (descartes de abatedouro bovino, restos de incubatório, resíduos da filetagem de peixes e restos alimentares de restaurante universitário) compostados em pilhas estáticas, recebendo ou não aeração.

\section{MATERIAL E MÉTODOS}

A pesquisa foi desenvolvida no Galpão Experimental e no Laboratório de Manejo dos Resíduos Agropecuário, ambos pertencentes à Faculdade de Ciências Agrárias da Universidade Federal da Grande Dourados, localizada no município de Dourados-MS, Brasil. Segundo a classificação climática de Köppen o clima da região é úmido mesotérmico-Cwa.

Os resíduos compostados foram: restos alimentares do restaurante universitário, resíduos de abatedouros de bovinos, restos da filetagem de pescado e resíduos da incubação de ovos para a produção de pintainhos de 1 dia. Para condução do experimento foi adotado o delineamento inteiramente casualizado, em esquema fatorial quatro x dois, composto pelos resíduos orgânicos compostados, com e sem a presença de aeração em pilhas estáticas, obtendo-se assim 16 tratamentos, com duas repetições (leiras).

Além dos resíduos orgânicos as leiras foram formadas com a inclusão de um material absorvente, composto por feno de gramínea de baixa qualidade moído e casca de arroz, na proporção de 80:20, respectivamente. A proporção entre resíduo orgânico e material absorvente foi de 3,0 a 3,5:1 (massa:massa), sendo esta uma condição recomendada pela literatura para otimizar a quantidade de resíduo a ser tratada e não formação de chorume, além de colaborar para menor adensamento do material enleirado e assim, proporcionar maiores condições de aeração.

As leiras foram formadas em camadas, utilizando as proporções descritas, sendo a base e a cobertura das pilhas sempre de material absorvente; na primeira camada formada, a casca de arroz foi acondicionada na parte inferior da base (em contato com a composteira) vedando melhor o seu fundo, sendo então seguida pelo feno moído e o resíduo orgânico. Nas camadas seguintes a casca de arroz foi colocada em contato com o resíduo da camada formada abaixo dela, auxiliando assim na vedação da camada superior. As células de compostagem foram construídas com madeira vazada nos lados, fundo, frente e piso da composteira (revestidas internamente com sombrite), apresentando as seguintes dimensões: 0,85 x 0,50 e 1,20m de altura, largura e profundidade, com capacidade estimada para acondicionar $170 \mathrm{~kg}$ de material in natura. Todas as pilhas foram formadas e mantidas no interior de uma casa de vegetação, protegidas da exposição direta ao sol e a chuva.

$\mathrm{Na}$ formação das leiras que receberam aeração foram inseridos tubos de PVC com diâmetro de $50 \mathrm{~mm}$ entre as camadas de resíduos formadas, sendo estes canos perfurados ao longo do comprimento para que pudessem conduzir a aeração por todo o perfil da leira. Estes canos foram distribuídos na horizontal, acompanhando a profundidade da célula, com distância de $25 \mathrm{~cm}$ da base para o primeiro cano e $55 \mathrm{~cm}$ da base para o segundo cano, sendo estes dois canos interligados na parte frontal da composteira em uma única entrada, onde foi acoplado um motor tipo soprador de ar, permitindo assim a injeção de ar com o fluxo médio 
de $0,9 \mathrm{~L} \cdot \mathrm{min}^{-1}$ por quilograma de material em compostagem, durante 15 minutos por dia. O período total de compostagem foi de 90 dias, ocorrendo o primeiro revolvimento aos 50 dias e o segundo aos 75 dias de compostagem, sendo no início e final do processo determinados os teores de N. No início, com os substratos iniciais, foram avaliados os teores de $\mathrm{C}$ e determinado o $\mathrm{pH}$.

O teor de carbono total e de nitrogênio foram mensurados utilizando-se o analisador elementar LECO modelo TruSpec CN628 (Leco Instruments, St Joseph, Michigan, USA). O pH foi determinado em solução contendo amostra e água na relação 1:10.

Os dados foram submetidos à análise de variância com teste de média e comparação pelo teste de Tukey, considerando-se como fonte de variação os resíduos orgânicos e a presença ou não de aeração, sendo as análises realizadas com o auxílio do pacote computacional $\mathrm{R}$ (versão 3.1.0 for Windows)

\section{RESULTADOS E DISCUSSÃO}

As perdas de $\mathrm{N}$ foram influenciadas $(\mathrm{p}<0,05)$ pela aeração em pilhas estáticas, sendo favorecidas na condição com aeração, com valores médios de 83 e $81 \%$ de perdas de $\mathrm{N}$ para a leiras aeradas e não aeradas, respectivamente. A aeração em pilhas estáticas é um critério amplamente discutido, pois tem o principal objetivo de promover condições de aerobiose no meio em degradação. No entanto, pode facilitar as perdas de $\mathrm{N}$, especialmente durante a fase inicial do processo, situada entre os primeiros 20 dias de compostagem, como mencionado por Ogunwande et al. (2008), que associou esta ocorrência com a formação de $\mathrm{NH}_{3}$, favorecida pela composição mais enriquecida do material no início do período de compostagem. Em relação a esta composição inicial, é possível verificar que os resíduos orgânicos utilizados neste trabalho apresentaram consideráveis teores de $\mathrm{N}$ no início do processo, e que estava associado a fontes prontamente utilizáveis pelos microrganismos, como na composição de tecidos musculares e sangue, principalmente.

As perdas de $\mathrm{N}$ também podem ser correlacionadas com o pH do meio e a relação C:N dos substratos originais. Em relação ao pH, Ogunwande et al. (2008) referenciaram que a condição acima de 7 proporciona maiores perdas de $\mathrm{N}$ pela formação de $\mathrm{NH}_{3}$, podendo alcançar com facilidade valores superiores a $50 \%$, dependendo do resíduo base, enquanto a indicação de relação C: $\mathrm{N}$ entre 25 a 35:1 foi mencionada. $\mathrm{O}$ pH inicial dos substratos trabalhados nesta pesquisa foi de 6,92; 7,52; 7,18 e 4,42, enquanto as relações C:N foram de 14,$1 ; 10,7 ; 12,1$ e 14,3 para os resíduos de abatedouro, incubatório, peixes e restaurante, respectivamente. Em relação ao $\mathrm{pH}$ poderia ter sido promovido um efeito de redução das perdas de $\mathrm{N}$ observadas para as leiras de resíduos de abatedouro e restaurante, já que estavam com o pH inicial abaixo de 7,0, no entanto, acredita-se que devido ao aquecimento acelerado das pilhas logo no início e a disponibilidade da fração $\mathrm{N}$ as perdas possam ter sido favorecidas. Apesar da relação C:N inicial recomendada para a compostagem situar-se no intervalo de 25 a 35:1, pesquisas mais recentes (Orrico et al., 2018 e Costa et al. (2017)) consideram que a sincronia entre as disponibilidades das frações $\mathrm{C}$ e $\mathrm{N}$ pode representar um parâmetro mais determinante para a eficiência do processo, do que o simples ajuste numérico da relação. Em trabalho realizado por Costa et al. (2017) foram compostados diferentes resíduos com o objetivo de selecionar fontes de C que pudessem otimizar a eficiência do processo, e para isso os autores formularam tratamentos experimentais com relações C:N inicial de 23 até 41:1, e verificaram que dos compostos formados a relação final oscilou entre 11 e 23:1. O interessante destes resultados foi que para leiras formadas por serragem e resíduos de produção avícola as relações C:N inicial e final foram de 34 e 23:1, enquanto que em leiras formadas por bagaço de cana e resíduos de produção avícola estes valores foram de 41 e 15:1, respectivamente, demonstrando assim que o ajuste da relação para valores que sigam o recomendado por muitos autores não foi suficiente para predizer a eficiência do processo e que a biodisponibilidade do material inicial influenciará os resultados alcançados.

\section{CONCLUSÃO}

A aeração forçada em pilhas estáticas aumenta as perdas de $\mathrm{N}$ durante a compostagem dos resíduos de abatedouro bovino, filetagem de peixes, incubatório de ovos e restaurante universitário. Recomendam-se que as leiras permaneçam sem aeração e que sejam pesquisadas condições que possam reduzir as perdas de $\mathrm{N}$ durante o processo, visando a obtenção de fertilizantes orgânicos com maior qualidade.

\section{AGRADECIMENTOS}

A CAPES, ao CNPq, ao Fundect e UFGD pelo apoio financeiro. 


\section{REFERÊNCIAS}

Chen, R.; Wang, Y.; Wang, W.; Wei, S.; Jing, Z.; Lin, $\mathrm{X}$. $\mathrm{N}_{2} \mathrm{O}$ emissions and nitrogen transformation during windrow composting of dairy manure. Journal Environmental Management, 160, 121-127, 2015.

Costa, M.S.S.M., Bernardi, F. H., Costa, L. A. M, Pereira, D. C.; Lorin, H. E. F, Rozatti, M. A. T.; Carneiro, L. J. Composting as a cleaner strategy to broiler agro-industrial wastes: Selecting carbon source to optimize the process and improve the quality of the final compost. Journal of Cleaner Production, 142: 2084-2092. 2017.

Gu, W.; Lu, Y.; Tana, Z.; Xu, P.; Xie, K.; Li, X.; Sun, L. Fungi diversity from different depths and times in chicken manure waste static aerobic composting. Bioresource Technology, 239, 447-453. 2017.

Moller, H.B.; Sommer, S.G.; Ahring, B.K. Biological degradation and greenhouse gas emissions during prestorage of liquid animal manure. Journal of Environmental Quality, 33, 27-36, 2004.

Ogunwande, G. A.; Osunade, J. A.; Adekalu, K. O.; Ogunjimi, L. A. O. 2008. Nitrogen loss in chicken litter compost as affected by carbon to nitrogen ratio and turning frequency. Bioresource Technology, 99: 74957503.

Orrico Jr., M. A. P.; Orrico, A. C. A.; Fava, A. F. F.; Sunada, N. S.; Schwingel, A. W.; Garcia, R. G.; Borquis, R. R. A. Crude glycerin in co-composting with laying hen manure reduces N, Scientia Agricola, 75, 361-367. 2018.

R: A language and environment for statistical computing. Vienna, Austria: R. Foundation for Statistical Computing, 2006. Disponível em: <http://www.R-project.org> Acessado em: 23 nov 2018.

Rasapoor, M.; Adl, M.; Pourazizi, B. Comparative evaluation of aeration methods for municipal solid waste composting from the perspective of resource management: A practical case study in Tehran, Iran. Journal of Environmental Management. 184, 528-534. 2016.

Tabela 1. Teores, quantidades e reduções de $\mathrm{N}$ observadas durante a compostagem de resíduos orgânicos em pilhas estáticas com e sem aeração forçada.

\begin{tabular}{lcccc}
\hline & \multicolumn{5}{c}{ Resíduo } \\
\hline Sem aeração & Abatedouro & Incubatório & Peixe & Restaurante \\
\hline N inicial (\% dos ST) & 4,36 & 2,71 & 5,15 & 3,14 \\
N inicial (kg) & 3,36 & 2,89 & 4,89 & 2,50 \\
N final (\% dos ST) & 2,09 & 1,26 & 2,77 & 2,45 \\
N final (kg) & 0,58 & 0,64 & 0,87 & 0,49 \\
Redução de N (\%) & $\mathbf{8 2 , 8 7 ~ b}$ & $\mathbf{7 7 , 7 5}$ b & $\mathbf{8 2 , 2 8}$ b & $\mathbf{8 0 , 4 8}$ b \\
\hline Com aeração & & & & \\
\hline N inicial (\% dos ST) & 5,77 & 2,85 & 4,90 & 3,45 \\
N inicial (kg) & 4,52 & 3,45 & 4,61 & 2,99 \\
N final (\% dos ST) & 2,61 & 1,25 & 2,90 & 2,16 \\
N final (kg) & 0,73 & 0,67 & 0,75 & 0,49 \\
Redução de N (\%) & $\mathbf{8 3 , 8 6 ~ a ~}$ & $\mathbf{8 0 , 5 7}$ a & $\mathbf{8 3 , 7 2}$ a & $\mathbf{8 3 , 6 6}$ a
\end{tabular}

Médias seguidas de letras, na coluna, comparam o efeito da aeração e quando distintas diferem entre si pelo teste de Tukey (p<0,05). Erro padrão da média: 0,98 . P valor para tipo de resíduo: 0,11. P valor para aeração: < 0,01. P valor para a interação resíduo x aeração: 0,37 . 


\title{
ALKALINITY CHANGING DURING NITROGEN REMOVAL IN A MLE REACTOR AT HIGH TSS CONCENTRATION
}

\author{
Hollas, C.H.*1; Chini, A. ${ }^{1}$; Bolsan, A. ${ }^{2}$; Goldschmidt, F.A. ${ }^{3}$; Kunz, A. ${ }^{4}$ \\ ${ }^{1}$ PhD student in the postgraduate program in Agricultural Engineering, Cascavel, PR - Brasil \\ ${ }^{2}$ Graduate in Biological Sciences, Universidade do Oeste de Santa Catarina, Joaçaba, SC-Brasil \\ ${ }^{3}$ Analist A at Embrapa Suínos e Aves, Concórdia, SC - Brasil \\ ${ }^{4}$ Researcher at Embrapa Suínos e Aves, Concórdia, SC - Brasil \\ camila.hollas@gmail.com.br
}

\begin{abstract}
The current scenario requires wastewater treatment systems with high efficiency, easy operation and low cost. Several factors influence the choice of nitrogen removal through nitrification and denitrification, and these are not always well enlightened in the literature. In this sense, the aim of this study was to evaluate the effect of the increase in total suspended solids (TSS) concentration in the MLE system on the efficiency of nitrification/denitrification and the behavior of alkalinity through the process. For this purpose swine wastewater was used, which has undergone a solid liquid separation (SLS) performed with a brush-roller screen ( $2 \mathrm{~mm}$ mesh) followed by a settling unit. The nitrogen removal unit was composed of a MLE process, operated in three phases, according to different sedimentation times in the SLS process. The MLE system endured total suspends solids concentration higher than $14 \mathrm{~g} \mathrm{~L}^{-1}$, reaching removal efficiency of $88.3 \%$ for nitrogen and $86.3 \%$ for total organic carbon. Alkalinity consumption lower than the stoichiometry were verified for nitrification and denitrification. The nitrogen removal system presented high efficiencies in the removal of both carbon and nitrogen, however the consumption of alkalinity was lower than expected, being necessary further studies to elucidate this discrepancy.
\end{abstract}

Keywords: Denitrification, nitrification, settling, swine wastewater

\section{INTRODUCTION}

Nitrogen compounds can cause severe damage to the environment, such as oxygen depletion in water bodies, or eutrophication (HEWAWASAM et al., 2017). There are several sources of contamination, one of which is animal production. More specifically swine farming is one of the activities with the highest volume of effluents generation and with elevated concentration of this pollutant (CESTONARO DO AMARAL et al., 2016). The biological nitrogen removal, in particular nitrification and denitrification, performed in Modified Ludzack-Ettinger (MLE) system, is an interesting alternative to minimize the environmental impacts of these wastes (LIU et al., 2018).

The nitrification and denitrification occurs in specific conditions such as $\mathrm{pH}$, dissolved oxygen, temperature, alkalinity, among others (ZHANG et al., 2014). Among these parameters, alkalinity is directly related to the nitrogen removal. Many residues that do not have enough natural alkalinity require an external source for the alkalinity requirement establishment (LI and IRVIN, 2007).

The requirement of alkalinity is calculated according to the quantity of bicarbonate required to neutralize the acidity generated in the nitrification. If denitrification is complete, there will be a compensation of $50 \%$ of the alkalinity consumed, due to the consumption of $\mathrm{H}^{+}$for denitrification process and consequently return of alkalinity to the system. Therefore, in the MLE system, for each gram of ammoniacal nitrogen supplied 3.57 $\mathrm{g} \mathrm{CaCO}_{3} \mathrm{~L}^{-1}$ are needed. This relation is important for the maintenance of the $\mathrm{pH}$ in the system in values close to neutrality, so that it does not occur inhibition of the processes by other chemical forms ( METCALF and EDDY, 2003).

In addition to these factors, pre-treatment of wastewater is an important step to have suitable conditions for the nitrogen removal. Conventionally, solid-liquid separation (SLS) is performed by means of flocculation, coagulation and sedimentation, with the use of chemical additives, which makes the treatment system more expensive (HJORTH et al., 2010).

Despite some studies dealing with the combination of SLS with nitrification and denitrification process, few is known about how much MLE system could withstand organic load increase by total suspended solids concentration. Also the combination of settling without chemical additives with the MLE system was not reported in the literature for swine effluents. 
Therefore, the aim of this study was to evaluate the effect of TSS concentration increase in the MLE system on the efficiency on nitrification/denitrification process and the behavior of alkalinity in the system.

\section{MATERIAL AND METHODS}

For the development of this study, swine wastewater from experimental facilities of Embrapa Suínos e Aves (Concordia, Santa Catarina state, Brazil) was used (KUNZ et al., 2009). The samples were collected directly after the separation into static sieve of rotating brushes ( $2 \mathrm{~mm}$ mesh).

After the mechanical separation the effluent was submitted to solids separation in a conic settler (volume of $1 \mathrm{~L}$ ) at retention times of 30 minutes (for phase I feeding), 10 minutes (for phase II feeding) and 5 minutes (for phase III feeding), aiming to increase total solids concentration in the effluent. Three separated aliquots $(130 \mathrm{~L})$ for each phase were collected and stored at $4{ }^{\circ} \mathrm{C}$.

The nitrogen removal from the effluent resulting from solid-liquid separation as performed in a MLE system. The system was operated at a hydraulic retention time (HRT) of 4.6 days, of $1.5 \mathrm{~mL} \mathrm{~min}^{-1}$ ( $\mathrm{Q}_{\text {in }}$ ), with a sludge recirculation rate of $1 \mathrm{Q}_{\text {in }}$ and nitrate recirculation rate of $5.5 \mathrm{Q}_{\text {in }}$ (BORTOLI, 2010). The solid retention time (SRT) was fixed at 25 days.

The system was monitored by physical-chemical analysis, performed in the Laboratory of Studies and Environmental Analyzes at Embrapa Suínos e Aves. The evaluated parameters were total ammoniacal nitrogen (TAN as $\mathrm{NH}_{3}-\mathrm{N}$ ), $\mathrm{pH}$, total organic carbon (TOC), total solids (TS), total suspend solids and alkalinity according to methodology described by Rice et al. (2017).

\section{RESULTS AND DISCUSSION}

The MLE system was operated for 52 days during phase I and II, and 61 days in phase III. The characteristics of effluent used in feeding each phase are presented in the table 1 . The removal efficiency obtained for inorganic nitrogen species (TAN, $\mathrm{NO}_{2}-\mathrm{N}$ and $\mathrm{NO}_{3}-\mathrm{N}$ ) was $91 \%$ in phase $\mathrm{I}$ and $\mathrm{II}$ and $88 \%$ in phase III. Results of MLE system effluent analysis showed TAN of $1.3( \pm 1.5) \mathrm{mg} \mathrm{L}^{-1}$ in phase I, $6.4( \pm 2.8) \mathrm{mg} \mathrm{L}^{-1}$ in phase II and $10.5( \pm 4.9) \mathrm{mg} \mathrm{L}^{-1}$ in phase III. Additionally the efficiency of TOC removal was $74 \%$ in phase I and $86 \%$ in phases II and III. These removal efficiencies are related mainly to the carbon consumption by denitrification process, since the presence of organic matter and NOx (nitrite and nitrate) electrons acceptor favors the denitrifying bacteria growth (LIU et al., 2010).

The TOC addition in the system resulted in a TSS concentration increase in the reactors. In phase I, TSS in nitrifying reactor was $9.7 \pm 0.9 \mathrm{~g} \mathrm{~L}^{-1}, 13.5 \pm 1.4 \mathrm{~g} \mathrm{~L}^{-1}$ in the phase II and $14.4 \pm 2.1 \mathrm{~g} \mathrm{~L}^{-1}$ in the phase III. The TSS in the denitrifying reactor in the phase I was $9.4 \pm 0.32 \mathrm{~g} \mathrm{~L}^{-1}, 14.3 \pm 1.9 \mathrm{~g} \mathrm{~L}^{-1}$ in the phase II and $15.1 \pm$ $0.8 \mathrm{~g} \mathrm{~L}^{-1}$ in phase III. As a comparison, conventional activated sludge systems operate at concentrations of TSS around 4 to $6 \mathrm{~g} \mathrm{~L}^{-1}$. (VON SPERLING, 2007). Despite the elevated TSS concentration in the system, the nitrogen removal was not impaired, which highlights the robustness of the employed MLE system.

The $\mathrm{pH}$ and temperature remained stable throughout all the experimental phases. The average $\mathrm{pH}$ was $8.15( \pm 0.23)$ in both reactors (nitrifying and denitrifying reactor) along the three experimental phases. These values do not cause inhibitory effects over the nitrogen removal processes studied (ZANG et al, 2014).

Although the $\mathrm{pH}$ in the three studied phases was high, loss of ammonia by volatilization was negligible. The calculated concentration of free ammonia (FA) was very low: $0.02 \pm 0.01 \mathrm{mg} \mathrm{L}^{-1}$ and $0.13 \pm 0.03 \mathrm{mg} \mathrm{L}^{-1}$ in nitrifying and denitrifying reactors respectively.

The effluent alkalinity used to fed MLE system changed according the different effluent characteristics collected for the different phases: $2907 \pm 225 \mathrm{mg} \mathrm{L}^{-1}, 5119 \pm 384 \mathrm{mg} \mathrm{L}^{-1}$ and $3001 \pm 293 \mathrm{mg} \mathrm{L}^{-1}$ in phases I, II and III, respectively (Figure 1). This variability of effluent characteristic is inherent to swine production systems (CESTONARO DO AMARAL et al., 2016).

The alkalinity consumption in the effluent was $34 \pm 12 \%$ lower than the requirement calculated to nitrification and denitrification processes in the phase I and up to the fortieth day of phase II (Figure 1). From the fortieth day onwards, the system presented crowding depletion in dissolved oxygen due to high concentration of solids and consequently incomplete nitrification, although the total nitrogen removal has not being affected. Although the system consumed less alkalinity than the theoretical requirement to nitrification and denitrification the process remains stable with no reductions of nitrogen removal efficiencies. 
One of the hypotheses that could justify this surplus of alkalinity in the process is that besides the alkalinity formed in the denitrification by the generation of hydroxide ions, a fraction could be formed by dissociation of carbon dioxide in bicarbonate ion. As a consequence, higher alkalinity is returning to the system (GERARDI et al., 2006).

Another hypothesis for the higher alkalinity concentration as expected according to the literature is that the alkalinity may has been supplemented by the solubilization of carbon dioxide formed due to organic matter degradation, in addition to the compensation caused by denitrification. Due to the alkaline $\mathrm{pH}, \mathrm{CO}_{2}$ chemical equilibrium is shifted to bicarbonate increasing the system alkalinity (Equation 1 and 2) (DUBLEN e STEINHAUSER, 2011; KUNZ e MUKHTAR, 2016).

$$
\begin{gathered}
\mathrm{CO}_{2(\mathrm{~g})}+\mathrm{H}_{2} \mathrm{O} \rightleftharpoons \mathrm{H}_{2} \mathrm{CO}_{3(\mathrm{aq})} \\
\mathrm{H}_{2} \mathrm{CO}_{3(\mathrm{aq})} \rightleftharpoons \mathrm{HCO}_{3}{ }_{(\mathrm{aq})}+\mathrm{H}^{+}{ }_{(\mathrm{aq})}
\end{gathered}
$$

The high concentrations of solids could favor the incorporation of $\mathrm{CO}_{2}$ into the solution instead of volatizing it to the atmosphere, this aspect could justify the fact that in this study the system had lower alkalinity consumption when compared to the theoretical values expected in nitrification and denitrification stoichiometry.

\section{CONCLUSION}

The MLE system fed with swine effluent subjected to a low cost SLS presented high efficiency in the nitrogen and carbon removal. It was verified that the alkalinity consumption in the system was lower than the calculated requirement. Authors believe that the dissolution of $\mathrm{CO}_{2}$ and the chemical equilibria involved are responsible by this behavior. However further studies are needed to confirm this hypothesis.

\section{ACKNOWLEDGEMENTS}

The authors gratefully acknowledge the support provided by the project SISTRATES FUNTECBNDES, CNPq and CAPES.

\section{REFERENCES}

BORTOLI, M. Partida, operação e otimização de um sistema de nitrificação/desnitrificação visando a remoção de nitrogênio de efluente da suinocultura pelo processo Ludzack-Ettinger modificado. 2010. 155 p. Dissertação (Mestrado em Engenharia Química) - Centro tecnológico, Universidade Federal de Santa Catarina, Florianópolis, 2010.

BUHA, D. M. E ATALIA, K. R. E SHAH, N. K. Continuous process study on simultaneous nitrificationdenitrification of high ammoniacal nitrogen load wastewater in aerobic-anoxic sequencing bioreactors. International journal of environmental science and technology, v. 14, n. 11, p. 2451-2458, 2017.

CESTONARO DO AMARAL, A., et al. Influence of solid-liquid separation strategy on biogas yield from a stratified swine production system. Journal of environmental management, v. 168, p. 229-235, 2016.

DUBLEN, D; STEINHAUSER, A. Biogas from waste and renewable resources: an introduction. $2^{\text {a }}$ ed. Wiley-VCH Verlag GmbH \& Co. KGa, 2011.

HEWAWASAM, C.; MATSUURA, N.; MAHARJAN, N.; et al. Oxygen transfer dynamics and nitrification in a novel rotational sponge reactor. Biochem. Eng. J., v. 128, p.162-167, 2017.

HJORTH, M.; CHRISTENSEN, K. V.; CHRISTENSEN, M.L.; SOMMER, S.G. Solid-liquid separation of animal slurry in therory and practice. A review. Agron. Sustain. Dev., v.30, p.153-180, 2010.

KUNZ, A.; MIELE, M.; STEINMETZ, R. L. R. Advanced swine manure treatment and utilization in Brazil. Bioresour Technol 100:5485-5489, 2009.

LI, B.; IRVIN, S. The comparison of alkalinity and ORP as indicators for nitrification and denitrification in a sequencing batch reactor (SBR). Biochemical Engineering Journal, v. 34, n. 3, p. 248-255, 2007.

LIU, F.; HU, X.; ZHAO, X.; ET AL. Rapid nitrification process upgrade coupled with succession of the microbial community in a full-scale municipal wastewater treatment plant (WWTP). Bioresource Technology, v. 249, p.1062-1065, 2018. 
LIU, Y.; SHI, H.; XIA, L.; SHI, H.; SHEN, T.; WANG, Z.; WANG, G.; WANG, Y. Study of operational conditions of simultaneous nitrification and denitrification in a Carrousel oxidation ditch for domestic wastewater treatment. Bioresource Technology, v. 101, n.3, p. 901-906, 2010.

RICE, E.W.; BAIRD, R.B.; EATON, A.D. (org.). Standard methods for the examination of water and wastewater. $23^{\mathrm{a}} \mathrm{ed}$. Washington dc: american water works association and water environment federatio, 2017. KUNZ, A.; MUKHTAR, S. Hydrophobic membrane technology for ammonia extraction from wastewaters. Engenharia agrícola, v. 36, n. 2, p. 377-386, 2016.

METCALF, L.; EDDY, H. Wastewater engineering treatment and reuse. 5 ed. McGraw-Hill Education, 2003.

GERARDI, M.H. (org.). Wastewater bacteria. A john wiley \& sons, inc, 2006.

VON SPERLING, M. Activated sludge and aerobic biofilm reactors. IWA publishing, 2007.

ZHANG, S., WANG, Y., HE, W., WU, M., XING, M., YANG, J., ET AL. Impacts of temperature and nitrifying community on nitrification kinetics in a moving-bed biofilm reactor treating polluted raw water.

Chem. Eng. J., v. 236, p. 242-250, 2014.

Table 1. Characteristics of effluent in each phase.

\begin{tabular}{cccc}
\hline & TAN $\left(\mathbf{m g ~}_{\mathbf{N}} \mathbf{L}^{-1}\right)$ & TOC $_{\text { }} \mathbf{~ L ~ L}^{-\mathbf{1}}$ & $\mathbf{T S}\left(\mathbf{g ~ L}^{-\mathbf{1}}\right)$ \\
\hline Phase I & $831( \pm 139)$ & $2023( \pm 378)$ & $7.8( \pm 1.3)$ \\
Phase II & $1386( \pm 217)$ & $3208( \pm 279)$ & $12.55( \pm 0.74)$ \\
Phase III & $875( \pm 138)$ & $3047( \pm 317)$ & $18.45( \pm 1.83)$ \\
\hline
\end{tabular}

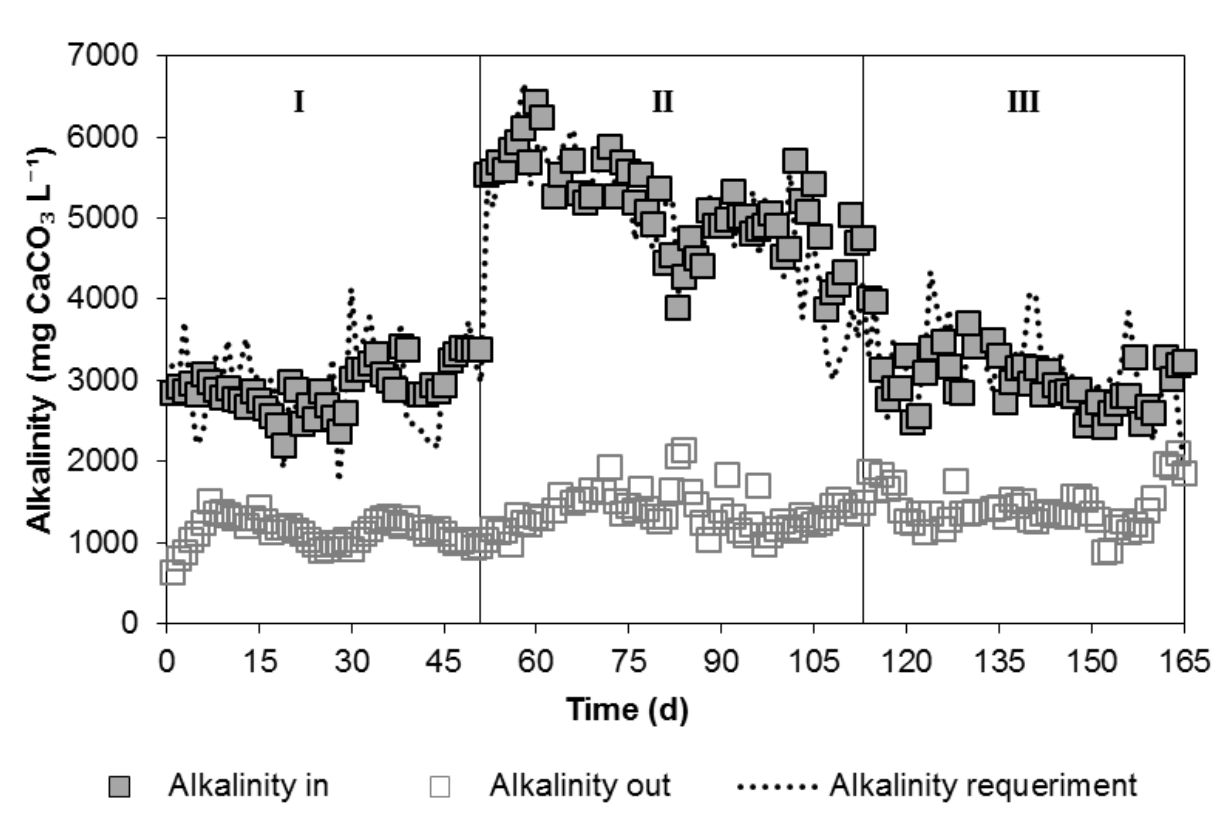

Figure 1. Alkalinity monitoring during the experimental phases of MLE system (nitrification and denitrification). (I, II and III in the figure corresponds to phases I, II and III respectively). 


\title{
ANAMMOX-BASED TREATMENT OF ANAEROBICALLY DIGESTED SEWAGE SLUDGE DEWATERING CENTRATE: FROM INOCULUM ENRICHMENT AND CULTURE TO PROCESS CONFIGURATIONS AND EMISSIONS
}

\author{
Magrí, A. ${ }^{* 1,2}$; Connan, R. ${ }^{1}$; Dabert, P. $^{1}$; Bridoux, G. ${ }^{3}$; Béline, F. ${ }^{1}$ \\ ${ }^{I}$ IRSTEA, UR OPAALE, Rennes, France \\ ${ }^{2}$ LEQUIA, UdG, Girona, Spain \\ ${ }^{3}$ SAUR, Guyancourt, France \\ *albert.magri@lequia.udg.cat
}

\begin{abstract}
There is high interest in developing autotrophic nitrogen removal (ANR) treatments based on anaerobic ammonium oxidation (anammox) since this is a low energy demand alternative to reduce the $\mathrm{N}$ content from wastewaters. This study characterizes a new implementation of the anammox process in view of treating anaerobically digested sewage sludge dewatering centrate. In particular, three major aspects were characterized: batch enrichment of anammox biomass depending on the availability of nitrite and using several inoculums; continuous culture of anammox biomass in an upflow anaerobic filter (UAF) as a biological reservoir for conducting further studies; and finally, startup of ANR systems considering one-reactor and tworeactor configurations using sequencing batch reactors (SBRs). Next, main results found are discussed.
\end{abstract}

Keywords: anaerobic ammonium oxidation, autotrophic nitrogen removal, digestate supernatant.

\section{INTRODUCTION}

ANR based on coupling partial nitritation (PN) and anammox is attracting increasing attention worldwide as an energy-efficient way to remove $\mathrm{N}$ from wastewaters typically characterized by a low carbonto-nitrogen ratio (Van Hulle et al., 2010; Magrí et al., 2013). Significant efforts are being devoted to research and development of this environmental biotechnology (Magrí et al., 2017), and the water industry has also identified it as a priority for innovation. The anammox reaction is mediated by chemolithoautotrophic bacteria belonging to the phylum Planctomycetes (Pereira et al., 2017) that oxidize ammonium $\left(\mathrm{NH}_{4}{ }^{+}\right)$to nitrogen gas $\left(\mathrm{N}_{2}\right)$ using nitrite $\left(\mathrm{NO}_{2}{ }^{-}\right)$as the electron acceptor. A minor fraction of nitrate $\left(\mathrm{NO}_{3}{ }^{-}\right)$is also produced. In particular, this reaction takes place according to molar ratios of 1.00:1.32:1.02:0.26 for $\mathrm{NH}_{4}{ }^{+}, \mathrm{NO}_{2}{ }^{-}, \mathrm{N}_{2}$, and $\mathrm{NO}_{3}{ }^{-}$, respectively (Strous et al., 1998). Owing sludge rich in anammox organisms is not always available; the procedure for a successful enrichment and culture can become the critical point for the startup of new implementations. The integrated PN-anammox process can be conducted either in two independent reactors connected in series or, alternatively, in the same reactor under limited aeration. The objective of this study is to assess (i) the enrichment of anammox biomass from different activated sludge sources depending on the concentration of nitrite applied, (ii) the culture of anammox biomass in a biofilm-type reactor, and (iii) the comparative application of coupled PN-anammox using one-reactor and two-reactor setups for treating digested sludge dewatering centrate.

\section{Enrichment}

MATERIAL AND METHODS

A 4-mo. enrichment test was performed in batch (duplicates) to investigate the effect of nitrite supply. Six different biomass sources were used; all they were collected in full-scale treatment plants targeting Nremoval. Just after sampling and before starting the test, endogenous denitrification was promoted by adding nitrate to the raw sludge samples. $575-\mathrm{mL}$ glass bottles were used. A basal synthetic nutritive solution was prepared weekly and two different nitrite supply strategies were followed; this is (i) initially low nitrite content at $0.025 \mathrm{~kg} \mathrm{NO}_{2}^{-}-\mathrm{N} \mathrm{m}^{-3}$ and progressive increase to $0.15 \mathrm{~kg} \mathrm{NO}_{2}^{-}-\mathrm{N} \mathrm{m}^{-3}$, and (ii) constant high nitrite content at $0.15 \mathrm{~kg} \mathrm{NO}_{2}^{-}-\mathrm{N} \mathrm{m}^{-3}$. The initial volatile solids content was adjusted to $3 \mathrm{~kg} \mathrm{VS} \mathrm{m}^{-3}$. Bottles were incubated in a shaker at $150 \mathrm{rpm}, 35^{\circ} \mathrm{C}$, and dark conditions. Biomass settling was allowed once per week. The supernatant was manually withdrawn while keeping the settled biomass inside. Subsequently, bottles were refilled with new nutritive solution, closed and its headspace flushed with synthetic $\mathrm{N}_{2}$. For bottles running at low nitrite concentration, once detected anammox activity, a second weekly addition of $\mathrm{N}$ was performed. The pH was controlled at 7-8 (Connan et al., 2016). The microbial community dynamics in anammox enrichments and subsequent culture was monitored by hydrazine oxidoreductase ( $h z o)$ gene or 16S rRNA gene quantification and sequencing (Connan et al. 2016, 2017). 


\section{Culture}

The most active anammox enrichment was transferred to an UAF. This 4.5-L continuous reactor was cylindrical, jacketed, and made of glass. Completely submerged, inside there was a polyester non-woven material aiming to enhance the retention of the biomass and the formation of a biofilm. Process temperature was controlled at $35^{\circ} \mathrm{C}$. The reactor was fed with a synthetic nutritive solution as detailed by Connan et al. (2017).

\section{Application}

PN-anammox for treating anaerobically digested sludge dewatering centrate was implemented in 3.5-L jacketed glass reactors. One- and two-reactor ANR systems were considered. All reactors ran as SBRs, with cycles lasting $8 \mathrm{~h}$, at $35^{\circ} \mathrm{C}$. In the aerated reactors, air was provided using a pump, a flow meter, and porous stones. In the anaerobic reactor, air was prevented from entering by blowing synthetic $\mathrm{N}_{2}$ in the headspace. Data acquisition, monitoring and control was performed using own software developed in LabView through a data-logger switch unit. Dissolved oxygen and/or pH probes were used. Nitrous oxide $\left(\mathrm{N}_{2} \mathrm{O}\right)$ in the off-gas from the SBRs was measured continuously by an on-line gas analyzer. The nitrifying biomass used as inoculum had previously been enriched in the PN SBR using activated sludge. The anammox biomass used as inoculum was collected from the UAF. Main characteristics of the centrate were as follows: $\mathrm{pH} 8.0-8.8,1.08-1.18 \mathrm{~kg}$ $\mathrm{NH}_{4}{ }^{+}-\mathrm{N} \mathrm{m}^{-3}, 1.12-1.20 \mathrm{~kg} \mathrm{~N} \mathrm{~m}^{-3}$ (total Kjeldahl N, TKN), 3.61-4.17 $\mathrm{kg} \mathrm{CaCO}_{3} \mathrm{~m}^{-3}$ (alkalinity), 0.41-0.51 kg $\mathrm{O}_{2} \mathrm{~m}^{-3}$ (chemical oxygen demand, COD) and 0.26-0.35 $\mathrm{kg} \mathrm{PO}_{4}-\mathrm{P} \mathrm{m}^{-3}$. Pre-conditioning of the centrate or PN effluent by dilution and phosphorus $(\mathrm{P})$ precipitation was considered. Thus, four different testing conditions were applied in the SBRs containing anammox biomass: (Phase I) half-diluted and P depleted influent, (Phase II) undiluted and $\mathrm{P}$ depleted influent, (Phase III) half-diluted and $\mathrm{P}$ depleted influent, and (Phase IV) halfdiluted influent with $\mathrm{P}$ adjusted to $0.30 \mathrm{~kg} \mathrm{PO}_{4}-\mathrm{P} \mathrm{m}^{-3}$ (Connan et al., 2018).

\section{Enrichment}

\section{RESULTS AND DISCUSSION}

The six inoculums tested developed anammox activity, but only when the enrichment was launched under low nitrite conditions. All the enrichments kept a typical brownish color at the end of the experiment, still reminding the aspect of the original activated sludge. For those enrichments started at low concentration of nitrite, after initial decline of endogenous denitrification, ammonium and nitrite start disappearing simultaneously under an increasing nitrite supply rate. Finally, concomitant consumption of ammonium and nitrite consolidated also at high nitrite levels (up to $0.15 \mathrm{~kg} \mathrm{NO}_{2}^{-}-\mathrm{N} \mathrm{m}^{-3}$ ), with evidence of nitrate formation and according to $\mathrm{NO}_{2}{ }^{-}: \mathrm{NH}_{4}{ }^{+}$reaction ratios tending to the expected value of 1.32 . Time for detecting ammonium consumption under anaerobic conditions was variable ranging from 0 to 92 days. Final $\mathrm{N}$ conversion rate (NCR) -including ammonium and nitrite removals- was measured within the range from 0.16 to $0.56 \mathrm{~kg} \mathrm{~N} \mathrm{~m}^{-3} \mathrm{~d}^{-1}$ (Fig. 1). Abundance of the functional hzo gene, which was measured by q-PCR, increased during the experiment in concordance with the anammox activity. The microbial community of all the enrichments tended to convergence (Fig. 1) and selection of anammox species belonging to the genus Candidatus Brocadia occurred.

\section{Culture}

Once finished the enrichment test, the most active biomass $\left(0.56 \mathrm{~kg} \mathrm{~N} \mathrm{~m}^{-3} \mathrm{~d}^{-1} ; 1.9 \mathrm{~g} \mathrm{VS}\right)$ was transferred to the UAF. Satisfactory N-removal performance was achieved under appropriate feeding conditions after solving some initial issues with the composition of the synthetic nutritive solution. Thus, the $\mathrm{N}$ loading rate (NLR) applied was progressively increased targeting from 0.11 to $1.03 \mathrm{~kg} \mathrm{~N} \mathrm{~m}^{-3} \mathrm{~d}^{-1}$ by modifying the volumetric flow rate (3-8 $\left.\mathrm{cm}^{3} \mathrm{~min}^{-1}\right)$ and/or changing the $\mathrm{N}$ concentration in the influent $\left(0.05-0.175 \mathrm{~kg} \mathrm{NO}_{2}^{-}\right.$ $-\mathrm{N} \mathrm{m}^{-3}$ at a $\mathrm{NO}_{2}^{-}: \mathrm{NH}_{4}^{+}$ratio of 1 ). High $\mathrm{N}$ conversion efficiencies (NCE) were reported (maximum of $89 \%$ ). After 2.5 months, a reddish biofilm was growing within the reactor, and it was assumed that the UAF had been started-up successfully. At this point, the targeted NLR was moved upward to $1.55 \mathrm{~kg} \mathrm{~N} \mathrm{~m}^{-3} \mathrm{~d}^{-1}\left(12 \mathrm{~cm}^{3} \min ^{-}\right.$ $\left.{ }^{1} ; 0.175 \mathrm{~kg} \mathrm{NO}_{2}^{-}-\mathrm{N} \mathrm{m}^{-3}\right)$. In the next 8 months, the reactor ran at an average NCR of $1.18 \pm 0.10 \mathrm{~kg} \mathrm{~N} \mathrm{~m}^{-3} \mathrm{~d}^{-1}$ and NCE of $88 \pm 1 \%$ (Table 1). A liquid flow regime far from the mixing patterns assumed in ideal plug-flow reactors without axial mixing was confirmed. The microbial community evolved markedly during this time resulting in a culture with $\sim 70 \%$ relative abundance of the anammox species $\mathrm{Ca}$. B. sinica. 


\section{Application}

Regarding the two-reactors system, operation of the PN SBR at an aeration rate of $2 \mathrm{dm}^{3} \mathrm{~min}^{-1}$ and NLR of $0.48-1.33 \mathrm{~kg} \mathrm{~N} \mathrm{~m}^{-3} \mathrm{~d}^{-1}$ resulted in nitrite production rates ranging from 0.23 to $0.61 \mathrm{~kg} \mathrm{NO}_{2}^{-}-\mathrm{N} \mathrm{m}^{-3} \mathrm{~d}^{-1}(\sim 48 \%$ conversion). By pushing the NLR to higher values, the maximum treatment capacity of the reactor may be surpassed easily according to its design and the amount of oxygen supplied, thus becoming very sensitive to overloads. No external alkalinity was added, so the $\mathrm{pH}$ was markedly lower after treatment (6.1-6.4). No nitrate was found in the effluent. Subsequently, the $\mathrm{N}$ removal rate (NRR) -considering ammonium and nitrite removals as well as nitrate production- achieved in the anammox SBR was $0.43-0.56 \mathrm{~kg} \mathrm{~N} \mathrm{~m}^{-3} \mathrm{~d}^{-1}$ depending on the testing conditions applied. Regarding the one-reactor system, the NRR achieved was $0.24-0.50 \mathrm{~kg} \mathrm{~N} \mathrm{~m}^{-}$ ${ }^{3} \mathrm{~d}^{-1}$ also depending on the experimental conditions (Table 2). Best performances were observed when the influent to the reactors harboring anammox activity had previously been conditioned. Emission of $\mathrm{N}_{2} \mathrm{O}$ was quantified in the three reactors, ranging from $0.4 \%$ to $4.6 \%$ of the $\mathrm{N}$ load. A peak of $\mathrm{N}_{2} \mathrm{O}$ was detected at the beginning of each new cycle, particularly in aerated reactors. Such evidence could be justified by a significant production of this compound at the end of the previous cycle, during the settling of the biomass. The $\mathrm{N}_{2} \mathrm{O}$ accumulated within the liquid bulk would be stripped out at the beginning of the new cycle due to the restoration of the aeration.

\section{Enrichment}

\section{CONCLUSIONS}

Importance of carefully controlling the availability of nitrite during the enrichment was proved. Anammox bacteria enrichment was successfully achieved, regardless the inoculum source, only when the process was started at low concentration of nitrite. In all cases, the dominant anammox genus was $\mathrm{Ca}$. Brocadia. A higher initial anammox bacteria content -measured as hzo gene copy number- did not necessarily imply a faster startup. Hence, other physicochemical and ecological properties of the inoculum impacted on the progress of the enrichment. Biomass origin, denitrification pretreatment and experimental conditions were determinant factors of the final microbial composition of the enrichments, with a clear convergence at the end of the test.

\section{Culture}

Under appropriate feeding conditions and NLR of $1.55 \mathrm{~kg} \mathrm{~N} \mathrm{~m}^{-3} \mathrm{~d}^{-1}$ (NRE $\sim 88 \%$ ), culture of Ca. $B$. sinica was accomplished in a continuous UAF packed with a fabric material to favor the attached growth of the biomass. This approach resulted in the selection of a bacterial community containing $\sim 70 \%$ of anammox DNA sequences.

\section{Application}

Comparatively, similar $\mathrm{N}$ removal rates were achieved for both reactor configurations. Yet, the onereactor setup used a smaller reaction volume, ran at a lower NLR, and emitted $\mathrm{N}_{2} \mathrm{O}$ at a lower rate than the two-reactor setup. Conditioning of the influent by dilution and phosphate precipitation before anammox-based treatment had a positive impact. Thus, a progressive pretreatment at the long-term is advisable to startup new reactors, favoring the adaptation of the anammox biomass to the high strength of the centrates.

\section{ACKNOWLEDGEMENT}

This research was conducted in the framework of the $\mathrm{PhD}$ Thesis of the second author (R. Connan) and it was supported by Rennes Métropole (AIS 14C0509).

\section{REFERENCES}

Connan R., Dabert P., Khalil H., Bridoux G., Béline F. and Magrí A. 2016. Batch enrichment of anammox bacteria and study of the underlying microbial community dynamics. Chemical Engineering Journal, 297, 217228.

Connan R., Dabert P., Le Roux S., Chapleur O., Bridoux G., Vanotti M. B., Béline F. and Magrí A. 2017. Characterization of a combined batch-continuous procedure for the culture of anammox biomass. Ecological Engineering, 106, 231-241.

Connan R., Dabert P., Moya-Espinosa M., Bridoux G., Béline F. and Magrí A. 2018. Coupling of partial nitritation and anammox in two- and one-stage systems: Process operation, $\mathrm{N}_{2} \mathrm{O}$ emission and microbial community. Journal of Cleaner Production, 203, 559-573. 
Magrí A., Béline F. and Dabert P. 2013. Feasibility and interest of the anammox process as treatment alternative for anaerobic digester supernatants in manure processing - An overview. Journal of Environmental Management, 131, 170-184.

Magrí A., Giovannini F., Connan R., Bridoux G. and Béline F. 2017. Nutrient management from biogas digester effluents: a bibliometric-based analysis of publications and patents. International Journal of Environmental Science and Technology, 14, 1739-1756.

Pereira A. D., Cabezas A., Etchebehere C., Chernicharo C. A. L. and de Araújo J. C. 2017. Microbial communities in anammox reactors: a review. Environmental Technology Reviews, 6, 74-93.

Strous M., Heijnen J. J., Kuenen J. G. and Jetten M. S. M. 1998. The sequencing batch reactor as a powerful tool for the study of slowly growing anaerobic ammonium-oxidizing microorganisms. Applied Microbiology and Biotechnology, 50, 589-596.

Van Hulle S. W. H., Vandeweyer H. J. P., Meesschaert B. D., Vanrolleghem P. A., Dejans P. and Dumoulin A. 2010. Engineering aspects and practical application of autotrophic nitrogen removal from nitrogen rich streams. Chemical Engineering Journal, 162, 1-20.
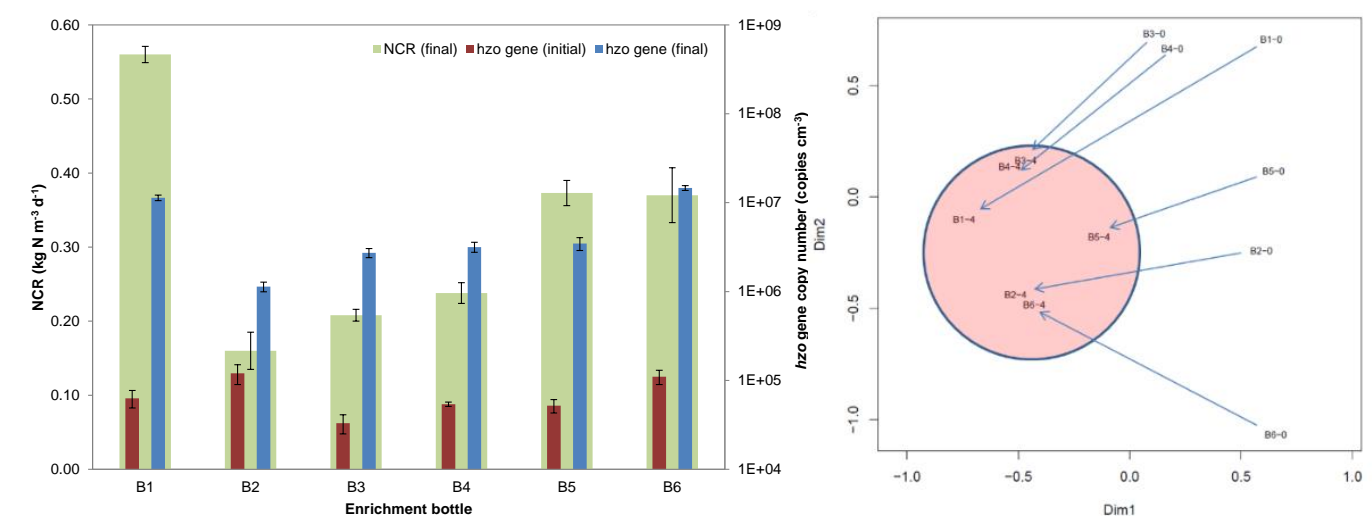

Figure 1. For the six enrichments started at low nitrite concentration; Left: N conversion rate (NCR) measured at the end of the 4-mo. test and progress of the hzo gene copy number. Right: NMDS-plot showing the evolution of the microbial community throughout the 4-mo. test.

Table 1. Performance of the UAF running under stable conditions (8-mo. period).

\begin{tabular}{lccccc}
\hline Nitrogen & Loading & Discharge & Consumption & Production & Removal \\
\cline { 2 - 5 } & \multicolumn{5}{c}{$\left(\mathbf{k g ~ N ~ m}^{-3} \mathbf{d}^{-\mathbf{1}}\right)$} \\
\hline $\mathrm{NH}_{4}{ }^{+}-\mathrm{N}$ & $0.67 \pm 0.05$ & $0.15 \pm 0.02$ & $0.52 \pm 0.04$ & - & $78 \pm 2$ \\
$\mathrm{NO}_{2}{ }^{-}-\mathrm{N}$ & $0.67 \pm 0.06$ & $0.01 \pm 0.01$ & $0.66 \pm 0.06$ & - & $99 \pm 1$ \\
$\mathrm{NO}_{3}{ }^{-}-\mathrm{N}$ & $0.02 \pm 0.00$ & $0.12 \pm 0.02$ & - & $0.11 \pm 0.02$ & - \\
$\mathrm{NH}_{4}{ }^{+}-\mathrm{N}+\mathrm{NO}_{2}{ }^{-}-\mathrm{N}$ & $1.34 \pm 0.11$ & $0.15 \pm 0.03$ & $1.18 \pm 0.10$ & - & $88 \pm 1$ \\
$\mathrm{TN}$ & $1.35 \pm 0.11$ & $0.28 \pm 0.05$ & $1.08 \pm 0.09$ & - & $80 \pm 3$ \\
\hline $\mathrm{TN}, \mathrm{NH}_{4}{ }^{+}-\mathrm{N}+\mathrm{NO}_{2}-\mathrm{N}+\mathrm{NO}_{3}{ }^{-} \mathrm{N}$ & & & &
\end{tabular}

$\mathrm{TN}, \mathrm{NH}_{4}^{+}-\mathrm{N}+\mathrm{NO}_{2}^{-}-\mathrm{N}+\mathrm{NO}_{3}^{-}-\mathrm{N}$.

Table 2. Comparison of running parameters for the one-reactor and two-reactor ANR-SBR systems.

\begin{tabular}{|c|c|c|c|c|c|c|c|}
\hline & \multirow{2}{*}{$\begin{array}{l}V_{\text {total }} \\
\left(\mathbf{d m}^{3}\right)\end{array}$} & \multicolumn{2}{|c|}{ Loading } & \multicolumn{2}{|c|}{ Removal } & \multicolumn{2}{|c|}{$\mathrm{N}_{2} \mathrm{O}$ emission } \\
\hline & & $\left(\mathrm{kg} \mathrm{N} \mathrm{m}^{-3} \mathrm{~d}^{-1}\right.$ & $\left(\mathrm{g} \mathrm{N} \mathrm{d}^{-1}\right)$ & $\left(\mathrm{kg} \mathrm{N} \mathrm{m}^{-3} \mathrm{~d}^{-1}\right)$ & $\left(\mathrm{g} \mathrm{N} \mathrm{d}^{-1}\right)$ & $\left(\mathrm{g} \mathrm{N} \mathrm{m}^{-3} d^{-1}\right)$ & $\left(\mathrm{mg} \mathrm{N} \mathrm{d}^{-1}\right)$ \\
\hline \multicolumn{8}{|l|}{ One-reactor } \\
\hline Phase I & 2.6 & 0.33 & 0.87 & 0.27 & 0.71 & 1.3 & 3.5 \\
\hline Phase II & 2.6 & 0.67 & 1.76 & 0.50 & 1.32 & 5.4 & 14.1 \\
\hline Phase III & 2.9 & 0.42 & 1.22 & 0.27 & 0.78 & 5.0 & 14.6 \\
\hline Phase IV & 2.6 & 0.34 & 0.89 & 0.24 & 0.63 & 15.6 & 41.2 \\
\hline Two-reactors & \multicolumn{7}{|c|}{ Condition PN $\left(N L R=0.90 \mathrm{~kg} \mathrm{~N} \mathrm{~m}^{-3} \mathrm{~d}^{-1}, N P R=48 \% N L R, V E R=0.27 \mathrm{~m}_{\text {exchanged }} \mathrm{m}^{-3}\right.$ end $)$} \\
\hline Phase I & 6.1 & 0.76 & 4.64 & 0.31 & 1.90 & - & - \\
\hline Phase II & 5.5 & 0.83 & 4.55 & 0.31 & 1.67 & 9.1 & 50.0 \\
\hline Phase III & 5.8 & 0.69 & 4.03 & 0.23 & 1.32 & 5.7 & 33.4 \\
\hline Phase IV & 5.7 & 0.75 & 4.29 & 0.23 & 1.34 & 15.6 & 89.0 \\
\hline
\end{tabular}

NLR, N loading rate; NPR, nitrite production rate; PN, partial nitritation; V, volume; VER, volume exchange ratio.

* The reaction volume (total) was considered as the sum of the volumes of the two reactors. 


\title{
CARACTERIZAÇÃO QUÍMICA DO DIGESTATO DE BOVINO EM DIFERENTES TEMPOS DE RETENÇÃO HIDRÁULICA
}

\author{
Matos, C.F. ${ }^{* 1}$; Silva, R.M. ${ }^{1}$; Oliveira, R.S.; Pinheiro, E.F.M. ${ }^{1}$; Leal, M.A.A. ${ }^{2}$; Stafanato, J.B. ${ }^{1}$ \\ ${ }^{1}$ Universidade Federal Rural do Rio de Janeiro - UFRRJ, Seropédica, RJ - Brasil. \\ ${ }^{2}$ Embrapa Agrobiologia, Seropédica, RJ - Brasil. \\ *email: camilamatos1@yahoo.com.br
}

\begin{abstract}
RESUMO: O objetivo deste estudo foi avaliar o efeito da digestão anaeróbia de dejetos de bovinos, provenientes do sistema orgânico de produção, nas características químicas e físicas do digestato produzido em diferentes tempos de retenção hidráulica (TRH). Para a realização do experimento foram construídos dezoito protótipos de biodigestores de bancada. Os tratamentos consistiam de diferentes TRH, a saber: T0 - 0 dias, T15 - 15 dias, T30 - 30 dias, T45 - 45 dias, T60 - 60 dias, T75 - 75 dias e T90 - 90 dias. Após 90 dias de digestão anaeróbia, foi observada uma redução do $\mathrm{pH}$ do digestato ao longo do processo, sendo justificado pela transformação dos ácidos orgânicos contidos nos dejetos em produtos gasosos. Não foi observada diferença estatística entre os tratamentos para os parâmetros umidade e sólidos totais. Pode-se constatar o efeito da digestão anaeróbia na redução de sólidos voláteis, uma vez que o tratamento $\mathrm{T} 0$ diferiu estatisticamente dos demais. Os teores de $\mathrm{C}$ e $\mathrm{N}$ ao final do processo (T90) não diferiram estatisticamente de $\mathrm{T} 0$ e a relação $\mathrm{C} / \mathrm{N}$ inicial se encontrou próximo à indicada como ideal para o crescimento bacteriano. Os teores dos nutrientes $\mathrm{Ca}, \mathrm{Mg}$ e $\mathrm{Fe}$ apresentaram um aumento ao final da digestão anaeróbia. Conclui-se, portanto, que os diferentes TRH interferiram em alguns parâmetros estudados, principalmente, no que tange os conteúdos de SV, Mg e a relação C/N. Recomenda-se que sejam avaliadas as características químicas do digestato, de modo a verificar se ocorreu a estabilização do material orgânico, antes de se recomendar a adição do mesmo ao solo.
\end{abstract}

Palavras-chave: digestão anaeróbia, dejetos animais, sistema orgânico de produção.

\section{CHEMICAL CHARACTERIZATION OF BOVINE DIGESTATE IN DIFFERENT HYDRAULIC RETENTION TIMES}

\begin{abstract}
The aim of this study was to evaluate the effect of anaerobic digestion of bovine manure from the organic production system on the chemical and physical characteristics of the digestate produced in different hydraulic retention times (HRT). For the accomplishment of the experiment eighteen prototypes of bench biodigesters were constructed. Treatments consisted of different HRT: T0- 0 days, T15- 15 days, T330 days, T45- 45 days, T60- 60 days, T75- 75 days and T9- 90 days. After 90 days of anaerobic digestion a reduction in the $\mathrm{pH}$ of the digestate was observed, being justified by the transformation of the organic acids into gaseous products. No statistical difference was observed between the treatments for the parameters humidity and total solids. The effect of anaerobic digestion on the reduction of volatile solids can be verified, since the $\mathrm{T} 0$ treatment differed statistically from the others. The $\mathrm{C}$ and $\mathrm{N}$ contents at the end of the process (T90) did not differ statistically from $\mathrm{T} 0$ and the initial $\mathrm{C} / \mathrm{N}$ ratio was found close to that indicated as ideal for bacterial growth. The contents of nutrients $\mathrm{Ca}, \mathrm{Mg}$ and $\mathrm{Fe}$ showed an increase at the end of the process. It is concluded that the different HRT interfered in some studied parameters, mainly, regarding the contents of SV, $\mathrm{Mg}$ and $\mathrm{C} / \mathrm{N}$ ratio. It is recommended that the chemical characteristics of the digestate be evaluated in order to verify the stabilization of the organic material, before recommending the addition of the same to the soil.
\end{abstract}

Keywords: anaerobic digestion, animal waste, organic production system.

\section{INTRODUÇÃO}

As grandes quantidades de estrume animal e lodos produzidos pelo setor de criação de animais, bem como os fluxos de resíduos orgânicos, representam um risco de poluição constante, uma vez que apresentam um potencial de impacto negativo sobre o meio ambiente quando não gerenciados de forma adequada (HOLMNIELSEN et al., 2009). A digestão anaeróbia apresenta-se como uma alternativa capaz de amenizar os impactos causados pelo manejo inadequado dos resíduos orgânicos, uma vez que esse processo biológico degrada a matéria orgânica contida na biomassa, na ausência de oxigênio, produzindo biogás (Tambone et al., 2010) e digestato que, dependendo das suas características, pode possuir valor fertilizante. 
O desempenho de um biodigestor é afetado por diversos fatores, entre eles, destaca-se a população microbiana, $\mathrm{pH}$, relação carbono/nitrogênio (relação $\mathrm{C} / \mathrm{N}$ ), temperatura de operação, tempo de retenção hidráulica (TRH), teor de sólidos e modo de alimentação do reator (batelada ou contínuo) (NAIK et al., 2014). Para que a qualidade do digestato produzido possa ser acessada, torna-se necessário à sua caracterização química em diferentes tempos de retenção hidráulica (TRH), permitindo assim analisar seu comportamento ao longo do processo de digestão anaeróbia. Sendo assim, o objetivo deste estudo foi avaliar o efeito da digestão anaeróbia de dejetos bovinos, provenientes do sistema orgânico de produção, nas características químicas do digestato em diferentes TRH.

\section{MATERIAL E MÉTODOS}

O experimento foi conduzido na Universidade Federal Rural do Rio de Janeiro (UFRRJ), Campus Seropédica, nas dependências do Instituto de Agronomia, Departamento de Solos. A coleta do dejeto bovino que abasteceu os biodigestores foi realizada no Setor Experimental de Produção Animal da Fazendinha Agroecológica do km 47, localizada no município de Seropédica (RJ).

Para a realização do experimento foram construídos dezoito protótipos de biodigestores de bancada, sendo o sistema de abastecimento em batelada. A câmara de biodigestão e o gasômetro que constituíam o biodigestor foram inseridos no interior de um recipiente preenchido com água, para servir de suporte para o gasômetro flutuar, proporcionar condições anaeróbias e armazenar o gás produzido. O volume total da câmara de biodigestão foi de 2,35 L e os biodigestores foram abastecidos com dejetos de bovinos sob sistema orgânico de produção. Os tratamentos consistiam de diferentes TRH, a saber: T0 - 0 dias (afluente), T15 - 15 dias, T30 - 30 dias, T45 - 45 dias, T60 - 60 dias, T75 - 75 dias e T90 - 90 dias (efluente).

Após a coleta, para a preparação do substrato, foi realizada a determinação de sólidos totais (ST), com base na metodologia descrita pela Apha (1995). Posteriormente, determinou-se a quantidade de água a ser adicionada à matéria-prima, a fim de se obter uma concentração de $8 \%$ de sólidos totais em todos os dezoito protótipos de biodigestores. Os diferentes tratamentos foram caracterizados por meio das análises de sólidos totais (ST), sólidos voláteis (SV) e pH, conforme as recomendações do Manual de análises químicas de solos, plantas e fertilizantes (SILVA et al., 2009). As análises de metais pesados foram realizadas através da digestão nitro-perclórica, segundo o método SW-846 3051A (USEPA, 2007). A análise dos teores de carbono e nitrogênio foi realizada através do uso de um analisador CHNS, modelo 2400, Perkin Elmer, padrão acetanilida $71,09 \% \mathrm{C}$ e $10,36 \% \mathrm{~N}$.

O delineamento experimental utilizado foi inteiramente casualizado, com três repetições para cada tratamento. Os procedimentos estatísticos foram realizados com o auxílio do programa estatístico "R- Project" versão 3.2.3 (R DEVELOPMENT CORE TEAM, 2014). As análises constaram do teste da normalidade e homocedasticidade. Após a constatação da normalidade e homogeneidade dos dados, estes foram submetidos à analise de variância, aplicando-se o teste Tukey à 5\% de significância.

\section{RESULTADOS E DISCUSSÃO}

Na Tabela 1, destacam-se os valores de $\mathrm{pH}$, umidade (U), sólidos totais (ST), sólidos voláteis (SV) e suas respectivas reduções e relação SV/ST, nos diferentes TRH. Tratando-se do pH, observou-se uma redução ao longo do processo, e um posterior aumento nos tempos de retenção de 75 e 90 dias. Os tratamentos T0, T15, T75 e T90 se estabeleceram dentro da faixa favorável aos microrganismos responsáveis pelo processo de digestão anaeróbia (pH entre 6,4-7,8) (MAO et al., 2015). O aumento do pH no último TRH (T90) pode ser justificado pela transformação dos ácidos orgânicos contidos em produtos gasosos. Além disso, a degradação de proteínas e uréia em meio anaeróbio produz amônia que, em meio aquoso e alcalino, passa para a forma de hidróxido de amônio, acarretando em um aumento dos valores do pH (SILVA et al. 2007; SOARES et al. 2017).

Não foi observada diferença estatística entre os tratamentos para os parâmetros umidade e ST. Com relação aos SV, pode-se constatar o efeito da digestão anaeróbia na sua redução, uma vez que o material de entrada diferiu estatisticamente dos demais. A remoção de SV, que é uma medida da capacidade do sistema de digestão anaeróbica em decompor material orgânico, juntamente com o rendimento de biogás, são parâmetros que podem ser utilizados para avaliar a eficiência do processo de digestão (HARYANTO et al., 2018). Observou-se baixa redução de ST e SV ao final do processo de digestão quando comparados a outros trabalhos (TAMBONE et al., 2009, ORRICO JR et al., 2009). A contínua e lenta degradação anaeróbia do material orgânico e a produção de biogás, ainda presente de forma significante no último TRH (T90), justifica a baixa redução de ST e SV, demonstrando ainda uma possível redução dos sólidos em TRH maiores que 90 dias. De acordo com recomendações da Legislação do CONAMA 375/06 (Brasil, 2006), o material em questão 
deve presentar relação SV/ST inferior à 0,70 para que seja considerável estável. Os resultados demonstram uma relação SV/ST de 0,81 ao final do processo (T90), indicando que o digestato não se apresentava estável, evidenciando assim a necessidade de maiores TRH para degradar a matéria orgânica.

Não foi observada diferença estatística no conteúdo de Ca nos diferentes TRH (Tabela 2). Para o Fe, foi constatado um aumento ao final da digestão anaeróbia, demonstrando que o Fe estava na forma precipitada no início do processo (T0) e, conforme houve uma redução do $\mathrm{pH}$, este elemento foi sendo disponibilizado (Tabela 1). Já para o Mg, torna-se importante destacar o considerável aumento de tal nutriente ao final dos 90 dias, característico do processo de digestão anaeróbia, apresentando diferença estatística entre o começo (T0) e o final da digestão anaeróbia (T90). Segundo Orrico Jr et al. (2009), esse aumento na concentração de nutrientes era esperado em função da redução da fração orgânica, por meio da produção de biogás, acarretando, assim, a concentração dos constituintes inorgânicos.

Observou-se uma ligeira redução no conteúdo de $\mathrm{C}$ com um posterior aumento, onde o conteúdo de $\mathrm{C}$ ao final do processo (T90) não diferiu estatisticamente do material afluente (T0). Para N, foi observado um declínio seguido de um posterior aumento, não apresentando diferença estatística entre T0 e T90. Pode-se observar que a relação $\mathrm{C} / \mathrm{N}$ inicial do processo se encontra próximo à ótima para o crescimento bacteriano (25/1) (LI et al., 2011, PANG et al., 2008), apesar da sua baixa redução ao final do processo. De acordo com Tambone et al. (2009), com a degradação do carbono orgânico total e a concentração de nitrogênio, a proporção carbono e nitrogênio $(\mathrm{C} / \mathrm{N})$ tende a diminuir no decorrer do processo, fato este que é observado no presente estudo, com uma redução de 4,6\% para este parâmetro. A baixa redução da relação $\mathrm{C} / \mathrm{N}$ relaciona-se à baixa degradação de matéria orgânica, demonstrando assim que a digestão anaeróbia do presente sistema ainda apresenta potencial para maior degradação do material afluente, uma vez que a produção de biogás aos 90 dias de TRH ainda se fazia presente.

\section{CONCLUSÃO}

Conclui-se, portanto, que os diferentes TRH interferiram nos valores de $\mathrm{pH}$, nos conteúdos de $\mathrm{SV}$, teores de $\mathrm{Mg}, \mathrm{Fe}, \mathrm{C}$ e $\mathrm{N}$ e relação $\mathrm{C} / \mathrm{N}$. Ao comparar o material de entrada (afluente) com o de saída (efluente), observou-se uma mudança significativa nos teores de $\mathrm{Mg}$, na relação $\mathrm{C} / \mathrm{N}$ e no conteúdo de $\mathrm{SV}$. Ademais, a relação SV/ST apresentou-se acima do recomendado pelo Conama 375/06 para ser considerado como um material estabilizado. Um maior TRH é recomendado para que ocorra a estabilização do material orgânico e recomendação do seu uso como adubo orgânico.

\section{AGRADECIMENTOS}

O presente trabalho foi realizado com apoio da Coordenação de Aperfeiçoamento de Pessoal de Nível Superior - Brasil (CAPES) - Código de Financiamento 001 e do Comitê Guandu e Associação Pró-gestão das Águas da Bacia Hidrográfica do Rio Paraíba do Sul - AGEVAP.

\section{REFERÊNCIAS}

APHA. AMERICAN PUBLIC HEALTH ASSOCIATION. Standard methods for examination of water and wastewater. 21 th ed. Washington: American Water Works Association, 2005, p.1386.

BRASIL. Ministério do Meio Ambiente. Conselho Nacional do Meio Ambiente. Resolução CONAMA no 375. Define critérios e procedimentos para o uso agrícola de lodos de esgoto gerados em estações de tratamento de esgoto sanitário e seus produtos derivados. Diário Oficial da República Federativa do Brasil, Brasília, n. 167, p. 141-146, 30 ago 2006.

HARYANTO, A.; TRIYONO, S.; WICAKSONO, N.H. Effect of hydraulic retention time on biogas production from cow dung in a semi continuous anaerobic digester. International journal of renewable energy development, v. 7, 93. 2018.

HOLM-NIELSEN, J.B.; AL SEADI, T.; OLESKOWICZ-POPIEL, P. The future of anaerobic digestion and biogas utilization. Bioresource Technology, v. 100, p. 5478-5484. 2009.

LI, Y.; PARK, S.Y.; ZHU, J. Solid-state anaerobic digestion for methane production from organic waste. Renewable and sustainable energy reviews, v. 15, p. 821-826. 2011.

MAO, C.; FENG, Y.; WANG, X.; REN, G. Review on research achievements of biogas from anaerobic digestion. Renewable and sustainable energy reviews, v. 45, p. 540-555.

NAIK, L.; GEBREEGZIABHER, Z.; TUMWESIGE, V.; BALANA, B.B.; MWIRIGI, J.; AUSTIN, G. Factors determining the stability and productivity of small scale anaerobic digesters. Biomass and Bioenergy. v. 70, p. 51-57. 2014. 
ORRICO JÚNIOR, M.A.P.; ORRICO, A.C.A.; LUCAS JÚNIOR, J. Biodigestão anaeróbia de dejetos de suínos com e sem separação da fração sólida em diferentes tempos de retenção hidráulica. Revista Engenharia agrícola, p. 474-482, 2009.

PANG, Y.Z.; LIU, Y.P.; LI, XJ, WANG, K.S.; YUAN, H.R. Improving biodegradability and biogas production of corn stover through sodium hydroxide solid state pretreatment. Energy \& fuels. v. 22, n. 4, p. 2761-6. 2008.

R DEVELOPMENT CORE TEAM. R: a language and environment for statistical computing. Version 3.1.0. Vienna: $\mathrm{R}$ foundation for statistical computing. 2014.

SILVA, F.C. Manual de análises químicas de solos, plantas e fertilizantes. $2^{\mathrm{a}}$ ed, Embrapa Informação Tecnológica, Brasília, 2009.

SILVA, W.T.L.; FAUSTINO, A.S.; NOVAES, A.P. Eficiência do processo de biodigestão em fossa séptica biodigestora inoculada com esterco de ovino. Documentos Embrapa Instrumentação Agropecuária, v. 34, n.1. 2007.

SOARES, M.T.S.; CALHEIROS, D.F.F.; GALVANI, F.; FEIDEN, A.; CAMPOLIN, A.I.; DA SILVA, W.T.L. Parâmetros físico-químicos e eficiência de fossa séptica biodigestora na redução da carga orgânica de esgoto originado de água doce ou salobra, na borda oeste do pantanal. Cadernos de agroecologia, v. 11. 2017. TAMBONE, F.; GENEVINI, P.L.; D'IMPORZANO, G.; ADANI, F. Assessing amendment properties of digestate by studying the organic matter composition and the degree of biological stability during the anaerobic digestion of the organic fraction of msw. Bioresource Technology. v.100, p. 3140-3142. 2009.

TAMBONE, F.; SCAGLIA, B.; D'IMPORZANO, G.; SCHIEVANO, A.; ORZI, V.; SALATI, S.; ADANI, F. Assessing amendment and fertilizing properties of digestate fromanaerobic digestion through a comparative study with digested sludge and compost. Chemosphere. v. 81, p. 577-583. 2010.

USEPA - United States Environmental Protection Agency. Microwave assisted acid digestion of sediments sludge, soils, and oils. EPA SW 846 3051a. 30p, 2007. Disponível em: http://www.epa.gov/epawaste/hazard/testmethods/sw846/pdfs/3051a.pdf. Acesso em: 3 set. 2018.

Tabela 1. Médias de cada parâmetro físico e químico avaliado nos diferentes tempos de retenção hidráulica (TRH).

\begin{tabular}{cccccccc}
\hline TRH (dias) & $\mathbf{p H}$ & $\mathbf{U}(\%)$ & $\mathbf{S T}(\%)$ & $\begin{array}{c}\text { Redução } \\
\text { ST }\end{array}$ & $\mathbf{S V}(\%)$ & $\begin{array}{c}\text { Redução } \\
\text { SV }\end{array}$ & $\begin{array}{c}\text { Relação } \\
\text { SV/ST }\end{array}$ \\
\hline T0 & $7,8 \mathrm{a}$ & $92,68 \mathrm{a}$ & $7,21 \mathrm{a}$ & & $6,43 \mathrm{a}$ & & 0,89 \\
T15 & $6,49 \mathrm{bc}$ & $92,66 \mathrm{a}$ & $7,14 \mathrm{a}$ & & $5,83 \mathrm{~b}$ & & 0,81 \\
T30 & $6,31 \mathrm{bc}$ & $92,57 \mathrm{a}$ & $7,26 \mathrm{a}$ & $2,22 \%$ & $5,91 \mathrm{~b}$ & $10,74 \%$ & 0,81 \\
T45 & $6,26 \mathrm{c}$ & $92,62 \mathrm{a}$ & $7,20 \mathrm{a}$ & & $5,88 \mathrm{~b}$ & & 0,81 \\
T60 & $6,01 \mathrm{c}$ & $92,75 \mathrm{a}$ & $7,07 \mathrm{a}$ & & $5,75 \mathrm{~b}$ & & 0,81 \\
T75 & $6,67 \mathrm{bc}$ & $92,71 \mathrm{a}$ & $7,25 \mathrm{a}$ & & $5,94 \mathrm{~b}$ & & 0,81 \\
T90 & $7,17 \mathrm{ab}$ & $92,74 \mathrm{a}$ & $7,05 \mathrm{a}$ & $5,74 \mathrm{~b}$ & & 0,81 \\
\hline *Médias seguidas pelas mesmas letras minúsculas na coluna, não apresentam diferenca significativa pelo teste de Tukey (p<0.05)
\end{tabular}

Tabela 2. Médias de cada parâmetro químico avaliado nos diferentes tempos de retenção hidráulica (TRH).

\begin{tabular}{|c|c|c|c|c|c|c|}
\hline TRH (dias) & Ca total & Mg total & Fe total & C total & $\mathbf{N}$ total & $\mathbf{C} / \mathbf{N}$ \\
\hline & & - & & & \multicolumn{2}{|c|}{------(\%)------ } \\
\hline T0 & $12.352,92 \mathrm{a}$ & $11.686,60 \mathrm{c}$ & $359,34 \mathrm{~b}$ & $36,16 a b$ & $1,37 \mathrm{ab}$ & $26,41 \mathrm{a}$ \\
\hline $\mathrm{T} 15$ & $12.149,83 \mathrm{a}$ & $12.922,92 \mathrm{c}$ & $405,67 a b$ & $36,62 \mathrm{ab}$ & $1,36 \mathrm{~b}$ & $27,05 \mathrm{ab}$ \\
\hline T30 & $11.045,76 \mathrm{a}$ & $13.599,36 \mathrm{bc}$ & $429,45 \mathrm{ab}$ & $35,54 \mathrm{ab}$ & $1,20 \mathrm{c}$ & $29,71 \mathrm{ab}$ \\
\hline $\mathrm{T} 45$ & $12.850,54 \mathrm{a}$ & $16.985,11 \mathrm{a}$ & $382,01 \mathrm{ab}$ & $34,74 \mathrm{~b}$ & $1,50 \mathrm{ab}$ & $23,23 \mathrm{ab}$ \\
\hline T60 & $10.697,41 \mathrm{a}$ & $16.315,65 \mathrm{ab}$ & $632,20 \mathrm{a}$ & $37,56 \mathrm{a}$ & $1,38 \mathrm{ab}$ & $27,22 \mathrm{ab}$ \\
\hline $\mathrm{T} 75$ & $11.532,2 \mathrm{a}$ & $16.373,71 \mathrm{ab}$ & $574,49 \mathrm{ab}$ & $38,20 \mathrm{a}$ & $1,43 a b$ & $26,53 \mathrm{~b}$ \\
\hline T90 & $14.434,13 \mathrm{a}$ & $19.033,04 \mathrm{a}$ & $545,40 \mathrm{ab}$ & $36,74 \mathrm{ab}$ & $1,52 \mathrm{a}$ & $24,09 \mathrm{~b}$ \\
\hline
\end{tabular}

*Médias seguidas pelas mesmas letras minúsculas na coluna, não apresentam diferença significativa pelo teste de Tukey ( $\mathrm{p} \leq 0.05)$. 


\title{
COMPOSTAGEM DE RESÍDUOS DA CADEIA AVÍCOLA: CONFORMIDADE COM PARÂMETROS DA IN No 25/2009/MAPA
}

\author{
Santos, F.T. ${ }^{1}$; Aloisio, C.M. ${ }^{1}$; Fehmberger, C. ${ }^{1}$; Zenatti, D.C. ${ }^{1}$; Hermes, E. ${ }^{1}$; Bautitz, I.R.*1 \\ ${ }^{1}$ Programa de Pós-graduação em Tecnologias de Bioprodutos Agroindustriais, Universidade Federal do Paraná (UFPR), Palotina, \\ $P R-$ Brasil \\ ivonete.rossi@ufpr.br
}

\begin{abstract}
RESUMO: No Brasil, a Instrução Normativa (IN) no 25 de 23 de julho de 2009, do Ministério da Agricultura, Pecuária e Abastecimento - MAPA, aprova as normas sobre as especificações e as garantias, as tolerâncias, o registro, a embalagem e a rotulagem dos fertilizantes orgânicos simples, mistos, compostos, organominerais e biofertilizantes destinados à agricultura. O objetivo deste trabalho foi submeter à compostagem resíduos gerados ao longo da cadeia produtiva de aves com a glicerina bruta (GB) em diferentes concentrações associada ao biocarvão para avaliar o atendimento dos compostos orgânicos obtidos a alguns parâmetros da IN $n^{\circ}$ 25/2009. As concentrações de GB em relação a massa seca dos resíduos foram de 0,$0 ; 1,5 ; 3,0 ; 4,5$ e $6,0 \%$ (totalizando cinco tratamentos). O experimento foi conduzido em composteiras construídas utilizandose paletes, com 4 repetições para cada tratamento. Adotaram-se como parâmetros de monitoramento, temperatura, umidade e revolvimentos semanais em todo o processo de compostagem. Após a compostagem os compostos orgânicos foram peneirados e caracterizados como substratos orgânicos. Os resultados para os tratamentos com 0,$0 ; 1,5 ; 3,0 ; 4,5$ e 6,0\% de GB para umidade foram de 48,30; 45,60; 48,70; 47,60 e 49,50\%, para nitrogênio foram de 2,92; 2,91; 3,16; 2,95 e 3,11\%, para COT foram de 35,60;34,90; 39,00; 37,80 e $38,40 \%$, para pH foram de 7,53; 7,74; 7,55; 7,61 e 7,30 e relação C:N foram de 12,$21 ; 12,11 ; 12,36 ; 12,93$ e 12,40. Os compostos orgânicos provenientes de resíduos orgânicos da cadeia de aves associados a GB atendem aos parâmetros avaliados estabelecidos na $\mathrm{IN} \mathrm{n}^{\circ} 25 / 2009$.
\end{abstract}

Palavras-chave: resíduos orgânicos, substratos alternativos, glicerina bruta.

\section{COMPOSTING OF BROILER PRODUCTION CHAIN WASTES: COMPLIANCE WITH PARAMETERS OF NI N 25/2009/MAPA}

\begin{abstract}
In Brazil, Normative Instruction (NI) No. 25 of July 23, 2009, of the Ministry of Agriculture, Livestock and Food Supply - MAPA, approves the norms on specifications and guarantees, tolerances, registration, packaging and labeling of organic fertilizers, mixed, compound, organomineral and biofertilizers for agriculture. The objective of this work was to submit to the composting residues generated along the productive chain of birds with the crude glycerin (CG) in different concentrations associated to the biochar to evaluate the attendance of the obtained organic substrates to some parameters of the IN $n^{\circ} 25 / 2009$. The concentrations of $\mathrm{CG}$ in relation to the dry mass of the residues were $0.0 ; 1.5 ; 3.0 ; 4.5$ and $6.0 \%$ (totaling five treatments). The experiment was conducted in composites constructed using pallets, with 4 replicates for each treatment. They were adopted as monitoring parameters, temperature, humidity and weekly revolves throughout the composting process. After composting the organic compounds were sieved and characterized as organic substrates. The results for treatments with $0.0 ; 1.5 ; 3.0 ; 4.5$ and $6.0 \% \mathrm{CG}$ for moisture were 48.30; $45.60 ; 48.70 ; 47.60$ and $49.50 \%$, for nitrogen were $2.92 ; 2.91 ; 3.16 ; 2.95$ and $3.11 \%$, for TOC were 35.60 ; $34.90 ; 39.00 ; 37.80$ and $38.40 \%$, for $\mathrm{pH}$ were $7.53 ; 7.74 ; 7.55 ; 7.61$ e 7.30 and $\mathrm{C}: \mathrm{N}$ were $12.21 ; 12.11 ; 12.36$; 12.93 and 12.40 . The organic compounds from organic waste from the bird chain associated to GB meet the parameters evaluated established in IN n 25 / 2009.
\end{abstract}

Keywords: organic residues, alternative substrates, crude glycerin.

\section{INTRODUÇÃO}

A região sul do Brasil destaca-se em número e desenvolvimento de agroindustriais, tendo a cadeia produtiva da avicultura de corte grande representatividade na região oeste do estado do Paraná. Essa cadeia é marcada por constantes evoluções técnicas em termos de genética, nutrição e ambiência. Essas evoluções permitiram um adensamento constante que aliada as estreitas colaborações entre seus integrantes resultou na 
conquista do mercado interno e externo gradativamente, suplantando concorrentes na oferta de proteína animal, superando assim os principais fornecedores avícolas mundiais (De Avila et al., 2007; FAO, 2017).

Com a exponencial produção de aves de corte há grande geração de resíduos orgânicos produzidos ao longo da cadeia. Os resíduos orgânicos agroindústrias possuem elevada quantidade de nitrogênio, por se tratar de material de origem animal. Sendo assim, para que o processo de compostagem ocorra de forma mais eficiente, fontes de carbono precisam ser acrescentadas à composição da massa a ser compostada para balancear a relação carbono/nitrogênio $(\mathrm{C}: \mathrm{N})$. Dessa forma, promove-se a estabilização dos resíduos em tempo satisfatório e com o mínimo de perdas de nutrientes, principalmente o nitrogênio, altamente volátil durante a fase termofílica do processo (Valente et al., 2009).

A preferência por uma fonte de carbono tem por princípio, especialmente em um segmento econômico, a prontidão na obtenção e a proximidade desta ao local de tratamento. Esta escolha, entretanto, pode não ser a ideal no que se refere à eficiência do processo. Relatos da literatura apontam para a importância da qualidade do carbono presente na fonte, se degradável ou recalcitrante (Li et al., 2013; Khan et al., 2014). A glicerina bruta (GB), coproduto gerado ao fim do processo de produção do biodiesel, necessita de tratamento e destino econômico e ambientalmente adequados. Esse coproduto pode conter até $83 \%$ de carbono (glicerol) em sua composição dessa forma, pode ser utilizada como fonte de carbono para o ajuste na relação C:N no processo de compostagem (Çelik et al., 2008).

Considerando os danos gerados pelos resíduos ao meio ambiente em 2010 foi aprovado a Política Nacional de Resíduos Sólidos (Lei $\mathrm{n}^{\circ}$ 12.305/2010) que dispõe sobre o aumento da quantidade de resíduos gerados, bem como manejo e tratamento adequados além da recomendação de agregação valor econômico aos resíduos. Além disso, a Instrução Normativa (IN) n ${ }^{\circ} 25$ de 23 de julho de 2009 aprova as normas sobre especificações e garantias, registro, embalagem e rotulagem dos fertilizantes orgânicos e biofertilizantes destinados à agricultura. No Anexo I, Capítulo II ocorre à classificação de acordo com a matéria-prima utilizada: I - Classe "A": fertilizante orgânico que, em sua produção, utiliza matéria prima de origem vegetal, animal ou de processamentos da agroindústria, onde não sejam utilizados, no processo, metais pesados tóxicos, elementos ou compostos orgânicos sintéticos potencialmente tóxicos, resultando em produto de utilização segura na agricultura (Brasil, 2009).

Diante do exposto, o objetivo do presente estudo foi submeter à compostagem resíduos gerados ao longo da cadeia produtiva de aves com a glicerina bruta associada em diferentes proporções ao biocarvão para avaliar o atendimento dos substratos orgânicos obtidos a alguns parâmetros da IN nº 25/2009

\section{MATERIAL E MÉTODOS}

O experimento foi conduzido na Universidade Federal do Paraná (UFPR-Setor Palotina). O processo de compostagem dos resíduos orgânicos agroindustriais foi conduzido em composteiras construídas com palletes. Construiu-se 4 divisórias dentro de cada composteira, de modo que cada uma possui-se 4 repetições de cada tratamento, revestidas com tela permeável, denominadas de células de compostagem. As composteiras foram confeccionadas manualmente e dispostas sobre lona para impermeabilização do pátio o qual apresentava cobertura para proteção da incidência solar direta e das chuvas.

Utilizou-se no processo de compostagem diferentes resíduos como fontes de carbono, tais como poda de árvores urbanas, bagaço de cana e glicerina bruta. A glicerina bruta foi adquirida de uma usina de biodiesel da região. A poda de árvore foi cedida pela prefeitura municipal, o bagaço de cana foi adquirido em uma garapeira da região e carvão remanescente da queima em caldeiras de frigorífico.

Os resíduos orgânicos agroindustriais configuram-se como as fontes de nitrogênio necessárias ao processo de compostagem. Os resíduos utilizados foram o resíduo de incubatório, a cama de frango, o lodo de flotador. Os resíduos utilizados neste experimento foram fornecidos por uma cooperativa de abate de aves e produtores de engorda de frango da região.

Os tratamentos foram constituídos de diferentes proporções dos resíduos orgânicos, bem como de glicerina bruta na massa natural do material compostado $(0,1,5 ; 3,0 ; 4,5$ e $6 \%)$ denominados de T0,0; T1,5; T3,0; T4,5 e T6,0\%. As misturas foram definidas em função da composição de carbono e nitrogênio dos resíduos, fixando a relação C:N de aproximadamente $26 / 1$ para todos os tratamentos.

A temperatura da leira foi monitorada a cada 3 dias, com auxílio de termômetro digital, a uma profundidade de aproximadamente $30 \mathrm{~cm}$. Por ocasião das medidas de temperatura das leiras, a temperatura ambiente foi monitorada, pois quando a temperatura do interior das leiras estava semelhante a temperatura ambiente, considerou-se o final do processo de compostagem. A umidade das leiras foi controlada 
semanalmente após cada revolvimento e ajustada com adição da quantidade de água necessária, para se obter aproximadamente $60 \%$ de umidade.

Ao final do processo de compostagem avaliou-se os parâmetros: umidade, nitrogênio total, carbono total, pH e relação $\mathrm{C}: \mathrm{N}$. Dessa forma, para o cálculo da umidade as amostras foram secas em estufa com circulação forçada de ar a $105{ }^{\circ} \mathrm{C}$ até peso constante. Os teores de nitrogênio total Kjeldahl (NTK) foram determinados com o uso do Destilador de Kjeldahl, segundo metodologia proposta por Malavolta et al., (1997). Para a digestão utilizou-se o bloco digestor, que promove a digestão total da matéria orgânica à base de ácido sulfúrico $\left(\mathrm{H}_{2} \mathrm{SO}_{4}\right)$. Para a determinação do teor de Carbono Orgânico Total (COT), os materiais secos obtidos após a determinação do teor de sólidos totais, foram levados à mufla em cadinhos de porcelana, devidamente pesados e mantidos a uma temperatura de $550{ }^{\circ} \mathrm{C}$ durante um período de $4 \mathrm{~h}$. Após resfriamento em dessecadores, os materiais foram pesados em balança com precisão de 0,0001 g, obtendo-se por gravimetria o conteúdo de COT, conforme metodologia de Cunha-Queda et al., (2003). O pH foi determinado na solução, preparada a partir da amostra em suspensão com água destilada na proporção de 1:5 (m/v) (Brasil, 2007).

Inicialmente foram verificadas as pressuposições do modelo, posteriormente havendo influência de algum tratamento na variável resposta utilizou-se o teste de Tukey $(\mathrm{p}<0,05)$ para comparação das médias. Os dados foram analisados utilizando o software estatístico STATISTIC 8.0.

\section{RESULTADOS E DISCUSSÃO}

De acordo com Revoredo et al., (2008) dentre as características de um substrato, podem-se citar propriedades químicas conhecidas e constantes. Assim o substrato deve ser um meio rico em nutrientes, não salino, não conter substâncias tóxicas, ser inodoro, não ser muito alcalino, nem muito ácido (valores de pH próximo da neutralidade), deve ser uniforme em toda a extensão, de fácil manuseio, ser facilmente disponível e de baixo custo.

No processo de compostagem avaliado à medida que o tempo do tratamento se prolongou, as perdas de carbono e nitrogênio aumentaram, pois enquanto os microrganismos consomem carbono como fonte de energia, o nitrogênio é usado na reprodução celular (BernaL et al., 2009). As reduções de carbono ao longo do processo de compostagem não apresentaram diferenças estatísticas entre os tratamentos (Tabela 1) e todos os substratos alternativos apresentam-se dentro do estipulado pela IN No 25/2009 que dispõe valor de no mínimo $15 \%$ de COT em substratos.

As perdas de nitrogênio não são desejadas devido à redução do valor agronômico do composto final. A perda de $\mathrm{N}$ está relacionada à volatilização da amônia, consequência do $\mathrm{pH}$ alcalino no início do processo e temperaturas elevadas (Bernal et al., 2009; Gavilanes-Terán et al., 2017). Neste estudo, observou-se que não houve diferença estatística entre os tratamentos no parâmetro teor de nitrogênio, o qual variou de 2,91 no T1,5 a 3,16\% noT3,0 (Tabela 1). A IN N 25/2009 estabelece que o teor mínimo de $\mathrm{N}$ nos substratos deve ser $0,5 \%$, sendo assim, todos os tratamentos apresentam-se dentro do recomendado.

$\mathrm{O}$ pH apresentou-se diferente estatisticamente entre os tratamentos (Tabela 1), no entanto obedece a IN No25/2009. O pH interfere diretamente na qualidade do composto orgânico quando utilizado na produção de mudas. Segundo Revoredo et al., (2008) a baixa solubilidade do ferro em um valor de $\mathrm{pH}$ maior que 6,5 e a elevada solubilidade do manganês em valor de $\mathrm{pH}$ abaixo de 5,5 são os maiores problemas. Além da possibilidade de ocorrer fitotoxicidade por excesso de manganês solúvel em valores de $\mathrm{pH}$ abaixo de 5,5, aumenta também o risco de toxidez de ferro, zinco e cobre do substrato.

A relação C:N que inicialmente encontrava-se em 26:1 reduziu para aproximadamente 12:1 ao fim do processo de compostagem em todos os tratamentos (Tabela 1), corroborando com Kiehl (2010) que afirma que o composto estabilizado deve apresentar uma relação C:N entre os valores de 8:1 e 12:1 atendendo assim as exigências prevista na Portaria No 25/2009 do Ministério de Agricultura, Pecuária e Abastecimento (MAPA) para comercialização de fertilizantes orgânicos que é de no máximo 20:1.

\section{CONCLUSÃO}

Os resultados da composição química do composto orgânico final nos diferentes tratamentos demonstraram de forma clara que a qualidade do composto produzido, alcançou, para os parâmetros monitorados, os requisitos mínimos exigidos pela legislação brasileira, mostrando-se eficiente para o tratamento de resíduos agroindustriais bem como para a geração de substratos orgânicos. 


\section{AGRADECIMENTOS}

O presente trabalho foi realizado com apoio da Coordenação de Aperfeiçoamento de Pessoal de Nível Superior - BRASIL (CAPES) - código de financiamento 001.

\section{REFERÊNCIAS}

BERNAL, M.P; ALBURQUERQUE, J.A; MORAL, R. Composting of animal manures and chemical criteria for compost maturity assessment. A review. Bioresource Tecnology, v. 100, p. 5444-5453, 2009.

BRASIL. Ministério da Agricultura, Pecuária e Abastecimento - MAPA. Secretaria de Defesa Agropecuária. Instrução Normativa $N^{\circ}$ 17, de 21 de maio de 2007. Aprova os Métodos Analíticos Oficiais para Análise de Substratos e Condicionadores de Solos, na forma do Anexo à presente Instrução Normativa. Diário Oficial da República Federativa do Brasil, Brasília, DF, 24 maio 2007. Seção 1, p. 8.

BRASIL, 2009 - Ministério da Agricultura, Pecuária e Abastecimento - MAPA. Instrução Normativa $\mathbf{N}^{\circ} \mathbf{2 5}$, de 23 de julho de 2009, Brasília, 2009.

BRASIL, 2010. Política Nacional de Resíduos Sólidos, Lei 12.305. Diário Oficial da República Federativa do Brasil, Brasília, DF, 2 ago. 2010.

ÇELIK, I. B. GHIA, U.; ROACHE, P.J.; FREITAS, C.J.; COLEMAN, H.; RAAD, P.E.Procedure for Estimation and Reporting of Uncertainty Due to Discretization in CFD Applications. Jornal de fluidos \{Engenharia-Transações\} da \{ASME\}, v. 130, n. 7 de 2008.

CUNHA-QUEDA, A.C.F., VALLINI, G., BRUNO DE SOUSA, R.F.X., ALMEIDA DUARTE, E. C. N. F. Estudo da evolução de actividades enzimáticas durante a compostagem de resíduos provenientes de mercados horto-frutícolas. Anais do Instituto Superior de Agronomia, p.193-208, 2003.

DE AVILA, V. S. ABREU, V. M. N.; FIGUEIREDO, E. A. P. de; BRUM, P. A. R. de; OLIVEIRA, U. de. Valor agronômico da cama de frangos após reutilização por vários lotes consecutivos. Embrapa Suínos e Aves-Comunicado Técnico (INFOTECA-E), 2007.

KHAN, N; CLARK, I; SANCHEZ-MONEDERO, M. A; SHEA, S; MEIER, S; BOLAM, N. Maturity índices in co-composting of chicken manure and sawdust with biochar. Bioresource Technology, v. 168, p 245-251, 2014.

FAO. Organização das Nações Unidas para a Alimentação e Agricultura. Anuário estatístico. Disponível em: < http://www.fao.org/brasil/pt/>. Acesso em: 01 novembro 2017.

GAVILANES-TERÁN, I. et al. Composto agroindustrial como alternativa de turfa na indústria hortícola do Equador. Revista de Gestão Ambiental, V186, p. 79-87, jan 2017.

LI, Y; LI, W; LIU, B. WANG, K; SU, C; WU, C. Ammonia emissions and biodegradation of organic carbon during sewage sludge composting with different extra carbon sources. International Biodeterioration \& Biodegradation, v. 85, p. 624-630, 2013.

MALAVOLTA, E.; VITTI, G.C.; OLIVEIRA, S.A. Avaliação do estado nutricional das plantas. 2.ed. Piracicaba: Potafos, 1997. 319p.

REVOREDO, M.D.; ARAÚJO, J.P.C.; CORTEZ, G.E.P.; DARLI, A.B. Uso de substratos para o cultivo de hortaliças. Jaboticabal: FUNESP, 55p. 2008.

VALENTE, B.S.; XAVIER, E.G.; MORSELLI, T.B.G.A.; JAHNKE, D.S., BRUM Jr, B.S.; CABRERA, B.R.; MORAES, P. O.; LOPES, D.C.N. Fatores que afetam o desenvolvimento da compostagem de resíduos orgânicos. Archivos de Zootecnia, v. 58, p. 59-85, 2009.

Tabela 1. Parâmetros de controle de compostos orgânicos IN 25/2009 MAPA.

\begin{tabular}{lcccccc}
\hline Parâmetro & Limite Mapa & T0,0 & T1,5 & T3,0 & T4,5 & T6,0 \\
\hline Umidade máxima $^{\mathrm{A}}$ & $50,0^{*}$ & $48,30 \mathrm{a}$ & $45,60 \mathrm{a}$ & $48,70 \mathrm{a}$ & $47,60 \mathrm{a}$ & $49,50 \mathrm{a}$ \\
NTK mínimo $^{\mathrm{A}}$ & $0,5^{*}$ & $2,92 \mathrm{a}$ & $2,91 \mathrm{a}$ & $3,16 \mathrm{a}$ & $2,95 \mathrm{a}$ & $3,11 \mathrm{a}$ \\
COT mínimo $^{\mathrm{A}}$ & $15,0^{*}$ & $35,60 \mathrm{a}$ & $34,90 \mathrm{a}$ & $39,00 \mathrm{a}$ & $37,80 \mathrm{a}$ & $38,40 \mathrm{a}$ \\
pH mínimo & $6,0^{*}$ & $7,53 \mathrm{ab}$ & $7,74 \mathrm{a}$ & $7,55 \mathrm{ab}$ & $7,61 \mathrm{a}$ & $7,30 \mathrm{~b}$ \\
Relação C:N máxima & $20,0^{*}$ & $12,21 \mathrm{a}$ & $12,11 \mathrm{a}$ & $12,36 \mathrm{a}$ & $12,93 \mathrm{a}$ & $12,40 \mathrm{a}$ \\
\hline
\end{tabular}

${ }^{\mathrm{A}}$ Valores expressos em \%; * IN No 25/2009.

Médias seguidas pelas mesmas letras não apresentam diferença significativa entre elas $p \leq 0.05$, nas linhas. 


\title{
CORRELAÇÕES ENTRE PARÂMETROS DA CO-DIGESTÃO ANAERÓBIA DE GLICERINAS COM DEJETO DE GALINHAS POEDEIRAS
}

\author{
Schwingel, A.W. ${ }^{* 1}$; Orrico, A.C.A. ${ }^{1}$; Leite, B.V. ${ }^{1}$; Macena, I.A. ${ }^{1}$; Dias, A.M.D.F. ${ }^{1}$; Machado, J.F. ${ }^{1}$ \\ ${ }^{1}$ Universidade Federal da Grande Dourados, Dourados, MS - Brasil. \\ alicewatte16@gmail.com
}

RESUMO: O biodiesel surgiu como uma opção promissora de combustível renovável para minimizar os impactos causados pelos combustíveis fósseis, porém seu processo de produção gera quantidades elevadas do resíduo glicerina bruta, considerado de baixa qualidade comercial por possuir baixo teor de glicerol. Para agregar valor a este subproduto algumas usinas fazem o processo de purificação para retirada de impurezas, no entanto, com o objetivo de reduzir custos com esta purificação muitas pesquisas são realizadas buscando processos de tratamento que utilize a glicerina com menor nível de pureza, como é o caso da co-digestão anaeróbia junto com outro resíduo de composição complementar, visando equilibrar o meio em digestão e aumentar o rendimento energético. Por isso, esta pesquisa foi realizada com o objetivo de avaliar as correlações entre os parâmetros avaliados para compreender qual a influência do conteúdo de glicerol em glicerinas com três diferentes purezas [40\% (G40), 60\% (G60) e 80\% (G80)] e, ainda, incluí-las ao processo em níveis diferentes de glicerol nos sólidos totais (ST) dos afluentes preparados com excretas de galinha poedeira. Com a inclusão da G40 houve alta correlação entre reduções de DQO e sólidos (ST: 0,83 e SV: 0,8), assim como maiores de 0,65 com o uso da G60. Houve maior influência da composição dos afluentes sobre os resultados de produção de metano por SV, pois foi possível observar maior correlação positiva com reduções de VS e COD, variando 0,27 e 0,55. As correlações confirmaram que a inclusão das três glicerinas influencia positivamente a co-digestão anaeróbia.

Palavras-chave: Digestão batelada, nível de pureza de glicerina, residuo de biodiesel

\section{CORRELATIONS BETWEEN PARAMETERS OF THE CO-DIGESTION ANAEROBIA OF GLYCERINS WITH LAYING HEN MANURE}

\begin{abstract}
Biodiesel has arisen as a promising option of renewable fuel to minimize the impacts caused by fossil fuels. However, its production process generates high amounts of crude glycerin as a residue, which is considered low-quality commercially due to its low glycerol content. In order to add value to this byproduct, some production plants employ a purification process. Nonetheless, aiming to cut down costs with this purification step, many researches have been seeking treatments that use glycerin with lower purity, such as anaerobic co-digestion with another residue of complementary composition so as to balance the digestion medium and increase energy yield. This research was carried out to evaluate the correlations between the evaluated parameters to assess the influence of glycerol content in glycerin containing the same impurities at three proportions (40\% (G40), 60\% (G60), and 80\% (G80)), and to add them to the process at different glycerol levels in the total solids (TS) of the affluents prepared with laying hen manure. With the inclusion of G40, there was a high correlation between COD and solid reductions (ST: 0.83 and SV: 0.8), as well as greater than 0.65 with G60. There was a greater influence of the composition of the tributaries on the results of methane production by SV, since it was possible to observe a higher positive correlation with VS and COD reductions, varying from 0.27 to 0.55 . Correlations confirmed that the inclusion of the three glycerins positively influences anaerobic co-digestion.
\end{abstract}

Keywords: Batch digestion, biodiesel waste, glycerin purity level.

\section{INTRODUÇÃO}

A produção mundial de biodiesel aumentou consideravelmente nos últimos anos, alcançando 30,1 bilhões de litros em 2015, dos quais o Brasil, como segundo maior produtor, participou com 13\% do montante (REN21, 2016), comprovando o destaque do Brasil no uso de fontes de energia renováveis. No entanto, o método de extração do biodiesel e a matéria prima utilizada, bem como a política de filtração ou purificação 
parcial da glicerina bruta, de cada usina, são fatores que interferem nas características do biodiesel e do resíduo glicerina, que é gerado em elevadas quantidades, o que ocasiona em uma oferta de altos volumes de resíduos com composição variável e difícil padronização.

A glicerina possui mais de 2000 aplicações comerciais, mas para a maioria delas é necessário alto grau de pureza, obtido por meio de processos de purificação custosos (Siles et al., 2009). Porém, na co-digestão anaeróbia pode-se aproveitar a glicerina na sua forma mais bruta, visando a redução de processos, de recursos financeiros e ambientais. $\mathrm{O}$ uso da glicerina na co-digestão anaeróbia com dejetos de animais promove uma destinação sustentável, com a degradação dos resíduos e produção de fertilizante orgânico, além da antecipação das produções de biogás e metano para obtenção de energia limpa.

Diante do exposto, a pesquisa teve como objetivo verificar as correlações entre os parâmetros avaliados durante co-digestão anaeróbia de glicerinas, preparadas com três distintos teores de glicerol, com excretas de aves de postura.

\section{MATERIAL E MÉTODOS}

Para a execução do ensaio foi utilizado delineamento inteiramente casualizado em esquema fatorial duplo, sendo constituído pelos fatores: pureza da glicerina (contendo 40, 60 e $80 \%$ de glicerol em sua composição) e teores de glicerol (0, 1, 2, 3 e 4\% em relação aos ST adicionados aos biodigestores). Cada tratamento contou com 4 repetições (biodigestores), sendo, portanto, utilizados 60 reatores.

Além dos dejetos e glicerinas, foi utilizado inóculo previamente preparado com dejetos de galinhas de postura e de bovinos, sendo considerado pronto após 90 dias de biodigestão. O inóculo possuía no momento do abastecimento: $7,1 \%$ de ST, dos quais $67,4 \%$ eram sólidos voláteis (SV) e uma demanda química de oxigênio (DQO), de 326,3 g de O2 por L.

Os dejetos de galinhas de postura foram coletados por raspagem do piso inferior às gaiolas de criação de sistema convencional, onde acumula-se restos de ração e penas junto às excretas produzidas em 24 horas. Após a coleta, os dejetos foram homogeneizados e analisados, contendo em sua composição: 40,1\% de ST, sendo $77,5 \% \mathrm{SV}$, e DQO igual a $451,9 \mathrm{~g} \mathrm{O}_{2}$ por $\mathrm{kg}$ de dejeto.

A glicerina bruta possuía 96,0\% de ST, 14,2\% de glicerol, 6,1\% de metanol, 74,7\% de lipídeos, e demanda química de oxigênio (DQO) igual a 1532 g de O2 L-1 de glicerina. Para obtenção das distintas purezas foram calculadas as necessidades de inclusão de glicerina pura (contendo 99,5\% de glicerol) junto à bruta, por meio de equações algébricas. Portanto, em 100 gramas de G40: 69,75g fora de glicerina bruta e $30,25 \mathrm{~g}$ de glicerina pura. Da mesma forma foram calculadas as proporções das glicerinas para obtenção dos teores de $60 \%$ (G60) e $80 \%$ (G80) de glicerol.

Os afluentes foram preparados para que todos os tratamentos estivessem com teor de ST de 4\%, sendo homogeneizados em liquidificador e adicionados aos biodigestores batelada simultaneamente. Os biodigestores permaneceram 105 dias em fermentação, em condições de temperatura ambiente, abrigados de luz solar e chuva durante todo o período experimental.

Os biodigestores batelada de bancada usados seguiram o modelo utilizado por Sunada et al. (2014). As produções específicas de biogás e metano foram calculadas considerando-se os volumes (L) produzidos e as quantidades $(\mathrm{kg})$ de ST, SV e DQO adicionados e reduzidos.

As análises de ST, SV, DQO e potencial hidrogeniônico $(\mathrm{pH})$ foram realizadas no início e final do processo (afluente e efluente) segundo metodologia descrita pela APHA (2012), o carbono foi determinado segundo Kiehl (1985) e o nitrogênio total kjedahl (TKN) foi obtido de acordo com Silva e Queiroz (2006). As reduções dos constituintes foram calculadas por diferença entre os valores de entrada e saída dos biodigestores.

Os resultados gerados no ensaio de co-digestão anaeróbia aqui apresentados foram submetidos à análise de correlação, sendo as análises realizadas pelo software R (versão 3.1.0 for Windows).

\section{RESULTADOS E DISCUSSÃO}

A alta correlação entre as variáveis de produções específicas de biogás e metano por ST, SV e DQO, apresentadas na Figura 1, demonstram o efeito positivo da composição do afluente, sobretudo da G40 (Figura1B), sobre os resultados de geração de energia na forma de biogás, evidenciando a importância da 
inclusão de constituintes de maior degradação, presentes na glicerina bruta, ao processo de co-digestão para resultados que valorizam o biogás gerado.

A redução de DQO foi negativamente influenciada pela redução de ST (-0.89) e SV (-0.84) somente na condição experimental sem o uso de glicerina (Figura 1A), já com a inclusão da G40 (Figura 1B) houve alta correlação positiva entre as reduções de DQO e sólidos (0.83 para TSR e 0.8 para VSR), assim como ocorreu com o uso da G60 (TSR: 0.67 VSR: 0.66), mas esta correlação diminuiu consideravelmente ao incluir a glicerina contendo $80 \%$ de glicerol em sua composição, apresentando os valores de 0.06 em relação a TSR e 0.2 entre COD e VSR. Estas correlações entre as reduções dos constituintes demonstram o efeito positivo da inclusão da glicerina em alterar a composição dos afluentes, pois, todos os afluentes continham TS entre 39 e 40 g.kg-1, mas a DQO nos afluentes passou de 579 no tratamento controle para 583 (G40 e G80) e 584 g O2.kg-1 (G60) após adição das glicerinas. O aumento da COD pela inclusão de fontes de difícil degradação pode ser um empecilho para o processo de degradação, mas a elevação da correspondência entre a redução destes constituintes com a inclusão das glicerinas, principalmente a G40 com mais impurezas, evidencia um efeito positivo deste resíduo para melhoria da remoção das frações orgânicas.

Com a inclusão das três glicerinas houve maior influência da composição dos afluentes sobre os resultados de produção de metano por VSa (MVS), pois foi possível observar maior correlação positiva com reduções de VS e COD, variando 0.27 e 0.55 (Figura 1 B, C e D), e sem as glicerinas (Figura 1A) constatouse valores negativos para estas correlações (SVR: -0.08 e CODR: -0.34), indicando que a adição das glicerinas contribui para melhoria da qualidade dos afluentes, favorecendo a redução de carga orgânica e geração de metano.

Em virtude das excretas das galinhas possuírem elevada quantidade de $\mathrm{N}$ com potencialidade de geração rápida de amônio (Chen et al., 2008), é comum a ocorrência da formação de $\mathrm{NH} 4 \mathrm{OH}$ na presença de água, facilitando a perda de $\mathrm{N}$ na forma de amônia, e criação de um substrato alcalino para os microrganismos. A alcalinização do meio poderia inibir as primeiras etapas da biodigestão, porém, com a inclusão do glicerol foram obtidos valores de $\mathrm{pH}$ decrescente, sem apresentar diferença significativa, e não afetando os demais resultados por não haver correlação com as outras variáveis.

As médias dos valores do $\mathrm{pH}$ de entrada para as doses $0,1,2,3$ e $4 \%$ de glicerol observadas na Tabela 2 e Figura 3, não demonstraram inibição do processo, mesmo com 0 e $1 \%$ acima de 7,4, destoando do sugerido por Calli et al. (2005), que defendem possível inibição quando o pH é superior a este valor. De acordo com Ferrer et al. (2010), a gama de pH entre 6.1 e 8.3 pode ser considerada aceitável para biodigestão de resíduos orgânicos com ST entre 4 e 10\%, portanto, nesta pesquisa os valores de $\mathrm{pH}$ dos afluentes e efluentes mantiveram-se próximos aos ideais, sendo observados na saída dos biodigestores fertilizantes com pH de 7.95 para dose $0 ; 8.03$ para as doses 1,2 e 3 e 8,02 para $4 \%$ de glicerol.

Com a adição do glicerol houve aumento da biodegradabilidade do substrato, pois com 2,2\% de glicerol observou-se melhora de $14,9 \%$ na remoção dos ST e com 2,4\% a redução de SV alcançou acréscimo de $13,1 \%$, comparados ao tratamento sem glicerol. Esta melhoria na biodegradabilidade ocorre devido ao glicerol disponibilizar nutrientes facilmente assimiláveis pelos microrganismos, proporcionando maior eficiência do processo pela degradação acentuada (Jensen et al., 2014), com consequente maior influência sobre a produção de biogás, demonstrada pelas correlações (Figura 1) entre a redução de SVa e os litros de biogás gerados (controle:-0,12; G40: 0,49; G60: 0,52; G80: 0,66).

\section{CONCLUSÃO}

A análise da correlação entre parâmetros importantes ao processo auxilia a avaliação dos efeitos causados pelos constituintes, contidos em diferentes proporções, nas glicerinas. A inclusão de glicerina contribuiu para melhoria do processo de degradação dos resíduos e, assim, melhorou as correlações entre DQO e produções específicas de biogás e metano pelos sólidos adicionados, bem como destas produções com as reduções dos constituintes avaliados.

À Capes, CNPq e UFGD.

\section{AGRADECIMENTOS}




\section{REFERÊNCIAS}

APHA, American Public Health Association. Standard Methods for the Examination of Water and Wastewater, 22 ed. Washington, 1.360p. 2012.

Calli, B., Mertoglu, B, Inanc, B, Yenigun, O. Effect of high free ammonia concentrations on the performances of anaerobic bioreactors. Process Biochem. V. 40, p. 1285-1292. 2005.

Ferrer, I., Vázquez, F., Font, X. Long term operation of a thermophilic anaerobic reactor: Process stability and efficiency at decreasing sludge retention time. Bioresour. Technol. v. 101, p.2972-2980. 2010.

Jensen, P.D., Astals, S., Lu, Y., Devadas, M., Batstone, D.J. Anaerobic codigestion of sewage sludge and glycerol, focusing on process kinetics, microbial dynamics and sludge dewaterability. Water Research. V. 67, p. 355-366. 2014.

REN21. Renewables 2016 Global Status Report (Paris: REN21 Secretariat). http://www.ren21.net/status-ofrenewables/global-status-report/. 2016.

Siles, J.A., Martín, M.A., Chica, A.F. Anaerobic digestion of glycerine derived from biodiesel manufacturing. Bioresour. Technol. v. 100, p. 5609-5615. 2009.

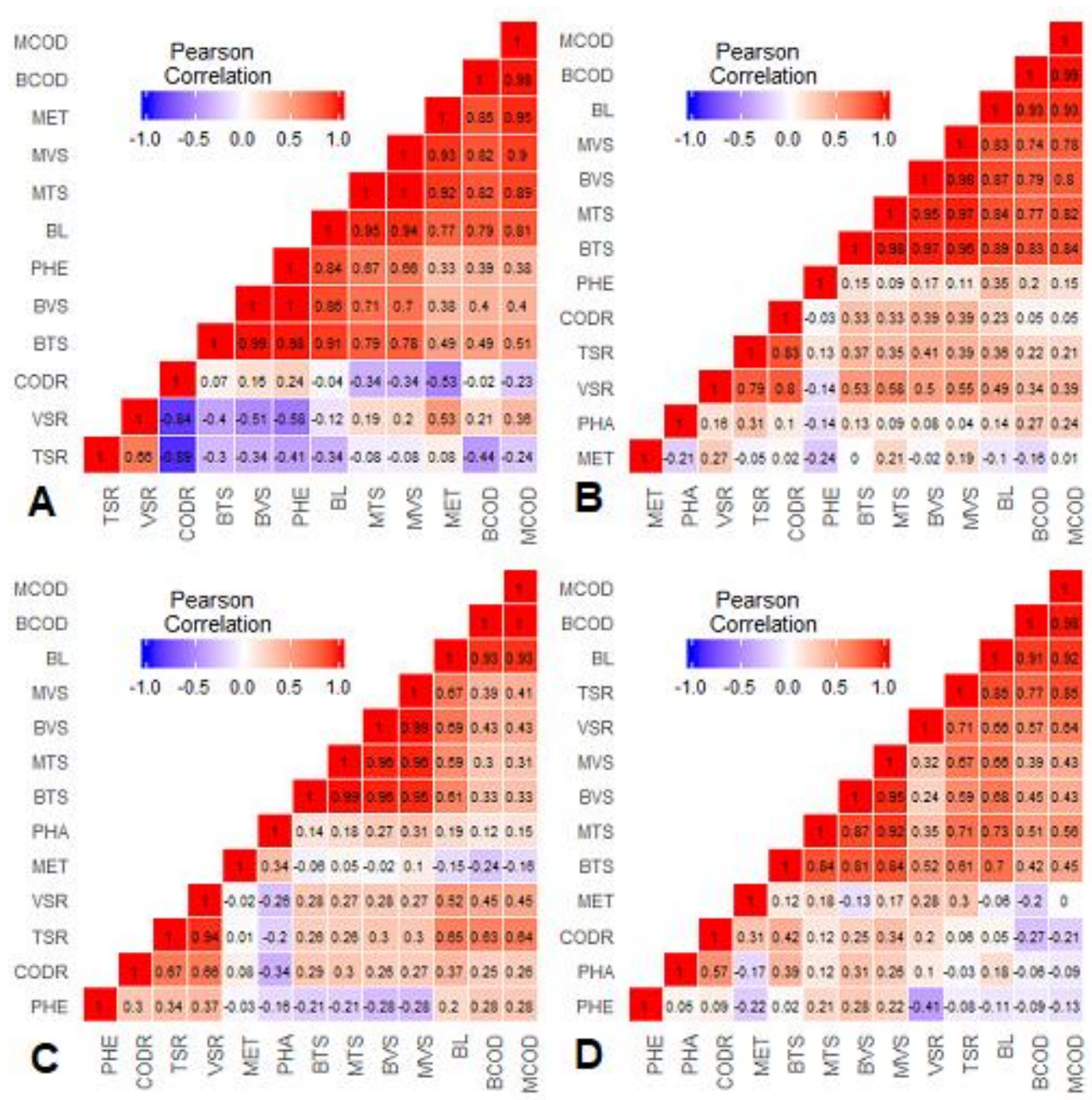

MCOD: litros de metano por kg DQO adicionada; BCOD: litros de biogás por kg de DQO; MET: teor de metano no biogás; MVS: litros de metano por kg de SV; MTS: litros de metano por kg de ST; BL: litros de biogás; PHA: potencial hidrogeniônico do afluente; PHE: potencial hidrogeniônico do efluente; BVS: litros de biogás por kg de SV; BTS: litros de biogás por kg de ST; CODR: redução de DQO; VSR: redução de SV; VTS: redução de ST;

Figura 1. Coeficiente de correlação de Pearson, para as variáveis avaliadas no processo de digestão anaeróbia de dejetos de galinhas de postura (A) sem adição de glicerina e com a inclusão de glicerina contendo (B) 40, (C) 60 e (D) $80 \%$ de glicerol em sua composição. 


\title{
DESEMPENHO DA MARAVALHA E CARVÃO COMO FILTRO NO TRATAMENTO DE ÁGUAS RESIDUÁRIAS
}

\author{
Pires, C.S. ${ }^{* 1}$; Oliveira, R.S. ${ }^{2}$; Santos Junior, A.J. ${ }^{3}$ Moraes, A.S. ${ }^{4}$; Andrade, A.M. ${ }^{5}$ Pinheiro, E.F.M. ${ }^{6}$ \\ ${ }^{1}$ Engenheira Agrícola e Ambiental, Mestranda do Programa de Pós-Graduação em Engenharia Agrícola e Ambiental, UFRRJ, \\ Seropédica, RJ-Brasil, carina.soarespires@gmail.com; ${ }^{2}$ Graduanda em Zootecnia, UFRRJ, Seropédica, RJ- \\ Brasil,raquel.oliveirasilva@gmail.com; ${ }^{3}$ Graduando em Engenharia Florestal, UFRRJ, Seropédica, RJ-Brasil, \\ alf.junior12@gmail.com; ${ }^{4}$ Gestora Ambiental, Mestranda do Programa de Pós-Graduação em Engenharia Agrícola e Ambiental, \\ UFRRJ, Seropédica, RJ-Brasil, aolibamasilva@bol.com.br; ${ }^{5}$ Eng. Florestal, Prof. Dr. do Departamento de Produtos Florestais, \\ UFRRJ, Seropédica, RJ-Brasil, azariasmachado3@icloud.com; ${ }^{6}$ Eng. Agrônoma, Prof. ${ }^{a}$ Dr ${ }^{a}$ do Departamento de Solos, UFRRJ, \\ Seropédica, RJ-Brasil,erika.solos@gmail.com
}

RESUMO: A produção de leite vem aumentando no Brasil e tem uma posição de destaque na economia nacional. É crescente a necessidade do desenvolvimento de tecnologias alternativas e acessíveis aos pequenos produtores, que possibilitem o manejo adequado e eficiente dos resíduos produzidos. A utilização de filtros utilizando materiais orgânicos facilmente encontrados em áreas rurais tem sido considerada uma alternativa promissora para o tratamento da água residuária da bovinocultura (ARB). Com o presente trabalho, objetivouse avaliar o desempenho da maravalha de madeira e do carvão vegetal no tratamento da água residuária da bovinocultura de leite. Para isso, foram utilizadas colunas de filtragem contendo o material filtrante nas seguintes proporções: $30 \%$ de carvão vegetal e $70 \%$ de maravalha de madeira. Para a avaliação da eficiência do sistema, o afluente (ARB bruta, antes da filtração) e o efluente (ARB após filtração) foram caracterizados em relação aos seguintes parâmetros: potencial hidrogeniônico $(\mathrm{pH})$, condutividade elétrica $(\mathrm{CE})$, sólidos totais (ST), sólidos fixos (SF) e sólidos voláteis (SV). Foi calculada a razão da concentração do efluente em relação à concentração do afluente para cada parâmetro medido em função do volume filtrado. De acordo com os resultados, pode-se concluir, que o filtro constituído por maravalha e carvão vegetal, nas granulometrias avaliadas (menores que 2,0mm), não foi eficiente na remoção da CE, ST, SF e SV tendo, inclusive, contribuído para o aumento desses parâmetros nos efluentes. Verificou-se também um aumento nos valores de $\mathrm{pH}$ nos efluentes, contudo, os mesmos mantiveram-se próximos ao da faixa de neutralidade.

Palavras-chave: adsorção, biochar, resíduo orgânico.

\section{WOOD CHIPS AND CHARCOAL PERFORMANCE AS A FILTER IN THE WASTEWATER TREATMENT}

\begin{abstract}
Milk production has been increasing in Brazil and has a prominent position in the national economy. The increasing capacity of adaptation and access to the small properties that allow the adequate and efficient management of the products produced in the activity. The use of the dairy cow allergy in rural areas has been a promising alternative for the treatment of wastewater of dairy cattle (WDC). With the present work, the performance of the wood chips and the charcoal, as filtering material, in the improvement of the treatment of the residual waters of the dairy cattle was objectified. For this purpose were $30 \%$ charcoal and $70 \%$ wood chips. In order to evaluate the efficiency of the system, the affluents and the greenhouse gases were characterized in their prospects: hydrogenation potential $(\mathrm{pH})$, electrical conductivity (EC), total solids (ST), fixed solids (SF) and volatile solids (SV). Four filtrations of the crude ARB were performed, and a concentration ratio was determined in relation to the concentration. According to the results, it can be concluded, in summary, what is constituted by the mechanism of cleaning of plants and plants, in the granulometries evaluated, was not effective in the removal of EC, ST, SF and SV, including, contributed to the increase in the effluent of some variables. It was verified that with respect to the $\mathrm{pH}$ there was also an increase in the effluent concentrations, however the values remained close to the neutrality range.
\end{abstract}

Keywords: adsorption, biochar, organic waste. 


\section{INTRODUÇÃO}

A bovinocultura de leite moderna, caracterizada pela adoção de sistemas de criação intensivo, produz elevados volumes de água residuária, proveniente de estábulos, que possuem características físico-químicas que podem causar efeitos deletérios a qualidade de corpos hídricos (SILVA e ROSTON, 2010; SILVA, 2012). As águas residuárias da bovinocultura (ARB) apresentam composição química e microbiológica extremamente variada que depende de alguns fatores, como a quantidade de água utilizada nas instalações, das condições de produção, armazenamento, alimentação, fase de crescimento e diluição dos resíduos com a incorporação das águas de lavagens ou da chuva (SOMMER e CHRISTENSEN, 2013).

Alternativas acessíveis, do ponto de vista técnico e econômico, para o tratamento e reaproveitamento dos dejetos produzidos em pequenas propriedades rurais têm sido investigadas nas pesquisas nos últimos anos. Dentre estas, o uso de filtros orgânicos tem sido considerado uma forma de tratamento de água acessível aos pequenos produtores, por fazer uso de materiais orgânicos disponíveis na própria propriedade e de materiais recicláveis, de fácil acesso. Vários materiais orgânicos, que não raro são resíduos de atividades agrossilvipastoris, têm sido avaliados em pesquisas nos últimos anos, tais como o sabugo de milho, bagaço de cana-de-açúcar, casca de arroz, fino de carvão vegetal, serragem de madeira, fibra de coco, pergaminho de grãos de café e carvão vegetal granulado (Brandão et al., 2003; Oliveira et al., 2017; Lo Monaco et al., 2009; Lo Monaco et al., 2004; Magalhães et al., 2006; Lo Monaco, 2014; Magalhães et al., 2013; Lo Monaco et al., 2011; Huggins et al., 2016). A serragem da madeira e o carvão vegetal têm se destacados e sido considerados eficientes na remoção de poluentes (Lo Monaco, 2014 e Huggins et al., 2016). As pesquisas têm mostrado ainda que a granulometria exerce papel importante no desempenho dos filtros. Além da serragem, a indústria madeireira produz outros resíduos com tamanhos e formas geométricas diferentes, como a maravalha. Não foram observados na literatura pesquisas que envolvessem o uso da maravalha na confecção de filtros orgânicos. Diante dos resultados promissores do uso do carvão vegetal na adsorção de nutrientes e da ausência de pesquisas utilizando a maravalha de madeira de eucalipto, esse trabalho objetivou avaliar a eficiência desses resíduos do Setor Florestal (maravalha de madeira e carvão vegetal), como material filtrante, no tratamento da água residuária da bovinocultura de leite.

\section{MATERIAL E MÉTODOS}

O experimento foi conduzido nas dependências do Departamento de Solos, no Instituto de Agronomia da Universidade Federal Rural do Rio de Janeiro (UFRRJ), Seropédica - RJ. A água residuária da bovinocultura de leite foi coletada na esterqueira do Sistema Integrado de Produção Agroecológica (SIPA "Fazendinha Agroecológica km 47"), em Seropédica - RJ.

Foram utilizados, como meio filtrante, os materiais orgânicos: maravalha e carvão vegetal. A maravalha utilizada foi obtida na serraria do Departamento de Produtos Florestais (UFRRJ), resultante do beneficiamento da madeira de Eucalipto (Eucalyptus spp). Friccionou-se o material em peneiras para obter um material com geometria mais uniforme e granulometria menor que $2,0 \mathrm{~mm}$. O carvão vegetal foi produzido nos meses de julho e agosto de 2018, no Laboratório de Energia da Madeira do Departamento de Produtos Florestais, no Instituto de Florestas (UFRRJ), por meio da pirólise da madeira de Eucalipto (Eucalyptus spp). As pirólises foram conduzidas até a temperatura máxima de $400^{\circ} \mathrm{C}$, utilizando-se amostras de aproximadamente $1650 \mathrm{~g}$ de Eucalipto (Eucalyptus spp), secas em estufa à temperatura de $105^{\circ} \pm 3^{\circ} \mathrm{C}$, durante 24 horas. Depois de atingir a temperatura ambiente, o material foi triturado em prensa hidráulica e peneirado num conjunto de peneira de diâmetro de 4,0 e 2,0 mm. O carvão utilizado foi o retido na peneira de 2,0 $\mathrm{mm}$.

A estrutura experimental foi constituída por um reservatório de $500 \mathrm{~L}$ para armazenamento da ARB, onde foram instalados registros de PVC para alimentação dos filtros. Foram confeccionadas quatro colunas filtrantes utilizando-se garrafas de Poli Tereftalato de Etileno (PET), com capacidade de 3,0 L, baseando-se no modelo proposto por Oliveira et al. (2017), com algumas modificações. Com o intuito de evitar o fluxo preferencial, colou-se em cada coluna maravalha triturada nas paredes internas das colunas filtrantes, aumentando a rugosidade, conforme indicado por Oliveira et al. (2017), Francisco et al. (2011), Magalhães et al. (2006). Para o preenchimento das colunas utilizou-se $562 \mathrm{~g}$ do material orgânico, sendo $30 \%$ de carvão vegetal e 70\% da maravalha de madeira. Para evitar o selamento superficial e acúmulo de sólidos na entrada da torneira, utilizou-se uma camada de pedra brita $\left(n^{\circ} 3\right)$ na parte superior e inferior do filtro, com aproximadamente $10 \mathrm{~cm}$ de espessura. 
O escoamento foi mantido constante, em meio saturado, durante o processo de filtragem. As amostras de ARB filtrada foram coletadas a cada 5,0 L utilizando-se galões plásticos, sendo coletadas alíquotas de 200 $\mathrm{mL}$ para a realização das análises laboratoriais. As variáveis avaliadas, os métodos e os equipamentos estão descritos a seguir: potencial hidrogeniônico $(\mathrm{pH})$ - peagâmetro de bancada; condutividade elétrica $(\mathrm{CE})$ condutivímetro de bancada; sólidos totais e sólidos fixos - método gravimétrico; sólidos voláteis - diferença entre ST e SF. As análises das variáveis, definidas para avaliar o desempenho dos filtros orgânicos, foram realizadas em triplicata nos laboratórios de Matéria Orgânica do Solo do Departamento de Solos do Instituto de Agronomia (UFRRJ) e Monitoramento Ambiental I do Departamento de Engenharia do Instituto de Tecnologia (UFRRJ).

Dos parâmetros físicos e químicos da $\mathrm{ARB}$ bruta e filtrada, foram obtidos valores médios e concentrações relativas $(\mathrm{C} / \mathrm{C} 0)$, que expressam a razão entre a concentração ou valor do atributo físico ou químico no efluente $(\mathrm{C})$ e no afluente $(\mathrm{C} 0)$. Foi feita a análise estatística descritiva $(\mathrm{P}<0,05)$.

\section{RESULTADOS E DISCUSSÃO}

$\mathrm{Na}$ Tabela 1 estão apresentados os atributos físicos e químicos da ARB bruta e filtrada com as respectivas concentrações relativas $(\mathrm{C} / \mathrm{C} 0)$. Ressalta-se que valores $\mathrm{C} / \mathrm{C} 0$ maiores que a unidade são indicativos do aumento da concentração do parâmetro avaliado no efluente e valores menores que um indicam a remoção desse parâmetro da água residuária. De acordo com os resultados apresentados na Tabela 1, observa-se que a filtração, utilizando maravalha e carvão vegetal, promoveu acréscimo nos valores dos parâmetros avaliados na maioria dos filtrados. Lo Monaco et al. (2011) explicam que o aumento nos atributos físicos, possivelmente, pode ter ocorrido devido a solubilização de íons e substâncias dos materiais orgânicos utilizados como meio filtrante.

De forma similar aos resultados encontrados por Oliveira et al. (2017), observou-se que o $\mathrm{pH}$ se manteve próximo da faixa da neutralidade. Houve uma discreta diminuição no valor do $\mathrm{pH}$ nos primeiros volumes coletados seguida de um aumento ínfimo nos volumes posteriores. Segundo Oliveira et al. (2017), a composição química do material orgânico pode aumentar ou diminuir os valores de $\mathrm{pH}$ do efluente. Com relação a $\mathrm{CE}$, os resultados mostraram que a $\mathrm{ARB}$ bruta possui elevados valores e ainda houve um pequeno acréscimo nos efluentes da ARB, exceto para os 15 e $20 \mathrm{~L}$ filtrados, quando houve uma pequena redução, enquadrando o efluente com grau de restrição para uso em irrigação como severo. A remoção de sólidos foi, em geral, inferior as verificadas na literatura (Lo Monaco et al.,2104; Magalhães et al., 2006), onde as maiores remoções não alcançaram uma remoção de $20 \%$ e verificou-se ainda que houve acréscimo em alguns volumes coletados $(5$ e $10 \mathrm{~L})$. Observou-se que a maravalha de madeira é extremamente pulverulenta e, com isso verificou-se um aporte de sólidos do material filtrante para o meio, diminuindo a porosidade e a eficiência desse tratamento que se baseia num principio físico, de retenção de sólidos num meio poroso.

\section{CONCLUSÃO}

Os materiais filtrantes maravalha e carvão vegetal, nas granulometrias avaliadas, não proporcionaram resultados satisfatórios para recomendar o seu uso como material filtrante. Observou-se que, principalmente, a maravalha de madeira, na granulometria utilizada, é extremamente pulverulenta, o que resultou na redução dos poros no sistema de filtração. No entanto, recomenda-se a avaliação do uso da maravalha em granulometrias maiores, e justifica-se maiores investigações no uso desses materiais filtrantes orgânicos por apresentarem potencial de adsorção e serem acessíveis, além de terem o potencial de produção de fertilizante após o uso nos filtros, via processo de estabilização.

\section{AGRADECIMENTOS}

Ao apoio da UFRRJ, PPGEAMB, Laboratório de Energia da Madeira do Departamento de Produtos Florestais, no Instituto de Florestas, AGEVAP (Edital nº 005/2018) e da CAPES na elaboração da pesquisa.

\section{REFERÊNCIAS}

BRANDÃO, V.S.; MATOS, A.T.; FONTES, M.P.P.; MARTINEZ, M.A. Retenção de poluentes em filtros orgânicos operando com águas residuárias da suinocultura. Revista Brasileira de Engenharia Agrícola e Ambiental, Campina Grande, v.7, n.2, p.329-334, 2003. 
HUGGINS, T. M.; HAEGER, A.; BIFFINGER, J. C.; REN, Z. J. Granular biochar compared with activated carbon for wastewater treatment and resource recovery. Water Research, v. 94, p. 225-232, 2016.

LO MONACO, P.A.; MATOS, A.T.; JORDÃO, C.P.; CECON, P.R.; MARTINEZ, M.A. Influência da granulometria da serragem de madeira como material filtrante no tratamento de águas residuárias. Revista Brasileira de Engenharia Agrícola e Ambiental, Campina Grande, v.8, n.1, p.116-119, 2004.

LO MONACO, P.A.V.; MATOS, A.T.; SARMENTO, A.P.; JÚNIOR, A.V.L.; LIMA, J.T. Desempenho de filtros constituídos por fibras de coco no tratamento de águas residuárias de suinocultura. Engenharia na Agricultura, Viçosa, v.17, n.6, p.473-480, 2009.

LO MONACO, P.A. V.; MATOS, A.T.; BRANDÃO, V.S. Influência da granulometria dos sólidos triturados de sabugo de milho e bagaço de cana-de-açúcar como materiais filtrantes no tratamento de águas residuárias da suinocultura. Revista Engenharia Agrícola, Jaboticabal, v.31, n.5, p.974-984, 2011.

LO MONACO, P.A.V.; MATOS, A.T.; RIBEIRO, I. C. A.; BATISTA, A. P. S., MIRANDA, S. T.; JÚNIOR, V. E. Tratamento de esgoto sanitário utilizando coagulante natural seguido de filtro orgânico. Revista Caatinga, Mossoró, v. 27, n. 1, p. 28 - 40, jan. - mar., 2014.

MAGALHÃES, M. A.; MATOS, A. T.; DENÍCULI, W.; TINOCO, I. F. F. Operação de filtros orgânicos utilizados no tratamento de águas residuárias da suinocultura. Revista Brasileira de Engenharia Agrícola e Ambiental, Campina Grande, v. 10, n. 2, p. 472-478, 2006.

OLIVEIRA, A. P. S.; PINHEIRO, E. F. M.; CAMPOS, D. V. B. Avaliação do tratamento da água residuária da suinocultura utilizando filtro orgânico constituído de bagaço de cana-de-açúcar. Revista Virtual de Química, vol 9, nº 5, 2017.

SILVA, E. M.; ROSTON, D. M. Tratamento de efluentes de sala de ordenha de bovinocultura: Lagoas de estabilização seguidas de leito cultivado. Revista engenharia agrícola, Jaboticabal, v. 30, n. 1, p. 67-73, jan./fev. 2010.

SILVA, J. B. G. Uso de água residuária de bovinocultura de leite no cultivo da figueira (Ficus carica): efeitos no solo e na cultura. Tese (Doutorado) - Universidade Federal de Viçosa - Viçosa, MG, 2012.

SOMMER, S. G.; CHRISTENSEN, M. L. Animal Production and Animal Manure Management. In: Animal Manure: Recycling, Treatment and Management. Editores: SOMMER, S. G.; CHRISTENSEN, M. L.; SCHMIDT, T.; JENSEN, L. S. Editora: John Wiley \& Sons, 2013. p. 6-7.

Tabela 1. Atributos físico-químicos médios da $\mathrm{ARB}$ bruta e filtrada e concentração relativa $(\mathrm{C} / \mathrm{C} 0)$ no efluente dos filtros.

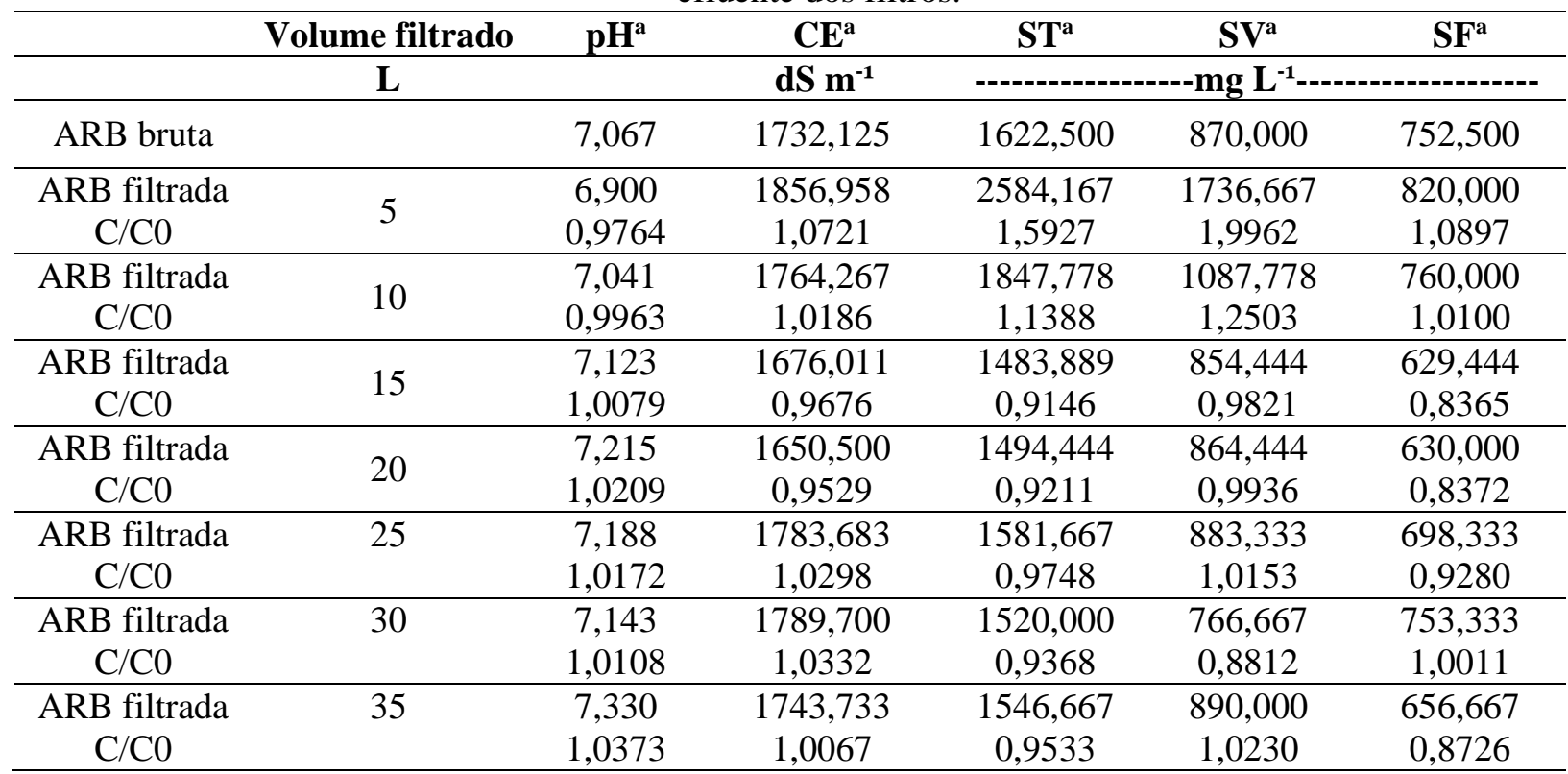

$\overline{\mathrm{pH}}=$ potencial hidrogeniônico; $\mathrm{CE}=$ condutividade elétrica; $\mathrm{ST}=$ sólidos totais; $\mathrm{SV}=$ sólidos voláteis; $\mathrm{SF}=$ sólidos fixos; $\mathrm{C}=$ concentração final; $\mathrm{C} 0=$ concentração inicial

a 4 repetições 


\title{
DESIDRATAÇÃO DE RESÍDUOS DE PEIXES COMO FORMA DE AGREGAÇÃO DE VALOR E SUSTENTABILIDADE AMBIENTAL
}

\author{
Teodoro, J.C.*11; Krabbe, E.L. ${ }^{2}$; Ávila, V.S. ${ }^{3}$ Costa, A.P.G.C. ${ }^{4}$; Bezerra, N.S. ${ }^{5}$ ' Vinhaga, C. ${ }^{6}$ \\ ${ }^{1}$ Graduanda em Medicina Veterinária, Instituto Federal Goiano Campus Urutaí, GO. Estagiária da Embrapa Suínos e Aves. \\ janaina.ct@hotmail.com \\ ${ }^{2 ; 3}$ Pesquisadores da Embrapa Suínos e Aves, Concórdia, SC - Brasil. \\ everton.krabbe@embrapa.br; valdir.avila@embrapa.br \\ 4;5 Graduandas em Zootecnia, Universidade Federal do Amazonas, AM. Estagiárias da Embrapa Suínos e Aves. \\ anapaulagcruz1@gmail.com; nataliadsantos@gmail.com \\ ${ }^{6}$ Graduanda em Medicina Veterinária, Instituto de Desenvolvimento Educacional do Alto Uruguai - Getúlio Vargas \\ carolinevinhaga@gmail.com
}

\begin{abstract}
RESUMO: Nos últimos anos houve crescimento da aquicultura no Brasil. Em 1996 o país produzia cerca de 700.000 toneladas de pescado, em 2010 a produção ultrapassou a quantia de 1.000 .000 toneladas. Mas apesar deste desenvolvimento a produção de peixe ainda é abaixo do esperado. Este fato pode ser explicado devido dificuldades ambientais vivenciadas, como a destinação correta de resíduos provenientes desse tipo de criação. O presente trabalho foi desenvolvido na Embrapa Suínos e Aves com o objetivo de estudar a viabilidade da produção da farinha de peixe por desidratação a partir dos resíduos da filetagem de Tilápias, revelando-se como método eficaz, seguro e sustentável para destinação correta dos resíduos desta cadeia produtiva. O processo mostrou-se um método alternativo adequado ao cumprir seu objetivo e como uma opção de agregação de renda extra para as indústrias de beneficiamento de pescado. Considerando a qualidade nutricional e microbiológica da farinha resultante deste processo, vislumbra-se seu uso na alimentação animal, como possível utilização para incremento em ração de poedeiras para obtenção de ovos nutricionalmente enriquecidos com ômega 3.
\end{abstract}

Palavras-chave: produção, alimentação animal, ovos enriquecidos.

\section{FISH OFFALL DEHIDRATION AS AN VALUE ADDEDING AND ENVIRONMENTAL SUSTAINABILITY PROCEDURE}

\begin{abstract}
Brazil has experienced intense aquaculture growth rate in recent years. In 1996 the country produced about 700.000 tons of fish. In 2010, the production exceeded 1.000.000 tons. But despite this development fish production is still below expected. This fact can be explained due to environmental difficulties, such as the correct destination of waste from this type of activity. The present work was developed at EMBRAPA Swine and Poultry with the objective of studying the feasibility of fishmeal production by dehydration of tilapia filleting residues as an effective, safe and sustainable method for the correct destination of the residues of this production chain. The process has proven to be an appropriate alternative method in fulfilling its purpose and as an option of adding extra income to the fish processing industries. Considering the nutritional and microbiological quality of the fish meal resulting from this process, it is possible to use it in animal feed, like egg-laying hen ration aiming to obtain eggs nutritionally enriched with omega- 3 .
\end{abstract}

Keywords: production, animal feed, enriched eggs.

\section{INTRODUÇÃO}

O Brasil apresenta uma ampla bacia hidrográfica com grande potencial para desenvolvimento da aquicultura, podendo representar uma importante fonte de renda complementar na agricultura familiar. Antes de sua fusão com o MAPA, o objetivo do MPA (2014) (Ministério da Pesca e Aquicultura) era que até 2030, o país se enquadre como um dos maiores produtores de pescado do mundo, com estimativa de produção de 20 milhões de toneladas por ano. Nos últimos anos a produção e comercialização de peixes do gênero Tilápia demonstrou crescimento em consequência à boa resposta aos sistemas de produção semi-intensivo e intensivo, fácil reprodução, elevada apreciação pelo mercado consumidor principalmente pelo filé, ótimo valor de mercado e baixos custos de produção (EMBRAPA,2007). De acordo com dados do IBGE (2017) a produção 
nacional de Tilápia chegou à 283.249.263kg em 2017, sendo mais expressiva na região Sul e Sudeste, seguida pelo Centro-Oeste.

Apesar deste progresso, a criação de peixes no país ainda é abaixo do potencial (VICENTE E FONSECA-ALVES, 2013). Isto pode ser explicado pelas dificuldades ambientais vivenciadas como a destinação correta dos resíduos orgânicos. Ao final do processo de filetagem da Tilápia cerca de 60 a $70 \%$ da carcaça do peixe não é aproveitada, tornando-se indispensável o aproveitamento destes resíduos para mitigar o impacto ambiental (BOSCOLO,2003).

O processamento dos resíduos pode originar a farinha de peixes. Esta transformação se torna uma opção de agregação de renda extra para as indústrias de beneficiamento de pescado, podendo aumentar sua lucratividade. A farinha tem aplicação principalmente na alimentação animal devido sua qualidade nutricional. Uma potencial utilização seria seu uso na ração de poedeiras visando a obtenção de ovos nutricionalmente enriquecidos com ácidos graxos poliinsaturados $\omega-3$. De acordo com VIDOTTI \& GONÇALVES (2006) as características de qualidade da farinha de peixe podem apresentar variações de acordo com a matéria-prima, controle adequado no processamento, método de proteção contra oxidação da gordura e no armazenamento.

Considerando do exposto, esse trabalho possui como objetivo apresentar o processo de fabricação da farinha de peixe pelo método de desidratação, atendendo a IN número 34 de 28 de maio de 2008 (normativa para produção de farinha de origem animal). Ressaltando sua composição nutricional através da análise físicoquímica e validação como um processo livre de contaminantes através de avaliações microbiológicas do produto final.

\section{MATERIAL E MÉTODOS}

Experimento foi realizado no Laboratório TEC-DAM (Tecnologias para Destinação de Animais Mortos) localizado na Embrapa Suínos e Aves. Utilizou-se resíduos de Tilápia do Nilo, Oreochromis niloticus, oriundos de um abatedouro industrial com inspeção municipal localizado no município de Concórdia - Santa Catarina. Foram produzidos diversos lotes até a definição dos parâmetros de produção, quando foi produzido um lote para a validação do processo, onde foram pesados $210 \mathrm{~kg}$ de resíduos que foram colocados no desidratador rotativo aquecido através da queima de lenha. Utilizou-se antioxidante na proporção de $1 \mathrm{~kg} / \mathrm{T}$. A desidratação se inicia quando a temperatura atinge $100-120^{\circ} \mathrm{C}$ na massa, e é mantida por no mínimo cinco horas, visando a perda de água do material e eliminação de possíveis agentes patogênicos presentes. Foi realizado o monitoramento da temperatura durante todo o procedimento através de termômetro infravermelho, bem como registrados os consumos de lenha e energia.

Em seguida adicionou-se o equivalente a $25 \%$ de farelo de trigo do peso inicial dos resíduos do pescado, ou seja, 52,63 kg. A inclusão teve como propósito promover a absorção do óleo resultante do processo de desidratação do peixe e reduzir a umidade ainda restante. Após adição, a massa permaneceu no desidratador por mais 30 minutos, totalizando ao final do processo, $150,80 \mathrm{Kg}$ de produto. Posteriormente o material foi deixado em descanso por 20 horas para resfriamento, resultando 142,60 Kg. Em seguida fez-se a moagem da farinha em moinho de martelo com peneira de $7 \mathrm{~mm}$. Ao final do procedimento obteve-se como produto final a farinha de peixe desidratada, alcançando um rendimento final do peixe desidratado de $37 \%$. Durante todas as etapas para fabricação da farinha, retirou-se amostras para análises físico-químicas e microbiológicas.

\section{RESULTADOS E DISCUSSÃO}

As amostras submetidas à análise microbiológica apresentaram resultados dentro dos limites preconizados para os parâmetros analisados. De acordo com a Tabela 1 a amostra quente, retirada após o fim do período diretamente no desidratador, assim como a amostra resfriada apresentaram niveis $<10 \mathrm{UFC} / \mathrm{g}$ para Coliformes não - Escherichia coli, o mesmo valor para Coliformes Escherichia coli e coliformes totais. A pesquisa de Salmonella spp qualitativa (ausência ou presença), apresentada na mesma tabela, apresentou resultado negativo (ausência) para as mesmas amostras. Este resultado evidencia uma ótima qualidade microbiológica do produto ao término da produção da farinha de peixe (OGAWA; MAIA, 1999). Verificouse também a ausência para Clostridium perfringens no material coletado. Os resultados estão em acordo com a legislação, que preconiza contagem máxima para pescado de $10^{2} \mathrm{NMP} / \mathrm{g}$ para contagem de coliformes e ausência de Salmonella spp (APPCC, 1998).

Para análise físico-química foram avaliados os teores de matéria seca, extrato etéreo, nitrogênio, cinzas, fibra bruta, proteína e cálcio na farinha de resíduos de filetagem de Tilápias. Observa-se na Tabela 2, que o 
teor de matéria seca neste experimento teve média de $80 \%$, valor inferior ao exposto por BOSCOLO et al. (2004) com o equivalente à 94\%. A equipe de trabalho já está desenvolvendo um processo de secagem/resfriamento para uma melhor remoção de umidade, alcançando assim níveis ideais. Quando avaliado o teor de extrato etéreo, o presente trabalho apresentou média de $20 \%$, próximo ao encontrado por BOSCOLO et al. (2008) com 21\%. Este mesmo autor, o teor proteína bruta obtida foi de 50,37\%, que se diferencia do exposto no experimento, com $23 \%$.

Uma das limitações quanto ao uso de farinhas de peixe produzidas com resíduos da filetagem de pescados é o alto teor de cinzas (MILLAMENA, 2002). Contudo, considerando o nível médio de 10\% obtido neste trabalho conclui-se que a farinha produzida apresenta boa qualidade, visto que comercialmente, as farinhas de melhor qualidade apresentam níveis de cinzas inferiores a 15\% (GAYLORD \& GATLIN, 1996). Este produto apresenta potencial para ser usado como fonte de macro minerais tais como cálcio e fósforo, devendo os teores de cálcio ser no máximo de $6 \%$ e fósforo mínimo de $3 \%$. O presente trabalho apresenta valores próximos, visto que ficaram em média de 3 e $2 \%$, respectivamente.

\section{CONCLUSÃO}

O processo de produção de farinha de peixe por desidratação é viável tecnicamente e apresenta resultados satisfatórios de qualidade físico-química e microbiológica, demonstrando ser técnica alternativa para a destinação correta dos resíduos de filetagem de Tilápia, consequentemente colaborando para redução do impacto ambiental que o descarte destes resíduos provoca ao meio ambiente. Este novo produto, pode se tornar uma fonte alternativa na dieta de poedeiras devido seu alto valor nutricional, visando a produção de ovos nutracêuticos.

\section{REFERÊNCIAS}

APPCC, (1998) - Análise dos perigos e pontos críticos de controle na qualidade e segurança microbiológica de alimentos. Editora varela, São Paulo.

BOSCOLO, W.R. Farinha de resíduos da indústria de filetagem de tilápia na alimentação da Tilápia do Nilo (oreochromis niloticus). Maringá: Universidade Estadual de Maringá, 2003. 83p. Tese (Dourorado em Zootecnia) - Universidade Estadual de Maringá, 2003.

BOSCOLO, W.R. ET AL. Digestibilidade aparente da energia e proteína das farinhas de resíduo da filetagem da tilápia do nilo (oreochromis niloticus), da corvina (plagioscion squamosissimus) e farinha integral do camarão canela (macrobrachium amazonicum) para a tilápia do nilo. Revista Brasileira de Zootecnia, v.33, n.1, p.8-13, 2004.

BOSCOLO, W.R. ET AL.Composição química e digestibilidade aparente da energia e nutrientes da farinha de resíduos da indústria de filetagem de tilápias, para a tilápia do nilo (oreochromis niloticus). para a Ciência Rural, v.38, n.9, dez, 2008.

BRASIL, Ministério da Pesca e da Aquicultura. $1^{\circ}$ Anuário Brasileiro da Pesca e Aquicultura. 2014.

EMBRAPA. Produção de tilápia: mercado, espécie, biologia e recria. 2007. disponível em: <file:///d:/documentos/downloads/circular45.pdf> Acesso: 20 nov 2018.

GAYLORD, T.G.; GATLIN III, D.M. Determination of various feedstuffs for red drum (sciaenops ocellatus). Aquaculture, v.139, p.303-314, 1996.

IBGE. Pesquisa da pecuária municipal. 2017. Disponível em: https://sidra.ibge.gov.br/tabela/3940 . Acesso: 20 nov 2018.

MILLAMENA, O.M. Replacement of fish meal by animal byproduct meals in a practical diet for grow-out culture of grouper epinephelus coiodes. Aquaculture, v.204, p.75-84, 2002.

OGAWA, M., MAIA, e. 1. (1999). Manual de pesca. Ciência e tecnologia de alimentos. São Paulo, Editora Varela, v. 1, p. 430.

VICENTE, I.S.T. E FONSECA-ALVES, C.E. (2013) - Impact of Introduced Nile Tilapia (Oerochromis niloticus) On Non-native Aquatic Ecosystems. Pakistan Journal of Biological Sciences, v. 16, n. 3, p. 121-126. VIDOTTI, R.M. E GONÇALVES, G.S. Produção e caracterização de silagem, farinha e óleo de tilápia e sua utilização na alimentação animal. 2006. Disponível em: ftp://ftp.sp.gov.br/ftppesca/producao_ caracterizacao.pdf. Acesso: 20 nov 2018. 
Tabela 1. Parâmetros microbiológicos da farinha de peixe obtida pelo processo de desidratação.

\begin{tabular}{cccccc}
\hline Farinha & $\begin{array}{c}\text { Coliformes } \\
\text { não-Ecoli } \\
\text { (UFC/g) }\end{array}$ & $\begin{array}{c}\text { Coliformes } \\
\text { Escherichia coli } \\
\text { (UFC/g) }\end{array}$ & $\begin{array}{c}\text { Coliform } \\
\text { es totais } \\
\text { (UFC/g) }\end{array}$ & $\begin{array}{c}\text { Clostridium } \\
\text { perfringens }\end{array}$ & $\begin{array}{c}\text { Salmonella } \\
\text { spp }\end{array}$ \\
\hline Quente & $<10$ & $<10$ & $<10$ & negativo & negativo \\
Resfriada & $<10$ & $<10$ & $<10$ & negativo & negativo \\
\hline
\end{tabular}

*Cultivo bacteriológico em meios específicos.

Tabela 2. Composição nutricional da farinha de peixe (tilápia) obtida pelo método de desidratação - análises físico-químicas.

\begin{tabular}{cccccccc}
\hline Farinha & MS(\%) & $\mathbf{C Z ~ ( \% )}$ & $\mathbf{P B}(\boldsymbol{\%})$ & $\mathbf{E E}(\boldsymbol{\%})$ & $\mathbf{F B}(\boldsymbol{\%})$ & $\mathbf{P}(\boldsymbol{\%})$ & $\mathbf{C a}(\boldsymbol{\%})$ \\
\hline Quente & 80,34 & 9,70 & 22,97 & 20,80 & 3,08 & 2,104 & 2,85 \\
Resfriada & 80,20 & 10,06 & 22,94 & 20,56 & 2,65 & 2,03 & 3,25 \\
Média & 80 & 10 & 23 & 21 & 3 & 2 & 3 \\
\hline
\end{tabular}

*MS= matéria seca. $\mathrm{CZ}=$ cinzas. $\mathrm{PB}=$ proteína bruta. $\mathrm{EE}=$ extrato etéreo. $\mathrm{FB}=$ fibra bruta. $\mathrm{P}=$ fósforo. $\mathrm{Ca}=$ cálcio. 


\title{
DETERMINAÇÃO DE COMPOSTOS VOLÁTEIS MICROALGAIS COM POTENCIAL DE APLICAÇÃO INDUSTRIAL
}

\author{
Oliveira, A.S. ${ }^{1}$; Vieira, K.R. ${ }^{1}$; Pinheiro, P.N. ${ }^{1}$; Wagner ${ }^{1}$, R.; Jacob-Lopes, E. ${ }^{1}$; Zepka, L.Q.*1 \\ ${ }^{1}$ Universidade Federal de Santa Maria, Departamento de Ciência e Tecnologia em Alimentos \\ *lqz@pq.cnpq.br
}

\begin{abstract}
RESUMO: O objetivo do estudo foi avaliar o potencial da microalga na produção de compostos orgânicos voláteis voltados para aplicações industriais utilizando água residuária como substrato. Os experimentos foram realizados em um reator de coluna de bolhas. Os experimentos foram realizados em biorreator descontínuo com aeração contínua e ausência de luminosidade, contendo $2 \mathrm{~L}$ de água residuária proveniente do abate e processamento de aves e suínos, inoculado com a microalga Phormidium autumnale. Os compostos orgânicos voláteis foram isolados por microextração em fase sólida no headspace (FIBRA DVB/Car/PDMS) e analisados por cromatografia gasosa acoplada a um detector de massas (SPME-GCMS). A amostragem foi realizada a cada 24 horas durante o de tempo de residência celular. Foi detectado um total de 15 compostos orgânicos voláteis, nos quais possuem uma ampla aplicação industrial.
\end{abstract}

Palavras-chave: voláteis, Phormidium autumnale, cultivo heterotrófico.

\section{DETERMINATION OF VOLATILE COMPOUNDS OF MICROALGAE WITH POTENTIAL FOR INDUSTRIAL APPLICATION}

\begin{abstract}
The objective of this work was to evaluate the production of volatile organic compounds to apply in industry, used microalgae cultivated in wastewater. The experiments were conducted in a discontinuous bioreactor with continuous aeration and absence of light, containing 2 liters of slaughter effluent and processing of birds and swine inoculated with the microalga Phormidium autumnale. The volatile organic compounds were isolated by solid phase microextraction in the headspace (DVB /Car/ PDMS FIBER) and analyzed by gas chromatography coupled to a mass detector (SPME-GCMS). Sampling was performed every 24 hours over the cell residence time. A total of 15 volatile organic compounds were detected, in which they have a wide industrial application.
\end{abstract}

Keywords: agriculture, symposium, wastes.

\section{INTRODUÇÃO}

A biotecnologia de microalgas é uma área emergente da tecnologia industrial, que vem se consolidando em função da potencialidade da exploração dos bioprodutos resultantes dos processos de produção. As microalgas podem ser consideradas um ingrediente alimentar inovador e promissor, rico em nutrientes, como proteínas, ácidos graxos poli-insaturados de cadeia longa, carotenoides, vitaminas, minerais e fenólicos, além de outras moléculas bioativas, possuindo potencial de aumentar o valor nutricional dos alimentos (RODRIGUES et al., 2014; ROBERTSON et al., 2016).

Diferentes espécies de microalgas apresentam capacidade de produzir metabólitos secundários, os quais podem ser intracelulares e/ou extracelulares. As microalgas liberam compostos voláteis para os ecossistemas circundantes, que desempenham papéis importantes na comunicação química. A emissão de compostos voláteis por microalgas é influenciada pelas condições ambientais (LOPEZ-PÉREZ et al., 2017).

Diante do exposto, o objetivo deste trabalho foi avaliar o potencial da microalga Phormidium autumnale na produção de compostos orgânicos voláteis voltados para aplicações industriais utilizando água residuária como substrato. 


\section{MATERIAL E MÉTODOS}

A microalga utilizada foi a Phormidium autumnale, isolada do Deserto Cuatro Sienegas no México $\left(26^{\circ} 59^{\prime} \mathrm{N} 102^{\circ} 03 \mathrm{~W}\right)$. As culturas reservas foram mantidas e propagadas em agar-agar solidificado $\left(20{\mathrm{~g} . \mathrm{L}^{-1}}^{-1}\right)$ com meio sintético BG11 (Rippka et al., 1979). As condições de manutenção usadas foram $25^{\circ} \mathrm{C}$ e intensidade luminosa constante de 1 klux.

Os experimentos foram realizados em um reator de coluna de bolhas. O sistema foi construído de vidro de borosilicato com diâmetro externo de $12,5 \mathrm{~cm}$ e altura de $16 \mathrm{~cm}$, com razão altura/diâmetro proporção igual a 1,28 e um volume nominal de 2,0 L. O sistema de dispersão do reator consistiu em um difusor de ar com 2,5 centímetros de diâmetro localizado no interior do biorreator. O fluxo de ar controlado pelo medidor de fluxo (Kl-Key Instruments ${ }^{\circledR}$, Trevose, PA, EUA) e a entrada de ar e a saída de gases foram filtrados com unidades filtrantes constituídas de membrana de polipropileno, com um diâmetro de poro de $0,22 \mu \mathrm{m}$ e o diâmetro total de $50 \mathrm{~mm}$ (Millex FG ${ }^{\circledR}$, Billerica, MA, EUA). O biorreator, incluindo unidades filtrantes foram esterilizados em autoclave a $121^{\circ} \mathrm{C}$ durante 20 minutos. Os experimentos foram realizados em biorreatores em regime de batelada, alimentado com 2,0 L de água residuária, oriundas do abate e processamento de aves e suínos (Concórdia, SC). As condições experimentais foram as seguintes: concentração inicial do inóculo de $100 \mathrm{mg} . \mathrm{L}^{-}$ ${ }^{1}$, a temperatura de $25^{\circ} \mathrm{C}$, o pH ajustado para 7,6, aeração de $1 \mathrm{VVM}$ (volume de ar por volume de meio por minuto), ausência de luz e relação C/N (Carbono/Nitrogênio) de 30.

Os compostos voláteis formados no bioprocesso foram isolados pela técnica de microextração em fase sólida aplicada em headspace (HS-SPME). A amostragem realizada no tempo zero e a cada $24 \mathrm{~h}$ durante o crescimento celular. A fibra de SPME de revestimento misto empregada foi a DVB/Car/PDMS $(50 / 30 \mu \mathrm{m} \times$ $20 \mathrm{~mm}$, Supelco Bellefonte, PA, USA), pré-condicionada conforme as recomendações fornecidas pelo fabricante. A temperatura de extração de $40^{\circ} \mathrm{C}$, com um tempo de equilíbrio de 5 minutos, após exposição da fibra por 45 minutos. A análise dos compostos voláteis foi realizada em um cromatógrafo a gás acoplado a um espectrômetro de massas (GC/MS Shimadzu QP-2010 Plus). As separações cromatográficas em coluna Chrompack WAX 52-CB $(60 \mathrm{~m} \times 0,25 \mathrm{~mm}$ d.i. $\times 0,25 \mu \mathrm{m}$ de diâmetro de fase estacionária). $\mathrm{O}$ gás de arraste utilizado foi o hélio com vazão constante de $1,6 \mathrm{~mL} \cdot \mathrm{min}^{-1}$. A temperatura inicial da coluna de $35^{\circ} \mathrm{C}$, permanecendo por 5 minutos, após elevada até $220^{\circ} \mathrm{C} \mathrm{com} \mathrm{gradiente} \mathrm{de} \mathrm{temperatura} \mathrm{de} 5^{\circ} \mathrm{C} . \mathrm{min}^{-1}$, mantendose isotermicamente por 5 minutos. A interface GC/MS e da fonte de ionização foram mantidos a $250{ }^{\circ} \mathrm{C}$. $\mathrm{O}$ detector de massas foi operado no modo de ionização por elétrons, com feixe de elétrons a $+70 \mathrm{eV}$. $\mathrm{O}$ analisador de massas do tipo quadrupolos foi utilizado no modo de varredura na faixa de 35 a $350 \mathrm{~m} / \mathrm{z}$. Os compostos foram identificados primeiramente por comparação dos seus espectros de massa com os do banco de dados espectral da própria biblioteca do GC-MS (NIST MS Search 2.0). A identificação foi confirmada por comparação dos Indices de Retenção Linear calculados.

\section{RESULTADOS E DISCUSSÃO}

A Tabela 1 mostra os compostos voláteis detectados no experimento. No tempo 0 horas apenas alguns compostos foram identificados, e estes são 6-metil-5-hepten-2-one, Mentol, Benzotiazole, 1-penten-3-ol. As cetonas podem ser formadas em muitas maneiras; cetonas alifáticas podem ser produtos da oxidação lipídica ou degradação e metil cetonas (C3-C17), tais como 6-metil- 5-hepten-2-ona, pode ser formado a partir da clivagem oxidativa de carotenóides. (RODRIGUES et al. 2014; SANTOS et al., 2016). Os quais dentro de industrias são aplicados como agentes de sabor e fragrância. No tempo 24 horas já foi possível a identificação de mais compostos voláteis, entre eles, como exemplo, acetaldeído que pode ser usado em indústria com um agente de cosméticos e sabor. Em tempo de 48 e 72horas, os números de compostos voláteis diminuiu, restando apenas alguns com a concentração baixa tais como 2-heptanone, 2-nonanone, mentol, benzotiazol e 1-penten3-ol como é possível observar na Tabela 1. 


\section{CONCLUSÃO}

A quantidade de compostos de interesse comercial que podem ser obtidos das microalgas parece ser imprevisível. Em nível mundial, o crescente interesse em tecnologias limpas, sustentáveis e orgânicas, na obtenção de produtos para o consumo humano, necessita de uma busca continua por espécies e/ou variedades capazes de sintetizar grandes quantidades de compostos específicos e de como é possível potencializar a biossíntese destes (condições de cultivo, melhoramento genético etc. Com os dados obtidos foi possível verificar os compostos voláteis produzidos e identificar sua aplicação industrial.

\section{AGRADECIMENTOS}

Coordenação de Aperfeiçoamento de Pessoal de Nível Superior (CAPES); Fundação de Amparo à Pesquisa do Estado do Rio Grande do Sul (FAPERGS); Conselho Nacional de Pesquisa (CNPq) e Universidade Federal de Santa Maria (UFSM).

\section{REFERÊNCIAS}

SANTOS, A. B.; FERNANDES, A. S.; WAGNER, R.; JACOB-LOPES, E.; ZEPKA, L. Q.; Biogeneration of volatile organic compounds produced by phormidium autumnale in heterotrophic bioreactor. Journal of applied phycology, 6 november 2015.

RIPPKA, R.; DERUELlES, J.; WATERBURY, J. B.; HERDMAN, M.; STANIER, R. Y. GENERIC Assignments strain histories and properties of pure cultures of cyanobacteria. Journal of General Microbiology. 1979, V.111, P.1-61.

ROBERTSON, R. C.; MATEO, M. R. G.; O'GRADY, M. N.; GUIHENEUF, F.; STENGEL, D. B.; ROSS, R. P.; FITZGERALD, G. F.; KERRY, J. P.; STANTON, C. An assessment of the techno-functional and sensory properties of yoghurt fortified with a lipid extract from the microalga pavlova lutheri. Innovative. Food Science and Emerging Technologies. 2016, V.37, P.237-246.

RODRIGUES, D. B.; FLORES, E. M. M.; BARIN, J. S.; MERCADANTE, A. Z.; JACOB-LOPES, E.; ZEPKA, L. Q. Production of carotenoids from microalgae cultivated using agroindustrial wastes. Food Research International. 2014, V.65, P.144-148. 
Tabela 1. Concentração dos compostos orgânicos voláteis $\left(\mu \mathrm{g} \cdot \mathrm{m}^{-3} \pm \sigma\right)$ do biorreator micoalgal utilizando aeração (1,0 volume de ar por volume de efluente por minuto).

\begin{tabular}{|c|c|c|c|c|c|c|c|}
\hline \multirow{2}{*}{ Pico } & \multirow{2}{*}{ Composto } & \multirow{2}{*}{$\begin{array}{l}\text { LRI DB- } \\
\text { Wax }^{a}\end{array}$} & \multicolumn{4}{|c|}{ Tempo residência $^{b}$} & \multirow{2}{*}{$\begin{array}{l}\text { Aplicação } \\
\text { industrial }\end{array}$} \\
\hline & & & $\mathbf{O} \mathbf{h}$ & $24 \mathrm{~h}$ & $48 \mathrm{~h}$ & $72 \mathrm{~h}$ & \\
\hline 5 & Acetaldeido & 890 & $\mathrm{nd}^{c}$ & $2,6 \pm 0,3$ & nd & nd & $\begin{array}{l}\text { cosméticos e } \\
\text { sabor }\end{array}$ \\
\hline 12 & 2-metil pentanol & 1099 & nd & $0,5 \pm 0,1$ & nd & nd & $\begin{array}{l}\text { Substâncias } \\
\text { naturais }\end{array}$ \\
\hline 13 & 2-metil-3-hexanone & 1140 & nd & $4,2 \pm 0,5$ & nd & nd & $\begin{array}{l}\text { Substâncias } \\
\text { naturais }\end{array}$ \\
\hline 14 & acetil valeril & 1153 & nd & $2,5 \pm 0,6$ & nd & nd & aromatizantes \\
\hline 16 & 2-heptanone & 1181 & nd & $1,2 \pm 0,4$ & $5,0 \pm 0,5$ & $5,0 \pm 0,7$ & $\begin{array}{c}\text { Sabor e } \\
\text { fragrância }\end{array}$ \\
\hline 20 & 3-metil butanol & 1221 & nd & $0,4 \pm 0,1$ & nd & nd & $\begin{array}{l}\text { sabor e } \\
\text { fragrância }\end{array}$ \\
\hline 26 & $\begin{array}{l}\text { 6-metil-5-hepten-2- } \\
\text { one }\end{array}$ & 1327 & $3,8 \pm 0,4$ & $3,8 \pm 0,4$ & $2,0 \pm 0,6$ & nd & $\begin{array}{l}\text { sabor e } \\
\text { fragrância }\end{array}$ \\
\hline 29 & 2-nonanone & 1382 & nd & $1,1 \pm 1,6$ & $1,4 \pm 0,8$ & $2,3 \pm 0,8$ & $\begin{array}{l}\text { sabor e } \\
\text { fragrância }\end{array}$ \\
\hline 30 & $\begin{array}{l}\text { metil 3-methil 2- } \\
\text { hidroxi butanoate }\end{array}$ & 1390 & nd & $2,4 \pm 0,4$ & nd & nd & $\begin{array}{l}\text { Substâncias } \\
\text { naturais }\end{array}$ \\
\hline 31 & Ciclo hexanol & 1395 & nd & $6,5 \pm 1,0$ & nd & nd & $\begin{array}{l}\text { aromatizantes } \\
\text { e cosméticas }\end{array}$ \\
\hline 32 & 5-ethil-2-nonanol & 1399 & nd & $2,3 \pm 0,2$ & nd & nd & $\begin{array}{l}\text { Substâncias } \\
\text { naturais }\end{array}$ \\
\hline 40 & Mentol & 1642 & $4,4 \pm 0,2$ & $5,7 \pm 0,4$ & $7,3 \pm 0,8$ & $7,6 \pm 0,6$ & $\begin{array}{l}\text { sabor e } \\
\text { fragrância }\end{array}$ \\
\hline 41 & $\begin{array}{l}\text { 3-metilpentanoic } \\
\text { acid }\end{array}$ & 1655 & nd & $0,7 \pm 0,2$ & nd & nd & aromatizantes \\
\hline 49 & Benzotiazole & 1896 & $3,3 \pm 0,7$ & $2,2 \pm 0,7$ & $3,8 \pm 1,0$ & $5,0 \pm 0,1$ & $\begin{array}{l}\text { sabor e } \\
\text { fragrância }\end{array}$ \\
\hline 53 & 1-penten-3-ol & 2041 & $0,6 \pm 0,3$ & $5,0 \pm 0,9$ & $1,0 \pm 0,7$ & $0,3 \pm 0,5$ & $\begin{array}{l}\text { sabor e } \\
\text { fragrância }\end{array}$ \\
\hline
\end{tabular}

${ }^{a}$ índice de retenção linear em coluna DB-Wax;

${ }^{b}$ média e desvio padrão, da repetição de experimentos independentes;

${ }^{c}$ nd: não detectado. 


\title{
EFEITO DA TETRACICLINA SOBRE A ATIVIDADE DE BACTÉRIAS NITRIFICANTES
}

\author{
Langbehn, R.K.*1'; Michels, C. ${ }^{1}$; Soares, H.M. ${ }^{1}$ \\ ${ }^{I}$ Departamento de Engenharia Química e Engenharia de Alimentos, Universidade Federal de Santa Catarina, Florianópolis, SC - \\ Brasil \\ rayanekl@yahoo.com.br
}

\begin{abstract}
RESUMO: Antibióticos, como a tetraciclina (TC), tem sido extensivamente utilizados na produção animal nos últimos anos. No entanto, estes compostos não são totalmente metabolizados pelos animais e alcançam o sistema de tratamento de efluentes, onde podem interferir nos processos biológicos e provocar impactos ambientais que ainda não são totalmente conhecidos. Deste modo, este trabalho tem como objetivo avaliar o efeito da TC sobre a atividade de culturas de bactérias nitrificantes. Foram realizados ensaios em bancada com diferentes concentrações de TC e culturas enriquecidas de bactérias oxidadoras de amônia (BOA) e bactérias nitrificantes. Os resultados mostraram maior efeito inibitório da TC sobre as cultura de BOAs em comparação às nitrificantes, indicando que a maior complexidade da comunidade bacteriana reduz os efeitos tóxicos da tetraciclina. Apesar das elevadas concentrações de TC, a concentração que inibe $50 \%$ da atividade bacteriana (CI50) somente foi alcançada na exposição das BOAs à TC, cujo valor foi de $273 \mathrm{mg} \mathrm{L}^{-1}$.
\end{abstract}

Palavras-chave: antibióticos, inibição, nitrificação, poluentes emergentes.

\section{TETRACYCLINE EFFECT ON NITRYFYING BACTERIA ACTIVITIES}

\begin{abstract}
Antibiotics, as tetracycline (TC), have been extensively used in food-production animal on the last years. However, some of these compounds can leave the digestive system on its active form and reach wastewater treatment, where they can disturb biological processes, bringing environmental impacts with dimensions not yet fully known. Therefore, the aim of this study was to evaluate the effect of TC over nitrifying bacteria cultures. Short-term exposure assays were performed with different concentrations of TC, on enriched ammonia oxidizing bacteria (AOB) culture and nitrifying bacteria. Results pointed out higher inhibitory effect for TC over AOB culture than nitrifying, therefore greater complexity of bacterial culture reduces the toxic effects of antibiotics. Although high antibiotic concentrations were applied, 50\% activity inhibitory concentration (IC50) was achieved only for AOB culture exposed to tetracycline, whose value was $273 \mathrm{mg} \mathrm{L}^{-}$ 1
\end{abstract}

Keywords: antibiotics, emerging pollutants, inhibition, nitrification.

\section{INTRODUÇÃO}

O uso indiscriminado de antibióticos na produção animal, como a suinocultura, tem contribuído para o acúmulo destes compostos no ambiente ao longo dos anos (KÜMMERER, 2009). Isto ocorre, pois, estes fármacos não são totalmente metabolizados no trato digestivo dos animais e, assim, são excretados na forma ativa ou em metabólitos, que podem ter atividade antimicrobiana (JJEMBA, 2006). Uma vez excretados junto aos dejetos animais, os antibióticos podem ser enviados para estações de tratamento de efluentes, cuja configuração convencional não é capaz de alcançar boas eficiências de remoção para estes compostos. Assim, os antibióticos podem alcançar o solo, as águas superficiais e subterrâneas (CAMPAGNOLO et al., 2002). A ocorrência de antibióticos nestes ambientes pode provocar modificações na microbiota e contribuir para a proliferação dos genes de resistência antimicrobiana, configurando um problema ambiental a nível global.

As tetraciclinas estão entre os antibióticos mais produzidos no mundo (DAGHRIR; DROGUI, 2013). Alguns dos antibióticos deste grupo, como a tetraciclina (TC), são utilizados em larga escala na produção de animais, principalmente com propósitos terapêuticos e, consequentemente, sua presença já foi detectada em sistemas de tratamento de efluentes, águas superficiais, solos e sedimentos (BORGHI; PALMA, 2014).

A nitrificação é um processo biológico importante para o tratamento de efluentes da suinocultura, devido à elevada concentração de nitrogênio, sendo realizada por dois grupos de bactérias: as oxidadoras de amônia (BOA) e oxidadoras de nitrito (BON) (METCALF; EDDY, 2003). As BOAs, em especial, são conhecidas pela sensibilidade à presença de compostos tóxicos sendo, muitas vezes, consideradas como indicadores de inibidores em sistemas aeróbios e, portanto, poderiam ser inibidas na presença da TC (CARUCCI; CAPPAI; PIREDDA, 2006). Deste modo, o objetivo deste trabalho foi avaliar os efeitos provocados pela presença de TC em culturas enriquecidas de BOAs e nitrificantes $(\mathrm{BOA}+\mathrm{BON})$ em ensaios cinéticos em batelada. 


\section{Cultura bacteriana}

\section{MATERIAL E MÉTODOS}

As culturas enriquecidas de BOAs e bactérias nitrificantes (BOAs + BONs), foram cultivadas em reatores de escala laboratorial de $8 \mathrm{~L}$ e $5 \mathrm{~L}$, respectivamente. Os reatores foram operados em batelada sequencial (RBS) (três ciclos de 8h00) e as principais diferenças operacionais entre eles foram a temperatura e o tempo de aeração. Para o cultivo das BOAs a temperatura foi ajustada em $32 \pm 1^{\circ} \mathrm{C}$ com aeração intermitente, sendo aerado por $0 \mathrm{~h} 15$ durante cada hora de reação. A cultura nitrificante foi mantida à temperatura de $30 \pm 1^{\circ} \mathrm{C}$ sob aeração contínua. As duas culturas foram cultivadas com o meio sintético adaptado de Campos et al. (1999), alterando a concentração de $\mathrm{NH}_{4} \mathrm{Cl}$ para $1,72 \mathrm{~g} \mathrm{~L}^{-1},\left(\mathrm{NH}_{4}\right)_{2} \mathrm{SO}_{4}$ para $2,12 \mathrm{~g} \mathrm{~L}^{-1}$ e $\mathrm{NaHCO}_{3}$ para 10,73 $\mathrm{g} \mathrm{L}^{-1}$.

\section{Ensaios de inibição em batelada}

Os ensaios de inibição da TC $\left(\mathrm{C}_{22} \mathrm{H}_{24} \mathrm{~N}_{2} \mathrm{O}_{8} \cdot \mathrm{HCl}\right)$ (grau HPLC, Sigma-Aldrich) sobre a comunidades bacterianas (BOAs e nitrificantes) foram realizados em erlenmeyers com defletores $(200 \mathrm{~mL})$, com concentração celular igual a $0,5 \mathrm{~g} \mathrm{SSV} \mathrm{L}^{-1}$. As culturas foram incubadas em shaker orbital (Tecnal, TE-420) a $200 \mathrm{rpm}$ por $12 \mathrm{~h} 00$ e sob a mesma temperatura de cultivo das bactérias nos reatores RBS. O meio de cultivo utilizado para os ensaios de inibição também foi o mesmo dos reatores RBS, porém a concentração de amônia foi reduzida para $200 \mathrm{mg} \mathrm{N}-\mathrm{NH}_{4}^{+} \mathrm{L}^{-1}\left(0,38 \mathrm{~g} \mathrm{~L}^{-1}\right.$ de $\mathrm{NH}_{4} \mathrm{Cl}$ e $0,47 \mathrm{~g} \mathrm{~L}^{-1}$ de $\left.\left(\mathrm{NH}_{4}\right)_{2} \mathrm{SO}_{4}\right)$, assim como a concentração de bicarbonato, que foi reduzida proporcionalmente $\left(2,39 \mathrm{~g} \mathrm{~L}^{-1}\right.$ de $\left.\mathrm{NaHCO}_{3}\right)$ para evitar altos valores de $\mathrm{pH}$ durante os ensaios. As concentrações de TC avaliadas neste experimento variaram de 0 a 500 $\mathrm{mg} \mathrm{L}^{-1}$ para a cultura de BOAs e de 0 a $1.000 \mathrm{mg} \mathrm{L}^{-1}$ para a cultura nitrificante. Apesar de algumas destas concentrações não serem encontradas nos efluentes da criação intensiva de animais, elas foram escolhidas para contribuir no entendimento dos efeitos e limitações provocadas pela TC sobre as comunidades microbianas.

A cada $2 \mathrm{~h} 00$ foram coletados $6 \mathrm{~mL}$ de amostra para quantificação das formas nitrogenadas e o $\mathrm{pH}$ foi corrigido para 7,5 (pHmetro portátil Hanna ${ }^{\circledR}, \mathrm{HI}$ 98.190). As amostras foram centrifugadas (centrífuga Eppendorf, 5804R) a $10.000 \mathrm{~g}$ por 00h10 para separar as células em suspensão e, em seguida, submetidas a uma extração em fase sólida com cartuchos HLB ${ }^{\circledR} 3$ cc (Oasis, Waters) para extrair o antibiótico e evitar interferência analítica. As formas nitrogenadas foram quantificadas por meio de métodos colorimétricos em espectrofotômetro UV-Vis (HACH, DR 5.000): a amônia foi quantificada pelo método de Nessler (VOGEL, 2008), o nitrito com o kit analítico Nitriver2 (HACH) e o nitrato com o método do ácido salićlíco (CATALDO et al., 1975). Os sólidos suspensos foram quantificados de acordo com APHA (2005).

\section{Cálculo da concentração inibitória (CI)}

A inibição foi calculada com base na velocidade máxima de consumo de amônia durante os ensaios cinéticos, como mostrado na equação (1):

$$
\mathrm{CI}=\left(\frac{\mathrm{q}_{\mathrm{N} \_\mathrm{NH}_{4}^{+}, 0}-\mathrm{q}_{\mathrm{N} \_\mathrm{NH}_{4}^{+}, \mathrm{i}}}{\mathrm{q}_{\mathrm{N} \_\mathrm{NH}_{4}^{+}, 0}}\right) \cdot 100 \%
$$

Na qual, $\mathrm{q}_{\mathrm{N}_{-} \mathrm{NH}_{4}^{+}, 0}\left(\mathrm{mg} \mathrm{L}^{-1} \mathrm{~h}^{-1}\right)$ é a velocidade máxima de consumo de amônia no controle $(\mathrm{TC}=0 \mathrm{mg} \mathrm{L}-$ $\left.{ }^{1}\right)$ e $\mathrm{q}_{\mathrm{N}_{-} \mathrm{NH}_{4}^{+}, \mathrm{i}}\left(\mathrm{mg} \mathrm{L}^{-1} \mathrm{~h}^{-1}\right)$ é a velocidade máxima de consumo de amônia no ensaio com $\mathrm{TC}=i \mathrm{mg} \mathrm{L}^{-1}$.

\section{RESULTADOS E DISCUSSÃO}

O efeito da TC sobre as culturas enriquecidas de BOAs e nitrificantes estão apresentados na Figura 1. Estes resultados mostraram que o aumento da concentração de TC diminuiu o consumo de amônia durante os ensaios cinéticos nos dois casos. No entanto, as BOAs mostraram maior sensibilidade que as nitrificantes na presença do antibiótico. Quando as BOAs foram expostas a $500 \mathrm{mg} \mathrm{L}^{-1}$ de TC, a eficiência de conversão de amônia reduziu em $90 \%$, enquanto que para as nitrificantes, na mesma concentração de antibiótico, foi observada uma redução de $65 \%$ na eficiência de remoção de amônia em relação ao ensaio controle $\left(0 \mathrm{mg} \mathrm{L}^{-1}\right.$ de TC).

Apesar de elevadas concentrações de TC levarem a um efeito inibitório, as menores concentrações avaliadas ( $3 \mathrm{mg} \mathrm{L}^{-1}$ e $30 \mathrm{mg} \mathrm{L}^{-1}$ para BOAs e $100 \mathrm{mg} \mathrm{L}^{-1}$ para nitrificantes) estimularam a velocidade de remoção de amônia (Tabela 1). Este efeito, conhecido como hormese, é característico a vários antibióticos que apresentam uma relação de dose-resposta bifásica, na qual concentrações subletais do antibiótico estimulam a 
atividade celular, enquanto que o aumento da dose administrada inibe a atividade (CALABRESE; BALDWIN, 2003).

Para obter a correlação entre concentração de TC e CI (Figura 2) foram desconsideradas as concentrações com efeito hormético. A concentração de antibiótico que inibiu 50\% da atividade bacteriana (CI50) foi encontrada somente para a exposição das BOAs à tetraciclina e foi igual a $273,07 \mathrm{mg} \mathrm{L}^{-1}$. Para as nitrificantes não foi possível obter o CI50 dentro da faixa de concentrações avaliada. No entanto, para comparação de resultados, a concentração referente ao CI50 sobre as BOAs inibiu a atividade nitrificante em $18,4 \%$. Estes resultados permitem inferir que as BOAs são mais sensíveis à presença de TC que as bactérias nitrificantes. Isto pode ser justificado pela maior diversidade bacteriana da comunidade nitrificante, pois a presença de espécies mais resistentes à TC poderia mascarar os efeitos inibitórios sobre os microrganismos mais sensíveis (KÜMMERER, 2009). Além disso, o mecanismo simbiótico de conversão do nitrito (que também é um inibidor do processo) a nitrato, também poderia influenciar na diminuição do efeito inibitório.

Para avaliar o impacto ambiental da TC em sistemas de tratamento de efluentes, também é importante considerar o tratamento e a disposição final do lodo, uma vez essa molécula pode ser adsorvida pelo lodo ativado (DAGHRIR; DROGUI, 2013). Uma prática comum à produção de suínos no Brasil é a utilização do logo como fertilizante para o solo (KUNZ; MIELE; STEINMETZ, 2009). Assim, o lodo contendo TC é depositado no solo, onde a TC pode ser adsorvida e concentrada, uma vez que seu coeficiente de adsorção pode ser superior a $1.000 \mathrm{~mL} \mathrm{~g}^{-1}$ (HAMSCHER et al., 2005). A presença de TC no solo poderia levar a efeitos similares aos observados sobre as culturas nitrificantes estudas neste trabalho, uma vez que estas bactérias também são encontradas no solo. Além do impacto no solo e na água, a presença de TC nestes ambientes pode contribuir para a disseminação de genes de resistência entre microrganismos comuns a estes sistemas e que, posteriormente, podem ser transferidos a patógenos animais. Isto acarretaria no decaimento da eficácia destes antibióticos no tratamento de doenças infecciosas e reflete na necessidade de controlar e reduzir o descante de antibióticos no meio ambiente.

\section{CONCLUSÃO}

O presente trabalho avaliou como um antibiótico de amplo espectro (TC) pode impactar culturas enriquecidas de BOAs e bactérias nitrificantes, comumente encontradas em sistemas de tratamento de efluentes. As duas comunidades tiveram sua velocidade de consumo de amônia diminuída na presença do antibiótico. No entanto, as BOAs sofreram maior inibição sendo encontrado CI50 igual a $273 \mathrm{mg} \mathrm{L}^{-1}$, enquanto que para as nitrificantes não foi possível obter o CI50. Com isso, foi possível concluir que a maior complexidade da comunidade bacteriana diminui o efeito inibitório da TC e que esta possui baixa toxicidade sobre as culturas nitrificantes.

\section{AGRADECIMENTOS}

Este trabalho foi realizado com apoio do Conselho Nacional de Desenvolvimento Científico e Tecnológico (CNPq).

\section{REFERÊNCIAS}

(APHA), AMERICAN PUBLIC HEALTH ASSOCIATION. Standard methods for the examination of water and wastewater. 21. ed. Washington, D.C.: American Public Health Association, 2005.

CALABRESE, Edward J.; BALDWIN, Linda A. Hormesis : The Dose-Response Revolution. Annual Review of Pharmacology and Toxicology, [s. 1.], v. 43, n. 1, p. 175-197, 2003. Disponível em: <http://www.annualreviews.org/doi/10.1146/annurev.pharmtox.43.100901.140223>

CAMPAGNOLO, Enzo R. et al. Antimicrobial residues in animal waste and water resources proximal to largescale swine and poultry feeding operations. Science of the Total Environment, [s. 1.], v. 299, n. 1-3, p. 8995, 2002.

CAMPOS, J. L. et al. Nitrification at high ammonia loading rates in an activated sludge unit. Bioresource Technology, [s. 1.], v. 68, n. 2, p. 141-148, 1999.

CATALDO, D. A. et al. Rapid colorimetric determination of nitrate in plant tissue by nitration of salicylic acid. Communications in Soil Science and Plant Analysis, [s. 1.], v. 6, n. 1, p. 71-80, 1975.

DAGHRIR, R.; DROGUI, P. Tetracycline antibiotics in the environment: A review. Environmental Chemistry Letters, [s. 1.], v. 11, n. 3, p. 209-227, 2013.

HAMSCHER, Gerd et al. Different behavior of tetracyclines and sulfonamides in sandy soils after repeated 


\section{VISIGERA OEF7 A09 MA0 2019

fertilization with liquid manure. Environmental Toxicology and Chemistry, [s. 1.], v. 24, n. 4, p. 861-868, 2005.

JJEMBA, Patrick K. Excretion and ecotoxicity of pharmaceutical and personal care products in the environment. Ecotoxicology and Environmental Safety, [s. 1.], v. 63, n. 1, p. 113-130, 2006.

KÜMMERER, Klaus. Antibiotics in the aquatic environment - A review - Part I. Chemosphere, [s. 1.], v. 75, n. 4, p. 417-434, 2009. Disponível em: 〈http://dx.doi.org/10.1016/j.chemosphere.2008.11.086>

KUNZ, A.; MIELE, M.; STEINMETZ, R. L. R. Advanced swine manure treatment and utilization in Brazil. Bioresource Technology, $[\mathrm{s} . \quad 1],$.$\quad v. 100, n. 22, p. 5485-5489, 2009. Disponível em:$ <http://dx.doi.org/10.1016/j.biortech.2008.10.039>

VOGEL, Arthur Israel. Análise Química Quantitativa. 6. ed. Rio de Janeiro: LTC, 2008.

(a)

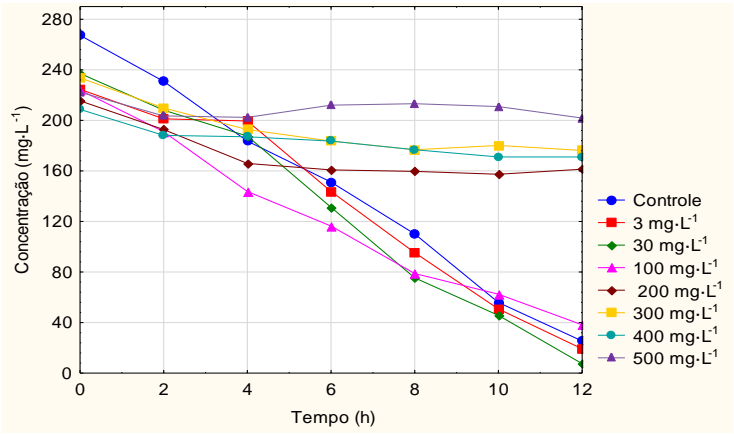

(b)

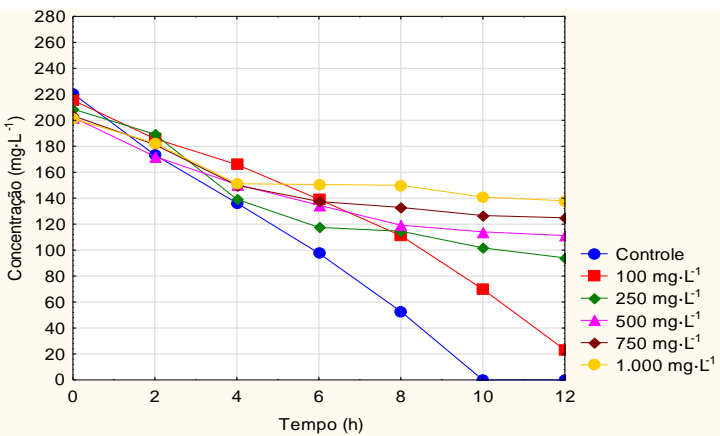

Figura 1. Concentração de nitrogênio na forma de amônio $\left(\mathrm{N}_{-} \mathrm{NH}_{4}{ }^{+}\right)$em função do tempo para distintas concentrações de tetraciclina em (a) BOAs e (b) nitrificantes.

(a)

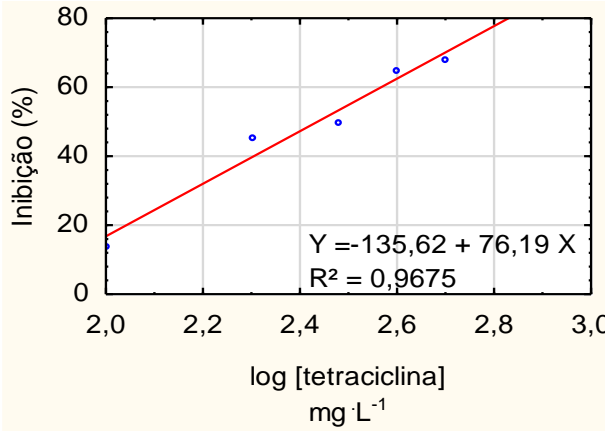

(b)

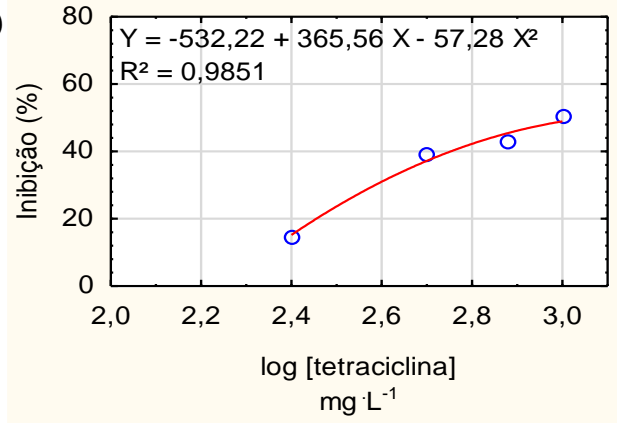

Figura 2. Correlação entre o grau de inibição da atividade bacteriana e o logaritmo da concentração de tetraciclina em (a) BOAs e (b) nitrificantes.

Tabela 3. Velocidades máximas de consumo de amônia e percentuais de inibição de diferentes concentrações de tetraciclina (TC) sobre bactérias oxidadoras de amônia (BOAs) e nitrificantes.

\begin{tabular}{|c|c|c|c|c|c|}
\hline \multicolumn{3}{|c|}{ BOAs } & \multicolumn{3}{|c|}{\begin{tabular}{|l} 
Nitrificantes \\
\end{tabular}} \\
\hline $\begin{array}{c}\mathrm{TC} \\
\left(\mathrm{mg} \mathrm{L}^{-1}\right)\end{array}$ & $\begin{array}{l}\text { Velocidade máxima } \\
\left(\mathrm{mg} \mathrm{N}^{-N_{4}}{ }_{4}^{+} \mathbf{L}^{-1} \mathbf{h}^{-1}\right)\end{array}$ & Inibição (\%) & $\begin{array}{c}\mathrm{TC} \\
\left(\mathrm{mg} \mathrm{L}^{-1}\right)\end{array}$ & $\begin{array}{l}\text { Velocidade máxima } \\
\left(\mathrm{mg} \mathrm{N}^{-N_{4}}{ }_{4}^{+} \mathbf{L}^{-1} \mathbf{h}^{-1}\right)\end{array}$ & Inibição (\%) \\
\hline 0 & 23,61 & 0,00 & 0 & 22,83 & 0,00 \\
\hline 3 & 24,31 & $-2,95$ & 100 & 22,93 & $-0,43$ \\
\hline 30 & 25,61 & $-8,47$ & 250 & 19,44 & 14,86 \\
\hline 100 & 20,26 & 14,21 & 500 & 13,95 & 38,87 \\
\hline 200 & 11,07 & 45,52 & 750 & 13,04 & 42,86 \\
\hline 300 & 11,87 & 49,75 & 1.000 & 11,38 & 50,17 \\
\hline 400 & 6,98 & 64,71 & & & \\
\hline 500 & 7,52 & 68,13 & & & \\
\hline
\end{tabular}




\title{
REMOÇÃO DE COMPOSTOS ORGÂNICOS HIDROFÓBICOS DE ÁGUA RESIDUÁRIA UTILIZANDO A MICROALGA, PHORMIDIUM AUTUMNALE
}

\author{
Lasta, P. ${ }^{1}$; Vieira, K.R. ${ }^{1}$; Pinheiro, P.N. ${ }^{1}$; Wagner ${ }^{1}$, R.; Jacob-Lopes, E. ${ }^{1}$; Zepka, L.Q. ${ }^{* 1}$ \\ ${ }^{1}$ Universidade Federal de Santa Maria, Departamento de Ciência e Tecnologia em Alimentos \\ lqz@pq.cnpq.br
}

\begin{abstract}
RESUMO: O objetivo do estudo foi avaliar a capacidade da microalga em remover compostos orgânicos hidrofóbicos de água residuária do processamento de carne em cultivo heterotrófico. Os experimentos foram realizados em biorreatores descontínuo com aeração contínua e ausência de luminosidade, contendo $2 \mathrm{~L}$ de água residuária, sendo que um foi inoculado com a microalga Phormidium autumnale, e um segundo biorreator não foi inoculado. Os compostos orgânicos voláteis foram isolados por microextração em fase sólida no headspace (FIBRA DVB/Car/PDMS) e analisados por cromatografia gasosa acoplada a um detector de massas (SPME-GCMS). A amostragem foi realizada a cada 24 horas durante o de tempo de residência celular. Um total de 10 compostos terpênicos foram detectados por GC-MS. A microalga demonstrou capacidade em remover todos os compostos detectado no efluente, após 72 horas de tempo de residência.
\end{abstract}

Palavras-chave: microalgas, terpenos, efluente.

\section{REMOVAL OF ODOR COMPOUNDS ORGANIC HIDROPHOBIC OF THE WASTEWATER USING MICROALGA PHORMIDIUM AUTUMNALE}

\begin{abstract}
The objective of this work was to evaluate the removal of odor compounds organic hydrophobic of the wastewater using microalga. The experiments were carried out in a discontinuous bioreactor with continuous aeration and absence of light, containing $2 \mathrm{~L}$ of wastewater from the slaughter and processing of poultry and pigs, inoculated with the microalga Phormidium autumnale and second bioreactor without inoculated. The volatile organic compounds were isolated by solid phase microextraction in the headspace (DVB / Car / PDMS FIBER) and analyzed by gas chromatography coupled to a mass detector (SPME-GCMS). Sampling was performed every 24 hours over cell residence time. A total of 10 terpene compounds were detected by GC-MS. The microalgae demonstrated the ability to remove all compounds detected in the effluent after 72 hours of residence time.
\end{abstract}

Keywords: microalgae, terpenes, effluent.

\section{INTRODUÇÃO}

Microalgas são microrganismos fotossintéticos, que estão sendo amplamente explorados devido as suas capacidades de atuar como biocatalisadores de uma série de reações bioquímicas. As microalgas podem ser usadas para remediar as águas residuais para simultaneamente a remoção de nutrientes e a produção de biomassa, reduzindo assim significativamente os custos da matéria-prima (LING YU, K., et al., 2017).

O perfil volátil de estações de tratamento de água residuária (ETAR) nas indústrias de processamento de carnes inclui grupos característicos de odores, como álcoois, ácidos graxos voláteis, aldeídos e cetonas, que são produtos de decomposição de carboidratos, proteínas e lipídios. No entanto, as emissões odoríferas de ETAR também contêm uma ampla gama de compostos orgânicos hidrofóbicos, como os terpenos, cuja remoção é obrigatória para uma eficiente redução de odores (LEBRERO et al., 2013).

A presença de moléculas químicas hidrofóbicas na poluição por odores e a contribuição significativa destes compostos para o odor desagradável das instalações industriais implicam nos desafios tecnológicos para a remoção de odores no tratamento de resíduos. Nesse sentido, considerando uma alternativa custo-efetiva e ambientalmente correta, bem como a vantagem da plasticidade metabólica, convertendo moléculas apolares das águas residuárias, o uso de processos baseados em microalgas pode ser uma tecnologia inovadora para a desodorização de efluentes de indústria alimentícia. Em face disso, o objetivo deste trabalho foi avaliar o potencial da microalga Phormidium autumnale em remover compostos terpênicos da água residuária de uma indústria de processamento de alimentos. 


\section{MATERIAL E MÉTODOS}

A microalga utilizada foi a Phormidium autumnale, isolada do Deserto Cuatro Sienegas no México $\left(26^{\circ} 59^{\prime} \mathrm{N} 102^{\circ} 03 \mathrm{~W}\right)$. As culturas reservas foram mantidas e propagadas em agar-agar solidificado (20 g.. $\left.{ }^{-1}\right)$ com meio sintético BG11 (Rippka et al., 1979). As condições de manutenção usadas foram $25^{\circ} \mathrm{C}$ e intensidade luminosa constante de 1klux.

Os experimentos foram realizados em um reator de coluna de bolhas. O sistema foi construído de vidro de borosilicato com diâmetro externo de $12,5 \mathrm{~cm}$ e altura de $16 \mathrm{~cm}$, com razão altura/diâmetro proporção igual a 1,28 e um volume nominal de 2,0 L. O sistema de dispersão do reator consistiu em um difusor de ar com 2,5 centímetros de diâmetro localizado no interior do biorreator. O fluxo de ar controlado pelo medidor de fluxo (Kl-Key Instruments ${ }^{\circledR}$, Trevose, PA, EUA) e a entrada de ar e a saída de gases foram filtrados com unidades filtrantes constituídas de membrana de polipropileno, com um diâmetro de poro de $0,22 \mu \mathrm{m}$ e o diâmetro total de $50 \mathrm{~mm}$ (Millex FG ${ }^{\circledR}$, Billerica, MA, EUA). O biorreator, incluindo unidades filtrantes foram esterilizados em autoclave a $121^{\circ} \mathrm{C}$ durante 20 minutos. Os experimentos foram realizados em biorreatores em regime de batelada, alimentado com 2,0 L de água residuária, oriundas do abate e processamento de aves e suínos (Concórdia, SC). As condições experimentais foram as seguintes: concentração inicial do inóculo de $100 \mathrm{mg} . \mathrm{L}^{-}$ ${ }^{1}$, a temperatura de $25^{\circ} \mathrm{C}$, o pH ajustado para 7,6, aeração de $1 \mathrm{VVM}$ (volume de ar por volume de meio por minuto), ausência de luz e relação C/N (Carbono/Nitrogênio) de 30, um segundo reator foi montado paralelamente com as mesmas condições de cultivos, porém sem inóculo.

Os compostos voláteis formados no bioprocesso foram isolados pela técnica de microextração em fase sólida aplicada em headspace (HS-SPME). A amostragem realizada no tempo zero e a cada $24 \mathrm{~h}$ durante o crescimento celular. A fibra de SPME de revestimento misto empregada foi a DVB/Car/PDMS $(50 / 30 \mu \mathrm{m} \times$ $20 \mathrm{~mm}$, Supelco Bellefonte, PA, USA), pré-condicionada conforme as recomendações fornecidas pelo fabricante. A temperatura de extração de $40^{\circ} \mathrm{C}$, com um tempo de equilíbrio de 5 minutos, após exposição da fibra por 45 minutos. A análise dos compostos voláteis foi realizada em um cromatógrafo a gás acoplado a um espectrômetro de massas (GC/MS Shimadzu QP-2010 Plus). As separações cromatográficas em coluna Chrompack WAX 52-CB $(60 \mathrm{~m} \times 0,25 \mathrm{~mm}$ d.i. $\times 0,25 \mu \mathrm{m}$ de diâmetro de fase estacionária). $\mathrm{O}$ gás de arraste utilizado foi o hélio com vazão constante de $1,6 \mathrm{~mL} \cdot \mathrm{min}^{-1}$. A temperatura inicial da coluna de $35^{\circ} \mathrm{C}$, permanecendo por 5 minutos, após elevada até $220^{\circ} \mathrm{C} \mathrm{com} \mathrm{gradiente} \mathrm{de} \mathrm{temperatura} \mathrm{de} 5^{\circ} \mathrm{C} \cdot \mathrm{min}^{-1}$, mantendose isotermicamente por 5 minutos. A interface GC/MS e da fonte de ionização foram mantidos a $250^{\circ} \mathrm{C}$. $\mathrm{O}$ detector de massas foi operado no modo de ionização por elétrons, com feixe de elétrons a $+70 \mathrm{eV}$. O analisador de massas do tipo quadrupolos foi utilizado no modo de varredura na faixa de 35 a $350 \mathrm{~m} / \mathrm{z}$. Os compostos foram identificados primeiramente por comparação dos seus espectros de massa com os do banco de dados espectral da própria biblioteca do GC-MS (NIST MS Search 2.0). A identificação foi confirmada por comparação dos Î́ndices de Retenção Linear calculados.

\section{RESULTADOS E DISCUSSÃO}

No presente estudo, a remoção de compostos hidrofóbicos é apresentada na Tabela 1 . Um total de 10 terpenos foram detectados no biorreator heterotrófico, sendo eles o limoneno (pico 2) e seus derivados (picos 4, 5, 9), $\alpha$-terpineol (pico 10) e seus derivados (picos 1, 3, 8), linalool (pico 6) e fenchol (pico 7). Limoneno (49,9 $\mu \mathrm{g} . \mathrm{m}-3)$, foi totalmente removido em $72 \mathrm{~h}$, os isômeros de limoneno, $\alpha$-terpineno e $\rho$-cimeno desapareceram em $24 \mathrm{~h}$ de tempo de residência, o mesmo ocorreu com 1,4-cineole, linalool e fenchol. Além disso, $\alpha$-terpineol, 4-terpineol e 1,8-cineole foram degradados em 48 horas de tempo de residência. Observase que a partir de 72 horas, praticamente não possui mais nenhum composto presente, assim a microalga Phormidium autumnale apresenta uma eficiência de remoção de $100 \%$ de remoção desses compostos terpênicos da água residuária durante o cultivo heterotrófico.

Paralelamente a este bioprocesso, um segundo biorreator heterotrófico foi analisado, como um comparativo para verificar se os compostos foram removidos pela microalga ou pelo método físico aplicado, aeração. Os resultados desta etapa estão descritos da Tabela 2. Após 24 horas de processo, apenas três compostos terpênicos foram removidos, sendo que o cultivo heterotrófico microalgal removeu cinco compostos neste mesmo período. Em 48 horas, cinco compostos foram detectados, sendo que no cultivo microalgal, apenas o limoneno com uma concentração de 13,4 $\mu \mathrm{g} \cdot \mathrm{m}^{-3}$. E após 72 horas de tempo de residência no cultivo heterotrófico apenas com aeração, foram detectados os compostos limoneno, 1,8-cineol e linalool nas respectivas concentrações $51,0 \mu \mathrm{g} \cdot \mathrm{m}^{-3}, 2,9 \mu \mathrm{g} \cdot \mathrm{m}^{-3}$ e $33,4 \mu \mathrm{g} \cdot \mathrm{m}^{-3}$. No entanto, o cultivo heterotrófico 
microalgal apresentou a capacidade de remover todos os compostos terpênicos da água residuária proveniente do processamento de carne.

\section{CONCLUSÃO}

As águas residuárias do processamento de carne apresentam um total de 10 compostos terpênicos, sendo que biorreator heterotrófico de microalgal, em comparação com o método físico aplicado, apresentou capacidade em remover totalmente estes compostos em 72 horas de tempo de residência.

\section{AGRADECIMENTOS}

Coordenação de Aperfeiçoamento de Pessoal de Nível Superior (CAPES); Fundação de Amparo à Pesquisa do Estado do Rio Grande do Sul (FAPERGS); Conselho Nacional de Pesquisa (CNPq) e Universidade Federal de Santa Maria (UFSM).

\section{REFERÊNCIAS}

LEBRERO, R.; GONDIM, A. C., PÉREZ, R., GARCIA-ENCINA, P. A., MUNÕZ, R. Comparative assessment of a biofilter, a biotrickling filter and a hollow fiber membrane bioreactor for odor treatment in wastewater treatment plants. Water Research 49 (2014) 339 e 350.

LING YU, K., et al, Microalgae from wastewater treatment to biochar - feedstock preparation and conversion technologies, Elsevier, 2017. Disponivel em: <https://www.sciencedirect.com/ science/article/pii/s01968904 17306957> Acesso em: 20/11/18.

R. Lebrero, R., Volckaert, D., Pérez, R., Munõz, R., Langenhove, H. V. A membrane bioreactor for the simultaneous treatment of acetone, toluene, limonene and hexane at trace level concentrations. Water Research 47 (2013) 2199 e 2212,

RIPPKA, R., DERUElleS, J., WATERBURY, J. B., HERDMAN, M., STANIER, R. Y. Generic assignments, strain histories and properties of purê cultures of cyanobacteria, J. Gen. Microbiol. 111, p. 1-61, 1979.

Tabela 1. Dinâmica de remoção dos compostos voláteis terpênicos $\left(\mu \mathrm{g} \cdot \mathrm{m}^{-3} \pm \sigma\right)$ no biorreator heterotrófico microalgal.

\begin{tabular}{|c|c|c|c|c|c|c|}
\hline \multirow{2}{*}{ Pico } & \multirow{2}{*}{ Composto } & \multirow{2}{*}{$\begin{array}{l}\text { LRI DB- } \\
\text { Wax }^{a}\end{array}$} & \multicolumn{4}{|c|}{ Tempo de Residência $^{b}$} \\
\hline & & & $\mathbf{O} \mathbf{h}$ & $24 \mathrm{~h}$ & $48 \mathrm{~h}$ & $72 \mathrm{~h}$ \\
\hline 1 & 1,4-cineol & 1168 & $3,6 \pm 0,1$ & $\mathrm{nd}^{c}$ & nd & nd \\
\hline 2 & limoneno & 1182 & $49,9 \pm 0,1$ & $20,4 \pm 0,4$ & $13,4 \pm 0,5$ & nd \\
\hline 3 & 1,8-cineol & 1193 & $4,9 \pm 0,7$ & $1,1 \pm 0,1$ & nd & nd \\
\hline 4 & $\alpha$-terpinene & 1226 & $3,7 \pm 0,5$ & nd & nd & nd \\
\hline 5 & $\rho$-cimene & 1253 & $6,8 \pm 1,4$ & nd & nd & nd \\
\hline 6 & linalool & 1552 & $36,0 \pm 2,3$ & nd & nd & nd \\
\hline 7 & fenchol & 1574 & $4,3 \pm 1,2$ & nd & nd & nd \\
\hline 8 & 4-terpineol & 1605 & $4,8 \pm 0,8$ & $3,7 \pm 0,5$ & nd & nd \\
\hline 9 & linomen-4-ol & 1687 & $5,3 \pm 0,9$ & $4,1 \pm 0,7$ & nd & nd \\
\hline 10 & $\alpha$-terpineol & 1697 & $17,3 \pm 1,9$ & $14,6 \pm 1,4$ & nd & nd \\
\hline
\end{tabular}

${ }^{a}$ Indice linear de retenção na coluna DB-Wax;

${ }^{b}$ Média e desvio padrão, da repetição de experimentos independentes;

${ }^{c}$ nd: não detectado. 
Tabela 2. Concentração de odor $\left(\mu \mathrm{g} \cdot \mathrm{m}^{-3} \pm \sigma\right)$ das águas residuárias utilizando aeração $(1,0$ volume de ar por volume de efluente por minuto) para remoção de odor no biorreator heterotrófico.

\begin{tabular}{cccccc}
\hline \multirow{2}{*}{ Pico } & Composto & \multicolumn{4}{c}{ Tempo de Residência ${ }^{a}$} \\
\cline { 2 - 5 } & & $\mathbf{0 ~ h}$ & $\mathbf{2 4} \mathbf{h}$ & $\mathbf{4 8} \mathbf{~ h}$ & $\mathbf{7 2} \mathbf{~ h}$ \\
\hline 1 & 1,4 -cineole & $2,0 \pm 0,1$ & nd & nd & nd \\
2 & limonene & $51,9 \pm 2,9$ & $50,0 \pm 3,1$ & $51,0 \pm 1,8$ & $51,0 \pm 1,4$ \\
3 & 1,8 -cineole & $4,5 \pm 0,5$ & $2,7 \pm 1,1$ & $2,3 \pm 1,6$ & $2,9 \pm 2,1$ \\
4 & $\alpha$-terpinene & $3,9 \pm 0,3$ & nd & nd & nd \\
5 & $\rho$-cymene & $6,7 \pm 0,1$ & nd & nd & nd \\
6 & linalool & $36,0 \pm 0,1$ & $32,8 \pm 1,7$ & $37,4 \pm 3,4$ & $33,4 \pm 2,2$ \\
7 & fenchol & $4,8 \pm 0,7$ & $0,9 \pm 0,2$ & $0,6 \pm 0,4$ & nd \\
8 & 4-terpineol & $4,1 \pm 0,9$ & $4,4 \pm 0,5$ & nd & nd \\
9 & limonen-4-ol & $4,7 \pm 1,6$ & $5,8 \pm 1,2$ & $3,4 \pm 0,9$ & nd \\
10 & $\alpha$-terpineol & $15,6 \pm 1,4$ & $14,0 \pm 0,4$ & nd & nd \\
\hline
\end{tabular}

${ }^{a}$ Média e desvio padrão, da repetição de experimentos independentes;

${ }^{b}$ nd: não detectado. 


\title{
VERMICOMPOSTING AS AN ALTERNATIVE WAS TO TREAT CATTLE MANURE AND CORN SILAGE WASTE
}

\author{
Tavares, A. ${ }^{1}$; Minikowski, A. ${ }^{1}$; Edwiges, T.*2 \\ ${ }^{I}$ Engenheiro Ambiental - Universidade Tecnológica Federal do Paraná - UTFPR, Medianeira, PR - Brasil, \\ alexs.sander_j@hotmail.com, leekowski@hotmail.com \\ ${ }^{2}$ Professor Adjunto do Departamento de Ciências Biológicas e Ambientais - Universidade Tecnológica Federal do Paraná- \\ UTFPR, Medianeira,PR-Brasil, thiago@utfpr.edu.br*
}

\begin{abstract}
The development of the agricultural and livestock sector and the consequent production of agrowaste increase the need for technologies and alternatives to effectively solve this problem. To evaluate the process of vermicomposting of cattle manure with corn silage waste, the following proportions were tested: 90:10; 70:30; 50:50; 30:70 and 10:90, being verified the initial and final $\mathrm{C} / \mathrm{N}$ ratio of the process, as well as the development of earthworms of the Eisenia andrei species. The process was conducted in 20 vermi-reactors during 42 days. In all treatments, the total organic carbon content decreased, while the total Kjeldahl nitrogen content increased, resulting in a drop in the $\mathrm{C} / \mathrm{N}$ ratio, which indicated the stabilization of the vermicompost process. It was observed an increase of earthworms in all vermicomposting units. The mixture of cattle manure with corn silage waste presented positive results for vermicomposting, besides environmental viability, since after treatments these residues will not be disposed of incorrectly.
\end{abstract}

Keywords: composting, earthworms, Eisenia andrei.

\section{INTRODUCTION}

The solid waste management in Brazil still faces problems regarding solutions to improve both the economic and environmental viability of the final disposal. According to Singh and Suthar (2012), one of the main factors contributing to this scenario is the urban population growth, which, among other necessities, demand products from the agricultural sector. Consequently, the generation of agro-waste, such as animal wastes and residues of forage silages, also grows.

This increase in the agro-waste generation, together with the high cost of chemical fertilizers and environmental damage caused by poor waste management on rural properties, encourage the search for cheaper, biologically produced fertilizers. These fertilizers include the organic fertilizer coming from composting processes and their variants, which is the case of the vermicomposting. Every year more research is being reported in this area, aiming to approach the generation of waste from day to day with organic fertilizers through vermicomposting process. The vermicomposting must be applied in parallel to the agricultural activities, in such a way that the maximum amount of agro-waste can be reused as organic fertilizer.

Thus, the objective of this work was to evaluate the biological stabilization process of solid residues by means of vermicomposting using corn silage and cattle manure, from the $\mathrm{C} / \mathrm{N}$ ratio and increased biomass point of view.

\section{MATERIAL AND METHODS}

The cattle manure (CM) and corn silage waste (CSW) were collected at a rural property located in Medianeira/Parana/Brazil. On the property there is a semiconfined cattle herd. The CSW represented the fraction of silage that is not used for animal feeding, either by discarding or leftovers. The vermi-reactors were built using wooden boards $(40 \mathrm{~cm} \times 30 \mathrm{~cm} \times 15 \mathrm{~cm})$. The bottom of the vermi-reactors was lined with a polyethylene screen ( $1 \mathrm{~mm}$ opening), in order to support the material without impeding aeration.

For each treatment, $8 \mathrm{~L}$ of substrate was used in each vermi-reactor, varying the proportion of $\mathrm{CM}$ and CSW in volume, being 90\%/10\% (treatment A), 70\%/30\% (treatment B), 50\%/50\% (treatment C), 30\%/70\% (treatment D) and 10\%/70\% (treatment E). Each treatment was applied in 4 replicates, totaling 20 sample units. After filling, 20 adult worms (Eisenia Andrei) were introduced in each reactor, as indicated by Aquino et al. (1992) and Veras and Povinelli (2004). 
The experiment were kept for 42 days, with weekly determination of the $\mathrm{pH}$, according to the methodology proposed by Tedesco et al. (1995). The $\mathrm{C} / \mathrm{N}$ ratio was determined at the beginning and at the end of the process, considering total organic carbon (TOC) and total Kjeldahl nitrogen (TKN). For the determination of NTK, the methodology described by Malavolta et al. (1997). The TOC was estimated through the volatile solids (SV) values, according to Kiehl (1998). The VS were determined according to the procedure indicated by APHA (2005). After the process, the worms of each vermicompost were counted manually, after the vermicompost was dumped on a prepared surface.

\section{RESULTS AND DISCUSSION}

It was observed a reduction in the $\mathrm{pH}$ values in the beginning of the treatment containing higher amount of CSW, since the presence of organic acids, especially lactic acid and acetic acid, can be responsible for the reduction of $\mathrm{pH}$ in the medium (Figure 1). The average $\mathrm{pH}$ behavior was similar for all treatments. During the first two weeks, increases in $\mathrm{pH}$ values were observed due to the consumption of acids from the silage, with subsequent reduction up to week 5 due to the degradation of the organic matter present in the CM, followed by a stabilization during week 6 .

The increase in the $\mathrm{pH}$ in the first two weeks may also have occurred due to the metabolism of the worms. According to Bidone (1995), this animal has calciferous glands in its esophagus that control the amount of calcium absorbed in the diet. When there is excess of this substance, it is eliminated together with the carbon dioxide produced by respiration, thus forming the calcium carbonate which, present in the compound, raises the $\mathrm{pH}$ thereof. On the other hand, the decrease of $\mathrm{pH}$, as explained by Albanell et al. (1988), is related to the production of carbonic gas and organic acids characteristic of the process. In treatments A, B and C, as well as in some moments in Treatments $\mathrm{D}$ and $\mathrm{E}$, the $\mathrm{pH}$ values were slightly above the range of 5 to 8 , as recommended by Lourenço (2010).

Figure 2 shows the average values for TOC, TKN and C/N ratio of the treatments. The average content of TOC in the treatments decreased with the course of the days due to the action of earthworms, which use the carbon present in organic matter as a source of energy for their growth, setting the same in their biomass, as stated by Silva et al. (2011). The authors further state that part of the carbon is converted to carbon dioxide $\left(\mathrm{CO}_{2}\right)$ and transferred to the atmosphere due to the process of mineralization of the compounds.

The concentration of the TKN increased slightly for all treatments. Silva et al. (2011), also reported an increase of the TKN in the vermicomposting of sewage sludge, affirming that this increase is due to the nutrient concentration related to the loss of organic matter during the process. This concentration of the nutrient adds value to the vermicompost, since Nitrogen is fundamental to vegetable growth.

The decrease in the TOC content and the increase in the TKN content resulted in a decrease in the C/N ratio in all treatments. According to Jiménez and Garcia (1992), all the treatments presented an acceptable relation to indicate the maturity of the compounds, since they were below 20 . It is noted that some treatments already had an initial $\mathrm{C} / \mathrm{N}$ ratio below 20 , which suggests that the materials collected were already in the process of decomposition.

Table 1 indicates the average amount of earthworms found in vermi-reactors at the end of the experiment. The best performance in terms of biomass production was observed for treatment B $(70 \% / 30 \%)$.

\section{CONCLUSIONS}

The vermicomposting with cattle manure and corn silage waste showed positive results for all tested mixtures. The five treatments showed a reduction in the $\mathrm{C} / \mathrm{N}$ ratio, as well as a high reproductive rate of the Eisenia andre $i$ worms. Treatment B, composed of $70 \%$ of cattle manure and $30 \%$ of corn silage waste was the best mixture for the vermicompost. This biological process presented technical and environmental feasibility, since there is efficiency in the treatment of the agro-waste studied, and, when used for such process, they are not inadequately disposed. For the future studies we recommend investigations regarding the effect of the vermicompost as an organic fertilizer for fruit and vegetable production.

\section{ACKNOWLEDGMENTS}

To the Graduate Program in Agricultural Engineering of the State University of the West of Paraná, Campus of Cascavel-PR, for the scientific support during the accomplishment of the experiment. 


\section{REFERÊNCIAS}

ALBANELL, E.; PLAIXATS, J.; CABRERO, T. Chemical changes during vermicomposting (Eiseinia foetida) of sheep manure mixed cotton industrial wastes. Biology and Fertility of Soils. n. 6, p. 266-269, 1988. AMERICAN PUBLIC HEALTH ASSOCIATION - APHA. Standard methods for the examination of water and waste water.20th. Washington, DC: APHA, 2005.

AQUINO, A. M.; ALMEIDA, D. L. de; SILVA, V. F. da. Utilização de minhocas na estabilização de resíduos orgânicos: vermicompostagem. Empresa Brasileira de Pesquisa Agropecuária (EMBRAPA) Centro Nacional da Pesquisa de Agrobiologia (CNPAB). Comunicado Técnico. Rio de Janeiro, n. 08, p. 1-6, jun. 1992.

BIDONE, F. R. A. A vermicompostagem dos resíduos sólidos de curtume, brutos e previamente lixiviados, utilizando composto de lixo orgânico urbano como substrato. 1995. 184 p. Tese (Doutorado em Engenharia Hidráulica e Saneamento) - Escola de Engenharia de São Carlos, Universidade de São Paulo, São Carlos, 1995.

JIMÉNEZ, Emeterio I.; GARCIA, Victor P. Determination of Maturity Indices for City Refuse Composts. Agriculture Ecosystems and Environment, v.38, p.331-343, 1992.

KIEHL, E. J. Manual de Compostagem: Maturação e Qualidade do Composto. Piracicaba: Kiehl,1998, $173 \mathrm{p}$.

LOURENÇO, N. M. G. Características da minhoca Epígea Eisenia Foetida -benefícios, características e mais-valias ambientais decorrentes da sua utilização. Lisboa-Portugal, 2010, 5 p.

MALAVOLTA, E.; VITTI, G. C.; OLIVEIRA, S. A. de. Avaliação do estado nutricional das plantas: princípios e aplicações. 2. ed. Piracicaba: Potafos, 1997, 319 p.

SILVA, P. R. D.; LANDGRAF, M. D.; REZENDE, M. O. O. Acompanhamento químico da vermicompostagem de lodo de esgoto doméstico. Química Nova, São Paulo, v. 34, n. 6, p. 956-961, 2011.

SINGH, D.; SUTHAR, S. Vermicomposting of herbal pharmaceutical industry waste: Earthworm growth, plant-available nutrient and microbial quality of end materials. Bioresource Technology, Dehradun, v. 112, p.179-185, 05/2012. Elsevier BV. http://dx.doi.org/10.1016/j.biortech.2012.02.101.

TEDESCO, M. J.; VOLKWEISS, S. J.; BOHNEN, H. Análise de solo, plantas e outros materiais. 2. ed., Universidade Federal do Rio Grande do Sul, Porto alegre, 1995. 174p.

VERAS, L. R. V.; POVINELLI, J. A vermicompostagem do lodo de lagoas de tratamento de efluentes industriais consorciada com composto de lixo urbano. Engenharia Sanitária Ambiental, Rio de Janeiro, v. 9, n. 3, p. 218-224, jul-set. de 2004.

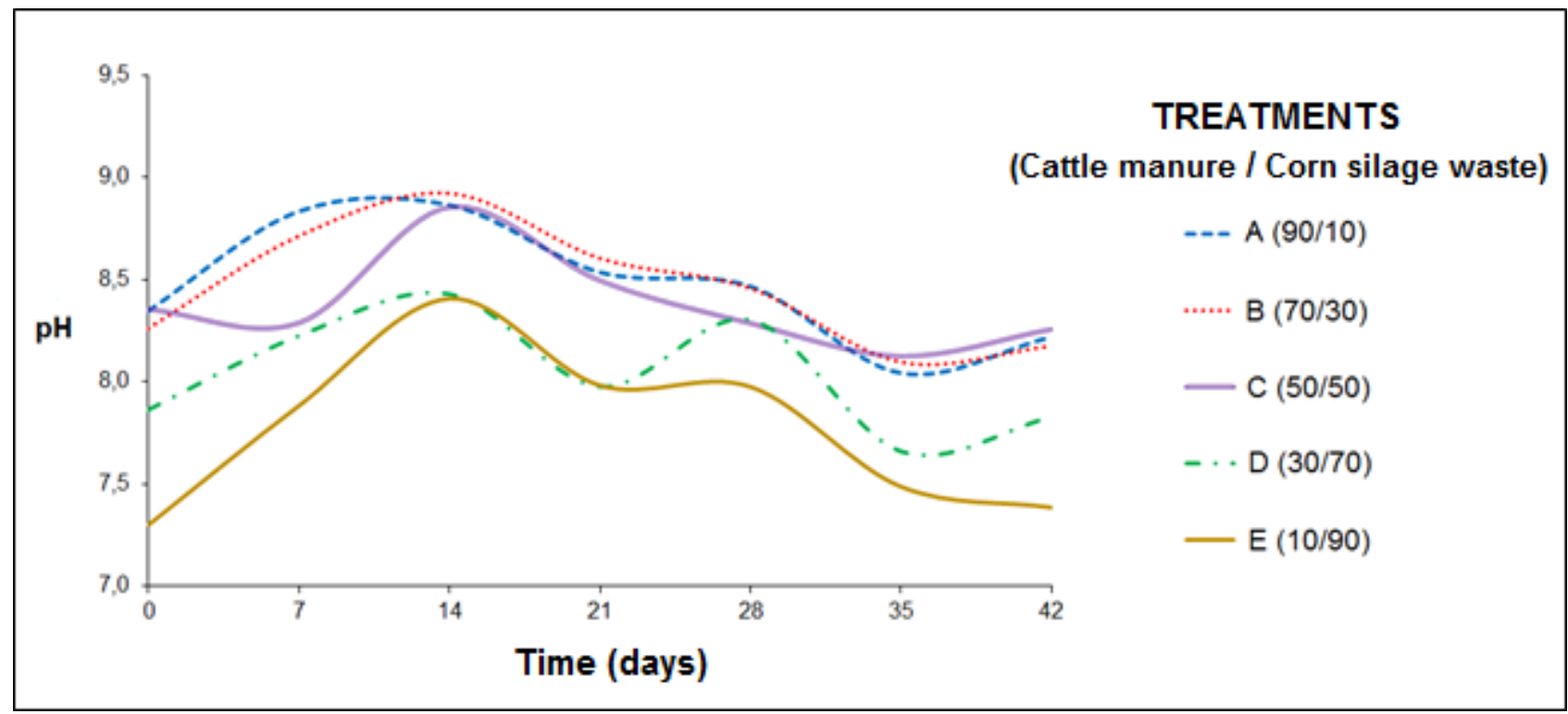

Figure 1. Mean values of $\mathrm{pH}$ in treatments over time. 
Table 1. Mean number of earthworms per vermi-reactors after 42 days.

\begin{tabular}{cc}
\hline Treatments (Cattle manure / Corn silage waste) & Number of earthworms* \\
\hline B (70/30) & $690 \pm 40 \mathrm{a}$ \\
A (90/10) & $643 \pm 55 \mathrm{a}$ \\
C (50/50) & $449 \pm 57 \mathrm{~b}$ \\
D (30/70) & $423 \pm 53 \mathrm{~b}$ \\
E (10/90) & $351 \pm 65 \mathrm{~b}$ \\
\hline
\end{tabular}

*Different letters indicate significant differences by Tukey test $(\mathrm{p} \leq 0,05)$.

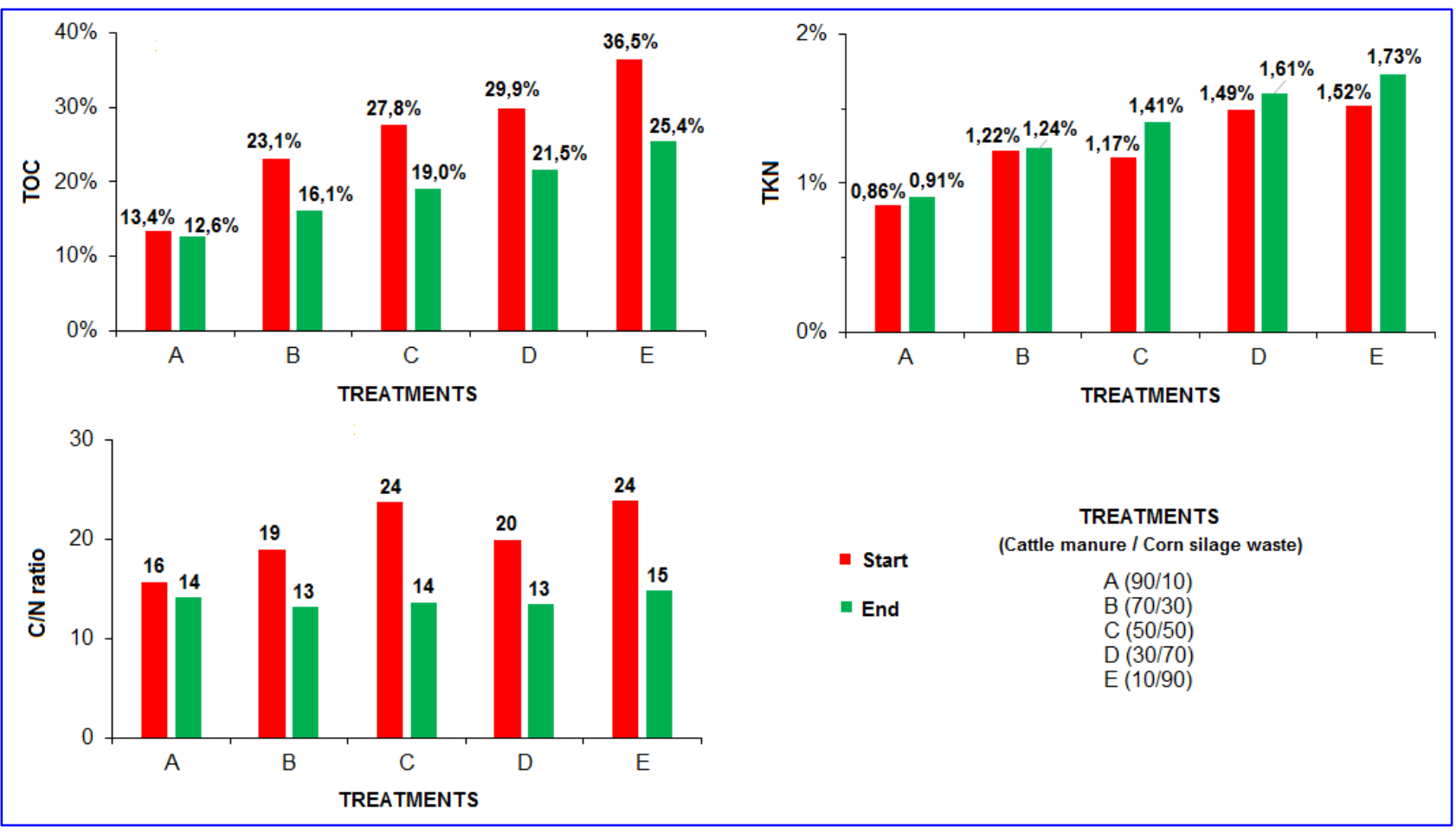

Figure 2. Mean total organic carbon (TOC), total Kjeldahl nitrogen (TKN) and initial and final C/N ratio of treatments. 


\section{PRODUCAOAO DE ENERGIA A PARTIR DERESIDUOS}




\title{
ANÁLISE ECONÔMICA PRELIMINAR DA PRODUÇÃO DE BIOETANOL DE RESÍDUOS VEGETAIS DA BANANIÇULTURA
}

\author{
Uchôa, P.Z. ${ }^{1}$; Porto, R.C.T. ${ }^{1}$; Marangoni, C. ${ }^{2}$; Souza, O.. ${ }^{* 3}$ \\ ${ }^{1}$ Mestrando em Engenharia de Processos, Universidade da Região de Joinville - Univille, Joinville, SC - Brasil \\ ${ }^{2}$ Professor da Universidade Federal de Santa Catarina, Blumenau, SC - Brasil \\ ${ }^{2}$ Professor da Univille, Joinville, SC-Brasil \\ ozair.souza@univille.br
}

\begin{abstract}
RESUMO: O Brasil vem se destacando no cenário mundial como o $4^{\circ}$ maior produtor de bananas, com uma produção média de, aproximadamente, 7 mil toneladas da fruta por ano. Santa Catarina tem sido responsável por mais de $10 \%$ dessa produção e as microrregiões de Joinville, Blumenau e Itajaí, por mais de $80 \%$ da produção estadual. Estima-se que para tonelada de bananas colhidas são gerados em torno de $4 \mathrm{t}$ de resíduos vegetais (biomassa). O principal objetivo deste trabalho foi realizar a fermentação alcóolica desse resíduo empregando diferentes composições de mosto e, através da simulação e análise econômica, indicar as condições mais adequadas para a produção de etanol e o município catarinense mais apropriado para instalação de uma usina alcooleira. A produção anual de etanol estimada a partir do uso de toda a biomassa gerada nas três microrregiões catarinenses (38 municípios) foi de $45.080 \mathrm{~m}^{3}$. Considerando apenas os três municípios com maior produção de bananas (Luiz Alves, Corupá e Massaranduba), essa produção reduz, apenas, para 32.712 $\mathrm{m}^{3}$ com gasto energético da ordem de $138,4 \mathrm{GJ} \mathrm{m}^{-3}$ e significativa redução no gasto com transporte da matériaprima do campo até a usina. O município catarinense indicado como o mais apropriado para instalação de uma usina desse porte foi Massaranduba. Numa proposta otimista, onde todo gasto energético seria suprido pelo biogás dos "novos resíduos" gerados na usina, o payback seria de 10,7 anos.
\end{abstract}

Palavras-chave: bioetanol, simulação, análise econômica

\section{PRELIMINARY ECONOMIC ANALYSIS OF THE PRODUCTION OF BANANICULTURE BIOMASS ETHANOL}

\begin{abstract}
Brazil has been standing out in the world scenario as the 4th largest producer of bananas, with an average production of approximately 7 thousand tons of fruit per year. Santa Catarina has been responsible for more than $10 \%$ of this production and the microregions of Joinville, Blumenau and Itajaí, for more than $80 \%$ of the state production. It is estimated that for ton of harvested bananas are generated around $4 \mathrm{t}$ of plant residues (biomass). The main objective of this work was to carry out the alcoholic fermentation of this residue using different wort compositions and, through the simulation and economic analysis, indicate the most suitable conditions for the ethanol production and the most appropriate Santa Catarina municipality for the installation of an alcohol plant. The annual production of ethanol estimated from the use of all the biomass generated in the three microregions of Santa Catarina (38 municipalities) was 45,080 $\mathrm{m}^{3}$. Considering only the three municipalities with the highest production of bananas (Luiz Alves, Corupá and Massaranduba), this production only reduces to $32,712 \mathrm{~m}^{3}$ with an energy expenditure of $138.4 \mathrm{GJ} \mathrm{m}^{-3}$ and a significant reduction in the transportation of matter from the field to the plant. The municipality of Santa Catarina indicated as the most appropriate to install a mill of this size was Massaranduba. In an optimistic proposal, where all energy expenditure would be supplied by the biogas of the "new waste" generated at the plant, the payback would be 10.7 years.
\end{abstract}

Keywords: bioethanol, simulation, economic analysis.

\section{INTRODUÇÃO}

O estado de Santa Catarina conta com 3.678 produtores de banana registrados, divididos em 74 municípios, que representam $48,5 \%$ da produção da fruticultura catarinense. A espécie Musa cavendish, popularmente conhecida na região sul do Brasil como caturra ou nanica é a mais cultivada nas mesorregiões Norte Catarinense e Vale do Itajaí, com produção anual de 622 mil toneladas. Dentre as suas microrregiões catarinenses, a de Joinville é a maior produtora, sendo responsável por, aproximadamente, 53\% de toda a produção do Estado, seguida pela de Blumenau (19\%) e de Itajaí (16\%) (EPAGRI/CEPA, 2016). Com base na safra de 2014/15 dessas microrregiões e na quantidade estimada de resíduos vegetais (biomassa) gerada por 
unidade de massa de bananas colhidas (SOUZA et al., 2010) é possível estimar-se a geração de, aproximadamente, 2,5 milhões de toneladas de biomassa, dentre as quais a polpa e as cascas de bananas e o pseudocaule da bananeira.

A maioria dos estudos sobre aproveitamento de resíduos lignocelulósicos para a produção de etanol, utilizando análise econômica precedida por simulação do processo para estimativa dos gastos com matériaprima e energia, estão voltados principalmente para processos com cogeração ou melhoria de processos já existentes. Grande parte desses trabalhos tratam de usinas de cana-de-açúcar, utilizando o bagaço e a palha de cana-de-açúcar e usinas de milho que utilizam os resíduos formados ao longo do processo. Os estudos de simulação e análise econômica utilizando outras biomassas e principalmente resíduos da bananicultura são escassos.

O objetivo deste trabalho foi realizar a análise econômica preliminar da produção de bioetanol de biomassa da cultura da banana utilizando como base de análise os resultados experimentais dos ensaios de fermentação realizados por Uchôa (2018).

\section{Simulação}

\section{MATERIAL E MÉTODOS}

Foi utilizado o programa computacional ProSimPlus (software Process Simulation, version 3.5.18, France). A partir dos resultados experimentais de fermentação obtidos por Uchôa (2018) com o uso dos resíduos pseudocaule de bananeira, polpa e cascas de bananas maduras, na mesma proporção de massa úmida que foram gerados após colheita e industrialização da banana (1:2:10) (SOUZA et al., 2010), foram realizadas simulações para validar os resultados dessas fermentações e estimar os respectivos volumes de etanol produzido (bioetanol) e quantidades de biomassa, energia e matérias-primas necessárias para a produção. Além da inclusão da quantidade de biomassa disponível, implementou-se as reações de conversão envolvidas no processo, desde as operações de pré-tratamentos específicas a cada uma das biomassas (obtenção do mosto de fermentação) até a obtenção do vinho fermentado e extração do etanol por destilação, conforme proposto por Souza et al. (2012), Souza (2015) e De Souza et al. (2017). Os equipamentos relativos a cada uma dessas etapas foram semelhantes aos citados por autores que realizaram análise econômica da produção de etanol de canade-açúcar Albarelli et al. (2014) ou de milho Liu et al (2016).

\section{Análise econômica preliminar}

Foram analisados diferentes cenários para a produção de bioetanol e instalação de uma usina alcooleira de grande porte nos três municípios de maior produção de bananas (Luis Alves, Corupá e Massaranduba) nas microrregiões catarinenses de Joinville, Blumenau e Itajaí (EPAGRI/CEPA, 2017). Cenário G1: uso da biomassa de todos os municípios produtores de bananas das Mesorregiões Norte Catarinense e Vale do Itajaí; Cenário G2: uso da biomassa dos cinco municípios catarinenses com maior produção da fruta (Luiz Alves, Corupá, Massaranduba, Jaraguá do Sul e São João do Itaperiú; Cenário G3: uso da biomassa gerada até 60 km de distância rodoviária entre os municípios com maior produção e os locais avaliados para a instalação da usina. Para estimativa da receita foi considerado o valor médio do $\mathrm{m}^{3}$ de etanol hidratado comercializado pelas usinas brasileiras de cana-de-açúcar entre 2008 a 2018 (CEPEA, 2018). Para o gasto com energia foi considerado o valor cobrado pela Centrais Elétricas de Santa Catarina - Celesc, para a região rural em julho de 2018, adicionado de $25 \%$ de imposto $\left(\mathrm{R} \$ 0,32189 \mathrm{kwh}^{-1}\right)$. O custo com transporte da biomassa do local de coleta até a usina foi estimado de acordo com a Agência Nacional de Transporte Terrestre (Resolução ANTT $\mathrm{n}^{\circ} 5820$ de 30 de maio de 2018). Em todos os cenários analisados, a aquisição da biomassa da bananicultura foi considerada gratuita, sem valor de compra. Esses resíduos normalmente são considerados pelo produtor de bananas como lixo agrícola e, em alguns casos, ainda precisam pagar para a sua remoção das propriedades.

\section{RESULTADOS E DISCUSSÃO}

Dentre todos os cenários avaliados (G1, G2 e G3), o município de Massaranduba (microrregião de Joinville), devido à sua posição geográfica em relação aos demais municípios catarinenses produtores da banana nanica, foi o que possibilitou menor gasto com transporte da biomassa. Esse valor, específico à cada um dos cenários, foi considerado na análise econômica preliminar como gasto de biomassa (Tabela 1).

A simulação do processo de produção de bioetanol a partir do mosto composto por pseudocaule da bananeira, polpa e cascas de bananas maduras mostrou que o consumo mínimo de energia foi de $2.550 \mathrm{MJ} \mathrm{t}^{-1}$ de massa úmida processada (cenário G2), que correspondeu ao gasto de energia de, aproximadamente, 138,9 GJ $\mathrm{m}^{-3}$ de etanol, conforme mostrado na Tabela 1. Esse gasto foi menor do que aqueles estabelecidos por Quintero et al., (2013) para a produção de bioetanol de bagaço de cana-de-açúcar (216,3 GJ m³), cacho de 
frutos da palmeira $\left(143,6 \mathrm{GJ} \mathrm{m}^{-3}\right)$, cascas de arroz $\left(195,1 \mathrm{GJ} \mathrm{m}^{-3}{ }^{3}\right)$ e caule do café $\left(214,3 \mathrm{GJ} \mathrm{m}^{-3}\right)$. O uso da polpa e cascas de banana na composição do mosto de fermentação, que não necessitaram de pré-tratamentos térmicos drásticos para a sua sacarificação foi, provavelmente, o responsável por esse menor gasto energético.

As quantidades de etanol obtidas nos cenários G1, G2 e G3 foram de $45.080 \mathrm{~m}^{3} / \mathrm{ano}, 32.713 \mathrm{~m}^{3} / \mathrm{ano}$ e $41.880 \mathrm{~m}^{3} / \mathrm{ano}$, respectivamente. Na Tabela 1 é possível observar, além das receitas relativas a esses volumes do produto, os custos diretos específicos para cada caso. Dentre esses cenários, a usina de grande porte que apresentou menor custo de produção em relação aos insumos foi a opção G2. Contudo, verifica-se que em todos os casos, que os processos se mostraram economicamente inviáveis (Lucro bruto negativo). Fica claro a necessidade de uma análise mais detalhada de todos os custos envolvidos, buscando-se alternativas para inverter esta condição, principalmente em relação ao consumo energético (responsável por mais de $96 \%$ do total do custo em todos os cenários).

Considerando a eliminação do valor devido ao consumo energético e acrescentando as estimativas dos custos de investimento; custo de mão-de-obra, custos operacionais, despesas gerais da fábrica e manutenção; e custo geral e administrativo baseados nos trabalhos de Albarelli et al. (2014) e Quintero et al. (2013), foi possível estruturar uma proposta otimista considerada como a ideal para a produção de etanol de biomassa da bananicultura nos diferentes cenários, conforme apresentado na Tabela 2. Nota-se que, com isto, o processo passa a apresentar um lucro bruto positivo de até US\$ 13,464 milhões de dólares/ano (cenário G1).

O menor tempo para o retorno do investimento, sem considerar os juros anuais no caso de realizar empréstimos (payback simples) foi de 10,7 anos para uma usina de grande porte instalada em Massaranduba (cenário G2). Valor de payback simples maior do que 4,0 anos é, normalmente, considerado alto e desaconselhável para investimentos em quaisquer tipos de processos. Porém, de acordo com Albarelli et al. (2014), especificamente no caso de produção de etanol de segunda geração (etanol celulósico), valores de payback da ordem de 10 anos são comuns.

\section{CONCLUSÃO}

Em todos os cenários avaliados, o custo energético foi responsável por aproximadamente $96 \%$ dos custos totais da produção de bioetanol a partir dos resíduos vegetais da bananicultura, o que não possibilitou obter lucro com o processo. Para viabilizar economicamente o processo, faz-se necessário minimizar esse impacto com a cogeração de energia ou com a produção de energia alternativa a partir dos "novos resíduos" gerados no processo produtivo. Zerando-se o consumo energético, é possível obter um lucro bruto máximo da ordem de US\$ 10 milhões/ano, com valor mínimo do payback de 10,7 anos para a instalação de uma usina de grande porte no município de Massaranduba - SC.

\section{REFERÊNCIAS}

ALBARELLI, J. Q; ENSINAS, A. V.; SILVA, M. A. Product diversification to enhance economicviability of second generation ethanol productionin Brazil: The case of the sugar and ethanoljoint production. Chemical engineering research and design, v. 92, p.1470-1481, 2014.

CEPEA - Centro de Estudos Avançados em Economia Aplicada. Indicador semanal do etanol hidratado combustível CEPEA/ESALQ. Disponível em:〈https://www.cepea.esalq.usp.br/br/indicador/ etanol.aspx> Acesso em: Janeiro de 2018.

DE SOUZA, E. L; SELLIN, N; MARANGONI, C; SOUZA, O. The influence of different strategies for the saccharification of the banana plant pseudostem and the detoxification of concentrated broth on bioethanol production. Applied Biochem Biotechnol, v. 183, p.943 - 965, 2017.

EMBRAPA - Empresa Brasileira de Pesquisa Agropecuária. O Brasil é o país dos resíduos. Disponível em: < https://www.embrapa.br >. Acesso em Julho de 2017.

EPAGRI/CEPA - Empresa de Pesquisa Agropecuária e Extensão Rural de Santa Catarina/ Centro de Socioeconomia e Planejamento Agrícola. Síntese anual da agricultura de Santa Catarina 2014-2015. Disponível em < http://docweb.epagri.sc.gov.br/website_cepa/publicacoes/Sintese_2015.pdf >. Acesso em Junho de 2017.

QUINTERO, J. A.; MONCADA, J.; CARDONA, C. A. Techno-economic analysis of bioethanol production from lignocellulosic residues in Colombia: A process simulation approach. Bioresource Technology, v 139, p. 300-307, 2013.

SOUZA, O., FEDERIZZI, M., COELHO, B., WAGNER, T.M., WISBECK, E. Biodegradação de resíduos lignocelulósicos gerados na bananicultura e sua valorização para a produção de biogás. Revista Brasileira de Engenharia Agrícola e Ambiental, vol. 14, n 4, p. 438-443, 2010. 
SOUZA, O., SCHULZ, M.A., FISCHER, G.A.A., WAGNER, T.M., SELLIN, N. Energia alternative de biomassa: Bioetanol a partir da casca e da polpa de banana. Revista Brasileira de Engenharia Agrícola e Ambiental, v. 16, n. 8, p. 915-921, 2012.

SOUZA, P. K. Simulação do processo de produção de etanol a partir de resíduos da bananicultura. Mestrado. Dissertação apresentada ao Curso de Mestrado em Engenharia de Processos da Universidade da Região de Joinville. Joinville. 2015.

UCHOA, P. Z. Etanol de biomassa da bananicultura: produção, simulação e análise econômica preliminar. Mestrado. Dissertação apresentada ao Curso de Mestrado em Engenharia de Processos da Universidade da Região de Joinville. Joinville, Agosto de 2018.

Tabela 1. Receita, custos de insumos e lucro bruto referentes à produção de etanol de biomassa da bananicultura em usinas de grande porte em diferentes cenários.

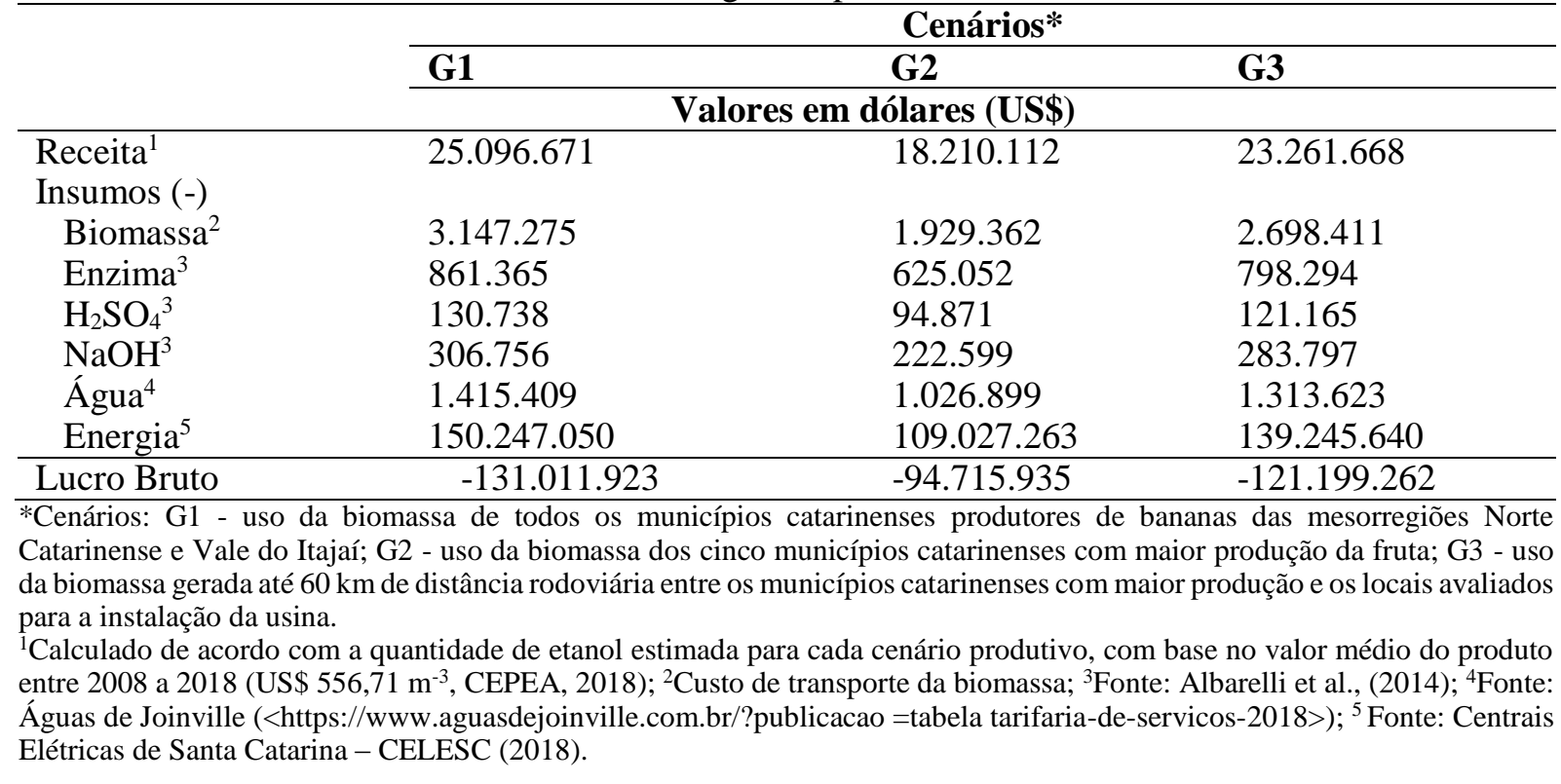

Tabela 2. Proposta otimista com a implementação da cogeração de energia, investimento e payback simples, para o processo de produção de etanol combustível nos cenários avaliados.

\begin{tabular}{|c|c|c|c|}
\hline & \multicolumn{3}{|c|}{ Cenários } \\
\hline & G1 & G2 & G3 \\
\hline & \multicolumn{3}{|c|}{ Valores em dólares (US\$) } \\
\hline RECEITA & 25.096 .671 & 18.210 .112 & 23.261 .668 \\
\hline Custos (-) & & & \\
\hline Matérias-primas $^{1}$ & $(5.861 .544)$ & $(3.898 .784)$ & $(5.215 .290)$ \\
\hline Energia & & 0 & 0 \\
\hline Mão-de-obra² & $(265.974)$ & (193.005) & (246.499) \\
\hline $\begin{array}{l}\text { Operacionais e } \\
\text { manutenção }^{2}\end{array}$ & $(620.982)$ & $(450.617)$ & $(575.512)$ \\
\hline Administrativo $^{2}$ & $(2.187 .523)$ & $(1.587 .383)$ & $(2.027 .348)$ \\
\hline Lucro Bruto & 19.235.127 & 14.311 .328 & 18.046 .378 \\
\hline Imposto $^{3}$ & $(5.770 .538)$ & $(4.293 .398)$ & $(5.413 .913)$ \\
\hline Investimento $^{4}$ & $(148.330 .000)$ & $(107.380 .000)$ & $(137.410 .000)$ \\
\hline Payback simples ${ }^{5}$ & 11,02 & 10,72 & 10,88 \\
\hline
\end{tabular}

${ }^{1}$ Custo de transporte da biomassa, aquisição de produtos químicos e consumo de água. ${ }^{2}$ Valores estimados de acordo com Quintero et al., (2013) com base no volume de etanol produzido. ${ }^{3} \mathrm{O}$ imposto foi calculado com taxa de $30 \%$ que engloba ICMS no estado de Santa Catarina (18\%) e PIS/CONFIS (12\%). ${ }^{4}$ Baseado de acordo com Albarelli et al (2014) e Quintero et al. (2013). ${ }^{5}$ Payback simples sem contabilizar a taxa de juro anual. 


\title{
AVALIAÇÃO DA HIDRÓLISE ÁCIDA DE RESÍDUOS LIGNOCELULÓSICOS ASSISTIDA POR MICRO-ONDAS PARA OBTENÇÃO DE PLATAFORMAS FURÂNICAS
}

\author{
Santos, D. ${ }^{1 *}$; Bizzi, C.A. ${ }^{1}$; Silva, C.M. ${ }^{1}$; Wohlmann, W. ${ }^{1}$; Mello, P.A. ${ }^{1}$; Flores, E.M.M. ${ }^{1}$ \\ ${ }^{1}$ Universidade Federal de Santa Maria, Departamento de Química, Santa Maria, RS, Brasil \\ *danielchemistryeng@gmail.com
}

\begin{abstract}
RESUMO: Plataformas furânicas, tais como furfural e álcool furfurílico, são produtos de alto valor agregado que podem ser obtidos pela conversão de biomassa. No presente estudo foi investigado o uso de energia de micro-ondas para a conversão de resíduos lignocelulósicos em plataformas furânicas. Foram avaliados os seguintes parâmetros de processo: concentração de $\mathrm{H}_{2} \mathrm{SO}_{4}\left(0,1 \mathrm{a} 4 \mathrm{~mol} \mathrm{~L}^{-1}\right)$, massa de matéria-prima $(50$ a 150 $\mathrm{mg})$ e temperatura de reação $\left(160\right.$ a $\left.200{ }^{\circ} \mathrm{C}\right)$. A solução ácida e o tempo de irradiação foram mantidos em 10 $\mathrm{mL}$ e $10 \mathrm{~min}$, respectivamente. Os produtos obtidos foram identificados por cromatografia a líquido de alta eficiência acoplada a espectrometria de massa por tempo-de-vôo (UPLC-ToF-MS). Nos experimentos utilizando $\mathrm{H}_{2} \mathrm{SO}_{4}$ a 4 mol L $\mathrm{L}^{-1}, 200{ }^{\circ} \mathrm{C}$ e $150 \mathrm{mg}$ de matéria-prima, foi observada uma alta seletividade para produção de furfural, chegando a $47 \%$ de conversão. Ao avaliar $\mathrm{H}_{2} \mathrm{SO}_{4}$ a $0,1 \mathrm{~mol} \mathrm{~L}^{-1}$, a $160{ }^{\circ} \mathrm{C}$ e $150 \mathrm{mg}$ de matéria-prima, a produção de álcool furfurílico foi favorecida chegando a $29 \%$ de conversão. Adicionalmente, os resíduos da matéria-prima após hidrólise foram caracterizados por microscopia eletrônica de varredura (SEM) e espectroscopia de infravermelho (FTIR). O processo de hidrólise ácida assistida por micro-ondas foi considerado adequado para a síntese de plataformas furânicas. Quando comparado com métodos convencionais para produção de compostos furânicos, a aplicação das micro-ondas permitiu uma redução no tempo e na temperatura de reação. A caracterização por SEM e FTIR contribuiu para uma melhor compreensão das mudanças físicas causadas pelo aquecimento micro-ondas.
\end{abstract}

Palavras-chave: micro-ondas, furfural, álcool furfurílico.

\section{MICROWAVE-ASSISTED ACID HYDROLYSIS OF LIGNOCELLULOSIC WASTE TO FURANIC PLATFORMS SYNTHESIS}

\begin{abstract}
Furanic platforms (e.g. furfural, furfuryl alcohol, and hydroxymethylfurfural) are derived from biomass and can be considered as a greener alternative to petrochemicals products such as fuels, solvents, and plastics. In this work, the use of microwave energy was investigated for the conversion of lignocellulosic waste into furanic compounds. The following parameters were evaluated: acid concentration $\left(0.1\right.$ to $4 \mathrm{~mol} \mathrm{~L}^{-1}$ $\mathrm{H}_{2} \mathrm{SO}_{4}$ ), feedstock amount (50 to $150 \mathrm{mg}$ ) and reaction temperature (160 to $200{ }^{\circ} \mathrm{C}$ ). The amount of acid solution and irradiation time were kept constant $(10 \mathrm{~mL}$ and $10 \mathrm{~min}$, respectively). The obtained products were identified by ultra-performance liquid chromatography with high-resolution time-of-flight mass spectrometry (UPLC-ToF-MS). For $4 \mathrm{~mol} \mathrm{~L}^{-1} \mathrm{H}_{2} \mathrm{SO}_{4}$, at $200{ }^{\circ} \mathrm{C}$ and $150 \mathrm{mg}$ of biomass, high selectivity to furfural was observed (47\% yield). When evaluating a $0.1 \mathrm{~mol} \mathrm{~L}^{-1} \mathrm{H}_{2} \mathrm{SO}_{4}$ solution, at $160{ }^{\circ} \mathrm{C}$ and $150 \mathrm{mg}$ of biomass, furfuryl alcohol was the main product (29\% yield). In addition, feedstock residues from hydrolysis were characterized using scanning electron microscopy (SEM) and infrared spectroscopy (FTIR). The proposed microwave-assisted acid hydrolysis (MAAH) was considered suitable for furanic platforms synthesis. It is important to highlight that the MAAH allowed the reduction of reaction time and temperature, saving energy. Characterization by SEM and FTIR contributed for a better comprehension of physicalchemical effects caused by microwave irradiation.
\end{abstract}

Keywords: Microwave, furfural, furfuryl alcohol.

\section{INTRODUÇÃO}

Atualmente, diversas pesquisas têm sido dedicadas à conversão de biomassa em plataformas furânicas, tais como furfural, álcool furfurílico e hidroximetilfurfural (Mülhaupt, 2013). De acordo com o relatório do United States Department of Energy sobre os principais produtos químicos de valor agregado da biomassa, as plataformas furânicas são consideradas importantes intermediários que podem ser usados na produção de 
diversos compostos químicos (Holladay et al., 2007; Werpy et al. ., 2004). O furfural é usado, principalmente, como um solvente seletivo para o refino de óleos lubrificantes e combustíveis, e como um intermediário químico na fabricação de solventes, como tetrahidrofurano, metil tetrahidrofurano e álcool furfurílico. (Hoydonckx et al., 2007; Wu et al., 2010; Zeitsch, 2000).

As plataformas furânicas são produzidas industrialmente por desidratação de açúcares, em um processo compreendido por inúmeras reações, adição de reagentes tóxicos e longos tempos de reação (Danon et al., 2014). Nesse sentido, o desenvolvimento de processos alternativos para obtenção de plataformas furânicas sob condições ambientalmente amigáveis é um importante tópico de pesquisa (Danon et al., 2014; Holladay et al., 2007; Werpy et al., 2004).

Dentre as fontes alternativas de energia para a intensificação de processos, as micro-ondas vem sendo utilizadas em inúmeras rotas de síntese orgânica. Cravotto et al. (2007) combinou o micro-ondas e ultra-som, aumentando a transferência de massa e reduzindo o tempo para hidrazinólise de ésteres com mono-hidrato de hidrazina sob condições sem solvente. Tabasso et al. (2014) propuseram a conversão da biomassa assistida por microondas para o ácido levulínico. Os resultados mostraram a redução drástica do tempo de reação e alta seletividade, com até $95 \%$ de rendimento. Lacerda et al. (2015) relataram a conversão lignocelulósica assistida por microondas em plataformas furânicas usando líquidos e dióxido de titânio a temperaturas inferiores a $200{ }^{\circ} \mathrm{C}$. Alguns estudos investigaram a hidrólise de biomassa catalisada por ácido sulfônico e líquidos iônicos (Wu et al., 2010; Zhang \& Zhao, 2010; Zhang \& Zhao, 2009). Nestes estudos, comparados com os processos convencionais, a irradiação de micro-ondas a uma potência adequada reduziu significativamente o tempo de reação e aumentou os rendimentos de conversão de biomassa.

Neste trabalho foi avaliada a aplicação de micro-ondas como fonte única de energia para a hidrólise ácida de resíduos lignocelulósicos. Resíduos de pastagem animal foram utilizados como modelo de matériaprima para a produção de plataformas furânicas. Foram investigados diversos parâmetros reacionais, tais como, temperatura, concentração ácida e massa de matéria-prima. Os produtos de conversão foram identificados por cromatografia a líquido de alta eficiência acoplada a espectrometria de massa por tempo-de-vôo (UPLC-ToFMS). Após o tratamento assistido por micro-ondas, os resíduos de biomassa foram avaliados por microscopia eletrônica de varredura (SEM) e por espectroscopia de infravermelho (FTIR).

\section{MATERIAL E MÉTODOS}

O resíduo de pastagem foi selecionado como biomassa lignocelulósica a ser usado como matéria-prima modelo. A água destilada e desionizada foi obtida usando um modelo Milli-Q sistema (Millipore Corp., EUA) e foi usado para preparar todos os reagentes. Ácido sulfúrico (95\%) foi de grau analítico (Merck, Alemanha). Nitrogênio e argônio (pureza de 99,999\% e 99,998\% respectivamente, White Martins, Brasil) foram utilizados para SEM, FTIR e como gás de ESI-ToF-MS. Acetonitrila e metanol usados em ESI-ToF-MS foram adquiridos da Fluka (Alemanha) e Tedia (EUA), respectivamente.

O processo de hidrólise ácida assistida por micro-ondas (MAAH) foi feito utilizando um sistema de micro-ondas (SpeedwaveTM Four, Berghof, Alemanha) equipado com um rotor para doze frascos de reação (capacidade de $60 \mathrm{~mL}$, pressão máxima e temperatura de 40 bar e $230^{\circ} \mathrm{C}$, respectivamente). A comparação com a conversão sem o uso de micro-ondas foi feita sob aquecimento convencional (modelo TE 015, Tecnal, Brasil) em frascos de politetrafluoretileno fechados (capacidade de $60 \mathrm{~mL}$ ).

O processo de MAAH foi otimizando utilizando um planejamento fatorial $2^{3} \mathrm{com} 6$ pontos axiais e repetições no ponto central. Foram avaliados os seguintes parâmetros de processo: concentração de ácido $(0,1$ a $\left.4 \mathrm{~mol} \mathrm{~L}^{-1}\right)$, massa de matéria-prima $(50$ a $150 \mathrm{mg})$ e temperatura de reação $\left(160\right.$ a $\left.200{ }^{\circ} \mathrm{C}\right)$. A massa matériaprima foi transferida para o frasco de reação e foram adicionados $10 \mathrm{~mL}$ de ácido diluído. Finalmente, a mistura foi submetida ao MAAH por $10 \mathrm{~min}$. Experimentos sob aquecimento convencional foram feitos utilizando o ponto central do planejamento fatorial: $\mathrm{H}_{2} \mathrm{SO}_{4} 2 \mathrm{~mol} \mathrm{~L}{ }^{-1}, 100 \mathrm{mg}$ de matéria prima e $180^{\circ} \mathrm{C}$.

\section{RESULTADOS E DISCUSSÃO}

Quando o processo de hidrólise ácida assista por micro-ondas foi avaliado, para todas as condições experimentais, foi possível observar a formação de pelo menos um composto furânico. O aumento de temperatura de 160 para $200{ }^{\circ} \mathrm{C}$ afetou a seletividade das conversões. Para a maior parte dos experimentos, picos de oligômeros e monômeros de carboidratos foram identificados. Nos experimentos utilizando $\mathrm{H}_{2} \mathrm{SO}_{4}$ a $4 \mathrm{~mol} \mathrm{~L}{ }^{-1}, 200{ }^{\circ} \mathrm{C}$ e $150 \mathrm{mg}$ de matéria-prima, foi observada uma alta seletividade para produção de furfural, 
chegando a $47 \%$ de conversão. Ao avaliar $\mathrm{H}_{2} \mathrm{SO}_{4}$ a $0,1 \mathrm{~mol} \mathrm{~L}^{-1}$, a $160{ }^{\circ} \mathrm{C}$ e $150 \mathrm{mg}$ de matéria-prima, a produção de álcool furfurílico foi favorecida chegando a $29 \%$ de conversão.

Durante os experimentos de MAAH, um resíduo sólido remanescente foi observado em todas as condições experimentais. O material não convertido, bem como o material de partida, foi caracterizado por SEM e FTIR, a fim de avaliar os efeitos físico-químicos da aplicação das micro-ondas. Esses estudos demonstraram diferenças substanciais entre o resíduo lignocelulósico bruto e o material restante após MAAH. As micrografias obtidas por SEM mostraram que a morfologia das partículas da biomassa era originalmente estratificada. Após o processo de MAAH, essas estruturas foram desorganizadas e a morfologia foi modificada e condicionada a micro fibrilas de menor diâmetro. Essas alterações na estrutura da biomassa em diferentes condições experimentais podem resultar em diferentes propriedades físico-químicas, tais como, menor diâmetro de partícula. Essas informações são de grande relevância, principalmente no que diz respeito à possibilidade de reciclagem das matérias primas no processo.

\section{CONCLUSÃO}

Esse estudo fornece informações que podem ser utilizadas para compreender os efeitos da radiação micro-ondas no processo de hidrólise ácida de biomassa. O processo proposto provou ser útil para a conversão de residuos de pastagem animal em plataformas furânicas, especificamente furfural e álcool furfurílico, utiliando menores tempos de reação, alta seletividade e reagente ácido diluído. Além disso, os estudos por SEM e FTIR indicam a possibilidade de reciclagem das matérias-primas remanecentes no processo.

\section{AGRADECIMENTOS}

Os autores agradecem ao Conselho Nacional de Desenvolvimento Científico e Tecnológico (CNPq), a Coordenação de Aperfeiçoamento de Pessoal de Nível Superior (CAPES) e a Fundação de Amparo à Pesquisa do Estado do Rio Grande do Sul (FAPERGS) por apoiar este estudo.

\section{REFERÊNCIAS}

CRAVOTTO, G. et al. The combined use of microwaves and ultrasound: improved tools in process chemistry and organic synthesis. Chemistry-A European Journal, 13 (7), 1902-1909, 2007.

DANON, B. et al. Mechanistic and kinetic aspects of pentose dehydration towards furfural in aqueous media employing homogeneous catalysis. Green Chemistry, 16(1), 39-54, 2014.

HOLLADAY, J.E. et al. Top Value Added Chemicals from Biomass-Volume II, Results of Screening for Potential Candidates from Biorefinery Lignin. Pacific Northwest National Lab.(PNNL), Richland, WA (United States); National Renewable Energy Laboratory (NREL), Golden, CO (United States), 2007.

LACERDA, V. et al. A kinetic study on microwave-assisted conversion of cellulose and lignocellulosic waste into hydroxymethylfurfural/furfural. Bioresource Technology, 180, 88-96, 2015.

MÜLHAUPT, R. Green Polymer Chemistry and Bio-based Plastics: Dreams and Reality. Macromolecular Chemistry and Physics, 214 (2), 159-174, 2013.

TABASSO, S. et al. Microwave-assisted flash conversion of non-edible polysaccharides and post-harvest tomato plant waste to levulinic acid. Green Chemistry, 16 (1), 73-76.

WERPY, T., et al. Top value added chemicals from biomass. Volume 1-Results of screening for potential candidates from sugars and synthesis gas. Department of Energy Washington DC, 2009.

WU, Y. et al. Microwave-assisted hydrolysis of crystalline cellulose catalyzed by biomass char sulfonic acids. Green Chemistry, 12(4), 696-700, 2010.

ZEITSCH, K.J. The chemistry and technology of furfural and its many by-products. Elsevier, 2000.

ZHANG, Z. et al. Microwave-assisted conversion of lignocellulosic biomass into furans in ionic liquid. Bioresource Technology, 101(3), 1111-1114, 2010.

ZHANG, Z. et al. Solid acid and microwave-assisted hydrolysis of cellulose in ionic liquid. Carbohydrate Research, 344(15), 2069-2072, 2009. 


\title{
DESAFIOS E OPORTUNIDADES DA GERAÇÃO DISTRIBUÍDA A PARTIR DO BIOGÁS
}

\author{
Belin, P.R.* ${ }^{1,2}$; Silpen, M.R. ${ }^{2}$ \\ ${ }^{I}$ Centro Internacional de Energias Renováveis - Biogás (CIBiogás-ER), Foz do Iguaçu, PR - Brasil. \\ ${ }^{2}$ Integrante do Projeto de P\&D ANEEL PD-06491-0287/2012. \\ pamela.rb@cibiogás.org; monique.riscado@cibiogás.org
}

\begin{abstract}
RESUMO: O mercado brasileiro de geração distribuída (GD) tem crescido consideravelmente nos últimos anos, devido ao interesse dos consumidores e ao desenvolvimento das regulamentações nacionais. Apesar da inserção crescente, a participação ainda é irrisória dentro panorama atual e deve ser incentivada, a fim de aproveitar os benefícios oriundos dessa forma de geração. O biogás compreende uma fonte de GD ainda pouco explorada e de elevado potencial, com benefícios ambientais diretos. Além disso, permite contribuir para o sistema elétrico, com características intrínsecas a essa fonte, como a previsibilidade de geração e controle de despacho, e características decorrentes da conexão em GD, como, a redução das perdas sistêmicas e a melhora do perfil de tensão. Assim, esta pesquisa traçou a presente conjuntura da geração distribuída com foco no biogás, identificando os desafios enfrentados para a sua maior disseminação, incluindo as tendências legais, de mercado e as oportunidades relacionadas especificamente ao uso dessa fonte.
\end{abstract}

Palavras-chave: Geração distribuída, biogás, energias renováveis.

\section{CHALLENGES AND OPPORTUNITIES OF DISTRIBUTED GENERATION FROM BIOGAS}

ABSTRACT: The Brazilian market for distributed generation (DG) has grown considerably in recent years, due to consumer interest and the development of a national regulatory framework. Regardless of the growing capacity, DG's share is still negligible within the current scenario and should be promoted in order to take advantage of the benefits related to this generation scheme. Biogas is a source of still underexploited and high potential DG with direct environmental benefits. In addition, it allows contributing to the Brazilian electrical system, due to characteristics intrinsic to this source, such as the predictability of generation and dispatch control, as well as characteristics resulting from the connection in DG, such as the reduction of systemic losses and the improvement of the voltage profile. Thus, this research described the present scenario of distributed generation focused on biogas, identifying the challenges for its market increase, including legal and market trends, as well as the opportunities specifically related to the use of this source.

Keywords: Distributed generation, biogas, renewable energies.

\section{INTRODUÇÃO}

O biogás é resultante do processo de biodigestão de diferentes substratos e pode ser utilizado energeticamente em rotas tecnológicas distintas, o que torna cada modelo de negócio único. Uma de suas finalidades é a geração de eletricidade, que exige produção de efluentes ou resíduos de forma concentrada em grande quantidade, ou ainda, produção de biogás de maneira descentralizada com transporte por rede de gás. Essa fonte apresenta vantagens competitivas em relação a outras fontes de energia renováveis, como a possibilidade de estocagem de gás e despacho de energia no momento mais adequado, permitindo ao consumidor utilizá-la em situações estratégicas para seu consumo ou para a rede.

O modelo de negócio a ser adotado em arranjos envolvendo o biogás é determinante para viabilidade ou não de um projeto. Variantes, como, arranjo utilizado para a compensação, enquadramento das unidades consumidoras participantes do sistema e tamanho das plantas, tem influência direta nos indicadores finais. $\mathrm{O}$ tamanho das plantas está condicionado à disponibilidade de substratos, isto é, seu dimensionamento é realizado de acordo com a oferta de biomassa e não conforme a demanda energética, caso comum em projetos de energia fotovoltaica.

Os investimentos necessários, geralmente de elevada grandeza, também são preponderantes e inviabilizam a maior parte dos modelos destinados ao autoconsumo local. Isso porque o potencial de geração de plantas de biogás é, em geral, muito superior à demanda da unidade consumidora, cerca de $85 \%$ em granjas 
de suínos de médio porte. Assim, faz-se necessário modelos de negócios complexos para compensar a energia gerada em outras propriedades.

Arranjos abrangentes dedicados a micro e minigeração distribuída foram preconizados pela Resolução Normativa $n^{\circ} 687$ de 2015, da Agência Nacional de Energia Elétrica - ANEEL, que atualizou a Resolução Normativa $n^{\circ} 482$ de 2012. A inclusão de modelos como Geração Compartilhada, que autoriza a associação de consumidores com diferentes CPF/CNPJ em um mesmo arranjo de compensação, ampliou o potencial de viabilidade econômica de fontes como o biogás, oportunizando seu uso na geração de energia elétrica, convertendo um potencial passivo ambiental em um ativo energético. No entanto, há muitos desafios a serem superados, entre eles tem-se a burocracia atrelada aos modelos de negócios com múltiplos atores envolvidos e os custos adicionais inerentes a essas configurações, como custos de administração e impostos.

Desta forma, o objetivo desta pesquisa consiste em traçar o panorama geral da inserção do biogás como fonte primária em micro e minigeração distribuída no país. Para tanto, identifica-se os desafios a serem superados para o seu desenvolvimento e as oportunidades vislumbradas por tendências regulatórias e de mercado.

\section{MATERIAL E MÉTODOS}

A metodologia baseia-se na coleta, análise, tabulação, descrição e interpretação de dados de órgãos públicos, bibliográficos e de mercado; pautado pela experiência obtida no cenário real de atuação do Centro Internacional de Energia Renováveis - Biogás (CIBiogás), pelas tendências regulatórias, oportunidades de mercado e movimentação internacional.

\section{RESULTADOS E DISCUSSÃO}

O mercado de micro e minigeração distribuída é formado por consumidores que geram energia e injetam seu excedente na rede da distribuidora. Atualmente, tem-se $592.370,40 \mathrm{~kW}$ de potência instalada em geração distribuída, 48.354 unidades consumidoras que geram energia e 66.847 unidades consumidoras que recebem créditos de energia, onde $76 \%$ das unidades com geração são residenciais. Para o biogás, há $14.767,40$ kW de potência instalada, com 110 unidades consumidoras gerando energia e 491 unidades consumidoras consumindo essa energia, onde $89 \%$ das unidades com geração pertencem à classe rural (ANEEL, 2018b).

Do total de unidades com geração de energia, $88 \%$ são para consumo junto à carga, $12 \%$ para autoconsumo remoto e menos de $1 \%$ para geração compartilhada. Os Empreendimentos com Múltiplas Unidades Consumidoras são os menos representativos neste mercado, com apenas 27 unidades instaladas até o momento. Quando observamos do ponto de vista das unidades consumidoras que recebem os créditos de energia, 63\% são as unidades junto à carga, 35\% são unidades de autoconsumo remoto e $1 \%$ recebem créditos através da geração compartilhada. Em termos de potência instalada, $71 \%$ da potência instalada estão em unidades com consumo junto à carga, $26 \%$ em unidades com autoconsumo remoto e $3 \%$ está em unidades com geração compartilhada (ANEEL, 2018b).

Do total de unidades com geração de energia elétrica distribuída a biogás, $79 \%$ são para consumo junto à carga, $20 \%$ para autoconsumo remoto e $1 \%$ por geração compartilhada. Quando observamos do ponto de vista das unidades consumidoras que recebem os créditos de energia, 18\% são as unidades junto à carga e $81 \%$ são as unidades que consomem energia elétrica através do autoconsumo remoto ou por geração compartilhada. Isso se dá pelo fato das propriedades que produzem biogás, em sua maioria, gerarem excedentes de energia, uma vez que o dimensionamento da planta é feito a partir da oferta de substrato e não pela demanda de energia da propriedade. Em termos de potência instalada, $80 \%$ da potência instalada são em unidades com consumo junto à carga, $19 \%$ é dedicado a unidades com autoconsumo remoto e menos de $1 \%$ em geração compartilhada.

A participação do biogás no cenário atual torna-se mais relevante quando se observa as mesmas informações em termos de potência média gerada (Figura 1), diminuindo a disparidade em relação às demais fontes, em especial à solar. Essa análise é obtida considerando o fator de capacidade de cada uma das fontes e traduz em termos de geração de energia líquida.

Em termos de unidades com geração distribuída no país, a maior parte das plantas de biogás estão concentradas nas regiões sul e sudeste, com destaque para os estados de Minas Gerais, Paraná e Santa Catarina (Figura 2), sendo que Minas Gerais é a pioneira nacional em geração distribuída, graças a incentivos específicos fornecidos. 
De acordo com as projeções da Empresa de Pesquisa Energética - EPE (Tabela 1), haverá um crescente uso do biogás para a geração distribuída nos próximos anos, podendo atingir representação de mais de $30 \%$ da capacidade média de geração, em comparação com a energia solar, até 2026.

Para que este crescimento no mercado de geração distribuída a biogás se realize, alguns desafios precisam ser superados, entre eles estão: complexidade dos sistemas de compensação, especialmente em consórcios e cooperativas, que tem sua constituição burocrática e morosa; descumprimento de prazos pelas distribuidoras, apesar de haver regulamentação específica para isso; falta de linhas de financiamento adequadas e de fácil acesso; e solução para a possível redução de receita da distribuidora, que deixa de receber pelo uso da rede de distribuição, e acaba fazendo pressão contrária à expansão da geração distribuída, conduzindo ao pagamento do uso da rede.

Frente a esses desafios, a regulamentação vigente caminha para uma série de atualizações, que apontam para mudanças no sistema de compensação de energia, aplicando-o apenas sob a parcela da tarifa referente à Tarifa de Energia (TE), que deve ser implementado parcialmente até o fim de 2019. Essa componente representa cerca de $40 \%$ da tarifa total, sendo assim, essa mudança tem grande potencial de comprometer a expansão do mercado de geração distribuída, ainda em desenvolvimento.

Outros aspectos que preocupam a maturação do biogás como fonte de micro e minigeração distribuída no país estão no fato da visão de desenvolvimento legal da GD no Brasil estar sendo delimitada sob a ótica das características do segmento solar. Isso coloca em risco o não desenvolvimento de aspectos relevantes inerentes à outras fontes, como, por exemplo, o desenvolvimento dos modelos de negócio que permitam o consumo remoto, ou pior, que inviabilizem o desenvolvimento do biogás, visto a existência de discussões sobre a possibilidade de reduzir o tamanho máximo permitido das plantas nesse modal, ou ainda a inserção totalitária da cobrança da Tarifa de Uso dos Sistemas Elétricos de Distribuição (TUSD) em caráter prematuro.

Por outro lado, se as mudanças englobarem as discussões específicas das demais fontes de energia, elas podem resultar em oportunidades para o biogás. Entre as demandas prioritárias estão a desburocratização dos atuais modelos de negócios possíveis pela Resolução Normativa n ${ }^{\circ} 482$ da ANEEL, e a inclusão de novos modelos ou ampliação dos atuais, permitindo a comercialização de excedentes, principalmente para fontes como o biogás, dimensionada a partir da oferta de substrato.

\section{CONCLUSÃO}

A micro e minigeração de energia elétrica está ampliando sua participação dentro da matriz energética brasileira. No entanto, essa penetração ainda se encontra em etapa inicial e necessita de agentes facilitadores para que ganhe maturação tecnológica e viabilidade econômica. As regulações vigentes e suas respectivas atualizações foram fundamentais para esse primeiro momento e precisam ser ampliadas e desburocratizadas para que essa inserção continue em processo de crescimento.

A inserção em grande escala acarreta em desafios e riscos para as concessionárias e para as redes elétricas com suas atuais características. Entretanto, essa inserção ainda é ínfima, não trazendo impactos significativos. As questões apontadas por uma corrente contrária a disseminação da geração distribuída devem ser analisadas, monitoradas e controladas para haver modificações no momento certo, para agora, espera-se que as novas atualizações dos documentos legais tragam melhorias e facilitem a ampliação de novas unidades de geração distribuída e não que tragam maiores entraves.

É importante respaldar as mudanças pela ótica de cada uma das fontes primárias existentes, e não restringir apenas às características da fonte de maior participação, uma vez que isso pode dificultar ainda mais que outras fontes ganhem mercado e se expandam, até porque existem características favoráveis em fontes como o biogás que ainda não foram exploradas pelo órgão regulador e podem melhorar o funcionamento da rede e a previsibilidade das operações.

\section{AGRADECIMENTOS}

Agradecimento ao CIBiogás-ER e a Itaipu Binacional pelo apoio institucional durante a execução do estudo e o apoio financeiro da Companhia Paranaense de Energia (COPEL) através do projeto de P\&D ANEEL PD-06491-0287/2012 denominado “Arranjo Técnico e Comercial de Geração Distribuída de Energia Elétrica a Partir do Biogás de Biomassa Residual da Suinocultura em propriedades Rurais no Município de Entre Rios do Oeste do Paraná". 


\section{REFERÊNCIAS}

ANEEL - Agência Nacional de Energia Elétrica. Consulta Pública 010/2018. Disponível em: <http://www.aneel.gov.br/consultas-publicas> com acesso em: 23 nov. 2018a.

ANEEL - Agência Nacional de Energia Elétrica. Resolução Normativa N ${ }^{\circ}$ 687, de 24 de novembro de 2015. ANEEL - Agência Nacional de Energia Elétrica. Unidades consumidoras com geração distribuída. Disponível em: <http://www2.aneel.gov.br/scg/gd/GD_Classe.asp > com acesso em: 13 dez. 2018b.

ANEEL - Agência Nacional de Energia Elétrica. Resolução Normativa $\mathbf{N}^{\circ} \mathbf{4 8 2}$, de 17 de abril de 2012.

EPE - Empresa de Pesquisa Energética. Plano Decenal de Expansão de Energia 2026. Disponível em <http://www.mme.gov.br/documents/10584/0/PDE2026.pdf/474c63d5-a6ae-451c-8155-ce2938fbf896> com acesso em: novembro de 2018.

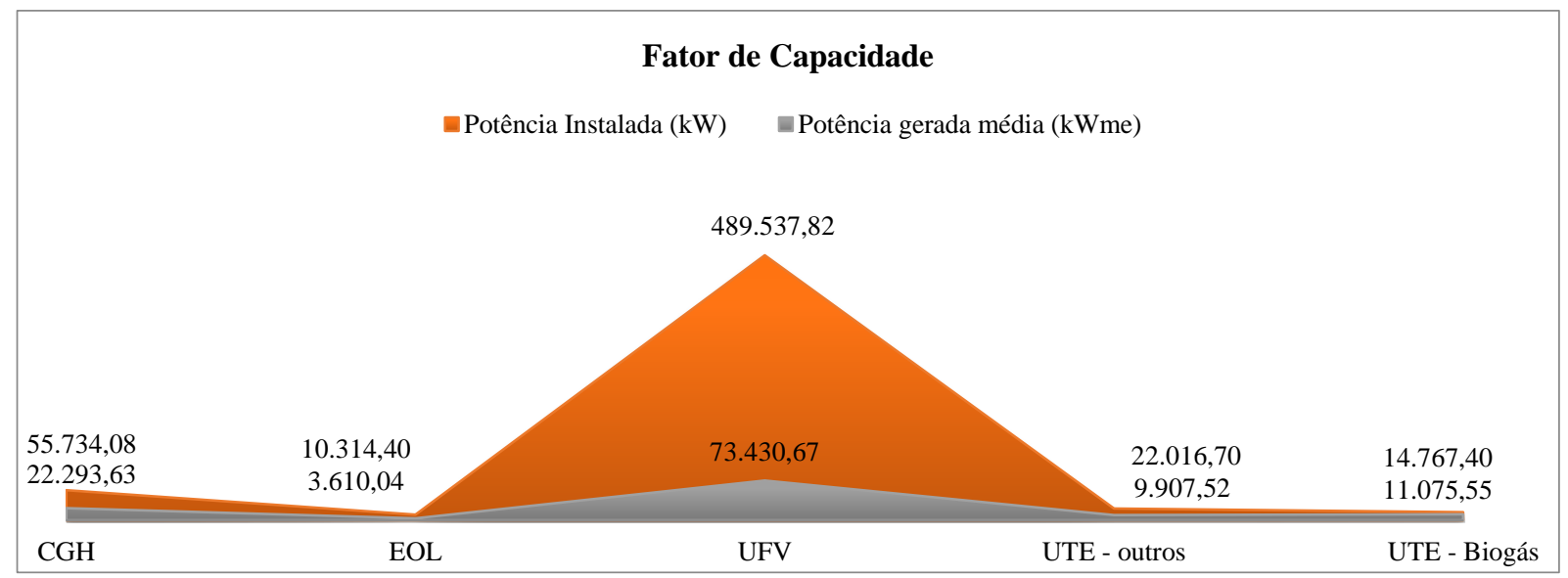

Fonte: Elaboração Própria, a partir de dados da ANEEL (2018b).

Figura 1. Potência instalada e geração de energia pelo fator de capacidade, por fonte (dez. 2018).

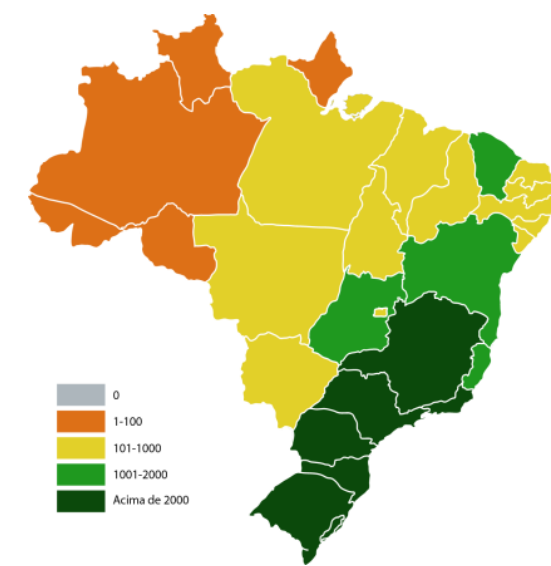

(a)

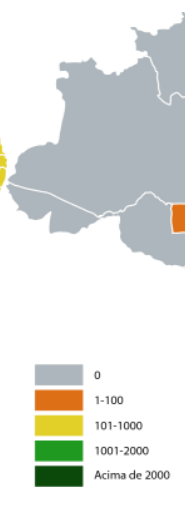

(b)

Fonte: Elaboração Própria, a partir de dados da ANEEL (2018b).

Figura 2. Geração Distribuída por estado para: (a) todas as fontes; e (b) biogás.

Tabela 1. Potência instalada x Potência média gerada (Projeções 2026).

\begin{tabular}{lcccc}
\hline & $\begin{array}{c}\text { Potência instalada } \\
\text { (MW) }\end{array}$ & Participação & $\begin{array}{c}\text { Potência média } \\
\text { gerada } \\
\text { (MWmed) }\end{array}$ & Participação \\
\hline Solar & 3.300 & $92 \%$ & 300 & $8 \%$ \\
Biogás & 495 & $69 \%$ & 225 & $31 \%$ \\
\hline
\end{tabular}

Fonte: Elaboração própria com base nos dados EPE, 2018 


\title{
ENRIQUECIMENTO DE CONSÓRCIO ELETROATIVO PARA UTILIZAÇÃO EM CÉLULAS A COMBUSTÍVEL MICROBIANAS
}

\author{
Mancilio, L.B.K. ${ }^{*}$; Silva, L.A. ${ }^{\text {; }}$ Guazzaroni, M.E. ${ }^{1}$; Santana, F.B. ${ }^{2}$; De Andrade, A.R. ${ }^{1}$; Reginatto, V. ${ }^{1}$ \\ 1Faculdade de Filosofia, Ciências e Letras de Ribeirão Preto - Universidade de São Paulo, 14040-901 - Ribeirão Preto - SP, Brasil \\ 2 Escola de Química e Alimentos, Universidade Federal do Rio Grande, Rio Grande, RS - Brasil \\ lucca.bonjy@usp.br
}

RESUMO: A forte dependência de matérias primas fósseis e a ameaça do seu término, bem como o seu poder poluidor, têm impulsionado a busca por fontes e tecnologias alternativas para a geração de energia a partir de resíduos. Atualmente pesquisa mundial procura desenvolver tecnologias que agreguem valor a resíduos e efluentes pela sua transformação em bioprodutos e/ou bioenergia. Neste contexto, as Células a Combustíveis Microbianas (CCMs) representam tecnologias inovadoras que podem gerar energia elétrica a partir da oxidação de compostos contidos em efluentes e resíduos, promovendo a sua biorremediação. As CCMs são sistemas bioeletroquímicos nos quais microorganismos exoeletrogênicos são biocatalizadores que crescem sobre o ânodo transferindo os elétrons oriundos dessa oxidação para um circuito externo ligado ao cátodo. Entretanto, ainda é necessário conhecer melhor a diversidade, ecologia e funcionamento dos consórcios microbianos responsáveis pela eletroatividade no ânodo. Neste trabalho três CCMs foram construídas e o ânodo foi inoculado com um consórcio microbiano proveniente de um sedimento marinho previamente cultivado em três diferentes meios de cultura, a fim de simular a composição de efluentes poluidores quais sejam: um contendo acetato (CCM-A), outro contendo acetato+ferro e um terceiro com acetato+enxofre (CCM-S). O desempenho das CCM-A, CCM-Fe e CCM-S foi monitorado pelas voltagens geradas, atingindo médias de $0,269( \pm 0,11)$, $0,448( \pm 0,033)$ e $0,447( \pm 0,05)$ Volts, respectivamente. Essas discrepâncias levantam uma série de perguntas e possibilidades quanto ao papel de cada componente dos meios e consórcios.

Palavras-chave: bioeletricidade, bioenergia, biorremediação, sistema bioeletroquímico, tratamento.

\section{ENRICHMENT OF MICROBIAL CONSORTIUM IN EXOELECTROGENIC BACTERIA FOR ITS USE AS BIOCATALYST IN MICROBIAL FUEL CELLS}

\begin{abstract}
The strong dependence on fossil raw materials and the threat of their end, as well as their polluting power, have driven the search for alternative sources and technologies for the generation of energy from waste. Currently, world research seeks to develop technologies that add value to waste and effluent by transforming it into bioproducts and / or bioenergy. In this context, Microbial Fuel Cells (CCMs) represent innovative technologies that can generate electrical energy from the oxidation of compounds contained in effluents and residues, promoting their bioremediation. CCMs are bioelectrochemical systems in which exoelectrogenic microorganisms are biocatalysts that grow on the anode by transferring the electrons from that oxidation to an external circuit connected to the cathode. However, it is still necessary to know better the diversity, ecology and functioning of the microbial consortia responsible for the electroactivity in the anode. In this work three CCMs were constructed and the anode was inoculated with a microbial consortium from a marine sediment previously cultured in three different culture media in order to simulate the composition of polluting effluents, such as: one containing acetate (CCM-A), another containing acetate + iron and a third with acetate + sulfur (CCM-S). The performance of CCM-A, CCM-Fe and CCM-S was monitored by the generated voltages, reaching averages of $0.296( \pm 0.11), 0.448( \pm 0.033)$ and $0.447( \pm 0.05)$ Volts, respectively. These discrepancies raise a series of questions and possibilities regarding the role of each component of media and consortia.
\end{abstract}

Keywords: Bioelectricity, Bioenergy, Bioremediation, Bioeletrochemical System, Treatment, 


\section{INTRODUÇÃO}

Com a matriz energética mundial em plena transição, as pesquisas por fontes energéticas alternativas ganham cada vez mais impulso, e a dificuldade e custo para tratamento de efluentes de todos os tipos apresenta um sério risco ao meio ambiente e saúde pública em todos os países. Assim, a promessa de geração de bioeletricidade concomitantemente com o tratamento de efluentes poluentes torna a Célula a Combustível Microbiana $(\mathrm{CCM})$ cada vez mais atraente. Estes sistemas bioeletroquímicos permitem acesso à energia química contida nos componentes de efluentes que costumam ser descartados, através da utilização destes compostos por biocatalizadores microbianos.

As CCMs são compostas por um compartimento anódico que é preenchido com meio de cultura e inoculado com uma cultura mista, em condições anaeróbicas, para a formação de um biofilme sobre o ânodo submerso. Este biofilme é constituído por consórcios microbianos contendo bactérias exoeletrogênicas, ou seja, bactérias que na ausência de $\mathrm{O}_{2}$ como aceptor final de elétrons, desenvolvem mecanismos alternativos de descarregar os elétrons oriundos de seu metabolismo oxidativo usando o ânodo. O ânodo precisa ser feito de um material condutor, biocompatível, e quimicamente inerte no meio de cultura, por isso, normalmente, são utilizados tecidos de carbono (VENKATA MOHAN et al., 2014). O influxo de elétrons no ânodo gera uma diferença de potencial (ddp) entre o ânodo (negativamente carregado) e o cátodo (terminal positivo da célula), onde a oxidação que ocorre no ânodo é compensada com a redução no cátodo. Ligados por um circuito externo, a diferença de potencial possibilita que se consolide um fluxo de elétrons do ânodo para o cátodo e um fluxo de carga positiva (prótons difusos na solução) do cátodo para o ânodo, através da membrana trocadora de prótons. Por fim, os elétrons emitidos pelos microrganismos exoeletrogênicos no ânodo atravessam o circuito externo até chegar ao cátodo. No cátodo é catalisada uma reação na qual os elétrons oriundos do ânodo, e os prótons presentes no meio (difundidos pela membrana trocadora de prótons - Nafionß) reduzem o oxigênio presente no ar atmosférico. Assim, no cátodo, os elétrons gerados na oxidação dos compostos poluentes geram água $\left(\mathrm{O} 2+4 \mathrm{H}^{+}+4 \mathrm{e}-\rightarrow 2 \mathrm{H} 2 \mathrm{O}\right)$. A diferença de potencial (ddp) criada por esse sistema pode ser mensurada e é então aproveitada para gerar trabalho (LIU et al., 2005).

A pesquisa em torno de CCM tem crescido imensamente nos últimos anos, explorando maneiras de maximizar a densidade de potência produzida e a oxidação do substrato, especialmente através do entendimento e controle dos fatores abióticos que afetam o sistema, como: temperatura; concentração de substrato; força iônica do meio; distância entre eletrodos; configuração do sistema; material dos eletrodos; resistência interna e externa da célula; e de forma geral a facilidade de difusão de prótons, elétrons e $\mathrm{O}_{2}$. (LIU et al., 2005). Entretanto, as densidades de potência obtidas têm-se estagnado, mesmo com diferentes arquiteturas nas CCM, meios de cultura, etc. Os estudos mais atuais têm se voltado para a manipulação da formação, metabolismo, e composição biológica dos biocatalizadores, que é bastante sensível, dinâmica e sujeita a relações ecológicas complexas.

Este trabalho teve como objetivo enriquecer inóculos microbianos exoeletrogênicos, a partir de um sedimento do território brasileiro, com substratos de interesse econômico que simulam aqueles gerados por mineradoras, usinas de açúcar e etanol, e outros efluentes industriais.

\section{MATERIAL E MÉTODOS}

Como fonte de biocatalizador no ânodo da CCM foi utilizado um sedimento proveniente de dragagem do porto de Rio Grande/RS. Este sedimento foi submetido a enriquecimento com meios de cultura visando enriquecer microrganismos que metabolizam compostos de interesse: Ferro (III), enxofre, e acetato (fonte de carbono principal e presente em todos os meios). Estes meios foram utilizados tanto no enriquecimento quanto durante a operação das CCM. O Meio-A (LOVLEY; PHILLIPS, 1988) foi usado para enriquecer e alimentar a CCM_A, e era composto por: acetato de sódio $(1 \mathrm{~g} / \mathrm{L}), \mathrm{CaCl}_{2} \cdot 2 \mathrm{H}_{2} \mathrm{O}(1 \mathrm{~g} / \mathrm{L})$, Extrato de Levedura $(0,05 \mathrm{~g} / \mathrm{L})$, $\mathrm{KCl}(1 \mathrm{~g} / \mathrm{L}), \mathrm{MgCl}_{2} \cdot 6 \mathrm{H}_{2} \mathrm{O},(1 \mathrm{~g} / \mathrm{L}), \mathrm{MgSO}_{4} .7 \mathrm{H}_{2} \mathrm{O}(1 \mathrm{~g} / \mathrm{L}) ; \mathrm{MnCl}_{2} \cdot 4 \mathrm{H}_{2} \mathrm{O}(0,005 \mathrm{~g} / \mathrm{L}) ; \mathrm{Na}_{2} \mathrm{HPO}_{4}(0,74 \mathrm{~g} / \mathrm{L}) ; \mathrm{NaCl}$ $(0,1) ; \mathrm{NaHCO}_{3}(2,5 \mathrm{~g} / \mathrm{L}) ; \mathrm{NaMoO}_{4} \cdot 2 \mathrm{H}_{2} \mathrm{O}(0,001 / \mathrm{L}) ; \mathrm{NH}_{4} \mathrm{Cl}(1,5 \mathrm{~g} / \mathrm{L})$; Resazurina $1 \%(1 \mathrm{ml} / \mathrm{L})$. O meio_Fe, usado na CCM_Fe continha a mesma composição, com a adição de $\mathrm{Fe}_{2} \mathrm{O}_{3}(0,57 \mathrm{~g} / \mathrm{L})$ (LOVLEY et al., 1993). O Meio_S, usado na CCM_S, era composto por: Acetato de Sódio $(1 \mathrm{~g} / \mathrm{L})$; CaCl2.6H2O $(0,041 \mathrm{~g} / \mathrm{L})$; Citrato de Sódio $\quad(0,342 \mathrm{~g} / \mathrm{L})$; Extrato de Levedura $(1 \mathrm{~g} / \mathrm{L})$; FeSO4.7H2O 0,1 g/L; $\quad \mathrm{KH} 2 \mathrm{PO} 4 \quad(0,5 \mathrm{~g} / \mathrm{L})$; $\mathrm{MgCl} 2.6 \mathrm{H} 2 \mathrm{O}(0,1 \mathrm{~g} / \mathrm{L}) ; \mathrm{MgSO} 4.7 \mathrm{H} 2 \mathrm{O}(0,123 \mathrm{~g} / \mathrm{L}) ; \mathrm{Na} 2 \mathrm{~S} .7 \mathrm{H} 2 \mathrm{O}$ o,4\% (5 mL/L); Na2SO4 (9g/L); NH4CL (1 $\mathrm{g} / \mathrm{L})$; Resazurina 1\% (1 ml/L) (POSTGATE, 1983). 
Foram construídas $3 \mathrm{CCMs}$, cada uma composta basicamente por um compartimento angódico e um catódico, ligados por um circuito externo com um resistor de $1000 \Omega$. O compartimento anódico continha o respectivo meio de cultura e inóculo em anaerobiose, no qual fica submerso o ânodo (sobre o qual crescerá o biofilme exoeletrogênico): um tecido de carbono suspenso pelo fio de $\mathrm{NiCr}$ (inerte), conectado ao circuito externo. O compartimento catódico é preenchido com água, e fica aberto ao ambiente, para permitir acesso do $\mathrm{O}_{2}$ ao seu cátodo, composto por um tecido de carbono com $20 \%$ de platina (catalizadora), prensado a quente com a membrana trocadora de prótons. Os compartimentos sem comunicam através da membrana trocadora de prótons. Cada CCM foi operada por 14 dias, sendo monitorada a ddp com um driver de aquisição de dados e o software correspondente (Labview ${ }^{\circledR}$ ). Os primeiros 7 dias foram dedicados ao crescimento do biofilme sobre o ânodo, e no sétimo dia o meio de cultura foi substituído por um meio novo e iniciou-se a fase de medição

Amostras do sobrenadante foram coletadas no primeiro, sétimo e último dia de operação da CCM para analisar a concentração de acetato (por Cromatografia Líquida de Alta Eficiência-CLAE). O DNA do biofilme foi extraído para posterior análise por PCR qualitativo para os principais genes participantes da exoeletrogênese. Uma porção do biofilme também foi submetida a Microscopia Eletrônica de Varredura (MEV), para visualização do consórcio em atuação (LIU; LOGAN, 2004)

\section{RESULTADOS E DISCUSSÃO:}

A Figura 1 apresenta as ddps atingidas pelas CCMs ao longo da semana de medição. As CCM_A, CCM_Fe e a CCM_S obtiveram ddps médias de de 0,269 $( \pm 0,11), 0,448( \pm 0,033)$ e 0,447 $( \pm 0,05)$ Volts, respectivamente. Portanto, as CCM_S e CCM_Fe apresentaram os melhores desempenhos, inclusive semelhantes entre si.

Isso representa uma diferença notável entre os potenciais, especialmente ao levar em conta o fato de que a única diferença entre os meios da CCM_Fe e da CCM_A é a presença de $\mathrm{Fe}_{2} \mathrm{O}_{3}$ no primeiro. Deve-se destacar os potenciais padrão de redução de cada composto nos meios de cultura utilizados, pois a semi reação do par redox $\mathrm{Fe}^{3+}-\mathrm{Fe}^{2+}$ produz $0,771 \mathrm{~V}$, e a de $\mathrm{SO}_{4}{ }^{2-}-\mathrm{SO}_{3}{ }^{2-}$ produz $0,93 \mathrm{~V}$, enquanto a oxidação de acetato por si só produz $0,3 \mathrm{~V}$.

É possível que a superioridade de potencial das CCMs alimentadas com os meios de cultura Fe e S sobre o A esteja relacionada à habilidade destes sais para agir como mediadores inorgânicos na transferência de elétrons, permitindo assim exoeletrogênese não apenas por bactérias aderidas diretamente ao biofilme mas também de vida livre. Além disso, uma maior gama de compostos no meio pode permitir uma diversidade maior de metabolismos se acoplando entre grupos diferentes de bactérias. O biofilme que serve de biocatalizador neste sistema pode realizar transferência externa de elétrons de três modos principais: i) indiretamente, através de compostos químicos mediadores solúveis de redox; ii) diretamente, através de citocromos-c dispostos em série na membrana ou em extensões pilosas da membrana que formam nanofios capazes de aumentar a distância de transferência; ou iii) indiretamente através da secreção de moléculas próprias que transferem os elétrons sem necessitar do contato direto entre microrganismo e ânodo (SYDOW et al 2014). As composições comunitárias recrutadas em cada CCM, provavelmente, possuirão teias ecológicas muito diferentes entre si, tanto na ciclagem de nutrientes quanto no mecanismo de transferência de elétrons, explicando diferenças em comportamento e desempenho.

\section{CONCLUSÃO}

A utilização de meios de cultura diferentes, contendo enxofre, ferro e acetato, permitiu enriquecimento diferencial dos consórcios microbianos em cada CCM, promovendo uma maior ddp nas CCMs alimentadas com os meios contendo enxofre e ferro.

\section{AGRADECIMENTOS}

FAPESP (Fundação de Amparo à Pesquisa do Estado de São Paulo) - Projeto 2018/00789-7 e L.B.K.M recebeu bolsa FAPESP (2018/15528-4). 


\section{VISIGER

\section{REFERÊNCIAS}

LIU, H.; LOGAN, B. E. Electricity generation using an air-cathode single chamber microbial fuel cell in the presence and absence of a proton exchange membrane. Environmental Science and Technology, v. 38, n. 14, p. 4040-4046, 2004. Disponível em: 〈https://pubs.acs.org/doi/abs/10.1021/es0499344〉. Acesso em: 20 nov. 2018.

LOVLEY, D. R. et al. Geobacter metallireducens gen. nov. sp. nov., a microorganism capable of coupling the complete oxidation of organic compounds to the reduction of iron and other metals. Archives of Microbiology, v. 159, n. 4, p. 336-344, abr. 1993. Disponível em: <http://link.springer.com/10.1007/BF00290916>. Acesso em: 20 nov. 2018.

LOVLEY, D. R.; PHILLIPS, E. J. Novel mode of microbial energy metabolism: organic carbon oxidation coupled to dissimilatory reduction of iron or manganese. Applied and environmental microbiology, v. 54, n. 6, p. 1472-80, jun. 1988. Disponível em: <http://www.ncbi.nlm.nih.gov/pubmed/16347658>. Acesso em: 20 nov. 2018.

POSTGATE, J. R. The Sulfate-Reducing Bacteria. [s.l.] Wiley-Blackwell, 1983.

SYDOW, A. et al. Electroactive bacteria-molecular mechanisms and genetic tools. Applied Microbiology and Biotechnology, v. 98, n. 20, p. 8481-8495, 20 out. 2014. Disponível em: <http://link.springer.com/10.1007/s00253-014-6005-z>. Acesso em: 20 nov. 2018.

VENKATA MOHAN, S. et al. Microbial fuel cell: Critical factors regulating bio-catalyzed electrochemical process and recent advancements. Renewable and Sustainable Energy Reviews, v. 40, p. 779-797, 1 dez. 2014.

em: <https://www.sciencedirect.com/science/article/pii/S1364032114005619?via\%3Dihub>. Acesso em: 20 nov. 2018 .

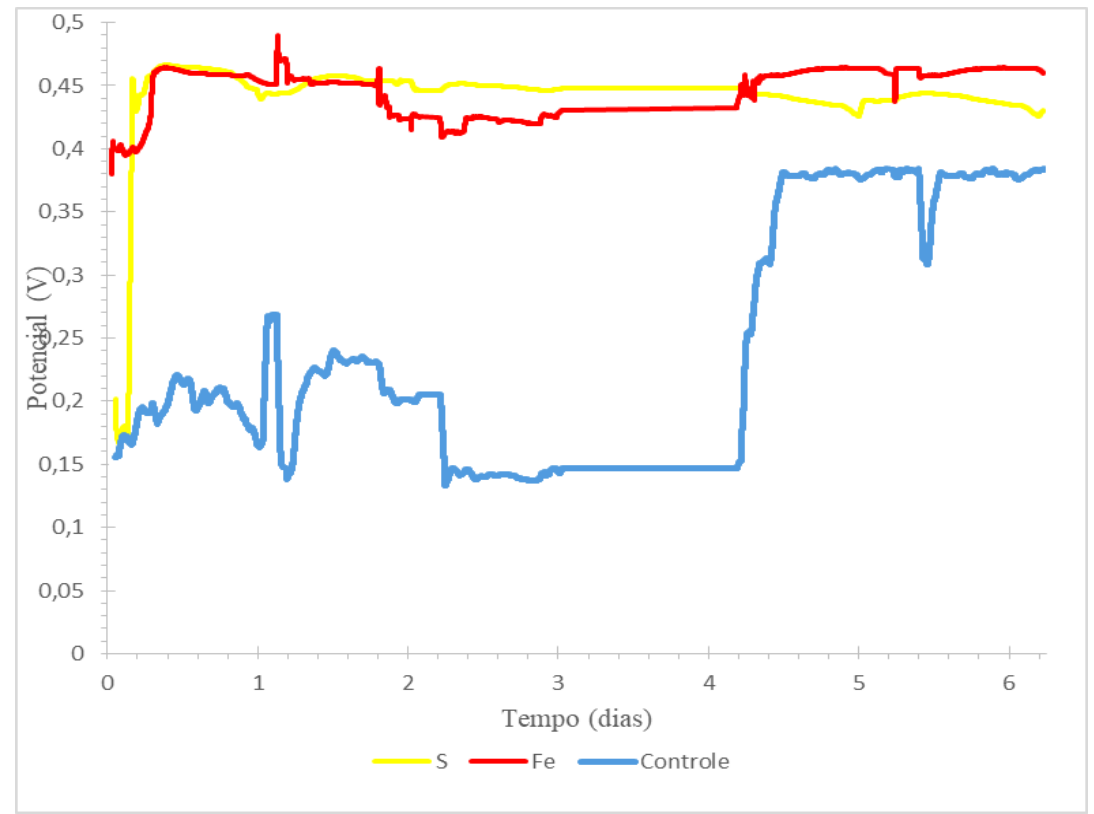

Figura 1. Diferença de potencial em função do tempo das CCMs inoculadas e alimentadas com os meios de cultura contendo acetato (controle), acetato e enxofre e acetato e ferro. 


\title{
FERMENTAÇÃO EM MICROAROBIOSE POR LEVEDURAS ISOLADAS DE BAGAÇO E PALHA DE MILHO
}

\author{
Baptista, C.W. ${ }^{*}$; Milani, L.M. ${ }^{1}$; Adorno, L.R. ${ }^{1}$; Mibielli, G.M. ${ }^{2}$; Müller, C. ${ }^{1}$; Alves, S.L.Jr. ${ }^{1}$ \\ ${ }^{1}$ Laboratório de Bioquímica e Genética, Campus Chapecó, Universidade Federal da Fronteira Sul, Chapecó/SC, Brasil. \\ ${ }^{2}$ Laboratório de Resíduos Sólidos, Campus Chapecó, Universidade Federal da Fronteira Sul, Chapecó/SC, Brasil. \\ *cristina.winkelmann@gmail.com
}

\begin{abstract}
RESUMO: As biomassas vegetais em decomposição abrigam microrganismos capazes de metabolizar os carboidratos que compõem a estrutura lignocelulósica. Desse modo, resíduos agroindustriais podem fornecer leveduras como potenciais microrganismos fermentadores para a produção do etanol de segunda geração, também conhecido como etanol celulósico ou simplesmente etanol 2G. Com o objetivo de selecionar leveduras com elevado desempenho fermentativo diante dos três principais açúcares encontrados em hidrolisados lignocelulósicos, o presente trabalho isolou de palha e bagaço de milho em decomposição três linhagens da espécie Meyerozyma caribbica, que foram submetidas a fermentações sob microaerobiose em meios sintéticos YNB contendo, alternadamente, glicose, xilose ou celobiose como fonte de carbono. As três linhagens testadas apresentaram $\sim 99 \%$ de eficiência fermentativa diante da glicose, porém foram incapazes de consumir a xilose e a celobiose durante as 12 horas de incubação a que as células foram submetidas. Contudo, apesar do desempenho negativo diante da pentose e do dissacarídeo, o rendimento de etanol a partir da glicose (açúcar majoritário em hidrolisados lignocelulósicos) esteve muito próximo do máximo teórico, demonstrando o potencial dessa espécie de levedura para a produção do etanol 2G.
\end{abstract}

Palavras-chave: celobiose, etanol, glicose, Meyerozyma caribbica, xilose.

\section{FERMENTATION UNDER MICROBIOSIS BY YEASTS ISOLATED FROM CORN BAGASSE AND STRAW}

\begin{abstract}
Rotting plant biomasses houses microorganisms capable of metabolizing the carbohydrates that make up the lignocellulosic structure. In this sense, agro-industrial waste can provide yeasts as potential fermenting microorganisms for the production of second-generation ethanol, also known as cellulosic ethanol or simply $2 \mathrm{G}$ ethanol. In order to select yeasts with high fermentative performance in relation to the three main sugars found in lignocellulosic hydrolysates, the present work isolated three strains of the Meyerozyma caribbica species from corn straw and bagasse, which were submitted to fermentations under microaerobiosis in synthetic YNB media alternately containing glucose, xylose or cellobiose as carbon source. The three tested strains showed $\sim 99 \%$ of fermentative efficiency against glucose, but were unable to consume xylose and cellobiose during the 12 hours of incubation to which the cells were submitted. However, in spite of the negative performance against that pentose and that disaccharide, the yield of ethanol from glucose (the major sugar in lignocellulosic hydrolysates) was very close to the theoretical maximum, demonstrating the potential of this yeast species for the production of $2 \mathrm{G}$ ethanol.
\end{abstract}

Keywords: cellobiose, ethanol, glucose, Meyerozyma caribbica, xylose.

\section{INTRODUÇÃO}

A produção de etanol de segunda geração $(2 \mathrm{G})$ depende da fermentação dos carboidratos presentes nos hidrolisados lignocelulósicos, sendo a glicose (uma hexose), a xilose (uma pentose) e a celobiose (um dissacarídeo composto por duas moléculas de glicose unidas entre si por uma ligação glicosídica do tipo $\square$ 1,4) os três principais (STAMBUK et al., 2008; LEE et al., 2013). Embora a levedura Saccharomyces cerevisiae seja o microrganismo mais amplamente utilizado em processos de fermentação alcoólica - incluindo a fabricação do etanol de primeira geração (obtido, no Brasil, a partir do caldo de cana) -, as cepas industriais dessa espécie são incapazes de fermentar a pentose e o dissacarídeo supramencionados (STAMBUK et al., 2008). Dessa forma, a otimização do etanol $2 \mathrm{G}$ depende da seleção de novas leveduras capazes de fermentar esses carboidratos. 
Considerando as características químicas de biomassas como caules, folhas, palhas e bagaços, é reconhecido o potencial de isolamento de leveduras fermentadoras de xilose e celobiose nesses materiais vegetais quando em decomposição (LARA et al., 2014). Assim sendo, as próprias matérias-primas que podem ser empregadas na produção de etanol de segunda geração, como os resíduos vegetais da produção de milho, podem também fornecer os microrganismos necessários para a etapa fermentativa. Nesse contexto, o presente trabalho teve como objetivo isolar, identificar e caracterizar leveduras a partir de amostras de palha e bagaço de milho. Dentre os isolados, foram identificadas três cepas da espécie Meyerozyma caribbica (VAUGHANMARTINI et al., 2005; KURTZMAN, SUZUKI, 2010), que foram selecionadas para ensaios de fermentação em microaerobiose.

\section{Isolamento e identificação das leveduras}

\section{MATERIAL E MÉTODOS}

As leveduras foram isoladas a partir de amostras de bagaço e palha de milho em decomposição, obtidas nas áreas experimentais do Campus Chapecó da Universidade Federal da Fronteira Sul. As amostras foram coletadas em tubos Falcon de $50 \mathrm{~mL}$ estéreis. Aproximadamente $1 \mathrm{~g}$ foi inoculado em $20 \mathrm{~mL}$ de meio sintético mínimo contendo $0,67 \%$ de base nitrogenada, $0,02 \%$ de cloranfenicol e $1 \%$ de xilose. Foram preparados quatro frascos erlernmeyers e incubados a $25^{\circ} \mathrm{C}$ por 3-10 dias, sob agitação periódica de $145 \mathrm{rpm}$. Quando se detectou crescimento celular por turbidez, uma alçada de células foi estriada por esgotamento em placas de Petri contendo os mesmos meios supracitados, além da adição de $2 \%$ de ágar. As placas foram incubadas a uma temperatura de $28^{\circ} \mathrm{C}$, e as leveduras foram isoladas pela morfologia da colônia. As cepas foram nomeadas conforme código pré-estabelecido pela coleção do grupo de pesquisa.

A identificação das leveduras foi realizada no Instituto Biológico do Estado de São Paulo através do sequenciamento da região ITS-5.8S e da subsequente comparação das sequências obtidas com aquelas disponíveis no banco de dados GenBank por meio da ferramenta BLAST (em http://www.ncbi.nlm.nih.gov). Três cepas da espécie Meyerozyma caribbica foram utilizadas neste trabalho: CHAP-091, CHAP-096 e CHAP103.

\section{Fermentação em microaerobiose}

Para a análise da fermentação, as leveduras foram pré-inoculadas em Erlenmeyers com volume de 25 $\mathrm{mL}$, em uma proporção de $1 / 5$ do volume de meio líquido YPD (1\% de extrato de levedura, $2 \%$ de peptona e $2 \%$ de glicose), em um período de $\sim 48$ horas com agitação de $145 \mathrm{rpm}$ a $25^{\circ} \mathrm{C}$. No passo seguinte, as leveduras do pré-inóculo foram inoculadas em um frasco Erlenmeyer de $1 \mathrm{~L}$ (transferindo-se 3,5 mL para $350 \mathrm{~mL}$ de meio YPD fresco) e subsequentemente incubadas a $25{ }^{\circ} \mathrm{C}$, com $145 \mathrm{rpm}$, overnight. Quando as células atingiram uma densidade óptica $\left(\mathrm{DO}_{570 \mathrm{~nm}}\right)$ de aproximadamente 10,0 , as elas foram centrifugadas $(5.000 \mathrm{~g}, 3$ min, $4^{\circ} \mathrm{C}$ ) e lavadas duas vezes com água destilada a $4^{\circ} \mathrm{C}$. Na sequência, as células foram ressuspensas em meio sintético YNB (0,67\% de base nitrogenada de levedura e $2 \%$ de açúcar - glicose, xilose ou celobiose) de modo a se obter uma suspensão celular de $20 \mathrm{~g} \mathrm{~L}^{-1}$. Essas suspensões foram mantidas em frascos snapcaps, a $25^{\circ} \mathrm{C}$, por 12 horas, sem agitação, com retirada de amostras a cada duas horas. De cada amostra, uma primeira alíquota foi utilizada para a determinação da biomassa celular $\left(\mathrm{DO}_{570 \mathrm{~nm}} \mathrm{x} 0,3\right)$, enquanto a segunda foi centrifugada $\left(5.000 \mathrm{~g}, 3 \mathrm{~min}, 4^{\circ} \mathrm{C}\right)$ e seu sobrenadante foi utilizado para a determinação do consumo de açúcares e da produção de etanol, por HPLC (fase móvel $5 \mathrm{mM} \mathrm{H}_{2} \mathrm{SO}_{4}, 50^{\circ} \mathrm{C}$, fluxo de $0,6 \mathrm{~mL} \mathrm{~min}^{-1}$ em coluna Aminex HPX-87H, Bio-Rad, e detecção por índice de refração RID-10, Shimadzu).

O rendimento de etanol $\left(Y_{\mathrm{e} / \mathrm{s}}\right)$ foi obtido pelo quociente entre a quantidade máxima de etanol produzida e o total de substrato (açúcar) consumido. A partir do $Y_{\mathrm{e} / \mathrm{s}}$ foi calculada a eficiência fermentativa, como percentual do rendimento máximo teórico de etanol (0,511 para glicose).

Foram realizados dois experimentos independentes para cada linhagem em cada uma das condições testadas. Os dados apresentados representam a média e o erro padrão em cada ponto de coleta de amostras ao longo das 12 horas de fermentação.

\section{RESULTADOS E DISCUSSÃO}

No intuito de analisar a capacidade fermentativa de leveduras selvagens isoladas de bagaço e palha de milho em decomposição, diante dos principais carboidratos encontrados em hidrolisados lignocelulósicos, três linhagens de $M$. caribbica foram submetidas a condições de microaerobiose. Duas das cepas analisadas 
(CHAP-091 e CHAP-103) consumiram toda a glicose disponível no meio nas primeiras seis horas de incubação e apresentaram eficiência fermentativa de 99\% (Figuras 1A e 2A). A linhagem CHAP-096, por outro lado, precisou das 12 horas para consumir $85 \%$ dessa hexose, embora tenha apresentado o mesmo patamar de eficiência fermentativa (Figura 3A). Esse grau de eficiência iguala-se ao que as leveduras industriais brasileiras de $S$. cerevisiae apresentam durante a fermentação do caldo de cana-de-açúcar, rico em sacarose, na produção de etanol de primeira geração (LOPES et al., 2016)

Haja vista a baixa disponibilidade de oxigênio nessas condições e a já conhecida capacidade de essa espécie metabolizar a xilose (CASSA-BARBOSA et al., 2015; SUKPIPAT et al., 2018), esperava-se que as células das leveduras fossem fermentar eficientemente essa pentose. Surpreendentemente, porém, as linhagens testadas não conseguiram consumir a xilose do meio durante as 12 horas de incubação e, consequentemente, não produziram etanol (Figuras 1B, 2B e 3B). Contudo, resultados semelhantes foram obtidos por Mattam et al. (2016), que demonstraram prejuízo no consumo dessa pentose quando as células foram submetidas a anaerobiose. De fato, se houver dependência da enzima xilose-redutase pela coenzima NADPH, que só pode ser regenerada sob condições aeróbicas, a utilização anaeróbica da xilose pode ser inibida (WEBB, LEE, 1990). Da mesma forma, a celobiose não pôde ser metabolizada pelas leveduras nas condições testadas (Figuras 1C, $2 \mathrm{C}$ e $3 \mathrm{C})$.

\section{CONCLUSÃO}

Embora as linhagens analisadas não tenham sido capazes de fermentar a xilose e a celobiose, os dados obtidos demonstram elevado desempenho fermentativo de Meyerozyma caribbica diante da glicose, com rendimento de etanol equivalente ao observado para as leveduras industriais de Saccharomyces cerevisiae durante a fermentação da sacarose na fabricação do etanol de primeira geração. Dessa forma, $M$. caribbica é igualada a S. cerevisiae num dos quesitos almejados para a produção do etanol $2 \mathrm{G}$. Há, contudo, a necessidade de submeter essa levedura a outras condições fermentativas para uma melhor avaliação do seu comportamento frente à xilose e à celobiose.

\section{REFERÊNCIAS}

CASSA-BARBOSA, L. A.; PROCÓPIO, R. E.; MATOS, I. T.; FILHO, S. A. Isolation and characterization of yeasts capable of efficient utilization of hemicellulosic hydrolyzate as the carbon source. Genet. Mol. Res. v. 14, p. 11605-11612, 2015.

KURTZMAN, C. P.; SUZUKI, M. Phylogenetic analysis of ascomycete yeasts that form coenzyme Q-9 and the proposal of the new genera Babjeviella, Meyerozyma, Millerozyma, Priceomyces, and Scheffersomyces. Mycoscience. v. 51, p. 2-14, 2010.

LARA, C. A.; SANTOS, R. O.; CADETE, R.M.; FERREIRA, C.; MARQUES, S.; GÍRIO, F.; OLIVEIRA, E. S.; ROSA, C. A.; FONSECA, C. Identification and characterisation of xylanolytic yeasts isolated from decaying wood and sugarcane bagasse in Brazil. Antonie Van Leeuwenhoek. v. 105, p. 1107-1119, 2014.

LEE, W. H.; NAN, H.; KIM, H. J.; JIN, Y. S. Simultaneous saccharification and fermentation by engineered Saccharomyces cerevisiae without supplementing extracellular $\beta$-glucosidase. J. Biotechnol. V. 167, p. 316322, 2013.

LOPES, M. L.; PAULILLO, S. C. L.; GODOY, A.; CHERUBIN, R. A.; LORENZI, M. S.; GIOMETTI, F. H. C.; BERNARDINO, C. D.; DE AMORIM NETO, H. B.; DE AMORIM, H.V. Ethanol production in Brazil: a bridge between science and industry. Braz. J. Microbiol. v. 475, p. 64-76, 2016.

MATTAM, A. J.; KUILA, A.; SURALIKERIMATH, N.; CHOUDARY. N.; RAO, P. V.; VELANKAR, H. R. Cellulolytic enzyme expression and simultaneous conversion of lignocellulosic sugars into ethanol and xylitol by a new Candida tropicalis strain. Biotechnol. Biofuels. v. 9, p. 157, 2016.

STAMBUK, B. U.; ELEUTHERIO, E. C. A.; FLOREZ-PARDO, L. M.; SOUTO-MAIOR, A. M.; BON, E. P. S. Brazilian potential for biomass ethanol: Challenge of using hexose and pentose cofermenting yeast strains. J. Sci. Ind. Res. v. 67, p. 918-926, 2008.

SUKPIPAT, W.; KOMEDA, H.; PRASERTSAN, P.; ASANO, Y. J. Purification and characterization of xylitol dehydrogenase with l-arabitol dehydrogenase activity from the newly isolated pentose-fermenting yeast Meyerozyma caribbica 5XY2. Biosci. Bioeng. v. 123, p. 20-27, 2017. 
VAUGHAN-MARTINI, A.; KURTZMAN, C.P.; MEYER, S. A.; O'NEILL, E. B. Two new species in the Pichia guilliermondii clade: Pichia caribbica sp. nov., the ascosporic state of Candida fermentati, and Candida carpophila comb. nov. FEMS Yeast Res. v. 5, p. 463-469, 2005.

WEBB, S. R.; LEE, H. Regulation of D-xylose utilization by hexoses in pentose-fermenting yeasts. Biotechnol. Adv. v. 8, p. 685-697, 1990.

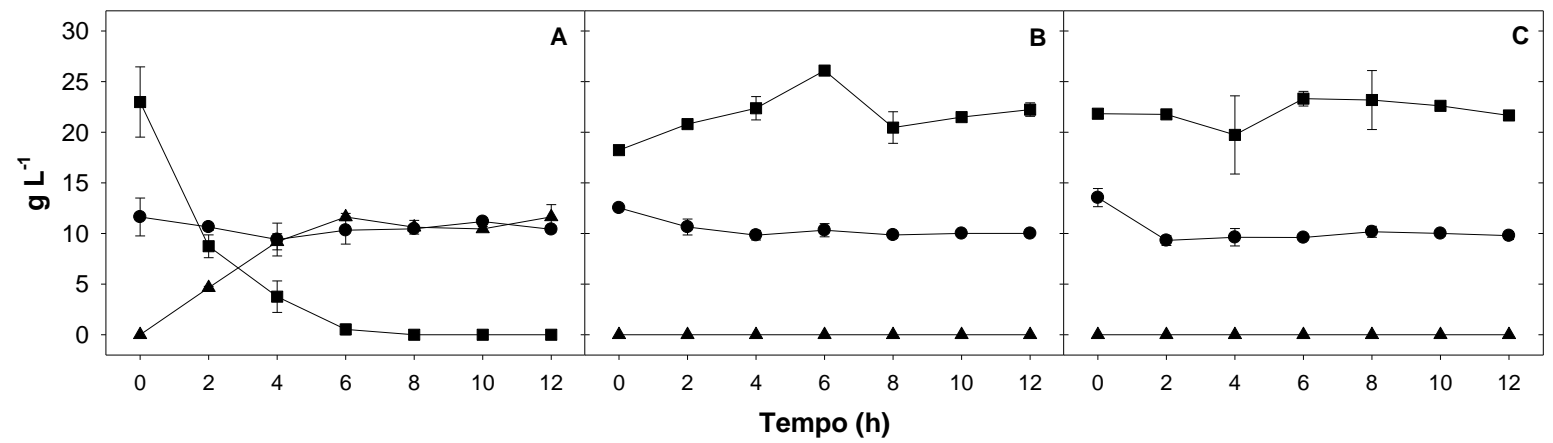

Figura 1. Fermentação em microaerobiose pela linhagem CHAP-091 em meios sintéticos contendo glicose (A), xilose (B) ou celobiose (C) como fonte de carbono. Nos tempos indicados, foram coletadas amostras para a determinação de biomassa celular $(\mathbf{O})$, consumo de açúcar $(\boldsymbol{\square})$ e produção de etanol $(\mathbf{A})$.

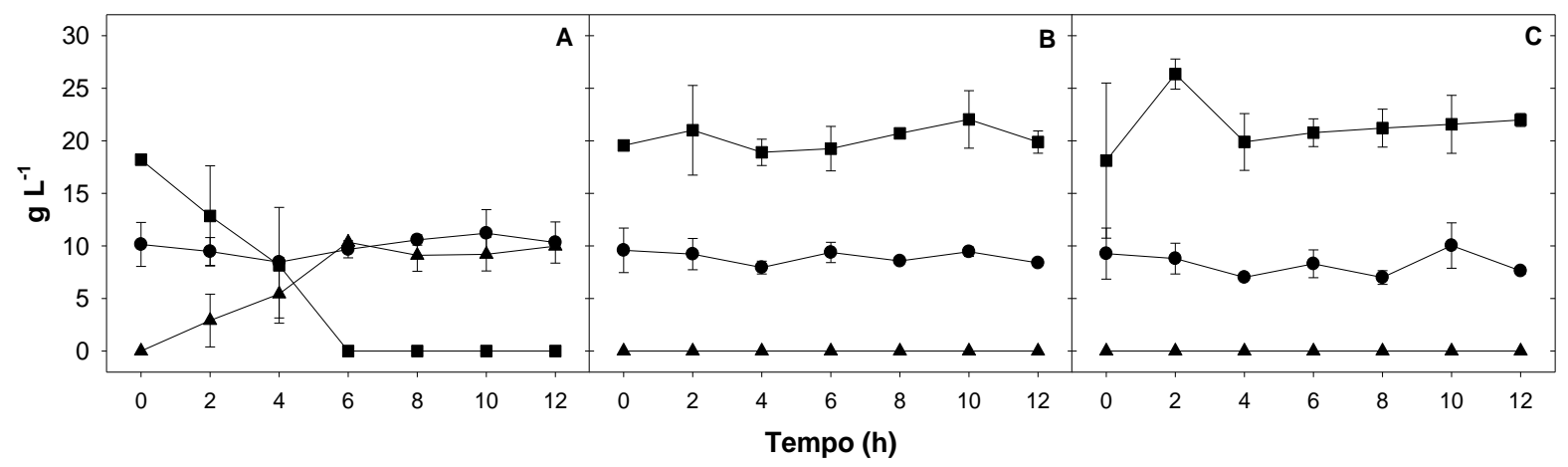

Figura 2. Fermentação em microaerobiose pela linhagem CHAP-103 em meios sintéticos contendo glicose (A), xilose (B) ou celobiose (C) como fonte de carbono. Nos tempos indicados, foram coletadas amostras para a determinação de biomassa celular $(\bullet)$, consumo de açúcar $(\boldsymbol{\square})$ e produção de etanol $(\boldsymbol{\Delta})$.

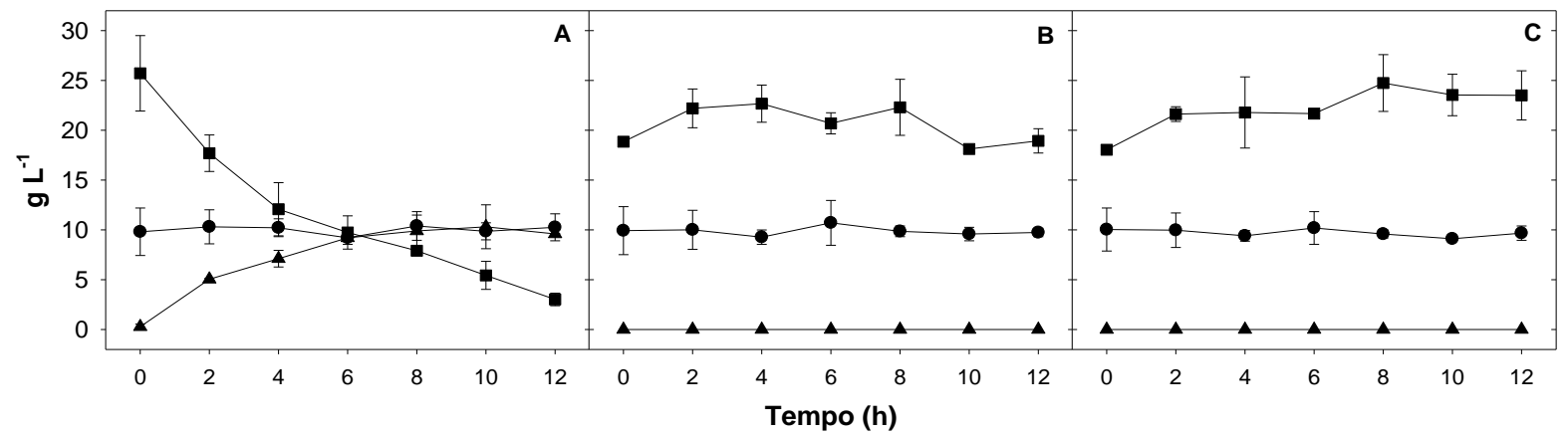

Figura 3. Fermentação em microaerobiose pela linhagem CHAP-96 em meios sintéticos contendo glicose (A), xilose (B) ou celobiose (C) como fonte de carbono. Nos tempos indicados, foram coletadas amostras para a determinação de biomassa celular $(\boldsymbol{\bullet})$, consumo de açúcar $(\boldsymbol{\square})$ e produção de etanol $(\mathbf{\Lambda})$. 


\title{
O QUE OCORREU COM OS PROJETOS DE MECANISMO DE DESENVOLVIMENTO LIMPO DA SUINOCULTURA NO BRASIL?
}

\author{
Mariani, L.*1; Mito, J.Y.L. ${ }^{2}$; Stilpen, M.R. ${ }^{2}$; Steinmetz, R. ${ }^{3}$; Marques, F.S. ${ }^{2}$; Cavaliero, C.K.N. ${ }^{1}$ \\ ${ }^{I}$ Faculdade de Engenharia Mecânica, Universidade Estadual de Campinas, Campinas, SP - Brasil \\ ${ }^{2}$ Centro Internacional de Energias Renováveis-Biogás, Foz do Iguaçu, PR - Brasil. \\ ${ }^{3}$ Embrapa Suínos e Aves, Concórdia, $S C$-Brasil. \\ leidiane.mariani@gmail.com
}

\begin{abstract}
RESUMO: A partir da assinatura do Protocolo de Kyoto a queima do biogás foi definida como medida mitigadora do aquecimento global pelo Mecanismo de Desenvolvimento Limpo (MDL). O biogás contém em sua composição o metano, um Gás de Efeito Estufa (GEE), e sua queima reduz o potencial impacto de aquecimento da atmosfera. Nesta época, várias instituições surgiram no mercado brasileiro "comprando" créditos antecipados e via de regra os trocando por biodigestores, com os potenciais produtores, principalmente de suínos, que por sua vez encontravam, nesta transação, uma saída para lidar com o efluente da atividade produtiva. Para obter créditos de carbono por meio do MDL, bastava queimar o biogás gerado, que era uma solução mais simples e barata do que usá-lo com fins energéticos. Isso facilitou a aprovação e o monitoramento dos projetos, porém impôs um desperdício injustificável de energético, além de deixar esses projetos suscetíveis apenas à benefícios oriundos do programa. Com a crise econômica europeia, o preço pago pelo crédito reduziu, até chegar a patamares que inviabilizaram os contratos. Isso se refletiu no abandono de muitas plantas pelo país, que deixaram de operar mesmo antes do fim de seus contratos, o que fez com que a redução de gases do efeito estufa estimada pelo programa não se concretizasse. Assim, nesse trabalho é realizada uma estimativa de quantos projetos de biodigestores para MDL na suinocultura do Brasil continuavam operando em 2014, após vários fatores terem reduzido a atratividade dos projetos.
\end{abstract}

Palavras-chave: efluentes, suinocultura, biogás, crédito de carbono, GEE, MDL.

\section{WHAT HAPPENED TO THE PROJECTS OF CLEAN DEVELOPMENT MECHANISM OF SWINE PRODUCTION IN BRAZIL?}

\begin{abstract}
Since the Kyoto Protocol biogas burning has been defined as a mitigation measure of global warming by the Clean Development Mechanism (CDM). The biogas contains in its composition methane, a greenhouse gas (GHG), and its burning reduces the potential impact of heating the atmosphere. At this time, several institutions appeared in the Brazilian market "buying" advanced credits and, as a rule, exchanging them for biodigestors, with potential producers, mainly of swines, who in this transaction found a solution for swine wastewater treatment. To obtain carbon credits through the CDM, it was enough to burn off the biogas generated, which was a simpler and cheaper solution than using it for energy purposes. This facilitated the approval and monitoring of the projects, but imposed an unjustifiable waste of energy, in addition to leaving these projects susceptible only to the benefits coming from the program. With the European economical crisis, the price paid by the carbono credit was reduced, until reaching levels that made the contracts unfeasible. This was reflected in the abandonment of many plants throughout the country, which ceased to operate even before the end of their contracts, which meant that the reduction of greenhouse gases estimated by the program did not materialize. In this study, an estimate is made of how many CDM biodigester projects in Brazil's swine farms continued to operate in 2014 , after several factors reduced their attractiveness.
\end{abstract}

Keywords: effluents, swine, biogas, carbon credit, GHG, CDM.

\section{INTRODUÇÃO}

O constante crescimento produtivo para atender a demanda atual e gerar contribuições econômicas, vem desencadeando diversas modificações sociais, econômicas e ambientais. Dentre essas atividades produtivas podemos destacar as produções dos setores agropecuário, agroindustrial, agrícola e de transporte, atividades que tem destaque em nossa economia, contudo, geram elevada produção de resíduos e emissão de Gases do Efeito Estufa (GEEs), entre outros impactos ao meio ambiente, e que contribuem na intensificação das mudanças climáticas globais. Segundo o IPCC (2002), isso têm se manifestado no aumento acelerado da 
temperatura, eventos climáticos extremos, alterações no regime de chuvas, retração de geleiras e elevação do nível dos oceanos.

As preocupações com os efeitos climáticos causados pela intensificação da ação do homem no planeta, levou a Organização das Nações Unidas (ONU) a fomentar tratados entre diversos países, estabelecendo ações de controle para diminuir a intervenção humana nas mudanças do clima em nosso planeta. O primeiro acordo, chamado de Protocolo de Kyoto, estabeleceu-se que países industrializados deveriam reduzir suas emissões de GEE, até 2012, e para fomentar essa redução da emissão de GEEs foi criado o Mecanismo de Desenvolvimento Limpo (MDL) para mitigar, remediar e reduzir os efeitos das mudanças climáticas. Esse mecanismo permitia a compensação de GEEs, onde os países desenvolvidos, ao não atingir suas metas de redução de emissões, passavam a comprar Certificados de Emissões Reduzidas de outros países.

No Brasil, após a criação do MDL, diversos projetos foram desenvolvidos para incentivar a instalação de sistemas de biodigestão em unidades agropecuárias, que permitissem tratar seus resíduos, diminuir a emissão de GEEs, além de contribuir para o desenvolvimento sustentável da região (CORNETTA, 2011). Entre as décadas de 70 e 80, centenas de biodigestores foram instalados e pouco tempo depois abandonados por problemas de dimensionamento, uso de materiais inadequados e falta de assistência técnica, segundo Jende et al. (2016). Da mesma forma, Bley (2015) e Jende et al. (2016) indicam que a maioria dos biodigestores instalados por motivação do MDL nos anos 2000 também deixaram de ser operados.

Hoje, mais do que uma tendência e um cumprimento de metas, o uso de sistemas de biodigestão permitem a produção do biogás, uma fonte energética que emitem menos GEE, a diversificação da matriz energética e a descentralização na geração de energia elétrica, térmica e biometano. De acordo com os dados do IEA, em 2016, 37,6\% das plantas utilizavam o biogás principalmente na geração de energia térmica e 56,4\% em energia elétrica. No entanto, somente $21,9 \%$ do total de biogás gerado no Brasil era utilizado para energia térmica, enquanto a energia elétrica era responsável por 77\% do uso final de todo o biogás produzido no país. Nos últimos anos, graças às novas possibilidades de modelos de negócios originadas pelas mudanças regulatórias para geração distribuída, um aumento crescente no uso do biogás para geração de energia elétrica vem ocorrendo.

Diante desse cenário, o presente trabalho teve por objetivo levantar dados sobre os biodigestores instalados em unidades produtivas de suínos no âmbito do MDL entre os anos de 2005 e 2012, analisando se estes ainda estavam em operação e as possíveis causas do encerramento.

\section{MATERIAL E MÉTODOS}

A fonte dos dados para esse trabalho foi o Banco de projetos de MDL Brasileiros da Companhia de Tecnologia de Saneamento Ambiental (CETESB) (2014), que lista todos os projetos que foram registrados na United Nations Framework Convention on Climate Change (UNFCCC) e Ministério da Ciência, Tecnologia e Inovação (MCTI) até fevereiro de 2014 no âmbito do MDL e que envolviam a recuperação acompanhada da destruição ou aproveitamento da energia do biogás para redução de emissão GEE. Cada um dos projetos estava disponível em um arquivo em formato PDF (Figura 1) e continha os dados de uma ou diversas propriedades rurais ou aterros sanitários registrados.

Entre janeiro e março de 2015, as informações de cerca de 1856 propriedades rurais com suinocultura foram coletadas dos projetos e organizadas em uma planilha da ferramenta Excel/Microsoft. Os seguintes dados foram coletados: Código do projeto; Nome da unidade; Nome do proprietário ou responsável; Estado; Município; Fonte do substrato; Aplicação do biogás; Localização geográfica: Latitude e Longitude; Data da versão do PDD para MDL; Quantidade de animais; Nome do projeto; e Nome do responsável pelo projeto.

Com base no dado de localização geográfica, foi realizada uma análise das imagens de satélite disponíveis no site GoogleMaps e no software GoogleEarth, da seguinte forma: (1) Busca pela propriedade conforme localização geográfica do projeto e confirmação de que estava em um local com construções similares a uma suinocultura; (2) Análise da situação do biodigestor no Google Earth. Se estava inflado, indicava a possibilidade de estar ainda em operação, se não, a propriedade era classificada como biodigestor desativado (Figura 2); e (3) Análise da imagem de satélite da região do ponto de localização em relação à data e à qualidade (ruim, razoável e ótima).

\section{RESULTADOS E DISCUSSÃO}

Aplicando a metodologia, constatou-se que das 1856 suinoculturas registradas em projetos de MDL entre 2005 e 2012, havia 675 com imagens de satélite que possibilitaram a identificação do biodigestor e que eram posteriores a janeiro de 2014 (Tabela 1). Dessas, 333 suinoculturas pareciam ter o biodigestor ainda em 
operação, ou seja, o biodigestor parecia inflado, o que equivale a 49\%, refletindo uma taxa relativamente baixa de continuidade da operação dos biodigestores,

Porém, esses dados também precisam ser analisados anualmente, pois alguns projetos em 2014 poderiam já estar chegando ao fim dos contratos de MDL, justificando-se a baixa taxa de operação dos biodigestores. Por isso, analisaram-se os dados distribuídos pelo ano de registro do projeto MDL, e foi possível observar que biodigestores que já estavam com cerca de 10 anos de instalação tinham uma grande porcentagem ainda em operação, por exemplo projetos de 2005 e 2006, respectivamente com $73 \%$ e $78 \%$ dos biodigestores em operação. Porém, projetos que ainda deveriam estar em operação pelos contratos, tinham uma porcentagem baixa de biodigestores em operação, como é o caso, por exemplo, dos anos de 2010 e 2011, ambos apenas 44\% dos biodigestores em operação.

Uma das razões pela qual mais de metade dos biodigestores parecia não estar em operação em 2014 poderia ser que o contrato entre os suinocultores e as empresas investidoras nos projetos de MDL tivesse chegado ao fim dos 10 anos de duração padrão. Porém, observa-se na Tabela 1 que os anos com menor índice de biodigestores em operação em 2014 foram os registrados em 2010 e 2011, ou seja, projetos com apenas 3 ou 4 anos de contrato, não parecendo ser a expiração do prazo do contrato um motivo para tão baixo índice.

Assim, outros motivos que podem ter levado ao fim da operação dos biodigestores podem ter sido a desistência dos investidores, causada, segundo Bley (2015) pela redução do valor do crédito de carbono internacionalmente. Com isso, tornava-se inviável a operação e manutenção dos biodigestores, já que a única fonte de receita planejada nos projetos era pela venda dos créditos. Outro motivo pode ter sido o aumento dos custos de implantação e monitoramento dos projetos e redução das receitas esperadas, devido a mudanças de metodologia de certificação dos projetos pelo IPCC e redução do potencial de geração de certificados pela suinocultura, citadas por Marcovitch (2008).

Outro fator pode ter sido a pouca participação efetiva e crítica dos produtores rurais integrados, no caso de projetos capitaneados pelas empresas integradoras produtoras de proteína animal. A participação dos proprietários da suinocultura era de cessão de uso da área de instalação do biodigestor e do efluente gerado diariamente nas granjas, com o retorno de cerca de 10 a $20 \%$ dos créditos de carbono que fossem gerados ao longo do contrato.

Além disso, os projetos de MDL da suinocultura do Brasil podem ter sido concebidos com mais foco no retorno financeiro para investidores, havendo pouco retorno percebido pelos suinocultores no seu cotidiano, os quais eram peças chave na operação e manutenção dos biodigestores. Talvez os suinocultores tivessem maior motivação se o biogás tivesse sido utilizado para a geração de energia e não apenas para a simples queima. Segundo a Cetesb (2014), a maioria dos projetos de redução de emissão de metano do MDL no Brasil optou pela simples queima desse gás de efeito estufa.

A geração de energia elétrica ou térmica em propriedades rurais possibilita a melhoria da infraestrutura, redução de custos e aumento da atividade produtiva, como destacado por Coimbra-Araújo et al. (2014). Além disso, a energia é um insumo demandado continuamente, podendo ser o diferencial para que o produtor mantenha o biodigestor operando com a máxima eficiência possível e valorize o efluente como um insumo.

\section{CONCLUSÃO}

Considerando-se os dados apresentados nesse estudo, pode-se concluir que mais da metade dos projetos de MDL da suinocultura deixaram de operar antes do fim de seus contratos, causando prejuízo financeiro para as empresas na implantação e certificação de projetos de MDL para a suinocultura no Brasil e descrédito à tecnologia de biodigestão. Também é importante destacar o desperdício de energia causada pela falta de visão dos investidores de que o uso energético do biogás seria um viabilizador dos projetos e um vetor de desenvolvimento da cadeia da suinocultura.

Por fim, mas não menos importante, a redução de emissões de carbono esperada por meio desses projetos não se realizou, sendo isso um prejuízo ambiental inestimável para toda a sociedade, considerando os impactos que o aquecimento global poderá causar ao planeta.

Jende et al. (2016) afirmam que as experiências com biodigestores no Brasil na década de 70 e 80 e depois nos anos 2000, em grande parte malsucedidas, criaram desconfiança entre os atores e resistência para novos investimentos, sendo esse um obstáculo a se ultrapassar. Por isso, considera-se importante que qualquer mecanismo de incentivo à adoção de uma tecnologia em larga escala deve ser planejado de forma sistêmica e implantado integrando todos os atores envolvidos. 


\section{AGRADECIMENTOS}

À ITAIPU Binacional, ao CIBiogás, à Embrapa Suínos e Aves, à Unicamp e a todas as instituições envolvidas pelo apoio financeiro e técnico, sem o qual esse estudo não teria sido realizado.

\section{REFERÊNCIAS}

BLEY, C. Biogás: A energia invisível. 2a ed.rev. São Paulo e Foz do Iguaçu: CIBiogás e ITAIPU Binacional, 2015.

CETESB. Projetos de biogás no MDL. 2a ed. ed. São Paulo: Cetesb, 2014.

COIMBRA-ARAÚJO, C. H.; MARIANE, L.; JÚNIOR, C. B.; et al. Brazilian case study for biogas energy: Production of electric power, heat and automotive energy in condominiums of agroenergy. Renewable and Sustainable Energy Reviews, v. 40, p. 826-839, 2014. Elsevier.

CORNETTA, A. Mecanismos de desenvolvimento limpo e conflitos locais. Revista Geográfica de América Central, Número Especial EGAL, 2011.

JENDE, O.; ROSENFELDT, S.; COLTURATO, L. F. DE D. B.; et al. Barreiras e Propostas de Soluções para o Mercado de Biogás no Brasil, p. 76, 2016.

IPCC - Intergovernmental Panel on Climate Change. (2002). Climate Change and Biodiversity. A Technical Paper of the IPCC. Edited by Gitay, H. Suarez,A. Watson, R.T and Dokken,D.WMO/IPCC publication.

MARCOVITCH, J. Projetos sustentáveis de 8 empresas brasileiras - Um survay com inovadores Primeira Avaliação - 2008. 2008.

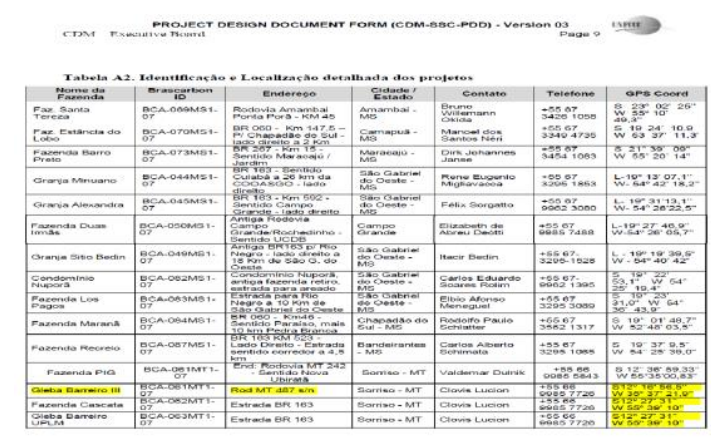

Figura 1. Exemplo de lista de suinoculturas em projeto de MDL.

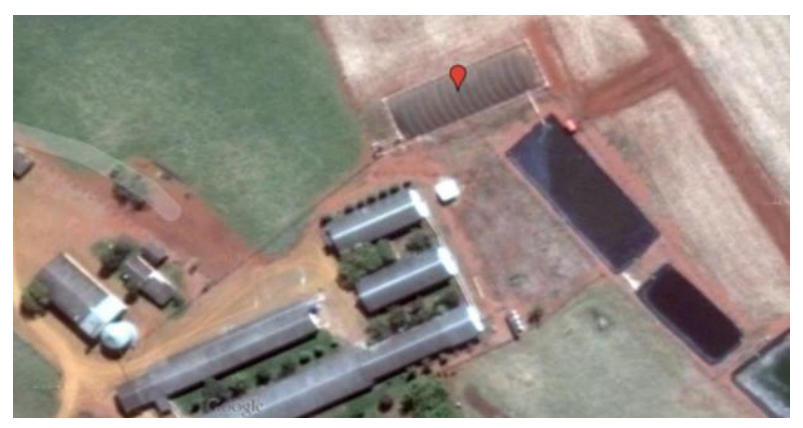

Figura 2. Exemplo de uma imagem de satélite com biodigestor inflado.

Tabela 1. Resultado da análise quantitativa dos projetos de MDL da suinocultura do Brasil registrados entre 2005 e 2012.

\begin{tabular}{|c|c|c|c|c|c|}
\hline \multirow{2}{*}{$\begin{array}{l}\text { Data de } \\
\text { registro do } \\
\text { projeto de } \\
\text { MDL }\end{array}$} & \multirow[t]{2}{*}{$\begin{array}{l}\text { Quantidade de } \\
\text { suinoculturas } \\
\text { registradas no MDL }\end{array}$} & \multirow{2}{*}{$\begin{array}{l}\text { Quantidade de suinoculturas } \\
\text { com qualidade ótima ou razoável } \\
\text { da imagem de satélite na } \\
\text { localização da propriedade }\end{array}$} & \multicolumn{3}{|c|}{$\begin{array}{l}\text { Quantidade de suinoculturas com } \\
\text { imagens de satélite mais recentes que } \\
\text { janeiro/2014 e onde era possível a } \\
\text { identificação do biodigestor }\end{array}$} \\
\hline & & & Total & Pare & m operação \\
\hline 2005 & 187 & 139 & 55 & 40 & $73 \%$ \\
\hline 2006 & 214 & 158 & 45 & 35 & $78 \%$ \\
\hline 2007 & 32 & 26 & 10 & 5 & $50 \%$ \\
\hline 2008 & 13 & 11 & 0 & 0 & - \\
\hline 2009 & 116 & 104 & 21 & 13 & $62 \%$ \\
\hline 2010 & 1144 & 973 & 524 & 230 & $44 \%$ \\
\hline 2011 & 144 & 120 & 16 & 7 & $44 \%$ \\
\hline 2012 & 5 & 5 & 4 & 3 & $75 \%$ \\
\hline- & 1856 & 1537 & 675 & 333 & $49 \%$ \\
\hline
\end{tabular}

Fonte: Elaboração própria baseada em dados de Cetesb (2014). 


\title{
POTENCIAL BIOQUÍMICO DE METANO DE CAMA DE PERU
}

\author{
Cé, A.*1; Bortoli, M. ${ }^{1}$; Steinmetz, R.L.R. ${ }^{2}$; Venturin, B. ${ }^{3}$; Tápparo, D.C. ${ }^{3}$ Kunz, A. ${ }^{2 ; 3}$

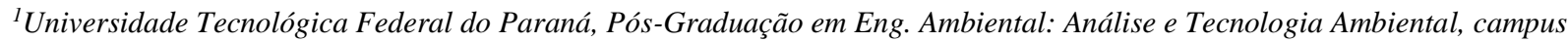 \\ Francisco Beltrão, $P R$ \\ ${ }^{2}$ Embrapa Suínos e Aves, Concórdia, SC-Brasil \\ ${ }^{3}$ Universidade Estadual do Oeste do Paraná, campus Cascavel, PR \\ *anaceamb@gmail.com
}

\begin{abstract}
RESUMO: Com o aumento dos resíduos provenientes da produção confinada de perus, uma fonte alternativa de energia pode ser alcançada através da digestão anaeróbia. Nesse sentido, avaliar o potencial bioquímico de metano desses substratos apresenta-se como uma alternativa para avaliar a máxima produção de $\mathrm{CH}_{4} \mathrm{e}$ concomitantemente a isto verificar a ocorrência de possíveis inibidores do processo. O objetivo do trabalho foi verificar o comportamento das diferentes relações da cama de peru com o inóculo $(0,2 ; 0,3 ; 0,4 ; 0,5)$, utilizando a equação de Gompertz para modelagem dos dados de cinética de produção de metano. Os ensaios cinéticos seguiram metodologia descrita pela VDI 4630 (2006). A produção diária de metano foi realizada utilizando sistema automático de testes de potencial de metano, com agitação automática a cada 10 minutos durante 35 dias. A cama de peru apresentou uma relação C/N de 7,3 e 0,75 de SV/ST. Os valores para as condições de $\mathrm{SV}_{\text {substrato }} / \mathrm{SV}_{\text {inóculo }}(0,2 ; 0,3 ; 0,4 ; 0,5)$ para o potencial de produção máxima de $\mathrm{CH}_{4}$ não apresentaram diferença estatística.
\end{abstract}

Palavras-chave: digestão anaeróbia, cama de aviário, cinética de produção.

\section{BIOCHEMICAL METHANE POTENTIAL OF TURKEY LITTER}

\begin{abstract}
With the increase of wastes from confined production of turkeys, an alternative energy source can be achieved through anaerobic digestion. In this way, the evaluation of the biochemical potential of methane of these wastes is an alternative way to evaluate the maximum $\mathrm{CH}_{4}$ production and concomitantly also verify the occurrence of possible inhibitors of the process. The aim of this study was to check the behavior of different turkey litter and inoculum ratios $(0.2 ; 0.3 ; 0.4 ; 0.5)$, using the Gompertz equation for modeling the kinetic data of methane production. Kinetic assays followed the methodology described by VDI 4630 (2006). The daily methane production was performed using automatic methane test system, with automatic stirring each 10 minutes during 35 days. The turkey litter show a $\mathrm{C} / \mathrm{N}$ ratio of 7.3 and 0.75 of VS/TS. The values for the $\mathrm{VS}_{\text {substrate }} / \mathrm{VS}_{\text {inoculum }}$ conditions $(0.2 ; 0.3 ; 0.4 ; 0.5)$ does not show statistical difference for the maximum $\mathrm{CH}_{4}$ potential production.
\end{abstract}

Keywords: anaerobic digestion, poultry litter, kinetic of production.

\section{INTRODUÇÃO}

A produção de perus no último ano foi de aproximadamente 390 mil toneladas de carne (ABPA, 2018). A mesma é realizada em um sistema produtivo em forma de confinamento, dividido em duas etapas: iniciador e terminador. A primeira caracteriza-se pela criação de filhotes (machos e fêmeas) e o sistema de terminação é dividido em: macho pesado, fêmea pesada e fêmea leve (MARTINS et al., 2011), que se difere conforme a finalidade comercial (exportação, produção regional ou natalina).

Os resíduos desses sistemas produtivos quando descartados sem tratamento prévio podem comprometer a qualidade do solo e água, pela elevada quantidade de nutrientes que os mesmos possuem. Assim, a digestão anaeróbia apresenta-se como uma alternativa para o aproveitamento energético desses resíduos, e concomitantemente a isto ao adequado manejo dos mesmos.

Alguns estudos recomendam uma relação C/N de 20/1 a 30/1 para a digestão anaeróbia, pois substratos com elevadas concentrações de nitrogênio podem causar inibição quando presentes na forma de amônia livre (a qual depende do $\mathrm{pH}$ e temperatura), já concentrações maiores de carbono ocasionam desequilíbrio no metabolismo dos microrganismos (KOTHARI, et al., 2014; ESTEVEZ et al., 2012; KHANAL, 2008). Nesse sentido, a avaliação da composição físico-química e potencial bioquímico de metano (PBM) desses substratos 
possibilita determinar a máxima produção de metano, bem como verificar a ocorrência de possíveis inibidores no processo, como amônia livre, por exemplo.

O guia VDI 4630 (2016) apresenta descrições detalhadas para os ensaios cinéticos em batelada para avaliar o PBM de diferentes substratos orgânicos. O guia destaca algumas informações referentes à quantidade de inóculo e substrato utilizada nos testes, como: a) quantidade de substrato não deve exceder a quantidade de inóculo considerando relação igual ou menor de 0,5 em sólidos voláteis $\left(\mathrm{SV}_{\text {substrato }} / \mathrm{SV}_{\text {inóculo }}\right)$ para prever inibições; b) a concentração de sólidos totais no reator não deve exceder $10 \%, \mathrm{~m} \mathrm{~m}^{-1}$; c) a produção de biogás a partir do substrato deve ser, no mínimo, $80 \%$ maior do que a contribuição do inóculo; e d) também deve-se utilizar substâncias ou amostras padrão em ensaios paralelos para avaliar a atividade do inóculo.

O objetivo do trabalho foi verificar o comportamento das diferentes relações da cama de peru em relação ao inóculo ( $\mathrm{SV}_{\text {substrato }} / \mathrm{SV}_{\text {inóculo }}$ ), utilizando a equação de Gompertz para modelagem dos dados da cinética de produção.

\section{MATERIAL E MÉTODOS}

A cama de peru utilizada para os ensaios foi coletada em uma granja de produção de perus no município de Francisco Beltrão - PR. A amostra constituiu-se principalmente de maravalha e elevadas quantidades de excretas, proveniente de um sistema de terminação de perus machos em 50 dias de criação.

As análises dos parâmetros físico-químicos [Sólidos Totais, Fixos e Voláteis $\left(\%, \mathrm{~m} \mathrm{~m}^{-1}\right)$; Nitrogênio Total $\left(\%, \mathrm{~m} \mathrm{~m}^{-1}\right)$ e Carbono Total $\left.\left(\%, \mathrm{~m} \mathrm{~m}^{-1}\right)\right]$ foram realizadas na Embrapa Suínos e Aves, localizada em Concórdia - SC, de acordo com APHA, (2012). Os ensaios cinéticos foram realizados em triplicata e em batelada, com o auxílio de reatores com capacidade de volume de $500 \mathrm{~mL}$. A produção diária de metano foi mensurada utilizando-se equipamento automático de testes de potencial de metano - AMPTS II, com agitação automática dos substratos a cada 10 minutos durante 35 dias (BIOPROCESS CONTROL, 2016). Foram utilizados quatro tratamentos com diferentes relações $\mathrm{SV}_{\text {substrato }} / \mathrm{SV}_{\text {inóculo }}(0,2 ; 0,3 ; 0,4 ; 0,5)$, de maneira que a quantidade de substrato não excedesse a quantidade de inóculo (VDI 4630, 2016). Também foram empregados ensaios controle, em paralelo, sem adição de substratos para descontar a produção de biogás proveniente do inóculo, assim como pela avaliação da produção de biogás de substrato padrão de celulose microcristalina (20 $\mu$ size, Sigma-Aldrich/Alemanha).

As amostras foram mantidas em temperaturas mesofílicas $\left(37 \pm 1{ }^{\circ} \mathrm{C}\right)$ VDI 4630 (2016). O inóculo anaeróbio mesofílico utilizado foi de acordo com Steinmetz, et al., (2016). Foi utilizada a equação (1) de Gompertz para os dados de produção de metano (SELVARAJ et al., 2018; PELLERA et al., 2016). Os coeficientes cinéticos e análises estatísticas foram determinados com o auxílio do software Statistica 12 (trial (B) (StatiSoft).

$$
M(t)=A * \exp \left(-\exp \left(\left(\frac{r m}{A}\right) *(\lambda-t) * e^{1}+1\right)\right)
$$

A: Potencial de produção máxima de $\mathrm{CH}_{4}\left(\mathrm{NmLCH}_{4} \mathrm{gSV}^{-1}\right)$;

$\mathbf{r}_{m}$ : Velocidade máxima de produção de $\mathrm{CH}_{4}\left(\mathrm{NmLCH}_{4} \mathrm{gSV} \mathrm{d}^{-1}\right)$;

$\lambda$ : fase lag (d).

\section{RESULTADOS E DISCUSSÃO}

O valor ótimo para a relação $\mathrm{C} / \mathrm{N}$ varia conforme o tipo de substrato e das fontes de digestibilidade do carbono e nitrogênio. A relação de $\mathrm{C} / \mathrm{N}$ da cama de peru apresentou um valor de 7,3 (Tabela 1) o que representa alta concentração de nitrogênio, podendo ocasionar inibições. Nesse contexto evidencia-se a importância de avaliar as diferentes relações de $\mathrm{SV}_{\text {substrato }} / \mathrm{SV}_{\text {inóculo }}$ da produção máxima de metano, para verificar a existência de uma possível inibição no processo. A cama de peru apresentou uma relação de SV/ST de 0,75 (Tabela 1), a qual indica um teor de matéria orgânica com potencial para digestão anaeróbia.

Os valores de $\mathrm{pH}$ tiveram um acréscimo do início ao final dos testes cinéticos que variaram de 7,48 a 7,57 para 7,78 a 7,97. A celulose microcristalina apresentou $84 \%$ de recuperação de biogás, indicando atividade satisfatória do inóculo mesofílico (>637 $\left.\mathrm{NmL}_{\text {biogás }} \mathrm{gSV}_{\text {substrato }}{ }^{-1}\right)$, conforme preconiza VDI 4630 (2016) e HOLLIGER et al., (2016). 
Foram encontrados resultados de produção de $\mathrm{CH}_{4}$, que variaram de 92,9 a 95,5 $\mathrm{L}_{\mathrm{N}} \mathrm{kg} \mathrm{MF}^{-1}$. Entretanto, é necessária diluição da cama de peru para digestão em fase líquida, pela elevada concentração de sólidos presentes nesses substratos (ST: $43 \% \mathrm{~m} \mathrm{~m}^{-1}$ ). $\mathrm{O}$ maior valor para a produção máxima de $\mathrm{CH}_{4}$ foi encontrado para a relação de $0,5\left(305,8 \mathrm{NmLCH}_{4} \mathrm{gSV}^{-1}\right)$, utilizando-se o modelo de Gompertz (Figura 1). Os quatro modelos teóricos exibiram ajuste satisfatório com coeficientes de determinação superiores a 0,99. Entretanto, não houve diferença estatística entre as médias para os valores de potencial de $\mathrm{CH}_{4}$ nas diferentes relações

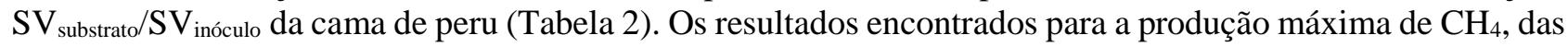
diferentes relações, apresentaram valor menor que $5 \%$ de coeficiente de variação, conforme recomendam HOLLIGER et al., (2016).

\section{CONCLUSÃO}

As relações de $\mathrm{SV}_{\text {substrato }} / \mathrm{SV}_{\text {inóculo }}$ testadas $(0,2 ; 0,3 ; 0,4 ; 0,5)$ obtiveram coeficientes com $\mathrm{R}^{2}$ maior que 0,99 pelo modelo de Gompertz. Ainda, os valores para o potencial de produção máxima de $\mathrm{CH}_{4}$ não apresentaram diferença estatística entre as médias, representando que para a cama de peru os intervalos de relação de 0,2 a 0,5 de $\mathrm{SV}_{\text {substrato }} / \mathrm{SV}_{\text {inóculo }}$ podem ser utilizados para os ensaios de potencial bioquímico de metano, conforme metodologia prescrita pela VDI 4630 (2016), sem causar inibição nos testes cinéticos.

\section{AGRADECIMENTOS}

Os autores agradecem o apoio prestado pela Fundação Araucária, Fundação CAPES, do Ministério de Educação do Brasil e SISTRATES-BNDES (Projeto n 23.17.00.023.00).

\section{REFERÊNCIAS}

ABPA. Associação Brasileira de Proteína Animal. Relatórios Anuais. 2018. Disponível em: $<$ http://abpabr.com.br/storage/files/relatorio-anual-2018.pdf >. Acesso em: 23 nov. 2018.

APHA - American public health association. Standard methods for examination of water and wastewater. 22ST. ED. Washington: APHA, 2012.

Bioprocess control. Operation and Maintenance Manual. Disponível em: 〈http://www.bioprocesscontrol.com/media/1511/bioprocess-control-manual-ampts-ii-ampts-ii-light.pdf $>$. 2016. Acesso em: 20 de nov. de 2018.

ESTEVEZ, M. M.; LINJORDET, R.; MORKEN, J. Effects of steam explosion and co-digestion in the methane production from salix by mesophilic batch assays. Bioresource technology, V. 104, P. 749-756, 2012.

HOLLIGER, C., ALVES, M., ANDRADE, D., ANGELIDAKI, I., ASTALS, S., BAIER, U., ... EBERTSEDER, F. (2016). Towards a standardization of biomethane potential tests. water science and technology, 74(11), 2515-2522.

KHANAL, S. Anaerobic biotechnology for bioenergy production: principles and applications. 2008.

KOTHARI, R.; PANDEY, A. K.; KUMAR, S.; TYAGI, V. V.; TYAGI, S. K. Different aspects of dry anaerobic digestion for bio-energy: an overview. Renewable and sustainable energy reviews, V. 39, P. 174195, 2014.

MARTINS M, F.; SANDI;, A, J.; ÁVILA, V, S.; FILHO, J, I, S. Comunicado 494 técnico. disponível em: <https://www.infoteca.cnptia.embrapa.br/bitstream/doc/920320/1/publicacao494.pdf>. Acesso em: 23 nov. 2018.

PELLERA F, GIDARAKOS E. Effect of substrate to inoculum ratio and inoculum type on the biochemical methane potential of solid agroindustrial waste. Journal of Environmental Chemical Engineering, v. 4, p. 3217-3229, 2016.

SELVARAJ, B.; KRISHNSAMY, S.; MUNIRAJAN, S.; ALAGIRISAMY, P.S.; DHANUSHKODI, M.; GOPALSAMY, S.; KUPPUSAMY, K.K. Kinetic modelling of augmenting biomethane yield from poultry litter by mitigating ammonia. International jornal of green energy. 2018.

STEINMETZ, r. 1. r.; MEZZARI, m. p.; DA SILVA, m. 1. b.; et al. Enrichment and acclimation of an anaerobic mesophilic microorganism's inoculum for standardization of bmp assays. Bioresource Technology, v. 219, p. 21-28, 2016.

VDI, 4630. Fermentation of organic materials e characterization of the substrate, sampling, collection of material data, fermentation tests. The association of german engineers. 2016. 
Tabela 1. Características químicas e físicas da amostra de cama de peru de sistema de terminação de machos alojados por 50 dias.

\begin{tabular}{lc}
\hline Parâmetro & Cama de peru (50 d) \\
\hline Sólidos Totais $\left(\%, \mathrm{~m} \mathrm{~m}^{-1}\right)$ & 43 \\
Sólidos Fixos $\left(\%, \mathrm{~m} \mathrm{~m}^{-1}\right)$ & 11,4 \\
Sólidos Voláteis $\left(\%, \mathrm{~m} \mathrm{~m}^{-1}\right)$ & 32,2 \\
$\mathrm{~N}_{\text {Total }}\left(\%, \mathrm{~m} \mathrm{~m}^{-1}\right)$ & 2,62 \\
$\mathrm{C}_{\text {Total }}\left(\%, \mathrm{~m} \mathrm{~m}^{-1}\right)$ & 19,06 \\
Relação C/N & 7,3 \\
SV/ST & 0,75 \\
\hline
\end{tabular}

Tabela 2. Dados cinéticos obtidos pelo modelo de Gompertz ajustados aos dados experimentais dos ensaios de produção de $\mathrm{CH}_{4}$ das diferentes proporções de $\mathrm{SV}_{\text {substrato }} / \mathrm{SV}_{\text {inóculo }}$ estudadas.

\begin{tabular}{|c|c|c|c|c|}
\hline $\begin{array}{c}\text { Relação } \\
\mathbf{S V}_{\text {substrato} /} / \mathbf{S V} V_{\text {inóculo }}\end{array}$ & $\begin{array}{c}\mathrm{A} \\
\left(\mathrm{NmLCH}_{4} \mathrm{gSV}^{-1}\right)\end{array}$ & $\begin{array}{c}\mathbf{r}_{m} \\
\left(\mathrm{NmLCH}_{4} \mathrm{gSV}^{-1} \mathbf{d}^{-1}\right)\end{array}$ & $\begin{array}{c}\lambda \\
(\mathbf{d})\end{array}$ & $\mathbf{R}^{2}$ \\
\hline 0,2 & $288,4 \pm 3,4^{\mathrm{a}}$ & $72,82 \pm 0,5^{\mathrm{bc}}$ & $0,00 \pm 0,0^{\mathrm{d}}$ & $0,9929 \pm 0,06$ \\
\hline 0,3 & $298,0 \pm 10,1^{\mathrm{a}}$ & $74,1 \pm 3,3^{\mathrm{c}}$ & $0,07 \pm 0,07^{\mathrm{de}}$ & $0,9960 \pm 0,07$ \\
\hline 0,4 & $294,8 \pm 13,2^{\mathrm{a}}$ & $66,6 \pm 5,0^{\mathrm{bc}}$ & $0,10 \pm 0,0^{\mathrm{de}}$ & $0,9961 \pm 0,19$ \\
\hline 0,5 & $305,8 \pm 2,0^{\mathrm{a}}$ & $66,0 \pm 0,3^{\mathrm{b}}$ & $0,16 \pm 0,01^{\mathrm{e}}$ & $0,9972 \pm 0,02$ \\
\hline
\end{tabular}

As médias seguidas de mesmas letras nas colunas não diferem estatisticamente pelo teste de Tukey (5\%).

A: Potencial máximo de $\mathrm{CH}_{4}\left(\mathrm{NmLCH}_{4} \mathrm{gSV}^{-1}\right)$;

$\mathbf{r}_{m}$ : Velocidade máxima de produção de $\mathrm{CH}_{4}\left(\mathrm{NmLCH}_{4} \mathrm{gSVd}^{-1}\right)$

$\lambda$ : fase lag (d).
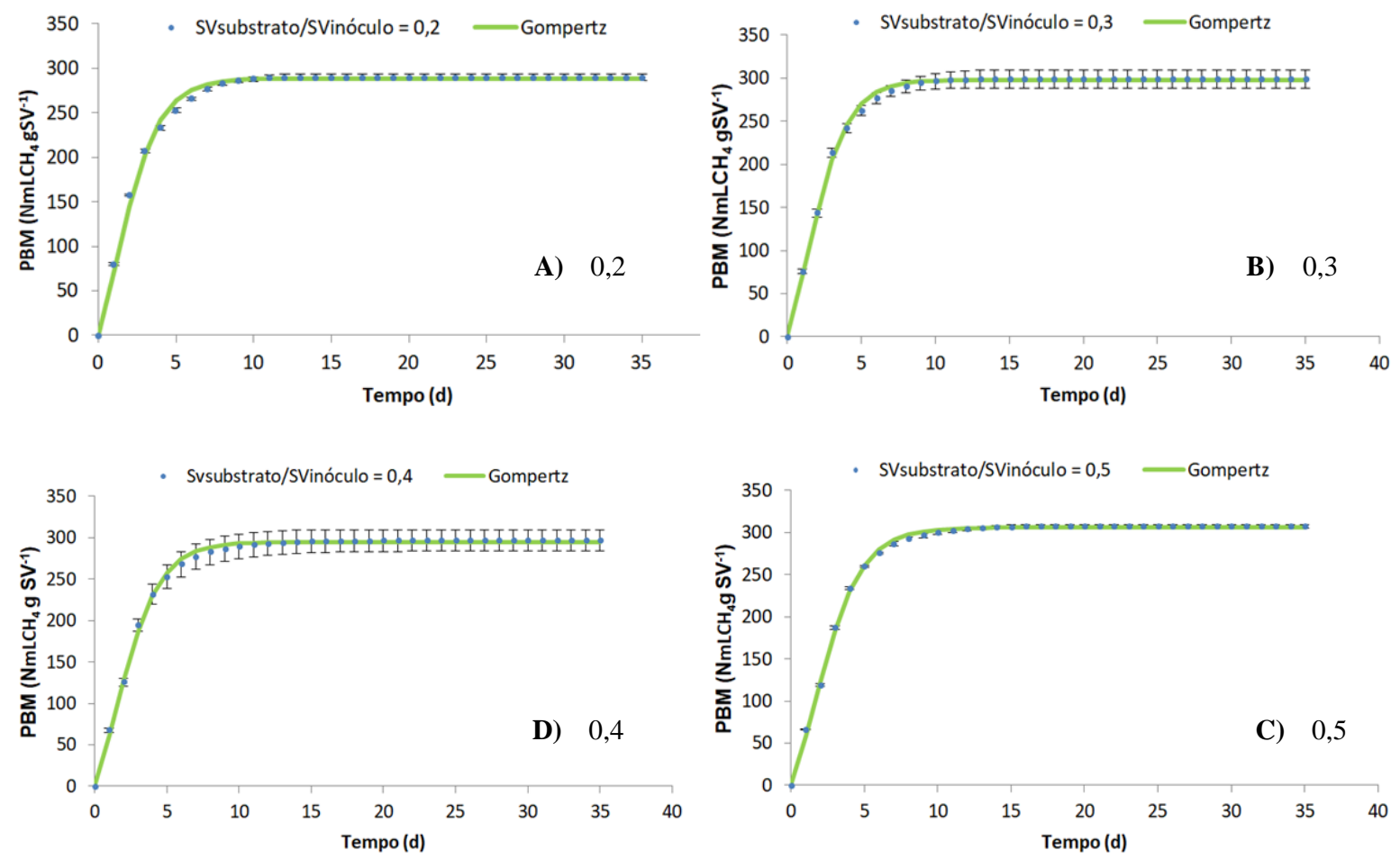

Figura 1. Perfil da produção acumulada de $\mathrm{CH}_{4}$ da amostra de cama de peru nas diferentes relações de $\mathrm{SV}_{\text {substrato }} / \mathrm{SV}_{\text {inóculo }}$ estudadas. 


\title{
PRÉ-TRATAMENTO DE BIOMASSA RESIDUAL DO PROCESSAMENTO DE AÇAÍ (EUTERPE OLERACEA) E SEU EFEITO NA PRODUÇÃO DE METANO
}

\author{
Lima, A.C.P.*1; Gutarra, M.L.E. ${ }^{2}$; Cammarota, M.C. ${ }^{1}$ \\ ${ }^{1}$ Escola de Química, Universidade Federal do Rio de Janeiro, Rio de Janeiro, RJ - Brasil. \\ ${ }^{2}$ Campus Xerém, Universidade Federal do Rio de Janeiro, Duque de Caxias, RJ-Brasil. \\ anna.pinheiro.lima@gmail.com
}

\begin{abstract}
RESUMO: Para obter as melhores condições de pré-tratamento de biomassas residuais do processamento de açaí para hidrólise/solubilização dos açúcares presentes na parede celular e fibra, empregou-se um planejamento composto central de face centrada, que avaliou temperatura, concentração de ácido e tempo. A maior concentração de carboidratos solúveis (CS) foi obtida com $0,55 \% \mathrm{v} / \mathrm{v}$ de ácido sulfúrico, $150{ }^{\circ} \mathrm{C}$ e 60 min. Nesta condição obteve-se $25 \mathrm{~g} / \mathrm{L}$ de CS na fração líquida resultante da hidrólise. Essa fração foi submetida à digestão anaeróbia a $30^{\circ} \mathrm{C}$ por 15 dias, verificando-se baixa remoção de DQOs (53-59\%) e baixa produção específica de metano (66-121 Nml CH$/ \mathrm{g}$ DQO removida) devido à inibição pela elevada concentração de sulfato e sódio. A fim de reduzir esta inibição, a neutralização com $\mathrm{CaO}$, em substituição ao $\mathrm{NaHCO}_{3}$, foi testada, verificando-se baixa capacidade de tamponamento e queda do $\mathrm{pH}$.
\end{abstract}

Palavras-chave: caroço de açaí, fibra de açaí, metano e pré-tratamento termoquímico.

\section{PRETREATMENT OF RESIDUAL BIOMASS OF THE AÇAÍ PROCESSING (EUTERPE OLERACEA) AND ITS EFFECT IN THE METHANE PRODUCTION}

\begin{abstract}
To obtain the best pre-treatment conditions of residual biomass from the açaí processing for hydrolysis/solubilization of the sugars present in the cell wall and fiber, a centralized face centered design was used, which evaluated temperature, acid concentration and time. The highest soluble carbohydrate (CS) concentration was obtained with $0.55 \% \mathrm{v} / \mathrm{v}$ sulfuric acid, $150{ }^{\circ} \mathrm{C}$ and $60 \mathrm{~min}$. In this condition $25 \mathrm{~g} / \mathrm{L}$ of CS was obtained in the liquid fraction resulting from the hydrolysis. This fraction was submitted to anaerobic digestion at $30^{\circ} \mathrm{C}$ for 15 days, with low COD removal (53-59\%) and low specific methane production (66-121 $\mathrm{nml} \mathrm{CH} / \mathrm{g}$ COD removed) due to inhibition by the high concentration of sulfate and sodium. To reduce this inhibition, neutralization with $\mathrm{CaO}$, instead of $\mathrm{NaHCO}_{3}$, was tested, with low buffering capacity and low $\mathrm{pH}$.
\end{abstract}

Keywords: Açaí seed, açaí fiber, methane and thermochemical pretreatment.

\section{INTRODUÇÃO}

O pré-tratamento de biomassas lignocelulósicas é extremamente necessário para desestruturação da parede celular e disponibilidade dos açúcares para conversões bioquímicas e/ou químicas (Zheng et al., 2014). Esses tratamentos permitem mudar a estrutura das biomassas, seja aumentando sua área superficial e porosidade, seja modificando ou removendo lignina e hemicelulose, objetivando aumentar a digestibilidade da biomassa e a acessibilidade das enzimas aos substratos na etapa de conversão dos carboidratos em seus monômeros. O emprego da temperatura no pré-tratamento das biomassas lignocelulósicas é muito estudado e tem sido aplicado em escala industrial (Ariunbaatar et al., 2014). Os tratamentos térmicos alteram a estrutura da biomassa, tornando-a mais biodegradável (Cesaro e Belgiorno, 2014). Já os métodos químicos envolvem o uso de ácidos, álcalis e extração com solventes (Silverstein et al., 2007). Geralmente, antes da aplicação dos pré-tratamentos térmicos, biológicos ou químicos a biomassa passa por um processo de redução de tamanho das partículas por corte e/ou moagem (Pingali et al., 2010).

Biomassas lignocelulósicas, portanto, necessitam de algum pré-tratamento para tornar os carboidratos de parede celular disponíveis para os processos químicos e/ou bioquímicos empregados na produção de algum composto de interesse industrial. E na maioria desses pré-tratamentos é liberada uma fração sólida e uma líquida. Geralmente, a parte sólida é levada para hidrólise enzimática objetivando a produção de açúcares, que apresentam alto valor agregado (Dhawan e Kaur, 2007). Em geral, a fração líquida é negligenciada, porém está 
ainda apresenta uma quantidade significativa de açúcares, que se forem levados para digestão anaeróbia podem produzir grandes volumes de biogás (Bharathiraja et al., 2018).

Trazendo o contexto de biorrefinaria e química verde para a cadeia produtiva do açaí, o desenvolvimento de processos químicos e/ou bioquímicos que possibilitem produzir biogás (por digestão anaeróbia) trará um importante avanço para a região, tanto no aspecto ambiental quanto no econômico e social. Portanto, este trabalho tem como objetivo avaliar as melhores condições de um pré-tratamento termoquímico para solubilização e aproveitamento dos açúcares presentes nos resíduos da produção do açaí (fibra e caroço) e seu efeito sobre a produção de metano por digestão anaeróbia.

\section{MATERIAL E MÉTODOS}

\section{Coleta e pré-tratamento termoquímico da biomassa residual da produção de açaí}

Amostras da biomassa residual da produção de açaí (caroço e fibra) foram coletadas em um estabelecimento comercial na cidade de Belém (PA), moídas em moinho de facas e peneiradas. Uma proporção de $90 \%$ caroço e $10 \%$ fibra (ambos com granulometria < $1,18 \mathrm{~mm})$ e razão sólido: liquido de 1:10 (m/v) foram empregadas em todos os experimentos. No planejamento composto central de face centrada foi utilizado um bloco digestor (Hach) e tubos de vidro $(10 \mathrm{~mL}$ ) contendo $0,6 \mathrm{~g}$ de resíduo (massa seca) e $6 \mathrm{~mL}$ de solução ácida. As faixas de valores estabelecidas para cada variável estudada no planejamento foram definidas a partir da literatura (Temperatura $=92,121$ e $150{ }^{\circ} \mathrm{C}$; Tempo $=20,60$ e $100 \mathrm{~min} ; \%$ v/v ácido $=0,1,0,55$ e 1$)$. A análise dos dados foi realizada utilizando o software Statistica, empregando-se como variável resposta a concentração de carboidratos solúveis (CS), quantificada de acordo com Dubois et al. (1956). A fração líquida obtida foi resfriada, filtrada à vácuo e estocada sob refrigeração para os ensaios de digestão anaeróbia.

\section{Digestão anaeróbia}

Os experimentos foram conduzidos em batelada no respirômetro BIOPROCESS CONTROL AMPTS II, utilizando frascos de vidro com $400 \mathrm{~mL}$ de misturas de lodo anaeróbio e fração líquida do pré-tratamento termoquímico. Em todos os experimentos foram feitas suplementações do meio com nitrogênio $\left(\mathrm{NH}_{4} \mathrm{Cl}\right)$ e fósforo $\left(\mathrm{KH}_{2} \mathrm{PO}_{4}\right)$ para uma relação ideal DQO: N: P de 350:5:1 (Von Sperling, 1996). Lodo anaeróbio proveniente de uma Estação de Tratamento de Esgoto (ETE) com concentração de SSV de $61 \mathrm{~g} / \mathrm{L}$, foi empregado como inóculo. $\mathrm{O} \mathrm{pH}$ inicial das amostras foi ajustado para 7,0 com bicarbonato de sódio $\left(\mathrm{NaHCO}_{3}\right)$ ou óxido de cálcio $(\mathrm{CaO})$. A quantidade de lodo e fração líquida utilizada nos frascos foi calculada para se manter uma relação DQO solúvel: SSV inicial do lodo de 1:1. A produção de metano foi acompanhada até estabilização, quando os frascos foram abertos para medida do pH e da DQOs finais. A quantificação de SSV e DQO solúvel foi realizada segundo metodologia padrão (APHA, 2005).

\section{RESULTADOS E DISCUSSÃO}

No intuito de aumentar a solubilização dos CS na fração líquida, foi empregado um planejamento de experimentos. Com base nos dados experimentais obtidos a partir da matriz do planejamento foi possível gerar dois gráficos de superfície de resposta (Figura 1), ao fixar a temperatura em $150^{\circ} \mathrm{C}$ (Figura 1a) é possível visualizar a formação de uma curvatura a partir do ponto central com tempo (60 min), concentração de ácido $(0,55 \%$ v/v) e CS ( $25 \mathrm{~g} / \mathrm{L})$ apresentando maiores valores nessa área. Com o tempo fixo (Figura $1 \mathrm{~b})$ no ponto central $(60 \mathrm{~min})$, valores de carboidratos solúveis são maiores quando a temperatura utilizada foi a mais elevada $\left(150^{\circ} \mathrm{C}\right)$ e concentração de ácido a partir do ponto central $(0,55 \% \mathrm{v} / \mathrm{v})$.

No entanto, a melhor condição encontrada no planejamento de experimentos apresenta elevada concentração de ácido sulfúrico $(0,55 \% \mathrm{v} / \mathrm{v})$, o que pode ser prejudicial para a digestão anaeróbia, pois aumenta a concentração de sulfato e, consequentemente, de sulfeto (da redução de sulfato por bactérias redutoras de sulfato). Além disso, uma maior concentração de ácido na fração líquida faz com que haja um maior consumo de álcalis para ajuste do $\mathrm{pH}$, aumentando a concentração de sódio no meio. Ambos, sulfeto e sódio, podem ser tóxicos para o consórcio microbiano (Chen et al., 2008). Logo, duas formas de neutralização da fração líquida foram testadas: uma utilizando bicarbonato de sódio $\left(\mathrm{NaHCO}_{3}\right)$, que não reduz a concentração de sulfato e introduz sódio no meio, e outra óxido de cálcio $(\mathrm{CaO})$, que permite a precipitação de sulfato, reduzindo sua concentração e introduzindo cálcio no meio, íon menos inibitório que sódio. 
Analisando os resultados apresentados na Tabela 1, a neutralização com óxido de cálcio levou a uma maior PEM (121 Nml CH $4 / \mathrm{g}$ DQO removida). Porém, não tamponou o sistema tão bem quanto com bicarbonato de sódio, pois o $\mathrm{pH}$ final ficou muito baixo $(4,9)$. Arqueas metanogênicas são inibidas em $\mathrm{pH}$ abaixo de 6 (Chernicharo, 2007). Já com o bicarbonato, o pH se manteve nas condições desejadas para produção de metano (6,5-7,4); no entanto, a PEM foi muito baixa, provavelmente, por conta da elevada concentração de sódio (3743-4432 mg/L), mais inibidor que o cálcio (Chen et al., 2008). Mesmo com o óxido de cálcio, a PEM final foi baixa, em comparação com experimentos preliminares conduzidos com fração líquida contendo menor concentração de ácido (pré-tratamento com 0,1\% v/v) e lodo de indústria de abate de aves, que atingiu até $327 \mathrm{Nml} \mathrm{CH}_{4} / \mathrm{g}$ DQO removida. Provavelmente, a menor atividade metanogênica do lodo empregado no planejamento (lodo de esgoto) e sua menor adaptação a elevadas concentrações de DQO e sais contribuiu para a baixa PEM obtida. Assim, mais estudos se fazem necessários a fim de encontrar uma condição de hidrólise/solubilização das biomassas que permita também uma boa produção de metano.

\section{CONCLUSÃO}

Realizado o planejamento de experimentos, concluiu-se que a temperatura teve maior influência na solubilização dos açúcares, com a melhor condição sendo $150^{\circ} \mathrm{C}, 0,55 \%$ v/v de ácido e 60 min. No entanto, ao se utilizar a condição apontada no planejamento de experimentos ocorreu inibição por sódio, oriundo do ajuste de $\mathrm{pH}$ com bicarbonato de sódio. Quando utilizado óxido de cálcio no ajuste de pH, ocorreu menor tamponamento do meio e queda do $\mathrm{pH}$.

\section{REFERÊNCIAS}

APHA. AMERICAN PUBLIC HEALTH ASSOCIATION. Standard methods for examination of water and wastewater. 21 th ed. Washington: American Water Works Association, 2005. 1.368 p.

ARIUNBAATAR, J. et al. Pretreatment methods to enhance anaerobic digestion of organic solid waste. Applied Energy, v. 123, p. 143-156, 2014.

BHARATHIRAJA, B. et al. Biogas production - A review on composition, fuel properties , feed stock and principles of anaerobic digestion. Renewable and Sustainable Energy Reviews, v. 90, p. 570-582, 2018.

CESARO, A.; BELGIORNO, V. Pretreatment methods to improve anaerobic biodegradability of organic municipal solid waste fractions. Chemical Engineering Journal, v. 240, p. 24-37, 2014.

CHEN, Y.; CHENG, J. J.; CREAMER, K. S. Inhibition of anaerobic digestion process: A review. Bioresource Technology, v. 99, n. 10, p. 4044-4064, 2008

CHERNICHARO, C.A.L. Reatores anaeróbios: princípios do tratamento biológico em águas residuárias. 2.ed. Belo Horizonte: DESA/UFMG, 2007. 359 p.

DHAWAN, S.; KAUR, J. Microbial mannanases: An overview of production and applications. Critical Reviews in Biotechnology, v. 27, n. 4, p. 197-216, 2007.

DUBOIS, M. et al. Colorimetric method for determination of sugars and related substances. Analytical Chemistry, v. 28, n. 3, p. 350-356, 1956.

PINGALI, S. V. et al. Breakdown of cell wall nanostructure in dilute acid pretreated biomass. Biomacromolecules, v. 11, n. 9, p. 2329-2335, 2010.

SILVERSTEIN, R. A. et al. A comparison of chemical pretreatment methods for improving saccharification of cotton stalks. Bioresource Technology, v. 98, n. 16, p. 3000-3011, 2007.

VON SPERLING, M. Princípios do Tratamento Biológico de Águas Residuárias - Lagoas de Estabilização, v. 03. Minas Gerais: ABES, 1996.

ZHENG, Y. et al. Pretreatment of lignocellulosic biomass for enhanced biogas production. Progress in Energy and Combustion Science, v. 42, n. 1, p. 35-53, 2014. 
(a)

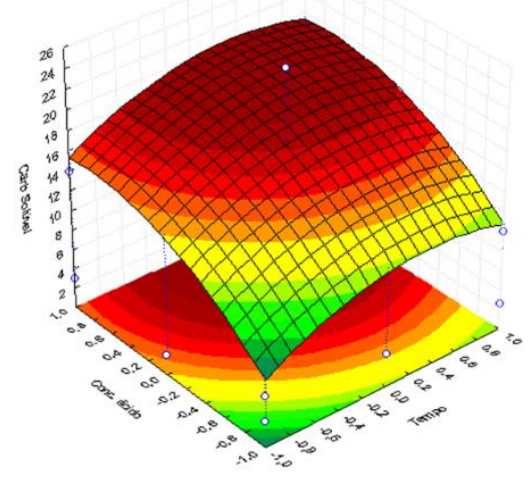

(b)

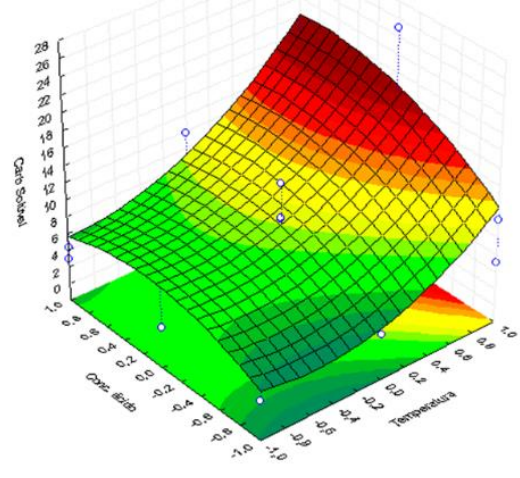

Figura 1. Superfície de resposta para a concentração de carboidratos solúveis (a) em função das variáveis concentração de ácido e tempo com temperatura fixa no +1 e (b) em função da concentração de ácido e temperatura com o tempo fixo no 0 .

Tabela 1. Resultados dos ensaios de biodegradabilidade anaeróbia da fração líquida obtida no pré-tratamento termoquímico com ácido diluído 0,55\% (v/v) neutralizada com Bicarbonato de sódio ou Óxido de cálcio

\begin{tabular}{|c|c|c|c|c|c|c|c|}
\hline \multirow[b]{2}{*}{ Condição } & \multicolumn{2}{|c|}{ Condição Inicial } & \multicolumn{5}{|c|}{ Condição Final $^{a}$} \\
\hline & pH & $\begin{array}{l}\text { DQOs } \\
(\mathrm{mg} / \mathrm{l})\end{array}$ & pH & $\begin{array}{l}\text { DQOs } \\
(\mathrm{mg} / \mathrm{l})\end{array}$ & $\begin{array}{c}\text { Remoção } \\
\text { DQO } \\
(\%)\end{array}$ & Volume $\mathrm{CH}_{4}(\mathrm{Nml})$ & $\begin{array}{c}\text { PEM } \\
\left(\mathrm{Nml} \mathrm{CH}_{4} / \mathrm{g}\right. \\
\left.\mathrm{DQO}_{\text {remov }}\right)\end{array}$ \\
\hline $\mathrm{NaHCO}_{3}$ & $7,4 \pm 0,2$ & 21633 & $6,5 \pm 0,3$ & $8955 \pm 125$ & 59 & $297 \pm 22$ & 66,4 \\
\hline $\mathrm{CaO}$ & $7,6 \pm 0,05$ & 17655 & $4,9 \pm 0,0$ & $8305 \pm 365$ & 53 & $378 \pm 11$ & 121,2 \\
\hline
\end{tabular}

${ }^{a}$ Média e desvio-padrão de 2 réplicas. 


\title{
PRODUÇÃO BIOLÓGICA DE H2 UTILIZANDO VINHAÇA CÍTRICULA COMO SUBSTRATO
}

\author{
Pachiega, R. ${ }^{1,2}$; Maintinguer, S.I. ${ }^{2,3 *}$ \\ ${ }^{1}$ Instituto de Química de Araraquara - UNESP, Araraquara, SP - Brasil. \\ ${ }^{2}$ Instituto de Pesquisa em Bioenergia - IPBEN - Laboratório Central, Rio Claro, SP-Brasil \\ Universidade de Araraquara - Uniara, Araraquara, SP - Brasil. \\ renanpachiega@gmail.com; mainting2008@gmail.com
}

\begin{abstract}
RESUMO: Devido a demanda mundial, várias pesquisas estão sendo realizadas a fim de buscar fontes renováveis de energia. Dentre tais possibilidades, o gás hidrogênio obtido por processos biológicos se mostra uma alternativa em potencial. Entretanto, poucos estudos são realizados em climas tropicais como o Brasil. As temperaturas médias anuais de $27^{\circ} \mathrm{C}$ podem favorecer o estabelecimento de consórcios de bactérias geradoras de $\mathrm{H}_{2}$. Na região central do Estado de São Paulo, está localizada a denominada região do cinturão citrícola, a qual é responsável por cerca de $80 \%$ da produção citrícola do país, gerando cerca de 670 mil toneladas em resíduos orgânicos. Uma investigação do potencial de produção de gás hidrogênio a partir de resíduos citrícolas se mostra necessário. Nesse sentido, inóculo proveniente de reator UASB tratando residuos avicolas foi prétratado e inoculado em reatores anaeróbios em batelada alimentados com vinhaça citrícola (12,0 e 36,0 g DQO $\mathrm{L}^{-1}$ ), sob pH inicial 5,5, a $37^{\circ} \mathrm{C}$ com headspace preenchido com $\mathrm{N}_{2}(99,99 \%)$. Foram obtidos 71,6 e $126 \mathrm{mmol}$ $\mathrm{H}_{2} \mathrm{~L}^{-1}$, respectivamente. Tal produção revelou a eficiência na inativação de microrganismos metanogênicos do inóculo. Foi observado predomínio de bacilos Gram + , morfologia característica de microrganismos com potencial de produção de $\mathrm{H}_{2}$, e quantificadas 3,73 unidades formadoras de colônia Clostridium sp. por mL.
\end{abstract}

Palavras-chave: vinhaça citrícola, lodo granular, $\mathrm{H}_{2}$, pré-tratamentos, processos biológicos anaeróbios

\section{BIOLOGIC PRODUCTION OF $\mathrm{H}_{2}$ USING CITRUS VINASSE AS SUBSTRATE}

\begin{abstract}
Many researches have been done aiming to find other sources of renewable energy due to worldwide demand. Among these possibilities, hydrogen gas obtained by biologic process shows itself a potential alternative. However, just a few studies have been conducted in tropical countries as Brazil, which average temperatures around $27^{\circ} \mathrm{C}$ can favor the maintenance of $\mathrm{H}_{2}$ producers' bacteria consortia. In the countryside of São Paulo State is located a region called citrus belt, which is responsible for $80 \%$ of the country citrus production generating almost 670 thousand tons of organic wastes. An investigation about the potential of production of $\mathrm{H}_{2}$ using citrus wastes seems necessary. Thus, an inoculum from UASB reactor treating poultry wastes was pretreated and hatched in $\mathrm{H}_{2}$ producer anaerobic batch reactors fed with citrus vinasse (12.0 and 36.0 g DQO L $\left.{ }^{-1}\right)$, with initial $\mathrm{pH} 5.5$ and under $36^{\circ} \mathrm{C}$ with $\mathrm{N}_{2}(99,99 \%)$ headspace. There were obtained 71.6 and $126 \mathrm{mmol} \mathrm{H}_{2} \mathrm{~L}^{-1}$, respectively. The $\mathrm{H}_{2}$ production revealed an efficiency in inactivation of methanogenic microorganisms from the inoculum. It was observed the predominance of Gram + rods, which morphology is characteristic from $\mathrm{H}_{2}$ producers' microorganisms and the enumeration by plating resulted in 3.73 Clostridium sp. colony forming unit $\mathrm{mL}^{-1}$.
\end{abstract}

Keywords: citrus vinasse, $\mathrm{H}_{2}$, granular sludge, pretreatment, anaerobic biologic processes

\section{INTRODUÇÃO}

A digestão anaeróbia se mostra promissora em relação às outras formas biológicas de obtenção de $\mathrm{H}_{2}$, na qual podem ser utilizados como substrato: águas residuárias agroindustriais, resíduos domésticos, efluentes industriais, entre outros. Processos anaeróbios podem ser aplicados no tratamento desta carga orgânica e na recuperação bioenergética. Daí a importância de se trabalhar com consórcios bacterianos na produção biológica de gás hidrogênio, focando, principalmente, na utilização de lodo de estações de tratamento de esgoto sanitário e de águas residuárias industriais, uma vez que em tais matrizes a diversidade de bactérias anaeróbias é elevada. Entretanto, poucos estudos são realizados em climas tropicais como o Brasil, onde as temperaturas médias anuais de $27^{\circ} \mathrm{C}$ podem favorecer o estabelecimento de consórcios de bactérias geradoras de $\mathrm{H}_{2}$. O país 
também se destaca como o maior produtor mundial de cultura citrícola, com a produção de laranja em 2014, chegando a 16,9 milhões de toneladas, representando assim, 33\% da produção mundial. O Estado de São Paulo representa $73 \%$ dessa produção e no ano de 2014, foram geradas pelas indústrias citrícolas brasileiras 8,4 milhões de toneladas de resíduos de laranja (TORQUATO et al., 2017). Além disso, a região central do Estado de São Paulo está localizada no denominado cinturão citrícola, o qual é responsável por cerca de $80 \%$ da produção do país (NEVES et al., 2010). Esses resíduos aliados a digestão anaeróbia podem resultar em uma utilização viável para a produção de $\mathrm{H}_{2}$, uma vez que contém carboidratos em sua composição. Entretanto, para que seja possível a produção do gás hidrogênio, é preciso inativar os microrganismos metanogênicos que o consomem. Nesse sentido, diversas técnicas têm sido empregadas para inativar a metanogênese e selecionar apenas microrganismos produtores de gás hidrogênio (ROSSI et al., 2011). Portanto, uma investigação do potencial de produção de gás hidrogênio utilizando resíduos da agroindústria citrícola, o qual é um recurso abundante no Brasil, pode resultar em uma possibilidade de sua utilização como fonte bioenergética, além de ser uma alternativa eficiente para tratamento adequado desses resíduos gerados. O objetivo do presente trabalho foi aplicar e comparar diferentes pré-tratamentos em consórcio bacteriano e comprovar sua respectiva potencialidade na produção de $\mathrm{H}_{2}$ utilizando vinhaça citrícola como substrato.

\section{Fonte de Inóculo}

\section{MATERIAL E MÉTODOS}

O inóculo utilizado foi o lodo granular proveniente de reator UASB (Upflow Anaerobic Sludge Blanket) de estação de tratamento de efluentes de abatedouro de aves, cedido pela avícola Dacar (Tietê -SP).

\section{Fonte de Carbono}

Foi utilizada como fonte de carbono a vinhaça citrícola, a qual foi cedida por uma indústria citrícola localizada em Matão, na região central do Estado de São Paulo, no cinturão citrícola. O resíduo foi mantido e acondicionado em frascos plásticos lacrados, com $1 \mathrm{~L}$ de volume, a $-20^{\circ} \mathrm{C}$ até sua utilização.

\section{Análise Físico-Químicas}

Análise de carboidratos totais foi realizada de acordo com Dubois et al. (1956). Tanto as análises finais de $\mathrm{pH}$ utilizando $\mathrm{HCl}(4 \mathrm{M})$ e $\mathrm{NaOH}(4 \mathrm{M})$ quanto as de demanda química de oxigênio (DQO) foram realizadas ao final de cada ensaio segundo APHA (2005).

\section{Pré-tratamento}

Duplicatas de reatores anaeróbios em batelada contendo $1 \mathrm{~L}$ de meio reacional (meio PYG, em g L ${ }^{-1}: 10$ - glicose, 5 - peptona, 5-extrato de carne e 5- extrato de levedura) e $1 \mathrm{~L}$ de volume de headspace $\left(\mathrm{N}_{2}\right.$ - 99,99\%) foram montadas para se aplicar o pré-tratamento ácido ( $\mathrm{pH} 3,0$ por 24 horas) do inóculo. Após o processo de pré-tratamento os inóculos foram reativados com valores de $\mathrm{pH}$ 5,5 e 7,0 e o biogás gerado no headspace foi caracterizado por cromatografia gasosa.

\section{Reatores anaeróbios em batelada}

Os reatores anaeróbios em batelada geradores de $\mathrm{H}_{2}$ eram frascos Duran ${ }^{\circledR} \operatorname{com} 2 \mathrm{~L}$ de volume total. Tais reatores foram acompanhados com $1 \mathrm{~L}$ de meio reacional contendo resíduo de vinhaça citrícola e água destilada como meio diluente, tendo valor de $\mathrm{pH}$ inicial ajustado em 5,5, mantidos sob $37^{\circ} \mathrm{C}$ e com headspace de $\mathrm{N}_{2}$, mantendo a anaerobiose. Os reatores foram montados em triplicatas e em duas condições distintas: (1) 12,0 e (2) 36,0 g DQO L ${ }^{-1}$. A quantificação do gás hidrogênio gerado, foi o sistema de deslocamento de volume adaptado de Aquino et al. (2007).

\section{Ajuste dos Dados Experimentais}

Os dados de produção de $\mathrm{H}_{2}$ dos reatores alimentados com resíduos citrícola, em $\mathrm{mmol} \mathrm{H}_{2} \mathrm{~L}^{-1}$, foram ajustados nos valores médios obtidos das triplicatas dos reatores em batelada, utilizando o software Statistica ${ }^{\circledR}$, a taxa máxima de produção de hidrogênio $(\mathrm{Rm})$, o valor máximo de produção estimado $(\mathrm{P})$ e o tempo estimado da fase lag (L). Tais parâmetros são obtidos pelo ajuste sigmoidal não linear da função de Gompertz modificado (TORQUATO et al., 2017). 


\section{Análise Microbiológicas}

Foram realizadas análises de microscopia ótica com técnica de coloração de Gram (MADIGAN et al., 2016) para observação das morfologias predominantes nos consórcios anaeróbios presentes. Quantificação de bactérias anaeróbias (em Unidades Formadoras de Colônias por $\mathrm{mL}$ ) produtoras de $\mathrm{H}_{2}$ foi realizada por plaqueamento com meio seletivos para gêneros produtores de $\mathrm{H}_{2}$ (SONG et al., 2012) Clostridium sp., Enterobacter sp., Lactobacillus sp., Bacteroidetes sp. e Veillonella sp..

\section{Pré-tratamento e inativação da metanogênese}

Gás metano não foi produzido em nos reatores com pré-tratamento aplicado. Portanto, foi observada somente a produção de gás hidrogênio, gerando 10,83 mmol H$_{2} \mathrm{~L}^{-1}$ sob $\mathrm{pH} 7,0$. Portanto, a inativação de microrganismos metanogênicos foi eficiente. Alguns parâmetros podem ser apontados como cruciais para uma efetiva seleção de microrganismos. A mudança nos valores de $\mathrm{pH}$ impostos no pré-tratamento influenciam diretamente na carga elétrica presente na membrana celular, afetando assim as funções enzimáticas e a absorção de nutrientes (WANG et al., 2017). Microrganismos hidrogenotróficos e não-formadores de esporos não resistem às condições extremas impostas por valores de $\mathrm{pH}$ ácido e/ou alcalino, resultando assim, na inativação de tais microrganismos. $\mathrm{O}$ inóculo pré-tratado com ataque ácido foi utilizado nos ensaios com resíduo citrícola.

\section{Reatores anaeróbios em batelada}

Dentre os ensaios operados com vinhaça citrícola, (1) 12,0 e (2) 36,0 g DQO L-1 foi observado comportamento diretamente proporcional entre a concentração de DQO e a produção acumulada de gás hidrogênio. Este fato se deve ao aumento na concentração de carboidratos presentes nos reatores como fonte de carbono para a fermentação. Os ensaios obtiveram ao final de 256 e 399 h, respectivamente, 36\% (ensaio 1) e $44 \%$ (ensaio 2) de consumo de carboidratos. O ensaio 2 apresentou valores mais elevados de produção máxima de $\mathrm{H}_{2}$ do que o obtido no ensaio 1, que, que foram de 71,6 e $126,0 \mathrm{mmol} \mathrm{H}_{2} \mathrm{~L}^{-1}$, respectivamente. Montoya-Pérez; Durán-Herrera (2017) avaliaram a produção de $\mathrm{H}_{2}$ utilizando reator anaeróbio em batelada com agitação (5 L) alimentado com coração de abacaxi $\left(5,0\right.$ g glicose $\left.\mathrm{L}^{-1}\right)$ com $50 \%$ (v/v) de lodo granular de reator UASB tratando água residuária de indústria de alimentos de Costa Rica. O reator foi operado com $21 \mathrm{~g}$ DQO L ${ }^{-1}$, por 30 horas sob $\mathrm{pH}$ inicial 5,5 e a $37^{\circ} \mathrm{C}$. Os autores obtiveram uma produção máxima de $41,2 \mathrm{mmol}$ $\mathrm{H}_{2} \mathrm{~L}^{-1}$, valores inferiores ao resultado apresentado no presente trabalho para os reatores alimentados com vinhaça citrícola $\left(71,06\right.$ e 126,0 mmol $\left.\mathrm{H}_{2} \mathrm{~L}^{-1}\right)$ para os ensaios $1\left(12 \mathrm{~g} \mathrm{DQO} \mathrm{L}^{-1}\right)$ e $2\left(36 \mathrm{~g} \mathrm{DQO} \mathrm{L}^{-1}\right)$, respectivamente. Reitera-se a comparação entre o ensaio 1 e o apresentado pelos autores, uma vez que com uma concentração menor aplicada no presente trabalho, foi possível a obtenção de uma produção máxima de hidrogênio superior sob condições similares de operação.

Pelo ajuste sigmoidal da função de Gompertz modificada (Figura 1), os parâmetros estimados de fase lag $(\mathrm{L})$, produção máxima $(\mathrm{P})$ e taxa de produção $(\mathrm{Rm})$, foram respectivamente para os ensaios 1 e 2: $\mathrm{L}=22,4$ e 67,3 horas; $\mathrm{P}=68,7$ e 121,8 $\mathrm{mmol} \mathrm{H}_{2} \mathrm{~L}^{-1}$; e $\mathrm{Rm}=1,2$ e $1,7 \mathrm{mmol} \mathrm{H}_{2} \mathrm{~L}^{-1} \mathrm{~h}^{-1}$. Os coeficientes de determinação $\left(\mathrm{R}^{2}\right)$, obtidos também pelo tratamento estatístico [(1) 0,990 e (2) 0,995], reforçam que o modelo adotado representa efetivamente bem os dados obtidos experimentalmente em reatores anaeróbios em batelada alimentados com resíduos citrícolas. Tais resultados indicam que não houve inibição do consórcio bacteriano com o aumento na concentração de DQO e, consequentemente, na concentração de carboidratos e compostos provenientes do resíduo bruto. Com o processo fermentativo efetivamente ocorrendo o $\mathrm{pH}$ tende a diminuir, entretanto o pH final medido ao término da incubação dos reatores, retornou valores de pH de 5,66 e 5,55, respectivamente para os ensaios 1 e 2 .

\section{Análises microbiológicas}

A quantificação das bactérias anaeróbias por plaqueamento no inóculo pré-tratado foi possível somente no meio seletivo às espécies do gênero Clostridium com 3,73 UFC mL ${ }^{-1}$. A microscopia por coloração de Gram revelou a predominância de bacilos Gram + , morfologia característica de microrganismos com potencial de produção de $\mathrm{H}_{2}$ (ETCHEBEHERE et al., 2016). 


\section{CONCLUSÃO}

Todos os pré-tratamentos aplicados foram efetivos para a inativação da metanogênese.

O inóculo pré-tratado se mostrou efetivo na produção de $\mathrm{H}_{2}$ em reatores operados com vinhaça citrícola como substrato.

Resíduos citrícolas apresentam grande potencial na produção de gás hidrogênio como uma fonte de energia renovável.

\section{REFERÊNCIAS}

APHA, A. and W. Standard methods for the examination of water and wastewater. 20th ed. Washington, D.C.: American Public Health Association, 2005.

Aquino, S. F. . et al. Metodologias para determinação da atividade metanogênica específica (ame) em lodos anaeróbios. Engenharia sanitaria ambiental, v. 12, n. 2, p. 192-201, 2007.

Dubois, M. et al. Colorimetric method for determination of sugars and related substances. Analytical chemistry, v. 28, n. 3, p. 350-356, 1956.

Etchebehere, C. et al. Microbial communities from 20 different hydrogen-producing reactors studied by 454 pyrosequencing. Applied microbiology and biotechnology, v. 100, n. 7, p. 3371-3384, 2016.

Madigan, M. T. et al. Microbiologia de brock. 14. ed. [S.L.] Artmed, 2016.

Montoya-Pérez, L.; Durán-Herrera, J. E. Producción de hidrógeno a partir de la fermentación de residuos agroindustriales de la piña hydrogen production from the fermentation of pineapple agroindustrial wastes.tecnología en marcha. v. 30, p. 106-118, 2017.

Neves, M. F. et al. O retrato da citricultura brasileira. [S.L: S.N.].

Rossi, D. M. et al. Comparison of different pretreatment methods for hydrogen production using environmental microbial consortia on residual glycerol from biodiesel. International journal of hydrogen energy, v. 36, n. 8, p. 4814-4819, 2011.

Song, Z. X. et al. Effects of pretreatment method of natural bacteria source on microbial community and biohydrogen production by dark fermentation. International journal of hydrogen energy, v. 37, n. 7, p. 5631-5636, 2012.

Torquato, L. D. M. et al. Potential of biohydrogen production from effluents of citrus processing industry using anaerobic bacteria from sewage sludge. Waste management, v. 59, 2017.

Wang, J., \& Yin, Y. (2017). Principle and application of different pretreatment methods for enriching hydrogen-producing bacteria from mixed cultures. International journal of hydrogen energy, v. 42(8), p. 4804-4823. https://doi.org/10.1016/j.ijhydene.2017.01.135

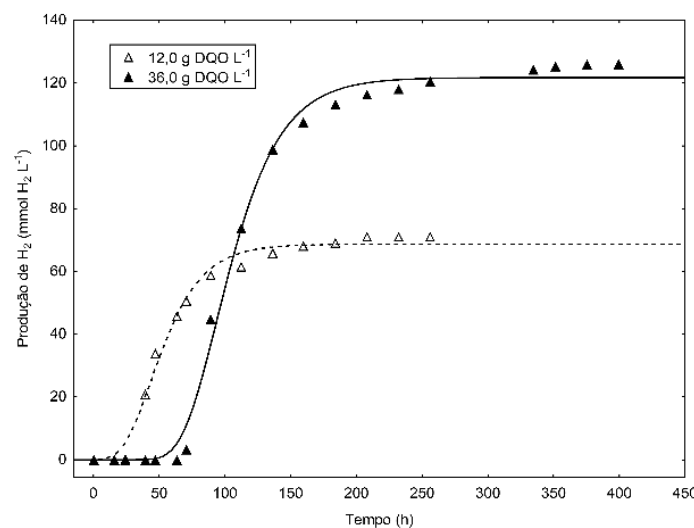

Figura 1. Ajuste sigmoidal da função de Gompertz modificada nos ensaios $1(\Delta)$ e $2(\boldsymbol{\Delta})$. 


\title{
PRODUZINDO BIOGÁS COM O SISTEMA ESPECIALIZADO OPUS.DIG
}

\author{
Cé, A.*1; Reinaldo, F. ${ }^{1}$; Bortoli, M. ${ }^{1}$; Staub, C.P.P. ${ }^{1}$; Steinmetz, R.L.R. ${ }^{2}$; Kunz, A. ${ }^{2}$ \\ ${ }^{1}$ Universidade Tecnológica Federal do Paraná, Pós-Graduação em Eng. Ambiental: Análise e Tecnologia Ambiental, campus \\ Francisco Beltrão, $P R$ \\ ${ }_{2}^{2}$ Pesquisadores da Embrapa Suínos e Aves, Concórdia, SC - Brasil \\ *anaceamb@gmail.com
}

\begin{abstract}
RESUMO: A otimização do processo de digestão anaeróbia para produção de biogás depende de diferentes parâmetros. Algumas técnicas não convencionais utilizando inteligência artificial estão sendo empregadas na captura do conhecimento especializado em diferentes áreas do conhecimento. O objetivo do trabalho foi utilizar um sistema especialista, denominado como OPUS.DIG, com a finalidade de auxiliar usuários sem conhecimentos específicos da área do problema a escolherem os parâmetros que interferem no processo de digestão anaeróbia para saber se o substrato está apto ou não para formação do biogás. Os passos para a construção da base de conhecimento foram: a) Escolha das variáveis dependentes; b) Escolha do objetivo; c) Construção das regras; e d) Interfaces. Com a utilização do software OPUS.DIG, constatou-se que a base de conhecimento elaborada por especialistas na área, permite que o usuário sem ser perito na área esteja habilitado a constatar as respostas para os parâmetros interferentes no processo de digestão anaeróbia para formação de biogás.
\end{abstract}

Palavras-chave: digestão anaeróbia, inteligência artificial, software.

\section{PRODUCING BIOGAS WITH OPUS.DIG EXPERT SYSTEM}

\begin{abstract}
The optimization of the anaerobic digestion process for biogas production depends on several parameters unmapped in traditional studies. To cover this problem, some unconventional techniques using artificial intelligence were used to capture specialized human knowledge. The goal of this work was to develop an expert system, titled OPUS.DIG, to assist users without detailed knowledge to fine-tune the anaerobic digestion process in order to obtain the substrate for biogas generating. The steps to build the knowledge base were: a) choice of dependent variables; b) choice of the objective; c) construction of the rules; and d) interfaces questions. OPUS.DIG results showed that the knowledge base allowed the user with the basic knowledge to verify the responses to the interfering parameters in the process of anaerobic digestion for the formation of biogas.
\end{abstract}

Keywords: anaerobic digestion, artificial intelligence, software.

\section{INTRODUÇÃO}

O biogás é gerado do processo de digestão anaeróbia da matéria orgânica. Esse processo ocorre em quatro etapas (hidrólise, acidogênese, acetogênese e metanogênese) e é realizado por diferentes grupos de microrganismos (CESTONARO DO AMARAL et al., 2016). A composição do biogás caracteriza-se principalmente por metano e gás carbônico. A composição é ainda influenciada por parâmetros físicos, químicos e microbiológicos, além de diferentes configurações de reatores, usinas, técnicas de fermentação e os substratos utilizados (SANTA'ANNA JR., 2013; DEUBLEIN e STEINHAUSER, 2010).

$\mathrm{Na}$ tentativa de aprimorar o processo de digestão anaeróbia e consequentemente a produção de biogás, tem se estudado técnicas não tradicionais, envolvendo inteligência computacional na captura do conhecimento humano especializado. O termo Inteligência Computacional está muitas vezes relacionado ao sólido desenvolvimento de Sistemas Especialistas. Tais sistemas são comumente implementados em shells e compostos de cadeias de regras de produção "SE... ENTÃO..." que reproduzem o conhecimento do perito ou conjunto destes em determinado assunto específico. Esta cadeia de regras, quando organizadas em módulos categóricos e atômicos, permitem obter respostas, simulando a tomada de decisão do especialista humano (REINALDO et al., 2009). 
Sistemas Especialistas são implementados com ferramentas de depuração para auxiliar profissionais e não profissionais a solucionar determinados problemas de seu domínio específico, e como não são influenciados por elementos externos, por exemplo, opiniões, estresses ou distúrbios corporais, oferecem sempre o mesmo conjunto de decisões aquando das mesmas condições (REINALDO et al., 2017).

A literatura atual em inteligência computacional apresenta diferentes paradigmas para permitir aos profissionais realizarem um detalhado monitoramento e controle pela manipulação dos dados brutos. Neste sentido, VANTI et al., (2015) desenvolveram um algoritmo de controle em MATLAB, e validado no software ModelSim para monitorar as pressões e taxas de fluxo de gases e otimizar a captura e filtração de biogás. GUEGUIM KANA et al., (2012) implementaram algoritmos genéticos para modelar e otimizar a produção de biogás de diferentes substratos. FUQING XU et al., (2014) utilizaram modelos de redes neurais artificiais com enfoque em regressão linear múltipla para prever o rendimento de metano na digestão anaeróbia de biomassa lignocelulósica, através da matéria-prima e parâmetros do processo.

Entretanto, a literatura atual apresenta poucas ferramentas capazes de auxiliar pessoas não profissionais no controle do processo de digestão anaeróbia. Sendo assim, sistemas especialistas podem permitir inferir respostas referentes às questões de interdependência, principalmente, das relações no fluxo hierárquico dos parâmetros interferentes, além das respectivas faixas de valores, durante o processo de digestão anaeróbia de substratos, com base na caracterização físico-química desses parâmetros pelo conhecimento espelho.

O objetivo do trabalho foi utilizar um sistema especialista que auxilie usuários sem conhecimentos específicos da área do problema a avaliar e escolher em tempo de execução, os parâmetros e valores corretos que interferem na digestão anaeróbia e saber se o substrato está apto ou não, para a formação de biogás.

\section{MATERIAL E MÉTODOS}

O sistema especialista utilizado foi denominado como OPUS.DIG, composto por regras cognitivas encadeadas e codificadas no formato sistema de produção. Os critérios extraídos dos especialistas abordaram a área de Engenharia Ambiental, Química, Eletrotécnica e de Computadores. O sistema OPUS.DIG também foi utilizado para a construção da base de conhecimento. OPUS.DIG é um software que obedece a concepção de softwares inteligentes em bases de conhecimento especialistas e está registrado no INPI (Instituto Nacional de Propriedade Intelectual) sob os números BR512018000658-2 (REINALDO, CÉ e BORTOLI, 2018) e BR512018000659-0 (REINALDO, CÉ e BORTOLI, 2018).

O processo de construção da base de conhecimento do sistema inteligente de digestão anaeróbia seguiu os respectivos passos: a) Escolha das variáveis dependentes; b) Escolha do objetivo (variável de saída ou diagnóstico); c) Construção das regras; e d) Interfaces (perguntas).

Os parâmetros escolhidos para confeccionar as regras para obtenção de uma resposta final foram: Micronutrientes ( $\left.\mathrm{mg} \mathrm{L}^{-1}\right)$; Inibidores $\left(\mathrm{mg} \mathrm{L}^{-1}\right) ; \mathrm{NH}_{4}{ }^{+} \mathrm{e} \mathrm{NH}_{3}\left(\mathrm{mg} \mathrm{L}^{-1}\right)$; Disponibilidade de nutrientes $\left(\mathrm{mg} \mathrm{L}^{-1}\right) \mathrm{e}$ Geração de biogás (variável-objetivo). Os valores de parâmetros utilizados como variáveis dependentes foram descritos no Guia Prático do Biogás: Geração e Utilização, desenvolvido por BMELV et al., (2010).

\section{RESULTADOS E DISCUSSÃO}

Na Figura 1 é exemplifica a interface, a qual apresenta ao usuário perguntas referentes a parâmetros dependentes da digestão anaeróbia. Quando o usuário utilizou a base de conhecimento deste sistema, a resposta foi obtida conforme os resultados dos parâmetros encontrados nas análises.

O usuário pode responder somente uma alternativa no sistema especialista, "Sim" e "Não". Dependendo da opção marcada nas próximas perguntas, o software apresenta uma resposta final, que obtém um resultado referente ao substrato utilizado, se o mesmo foi apto ou não para geração de biogás.

O substrato utilizado é considerado satisfatório para produzir biogás, quando todos os valores de parâmetros são executados e a resposta final da interface do sistema especialista aparece como "Apto" (Figura 2a). No entanto, quando algum resultado não estiver entre os valores de parâmetros determinados nas regras, o usuário se depara com um resultado descrito como: "Nenhum valor encontrado" (Figura 2b), que significa que determinado valor de parâmetro respondido na execução do programa, não atendeu ao recomendado, logo, tais valores do substrato caracterizado não são aptos para geração do biogás, conforme recomendado por BMELV et al., (2010). 
O software OPUS.DIG apresenta uma memorização na sua interface, correspondente a "Árvore de Pesquisa". $\mathrm{Na}$ árvore de pesquisa são armazenadas informações que apresentam o histórico das respostas realizadas pelo usuário em cada regra, ou seja, a quantificação de dados respondidos na execução da base de conhecimento (Figura 3).

\section{CONCLUSÃO}

Com a utilização do software OPUS.DIG, uma base de conhecimento constituída por regras de especialistas na área, permite que o usuário tenha conhecimento do processo de digestão anaeróbia para geração do biogás sem ser perito na área. A vantagem do uso pelo OPUS.DIG está na recepção da transferência do conhecimento dos profissionais para pessoas que não são especialistas na área, as quais podem executar o programa, e obter uma resposta final.

Com a intersecção destas ciências, o trabalho possibilitou que pessoas não especialistas estejam habilitadas a corretamente calibrar os parâmetros interferentes no processo de digestão anaeróbia para formação de biogás.

\section{AGRADECIMENTOS} do Brasil.

Os autores agradecem o apoio prestado pela Fundação Araucária e CAPES, do Ministério de Educação

\section{REFERÊNCIAS}

BMELV. Guia prático do biogás: geração e utilização. Projeto Brasil e Alemanha de provento ao aproveitamento energético do biogás - PROBIOGÁS. Gülzow, Alemanha, Ed 5. 2010.

CESTONARO DO AMARAL, A.; KUNZ, A.; RADIS STEINMETZ, R. L.; ET AL. Influence of solid-liquid separation strategy on biogas yield from a stratified swine production system. Journal of Environmental Management, V. 168, P. 229-235, 2016.

DEUBLEIN, D.; STEINHAUSER, A. Biogas from waste and renewable resources: an introduction. 2010.

FUQING, X; ZHI-WU W; YEBO L. Predicting the methane yield of lignocellulosic biomass in mesophilic solid-state anaerobic digestion based on feedstock characteristics and process parameters. Bioresource Technology, 173:168-176, 2014.

GUEGUIM KANA, E.B. OLOKE, J.K. LATEEF, A. ADESIYAN, M.O. Modeling and optimization of biogás production on saw dust and other co-substrates using artificial neural network and genetic algorithm. Renewable Energy, 46:276-281, 2012.

REINALDO, F; BARROS, F. S.; LEONE, R. S. SIRP - Sistema de Recomendação a Pesquisadores. In: XII Congresso Brasileiro de Bioética. Promoção: Sociedade Brasileira De Bioética. Iv Congresso Brasileiro De Bioética Clínica. Promoção: Conselho Federal De Medicina, 2017.

REINALDO, F; CÉ, A; BORTOLI, M. Programa de computador: "DigestBiogás”. Brasil. BR5120180006582, 15 de abril de 2018. INPI - Instituto Nacional da propriedade industrial. 2018.

REINALDO, F; CÉ, A; BORTOLI, M. Programa de computador: "ExpertBiogás”. Brasil. BR5120180006590, 15 de abril de 2018. INPI - Instituto Nacional da propriedade industrial. 2018.

REINALDO, F; RAHMAN, Md. A.; MALUCELLI, A. ; CAMACHO, R. Assessing the Eligibility of Kidney Transplant Donors. In: Perner, Petra. (Org.). Machine Learning and Data Mining in Pattern Recognition: Lecture Notes in Computer Science. Berlin: Springer-Verlarg, 2009, v. 5632, p. 802-809.

SANT'ANNA JR, G. L. Tratamento biológico de efluentes: fundamentos e aplicações. Interciência Ed. 2013. VANTI, C.V.M; LEITE, L.C.; BATISTA E. A. Monitoring and control of the processes involved in the capture and filtering of biogas using fpga embedded fuzzy logic. IEEE Latin America Transactions, 13:232-2238, 2015. 


\section{VISIGERA DE 07 A 09 MAI 2019}

GERAR BIOGÁS

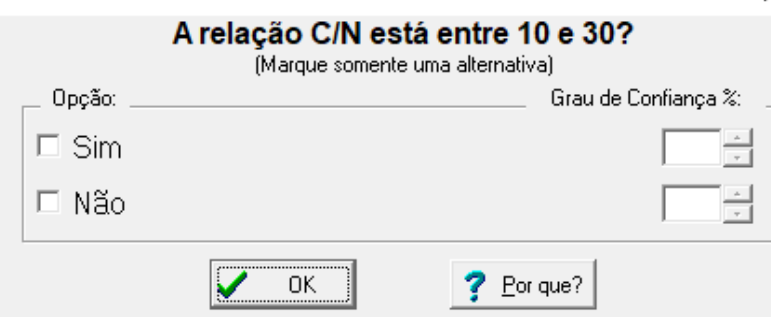

GERAR BIOGÁS

O valor de Nitrogênio amoniacal é maior que $3.500 \mathrm{mg} / \mathrm{L}$ ? (Marque somente uma alternativa)

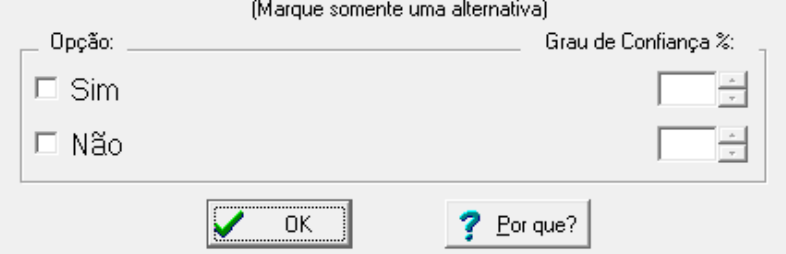

GERAR BIOGÁS
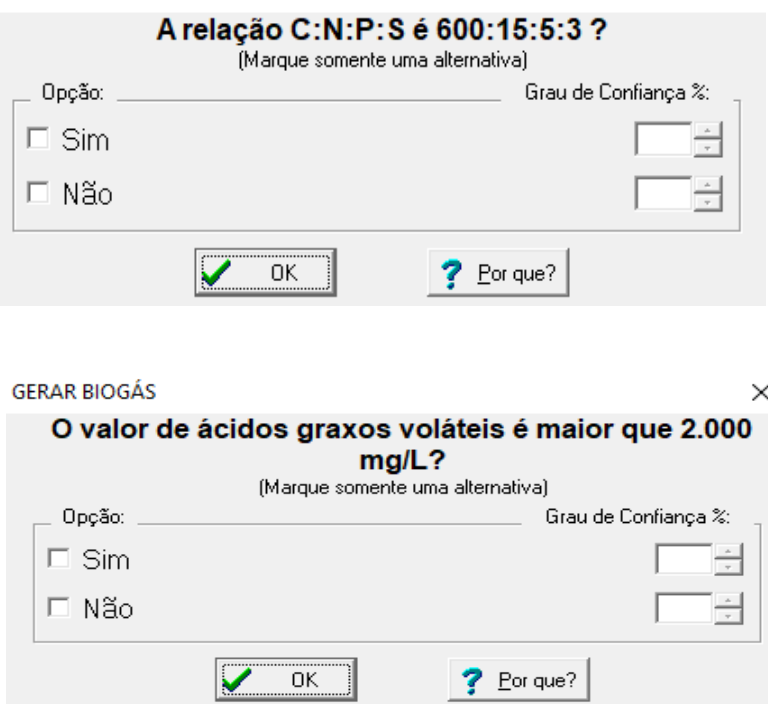

Figura 1. Perguntas pertinentes a alguns parâmetros dependentes da digestão anaeróbia.
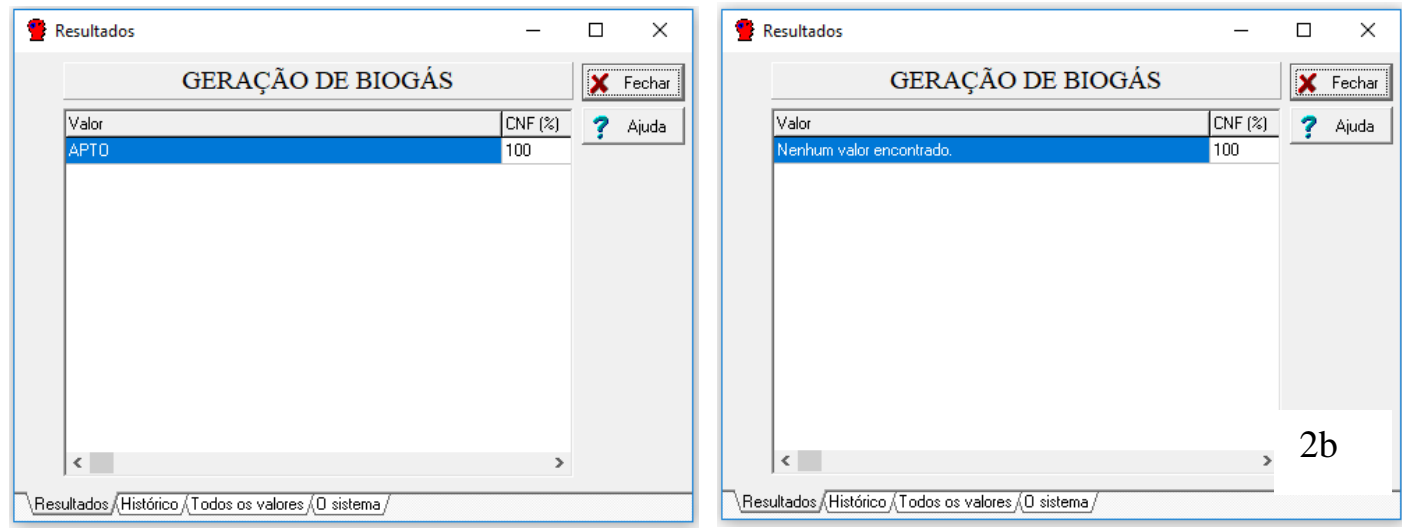

Figura 2. Resposta final da variável de saída quando apto (2a) ou não (2b) para geração de biogás.

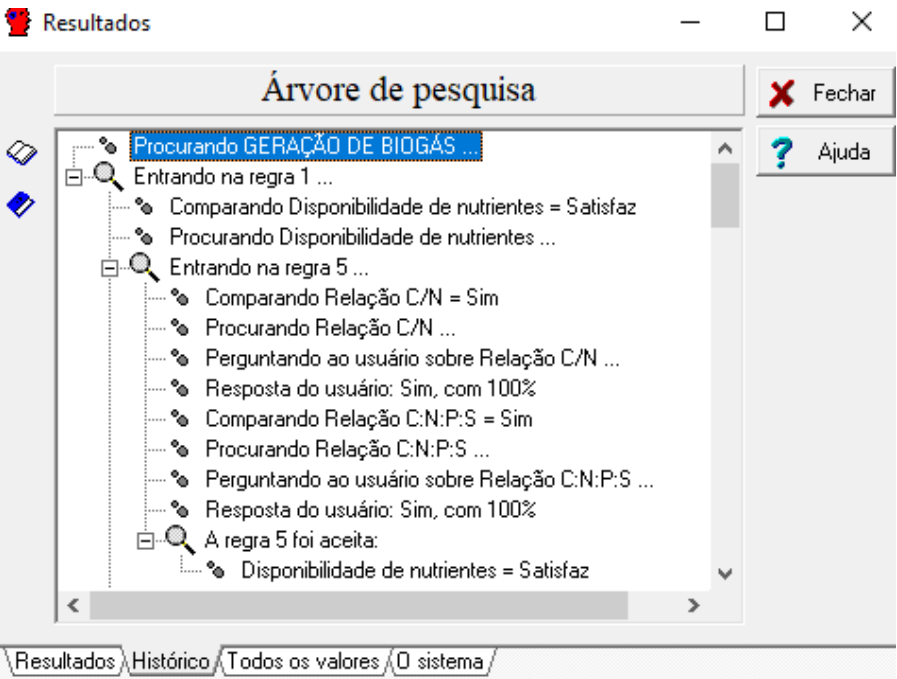

Figura 3. Histórico de perguntas respondidas ao executar o software. 


\title{
USO DO PLASMA NÃO TÉRMICO PARA A DESLIGNIFICAÇÃO DO BAGAÇO DA CANA DE AÇÚCAR VISANDO À PRODUÇÃO DE BIOETANOL
}

\author{
Silva, B.M.*1; Sander, A.K. ${ }^{2}$; Cubas, A. L.V. ${ }^{3}$; Moecke, E.H.S. ${ }^{4}$ \\ ${ }^{I}$ Graduanda do curso de Engenharia Química da Universidade do Sul de Santa Catarina - UNISUL; ${ }^{2}$ Graduando do curso de \\ Engenharia Química da UNISUL; ${ }^{3}$ Prof ${ }^{a}$ do mestrado em Ciências Ambientais e Coordenadora do Laboratório de Plasma da \\ Unisul; ${ }^{4}$ Prof ${ }^{a}$ Orientadora do Mestrado em Ciências Ambientais e Coordenadora do Laboratório do LEAS da Unisul/Pedra Branca, \\ Palhoça, SC-Brasil.byankamds@gmail.com
}

RESUMO: O etanol brasileiro é produzido a partir da cana-de-açúcar, com a geração de bagaço e palha como resíduo agroindustrial. Além de seu uso na geração de eletricidade, este resíduo também pode ser aplicado na produção de etanol de segunda geração $(2 \mathrm{G})$, o etanol celulósico. O presente estudo tem o objetivo deslignificar o bagaço da cana-de-açúcar a partir do uso do plasma não térmico e disponibilizar a celulose para o processo de sacarificação enzimática visando à produção de etanol. Durante o processo, foi utilizado um reator de plasma do tipo ponta plano com fluxo de ar atmosférico de 4,5 $\mathrm{L} \mathrm{min} \mathrm{m}^{-1}$ com tempos variando de 30 a 60 minutos. A formação de espécies oxidantes (radicais - $\mathrm{H} \cdot, \mathrm{O} \cdot, \mathrm{OH} \cdot$ e moléculas $-\mathrm{H}_{2} \mathrm{O}_{2}, \mathrm{O}_{3}$, etc.) geradas pelo plasma promoveu a oxidação da lignina com a formação de compostos menores, facilitando assim sua remoção da estrutura da rede da fibra lignocelulolítica. Esta remoção foi acompanhada pela reação histoquímica do corante floroglucinol com a lignina, à medida que a lignina foi oxidada a intensidade da coloração rosa diminuiu. Com 30 minutos de aplicação de plasma houve um aumento da celulose devido à remoção da lignina, porém com 45 e 60 minutos verificou-se uma redução da celulose em função da despolimerização das glicanas, xilanas, mananas e arabianas que compõem a celulose com a formação de cadeias carbônicas de menor peso molecular.

Palavras-chave: bagaço de cana-de-açúcar, plasma não térmico, etanol.

ABSTRACT: Brazilian ethanol is produced from sugarcane, with the generation of bagasse and straw as agroindustrial residue. Besides its use in the generation of electricity, this residue can also be applied in the production of second generation ethanol - $2 \mathrm{G}$, cellulosic ethanol. The present study has the objective of delignifying sugarcane bagasse from the use of non-thermal plasma and making the cellulose available for the enzymatic saccharification process in order to produce ethanol. During the process, a flat tip type plasma reactor with atmospheric air flow of $4.5 \mathrm{~L}$ min-1 was used with times ranging from 30 to 60 minutes. The formation of oxidant species (radicals - $\mathrm{H}, \mathrm{O}, \mathrm{OH}$ and molecules $-\mathrm{H}_{2} \mathrm{O}_{2}, \mathrm{O}_{3}$, etc.) generated by plasma promoted the oxidation of lignin with the formation of smaller compounds, thus facilitating the removal of lignin from the structure of lignocellulolytic fiber network. This removal was accompanied by the histochemical reaction of the floroglucinol dye with the lignin, as the lignin was oxidized the intensity of the pink staining decreased. With 30 minutes of plasma application there was an increase of the cellulose due to the removal of the lignin, but with 45 and 60 minutes a reduction of the cellulose was verified as a function of the depolymerization of the glycans, xylans, mannan and arabianas that compose the cellulose with the formation of lower molecular weight carbon chains.

Keywords: sugarcane bagasse, non-thermal plasma, ethanol.

\section{INTRODUÇÃO}

A celulose é um dos principais constituintes dos resíduos lignocelulósicos renováveis disponíveis em grandes quantidades e é considerado o mais importante reservatório de carbono para a produção de glicose, para combustível alternativo e como matéria-prima química.

Os resíduos agroindustriais da cana-de-açúcar gerados pela indústria álcool-açucareiras, como o bagaço e a palha são aproveitados na geração de vapor e de eletricidade pelas usinas. Porém, ainda existe um excedente que não é aproveitado e se acumula na planta industrial levando a ocupação de espaço e risco de incêndio. (OJEDA et al., 2011). 
A produção atual de bioetanol é proveniente quase que exclusivamente de matérias primas açucaradas como a cana-de-açúcar, a beterraba açucareira, sorgo sacarino e melaço ou materiais amiláceos ou feculentes provenientes de grãos, raízes e tubérculos. Porém, com os debates gerados sobre a sua sustentabilidade, o bioetanol produzido a partir de biomassa lignocelulósica como o bagaço e palha da cana-de-açúcar é uma alternativa interessante uma vez que, estas matérias-primas não competem com as culturas alimentares, além disso, apresentam um custo menor que as matérias-primas convencionais. (ALVIRA et al., 2010).

O processo para a conversão do material lignocelulósico em etanol necessita de três etapas importantes: deslignificação com a solubilização da lignina e liberação da celulose e da hemicelulose; hidrólise com despolimerização dos polissacarídeos (com liberação de açúcares fermentáveis (glicose e xilose); e fermentação dos monossacarídeos com a produção de etanol. Para o processo fermentativo são utilizados micro-organismos capazes de fermentar glicose e xilose simultaneamente em etanol As etapas de deslignificação e despolimerização dos materiais lignocelulósicos, envolvem processos físico-químicos que utilizam tecnologias complexas e multifásicas, como o processo de derivatização seguida de clivagem redutora com brometo de metila, outro processo usado é hidrólise ácida e básica na presença de elevadas temperatura e pressão, ou através da hidrólise enzimática para a separação dos açúcares e remoção da lignina (PEREIRA Jr. et al., 2008). Muitas dessas tecnologias são agressivas ao meio ambiente e/ou de elevado custo.

O objetivo do trabalho é promover o processo de deslignificação do bagaço da cana-de- açúcar e sacarificação a partir do uso do plasma não térmico visando à produção de bioetanol de $2 \mathrm{G}$.

O plasma não térmico ou plasma frio é denominado como um gás parcialmente ionizado, no qual a energia média dos elétrons é consideravelmente mais elevada do que o dos íons e moléculas de gás (RAGAZZI et. al., 2014; PANKAJ et al., 2014. A energia produzida para gerar o plasma frio é muito pequena sendo proporcional ao aumento temperatura que fica próxima a $25^{\circ} \mathrm{C}$. A descarga é formada através da aplicação de um campo elétrico intenso, o que provoca a formação de auto propagação eletrônica dentro do volume de gás. Uma vez gerado o gás ionizado, os elétrons colidem com as moléculas, criando quimicamente espécies ativas conhecidas como radicais (DEBACHER et al., 2015). Este método não necessita de reagentes químicos como ácidos e bases fortes ou solventes e não requer condições drásticas de temperatura e pressão como a maioria dos métodos apresentados na literatura.

Novas tecnologias de transformação de biomassa em bioetanol são fundamentais para o aproveitamento de matérias-primas de baixo custo e que não competem com a produção de alimentos.

\section{MATERIAL E MÉTODOS}

As amostras de bagaço foram adquiridas em garapeiras que comercializam caldo de cana-de-açúcar na região de Palhoça. Inicialmente o bagaço foi lavado com água de torneira até não houver mais a presença de açúcares (teste do DNS). Após a secagem em estufa a $50^{\circ} \mathrm{C}$, o bagaço foi moído em liquidificador e peneirado a fim de obter partículas com diâmetro médio de $0,302 \mathrm{~mm}$.

Para caracterização do bagaço foram determinados os teores de umidade, cinzas, extrativos nas amostras in natura baseados nos procedimentos padrões do NREL "Determination of Total Solids in Biomass" (SLUITER et al., 2005a), NREL "Determination of Ash in Biomass" (SLUITER et al., 2005b) e NREL "Determination of Extractives in Biomass" (SLUITER et al., 2005c) e na norma TAPPI T 204 om-88 "Solvent Extractives of Wood and Pulp". Para isolar a celulose e hemicelulose da fibra utilizou-se a metodologia proposta pelo método Tappi T-203 cm-99. Para este método, o bagaço, foi previamente branqueado. Inicialmente o bagaço foi mercerizado com solução de hidróxido de sódio 5\% por duas horas. Posteriormente o bagaço foi lavado com água destilada, até que a solução filtrante adquirisse um pH neutro, sendo seco à $50^{\circ} \mathrm{C}$ por 24 horas. Para o branqueamento utilizou-se uma solução tampão 1:1 de hidróxido de sódio 5\% e ácido acético $5 \%$ com hipoclorito de sódio 2,5\%. A fibra resultante dessa etapa foi lavada até a obtenção de uma solução filtrante de $\mathrm{pH}$ neutro e então a fibra foi seca em estufa a $50^{\circ} \mathrm{C}$ por 24 horas. A fibra branqueada foi submetida a uma solução de hidróxido de sódio 17,5\% para a separação da celulose, que não é solúvel em meio básico, da hemicelulose, que é solúvel nesse $\mathrm{pH}$. A celulose foi separada da hemicelulose através de filtração. A celulose após a separação foi lavada, seca e analisada. A hemicelulose foi precipitada do licor através da mistura deste com uma solução de etanol $95 \%$ contendo $10 \%$ (v/v) de ácido acético glacial. Alternativamente, separou-se parte do licor obtido e precipitaram-se os açucares degradados, conhecidos como $\beta$-celulose, com ácido sulfúrico $3 \mathrm{~N}$. As frações assim separadas foram filtradas em cadinho de vidro sinterizado e secas em estufa a $60^{\circ} \mathrm{C}$. Para isolar a lignina utilizou-se o método lignina Klason. 
Para o processo de deslignificação com o plasma não térmico foram usadas em torno de $2,5 \mathrm{~g}$ de amostra triturada peneiradas (partículas com diâmetro médio de $0,302 \mathrm{~mm}$ ) com $70 \mathrm{~mL}$ de solução de hidróxido de sódio e carbonato de sódio (com pH 12,5) e mantidas no reator durante 30, 45 e 60 minutos com descarga direta de plasma sobre a mistura reacional. No reator foi usado um fluxo de 4,5 $\mathrm{L} \mathrm{min}^{-1}$ de ar atmosférico como gás plasmogênico. A geometria do reator de vidro borosilicato foi do tipo ponta-plano em relação aos eletrodos metálicos. O sistema elétrico usado foi composto de uma fonte de corrente alternada de alta tensão ( $\pm 17 \mathrm{kv})$ e corrente $30 \mathrm{~mA}$ foi empregada para gerar o plasma (Figura 1). A fonte de alta tensão foi ligada a um transformador Variac ATP-215-MP (220-240V; $60 \mathrm{~Hz}$; 6,3 A; 1-1,5 kVA), usado para controlar a tensão elétrica entregue ao reator. O primeiro teste para verificar se houve a deslignificação consistiu em analisar microscopicamente a amostra submetida à reação histoquímica de complexação, utilizando o corante floroglucina (solução saturada em 10\% de $\mathrm{HCl}$ ). Este corante se complexa com a molécula de lignina formando uma coloração rosa.

\section{RESULTADOS E DISCUSSÃO}

$\mathrm{Na}$ Tabela 1 encontram-se os valores da caracterização físico-química do bagaço in natura triturado em partículas médias de 0,302 $\mathrm{mm}$ e os desvios médios de cada parâmetro. As amostras apresentaram perda de massa após a aplicação do plasma não térmico. A perda de massa foi maior com o aumento do tempo de aplicação (Figura 1). O plasma gera um gás ionizado onde os elétrons colidem com as moléculas, criando espécies quimicamente ativas, o efeito químico primário do plasma gerado por descargas elétricas na fase líquida ou na interface gás-liquido produz radicais hidroxila e íon hidrogênio a partir da dissociação e/ou ionização de moléculas de água pelos elétrons com a formação de espécies oxidantes: radicais $(\mathrm{H} \cdot, \mathrm{O} \cdot, \mathrm{OH} \cdot)$ e moléculas $\left(\mathrm{H}_{2} \mathrm{O} 2, \mathrm{O}_{3}\right.$, etc.). Essas espécies oxidantes podem oxidar a lignina em compostos menores.

A partir da reação histoquímica com o corante floroglucinol se verificou uma coloração rosa intensa provocada pela complexação com a lignina na amostra in natura, nas amostras submetidas ao plasma se verificou uma redução na coloração rosa.

Na Figura 1 se observa um aumento da celulose com 30 minutos de aplicação de plasma em relação a amostra in natura e com a aplicação do plasma com 45 e 60 minutos ocorre a redução nos teores de celulose. Isso pode estar associado à despolimerização das glicanas, xilanas, mananas e arabianas, que compõem a celulose e hemicelulose, constituindo um valor de aproximadamente 75\% em massa da amostra, formando cadeias menores (monossacarídeos), de modo que, quando foi feito a análise de celulose esses monossacarídeos foram destruídos pela ação da base usada no teste e assim a concentração foi menor.

\section{CONCLUSÃO}

Utilizando a tecnologia do plasma não térmico foi possível diminuir a quantidade de lignina ligada à celulose através dos processos de oxidação possibilitando também à despolimerização das glicanas, xilanas, mananas e arabianas com a formação de cadeias carbônicas de menor peso molecular, o que irá facilitar a ação das enzimas no processo de sacarificação e posteriormente o processo de fermentação.

\section{AGRADECIMENTOS}

Os autores agradecem pela concessão de bolsa do Programa Institucional de bolsas de iniciação Científica (PIBIC) do CNPQ e do Programa Unisul de Iniciação Científica Unisul.

\section{REFERÊNCIAS}

ALVIRA, P.; TOMÁS-PEJÓ, E.; BALLESTEROS, M.; NEGRO, M.J. Pretreatment technologies for an efficient bioethanol production process based on enzymatic hydrolysis: a review. Bioresource Technology, v. 101, p. 4851-4861, 2010.

DEBACHER, N.A., FOUODJOUO, M., LAMINSI, S., KAMGANG, G.Y., MENGUE, M.T. Non-thermal plasma induced total mineralization of glyphosate in water in the presence of iron ii ions. J. Braz. Chem. Soc., v. 26, n. 3, p. 411- 419, 2015.

OJEDA, K. et al. Evaluation of technological alternatives for process integration of sugarcane bagasse for sustainable biofuels production - part 1. Chemical Engineering Research and Design, v. 89, p. 270-279, 2011. 
PEREIRA JR., N.; COUTO, M.A.P.G.; SANTA ANNA, L.M.M. Biomass of lignocellulosic composition for fuel ethanol production and the context of biorefinery. Series on Biotechnology, Ed. Amiga digital UFRJ, Rio de Janeiro, 2008. v.2, 45 p.

RAGAZZI, M.; TOSI, P.; RADA, E.C.; TORRETTA, V.; SCHIAVON, M. Effluents from mbt plants: plasma techniques for the treatment of vocs. Waste Manage, v. 34 n. 11, p. 2400-2406, 2014

SLUITER, A.; HAMES, B., RUIZ, R.; SCARLATA, C.; SLUITER, J., TEMPLETON, D. Determination of total solids in biomass. National renewable energy laboratory (NREL), 1-6, 2005a.

SLUITER, A.; HAMES, B., RUIZ, R.; SCARLATA, C.; SLUITER, J., TEMPLETON, D. Determination of ash in biomass. National renewable energy laboratory (NREL), 1-8, 2005 b.

SLUITER, A.; HAMES, B., RUIZ, R.; SCARLATA, C.; SLUITER, J., TEMPLETON, D. Determination of extractives in biomass. National renewable energy laboratory (NREL), 1-12, 2005c.

TAPPI - Technical Association of the Pulp and Paper Industry. Tappi test methods T 204 OM-88: Solvent extractives of wood and pulp. Atlanta: Tappi Technology Park, 1996.

Tabela 1. Composição físico-química bagaço in natura triturado.

\begin{tabular}{|c|c|c|c|c|c|c|c|}
\hline Amostra & $\begin{array}{c}\text { Umidade } \\
(\%)\end{array}$ & $\begin{array}{c}\text { Extrativos } \\
(\%)\end{array}$ & $\begin{array}{c}\text { Cinzas } \\
(\%)\end{array}$ & $\begin{array}{c}\text { Lignina } \\
\text { Total* (\%) }\end{array}$ & $\begin{array}{c}\text { Celulose } \\
(\%)\end{array}$ & $\begin{array}{c}\text { Hemielulose } \\
(\%)\end{array}$ & $\begin{array}{c}\text { B-celulose } \\
(\%)\end{array}$ \\
\hline Bagaço in Natura & $3.10 \pm 0.18$ & $4.46 \pm 0.05$ & $2.52 \pm 1.51$ & $28.64 \pm 0.96$ & $49.41 \pm 0.87$ & $7.05 \pm 1.87$ & $0.79 \pm 0.28$ \\
\hline
\end{tabular}

*Lignina Total $=$ lignina solúvel $(10.01 \% \pm 1.49)+$ Lignina Insolúvel $(18.63 \% \pm 0.43)$

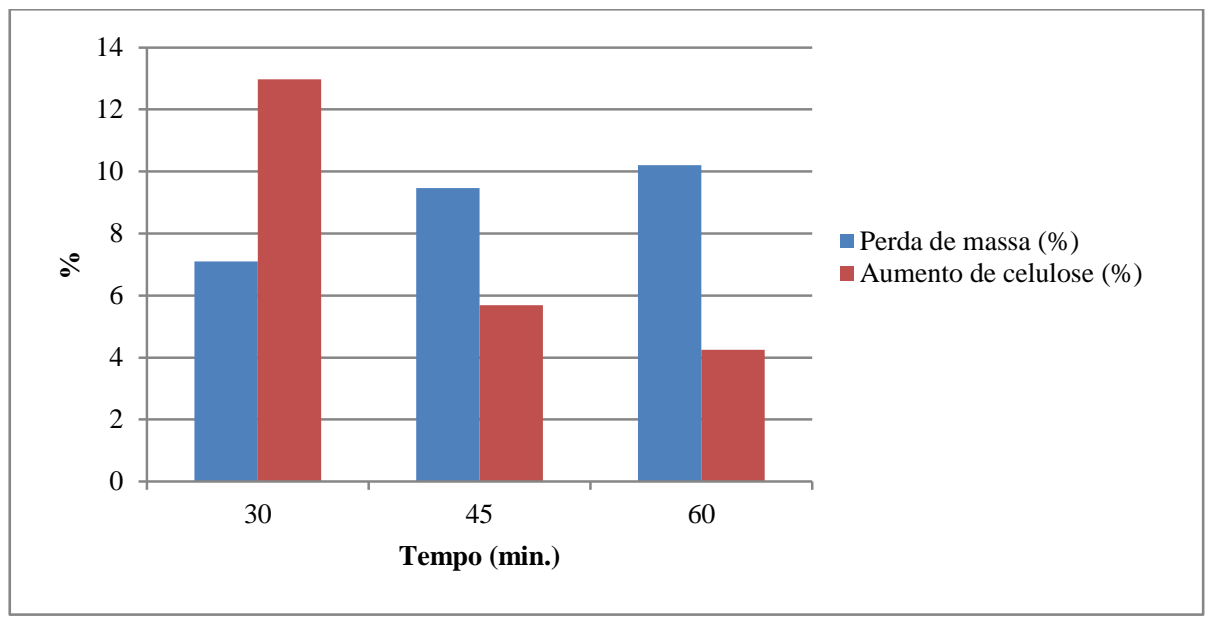

Figura 1. Perda de massa e ganho de celulose. 


\title{
ADIÇÃO FRACIONADA DE HIDROLISADO DE BAGAÇO DE MANDIOCA NA DIGESTÃO ANAERÓBIA DA MANIPUEIRA
}

\author{
Da Silva, A.F.M. ${ }^{\text {; }}$ Bautitz, I.R. ${ }^{1 *}$; Aguiar, E.G.P. ${ }^{2}$; Hermes, E. ${ }^{1}$; Zenatti, D.C. ${ }^{3}$ \\ ${ }^{1}$ Docente do Programa de Pós-graduação em Tecnologia de Bioprodutos Agroindustriais - UFPR, Palotina, PR - Brasil \\ i.rossi@hotmail.com.br \\ ${ }^{2}$ Graduando do Curso de Engenharia de Bioprocessos e Biotecnologia-UFPR, Palotina, PR - Brasil \\ ${ }^{3}$ Docente do Departamento de Engenharias e Exatas -UFPR, Palotina, PR - Brasil
}

\begin{abstract}
RESUMO: Graças as suas propriedades e importância econômica, o bagaço apresenta grande relevância nas tecnologias renováveis, sendo assim, um desperdício de matéria-prima quando descartado. Uma forma de agregar valor a esse resíduo é a utilização do bagaço em digestores anaeróbios, porém as grandes moléculas dificultam a degradação pelos microrganismos, sendo necessário a pré-hidrólise, em que as moléculas complexas são convertidas em simples compostos, viabilizando a digestão anaeróbia. Este trabalho tem como objetivo quantificar o volume de metano produzido a partir da adição de diferentes frações de hidrolisado do bagaço da mandioca na digestão anaeróbia da manipueira. Foram montados quatro reatores em vidro com volume útil de $1000 \mathrm{~mL}$, em cada reator foram adicionadas frações de inóculo, hidrolisado e manipueira, sendo $\mathrm{T}_{1}(10 \%, 0 \%, 90 \%) ; \mathrm{T}_{2}(10 \%, 30 \%, 60 \%) ; \mathrm{T}_{3}(10 \%, 23 \%, 67 \%)$ e $\mathrm{T}_{4}(10 \%, 45 \%, 45 \%)$. Os reatores foram mantidos em estufa com temperatura controlada de $35^{\circ} \mathrm{C}$ com TDH de 13 dias. Foram quantificadas as concentrações de ST (sólidos totais), SV (sólidos voláteis), DQO (demanda química de oxigênio) e AR (açúcares redutores) antes e depois da digestão anaeróbia. Durante o período do experimento quantificou-se a produção de $\mathrm{CH}_{4}$ (metano). Os resultados indicaram que o $\mathrm{T}_{3}$ apresentou melhor produção específica de $\mathrm{CH}_{4}$ com $89,15 \mathrm{~mL} \mathrm{CH}_{4} \mathrm{~g}^{-1} \mathrm{SV}$ removido e $3,46 \mathrm{~mL} \mathrm{CH}_{4} \mathrm{mg}^{-1}$ AR removido.
\end{abstract}

Palavras-chave: açúcar redutor, digestão anaeróbia, resíduo agroindustrial.

\section{FRACTIONAL ADDITION OF HYDROLYZED OF BAGASSE OF CASSAVA IN THE ANAEROBIC DIGESTION GIVES MANIPUEIRA}

\begin{abstract}
Thanks their properties and economical importance, the bagasse presents great relevance in the renewable technologies, being like this, a raw material waste when discarded. A form of joining value to that waste is with the use of the bagasse in anaerobic digesters, however the great molecules hinder the degradation for the microorganisms, being necessary the pré-hydrolyse, in that the complex molecules are converted in composed simple, enabling the anaerobic digestion. This work has as objective quantifies the volume of methane produced starting from the addition of different fractions of hidrolisado of the bagasse of the cassava in the anaerobic digestion of the manipueira. They were mounted four reactors in glass with usable volume of $1000 \mathrm{~mL}$, in each reactor inóculo fractions, hydrolyzed and manipueira were added, being $\mathrm{T}_{1}(10 \%, 0 \%, 90 \%)$; $\mathrm{T}_{2}(10 \%, 30 \%, 60 \%) ; \mathrm{T}_{3}(10 \%, 23 \%, 67 \%)$ and $\mathrm{T}_{4}(10 \%, 45 \%, 45 \%)$. The reactors were maintained in controlled temperature of $35^{\circ} \mathrm{C}$ with TDH of 13 days. The concentrations of TS (total solids) were quantified, VS (volatile solids), COD (chemical oxygen demand) and RS (reducing sugars) before and after the anaerobic digestion. During the period of the experiment the production of $\mathrm{CH}_{4}$ (methane) was quantified. The results indicated that $\mathrm{T}_{3}$ presented better specific production of $\mathrm{CH}_{4}$ with $89,15 \mathrm{~mL} \mathrm{CH}_{4} \mathrm{~g}^{-1}$ removed $\mathrm{VS}$ and 3,46 mL $\mathrm{CH}_{4} \mathrm{mg}^{-1}$ removed RS.
\end{abstract}

Keywords: reducing sugars, anaerobic digestion, agroindustrial waste.

\section{INTRODUÇÃO}

De modo geral, o processamento agroindustrial tem gerado resíduos que podem causar grandes impactos ambientais. Em vista a esse fato, as indústrias responsáveis por esses resíduos procuram torná-los subprodutos, agregando valor e reduzindo o impacto ambiental. Além disso, após a crise do petróleo, viu-se a necessidade 
de revisar o modelo energético industrial, que juntamente com as ameaças ambientais constituem as principais problemáticas dos últimos anos (JASKO et al., 2011; CAMACHO E CABELLO, 2012)

A biomassa é considerada uma das principais alternativas para a diversificação da matriz energética, tendo um grande potencial para a produção de energia e destacando-se entre as principais fontes energéticas. Desse modo, a utilização da biomassa confronta diretamente a dependência dos combustíveis fósseis (NETO et al., 2010).

No processamento da mandioca, Manihot esculenta Crantz, são gerados uma série de resíduos, os quais podem ser extremamente prejudiciais ao ambiente. O bagaço de mandioca é um resíduo do processo de fabricação do polvilho, que contém uma notória taxa de amido (65\% a 75\%), além de possuir fibras de boa qualidade e ser abundante em materiais lignocelulósicos. No Brasil, o balanço de bagaço produzido nas fecularias é de 928,6kg por tonelada de raiz de mandioca processada, tendo um grande percentual de umidade (cerca de 85\%) (LIMA, 2006; EMBRAPA RONDÔNIA, 2005; JASKO et al., 2011).

Uma alternativa para valorizar este resíduo é utilzá-lo no processo de biodigestão anaeróbia, uma vez que algumas indústrias processadoras de mandioca já adotam os biodigestores em suas plantas de tratamento de efluentes. Entretanto, o teor de fibras contido no bagaço torna o processo lento, havendo a necessidade de um pré-tratamento como a hidrólise hidrotérmica ácida, que converte as fibras (celulose, hemicelulose e lignina) em compostos mais simples e prontamente disponíveis para os microorganismos.

\section{Coleta do resíduo}

\section{MATERIAL E MÉTODOS}

$\mathrm{O}$ bagaço de mandioca utilizado para realização do experimento foi coletado em uma amidonaria localizada na cidade de Terra Roxa - PR, na PR 364, km 2,9 na latitude $-24^{\circ} 11^{\prime} 52.95^{\prime \prime}$ e longitude $53^{\circ} 59^{\prime} 13.59^{\prime \prime}$. Esta amidonaria processa e modifica o amido para que o mesmo seja usado como suplemento na indústria de papel e celulose.

A coleta do resíduo foi realizada durante o horário de processamento da matéria-prima, em horário de funcionamento dos equipamentos, para que não houvesse alteração na rotina de produção da indústria. A amostragem foi feita durante um dia, em intervalos de hora em hora, a fim de se obter uma amostra homogênea e composta dos resíduos numa quantidade substancial para ser utilizada durante todo o experimento. O bagaço foi coletado após o processo de extração e peneiração, em que sua composição é altamente fibrosa.

Após a coleta, o resíduo foi conduzido ao Laboratório de Química Analítica e Análises Ambientais da Universidade Federal do Paraná, setor Palotina, onde foi subdividido em porções de aproximadamente $2 \mathrm{Kg}$ (bagaço), em potes de polietileno e armazenado no congelador a temperatura de $-18^{\circ} \mathrm{C}$ até o momento da realização do experimento.

\section{Pré-tratamento do bagaço}

Secou-se o bagaço na estufa com circulação forçada de ar por 72 horas, em uma temperatura de $600 \mathrm{o}$. Logo após o bagaço foi triturado em moinho de facas tipo Willye modelo STAR FT 49.

Foram realizadas análises para caracterização do bagaço, da manipueira e do inóculo, quantificando os teores de açúcares redutores, $\mathrm{pH}$, nitrogênio total e amoniacal, demanda química de oxigênio, sólidos totais e voláteis.

Para a hidrólise ácida do bagaço adicionou-se em frascos de PE (polietileno) bagaço de mandioca e solução 0,1 $\mathrm{mol} \mathrm{L}^{-1}$ de ácido sulfúrico, em razão de 5:50 (m/v), com as tampas em meia rosca foram levados para a autoclave sobre temperatura constate de $121^{\circ} \mathrm{C}$ por 40 minutos, após este período filtrou-se o material obtendo-se duas fases, o resíduo sólido do bagaço e o líquido (hidrolisado).

\section{Co-digestão anaeróbia}

Foram montados quatro reatores em vidro de borosilicato com volume útil de $1 \mathrm{~L}$ foram montados, onde foram incubadas frações de manipueira/hidrolisado em inóculo, de acordo com a Tabela 1.

Os reatores foram mantidos em anaerobiose à $35^{\circ} \mathrm{C}$ com TDH (Tempo de Detenção Hidráulica) de 13 dias. $\mathrm{O}$ volume de biogás gerado foi medido pela técnica de deslocamento de líquido. 


\section{RESULTADOS E DISCUSSÃO}

A caracterização do inóculo, bem como do hidrolisado de bagaço e da manipueira podem ser observados na Tabela 2. A eficiência dos reatores pode ser vista na Tabela 3, onde observou-se uma remoção de 82,9 \% dos $\mathrm{AR}$ no $\mathrm{T}_{4}$, entretanto, comparado ao $\mathrm{T}_{2}$ nota-se uma redução no aproveitamento dos açúcares para produção de metano. Por fim, o $T_{2}$, mesmo apresentando a menor eficiência de remoção de açúcares, destacou-se em produção de metano.

$\mathrm{O} \mathrm{T}_{2}$ apresentou maior volume de metano tanto por sólidos voláteis removidos quanto por açúcar redutor, seguido pelo $T_{3}$, para o $T_{1}$ não se obteve produção de metano, estes valores podem ser observados nas Tabelas 3 e 4.

Encontrou-se uma variação na produção de metano nos 13 dias, conforme da porcentagem de hidrolisado e manipueira. Esse trabalho contatou que a melhor porporção na geração de biogás foi de 10\% de inóculo, 23\% de hidrolisado e 67\% de manipueira, finalizando com $337 \mathrm{ml}$ de metano.

Segundo Paul e Dutta (2017), a biomassa lignocelulósica é uma matéria-prima de alta potência para produzir metano, entretanto sua complexidade estrutural e valor de relação $\mathrm{C} / \mathrm{N}$ inibi seu potencial quando usada na monodigestão. A co-digestão anaeróbica de biomassa lignocelulósica com outra biomassa rica em nitrogênio, tem elevada tendência a mantar a relação $\mathrm{C} / \mathrm{N}$ ótima e assim aumentar a produção do biogás.

\section{CONCLUSÃO}

A partir do experimento realizado pode-se observar que a adição de hidrolisado do bagaço da mandioca na digestão da manipueira influencia positivamente na produção de metano, podendo ser uma alternativa para destinação do resíduo sólido gerado na agroindústria processadora de mandioca, agregando valor ao resíduo e colaborando com o meio ambiente pela geração de uma energia renovável.

\section{REFERÊNCIAS}

JASKO, A. C.; DE ANDRADE, J.; DE CAMPOS, P. F.; PADILHA, L.; DE PAULI, R. B.; QUAST L. B.; SCHNITZER E.; DEMIATE I. M. Caracterização físico-química de bagaço de mandioca in natura e após tratamento hidrolítico. Revista Brasileira de Tecnologia Agroindustrial. V. 05, P. 427- 441, 2011.

CAMACHO, I. CABELLO, C. Caracterização dos resíduos do processamento de mandioca para produção de bio-etanol. Revista Energia na Agricultura., Botucatu. V. 27, N. 1, P. 82-88, 2012.

NETO, E.D.D. ALVARENGA, L.H. et al. Implementação e avaliação de um biodigestor de produção descontínua. Revista Eletrônica E-Xacta, V.3, N.2. 2010.

LIMA, L. P. Bagaço de mandioca (manihote suculenta crantz) na dieta de vacas leiteiras. 2006. $46 \mathrm{~F}$. Dissertação (Mestrado Em Concentração Em Produção De Ruminantes) - Zootecnia. Universidade Estadual Do Sudoeste Da Bahia, Itapetinga. 2006.

EMBRAPA Empresa Brasileira De Pesquisa Agropecuária Centro De Pesquisa Agroflorestal De Rondônia. Disponível Em: <Http://Ainfo.Cnptia.Embrapa.Br/Digital/Bitstream/Item/24804/1/Folder-Mandioca.Pdf>. Acesso Em: Janeiro/2018.

PAUL, S.; DUTTA, A. Challenges And Opportunities Of Lignocellulosic Biomass For Anaerobic Digestion. Cience Of The Total Environment, V. 645, P. 164-174, 2017.

Tabela 1. Frações de inóculo, hidrolisado e manipueira em cada ensaio.

\begin{tabular}{cccc}
\hline Ensaio & Inóculo & Hidrolisado & Manipueira \\
\hline 1 & $10 \%$ & - & $90 \%$ \\
2 & $10 \%$ & $30 \%$ & $60 \%$ \\
3 & $10 \%$ & $23 \%$ & $67 \%$ \\
4 & $10 \%$ & $45 \%$ & $45 \%$ \\
\hline
\end{tabular}


Tabela 2. Caracterização do inóculo, hidrolisado e manipueira.

\begin{tabular}{cccc}
\hline Parâmetro & Inóculo & Hidrolisado & Manipueira \\
\hline $\mathrm{pH}$ & 7,7 & 7,75 & 3,53 \\
$\mathrm{AR}\left(\mathrm{mg} \mathrm{L}^{-1}\right)$ & 151,2 & 186,6 & 177,75 \\
$\mathrm{~N}-\mathrm{NH}_{3}\left(\mathrm{mg} \mathrm{de} \mathrm{N} \mathrm{L}^{-1}\right)$ & 470,81 & 8,99 & 17,99 \\
$\mathrm{NTK}\left(\mathrm{mg} \mathrm{de} \mathrm{N} \mathrm{L}^{-1}\right)$ & 1255,1 & 46,2 & 138,6 \\
$\mathrm{DQO}\left(\mathrm{mg} \mathrm{de} \mathrm{O}_{2} \mathrm{~L}^{-1}\right)$ & 434,14 & 2836,58 & 16621,95 \\
$\mathrm{ST}\left(\mathrm{g} \mathrm{L}^{-1}\right)$ & 0,295 & 2,85 & 0,523 \\
$\mathrm{SV}\left(\mathrm{g} \mathrm{L}^{-1}\right)$ & 0,132 & 61,559 & 0,309 \\
\hline
\end{tabular}

Tabela 3. Eficiências dos reatores.

\begin{tabular}{cccccc}
\hline & \multicolumn{2}{c}{ Eficiência de remoção } & \multicolumn{2}{c}{ Produção } \\
\hline Tratamento & NT (\%) & ST(\%) & SV(\%) & AR(\%) & CH4 $_{\mathbf{4}}(\mathbf{m l})$ \\
\hline 1 & 0 & 3,6 & 1,6 & 54,5 & 0 \\
2 & 64,5 & 6,3 & 2,8 & 54,0 & 337 \\
3 & 53,6 & 5,7 & 2,2 & 65,0 & 180 \\
4 & 39,5 & 12,9 & 4,5 & 82,9 & 271 \\
\hline
\end{tabular}

Tabela 4. Produção de metano por substrato removido.

\begin{tabular}{ccc}
\hline Tratamento & $\begin{array}{c}\mathrm{V} \mathrm{CH}_{\mathbf{4}} \mathbf{g}^{-\mathbf{1}} \mathbf{S V} \\
\text { removido }(\mathbf{m L})\end{array}$ & $\begin{array}{c}\mathbf{V ~ C H}_{\mathbf{4}} \mathbf{m g}^{-\mathbf{1}} \mathbf{A R} \\
\text { removido }(\mathbf{m L})\end{array}$ \\
\hline 1 & 0 & 0 \\
2 & 89,15 & 3,46 \\
3 & 56,78 & 1,5 \\
4 & 10,44 & 1,45 \\
\hline
\end{tabular}




\title{
ANÁLISE DA TOLERÂNCIA DE UMA NOVA LINHAGEM DE CANDIDA PSEUDOINTERMEDIA A INIBIDORES DE FERMENTAÇÃO PRESENTES EM HIDROLISADOS LIGNOCELULÓSICOOS
}

\author{
Giehl, A. ${ }^{1}$; Deoti, L. ${ }^{1}$; Lucaroni, A.C. ${ }^{1}$; Baptista, C.W. ${ }^{\text {; }}$;reichel, H. ${ }^{2}$; Alves, S.L.Jr. ${ }^{1}$ \\ ${ }^{1}$ Laboratório de Bioquímica e Genética, Campus Chapecó, Universidade Federal da Fronteira Sul, Chapecó/SC, Brasil \\ ${ }^{2}$ Laboratório de Microbiologia e Bioprocessos, Campus Erechim, Universidade Federal da Fronteira Sul, Erechim/RS, Brasil \\ *cristina.winkelmann@gmail.com
}

\begin{abstract}
RESUMO: Durante as etapas de pré-tratamento e hidrólise de resíduos agroindustriais para a produção de etanol 2G, são gerados inibidores de fermentação. Nesse sentido, é desejável que as leveduras empregadas no processo apresentem elevada tolerância a compostos como ácido acético e ácido fórmico. A levedura Saccharomyces cerevisiae é a espécie mais utilizada em fermentações alcoólicas, e as cepas industriais empregadas na atual produção de etanol brasileira pertencem todas a essa espécie. Essas linhagens são majoritariamente tolerantes a esses inibidores, contudo são incapazes de fermentar a xilose, o segundo monossacarídeo mais abundante (depois da glicose) nos hidrolisados lignocelulósicos. Assim, torna-se necessário encontrar leveduras capazes de metabolizar a referida pentose diante de diferentes inibidores de fermentação. Neste cenário, isolamos, de matéria vegetal em decomposição, uma nova linhagem da espécie Candida pseudointermedia e a submetemos a meios sintéticos contendo alternadamente glicose ou xilose como fontes de carbono e concentrações crescentes de ácido acético e ácido fórmico. As células dessa levedura foram capazes de tolerar até $0,18 \%$ de ácido acético e $0,03 \%$ de ácido fórmico. O crescimento celular em glicose foi sempre acompanhado de produção de etanol, com eficiência fermentativa variando entre $49 \%$ e $82 \%$. Diante da xilose, entretanto, não houve produção de etanol em meios com ácido acético, e, nos meios com ácido fórmico, o rendimento de etanol a partir da xilose não excedeu $0,09 \mathrm{~g} \mathrm{~g}^{-1}$. Portanto, embora tenha demonstrado baixo rendimento fermentativo a partir da pentose, a cepa analisada apresentou satisfatória tolerância aos inibidores avaliados e elevada capacidade fermentativa frente a glicose.
\end{abstract}

Palavras-chave: ácido acético, ácido fórmico, etanol, levedura, xilose.

\section{TOLERANCE OF A NEW CANDIDA PSEUDOINTERMEDIA STRAIN TO FERMENTATION INHIBITORS FOUND IN LIGNOCELLULOSIC HYDROLYSATES}

\begin{abstract}
Fermentation inhibitors are generated during the pretreatment and hydrolysis steps of agroindustrial residues in the production of $2 \mathrm{G}$ ethanol. In this regard, it is desirable that the yeasts employed in the process exhibit high tolerance to compounds such as acetic acid and formic acid. The yeast Saccharomyces cerevisiae is the most used species in alcoholic fermentations, and the industrial strains applied at the current production of Brazilian ethanol belong to this species. These strains are mostly tolerant to these inhibitors, but are unable to ferment xylose, the second-most abundant monosaccharide (after glucose) in lignocellulosic hydrolysates. Thus, it is necessary to find yeasts capable of metabolizing such pentose in the presence of different fermentation inhibitors. In this scenario, we isolated a new Candida pseudointermedia strain from decaying wood and subjected it to synthetic media alternately containing glucose or xylose as carbon sources and increasing concentrations of acetic acid and formic acid. This yeast cells were able to tolerate up to $0.18 \%$ acetic acid and $0.03 \%$ formic acid. Cell growth in glucose was always followed by ethanol production, with fermentative efficiency ranging from $49 \%$ to $82 \%$. However, when the cells were metabolizing xylose there was no ethanol production in the media with acetic acid, and, in the media with formic acid, the yield of ethanol did not exceed $0.09 \mathrm{~g} \mathrm{~g}^{-1}$. Therefore, although it showed low fermentative yield from xylose, the analyzed strain presented satisfactory tolerance to the evaluated inhibitors and high fermentative capacity with glucose.
\end{abstract}

Keywords: acetic acid, ethanol, formic acid, xylose, yeast. 


\section{INTRODUÇÃO}

O etanol de segunda geração pode ser produzido a partir de diferentes resíduos lignocelulósicos agroindustriais. Quase que invariavelmente, entretanto, independentemente da matéria-prima utilizada, durante as etapas de pré-tratamento e hidrólise da biomassa, como ácido acético e furfural, são gerados compostos que podem inibir o metabolismo fermentativo das leveduras empregadas no processo (STRITRAKUL et al., 2017). Nesse sentido, a eficiência da transformação de carboidratos em etanol depende de linhagens capazes de tolerar esses inibidores e de fermentar os carboidratos presentes nos hidrolisados lignocelulósicos.

Atualmente, a espécie Saccharomyces cerevisiae é a principal levedura utilizada em processos de fermentação alcoólica. Contudo, embora normalmente pouco sensível a esses inibidores, cepas industriais de S. cerevisiae não podem fermentar a xilose, o segundo monossacarídeo mais abundante nos hidrolisados de resíduos lignocelulósicos agroindustriais (STAMBUK et al., 2008). Dessa forma, o presente trabalho analisou o perfil de tolerância de uma nova cepa selvagem de Candida pseudointermedia (isolada de matéria vegetal em decomposição) a ácido acético e ácido fórmico, em meios sintéticos contendo alternadamente glicose e xilose como fontes de carbono.

\section{Isolamento e identificação das leveduras}

A cepa UFFS-CE-3.6 de Candida pseudointermedia foi isolada, conforme descrito por Bazoti et al. (2017), a partir de amostras de matéria vegetal em decomposição (restos de troncos e galhos), obtidas da serapilheira, em áreas sob o domínio da Mata Atlântica, nas matas do Campus Chapecó da Universidade Federal da Fronteira Sul. As amostras foram coletadas em tubos Falcon de $50 \mathrm{~mL}$ estéreis. Aproximadamente $1 \mathrm{~g}$ foi inoculado em $20 \mathrm{~mL}$ de meio sintético mínimo contendo $0,67 \%$ de base nitrogenada, $0,02 \%$ de cloranfenicol e $1 \%$ de celobiose. Foram preparados quatro frascos erlernmeyers e incubados a $25^{\circ} \mathrm{C}$ por $3-10$ dias, sob agitação periódica de $145 \mathrm{rpm}$. Quando se detectou crescimento celular por turbidez, uma alçada de células foi estriada por esgotamento em placas de Petri contendo os mesmos meios supracitados, além da adição de $2 \%$ de ágar. As placas foram incubadas a uma temperatura de $28^{\circ} \mathrm{C}$, e as leveduras foram isoladas pela morfologia da colônia. As cepas foram nomeadas conforme código pré-estabelecido pela coleção do grupo de pesquisa.

A identificação da levedura foi realizada através do sequenciamento da região ITS-5.8S e do domínio D1/D2 da subunidade maior do rRNA, com subsequente comparação das sequências obtidas com aquelas disponíveis no banco de dados GenBank por meio da ferramenta BLAST (em http://www.ncbi.nlm.nih.gov).

\section{Crescimento celular, consumo de açúcares e produção de etanol}

Após pré-cultivo de $48 \mathrm{~h}$ a $25^{\circ} \mathrm{C}$ e $145 \mathrm{rpm}$, em meio YPD (1\% de extrato de levedura, $2 \%$ de peptona e $2 \%$ de glicose), as células foram inoculadas (1/100 do volume final) em meios sintéticos mínimos YNB ( $0,67 \%$ de base nitrogenada de levedura e $2 \%$ de glicose ou xilose como fonte de carbono), $\mathrm{pH} 5,0$, com concentrações crescentes de inibidores: $0 \%, 0,06 \%, 0,18 \%$ e $0,36 \%$ de ácido acético e $0 \%, 0,01 \%, 0,03 \%$ e $0,06 \%$ de ácido fórmico, conforme indicado nas figuras 1 e 2 .

O crescimento celular foi determinado por espectrofotometria $\left(\mathrm{DO}_{570 \mathrm{~nm}}\right)$ a partir de amostras retiradas nos tempos indicados nas figuras 1 e 2 .

Para a determinação do consumo de açúcares e da produção de etanol, amostras foram retiradas dos meios de cultura (nos tempos indicados nas figuras $1 \mathrm{e} \mathrm{2}$ ), centrifugadas (5.000 $\mathrm{g}, 3 \mathrm{~min}$ ) e seus sobrenadantes foram filtrados (com filtros contendo poros de $0,45 \mu \mathrm{m}$ ) para subsequente análise em HPLC (fase móvel $5 \mathrm{mM}$

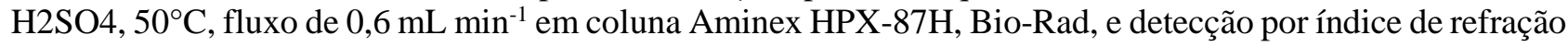
RID-10, Shimadzu).

O rendimento de etanol $\left(Y_{\mathrm{e} / \mathrm{s}}\right)$ foi obtido pelo quociente entre a quantidade máxima de etanol produzida e o total de substrato (açúcar) consumido. A partir do $Y_{\mathrm{e} / \mathrm{s}}$ foi calculada a eficiência fermentativa, como percentual do rendimento máximo teórico de etanol $(0,511)$. 


\section{RESULTADOS E DISCUSSÃO}

No intuito de analisar o grau de tolerância de Candida pseudointermedia a diferentes concentrações de inibidores de fermentação e de avaliar o metabolismo celular diante da xilose, uma nova linhagem dessa espécie (UFFS-CE-3.6) foi submetida a meios contendo glicose ou xilose e concentrações crescentes de ácido acético ou ácido fórmico.

As células da UFFS-CE-3.6 conseguiram metabolizar ambos os carboidratos testados até $0,18 \%(1,8 \mathrm{~g}$ $\mathrm{L}^{-1}$ ) de ácido acético (Figura 1). Nessa concentração do inibidor, as leveduras tiveram apenas um atraso de $\sim 5$ h para o início do consumo da glicose disponível e uma redução de apenas $14 \%$ na produção de etanol, em comparação com o controle ( $0 \%$ de ácido acético). O consumo de xilose também foi pouco afetado até $0,18 \%$ de ácido acético, contudo o metabolismo dessa pentose foi estritamente respiratório, não havendo, portanto, produção de etanol (Figura 1). Embora não tenha fermentado a xilose, cabe destacar que a concentração de ácido acético tolerada por essas leveduras se assemelha à encontrada nos hidrolisados lignocelulósicos diluídos, a partir dos quais se obtém melhor rendimento fermentativo (BAZOTI et al., 2017). Além disso, é possível também que, em meios com valores de $\mathrm{pH}$ mais próximos da neutralidade, o desempenho da levedura possa vir a ser melhor, haja vista que a forma indissociada do ácido acético é a responsável pela sua toxicidade (CASEY et al., 2010).

Frente ao ácido fórmico, a UFFS-CE-3.6 tolerou até a concentração de 0,03\% (Figura 2). Da mesma forma como foi verificado frente ao ácido acético, o rendimento fermentativo a partir da glicose não foi completamente prejudicado pela presença do inibidor: $0,42 \mathrm{~g} \mathrm{~g}^{-1}$ no controle ( $0 \%$ de ácido fórmico) e $0,25 \mathrm{~g}$ $\mathrm{g}^{-1}$ com $0,03 \%$ de ácido fórmico, o que representa uma eficiência fermentativa de $82 \%$ e $49 \%$, respectivamente. Contudo, diferentemente do observado nos meios com ácido acético, houve um aumento de $\sim 20 \mathrm{~h}$ e $\sim 30 \mathrm{~h}$ na fase lag enquanto as células metabolizavam a glicose e a xilose, respectivamente, em comparação com o controle. Além disso, mesmo diante de 0,03\% de ácido fórmico, a UFFS-CE-3.6 fermentou xilose com rendimento de $0,09 \mathrm{~g} \mathrm{~g}^{-1}$.

\section{CONCLUSÃO}

A levedura Candida pseudointermedia UFFS-CE-3.6 apresentou satisfatório rendimento fermentativo em glicose mesmo diante de $0,18 \%$ de ácido acético e $0,03 \%$ de ácido fórmico. Assim sendo, embora tenha produzido apenas $\sim 2 \mathrm{~g} \mathrm{~L}^{-1}$ de etanol a partir de $\sim 20 \mathrm{~g} \mathrm{~L}^{-1}$ de xilose, a cepa analisada se mostrou vantajosa às linhagens industriais de $S$. cerevisiae, pois tolerou níveis de concentração de inibidores normalmente encontrados em hidrolisados lignocelulósicos e foi capaz de metabolizar a pentose presente nos meios de cultura.

\section{REFERÊNCIAS}

BAZOTI, S. F.; GOLUNSKI, S.; SIQUEIRA, D. P.; SCAPINI, T.; BARRILLI, E. T.; MAYER, D. A.; BARROS, K. O.; ROSA, C. A.; STAMBUKE, B. U.; ALVES JR, S. L.; VALÉRIO, A.; OLIVEIRA, D.; TREICHEL, H. Second-generation ethanol from non-detoxified sugarcane hydrolysate by a rotting wood isolated yeast strain. Bioresour. Technol. v. 244, p. 582-587, 2017.

CASEY, E.; SEDLAK, M.; HO, N. W. Y.; MOSIER, N. S. Effect ofacetic acid and pH on the cofermentation of glucose and xylose to ethanol by a genetically engineered strain of Saccharomyces cerevisiae, FEMS Yeast Res. v. 10, p. 385-393, 2010.

STAMBUK, B. U.; ELEUTHERIO, E. C. A.; FLOREZ-PARDO, L. M.; SOUTO-MAIOR, A. M.; BON, E. P. S. Brazilian potential for biomass ethanol: Challenge of using hexose and pentose cofermenting yeast strains. J. Sci. Ind. Res. v. 67, p. 918-926, 2008.

SRITRAKUL, N.; NITISINPRASERT, S.; KEAWSOMPONG, S. Evaluation of dilute acid pretreatment for bioethanol fermentation from sugarcane bagasse pith. Agric. Nat. Resour. v. 51, p. 512-519, 2017. 


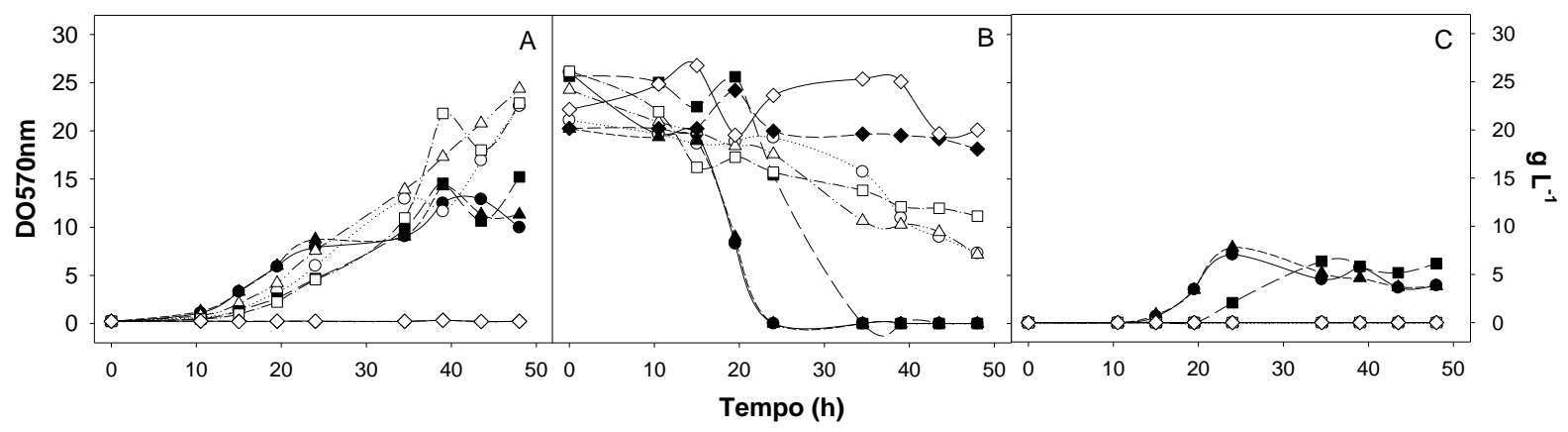

Figura 1. Perfis de crescimento celular (A), consumo de açúcares (B) e produção de etanol (C) da Candida pseudointermedia UFFS-CE-3.6 em meios sintéticos YNB contendo, alternadamente, $2 \%$ de glicose (símbolos abertos) ou 2\% de xilose (símbolos fechados) e 0\% (círculos), 0,06\% (triângulos), 0,18\% (quadrados) ou $0,36 \%$ (losangos) de ácido acético.

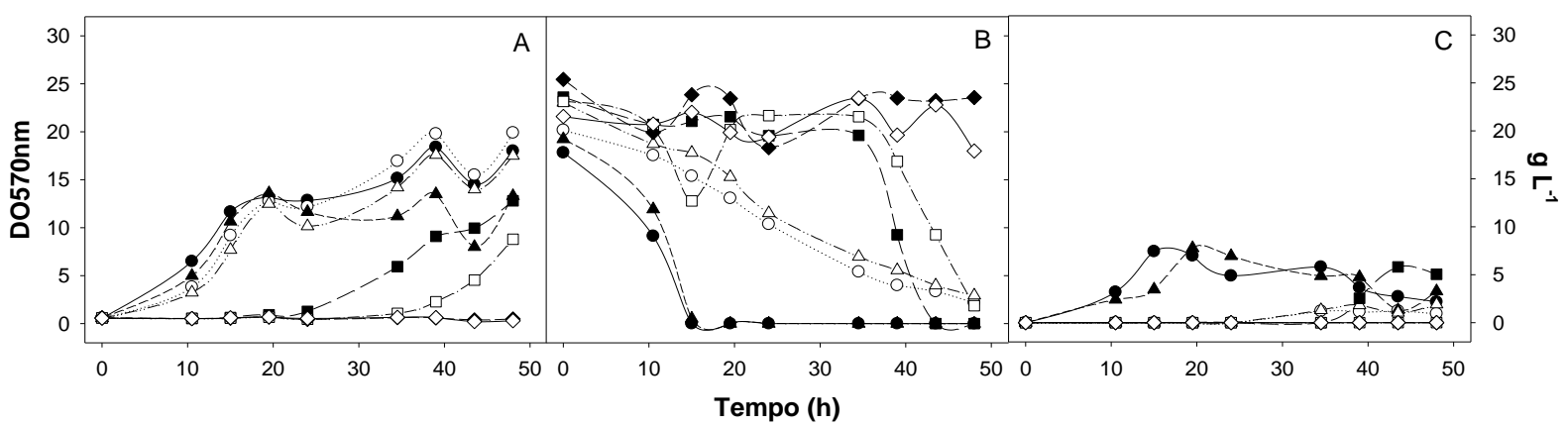

Figura 2. Perfis de crescimento celular (A), consumo de açúcares (B) e produção de etanol (C) da Candida pseudointermedia UFFS-CE-3.6 em meios sintéticos YNB contendo, alternadamente, $2 \%$ de glicose (símbolos abertos) ou 2\% de xilose (símbolos fechados) e 0\% (círculos), 0,01\% (triângulos), 0,03\% (quadrados) ou $0,06 \%$ (losangos) de ácido fórmico. 


\title{
AVALIAÇÃO DA ATIVIDADE METANOGÊNICA ESPECÍFICA DE LODOS ANAERÓBIOS DISTINTOS VISANDO A PRODUÇÃO DE BIOGÁS
}

\author{
Almeida, R.*1'; Marana, K.B.B. ${ }^{1}$; Toneli, J.T.C. ${ }^{1}$ \\ ${ }^{1}$ Pesquisadores da Universidade Federal do ABC, Centro de Engenharia, Modelagem e Ciências Sociais. Santo André, SP - Brasil. \\ *r.almeida@ufabc.edu.br
}

RESUMO: Este estudo apresenta uma análise da atividade metanogênica específica (AME) realizada com dois inóculos distintos: Dacar (lodo do reator anaeróbio da granja Dacar, avicultura localizada em Tietê - SP) e GOP (lodo do reator anaeróbio da granja Ouro Preto, suinucultura localizada em Ibiúna - SP). O produto final obtido, o biogás, além de ser considerado uma fonte alternativa de energia é também uma solução para o tratamento dos resíduos da pecuária e poluição ambiental gerada por esta atividade. Neste estudo foi realizada a análise de sólidos totais e voláteis dos inóculos. Em seguida, de acordo com os padrões fixados (quantidade alimento/inóculo de 0,25 g DQO/SVT, concentração de substrato de 2,5 g DQO/l e concentração de inóculo de $10 \mathrm{~g} \mathrm{SVT/l)}$ obteve-se a quantidade de substrato relativa para cada lodo. Para a reação da atividade metanogênica específica, o equipamento Automatic Methane Potential Test System (AMPTS) II foi utilizado, sendo programado para manter a temperatura à $35^{\circ} \mathrm{C}$ e os frascos sob agitação constante. Os resultados mostraram que em 3 dias houve uma produção acumulada de 28,02 $\pm 9,43$ de $\mathrm{CH}_{4}$ para o inóculo Dacar, não havendo produção após este período. Já para o inóculo GOP foi registrada uma produção acumulada de 887,4 $\pm 50,3$ de $\mathrm{CH}_{4}$ ao longo de 9 dias.

Palavras-chave: lodo anaeróbio, resíduo agroindustrial, metano, biogás.

\section{EVALUATION OF THE SPECIFIC METHANOGENIC ACTIVITY OF DIFFERENT ANAEROBIC SLUDGES AIMING BIOGAS PRODUCTION}

\begin{abstract}
This study presents an analysis of the specific methanogenic activity (SMA) performed with two distinct inocula: Dacar (anaerobic reactor sludge from the Dacar farm, aviculture located in Tietê - SP) and GOP (sludge from the anaerobic reactor at Ouro Preto farm, Ibiúna - SP). The final product obtained, biogas, besides being considered an alternative source of energy is also a solution for the treatment of livestock residues and environmental pollution generated by this activity. In this study the analysis of total and volatile solids of the inocula was carried out. Then, according to the set standards (feed / inocula amount of $0.25 \mathrm{~g}$ COD / SVT, substrate concentration $2.5 \mathrm{~g}$ COD / 1 and inocula concentration of $10 \mathrm{~g} \mathrm{SVT} \mathrm{/} \mathrm{1)} \mathrm{the} \mathrm{amount} \mathrm{of}$ substrate for each sludge. For the reaction of the specific methanogenic activity, the equipment Automatic Methane Potential Test System (AMPTS) II was used, being programmed to maintain the temperature at $35^{\circ} \mathrm{C}$ and the bottles under constant agitation. The results showed that in 3 days there was an accumulated production of $28.02 \pm 9.43 \mathrm{CH}_{4}$ for the Dacar inocula, with no production after this period. For the GOP inocula an accumulated production of $887.4 \pm 50.3 \mathrm{CH}_{4}$ was recorded over the course of 9 days.
\end{abstract}

Keywords: anaerobic sludge, agroindustrial waste, methane, biogas.

\section{INTRODUÇÃO}

O atual cenário energético do país permite o crescimento de tecnologias limpas, como o maior aproveitamento da biomassa (ANEEL, 2002). De acordo com a agência internacional de energia (1998), apud ANEEL (2002) estima-se que para 2020 a matriz energética mundial seja constituída por $11 \%$ de biomassa. Esta é uma das estratégias utilizadas para promover um mercado descentralizado e, ao mesmo tempo, que intensifique a necessidade do uso mais racional da energia (EPE, 2016). Dentre as biomassas, destacam-se os lodos, também conhecidos como inóculos, provenientes do tratamento da agroindústria, a saber, suinocultura, avícolas e bovinocultura.

Este produto é rico em uma diversidade microbiológica que em estado de equilíbrio, produz uma série de reações cujo principal produto é o biogás $\left(\mathrm{CH}_{4}+\mathrm{CO}_{2}\right.$, entre outros gases). Uma das formas de aproveitar o biogás produzido por estes microrganismos é realizar o tratamento destes inóculos por meio da atividade 
metanogênica específica (AME). Esta técnica fornece informações acerca do quanto a comunidade microbiana anaeróbia presente nos lodos é capaz de produzir metano e desta forma, o quanto estes resíduos provenientes da agroindústria podem ser convertidos a biogás (AQUINO et al., 2007).

Portanto, estudos sobre a AME são de grande importância para compreensão dos microrganismos anaeróbios e uma solução para o destino dos lodos provenientes destas indústrias.

\section{MATERIAL E MÉTODOS}

As amostras de inóculos foram coletadas diretamente no local de origem (avícola DACAR, em Tietê, SP e granja Ouro Preto, em Ibiúna, SP), armazenadas em bombonas de plástico, e acondicionadas em freezer ao chegar no laboratório de biogás, na Universidade Federal do ABC.

A análise da série de sólidos foi realizada de acordo com os procedimentos estabelecidos no Standard Methods for the Examination of Water and Wastewater (APHA, 2005) e as medições de pH foram obtidas antes e após AME com o auxílio do pHmetro da marca DGIMED, modelo DM - 22.

Para a AME foram preparadas amostras com os inóculos e substrato (ácido acético) e amostras em branco, ambas em triplicata. Uma solução de nutrientes (macronutrientes e micronutrientes foi preparada conforme estabelecido por SIMÕES (2017) e adicionada em todas as amostras.

O equipamento AMPTS II, da bioprocess control, foi utilizado para realizar a análise da AME dos inóculos. Este equipamento permite a análise simultânea de até 15 frascos reatores com capacidade máxima de $400 \mathrm{~mL}$ cada. Para este ensaio optou-se por preparar 12 frascos reatores com $300 \mathrm{ml}$ cada.

A partir dos valores dos sólidos voláteis e de acordo com alguns parâmetros recomendados por AQUINO et al., (2007) como a relação alimento (substrato)/inóculo (microrganismos) de 0,25 g DQO/SVT, concentração de substrato de $2,5 \mathrm{~g}$ DQO/l e concentração de inóculo de $10 \mathrm{~g} \mathrm{SVT/1}$ e considerando a DQO do ácido acético de 106,67 g/l, o desenho experimental foi obtido (Tabela 1).

\section{RESULTADOS E DISCUSSÃO}

As Figura 1 e 2 mostram o volume acumulado de metano, em Nml, ao longo dos dias para o inóculo Dacar e GOP, respectivamente.

Houve uma produção acumulada de 28,02 $\pm 9,43$ de $\mathrm{CH}_{4}$, em 3 dias de análise. Após este período o equipamento não detectou mais produção de gás nestes frascos. 9 dias.

Já para o inóculo GOP foi registrada uma produção acumulada de 887,4 \pm 50,3 de $\mathrm{CH}_{4}$ ao longo dos

Embora a concentração inicial de sólidos voláteis do inóculo Dacar tenha se apresentado maior que a do inóculo GOP (35,81g/l e 11,08 g/l, respectivamente) o que indica maior concentração de matéria orgânica e por consequência, maior quantidade de microrganismos, houve uma pequena produção de metano que pode ser explicada pelo tempo de armazenamento deste lodo no laboratório, aproximadamente 2 anos. Ao longo deste período foram realizados alguns testes de alimentação contínua afim de manter o metabolismo dos microrganismos presentes, seguido do seu armazenamento em freezer, sem qualquer tipo de fornecimento de nutrientes para os mesmos. Esta mudança brusca de atividade dos microrganismos, ora fornecendo nutrientes para seu metabolismo, ora restringindo sua alimentação e atividade ao colocar em temperatura amena, pode ter causado a morte de parte do consórcio existente neste inóculo, diminuindo seu rendimento relativo a produção de metano.

Já o lodo da granja Ouro Preto nunca foi alimentado artificialmente em laboratório e seu uso neste ensaio foi realizado apenas um dia após sua chegada ao laboratório, o que indica que os microrganismos presentes estavam sob intensa atividade metabólica e responderam positivamente e por mais tempo à adição de substrato nos frascos reatores. A Figura 3 apresenta a variação de $\mathrm{pH}$ inicial e $\mathrm{pH}$ final do ensaio de AME.

Exetuando-se as amostras em branco do lodo da Dacar, houve o aumento do pH final em relação ao inicial para todos os demais frascos reatores, branco e com adição de substrato. Tratando-se de um ambiente onde bactérias acidogênicas são abundantes, é normal que haja uma diminuição do pH inicial da amostra, embora decaimentos muito expressivos do valor inicial devam atenção epsecial devido a possibilidade de acidificação do meio e consequente morte das arqueias metanogênicas, grupo sensível as mudanças de $\mathrm{pH}$ (SIMÕES, 2017).

Segundo BITTON (2005), a faixa de pH ideal para o desenvolvimento e atividade das arqueias metanogênicas é de 6,8 a 7,4. Nesta faixa de valores, os resultados do lodo GOP com adição de substrato 
mostraram-se os mais adequados, ainda que o valor médio do $\mathrm{pH}$ inicial tenha se apresentado inferior. A partir desta informação nota-se que o consórcio de microrganismos presentes neste lodo é abundante, visto que foram as amostras que apresentaram a maior produção acumulada de $\mathrm{CH}_{4}$ e que também reverteu a situação inicial de ambiente levemente ácido.

Embora os resultados expressos na Figura 3 apresentem algumas hipóteses sobre o comportamento microbiano nos frascos reatores ao longo do ensaio, é necessário que análises mais completas sejam feitas avaliando precisamente os inóculos. Para tanto, as técnicas de biologia molecular como a reação da cadeia da polimerase (PCR) seguida da eletroforese em gel com gradiente desnaturante (DGGE) são opções que avaliam o comportamento e a estrutura do consórcio de microrganismos presentes nos inóculos. Diante do exposto, uma etapa de análises envolvendo estas técnicas serão realizadas futuramente.

\section{CONCLUSÃO}

O experimento da atividade metanogênica específica para os inóculos presentes no laboratório de biogás da Universidade Federal do ABC é uma importante análise para verificar o comportamento e a capacidade de produção de metano dos mesmos, objetivando a produção de biogás, fonte alternativa de energia.

Os resultados para o inóculo GOP foram satisfatórios, e embora o inóculo Dacar não tenha se comportado de maneira esperada, é necessário que outras análises, principalmente que envolvam biologia molecular sejam realizadas para então compreender o que de fato pode ter ocorrido com a evolução dos microrganismos deste lodo.

\section{AGRADECIMENTOS}

Esta pesquisa foi apoiada pela Coordenação de Aperfeiçoamento de Pessoal de Nível Superior - CAPES.

\section{REFERÊNCIAS}

ANEEL. Agência Nacional De Energia Elétrica (Brasil). Atlas de energia elétrica do Brasil. Brasília, 2002. $153 \mathrm{p}$.

APHA, AWWA; WEF. Standard Methods for the Examination of Water and Wastewater. $21^{\text {a }}$ Edição. Washington: American Public Health Association, 2005. 1368 p.

AQUINO, S. F. CHERNICHARO, C. A. L., FORESTI, E., SANTOS, M. L. F., MONTEGGIA, L. O. Metodologias para determinação da Atividade Metanogênica Específica (AME) em Lodos Anaeróbios. Engenhari Sanitária e Ambiental, v 12, n 2, p 192-201, 2007.

BITTON, G. Waste Water Microbiology. $3^{\text {a }}$ ed. Hoboken, Nova Jersey, EUA: John Wiley \& Sons, 2005. EPE. Empresa de Pesquisa Energética. Energia Renovável Hidráulica, Biomassa, Eólica, Solar, Oceânica. Rio de Janeiro, 2016. 452 p.

SIMÕES, A. L. G. Estudo da aclimatação de lodos anaeróbios como estratégia de inoculação para partida de biometanizadores alimentados com fração orgânica dos resíduos sólidos urbanos. Dissertação (Mestrado). Programa de Pós-graduação em energia Hidráulica e Saneamento e Área de Concentração em Hidráulica e Saneamento. Escola de Engenharia de São Carlos da Universidade de São Paulo. 2017. 316 p.

Tabela 1. Relação das amostras preparadas para a AME.

\begin{tabular}{clcccc}
\hline & Amostra & Ióculo $(\mathbf{g})$ & Substrato $(\mathbf{g})$ & Nutrientes $(\boldsymbol{\mu L})$ & Água destilada $(\mathbf{g})$ \\
\hline 1 & Dacar Branco (1) & 83,78 & - & & 216,22 \\
2 & Dacar Branco (2) & 83,78 & - & & 216,22 \\
3 & Dacar Branco (3) & 83,78 & - & & 216,22 \\
4 & Dacar Subst. (1) & 83,78 & 7,03 & & 209,19 \\
5 & Dacar Subst. (2) & 83,78 & 7,03 & 3 & 209,19 \\
6 & Dacar Subst. (3) & 83,78 & 7,03 & & 209,19 \\
7 & GOP Branco (1) & 270,81 & - & & 29,19 \\
8 & GOP Branco (2) & 270,81 & - & & 29,19 \\
9 & GOP Branco (3) & 270,81 & - & & 29,19 \\
10 & GOP Subst. (1) & 270,81 & 7,03 & & 22,16 \\
11 & GOP Subst.(2) & 270,81 & 7,03 & & 22,16 \\
12 & GOP Subst.(3) & 270,81 & 7,03 & & 22,16 \\
\hline
\end{tabular}




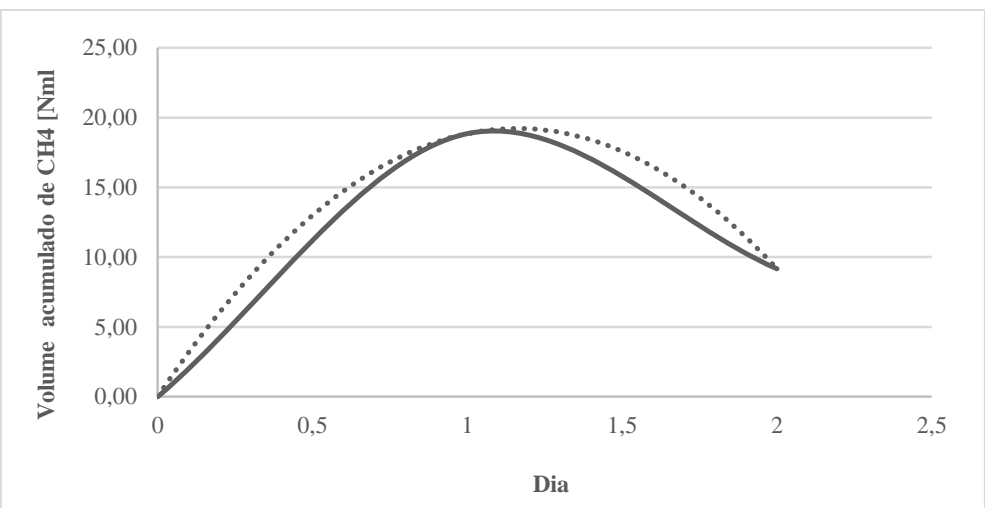

Figura 1. Produção acumulada de $\mathrm{CH}_{4}$ do lodo dacar [Nml].

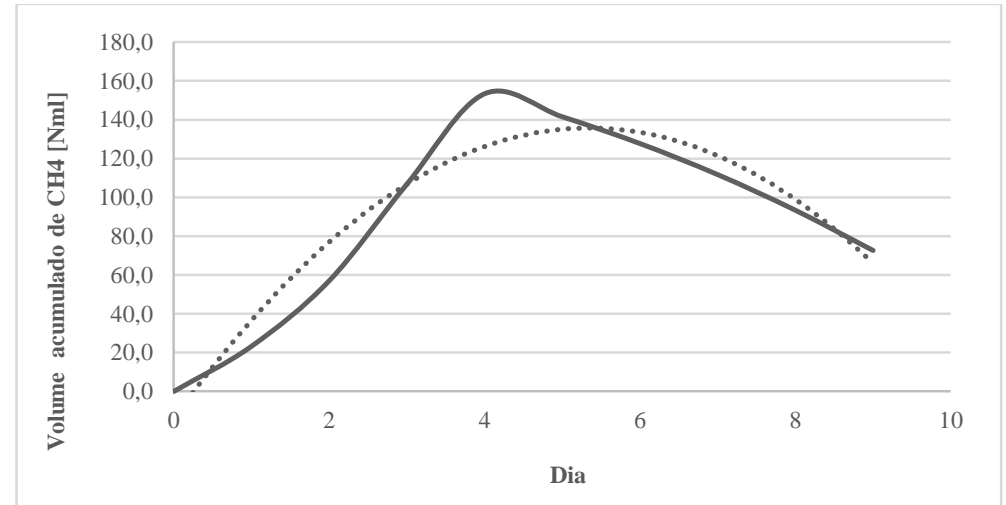

Figura 2. Produção acumulada de $\mathrm{CH}_{4}$ do lodo GOP [Nml].

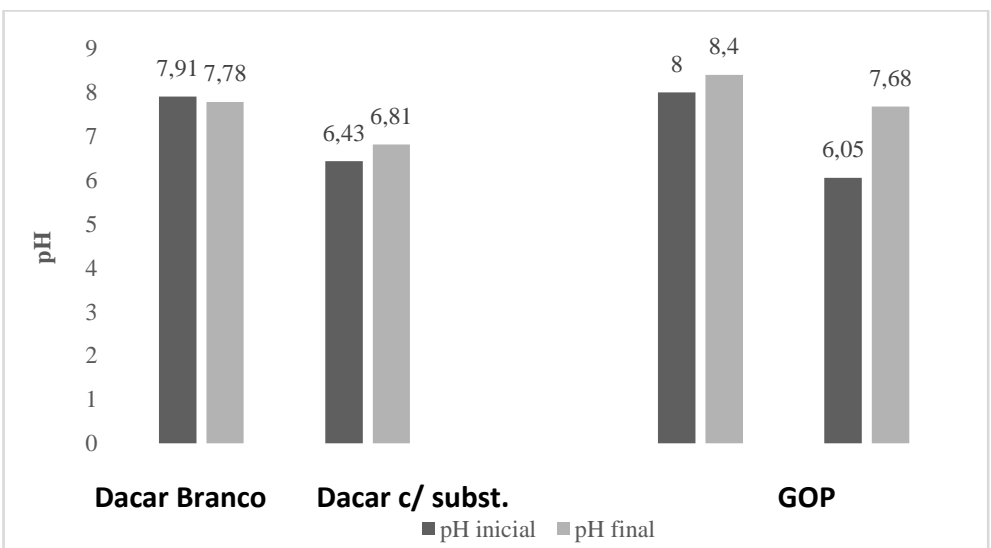

Figura 3. Variação do pH nas amostras em branco e com substrato de ambos os inóculos. 


\title{
AVALIAÇÃO DO DIGESTATO RESULTANTE DA CODIGESTÃO DE EFLUENTES BOVINO E SUÍNO COM SORO DE LEITE
}

\author{
Thomas, N. ${ }^{1 *}$; Marteres, T.J. ${ }^{1}$; Somer, J.G. ${ }^{1,2}$; Estevam, F.N.L. ${ }^{1,2}$; Mito, J.Y.L. ${ }^{1}$; Carvalho, E.L. ${ }^{3}$

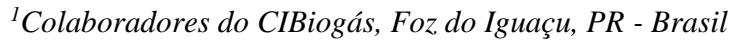 \\ labiogas@cibiogas.org \\ ${ }^{2}$ Integrantes do Projeto P\&D ANEEL PD-06491-0287/2012 \\ ${ }^{3}$ Pesquisadora da UTFPR, Medianeira, PR - Brasil
}

\begin{abstract}
RESUMO: Este trabalho tem por objetivo comparar as características do digestato de amostras de codigestão anaeróbia, a partir da mistura de efluentes suínos e bovinos com subprodutos lácteos (soro de leite), a fim de obter maior eficiência na quantidade de biogás produzido e consequentemente, para utilização do digestato como biofertilizante. Para o experimento foram utilizados biodigestores em sistema de batelada, os quais foram monitorados por 45 dias. As codigestões realizadas nas proporções de 3,10 e 30\% de soro de leite com cada efluente foram escolhidas conforme a realidade do produtor e assim caracterizadas com parâmetros físicoquímicos: sólidos totais, voláteis e fixos, além da determinação dos teores de macronutrientes (NPK) do digestato resultante. Os resultados obtidos demonstraram a relação de aumento na produção de biogás conforme o incremento de soro nos efluentes, assim como a diferença no efluente suíno em relação ao bovino, com a produção de biogás superior na amostra com efluente bovino, levando em consideração o manejo de produção desses animais. Em relação ao digestato, observou-se a diminuição dos sólidos totais, fixos e voláteis, demonstrando que o processo de biodigestão foi eficaz ao consumo de matéria orgânica disponível, além da fixação de Potássio e Fósforo. O Nitrogênio mostrou-se constante.
\end{abstract}

Palavras-chave: potencial metanogênico bioquímico, metano, biofertilizante.

\section{EVALUATION OF DIGESTATION RESULTING FROM CODIGESTION OF BOVINE AND SWINE EFFLUENTS WITH WHEY}

\begin{abstract}
The objective of this work is compare the digestate characteristics of the samples in anaerobic codigestion, from the mix of swine and bovine effluents with dairy byproducts (whey), in order to obtain greater efficiency in the amount of biogas produced and consequently, for use of the digestate as biofertilizer. Were used biodigesters in the batch system, which monitored during 45 days. The proportions of 3,10 and $30 \%$ from whey with each effluent was chosen according to the disponibility of the producer and characterized with physico chemical parameters: total, volatile and fixed solids, as well as determination of macronutrient contents (NPK) of the digestate. The results demonstrated the increase ratio in the biogas production as the whey increment in the effluents. As well as the difference in the production of swine effluent in relation to the bovine, with the production of superior biogas in bovine effluent, in according with the management of production of these animals. About the digestate, it was observed the decrease of the total fixed and volatile solids, because of the biodigestion process was effective to consume of available organic matter, besides the fixation of Potassium and Phosphorus. Nitrogen was constant.
\end{abstract}

Keywords: biochemical methanogenic potential, methane, biofertilizer.

\section{INTRODUÇÃO}

No Brasil há uma produção elevada de suínos e bovinos em escala industrial, onde geralmente se concentram grandes quantidades de animais em pequenas áreas territoriais. Essas atividades agropecuárias geram efluentes ricos em matéria orgânica, que necessitam ser corretamente destinados. Do mesmo modo, o leite residual (soro) vindo das atividades de laticínios possui elevada proporção de descarte em relação à sua industrialização. Tais materiais podem ser utilizados como fonte de geração de biogás e, por consequência, produção de biofertilizante (BRASIL, 2008). 
O produto resultante da biodigestão desses efluentes é denominado digestato. Por conta dos teores de macronutrientes presentes no digestato, é um material que pode ser utilizado como biofertilizante (PRAZERES et al., 2012).

Como Carreas (2013) descreve, a biometanização é uma excelente oportunidade para a sustentabilidade, pois com tecnologias apropriadas e uma boa capacitação, o tratamento de resíduos orgânicos pode acabar resolvendo uma cadeia de problemas ambientais e ainda produzir energia elétrica, térmica e um fertilizante natural.

\section{MATERIAL E MÉTODOS}

Neste estudo avaliou-se o digestato resultante da biodigestão de efluentes bovinos e suínos, com subprodutos da indústria lática (soro de leite), em proporções de 3, 10, 30\% de soro, conforme a disponibilidade dos materiais na propriedade rural.

A avaliação dos nutrientes presentes no digestato é importante, pois permite calcular a quantidade a ser aplicada em cada cultura, quando utilizado como biofertilizante. A maior parte do experimento foi desenvolvido no Laboratório de Biogás do Centro Internacional de Energias Renováveis - CIBiogás, com exceção das análises de P e K, que foram realizadas na Universidade Tecnológica Federal do Paraná - UTFPR. Os dejetos bovinos e suínos, assim como o soro de leite, foram fornecidos por propriedades rurais de grande porte do oeste do Paraná.

Para a realização da pesquisa foram realizados ensaios de Sólidos Totais (ST), Fixos (SF) e Voláteis (SV), antes e após incubação, para avaliação da carga orgânica disponível. Também se avaliou NPKNitrogênio Total (N), Fósforo (P) e Potássio (K) do digestato, por serem esses os principais nutrientes minerais. O ensaio de Potencial Metanogênico Bioquímico (PMB) foi realizado para avaliar a produção de biogás, metano e para obtenção do digestato.

Para análise de ST, SV e SF foi utilizado método adaptado do Standard Methods for the Examination of Water and Wastewater (APHA, 2017). Para análise de N, utilizou-se método colorimétrico com um kit Merck® com faixa de leitura de (10 a 150) $\mathrm{mg} \mathrm{l}^{-1}$, um termo reator e um espectrômetro de feixe simples. E para análise de $\mathrm{P}$ e K, foi utilizado um espectrofotômetro de absorção atômica para leitura.

O ensaio de PMB foi realizado seguindo as recomendações da norma VDI 4630 (2016) e DIN 38414 (1985), utilizando o método em batelada. A caracterização do de biogás foi efetuada através do analisador de gás Drager®, modelo $\mathrm{X}$-am 7000, onde obteve-se os valores de $\mathrm{CH}_{4}$. Foram incubados as codigestões, sendo elas: $\operatorname{com} 3,10$ e $30 \%$ de soro com dejeto de suinocultura e 3,10 e 30\% de soro com dejeto de bovinocultura, além das amostras puras para utilizar como parâmetros e do inóculo puro como branco.

\section{RESULTADOS E DISCUSSÃO}

A lactose presente no soro sofre ação dos microrganismos acidogênicos, que são convertidos em ácidos orgânicos. O acúmulo desses ácidos acarretaria em diminuição na atividade microbiana (GHALY, 1996), mas no caso das proporções utilizadas em estudo, essa diminuição apenas ocorreu após o consumo da matéria orgânica disponível. Conseguiu-se perceber que os sólidos do efluente de suinocultura após o processo de biodigestão teve uma queda mais significativa do que o de bovinocultura em sua concentração, o que explica a maior produção de biogás em efluentes de suinocultura. Onde verificou-se também diferenças significativas no rendimento entre o efluente bruto e as codigestões realizadas, elevando a produção de biogás conforme o incremento da proporção de soro de leite utilizado. Esses comportamentos foram mais perceptíveis no efluente de bovinocultura, como visualizado nas Figuras 1 e 2.0 aumento na produção de biogás foi diretamente proporcional ao incremento na proporção de soro com o efluente de bovinocultura e inversamente proporcional ao efluente de suinocultura.

Os resultados de codigestões a partir de dejetos da produção animal e resíduos agroindustriais, como o soro de leite, possuem altos teores de N, P, K sobretudo o de origem bovino. Após o processo de digestão anaeróbia, há uma diminuição no teor de carbono na forma de $\mathrm{CH}_{4}$ (metano) e $\mathrm{CO}_{2}$ (dióxido de carbono), ocasionando o aumento do teor desses nutrientes.

Após os 45 dias de incubação das amostras, houve aumento de $\mathrm{P}$ e K, porém, pouca variação de N. Isso pode ter ocorrido pelo fato da mistura reagir como tampão e auxiliado no equilíbrio orgânico para o crescimento microbiano, sem comprometer a formação de biogás, como apresentado também por Song et al., 2011 e verificado na Figura 3. 
Outro fator analisado foi o aumento da concentração dos nutrientes na amostra com efluente bovino em relação ao suíno. Isso pode ser explicado pelo efluente suíno naturalmente já possuir maior concentração dos de tais nutrientes. A diferença entre as proporções de soro adicionadas mostrou-se constante com efluentes de bovinocultura e reduziu conforme o aumento de soro em efluente de suinocultura.

\section{CONCLUSÃO}

O digestato desempenha excelentes benefícios ao solo, como o poder fixação de sais minerais, melhora a estrutura e textura do solo, favorece o enraizamento das plantas e umidade do solo, aumenta a porosidade e a multiplicação de bactérias, além de ser importante na fixação de nitrogênio no solo. Com o desenvolvimento deste trabalho, conseguiu-se concluir que as codigestões de dejeto bovino e suíno com soro favorecem a obtenção do aumento dos nutrientes disponíveis. Para K, o aumento foi de $7 \%$ em relação ao efluente de suinocultura e 5\% em relação a bovinocultura; $11 \%$ de aumento de P para bovinocultura e não houve alteração para efluente de suinocultura. Para o $\mathrm{N}$ também não se verificou alteração na concentração desse nutriente. Além dos nutrientes, houve incremento de $56 \%$ na produção de biogás, em relação ao efluente de suinocultura e $82 \%$ de aumento em relação ao efluente de bovinocultura.

\section{AGRADECIMENTOS}

Os autores agradecem ao CIBiogás pelo apoio financeiro e institucional, em especial ao Projeto Entre Rios em parceria da COPEL, com o P\&D ANEEL PF-06491-0287/2012 denominado "Arranjo Técnico e Comercial de Geração Distribuída de Energia Elétrica a Partir do Biogás de Biomassa Residual da Suinocultura em propriedades Rurais no Município de Entre Rios do Oeste do Paraná". Ao Parque Tecnológico de Itaipu e a Itaipu por todo espaço disponibilizado e apoio técnico para desenvolvimento das atividades. E a UTFPR pela parceria na realização das análises, representada pelo professor Éder Lisandro Flores.

\section{REFERÊNCIAS}

APHA - American Public Health Association. Standard Methods for Examination of Water and Wastewater. 23rd. Ed. Washington: APHA, 2017.

BRASIL. A. M. P. EMBRAPA. Avaliação da viabilidade do uso de resíduos na agricultura. Jaguariuna: Edislene Ap. Bueno Ruza, 2008. Disponível em: 〈http://www.cnpma.embrapa.br/download/circular_19.pdf〉. Acesso em: 11/12/2018.

CARREAS, N. O biogás. Programa de Capacitação em Energias Renováveis. Observatório de Energias Renováveis para America Latina e Caribe, 2013.

DIN 38414 - Sludge and sediments (groups), determination of the amenability to anaerobic digestion (part 8), 1985.

GHALY, A. A comparative study of anaerobic digestio of acid cheese whey and dairy manure in a twostage reactor. Bioresource Technology, v.58, n.1, p. 61-72, 1996.

PRAZERES, A.R.; Carvalho, F.; Rivas, J. Cheese whey management: A review. J. Environ. Manage, 110, p.48-68, 2012.

SONG, Y. H.; QIU, G.L.; YUAN, P. CUI, X.Y.; PENG, J.F.; ZENG, P.; QIAN, F. Nutrients removal and recovery from anaerobically digested swine wastewater bu struvite crystalizattion without chemical additions. J. Hazard. Mater. 19, p.140-149, 2011.

VDI - VEREIN DEUTSCHER INGENIEURE. Vergärung organischer stoffe - substratcharakterisierung, probenahme - stoffdatenaerhebung, gärversuche. German, 2016. 


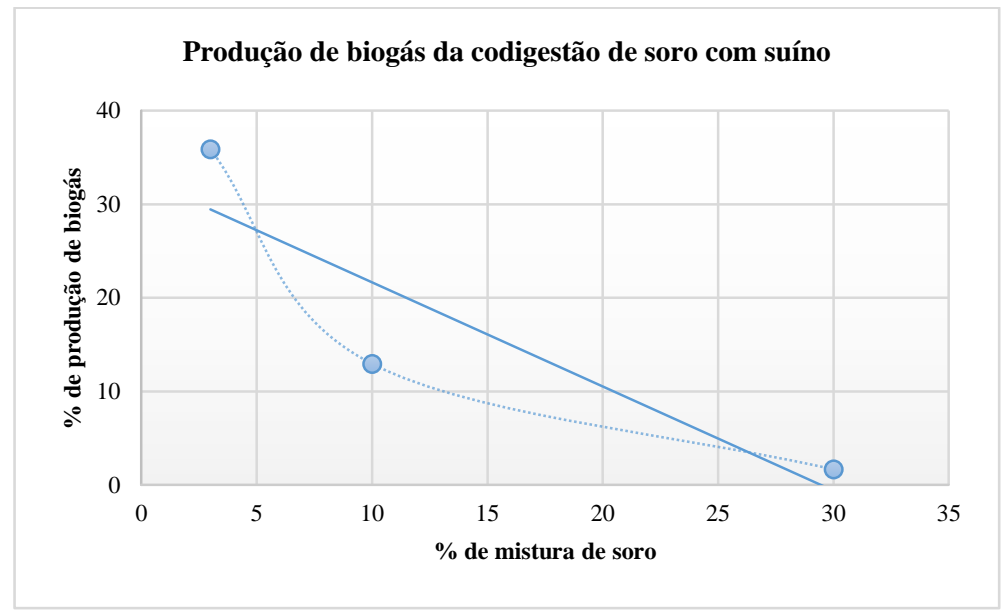

Figura 1. Produção de biogás em relação a mistura de soro com efluente suíno.

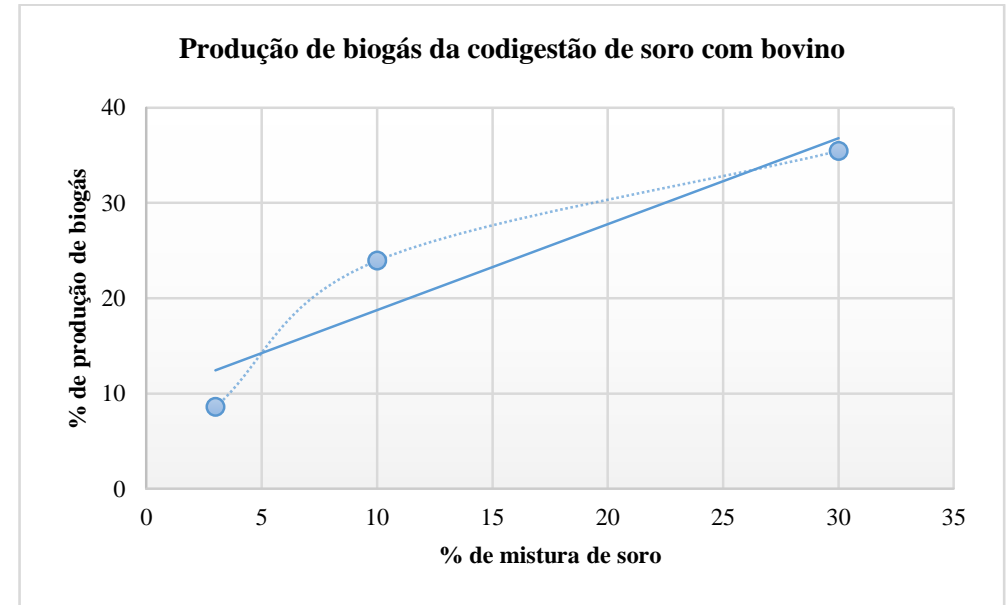

Figura 2. Produção de biogás em relação a mistura de soro com efluente bovino.

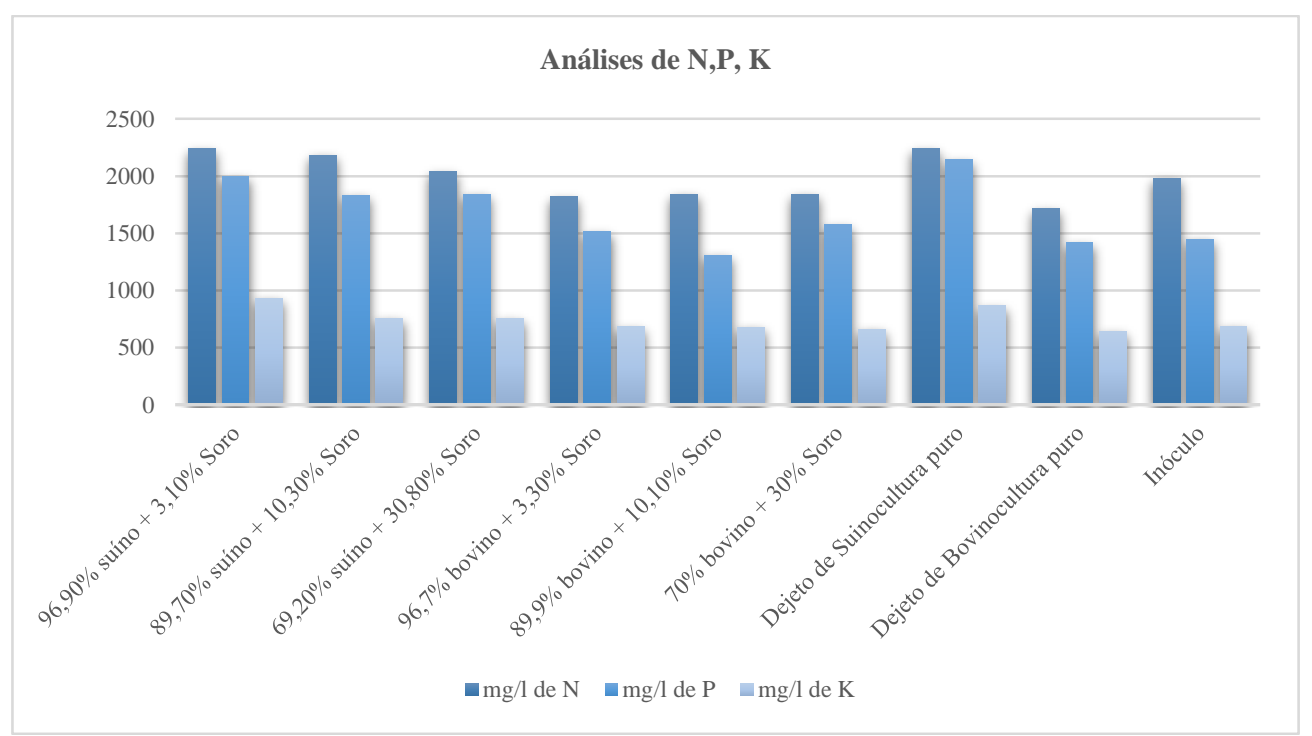

Figura 3. Resultados de N, P e K. 


\title{
CARACTERIZAÇÃO DE DIFERENTES CASCAS DE FRUTAS (LARANJA, LIMA, LIMÃO E BERGAMOTA) PARA FINS ENERGÉTICOS
}

\author{
Perondi, D.*1; Manera, C. ${ }^{1}$; Bassanesi, G.R. ${ }^{2}$; Zancanaro, D.A. ${ }^{2}$; Godinho, M. ${ }^{1}$; Zattera, A.J. ${ }^{1}$ \\ ${ }^{1}$ Programa de Pós-Graduação em Engenharia de Processos e Tecnologias, Caxias do Sul, RS - Brasil. \\ ${ }^{2}$ Programa de Graduação em Engenharia Química, Caxias do Sul, RS - Brasil. \\ dani.perondi@gmail.com
}

\begin{abstract}
RESUMO: Os resíduos agroindustriais destacam-se como fonte de energia renovável. Dentre eles, é possível mencionar a casca das frutas. A valorização energética dos resíduos agroindustriais pode reduzir a dependência pelos combustíveis fósseis, além de contribuir para a redução das emissões de gases causadores do efeito. Neste trabalho realizou-se a caracterização dos seguintes resíduos agroindustriais: casca de laranja, lima, limão e bergamota; através da análise termogravimétrica, imediata (teor de matéria volátil, cinzas e carbono fixo) e de poder calorífico superior, com o objetivo de utilizar os referidos resíduos para fins energéticos. Os ensaios indicaram que a principal região de desvolatilização das quatro cascas ocorre entre 200 e $500{ }^{\circ} \mathrm{C}$. Os elevados teores de matéria volátil, bem como os baixos teores de cinzas encontrados nas amostras, tornam estes resíduos atrativos para processos de conversão termoquímica.
\end{abstract}

Palavras-chave: casca de frutas, aproveitamento energético, resíduos.

\section{CHARACTERIZATION OF DIFFERENT FRUIT PEELS (ORANGE, LIMA, LEMON AND BERGAMOTA) FOR ENERGY PURPOSES}

\begin{abstract}
Agro-industrial waste stands out as a source of renewable energy. Among them, it is possible to mention the fruit peels. The energy recovery of agro-industrial waste can reduce dependence on fossil fuels, as well as contribute to the reduction of greenhouse gas emissions. In this work, the following agro-industrial residues were characterized: orange peel, lime, lemon and bergamot. Thermogravimetric analysis, proximate analysis (volatile matter content, ash and fixed carbon) and higher calorific value were used for energy purposes. The tests indicated that the main devolatilization region of the four peels occurs between 200 and $500{ }^{\circ} \mathrm{C}$. The high contents of volatile matter, as well as the low ash content found in the samples, make these residues attractive for thermochemical conversion processes.
\end{abstract}

Keywords: fruit peel, energy use, wastes.

\section{INTRODUÇÃO}

Os resíduos agroindustriais destacam-se como fonte de energia renovável. Dentre eles, é possível mencionar a casca das frutas. Entre as frutas cítricas mais comercializadas no país destacam-se as laranjas, mandarinas, as tangerinas, os limões, as limas e os pomelos (AGOSTINI, 2012).

Especificamente com relação a laranja, estudos reportam que 50\% da fruta são convertidos em suco, enquanto o restante é transformado em bagaço, também conhecido como resíduo de processamento cítrico (CPW) (CYPRIANO, 2015). Somente no ano de 2006, entre 19,8 e 33 milhões de toneladas de laranjas foram processadas em todo o mundo, para produzir aproximadamente 2,2 milhões de toneladas de suco e gerar entre 8 e 20 milhões de toneladas de resíduos (AGUIAR et al., 2008).

A valorização energética dos resíduos agroindustriais pode reduzir a dependência pelos combustíveis fósseis, além de contribuir para a redução das emissões de gases causadores do efeito estufa (VOLPE et al., 2015).

Diferentes formas de reaproveitamento destes resíduos têm sido propostas. Bioetanol (BOLUDAAGUILAR; LÓPEZ-GÓMEZ, 2013), flavonoides (COLL, M D; COLL, L, LAENICNA, 1998), recuperação de produtos químicos (YI et al., 2013), fertilizante orgânico para o solo (GUERRERO et al., 1995) e, ração animal (TRIPODO et al., 2004) são algumas das propostas reportadas na literatura. Adicionalmente, a elevada perecibilidade do resíduo, devido ao seu alto teor de água, associado ao custo de transporte, levou pesquisadores a investigar a conversão termoquímica como uma alternativa de aproveitamento destes materiais (VOLPE et al., 2015).

Neste sentido, a contribuição científica deste trabalho está na caracterização dos seguintes resíduos agroindustriais: casca de laranja, lima, limão e bergamota; através da análise termogravimétrica, imediata (teor 
de matéria volátil, cinzas e carbono fixo) e de poder calorífico superior, com o objetivo de utilizar os referidos resíduos para fins energéticos.

\section{MATERIAL E MÉTODOS}

As frutas utilizadas para o desenvolvimento deste trabalho foram colhidas em uma propriedade rural, localizada no interior da cidade de Dois Lajeados/RS. Inicialmente, as frutas foram pesadas e, posteriormente fez-se a extração do suco para obtenção das cascas (objeto do presente estudo). Em seguida, conduziu-se a etapa de secagem em estufa na temperatura de $80{ }^{\circ} \mathrm{C}$ por aproximadamente $48 \mathrm{~h}$ e, por fim as cascas foram cominuídas em um moinho de facas até granulometria menor do que $1 \mathrm{~mm}$ para posterior caracterização. A Figura 1 apresenta as etapas realizadas durante o preparo das amostras.

Os experimentos termogravimétricos foram conduzidos com amostras de diâmetro inferior a $0,9 \mathrm{~mm}$ e massa inicial de aproximadamente $10 \mathrm{mg}$. Os ensaios foram realizados em uma balança termogravimétrica STA 449 F3 Jupiter ${ }^{\circledR}$ da marca Netzsch em atmosfera inerte $\left(\mathrm{N}_{2}\right)$ a uma vazão volumétrica de $50 \mathrm{~mL} \mathrm{~min}^{-1}$. $\mathrm{O}$ cadinho utilizado foi de alumina. Uma taxa de aquecimento de $25^{\circ} \mathrm{C} \mathrm{min}{ }^{-1}$ foi utilizada. As temperaturas dos experimentos variaram desde a temperatura ambiente até a temperatura final de $800{ }^{\circ} \mathrm{C}$.

Os ensaios para a realização da análise imediata (determinação dos teores matéria volátil, cinzas e carbono fixo) foram realizados seguindo os procedimentos descritos na norma ASTM D1762.

As análises de poder calorífico superior foram conduzidas fazendo-se uso de uma bomba calorimétrica da marca IKA C-200 e, seguindo os procedimentos descritos na norma ASTM D5865.

\section{RESULTADOS E DISCUSSÃO}

A Figura 2 apresenta os termogramas obtidos para as quatro cascas (laranja, lima, limão e bergamota), fazendo-se uso de uma taxa de aquecimento de $25^{\circ} \mathrm{C} \mathrm{min}$. . Os referidos termogramas fornecem a curva de perda de massa em função da temperatura.

É possível observar que todas as curvas apresentam valores de perda de massa em temperaturas abaixo de $200{ }^{\circ} \mathrm{C}$, onde acontece a remoção da umidade e dos orgânicos voláteis (óleos, terpenos e pigmentos) (PATHAK; MANDAVGANE; KULKARNI, 2017). Os teores médios de umidade encontrados para as referidas amostras foram de $15 \%$ para a casca de limão, $12 \%$ para a casca de lima, $8 \%$ para a casca de bergamota e $4 \%$ para a casca de laranja.

A região de principal perda de massa observada nos termogramas ocorreu entre 200 e $500{ }^{\circ} \mathrm{C}$. Esta perda de massa corresponde à decomposição da celulose e da hemicelulose. De acordo com (OROZCO et al., 2014), fontes lignocelulósicas são suscetíveis à reações químicas e, a sua decomposição térmica ocorre até aproximadamente $360^{\circ} \mathrm{C}$. Adicionalmente, de acordo com os mesmos autores, a degradação térmica da lignina ocorre entre 280 e $500^{\circ} \mathrm{C}$.

Na Figura 3 são apresentados os teores de matéria volátil, cinzas e carbono fixo das amostras estudadas. O elevado teor de matéria volátil encontrado para as quatro amostras estudadas (71\% para casca de limão, $73 \%$ para a casca de laranja, $72 \%$ para a casca de lima e $71 \%$ para a casca de bergamota), associado ao baixo teor de cinzas (4\% para casca de limão, $2 \%$ para a casca de laranja, $4 \%$ para a casca de lima e $3 \%$ para a casca de bergamota), torna estes materiais atrativos para um processo de conversão termoquímica. Dentre os quatro materiais estudados, a casca de laranja apresentou o maior teor de voláteis, associado ao menor teor de cinzas.

O poder calorífico superior obtido para as quatro amostras estudadas foi de $14,71 \mathrm{MJ} \mathrm{kg}^{-1}$ para casca de limão, 18,59 MJ kg-1 para a casca de laranja, $15,78 \mathrm{MJ} \mathrm{kg}^{-1}$ para a casca de lima e $17,98 \mathrm{MJ} \mathrm{kg}^{-1}$ para a casca de bergamota. Estes valores estão de acordo com os dados reportados por (AGUIAR et al., 2008) e (VOLPE et al., 2015). Dentre as amostras testadas, a casca de laranja apresentou o maior poder calorífico superior, corroborando com os resultados da análise imediata (alto teor de voláteis e baixo teor de cinzas).

\section{CONCLUSÃO}

A partir dos resultados apresentados neste trabalho é possível identificar que a conversão termoquímica das cascas de frutas é uma alternativa para a sua disposição, uma vez que elevados teores de matéria volátil e baixos teores de cinzas foram encontrados nas quatro amostras avaliadas.

\section{AGRADECIMENTOS}

Os autores gostariam de agradecer a Coordenação de Aperfeiçoamento de Pessoal de Nível Superior (CAPES) e a Fundação de Amparo à pesquisa do Estado do Rio Grande do Sul (FAPERGS), pelo apoio financeiro (Processo TO 18/2551-0000555-0-Edital Doc Fix). 


\section{REFERÊNCIAS}

AGOSTINI, J. D. Caracterização, conservação pós-colheita, processamento mínimo e adubação na qualidade de laranja ' Champagne' (Citrus sinensis L. Osbeck). Tese de doutorado da Universidade Federal da Grande Dourados, p. 143, 2012.

AGUIAR, L. et al. Influence of temperature and particle size on the fixed bed pyrolysis of orange peel residues. Journal of Analytical and Applied Pyrolysis, v. 83, n. 1, p. 124-130, 2008.

BOLUDA-AGUILAR, M.; LÓPEZ-GÓMEZ, A. Production of bioethanol by fermentation of lemon (Citrus limon L.) peel wastes pretreated with steam explosion. Industrial Crops and Products, v. 41, n. 1, p. 188-197, 2013.

COLL, M D; COLL, L, LAENICNA, J. T.-B. F. A. Recovery of flavanones from wastes of industrially processed lemons. Z.lebensum unters forsh A, v. 206, p. 404-407, 1998.

CYPRIANO, D. Z. Biomassa de casca de laranja industrial como fonte de bioetanol e produtos de alto valor agregado. Dissertação de mestrado da Universidade Estadual de Campinas, p. 103, 2015.

GUERRERO, C. C. et al. Re-use of industrial orange wastes as organic fertilizers. Bioresource Technology, v. 53 , n. 1 , p. $43-51,1995$.

OROZCO, R. S. et al. Characterization of lignocellulosic fruit waste as an alternative feedstock for bioethanol production. BioResouces, v. 9, n. 2, p. 1873-1885, 2014.

PATHAK, P. D.; MANDAVGANE, S. A.; KULKARNI, B. D. Fruit Peel Waste: Characterization and its Potential Uses. Current Science, v. 113, n. 03, p. 444, 2017.

TRIPODO, M. M. et al. Citrus waste recovery: A new environmentally friendly procedure to obtain animal feed. Bioresource Technology, v. 91, n. 2, p. 111-115, 2004.

VOLPE, M. et al. Upgrade of citrus waste as a biofuel via slow pyrolysis. Journal of Analytical and Applied Pyrolysis, v. 115, p. 66-76, 2015.

YI, Y. B. et al. Direct conversion of citrus peel waste into hydroxymethylfurfural in ionic liquid by mediation of fluorinated metal catalysts. Journal of Industrial and Engineering Chemistry, v. 19, n. 2, p. 523-528, 2013.

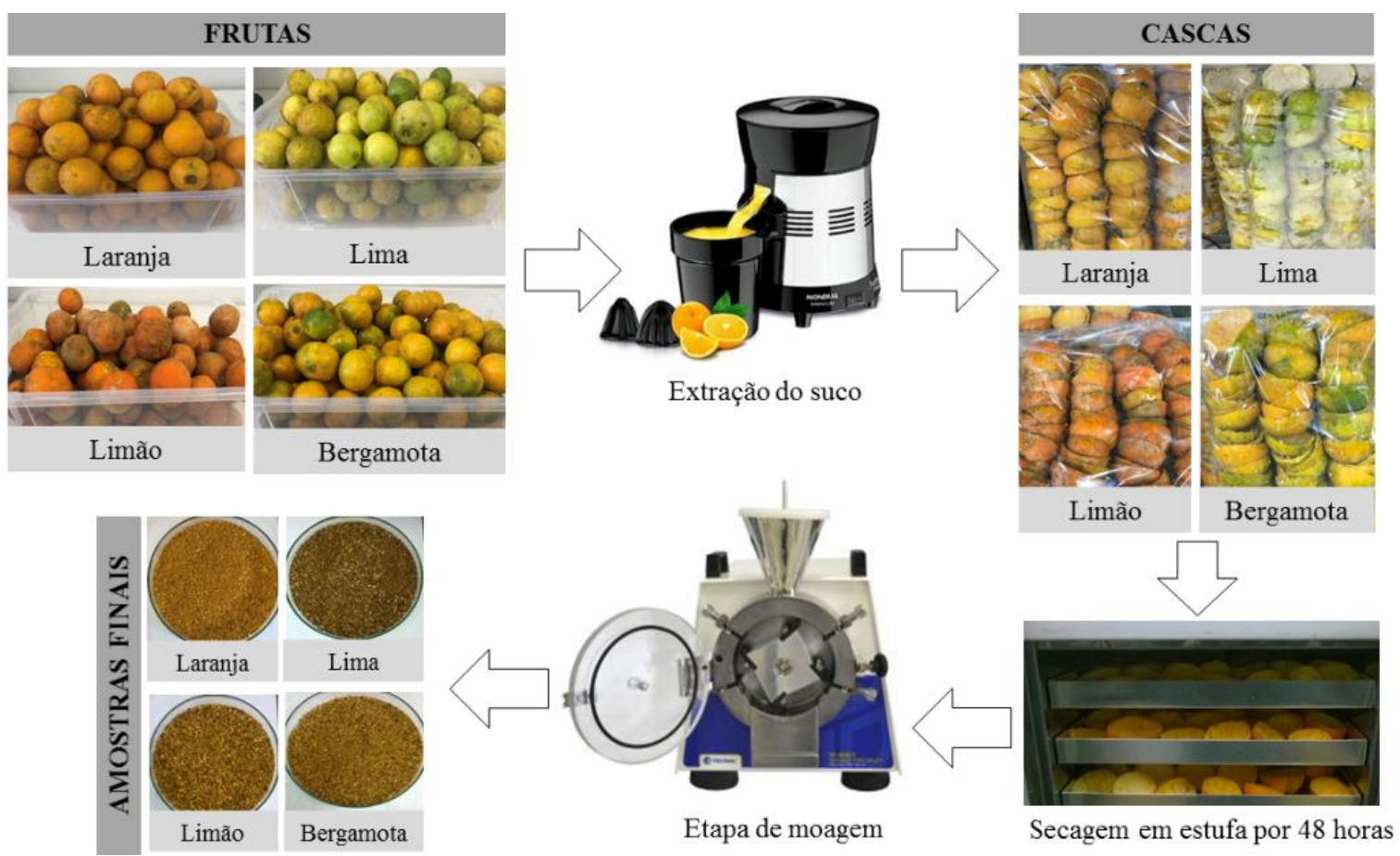

Figura 1. Etapas realizadas durante o preparo das amostras. 


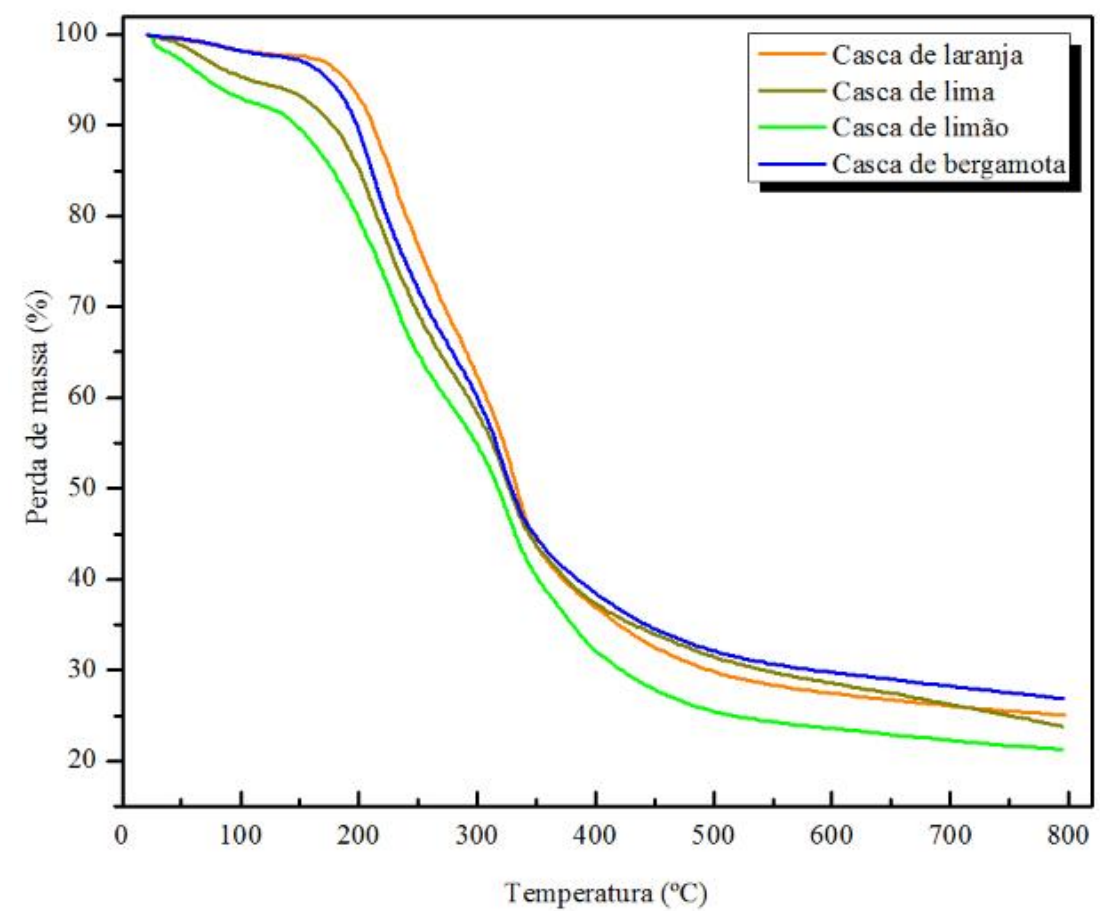

Figura 2. Termogramas obtidos para as amostras de casca de laranja, lima, limão e bergamota (taxa de aquecimento de $25^{\circ} \mathrm{C} \mathrm{min}^{-1}$ ).

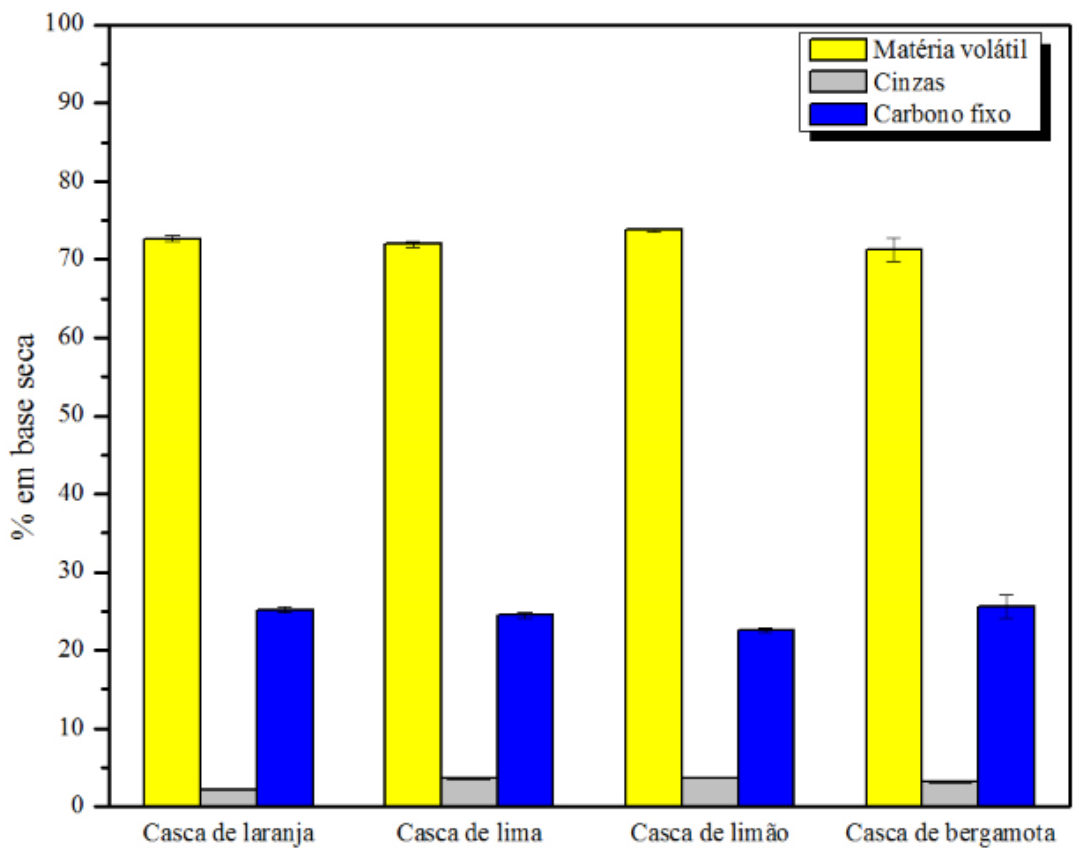

Figura 3. Análise imediata das amostras de casca de laranja, lima, limão e bergamota. 


\title{
COMPARISON OF THE BIOCHEMICAL METHANE POTENTIAL OF DIFFERENT ORGANIC BIOMASS
}

\author{
Tavares, A. ${ }^{1}$; Ziglioli, E. ${ }^{1}$; Remor, P. ${ }^{1}$; Cavaler, J. ${ }^{1}$; Alino, J. ${ }^{1}$; Edwiges, T. ${ }^{2 *}$ \\ ${ }^{l}$ Mestrando(a) do Programa de Pós-Graduação em Tecnologias Ambientais - Universidade Tecnológica Federal do Paraná- \\ UTFPR, Medianeira, PR - Brasil, alexs.sander_j@hotmail.com; eduardo.ziglioli@hotmail.com; paularemor94@hotmail.com; \\ jadianecavaler@alunos.utfpr.edu.br; joaoalino94@gmail.com \\ ${ }^{2}$ Professor Adjunto do Departamento de Ciências Biológicas e Ambientais - Universidade Tecnológica Federal do Paraná- \\ UTFPR, Medianeira, PR - Brasil, thiagoe@utfpr.edu.br*
}

\begin{abstract}
Anaerobic digestion is often used as an alternative treatment for wastes with high polluting potential, and their biodegradability can be estimated by Biochemical Methane Potential (BMP). Thus, the aim of this study was to determine the PME and the rate of enzymatic hydrolysis of substrates such as: Whey (SO), Pig Manure (SN), Sugarcane Bagasse (BG) and Macrophytes (MA) (Pistia stratiotes). BG and MA had particle diameter reduction pretreatment $(<10 \mathrm{~mm})$ and $\mathrm{BG}$ was oven dried $\left(24\right.$ hours, $\left.60^{\circ} \mathrm{C}\right)$. The characterization took place through analyzes of total solids (TS), volatile solids (VS) and $\mathrm{pH}$. The assays were performed in $100 \mathrm{~mL}$ glass bottles at $37^{\circ} \mathrm{C}$, with $50 \%$ headspace and conditions established by VDI standard 4630 (2006). Biogas composition was determined by gas chromatography and the results were treated using Analysis of Variance and Tukey Test $(\mathrm{p}<0,05)$. SO showed the highest methane production and SN remained constant between the second and sixth day, but the maximum production point was obtained by $\mathrm{SO}$ and $\mathrm{BG}$ after two days. For the BMP, SO and SN presented the highest accumulated methane yields, 314 and $301 \mathrm{~L} \mathrm{CH}_{4} \mathrm{KgVS}^{-1}$, respectively. BG produced $249 \mathrm{~L} \mathrm{CH}_{4} \mathrm{KgVS}^{-1}$ and MA showed the lowest methane generation $\left(43 \mathrm{~L} \mathrm{CH}_{4} \mathrm{KgVS}^{-1}\right)$. In this sense, due to the characteristics of the substrates studied, it's suggested that co-digestion is important to make biogas production feasible, since it favors the synergistic effects, increases the methane content and improves the operation of the biodigester.
\end{abstract}

Keywords: agricultural waste, biogas, BMP, anaerobic digestion.

\section{INTRODUCTION}

Anaerobic digestion emerges as an alternative treatment to transform waste with high polluting potential into added value by-products such as biogas and biofertilizer. In Brazil, the use of biomass represents $9 \%$ of the energy matrix and provides about 14.000 MW for the electrical system. Among the available sources, biogas production from agro-industrial waste, animals and urban solid waste contribute only with 119 MW, which represents less than $1 \%$ of the total energy produced by all biomass sources (ANEEL, 2017).

Residues used as biomass can come from agroindustrial wastewater, energy crops, sewage sludge, among others (Tian et al., 2018). However, the characteristics of each residue can result in different methane productions, as well as impacting the biodigester operating system. For Holliger et al. (2016) the production of biogas from different biomasses, make it possible to use the Biochemical Potential of Methane (BMP) as a way to obtain anaerobic reactors of key parameters in real scale.

Thus, this study aimed to determine the BMP of distinct substrates such as whey, pig manure, sugar cane bagasse and macrophytes, for comparison purposes regarding methane production and enzymatic hydrolysis rate.

\section{Substrate and inoculum}

\section{MATERIAL AND METHODS}

The inoculum (IN) used in the batch tests was composed of two different types of digestates from biodigesters that treat pig and cattle manure, together with raw cattle manure in the ratio of 1:0,5:0,5 (ww/ww), respectively. Acclimatization was performed according to Edwiges et al. (2018) and the substrates used were:

$\checkmark$ Sugarcane bagasse (BG): Collected a local company which produces sugarcane products (Medianeira/Paraná);

$\checkmark$ Aquatic macrophyte (MA): Pistia stratiotes collected in the Arroio Tucano river, located in the Domingos Zanette Ecological Park (Santa Terezinha de Itaipu/Paraná);

$\checkmark$ Whey (SO): Collected from dairy industry Located in Céu Azul/Paraná. 
$\checkmark$ Pig manure (PM): Collected in rural property on a family scale swine breeding, confined.

$\checkmark$ The BG and MA substrates were ground to reduce the particle size $(<10 \mathrm{~mm})$. The BG sample was dried for 24 hours at $60^{\circ} \mathrm{C}$ to ensure sample heterogeneity and eliminate extra water allowing the grinding process. The characterization was obtained through the analyzes of total solids (TS), volatile solids (VS) and $\mathrm{pH}$ (APHA, 2006).

\section{Biochemical methane potential (BMP)}

The determination of the BMP was performed using glass bottles with capacity of $100 \mathrm{~mL},(50 \%$ headspace), adopting the conditions established by the VDI 4630 (2006). The batch bottles were kept at $37^{\circ} \mathrm{C}$ in a water bath and the volume of biogas was measured by means of $100 \mathrm{~mL}$ glass syringe. The monitoring was performed from the daily biogas production and atmospheric pressure until the daily biogas volume was less than $1 \%$ of the accumulated volume. The biogas composition was determined by gas chromatography (ASTM D1945-14, 2014) in a chromatograph (Perkin Elmer - Clarus 680).

\section{Statistical analysis}

Analysis of variance (ANOVA) was applied to identify the significant difference between the treatments and the Tukey test $(\mathrm{p}<0,05)$ was used to evaluate differences among between means.

\section{RESULTS AND DISCUSSION}

Regarding the TS of the substrates, SO and SN presented the lowest values, $6 \%$ and $2 \%$ respectively. BG had the highest value with $87 \%$ and MA presented $21 \%$. The mesophilic inoculum presented a good VS value of $68 \pm 1 \% \mathrm{TS}$, and in the case the substrates BG presented the highest value ( $98 \pm 1 \% \mathrm{TS}$ ), followed by MA $(94 \pm 1 \% \mathrm{TS}), \mathrm{SO}(92 \pm 1 \% \mathrm{TS})$ and SN $(92 \pm 1 \% \mathrm{TS})$. The total solids content indicates the transformation potential of the organic matter present in the substrate in biogas (Table 1). The lowest $\mathrm{pH}$ was observed for the $\mathrm{SO}(3,1)$ (Table 1) and all of other substrates presented neutral $\mathrm{pH}$ values $(6,5$ to 7,5$)$ what is favorable for the growth of methanogenic bacteria.

The BMP of the substrates SO and SN presented the highest values for the accumulated methane production, being $314 \pm 24$ and $301 \pm 9 \mathrm{~L} \mathrm{CH}_{4} \mathrm{KgVS}^{-1}$, respectively (Figure 1a). Vivekanand et al. (2018) and Pham et al. (2014) reported lower values in their studies, being 264 and $211 \mathrm{~L} \mathrm{CH}_{4} \mathrm{~kg} \mathrm{VS}^{-1}$, respectively. This difference can be explained by the influence of swine production system and dairy industrial activity. The BMP of the BG was $249 \pm 18 \mathrm{~L} \mathrm{CH}_{4} \mathrm{Kg} \mathrm{VS}^{-1}$, this high result can be explained by the previous rupture of the lignocellulose in the pre-treatment. The macrophyte had the lower BMP $\left(43 \pm 3 \mathrm{~L} \mathrm{CH}_{4} \mathrm{KgVS}^{-1}\right)$ what the lack of chemical pre-treatment may be the reason.

The rate of hydrolysis (Figure 1b), showed it was observed that the maximum point of methane production was obtained by SO $\left(149 \mathrm{~L} \mathrm{CH}_{4} \mathrm{KgVS}^{-1}\right)$ and $\mathrm{BG}\left(53 \mathrm{~L} \mathrm{CH}_{4} \mathrm{KgVS}^{-1}\right)$ after two days. However, SO showed the highest production due to the presence of non-structural carbohydrates, mainly lactose (Escalante et al., 2017). The BG presented similar behavior, however, it was $35 \%$ lower than SO. For Rodriguez et al., (2017), the reduction of the particle diameter increases the contact of the biodegradable matter with the microorganisms but does not improve the yield of the methane production. SN showed the maximum methane production point on day six $\left(41 \mathrm{~L} \mathrm{CH}_{4} \mathrm{KgVS}^{-1}\right)$. However, the rate of hydrolysis remained constant between the second and sixth day due to the degradation stage of carbohydrates, proteins and lipids. In contrast, the rate of MA hydrolysis remained below $\left(5 \mathrm{~L} \mathrm{CH}_{4} \mathrm{KgVS}^{-1}\right)$, which may be explained by the presence of inhibitory compounds, such as heavy metals (Figure 1b).

The comparison between the volume of methane per gram of fresh matter, the substrates of SO, MA and SN show low production. This is due to the low TS content of the substrates. In this case, the BG presents better production $\left(212 \mathrm{~L} \mathrm{CH}_{4} \mathrm{Kg} \mathrm{FM}^{-1}\right)$, when compared to the other substrates, already the $\mathrm{SN}$ has worst case scenario (5 $\left.\mathrm{L} \mathrm{CH}_{4} \mathrm{Kg} \mathrm{FM}^{-1}\right)$ (Table 2).

\section{CONCLUSIONS}

On the basis of fresh matter, the BG presented the highest production when compared to the other substrates, as well as the SO that obtained the highest value in volatile solids (VS). However, biomasses that have a high generation of VFA (volatile fatty acids), high hydrolysis rate and low TS content are inhibited by acidification in biodigesters. 
An alternative would be the co-digestion, in which two or more substrates are used in a mixture for the production of methane, allowing the stabilization of the system and promoting the balance of nutrients, TS and trace elements through the complementation between the biomasses used, besides the dilution of potential toxic compounds and the increase in the load of biodegradable matter, maximizing the biogas production potential.

Therefore, the use of $\mathrm{SO}$ and $\mathrm{SN}$ in co-digestion with the other substrates presented favors the synergistic effects of both samples, increasing the methane content and the operation of the biodigesters.

\section{REFERENCES}

Agência Nacional de Energia Elétrica - ANEEL. Banco de Informações de Geração. Brasília: (2017). American Public Health Association - APHA. Standard methods for the examination of water and wastewater.21 ed. Washington: American Water Works Association, 2005. 1368 p.

EDWIGES, Thiago et al. Influence of chemical composition on biochemical methane potential of fruit and vegetable waste. Waste Management, v. 71, p. 618-625, 2018.

ESCALANTE, H., CASTRO, L., AMAYA, M. P., JAIMES, L., JAIMES-ESTÉVES, J. Anaerobic digestion of cheese whey: Energetic and nutritional potential for the dairy sector in developing countries. Waste management. v. 71, p. 711-718, 2017. Available at: < https://www.ncbi.nlm.nih.gov/pubmed/29017872> Accessed on: 20 nov. 2018.

TIAN, Hailin, et al. A proposed mechanism for the ammonia-LCFA synergetic co-inhibition effect on anaerobic digestion process, Chemical Engineering Journal (2018), Vol. 349, pág. 574 - 580. Doi: https://doi.org/10.1016/j.cej.2018.05.083

HOLLIGER, Christof, et al. Towards a standardization of biomethane potential tests. Water Science \& Technology (2016), Pág. 2515 - 2522. Available at: < https://www.ncbi.nlm.nih.gov/pubmed/27973356> Accessed on: 13 nov. 2018. Doi: https://doi.org/10.2166/wst.2016.336.

PHAM, C. H.; TRIOLO, J. M.; SOMMER, S. G. Predicting methane production in simple and unheated biogas digesters at low temperatures. Applied Energy, v. 136, p. 1-6, 2014. Elsevier. Available at: <https://www.sciencedirect.com/science/article/pii/S030626191400868X>. Accessed on: 23 nov. 2018.

RODRIGUEZ, C., ALASWAD, A., BENYOUNIS, K. Y., \& OLABI, A. G. Pretreatment techniques used in biogas production from grass. Renewable and Sustainable Energy Reviews, (2017). v.68, p. 1193-1204. Available at: <https://research-portal.uws.ac.uk/en/publications/pretreatment-techniques-used-in-biogasproduction-from-grass >. Accessed on: 20 nov. 2018. Doi:10.1016/j.rser.2016.02.022.

VEREIN DEUTSCHER INGENIEURE. VDI 4630: Fermentation of organic materials Characterisation of the substrate, sampling, collection of material data, fermentation tests. Düsseldorf, 2006. $92 \mathrm{p}$.

VIVEKANAND, V.; MULAT, D. G.; EIJSINK, V. G. H.; HORN, S. J. Synergistic effects of anaerobic codigestion of whey, manure and fish ensilage. Bioresource Technology, v. 249, p. 35-41, 2018. Elsevier. Available at: <https://www.sciencedirect.com/science/article/pii/S0960852417317340>. Accessed on: 23/11/2018.

Table 1. Characterization of inoculum and substrates.

\begin{tabular}{cccccc}
\hline Parameter & IN & MA & BG & SO & SN \\
\hline TS $(\%)$ & $3 \pm 0$ & $21 \pm 1$ & $87 \pm 1$ & $6 \pm 0$ & $2 \pm 0$ \\
VS (\% db) & $68 \pm 1$ & $94 \pm 1$ & $98 \pm 1$ & $92 \pm 1$ & $92 \pm 1$ \\
pH & 7.4 & 6,9 & NA & 3,1 & 8,1 \\
\hline
\end{tabular}

TS: total solids; VS: volatile solids; db: dried basis; NA: not applicable. 
Table 2. Methane production.

\begin{tabular}{ccc}
\hline Substrate & LN CH $\mathbf{~} \mathbf{~ k g ~ V S}^{-\mathbf{1}}$ & LN CH$_{\mathbf{4}} \mathbf{~ k g ~ F M}^{\mathbf{1}}$ \\
\hline SO & $314 \pm 24 \mathrm{a}$ & $17 \pm 1 \mathrm{~b}$ \\
SN & $301 \pm 9 \mathrm{a}$ & $5 \pm 0 \mathrm{~b}$ \\
BG & $249 \pm 18 \mathrm{~b}$ & $212 \pm 16 \mathrm{a}$ \\
MA & $43 \pm 3 \mathrm{c}$ & $8 \pm 1 \mathrm{~b}$ \\
\hline
\end{tabular}

* Different letters indicate significant differences by Tukey test $(p \leq 0,05)$. FM: fresh matter.

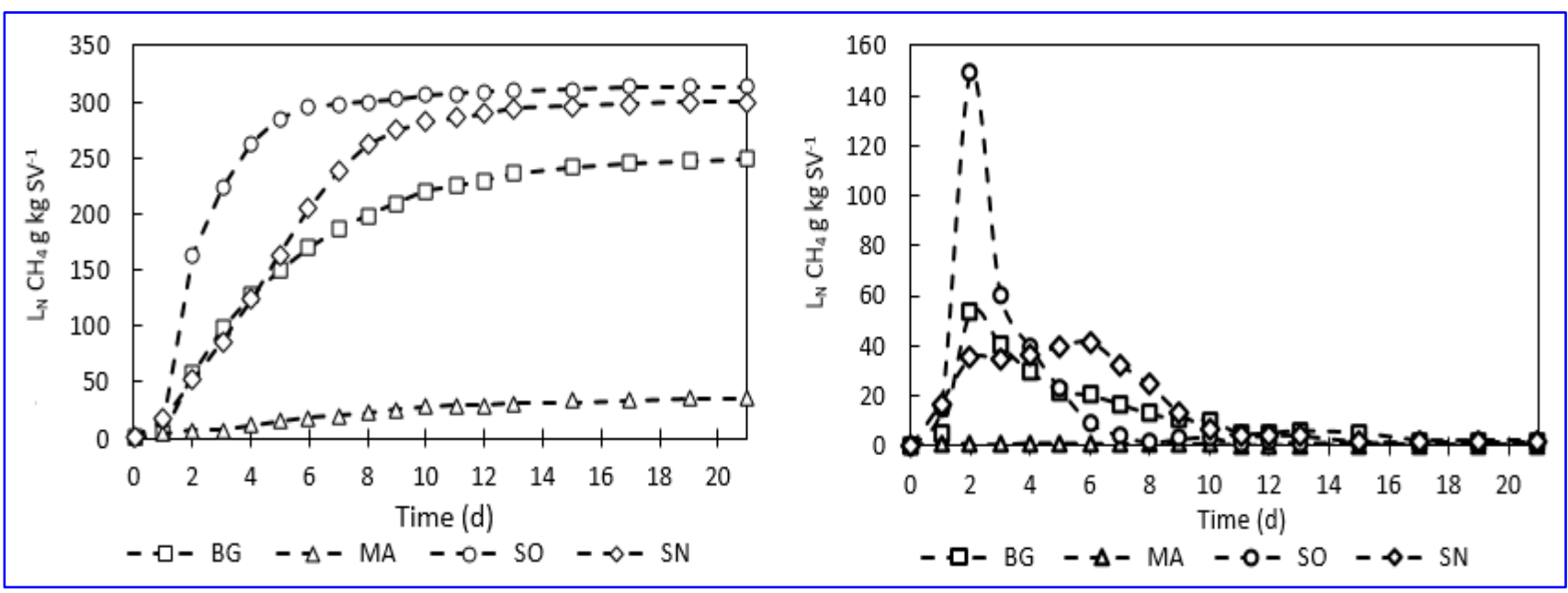

Figure 1. Cumulative methane (a) e Daily methane (b) 


\title{
CONSTRUÇÃO DE UM BIODIGESTOR PARA A PRODUÇÃO DE BIOGÁS A PARTIR DE DEJETOS BOVINOS
}

\author{
Silva, L.F.S.*1; Leidens, N. ${ }^{\text {; }}$; Nunes, I.S. ${ }^{1}$; Neto, E.R. ${ }^{1}$ \\ ${ }^{1}$ Universidade Regional Integrada do Alto Uruguai e das Missões (URI), Santo Ângelo, RS - Brasil. \\ luisfelipesachs@hotmail.com.br
}

\begin{abstract}
RESUMO: Por questões ambientais e econômicas, a busca por novas fontes de energia e combustíveis tem sido cada vez mais visada, dentre essas está o biogás que provém da digestão anaeróbia da matéria orgânica, ou seja, processo isento de oxigênio efetuado por microrganismos anaeróbios. Os equipamentos utilizados nesse processo são os biodigestores. O biogás é constituído principalmente de metano que pode ser utilizado como fonte de energia térmica, elétrica e mecânica. O líquido gerado na fermentação é rico em nutrientes essências para o cultivo de plantas e pode ser utilizado com um fertilizante foliar, complementando a adubação orgânica. $\mathrm{O}$ presente trabalho teve por objetivo construir um biodigestor para efetuar a digestão anaeróbia de dejetos de bovinos, para deste obter o biogás. Para a biodigestão foram utilizados resíduos bovinos, onde foram adicionados $31 \mathrm{~kg}$ de esterco dissolvidos em água, totalizando $130 \mathrm{~L}$. Após a alimentação do equipamento, deu-se início a produção de biogás, que durou 56 dias. As pressões observadas no manômetro foram registradas diariamente e, ao final do processo, os manômetros registravam uma pressão de 3,94 $\mathrm{mH}_{2} \mathrm{O}$. O volume de gás gerado foi de $0,0787 \mathrm{~m}^{3}$. Com base em dados preestabelecidos da quantidade de gás que pode ser gerado através dos dejetos bovinos, foi encontrada uma eficiência de $25,4 \%$ na produção do biogás, principalmente devido às temperaturas baixas registradas durante o processo.
\end{abstract}

Palavras-chave: dejetos bovinos, biodigestor, biogás.

\section{CONSTRUCTION OF A BIODIGESTER FOR BIOGAS PRODUCTION FROM BOVINE MANURE}

\begin{abstract}
For environmental and economic reasons, the search for new sources of energy and fuel has been increasingly targeted. Among of these new sources is the biogas that comes from the anaerobic digestion of organic matter, an oxygen-free process performed by anaerobic microorganisms. The equipment used in this process are biodigesters. Biogas consists basically of methane that can be used as a source of thermal, electrical and mechanical energy. The liquid generated in the fermentation is rich in essential nutrients for plant cultivation, which can be used as fertilizer, complementing organic fertilization. The aim of the present work was to build a biodigester to conduct the bovine manure anaerobic digestion in order to obtain biogas. For the biodigestion, it was used a mix of bovine manure, being $31 \mathrm{~kg}$ of manure, dissolved in water, totaling $130 \mathrm{~L}$. After the equipament feeding, the biogas production has begun, which lasted 56 days. The pressures observed in the manometer were recorded daily and at the end of the experiment the manometers registered a pressure of 3,94 $\mathrm{mH}_{2} \mathrm{O}$. The volume of gas generated was $0.0787 \mathrm{~m}^{3}$. Based on pre-established data on the amount of gas that can be generated through bovine waste, a $25.4 \%$ efficiency in biogas production was found, mainly due to the low temperatures recorded during the process.
\end{abstract}

Keywords: bovine manure, biodigester, biogas.

\section{INTRODUÇÃO}

Os resíduos gerados da atividade pecuária são constituídos por esterco e outros resíduos provenientes da atividade biológica de suínos, aves, bovinos, entre outros animais. Estes resíduos são matéria-prima importante para a produção de biogás e fertilizante orgânico por meio da digestão anaeróbia, por possuírem uma composição com alto teor de matéria orgânica (FEISTEL, 2011).

Os dejetos de bovinos geram altos índices de poluição quando lançados sem tratamento nos corpos hídricos. Além do volume produzido, é preocupante também a composição físico-química e microbiológica dos dejetos de bovinos. Pelo fato de possuir altas concentrações de nutrientes como nitrogênio e fósforo, e a elevada concentração de sólidos voláteis em relação aos sólidos fixos, conferem a esses dejetos um elevado potencial poluidor (ZANETTE, 2009). 
Caso não haja um descarte correto dos resíduos gerados na criação de bovinos por confinamento, resultará em sérios impactos aos mananciais, tanto superficiais como subterrâneos, mau cheiro (odores), a concentração de amônia no ar, o nitrato na água subterrânea, o elevado potencial de eutrofização dos corpos de água superficiais, a exasperação de aspectos sanitários e a geração de dióxido de carbono, principal responsável pelo aquecimento global (CABRAL, 2011).

Desse modo, os processos anaeróbios de tratamento e armazenamento se apresentam como uma solução adequada nas propriedades de criação de gado e em abatedouros no sentido de minimizar a poluição e os impactos ambientais provenientes dos dejetos de bovinos, pois valorizam este efluente do ponto de vista energético, com a produção de biogás e como biofertilizante para agricultura. Os dejetos bovinos apresentam um potencial de geração de biogás de $0,25 \mathrm{~m}^{3}$ por dia, aproximadamente (CABRAL, 2011).

Diante do exposto, o objetivo deste trabalho foi construir um biodigestor e avaliar a eficiência da digestão anaeróbia de dejetos bovinos na geração de biogás.

\section{MATERIAL E MÉTODOS}

A Figura 1 mostra o biodigestor construído para a produção de biogás a partir de dejetos bovinos. Em um tambor de $200 \mathrm{~L}$ foram feitas duas aberturas na parte de cima e uma na região inferior. Em uma das aberturas foi feita a alocação do manômetro. Na outra abertura da parte superior alocou-se a mangueira de gás. $\mathrm{Na}$ parte inferior do reator foi instalado um registro de globo para retirada do biofertilizante. Em outro tambor de 200 L, que foi utilizado como reservatório do biogás, fez-se 3 aberturas para acoplar os flanges. Em um dos flanges foi embutida a mangueira de entrada do gás. Outra mangueira foi acoplada em um dos flanges do reservatório para a retirada do gás gerado, junto com o registro de gás e a válvula de segurança. Outro manômetro também foi acoplado na parte superior do reservatório de gás.

Os dejetos utilizados foram cedidos por um frigorífico situado na cidade de Santo Ângelo (RS), que trabalha com abate de bovinos. Os resíduos foram previamente diluídos em água, sendo utilizados 23,4 kg de esterco bovino para cada 100 L de água. Então, 130 L da mistura foram despejados na câmara de fermentação. Estes resíduos ficaram contidos no biodigestor por 56 dias, média de tempo de residência necessário para que a fermentação completa ocorresse. Após isso, os resíduos foram retirados do biodigestor pela abertura do registro de gás e do registro de saída da biomassa fermentada.

O volume de gás gerado foi determinado a cada 24 horas através de leituras da pressão no manômetro. O cálculo de volume de gás produzido foi efetuado com o uso da Equação de Clapeyron, que considera o sistema como um gás ideal.

\section{RESULTADOS E DISCUSSÃO}

Após ser realizada a montagem do biodigestor e a efetuação de testes de resistência, foi efetuada a alimentação de resíduos no interior do reator. Então observou-se diariamente o aumento da pressão no interior do equipamento. Os aumentos diários de pressão foram pequenos e, por esse motivo, foram analisados os aumentos de pressão semanalmente, conforme a Tabela 1. As pressões foram convertidas para metros de água para adequá-las a equação de quantificação de biogás gerado.

A digestão anaeróbica depende diretamente da temperatura. A produção de gás foi efetuada durante o outono, nos meses de abril e maio de 2018. As primeiras cinco semanas obtiveram uma produção de gás relativamente efetiva. Observou-se que a segunda semana apresentou um pico no aumento da pressão, que pode ser relacionado as altas temperaturas registradas nesse período.

Na semana 6 observou-se uma pequena queda na produção do gás, devido a quedas na temperatura, onde registrou-se uma mínima de $11^{\circ} \mathrm{C}$, sabe-se que a produção de gás praticamente cessa em temperaturas inferiores a $15^{\circ} \mathrm{C}$ (CABRAL, 2011). Na semana 7 as temperaturas continuaram baixando, e observou-se uma brusca queda no aumento da pressão. Na semana 8 o aumento da pressão foi mínimo, devido as baixas temperaturas e a diminuição da capacidade de produção devido ao longo tempo de retenção da amostra dentro do equipamento. Esses dados comprovam a baixa eficácia do biodigestor em baixas temperaturas, sinalizando a necessidade de haver outro método para mantê-lo aquecido em temperaturas favoráveis a ação das bactérias metanogênicas.

O reator foi alimentado com $130 \mathrm{~L}$ da mistura de esterco e água, esta continha $31 \mathrm{~kg}$ de esterco bovino, o tempo de retenção foi de 56 dias. Ao final desses dias obteve-se uma produção de biogás de $0,0787 \mathrm{~m}^{3}$ de gás, apresentando uma eficiência de aproximadamente $25,4 \%$ na produção de biogás, calculada em relação aos 
dados fornecidos por Cabral (2011). A produção de gás em relação ao tempo de retenção está exposta na Tabela 2.

O volume de biogás é diretamente proporcional a pressão dentro do equipamento, levando-se em consideração que os aumentos de pressão foram relativamente baixos durante o processo a produção do biogás também foi baixa.

Testes de chama foram realizados semanalmente, porém na primeira semana não se obteve chama. A partir da segunda semana já se obteve a chama, a mesma aumentou conforme o aumento do volume de gás no interior do equipamento, devido à pressão exercida. A obtenção da chama comprovou a efetividade do equipamento na produção de biogás.

\section{CONCLUSÃO}

Os biodigestores representam uma ótima finalidade para as grandes quantidades de resíduos orgânicos gerados diariamente por inúmeros meios, o que acarreta em uma diminuição da poluição causada pelos mesmos. O biogás que é o principal produto gerado na digestão anaeróbica pelas bactérias metanogênicas dentro desses equipamentos demonstrou ser eficiente na geração de energia térmica. $\mathrm{O}$ modelo construído neste trabalho demonstrou ser um equipamento eficaz na produção de biogás como produto principal e de biofertilizante como subproduto. Porém apresentou um baixo rendimento na produção do biogás $(25,4 \%)$, devido às temperaturas registradas durante o processo. Pelo fato da digestão anaeróbica depender diretamente da temperatura do meio, o processo se torna ineficaz em meses de temperaturas baixas. Isso demonstra a necessidade da implantação de tecnologias para manter a biomassa aquecida para promover um meio favorável às bactérias metanogênicas atuarem sobre ela. Contudo, o biodigestor demonstrou ser um equipamento de fácil construção, que opera de forma segura, não permitindo que a pressão no interior exceda a pressão crítica. Os manômetros auxiliam nesse controle de pressão de forma visual, além de atuar com indicador da quantidade de gás que o equipamento possui.

\section{REFERÊNCIAS}

CABRAL, C. Valorização energética do biogás da digestão anaeróbica de resíduos pecuários. 2011.87 f. Trabalho de Conclusão de Curso (Graduação em Engenharia Sanitária e Ambiental) - Universidade Federal de Santa Catarina, Florianópolis, 2011.

FEISTEL, J. Tratamento e destinação de resíduos e efluentes de matadouros e abatedouros. $2011.37 \mathrm{f}$. Seminários Aplicados (Mestrado em Ciência Aninal) - Universidade Federal de Goiás, Gôiania, 2011.

ZANETTE, A. Potencial de aproveitamento do biogás no Brasil. 2009. 105 f. Dissertação (Mestrado em Planejamento Estratégico) - Universidade Federal do Rio de Janeiro, Rio de Janeiro, 2009.

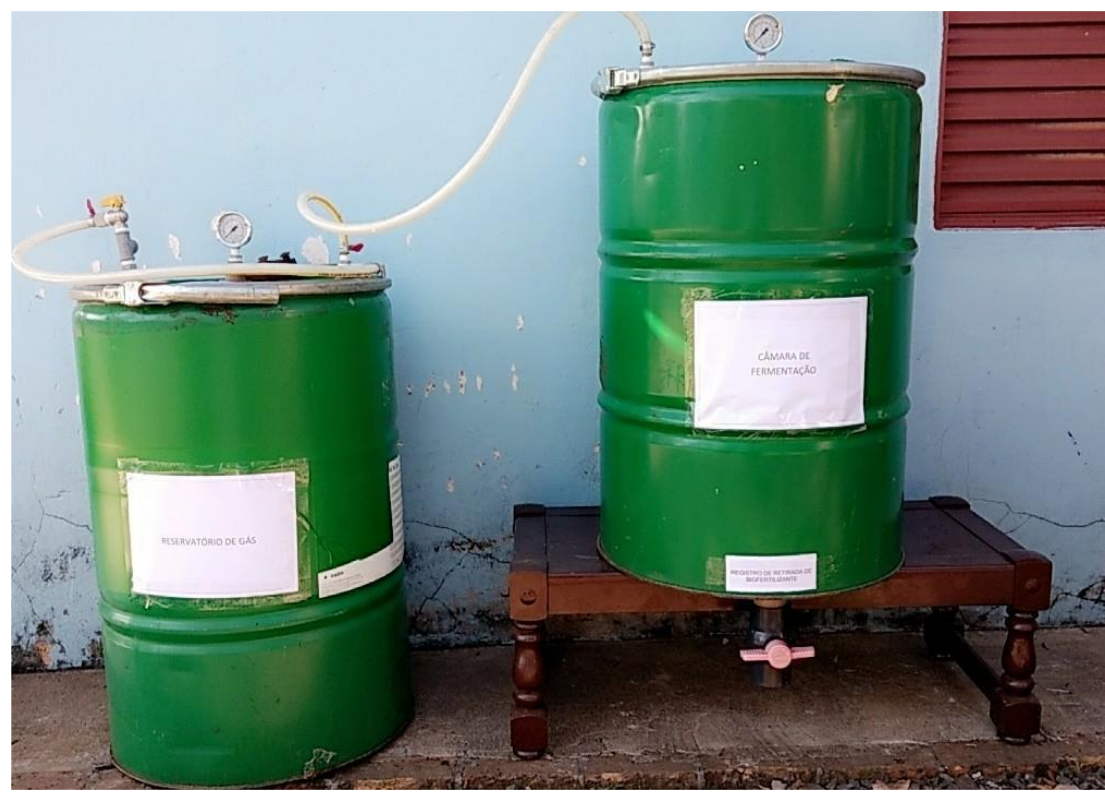

Figura 1. Biodigestor construído para a produção de biogás a partir de dejetos bovinos. 
Tabela 1. Registro das pressões em relação ao tempo de retenção.

\begin{tabular}{ccc}
\hline Semana & $\begin{array}{c}\text { Aumento da pressão } \\
\left(\mathrm{mH}_{2} \mathrm{O}\right)\end{array}$ & $\begin{array}{c}\text { Variação da pressão } \\
\left(\mathrm{mH}_{2} \mathrm{O}\right)\end{array}$ \\
\hline 1 & 0,633 & 0,633 \\
2 & 1,406 & 0,773 \\
3 & 2,039 & 0,635 \\
4 & 2,672 & 0,632 \\
5 & 3,304 & 0,630 \\
6 & 3,727 & 0,422 \\
7 & 3,867 & 0,140 \\
8 & 3,937 & 0,070 \\
\hline
\end{tabular}

Tabela 2. Volume de gás produzido durante o processo.

\begin{tabular}{ccc}
\hline Semana & $\begin{array}{c}\text { Volume semanal } \\
\left(\mathrm{m}^{3}\right)\end{array}$ & Volume acumulado $\left(\mathrm{m}^{3}\right)$ \\
\hline 1 & 0,013 & 0,013 \\
2 & 0,015 & 0,028 \\
3 & 0,013 & 0,041 \\
4 & 0,012 & 0,053 \\
5 & 0,011 & 0,066 \\
6 & 0,008 & 0,075 \\
7 & 0,003 & 0,077 \\
8 & 0,001 & 0,079 \\
\hline
\end{tabular}




\title{
DETERMINAÇÃO DO PODER CALORÍFICO EXPERIMENTAL DO RESÍDUO DE DESPOLPAMENTO DA FRUTA MARACUJÁ
}

\author{
Souza, A.L.B.*1; Marana, K.B.B.'; Rodrigues, D.S.'; Colato, G.A. ${ }^{\text {; }}$ Toneli, J.T.C.L. ${ }^{1}$ \\ ${ }^{1}$ Programa de Pós-Graduação em Energia, Universidade Federal do ABC, Santo André, SP - Brasil. \\ decobritos@yahoo.com.br
}

\begin{abstract}
RESUMO: O Brasil é o maior produtor e consumidor mundial de maracujá, sendo uma fruta tropical que produz uma grande quantidade de resíduos em seu processo. Como esse resíduo é mais de $60 \%$ da massa da fruta, há um problema direcionado ao descarte do mesmo. Uma forma de agregar valor econômico e financeiro à indústria de maracujá seria utilizar o resíduo como fonte de combustível em um processo de conversão de biomassa em energia. O objetivo deste trabalho foi caracterizar amostras de resíduos de maracujá por meio da análise do teor de umidade e do poder calorífico experimental, visando seu aproveitamento energético, de forma a obter informações iniciais que ajudem a definir a melhor rota de conversão desta biomassa: termoquímica ou bioquímica. Após análises, concluiu-se que a via de utilização da biomassa mais adequada seria a biodigestão anaeróbia devido ao elevado teor de umidade apresentado nas amostras (maior que 80\%). No entanto, os mesmos, se em base seca, também possuem alto poder calorífico, comparados, por exemplo, com o bagaço de cana. Com os resultados, foi demonstrado que a biomassa da polpa de maracujá se apresenta como alternativa em potencial para o aproveitamento energético.
\end{abstract}

Palavras-chave: biomassa, biometanização, energia, maracujá, termoquímico.

\section{DETERMINATION OF THE EXPERIMENTAL CALORIFIC PERFORMANCE OF PASSION FRUIT SPREADING WASTE}

\begin{abstract}
Brazil is the world's largest producer and consumer of passion fruit, being a tropical fruit that produces a lot of waste in its process. As this residue is more than $60 \%$ of the mass of the fruit, there is a problem directed to the discard of the same. One way to add economic and financial value to the passion fruit industry would be to use the waste as a source of fuel in a process of converting biomass to energy. The objective of this work was to characterize samples of passion fruit residues by analyzing the moisture content and the experimental calorific value, aiming at its energy utilization, in order to obtain initial information to help define the best conversion path of this biomass: thermochemistry or biochemistry. After analysis, it was concluded that the most appropriate biomass utilization route would be anaerobic biodigestion due to the high moisture content presented in the samples (greater than 80\%). However, the same ones, if in dry basis, also have high calorific value, compared, for example, with sugarcane bagasse. With the results, it was demonstrated that the biomass of the passion fruit pulp presents itself as a potential alternative for the energy utilization.
\end{abstract}

Keywords: biomass, biomethanization, energy, passion fruit, thermochemical.

\section{INTRODUÇÃO}

Maracujá é uma denominação geral dada ao fruto e à planta do gênero passiflora, uma planta de origem tropical, rica em vitamina $\mathrm{C}$, cálcio e fósforo. O Brasil é o maior produtor e consumidor mundial de maracujá por ano, sendo as espécies com maior expressão comercial é a Passiflora edulis (maracujá-azedo) devido a sua qualidade de frutos e do maior rendimento industrial (FALEIRO, 2016).

$\mathrm{Na}$ indústria de processamento do suco do maracujá, o descarte ou o destino dos resíduos representam um crescente problema, devido ao aumento da produção a cada ano, uma vez que esses resíduos constituem a maior parte do peso do fruto, cerca de 60 a $70 \%$ total (MELETTI, 2011).

Esses resíduos são compostos basicamente de cascas e sementes provenientes do processo de extração de polpa para destinação final em sucos, refrescos ou doces. São um problema para o meio ambiente devido à grande quantidade descartada para aterros ou problema de custos por serem enviadas como insumos de compostagem. Esse descarte representa milhares de toneladas que poderiam gerar algum valor econômico para indústria. 
Segundo emprapa (2016), se estima que 60\% dessa produção de 1 milhão de toneladas por ano de maracujá ao ano seja comercializado in natura, ou seja, como fruta de mesa ou sem fins industriais (FALEIRO, 2016). Sendo os outros $40 \%$ destinado ao processamento industrial e tendo um rendimento médio de $35 \%$ do despolpamento devido à alta quantidade de bagaço e sementes, pode se chegar a uma quantidade estimada de 260 mil toneladas de resíduos ao ano.

Agregar valor a estes subprodutos é de interesse econômico, científico e tecnológico. As sementes e cascas podem ser utilizadas na suplementação da alimentação animal, como ração para bovinos e aves, mas ainda sem uma informação técnica adequada. As sementes, cerca de 6 a 12\% total do peso do fruto, podem ser boas fontes de óleo, carboidrato, proteínas e minerais, apesar do alto conteúdo de celulose e lignina que limita seu uso na alimentação animal (FERRARI, 2004).

Outra forma que poderia agregar valor a essa cadeia de fornecimento e industrialização, seria utilizar esse resíduo como forma de produção de energia através de sua biomassa. A biomassa, que contém energia química proveniente da conversão da energia luminosa graças à fotossíntese, tem sido cogitada como uma das alternativas aos combustíveis fósseis pelas suas características ambientais, renovável, por possuir baixo preço, ser farta e possuir um potencial de produção no limite das terras cultiváveis que o planeta oferece (ROSILLOCALLE, 2004).

De acordo EPE (2017), o Brasil possui cerca de 17,5\% da matriz energética advinda da biomassa da cana (EPE, 2017). Se considerar o valor apresentado nesse mesmo relatório para lenha e carvão vegetal, outros produtos também advindos da biomassa, teríamos adicionados mais $8 \%$ de representatividade de fontes renováveis vindas de biomassa no Brasil.

Esse estudo visa estudar o aproveitamento dessa energia da biomassa de cascas e sementes de maracujá, proveniente de uma indústria de despolpamento de frutas presente no norte do estado do Espirito Santo Brasil, por meio da caracterização destes resíduos, analisando-se seu teor de umidade e Poder Calorífico experimental, de forma a obter informações iniciais que ajudem a definir a melhor rota de conversão desta biomassa: termoquímica ou bioquímica.

\section{Preparo das amostras}

\section{MATERIAL E MÉTODOS}

As amostras de biomassa residual do processamento de maracujá foram coletadas da etapa do processo de despolpamento. Foram obtidas três amostras, cada uma num intervalo de 1 hora, a fim de garantir uma representatividade dos resíduos, cujas massas foram de $1,150 \mathrm{~kg}, 1,805 \mathrm{~kg}$ e $0,6 \mathrm{~kg}$. As frações coletadas foram misturadas, totalizando $3,553 \mathrm{~kg}$ de amostras, as quais foram acondicionadas em sacos plásticos de polietileno de baixa densidade (PEBD).

O produto acondicionado e homogeneizado foi levado da cidade de Linhares - ES de transporte aéreo para o laboratório da Universidade Federal do ABC (LACABIO/UFABC) -SP, onde foram conduzidos alguns ensaios de caracterização. Assim, as amostras foram trituradas em um aparelho Philips modelo RI2034/21 para garantir a homogeneidade total dos resíduos que possuem cascas, talos, folhas e sementes.

\section{Análises laboratoriais}

Umidade

As amostras homogeneizadas e trituradas foram encaminhadas para um forno de circulação forçada de ar, a $70^{\circ} \mathrm{C}$, até massa constante, uma vez que o teor de sólidos totais é calculado excluindo o teor de umidade.

Todas as determinações de massa foram realizadas utilizando uma balança analítica balança semianalítica BL-320H do fabricante Shimadzu com capacidade de $320 \mathrm{~g}$, reduzindo assim o tamanho de partículas, aumentando sua superfície de contato e todas as análises foram realizadas em triplicata.

Para calcular a umidade foi utilizada a equação 1:

$$
W=100-\left[\left(\frac{m_{f}-m_{c}}{m_{a}}\right)-100\right]
$$

Em que: $\mathrm{m}_{f}$ é a massa final após secagem, em gramas;

$\mathrm{m}_{c}$ é massa do cadinho, em gramas;

$\mathrm{m}_{\mathrm{a}}$ é a massa da amostra antes da secagem (in natura), em gramas. 


\section{Poder calorífico}

O PCS (Poder Calorífico Superior) em base seca foi determinado através de uma bomba calorimétrica (C2000, IKA), de acordo com a norma ASTM D2015-00 Standard Test Method for Gross Calorific Value of Coal and Coke by the Adiabatic Bomb Calorimeter (2000).

$\mathrm{O}$ método constituiu em confeccionar pastilhas ou pequenos briquetes de $1 \mathrm{~g}$ de biomassa com uma prensa. Essas pastilhas foram colocadas em um cadinho junto a um fio de algodão, que é o responsável a fazer a ignição junto a um fio de ignição. A bomba foi pressurizada com oxigênio a 30bar e mergulhada em água para garantir uniformidade da temperatura ao redor da bomba.

Após isso, o processo é automático, onde apenas necessário inserir os dados, e com a biomassa analisada, aguardar cerca de 9 minutos para coletar o resultado.

\section{RESULTADOS E DISCUSSÃO}

O teor de umidade da amostra em triplicata, bem como sua média, encontra-se na Tabela 1. Segundo a literatura, a casca do maracujá possui 88,37\% $\pm 0,17$ de umidade, o que indica que a análises realizadas com a soma de casca e sementes possui um valor relativamente próximo (CORDOVA, 2005).

O resultado da análise do poder calorífico superior obtido experimentalmente das amostras de resíduos de maracujá é apresentado também na Tabela 1 tanto para sua triplicata quanto o valor médio calculado.

Na Tabela 2, é possível observar um comparativo das umidades e poder calorífico superior encontradas em análise experimental com outras biomassas utilizando a mesma referência de análise. Nas análises mostram que o item na base seca possui um bom potencial termoquímico devido ao alto poder calorífico.

\section{CONCLUSÃO}

A umidade encontrada, em torno de $84 \%$, é indesejada a processo termoquímico e desejável a rota bioquímica. Isso faz com que essa última rota seja a mais indicada. Entretanto, são necessários estudos mais aprofundados a respeito dessa rota, uma vez que não foram realizadas os testes e estudos de biodigestão anaeróbia e os impactos que o $\mathrm{pH}$ da biomassa pode interferir no processo biológico.

Para a rota termoquímica, possui um PCS mais alto comparado a outras biomassas, e próximo do bagaço de cana, uma importante fonte energética na matriz energética brasileira. Sendo extraída a umidade, a biomassa analisada possui alto potencial energético para esses processos. São necessários estudos mais aprofundados a respeito dessa rota, como exemplo composição elementar, a fim de avaliar o potencial total de utilização nessa rota.

\section{REFERÊNCIAS}

CORDOVA, Katielle R. Voncik; Gama, Thais M. M. Tavares Bastos; Winter, Cristina M. Guolo; Neto, Georges Kaskantzis; Freitas, Renato João Sossela. Características físico-químicas da casca do maracujá amarelo (Passiflora edulis Flavicarpa Degener) obtida por secagem. B.Ceppa, Curitiba, v.23, n.2 p. 221 230, jan./jun. 2005.

Empresa de Pesquisa Energética (EPE).Ministério de Minas e Energias. Balanço Energético Nacional. Relatório Síntese | Ano base 2016 |. Rio de Janeiro, RJ, Junho de 2017.

FALEIRO G.F.O, JUNQUEIRA,N. JUNQUEIRA. T.V., Editores técnicos. Maracujá: o produtor pergunta, a Embrapa responde. Brasília, DF. Embrapa, 2016.

FERRARI, R.A.; COLUSSI, F.; AYUB, R.A. Caracterização de subprodutos da industrialização do maracujá - aproveitamento das sementes. REV. BRAS. FRUTIC., Jaboticabal - SP, v. 26, n. 1, p. 101-102, abril 2004.

MARANA, K.B.B.; SILVA, C.A.; TONELI, J.T.C.L.; NETO, A.M.P.;ANTONIO,G.C. Comparativo de metodologia de análise imediata visando o processamento termoquímico de conversão energética da fração orgânica de RSU do município de Santo André. 6th International Conference on Engineering for Waste and Biomass Valorisation - May 23-26, 2016 - Albi, France.

MELETTI,L.M.M. Avanços na cultura do maracujá no Brasil. REV BRAS FRUTIC, VOL ESP:83-91. 2011 .

NIÑO, A.D.L. Caracterização da biomassa residual de cana-de-açúcar visando seu aproveitamento energético. Universidade Federal do ABC, 2014. 
RODRIGUES, D. S.; DE SANTANA, A.R; RÍOS, J.M.G.; GADELHA, M.T.; TONELI, J.T.C.L.; ANTONIO, G.C. Propriedades físicas, químicas e potencial energético de biomassas da região amazônica. Universidade Federal do ABC, 2016.

RODRIGUES, D.S.; SANTANA, A.R.; RÍOS, J.M.G.; MARANA, K.B.B.; SILVA, C.A.; TONELI, J.T.C.L.; ANTONIO, G.C. Energetic potencial of tropical biomass. Universidade Federal do ABC, 2016.

ROSILLO-CALLE, F. Uma breve análise do potencial da biomassa no Brasil. RENABIO: Biomassa \& Energia, v. 1, n. 3, p. 225-236, 2004.

Tabela 1. Resultados obtidos nas análises do teor de umidade e de Poder Calorífico Superior das amostras de despolpamento da fruta maracujá.

\begin{tabular}{ccc}
\hline & \multicolumn{2}{c}{ Parâmetros } \\
\hline Amostras & $\begin{array}{c}\text { Umidade } \\
(\mathbf{\%})\end{array}$ & $\begin{array}{c}\mathbf{P C S}(\mathbf{M J} \\
\left.\mathbf{K g}^{-1}\right)\end{array}$ \\
\hline 1 & 84,26 & 18,97 \\
2 & 85,51 & 19,23 \\
3 & 82,87 & 19,11 \\
Média & $\mathbf{8 4 , 2 1}$ & $\mathbf{1 9 , 1 0}$ \\
\hline
\end{tabular}

Tabela 2. Comparativo entre biomassa estudada e outras biomassas utilizando o mesmo procedimento de literatura.

\begin{tabular}{cccc}
\hline Biomassa & Umidade $\mathbf{\%})$ & PCS $\left(\mathbf{M J ~ K g}^{-1}\right)$ & Referências \\
\hline Maracujá (cascas + sementes após despolpamento) & 84,52 & 19,1 & - \\
Ouriço Castanha-do-Pará & 9,71 & 18,95 & RODRIGUES ET AL. \\
Casca Castanha-do-Pará & 11,02 & 19,53 & RODRIGUES ET AL. \\
RSU Santo André (CRAISA) & 71,48 & - & MARANA \\
Bagaço de Cana (pós moenda) & 50,88 & 19,17 & NIÑO \\
Semente Caroço de Açaí & 12,43 & 17,93 & RODRIGUES ET AL. \\
Casca Coconut & - & 17,69 & RODRIGUES ET AL. \\
\hline
\end{tabular}




\title{
DYNAMICS OF CARBON DIOXIDE CAPTURE AND EMISSION IN AN INTEGRATED BIOPROCESS
}

\author{
Severo, I.A. ${ }^{\text {; }}$ Lasta, P. ${ }^{* 1}$; Pujol, S.B. ${ }^{2}$; Bizello, R.S. ${ }^{1}$; Zepka, L.Q. ${ }^{1}$; Jacob-Lopes, E. ${ }^{1}$ \\ ${ }^{1}$ Department of Food Science and Technology, Federal University of Santa Maria (UFSM), Santa Maria, RS - Brazil \\ ${ }^{2}$ Department of Soil Science, Federal University of Santa Maria (UFSM), Santa Maria, RS - Brazil \\ ihana.aguiar@gmail.com
}

\begin{abstract}
The objective of this work was to evaluate the dynamics of carbon dioxide capture and emissions in an integrated bioprocess. The experiments were performed in a bubble column photobioreactor with volume of $2 \mathrm{~L}$, luminous intensity of $15 \mu \mathrm{mol} / \mathrm{m}^{2} / \mathrm{s}$, aeration of $1 \mathrm{VVM}$ with air injection enriched with $15 \% \mathrm{CO}_{2}$. The photobioreactor was integrated into a bio-combustion furnace designed on a laboratory scale, where the emissions were evaluated. The fuel used was the petroleum coke. The experimental conditions in the were: initial coke mass $1.0 \mathrm{~g}$, total combustion time of $20 \mathrm{~min}$ and air flow $1.0 \mathrm{~L} / \mathrm{min}$. A gas chromatograph to determine greenhouse gases emissions was used. The results showed a $\mathrm{CO}_{2}$ capture and $\mathrm{O}_{2}$ production in the photobioreactor of 0.46 and $0.40 \mathrm{~kg} / \mathrm{m}^{3}$, respectively. Furthermore, the $\mathrm{CO}_{2}$ emissions in the furnace were $0.71 \mathrm{~kg} / \mathrm{m}^{3}$. In this sense, the photobioreactor demonstrated the ability to capture carbon and produce bioproducts, and when integrated in a bio-combustion process, presented the potential to mitigate $\mathrm{CO}_{2}$.
\end{abstract}

Keywords: microalgae, photobioreactor, carbon capture, bio-combustion, greenhouse gas.

\section{INTRODUCTION}

The impending energy crisis related to the massive use of fossil resources has caused serious environmental damage mainly due to carbon dioxide $\left(\mathrm{CO}_{2}\right)$ emissions (De Bhowmick et al., 2019). According to the International Energy Agency, global energy needs are expected to increase by $55 \%$ by 2030 at a rate of $1.8 \%$ per year (IEA, 2018).

Given these estimates, several technologies for carbon capture, utilization, and storage by physical and chemical methods have been suggested to reduce atmospheric levels of $\mathrm{CO}_{2}$ and other polluting gases (Zhu et al., 2017). Among the various options available, biological carbon capture and utilization (BCCU) by microalgae is considered as a biotechnological route with application potential to the treatment and reuse of gaseous effluents, especially towards the carbon neutral footprint (Moreira and Pires, 2016).

Microalgae-based processes are developed in photobioreactors whose cultivation systems are designed to obtain double benefit: to achieve an efficient $\mathrm{CO}_{2}$ bioconversion rate and to generate several interesting products, for example, $\mathrm{O}_{2}$ and volatile organic compounds (VOCs) (Jacob-Lopes et al., 2010). These metabolic products could be integrated into industrial systems as improved thermal performance of bio-combustion equipment, as demonstrated previously in Severo et al. (2018), where $\mathrm{O}_{2}$ and VOCs could be used as an oxidizer and gaseous fuels, respectively.

Therefore, the process integration engineering strategy seems to be a viable alternative to solve the sustainability issues that resilient fossil-based processes play in nature. Therefore, although considered sustainable, it is necessary to evaluate microalgae processes in terms of environmental performance through GHG emissions (Deprá et al., 2018).

In this sense, the objective of this work was to evaluate the dynamics of $\mathrm{CO}_{2}$ capture and emission in an integrated bioprocess.

\section{Microorganism and culture conditions}

\section{MATERIAL AND METHODS}

The microalgae used was the Scenedesmus obliquus CPCC05, obtained from the Canadian Phycological Culture Centre. Stock cultures were propagated and maintained in synthetic BG-11 medium (Rippka et al., 1979) and $\mathrm{pH}$ 7.6. The incubation conditions used were $30^{\circ} \mathrm{C}$, photon flux density of $15 \mu \mathrm{mol} \mathrm{m} \mathrm{m}^{-2} \mathrm{~s}^{-1}$ and a photoperiod of $12 \mathrm{~h}$. 


\section{Description of the integrated bio-combustion systemn - Photobioreactor design and obtaining the kinetic data}

Measurements were made in a bubble column photobioreactor (Maroneze et al., 2016), operating in batch mode, fed with $2 \mathrm{~L}$ of culture medium, initial cell concentration of $0.1 \mathrm{~g} \mathrm{~L}^{-1}$, isothermal reactor operating at a temperature of $26^{\circ} \mathrm{C}$, photon flux density of $150 \mu \mathrm{mol} \mathrm{m}^{-2} \mathrm{~s}^{-1}$ and continuous aeration of $1 \mathrm{VVM}$ (volume of air per volume of culture per minute) with the injection of air enriched with $15 \% \mathrm{CO}_{2}$.

The cell density, $\mathrm{CO}_{2}$, and $\mathrm{O}_{2}$ concentrations were monitored every $24 \mathrm{~h}$ during the growth phase of the microorganism. The tests were carried out in triplicate. Carbon dioxide and oxygen concentration data were used to calculate the gaseous exchange rates according to the methodology described by Jacob-Lopes et al. (2010).

The determination of the concentrations of $\mathrm{CO}_{2} / \mathrm{O}_{2}$ of photobioreactor exhaust gases was performed according to Jacob-Lopes \& Franco (2013) and Severo et al. (2018).

\section{Bio-combustion furnace and obtaining the kinetic data}

The experiments were carried out in a laboratory-scale biofuel furnace according to Severo et al. (2018). The experimental apparatus consisted of a furnace made of stainless-steel plates, with the coating composed of the refractory material to reduce the loss of heat through the walls. The internal dimensions of the combustion chamber were height $(H)=40 \mathrm{~cm}$, depth $(D)=20 \mathrm{~cm}$ and width $(W)=20 \mathrm{~cm}$. The furnace was equipped with two $300 \mathrm{~W}$ electrical resistors. A ceramic holder was inserted into the central combustion chamber, which was used to introduce the fuel sample. The exhaust gases from the photobioreactor were directed into the chamber through a stainless-steel tube, located at the bottom of the furnace, measuring the length $(\mathrm{L})=80 \mathrm{~cm}$ and internal diameter (ID) $=3 \mathrm{~mm}$. The gases resulting from combustion were routed through the outlet channel, located at the top of the chamber. The system features a moisture filter and two pumps to control the flow of gas.

The experiments were monitored every $24 \mathrm{~h}$ during the growth phase of the microorganism by the injection of the exhaust gases from the photobioreactor and other oxidants tested in the biofuel furnace. The experimental conditions were as follows: initial coke mass $1.0 \mathrm{~g}$, total combustion time of $20 \mathrm{~min}$ and air flow $1.0 \mathrm{~L} / \mathrm{min}$.

\section{Fuel composition}

The fuel used in the combustion experiments was petroleum coke. The sample was characterized using a PerkinElmer $2400 \mathrm{CHNS/O}$ elemental analyzer (PerkinElmer, Waltham-MA, USA). For furnace feed, the exhaust gases from the photobioreactor in different times of residence.

\section{$\mathrm{CO}_{2}$ determinations in the furnace output}

A gas chromatograph (GC) was used to experimentally determine the $\mathrm{CO}_{2}$ emissions. The equipment used was a GC-2014 Greenhouse Gas Analyzer (Shimadzu, Kyoto, Japan), equipped with six packed columns connected to the flame ionization detector (FID), thermal conductivity detector (TCD) and electron capture detector (ECD), and helium as carrier gas. The samplings were obtained from the collection of $50 \mu \mathrm{L}$ of gases flow in the furnace output with a gas-tight microsyringe (Hamilton, Bellefonte-PA, USA). The areas of the peaks were obtained using the integrator Software GCsolution, where the concentrations of gases were determined.

\section{RESULTS AND DISCUSSION}

Figure 1 shows the dynamics of $\mathrm{CO}_{2}$ capture rates and $\mathrm{O}_{2}$ production of Scenedesmus obliquus microalgae in the photobioreactor at different cell residence times. The maximum $\mathrm{O}_{2}$ production reached was $0.40 \pm 0.11 \mathrm{~kg} / \mathrm{m}^{3}$ in $96 \mathrm{~h}$ of cultivation. For the captured $\mathrm{CO}_{2}$, the value obtained was $0.46 \pm 0.13 \mathrm{~kg} / \mathrm{m}^{3}$ at the same residence time. It can be observed that the behavior of both curves is similar throughout the experiment, which demonstrates the direct relationship between consumption versus production rates. According to JacobLopes et al. (2010), this behavior is related to the depletion of nutrients and inorganic carbon in the culture medium associated with the excretion of bioproducts. Among them, can be generated metabolically $\mathrm{O}_{2}$, VOCs, and $\mathrm{CO}_{2}$ unconverted, which could be reused as an oxidizer, gaseous fuels and nitrogen diluent, respectively, in combustion processes (Jacob-Lopes et al., 2017). 
In addition, the photobioreactor exhaust gases were injected into the bio-combustion furnace and the thermal performance of the system was evaluated, according to the data obtained in Severo et al. (2018). The VOCs presented energy potential of $86.32 \mathrm{MJ} \mathrm{kg}^{-1}$. From this, $\mathrm{CO}_{2}$ emissions were analyzed, as shown in Figure 2.

Based on the analysis of the $\mathrm{CO}_{2}$ emission profile, about $0.71 \pm 0.14 \mathrm{~kg}$ of $\mathrm{CO}_{2}$ is emitted for every 1 $\mathrm{kg}$ of petroleum coke burned. This value is quite different from the theoretical stoichiometric value, however, which is $3.30 \mathrm{~kg}_{\mathrm{CO} 2} / \mathrm{kg}_{\text {fuel }}$, indicating that the bio-combustion system emits $80 \%$ less $\mathrm{CO}_{2}$ than a conventional combustion technology. This may be related to the fact that the amount of $\mathrm{CO}_{2}$ produced is directly related to the percentage of $\mathrm{O}_{2}$ injected into the system, which also reflects the reduction of the amount of fuel burned. When considerable $\mathrm{O}_{2}$ concentrations are enriched in the combustion, there is the volumetric displacement of the $\mathrm{N}_{2}$ of the air, favoring the heat transfer inside the furnace and, therefore, the thermal performance is improved and the emissions are reduced (Yin and Yan, 2016).

\section{CONCLUSION}

In this sense, the results obtained demonstrate that photobioreactors have the potential for $\mathrm{CO}_{2}$ capture and parallel production of substances that have the potential to improve the energy performance of combustion systems. Besides, process integration showed that photobioreactors could play a key role towards the sustainability of resilient fossil-based industrial processes since GHGs emissions could be substantially minimized.

\section{REFERENCES}

DE BHOWMICK, G.; SARMAH, A. K.; SEN, R. Zero-waste algal biorefinery for bioenergy and biochar: A green leap towards achieving energy and environmental sustainability. Science of The Total Environment, v. 650, p. 2467-2482, 2019.

DEPRÁ, M. C.; DOS SANTOS, A. M.; SEVERO, I. A.; SANTOS, A. B.; ZEPKA, L. Q.; JACOB-LOPES, E. Microalgal biorefineries for bioenergy production: Can we move from concept to industrial reality? Bioenergy research, v.11, p. 727-747, 2018.

IEA. International Energy Agency, 2018. Available at: https://www.iea.org/. Accessed in: 26/11/2018.

JACOB-LOPES, E.; FRANCO, T. T. From oil refinery to microalgal biorefinery. Journal of $\mathrm{CO}_{2}$ Utilization, v. 2, p. 1-7, 2013.

JACOB-LOPES, E.; SEVERO, I. A.; BIZELLO, R. S.; BARIN, J. S.; MENEZES, C. R. D.; CICHOSKI, A. J.; WAGNER, R.; SUZUKI, S.; PEREIRA, T. R.; TISCHER, B.; MENEZES, M. F. L. D.; ZEPKA, L. Q.; ZOTTIN, L. S. Process and system for re-using carbon dioxide transformed by photosynthesis into oxygen and hydrocarbons used in an integrated manner to increase the thermal efficiency of combustion systems, 2017.

JACOB-LOPES, E.; SCOPARO, C.H.G.; QUEIROZ, M. I.; FRANCO, T. T. Biotransformations of carbon dioxide in photobioreactors. Energy Conversion and Management, v. 51, p. 894-900, 2010.

MARONEZE, M. M.; SIQUEIRA, S. F.; VENDRUSCOLO, R. G.; WAGNER, R.; DE MENEZES, C. R.; ZEPKA, L. Q.; JACOB-LOPES, E. The role of photoperiods on photobioreactors - A potential strategy to reduce costs. Bioresource Technology, v. 219, p. 493-499, 2016.

MOREIRA, D.; PIRES, J. C. M. Atmospheric $\mathbf{C O}_{2}$ capture by algae: Negative carbon dioxide emission path. Bioresource Technology, v. 215, p. 371-379, 2016.

RIPPKA, R.; DERUELlES, J.; WATERBURY, J. B.; HERDMAN, M.; STANIER, R. Y. Generic assignments, strain histories and properties of pure cultures of cyanobacteria. Journal of General Microbiology, v. 111, p. 1-61, 1979.

SEVERO, I. A.; DEPRÁ, M. C., BARIN, J. S.; WAGNER, R.; MENEZES, C. R. DE; ZEPKA, L. Q.; JACOBLOPES, E. Bio-combustion of petroleum coke: The process integration with photobioreactors. Chemical Engineering Science, v. 177, p. 422-430, 2018.

YIN, C.; YAN, J. Oxy-fuel combustion of pulverized fuels: combustion fundamentals and modeling. Applied Energy, 162, 742-762, 2016.

ZHU, B.; CHEN, G.; CAO, X.; WEI, D. Molecular characterization of $\mathrm{CO}_{2}$ sequestration and assimilation in microalgae and its biotechnological applications. Bioresource Technology, v. 244, p. 1207-1215, 2017. 


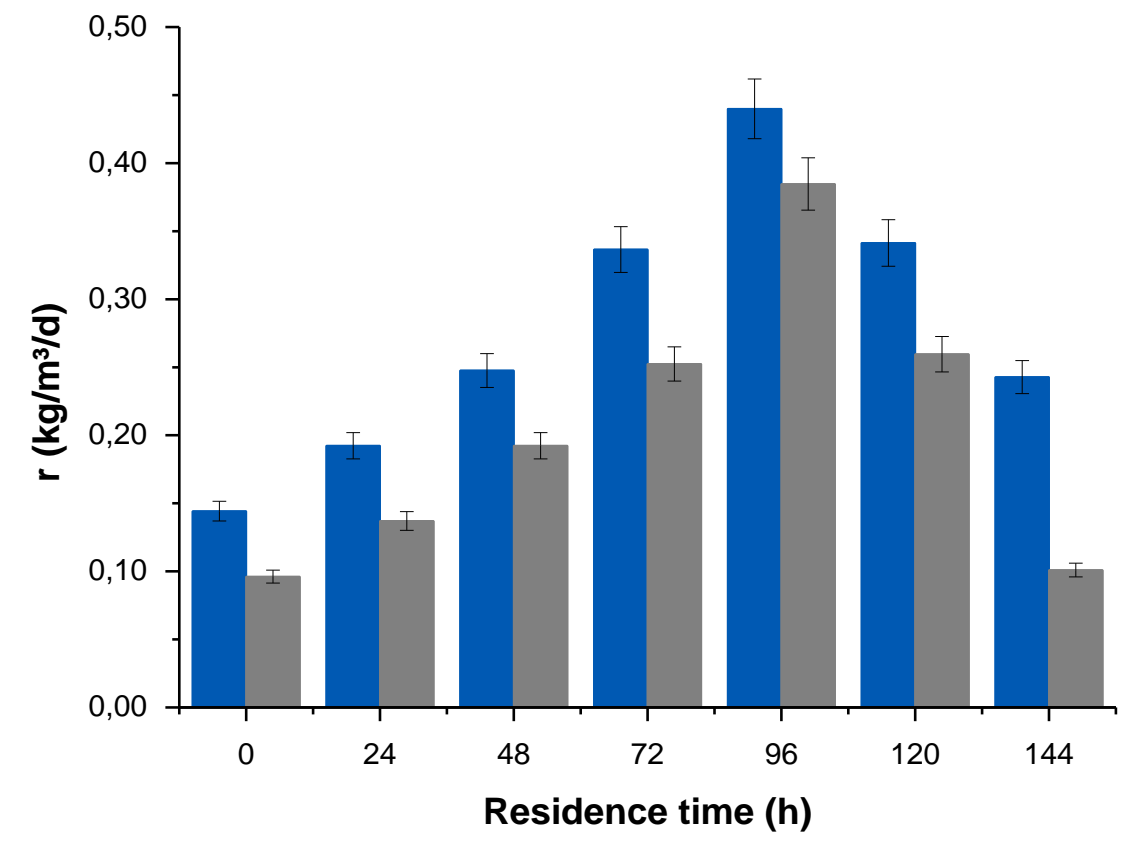

Figure 1. Carbon dioxide capture and oxygen release rates. $\square \mathrm{CO}_{2}$ and $\square \mathrm{O}_{2}$.

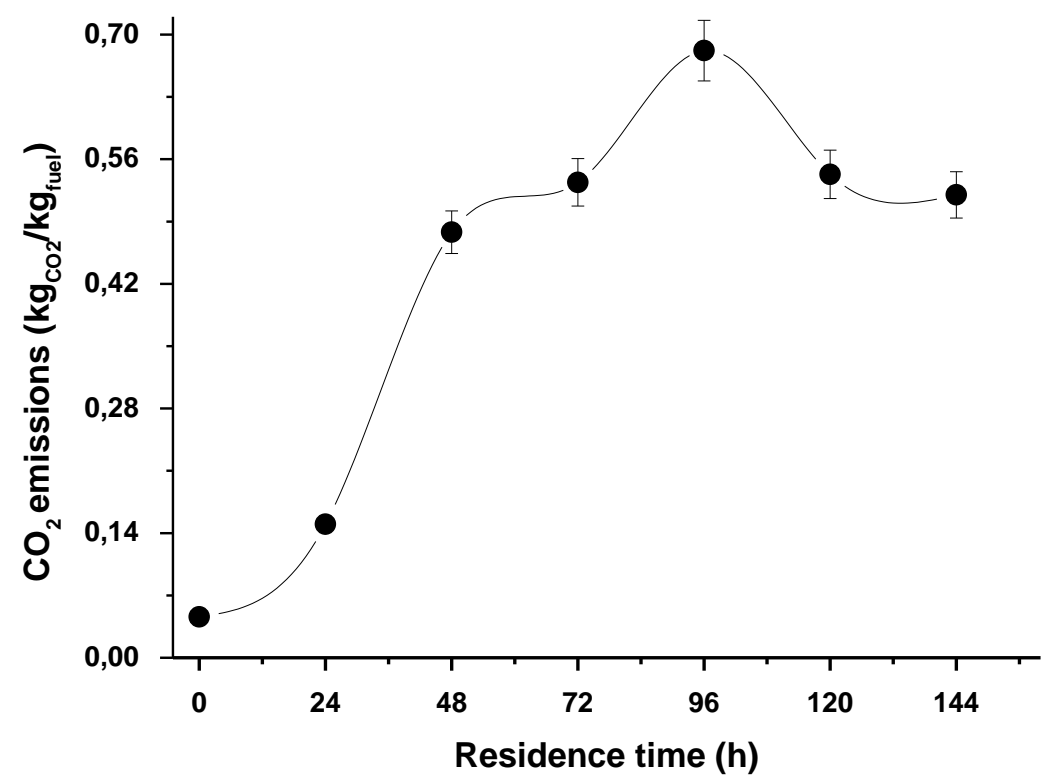

Figure 2. Dynamics of $\mathrm{CO}_{2}$ emissions in the bio-combustion furnace. 


\title{
ENSAIOS CINÉTICOS DE FERMENTAÇÃO DE XILOSE POR DIFERENTES CEPAS DE CLOSTRIDIUM
}

\author{
Fonseca, B.C. ${ }^{1}$; Reginatto, V**1 \\ ${ }^{1}$ Universidade de São Paulo, Faculdade de Filosofia Ciências e Letras de Ribeirão Preto, SP, Departamento de Química \\ LABIORE - Laboratório de Biotecnologia Ambiental e Energias Renováveis \\ valeriars@ffclrp.usp.br
}

\begin{abstract}
RESUMO: O desenvolvimento de tecnologias para a obtenção de energia renovável e mais limpa é uma questão de interesse global. Resíduos agroindustriais de natureza lignocelulósica, tais como a palha da cana, apresentam um grande potencial para uma nova geração de biocombustíveis renováveis a partir de matériaprima barata. Os processos biológicos, como a fermentação de carboidratos, podem ser utilizados para produzir uma ampla gama de biocombustíveis, tais como o bioetanol, o biometano, o biohidrogênio e o biobutanol. Algumas espécies de Clostridium, especialmente o Clostridium beijerinckii e o Clostridium acetobutylicum tem um metabolismo bastante abrangente e são capazes de produzir tanto o hidrogênio $\left(\mathrm{H}_{2}\right)$ e os ácidos acético e butírico, quanto o butanol, em diferentes fases do seu crescimento, podendo utilizar como matérias-primas, biomassas ricas em carboidratos, como as biomassas lignocelulósicas. Dessa forma, investigamos a utilização de um dos principais monossacarídeos derivados de materiais lignocelulósicos, a xilose (C5), pelo $C$. acetobutylicum ATCC0824, pelo $C$. beijerinckii ATCC35702 e por uma nova cepa isolada em nosso laboratório, o $C$. beijerinckii $\mathrm{Br} 21$. Os resultados mostraram que as três cepas de Clostridium analisadas foram capazes de crescer em todas as concentrações de xilose testadas entre 3 e $50 \mathrm{~g} / \mathrm{L}$. Os meios contendo $15 \mathrm{~g} / \mathrm{L}$ de xilose foram mais adequados para o crescimento celular de todas as cepas de Clostridium, nas condições estudadas, com destaque ao $C$. beijerinckii $\mathrm{Br} 21$ que apresentou uma velocidade de crescimento com valor maior comparado às outras cepas.
\end{abstract}

Palavras-chave: Clostridium, xilose, biomassa lignocelulósica, ácido butírico.

\section{KINETIC FERMENTATION TESTS OF XYLOSIS BY DIFFERENT CLOSTRIDIUM STRAIN}

ABSTRACT: Developing technologies to obtain renewable and cleaner energy is a global concern. Lignocellulosic agroindustrial residues, such as sugarcane straw, present great potential for a new generation of renewable biofuels from cheap raw material. Biological processes, such as carbohydrate fermentation, are an alternative strategy to produce several biofuels, including bioethanol, biomethane, biohydrogen, and biobutanol, as well as organic acids. Some Clostridium species, particularly $C$. beijerinckii and $C$. acetobutylicum, have broad metabolism: at different growth stages, these bacteria can produce hydrogen $\left(\mathrm{H}_{2}\right)$, acetic and butyric acids, and butanol from carbohydrate-rich biomasses, such as lignocellulosic materials. We investigated how different Clostridium species including a new strain isolated in our laboratory, Clostridium beijerinckii $\mathrm{Br} 21$, use xylose (C5) and glucose (C6), the main monosaccharides derived from lignocellulose. The results showed that the three Clostridium strains analyzed were able to grow at all xylose concentrations tested, the media containing $15 \mathrm{~g} / \mathrm{L}$ xylose appeared to be more suitable for the cell growth of all Clostridium strains under the conditions studied, with emphasis on $C$. beijerinckii $\mathrm{Br} 21$, which presented a higher growth rate compared to all other tests.

Keywords: Clostridium, xylose, lignocellulosic biomass, butyric ácid.

\section{INTRODUÇÃO}

A matriz energética mundial ainda é majoritariamente baseada em matérias primas fósseis, sobretudo no petróleo, no gás natural e no carvão mineral. A utilização destas matérias primas, além de causar o seu esgotamento, também causa o aumento de monóxido e dióxido de carbono na atmosfera, contribuindo para o aquecimento global. Tal quadro evidencia a importância de se diversificar a matriz energética atual e investir na geração de energia advinda de fontes renováveis, seja para a diminuição dos poluentes emitidos ou, simplesmente, para reduzir a dependência de determinadas matérias primas não renováveis (LI; HE, 2016).

A intensa atividade agrícola no Brasil gera uma enorme e contínua quantidade de biomassa residual de composição lignocelulósica, a composição dessa biomassa varia conforme sua origem e variabilidade genética 
entre diferentes fontes, e, de uma maneira geral, é constituída principalmente pelos polímeros, lignina (cerca de 15 a $45 \%$ ), celulose (30-65\%) e hemicelulose (20 a 38\%). Dentre esses polímeros a hemicelulose é um heteropolissacarídeo constituída principalmente por D-xilose (C5) possível de ser fermentada, após a sua sacarificação (ALVIRA et al., 2010).

Algumas espécies de Clostridium, especialmente o Clostridium beijerinckii e o Clostridium acetobutylicum tem um metabolismo bastante abrangente e são capazes de produzir tanto o hidrogênio $\left(\mathrm{H}_{2}\right)$ e os ácidos acético e butírico, quanto o butanol, em diferentes fases do seu crescimento, podendo utilizar como matérias-primas biomassas ricas em carboidratos.

No entanto, dentre os vários desafios para o desenvolvimento de biocombustíveis obtidos por bioprocessos a partir de materiais lignocelulósicos está o aproveitamento integral por parte dos microrganismos dos carboidratos que compõe a biomassa. Neste sentido, é importante o conhecimento das características do microrganismo a ser utilizado com relação à assimilação da xilose.

Neste trabalho foi estudada a assimilação de xilose por duas cepas de C. beijerinckii, Br21 e ATCC35702 e C. acetobutylicum ATCC0824.

\section{MATERIAL E MÉTODOS}

Uma vez que a xilose é a principal pentose constituinte da biomassa lignocelulósica foram realizados ensaios fermentativos com as cepas de $C$. beijerinckii Br21(FONSECA; GUAZZARONI; REGINATTO, 2016), Clostridium beijerinckii ATCC35702 e Clostridium acetobutylicum ATCC824 utilizando diferentes concentrações de xilose como fonte de carbono $(3 ; 6 ; 15 ; 25$ e 50 g/L) em meio Reinforced Clostridium Medium - RCM.

Todos os ensaios foram realizados em frascos tipo penicilina de $100 \mathrm{~mL}$, contendo $60 \mathrm{~mL}$ de meio RCM autoclavado, $\mathrm{pH}$ inicial de 7, em ausência de oxigênio garantida pelo borbulhamento de gás nitrogênio nos frascos. Durante os ensaios foram coletadas alíquotas periódicas para medida da concentração celular, pH, e para análises dos metabólitos.

O crescimento celular foi determinado pela densidade ótica (DO) em 600 nm utilizando espectrofotômetro UV/Vis (BEL Engineering - UV - M51) e transformando-se este valor em concentração de massa celular seca representado em $\mathrm{mg} / \mathrm{L}$. O pH no decorrer dos ensaios foi medido utilizando pHmetro MS TECHNOPON®.

As amostras periódicas retiradas, foram filtradas em seringa com filtro de acetato-celulose 0,45 um, guardadas a $-16^{\circ} \mathrm{C}$ até o momento das análises químicas. A quantificação da concentração de açúcares (glicose e xilose) durante os ensaios de fermentação, assim como a concentração de metabólitos formada foi realizada utilizando Cromatografia Líquida de Alta Eficiência - CLAE, com uso da coluna Aminex HPX-87H (7,8 mm x $300 \mathrm{~mm}$ ) com temperatura controlada em $60^{\circ} \mathrm{C}$, sob condições isocráticas. A fase móvel utilizada foi de $\mathrm{H}_{2} \mathrm{SO}_{4} 5 \mathrm{mmol} / \mathrm{L}$ com o fluxo de $0,4 \mathrm{~mL} / \mathrm{min}$. O detector utilizado foi o RID (índice de refração) e a aquisição e o tratamento dos dados foram realizados pelo software LabSolutions.

Alíquotas retiradas no início e no final de cada ensaio de fermentação foram analisadas para verificar o consumo de xilose e os metabólitos solúveis formados. A partir destes dados foi possível calcular o $\mathrm{Y}_{\mathrm{P} / \mathrm{s}}$, que corresponde ao fator de conversão de substrato em um produto de interesse, no caso, analisamos a conversão de xilose à ácido butírico.

Todos os experimentos foram realizados em triplicatas de forma independente, e os resultados apresentados como a média e seus desvios médios. A curva de crescimento celular, após conversão da densidade ótica (DO) em concentração de massa celular seca (mg/L) assim como a variação do pH no ensaio, foram obtidas para as diferentes concentrações de xilose em função do tempo. A equação de Boltzmann (sigmóide) foi o modelo estatístico ajustado aos dados experimentais (KANURIĆ et al., 2018; LONCAR et al., 2014).

\section{RESULTADOS E DISCUSSÃO}

Os resultados de crescimento celular e pH durante os ensaios cinéticos com diferentes concentrações de xilose estão expressos na Figura $1 \mathrm{~A}, \mathrm{C}$ e E para o C.beijerincki Br21, C.beijerinckii ATCC35702 e $C$. acetobutylicum ATCC824, respectivamente. Os valores de $\mathrm{pH}$ obtidos em função do tempo de ensaio também foram tratados com ajuste sigmoidal de Boltzmann. Estas curvas estão expressas na Figura 1 B, D e F, para os mesmos microrganismos, respectivamente. 
Os resultados mostraram que as três cepas de Clostridium analisadas foram capazes de crescer em todas as concentrações de xilose testadas, mas a fase lag, de uma maneira geral, aumentou com o aumento da concentração de xilose. As maiores concentrações celulares foram observadas nas concentrações intermediárias de xilose, ou seja, 6 e 15 g/L. Numa primeira análise, os meios contendo 15 g/L de xilose pareceram ser mais adequados para o crescimento celular de todas as cepas de Clostridium, nas condições estudadas.

Quanto ao pH, a formação dos ácidos orgânicos na primeira fase da fermentação (acidogênese), causa uma queda no $\mathrm{pH}$ do meio conforme pode-se observar nas Figuras 1B, 1D, 1F. Os valores de $\mathrm{pH}$ variaram de forma similar entre 6,8 a 5,2 aproximadamente. $\mathrm{O}$ pH se manteve constante ao final da fase exponencial. Em todos os ensaios foi observado um decaimento do $\mathrm{pH}$ durante a fase exponencial de crescimento do microrganismo.

A partir da estequiometria da reação de xilose sendo convertida a ácido butírico, sabe-se que a cada $6 / 5$ ou 1,2 mol de xilose, 1 mol de ácido butírico é produzido, o que fornece um fator teórico de conversão de 0,80 mol de ácido butírico/mol de xilose, que corresponderia a 100\% de rendimento. Dessa forma, foi calculado o rendimento obtido na conversão de xilose a ácido butírico nos ensaios realizados, expressos na Tabela 1.

$\mathrm{O}$ ácido butírico foi o principal produto observado pela fermentação de xilose por todas as cepas. As maiores concentrações e rendimentos foram observados com $15 \mathrm{~g} / \mathrm{L}$ de xilose, corroborando mais uma vez que esta concentração inicial mais adequada para o crescimento celular das cepas. A cepa Br21 apresentou o maior rendimento comparado aos outros ensaios, alcançando o valor de $98 \%$ de conversão de xilose a ácido butírico, na concentração inicial de $15 \mathrm{~g} / \mathrm{L}$ de xilose. Já para o C.beijerinckii ATCC35702, os rendimentos foram entre $9 \%$ e $68 \%$. Em relação ao C. acetobutylicum ATCC824, apenas o ácido butírico foi observado como metabólito formado, alcançando um rendimento máximo de $88 \%$ também para a concentração de $6 \mathrm{~g} / \mathrm{L}$ de xilose.

\section{CONCLUSÃO}

Os resultados mostraram que os três microrganismos explorados apresentaram um grande potencial para consumo da xilose. Nota-se que o $C$. beijerinckii $\mathrm{Br} 21$ produziu a maior quantidade de ácido butírico. A elevada conversão de xilose em ácido butírico e o seu elevado valor agregado, especialmente quando obtido de fontes renováveis, justifica a investigação dessa cepa na produção desse ácido de interesse.

Ao observar os metabólitos formados nos ensaios, vemos que apenas a cepa de C.beijerinckii ATCC35702 foi capaz de produzir butanol, mesmo que em baixa concentração, produto da fase solvetogênica de crescimento dessa espécie. Esse mesmo produto não foi observado nas demais cepas, o que pode ser decorrente da possível degeneração destas.

\section{AGRADECIMENTOS \\ Este trabalho foi apoiado pelo Processo FAPESP 2018/00789-7 e pela CAPES.}

\section{REFERÊNCIAS}

ALVIRA, P. et al. Pretreatment technologies for an efficient bioethanol production process based on enzymatic hydrolysis: A Review. Bioresource Technology, V. 101, N. 13, P. 4851-4861, jul. 2010.

FONSECA, B. C.; GUAZZARONI, M. E.; REGINATTO, V. Fermentative production of H2from different concentrations of galactose by the new isolate Clostridium Beijerinckii Br21. International Journal Of Hydrogen Energy, V. 41, N. 46, P. 21109-21120, 2016.

KANURIĆ, K. G. et al. Kinetics of lactose fermentation in milk with kombucha starter. Journal of Food and Drug Analysis, V. 26, N. 4, P. 1229-1234, 1 out. 2018.

LI, T.; HE, J. Simultaneous saccharification and fermentation of hemicellulose to butanol by a non-sporulating clostridium species. Bioresource Technology, V. 219, P. 430-438, 1 nov. 2016.

LONCAR, E. ET AL. Kinetics of saccharose fermentation by kombucha. Chemical Industry and Chemical Engineering Quarterly, V. 20, N. 3, P. 345-352, 2014. 

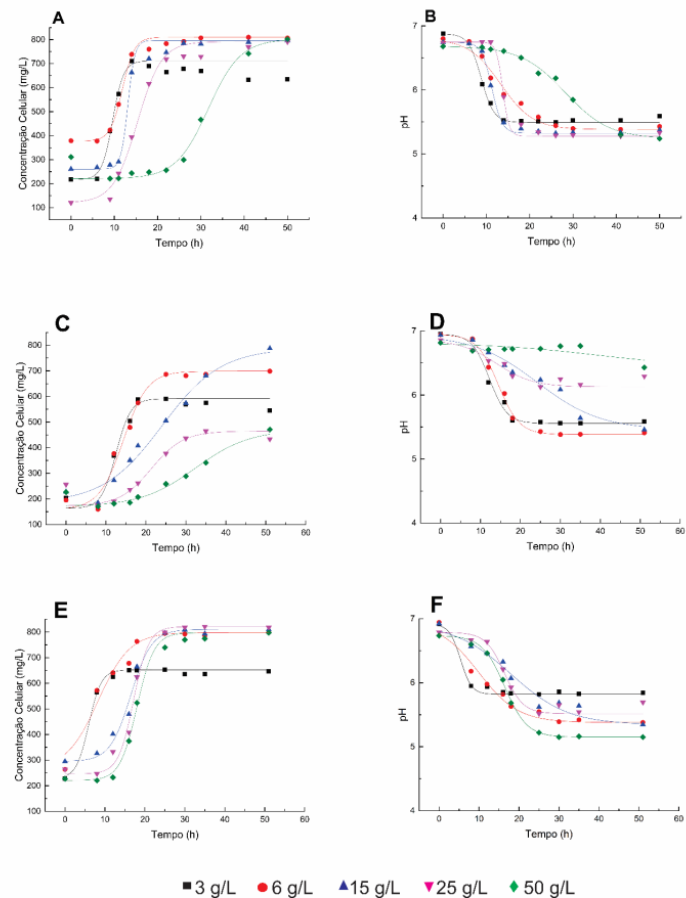

Figura 1. Concentração de massa celular seca $(\mathrm{mg} / \mathrm{L})$ e valores de $\mathrm{pH}$ em função do tempo (h) durante os ensaios cinéticos de fermentação com o $C$. beijerinckii Br21 (A e B), C. beijerinckii ATCC35702 (C e D) e $C$. acetobutylicum ATCC824 (E e F) em diferentes concentrações iniciais de xilose.

Tabela 1. Concentração de xilose consumida e metabólitos solúveis formados e rendimento obtido durante os ensaios de fermentação com diferentes concentrações iniciais de xilose para as diferentes cepas de Clostridium.

\begin{tabular}{|c|c|c|c|c|c|c|}
\hline \multicolumn{2}{|c|}{ Concentração inicial de Xilose } & $\begin{array}{c}3 \mathrm{~g} / \mathrm{L} \\
(20 \mathrm{mmol})\end{array}$ & $\begin{array}{c}6 \mathrm{~g} / \mathrm{L} \\
(40 \mathrm{mmol}) \\
\end{array}$ & $\begin{array}{c}15 \mathrm{~g} / \mathrm{L} \\
(100 \mathrm{mmol})\end{array}$ & $\begin{array}{c}25 \mathrm{~g} / \mathrm{L} \\
(166 \mathrm{mmol})\end{array}$ & $\begin{array}{c}50 \mathrm{~g} / \mathrm{L} \\
(333 \mathrm{mmol})\end{array}$ \\
\hline \multirow{4}{*}{$\begin{array}{c}\text { C.beijerinckii } \\
\text { Br21 }\end{array}$} & $\begin{array}{c}\text { Xilose } \\
\text { consumida } \\
(\mathrm{mmol} / \mathrm{L})\end{array}$ & $10,97 \pm 0,41$ & $29,74 \pm 1,10$ & $47,68 \pm 1,04$ & $109,53 \pm 1,43$ & $79,12 \pm 3,18$ \\
\hline & $\begin{array}{l}\text { Ácido butírico } \\
\text { (mmol/L) }\end{array}$ & $8,25 \pm 0,33$ & $19,45 \pm 1,14$ & $37,51 \pm 0,14$ & $28,38 \pm 2,75$ & $22,60 \pm 1,15$ \\
\hline & $\begin{array}{c}\mathrm{Y}_{\mathrm{P} / \mathrm{S}} \\
(\mathrm{mmol} / \mathrm{mmol})\end{array}$ & $0,75 \pm 0,07$ & $0,65 \pm 0,02$ & $0,78 \pm 0,01$ & $0,26 \pm 0,03$ & $0,29 \pm 0,04$ \\
\hline & $\Pi(\%)$ & $94,01 \pm 0,07$ & $81,75 \pm 0,02$ & $98,34 \pm 0,01$ & $32,39 \pm 0,03$ & $35,70 \pm 0,04$ \\
\hline \multirow{6}{*}{$\begin{array}{l}\text { C. beijerinckii } \\
\text { ATCC } 35702\end{array}$} & $\begin{array}{c}\text { Xilose } \\
\text { consumida } \\
(\mathrm{mmo} / \mathrm{L})\end{array}$ & $17,50 \pm 0,06$ & $20,80 \pm 1,77$ & $40,04 \pm 0,71$ & $41,17 \pm 1,69$ & $58,20 \pm 0,16$ \\
\hline & $\begin{array}{l}\text { Ácido acético } \\
(\mathrm{mmol} / \mathrm{L})\end{array}$ & $10,68 \pm 0,10$ & $11,50 \pm 0,13$ & $4,12 \pm 0.71$ & $6,91 \pm 1,98$ & $6,91 \pm 1,98$ \\
\hline & $\begin{array}{l}\text { Ácido butírico } \\
\text { (mmol/L) }\end{array}$ & $6,81 \pm 0,17$ & $11,37 \pm 0,17$ & $14,51 \pm 0.37$ & $3,11 \pm 0,68$ & $15,82 \pm 0,42$ \\
\hline & $\begin{array}{c}\text { Butanol } \\
(\mathrm{mmol} / \mathrm{L})\end{array}$ & - & $3,48 \pm 0.08$ & $5,75 \pm 0.02$ & - & $1,81 \pm 0.02$ \\
\hline & $\begin{array}{c}\mathrm{Y}_{\mathrm{P} / \mathrm{S}} \\
(\mathrm{mmol} / \mathrm{mmol})\end{array}$ & $0,39 \pm 0,01$ & $0,55 \pm 0,02$ & $0,36 \pm 0,01$ & $0,10 \pm 0,01$ & $0,27 \pm 0,02$ \\
\hline & $\Pi(\%)$ & $48,64 \pm 0,01$ & $68,33 \pm 0,02$ & $45,29 \pm 0,01$ & $9,44 \pm 0,01$ & $33,97 \pm 0,02$ \\
\hline \multirow{4}{*}{$\begin{array}{c}C . \\
\text { acetobutylicum } \\
\text { ATCC824 }\end{array}$} & $\begin{array}{c}\text { Xilose } \\
\text { consumida } \\
(\mathrm{mmol} / \mathrm{L})\end{array}$ & $14,48 \pm 0,21$ & $27,09 \pm 0,32$ & $32,59 \pm 0,12$ & $37,09 \pm 0,39$ & $29,80 \pm 1,04$ \\
\hline & $\begin{array}{l}\text { Ácido butírico } \\
\text { (mmol/L) }\end{array}$ & $9,32 \pm 0,13$ & $19,13 \pm 0,89$ & $26,92 \pm 0,46$ & $18,35 \pm 2,89$ & $19,52 \pm 0,13$ \\
\hline & $\begin{array}{c}\mathrm{Y}_{\mathrm{P} / \mathrm{S}} \\
(\mathrm{mmol} / \mathrm{mmol})\end{array}$ & $0,64 \pm 0,01$ & $0,71 \pm 0,01$ & $0,69 \pm 0,05$ & $0,49 \pm 0,03$ & $0,65 \pm 0,01$ \\
\hline & $\Pi(\%)$ & $80,46 \pm 0,01$ & $88,27 \pm 0,01$ & $87,19 \pm 0,05$ & $61,84 \pm 0,03$ & $81,88 \pm 0,01$ \\
\hline
\end{tabular}




\title{
ESTUDO DO POTENCIAL ENERGÉTICO DO BIOGÁS EM SUINOCULTURAS NO VALE DO PIRANGA - MG
}

\author{
Sousa, I.P.*11; Rosa, A.P. ${ }^{1}$; Oliveira, N.S. ${ }^{1}$; Lopes, J.O. ${ }^{1}$; Ferreira. F.L.V. ${ }^{1}$, Perez, R. ${ }^{1}$ \\ ${ }^{1}$ Universidade Federal de Viçosa, Viçosa, MG - Brasil. \\ izabelle.sousa@ufv.br
}

\begin{abstract}
RESUMO: O objetivo do estudo foi estimar o potencial de produção de biogás produzido a partir do tratamento de dejetos suínos na região do vale do Piranga a partir do emprego de biodigestores. Buscou-se através de visitas às granjas e contato direto com os empreendedores e cooperativa de suinocultores levantar a quantidade de animais distribuídos em suas fases de crescimento junto a 73 suinocultores distribuídos em 12 municípios da bacia hidrográfica do rio Piranga/MG. Em seguida, através do volume de dejetos estimados, determinou-se o volume de biogás e o seu potencial energético advindo das granjas pela recuperação do biogás, o qual foi expresso para o Vale do Piranga através de um mapa temático gerado pelo uso do software ArcGIS ${ }^{\circledR}$ 10.3. Após o levantamento, 30 granjas faziam uso de biodigestores como alternativa de tratamento de efluentes em suas propriedades, e destes, somente 17 realizam o aproveitamento energético do biogás. Estima-se que o potencial energético de todas as granjas corresponde à 176,32 $\mathrm{GWh}$ ano ${ }^{-1}$, o que seria capaz de suprir a demanda energética de uma população de 23.757 habitantes, todavia, apenas 39\% da energia $\left(68,93 \mathrm{GWh}^{-a n o}\right.$ $\left.{ }^{1}\right)$ são efetivamente gerados. Observou-se que a recuperação energética do biogás ainda é incipiente em umas das regiões suinícolas mais importantes do estado. Maiores investimentos no tratamento dos efluentes de suinoculturas por biodigestores e na produção de energia a partir de seu principal subproduto, o biogás, podem trazer benefícios econômicos e ambientais, assim como expandir a produção descentralizada de energia.
\end{abstract}

Palavras-chave: digestão anaeróbia, biodigestores, biogás, energia, suinocultura.

\section{ASSESSING THE ENERGY POTENTIAL OF BIOGAS IN PIG FARMING IN PIRANGA VALLEY - MG}

\begin{abstract}
This study aimed at estimating the energy potential of biogas from biodigesters in pig farming in the Piranga valley/MG. The number of animais by stages of development was obtained after visits and direct contact with pig farmers cooperatives, the study was carried out with 73 pig farmers in 12 towns in Piranga Valley. Afterward, it was estimated the biogas volume and its energetic potential for the valley that was represented in a thematic map using the software ArcGIS ${ }^{\circledR}$ 10.3. Out of 73 pig farming only 30 units treated the sewage using biodigesters and 17 recovery the biogas to produce electricity. The total energy potential for the pig farming was around $176.32 \mathrm{GWh}_{\text {.year }}{ }^{-1}$ that could be enough to supply the energy demand of 23,757 inhabitants, however only $39 \%\left(68.93 \mathrm{GWh}^{-a n o^{-1}}\right)$ are produced in fact. The energetic recovery of biogas is still incipient in this region that is one of the more importante in the state. More investiments in sewage treatment by the use of biodigestors and the biogas energy recovery could bring economic and environmental benefits, as well as increase of descentralized energy production.
\end{abstract}

Keywords: anaerobic digestion, biodigesters, biogas, energy, pig farming.

\section{INTRODUÇÃO}

O Brasil no ano de 2017 produziu 3,75 toneladas de carne suína, ocupando o $4^{\circ}$ lugar no ranking mundial, em que $83 \%$ da produção são destinados para consumo interno e $19 \%$ para a exportação. Dentre os estados, Minas Gerais é responsável por $11 \%$ da produção total (ABPA 2017), e entre as regiões mineiras a Zona da Mata se destaca com $21 \%$ da produção do estado (ABCS, 2016).

Visto a importância econômica da produção de suínos, faz-se necessário otimizar a produção com sustentabilidade. De forma geral, o sistema intensivo de criação de suínos produz grande quantidade de dejetos com alta concentração de matéria orgânica. De acordo com Oliveira (1993), a produção média por animal de dejetos é da ordem de 2,5 kg.dia ${ }^{-1}$, sendo que esse valor varia de acordo com a idade do animal, alimentação e consumo de água.

Nas granjas, uma alternativa de tratamento recorrente é o emprego de biodigestores, onde é predominante a degradação anaeróbia da matéria orgânica, o principal subproduto do tratamento corresponde ao biogás. De acordo com Seixas e Marchetti (1982), o biogás gerado a partir de biodigestores tratando 
efluentes de suinocultura apresenta concentrações de metano $\left(\mathrm{CH}_{4}\right)$ de 55 a $65 \%$ e dióxido de carbono $\left(\mathrm{CO}_{2}\right)$ de 35 a 45\%. Para Chernicharo (1997) o baixo custo de implantação, tolerância a elevadas cargas orgânicas, baixa demanda energética, assim como o elevado potencial de uso do biogás para fins energético correspondem a vantagens do tratamento anaeróbio.

O avanço nos estudos de produção de biogás faz-se necessário com o intuito de difundir o seu uso e diversificar a matriz energética brasileira pela produção descentralizada de energia, que apesar de ter um alto potencial ainda é pouco explorado. Em adição, o levantamento mais recente realizado acerca da atividade suinícola não caracteriza as granjas quanto às condições de tratamento de efluentes, assim como não informa sobre o potencial de geração de biogás nas granjas (ABCS, 2016). Estudos que busquem incorporar este tipo de levantamento objetivam a creditação dos sistemas de tratamento anaeróbio como alternativa para a produção e recuperação de biogás para fins energéticos no setor. O objetivo deste estudo foi estimar a produção e o potencial energético do biogás produzido a partir do tratamento de dejetos suínos na região do vale do Piranga (Minas Gerais).

\section{MATERIAL E MÉTODOS}

O levantamento do potencial de geração de energia a partir de resíduos da suinocultura na região da bacia hidrográfica do rio Piranga foi realizado junto a 73 suinocultores em 12 cidades da região, a saber: Amparo da Serra, Guaraciaba, Jequeri, Oratórios, Piedade de Ponta Nova, Piranga, Ponte Nova, Rio Casca, Santa Cruz do Escalvado, Teixeiras, Urucânia e Viçosa. O mapeamento foi realizado para o ano de 2014 a partir de visitas às granjas e por consulta direta aos empreendimentos, os dados requeridos correspondiam ao número total de suínos, a especificação dos animais por fase de desenvolvimento (creche, crescimento/terminação e matriz) e a condição de tratamento e aproveitamento energético na propriedade: (i) sem biodigestor; (ii) com biodigestor; (iii) com biodigestor + produção de energia. A estimativa teórica da produção e potencial energético do biogás foi calculada por meio da metodologia proposta pelo Centro Nacional de Referência em Biomassa (CENBIO, 2011) em que:

$$
\begin{gathered}
\mathrm{V}_{\mathrm{CH} 4}\left(\mathrm{~m}^{3} \mathrm{CH}_{4} \mathrm{~d}^{-1}\right)=\frac{\mathrm{Q}(\text { animal }) \times \text { Et }\left(\mathrm{kg} \text { esterco.animal }{ }^{-1} \cdot \mathrm{d}^{-1}\right) \times \mathrm{P}_{\mathrm{b}}}{\rho_{\mathrm{CH} 4}\left(\mathrm{~kg} \text { biogás. } \mathrm{m}^{-3} \mathrm{CH} 4\right)} \\
\operatorname{Pot}\left(\mathrm{kWh} \mathrm{d}^{-1}\right)=\mathrm{V}_{\mathrm{CH} 4}\left(\mathrm{~m}_{\mathrm{CH} 4}^{3} \cdot \mathrm{d}^{-1}\right) \times \text { PCI }\left(\mathrm{kWh} \cdot \mathrm{m}^{-3} \mathrm{CH}_{4}\right)
\end{gathered}
$$

Em que: $\mathrm{V}_{\mathrm{CH} 4}$ é o volume de metano, Q é a quantidade de animais por fase, Et é a quantidade de esterco produzidos por animal, sendo considerado $(3,60,0,35$ e 2,30 para matriz, creche e crescimento/terminação, respectivamente) (BONETT e MONTICELLI 1998). $\mathrm{P}_{\mathrm{b}}$ é o fator de conversão da produção de biogás, sendo igual a 0,062 (MOTTA, 1986), $\mathrm{C}_{\mathrm{CH} 4}$ é a concentração de metano no qual foi adotado $75 \%$ como valor médio a partir do monitoramento (a caracterização do biogás em termos de composição de metano ocorreu pelo uso do analisador de gás GAS 3100Syngas e do kit biogás da embrapa suínos e aves com parceria com a empresa Alfakit) no período de nov/2017 a nov./2018 em uma granja na cidade de Teixeiras, e por fim, $\rho_{\mathrm{CH} 4}$ é a massa específica do gás metano sendo considerado 0,670 (MOTTA, 1986). A determinação do potencial energético do biogás (Pot) fez uso do poder calorífico do metano (PCI), considerado igual a $10 \mathrm{kWh} \cdot \mathrm{m}^{-3} \mathrm{CH}_{4}$ (PROBIOGÁS, 2010). Em seguida, os dados foram espacializados para a região em estudo pelo uso do software ArcGIS® 10.3 .

O potencial energético de biogás por município foi avaliado ainda em termos de seu potencial total (caso todas as granjas com biodigestores promovessem a geração de energia), de seu potencial gerado (em função dos empreendimentos com biodigestores que já realizam a recuperação energética do biogás) e do potencial de expansão das granjas para recuperar o biogás, este último considerou a viabilidade para a implantação do aproveitamento energético do biogás em granjas com no mínimo 4.167 suínos ou que possuam um plantel com no mínimo 300 matrizes, conforme limite proposto por Martins et al. (2011) e Carvalho e Nolasco (2006).

\section{RESULTADOS E DISCUSSÃO}

Com base nos 72 suinocultores entrevistados, observou-se que os municípios de Urucânia, Jequeri e Piranga apresentaram o maior número de empreendimentos suinícolas que as demais regiões estudadas. No entanto, foi constatado que do total de suinoculturas apenas 30 possuem biodigestor em suas propriedades e destes, 17 fazem o aproveitamento energético do biogás. 
O município de Piranga se destacou entre os demais, por apresentar nove empreendimentos suinícolas, sendo que todos realizam o tratamento por biodigestor e cinco destes já reutilizam o biogás como fonte energética. Em contrapartida, o município de Urucânia com 23 empreendimentos, 17 não possuem tratamento por biodigestores, e os suinocultores pertencentes a Guaraciaba, Piedade de Ponte Nova e Viçosa ainda não realizam tratamento por biodigestão anaeróbia (Figura 1).

A quantidade de animais confinados nos 12 municípios mapeados alcançou 394.209 suínos, ultrapassando em $75 \%$ à população humana residente nessa região e correspondendo a um equivalente populacional da ordem de 12.889.407 habitantes (considerando uma geração per capita de 54 g.hab ${ }^{-1} . \mathrm{d}^{-1}$, conforme indicado na DZ-215.R-4).

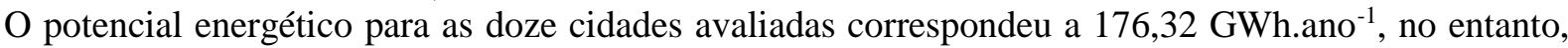
estima-se que apenas 39\% (68,93 $\mathrm{GWh} \mathrm{ano}^{-1}$ ) desse potencial está sendo explorando (Figura 2), considerando as 17 propriedades que possuem biodigestor e que promovem aproveitamento do biogás. Em adição, observase um reduzido aproveitamento do potencial do biogás na região, sendo que em quatro cidades não há recuperação da energia contida no biogás.

Considerando um rendimento de conversão de $30 \%$ nos equipamentos de conversão (sistema motogerador) e tendo como base um consumo per capita de 0,0061 $\mathrm{MWh} \mathrm{hab}^{-1} \mathrm{~d}^{-1}$ (Balanço Energético Nacional, 2017), estima-se que a eletricidade gerada para a situação de potencial energético total (quando do aproveitamento do biogás nos biodigestores da região) e potencial gerado (biodigestores que já promovem a recuperação energética) poderia suprir a demanda de populações de 23.757 e 9.162 habitantes, respectivamente.

Considerando-se os limites propostos por Martins et al. (2011) e Carvalho e Nolasco (2006) que sugerem viabilidade econômica das granjas, conforme especificado na metodologia, 23 propriedades apresentam potencial para o aproveitamento energético, apesar de ainda não explorarem este potencial, o que poderia proporcionar um aumento de 94,06 GWh.ano $\mathrm{GH}^{-1}$ de energia para a região (Figura 3). No entanto, mesmo as 32 granjas que apresentam menor viabilidade para o aproveitamento energético, a instalação do sistema de tratamento por biodigestão anaeróbia se torna crucial para minimizar os impactos ocasionados pelo confinamento dos suínos.

\section{CONCLUSÃO}

A partir desse estudo foi possível constatar que a maioria dos suinocultores da região do Vale do Piranga ainda não utilizam o processo de biodigestão anaeróbia como alternativa para tratamento dos dejetos e ignoram o potencial para a obtenção de energia a partir do principal subproduto do tratamento, o biogás. O potencial energético advindo da recuperação energética do biogás ficou evidenciado e pode indicar o aprimoramento da autossuficiência energética das granjas e da geração descentralizada de energia.

\section{AGRADECIMENTOS}

"O presente trabalho foi realizado com o apoio da CNPq, FAPEMIG, CAPES - Código de Financiamento 001 e a Universidade Federal de Viçosa (UFV) ".

\section{REFERÊNCIAS}

ABPA. Relatório anual 2018- Disponível em: http://abpa-br.com.br/storage/files/relatorio-anual-2018.pdf. Acesso em: 10 de dezembro de 2018.

ABCS. Mapeamento da Suinocultura brasileira. $1^{\circ} \mathrm{ed}$. Brasília, DF. 2016. Disponível em: http://www.abcs.org.br/attachments/-01_Mapeamento_COMPLETO_bloq.pdf Acesso em: 10 de dezembro de 2018.

BONETT, L. P.; MONTICELLI, C. J. Suínos, o produtor pergunta, a Embrapa responde. 2. ed., rev. Brasília, DF: Embrapa-SPI; Concórdia: Embrapa Suínos e Aves, 243 p.: il. - (Coleção 500 Perguntas, 500 Respostas), 1998.

CARVALHO, T.; NOLASCO, M. A. Créditos De Carbono e Geração de Energia com uso de Biodigestores no Tratamento de Dejetos Suínos. Rev. Acad., v.4, n.3, p. 23-32, Curitiba, 2006.

CENBIO - Centro Nacional de Referência em Biomassa, 2011. Disponível em: http://cenbio.iee.usp.br/. Acesso: 10 dezembro 2018.

CHERNICHARO, C. A. L. Princípios do Tratamento Biológico de Águas Residuárias: Reatores Anaeróbios. DESA/UFMG, Belo Horizonte, p. 23- 95, 1997. 
MARTINS, F. M.; OLIVEIRA, P. A. V. Análise econômica da geração de energia elétrica a partir do biogás na suinocultura. Eng. Agríc. Jaboticabal, v.31, n.3, p.477-486, maio/jun. 2011.

MOTTA, F.S. Produza sua energia - biodigestores anaeróbicos. Recife gráfica, Editora AS, 1986.

OLIVEIRA, P.A.V. Manual de Manejo e utilização de dejetos suínos. Concórdia, SC. 1993.

PROBIOGÁS. Guia Prático do Biogás. 5a edição, Gülzow - Alemanha. 2010.

SEIXAS, J.; MARCHETTI, D. Algumas sugestões para o aproveitamento de energia renovável na propriedade agrícola, circular técnica n 8, Embrapa, Planaltina, DF, 1982.

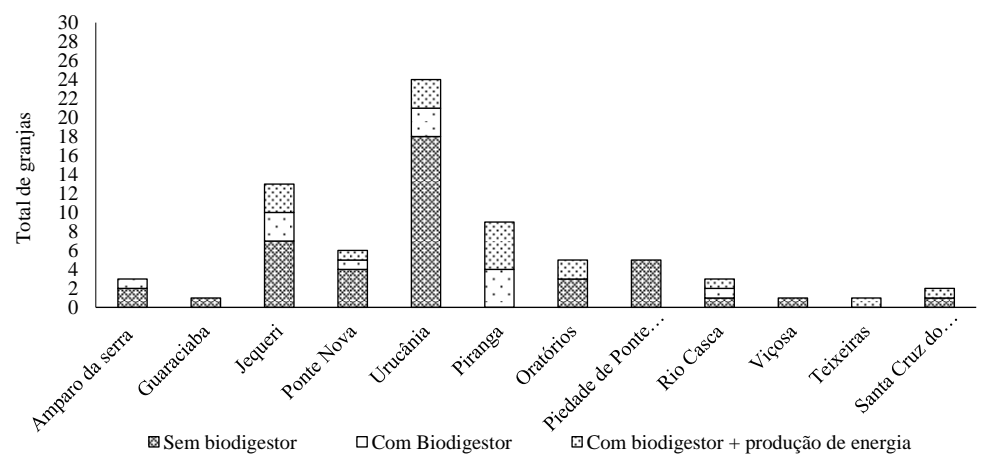

Figura 1. Número de suinoculturas distribuídos por município, a partir das características do sistema de tratamento e da recuperação energética do biogás.

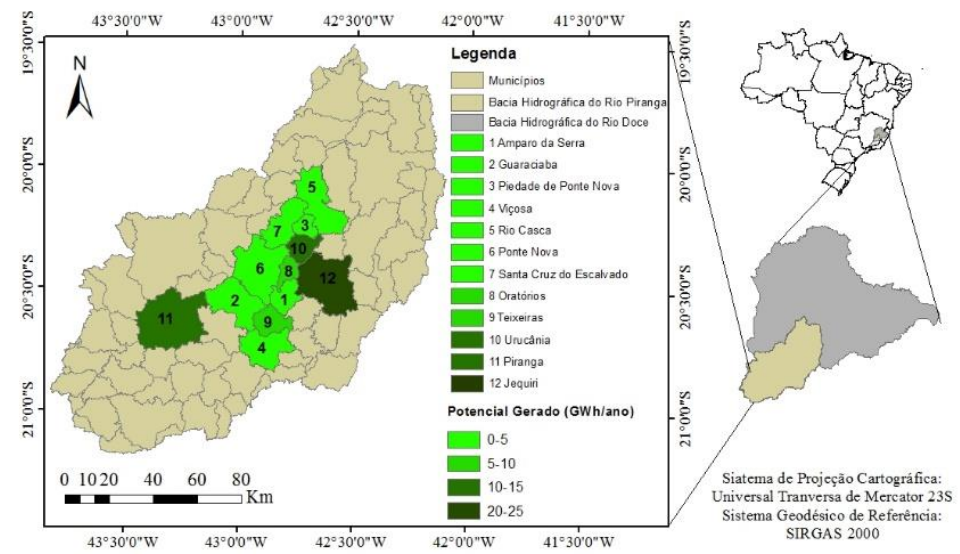

Figura 2. Representação espacial do potencial energético gerado a partir do biogás nas suinoculturas no Vale do Piranga (MG).
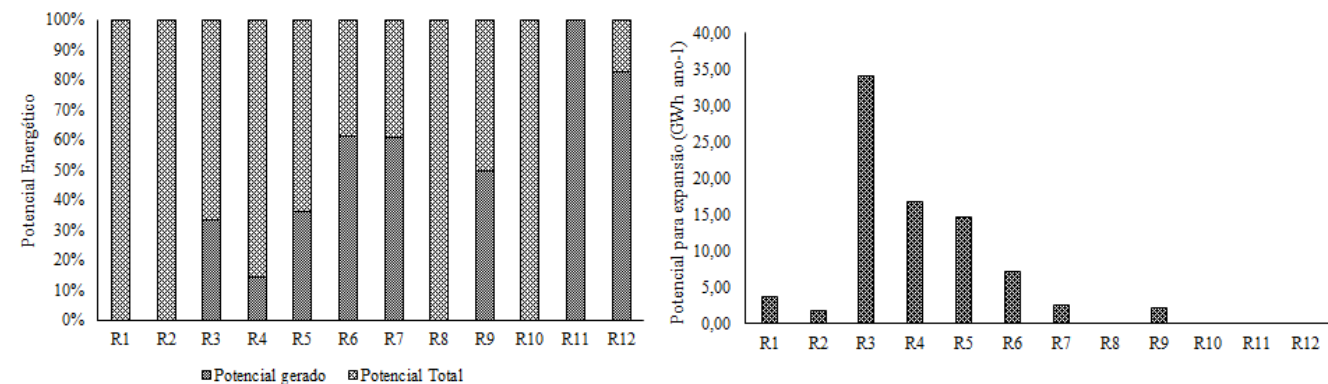

Legenda: Amparo da Serra (R1), Guaraciaba (R2), Jequeri (R3), Oratórios (R4), Piedade de Ponta Nova (R5), Piranga (R6), Ponte Nova (R7), Rio Casca (R8), Santa Cruz do Escalvado (R9), Teixeiras (R10), Urucânia (R11) e Viçosa (R12).

Figura 3. Indicação do potencial energético total e do potencial gerado nas doze cidades estudadas na região do Vale do Piranga/MG. 


\title{
IMPLANTAÇÃO DE UM BIODIGESTOR DE BAIXO CUSTO PARA PROCESSAR DEJETOS DE GADO LEITEIRO
}

\author{
Pereira, G.S. ${ }^{\text {; }}$ Paim, J.V. ${ }^{\text {; }}$ Madruga, K.C.R. ${ }^{3}$; Virmond, E. ${ }^{* *}$ \\ ${ }^{1}$ Estudante da Universidade Federal de Santa Catarina, Campus Araranguá, SC, Brasil. gustavo.silveira@grad.ufsc.br \\ ${ }^{2}$ Estudante da Universidade Federal de Santa Catarina, Campus Araranguá, SC, Brasil. julianavitoriop@ gmail.com \\ ${ }^{3}$ Professora da Universidade Federal de Santa Catarina, Campus Araranguá, SC, Brasil. katia.madruga@ufsc.br \\ ${ }^{4}$ Professora da Universidade Federal de Santa Catarina, Campus Araranguá, SC, Brasil. elaine.virmond@ufsc.br
}

\begin{abstract}
RESUMO: Uma das principais problemáticas associadas à criação de bovinos é a alta produção de rejeitos, principalmente esterco. O descarte final correto desses rejeitos animais é um desafio que abrange os aspectos técnicos, sanitários e econômicos. O objetivo deste trabalho foi implantar um biodigestor de baixo custo para processar dejetos de gado leiteiro no âmbito do primeiro projeto da Associação Técnica sem Fronteiras (TsF) Brasil em uma propriedade rural localizada em Araranguá, SC, Brasil para a produção de biogás visando à substituição parcial do gás liquefeito de petróleo (GLP) na fábrica de queijo anexa. Para isso, foi selecionado o modelo e um projeto de biodigestor a ser instalado, o mesmo foi construído, colocado em operação e seu desempenho analisado.
\end{abstract}

Palavras-chave: Dejeto bovino, biodigestor, biogás.

\section{IMPLEMENTATION OF A LOW-COST BIODIGESTER TO PROCESS DAIRY CATTLE MANURE}

\begin{abstract}
One of the main problems associated with cattle rearing is the high production of waste, mainly manure. The correct final disposal of these animal wastes is a challenge that covers the technical, sanitary and economic aspects. The objective of this work was to implement a low cost biodigester to process dairy cattle manure under the first project of the Association Technology without Borders (TwB) Brazil in a rural property located in Araranguá, SC, Brazil, aiming the application of the biogas in the partial substitution of the liquefied petroleum gas (LPG) used in the cheese factory annexed to the biodigester. For that, the biodigester model and a project of reference were selected, the biodigester was built, operated and evaluated.
\end{abstract}

Keywords: Bovine manure, biodigester, biogas.

\section{INTRODUÇÃO}

De acordo com a revista Agroenergia da Biomassa Residual (2009), a pecuária mundial emitiria 88 milhões de toneladas de metano no ano de 2006, das quais 17,6 milhões de toneladas são provenientes da degradação natural dos seus dejetos. Na proporção de aproximadamente $8 \%$ da pecuária mundial o Brasil responderia por 1,4 milhão de toneladas de $\mathrm{CH}_{4}$ (equivalentes a 29,6 milhões de toneladas de $\mathrm{CO}_{2}$ ), sendo que 1 milhão desse metano é referente a criação de bovinos, incluindo o gado leiteiro e a criação extensiva para gado de corte (JUNIOR et al., 2009).

Dentre as melhores práticas de gerenciamento dos dejetos da bovinocultura leiteira está a digestão anaeróbica, ou biodigestão, por meio da qual ocorrem simultaneamente o tratamento de resíduos, produção de bioenergia (biogás) e de fertilizante orgânico (mistura de frações sólida e líquida de produtos) (ABDESHAHIAN et. al, 2016; TOLMASQUIM, 2016; NESHAT et. al, 2017).

Visto isso, apenas com a criação de bovinos de leite é notável o grande potencial para a difusão da tecnologia de biodigestão, que ainda é pouco explorada. A biomassa é composta principalmente de carboidratos, proteínas e lipídios, que podem ser degradados por meio de processos físicos, químicos e bioquímicos executados por microrganismos presentes na própria biomassa (CORTEZ et al., 2008) para compostos mais simples em um ambiente livre de oxigênio por meio do processo de biodigestão. Tal processo ocorre em biodigestores, estruturas projetadas e construídas de modo a prover as condições necessárias à degradação da biomassa pelos grupos de microrganismos predominantes no meio em cada etapa de processamento: hidrólise, acidogênese, acetogênese e metanogênese (JÚNIOR et al., 2009; HAGO et al., 2017). 
Os modelos de biodigestores de baixo custo mais comuns são o indiano, o chinês e o canadense, e têm sido implementados em propriedades rurais em que a produção de biomassa ocorre em períodos curtos, como por exemplo, na criação extensiva (em pasto) de gado leiteiro, que duas vezes ao dia é recolhido para ordenha, permitindo coleta diária (ou em intervalos de tempo maiores) de biomassa que pode ser encaminhada ao biodigestor (DEGANUTTI et al., [s.d.]).

$\mathrm{O}$ biodigestor modelo indiano pode ser descrito como um cilindro vertical, construído com tijolos e revestido internamente por cimento impermeabilizante (TOLMASQUIM, 2016). O processo é considerado contínuo porque a cada carga (afluente) corresponde uma descarga de material fermentado (efluente tratado), sendo a produção do biocombustível (biogás) contínua e seu suprimento mantido à pressão constante. A biomassa do biodigestor se movimenta por diferença da pressão hidráulica no momento da carga. Cada carga requer um tempo de retenção hidráulica $(\mathrm{TRH})$ que varia em função das condições e objetivos do processamento, tipicamente, entre 30 a 50 dias dependendo das variações climáticas (especialmente da temperatura ambiente se esse parâmetro não puder ser controlado). Esse modelo de biodigestor é subterrâneo para evitar as mudanças bruscas de temperatura da biomassa ao aproveitar o isolamento térmico conferido pelo solo (OLIVEIRA, 1983).

Nesse contexto, este trabalho teve como objetivo geral implantar um biodigestor de baixo custo abastecido com dejetos de gado leiteiro em uma propriedade rural para a produção de biogás visando à substituição parcial do gás liquefeito de petróleo (GLP) no processo de fabricação de queijo realizado no local. Para isso, foi selecionado o modelo e um projeto de biodigestor a ser instalado, o mesmo foi construído, colocado em operação e seu desempenho analisado.

\section{MATERIAL E MÉTODOS}

Este trabalho foi realizado no âmbito das atividades da Associação Técnica sem Fronteiras (TsF) Brasil, uma associação de origem alemã trazida para o Brasil que tem como foco principal o desenvolvimento e a aplicação de projetos de baixo custo que beneficiem a sociedade, iniciou em dezembro de 2017 e tem término previsto para dezembro de 2018.

A propriedade rural familiar com criação de gado bovino leiteiro na qual o biodigestor foi implantado foi selecionada com o auxílio da Empresa de Pesquisa Agropecuária e Extensão Rural de Santa Catarina (EPAGRI), unidade de Araranguá - SC. Dentre os critérios de seleção incluíram-se a motivação do produtor rural em participar do projeto, o potencial para geração de biogás, e o potencial da propriedade para posteriormente servir de unidade de referência para que estudantes, professores e pessoas interessadas pudessem visitar o projeto depois de finalizado.

A propriedade rural de referência possui 30 cabeças de gado leiteiro da raça Jersey (peso médio de 350 $\mathrm{kg}$ por cabeça). A alimentação desses animais tem como base $10 \%$ do seu peso total, sendo aproximadamente $5 \mathrm{~kg}$ de ração, $10 \mathrm{~kg}$ de feno verde ou pasto, $20 \mathrm{~kg}$ de silagem de milho. Depois de realizada a ordenha, as vacas são encaminhadas para uma sala de alimentação e nesse local, além de se alimentarem, é onde liberam a maior quantidade de dejetos (mistura de esterco e urina).

O modelo de biodigestor selecionado para construção na propriedade rural em estudo foi o modelo indiano. Para realização do projeto foi utilizada uma cartilha de construção de biodigestor elaborada pela Diaconia Actaliança com o apoio da Caixa Econômica Federal (DIACONIA, 2013), a qual resume a construção do biodigestor em 12 passos. Outro material utilizado como referência para a construção do biodigestor foi o projeto técnico de construção do biodigestor de modelo indiano disponibilizado pela EPAGRI de Araranguá.

Para quantificação da produção de dejetos passíveis de processamento no biodigestor utilizou-se um carrinho de mão com volume de aproximadamente 50 L. Essa quantificação foi necessária para ajuste da operação do biodigestor dado que o projeto de referência foi executado sem dimensionamento relativo à quantidade de biomassa disponível para processamento na propriedade rural em estudo. O Tempo de Retenção Hidráulica (TRH) do biodigestor foi definido em 15 dias, de acordo com a disponibilidade do proprietário em abastecer o biodigestor considerando a rotina de manejo das vacas praticada na propriedade.

Para quantificar a produção de biogás, monitorou-se a elevação do gasômetro sem o sobrepeso a fim de quantificar a produção de biogás à pressão atmosférica. Utilizou-se uma escala métrica, que foi fixada ao lado do gasômetro, com comprimento de $1,60 \mathrm{~m}$, variando de $2 \mathrm{~cm}$ (nível inferior do gasômetro) a 1,60 m (nível superior máximo que o gasômetro alcança). A variação de altura do gasômetro foi registrada em três intervalos de tempo ao longo de um TRH (15 dias) a partir de uma carga equivalente a 20 carrinhos de mão, equivalente 
a $1.000 \mathrm{~L}$ de dejetos e mais $1.000 \mathrm{~L}$ de água seguindo a proporção de 1:1 tal como recomendado por Filho (1981), que ocorreu no dia 0 . O intervalo de tempo 1 correspondeu a dia 0 até dia 4 , o intervalo de tempo 2 correspondeu a dia 4 até dia 9 , e o intervalo de tempo 3 do dia 9 até o dia 15 . O gasômetro foi esvaziado após registro e análise da composição do biogás a fim de se verificar a elevação do gasômetro no período subsequente. Em conjunto com o monitoramento da elevação do gasômetro nos intervalos de tempo previamente descritos, determinou-se a composição do biogás produzido, tal como descrito por Paim (2018). Destaca-se que tal período de tempo correspondeu à primavera, com temperatura ambiente média de $20{ }^{\circ} \mathrm{C}$ (INMET, 2018).

\section{RESULTADOS E DISCUSSÃO}

O local para instalação do biodigestor foi definido conforme orientação de Junqueira (2014), considerando fatores tais como ter fácil acesso para facilitar o transporte da biomassa a ser carregada diariamente, e também a facilidade de remoção e transporte do biogás e do fertilizante orgânico para utilização. Com isso, de acordo com as especificidades de local e distância de Diaconia (2013), foi escolhido um local distante $12 \mathrm{~m}$ do ponto de utilização do biogás, onde não há sombreamento, pois o calor é importante para produção do biogás. Após escolha do local, foi dado sequência no processo de construção do biodigestor.

A quantificação da produção dos dejetos (mistura de esterco e urina) a cada 15 dias indicou que são coletados em média 35 carrinhos de dejetos, estando em concordância com a quantidade previamente informada pelo proprietário (30-40 carrinhos de mão). Então, o volume equivalente de dejetos passível de processamento no biodigestor nesse intervalo de tempo é de aproximadamente $1.750 \mathrm{~L}\left(1,75 \mathrm{~m}^{3}\right)$. Na proporção de mistura dejetos com água de 1:1, realizada diretamente no ponto de carga do biodigestor, o abastecimento do volume total de dejetos mais água a cada 15 dias $\left(3.500 \mathrm{~L}\right.$ ou $\left.3,5 \mathrm{~m}^{3}\right)$ corresponderia à utilização de apenas $50 \%$ da capacidade nominal do biodigestor (aproximadamente $7 \mathrm{~m}^{3}$ ). $\mathrm{O}$ desempenho do biodigestor foi avaliado quando uma carga de apenas 20 carrinhos de mão, ou seja, aproximadamente $1.000 \mathrm{~L}$ de dejetos, mais $1.000 \mathrm{~L}$ de água na proporção de 1:1 (totalizando aproximadamente $2.000 \mathrm{~L}$ ), sendo esse valor $29 \%$ da capacidade nominal do tanque de fermentação. $\mathrm{O}$ motivo pelo qual o biodigestor não fora abastecido com $100 \%$ dos dejetos produzidos mesmo possuindo capacidade para isso se deve ao subdimensionamento da caixa de saída pois não havia onde armazenar o efluente do biodigestor (fertilizante orgânico), que sai do biodigestor à medida que a nova carga entra. A exemplo de um biodigestor de mesmo modelo porém de menor tamanho, instalado no município de São João do Sul/SC na qual que utilizou o mesmo projeto de referência utilizado neste trabalho, o agricultor utiliza o fertilizante orgânico uma vez ao mês para irrigação do pasto, e a caixa de saída de tal biodigestor, foi substituída por um tanque a céu aberto com dimensões de 5x9x1,5 m $\left(67,5 \mathrm{~m}^{3}\right)$, servindo assim de reservatório temporário de fertilizante orgânico.

A altura do gasômetro registrada nos dias 4, 9 e 15 ao longo de um TRH de 15 dias foi de, $114 \mathrm{~cm}, 103$ $\mathrm{cm}$ e $101 \mathrm{~cm}$, respectivamente. Considerando-se as medidas internas do gasômetro fornecidas pelo fornecedor (1,70 m de altura, $1,70 \mathrm{~m}$ diâmetro superior e 1,30 m diâmetro inferior, totalizando volume de $\left.3 \mathrm{~m}^{3}\right) \mathrm{e}$ utilizando-se a equação do volume do tronco de cone e somando as alturas encontradas em cada análise com o valor de $0,55 \mathrm{~m}$ que corresponde à diferença de altura entre o fundo do gasômetro e o nível dos dejetos para a carga avaliada, obteve-se os valores do volume de biogás produzido nos dias 4, 9 e 15 de aproximadamente $3,04 \mathrm{~m}^{3}, 2,84 \mathrm{~m}^{3}$ e $2,77 \mathrm{~m}^{3}$, respectivamente, totalizando de $8,62 \mathrm{~m}^{3}$ de biogás produzidos em 15 dias utilizando-se apenas $29 \%$ da capacidade de processamento do biodigestor.

De acordo com os dados obtidos por Paim (2018), a concentração média de metano $\left(\mathrm{CH}_{4}\right)$ determinada nos três intervalos de tempo considerados foi de $(71 \pm 9,1) \%$ e está na faixa de valor aceitável pela literatura (50\% a 80\%), indicando bom desempenho do processo nas condições avaliadas e o potencial de aplicação desse biocombustível em substituição ao GLP nas produção de queijo. No entanto, tal aplicação deve ser estudada a fim de se relacionar produção de biogás, composição do biogás, demanda de GLP e requisitos para substituição parcial ou total em sistemas de conversão adequados, tal como apresentado por Paim (2018). Sabendo-se que a temperatura é um dos principais fatores que afetam o processo de biodigestão, faz-se necessário, na continuidade deste trabalho, avaliar o desempenho do biodigestor nas outras estações do ano, especialmente em menores temperaturas, a fim de se avaliar o efeito de sua variação sobre a produção de biogás e também sobre sua composição. 


\section{CONCLUSÃO}

O estágio da implementação do biodigestor na propriedade rural em estudo que foi alcançado e descrito neste trabalho possibilitou melhor gerenciamento dos resíduos orgânicos da atividade leiteira, que antes eram dispostos em esterqueira a céu aberto, sem manejo adequado e com potenciais impactos ambientais negativos associados, tais como contaminação de águas subterrâneas e emissão de gases de efeito estufa. Conclui-se a partir dos resultados apresentados que o biogás produzido no biodigestor de baixo custo instalado tem potencial para suprir biocombustível para substituir parcial ou totalmente o GLP nas operações de cocção agroindustrial praticadas na queijaria, com potencial para reduzir os custos da propriedade e os impactos ambientais negativos associados à utilização de um combustível fóssil (GLP), contribuindo assim para o fomento ao uso de tecnologias de baixo custo pela população na geração de energia renovável.

\section{REFERÊNCIAS}

ABDESHAHIAN, $P$. et al. Potential of biogas production from farm animal waste in Malaysia. Renewable and Sustainable Energy Reviews, v. 60, p. 714-723, 2016.

CORTEZ, L.A.B. et al. Biomassa para energia. Campinas - SP. Editora Unicamp, 2008. 733p.

DEGANUTTI, R. et al. Biodigestores rurais: modelo indiano, chinês e batelada. Departamento de Artes e Representação Gráfica, Universidade Estadual Paulista Julis de Mesquita Filho, [s.d.].

DIACONIA. 12 Passos Para Construir Um Biodigestor. Fundo Socioambiental CAIXA. ed. Recife: 2013.

FILHO, J.A.C. Biogás independência energética do pantanal mato-grossense. Corumbá, 1981. 53p. ilust. (EMBRAPA. UEPAE de Corumbá. Circular Técnica, 9).

HAGOS, K. et al. Anaerobic co-digestion process for biogas production: Progress, challenges and perspectives. Renewable and Sustainable Energy Reviews, v. 76, n. March 2016, p. 1485-1496, 2017.

HENN, A. Avaliação de dois sistemas de manejo de dejetos em uma pequena propriedade produtora de suínos - condição de partida. 157p, Dissertação, Departamento de Engenharia Ambiental, Universidade Federal de Santa Catarina, 2005.

INMET. Instituto Nacional de Metereologia: Estação Meteorológica de Observação de Superfície Automática. 2018. Disponível em: <http://www.inmet.gov.br/portal/index.php?r=estacoes/estacoesAutomaticas>. Acesso em: 20 nov. 2018.

JÚNIOR, C.B. et al. Agroenergia da biomassa residual: perspectivas energéticas, socioeconômicas e ambientais. Agroenergia da biomassa residual, v. 2, p. 138, 2009.

JUNQUEIRA, Sérgio Luís Coelho Diniz. Geração de energia através de biogás proveniente de esterco bovino: estudo de caso na fazenda aterrado. 2014. 55 p. TCC (Graduação) - Curso de Engenharia Mecânica, Universidade Federal do Rio de Janeiro, Rio de Janeiro, 2014.

NESHAT, S.A. et al. Anaerobic co-digestion of animal manures and lignocellulosic residues as a potent approach for sustainable biogas production. Renewable and Sustainable Energy Reviews, v. 79, n. July 2016, p. 308-322, 2016.

NISHIMURA, R. Análise de balanço energético de sistema de produção de biogás em granja de suínos: implementação de aplicativo computacional. 84p. Tese de Mestrado, Departamento de Engenharia Elétrica, Universidade Federal de Mato Grosso do Sul, 2009.

OLIVEIRA, P. A. V. DE. Manual de manejo e utilização dos dejetos suínos. Documentos / Embrapa, n. 27, p. 188, 1993.

PAIM, J.V. Aplicação do biogás produzido a partir de dejetos de gado leiteiro como fonte alternativa de energia em uma queijaria. TCC (Graduação). Universidade Federal de Santa Catarina, UFSC. Araranguá, SC, Brasil. 2018. 39 p.

TOLMASQUIM, M.T. Energia Termelétrica: Gás Natural, Biomassa, Carvão, Nuclear / Mauricio Tiomno, Tolmasquim (coord). - EPE: Rio de Janeiro, 2016 417p.: il; 21 x 29,7cm. 


\title{
OBTENÇÃO DE BIOPRODUTOS POR CEPAS DE CLOSTRIDIUM BEIJERINCKII A PARTIR DE GLICOSE E XILOSE
}

\author{
Bortolucci, J. ${ }^{1}$; Fonseca, B.C. ${ }^{1}$; Reginatto, V. ${ }^{1}$ \\ ${ }^{I}$ Departamento de Química / Faculdade de Filosofia, Ciências e Letras de Ribeirão Preto / Universidade de São Paulo, Ribeirão \\ Preto, SP, Brasil \\ jonata.bortolucci@usp.br
}

\begin{abstract}
RESUMO: A crescente demanda por biocombustíveis provém do fato de que estes diminuem o efeito estufa, devido à reabsorção dos gases emitidos durante o processo de crescimento dos vegetais. Os biocombustíveis podem ser produzidos a partir de derivados da hidrólise de biomassa lignocelulósica, que está contida em alguns resíduos agroindustriais e é composta por celulose, hemicelulose e lignina. Após a degradação destes componentes, obtêm-se alguns monossacarídeos, principalmente glicose e xilose, que podem ser utilizados para a obtenção de bioprodutos. Bactérias do gênero Clostridium, são capazes de produzir $\mathrm{H}_{2}$, acetona, butanol, etanol, entre outros. Neste trabalho, ensaios de fermentação foram realizados em meio contendo uma mistura de glicose e xilose, ambos em uma concentração de $15 \mathrm{~g} / \mathrm{L}$. Os microrganismos utilizados foram o Clostridium beijerinckii $\operatorname{Br} 21$ (KT626859) e o Clostridium beijerinckii ATCC 35702. Observou-se a produção de acetona, butanol e etanol pelo Clostridium beijerinckii ATCC 35702 e produção de ácido butírico pelo Clostridium beijerinckii $\mathrm{Br} 21$. Ambos os microrganismos apresentam grande potencial para obtenção de bioprodutos e tem potencial para serem usados em co-cultura.
\end{abstract}

Palavras-chave: biocombustíveis, butanol, ácido butírico, biomassa, fermentação.

\section{OBTAINING BIOPRODUCTS BY CLOSTRIDIUM BEIJERINCKII STRAINS FROM GLUCOSE AND XYLOSE}

\begin{abstract}
The growing demand for biofuels comes from the fact that they have minimal contribution to the increase of the greenhouse effect, due to the reabsorption of the gases emitted in the combustion during the growth process of the plants. Biofuels can be produced from derivatives of lignocellulosic biomass hydrolysis, contained in some agroindustrial waste and is composed of cellulose, hemicellulose and lignin. After the degradation of these components, some monosaccharides are obtained, mainly glucose and xylose, and can be used to obtain bioproducts. Bacteria of the genus Clostridium, are capable of producing $\mathrm{H}_{2}$, acetone, butanol, ethanol, among others. In this work, fermentation experiments were performed in medium containing a mixture of glucose and xylose, both at a concentration of $15 \mathrm{~g} / \mathrm{L}$. The microorganisms used were Clostridium beijerinckii Br21 (KT626859) and Clostridium beijerinckii ATCC 35702. Acetone, butanol and ethanol production was observed by Clostridium beijerinckii ATCC 35702 and butyric acid production was observed by Clostridium beijerinckii $\mathrm{Br} 21$. Both microorganisms present great potential for obtaining bioproducts and have the potential to be used in co-culture.
\end{abstract}

Keywords: biofuels, butanol, butyric acid, biomass, fermentation.

\section{INTRODUÇÃO}

Os combustíveis obtidos a partir de biomassa, como a lignocelulósica, são considerados renováveis e denominados biocombustíveis. Atualmente, os biocombustíveis são utilizados como substitutos dos combustíveis fósseis. A principal razão para o aumento da utilização de biocombustíveis deve-se ao fato de que estes contribuem pouco para o aumento do efeito estufa, pois os gases emitidos na queima dos biocombustíveis são reabsorvidos no processo de crescimento dos vegetais dos quais se originam (Petrobrás, 2007).

Desse modo, a crescente utilização de biocombustíveis determina a diminuição de gases poluentes na atmosfera e também a diminuição da dependência de matérias-primas não-renováveis (Gomes-Neto, 2005).

No Brasil, há um grande desenvolvimento agroindustrial que promove a geração de grandes quantidades de resíduos agroindustriais, em especial o bagaço de cana-de-açúcar. Esta biomassa residual é composta por materiais lignocelulósicos, podendo ser utilizada como substrato para a obtenção de biocombustíveis. (Nunes et al, 2013). 
A biomassa lignocelulósica é constituída, majoritariamente, por celulose, hemicelulose e lignina. A celulose, um homopolímero, é constituída por D-glicose, possibilitando a formação de cadeias lineares de até 12000 resíduos; já a hemicelulose, um heteropolímero, é formada por uma combinação aleatória de diversos monômeros, como pentoses ( $\beta$-D-xilose, $\beta$-L-arabinose), hexoses ( $\beta$-D-glicose, $\beta$-D-manose, $\beta$-D-galactose) e ácidos urônicos (Anwara et al, 2014). Por fim, a lignina possui uma estrutura polifenólica, ou seja, não é constituída por monossacarídeos. Desse modo, não é diretamente utilizada na fermentação.

A hidrólise da celulose e hemicelulose produz uma mistura de açúcares, especialmente glicose e xilose, que podem ser utilizados em processos fermentativos de produção de biocombustíveis, os denominados biocombustíveis de segunda geração.

Dentro desse contexto, um dos biocombustíveis que pode ser gerado por fermentação a partir de biomassa é o $\mathrm{H}_{2}$. Este pode ser produzido por bactérias do gênero Clostridium, capazes de produzir, também, outros biocombustíveis, como o etanol e o butanol.

O C. beijerinckii possui um metabolismo bifásico. $\mathrm{Na}$ fase acidogênica, que ocorre durante a fase logarítmica de crescimento do microrganismo, são produzidos os ácidos acético e butírico, juntamente com o $\mathrm{H}_{2}$; e na fase solventogênica, que ocorre durante a fase estacionária do microrganismo, são produzidos acetona, butanol e etanol, denominada de fermentação ABE (Xiao et al, 2017).

Neste trabalho foi feita uma comparação entre duas cepas de C. beijerinckii, usando glicose e xilose como fontes de carbono. A cepa padrão ATCC 35702 e o C. beijerinckii Br21 (KT626859), isolada em nosso laboratório (Fonseca et al 2016), o qual apresenta as enzimas relacionadas à fermentação ABE; exceto a enzima acetoacetato descarboxilase (AADC).

\section{MATERIAL E MÉTODOS}

Foram utilizadas cepas $C$. beijerinckii $\mathrm{Br} 21$ (KT626859) (Br), isolada e identificada em nosso laboratório (Fonseca et al 2016) e C. beijerinckii ATCC 35702 (Cb).

O pré-inóculo foi realizado em frascos tipo penicilina de $100 \mathrm{~mL}$, com $56 \mathrm{~mL}$ de meio Reinforced Clostridial Medium - RCM (Al-Shorgani et al., 2016) contendo glicose e xilose, ambos os a uma concentração de $15 \mathrm{~g} / \mathrm{L}$. Antes de fechar os frascos, gás nitrogênio foi borbulhado para assegurar a anaerobiose do sistema. Após, os frascos foram lacrados e autoclavados por $20 \mathrm{~min}$. Após resfriamento foram inoculados $4 \mathrm{~mL}$ de uma das culturas citadas anteriormente e o frasco foi colocado em agitação por 24 horas a $35^{\circ} \mathrm{C}$.

Os inóculos dos ensaios de fermentação foram preparados a partir do pré-inóculo, conforme descrito acima, após centrifugação a $9000 \mathrm{rpm}$ por 5 minutos, seguido pela ressuspensão em meio RCM. Este procedimento de lavagem das células foi efetuado duas vezes. Por fim, o pré-inóculo foi padronizado com densidade óptica de 0,5 , a $600 \mathrm{~nm}$.

Os ensaios de fermentação em batelada também foram conduzidos em frascos tipo penicilina de 100 $\mathrm{mL}$, contendo $56 \mathrm{~mL}$ de meio RCM (já contendo os açúcares) e $4 \mathrm{~mL}$ do pré-inóculo previamente preparado, totalizando $60 \mathrm{~mL}$. O substrato utilizado foi uma mistura de glicose e xilose, em uma concentração de $15 \mathrm{~g} / \mathrm{L}$ cada, que corresponde a $83 \mathrm{mmol} / \mathrm{L}$ de glicose e $100 \mathrm{mmol} / \mathrm{L}$ de xilose. Os ensaios foram feitos em triplicata.

Durante os ensaios de fermentação, foram retiradas amostras periodicamente para a determinação do pH e absorbância a $600 \mathrm{~nm}$; em seguida, as amostras foram filtradas a $0,45 \mu \mathrm{m}$ e armazenadas para posterior análise dos produtos.

A concentração celular foi determinada pela leitura da densidade ótica (DO) do cultivo em um espectrofotômetro (BEL Engineering - UV-M51), a 600 nm. Para se obter os dados de concentração celular em massa seca, uma correlação entre valores de densidade ótica a $600 \mathrm{~nm}$ de uma suspensão de células e a massa celular seca foi obtida.

Os substratos consumidos e os produtos obtidos na fermentação foram quantificados através da análise por Cromatografia Líquida de Alta Eficiência - CLAE, em cromatógrafo líquido Shimadzu LC-20AT., de acordo com adaptações nas metodologias descritas por (Kumar et al, 2014; Bellido et al, 2015). Utilizou-se a coluna Aminex HPX-87H (7,8 mm x $300 \mathrm{~mm})$ com temperatura controlada em $30^{\circ} \mathrm{C}$, sob condições isocráticas. A fase móvel consistiu de $\mathrm{H}_{2} \mathrm{SO}_{4}$ 0,005 mol.L ${ }^{-1}$, com o fluxo de 0,6 mL.min ${ }^{-1}$ (60 Kgf cm-2). O detector utilizado foi o RID (índice de refração) e a aquisição e tratamento dos dados foram realizados pelo software LabSolutions. 


\section{RESULTADOS E DISCUSSÃO}

A Figura 1 a seguir apresenta os resultados de massa celular seca (mg/L) e pH em função do tempo (h).

Analisando-se a figura acima, observa-se que o meio no qual o $C$. beijerinckii $\mathrm{Br} 21$ foi cultivado sofreu redução de $\mathrm{pH}$ com o crescimento do microrganismo, que pode ser atribuída à biossíntese de ácido butírico (figura 4). Em contrapartida, o meio contendo o C. beijerinckii ATCC 35702 inicialmente sofreu uma pequena redução de pH de 6,0 para 5,8, seguida de elevação do mesmo. Isto é típico da fase solventogênica do Clostridium, na qual os ácidos gerados durante a fase acidogênica são reabsorvidos para a síntese de solventes (Figura 4).

A Figura 2 apresenta a velocidade de crescimento específica $\left(\mathrm{h}^{-1}\right)$ em função do tempo $(\mathrm{h})$, para as duas cepas de Clostridium. Observa-se que C. beijerinckii ATCC 35702 apresentou velocidade específica máxima de aproximadamente $0,15 \mathrm{~h}^{-1}$, durante os períodos iniciais da fermentação. Já o C. beijerinckii $\mathrm{Br} 21$ apresentou velocidade específica máxima de $0,8 \mathrm{~h}^{-1} \mathrm{em}$, aproximadamente, 14 horas de fermentação.

Nas Figuras 3 e 4 a seguir, encontram-se os dados de consumo do substrato e produção de metabólitos. Houve maior consumo dos dois substratos pelo C. beijerinckii ATCC35702. O C. beijerinckii Br21 consumiu maior quantidade de glicose, em comparação com xilose; já o C. beijerinckii ATCC35702 consumiu maior quantidade de xilose.

Em relação aos bioprodutos formados, observa-se que $C$. beijerinckii ATCC 35702 produziu os solventes acetona $(16,3 \mathrm{mmol} / \mathrm{L})$, butanol $(74,9 \mathrm{mmol} / \mathrm{L})$ e etanol $(14,0 \mathrm{mmol} / \mathrm{L})$, enquanto o $C$. beijerinckii Br21 produziu apenas ácido butírico $(36,7 \mathrm{mmol} / \mathrm{L})$, não tendo migrado para a fase solventogênica.

\section{CONCLUSÃO}

Ambas as cepas de $C$. beijerinckii exploradas apresentaram potencial para obtenção de bioprodutos, como acetona, butanol, etanol e ácido butírico, a partir dos principais carboidratos derivados da hidrólise de biomassas, glicose e xilose.

Observou-se que o $C$. beijerinckii $\mathrm{Br} 21$ produziu considerável quantidade de ácido butírico, ao contrário da cepa ATCC 35702 que produziu principalmente butanol. Portanto, a enzima acetoacetato descarboxilase, que não é biossintetizada pela cepa $\mathrm{Br} 21$, parece estar envolvida na produção de butanol.

Experimentos futuros irão investigar se uma cocultura destes dois microrganismos pode aumentar a produção de butanol a partir de glicose e xilose.

\section{REFERÊNCIAS}

Anwara, Z.; Gulfrazb, M.; Irshad, M. Agro-industrial lignocellulosic agro residuals a key to unlock the future bio-energy: A brief review. J. Radia. Res. Appl. Sci. v. 7 (2): 163-173, 2014.

Xiao, C.; Fan, W.; Du, S.; Liu, L.; Wang, C.; Guo, M.; Zhang, L.; Zhang, M.; Yu, L. A novel glycosylated solution from Dioscoreazingiberensis C.H. Wright significantly improves the solvent productivity of Clostridium beijerinckii. Bioresource Technology, v. 241: 317-324, 2017.

Fonseca, B.C. Produção de hidrogênio por fermentação por um novo isolado de Clostridium beijerinckii. Dissertação de Mestrado - Universidade de São Paulo - Ribeirão Preto - SP. p. 107, 2016.

Fonseca B.C., Guazzaroni M.E., Reginatto V. Fermentative production of $\mathbf{H}_{2}$ from different concentrations of galactose by the new isolate Clostridium beijerinckii Br21. International Journal of Hydrogen Energy, 41: 21109-21120, (2016).

Gomes-Neto, E. H. Hidrogênio, Evoluir sem poluir: a era do hidrogênio, das energias renováveis e das células a combustível. Brasil H2 Fuel Cell Energy. Curitiba - PR, 2005.

Nunes, R.M.; Guarda, E.A.; Serra J.C.V.; Martins, A.A. Resíduos agroindustriais: potencial de produção do etanol de segunda geração no Brasil. Revista Liberato, Novo Hamburgo, v.14, n. 22, p. 113-238, 2013. Petrobrás, 2007. Biocombustíveis: 50 perguntas e respostas sobre este novo mercado. Ministério das Minas e Energia. Disponível em: https://www.agencia.cnptia.embrapa.br/Repositorio/matprima1_000g7pcetcc 02wx5ok0wtedt32e6jis7.pdf. Acesso em: dezembro de 2018. 


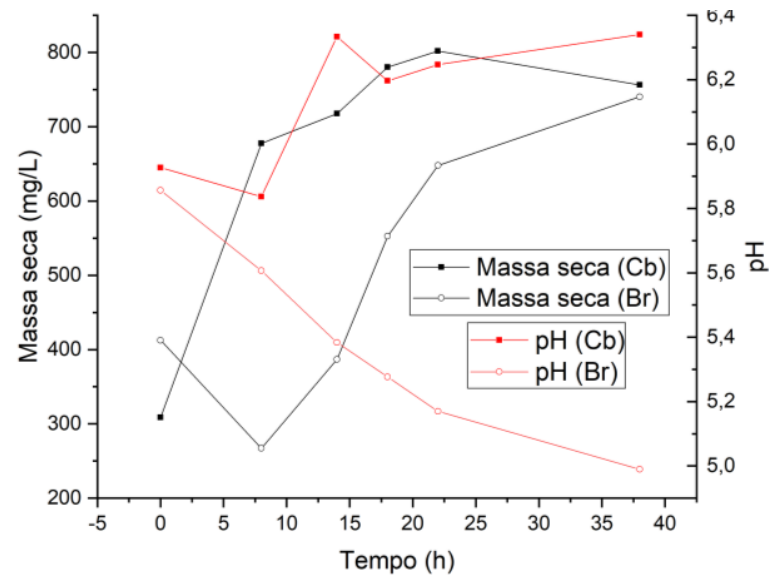

Figura 1. Variação da massa seca e pH em função do tempo para o C. beijerinckii $\mathrm{Br} 21(\mathrm{Br})$ e o C. beijerinckii ATCC $35702(\mathrm{Cb})$ crescidos em meio RCM, contendo glicose e xilose a $15 \mathrm{~g} / \mathrm{L}$.

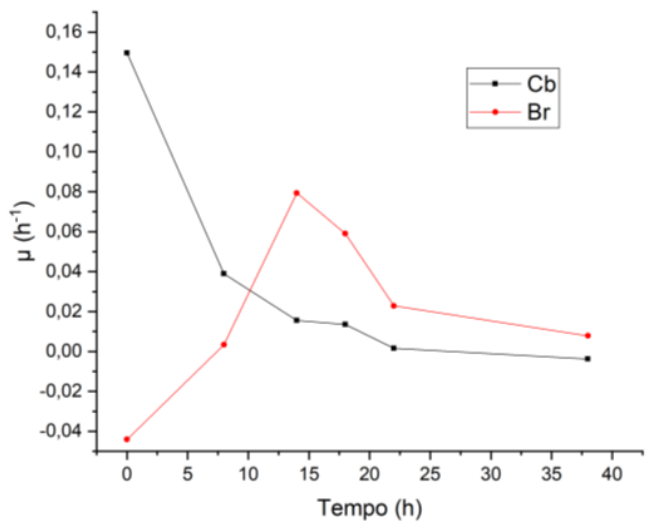

Figura 2. Velocidade específica de crescimento em função do tempo do C. beijerinckii $\mathrm{Br} 21(\mathrm{Br})$ e $C$. beijerinckii ATCC $35702(\mathrm{Cb})$ em meio RCM, contendo glicose e xilose a $15 \mathrm{~g} / \mathrm{L}$.

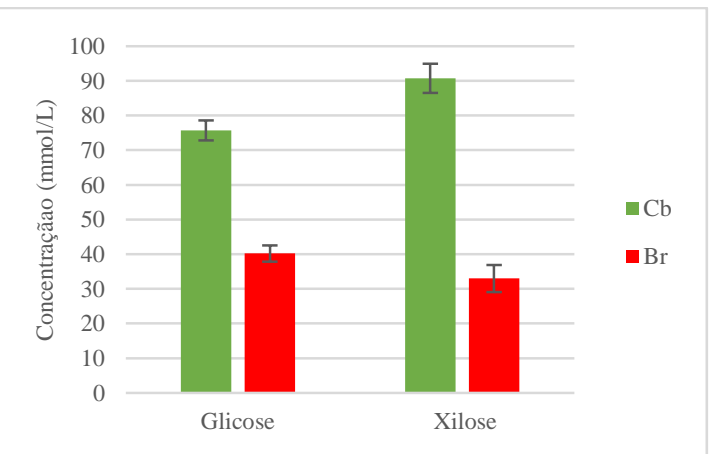

Figura 3. Consumo de glicose e xilose em $40 \mathrm{~h}$ de fermentação para o $C$. beijerinckii $\mathrm{Br} 21(\mathrm{Br})$ e $C$. beijerinckii ATCC $35702(\mathrm{Cb})$ em meio RCM, contendo glicose e xilose ( $15 \mathrm{~g} / \mathrm{L}$ cada).

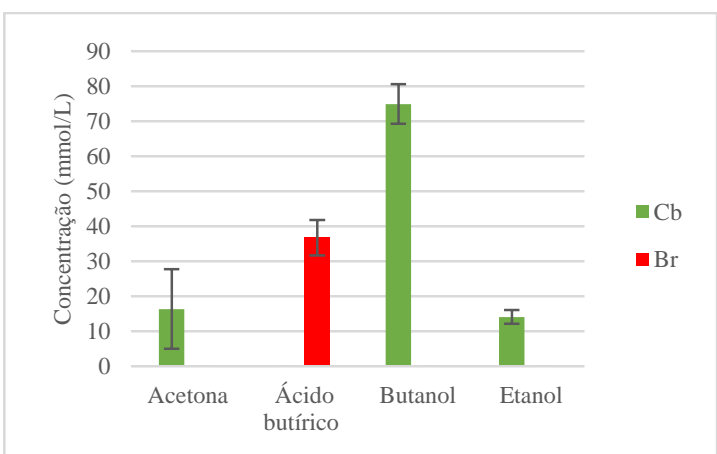

Figura 4. Concentração dos produtos obtidos em $40 \mathrm{~h}$ de fermentação para o C. beijerinckii $\mathrm{Br} 21(\mathrm{Br})$ e $C$. beijerinckii ATCC $35702(\mathrm{Cb})$ em meio RCM, contendo glicose e xilose (15 g/L cada). 


\title{
PROCESS PERFOMANCE OF SWINE CARCASS AND MANURE CO-DIGESTION IN COMPARING OF MANURE MONO-DIGESTION: IMPACT OF ORGANIC LOADING RATE
}

\author{
Tápparo, D.C.*1; Steinmetz, R.L.R. ${ }^{2}$; Amaral, A.C. ${ }^{3}$; Gasparetto, T.C. ${ }^{4}$; Cé, A. ${ }^{5}$; Kunz, A. ${ }^{1,2}$ \\ ${ }^{1}$ Universidade Estadual do Oeste do Paraná - UNIOESTE/CCET/PGEAGRI Cascavel, PR, Brazil \\ (deisictapparo@gmail.com) \\ ${ }^{2}$ Embrapa Suínos e Aves, Concórdia, SC, Brazil \\ ${ }^{3}$ Universidade do Contestado, Concórdia, SC, Brazil \\ ${ }^{4}$ Universidade Federal da Fronteira Sul, Erechim, RS, Brazil \\ ${ }^{5}$ Universidade Tecnológica Federal do Paraná, Fracisco Beltrão, PR, Brazil
}

\begin{abstract}
Swine farming is important agriculture activity in Brazil, and intensive production increases the necessity of efficient animal residues management and treatment. Anaerobic co-digestion of two main residues of swine production (dead animal carcass and manure) are an excellent alternative to management and produced biogas. Considering this, the present study aimed to evaluate swine carcass and manure co-digestion in comparison of swine manure mono-digestion in a mesophilic CSTR biodigester. Two CSTR (R1 and R2) biodigester $(12 \mathrm{~L})$ was operated in a lab scale and maintained at mesophilic conditions $\left(37^{\circ} \mathrm{C} \pm 1\right)$ and fed once a day. The R1 reactor was fed only with swine manure and R2 fed with swine carcass and manure. The R2 organic loading rate progression was performed increasing the swine carcass and manure ratio at four different phases. At phase I the reactors were operated only with swine manure, and presented similar biogas productiveness of $0.40 \pm 0.03 \mathrm{~L}_{\mathrm{N} \text { biogas }} \cdot \mathrm{L}_{\text {reactor }}{ }^{-1} \cdot \mathrm{d}^{-1}$ and $0.41 \pm 0.03 \mathrm{~L}_{\mathrm{N} \text { biogas }} \cdot \mathrm{L}_{\text {reactor }}{ }^{-1} \cdot \mathrm{d}^{-1}, \mathrm{R} 1$ and $\mathrm{R} 2$ respectively. Comparing R1 and R2 during other phases, biogas productiveness increased up to $200 \%, 450 \%$ and $500 \%$, for phase II, III, and IV respectively. However, when comparing phase III and IV in R2, the increment in biogas productiveness was not expressive, at the same time the free ammonia concentration and VFA/TA ratio increased. Besides that, begun foam formation, indicating a possible imbalance. Comparing mono-digestion and co-digestion, biogas productiveness increased until $500 \%$, showing that anaerobic co-digestion of carcass and manure is an excellent alternative for VS concentration increases in the reactor, and consequently biogas yield improvement.
\end{abstract}

Keywords: swine farming, animal residues, biogas.

\section{INTRODUCTION}

Anaerobic digestion (AD) has considerable importance in the scenario of residues treatment because occurs biogas generation, a form of renewable energy, and organic materials stabilization (Weiland, 2010). A variety of substrates can be used in digesters, and many factors exert influence in the process.

Swine farming is important livestock activity in Brazil, and intensive production increases the necessity of efficient manure management and treatment due to the amount of waste produced (Kunz et al., 2012). In addition to manure volume produced another concern of swine production is the disposal of dead animal carcasses. Substrates of lipids-rich (like carcass and slaughterhouse wastes) are excellent for AD, according described by Tápparo et al (2018), swine carcass has a higher biogas potential, around $1076 \pm 48 \mathrm{~L}_{\mathrm{Nbiogas}} \cdot \mathrm{kg}_{\mathrm{VSadd}}{ }^{-}$ ${ }^{1}$, five times more than swine manure. However during carcass degradation inhibitory compounds can be produced (free ammonia and volatile fatty acid accumulation).

Besides that swine manure mono-digestion is one alternative of management already consolidated in Brazil, and the co-digestion with carcass is an excellent opportunity to increase biogas production. It has been suggested that co-digestion (AcoD) can significantly attenuate inhibitory compounds. Furthermore the AcoD process can be improving methane production, nutrient balance, and the synergistic effects of microorganisms (Mata-Alvarez et al. 2011; Xie et al. 2016).

Considering this, the present study aimed to evaluate the effect of swine carcass and manure co-digestion on biogas production and process stability in comparison of swine manure mono-digestion in a mesophilic CSTR. 


\section{CSTR reactor configuration}

\section{MATERIAL AND METHODS}

Two Continuous Stirred Tank Reactors were used in this experiment, built in acrylic, with $12 \mathrm{~L}$ working volume and jacketed, with water circulation for temperature control. Temperature was controlled by a thermostatic bath (JULABO, Model M8) maintained in mesophilic range $\left(37^{\circ} \mathrm{C} \pm 1\right)$.

\section{Start-up strategy}

$9 \mathrm{~L}$ of CSTR reactor digestate (fed with swine manure), for both reactors (R1 and R2), were collected and used with an inoculum source, after reactors were feed with manure until the useful volume. Reactors were fed once a day. After biogas productiveness stabilization of R2 (phase I), was started the organic loading rate progression. The R1 was feed in all phases only with swine manure.

\section{Reactor feeding medium}

Representative swine manure samples, were collected from a swine manure treatment system (SMTS), with 500 breeder sows, located in Concórdia, Santa Catarina-State, Brazil. Swine carcass (a sow, approximately $250 \mathrm{~kg}$ in weight, that include blood and viscera), were processed through a meat grinder, after which a representative sample $(30 \mathrm{~kg})$ was collected and stored $\left(-10^{\circ} \mathrm{C}\right)$ for use in the experiment.

\section{Organic Loading Rate (OLR) progression in R2}

It was performed increasing swine carcass and swine manure ratio in the CSTR reactor. The OLR increase was of $0.5 \mathrm{~kg} \mathrm{vSadd}_{\mathrm{S}} \mathrm{m}^{-3}$ reactor. $\mathrm{d}^{-1}$ whenever the reactor reaches stationary conditions of biogas productiveness (it is considered stablish when the variation was lower than $10 \%$ after 8 consecutive days).

\section{Biogas monitoring}

Biogas production was measured using Milligascounter (Ritter, MGC-1 V3.3 PMMA). Methane concentration was evaluated using BIOGAS 5000 (Geotech).

\section{Analytical techniques}

Volatile fatty acid/total alkalinity (VFA/TA) was performed according to the procedure described by Liebetrau et al. (2016), $\mathrm{pH}$ and ammonia as described in Standard Methods for the Examination of Water and Wastewater, and free ammonia as proposed by Hansen et al. (1998).

\section{RESULTS AND DISCUSION}

Technical coefficients of CSTR reactors (R1 and R2) are presented in Table 1, the results presented are the averages of stationary period, both reactors were fed with the same manure. In phase I the reactors were operated only with swine manure and presented similar coefficients of biogas productiveness $\left(0.40 \pm 0.03 \mathrm{~L}_{\mathrm{N}}\right.$ biogas. $\mathrm{L}_{\text {reactor }}{ }^{-1} \cdot \mathrm{d}^{-1}$ and $\left.0.41 \pm 0.03 \mathrm{~L}_{\mathrm{N} \text { biogas }} \cdot \mathrm{L}_{\text {reactor }}{ }^{-1} \cdot \mathrm{d}^{-1}\right)$, respectively for $\mathrm{R} 1$ and $\mathrm{R} 2$, biogas yield of $0.33 \pm 0.01$ $\mathrm{L}_{\mathrm{N} \text { biogas }} \cdot \mathrm{kg}_{\mathrm{VSadd}}{ }^{-1}$ and $0.33 \pm 0.03 \mathrm{~L}_{\mathrm{N} \text { biogas }} \cdot \mathrm{kg}_{\mathrm{VSadd}}{ }^{-1}$ respectively for $\mathrm{R} 1$ and $\mathrm{R} 2$. Comparing reactor $\mathrm{R} 1$ and $\mathrm{R} 2$ during other phases biogas productiveness increased up to $200 \%, 450 \%$ and $500 \%$, for phase II, III, and IV respectively. Different OLR in R1 reactor are because different manure samples.

During all phases the $\mathrm{R} 1$ reactor presented high stability in the anaerobic digestion process, proved by the low variation in the results of the VFA/TA ratio, average of $0.109 \mathrm{mgHAc}_{\mathrm{mgCaCO}}{ }^{-1}$ and average of 0.113 mgHAc. $\mathrm{mCaCO}_{3}{ }^{-1}$ until phase III and increase on the last phase for R2. (Table 2). Despite the increase VFA/TA ratio according Mézes et al. (2011), suggest that until $0.400 \mathrm{mgHAc} \mathrm{mgCaCO}_{3}{ }^{-1}$ no problems occurs in the process for volatile fatty acids.

Free ammonia in R1 reactor remained around $200 \mathrm{mg} \cdot \mathrm{L}^{-1}$ instead R2 reactor that free ammonia concentration increased with carcass/manure ratio increase (from 0 to $100 \mathrm{~kg}_{\text {carcass }} \cdot \mathrm{m}^{-3 \text { manure }}$ ). Hasen et al (1998) studding swine manure mono-digestion defined that ammonia will only be a serious problem after the free ammonia concentration has exceeded threshold value of $1.10 \mathrm{~g}-\mathrm{N} . \mathrm{L}^{-1}$.

When comparing phase III and IV in R2, the increment in biogas productiveness was not expressive, at the same time the free ammonia concentration and VFA/TA ratio increased. Besides that, with increase on OLR begun foam formation, indicating a possible imbalance. Several studies demonstrated a decrease of methane production because foaming problems and accumulation of fats occurred in the reactor during digestion or co-digestion of animal by-products (Pitk et al. 2013; Borowski and Kubacki 2015; Pagés-Díaz et 
al. 2015), because when residues with high-lipids concentrations are degraded have a tendency to form floating aggregates of lipids and forming foam (Cuetos et al. 2008). An ideal ratio between animal by-products and others residues are necessary for the process occurred without declining in biogas production., $\mathrm{R} 2$ has a better biogas yield in phase III, suggested co-digestion should be maintained at a $68 \mathrm{~kg}_{\text {carcass }} \cdot \mathrm{m}^{-3}$ manure ratio.

\section{CONCLUSION}

Comparing R1 (mono-digestion) and R2 (co-digestion), the increase in biogas productiveness until $500 \%$, representing that anaerobic co-digestion of carcass and manure is an excellent opportunity for increase concentration of solids in the reactor, and consequently biogas production on swine farming.

The increment in OLR from 1.3 to $2.1 \mathrm{~kg}_{\mathrm{vSadd}} \cdot \mathrm{m}^{-3}$ reactor. $\mathrm{d}^{-1}$, in $\mathrm{R} 2$ reactor contributes to better biogas yield, which results in a substancial increase on biogas productiveness. However considering foam generation, in phase IV, suggested that is better reactor operated in $68 \mathrm{~kg}_{\text {carcass }} \cdot \mathrm{m}^{-3}$ manure ratio, corresponding to phase III. For a full scale application it is important to consider carcass pre-treatment for sanitary reasons (EC, 2009; Kirby, 2018).

\section{ACKNOWLEDGEMENTS}

The authors gratefully acknowledge the support provide by Capes, CNPq, BiogásFert Network (Project $\mathrm{N}^{\circ}$ 021280400-02), SISTRATES-BNDES (Project $\mathrm{N}^{\circ}$ 23.17.00.023.00.00) and TECDAM (Project $\mathrm{N}^{\circ}$ 02131000500-02).

\section{REFERENCES}

BOROWSKI, S.; KUBACKI, P. Co-digestion of pig slaughterhouse waste with sewage sludge. Waste Management, v. 40, p. 119-126, 2015. .

CUETOS, M. J.; GÓMEZ, X.; OTERO, M.; MORÁN, A. Anaerobic digestion of solid slaughterhouse waste (SHW) at laboratory scale: Influence of co-digestion with the organic fraction of municipal solid waste (OFMSW). Biochemical Engineering Journal, v. 40, n. 1, p. 99-106, 2008.

European Parliament and Council. REGULATION (EC) No 1069/2009 OF THE EUROPEAN PARLIAMENT AND OF THE COUNCIL of 21 October 2009 laying down health rules as regards animal byproducts and derived products not intended for human consumption and repealing Regulation (EC) No $1774 / 2002$.

HANSEN, K. H.; ANGELIDAKI, I.; AHRING, B. K. Anaerobic digestion of swine manure: inhibition by ammonia. Water Research, v. 32, n. 1, p. 5-12, 1998.

KIRBY ME, THEODOROU MK, BRIZUELA CM, et al. The anaerobic digestion of pig carcase with or without sugar beet pulp, as a novel on-farm disposal method. Waste Management. 2018;75:251-260.

KUNZ, A.; STEINMETZ, R.; DAMASCENO, S.; COLDEBELA, A. Nitrogen removal from swine wastewater by combining treated effluent with raw manure. Scientia Agricola, v. 69, n. 6, p. 352-356, 2012.

LIEBETRAU J., PFEIFFER D., THRAN D. Collections onf methods for biogas: Methods to determine parameters for analysis purposes and parameters that describe process in the biogas sector. Biomass Energy Use. V. 7, 2016.

MATA-ALVAREZ, J.; DOSTA, J.; MACÉ, S.; ASTALS, S. Codigestion of solid wastes: A review of its uses and perspectives including modeling. Critical Reviews in Biotechnology, v. 31, n. 2, p. 99-111, 2011.

MÉZES, L.; BIRÓ,G.; SULYOK, E.; PETIS, M.; BORBÉLY, J.; TAMÁS, J. Novel Approach on the basis of FOS/TAC method. Analele Universitãti din Oradea, Fascicula Protectia Mediului Vol. 17, 2011.

PAGÉS-DÍAZ, J.; WESTMAN, J.; TAHERZADEH, M. J.; PEREDA-REYES, I.; SÁRVÁRI HORVÁTH, I. Semi-continuous co-digestion of solid cattle slaughterhouse wastes with other waste streams: Interactions within the mixtures and methanogenic community structure. Chemical Engineering Journal, v. 273, p. 28-36, 2015.

PITK, P.; KAPARAJU, P.; PALATSI, J.; AFFES, R.; VILU, R. Co-digestion of sewage sludge and sterilized solid slaughterhouse waste: Methane production efficiency and process limitations. Bioresource Technology, v. 134, p. 227-232, 2013.

STANDARD METHODS FOR EXAMINATION OF WATER AND WASTEWATER. 22nd ed.Washington, DC: American Public Health Association; 2012.

TÁPPARO, D. C.; VIANCELLI, A.; AMARAL, A. C. DO; et al. Sanitary effectiveness and biogas yield by anaerobic co-digestion of swine carcasses and manure. Environmental Technology, p. 1-9, 2018. 


\section{VISIGERE DE 07 A09 MA102019

WEILAND, P. Biogas production: current state and perspectives. Applied Microbiology and Biotechnology, v. 85 , n. 4 , p. 849-860, 2010.

XIE, S.; HAI, F. I.; ZHAN, X.; et al. Anaerobic co-digestion: A critical review of mathematical modelling for performance optimization. Bioresource Technology, v. 222, p. 498-512, 2016.

Table 1. Technical coefficient of swine manure mono-digestion (R1) and co-digestion with swine carcass (R2) using a CSTR reactor.

\begin{tabular}{|c|c|c|c|c|c|c|c|c|c|}
\hline & \multicolumn{4}{|c|}{ R1 } & \multicolumn{5}{|c|}{$\mathrm{R} 2$} \\
\hline & $\begin{array}{c}\text { OLR } \\
\left(\mathrm{kg}_{\mathrm{VS} \text { add }} \cdot \mathrm{m}_{\text {reactor }}^{-3} \mathrm{~d}^{-1}\right)\end{array}$ & $\begin{array}{l}\text { Biogas Productivity } \\
\left(\mathrm{L}_{\mathrm{N} \text { biogas }} \cdot \mathrm{L}_{\text {reactor }}^{-1} \cdot \mathrm{d}^{-1}\right)\end{array}$ & $\begin{array}{l}\text { Biogas Yield } \\
\mathrm{N}_{\mathrm{Niogas}} \cdot \mathrm{kg}_{\mathrm{VSadd}}{ }^{-1} \text { ) }\end{array}$ & $\begin{array}{l}\mathrm{CH} 4 \\
(\%)\end{array}$ & $\begin{array}{c}\text { OLR } \\
\left(\mathrm{kg}_{\mathrm{VS} \text { add }} \cdot \mathrm{m}^{-3}{ }_{\text {reactor }} \mathrm{d}^{-1}\right)\end{array}$ & $\begin{array}{l}\text { Carcass/manure } \\
\text { ratio }\left(\mathrm{kg} \cdot \mathrm{m}^{-3}\right)\end{array}$ & $\begin{array}{l}\text { Biogas Productivity } \\
\left(\mathrm{L}_{\mathrm{N} \text { biogas }} \cdot \mathrm{L}_{\text {reactor }}^{-1} \cdot \mathrm{d}^{-1}\right)\end{array}$ & $\begin{array}{c}\text { Biogas Yield } \\
\left(\mathrm{L}_{\mathrm{N} \text { biogas }} \cdot \mathrm{kg}_{\mathrm{VS} \text { add }}{ }^{-1}\right)\end{array}$ & $\begin{array}{l}\mathrm{CH} 4 \\
(\%)\end{array}$ \\
\hline Phase I & 1.30 & $0.40 \pm 0.03$ & $0.33 \pm 0.01$ & 58 & 1.30 & 0 & $0.41 \pm 0.03$ & $0.33 \pm 0.03$ & 65 \\
\hline Phase II & 0.87 & $0.34 \pm 0.03$ & $0.39 \pm 0.03$ & 57 & 1.43 & 35 & $1.05 \pm 0.03$ & $0.70 \pm 0.07$ & 64 \\
\hline Phase III & 0.87 & $0.34 \pm 0.14$ & $0.39 \pm 0.07$ & 55 & 1.93 & 68 & $1.63 \pm 0.14$ & $0.87 \pm 0.10$ & 59 \\
\hline Phase IV & 0.53 & $0.31 \pm 0.08$ & $0.52 \pm 0.07$ & 51 & 2.10 & 100 & $1.64 \pm 0.08$ & $0.76 \pm 0.07$ & 52 \\
\hline
\end{tabular}

Table 2. Free ammonia concentration and VFA/TA ratio during swine manure mono-digestion (R1) and your co-digestion with swine carcass (R2) using a CSTR reactor.

\begin{tabular}{|c|c|c|c|c|c|c|c|c|}
\hline & \multicolumn{5}{|c|}{$\mathrm{R} 1$} & \multicolumn{3}{|c|}{$\mathrm{R} 2$} \\
\hline & & $\mathrm{pH}$ & & 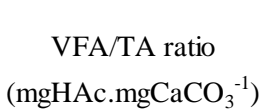 & $\begin{array}{c}\text { Free ammonia } \\
\left(\mathrm{NH}_{3}-\mathrm{N} \text { mg. } \mathrm{L}^{-1}\right)\end{array}$ & $\mathrm{pH}$ & 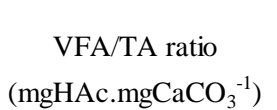 & $\begin{array}{c}\text { Free ammonia } \\
\left(\mathrm{NH}_{3}-\mathrm{N} \mathrm{mg.} \mathrm{L}^{-1}\right)\end{array}$ \\
\hline Phase I & 7.86 & \pm & 0.05 & $0.123 \pm 0.012$ & $187 \pm 38$ & $7.80 \pm 0.2$ & $0.125 \pm 0.005$ & $164 \pm 50$ \\
\hline Phase II & 7.86 & \pm & 0.04 & $0.100 \pm 0.005$ & $182 \pm 21$ & $7.93 \pm 0.04$ & $0.109 \pm 0.006$ & $262 \pm 51$ \\
\hline Phase III & 7.85 & \pm & 0.06 & $0.100 \pm 0.008$ & $198 \pm 14$ & $7.89 \pm 0.26$ & $0.107 \pm 0.004$ & $254 \pm 15.5$ \\
\hline Phase IV & 7.69 & \pm & 0.09 & $0.113 \pm 0.014$ & $127 \pm 37$ & $7.88 \pm 0.10$ & $0.258 \pm 0.090$ & $308 \pm 86$ \\
\hline
\end{tabular}




\title{
PRODUÇÃO BIOLÓGICA DE H2 UTILIZANDO RESÍDUO CITRÍCOLA
}

\author{
Silva, D. C. ${ }^{1,2}$; Maintinguer, S.I. ${ }^{2,3 *}$ \\ ${ }^{1}$ Instituto de Química de Araraquara - UNESP, Araraquara, SP - Brasil \\ ${ }^{2}$ Instituto de Pesquisa em Bioenergia - IPBEN - Laboratório Central, Rio Claro, SP-Brasil \\ ${ }^{3}$ Universidade de Araraquara - Uniara, Araraquara, SP - Brasil \\ daianacsilva91@gmail.com; mainting2008@gmail.com
}

\begin{abstract}
RESUMO: Nos últimos anos, há um interesse crescente no uso eficiente de diversos resíduos agroindustriais. As indústrias de alimentos no Brasil acumulam uma enorme quantidade de resíduos principalmente as de processamento de frutos cítricos. Entre as possibilidades de valorização destes resíduos, a digestão anaeróbia é uma alternativa promissora na geração de energia renovável e controle da poluição. Nesse sentido, esse estudo avaliou o processo de digestão anaeróbia de efluente bruto citrícola, visando à produção biológica de hidrogênio a partir de três inóculos: (1) Clostridium acetobutylicum ATCC 824, (2) Clostridium beijerinckii ATCC 10132 e (3) consorcio anaeróbio obtido do próprio resíduo citrícola. O experimento foi realizado em reatores anaeróbios em batelada alimentados com efluente citrícola $\left(20 \mathrm{~g} \mathrm{DQO} \mathrm{L}{ }^{-1}\right), \mathrm{pH}$ inicial 7,0 , a $37^{\circ} \mathrm{C}$ com headspace preenchido com $\mathrm{N}_{2}(99,99 \%)$. Na caracterização do consorcio anaeróbio do resíduo citrícola foi realizada microscopia ótica com técnica de coloração de Gram, e para a quantificação de bactérias anaeróbias em unidades formadoras de colônias por mL (UFC) por pour plate, em meio seletivo para os gêneros Clostridium sp., Bacteroides sp., Lactobacillus sp. e Streptococcus sp. Os resultados obtidos para produção de hidrogênio foram de $37,6 \mathrm{mmol} \mathrm{H}_{2} \mathrm{~L}^{-1}$ com o consorcio anaeróbio e 21,2 e $15,7 \mathrm{mmol} \mathrm{H}_{2} \mathrm{~L}^{-1}$ nos ensaios com as culturas puras $\mathrm{Cl}$. acetobutylicum e $\mathrm{Cl}$. beijerinckii, respectivamente. Na quantificação das bactérias anaeróbias do consorcio anaeróbio citrícola foram obtidas contagens de $3 \times 10^{5}$ a $5 \times 10^{4} \mathrm{UFC} \mathrm{ml}^{-1}$. A microscopia revelou morfologia predominante de bacilos Gram + , que podem ser de bactérias produtoras de hidrogênio.
\end{abstract}

Palavras-chave: processos anaeróbios, efluente citrícola, produção $\mathrm{H}_{2}$, crescimento microbiano

\section{BIOLOGIC PRODUCTION OF $\mathrm{H}_{2}$ USING CITRICOLA RESIDUE}

\begin{abstract}
In recent years, there is a growing interest in the efficient use of various agro-industrial wastes. Food industries in Brazil accumulate a huge amount of waste especially citrus processing. Among the possibilities of recovery of these residues, anaerobic digestion is a promising alternative renewable energy generation and pollution control. In this sense, this study evaluated the process of anaerobic digestion of raw wastewater citrícola aimed at biological production of hydrogen from three types: (1) Clostridium acetobutylicum (ATCC 824), (2) Clostridium beijerinckii (ATCC 10132 and (3) anaerobic consortium obtained from own citrícola residue.The experiment was carried out in batch anaerobic reactors fed with wastewater citrícola (20 g COD L $\mathrm{g}^{-1}$ ), under initial $\mathrm{pH} 7.0,37^{\circ} \mathrm{C}$ with headspace filled with $\mathrm{N}_{2}$ (99.99\%). On characterization of anaerobic consortium of the citrícola residue optical microscopy was performed with Gram stain technique, and for the quantification of anaerobic bacteria in colony forming units (CFU) per $\mathrm{mL}$ by pour plate with selective medium for the genus Clostridium sp., Bacteroides sp., Lactobacillus sp. e Streptococcus sp. The results obtained for hydrogen production were $37.6 \mathrm{mmol} \mathrm{L}^{-1} \mathrm{H}_{2}$ with the Consortium and 21.2 and $15.7 \mathrm{mmol} \mathrm{L}^{-1} \mathrm{H}_{2}$ in the tests with the pure cultures $\mathrm{Cl}$. acetobutylicum and beijerinckii, respectively. On quantification of the anaerobic bacteria consortium counts were obtained for the citrícola from $3 \times 10^{5}$ the $5 \times 10^{4}$ UFC $\mathrm{mL}^{-1}$. Microscopy revealed predominant of bacilli Gram + , which can be hydrogen producing bacteria.
\end{abstract}

Keywords: anaerobic processes, citrus effluent, $\mathrm{H}_{2}$ production, microbial growth

\section{INTRODUÇÃO}

O atual cenário mundial tem apresentado baixa oferta de combustíveis fósseis. Como consequência uma demanda por fontes de energia com produtos de combustão mais limpos e sustentáveis tem sido requeridos. O desenvolvimento e a aplicação da digestão anaeróbia se tornou um processo alternativo e econômico utilizado no tratamento de vários tipos de resíduos industriais, devido ao valioso biogás produzido pelo 
processo microbiano, mas também a redução da emissão de gases de efeito estufa e diminuição da poluição ambiental (KHAN, et al., 2018). Uma das alternativas para as fontes convencionais de energia fóssil é o hidrogênio $\left(\mathrm{H}_{2}\right)$, devido a sua alta densidade de energia (143 $\mathrm{MJ} \mathrm{Kg}^{-1}$ ) (MAZLOOMI e GOMES, 2012) e ser produto de combustão limpa (vapor de água). O Brasil se destaca como o maior produtor mundial da cultura citrícola, com a produção de laranja na safra 2016/2017 de 18.197 mil toneladas, correspondendo a 36,7\% da produção mundial (CITRUSBR, 2017). Em 2017, foram geradas pelas industrias citrícolas brasileiras cerda de 1.222 mil toneladas de suco de laranja. O estado de São Paulo representa 70,6\% da produção citrícola no Brasil (CITRUSBR, 2017). Processos industriais de citrus podem gerar águas residuárias altamente poluidoras em termos de valores de demanda química e demanda biológica de oxigênio (DQO e DBO), tornando-se um risco significativo para os cursos de águas locais e solos além da produção de gás de efeito estufa (ABBASI e ABBASI, 2011). A utilização deste resíduo como fonte de carbono para microrganismo no processo de digestão anaeróbia, para a produção de hidrogênio, é uma alternativa eficiente no tratamento deste resíduo. Uma proposta promissora em tratar e valorizar a utilização de resíduos de laranja pode ser por processo de digestão anaeróbia que utiliza microrganismos como agentes para a redução de matéria orgânica e eliminar ou reduzir compostos tóxicos, alcançando o controle da poluição ambiental e recuperação de energia. $\mathrm{O}$ objetivo do presente trabalho foi aplicar e comparar diferentes culturas puras e consorcio anaeróbio visando a produção de hidrogênio em reatores anaeróbios alimentados com efluente citrícola.

\section{MATERIAL E MÉTODOS}

Foram utilizados três tipos de inóculos: as culturas puras de (1) Clostridium acetobutylicum ATCC 824, (2) Clostridium beijerinkii ATCC 10132 e (3) consorcio anaeróbio obtido do próprio efluente citrícola.

Efluente bruto citrícola foi utilizado como fonte de carbono, cedido pela indústria citrícola localizada em Araras, na região central do Estado de São Paulo, no cinturão citrícola. O resíduo foi mantido e acondicionado em frascos plásticos lacrados, com $1 \mathrm{~L}$ de volume, a $-20^{\circ} \mathrm{C}$ até sua utilização. A caracterização do resíduo foi realizada por análises de pH e DQO (Demanda Química de Oxigênio) de acordo com APHA, AWWA, WEF (2005).

Carboidratos totais foram realizados de acordo com Dubois et al. (1956); crescimento microbiano foi acompanhado durante o ensaio por espectrofotometria sob absorbância de $600 \mathrm{~nm}$ e DQO foram realizadas ao final de cada ensaio, ambos segundo APHA, AWWA, WEF (2005).

Na obtenção do consórcio anaeróbio foi coletado uma alíquota de $1 \mathrm{~mL}$ do resíduo citrícola e inoculado em reatores anaeróbios batelada $(100 \mathrm{~mL})$, sendo $50 \mathrm{~mL}$ contendo meio PYG (peptone, yeast, glucose) que continha $\left(\mathrm{g} \mathrm{L}^{-1}\right)$ : glicose $(10,0)$, extrato de levedura $(5,0)$; extrato de carne $(5,0)$; peptona $(5,0)$, pH 7,0 e 50 mL headspeace $\left(\mathrm{N}_{2}\right)$, mantidos a $37^{\circ} \mathrm{C}$ em repouso por 72 horas. A seguir, foi realizada a purificação celular por técnica de diluições seriais $\left(10^{-1}\right.$ a $\left.10^{-5}\right)$, repetidas diversas vezes, em meio $\mathrm{PYG}, \mathrm{pH} 7,0$ e mantidos a $37^{\circ} \mathrm{C}$ por 120 horas.

Os inóculos (1), (2) e (3) foram reativados em triplicatas de reatores anaeróbios em batelada $(30 \mathrm{~mL})$ contendo $15 \mathrm{~mL}$ de meio PYG a pH 7,0, por $72 \mathrm{~h}$, com o objetivo de favorecer o crescimento das bactérias anaeróbias presentes na amostra. A seguir, as amostras foram centrifugadas e $20 \%$ (v/v) do sedimentado foram inoculados em reatores anaeróbios em batelada $(250 \mathrm{~mL})$ em meio PYG.

Os ensaios de geração de $\mathrm{H}_{2}$ foram realizados em triplicatas de reatores anaeróbios em batelada (500 $\mathrm{mL})$ que consistiam de $250 \mathrm{~mL}$ de meio reacional contendo efluente bruto citrícola ( $\left.20 \mathrm{~g} \mathrm{~L}^{-1} \mathrm{DQO}\right)$ como fonte de Carbono e $\left(\mathrm{g} \mathrm{L}^{-1}\right)$ : peptona $(5,0)$, extrato de carne $(5.0)$ e extrato de levedura $(5,0)$ em $\mathrm{pH}$ inicial 7,0, mantidos em repouso a $37^{\circ} \mathrm{C}$ por 51 horas com headspace $(500 \mathrm{~mL})$ preenchido com $\mathrm{N}_{2}$, para manter a anaerobiose, com a biomassa microbiana em $20 \%(\mathrm{v} / \mathrm{v})$. A quantificação do gás hidrogênio gerado, foi realizada por deslocamento de volume adaptado de Aquino et al. (2007). Os dados de produção de $\mathrm{H}_{2}$ dos reatores alimentados com resíduos citrícola, em mmol $\mathrm{H}_{2} \mathrm{~L}^{-1}$, foram ajustados nos valores médios obtidos das triplicatas dos reatores em batelada, utilizando o software Statistica ${ }^{\circledR}$, a taxa máxima de produção de hidrogênio $(\mathrm{Rm})$, o valor máximo de produção estimado $(\mathrm{P})$ e o tempo estimado da fase lag (L). Tais parâmetros são obtidos pelo ajuste sigmoidal não linear da função de Gompertz modificado (TORQUATO et al., 2017).

Foram realizadas análises de microscopia ótica com técnica de coloração de Gram para observação das morfologias predominantes nos consórcios anaeróbios presentes. Quantificação de Clostridium sp., Bacteroides sp., Lactobacillus sp. e Streptococcus sp. foram realizadas por técnica de pour plate (em Unidades Formadoras de Colônias por mL) em meio seletivo (SONG et al., 2012). 


\section{RESULTADOS E DISCUSSÃO}

O efluente citrícola apresentou pH de 11,12 e DQO de 14,73 g L-1. Os inóculos (1), (2) e (3) apresentaram crescimento exponencial da biomassa microbiana (Figura 1) onde as culturas puras (inóculos 1 e 2) tiveram crescimento similar. Entretanto o inóculo 3 prevaleceu crescimento da biomassa microbiana mais elevado. Em todos reatores alimentados com efluente bruto citrícola foi observado comportamento diretamente proporcional entre o consumo de carboidratos e a produção acumulada de gás hidrogênio. Os consumos de carboidratos foram de, $68 \%, 43 \%$ e $56 \%$ respectivamente, com os inóculos (1), (2) e (3). Os valores de DQO no inicio e final da operação não se alteraram significativamente e foram de $16,4 \mathrm{~g} \mathrm{~L}^{-1}$ para $14,7 \mathrm{~g} \mathrm{~L}^{-1}$ nos ensaios com as culturas puras (inóculos 1 e 2) e de 14,0 para $11,4 \mathrm{~g} \mathrm{~L}^{-1}$ no ensaio com o consorcio anaeróbio (inóculo 3). Fato este que pode ser explicado pela rota metabólica da glicose conhecida para os microrganismos fermentativos produtores de $\mathrm{H}_{2}$ onde alguns produtos intermediários como etanol, butanol, acetato, butirato podem ser produzidos no metabolismo oxidativo da glicose (SHINTO et al., 2008). Isto sugeriu que houve uma transformação do substrato inicial a outros compostos orgânicos na fase liquida, causando a manutenção da DQO ao longo dos ensaios. Além disso, como não foi verificada a geração de metano, certamente, a ausência de microrganismos consumidores desses metabólitos como arquéias metanogênicas foi a principal causa da manutenção da DQO no meio líquido.

Os reatores com inóculo (3) apresentaram valores mais elevados de geração de Hidrogênio (37,6 mmol $\mathrm{H}_{2} \mathrm{~L}^{-1}$ ) do que os obtidos nos reatores contendo as culturas puras, que foram de $21,2 \mathrm{mmol} \mathrm{H}_{2} \mathrm{~L}^{-1}$ (inóculo 1) e $15,7 \mathrm{mmol} \mathrm{H}_{2} \mathrm{~L}^{-1}$ (inoculo 2). Soares et. al., (2018) avaliaram a produção de hidrogênio a partir de bagaço de cana em pré-tratamento hidrotérmico em reatores anaeróbios em batelada $(1 \mathrm{~L})$, com inóculo (10\% v/v) proveniente de solo e resíduo de compostagem e substrato, em $\mathrm{pH} 6,0$ a $37^{\circ} \mathrm{C}$ por 400 horas e obtiveram 1,50 mmol $\mathrm{H}_{2} \mathrm{~L}^{-1}$ utilizando $2,77 \mathrm{~g} \mathrm{~L}^{-1}$ de extrato de levedura e $5,84 \mathrm{~g} \mathrm{~L}^{-1}$ de bagaço de cana pré-tratado. Tais resultados foram inferiores aos do presente trabalho para os reatores alimentados com efluente bruto citrícola gerando $\mathrm{H}_{2}\left(21,2 ; 15,7\right.$ e $\left.37,6 \mathrm{mmol} \mathrm{H}_{2} \mathrm{~L}^{-1}\right)$ respectivamente para os ensaios com os inóculos $(1,2 \mathrm{e} 3)$ testados.

Pelo ajuste sigmoidal da função de Gompertz modificada (Figura 2), os parâmetros estimados de fase lag $(\mathrm{L})$, produção máxima $(\mathrm{P})$ e taxa de produção $(\mathrm{Rm})$, foram respectivamente para os ensaios 1,2 e $3: \mathrm{L}=$ 7,6; 10,8 e 23,3 horas; $\mathrm{P}=37,8 ; 21,0$ e $16,0 \mathrm{mmol} \mathrm{H}_{2} \mathrm{~L}^{-1}$; e $\mathrm{Rm}=0,9 ; 3,1$ e $4,9 \mathrm{mmol} \mathrm{H}_{2} \mathrm{~L}^{-1} \mathrm{~h}^{-1}$. Os coeficientes de determinação $\left(\mathrm{R}^{2}\right)$, obtidos também pelo tratamento estatístico [(1) 0,997; (2) 1,0 e (3) 1,0], reforçam que o modelo adotado representa efetivamente bem os dados obtidos experimentalmente em reatores anaeróbios em batelada alimentados com resíduos citrícolas.

A quantificação das bactérias anaeróbias por pour plate do consorcio anaeróbio do resíduo citrícola (inoculo 3) com meios seletivos para o gênero Clostridium sp., Bacteroides sp., Lactobacillus sp. e Streptococcus foram respectivamente de $\left(\mathrm{mL}^{-1}\right) 3 \times 10^{5} ; 4 \times 10^{5} ; 4 \times 10^{5}$ e $5 \times 10^{4}$ UFC. A microscopia por coloração de Gram (Figura 3) revelou a predominância de bacilos Gram + , morfologia característica de microrganismos com potencial de produção de $\mathrm{H}_{2}$ (ETCHEBEHERE et al., 2016).

\section{CONCLUSÃO}

Os testes com efluente bruto citrícola como fonte de carbono apresentaram potencial na produção de hidrogênio. O consorcio anaeróbio advindo do resíduo citrícola apresentou melhores resultados de geração de $\mathrm{H}_{2}$ do que as culturas puras de Clostridium que são reconhecidas em produção de hidrogênio. Na quantificação de bactérias anaeróbias foi revelado diversidade de bactérias anaeróbias presente no efluente bruto citrícola. A digestão anaeróbia de efluente bruto citrícola se mostrou eficiente no tratamento e no seu re-aproveitamento e na geração de energia renovável.

\section{REFERÊNCIAS}

Abbasi, T., Abbasi, S. A. 'Renewable' Hydrogen: prospects and challenges. Renewable Sustainable Energy Reviews, v.15, p. 3034-3040, 2011.

Apha, A. and W. Standard methods for the examination of water and wastewater. 20th ed. Washington, D.C.: American Public Health Association, 2005.

Aquino, S. F. . et al. Metodologias para determinação da atividade metanogênica específica (ame) em lodos anaeróbios. Engenharia sanitaria ambiental, v. 12, n. 2, p. 192-201, 2007.

Citrusbr- Associação Nacional dos Exportadores de Sucos Cítricos. Release: Dados Fechamento Safra 2016/2017 e Estimativa de Estoque de Suco de Laranja para 30/06/2018. Disponível em:< http://www.Citrusbr.Com/Pressreleases/?Id=311580 >. Acesso em: Novembro, 2018. 
Dubois, M. et al. Colorimetric method for determination of sugars and related substances. Analytical chemistry, v. 28, n. 3, p. 350-356, 1956.

Etchebehere, C. et al. Microbial communities from 20 different hydrogen-producing reactors studied by 454 pyrosequencing. Applied microbiology and biotechnology, v. 100, n. 7, p. 3371-3384, 2016.

Khan, M. A. et al. Biohydrogen production from anaerobic digestion and its potential as renewable energy. Renewable Energy, v. 129, p. 754-768, 2018.

Mazloomi, K., Gomes, C. Hydrogen as an energy carrier: prospects and challenges. Renewable and Sustainable Energy Reviews, v.16, p. 3024-3033, 2012.

Shinto, H., et al. Kinetic study of substrate dependency for higher butanol production in acetone-butanolethanol fermentation. Process Biochemistry, v. 43, p.1452-1461, 2008.

Soares, L. A. et al. Metagenomic analysis and optimization of hydrogen production from sugarcane bagasse. Biomass and Bioenergy, v. 117, p. 78-85, 2018.

Song, Z. X. et al. Effects of pretreatment method of natural bacteria source on microbial community and biohydrogen production by dark fermentation. International journal of hydrogen energy, v. 37, n. 7, p. 5631-5636, 2012.

Torquato, L. D. M. et al. Potential of biohydrogen production from effluents of citrus processing industry using anaerobic bacteria from sewage sludge. Waste management, v. 59, 2017.

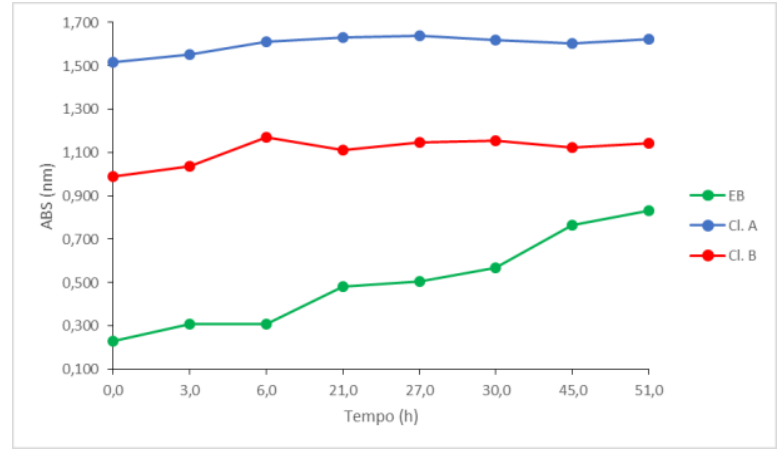

Figura 1. Crescimento da biomassa microbiana dos inóculos testados.

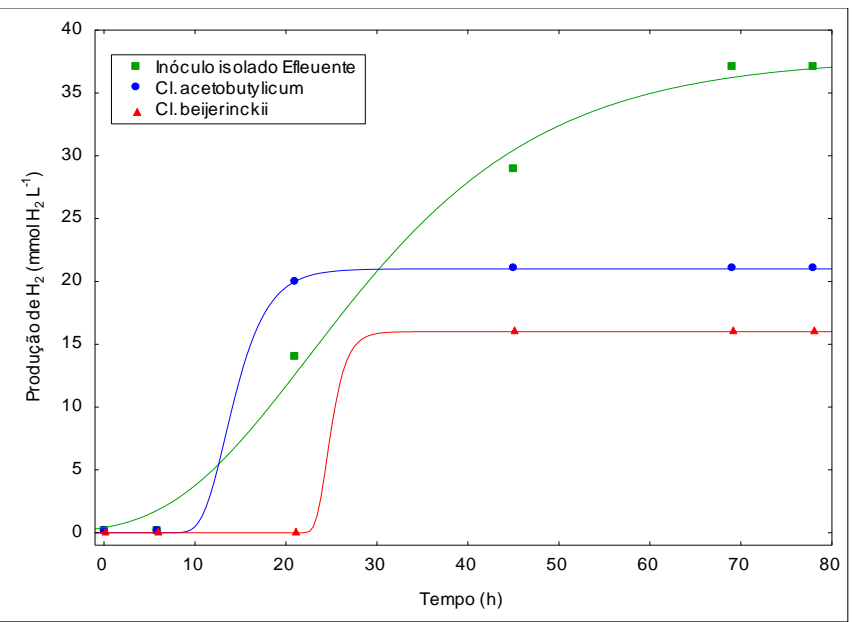

Figura 2. Ajuste sigmoidal da função de Gompertz modificada nos ensaios 1 (•), 2 (•) e 3( $\mathbf{\Delta})$.

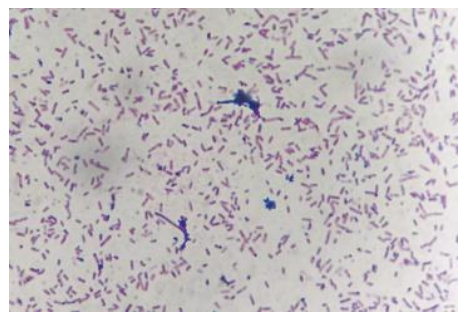

Figura 3. Microscopia do inóculo isolado do efluente bruto citrícola. 


\title{
PRODUÇÃO DE BIOETANOL DE RESÍDUOS DA BANANICULTURA POR MONO E COCULTURA MICROBIANA
}

\author{
Uchôa, P.Z. ${ }^{1}$; Sellin, N. ${ }^{2}$; Souza, O.*2 \\ ${ }^{1}$ Mestrandos em Engenharia de Processos, Univille, Joinville, SC-Brasil \\ ${ }^{2}$ Professores da Univille, Joinville, SC - Brasil \\ ozair.souza@univille.br
}

\begin{abstract}
RESUMO: A banana é uma fruta mundialmente cultivada por diversos países. Em 2014, o Brasil foi o quarto produtor mundial com aproximadamente 7 milhões de toneladas de bananas comercializadas. $\mathrm{O}$ estado de Santa Catarina gera mais de 2,8 milhões de toneladas anuais de biomassa residual, a partir da colheita, comercialização e industrialização da banana (Musa cavendischi, popularmente conhecida como nanica e nanicão). Para cada tonelada de banana, colhida são gerados, aproximadamente, quatro toneladas de resíduos vegetais, dentre os quais três toneladas de pseudocaule, $440 \mathrm{~kg}$ de cascas de banana e $460 \mathrm{~kg}$ do fruto integral impróprio para consumo humano. $\mathrm{O}$ trabalho em questão avalia o aproveitamento energético dessas biomassas (pseudocaule, casca e polpa de banana) como substrato da fermentação alcoólica na mesma proporção que são geradas no campo. Fermentações foram conduzidas em $30^{\circ} \mathrm{C}$ e pH inicial de 4,5 em frascos de Erlenmeyer com volume de trabalho $100 \mathrm{~mL}$ e $20 \% \mathrm{v} \mathrm{v}^{-1}$ de inóculo, com $150 \mathrm{~g} \mathrm{~L}^{-1}$ de açúcares redutores obtidos de dois diferentes mostos compostos por caldos de polpa, cascas e pseudocaule úmido ou previamente seco e moído. Dois tipos de inóculo foram avaliados: formado por cultura pura de Sacharomyces cerevisiae e composto por cocultura microbiana (S. cerevisiae e Pachysolen tannophilus). Os maiores valores de rendimento em etanol $\left(\mathrm{Y}_{\mathrm{P} / \mathrm{AR}}=0,4 \mathrm{~g} \mathrm{~g}^{-1}\right)$, produtividade volumétrica $\left(\mathrm{Q}_{\mathrm{p}}=1,1 \mathrm{~g} \mathrm{~L}^{-1} \mathrm{~h}^{-1}\right)$, produção anual de etanol de $32.713 \mathrm{~m}^{3}$ foram obtidos com a fermentação por cocultura de mosto contendo pseudocaule úmido.
\end{abstract}

Palavras-chave: biocombustível, biomassa, etanol celulósico.

\section{BIOETHANOL PRODUCTION FRON VEGETABLE WASTE OF THE BANANA CULTURE BY MONO-AND CO-CULTURE SYSTEM}

\begin{abstract}
The banana is a world-wide fruit cultivated by several countries. In 2014, Brazil was the fourth largest producer in the world with approximately 7 million tons of bananas commercialized. The state of Santa Catarina generates more than 2.8 million tons of residual biomass annually from the harvest, commercialization and industrialization of the banana (Musa cavendischi, popularly known as nanica and nanicão). For each tonne of banana harvested, approximately four tons of vegetable waste are generated, among them three tons of pseudo-stem, $440 \mathrm{~kg}$ of banana peels and $460 \mathrm{~kg}$ of the integral fruit unfit for human consumption. The work in question evaluates the energy utilization of these biomass (pseudo-stem, peels and banana pulp) as substrate of the alcoholic fermentation in the same proportion that are generated in the field. The fermentations were conducted at $30^{\circ} \mathrm{C}$ and initial $\mathrm{pH}$ of 4.5 in Erlenmeyer flasks with a working volume of $100 \mathrm{~mL}$ and $20 \% \mathrm{v} \mathrm{v}^{-1}$ of inoculum, with $150 \mathrm{~g} \mathrm{~L}^{-1}$ of reducing sugars obtained from two different musts composed of broths of pulp, peel and pseudo-stem moist or previously dry and ground. Two types of inoculum were evaluated: formed by pure culture of Sacharomyces cerevisiae and composed of microbial coculture ( $S$. cerevisiae and Pachysolen tannophilus). The fermentation. The highest values of yield in ethanol $\left(\mathrm{Y}_{\mathrm{P} / \mathrm{AR}}=0.4\right.$ $\left.\mathrm{g} \mathrm{g}^{-1}\right)$, volumetric productivity $\left(\mathrm{Q}_{\mathrm{p}}=1.1 \mathrm{~g} \mathrm{~L}^{-1} \mathrm{~h}^{-1}\right)$, annual ethanol production of 32,713 $\mathrm{m} 3$ were obtained with fermentation by co-cultureof must containing moist pseudo-stem.
\end{abstract}

Keywords: biofuel, biomass, cellulosic ethanol.

\section{INTRODUÇÃO}

Em 2014, o Brasil foi o quarto maior produtor mundial de bananas com a produção de sete milhões de toneladas de bananas no ano, ficando atrás da Índia, China e Filipinas (FAO, 2017). Em 2016, dentre os estados brasileiros, São Paulo apresentou maior produção seguido pelos estados da Bahia, Minas Gerais e Santa Catarina. Essa configuração se mantém desde o ano de 2012 e o estado catarinense tem sido o responsável por mais de $11 \%$ dessa produção (EPAGRI/CEPA, 2017). 
Após cultura e industrialização da banana, são geradas em torno de quatro toneladas de massa úmida de resíduos vegetais para cada tonelada de banana colhida, sendo que $74 \%$ é de pseudocaule, $12 \%$ de folhas, $11 \%$ de cascas e 4\% de engaço (SOUZA et al., 2010). Para cada tonelada de fruta comercializada, são estimados que $460 \mathrm{~kg}$ são consideradas impróprias para o consumo humano - frutas rejeitadas (EMBRAPA, 2006). Devido à grande disponibilidade dessa biomassa no estado catarinense, principalmente em relação ao pseudocaule, busca-se alternativas para o seu aproveitamento visando, não só a valorização dos resíduos mas, também, contribuir com a redução do seu impacto ambiental no caso de permanecerem no campo.

Em estudo recente, Sandrin (2018) avaliou pela primeira vez o uso conjunto desses resíduos na composição do mosto de fermentação. Foi utilizada a proporção em massa úmida entre polpa, cascas e pseudocaule de 1:2:7. Neste trabalho, avaliou-se a produção de etanol a partir do mesmo tipo de mosto, porém, usando a mesma proporção de massa na qual os resíduos são gerados no campo (1:2:10). Reavaliou-se o processo fermentativo com o uso do pseudocaule no seu estado seco (farelo) e úmido seguindo metodologia proposta por De Souza et al. (2017). O uso da monocultura de Saccharomyces cerevisiae como inóculo da fermentação utilizada por Sandrin (2018) e De Souza (2017) foi comparada com o emprego da cocultura composta por S. cerevisiae e Pachysolen tannophilus, sugerida por Montagnoli (2017).

\section{Preparo do Mosto de fermentação}

\section{MATERIAL E MÉTODOS}

Dois diferentes tipos de mostos foram avaliados. O primeiro foi composto pelos caldos de polpa (Pol), cascas de banana (Cas) e de farelo de pseudocaule de bananeira (caldo Pseudo F), conforme proposto por Sandrin (2018), porém com a proporção de massa úmida entre os resíduos de 1:2:10; e o segundo, semelhante ao primeiro, exceto que o caldo Pseudo $\mathrm{F}$ foi substituído pelo caldo de pseudocaule de bagaço úmido (caldo Pseudo B), conforme sugerido por De Souza et al. (2017). Os mostos compostos foram submetidos à evaporação aberta (pressão ambiente) a $70^{\circ} \mathrm{C}$ até obtenção de uma concentração de açúcares redutores (AR) da ordem de $187 \mathrm{~g} \mathrm{~L}^{-1}$. Após concentrado, foram adicionados os nutrientes propostos por Souza et al. (2010). Em seguida, o pH da mistura foi ajustado para 4,5 (uso de $\mathrm{NaOH}$ anidro) e esterilizado em autoclave a vapor a $120^{\circ} \mathrm{C}$, durante $15 \mathrm{~min}$.

\section{Inóculo}

Cultura pura de Sacharomyces cerevisiae isolada de fermento comercial, mantida e identificada no banco de cepas da Universidade da Região de Joinville como Univille 9080, foi utilizada como monocultura conforme indicado por Hofner (2015). Para cocultura, foi empregada mistura de mesma cultura de $S$. cerevisiae com cultura pura Pachysolen tannophilus CCT 1891 (ATCC 32691), na proporção de massa de 1:1 de acordo

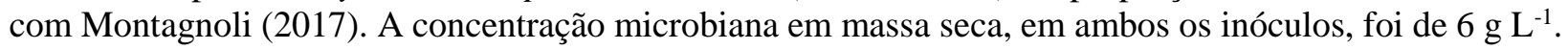

\section{Fermentação}

Foram realizados três ensaios de fermentação com, no mínimo, uma replicata: (1) F1_PCB_MC fermentação utilizando bagaço úmido (após prensagem e trituração) de pseudocaule de bananeira, casca e polpa de banana com monocultura microbiana; (2) F2_PCB_CC - idem ao ensaio anterior, com cocultura microbiana; (3) F3_PCF_CC - fermentação utilizando farelo (com prensagem, secagem e moagem) de pseudocaule de bananeira, casca e polpa de banana com cocultura microbiana. Os ensaios foram conduzidos em frascos de Erlenmeyer com $100 \mathrm{~mL}$ de volume de trabalho, incubados em agitador orbital, com frequência de agitação de $120 \mathrm{~min}^{-1}, 30{ }^{\circ} \mathrm{C}$ até término do consumo de $\mathrm{AR}(\mathrm{dAR} / \mathrm{dt}=0)$. Durante os ensaios, periodicamente foram retiradas amostras em triplicata, para determinações das concentrações de açúcares (AR) e de etanol $(\mathrm{P})$.

\section{Análises químicas}

Para AR foi utilizado o método colorimétrico do ácido dinitrosalicílico (DNS) adaptado de Miller (1959) conforme proposto por Sandrin (2018). Os valores de P foram determinados por cromatografia gasosa utilizando cromatógrafo Agilent, modelo 6890, acoplado com amostrador automático modelo 7683 e coluna da Hewlett-Packard HP-1 de comprimento $50 \mathrm{~m}$ e diâmetro externo de 0,32 mm. Como fase estacionária foi utilizado $100 \%$ dimetilpoli-siloxano. 


\section{RESULTADOS E DISCUSSÃO}

O menor tempo de fermentação ( $\mathrm{tf}=36 \mathrm{~h}$ ) foi obtido em F1_PCB_MC, com acúmulo médio de etanol no vinho de 37,8 g.L $\mathrm{L}^{-1}$, conforme é mostrado na Tabela 1. Enquanto o inóculo de F1_PCB_MC foi composto por cultura pura de $S$. cerevisiae com concentração celular em torno de $6 \mathrm{~g} \mathrm{~L}^{-1}$, o inóculo com cocultura, com mesma concentração celular da monocultura, foi composto por $3 \mathrm{~g} \mathrm{~L}^{-1}$ de $S$. cerevisiae e $3 \mathrm{~g} \mathrm{~L}^{-1}$ de $P$. tannophilus. Segundo Hopfner (2015), a velocidade de metabolismo de P. tannophilus expressa em unidade de substrato consumido por unidade de tempo é $50 \%$ menor do que a de $S$. cerevisiae.

Ao comparar os ensaios com cocultura com o de monocultura verifica-se que a adição de $P$. tannophilus no inóculo favoreceu o consumo do substrato. Ao contrário de $S$. cerevisiae, esse microrganismo é capaz de fermentar, além de hexoses e alguns de seus dímeros, as pentoses como xilose, glicose, manose, galactose, celobiose e arabinose, provenientes, principalmente, da hidrólise e sacarificação da hemicelulose (ZABED et al., 2016).

A partir dos valores obtidos nas fermentações, estimou-se os respectivos valores de rendimento ( $\left.\mathrm{Y}_{\mathrm{P} / \mathrm{AR}}\right)$ e produtividade volumétrica em etanol $\left(\mathrm{Q}_{\mathrm{P}}\right)$, mostrados na Figura 1. Houve diferença significativa $(\mathrm{p}<0,05)$ entre todos os valores de QP. Para Y Y/AR, apenas em F2_PCB_CC este valor foi diferente dos demais ensaios.

Percebe-se pela Figura 4 que os melhores resultados tanto de $Y_{P / A R}$ quanto de $Q_{P}$ foram obtidos no ensaio F2_PCB_CC. Nota-se que tanto Y Y/AR como QP deste ensaio foram, respectivamente, 25\% e 27,3\%, maiores que em F3_PCF_CC, que utilizou o mesmo tipo de inóculo, porém com processamento do pseudocaule na forma de farelo ao invés de bagaço úmido. Em relação à F1_PCB_MC (uso de inóculo com monocultura e bagaço úmido na sacarificação), os valores de F2_PCB_CC foram 25\% e 9,1\% maiores, respectivamente.

Em relação à produtividade, foi possível observar que a fermentação do mosto composto por resíduos vegetais da bananicultura, tanto na composição utilizada neste trabalho (1:2:10) como na empregada por Sandrin (2018) (1:2:7) foram superiores à maioria dos valores obtidos por outros autores com diferentes biomassas, exceção ao bagaço de cana-de-açúcar $\left(\mathrm{Q}_{\mathrm{P}}=1,58 \mathrm{~g} \mathrm{~L}^{-1} \mathrm{~h}^{-1}\right)$ empregado por Pitarelo et al. (2016) e sabugo de milho $\left(\mathrm{Q}_{\mathrm{P}}=1,39 \mathrm{~g} \mathrm{~L}^{-1} \mathrm{~h}^{-1}\right)$ utilizado por Cai et al. (2016).

\section{CONCLUSÃO}

Tanto na fermentação realizada com monocultura (S. cerevisiae) quanto nas fermentações conduzidas com o uso de cocultura (S. cerevisiae $+P$. tanophilus), empregando mosto composto por polpa, cascas e bagaço úmido de pseudocaule, a cocultura apresentou maiores rendimento e produtividade em etanol; sendo, portanto, indicada para o processo fermentativo. Ao comparar o uso da cocultura na produção de etanol de mosto composto por bagaço úmido com o mosto onde empregou-se o bagaço seco e moído (farelo), verificou-se que o bagaço úmido conduziu a uma produtividade da ordem de $37 \%$ maior do que o farelo. Comportamento semelhante ocorreu com o rendimento, demonstrando sua potencialidade para continuidade dos estudos.

\section{REFERÊNCIAS}

CAI, D.; DONG, Z.; WANG, Y.; CHEN, C.; LI, P.; QIN, P.; WANG, Z.; TAN, T. Biorefinery of corn cob for microbial lipid and bio-ethanol production: An environmental friendly process. Bioresource Technology, v. 211, p. 677-684, 2016.

DE SOUZA, E. L; SELLIN, N; MARANGONI, C; SOUZA, O. The influence of different strategies for the saccharification of the banana plant pseudostem and the detoxification of concentrated broth on bioethanol production. Applied Biochem Biotechnol, v. 183, p.943 - 965, 2017.

EMBRAPA - Empresa Brasileira de Pesquisa Agropecuária. O Brasil é o país dos resíduos. Disponível em: < https://www.embrapa.br >. Acesso em Julho de 2017.

EPAGRI/CEPA - Empresa de Pesquisa Agropecuária e Extensão Rural de Santa Catarina/ Centro de Socioeconomia e Planejamento Agrícola. Síntese anual da agricultura de Santa Catarina 2014-2015. Disponível em < http://docweb.epagri.sc.gov.br/website_cepa/publicacoes/Sintese_2015.pdf >. Acesso em Junho de 2017.

FAO - Food and Agriculture Organization of the United Nations. Disponível em: <fttp://www.fao.org>. Acesso em: agosto de 2017.

HOPFNER, S.A. Produção de etanol por diferentes espécies de micro-organismos a partir de mostos de cascas de banana (frescas ou sacarificadas) com diferentes concentrações de açúcares redutores. Dissertação,103p. Mestrado em Engenharia de Processos, Universidade da Região de Joinville, Joinville, 2015. 
MILLER, G. L. Use of dinitrosalicylic acid reagent for determination of reducing sugar. Analytical Chemistry, v. 31, n. 3, p. 426- 428, 1959.

MONTAGNOLI, M. S. Análise da produção de etanol $2 \mathrm{~g}$ de pseudocaule de bananeira por cocultura microbiana em bateladas sequenciais. Tese 140 p. Doutorado em Engenharia Química, Universidade Federal de Santa Catarina - UFSC, Florianópolis, 2017.

PITARELO, A. M.; FONSECA, C. S.; CHIARELLO, L. M.; GÍRIO, F. M.; RAMOS, L. P. Ethanol production from sugarcane bagasse using phosphoric acid-catalyzed steam explosion. Journal of the Brazilian Chemical Society, v. 27, n 10, p 1889-1898, 2016.

SANDRIN, B. M. Fermentação alcoólica de mosto composto por diferentes combinações de biomassas residuais da bananicultura. Dissertação, 107p. Mestrado em Engenharia de Processos, Universidade da Região de Joinville, Joinville, 2010.

SOUZA, O., FEDERIZZI, M., COELHO, B., WAGNER, T.M., WISBECK, E. Biodegradação de resíduos lignocelulósicos gerados na bananicultura e sua valorização para a produção de biogás. Revista Brasileira de Engenharia Agrícola e Ambiental, vol. 14, no 4, p. 438-443, 2010.

ZABED, H.; SAHU, J.N.; BOYCE, A.N.; FARUQ, G. Fuel ethanol production from lignocellulosic biomass: An overview on feedstocks and technological approaches. Renewable and Sustainable Energy Reviews, v. 66, p. 751-774, 2016.

Tabela 1. Tempo final de fermentação $\left(t_{f}\right)$ e valores médios com desvio padrão das concentrações iniciais e finais de açúcares redutores $\left(\mathrm{AR}_{0} \mathrm{AR}_{\mathrm{f}}\right)$ e de etanol $\left(\mathrm{P}_{0}\right.$ e $\left.\mathrm{P}_{\mathrm{f}}\right)$ obtidos nas fermentações F1_PCB_MC,

F2_PCB_CC e F3_PCF_CC. Letras iguais na coluna indicam, pelo teste de Tukey com nível de segurança de 95\%, que as médias obtidas nos diferentes ensaios são significativamente iguais.

\begin{tabular}{llllll}
\hline Ensaio & $\mathbf{t}_{\mathbf{f}}(\mathbf{h})$ & $\mathbf{A R}_{\mathbf{0}}(\mathbf{g} / \mathbf{L})$ & $\mathbf{A R}_{\mathbf{f}}(\mathbf{g} / \mathbf{L})$ & $\mathbf{P}_{\mathbf{0}}(\mathbf{g} / \mathbf{L})$ & $\mathbf{P}_{\mathbf{f}}(\mathbf{g} / \mathbf{L})$ \\
\hline F1_PCB_MC & 36 & $149,1 \pm 8,5^{\mathrm{a}}$ & $32,4 \pm 2,3^{\mathrm{b}}$ & $0,9 \pm 0,1^{\mathrm{e}}$ & $37,8 \pm 1,4^{\mathrm{f}}$ \\
F2_PCB_CC & 48 & $151,6 \pm 8,0^{\mathrm{a}}$ & $19,5 \pm 0,5^{\mathrm{c}}$ & $0,8 \pm 0,1^{\mathrm{e}}$ & $53,1 \pm 3,6^{\mathrm{g}}$ \\
F3_PCF_CC & 48 & $154,7 \pm 8,0^{\mathrm{a}}$ & $23,1 \pm 3,1^{\mathrm{d}}$ & $1,1 \pm 0,5^{\mathrm{e}}$ & $41,6 \pm 3,2^{\mathrm{h}}$ \\
\hline
\end{tabular}

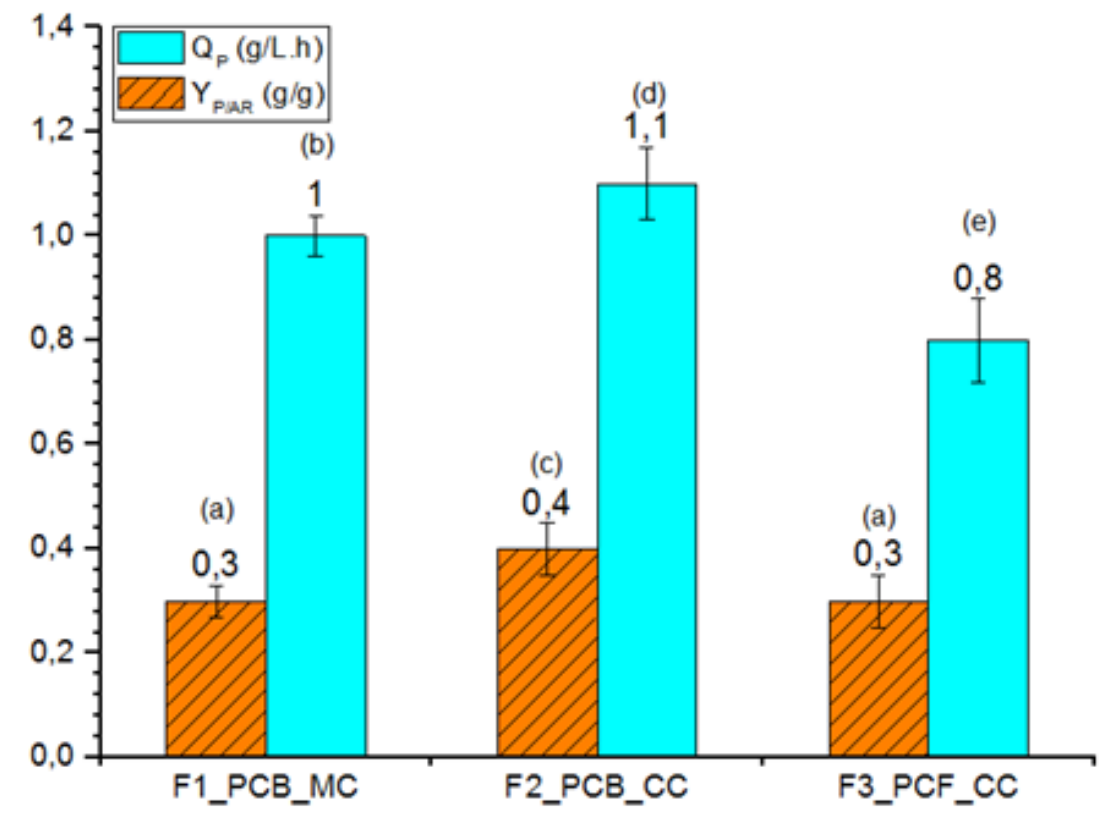

Figura 1. Rendimento $\left(\mathrm{Y}_{\mathrm{P} / \mathrm{AR}}\right)$ e produtividade volumétrica $\left(\mathrm{Q}_{\mathrm{P}}\right)$ em etanol obtidos nas fermentações

F1_PCB_MC (uso de pseudocaule úmido e monocultura de $S$. cerevisiae), F2_PCB_CC (uso de pseudocaule úmido e cocultura microbiana composta por S. cerevisiae e P. tannophilus) e F3_PCF_CC (uso de farelo de pseudocaule seco e cocultura microbiana composta por S. cerevisiae e P. tannophilus).

Letras diferentes entre os valores de cada um dos ensaios indicam, pelo teste de Tukey com nível de segurança de 95\%, que as médias são significativamente diferentes. 


\title{
PRODUÇÃO DE BIOGÁS A PARTIR DE DEJETOS DE VACA LEITEIRA UTILIZANDO CINZA DE CASCA DE ARROZ COMO CATALISADOR
}

\author{
Batti, J.C.B. ${ }^{1}$; Geremias, R..$^{*}$; Antônio, R.V. ${ }^{3}$ \\ ${ }^{1}$ Engenharia de Energia, UniversidadeFederal de Santa Catarina, Araranguá, SC, Brasil. juliabezbatti@ gmail.com \\ ${ }^{2}$ Engenharia de Energia, UniversidadeFederal de Santa Catarina, Araranguá, SC, Brasil.reginaldogeremias@ gmail.com \\ ${ }^{3}$ CE - Física, Química e Matemática, CTS - Universidade Federal de Santa Catarina, Araranguá, SC, Brasil \\ regina.antonio@ufsc.br
}

\begin{abstract}
RESUMO: O objetivo principal desse trabalho foi investigar o potencial de aumento da produção de biogás ao introduzir cinza de casca de arroz na digestão anaeróbia de dejetos de vaca leiteira. Amostras de dejetos de vaca leiteira e de biofertilizantes foram coletadas em uma pequena propriedade rural no município de Araranguá/SC. Os valores de sólidos totais, sólidos fixos, sólidos voláteis e pH foram determinados. 13 reatores de bancada com capacidade de $250 \mathrm{ml}$ foram confeccionados. Testes de digestão anaeróbica foram executados em regime de batelada. Os reatores foram abastecidos com dejetos de vaca leiteira (substrato), biofertilizante (inóculo), sílica comercial ou cinza de casca de arroz em diferentes concentrações (catalisadores). Os ensaios foram realizados em temperaturas ambiente (em torno de $25^{\circ} \mathrm{C}$ ) e a $40{ }^{\circ} \mathrm{C}$, por um período de 10 dias, sendo monitorada a produção de biogás. Os resultados obtidos nos testes para a determinação de sólidos totais, fixos, voláteis e pH indicaram, em geral, valores adequados aos testes de digestão. $\mathrm{O}$ aumento da temperatura provocou aumento na produção de biogás. Observou-se que a melhor condição de operação foi com a adição de $1 \mathrm{~g}$ de cinza da casca de arroz nos reatores operados a $40{ }^{\circ} \mathrm{C}$, a qual foi capaz de aumentar a produção de biogás em $151 \%$, quando comparada com o reator à temperatura ambiente. Conclui-se que o uso da cinza de casca de arroz como catalisador é uma alternativa viável para aumentar a produção de biogás, valorar este resíduo, conferindo vantagens econômicas e ambientais ao processo.
\end{abstract}

Palavras-chave: digestão anaeróbia, reatores laboratoriais, sílica gel, casca de arroz.

\section{BIOGAS PRODUCTION FROM DAIRY CATTLE MANURE USING RICE RUSK ASH AS CATALYST}

\begin{abstract}
This research aimed at investigating the increase potential of biogas production using rice husk ash as a catalyst for anaerobic digestion of cattle manure. Samples of cattle manure and cattle manurebased fertilizers were collected in a small rural property in Araranguá city (Santa Catarina State-Brazil). The total, fixed and volatile solids and $\mathrm{pH}$ were determined. 13 bench reactors with capacity of $250 \mathrm{ml}$ were made. Anaerobic biodigestion tests were performed in a batch regime. Dairy cow manure (substrate), biofertilizer (inoculum), commercial silica and different concentrations of rice husk ash (catalysts). The tests were carried out at two ambient temperatures (around $25{ }^{\circ} \mathrm{C}$ ) and at $40{ }^{\circ} \mathrm{C}$ for a period of 10 days. The biogas production was controlled. The results obtained from the solids and $\mathrm{pH}$ series indicated, in general, adequate values for the biodigestion tests. The tests showed that the increase in temperature caused an increase in biogas production. It was observed that the best condition was the addition of 1 grams of rice husk ash in the reactors operated at $40{ }^{\circ} \mathrm{C}$. The biogas production increased by $151 \%$ compared to the reactor at the room temperature. It is concluded that the use of rice husk ash as a catalyst is a viable alternative to increase the biogas production. This allows the valuation of this waste, providing economic and environmental benefits to the process.
\end{abstract}

Keywords: anaerobic digestion, laboratory reactors, silica gel, waste.

\section{INTRODUÇÃO}

A queima de combustíveis fósseis e a atividade pecuarista contribuem para a liberação de gases nocivos ao ambiente e favorecem as mudanças climáticas. Nos dois últimos semestres do ano de 2018, o estado de Santa Catarina teve uma produção de mais de 6 toneladas de dejetos oriundos da atividade de bovinocultura leiteira (Alvarenga, 2011). 
O arroz, juntamente com trigo e leguminosas, é parte importante da dietabrasileira. Em 2017, somente o estado de Santa Catarina produziu 205.310 toneladas de casca de arroz (Epagri, 2017). A valoraçãoda casca é, atualmente, feita principalmente por meio da sua combustão, que deixa como resíduo a cinza de casca de arroz, que por sua vez contém a sílica como componente principal (Della e Kühn, 2002).

Os prejuízos sofridos pela falta de tratamento e pelo manejo inadequado desses resíduos podem ser vastos, no entanto, quando esses passam a ser manejados e tratados adequadamente, deixam de ser poluentes e acabam por constituir valiosos insumos para a produção agrícola sustentável (Campos, 2018).

Investir na produção e consumo de combustíveis provenientes de fontes renováveis e que valorizem os resíduos que antes seriam descartados no ambiente, é um passo em direção à garantia do suprimento energético e constituição de um meio ambiente mais limpo, seguro e equilibrado.Neste contexto, trabalhos na literatura tem proposto a utilização de sílica gel como catalisador na produção de biogás, tendo-se obtido resultados promissores (Ahamed et al., 2016; Desai eMadamwar, 1994; Salam et al, 2015).

Partindo destes pressupostos, o objetivo geral desse trabalho foi investigar o potencial de aumento na produção de biogás ao adicionar cinza de casca de arroz à digestão anaeróbio de dejetos de vaca leiteira.

\section{MATERIAL E MÉTODOS}

Amostras de dejeto bovino fresco (mistura de esterco, urina e água) e de biofertilizante (produto secundário da fermentação do dejeto de um biodigestor instalado em campo) foram coletados nos meses de junho e outubro de 2018, em uma pequena propriedade rural, no município de Araranguá/SC. A cinza de casca de arroz (CCA) foi coletada no município de Morro da Fumaça/SC, com granulometria de 0,227 $\mu \mathrm{m}$ (Ferro, 2018). A sílica utilizada foi adquirida comercialmente, sendo Sílica Gel 60, da marca Vetec, com granulometria de $0,05-0,2 \mathrm{~mm}$. Os dejetos foram utilizados como substrato para os experimentos, o biofertilizante serviu como inóculo e a cinza de casca de arroz e sílica gel atuaram como catalisadores.

A determinação dos teores de sólidos totais, sólidos fixos, e sólidos voláteis foi realizada tanto para as amostras de dejetos quanto para de biofertilizante, de acordo com o Standard Methods for the Examination of Water and Wastewater (1997). A medição do $\mathrm{pH}$ foi realizada duas vezes para cada reator, usando-se fita indicadora de $\mathrm{pH}$, no início e ao final da sua operação.

Bioerreatores foram confeccionados utilizando-se frascos de vidro com capacidade de $250 \mathrm{ml}$ cada um, que serviram como fermentadores. Foram fechados e tiveram um tubo fixado em sua tampa, pelo qual o biogás produzido foi transferido para um de coletor de gás. $\mathrm{O}$ coletor de gás consistiu em um frasco de vidro, também com capacidade de $250 \mathrm{ml}$, preenchido com água. Em sua tampa, foram conectadas duas mangueiras, uma para a entrada de biogás no coletor e outra para a saída de água. Conforme o biogás é produzido no reator ele passa pela mangueira e entra no coletor de gás, então, a água que está armazenada nesse tanque é empurrada para fora dele e coletada no coletor de água.

No total, 13 (treze) reatores foram abastecidos com dejeto, inóculo, água, sílica comercial ou CCA, sendo nomeados sequencialmente R1 a R13. Todos os reatores tiveram um TRH de 10 dias, operaram com volume de $200 \mathrm{ml}$ e um headspace de $50 \mathrm{ml}$. Foram abastecidos com uma mistura de dejeto, inóculo e água, conforme a necessidade, de forma que ao final do abastecimento tiveram um percentual de $6 \%$ de sólidos totais (em base mássica).

Foram realizados 2 (dois) testes distintos. No primeiro, operaram os reatores de R1 a R10. Os reatores R1 e R6 serviram como controle, de forma que não receberam adição de catalisador. Os reatores R2 e R7 receberam, adicionalmente, $1 \mathrm{~g}$ de sílica comercial. Os reatores R3 e R8 receberam $1 \mathrm{~g}$ de CCA, R4 e R9 receberam 1,25 g de CCA, e R5 e R10 receberam de CCA. Os reatores R1, R2, R3, R4 e R5 foram operados a temperatura ambiente (em torno de $25^{\circ} \mathrm{C}$ ). Os reatores R6, R7, R8, R9 e R10 foram operados a temperatura controlada a $40{ }^{\circ} \mathrm{C}$, por meio de banho-maria, para investigar também a influência da temperatura na produção de biogás.

No segundo teste foram operados três reatores (R11, R12 e R13). Estes reatores foram operados nas mesmas condições do reator R8, o qualmostrou melhor produção de biogás no primeiro teste, tendo-se como objetivo diminuir os erros relacionados ao experimento e obter um resultado mais confiável. Todos os 3 reatores operaram a $40{ }^{\circ} \mathrm{C}$, volume de $250 \mathrm{ml}$ e $6 \%$ de sólidos totais.

Durante os 10 (dez) dias de operação dos reatores nos dois testes, o volume de biogás gerado por cada reator foi medido a cada 24 horas, por meio do método de deslocamento de água, dado que o volume do biogás que entra no coletor de gás é equivalente ao volume de água recolhida no coletor de água. 


\section{RESULTADOS E DISCUSSÃO}

O teor de sólidos totais da primeira amostra de dejetos foi de $18 \%$, no entanto a segunda amostra apresentou um teor de $9 \%$. Essa variação na quantidade de sólidos totais entre as duas amostras pode ocorrer devido a fatores como idade e alimentação dos animais, manejo dos dejetos, entre outros (Santos e Nogueira, 2012). Esses resultados permitiram a mistura adequada dos dejetos, água e inóculo para manter o mesmo teor de sólidos totais em todos os reatores.

Os teores de sólidos voláteis foram medidos apenas na primeira amostra de dejetos e representaram $59 \%$ em relação aos teores de sólidos totais. Esse valor está abaixo do comumente encontrado na literatura, que é cerca de $80 \%$ (Alvarez e Lidén, 2009). No entanto, é justificado devido estarem referenciando amostras de esterco (fração sólida), sendo assim, espera-se um valor menor ao avaliar uma amostra de dejeto (misturada com urina).

Os valores de $\mathrm{pH}$ iniciais e finais em todos os reatores medidos apresentaram valores próximos a 8 . Considerando que a literatura apresenta um $\mathrm{pH}$ igual a 7 como ótimo, pode-se dizer que os resultados podem ser melhorados ao se fazer a correção do pH (Khalid et al., 2011).

$\mathrm{Na}$ produção de biogás na temperatura ambiente, observou-se que o reator $\mathrm{R} 1$, sem adição de catalisador, foi o que produziu o maior volume $(236,5 \mathrm{ml})$. Sendo assim, em relação à quantidade de gás gerado não é perceptível a necessidade do uso de catalisador ao operar um biodigestor a temperatura ambiente.

Em relação à concentração de CCA, observa-se que quanto maior a concentração, maior a quantidade de gás gerado. O reator R5 (1,5 g) foi o que apresentou uma maior produção de gás, seguido de R4 (1,25 g) e R3 (1 g). Mesmo que a adição da CCA não tenha apresentando a melhor produção absoluta, com esse resultado, abre-se a possibilidade para uma investigação quanto à adição de uma concentração maior que $1,5 \mathrm{~g}$ de CCA.

Por outro lado, a adição de $1,5 \mathrm{~g}$ de CCA diminuiu o tempo de início de produção de biogás em relação aos outros reatores. Dessa forma, apesar de não ter apresentado uma maior quantidade de gás gerada, permitiu uma produção de gás mais rápida quando comparada a todos os demais reatores.

Entre os reatores operados à $40^{\circ} \mathrm{C}$ observou-se que o reator R8, com adição de $1 \mathrm{~g}$ de CCA, foi o que atingiu a maior produção de biogás $(959,5 \mathrm{ml})$, que foi $306 \%$ maior que o valor alcançado no reator R1 (melhor produção a $25^{\circ} \mathrm{C}$ ). Os reatores operados à $40{ }^{\circ} \mathrm{C}$ tiveram o tempo de início de produção de biogás menor quando comparados aos reatores operados em temperatura ambiente.

Considerando que entre os nutrientes mais importantes para a vida dos microrganismos estão alguns elementos como nitrogênio, enxofre, fósforo e ferro, os quais fazem parte da composição da CCA, é possível relacionar o aumento da produção de biogás quando adicionado a CCA ao atendimento nutricional das bactérias (Kadamet al, 2000; Tortora et al, 2012).

No segundo teste, os reatores R11, R12 e R13, operados também a $40{ }^{\circ} \mathrm{C}$, tiveram uma produção média de biogás de $591,0 \pm 75,1 \mathrm{ml}$. Esse valor é menor que o volume produzido pelo reator R8. Embora tenha sido tomado o cuidado de manter o teor de sólidos totais o mais próximo possível tem todos os reatores testados $(6 \%)$, o uso de um substrato diferente nos dois testes pode ser um fator que influenciou na diferença de produção de biogás entre os reatores.

Com base na Tabela 1, é possível observar que o aumento da temperatura provocou o aumento na produção de biogás em todos os reatores, quando comparado à temperatura ambiente.

Observa-se também que a $40{ }^{\circ} \mathrm{C}$, a melhor produção de biogás se deu ao utilizar uma concentração de $1 \mathrm{~g}$ de CCA. Nessa condição, houve uma produção $151 \%$ maior quando comparada à melhor produção na temperatura ambiente. Ao se comparar com a mesma concentração de CCA na temperatura ambiente, o aquecimento dos reatores proporcionou um aumento $989 \%$ na produção.

\section{CONCLUSÃO}

Com os resultados dos experimentos para avaliação da produção de biogás a partir de dejeto de vaca leiteira como substrato e uso da CCA como catalisador, conclui-se que a adição do catalisador ao digestor se mostrou como uma alternativa viável para aumentar a produção de biogás na temperatura de $40^{\circ} \mathrm{C}$. A operação à temperatura de $40^{\circ} \mathrm{C}$ aumentou a produção de biogás em $151 \%$, quando comparada à melhor produção na temperatura ambiente, e também diminuiu o tempo de partida dos biodigestores, sendo esse um fator importante por permitir uma produção de biogás mais rápida, além de um aumento direto no volume de biogás produzido. 
Com os resultados obtidos, é perceptível o potencial de utilização dos dejetos bovinospara fins energéticos, permitindo incorporar ainda mais valor às atividades agropecuárias. Além disso, possibilita a valoração da CCA, considerada como um resíduo da rizicultura, conferindo vantagens econômicas e ambientais no gerenciamento desse material.

\section{REFERÊNCIAS}

AHAMED, J. U. Et al. Production of biogas from anaerobic digestion of poultry droppings and domestic waste using catalytic effect of silica gel. International Journal of Automotive and Mechanical Engineering, v. 13, n. 2, p. 3503-3517, 2016.

ALVARENGA, R. C. Cultivo do milho. P. 4-9, 2011.

ALVAREZ, R.; LIDÉN, G. Low temperature anaerobic digestion of mixtures of llama, cow and sheep manure for improved methane production. Biomass and Bioenergy, v. 33, n. 3, p. 527-533, 2009.

CAMPOS, A. T. DE. Manejo dos dejetos. Disponível em: 〈http://www.agencia.cnptia.embrapa.br〉. Acesso em: 17 jul. 2018.

DELLA, V. P.; KÜHN, I.Obtenção de sílica de alta pureza a partir do tratamento da cinza de casca de arroz.João pessoa - pb: ii congresso nacional de engenharia mecânica, 2002

DESAI, M.; MADAMWAR, D. Anaerobic digestion of a mixture of cheese whey, poultry waste and cattle dung: a study of the use of adsorbents to improve digester performance. Environmental pollution, v. 86, n. 3, p. 337-340, 1994.

EPAGRI; CEPA. Síntese Anual da Agricultura de Santa Catarina. Florianópolis: [s.n.].

FERRO, J. K. C. Indigo carmine removed using geopolymers from rice husk ash as adsorbent. [s.1.] Universidade Federal de Santa Catarina, 2018.

KADAM, K. L.; FORREST, L. H.; JACOBSON, W. A. Rice straw as a lignocellulosic resource: collection, processing, transportation, and environmental aspects. Biomass and Bioenergy, v. 18, n. 5, p. 369-389, 2000.

KHALID, A. Et al. The anaerobic digestion of solid organic waste. Waste Management, v. 31, n. 8, p. 1737-1744, 2011.

SALAM, B.; BISWAS, S.; RABBI, M. S. Biogas from mesophilic anaerobic digestion of cow dung using silica gel as catalyst. Procedia Engineering, v. 105, p. 652-657, 2015.

SANTOS, I. A. DOS; NOGUEIRA, L. A. H. Estudo energético do esterco bovino: seu valor de substituição e impacto da biodigestão anaeróbia. Revista Agrogeoambiental, v. 4, n. 1, p. 41-49, 2012.

TORTORA, G. J.; FUNKE, B. R.; case, c. L. Microbiologia. 10. Ed. [s.l: s.n.].

WILDER, B. H. Et al. 2540 solids. In: Standard methods for the examination of water and wastewater. [s.l: s.n.]. P. 55-61.

Tabela 1. Produção total de biogás após 10 dias de digestão atemperatura ambiente e a $40{ }^{\circ} \mathrm{C}$.

\begin{tabular}{lcc}
\hline \multirow{2}{*}{ Amostra } & \multicolumn{2}{c}{ Produção de biogás (ml) } \\
\cline { 2 - 3 } & Temperatura ambiente & Temperatura de 40 ${ }^{\circ} \mathbf{C}$ \\
\hline Controle & 236,5 & 342,5 \\
Sílica comercial 1,0 g & 143,3 & 392,0 \\
Cinza casca arroz 1,0 g & 54,5 & $593,7 \pm 214,0^{*}$ \\
Cinza casca arroz 1,25 g & 77,9 & 546,6 \\
Cinza casca arroz 1,5 g & 197,7 & 378,8 \\
\hline
\end{tabular}

*Produção média de biogás nos reatores R8, R11, R12 e R13 (Média \pm Desvio Padrão). 


\title{
PRODUÇÃO DE BIOGÁS DE EFLUENTE DE SUINOCULTURA E SORO DE LEITE EM CONDIÇÕES MESOFÍLICAS
}

\author{
Lins, L.P.*1,2; Mito, J.Y.L. ${ }^{1}$; Pinheiro, B.C. ${ }^{1,2}$; Freddo, A. ${ }^{1,2}$ \\ ${ }^{I}$ Centro Internacional de Energias Renováveis - Biogás (CIBiogás-ER), Foz do Iguaçu, PR - Brasil \\ ${ }^{2}$ Integrante do Projeto de P\&D ANEEL PD-06491-0287/2012 \\ leonardo.pereira@cibiogas.org
}

\begin{abstract}
RESUMO: A atividade suinícola possui grande representatividade econômica. Entretanto, os resíduos produzidos por essa atividade têm um alto potencial poluidor, assim como o soro de leite que é gerado nos laticínios. $\mathrm{O}$ aproveitamento desses resíduos como fonte de geração de energia está cada vez mais presente nas unidades de produção de leite, sobretudo devido à elevada demanda energética desses empreendimentos. Diante disso, identificou-se a oportunidade de aumentar o potencial da produção de biogás por meio da mistura destes dois resíduos. Sendo assim, foi realizado, em escala laboratorial, o ensaio de Potencial Metanogênico Bioquímico - PMB da mistura, que tem objetivo de avaliar a potencial máximo de produção de biogás de uma determinada amostra. Foram testadas, além da amostra de efluente de suinocultura, mais três misturas, sendo elas: $97 \%$ de efluente de suinocultura $+3 \%$ de soro de leite, $90 \%+10 \%$ e $70 \%+30 \%$, respectivamente. Os resultados mostraram que o teste com $70 \%$ de efluente de suinocultura $+30 \%$ de soro de leite produziu 674 LN biogás $\mathrm{kg} \mathrm{SV}^{-1}$, cerca de $14 \%$ mais biogás do que a amostra só com efluente de suinocultura. Considerando o volume de biogás gerado com $1 \mathrm{~kg}$ de substrato, a variação é ainda maior, cerca de $280 \%$ mais biogás do que a amostra de efluente de suinocultura o que resulta na viabilidade da codigestão das duas amostras.
\end{abstract}

Palavras-chave: codigestão, biodigestão anaeróbica, batelada.

\section{BIOGAS PRODUCTION WITH EFFLUENT OF SUINOCULTURE AND MILK SERUM IN MESOPHILIC CONDITIONS}

\begin{abstract}
The pig farming activity has great economic representativity. However, the residues produced by this activity have a high polluting potential, as well as the whey that is generated in dairy products. The use of these wastes as a source of energy is increasingly present in milk production units, mainly due to the high energy demand of these enterprises. In view of this, the opportunity to increase the biogas production potential was identified by mixing these two residues. Thus, the test of Bioquimic Methanogenic Potencial - PMB of the mixture was carried out on a laboratory scale, with the objective of evaluating the maximum biogas production potential of a given sample. In addition to the swine effluent sample, three other mixtures were tested: $97 \%$ swine effluent $+3 \%$ whey, $90 \%+10 \%$ and $70 \%+30 \%$, respectively. The results showed that the test with $70 \%$ swine effluent $+30 \%$ whey produced $674 \mathrm{LN}_{\text {biogas }} \mathrm{kg} \mathrm{SV}^{-1}$, about $14 \%$ more biogas than the swine effluent sample alone. Considering the volume of biogas generated with $1 \mathrm{~kg}$ of substrate, the variation is even greater, about $280 \%$ more biogas than the swine effluent sample, which results in the feasibility of the codigestion of the two samples.
\end{abstract}

Keywords: codigestion, anaerobic biodigestion, batch.

\section{INTRODUÇ̃̃O}

Embora considerada altamente poluidora em razão da carga orgânica e do volume dos dejetos gerados, a suinocultura vem demonstrando-se uma alternativa energética atrativa e viável, possibilitando transformar um passivo ambiental em um ativo energético. De acordo com Leitão e Silva (2018), a atividade suinícola possui grande potencial de geração de energia elétrica em caráter renovável, por meio da utilização do biogás.

Segundo a Agência Nacional de Petróleo, Gás Natural e Biocombustíveis - ANP (2018), embora o mercado de biogás esteja em desenvolvimento, espera-se um crescimento exponencial tanto na produção de biogás como de biometano no Brasil, produtos que podem incrementar a produção agrícola e com esse potencial energético gerar desenvolvimento, trabalho e renda. Como exemplo de eficiência na produção e uso do biogás, temos a Europa que, como afirma Scarlat et al. (2018), a produção de biogás na União Europeia aumentou em decorrência de políticas de energias renováveis, além de benefícios econômicos, ambientais e 
climáticos. Essa conjunção de fatores levou o continente europeu a atingir em produção de biogás o equivalente à metade da produção global desse combustível.

Como forma de garantir qualidade e quantidade, pesquisas com a adição de outros materiais estão em andamento. Essas misturas são chamadas de codigestão, e que podem resultar no aumento da produção de biogás simplesmente pela introdução de outra substância.

Um desses materiais que atualmente são usados para aumentar a produção de biogás é o soro de leite. De acordo com Gelenesis, et al. (2007), na fabricação de queijos há dois fluxos de resíduos: águas residuárias do chão e equipamentos e o soro do queijo, que é o líquido restante após a precipitação e remoção de caseína de leite, durante o processo de fabricação do queijo. O soro, embora em menor volume, possui um potencial poluidor elevado, e atualmente, metade da produção mundial de soro não é reutilizada na indústria, mas descartada como efluente residual. A digestão anaeróbica é um dos métodos biológicos viáveis para tratá-lo e destiná-lo adequadamente. Diante deste cenário favorável ao biogás, o objetivo deste trabalho foi avaliar a produção de biogás em escala laboratorial por meio do ensaio de Potencial Metanogênico Bioquímico - PMB de amostras de efluente de suinocultura e associada a codigestão com soro de leite, em três misturas, com 97 e $3(\%), 90$ e $10(\%)$ e 70 e $30(\%)$, respectivamente.

\section{MATERIAL E MÉTODOS}

Os ensaios de PMB foram realizados no Laboratório de Biogás do Centro Internacional de Energias Renováveis - Biogás (CIBiogás-ER), localizado em Foz do Iguaçu-PR. As amostras do efluente de suinocultura e do soro de leite foram coletadas em uma propriedade rural do município de Entre Rios do OestePR.

Além do ensaio de PMB, realizado de acordo com a VDI 4630 (2017), foram realizados os ensaios para determinação de sólidos totais (ST), fixos (SF) e voláteis (SV), conforme método 2540G (com alterações) da APHA (2017). Para o ensaio de PMB, é necessário o uso de inóculo, que é um material rico em microrganismos. O inóculo utilizado foi preparado no laboratório a partir da mistura de porções iguais (v/v) de efluentes de suínos e bovinos acondicionados em reator de material inoxidável, com agitação constante e temperatura controlada na faixa de $37,0 \pm 2,0{ }^{\circ} \mathrm{C}$. O inóculo recebeu alimentação diária balanceada na proporção de $0,5 \mathrm{~g}$ de SV para cada litro de inóculo. No ensaio de PMB, as amostras e o inóculo foram medidos e incubados em frascos digestores de vidro $(250 \mathrm{ml})$ e acoplados a tubos graduados de $500 \mathrm{ml}$, denominados eudiômetros, com divisões de escala de $1 \mathrm{ml}$. A massa das amostras foi calculada e medida com base nos SV na proporção de 1:3 (massa: inóculo). O padrão positivo utilizado foi a celulose microcristalina SigmaAldrich ${ }^{\circledR}$ e o padrão negativo o inóculo puro. O teste de fermentação foi realizado em triplicata, no regime de batelada e com temperatura controlada na faixa mesofílica $37,0 \pm 2,0^{\circ} \mathrm{C}$.

As misturas entre o efluente de suinocultura (ES) com o soro de leite (SL) foram definidas para fins de codigestão, baseadas na porcentagem final de ES com SL, sendo assim determinadas: 97\% e 3\%; 90\% e 10\%; e $70 \%$ e $30 \%$, respectivamente. Optou-se por usar essas percentagens em razão da quantidade de soro disponível para uso na propriedade.

O ensaio de BMP foi conduzido durante 31 dias, com leituras do volume e medições das concentrações de gases realizadas durante todo o experimento. A medição da concentração de biogás foi realizada durante os testes, usando um analisador de gases (modelo Dräger X-am 7000). Foram medidos os gases: metano $\left(\mathrm{CH}_{4}\right)$, dióxido de carbono $\left(\mathrm{CO}_{2}\right)$, oxigênio $\left(\mathrm{O}_{2}\right)$, sulfeto de hidrogênio $\left(\mathrm{H}_{2} \mathrm{~S}\right)$ e hidrogênio $\left(\mathrm{H}_{2}\right)$.

\section{RESULTADOS E DISCUSSÃO}

Os resultados apresentados na Tabela 1 indicam a quantidade de ST e SV, a produção de biogás e metano, a relação entre metano e biogás, a quantidade de substrato necessário para obtenção de $1 \mathrm{~kg}$ de $\mathrm{SV}$, o volume de biogás em litros produzido por um $1 \mathrm{~kg}$ de substrato e a variação em porcentagem entre as amostras analisadas. Esses resultados foram importantes para uma avaliação completa e eficiente do uso desses substratos.

Observa-se que o melhor resultado para o ensaio de PMB foi para a amostra de codigestão com $70 \%$ de ES + 30\% SL, com $674 \mathrm{LN}$ biogás kg SV$^{-1}$, diferente dos $591 \mathrm{LN}$ biogás kg SV${ }^{-1}$ da amostra de ES. Comparando o resultado do volume de biogás produzido por quilograma de substrato dessa mesma amostra com a de ES o valor é superior a $283 \%$ do resultado, conforme observado no gráfico da Figura 1. Além disso, com relação ao fator do volume de biogás por quilograma de substrato, todas as codigestões apresentaram valor superior à amostra de ES. Este alto rendimento na produção de biogás, pode estar relacionado com as características do 
soro de leite, que possuem lactose, proteínas, sais solúveis e gorduras (VENETSANEAS, et al. 2009), muito embora de acordo com Carlini, et al. (2015) o seu uso pode ser problemático, em razão da baixa alcalinidade, e tendência de se acidificar muito rapidamente. Contudo, vale ressaltar que não foram observadas reações adversas a produção de biogás durante a realização do experimento.

No gráfico da Figura 2, pode-se observar as curvas de produção de biogás obtidas durante o experimento com nítida sobressaliência da mistura ES 70\% + SL 30\%

\section{CONCLUSÃO}

A adição de soro para realização da codigestão, demonstrou aumento significativo para a produção de biogás. A codigestão de $70 \%$ de ES $+30 \%$ SL apresentou os melhores resultados e mostrou-se uma opção positiva para a produção de biogás. Contudo, vale ressaltar que a viabilidade do seu uso está relacionada ao manejo dos resíduos, a qualidade do soro, características do efluente e também do sistema de biodigestão adotado.

\section{AGRADECIMENTOS}

Agradecimento ao CIBiogás-ER e a Itaipu Binacional pelo apoio institucional durante a execução do estudo e o apoio financeiro da Companhia Paranaense de Energia (COPEL) através do projeto de P\&D ANEEL PD-06491-0287/2012 denominado "Arranjo Técnico e Comercial de Geração Distribuída de Energia Elétrica a Partir do Biogás de Biomassa Residual da Suinocultura em propriedades Rurais no Município de Entre Rios do Oeste do Paraná".

\section{REFERÊNCIAS}

ANP. Agência Nacional do Petróleo, Gás Natural e Biocombustíveis. ANP destaca o potencial do biogás. Disponível em: <http://www.anp.gov.br/noticias/4874-anp-destaca-potencial-do-biogas>. Acesso em: 25 nov. 2018.

APHA - American Public Health Association. Standard Methods for Examination of Water and Wastewater. 23RD. ED. Washington: APHA, 2017.

Carlini, M., Castellucci, S., Moneti, M. (2015). Biogas production from poultry manure and cheese whey wastewater under mesophilic conditions in batch reator. Energy Procedia, 82 811-818.

Gelegenis, J., Georgakakis, D., Angelidaki, I., \& Mavris, V. (2007). Optimization of biogas production by co-digesting whey with diluted poultry manure. Renewable Energy, 32(13), 2147-2160. doi:10.1016/j.renene.2006.11.015

Leitão, Fabrício Oliveira; SILVA, Warley Henrique da. Geração de energia e renda a partir do tratamento dos resíduos da suinocultura. Informe GEPEC, [S.1.], v. 22, n. 1, p. 116-132, jul. 2018. ISSN 1679-415X. Disponível em: <http://e-revista.unioeste.br/index.php/gepec/article/view/18024>. Acesso em: 25 nov. 2018. Scarlat, N., Dallemand, J.-F., \& Fahl, F. (2018). Biogas: Developments and perspectives in Europe. Renewable Energy, 129, 457-472. doi:10.1016/j.renene.2018.03.006

VDI - VEREIN DEUTSCHER INGENIEURE. Vergärung organischer stoffe - substratcharakterisierung, probenahme - stoffdatenaerhebung, gärversuche. German. 2017.

Venetsaneas, N., Antonopoulou, G., Stamatelatou, K., Kornaros, M., \& Lyberatos, G. (2009). Using cheese whey for hydrogen and methane generation in a two-stage continuous process with alternative $\mathbf{p H}$ controlling approaches. Bioresource Technology, 100(15), 3713-3717. doi:10.1016/j.biortech.2009.01.025. 


\section{VISIGERA DE 07 A 09 MA10 2019

Tabela 1. Resultados dos ensaios das amostras no Laboratório de Biogás.

\begin{tabular}{ccccccccc}
\hline & ST & SV & $\begin{array}{c}\text { Produção de } \\
\text { biogás }\end{array}$ & $\begin{array}{c}\text { Produção de } \\
\text { metano }\end{array}$ & $\begin{array}{c}\text { Metano x } \\
\text { Biogás }\end{array}$ & $\begin{array}{c}\text { Quantidade } \\
\text { de substrato } \\
\text { necessário p/ 1 } \\
\text { kg de SV }\end{array}$ & $\begin{array}{c}\text { Vol. de } \\
\text { biogás por } \\
\text { 1 kg de } \\
\text { substrato }\end{array}$ & $\begin{array}{c}\text { Variação } \\
\text { em } \\
\text { relação } \\
\text { ao ES }\end{array}$ \\
\cline { 2 - 9 } & $\mathrm{g} \mathrm{kg}^{-1}$ & $\mathrm{~g} \mathrm{~kg}^{-1}$ & $\begin{array}{c}\text { LN biogás kg } \\
\mathrm{SV}^{-1}\end{array}$ & $\begin{array}{c}\mathrm{LN} \mathrm{CH}_{4} \mathrm{~kg} \\
\mathrm{SV}^{-1}\end{array}$ & $\%$ & $\mathrm{~kg}$ & $\mathrm{~L}$ & $\%$ \\
\hline ES & 20,5 & 688,5 & 591 & 311,5 & 53 & 70,9 & 8,3 & - \\
\hline $\begin{array}{c}\text { ES 97\% }+ \\
\text { SL 3\% }\end{array}$ & 24,4 & 718,5 & 587 & 394 & 67 & 57,0 & 10,3 & 23 \\
$\begin{array}{c}\text { ES 90\% }+ \\
\text { SL 10\% }\end{array}$ & 33,3 & 760,7 & 663 & 394 & 59 & 39,5 & 16,8 & 101 \\
$\begin{array}{c}\text { ES 70\% + } \\
\text { SL 30\% }\end{array}$ & 58,5 & 810,8 & 674 & 340 & 50 & 21,1 & 32,0 & 283 \\
\hline
\end{tabular}

*ES=Efluente suíno; $\mathrm{SL}=$ Soro de leite.

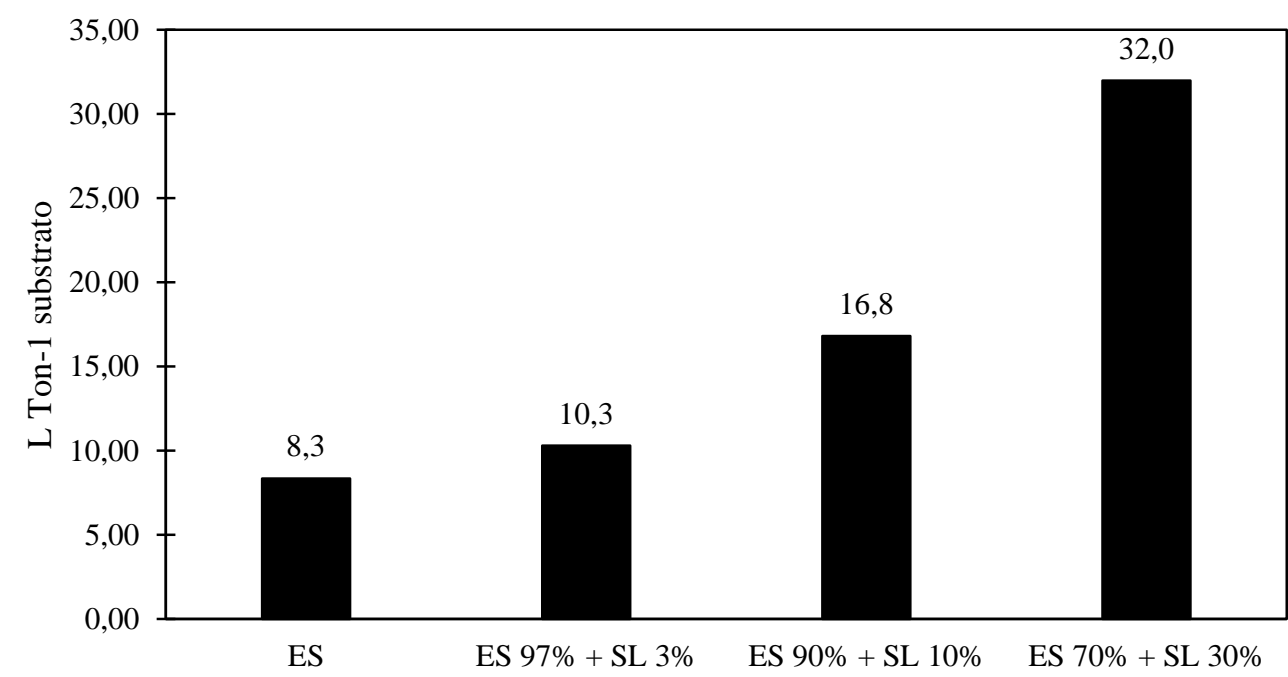

Figura 1. Volume (litros) de biogás produzido por tonelada de substrato (amostra).

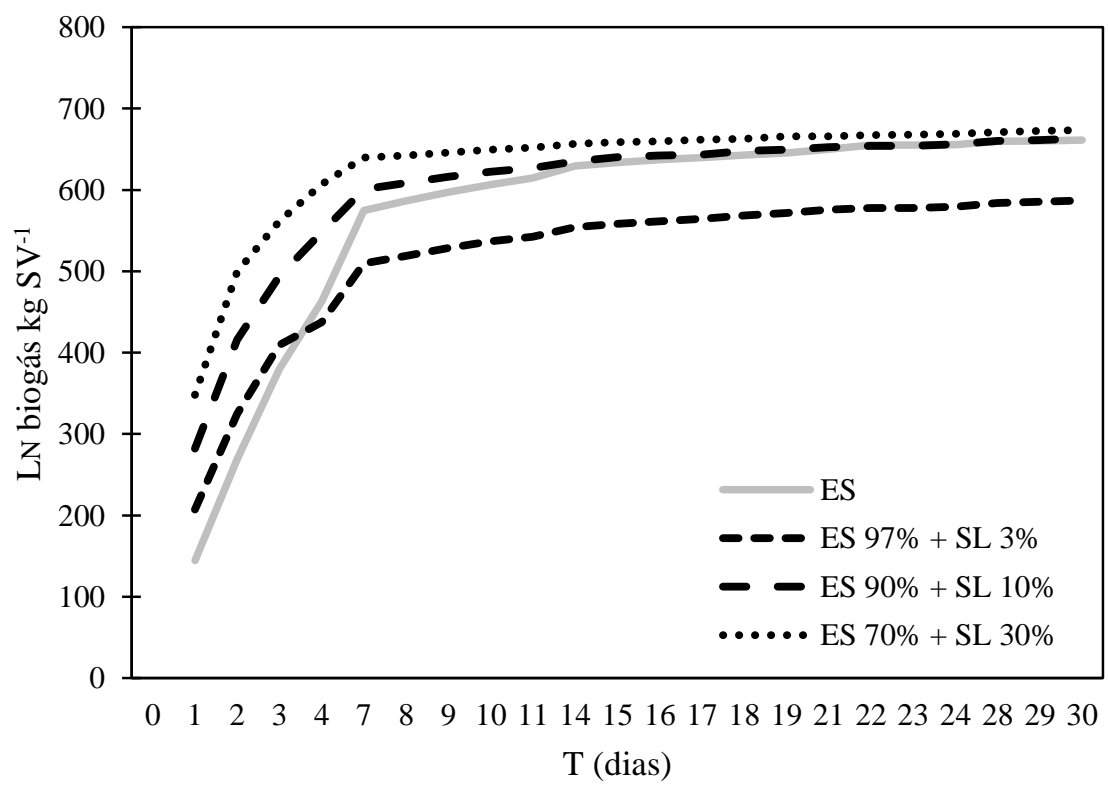

Figura 2. Curva da produção de biogás durante o experimento. 


\title{
PRODUÇÃO DE BIOGÁS E ENERGIA ELÉTRICA COM BIODIGESTOR DE LAGOA COBERTA E CSTR A PARTIR DE DEJETO SUÍNO
}

\author{
Amaral, A.C.*1; Candido, D. ${ }^{1}$; Steinmetz, R.L.R. ${ }^{2}$; Tapparo, D.C. ${ }^{3}$ Kunz, A. ${ }^{2,3}$ \\ ${ }^{I}$ Fundação de Apoio a Pesquisa e ao desenvolvimento - FAPED, Sete Lagoas, MG - Brasil \\ ${ }^{2}$ Embrapa Suínos e Aves, Concórdia, SC - Brasil \\ ${ }^{3}$ Universidade do Oeste do Paraná - Unioeste, Cascavel, PR - Brasil \\ andrec.doamaral@gmail.com
}

\begin{abstract}
RESUMO: A produção de suínos ocorre em escala industrial, existindo grandes unidades produtoras, acarretando na geração de elevadas quantidades de efluentes, bem como elevada necessidade energética (calor, eletricidade etc.,). Esse trabalho teve como objetivo avaliar o desempenho de um sistema de digestão anaeróbia, visando à produção de biogás e energia elétrica em uma granja comercial de suínos, produtora de leitões, com 5000 matrizes. O efluente produzido na granja passa por uma peneira rotativa e em um decantador. A fração líquida foi dividida em dois biodigestor BLCs $\left(2.500 \mathrm{~m}^{3}\right)$. O biodigetor CSTR $\left(700 \mathrm{~m}^{3}\right)$ recebeu as frações sólidas: sólido da peneira, lodo do decantador e lodo dos BLCs. Os biodigestores BLCs produziram $901 \mathrm{~m}^{3}$ biogás. $\mathrm{d}^{-1}$, com produtividade de $0,18 \mathrm{~m}_{\text {biogás. }} \mathrm{m}_{\text {reator }}^{-\mathrm{d}^{-1}}$. Já biodigestor CSTR produziu $293 \mathrm{~m}^{3}$ biogás. $\mathrm{d}^{-1}$, com produtividade de $0,42 \mathrm{~m}_{\text {biogás. }}^{3} \mathrm{~m}^{-3}$ reator. $\mathrm{d}^{-1}$. Durante os meses de Outubro e Novembro, foram produzidos $38.028 \mathrm{~kW}$ e $42.398 \mathrm{~kW}$ de energia elétrica, respectivamente. Considerando os valores médios, observa-se que foi gerado $1,12 \mathrm{~kW} \cdot \mathrm{m}^{-3}$ biogás. Há necessidade de adequações operacionais no sistema, como aumento da temperatura de trabalho e incremento na COV no biodigestor CSTR e melhoria na conversão do biogás em energia elétrica.
\end{abstract}

Palavras-chave: biodigestão, digestão anaeróbia, metano.

\section{BIOGAS AND ENERGY PRODUCTION BY SWINE MANURE}

\begin{abstract}
Swine production is an industrial scale activity, with large production units, leading to the generation of high quantity of manure, as well as high energy need (heat, electricity, etc.). This work aimed to evaluate an anaerobic digestion system performance, at the biogas and electricity production in a commercial swine farm, which produces piglets, with 5000 sows. The manure produced passes through a rotary sieve and a decanter tank. The liquid fraction was divided into two biodigester covered lagoon (BCLs) $\left(2,500 \mathrm{~m}^{3}\right)$. The CSTR biodigester $\left(700 \mathrm{~m}^{3}\right)$ received the solid fractions: solid retained in sieve ( $\left.2 \mathrm{~mm} \mathrm{screening}\right)$, settled sludge and BLCs biodigester sludge. The biodigestors BCLs produced $901 \mathrm{~m}^{3}$ biogas. $\mathrm{d}^{-1}$, with productivity of 0.18 $\mathrm{m}^{3}{ }_{\text {biogas }} \cdot \mathrm{m}^{-3}$ reactor $\cdot \mathrm{d}^{-1}$. Already, biodigester CSTR produced $293 \mathrm{~m}_{\text {biogas }}^{3} \mathrm{~d}^{-1}$, with productivity of $0.42 \mathrm{~m}^{3}$ biogas $\cdot \mathrm{m}^{-}$ ${ }_{\text {reactor. }}^{3} \mathrm{~d}^{-1}$. During the months of October and November, $38,028 \mathrm{~kW}$ and $42,398 \mathrm{~kW}$ of electricity were produced, respectively. Considering the average values, it is observed that $1.12 \mathrm{~kW} . \mathrm{m}^{-3}$ biogas was generated. There is a need for operational adjustments in the system, such as increased working temperature and increased organic loading rate (OLR) in the CSTR biodigester and improved conversion of biogas to electric energy.
\end{abstract}

Keywords: biodigestion, anaerobic digestion, methane.

\section{INTRODUÇÃO}

A suinocultura destaca-se no cenário mundial com uma importante fonte de proteína animal. Têm como característica sistemas de produção que concentram um grande número de animais em pequenas áreas territoriais (SPAC's), sendo necessário planejamento e gestão dos efluentes produzidos. A digestão anaeróbia é uma alternativa interessante de tratamento, considerando a diminuição da carga orgânica e a produção de biogás.

Devido ao baixo custo e fácil operação intensificou-se o uso de biodigestores modelo lagoa coberta (BLC), no entanto estes biodigestores possuem limitações, como: elevada necessidade de área, baixa carga de alimentação (aproximadamente $\left.0,5 \mathrm{kgSV} \cdot \mathrm{m}^{-3} \cdot \mathrm{d}^{-1}\right)$ e baixa concentração de sólidos totais $\left(<3 \% \mathrm{~m} \cdot \mathrm{v}^{-1}\right.$ ) (Cantrell et al. 2008), além de serem limitados quanto ao manejo de lodo, favorecendo o assoreamento. Neste caso a separação de sólidos deve ser aplicada para prolongar a vida útil do BLC. Por outro lado, biodigestores com o tanque agitado e sistemas de aquecimento (CSTR) permitem melhor manejo de sólidos e aceleram a degradação, pois comportam aquecimento da biomassa e favorecem a cinética de degradação, permitindo 
aumento da carga de alimentação e aumento da produção de biogás. Entretanto, são mais onerosos quanto à instalação e operação. Amaral et al. (2016) demostraram que a separação de sólidos por peneiramento e decantação são possibilidades viável, pois estas frações apresentam diferentes rendimentos de biogás em relação ao dejeto bruto. Assim, sistemas híbridos utilizando CSTR e BLC podem resultar em sistemas mais robustos com relações custo/benefício adequadas à grande escala.

No Brasil, é possível gerar energia elétrica a partir de fontes renováveis (biogás) e fornecer rede de distribuição de sua localidade (ANEEL n 482/2012), o que pode viabilizar diversos projetos com biogás.

O objetivo do trabalho foi avaliar o desempenho de um sistema de digestão anaeróbia, visando à produção de biogás e energia elétrica em uma granja comercial de suínos.

\section{MATERIAL E MÉTODOS}

O estudo foi realizado durante os meses de outubro e novembro de 2018, em uma granja comercial de suínos, produtora de leitões (UPL), com 5.000 matrizes adultas. O volume de efluentes que passou pelo sistema de tratamento foi quantificado utilizando medidor Yokogawa AXFA14G/C. O volume de biogás produzido foi monitorado com o medidor de vazão termal FT2, Contech.

O efluente produzido na granja passa por uma peneira rotativa e em um decantador. A fração líquida é dividida em dois biodigestores BLC $\left(2.500 \mathrm{~m}^{3}\right)$. O biodigetor CSTR $\left(700 \mathrm{~m}^{3}\right)$ recebe as frações sólidas: sólido da peneira, lodo do decantador e lodo dos BLCs, conforme ilustrado na Figura 1.

O biodigestor CSTR possui sistema de agitação e aquecimento. Já o biodigestor BLC opera a temperatura ambiente e sem agitação.

O sistema de geração de energia elétrica tem a disposição dois motores de 120 kva e um motor de 330 kva, porém são operados de forma intermitente em função da disponibilidade de biogás e necessidade de granja. Para cálculo de retorno financeiro, o valor do $\mathrm{kW} / \mathrm{h}$ foi considerado $\mathrm{R} \$ 0,50$.

\section{Biodigestores BLCs}

\section{RESULTADOS E DISCUSSÃO}

Os biodigestores BLCs receberam em média 171,47 $\mathrm{m}^{3}$ de dejeto por dia, resultando em um tempo de retenção hidráulico de 29,16 dias. A carga orgânica volumétrica (COV) aplicada aos biodigestores BLC foi de $0,434 \mathrm{kgSV} \cdot \mathrm{m}^{-3}$ biodigestor. $\mathrm{d}^{-1}$, atingindo produção de $901 \mathrm{~m}^{3}$ biogás. $\mathrm{d}^{-1}$. A produtividade de biogás foi de 0,18 $\mathrm{m}^{3}$ biogás. $\mathrm{m}^{-3}$ reator. $\mathrm{d}^{-1}$. Por ser um modelo de biodigestor mais simples, a COV aplicada geralmente é entre 0,05 a $0,5 \mathrm{kgSV} . \mathrm{m}^{-3}$ biodigestor. $\mathrm{d}^{-1}$, atingindo produção de biogás de 0,03 e $0,15 \mathrm{~m}^{3}$ biogás. $\mathrm{m}^{-3}$ reator.dia ${ }^{-1}$ (Cantrel, 2008). Os valores obtidos durante esse estudo foram satisfatórios, com produção de biogás superior ao indicado na literatura. Esse fato deve estar relacionado ao recebimento da fração sobrenadante, a qual é mais biodegradável do que o dejeto suíno bruto (Amaral et al., 2016).

\section{Biodigestor CSTR}

O biodigestor CSTR recebeu em média 19,25 $\mathrm{m}^{3}$ de efluente por dia, resultando em um tempo de retenção hidráulica de 36,36 dias. A carga orgânica volumétrica (COV) aplicada aos biodigestores CSTR foi de $1,68 \mathrm{kgSV} . \mathrm{m}^{-3}$ biodigestor. $\mathrm{d}^{-1}$, atingindo produção de $293 \mathrm{~m}_{\text {biogás. }}$ dia ${ }^{-1}$. A produtividade de biogás foi de 0,42 $\mathrm{m}^{3}$ biogás. $\mathrm{m}^{-3}$ reator. dia ${ }^{-1}$. A temperatura média de operação foi de $32,67^{\circ} \mathrm{C}$. Por ser um biodigestor com agitação e aquecimento, a COV aplicada pode ser bastante superior ao biodigestor BLC. Geralmente os biodigestores CSTR operam com COV entre 2,11 e $4,25 \mathrm{kgSV} . \mathrm{m}^{-3}$ biodigestor. $\mathrm{d}^{-1}$, atingindo produtividade de biogás de 1,00 e $1,45 \mathrm{~m}_{\text {biogás. }} \mathrm{m}^{-3}$ reator. $\mathrm{d}^{-1}$ e temperatura próxima $37^{\circ} \mathrm{C}$ (Cantrel, 2008). Esses fatores podem ser determinantes em relação à menor produtividade de biogás quando comparado com Cantrel, 2008. É possível aumentar a COV utilizando outros resíduos da produção de suínos, como carcaças, porém há necessidade de tratamento térmico para garantir a segurança sanitária (Tapparo et al., 2018).

A granja produziu, em média $190,72 \mathrm{~m}_{\text {dejeto. }} \mathrm{d}^{-1}$, resultando em $38,14 \mathrm{~L} \cdot \mathrm{matriz}^{-1} \cdot \mathrm{d}^{-1}$, valor abaixo do relatado médio encontrado na literatura, 58,23 L.matriz ${ }^{-1} \cdot \mathrm{d}^{-1}$ (Mito et al., 2018). O sistema de produção de biogás produziu, em média, $1.194 \mathrm{~m}^{3} \cdot \mathrm{d}^{-1}$, ou seja, $0,239 \mathrm{~m}^{3}$ de biogás por matriz instalada.

\section{Produção de energia elétrica}

Durante os meses de outubro e novembro, foram produzidos $38.028 \mathrm{~kW}$ e $42.398 \mathrm{~kW}$ de energia elétrica, respectivamente. Isso indica um retorno econômico de R \$ 19.014,00 e R \$ 21.199,00 por mês. Considerando 
os valores médios de produção de energia e biogás, temos que foi gerado $1,12 \mathrm{~kW} \cdot \mathrm{m}^{-3}$ biogás. Valor abaixo ao indicado por fornecedores de motores, 1,8 a 2,2 kW.m ${ }^{-3}$ biogás (Brondani et al., 2009).

\section{CONCLUSÃO}

O manejo de água e dejetos na granja mostrou-se bastante satisfatório, atingindo volumes de efluentes $52,67 \%$ inferiores a valores médios reportados na literatura. Os biodigestores BLCs recebem apenas a fração líquida, que é extremamente biodegradável, com isso a produção de biogás foi superior à literatura.

O biodigestor CSTR apresenta elevada produtividade comparada aos biodigestores BLCs, porém inferior a literatura. Há necessidade de adequações operacionais, como aumento da temperatura de trabalho e incremento na COV.

A conversão de biogás em energia elétrica foi inferior ao indicado por fabricantes de motores. Essa fato indica que pode haver perdas de biogás no sistema após medição, ou necessidade de melhor regulagem dos motores.

\section{AGRADECIMENTOS}

Os autores agradecem ao projeto Sistrates BNS, CNPq e Capes.

\section{REFERÊNCIAS}

Agência Nacional de Energia Elétrica - Aneel. Resolução Normativa n ${ }^{\circ}$ 482, de 17 de abril de 2012. Amaral A. C.; Kunz, A.; Steinmetz., R. L. R.; Scussiato, L. A.; Tapparo, D. C.; Gaspareto, T. C. Influence of solid-liquid separation strategy on biogas yield from a stratified swine production system. Journal of Environmental Management, v. 168, p. 229-235, 2016.

Brondani J. C. Biodigestores e biogás: Balanço energético, possibilidade de utilização e mitigação do efeito estufa. Dissertação de Mestrado, UFSM, 2010.

Cantrel, K. B., Ducey, T., Ro, K. S., Hunt, P. G. Livestock waste-to-bioenergy generation opportunities. Bioresource Technology, v. 99, p. 7941-7953, 2008.

Mito, J. Y. L., Kerkhoff, S., Silva, F. L. G., Vendrame, M. G., Steinmetz, R. L. R., Kunz, A. Metodologia para estimar o potencial de biogás e biometano a partir de plantéis suínos e bovinos no Brasil. Concórdia : Embrapa Suínos e Aves, 2018.

Tapparo, D. C.; Viancelli, A.; Amaral, A. C. do; Fongraro, G.; Steinmetz, R. L. R.; Magri, M. E.; Barardi, C. R. M.; Kunz, A. Sanitary effectiveness and biogas yield by anaerobic co-digestion of swine carcasses and manure. Environmental Technology, v. 1, p. 1-28, 2018.

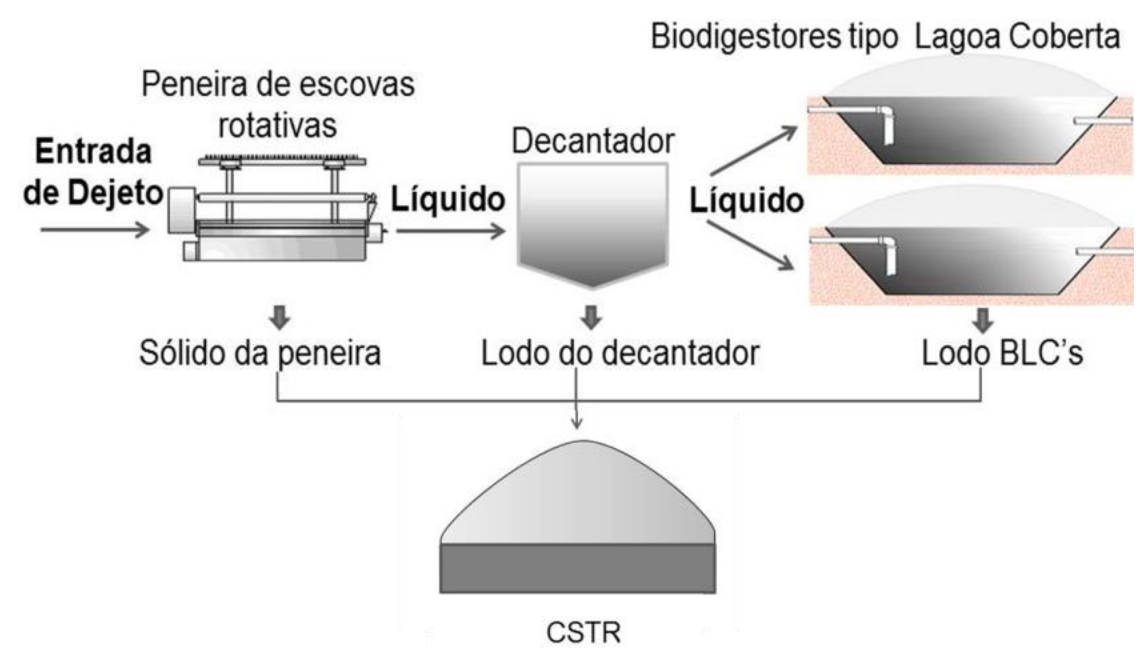

Figura 1. Manejo do efluente e separação de sólidos na granja estudada. 


\title{
PRODUÇÃO DE BIOGÁS EM SISTEMAS DE PRODUÇÃO DE LEITE DE BOVINOS, COM E SEM SEPARAÇÃO DE SÓLIDOS NOS SUBSTRATOS EM BIODIGESTORES CONTINUOS
}

\author{
Isisanjos, I.S. ${ }^{1 * ;}$ Toneli, J.C.L. ${ }^{2}$; Sagula, A.L.; Lucas, J. \\ ${ }^{l}$ Doutoranda em Energia, Universidade Federal do ABC, UFABC, Santo André-SP ${ }^{2}$ Prof ${ }^{a}$ Adjunta, Centro de Engenharia, \\ Modelagem e Ciências Sociais Aplicadas, Universidade Federal do ABC, UFABC, Santo André-SP, juliana. ${ }^{3}$ Doutorando em \\ Energia na Agricultura, UNESP, Botucatu-SP, ${ }^{4}$ Prof. Titular, Departamento de Engenharia Rural, Faculdade de Ciências Agrárias \\ e Veterinárias, UNESP, Jaboticabal-SP
}

\begin{abstract}
RESUMO: Nesse trabalho, objetivou-se avaliar a produção de biogás durante o processo de biodigestão anaeróbia de dejetos de bovinos leiteiros, com e sem a separação de sólidos. Foi realizada a biodigestão em 8 biodigestores do tipo contínuo, abastecidos com dejetos sem separação da fração sólida e com separação da fração sólida em uma peneira de malha de $1,0 \mathrm{~mm}$. O período convencionado para a avaliação do processo de biodigestão foi de 5 semanas, após a estabilização do biodigestor que durou aproximados 30 dias. Os potenciais de produção de metano $\left(\mathrm{CH}_{4}\right)$ foram superiores para os biodigestores com separação de sólidos com relação ao teor de sólidos voláteis adicionados. Na produção de biogás os biodigestores sem a separação da fração sólida obtiveram valores superiores comparados com biodigestores com a separação da fração sólida, porém o teor médio de metano (67\%) foi mais elevado nos biodigestores com a separação de sólidos. Observaram-se melhores potenciais de produção de metano quando ocorre uma redução na concentração de sólidos nos dejetos e, nesse caso, os tempos de retenção hidráulica podem ser mais reduzidos, o que reduz o volume do biodigestor e custos de implantação e de manutenção. Caso haja limitação de área e não seja desejável a mecanização ou manutenção dos biodigestores, a separação de sólidos é mais vantajosa, mas o resíduo separado deve ter uma destinação adequada para tratamento. Se o interesse for energético e não houver limitação de área, a não separação de sólidos propicia maiores ganhos, porém, o biodigestor necessitará de maior manutenção.
\end{abstract}

Palavras-chave: Biogás, biodigestor, dejetos, bovinos leiteiros, separação de sólidos.

\section{INTRODUÇÃO}

O Brasil se apresenta como um grande produtor de bovinos sendo que, em 2012, possuía um rebanho com mais de 218 milhões de bovinos e, segundo o IBGE (2016), o total de vacas ordenhadas contabilizava cerca de $10,9 \%$ do efetivo bovino, sendo de aproximadamente 24 milhões o número de cabeças de vacas ordenhadas. $\mathrm{O}$ aumento da demanda por produtos de origem animal provoca a exploração intensiva de animais, que são agrupados em grande número, produzindo grande volume de dejetos em pequenas áreas, gerando problemas tanto para o seu tratamento e disposição, quanto de poluição ambiental. A possibilidade de recuperação do biogás no tratamento dos dejetos, tem destacado a bovinocultura como uma das principais atividades por produzir grande quantidade de dejetos.

Na prática, a recuperação de biogás é possível com a utilização de biodigestores e, segundo BARBOSA \& LANGER (2011), o biodigestor representa uma excelente alternativa para o tratamento dos resíduos gerados, já que são de responsabilidade do produtor, o qual deve fornecer um destino adequado a eles. Os biodigestores do tipo batelada são carregados de uma só vez, mantendo-se em fermentação por um período conveniente, sendo o material descarregado posteriormente após o término do período efetivo de produção de biogás (BONTURI \& VAN DIJK, 2012).

Os dejetos, ao serem recolhidos para entrar no biodigestor, podem conter frações que podem ser consideradas não biodegradáveis ou lentamente biodegradáveis, advindas de partes da alimentação não degradadas pelo animal, como é o caso das fibras, ou de restos provenientes do processo de lavagem como a areia, por exemplo. Essas frações podem afetar o processo de biodigestão anaeróbia e a separação dessa fração pode contribuir para que processo se torne mais eficiente (maior produção de biogás/ kg de sólido), rápido (menor tempo de retenção hidráulica) e mais econômico por necessitar de reatores com menor tamanho para um mesmo número de animais

Nesse sentido, objetivou-se avaliar a produção de biogás em biodigestores continuos, com e sem a separação de sólidos nos substratos com dejetos de bovinos leiteiros, avaliando-se os potenciais de produção de metano e as reduções dos teores de sólidos voláteis para obtenção de parâmetros de produção de biogás.

\section{MATERIAIS E MÉTODOS}

Os experimentos foram realizados na Faculdade de Ciências Agrárias e Veterinárias (FCAV) da Universidade Estadual Paulista (UNESP) - Campus de Jaboticabal - SP. Foram utilizados os resíduos de 
bovinos da raça Holandesa em lactação, com peso corporal médio de $640 \mathrm{~kg}$ localizados no setor de Bovinocultura de Leite. A instalação era do tipo Tie stall (Estabulação em que os animais permanecem lado a lado, em baias individuais) em piso de concreto.

Foram utilizados 8 biodigestores que possuíam uma capacidade útil de fermentação de 60 litros de substrato cada um, cujo o esquema do modelo utilizado por ser visto na Figura 1.

Para realizar o preparo das cargas, foram utilizados dejetos coletados manualmente por meio de raspagem do piso concretado, com auxílio de enxada. Foram estudados os dejetos provenientes de vacas leiteiras alimentadas com uma dieta composta de $60 \%$ de concentrado e $40 \%$ de volumoso. Em cada abastecimento, a mistura (dejeto + água) foi preparada para ter um teor de sólidos totais próximo a $3 \%$.

Inicialmente, os biodigestores contínuos foram abastecidos com $60 \mathrm{~kg}$ dos substratos que foram homogeneizados manualmente com o auxílio de pás e introduzidos nos biodigestores contínuos.

As amostras foram dispostas nos biodigestores contínuos e mantidas por um tempo de retenção hidráulica (TRH) de 30 dias. As cargas foram realizadas diariamente por 23 semanas, entretanto, foi convencionado um período de 5 semanas para analisar o processo.

Para o ensaio de biodigestão anaeróbia foram utilizados biodigestores do tipo contínuo com os seguintes tratamentos para o dejeto, com 4 repetições:

$\checkmark$ sem separação da fração sólida (SSFS); e

$\checkmark$ com separação da fração sólida (CSFS)

No tratamento descrito como sem separação da fração sólida (SSFS) utilizou-se apenas essa fração líquida, já no tratamento com separação da fração sólida (CSFS) foi efetuado o peneiramento dessa mistura em peneira com malha de $1,0 \mathrm{~mm}$ e assim, o líquido que atravessou a peneira foi utilizado para abastecer os biodigestores. Diariamente, os biodigestores foram abastecidos com 250 gramas do dejeto bovino e diluídos em 1,65 litros de água. Essa fração líquida foi a base para todos os tratamentos.

As análises de caracterização dos dejetos foram realizadas no Laboratório de Biomassa e Biodigestão Anaeróbia, pertencente ao Departamento de Engenharia Rural da Unesp/Jaboticabal (SP). Os teores de ST (sólidos totais) e de SV (sólidos voláteis) foram determinados segundo metodologia descrita por APHA (2005).

As produções de biogás foram calculadas com base nos deslocamentos dos gasômetros, medidos com régua. $\mathrm{O}$ número obtido na leitura foi multiplicado pela área da seção transversal interna dos gasômetros, igual a 0,04909 $\mathrm{m}^{3}$. Após cada leitura, os gasômetros foram zerados, utilizando-se o registro de descarga do biogás. A correção do volume de biogás, para as condições de $1 \mathrm{~atm}$ e $20{ }^{\circ} \mathrm{C}$, foi efetuada com base no trabalho de CAETANO (1985).

Os potenciais de produção de biogás e de metano foram calculados utilizando-se dos dados de produção total de biogás de cada biodigestor e as quantidades de dejetos, de ST e SV adicionados no biodigestor e dos $\mathrm{SV}$ reduzidos durante o processo. Os valores foram expressos em $\mathrm{m}^{3}$ de biogás e de metano por $\mathrm{kg}$ de dejeto, ST adicionados, SV adicionados e de SV reduzidos.

As análises de qualidade do biogás produzido foram feitas semanalmente para determinação dos teores de metano $\left(\mathrm{CH}_{4}\right)$ e dióxido de carbono $\left(\mathrm{CO}_{2}\right)$, analisadas em cromatógrafo de fase gasosa FINNINGAN GC2001.

Para o ensaio de biodigestão anaeróbia, utilizou-se um modelo linear geral com 4 repetições. As pressuposições para análise de variância foram verificadas e as médias comparadas pelo teste de Tukey ao nível de 5\% de probabilidade no programa SAS (Statistical Analysis System).

\section{RESULTADOS E DISCUSSÕES}

Os teores de sólidos voláteis (SV), estes representavam 77,8\% e 74,3\% dos teores de sólidos totais (ST), ou seja, a quantidade de SV presente nos ST para os biodigestores sem separação de sólidos (SSFS) e com separação de sólidos (CSFS), respectivamente. Esses valores foram próximos aos encontrados por Amaral et al. (2004) que trabalharam com dejetos de bovinos leiteiros, em biodigestores contínuos e diferentes tempos de retenção hidráulica (TRH), para o TRH de 30 dias (81\%) e TRH de 20 dias (79\%).

Durante o processo de biodigestão, ocorreram reduções bem maiores nos teores de ST (74\%) e SV (73\%) no tratamento em que se separaram os sólidos (CSFS) ao passo que, no tratamento sem a separação de sólidos (SSFS) obtiveram-se valores de $40 \%$ e $38 \%$, respectivamente para ST e SV. Estas diferenças indicam que a separação de sólidos pode ser particularmente importante para propriedades rurais que dispõem de pequenas áreas para a aplicação dos dejetos, pois a separação de sólidos permite a retirada de um composto orgânico com mais alto teor de sólidos totais e a fração líquida obtida durante a separação sofre grandes reduções nos teores de sólidos totais durante o processo de biodigestão anaeróbia. A redução de SV nos biodigestores com separação da fração sólida (CSFS) foram próximas aos valores encontrados por Miranda et al. (2006), que 
trabalharam com dejetos de bovinos em biodigestores de bancada em batelada, e tiveram redução de sólidos voláteis de $76 \%$.

O tempo para partida dos biodigestores nos dois tratamentos foi semelhante e a partida ocorreu com tempo aproximado de 25 dias, quando os dois tratamentos mostraram estabilidade na produção diária de metano, com os biodigestores abastecidos com dejetos sem separação de sólidos (SSFS) sempre apresentando maiores produções. Para melhor análise dos resultados, optou-se por apresentar e discutir separadamente os resultados obtidos quando os biodigestores apresentavam estabilidade de produção. Desta forma, foram utilizados separadamente os dados obtidos em 5 semanas, ou seja, dos 30 dias após o abastecimento inicial dos biodigestores (Figura 2).

A média de produção de biogás semanal para os biodigestores sem separação de sólidos (SSFS) e com separação de sólidos (CSFS) foram respectivamente 0,07984 e 0,0557 $\mathrm{m}^{3}$. Galbiatti (2013) obteve valores próximos aos biodigestores com separação da fração sólida (CSFS), com média semanal de 0,0465 e 0,0557 $\mathrm{m}^{3}$ de biogás para os dejetos sem cana-de-açúcar e com cana-de-açúcar, respectivamente.

Quando se avalia a produção de metano, a separação da fração sólida levou a uma redução de $26 \%$ na produção de metano, porém os teores médios de metano no biogás foram de $63 \%$ para os biodigestores sem separação de sólidos (SSFS) e de 67\% para os biodigestores com separação de sólidos (CSFS). Xavier (2005), trabalhando com dejetos de bovinos leiteiros e co-digestão de caldo de cana-de-açúcar em biodigestores contínuos, obteve média de $62 \%$ de metano no biogás para os biodigestores abastecidos apenas com dejetos de bovinos leiteiros sendo próximo ao encontrado nos biodigestores sem a separação da fração sólida (SSFS) (63\%). Os teores de metano encontrados por Amaral et al. (2004), que trabalharam com dejetos de bovinos leiteiros submetidos a diferentes tempos de retenção hidráulica e tipos de biodigestores contínuos, foram inferiores e variaram de 60 a $54 \$$ de metano no biogás.

$\mathrm{Na}$ Tabela 3 são apresentados os valores dos potenciais de produção de metano, expressos em $\mathrm{m}^{3}$ por $\mathrm{kg}$ dejeto, por $\mathrm{kg}$ de sólidos totais (ST) adicionados, por kg de sólidos voláteis (SV) adicionados e reduzidos.

Com relação à produção de metano por kg de dejetos, essa diferença do potencial de produção de metano por kg de dejeto cai para $26 \%$ já que o biogás proveniente dos biodigestores com separação da fração sólida (CSFS) apresentou um maior teor de metano em sua composição. Os biodigestores com separação da fração sólida (CSFS) apresentaram maiores potenciais de produção quanto ao volume de biogás e metano produzido por kg de sólidos totais e voláteis adicionados o que indica uma melhor eficiência para tratamento dos resíduos.

Orrico Jr. et al. (2010) encontraram valores de 0,110 a 0,350 $\mathrm{m}^{3}$ de metano por $\mathrm{kg}$ de $\mathrm{ST}$ adicionados e 0,130 a $0,410 \mathrm{~m}^{3}$ de metano por $\mathrm{kg}$ de $\mathrm{SV}$ adicionados. Os potenciais encontrados foram maiores para os dejetos dos animais alimentados com teor de concentrado de $60 \%$ de volumoso $40 \%$.

Os biodigestores sem separação de sólidos (SSFS) e com separação da fração sólida (CSFS) apresentaram diferenças estatísticas significativas tanto para os potenciais de produção de metano, inclusive na produção de metano em $\mathrm{m}^{3}$ por $\mathrm{kg}$ de ST adicionados.

\section{CONCLUSÕES}

A separação da fração sólida aumentou a redução de sólidos totais e voláteis durante o processo de biodigestão anaeróbia. Este aspecto e a separação de sólidos em si tornam-se particularmente interessantes em propriedades rurais que têm limitação de áreas para a disposição dos resíduos, pois, muito embora haja redução na produção de biogás, boa parte dos dejetos pode ser transportada na forma sólida para outros locais. A separação da fração sólida reduziu a produção de metano em $26 \%$, consequentemente apresentou melhoria na qualidade do biogás. E os biodigestores com separação de sólidos apresentaram melhor eficiência na produção de biogás e metano por kg de sólidos totais e voláteis adicionados, o que indica uma melhor eficiência para tratamento dos resíduos.

\section{REFERÊNCIA BIBLIOGRÁFICA}

AMERICAN PUBLIC HEALTH ASSOCIATION (APHA). Standart methods for the examination of water and wastewater.2540-SOLIDS.25th ed. Washington, DC, 2005.

AMARAL, C. C., AMARAL, L. A., LUCAS JUNIOR, J. Biodigestão anaeróbia de dejetos de bovinos leiteiros submetidos a diferentes tempos de retenção hidráulica. Ciência Rural, v.34, n.6, p.1897-1902, nov/dez., 2004. BARBOSA, G.; LANGER, M. Uso de biodigestores em propriedades rurais: uma alternativa à sustentabilidade ambiental. Unoesc \& Ciência, Joaçaba, v.2, n. 1, p. 87-96, jan./jun., 2011.

BONTURI, G. de L.; VAN DIJK, M. Instalação de biodigestores em pequenas propriedades rurais: análise de vantagens socioambientais. Revista Ciências do Ambiente On-Line, v.8, n.2, p.88-95, 2012. 
CAETANO, L. Proposição de um sistema modificado para quantificação de biogás. Botucatu: Universidade Estadual Paulista, 1985. 75f. Dissertação (Mestrado em Energia na Agricultura) Faculdade de Ciências Agronômicas, Universidade Estadual Paulista, Botucatu, 1985.

GALBIATTI, J.A.; CARAMELO, A.D.; SILVA, F.G.; GERARDI, E.A.B.; CHICONATO, D.A. Estudo qualiquantitativo do biogás produzido por substratos em biodigestores tipo batelada. Revista Brasileira de Engenharia Agrícola e Ambiental, Campina Grande, v.14, n.4, 2010.

MIRANDA, A. P.; AMARAL, L. A.; LUCAS JUNIOR, J. Influência da temperatura na biodigestão anaeróbia de dejetos de bovinos e suínos. In: $X$ Encontro Latino Americano de Iniciação Científica e VI Encontro Latino Americano de Pós-Graduação - Universidade do Vale do Paraíba. p. 2829 - 2831. 2006.

ORRICO JÚNIOR M, O. P.; ORRICO A. C. A.; LUCAS JÚNIOR, J. Influência da relação volumoso: concentrado e do tempo de retenção hidráulica sob a biodigestão anaeróbia de dejetos de bovinos. Revista Engenharia Agrícola, Jaboticabal, v.30, p.386-394. 2010.

XAVIER, C. A. N. Biodigestão anaeróbia de dejetos em sistema de produção de leite: obtenção de parâmetros e dimensionamento. 2005. 90f. . Dissertação (Mestrado em Zootecnia- Área de Concentração em Produção Animal) - Faculdade de Ciências Agrárias e Veterinárias, Universidade Estadual Paulista, Jaboticabal, 2005.

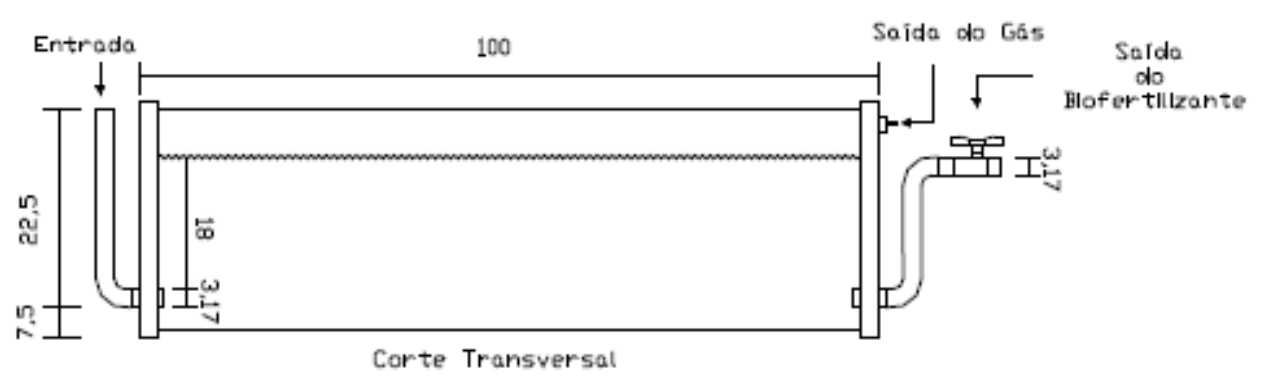

Figura 1. Corte transversal dos biodigestores tubulares utilizados no experimento (medidas em $\mathrm{cm}$ e desenho sem escala).

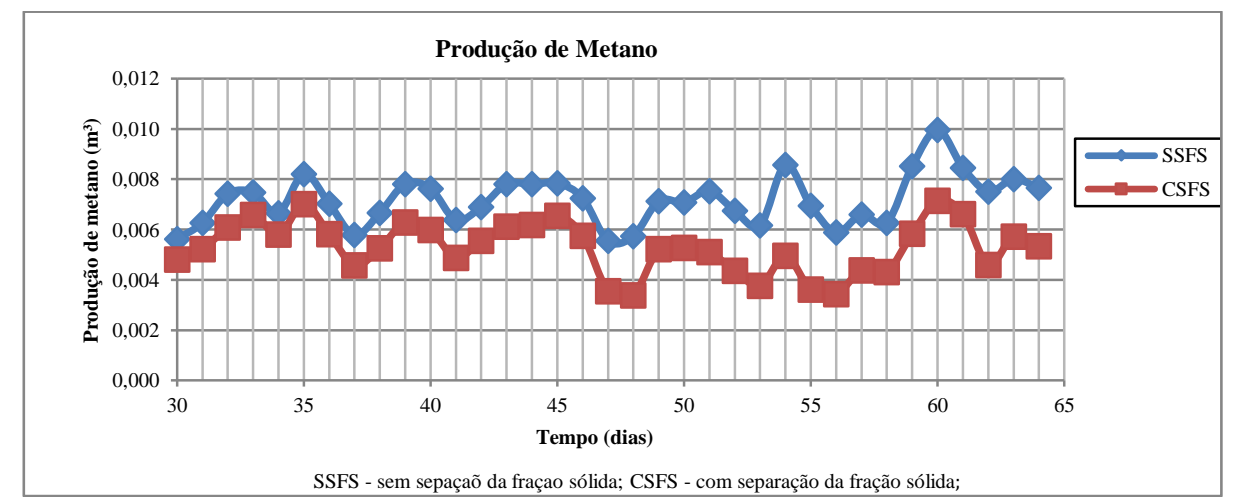

Figura 2. Produção de metano $\left(\mathrm{m}^{3}\right)$, no período de 5 semanas de experimento selecionado, em biodigestores contínuos, TRH de 30 dias e operados com dejetos de bovinos leiteiros obtidos com os dejetos sem separação de sólidos (SSFS) e com separação de sólidos (CSFS)

Tabela 1. Potenciais de produção de metano gás, expressos em $\mathrm{m}^{3}$ de metano por kg de dejeto, por kg de ST e SV adicionados e por kg de SV reduzidos.

\begin{tabular}{cccc}
\hline & \multicolumn{3}{c}{ PRODUÇÃO DE METANO } \\
\cline { 2 - 4 } & $\mathbf{m}^{\mathbf{3}} \mathbf{k g}^{\mathbf{- 1}}$ Dejeto & $\mathbf{~ m}^{\mathbf{3}} \mathbf{k g}^{\mathbf{- 1}} \mathbf{S T}$ adicionado & $\mathbf{~ m}^{\mathbf{3}} \mathbf{k g}^{\mathbf{- 1}} \mathbf{S V}$ adicionado \\
\hline SSFS & $0,0287 \mathrm{a}$ & $0,1631 \mathrm{~b}$ & $0,2101 \mathrm{~b}$ \\
CSFS $^{2}$ & $0,0212 \mathrm{~b}$ & $0,1785 \mathrm{a}$ & $0,2407 \mathrm{a}$ \\
\hline Valores de P & $<0,0001$ & $<0,0005$ & $<0,0001$ \\
Valores de F & 171,70 & 13,79 & 30,71 \\
CV $(\%)$ & 3,26 & 3,43 & 3,46 \\
\hline
\end{tabular}

$\mathrm{P}$ - probabilidade; F- significância; $\mathrm{CV}$ - coeficiente de variação;

Médias na colunas com letras distintas diferem pelo teste Tukey $(\mathrm{P}<0,05)$

${ }^{1}$ sem separação da fração sólida; ${ }^{2}$ com separação da fração sólida 


\title{
PRODUÇÃO DE ETANOL 2G POR MEYEROZYMA CARIBBICA EM HIDROLISADO DE CAULE E PALHA DE MILHO
}

\author{
Tadioto, V. ${ }^{\text {; }}$ Barrilli, E.T. ${ }^{1}$; Bohn, L.R. ${ }^{2}$; Dresch, A.P. ${ }^{2}$; Baptista, C.W. ${ }^{*}$; Alves, S.L. Jr. ${ }^{1}$ \\ ${ }^{1}$ Laboratório de Bioquímica e Genética, Campus Chapecó, Universidade Federal da Fronteira Sul, Chapecó/SC, Brasil \\ ${ }^{2}$ Laboratório de Resíduos Sólidos, Campus Chapecó, Universidade Federal da Fronteira Sul, Chapecó/SC, Brasil \\ *cristina.winkelmann@gmail.com
}

\begin{abstract}
RESUMO: A produção de etanol $2 \mathrm{G}$ tem merecido destaque recentemente por proporcionar maior segurança hídrica e alimentar em comparação com a primeira geração do combustível. Isso se deve à possibilidade de utilizar resíduos agrícolas, dispensando áreas para plantio de culturas energéticas com essa finalidade e evitando a concorrência com a produção de alimentos. Nesse contexto, surge como alternativa a utilização de caule e palha de milho como matéria-prima. A partir do pré-tratamento desses resíduos e da hidrólise dos seus polissacarídeos, é possível obter açúcares para fermentação alcoólica. No entanto, as leveduras empregadas nas usinas sucroalcooleiras brasileiras, representantes da espécie Saccharomyces cerevisiae, são incapazes de fermentar xilose, o segundo açúcar mais abundante nos hidrolisados lignocelulósicos. Diante disso, este trabalho se propôs a avaliar o desempenho fermentativo de três linhagens selvagens de Meyerozyma caribbica em hidrolisados enzimáticos de caule e palha de milho, durante $30 \mathrm{~h}$ de incubação. Para isso, as suas células foram inoculadas nesses hidrolisados, contendo $\sim 15 \mathrm{~g} \mathrm{~L}^{-1}$ de glicose e $\sim 10 \mathrm{~g} \mathrm{~L}^{-1}$ de xilose ou suplementados de modo a atingirem $25 \mathrm{~g} \mathrm{~L}^{-1}$ de cada açúcar. Os resultados obtidos demonstram que duas das três cepas testadas, embora tenham consumido no máximo 55\% da xilose disponível, foram capazes de fermentar essa pentose entre duas a seis horas após a exaustão da glicose presente, aumentando em até $15 \%$ a produção de etanol. Portanto, as linhagens de $M$. caribbica analisadas mostraram-se vantajosas em relação à $S$. cerevisiae para a produção de etanol $2 \mathrm{G}$, haja vista sua capacidade de fermentação de xilose.
\end{abstract}

Palavras-chave: fermentação, glicose, levedura, xilose.

\section{SECOND-GENERATION ETHANOL PRODUCTION BY Meyerozyma caribbica FROM CORN STALK AND STRAW HYDROLYSATE}

\begin{abstract}
Second-generation ethanol production has recently been highlighted as providing higher water and food security compared to the first generation of the fuel. This is due to the possibility of using agricultural residues, dispensing areas for planting energy crops with that purpose and avoiding competition with food production. In this context, the use of stalk and corn straw as raw material is an alternative. Through the pretreatment of these residues and the hydrolysis of their polysaccharides, it is possible to obtain sugars for alcoholic fermentation. However, the yeasts used in Brazilian sugarcane plants, representatives of the species Saccharomyces cerevisiae, are incapable of fermenting xylose, the second-most abundant sugar in the lignocellulosic hydrolysates. The aim of this work was to evaluate the fermentative performance of three wild strains of Meyerozyma caribbica in corn stalk and straw enzymatic hydrolysates, during a $30 \mathrm{~h}$ incubation period. For this end, their cells were inoculated into these hydrolysates containing $\sim 15 \mathrm{~g} \mathrm{~L}^{-1}$ glucose and $\sim 10$ $\mathrm{g} \mathrm{L}^{-1}$ xylose or supplemented to reach $25 \mathrm{~g} \mathrm{~L}^{-1}$ of each sugar. Although they have consumed at most $55 \%$ of the available xylose, two of the three analyzed strains were able to ferment this pentose between two and six hours after the glucose exhaustion, increasing up to $15 \%$ ethanol production. Therefore, the $M$. caribbica strains herein analyzed were advantageous in relation to $S$. cerevisiae for the production of second-generation ethanol, due to their xylose fermentation capacity.
\end{abstract}

Keywords: fermentation, glucose, xylose, yeast.

\section{INTRODUÇÃO}

O Brasil é o terceiro maior produtor mundial de milho, com uma produção anual de cerca de 92 milhões de toneladas (safra 2017/2018; CONAB, 2018). Como subproduto de cada safra, estima-se que sejam gerados um quilograma de resíduo (palha, caule e bagaço) para cada quilograma de grão (KIM, DALE, 2004). Atualmente, esses resíduos são majoritariamente utilizados para a produção de silagem, com demanda anual de 52 mil toneladas (ABIMILHO, 2018; ANTUNES, 2018). No entanto, essa biomassa lignocelulósica pode 
ter como destino a fabricação de um produto de maior valor agregado, que garanta segurança alimentar, hídrica e energética: o etanol de segunda geração (etanol $2 \mathrm{G}$ ).

Esse combustível, produzido a partir de biomassa lignocelulósica, depende essencialmente de três etapas: (1) pré-tratamento da biomassa, para promover a separação entre lignina e polissacarídeos; (2) hidrólise dos polissacarídeos celulose e hemicelulose; e, (3) fermentação dos açúcares oriundos do processo de hidrólise. A levedura Saccharomyces cerevisiae é o microrganismo majoritariamente empregado em processos de fermentação alcoólica, incluindo a produção de etanol 1G (obtido, no Brasil, da fermentação do caldo de cana). Contudo, essa levedura, embora seja um fermentador eficiente da glicose (o principal produto da etapa hidrolítica), é incapaz de fermentar a xilose, o segundo monossacarídeo mais abundante nos hidrolisados lignocelulósicos (revisto por STAMBUK et al., 2008). Nesse sentido, passa a ser extremamente desejável a caracterização de novas espécies de leveduras que sejam capazes de fermentar a pentose em questão e de garantir a mesma eficiência fermentativa apresentada por $S$. cerevisiae diante da glicose.

\section{MATERIAL E MÉTODOS}

\section{Pré-tratamento e hidrólise de caule e palha de milho}

Para a realização do pré-tratamento alcalino, $20 \mathrm{~g}$ de biomassa foram adicionados a $200 \mathrm{~mL} \mathrm{de} \mathrm{Ca}(\mathrm{OH})_{2}$, na concentração de $0,2 \mathrm{~g} \mathrm{~g}^{-1}$ biomassa. Essa suspensão foi mantida por $24 \mathrm{~h}$ a $50^{\circ} \mathrm{C}$ e $200 \mathrm{rpm}$. Na sequência, o pH foi corrigido para 5,0 e foram adicionados $2 \%$ do complexo enzimático CTec2 ( $\mathrm{mL} \mathrm{g}^{-1}$ biomassa) e $0,5 \%$ do HTec2 ( $\mathrm{mL} \mathrm{g}^{-1}$ biomassa) (Novozymes A/S - Dinamarca), e a reação foi mantida por $24 \mathrm{~h}$ a $50^{\circ} \mathrm{C}$ e $200 \mathrm{rpm}$.

\section{Fermentação em batelada}

As leveduras, da Coleção de Leveduras do Campus Chapecó da UFFS, foram inicialmente précultivadas em YPD (1\% de extrato de levedura, $2 \%$ de peptona e $2 \%$ de glicose) até sua fase exponecial de crescimento. Em seguida, as células foram lavadas e ressuspensas no hidrolisado de milho (que foi acrescido de $10,5 \mathrm{~g} \mathrm{~L}^{-1}$ de extrato de levedura e 3,0 $\mathrm{g} \mathrm{L}^{-1}$ de $\mathrm{KH}_{2} \mathrm{PO}_{4}$, teve $\mathrm{pH}$ ajustado para 5,0 e foi esterilizado por filtração) de modo a atingirem a concentração de $\sim 6 \mathrm{~g} \mathrm{~L}^{-1}$. As fermentações foram realizadas a $25^{\circ} \mathrm{C}$, sob 145 rpm, durante $30 \mathrm{~h}$ com retirada de amostras (nos intervalos apresentados na Figura 1) para determinação do consumo de açúcares e da produção de etanol.

Antes da fermentação, parte do hidrolisado foi suplementado com xilose e glicose de modo a se atingir $\sim 25 \mathrm{~g} \mathrm{~L}^{-1}$ de cada açúcar. O consumo de açúcares e a produção de etanol foram determinadas em HPLC (fase móvel $5 \mathrm{mM} \mathrm{H}_{2} \mathrm{SO}_{4}, 50^{\circ} \mathrm{C}$, fluxo de $0,6 \mathrm{~mL} \mathrm{~min}^{-1}$ em coluna Aminex HPX-87H, Bio-Rad, e detecção por índice de refração RID-10, Shimadzu).

\section{RESULTADOS E DISCUSSÃO}

Foram analisadas três linhagens selvagens de Meyerozyma caribbica (VAUGHAN-MARTINI et al., 2005; KURTZMAN, SUZUKI, 2010) que fazem parte da coleção deste grupo de pesquisa. As três cepas testadas foram capazes de consumir $100 \%$ da glicose disponível no hidrolisado nas primeiras 4-6 horas de incubação, tanto nos ensaios sem suplementação de açúcares quanto nos ensaios com suplementação (Figura 1). O consumo de xilose, por outro lado, teve um comportamento bastante distinto: a linhagem CHAP-087 não foi capaz de consumir essa pentose durante as 30 horas, enquanto as cepas CHAP-091 e CHAP-096 consumiram entre $10 \%$ e $55 \%$ do açúcar. Cabe destacar que o consumo da xilose foi maior nos hidrolisados

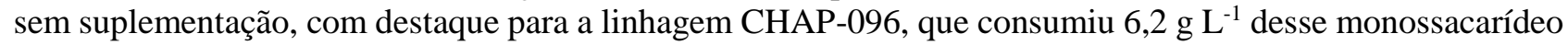
(Figura 1-E). Esses resultados sugerem que a maior concentração de carboidratos no hidrolisado suplementado pode ter aumentado o estresse celular em vista de uma maior pressão osmótica. De fato, já foi verificado que esse fator pode prejudicar o desempenho fermentativo das leveduras (KIM et al., 2013).

Por não ter consumido a xilose, a levedura CHAP-087 produziu menos etanol em comparação às outras duas cepas testadas no hidrolisado não suplementado (Figura 1-G). Todavia, considerando apenas o consumo de glicose, a CHAP-087 teve rendimento fermentativo $\left(Y_{\mathrm{e} / \mathrm{s}}\right)$ equivalente ao máximo teórico. Já as linhagens CHAP-091 e CHAP-096, que, na condição sem suplementação, consumiram em média 50\% da xilose disponível, produziram até $15 \%$ mais etanol, indicando que a xilose não foi apenas respirada, mas também fermentada pelas células. Com este indicativo, corrobora o fato de o pico de etanol para essas leveduras ocorrer de 2 a 6 horas após a exaustão da glicose, o que demonstra que parte do etanol continuou sendo produzido quando terminou o consumo de glicose e iniciou o de xilose. Por outro lado, os dados obtidos a partir do hidrolisado suplementado sugerem que a produção de etanol foi pouco ou quase nada influenciada pela xilose, 


\section{VISIGERAि DE 07 A A9 MA1 2019

haja vista a pequena quantidade de xilose consumida e o fato de o pico de etanol coincidir com o tempo da exaustão da glicose. Portanto, levando-se em conta a incapacidade de a levedura $S$. cerevisiae fermentar a xilose (STAMBUK et al., 2008), as leveduras aqui testadas apresentam-se em vantagem para a produção de etanol de segunda geração.

\section{CONCLUSÃO}

As cepas analisadas no presente trabalho indicam potencial de aplicação da espécie $M$. caribbica na produção de etanol 2G, uma vez que apresentaram rendimento máximo de etanol diante da glicose (assim como se observa para S. cerevisiae) e duas delas fermentaram a xilose disponível no meio, o que representa uma superioridade em relação a levedura atualmente empregada na produção brasileira de etanol a partir do caldo de cana.

\section{REFERÊNCIAS}

ABIMILHO - ASSOCIAÇÃO BRASILEIRA DAS INDÚSTRIAS DE MILHO. Estatística - Oferta e Demanda Mundial do Milho - 2017/18. Disponível em: 〈www.abimilho.com.br〉. Acesso: 24 nov. 2018.

ANTUNES, J. M. Silagem para suprir a escassez de pasto, 2018. Empresa Brasileira de Pesquisa Agropecuária - EMBRAPA. Disponível em: <https://www.embrapa.br/busca-de-noticias/-/noticia/34247153/silagem-parasuprir-a-escassez-de-pasto>. Acesso: 24 nov. 2018.

CONAB - COMPANHIA NACIONAL DE ABASTECIMENTO. Acompanhamento de safra brasileira grãos: Segundo levantamento, novembro 2018 - safra 2017/2018.: Brasília: Companhia Nacional de Abastecimento. 2018. Disponível em: <https://www.conab.gov.br/info-agro/safras/graos>. Acesso em: 24 nov. 2018.

KIM, S.; DALE, B. E. Global potential bioethanol production from wasted crops and crop residues. Biomass Bioenergy. v. 26, p. 361-375, 2004.

KIM, S. R; SKERKER, J. M.; KANG, W.; LESMANA, A.; WEI, N.; ARKIN, A. P.; JIN, Y. S. Rational and evolutionary engineering approaches uncover a small set of genetic changes efficient for rapid xylose fermentation in Saccharomyces cerevisiae. PLoS One. v. 8, p. e57048, 2013.

KURTZMAN, C. P.; SUZUKI, M. Phylogenetic analysis of ascomycete yeasts that form coenzyme Q-9 and the proposal of the new genera Babjeviella, Meyerozyma, Millerozyma, Priceomyces, and Scheffersomyces. Mycoscience. v. 51, p. 2-14, 2010.

STAMBUK, B. U.; ELEUTHERIO, E. C. A.; FLOREZ-PARDO, L. M.; SOUTO-MAIOR, A. M.; BON, E. P. S. (2008) Brazilian potential for biomass ethanol: Challenge of using hexose and pentose cofermenting yeast strains. J. Sci. Ind. Res. v. 67, p. 918-926, 2008.

VAUGHAN-MARTINI, A.; KURTZMAN, C.P.; MEYER, S. A.; O'NEILL, E. B. Two new species in the Pichia guilliermondii clade: Pichia caribbica sp. nov., the ascosporic state of Candida fermentati, and Candida carpophila comb. nov. FEMS Yeast Res. v. 5, p. 463-469, 2005. 


\section{VISIGER_心

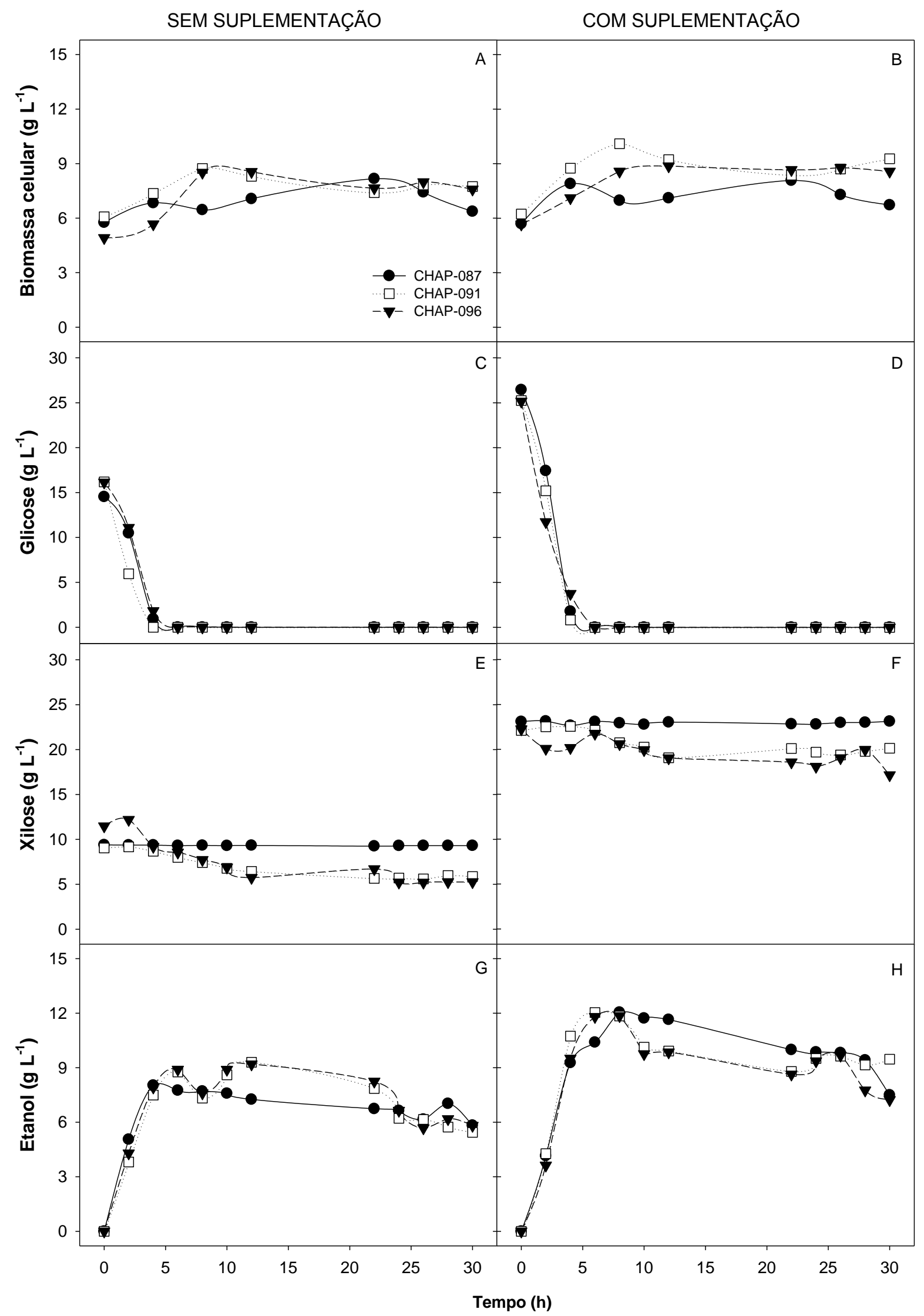

Figura 1. Fermentações em batelada de hidrolisado de caule e palha de milho sem suplementação (A, C, E, G) e com suplementação (B, D, F, H) de açúcares, conduzidas pelas linhagens CHAP-087 (•), CHAP-091 $(\square)$ e CHAP-096 ( $\boldsymbol{\nabla})$. 


\title{
PRODUÇÃO DE ETANOL UTILIZANDO HIDROLISADO DE BAGAÇO DE CANA-DE- AÇÚCAR EM BIORREATOR
}

\author{
Bonatto, C. ${ }^{1,4}$; Venturin, B..$^{2,4}$; Alves, S.L. Jr. ${ }^{3}$; Bazoti, S.F. ${ }^{4}$; Treichel, H. ${ }^{4}$ \\ ${ }^{1}$ Universidade Federal de Santa Catarina (UFSC) \\ ${ }^{2}$ Universidade Estadual do Oeste do Paraná (UNIOESTE) \\ ${ }^{3}$ Universidade Federal da Fronteira Sul (UFFS), campus Chapecó/SC \\ ${ }^{4}$ Universidade Federal da Fronteira Sul (UFFS), campus Erechim/RS \\ *helentreichel@gmail.com
}

\begin{abstract}
RESUMO: Diversos resíduos agroindustriais podem ser utilizados como substrato em processos de fermentação, como é o caso dos resíduos lignocelulósicos. Os lignocelulósicos são ricos em polissacarídeos que podem ser convertidos à etanol, após etapas de pré-tratamento, hidrólise e fermentação. Nesse sentido, este estudo avaliou a produção de etanol utilizando hidrolisado de bagaço de cana-de-açúcar, oriundo da indústria canavieira, a partir da fermentação com uma levedura selvagem (Wicherhamomyces sp. UFFS-CE3.1.2). A fermentação foi conduzida em biorreator, utilizando as condições otimizadas por Bazoti et al. (2017), em escala de bancada $(100 \mathrm{~mL})$, com a mesma cepa e hidrolisado que os utilizados neste estudo. Em $96 \mathrm{~h}$ de fermentação, foram obtidos $8,35 \mathrm{~g} \mathrm{~L}^{-1}$ de etanol, a partir de 27,48 $\mathrm{g} \mathrm{L}^{-1}$ de açúcares fermentescíveis disponíveis no hidrolisado, na presença de $\sim 2,3 \mathrm{~g} \mathrm{~L}^{-1}$ de ácido acético. Resultados semelhantes foram obtidos por Bazoti et al. (2017) na produção de etanol em volume inferior ao usado neste trabalho, isso indica a possibilidade de futuros ganhos na produção de etanol de segunda geração.
\end{abstract}

Palavras-chave: fermentação, ampliação de escala, resíduo lignocelulósico.

\section{ETHANOL PRODUCTION USING SUGARCANE BAGASSE HYDROLYSATE IN BIOREACTOR}

ABSTRACT: Several agro-industrial wastes can be used as substrate in fermentation processes, such as lignocellulosic wastes, since they are rich in polysaccharides which can be converted to ethanol, after stages of pretreatment, hydrolysis and fermentation. In this sense, this study evaluated the production of ethanol using sugarcane bagasse hydrolysate, derived from the sugar industry, from the fermentation with a wild yeast strain (Wicherhamomyces sp. UFFS-CE-3.1.2). The fermentation was conducted in bioreactor, using the conditions optimized by Bazoti et al. (2017), in bench scale $(100 \mathrm{~mL})$, with the same strain and hydrolyzate than those used in this study. In 96 hours of fermentation, $8.35 \mathrm{~g} \mathrm{~L}^{-1}$ of ethanol were obtained from $27.48 \mathrm{~g} \mathrm{~L}^{-1}$ of fermentable sugars available in the hydrolysate, in the presence of $\sim 2.3 \mathrm{~g} \mathrm{~L}^{-1}$ of acetic acid. Similar results were obtained by Bazoti et al. (2017) in ethanol production in a lower volume than the one used in the present study. Thus, our results indicate the possibility of future gains in the production of second-generation ethanol.

Keywords: fermentation, scaling-up, lignocellulosic waste.

\section{INTRODUÇÃO}

O etanol é o biocombustível mais utilizado em veículos a motor e meios de transporte (BALAT, 2011). O Brasil e os EUA são líderes na produção de etanol a partir de matérias-primas de primeira geração, responsáveis por $84 \%$ da produção mundial (BERTRAND et al., 2016). No Brasil, a produção está baseada na fermentação da sacarose da cana de açúcar e nos EUA, na fermentação do amido, principalmente do milho. Porém, a utilização de milho e cana-de-açúcar para produção de etanol tem sido questionada por serem fontes alimentares (SARKAR et al., 2012).

Diante disso, a biomassa lignocelulósica tem sido considerada como a matéria-prima ideal para produção de biocombustíveis, já que não compete com recursos alimentares, pois pode ser obtida a partir de resíduos, não sendo necessário ampliar áreas produtivas para aumentar a produção. Os materiais lignocelulósicos são ricos em polissacarídeos que podem ser hidrolisados em açúcares fermentáveis e consequentemente convertidos à biocombustíveis (NEVES; PITARELO; RAMOS, 2016). Além disso, as biomassas lignocelulósicas estão disponíveis em abundância, são renováveis e ainda contribuem positivamente para a redução das emissões de dióxido de carbono (SARKAR et al., 2012). 
No Brasil, o bagaço de cana de açúcar é a biomassa com maior potencial para ser utilizada como matériaprima para produção de etanol de segunda geração, já que cada tonelada de cana de açúcar triturada produz cerca de $250 \mathrm{~kg}$ de bagaço (RABELO; FILHO; COSTA, 2013). Somente a região Centro-Sul do Brasil processou 596 milhões de toneladas de cana-de-açúcar na safra 2017/2018 (UNICA, 2018).

Nesse sentido, este estudo buscou avaliar a produção de etanol utilizando hidrolisado de bagaço de canade-açúcar, tratado industrialmente, como substrato, em uma fermentação conduzida em biorreator, utilizando as condições otimizadas por Bazoti et al. (2017), a partir de uma levedura selvagem.

\section{MATERIAL E MÉTODOS}

O hidrolisado, utilizado como substrato na fermentação, foi doado pelo Centro de Tecnologia Canavieira (CTC), localizado em São Paulo. O caldo foi obtido a partir do pré-tratamento do bagaço de cana-de-açúcar por meio de explosão a vapor, seguido de hidrólise enzimática pela enzima Cellic CTec3 (Novozymes).

A fermentação foi conduzida em biorreator (BIO-TEC, Tecnal) com adição de 3 L de hidrolisado diluído 1:3 (v/v) com água ultrapura - condição otimizada por Bazoti et al. (2017) - e adição de 10\% de inóculo da levedura UFFS-C.E-3.1.2, que ocorreu após esterilização do biorreator e polarização do sensor de oxigênio dissolvido acoplado ao biorreator. A levedura utilizada foi recentemente isolada do ecossistema brasileiro e identificada por Bazoti et al. (2017) como uma nova cepa de Wickerhamomyces.

$\mathrm{O}$ biorreator foi mantido em condições anaeróbias, agitação de 80 RPM e temperatura de $30{ }^{\circ} \mathrm{C}$. Amostras foram retiradas a cada 24 horas e as concentrações de glicose, xilose, celobiose, ácido acético, etanol, hidroximetilfurfural (HMF) e furfural foram determinadas por meio de Cromatografia Líquida de Alta Eficiência (HPLC) utilizando cromatógrafo Shimadzu com detectores RID 10-A e PDA 10-A.

Antes das análises por HPLC, o eluente foi filtrado a vácuo com membrana de $0,45 \mu$ m Millipore ${ }^{\circledR}$ e desgaseificado em banho de ultrassom por 15 minutos, e as amostras foram pré-filtradas e diluídas apropriadamente. A concentração dos compostos foi determinada usando curvas de calibração para cada composto.

\section{RESULTADOS E DISCUSSÃO}

O hidrolisado de bagaço de cana-de-açúcar apresentou alta quantidade de carboidratos $\left(53,17 \mathrm{~g} \mathrm{~L}^{-1} \mathrm{de}\right.$ glicose, 49,40 $\mathrm{g} \mathrm{L}^{-1}$ de xilose, $6,57 \mathrm{~g} \mathrm{~L}^{-1}$ de celobiose e $1,14 \mathrm{~g} \mathrm{~L}^{-1}$ de arabinose), especialmente glicose, carboidrato mais utilizado por microrganismos nos processos fermentativos, o que indica potencial de uso para produção de etanol. Também foram identificados no hidrolisado compostos inibidores de fermentação como o furfural $\left(0,42 \mathrm{~g} \mathrm{~L}^{-1}\right)$, o hidroximetilfurfural (HMF) $\left(0,19 \mathrm{~g} \mathrm{~L}^{-1}\right)$ e o ácido acético $\left(10,78 \mathrm{~g} \mathrm{~L}^{-1}\right)$, que podem diminuir a eficiência do processo de fermentação e inibir o metabolismo das leveduras, dependendo da linhagem do microrganismo utilizado (BELLIDO et al., 2011).

Durante a fermentação, foi verificado que a glicose é a fonte preferencial de carbono da levedura Wickerhamomyces sp. UFFS-C.E-3.1.2, já que decorridas 72 horas de fermentação, esse carboidrato estava completamente esgotado (Figura 1), enquanto açúcares como xilose, arabinose e celobiose permaneceram constantes na fermentação (Figura 2). O consumo de xilose, nesse caso, foi afetado pela presença do ácido acético no hidrolisado, na sua forma indissociada (CASEY et al., 2010). Mesmo assim, a concentração de etanol de 8,35 $\mathrm{g} \mathrm{L}^{-1}$ obtida após 96 horas de fermentação (Figura 1) representa uma produção promissora, em comparação com outros estudos.

Resultados semelhantes foram obtidos por Bazoti et al. (2017) ao produzir etanol, com as mesmas condições deste trabalho, a partir da fermentação conduzida em erlenmeyer com volume total de $100 \mathrm{~mL}$. Isso indica a possibilidade de ampliação de escala da produção de etanol com a levedura Wickerhamomyces a partir de hidrolisados industriais não detoxificados.

\section{CONCLUSÃO}

A produção de etanol utilizando hidrolisado de bagaço de cana-de-açúcar como substrato se mostrou eficiente, uma vez que o hidrolisado não necessitou ser detoxificado, o que reduz custos operacionais, e a produção obtida em biorreator, com volume de $3 \mathrm{~L}$, apresentou resultados semelhantes aos obtidos na fermentação conduzida em erlenmeyer, com volume de $100 \mathrm{~mL}$. Portanto, esse estudo sugere possibilidades de diminuição de custos no setor de biocombustíveis, uma vez que mostra a viabilidade de produção de um produto de alto valor agregado a partir de um resíduo agroindustrial e apresenta uma levedura selvagem capaz de tolerar compostos inibidores. 


\section{AGRADECIMENTOS}

Os autores agradecem o CNPq, CAPES, FAPERGS e o Centro de Tecnologia Canavieira (CTC) pelo suporte financeiro.

\section{REFERÊNCIAS}

Balat, M. Production of bioethanol from lignocellulosic materials via the biochemical pathway: a review. Energy Conversion and Management, v. 52, p. 858-875, 2011.

Bazoti, S. F. et al. Second-generation ethanol from non-detoxified sugarcane hydrolysate by a rotting wood isolated yeast strain. Bioresource Technology, v. 244, p. 582-587, 2017.

Bellido, C. et al. Effect of inhibitors formed during wheat straw pretreatment on ethanol fermentation by pichia stipitis. Bioresource Technology, v. 102, p. 10868-10874, 2011.

Casey, E. et al. Effect of acetic acid and ph on the cofermentation of glucose and xylose to ethanol bya genetically engineered strain of Saccharomyces Cerevisiae. FEMS Yeast Research, v. 10, p. 385-393, 2010. Bertrand E. et al. First generation bioethanol. In: Soccol CR, Brar SK, Faulds, C, Ramos LP, editors. Green fuels technology: biofuels. Switzerland: Springer; 2016. pp. 175-212.

Neves, P. V; Pitarelo, A. P.; Ramos, L. P. Production of cellulosic ethanol from sugarcane bagasse by steam explosion: effect of extractives content, acid catalysis and different fermentation technologies. Bioresource Technology, v. 208, p. 184-194, 2016.

Rabelo, S. C.; Filho, R. M.; Costa, A. C. Lime pretreatment and fermentation of enzymatically hydrolyzed sugarcane bagasse. Applied Biochemistry and Biotechnology, v. 169, p. 1696-1712, 2013.

Sarkar, N. et al. Bioethanol production from agricultural wastes: an overview. Renewable Energy, v. 37, p. 19-27, 2012.

UNICA - União da Indústria de Cana-de-Açúcar. Relatório Final da Safra 2017/2018 da Região Centro-Sul. 2018.

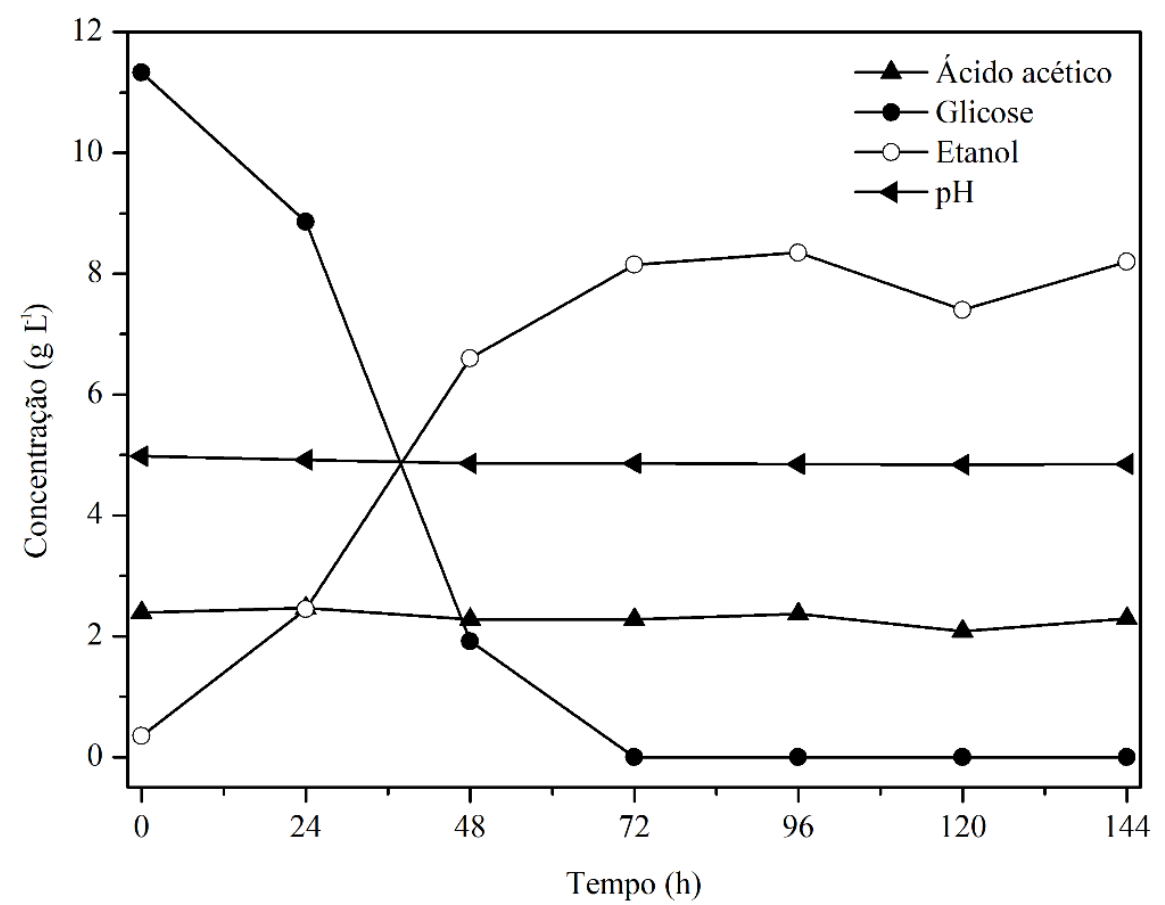

Figura 1. Consumo de glicose, comportamento do ácido acético, pH e produção de etanol na fermentação. 


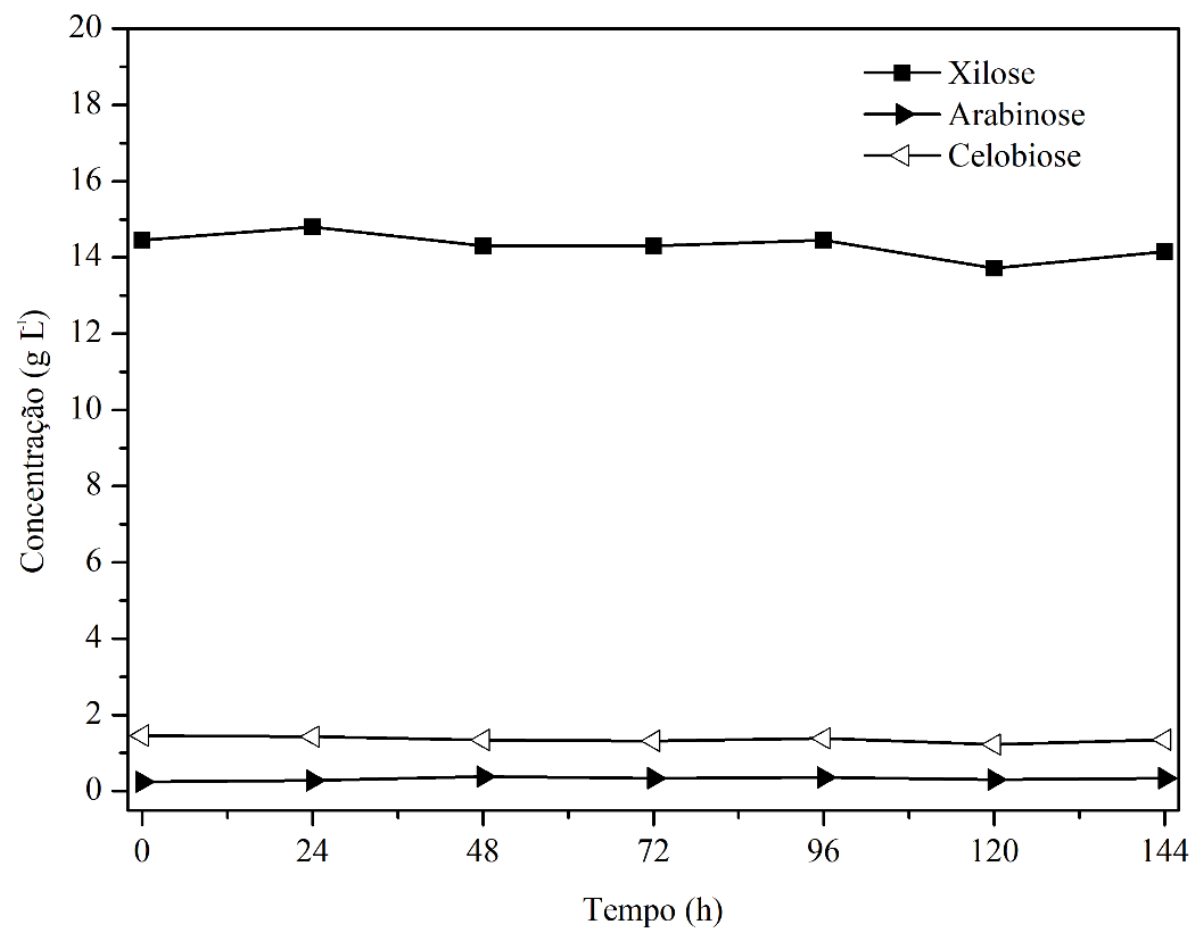

Figura 2. Comportamento da xilose, arabinose e celobiose durante a fermentação. 


\title{
PRODUÇÃO DE METANO A PARTIR DA BIOMASSA RESIDUAL DO PROCESSAMENTO DE AÇAÍ (EUTERPE OLERACEA)
}

\author{
Lima, A.C.P.*1; Gutarra, M.L.E. ${ }^{2}$; Cammarota, M.C. ${ }^{1}$ \\ ${ }^{I}$ Escola de Química, Universidade Federal do Rio de Janeiro, Rio de Janeiro, RJ - Brasil \\ ${ }^{2}$ Campus Xerém, Universidade Federal do Rio de Janeiro, Duque de Caxias, RJ-Brasil \\ anna.pinheiro.lima@gmail.com
}

\begin{abstract}
RESUMO: Biomassas residuais do processamento de açaí submetidas a pré-tratamento com ácido sulfúrico $0,1 \%$ (v/v) em autoclave $\left(121^{\circ} \mathrm{C}\right)$ por 60 min tiveram incrementos de $43 \%$ na demanda química de oxigênio solúvel (DQOs) e de 38\% na concentração de carboidratos solúveis (CS) na fração líquida obtida, em comparação à biomassa sem pré-tratamento. Essa fração foi submetida à digestão anaeróbia a $30^{\circ} \mathrm{C}$ por 15 dias, obtendo-se $97 \%$ de remoção de DQOs e produção específica de metano (PEM) de $327 \mathrm{NmL} \mathrm{CH}_{4} / \mathrm{g}$ DQO removida comprovando a viabilidade técnica da produção de metano a partir das biomassas residuais.
\end{abstract}

Palavras-chave: caroço de açaí, fibra de açaí, metano e pré-tratamento termoquímico.

\section{METHANE PRODUCTION FROM THE RESIDUAL BIOMASS OF THE AÇAÍ PROCESSING (EUTERPE OLERACEA)}

\begin{abstract}
Residual biomasses of açaí processing submitted to pretreatment with $0.1 \%$ (v/v) sulfuric acid in autoclave $\left(121^{\circ} \mathrm{C}\right)$ for $60 \mathrm{~min}$ had increases of $43 \%$ in the soluble chemical oxygen demand (CODs) and $38 \%$ in the soluble carbohydrates concentration (CS) in the liquid fraction obtained, compared to the biomass without pretreatment. This fraction was submitted to anaerobic digestion at $30^{\circ} \mathrm{C}$ for 15 days, obtaining $97 \%$ COD removal and specific methane production (SMP) of $327 \mathrm{Nml} \mathrm{CH}_{4} / \mathrm{g}$ COD removed, proving the technical viability of the methane production from the residual biomasses.
\end{abstract}

Keywords: Açaí seed, açaí fiber, methane and thermochemical pretreatment.

\section{INTRODUÇÃO}

A comercialização do açaí nos mercados nacionais e internacionais aumentou muito nos últimos anos. Devido às suas propriedades funcionais, indústrias farmacêuticas e alimentícias usam esse fruto como base de seus produtos (Yamaguchi et al., 2015). A agroindústria do açaí (Euterpe oleracea) gera grande quantidade de resíduos sólidos, na forma de caroço e epicarpo do fruto. Estima-se que, em 2016, foram produzidas aproximadamente 120 mil toneladas de resíduos somente no estado do Pará (IBGE, 2016). Nas cidades produtoras da bebida de açaí, é possível verificar seu acúmulo em frente aos estabelecimentos que comercializam o produto, que geralmente são descartados de forma irregular, ocasionando uma problemática ambiental (Domingues et al., 2017). Além disso, foi instituída em 2010 a Lei $\mathrm{n}^{\circ} 12.305$, que estabelece a Política Nacional de Resíduos Sólidos (PNRS), a qual dispõe de diretrizes relativas à gestão integrada e ao gerenciamento de resíduos, identificando as responsabilidades dos geradores e do poder público (BRASIL, 2010). Sendo assim, os produtores necessitam de soluções tecnológicas para essa problemática. O caroço (semente) apresenta uma parte externa fibrosa e uma parte interna onde se localiza o embrião (Pessoa et al., 2010) e essa biomassa residual é descrita na literatura como constituída de cerca de $70 \%$ de carboidratos (Rambo et al., 2015). É possível utilizar os carboidratos da parede celular dos resíduos para obtenção de energia (biogás) através da digestão anaeróbia. Portanto, este trabalho tem como objetivo avaliar a viabilidade de um pré-tratamento termoquímico para a solubilização dos açúcares presentes nos resíduos da produção do açaí (fibra e caroço) e seu posterior aproveitamento para obtenção de metano, por meio da digestão anaeróbia da fração líquida.

\section{MATERIAL E MÉTODOS}

\section{Coleta e pré-tratamento termoquímico da biomassa residual da produção de açaí}

Amostras da biomassa residual da produção de açaí (caroço e fibra) foram coletadas em um estabelecimento comercial na cidade de Belém (PA), moídas em moinho de facas e peneiradas. Uma proporção de $90 \%$ caroço e $10 \%$ fibra (ambos com granulometria < 1,18 mm) e razão sólido : liquido de 1:10 (m/v) foram 
empregadas no experimento de solubilização, conduzido em frascos do tipo Shott de $250 \mathrm{~mL}$, com $15 \mathrm{~g}$ da mistura de resíduos e $150 \mathrm{~mL}$ de solução de ácido sulfúrico $0,1 \%$ (v/v), em autoclave $\left(121{ }^{\circ} \mathrm{C}, 1,05\right.$ bar) por 60 minutos. A fração líquida obtida foi resfriada, filtrada à vácuo e estocada sob refrigeração. Um controle foi conduzido nas mesmas condições experimentais, porém com água destilada e sem autoclave. A solubilização foi avaliada pelas concentrações de carboidratos solúveis (CS), açúcares redutores totais (ART) e DQOs na fração líquida, quantificadas de acordo com Dubois et al. (1956), Miller (1959) e APHA (2005), respectivamente.

\section{Digestão anaeróbia}

Os experimentos foram conduzidos a $30^{\circ} \mathrm{C}$, em batelada, em respirômetro BIOPROCESS CONTROL AMPTS II, utilizando frascos de vidro com $400 \mathrm{~mL}$ de misturas de lodo anaeróbio e fração líquida do prétratamento termoquímico. Em todos os experimentos foram feitas suplementações do meio com nitrogênio $\left(\mathrm{NH}_{4} \mathrm{Cl}\right)$ e fósforo $\left(\mathrm{KH}_{2} \mathrm{PO}_{4}\right)$ para uma relação ideal DQO: N: P de 350:5:1 (Von Sperling, 1996). Lodo anaeróbio proveniente de reator UASB - upflow anaerobic sludge blanket em operação em uma indústria de abate de aves, com sólidos suspensos voláteis (SSV) de $24 \mathrm{~g} / \mathrm{L}$, foi empregado como inóculo. Foram avaliadas três concentrações iniciais de DQO solúvel (18.700, 9.350 e $6.233 \mathrm{mg} / \mathrm{L})$, por meio de diferentes diluições da fração líquida obtida, que resultaram em diferentes relações $\mathrm{S}_{0} / \mathrm{X}_{0}(\mathrm{mg}$ DQOs da fração líquida/ mg SSV do lodo). $\mathrm{O}$ pH inicial das amostras foi ajustado para 7,0 com bicarbonato de sódio $\left(\mathrm{NaHCO}_{3}\right)$. A produção de metano foi acompanhada até estabilização, quando os frascos foram abertos para medida do pH e da DQOs finais. A quantificação de SSV e DQOs foi realizada segundo metodologia padrão (APHA, 2005).

\section{RESULTADOS E DISCUSSÃO}

Na Figura 1 estão os resultados da fração líquida do pré-tratamento termoquímico das biomassas residuais de açaí (caroço e fibra) empregando ácido sulfúrico diluído (0,1\% v/v), em comparação com a fração líquida sem pré-tratamento. A concentração de ART se manteve, no entanto, houve um incremento da DQOs e dos CS de $43 \%$ e $38 \%$, respectivamente, com o pré-tratamento.

Após o pré-tratamento termoquímico a fração líquida foi submetida à digestão anaeróbia a fim de produzir metano, os resultados podem ser visualizados na Figura 2 e Tabela 1. Na Figura 2 é apresentada a evolução da produção de metano ao longo do tempo de incubação dos frascos. Pode-se observar que as réplicas das condições $\mathrm{S}_{0} / \mathrm{X}_{0}$ avaliadas apresentam valores próximos e um aumento da produção de metano com a carga inicial de DQO. Verificou-se uma correlação linear $\left(\mathrm{R}^{2}=1\right)$ entre a DQOs inicial e a PEM (Figura 3), indicando ausência de inibição dos microrganismos metanogênicos mesmo sob maiores concentrações da fração líquida. $\mathrm{O}$ pH final se manteve próximo a 7,6 (Tabela 1), valor adequado à digestão anaeróbia (Chernicharo, 2007). Com base nos resultados obtidos, pode-se inferir que a fração solúvel do pré-tratamento termoquímico avaliado é de fácil digestão anaeróbia, uma vez que houve remoção de até $97 \%$ da DQO solúvel ao final da digestão. A PEM (produção específica de metano) foi coerente em todas as condições e próxima ao valor teórico (350 $\mathrm{NmL} \mathrm{CH}_{4} / \mathrm{g}$ DQO removida), ou seja, de 87 a 93\% da DQO foi convertida a metano.

\section{CONCLUSÃO}

O pré-tratamento termoquímico com ácido diluído $(0,1 \% \mathrm{v} / \mathrm{v})$ e temperatura $\left(121^{\circ} \mathrm{C}\right)$ por $60 \mathrm{~min}$ permitiu a solubilização e liberação de parte dos carboidratos presentes nas biomassas residuais do açaí na fração líquida. A fração líquida assim obtida se mostrou de fácil digestão anaeróbia, com PEM próxima ao valor teórico, indicando a viabilidade técnica de produção de metano a partir das biomassas residuais do processamento de açaí.

\section{REFERÊNCIAS}

APHA. AMERICAN PUBLIC HEALTH ASSOCIATION. Standard methods for examination of water and wastewater. 21 th ed. Washington: American Water Works Association, 2005. $1.368 \mathrm{p}$.

BRASIL. Lei $\mathbf{N}^{\mathbf{0}} \mathbf{1 2 . 3 0 5}$, de 2 de agosto de 2010. 2010.

CHERNICHARO, C.A.L. Reatores anaeróbios: princípios do tratamento biológico em águas

residuárias. 2.ed. Belo Horizonte: DESA/UFMG, 2007. 359 p.

DOMINGUES, A. F. N.; MATTIETTO, R. DE A.; OLIVEIRA, M. DO S. P. Teor de Lipídeos em Caroços de Euterpe oleracea Mart. Boletim de pesquisa e desenvolvimento / Embrapa Amazônia Oriental, v. 1, p. 1-19, 2017. 
DUBOIS, M. et al. Colorimetric method for determination of sugars and related substances. Analytical Chemistry, v. 28, n. 3, p. 350-356, 1956.

IBGE - Instituto Brasileiro de Geografia e Estatistica. PEVS - Produção da extração vegetal e silvicultura 2016. Disponível em: <https://www.ibge.gov.br/estatisticas-novoportal/economicas/agricultura-epecuaria/9105-producao-da-extracao-vegetal-e-da-silvicultura.html?=\&t=o-que-e>. Acesso em: 28 maio 2018.

MILLER, G. L. Use of Dinitrosalicylic Acid Reagent for Determination of Reducing Sugar. Analytical Chemistry, v. 31, n. 3, p. 426-428, 1959.

PESSOA, J. D. C. et al. Characterization of Açaí (E. oleracea) fruits and its processing residues. Brazilian Archives of Biology and Technology, v. 53, n. 6, p. 1451-1460, 2010.

RAMBO, M. K. D.; SCHMIDT, F. L.; FERREIRA, M. M. C. Analysis of the lignocellulosic components of biomass residues for biorefinery opportunities. Talanta, v. 144, p. 696-703, 2015.

YAMAGUCHI, K. K. D. L. et al. Amazon acai: Chemistry and biological activities: A review. Food Chemistry, v. 179, p. 137-151, 2015.

VON SPERling, M. Princípios do Tratamento Biológico de Águas Residuárias - Lagoas de Estabilização, v. 03. Minas Gerais: ABES, 1996.

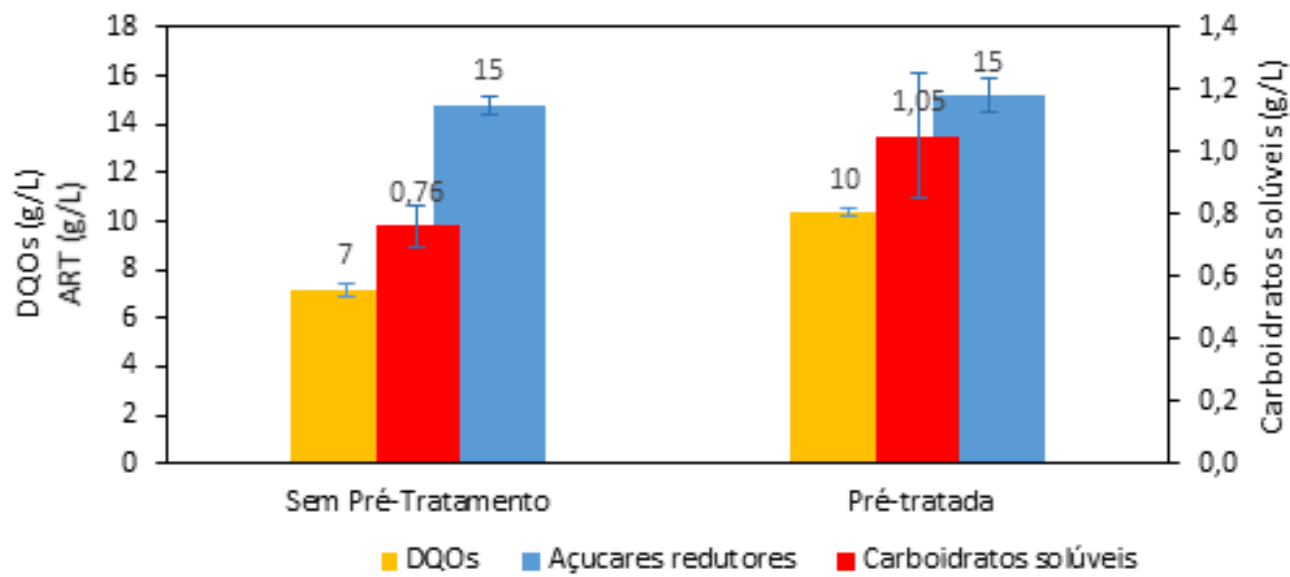

Figura 1. Comparação de DQOs, açúcares redutores totais e carboidratos solúveis na fração líquida sem tratamento e na obtida após tratamento termoquímico com ácido diluído $(0,1 \% \mathrm{v} / \mathrm{v})$. Média e desvio padrão de três réplicas. 


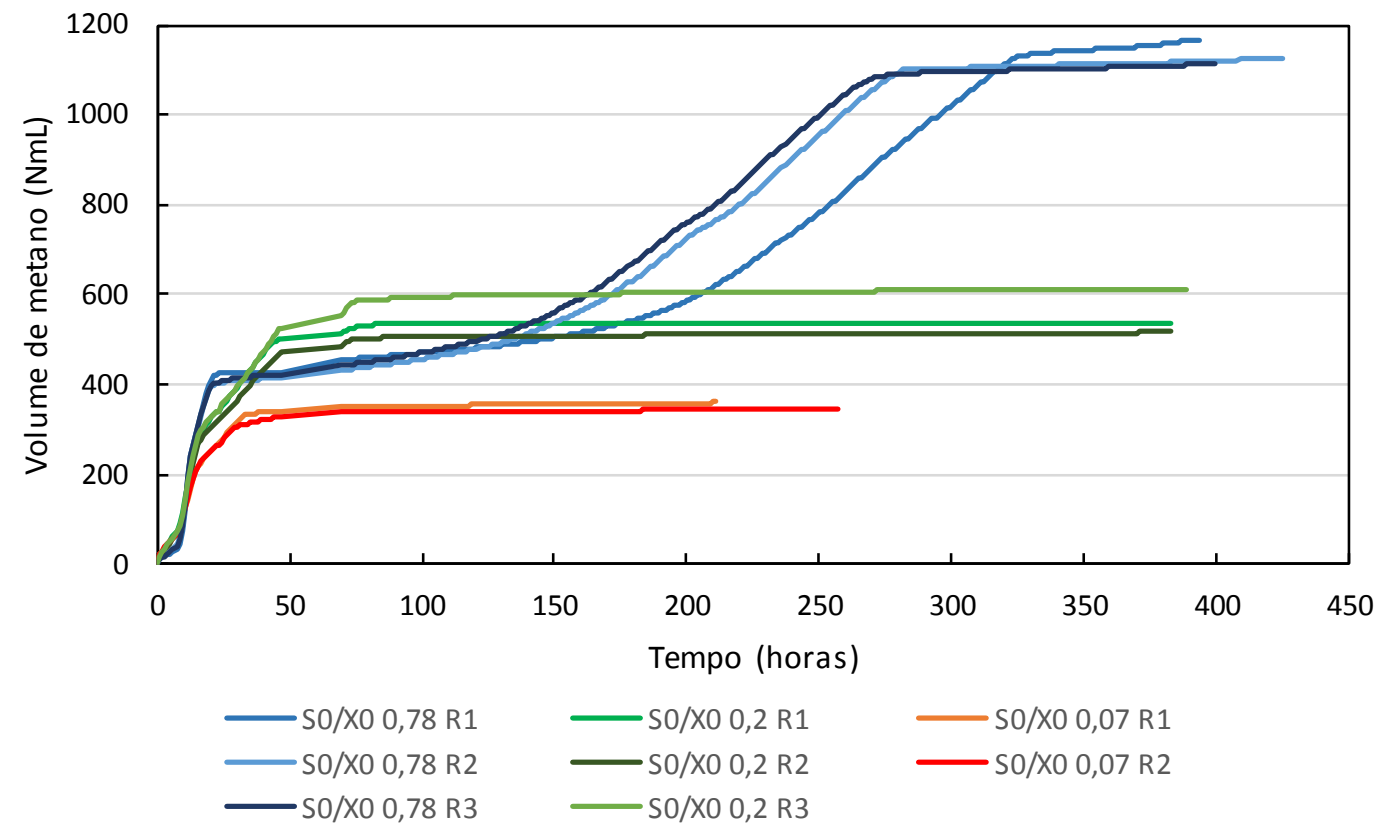

Figura 2. Produção acumulada de metano $(\mathrm{Nml})$ na digestão anaeróbia da fração líquida sob diferentes condições iniciais da relação $\mathrm{S}_{0} / \mathrm{X}_{0}$.

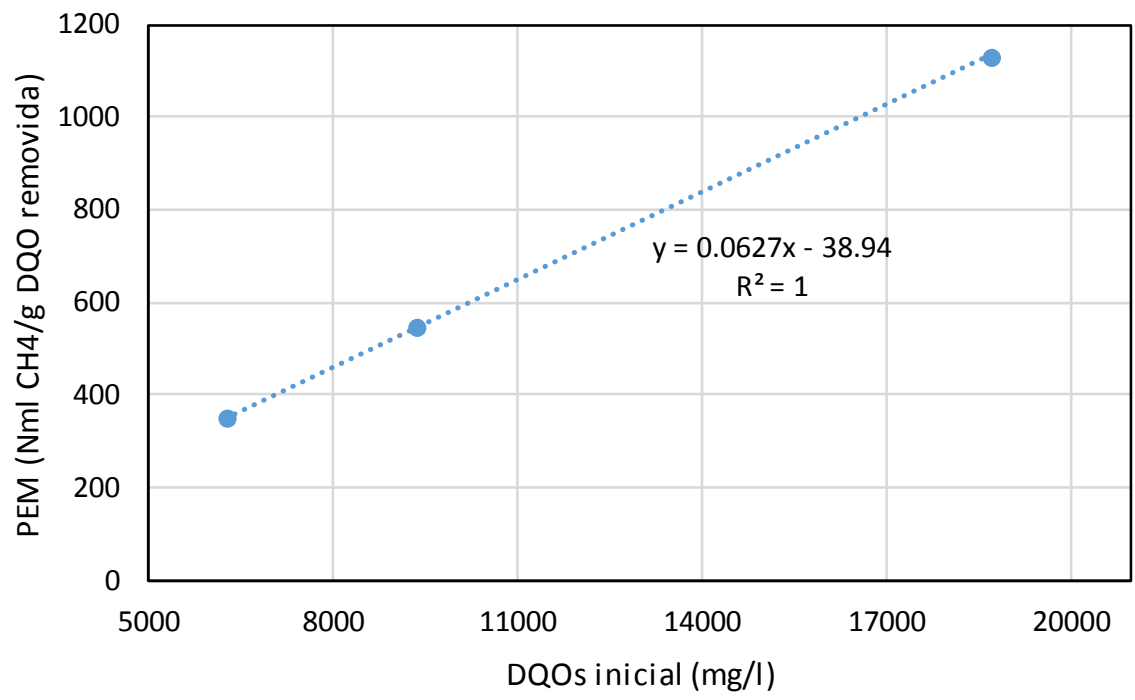

Figura 3. Correlação entre produção específica de metano (PEM) e a DQOs inicial na digestão anaeróbia da fração líquida sob diferentes condições iniciais da relação $\mathrm{S}_{0} / \mathrm{X}_{0}$.

Tabela 1. Resultados dos ensaios de biodegradabilidade anaeróbia da fração líquida obtida no pré-tratamento termoquímico com ácido diluído 0,1\% (v/v)/autoclave/60 min com diferentes razões $\mathrm{S}_{0} / \mathrm{X}_{0}$ (DQOs:SSV).

\begin{tabular}{|c|c|c|c|c|c|c|}
\hline \multicolumn{2}{|c|}{ Condição inicial } & \multicolumn{5}{|c|}{ Condição final ${ }^{a}$} \\
\hline $\begin{array}{l}\text { DQOs } \\
(\mathrm{mg} / \mathrm{l})\end{array}$ & $\begin{array}{c}\mathrm{S}_{\mathbf{0}} / \mathbf{X}_{\mathbf{0}} \\
(\mathrm{mg} \mathrm{DQO} / \mathrm{mg} \\
\text { SSV) }\end{array}$ & pH & $\begin{array}{l}\text { DQOs } \\
(\mathrm{mg} / \mathrm{l})\end{array}$ & $\begin{array}{l}\text { Remoção } \\
\text { DQO (\%) }\end{array}$ & $\underset{(\mathrm{Nml})}{\text { Volume } \mathrm{CH}_{4}}$ & $\begin{array}{c}\text { PEM }(\mathrm{Nml} \\
\mathrm{CH}_{4} / \mathrm{g} \\
\left.\mathrm{DQO}_{\text {remov }}\right)\end{array}$ \\
\hline 18700 & 0,78 & $7,61 \pm 0,01$ & $520 \pm 92$ & 97 & $1136,5 \pm 28,7$ & 321,8 \\
\hline 9350 & 0,20 & $7,56 \pm 0,03$ & $420 \pm 133$ & 96 & $556,6 \pm 51,2$ & 327,0 \\
\hline 6233 & 0,07 & $7,45 \pm 0,04$ & $212 \pm 14$ & 97 & $353,2 \pm 9,8$ & 304,0 \\
\hline
\end{tabular}

${ }^{a}$ média e desvio-padrão de 3 réplicas, entre 14 e 17 dias de incubação. 


\title{
USO DO NARIZ ELETRÔNICO PARA PRODUÇÃO DE BIODIESEL A PARTIR DE ÓLEO E GORDURA RESIDUAL (OGR)
}

\author{
Vidigal, I.G. ${ }^{\text {; }}$ Batista, P.S. ${ }^{\text {; }}$ Siqueira, A.F. ${ }^{\text {; }}$ Giordani, D.S. ${ }^{\text {; }}$ Ferreira, A.L.G.*2 \\ ${ }^{1}$ Universidade de São Paulo, Escola de Engenharia de Lorena, Departamento de Engenharia Química, Brasil \\ igor.vidigal@usp.br; pollyanna@usp.br; dsgiordani@usp.br \\ ${ }^{2}$ Universidade de São Paulo, Escola de Engenharia de Lorena, Departamento de Ciências Básicas e Ambientais, Brasil \\ adriano@debas.eel.usp.br; gabas@usp.br
}

\begin{abstract}
RESUMO: Óleos e gorduras residuais (OGR) são uma matéria-prima alternativa para a produção de biodiesel, entretanto, para ser economicamente viável, métodos simples e baratos são necessários para avaliar seu potencial a ser utilizado nesse processo. Este trabalho avaliou o uso do nariz eletrônico para seleção de OGR para produção de biodiesel, substituindo os métodos físico-químicos convencionais. 36 amostras de OGR foram analisadas pelo equipamento e em seguida submetidas para transesterificação. Os ésteres produzidos foram considerados biodiesel quando o rendimento da reação foi maior que $97 \%$. Os dados do nariz eletrônico foram interpretados com o modelo estocástico e análise discriminante quadrática. Os resultados indicaram que o nariz eletrônico é uma ferramenta promissora para seleção deste importante resíduo para a produção de biocombustível, com uma classificação correta das amostras superior a $80 \%$.
\end{abstract}

Palavras-chave: fritura, modelagem, resíduo.

\section{USE OF ELECTRONIC NOSE (E-NOSE) TO BIODIESEL PRODUCTION FROM WASTE COOKING OILS (WCO)}

\begin{abstract}
Waste cooking oils (WCO) are an alternative raw material to produce biodiesel, however, to be economically viable, simple and inexpensive methods are needed to assess its potential to be used. This work evaluated the use of electronic nose in the selection of WCO to produce biodiesel, replacing the conventional methods of physical-chemical analysis. 36 samples of WCO were initially smelt by e-nose and then submitted to transesterification, the esters produced were considered biodiesel when the reaction had a yield greater than 97\%. The e-nose data were interpreted with the stochastic model and quadratic discriminant analysis. The results indicated that the electronic nose is a promising tool in the selection of WCO for biodiesel production, with correct classification of samples above $80 \%$.
\end{abstract}

Keywords: frying, modelling, wastes.

\section{INTRODUÇÃO}

Os biocombustíveis representam um importante papel diante da necessidade de exploração de recursos energéticos alternativos aos combustíveis fósseis, principal fonte de energia utilizada no mundo. A crescente demanda energética resultou na diminuição substancial dos reservatórios de petróleo, gás natural e carvão mineral e, aliado a este problema, o aumento no uso de combustíveis fósseis é apontado como a principal causa da poluição atmosférica.

O biodiesel é um exemplo de biocombustível que, além de colaborar com a diversificação da matriz energética de um país, é vantajoso em termos ambientais e sociais. No Brasil, desde 2002 é obrigatória a adição de uma porcentagem deste biocombustível ao diesel comercializado e atualmente este valor corresponde a $10 \%$ (ANP, 2018). O principal desafio na cadeia de produção do biodiesel é viabilizá-la econômica e sustentavelmente e, neste contexto, a escolha da matéria-prima é um dos principais fatores de impacto no preço final do biodiesel. O óleo de soja é a matéria-prima mais utilizada no país, em razão de sua alta disponibilidade, porém tem-se incentivado a diversificação das matérias-primas, priorizando aquelas que não competem com a produção de alimentos.

Uma alternativa é a reutilização de óleos e gorduras residuais (OGR) de processos de fritura de alimentos que, além de contribuir para viabilização econômica do biodiesel, resulta no reaproveitamento energético de um resíduo que, se descartado de forma inadequada, pode causar danos ao meio ambiente. 
No entanto, o OGR representa menos de $1 \%$ do total da matéria-prima destinada à produção de biocombustíveis no Brasil. A principal limitação é que, no processo de fritura, o óleo tende a sofrer degradação e modificação de propriedades que influenciam no processo de obtenção do biodiesel.

Para monitorar o estado de degradação do OGR e avaliar seu potencial de uso, geralmente são utilizados métodos analíticos físico-químicos que, apesar de confiáveis, são complexos e utilizam grande quantidade de solventes e reagentes químicos. Portanto, para que o OGR se torne uma matéria-prima mais representativa é importante o desenvolvimento de métodos alternativos de monitoramento da qualidade de óleos e gorduras residuais, que priorize rapidez, simplicidade e baixo custo.

Neste contexto, o nariz eletrônico (e-nose), um instrumento que se baseia no sistema biológico de recepção e interpretação de odores, pode ser uma ferramenta utilizada na seleção de amostras de OGR destinadas à produção de biodiesel, fornecendo uma análise rápida e não destrutiva. Este equipamento tem sido aplicado na área médica, no monitoramento da qualidade do ar, na indústria de alimentos, dentre outros (Guohua et al., 2015; Xu et al., 2016).

Este trabalho objetivou a criação de uma metodologia de pré-classificação do óleo residual de fritura, a partir de diferentes fontes, a fim de garantir a qualidade na produção de biodiesel. Através da utilização de um perfil olfativo, o óleo residual foi classificado em relação às suas diferentes origens, e correlacionadas com a qualidade do biodiesel produzido (taxa de conversão, viscosidade e densidade). Além disso, o biodiesel produzido também foi classificado de acordo com as normas vigentes através do seu perfil olfativo.

\section{MATERIAL E MÉTODOS}

Trinta e seis amostras de OGR foram coletadas, filtradas, homogeneizadas e caracterizadas através de parâmetros físico-químicos convencionais (índice de acidez, índice de peróxido e viscosidade cinemática) e também pelo perfil olfativo.

$\mathrm{O}$ índice de acidez foi determinado pela metodologia da Association of Official Analytical Chemists (AOAC, 1995) e o índice de peróxido foi obtido pela metodologia da American Oil Chemists'Society (AOCS, 1990). A densidade e a viscosidade absoluta foram determinadas conforme normas da Agência Nacional do Petróleo, Gás Natural e Biocombustíveis (ANP, 2016). A viscosidade cinemática foi calculada a partir da razão entre a viscosidade absoluta e a densidade.

O perfil olfativo foi obtido a partir da medição no equipamento Cyranose 320 (Smiths Detection) baseada na variação das resistências elétricas de seus sensores. A interpretação dos resultados foi baseada na modelagem diferencial estocástica proposta por Siqueira et al (2018).

$\mathrm{O}$ biodiesel foi produzido por transesterificação alcalina em um reator encamisado por $2 \mathrm{~h}$ na temperatura fixa de $60^{\circ} \mathrm{C}$ e agitação de $400 \mathrm{rpm}$. O catalisador utilizado foi o hidróxido de potássio em proporção de $1 \%$ em massa em relação ao óleo. $\mathrm{O}$ agente acilante foi o etanol, adicionado na proporção molar de 9:1 em relação ao óleo. Em seguida, o produto foi submetido a lavagens com água destilada para remoção do subproduto e ajuste de $\mathrm{pH}$. Após repouso, o biodiesel foi submetido ao processo de evaporação rotativa e secagem com sulfato de sódio.

Os ésteres produzidos foram caracterizados conforme acidez, viscosidade cinemática, perfil olfativo e teor de ésteres. As três primeiras análises foram realizadas com o procedimento descrito para o OGR. O teor de ésteres foi determinado pelo uso da espectroscopia por ressonância magnética nuclear (RMN) conforme metodologia descrita por Paiva et al (2013).

\section{RESULTADOS E DISCUSSÃO}

A média dos resultados da caracterização do OGR é apresentada na Tabela 1. Em relação ao índice de acidez, as amostras de OGR apresentaram valores entre 0,39 e 12,59 $\mathrm{mg} \mathrm{KOH} \mathrm{g}^{-1}$ óleo. Essa análise é um importante parâmetro para avaliar o grau de degradação de OGR, uma vez que no processo de fritura ou de armazenamento do óleo, ácidos graxos livres são formados por reações de oxidação e hidrólise (Leung et al., 2010). Estes valores são compatíveis com índice de acidez para OGR descritos na literatura (Felizardo et al., 2006).

Os valores obtidos para o índice de peróxido das amostras de OGR estão na faixa de 1,98 a 71,82 mEq $\mathrm{kg}^{-1}$ óleo. Esse parâmetro caracteriza o OGR quanto à rancidez oxidativa, sendo também influenciado pelas suas condições de uso e armazenamento. A Agência Nacional de Vigilância Sanitária, ANVISA, recomenda que os óleos usados para fritura tenham índice de peróxido máximo de $10,0 \mathrm{mEq} \mathrm{kg}^{-1}$ (ANVISA, 1999). Portanto, a maioria das amostras coletadas se encontrava imprópria para consumo na alimentação. 
A média dos resultados da caracterização dos ésteres produzidos estão na Tabela 2. Neste trabalho, os teores de éster dos produtos da transesterificação alcalina de OGR apresentam valores entre 0 e $100 \%$ de conversão em ésteres etílicos. Os teores de éster de $75 \%$ das amostras analisadas apresentam valores acima do mínimo previsto em norma, $97 \%$.

Os valores de índice de acidez encontrados para o biodiesel produzido neste trabalho variaram de 0,14 a $6,3 \mathrm{mg} \mathrm{KOH} \mathrm{g}^{-1}$, sendo que $61 \%$ do total de amostras analisadas apresentaram acidez acima do valor exigido pela ANP, que é $0,5 \mathrm{mg} \mathrm{KOH} \mathrm{g}^{-1}$ de biodiesel. Os altos valores podem indicar presença de água do meio, que inicia reações de hidrólise, aumentando o teor de ácidos.

A densidade do biodiesel afeta diretamente seu desempenho no motor, já que influencia na atomização do biocombustível (Basso et al., 2013). As amostras de biodiesel estudadas apresentam valores de densidade na faixa de $812-928 \mathrm{~kg} \mathrm{~m}^{-3}$, sendo que $77 \%$ delas estão de acordo com as especificações da ANP.

Para a viscosidade cinemática das amostras de biodiesel, medida a $40^{\circ} \mathrm{C}$, observou-se valores na faixa de 4,67 a 57,53 $\mathrm{mm}^{2} \mathrm{~s}^{-1}$, em que $77 \%$ estão dentro dos padrões exigidos pela ANP. Esse parâmetro é também uma ferramenta para avaliar a eficiência da transesterificação, já que a redução da viscosidade do óleo vegetal ou gordura após a reação geralmente é proporcional à conversão em ésteres (Usmanov et al., 2015). A viscosidade cinemática do biodiesel, de acordo com a norma vigente, deve estar entre 3,0 e $6,0 \mathrm{~mm}^{2} \mathrm{~s}^{-1}$.

Três sensores do nariz eletrônico foram selecionados para a análise do perfil olfativo do OGR, por apresentarem o comportamento típico descrito em Siqueira et al (2018). Foi possível observar diferenças entre as amostras de OGR que geraram biodiesel compatível com as especificações ANP e as que geraram biodiesel não compatível.

A análise discriminante quadrática foi empregada para examinar a possibilidade de prever se o biodiesel seria compatível com as especificações ANP, com base nas correlações das variáveis do perfil olfativo e origem do OGR com os parâmetros do biodiesel. De maneira inovadora, o modelo estocástico associado à análise discriminante propôs uma abordagem para modelar a variabilidade do sinal do nariz eletrônico, através de uma equação diferencial estocástica. Essa equação reproduziu os diferentes comportamentos das fases de dessorção e adsorção do sensor e sua aplicação nesse trabalho possibilitou a classificação correta de $80 \%$ a $92 \%$ das amostras de OGR.

A respeito da análise do perfil olfativo do biodiesel, essa apresentou uma menor variabilidade dos dados em comparação com os perfis obtidos para o OGR. Esse comportamento pode ser atribuído à composição mais homogênea desse biocombustível, após sofrer um processamento para a sua obtenção. Utilizando o modelo estocástico proposto obteve-se uma classificação corretas das características do biodiesel, a partir de seu perfil olfativo, de $86 \%$ a $91 \%$ das amostras.

\section{CONCLUSÃO}

O nariz eletrônico mostrou-se uma ferramenta promissora na seleção de óleo e gordura residual (OGR) de fritura de alimentos destinado à produção de biodiesel, fornecendo uma análise rápida e não destrutiva. Isso se deve a interpretação através do modelo estocástico que de mostrou adequada para a classificação do biodiesel e da predição de quais amostras de OGR geraram biocombustível de acordo com normas vigentes. Esses resultados podem contribuir para o melhor reaproveitamento de um resíduo alimentar e diversificação da fonte de matéria-prima destinada à produção de biodiesel, gerando impactos ambientais e sociais positivos.

\section{AGRADECIMENTOS}

Os autores agradecem o apoio financeiro concedido pela Fundação de Amparo à Pesquisa do Estado de São Paulo, Programa de Pesquisa em Bioenergia / BIOEN (Processo no 2014 / 25001-2) e a bolsa de Mestrado (Processo $n^{\circ}$ 2017/25340-0). O presente trabalho foi realizado com apoio da Coordenação de Aperfeiçoamento de Pessoal de Nível Superior - Brasil (CAPES) - Código de Financiamento 001 (bolsa de Mestrado).

\section{REFERÊNCIAS}

. Lei $n^{\circ} 13.263$ de 23 de março de 2016. Legislação ANP 2016. Disponível em: < http: //anp.gov.br > Acesso em: 01 de fevereiro de 2017.

AGÊNCIA NACIONAL DE VIGILÂNCIA SANITÁRIA - ANVISA. Resolução RDC no 482 , de 23 de setembro de 1999. Regulamento Técnico para Fixação de Identidade e Qualidade de Óleos e Gorduras Vegetais. Disponível em: <http://elegis.bvs.br/leisref/public > Acesso em: 12 abr. 2017. AGÊNCIA NACIONAL DO PETRÓLEO, GÁS NATURAL E BIOCOMBUSTÍVEIS- ANP. Dados 


\section{VISIGER AE DE7 A 09 MA10 2019

estatísticos 2018. Disponível em: < http:// http://anp.gov.br > Acesso em: 01 de março de 2018.

AMERICAN OIL CHEMISTS' SOCIETY- AOCS. Official methods and recommended pratices. Champaign: USA, 1990.

ASSOCIATION OF OFFICIAL ANALYTICAL CHEMISTS- AOAC. Official methods and recommended pratices. Arlington: USA, 1995.

BASSO, R. C.; MEIRELLES, A. J. de A.; BATISTA, E. A. C. Densities and viscosities of fatty acid ethyl esters and biodiesels produced by ethanolysis from palm, canola, and soybean oils: Experimental data and calculation methodologies. Industrial and Engineering Chemistry Research, v. 52, n. 8, p. 2985-2994, 2013.

FELIZARDO, P.; NEIVA CORREIA, M. J.; RAPOSO, I.; MENDES, J. F.; BERKEMEIER, R.; BORDADO, J. M. Production of biodiesel from waste frying oils. Waste Management, v. 26, n. 5, p. 487-494, 2006.

GUOHUA, H.; JIAOJIAO, J.; DENG, S.; XIAO, Y.; MENGTIAN, Z.; MINMIN, W.; DANDAN, Y. Winter jujube ( Zizyphus jujuba Mill .) quality forecasting method based on electronic nose. Food chemistry, v. 170, n. 1, p. 484-491, 2015.

LEUNG, D. Y. C.; WU, X.; LEUNG, M. K. H. A review on biodiesel production using catalyzed transesterification. Applied Energy, v. 87, n. 4, p. 1083-1095, 2010.

PAIVA, E. J. M.; DA SILVA, M. L. C. P.; BARBOZA, J. C. S.; DE OLIVEIRA, P. C.; DE CASTRO, H. F.; GIORDANI, D. S. Non-edible babassu oil as a new source for energy production-a feasibility transesterification survey assisted by ultrasound. Ultrasonics Sonochemistry, v. 20, n. 3, p. 833-838, 2013.

SIQUEIRA, A. F.; MELO, M. P.; GIORDANI, D. S.; GALHARDI, D. R. V.; SANTOS, B. B.; BATISTA, P. S.; FERREIRA, A. L. G. Stochastic modeling of the transient regime of an electronic nose for waste cooking oil classification. Journal of Food Engineering, v. 221, n. 1, p. 114-123, 2018.

USMANOV, R. A.; MAZANOV, S. V.; GABITOVA, A. R.; MIFTAKHOVA, L. K.; GUMEROV, F. M.; MUSIN, R. Z.; ABDULAGATOV, I. M. The Effect of Fatty Acid Ethyl Esters Concentration on the Kinematic Viscosity of Biodiesel Fuel. Journal of Chemical and Engineering Data, v. 60, n. 11, p. 3404-3413, 2015. XU, L.; YU, X.; LIU, L.; ZHANG, R. A novel method for qualitative analysis of edible oil oxidation using an electronic nose. Food Chemistry, v. 202, n. 1, p. 229-235, 2016.

Tabela 1. Médias de cada parâmetro da caracterização do OGR.

\begin{tabular}{|c|c|c|c|c|}
\hline & $\begin{array}{c}\text { Acidez } \\
\left(\mathrm{mgKOH} \mathrm{g}^{-1}\right) \\
\end{array}$ & $\begin{array}{c}\text { Peróxido } \\
\left(\mathrm{mEq} \mathbf{k g}^{-1}\right)\end{array}$ & $\begin{array}{c}\text { Densidade } \\
\left(\mathrm{g} \mathrm{cm}^{-3}\right)\end{array}$ & $\begin{array}{c}\text { Viscosidade } \\
\left(\mathrm{mm}^{2} \mathbf{s}^{-1}\right)\end{array}$ \\
\hline Média & 1,78 & 18,36 & 0,917 & 42,69 \\
\hline Desvio padrão & 2,56 & 16,15 & 0,006 & 7,62 \\
\hline
\end{tabular}

Tabela 2. Médias de cada parâmetro da caracterização do biodiesel.

\begin{tabular}{lcccc}
\hline & $\begin{array}{c}\text { Éster } \\
(\mathbf{\%})\end{array}$ & $\begin{array}{c}\text { Acidez } \\
\left(\mathbf{m g K O H ~ g}^{-\mathbf{1}}\right)\end{array}$ & $\begin{array}{c}\text { Densidade } \\
\left(\mathbf{g ~ c m}^{-\mathbf{3}}\right)\end{array}$ & $\begin{array}{c}\text { Viscosidade } \\
\left(\mathbf{m m}^{\mathbf{2}} \mathbf{~ s}^{-\mathbf{1}}\right)\end{array}$ \\
\hline Média & 90,51 & 0,91 & 0,88 & 8,66 \\
Desvio padrão & 24,73 & 1,14 & 0,02 & 10,71 \\
\hline
\end{tabular}




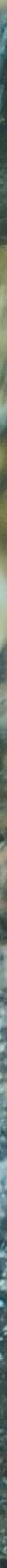

$\frac{1}{4 x}$ $x$ -

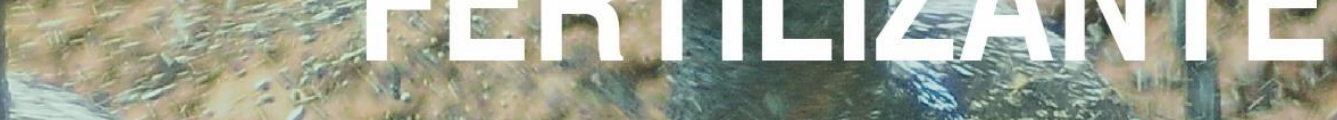




\title{
AVALIAÇÃO DE PÓ DE ROCHA DE ARDÓSIA ASSOCIADO AO COMPOSTO DE RESÍDUDOS DA AGROINDUSTRIA FRIGORÍFICA NO CULTIVO DE ALFACE
}

\author{
Schallenberger, E.*1; Cantú, R.R. ${ }^{1}$; Morales, R.G.F. ${ }^{1}$; Visconti, A. ${ }^{1}$; Vale, M.L.C.; Ceccon, A.P. ${ }^{2}$ \\ ${ }^{1}$ Pesquisadores da Epagri, Itajaí, SC - Brasil; schallenberger@epagri.sc.gov.br \\ ${ }^{2}$ Estudante de agronomia-UFPR-Campus Palotina-PR
}

\begin{abstract}
RESUMO: As reservas de rocha de ardósia são muito grandes em Santa Catarina e as análises químicas do produto demonstram entre $3 \%$ a $6 \%$ de potássio, alta concentração de silício e outros minerais. Para o pó de rocha de ardósia se tornar um insumo agrícola com registro no MAPA como remineralizador de solo é necessária sua avaliação agronômica. Assim, o objetivo deste trabalho foi avaliar seu uso isolado ou em combinação ao composto orgânico de resíduos da agroindústria frigorífica $(\mathrm{CF})$ para uso como remineralizador de solo na nutrição de alface. $\mathrm{O}$ trabalho constou de seis tratamentos avaliados em três diferentes ambientes. Cultivo à céu aberto em área de alta fertilidade, cultivo à céu aberto em área de média fertilidade e cultivo em abrigo de cultivo. Tratamentos: T1: Testemunha (dose zero); T2: $10 \mathrm{t} \mathrm{ha}^{-1}$ de pó de rocha; T3: $30 \mathrm{t} \mathrm{ha}^{-1}$ de CF; T4: $5 \mathrm{t} \mathrm{ha}^{-1}$ de pó de rocha $+30 \mathrm{t} \mathrm{ha}^{-1} \mathrm{de}$ CF; T5: $10 \mathrm{tha}^{-1}$ de pó de rocha $+30 \mathrm{t} \mathrm{ha}^{-1} \mathrm{de}$ CF; T6: $20 \mathrm{t} \mathrm{ha}{ }^{-1}$ de pó de rocha $+30 \mathrm{t} \mathrm{ha}^{-1}$ de CF. Os resultados demonstraram que o pó de rocha de ardósia pode ser utilizado na nutrição de alface pois permite desenvolvimento e produtividade normal às plantas. A associação do pó de rocha de ardósia nas doses de $5 \mathrm{t} \mathrm{ha}^{-1}, 10 \mathrm{t} \mathrm{ha}^{-1}$ e $20 \mathrm{t} \mathrm{ha}^{-1}$ com o composto de resíduos da agroindústria frigorífica na nutrição da alface promove bom rendimento na cultura da alface.
\end{abstract}

Palavras-chave: remineralizador, adubação, nutrientes minerais.

\section{EVALUATION OF POWDER OF ROCK OF SLATE ASSOCIATED WITH THE COMPOUND OF RESIDUES OF THE REFRIGERATED AGROINDUSTRY IN LETTUCE CROPS}

\begin{abstract}
Slate rock reserves are very large in Santa Catarina and the chemical analyzes of the product show between $3 \%$ and $6 \%$ of potassium, high concentration of silicon and other minerals. For the slate rock powder to become an agricultural input with MAPA registration as a soil remineralizer, the agronomic evaluation is necessary. Thus, the objective of this work was to evaluate its use alone or in combination with the organic compost from residues of the refrigerated agroindustry (CF) for use as a soil remineralizer in lettuce nutrition. The study consisted of six treatments evaluated in three different environments. Open-air cultivation in an area of high fertility, open-air cultivation in an area of medium fertility and cultivation in agricultural greenhouses. Treatments: T1: Witness (dose zero); T2: $10 \mathrm{t} \mathrm{ha}^{-1}$ of rock dust; T3: $30 \mathrm{tha}^{-1} \mathrm{CF}$; T4: $5 \mathrm{t} \mathrm{ha}^{-1}$ of rock powder $+30 \mathrm{tha}^{-1}$ of CF; T5: $10 \mathrm{t} \mathrm{ha}^{-1}$ of rock powder $+30 \mathrm{t} \mathrm{ha}^{-1}$ of CF; T6: $20 \mathrm{t} \mathrm{ha}^{-1}$ of rock powder + $30 \mathrm{t} \mathrm{ha}^{-1}$ of CF. The results showed that slate rock powder can be used in lettuce nutrition because it allows normal development and productivity of plants. The association of slate rock powder at $5 \mathrm{t} \mathrm{ha}^{-1}, 10 \mathrm{tha}^{-1}$ and $20 \mathrm{t} \mathrm{ha}^{-1}$ with the residues compost from the refrigeration agroindustry in lettuce nutrition promotes good yield in lettuce crops.
\end{abstract}

Keywords: remineralizer, fertilization, mineral nutrients

\section{INTRODUÇÃO}

A ardósia é uma rocha caracterizada como de uso artesanal. As reservas em Santa Catarina são de aproximadamente 214.298.574 toneladas. Muitas pedreiras que trabalham com beneficiamento de ardósia possuem uma central de britagem para o reaproveitamento das pedras, reciclando os resíduos gerados no processo de beneficiamento, aproximadamente $70 \%$ da lavra, resultando num resíduo comumente chamado de pó de rocha. (DNPM, 2016).

Análises preliminares da ardósia têm demonstrado a presença de até $6 \%$ de potássio e microelementos podendo-se tornar um potencial fertilizante de liberação lenta, convertendo-se em um remineralizador com finalidade agrícola. $\mathrm{O}$ pó de rocha de ardósia pode se tornar um insumo agrícola com registro no mapa como remineralizador de solo. Para isto, é necessário a avaliação agronômica de seu uso, demonstrando efetividade 
como remineralizador do solo e o enquadramento das características físicas e químicas nas normas para o registro de remineralizadores de solo (MAPA, 2016).

Caracteriza-se como um grande problema do resíduo de pó de rocha a falta de um estudo demonstrando a viabilidade técnica e econômica de seu uso como remineralizador de solo, fazendo com que este resíduo seja mal aproveitado, deixando de gerar renda para as mineradoras e também deixando de ofertar para a agricultura um insumo de baixo custo, podendo reduzir o investimento em fertilização de plantas. A baixa disponibilidade natural de nutrientes em solos brasileiros e a dependência externa do país por fertilizantes abrem espaço à procura por novas fontes locais, dentre elas, os materiais rochosos contendo nutrientes na sua composição.

No Brasil, cerca de $73 \%$ do nitrogênio, $54 \%$ do fósforo e $92 \%$ do potássio são comprados de outros países. A busca por fontes de nutrientes eficientes, econômicas e mais acessíveis tem importante papel na economia brasileira e vários projetos que buscam novas fontes nacionais de nutrientes para agricultura.

O uso de rochas moídas como fontes agrominerais com fins de fertilização do solo é conhecido como rochagem e, embora possa parecer uma novidade, já é praticado há vários anos, tendo como exemplos as práticas agrícolas da calagem e a fosfatagem. Esta técnica tem despertado a atenção de pesquisadores em todo o mundo como uma das alternativas às fontes convencionais de nutrientes. A rochagem pode tornar-se uma importante técnica de fertilização, complementar às práticas tradicionalmente utilizadas no Brasil, indicada, a princípio, para pequenos produtores e em escala regional, como ocorre com o calcário atualmente, destacandose pela diversidade de matérias-primas com potencial para uso como agrominerais.

O emprego de compostos orgânicos na produção agrícola é uma prática adotada no mundo inteiro. Seu grau de eficiência depende do sistema e da forma como se executa o processo de seu preparo e das matérias primas utilizadas, podendo ocorrer elevadas variações de qualidade. Segundo Shallenberger et al (2016) a adubação orgânica quando realizada com composto orgânico estabilizado e de boa qualidade nutricional, resulta em excelentes produtividades e pode ser aplicado em dose única por ocasião do plantio.

A elaboração de compostos orgânicos provenientes de resíduos de agroindústrias é uma atividade promissora em Santa Catarina, uma vez que o estado é um grande produtor e exportador de produtos agroindustriais, gerando muitos resíduos que podem ser transformados em compostos para utilização na nutrição mineral de plantas. Os resíduos provenientes de frigoríficos localizados nos municípios de Rio do Sul e Presidente Getúlio e da criação de suínos estão sendo transformados em composto orgânico através do processo de compostagem automatizada realizada com sucesso e o fertilizante produzido apresenta as características químicas e de fertilidade promissoras.

O objetivo deste trabalho foi avaliar o uso do pó de rocha de ardósia isolado ou em combinação ao composto orgânico de resíduos da agroindústria frigorífica para uso como remineralizador de solo na nutrição de alface.

\section{MATERIAL E MÉTODOS}

O trabalho constou da avaliação de doses de pó de rocha de ardósia na adubação de alface associada ao uso de composto de resíduos da agroindústria frigorífica. O Pó de rocha de ardósia foi proveniente da Central de Britagem Castelinho Ltda, localizado no município de Trombudo Central - SC. O composto foi desenvolvido na unidade de compostagem automatizada Lauro Pamplona localizada no município de Trombudo Central - SC. Os resíduos foram provenientes dos frigoríficos, localizados em Rio do Sul e Presidente Getúlio, das criações de suínos de granjas localizadas em Ituporanga e Rio do Sul e da fábrica de rações localizada em Agronômica.

O trabalho foi realizado em Itajaí/SC no ano de 2018 na Estação Experimental da Epagri-EEI, situada a $27^{\circ} 34^{\prime}$ de latitude Sul, $48^{\circ} 30^{\prime}$ de longitude Oeste de Greenwich e altitude de 5m. De acordo com Köeppen (1948) o clima do lugar é subtropical, com chuvas bem distribuídas e verão quente e úmido, do tipo Cfa.

O experimento constou de seis tratamentos avaliados em três diferentes ambientes e em duas épocas de cultivo (Esquema fatorial 6x3x2). Tratamentos T1: Testemunha (dose zero); T2: $10 \mathrm{t} \mathrm{ha}^{-1}$ de pó de rocha de ardósia; T3: $30 \mathrm{t} \mathrm{ha}^{-1}$ de composto da agrindústria frigorífica; T4: $5 \mathrm{t} \mathrm{ha}^{-1}$ de pó de rocha de ardósia $+30 \mathrm{tha}{ }^{-1}$ de composto da indústria frigorífica; T5: $10 \mathrm{t} \mathrm{ha}^{-1}$ de pó de rocha de ardósia $+30 \mathrm{t} \mathrm{ha} \mathrm{a}^{-1}$ de composto da indústria frigorífica; T6: $20 \mathrm{t} \mathrm{ha-1}$ de pó de rocha de ardósia +30 t ha ${ }^{-1}$ de composto da indústria frigorífica. Os ambientes de cultivo foram o cultivo à céu aberto em área de alta fertilidade, cultivo à céu aberto em área de média fertilidade e cultivo em abrigo de cultivo. Foram realizados dois cultivos. O primeiro plantio foi realizado no dia 30/05/2018 e a colheita no dia 17/07 e o segundo foi plantado no dia 10/08/2018 e a colheita no dia 19/09/2018. Foi utilizado o cultivar de alface SCS374 Litorânea. As mudas foram transplantadas aos 28 dias. 
As doses do pó de rocha foram estabelecidas buscando encontrar a melhor dose para o cultivo de alface baseadas nos teores de nutrientes do produto (Tabela 1) A dose do composto foi estabelecida considerando suas características químicas (Tabela 2), tomando como base trabalhos já publicados onde foram estudados outros compostos (Cantú et al. 2017) e a recomendação da CQFS- RS/SC (2016) para o cultivo em questão.

Cada tratamento teve quatro repetições compostas por 16 plantas, onde foram analisados o peso e número de folhas de cada planta. Os resultados foram submetidos à análise de variância e as médias dos dados foram comparados pelo teste Tukey, ao nível de 5\% de probabilidade.

\section{RESULTADOS E DISCUSSÃO}

Os resultados do trabalho demonstram que o pó de rocha de ardósia pode ser utilizado na nutrição de alface. No tratamento com a utilização apenas do pó de rocha de ardósia, o peso das plantas de alface foi semelhante tanto com o tratamento testemunha como no tratamento com associação ao composto de resíduos da agroindústria frigorífica na dosagem de $20 \mathrm{t} \mathrm{h}^{-1}$. Quanto às doses do pó de rocha associadas ao composto de resíduos da indústria frigorífica, não houve diferença entre as doses aplicadas e também quando comparada ao uso somente do pó de rocha sem composto (Tabela 3). Quanto ao número de folhas nas plantas de alface, o resultado mostrou que o uso do pó de rocha de ardósia proporciona bom desenvolvimento das plantas, uma vez que o número de folhas foi igual quando comparado o tratamento só com pó de rocha à testemunha e também com os diferentes tratamentos (Tabela 3). Isto demonstra que os minerais presentes no pó de rocha de ardósia podem ser benéficos ao solo mantendo a produtividade das lavouras de alface. Melamed et al., (2007) destacam que os benefícios advindos da utilização de pós de rocha são: o fornecimento lento de macro e micronutrientes; aumento da disponibilidade desses nutrientes nos solos cultivados; reequilíbrio do $\mathrm{pH}$ do solo e aumento da reserva nutricional do solo. No Brasil, Leonardos et al. (1987) mostram que as culturas do feijão (Phaseolus vulgaris), do capim napier (Penissetum purpureum) e mesmo árvores de crescimento lento responderam positivamente ao uso de pó de rocha. Na avaliação do uso de pó de rocha no rendimento da cultura de mandioca, Souza et al., (2013) constataram que as médias de produtividade da variedade Japonesinha sob adubação com todas as rochas avaliadas foram superiores às médias dos demais tratamentos, incluindo o tratamento da variedade com adubação convencional. Segundo a EMBRAPA, (2013) o pó de rocha tem potencial de uso agrícola viabilizando pequenas mineradoras nacionais e gerando empregos, já que agregaria valor ao que, até agora, era apenas rejeito de mineração. Também a agricultura familiar seria beneficiada com a tecnologia, já que o pó de rocha poderia ser utilizado a baixo custo, desde que a propriedade rural estivesse situada próxima a uma área de ocorrência da rocha.

Quanto ao uso de composto de resíduos da agroindústria frigorífica, os resultados demonstram que sua utilização propiciou melhor peso e número de folhas das plantas de alface quando comparada ao tratamento testemunha sem utilização de composto e pó de rocha (Tabela 3). Schallenberger et al., (2018) avaliando a utilização do composto de resíduos da agroindústria frigorífica na nutrição de alface, concluíram que seu uso proporciona excelente produtividade e qualidade das plantas de alface.

\section{CONCLUSÃO}

O pó de rocha de ardósia pode ser utilizado na nutrição de alface pois permite desenvolvimento e produtividade normal às plantas. A associação do pó de rocha de ardósia nas doses de $5 \mathrm{t} \mathrm{ha}^{-1}, 10 \mathrm{tha}^{-1} \mathrm{e} 20 \mathrm{t}$ $\mathrm{ha}^{-1}$ com o composto de resíduos da agroindústria frigorífica na nutrição da alface promove bom rendimento na cultura da alface.

\section{AGRADECIMENTOS}

A Fundação de Amparo à Pesquisa e Inovação de Santa Catarina - FAPESC, ao Conselho Nacional de Desenvolvimento Científico e Tecnológico - CNPq e à Central de Britagem Castelinho Ltda.

\section{REFERÊNCIAS}

DPNM - Departamento Nacional de Produção Mineral - Anuário Mineral Estadual - Santa Catarina - anos base 2010 - 2013- DNPM - Superintendência de Santa Catarina, 112p. 2016.

CANTÚ, R. R.; MORALES, R. G. F.; SCHALlENBERGER, E.; VISCONTI, A.; HARO, M. M.; SCHVEITZER, B. Adubação da alface com composto dos resíduos da indústria do palmito. In: Simpósio Sul Brasileiro de Olericultura, 1, 2017, Maringá, PR. Resumos... Maringá, PR: Associação Brasileira de Olericultura, 2017. 
EMBRAPA, 2013 - Pó de rocha será nova fonte de potássio para agricultura. (https://www.embrapa.br/noticias) / busca de notícias (https://www.embrapa.br/busca-de-noticias) /

LEONARDOS, O.H.; FYFE, W.S.; KRONBERG, B.I. 1987. The use of ground rocks in laterite systems: an improvement to the use of conventional soluble fertilizers. Chemical Geology, 60:361-370.

MAPA - Ministério da Agricultura, Pecuária e Abastecimento. Instrução normativa no 5, de 10 de março de 2016. Disponível em: http://www.agricultura.gov.br/assuntos/insumos-agropecuarios/insumos-agricolas/.

MELAMED, R.; GASPAR, J.C.; MIEKELEY, N. Pó-de-rocha como fertilizante alternativo para sistemas de produção sustentáveis em solos tropicais. (Série estudos e documentos, 72). 2007

SCHALLENBERGER, E.; CANTÚ, R. R.; MORALES, R. G. F.; SQUERZZATO, N.; MISFELD, A. G. Uso de composto de resíduos da indústria frigorífica na nutrição de alface em sistema orgânico de produção. In: Congresso Brasileiro de Olericultura, 55, 2018, Bonito, Ms. Resumos... Campo Grande, MS: UEMS, 2018. p. 9-10.

SCHALLENBERGER, E.; CANTÚ, R. R.; HARO, M. M.; MORALES, R. G. F.; HEINZEN, J. Método e Dose de Adubação de Hortaliças com Composto Orgânico em Sistema Orgânico de Produção. In: Seminario de Agroecologia da America do Sul, 2, 2016, Dourados, Ms. Resumos... Dourados, MS: Associação Brasileira de Agroecologia, 2016. p. 1-10.

SOUZA, F. P.; MARTINS, E. S. et al. Avaliação do uso do pó de rocha no desempenho de duas variedades de mandioca de mesa. In: II Congresso Brasileiro de Rochagem. Poços de Caldas-MG. Anais - Maio de 2013 Poços de Caldas/MG. 2013.

Tabela 1. Características químicas (\%) do pó de rocha de ardósia utilizado no experimento.

\begin{tabular}{|c|c|c|c|c|c|c|c|}
\hline Material & $\mathrm{SiO}_{2}$ & $\mathbf{A l}_{2} \mathbf{O}_{3}$ & $\mathrm{Fe}_{2} \mathrm{O}_{3}$ & $\mathrm{~K}_{2} \mathrm{O}$ & MgO & $\mathrm{CaO}$ & $\mathbf{P}_{2} \mathrm{O}_{5}$ \\
\hline …............... & ............. & .............. & ............... & ............. & .............. & ............. & (.............. \\
\hline $\begin{array}{c}\text { Pó de rocha de } \\
\text { ardósia }\end{array}$ & 54,8 & 16,6 & 10,0 & 3,6 & 3,5 & 1,7 & 0,2 \\
\hline
\end{tabular}

Tabela 2. Características do composto de resíduos da agroindústria frigorífica utilizado no experimento.

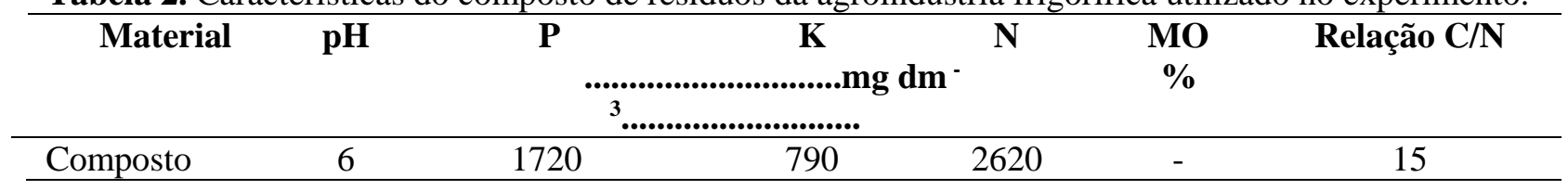

Tabela 3. Peso das plantas (g) e número de folhas por planta de alface nos diferentes tratamentos com o uso de pó de rocha de ardósia associado à composto de resíduos da agroindústria frigorífica (2018).

\section{Tratamentos}

T1 - Testemunha (dose zero)

$\mathrm{T} 2$ - $10 \mathrm{t}$ ha-1 de pó de rocha

T3 - Composto + 20 t ha-1 de pó de rocha

T3 - Composto + 10 t ha-1 de pó de rocha

T3 - Composto + 50 t ha-1 de pó de rocha

T3 - Composto
Peso da planta (g)

211,5 A1

261,7 A1 A2

$332,1 \quad$ A2 $\quad$ A3

391,0

427,2

440,9
Número de folhas por planta

36,5 A1

40,3 A1 A2

$44,7 \quad$ A2

$45,2 \quad$ A2

$45,2 \quad \mathrm{~A} 2$

*Médias seguidas pelas mesmas letras não apresentam diferença significativa entre elas $\mathrm{p} \leq 0.05$. 


\title{
EFEITO DA APLICAÇÃO DE DEJETOS SUÍNOS NO ESTOQUE DE CARBONO ORGÂNICO DO SOLO
}

\author{
Medeiros, S.F.1*; De Paiva Filho, S.V.'; Ferreira, R.V.²; De Oliveira, C.L.'; Brunetta, R.F.'; Tavares, \\ R.L. ${ }^{3}$ \\ ${ }^{1}$ Graduandos da Universidade de Rio Verde, Rio Verde-GO, Brasil, sandrielle_furquim@ hotmail.com*; silviofilho1997@gmail.com; \\ romulo.fb13@hotmail.com \\ ${ }^{2}$ Mestrando da Universidade de Rio Verde, Rio Verde-GO, Brasil, raniervieiraferreira@hotmail.com; cleire.oliveira@gmail.com \\ ${ }^{3}$ Orientadora, Prof. Dr. da Faculdade de Agronomia, roseluiza@unirv.edu.br;
}

\begin{abstract}
RESUMO: A adição de dejetos suínos no solo é considerada como importante prática para aumento no teor de carbono no solo, pois possui um alto teor de matéria orgânica. O objetivo deste trabalho foi quantificar o estoque de carbono no solo sob sistema de plantio direto com adição de dejetos de suínos em Rio Verde, GO. Foi utilizada uma área experimental sob sistema de plantio direto utilizando o esquema de sucessão soja/milho, localizada na Universidade de Rio Verde, GO. O experimento recebeu aplicação anual de dejetos suínos em diferentes doses $\left(0,25,50,75 \mathrm{e} 100 \mathrm{~m}^{3} \mathrm{ha}^{-1}\right)$. Foram realizadas análises de teor de carbono orgânico e densidade do solo nas profundidades de 0-10, 10-20, 20-40, 40-60, 60-80 e 80-100 cm. Os resultados mostraram que a dose de $75 \mathrm{~m}^{3}$ ha $^{-1}$ promoveu incremento de carbono no solo, gerando balanço positivo de carbono no sistema. Esses resultados indicam o potencial no uso de dejetos suínos na agricultura e sugerem seu uso de forma complementar à adubação mineral.
\end{abstract}

Palavras-chave: adubação orgânica, matéria orgânica, plantio direto.

\section{SOIL ORGANIC CARBON CONTENT IN NO-TILLAGE SYSTEM WITH ADDITION OF SWINE MANURE}

\begin{abstract}
The addition of pig manure in the soil is considered as an important practice to increase soil carbon content, since it has a high content of organic matter. The objective of this work was to quantify the carbon stock in the soil under no - tillage system with addition of swine manure in Rio Verde, GO. An experimental area was used under no - tillage system using the soybean / corn succession scheme, located at the University of. The experiment received annual application of swine manure in different doses $(0,25,50$, 75 and $100 \mathrm{~m} 3 \mathrm{ha}-1)$. Analyzes of organic carbon content and soil density were performed at depths of $0-10$, $10-20,20-40,40-60,60-80$ and $80-100 \mathrm{~cm}$. The results showed that the dose of $75 \mathrm{~m} 3$ ha- 1 increased soil carbon, generating a positive carbon balance in the system. These results indicate the potential for the use of pig manure in agriculture and suggest its use in a complementary way to mineral fertilization.
\end{abstract}

Keywords: organic manure, organic matter, no tillage.

\section{INTRODUÇÃO}

No Brasil, a demanda por carne suína tem aumentando, principalmente no Centro-Oeste do Brasil, com grandes investimentos no parque industrial visando exportação. De acordo com Penha et al. (2015), a produção de dejetos de suínos na região do Cerrado é relevante, levando em consideração a possibilidade de utilização deste material como importante fonte de nutrientes para a produção agrícola em solos do Cerrado brasileiro. O volume de dejetos líquidos suínos (DLS) produzidos na região de Rio Verde representa $21 \%$ do total produzido em Goiás e $60 \%$ do total produzido no sudoeste goiano e aumentou significativamente nos últimos dez anos (1994 a 2004), de 69 mil m³ em 1994 para 1,4 milhões de $\mathrm{m}^{3}$ em 2004 (cerca de 10\% do total da região Centro-Oeste), despejando no ecossistema em 2004 vinte vezes mais comparado ao ano de 1994. (Silva, 2003).

\section{MATERIAL E MÉTODOS}

A área experimental está localizada no município de Rio Verde - GO, nas coordenadas $17^{\circ} 48^{\prime}$ de latitude sul e $55^{\circ} 55^{\prime}$ de longitude oeste, com $760 \mathrm{~m}$ de altitude e $4 \%$ de declividade. É uma área utilizada para pesquisa experimental em parceria entre as instituições: Universidade de Rio Verde, EMBRAPA solos e empresa Perdigão Agroindústrias S.A. O clima da região é do tipo Aw, característico de duas estações bem definidas 
(seco no inverno e úmido no verão) de acordo com classificação de Koppen. O solo da área foi classificado como Latossolo Vermelho distrófico, com textura argilosa (60\% de argila, $15 \%$ de silte e $25 \%$ de areia).

A área recebe aplicação de dejetos líquidos suínos desde a safra 2000/2001 e, vem sendo cultivada no esquema de sucessão soja/milho (safra/safrinha) sob sistema de plantio direto. Na área foram instaladas parcelas experimentais que consistem na aplicação ou não de dejetos suínos com diferentes doses. O experimento tem sido conduzido em campo com delineamento experimental de blocos ao acaso (dbc) com 5 tratamentos (doses de dejetos suínos nas quantidades 0, 25, 50, 75 e $100 \mathrm{~m}^{3} \mathrm{ha}^{-1}$ ) e 3 blocos. Além disso, foi adicionado um tratamento com uso de adubação mineral com NPK.

Ao redor das trincheiras, foram coletadas amostras deformadas com trado manual nas mesmas profundidades de coleta. Estas amostras foram utilizadas para análises de teor de carbono no solo. Os dados de análises de solo foram submetidos ao teste estatístico de normalidade dos dados shapiro-wilk. Para comparação entre adubação orgânica com DLS e mineral foi feita análise de contraste e para comparação entre profundidades de solo, foi utilizado teste de Tukey a 5\% de probabilidade.

\section{RESULTADOS E DISCUSSÃO}

Considerando a quantidade de $0,29 \%$ de matéria seca no DLS (Tabela 1) e dose de aplicação de $50 \mathrm{~m}^{3}$ ha $^{-1}$, a adição de MO seria de aproximadamente $0,15 \mathrm{mg} \mathrm{ha}^{-1}$ ano $^{-1}$. Porém, apesar do baixo teor de MO, quando foi aplicado $75 \mathrm{~m}^{-3} \mathrm{ha}^{-1}$ de DLS, os resultados mostraram um saldo positivo de carbono, com incremento médio de 2,09 $\mathrm{mg} \mathrm{c} \mathrm{ha}^{-1}$ ano $^{-1}$ (tabela 2), cujo resultado pode ser explicado pelo longo tempo de aplicação de DLS na área, de 17 anos.

Em estudo de Mafra et al. (2014), os autores calcularam a deposição de carbono de 0,64 mg ha ${ }^{1}$ ano $^{-1}$ em área com dls contendo $2 \%$ de mos, taxa de aplicação de $25 \mathrm{~m}^{3} \mathrm{ha}^{-1}$ e com histórico de uso de DLS por 10 anos. Enquanto que Scherer et al. (2010) detectaram a deposição de $1,3 \mathrm{mg} \mathrm{ha}^{-1}$ ano ${ }^{-1}$ de mo com dls contendo $3 \%$ de mo e taxa de aplicação de $45 \mathrm{~m}^{3}$ ha ${ }^{-1}$, cujo adição de mo foi considerada baixa após 20 anos de uso de DLS.

O estoque de carbono, no geral, foi maior nas camadas superficiais $(0-10$ e 10-20 cm), diminuindo em profundidade no solo (tabela 2), cujo resultado devem-se mais ao sistema de manejo praticado do que ao tipo de adubação. Isto porque o sistema de plantio direto preconiza a deposição de palhada sobre o solo provinda dos restos culturais, o que aumenta a matéria orgânica e tende a beneficiar as camadas do solo mais próximas da superfície de deposição. (Scherer et al., 2010).

Apesar das maiores adições de carbono pela vegetação na superfície, esta camada está mais sujeita às alterações durante o cultivo agrícola, principalmente no período de semeadura e colheita.

\section{CONCLUSÃO}

A dose de aplicação de $75 \mathrm{~m}^{3}$ ha-1 promoveu incremento de carbono no solo, gerando balanço positivo de carbono no sistema. Além disso, o uso de dejetos suínos influenciou o estoque de carbono em profundidade, com maiores teores nas camadas superficiais de 0-10 e 10-20 cm. Esses resultados indicam o potencial no uso de dejetos suínos na agricultura e sugerem seu uso de forma complementar à adubação mineral.

\section{REFERÊNCIAS}

MAFRA, M.S.H.; CASSOL, P.C.; ALBUQUERQUE, J.A.; CORREA, J.C.; GROHSKOPF, M.A.; PANISSON, J. acúmulo de carbono em latossolo adubado com dejeto líquido de suínos e cultivado em plantio direto. Pesquisa agropecuária brasileira, v.49 brasília, p.08-10, 2014.

PENHA, H. G. V.; MENEZES, J. F. S.; SILVA, C. A.; LOPES, G.; DE ANDRADE CARVALHO, C.; RAMOS, S. J.; GUILHERME, L. R. G. Nutrient accumulation and availability and crop yields following longterm application of pig slurry in a brazilian cerrado soil. Nutrient cycling in agroecosystems, v. 101, n. 2, p. 259-269, 2015.

SCHERER, E. E.; NESI, C. N.; MASSOTTI, Z. Atributos químicos do solo influenciados por sucessivas aplicações de dejetos suínos em áreas agrícolas de santa catarina. Revista brasileira de ciência do solo, v. 34, p. 1375-1383, 2010.

SILVA, M. A. R.; Economia dos recursos naturais. in: economia do meio ambiente - Teoria e Prática, 3., 2003, rio de janeiro. Anais... Rio de janeiro: Campus, 2003. p. 1-29 
Tabela1. Composição química do dejeto líquido de suíno (DLS) aplicado na área experimental na safra 2016/2017. Rio Verde, 2017.

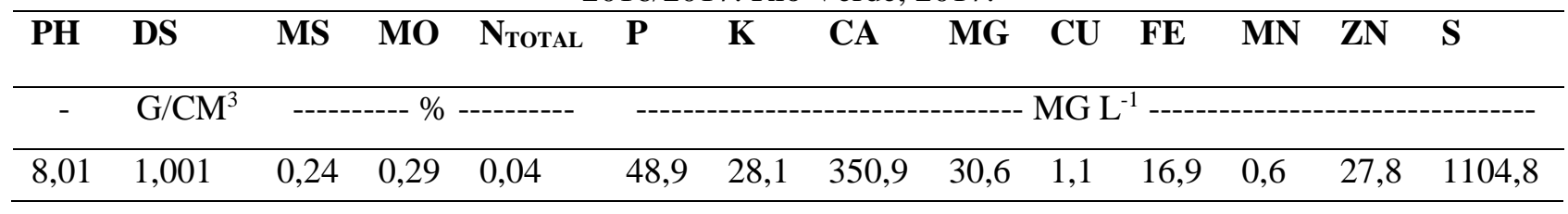

Tabela 2. Valores médios do estoque de carbono e incremento de carbono em diferentes camadas do solo em área sob sistema de plantio direto manejado com adubação orgânica (dejeto líquido de suínos - DLS) e mineral em Rio Verde/GO.

\begin{tabular}{|c|c|c|c|c|c|c|}
\hline \multirow[b]{2}{*}{ Profundidade } & \multicolumn{5}{|c|}{ Adubação orgânica } & \multirow{2}{*}{$\begin{array}{c}\text { Adubação } \\
\text { mineral }\end{array}$} \\
\hline & $\mathbf{0}$ & 25 & 50 & 75 & 100 & \\
\hline$(\mathbf{c m})$ & \multicolumn{5}{|c|}{ Estoque de carbono (MG HA HA $\left.^{-1}\right)$} & \\
\hline $0-10$ & $14.36 \mathrm{~A}$ & $\begin{array}{c}15.72 \\
\mathrm{AB}\end{array}$ & $\begin{array}{c}14.73 \\
\mathrm{AB}\end{array}$ & $16.23 \mathrm{~A}$ & $16.08 \mathrm{~A}$ & $12.59 \mathrm{BC}$ \\
\hline $10-20$ & $14.93 \mathrm{~A}$ & $17.75 \mathrm{~A}$ & $15.96 \mathrm{~A}$ & $16.32 \mathrm{~A}$ & $18.34 \mathrm{~A}$ & $17.07 \mathrm{~A}$ \\
\hline $20-40$ & $\begin{array}{c}12.60 \\
\mathrm{AB}\end{array}$ & $12.66 \mathrm{BC}$ & $11.00 \mathrm{BC}$ & $\begin{array}{c}12.59 \\
\mathrm{AB}\end{array}$ & $11.50 \mathrm{~B}$ & $14.10 \mathrm{AB}$ \\
\hline $40-60$ & $8.76 \mathrm{BC}$ & $10.80 \mathrm{C}$ & $8.73 \mathrm{CD}$ & $8.81 \mathrm{BC}$ & $9.26 \mathrm{BC}$ & $11.56 \mathrm{BC}$ \\
\hline $60-80$ & $7.34 \mathrm{C}$ & $6.61 \mathrm{D}$ & $7.43 \mathrm{CD}$ & $7.20 \mathrm{C}$ & $6.73 \mathrm{C}$ & $9.01 \mathrm{CD}$ \\
\hline $80-100$ & $7.94 \mathrm{C}$ & $6.39 \mathrm{D}$ & $6.43 \mathrm{D}$ & $5.63 \mathrm{C}$ & $6.14 \mathrm{C}$ & $7.00 \mathrm{D}$ \\
\hline \multicolumn{7}{|c|}{ Incremento de carbono $\left(\mathrm{MG} \mathrm{HA}^{-1} \mathrm{ANO}^{-1}\right)$} \\
\hline $0-10$ & - & -3.40 & -8.56 & 1.30 & -2.66 & -8.52 \\
\hline $10-20$ & - & 0.53 & -6.88 & 1.98 & 0.14 & -7.52 \\
\hline $20-40$ & - & -2.44 & -5.63 & 0.81 & -2.60 & -7.21 \\
\hline $40-60$ & - & -5.95 & -9.81 & 3.27 & -4.36 & -7.19 \\
\hline $60-80$ & - & -6.53 & -6.27 & 2.17 & -2.34 & -8.87 \\
\hline $80-100$ & - & -6.03 & -4.88 & 3.02 & -5.70 & -9.55 \\
\hline
\end{tabular}

Médias seguidas de mesma letra na coluna não diferem entre si pelo teste de Tukey a $5 \%$ de probabilidade. 


\title{
ÓXIDO DE MAGNÉSIO AUMENTA A DUREZA E EFICIÊNCIA AGRONÔMICA DE FERTILIZANTES FOSFATADOS
}

\author{
Nascimento, C.O. ${ }^{* 1}$; Mattos, B.B. ${ }^{2}$; Fialho, R.L. ${ }^{1}$; Cabral-Albuquerque, E.C.M. ${ }^{1}$; Benites, V.M. ${ }^{2}$ \\ ${ }^{1}$ Pesquisadores da Universidade Federal da Bahia, Salvador, BA - Brasil. \\ ${ }^{2}$ Pesquisadores da Embrapa Solos, Rio de Janeiro, RJ-Brasil. \\ Carla.nascimento@ufba.br
}

\begin{abstract}
RESUMO: A cama de frango é um resíduo originado a partir da produção de frango de corte, que é utilizada para forrar o piso do aviário, proporcionando conforto às aves confinadas. Por ser rica em nutrientes essenciais para as plantas, a cama de frango tem sido usada como fertilizante sendo a principal forma de disposição, porém devido à poluição dos recursos hídricos em virtude da lixiviação e escoamento esse uso tem sido ameaçado. Uma alternativa para minimizar esses problemas é produzir fertilizantes organominerais granulados para melhorar o aproveitamento dos nutrientes pelo solo e plantas. Entretanto, as características físicas desses grânulos ainda são um limitante para a produção em escala comercial. Dessa forma, o objetivo desse trabalho foi avaliar a eficiência agronômica de fertilizantes organominerais contendo óxido de magnésio para melhorar a dureza dos grânulos. Para isso foram utilizados diferentes percentuais $(0,5 \%, 1 \%, 2 \%$ e $3 \%)$ na mistura de Monoamônio Fosfato (MAP) com a cama de frango. A adição desse material melhora a dureza, avaliada por meio do durômetro e aumenta a absorção de nutrientes, feita por meio de experimentos de vasos em casa de vegetação. A otimização dessa mistura, buscando melhorias físicas a um custo de produção viável, é o principal resultado deste trabalho.
\end{abstract}

Palavras-chave: agricultura, cama de frango, fertilizante organomineral, propriedades mecânicas, resíduo agroindustrial.

\section{MAGNESIUM OXIDE INCREASES THE HARDNESS AND AGRONOMIC EFFICIENCY OF PHOSPHATE FERTILIZERS}

\begin{abstract}
The chicken litter is a waste originated from the production of broiler chicken, which is used to cover the floor of the aviary, providing comfort to the confined chickens. Because it is rich in essential nutrients for plants, the chicken litter has been used as fertilizer and is the main form of disposal, but due to the pollution of the water resources owing to the leaching and runoff, this use has been threatened. An alternative to minimize these problems is to produce granular organomineral fertilizers to improve nutrient utilization by soil and plants. However, the physical characteristics of these granules are still a limiting factor for commercial scale production. Thus, the objective of this work was to evaluate the agronomic efficiency of organomineral fertilizers containing different binder materials to improve the hardness of the granules. Different percentages $(0.5 \%, 1 \%, 2 \%$ and $3 \%)$ of magnesium oxide were used in the mixture of Monoammonium Phosphate (MAP) and chicken litter. The addition of this material improves the hardness, evaluated by means of the durometer and increases the nutrient absorption, by means of experiments of pots under greenhouse conditions. The optimization of this mixture, seeking physical improvements at a viable production cost, is the main result of this work.
\end{abstract}

Keywords: agriculture, agroindustrial waste, chicken litter, mechanical properties, organomineral fertilizer.

\section{INTRODUÇÃO}

A cama de frango $(\mathrm{CF})$ é todo material que possa ser utilizado para forrar o piso do aviário, contendo espessura entre 5 e $10 \mathrm{~cm}$ de altura, com o intuito de tornar mais confortável o ambiente para as aves confinadas. Ao longo do tempo, esse material de forro recebe resto de ração, excreções, penas e descamações de pele. Dentre os materiais utilizados para o forro do piso estão a casca de arroz, serragem, bagaço de cana, casca de amendoim, casca de café e sabugo de milho (WILKINSON et. al., 2011; CHEN e JIANG, 2014).

O Brasil foi o segundo maior produtor de carne de frango do mundo em 2016, produzindo 12,9 milhões de toneladas (ABEF, 2017), o que representa um abate de aproximadamente 5,84 bilhões de cabeça (IBGE, 2017). Essa alta produção de carne de frango eleva, por consequência, a quantidade de cama de frango 
produzida no Brasil, que em 2011, foi estimada em quase 7 milhões de $\mathrm{m}^{3}$, com previsão de aumento (CORRÊA e MIELE, 2011). Benites, et. al. (2010) já atentaram para o crescimento da taxa de produção de frango e consequentemente da cama de aviários, trazendo à tona a necessidade de desenvolver novas tecnologias para minimizar os impactos ambientais gerados por esses resíduos.

Uma alternativa sustentável que vem sendo desenvolvida e comercializada visando o aproveitamento da cama de frango é a produção de fertilizantes organominerais. Porém, quando se trata desse tipo de fertilizante na forma granular, os problemas relacionados as propriedades físicas são ainda consideráveis, tendo em vista que a matéria orgânica tende a se desintegrar de forma acentuada no transporte e armazenamento, após a formação do grânulo, dificultando a sua comercialização. Assim, fica clara a necessidade de buscar formas mais eficientes para produzir esses grânulos, de modo a melhorar propriedades mecânicas desse fertilizante (BENITES et. al., 2010).

Assim, o objetivo desse trabalho foi avaliar o potencial do óxido de magnésio na melhoria das propriedades mecânicas dos fertilizantes, como a dureza e eficiência agronômica. Para isso foram utilizados diferentes percentuais $(0,5 \%, 1 \%, 2 \%$ e $3 \%)$ do óxido de magnésio na mistura de monoamônio fosfato (MAP) com a cama de frango.

\section{MATERIAL E MÉTODOS}

Os fertilizantes organominerais (FOM) foram produzidos por meio da mistura em pó contendo MAP e CF e adicionado o óxido de magnésio em diferentes concentrações $0,5,1,2$ e $3 \%$.

Os fertilizantes foram granulados em disco pelotizador, com velocidade e inclinação constantes e adição manual de água e secados a $60^{\circ} \mathrm{C}$ em estufa de circulação forçada de ar.

A determinação da dureza dos grânulos organominerais produzidos foi feita em durômetro digital, com dez repetições para cada concentração diferente do aditivo.

Os experimentos de vasos foram conduzidos em casa de vegetação de forma simultânea. Esses experimentos avaliaram a eficiência agronômica dos fertilizantes organominerais como fonte de $\mathrm{P}$ para as plantas. Os tratamentos foram constituídos pelo fertilizante sem material aglutinante $(\mathrm{CF}+$ MAP); pelos fertilizantes com óxido de magnésio a 3\%, além de um controle sem a adição de fertilizante. Todos os fertilizantes foram aplicados na dose de $100 \mathrm{mg}$ de $\mathrm{P}$ total por vaso. Foi utilizado o delineamento experimental de blocos casualizados com cinco repetições.

\section{RESULTADOS E DISCUSSÃO}

Foi observado que o efeito positivo na dureza dependia da concentração utilizada do aditivo. O óxido de magnésio, na concentração de 3\% (Figura 1), foi capaz de aumentar a dureza do grânulo em até quatro vezes, quando comparado com o FOM controle (CF + MAP), mostrando-se como um aditivo potencial a ser adicionado a essa mistura. Esse resultado já era esperado, pois outros trabalhos que utilizaram o óxido de magnésio para aumentar a dureza de fármacos e fertilizantes granulados obtiveram resultados positivos. Isso porque o óxido de magnésio quando adicionado em pequena quantidade à mistura em pó de fertilizante de sal é capaz de suprimir a água por longos períodos de tempo, evitando assim a desintegração do grânulo mesmo em condições de alta umidade do ar e temperatura. Além disso, a presença do óxido de magnésio influencia de forma positiva à integração do fertilizante quando na sua produção envolve a reação de ácido fosfórico e amônia (GEZERMAN \& ÇORBACIOĞLU, 2014; POLSKI et. al., 2014).

A produção de matéria seca foi significativamente maior nos tratamentos com fertilizantes, quando comparada ao controle (Figura 2). Entretanto, não houve diferença significativa entre os tratamentos com fertilizantes organominerais com e sem óxido de magnésio, como pode ser comprovado pelo teste Tukey.

A Figura 3 mostra a quantidade em mg de $\mathrm{P}$ absorvido pela planta dos diferentes grânulos fertilizantes utilizando ou não material aditivo. Os resultados mostraram que o MgO possibilitou o aumento da absorção de $\mathrm{P}$ pela planta, visto que ao comparar com o fertilizante organomineral sem aditivo, houve um aumento médio de $48 \mathrm{mg}$ para $64 \mathrm{mg}$ de $\mathrm{P}$ absorvido, elevando o teor de $\mathrm{P}$ na planta em $16 \mathrm{mg}$.

Apesar da produção de matéria seca não ter tido diferença significativa entre os tratamentos com fertilizantes, o teste Tukey comprovou que a absorção de fósforo foi significativamente maior no tratamento que continha óxido de magnésio na sua formulação. Isso pode ser atribuído à presença do magnésio, visto que o magnésio contribui para a absorção de fósforo pelas plantas, devido a interação do $\mathrm{Mg}$ com o P que pode 


\section{VISIGERA DE 07 A 09 MA10 2019

estar relacionada com as reações de transferência de energia na célula e também na transferência de fosfato (PAULA NETO et. al., 2013).

\section{CONCLUSÃO}

Este trabalho permitiu verificar que o óxido de magnésio pode ser usado para aumentar a dureza dos fertilizantes organominerais e ainda aumentar a eficiência agronômica. É preciso avaliar outras concentrações desse material aditivo para certificar se os resultados podem ser ainda melhores.

\section{REFERÊNCIAS}

ASSOCIAÇÃO BRASILEIRA DOS PRODUTORES E EXPORTADORES DE FRANGOS. ABEF. Relatório Anual, 2017. Disponível em: <www.abef.com.br> Acesso em 10/02/2018.

BENITES, V. M.; CORREA, J. C.; MENEZES, J. F. S.; POLIDORO, J. C. Produção de fertilizante organomineral granulado a partir de dejetos de suínos e aves no Brasil. XXIX Reunião Brasileira de Fertilidade do Solo e Nutrição de Plantas. Espírito Santo, 2010. 5 p.

CORRÊA, J. C.; MIELE, M. A cama de aves e os aspectos agronômicos, ambientais e econômicos. In.: PALHARES, J. C. P.; KUNZ, A. (Eds). Manejo ambiental na avicultura. Concórdia: Embrapa Suínos e Aves, 2011. p.126-152. (Documentos, 149).

CHEN, Z.; JIANG, X. Microbiological Safety of Chicken Litter or Chicken Litter-Based Organic Fertilizers: A Review. Agriculture 2014, 4, 1-29; doi:10.3390/agriculture4010001

GEZERMAN, A. O.; ÇORBACIOĞLU, B. D. Effects of Calcium Lignosulfonate and Silicic Acid on Ammonium Nitrate Degradation. Hindawi Publishing Corporation. Journal of Chemistry. Volume 2014, Article ID 426014, 6 p.

INSTITUTO BRASILEIRO DE GEOGRAFIA E ESTATÍSTICA - IBGE. Diretoria de Pesquisas, Coordenação de Agropecuária - Pesquisa Trimestral do Abate de Animais 2017.

PAUlA NETO, A.; FAVARIN, J.L.; CARVAlHO, P.P.T.; TEZOTTO, T.; SOUZA, K.M. Cinética de absorção de fósforo em razão do teor de magnésio em cafeeiro. VIII Simpósio de Pesquisa dos Cafés do Brasil. 2013.

POLSKI, A.; IWANIAK, K.; NALESNIAK, M.; POLESZAK, E. The excipients used in the non-coated tablets - a review. 26-a volumo. MIR N-ro 1 (102) Junio 2014.

WILKINSON, K. G.; TEE, E.; TOMKINS, R. B.; HEPWORTH, G.; PREMIER, R. Effect of heating and aging of poultry litter on the persistence of enteric bacteria. 2011, Poultry Science 90 :10-18. doi:10.3382/ps.2010-01023

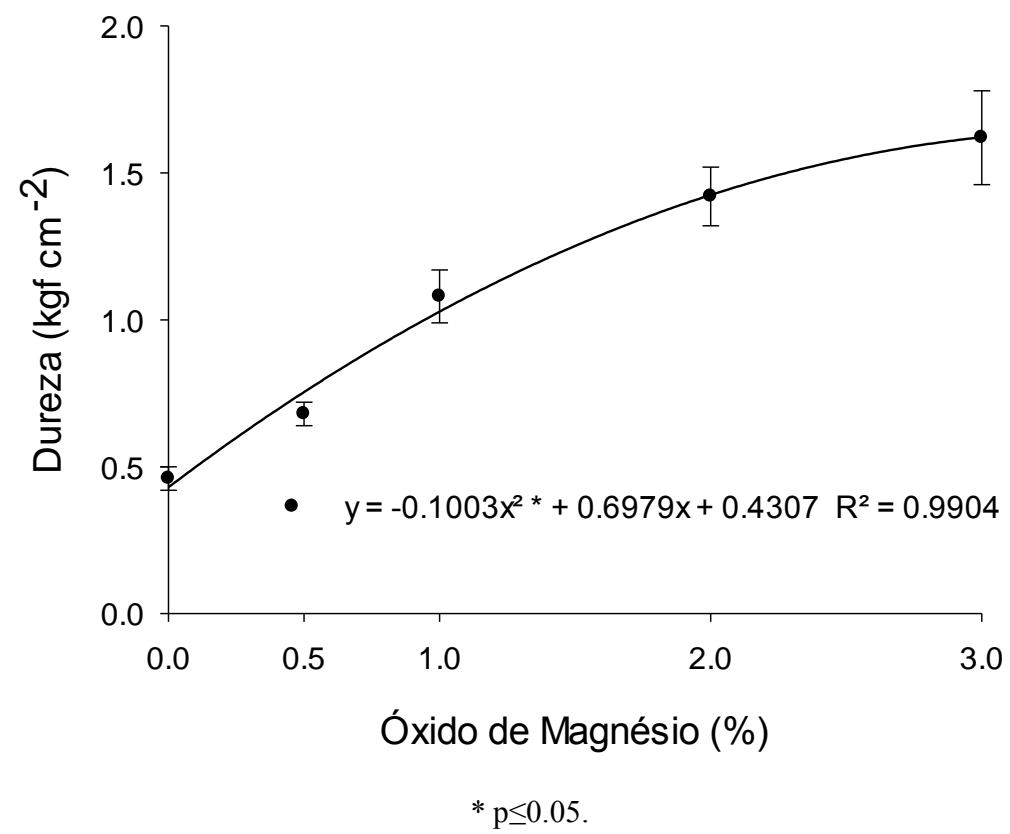

Figura 1. Dureza dos grânulos de fertilizantes organominerais em diferentes concentrações com óxido de magnésio e o controle sem material aglutinante. 


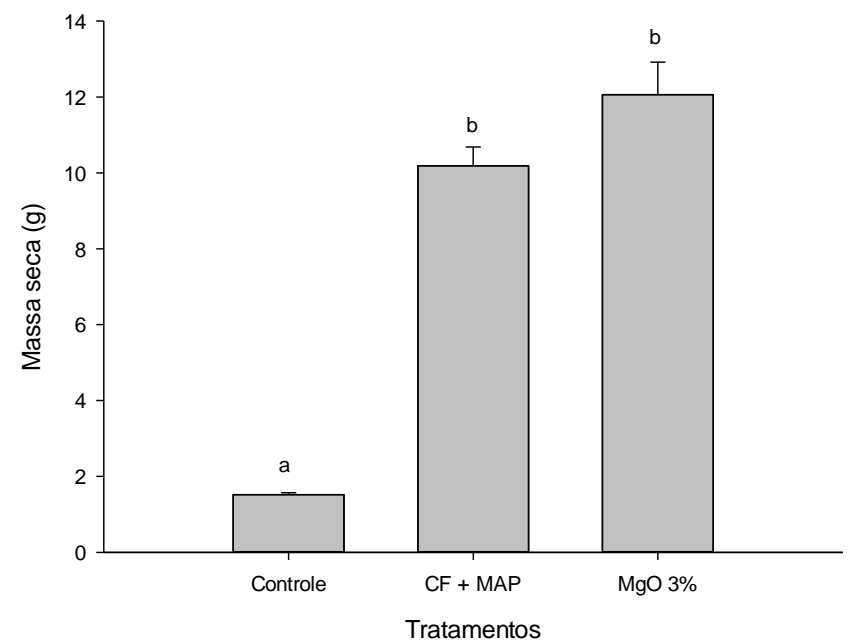

Figura 2. Produção de massa seca em grama dos diferentes tratamentos. Letras iguais nos tratamentos não diferem pelo teste de Tukey $(\mathrm{P} \leq 0,05)$.

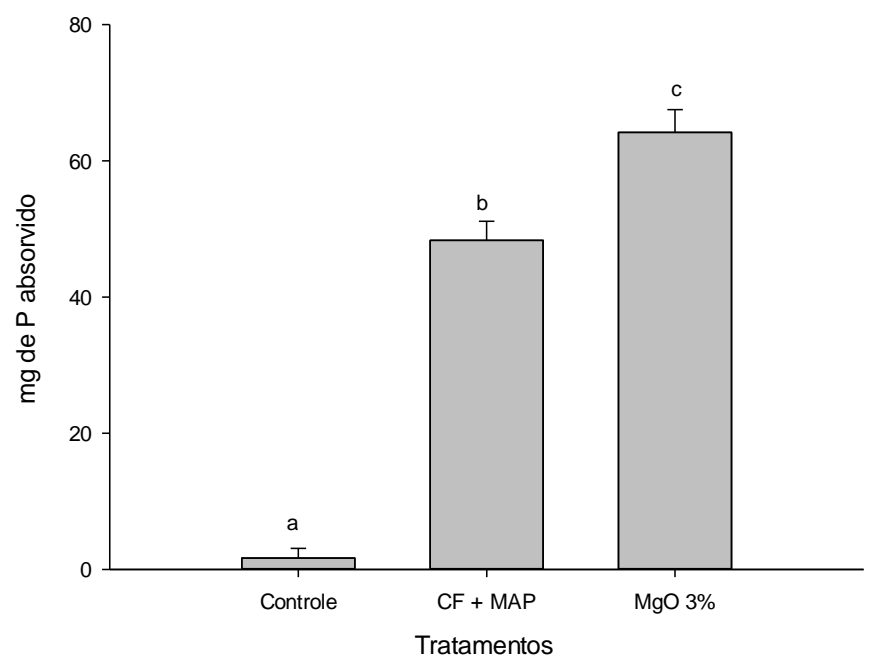

Figura 3. mg de $\mathrm{P}$ absorvido pela planta nos diferentes tratamentos. Letras iguais nos tratamentos não diferem pelo teste de Tukey $(\mathrm{P} \leq 0,05)$. 


\title{
TEOR DE CARBONO E DENSIDADE DE UM LATOSSOLO APÓS 15 ANOS DE FERTILIZAÇÃO COM DEJETO LÍQUIDO DE SUÍNO
}

\author{
Cassol, P.C. ${ }^{1}$; Sacomori, W.1; Erdmann, L.F. \\ ${ }^{1}$ Professor da Universidade do Estado de Santa Catarina-UDESC, Lages, SC-Brasil, paulo.cassol@udesc.br \\ ${ }^{2}$ Estudante de doutorado do Programa de pós-Graduação em Ciência do Solo da UDESC, Lages, SC-Brasil
}

\begin{abstract}
RESUMO: Além de fornecer nutrientes às plantas, os fertilizantes orgânicos, como o dejeto líquido de suíno (DLS), podem promover melhorias em atributos do solo. Assim, realizou-se esse estudo para avaliar a influência de 15 anos de aplicações anuais de DLS, adubação mineral, e a combinação de adubação mineral com DLS, no teor de carbono orgânico (CO) e na densidade (Ds) de um Latossolo Vermelho Distroférrico, cultivado com milho e aveia e manejado sob sistema de plantio direto. Os tratamentos foram adubações anuais com DLS nas doses de 0 (controle), 25, 50, 100 e $200 \mathrm{~m}^{3} \mathrm{ha}^{-1}$ ano $^{-1}$, DLS na dose de $25 \mathrm{~m}^{3} \mathrm{ha}^{-1}$ combinado com fertilizante mineral (DLS+FM) e fertilizante mineral solúvel (FM). Os atributos do solo foram determinados em cinco camadas, até $60 \mathrm{~cm}$ de profundidade. $\mathrm{O}$ teor de $\mathrm{CO}$ de camadas de $5 \mathrm{a} 20 \mathrm{~cm}$ de profundidade do solo aumentou com a aplicação de DLS em doses a partir de $100 \mathrm{~m}^{3} \mathrm{ha}^{-1}$, porém, a densidade do solo não foi influenciada pelos tratamentos testados. Em geral, evidenciou-se que a fertilização anual com DLS em doses a partir de $100 \mathrm{~m}^{3} \mathrm{ha}^{-1}$, aumenta o conteúdo de CO em camadas superficiais até $20 \mathrm{~cm}$ de profundidade, mas não afeta a densidade do solo.
\end{abstract}

Palavras-chave: esterco, milho, resíduos.

\section{CARBON CONTENT AND DENSITY OF AN OXISOL AFTER 15 YEARS OF FERTILIZATION WITH SWINE SLURRY}

\begin{abstract}
DLS), can promote improvements in soil attributes. Thus, this study was carried out to evaluate the influence of 15 years of annual applications of DLS, mineral fertilization, and the combination of mineral fertilization with DLS on the organic carbon content (CO) and density (Ds) of a Typic Hapludox, cultivated with maize and oats and managed under no-tillage system. The treatments were DLS annual fertilization at doses of 0 (witness), 25, 50, 100 and $200 \mathrm{~m}^{3} \mathrm{ha}^{-1}$ year ${ }^{-1}$, DLS at the dose of $25 \mathrm{~m}^{3} \mathrm{ha}^{-1}$ combined with mineral fertilizer (DLS + FM) and mineral fertilizer soluble (FM). Soil attributes were determined in five layers, up to $60 \mathrm{~cm}$ deep. The CO content of layers from five to $20 \mathrm{~cm}$ of soil depth increased with the application of DLS in doses from $100 \mathrm{~m}^{3}$ $\mathrm{ha}^{-1}$, but the soil density was not influenced by the treatments tested. In general, it has been shown that annual fertilization with DLS at doses equal or greater of $100 \mathrm{~m}^{3} \mathrm{ha}^{-1}$ increases the CO content in surface layers up to $20 \mathrm{~cm}$ depth, but does not affect soil density.
\end{abstract}

Keywords: manure, corn, wastes.

\section{INTRODUÇÃO}

A produção de carne suína em grandes unidades de animais confinados gera grande quantidade de dejeto líquido de suíno (DLS), resíduo que tem sido utilizado como fertilizante nas propriedades rurais. No entanto, restam dúvidas sobre os efeitos da aplicação de altas doses de DLS em importantes atributos do solo, como o teor de carbono orgânico $(\mathrm{CO})$ e a densidade. O conhecimento sobre alterações promovidas pela adubação orgânica é particularmente interessante para o estado de Santa Catarina, devido à importância econômica da suinocultura e da variedade de solos e de condições de cultivo em áreas que recebem aplicação de dejetos no solo (SCHERER et al., 2010).

O teor de $\mathrm{CO}$ do solo resulta da decomposição de restos vegetais e animais é contém diversos compostos que favorecem a formação dos agregados do solo. Alguns estudos evidenciaram que aplicação de DLS, em doses altas e repetidas no tempo, pode aumentar o teor de $\mathrm{CO}$ em camadas superficiais do solo (BRUNETTO et al., 2012; MAFRA et al., 2015). Assim, além do fornecimento de nutrientes vegetais, a adubação com resíduos orgânicos em diferentes sistemas de manejo pode apresentar outros benefícios no solo (MATOS et al., 2010; OLIVEIRA et al., 2015), como a diminuição da densidade do solo, decorrente do aumento do volume 
de poros, o que favorece a infiltração água, a aeração e o desenvolvimento das raízes das plantas (CUNHA et al., 2011).

Ribeiro et al., (2007) e Rauber et al. (2012), relataram que a aplicação de dejetos animais pode aumentar o tamanho e a quantidade de poros no solo, resultando em decréscimos na densidade e resistência à penetração de raízes. Com isso, aumenta o crescimento das raízes das plantas, o que geralmente também aumenta a absorção de água e nutrientes (MOSADDEGHI et al., 2009).

Já, Arruda et al., (2010) avaliando a estrutura do Latossolo Vermelho Distroférrico, após nove anos sob aplicação de DLS, não observaram efeito dessa adubação orgânica no teor de carbono orgânico e na densidade do solo. Agne \& Klein, (2014) também não obtiveram efeito significativo em atributos físicos do solo após dois anos de aplicação de DLS.

Assim, o objetivo desse trabalho foi avaliar a influência de 15 anos de fertilizações anuais com quatro doses de DLS, adubação mineral, e a combinação de adubação mineral com DLS no teor de CO e na Ds de um Latossolo Vermelho Distroférrico, sob cultivo com a sucessão milho-aveia e manejo em plantio direto.

\section{MATERIAL E MÉTODOS}

O estudo foi realizado no município de Campos Novos/SC, durante o período de outubro de 2001 a junho de 2016. O local do experimento se situa nas coordenadas $27^{\circ} 23^{\prime} 33^{\prime \prime}$ de latitude sul e $51^{\circ} 21^{\prime} 48^{\prime \prime}$ longitude oeste, com altitude de $862 \mathrm{~m}$ acima do nível do mar e apresenta clima mesotérmico úmido com verão ameno (Cfb), segundo a classificação de Köppen. As chuvas são distribuídas durante o ano e as médias anuais de precipitação e temperatura são de $1.480 \mathrm{~mm}$ e $16^{\circ} \mathrm{C}$, respectivamente (EPAGRI/CIRAM, 2013).

O solo é classificado como Latossolo Vermelho Distroférrico (EMBRAPA, 2013) que na implantação do experimento apresentou as seguintes características químicas na camada de 0 a $20 \mathrm{~cm}$ : $\mathrm{pH}$ 6,1; Índice SMP 6,0; saturação por base de 87\%; teores de $\mathrm{Al}$, Ca e $\mathrm{Mg}$ trocáveis de 0,$01 ; 8,2$ e 4,6 $\mathrm{cmol}_{\mathrm{c}} \mathrm{kg}^{-1}$; teores extraíveis (Mehlich 1) de P e K de 6,4 e $97 \mathrm{mg} \mathrm{kg}^{-1}$; e, teores de argila e carbono orgânico total de 680 e $25 \mathrm{~g} \mathrm{~kg}^{-1}$, respectivamente. A área vinha sendo utilizada com cultivos de plantas de lavoura como milho, soja, trigo, feijão e aveia em sistema de plantio direto e na safra anterior a implantação do experimento 2000/2001, recebeu uma fertilização com a dose de $25 \mathrm{~m}^{3} \mathrm{ha}^{-1}$ de DLS.

Os tratamentos consistiram em adubações anuais com DLS nas doses 0 (Testemunha), 25, 50, 100 e 200 $\mathrm{m}^{3} \mathrm{ha}^{-1}$ ano $^{-1}$, fertilizante mineral combinado com DLS na dose de $25 \mathrm{~m}^{3} \mathrm{ha}^{-1}$ (DLS+FM) e fertilizante mineral solúvel (FM). O delineamento utilizado foi em blocos ao acaso com quatro repetições. Os fertilizantes solúveis empregados como fontes de N, P e K foram ureia, superfosfato triplo (SFT) e cloreto de potássio (KCl), respectivamente. Foram utilizadas parcelas de 5,3 por $11 \mathrm{~m}$ de área útil, totalizando $58,3 \mathrm{~m}^{2}$.

As doses de N, P e K dos tratamentos DLS+FM e FM foram estabelecidas para a cultura de milho. No FM foram aplicadas as doses equivalentes a 170,130 e $80 \mathrm{~kg} \mathrm{ha}^{-1}$ de $\mathrm{N}, \mathrm{P}_{2} \mathrm{O}_{5}$ e $\mathrm{K}_{2} \mathrm{O}$, respectivamente e o DLS+FM em doses conjuntas de $25 \mathrm{~m}^{3} \mathrm{ha}^{-1}$ de DLS e FM nas doses de 75, 16 e $15 \mathrm{~kg} \mathrm{ha}^{-1} \mathrm{de} \mathrm{N} \mathrm{P}_{2} \mathrm{O}_{5}$ e $\mathrm{K}_{2} \mathrm{O}$, respectivamente, tendo-se considerado a quantidade de nutriente adicionada pelo DLS. No tratamento FM, o $\mathrm{N}$ foi aplicado em parcelas de $20 \%$ na base e o restante, divididos em duas coberturas realizadas no estádio V5 e V9 da cultura do milho. No tratamento DLS+FM, o $\mathrm{N}$ da fonte mineral solúvel foi totalmente aplicado em uma cobertura na primeira época comentada acima.

A aplicação do DS foi realizada na superfície do solo com distribuidor pressurizado de esterco líquido, com uso de mangueira de menor diâmetro para manter a pressão do sistema de bombeamento constante e facilitar a aplicação homogênea em área total das parcelas. Os fertilizantes minerais foram distribuídos manualmente, a lanço na superfície do solo.

O DLS utilizado nas diversas aplicações foi proveniente de animais em terminação e/ou recria, sendo recolhido e armazenado por cerca de 120 dias antes das aplicações no solo em esterqueira descoberta e apresentou teores totais médios de 44,5, 18,6,3,3,1,4,1,3 $\mathrm{kg} \mathrm{m}^{-3}$ de massa seca, carbono orgânico, nitrogênio, fósforo e potássio, respectivamente.

Durante a condução do experimento foram cultivados milho (Zea mays) no verão e, preponderantemente, aveia (Avena sativa) no inverno em sucessão e no sistema de plantio direto. A cada quatro anos o cultivo de aveia foi substituído pelo de nabo forrageiro (Raphanus sativus).

As amostras de solo foram coletadas em anéis volumétricos de aço com borda cortante e volume de 50 $\mathrm{cm}^{3}$ nas camadas de 00 a 05, 05 a 10, 10 a 20, 20 a 40 e 40 a $60 \mathrm{~cm}$, em cada parcela. No laboratório, os anéis foram saturados e submetidos à tensão de $6 \mathrm{kPa}$ em mesa de coluna de areia e posteriormente secos em estufa a $105^{\circ} \mathrm{C}$ por $48 \mathrm{~h}$, conforme método descrito por EMBRAPA (1997). A densidade do solo foi obtida pela 
divisão da massa do solo seco pelo volume do anel. O teor de CO foi determinado em analisador elementar (TOC). Os resultados foram submetidos à análise de variância, as médias comparadas pelo teste DMS a $5 \%$ de significância.

\section{RESULTADOS E DISCUSSÃO}

Houve efeito dos tratamentos no teor de CO do solo (Tabela 1) nas três camadas mais superficiais, até $20 \mathrm{~cm}$ de profundidade. Os maiores teores em geral foram observados nos dois tratamentos com as maiores doses de DLS. Entretanto, o efeito foi mais pronunciado na camada de 00 a $05 \mathrm{~cm}$, onde os maiores teores de CO foram observados nos tratamentos DLS100 e DLS 200 e o menor no DLS0 que não teve nenhuma adubação (Tabela 1). O incremento de COT com a dose de $100 \mathrm{~m}^{3} \mathrm{ha}^{-1}$ foi em torno de $23 \%$ em relação ao tratamento controle. Adições de dejetos animais e outros fertilizantes orgânicos geralmente não promovem incremento de C orgânico no solo em curto prazo (SCHERER et al., 2010; AGNE; KLEIN, 2014). No entanto, com aplicações repetidas por longo prazo, esses fertilizantes podem aumentar o teor de CO do solo. Entretanto, cabe ressaltar que esse aumento resulta principalmente da maior produção de matéria seca e ciclagem de raízes pelas culturas que quando morrem depositam esse material orgânico na superfície e no interior do solo, respectivamente (KARHU et al., 2012; MAFRA et al., 2014), e com isso, aumentam a entrada de CO no sistema solo.

Mafra et al. (2014) estimaram taxas de acúmulo de CO em Latossolo Vermelho adubado com fertilizante mineral e doses de DLS e cultivado em plantio direto, e observaram que o tratamento sem adubação apresentou a menor adição de $\mathrm{C}$ pela massa seca das plantas (milho e aveia-preta), o que pode ser atribuído à baixa disponibilidade de nutrientes no solo e consequente menor produção de matéria seca das culturas. Os tratamentos com DLS apresentaram adições crescentes de $\mathrm{C}$ ao solo com o aumento da dose.

A Ds não foi influenciada pelos tratamentos, sendo observada variação somente com a profundidade. Conforme Tabela 2, a Ds situou-se entre 1,10 e 1,34 kg dm³ valores observados nos tratamentos FM e DLS25, respectivamente. Já, Arruda et al. (2010), após os primeiros 5 anos de condução do mesmo experimento observaram Ds entre 1,34 e $1,50 \mathrm{~kg} \mathrm{dm}^{-3}$, sendo esses valores encontrados nos tratamentos DLS100 e DLS+FM, respectivamente, porém, também não detectaram diferença entre tratamentos e camadas. No atual estudo, os maiores valores de Ds situaram-se entre as camadas de 5 a $15 \mathrm{~cm}$ de profundidade, onde geralmente há intenso crescimento de raízes. No entanto, essa maior densidade pode ser atribuída ao manejo sob sistema de plantio direto que geralmente causa compactação do solo (COSTA et al., 2010), provocada pelo tráfego de máquinas e acomodação natural das partículas sólidas, sobretudo em camada sub-superficial entre 5 e 15 cm. No entanto, Mecabô Júnior (2013) analisando o efeito de três doses de DLS em Latossolo Manejado sob plantio direto observou que esse fertilizante orgânico afetou positivamente as propriedades físicas do solo, com tendência de aumento da macroporosidade e diminuição da densidade do solo. Dortzbach (2009) também observou a diminuição da Ds em solo tratado com aplicação de DLS, efeito que foi associado à promoção do desenvolvimento radicular e pelo aumento da atividade biológica no solo.

\section{CONCLUSÃO}

Em geral, evidenciou-se que a fertilização anual com DLS em doses a partir de $100 \mathrm{~m}^{3} \mathrm{ha}^{-1}$, aumenta o conteúdo de $\mathrm{CO}$ em camadas superficiais até $20 \mathrm{~cm}$ de profundidade, mas não afeta a densidade do solo.

\section{REFERÊNCIAS}

AGNE, S. A. A. \& KLEIN, V.A. Matéria orgânica e atributos físicos de um Latossolo Vermelho após aplicações de dejeto de suínos. R. Bras. Eng. Agríc. Ambiental, v.18, n.7, p.720-726, 2014.

ARRUDA, C.A.O.; ALVES, M.V.; MAFRA, A.L.; CASSOL, P.C.; ALBUQUERQUE, J.A.; SANTOS, J.C.P. Aplicação de dejeto suíno e estrutura de um Latossolo Vermelho sob semeadura direta. Ciênc. Agrotec., Lavras, v. 34, n. 4, p. 804-809, 2010.

DORTZBACH, D. Dinâmica de atributos físicos e químicos em solo sob plantio direto adubado com dejetos suínos e ureia. Florianópolis: UFSC, 2009. 127p. Dissertação Mestrado.

EMPRESA BRASILEIRA DE PESQUISA AGROPECUÁRIA - EMBRAPA. Centro Nacional de Pesquisa de Solos. Manual de métodos e análise de solo. 2.ed. Rio de Janeiro: EMBRAPA, 1997. 212p.

EMPRESA BRASILEIRA DE PESQUISA AGROPECUÁRIA - EMBRAPA. Centro Nacional de Pesquisa de Solos. Sistema brasileiro de classificação de solos. 2.ed. Rio de Janeiro, 2013. 306p.

EPAGRI/CIRAM. Monitoramento dos fenômenos climáticos e seus impactos: climatologia de chuvas. Florianópolis, 2013. 


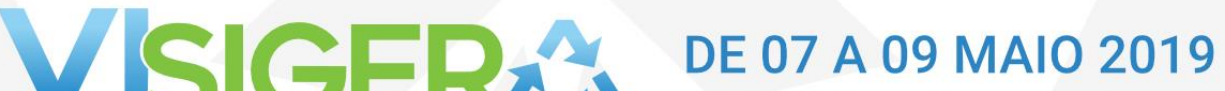

MAFRA, M.S.H.; CASSOL, P.C.; ALBUQUERQUE, J.A.; GROHSKOPF, M.A.; ANDRADE, A.P.; RAUBER, L.P.; FRIEDERICHS, G.A. Organic Carbon Contents and Stocks in Particle Size Fractions of a Typic Hapludox Fertilized with Pig Slurry and Soluble Fertilizer. R. Bras. Ci. Solo, Viçosa, v. 39, p. 1161$1171,2015$.

MAFRA, M.S.H.; CASSOL, P.C. ALBUQUERQUE, J.A.; CORREA, J.C.; GROHSKOPF, M.A.; PANISSON, J. Acúmulo de carbono em Latossolo adubado com dejeto líquido de suínos e cultivado em plantio direto. Pesq. Agropec. Bras., Brasília, v.49, n.8, p.630-638, 2014

RIBEIRO, K.D.; MENEZES, S.M.; MESQUITA, M.G.B.F.; SAMPAIO, F.M.T. Propriedades físicas do solo, influenciadas pela distribuição de poros, de seis classes de solos da região de Lavras-MG. Ciênc. Agrotec., Lavras, v.31, n.4, p.1167-1175, 2007.

SCHERER, E.E.; NESI, C.N.; MASSOTTI, Z. Atributos químicos do solo influenciados por sucessivas aplicações de dejetos suínos em áreas agrícolas de Santa Catarina. Revista Brasileira de Ciência do Solo, v.34, p.1375-1383, 2010.

Tabela 1. Teor de carbono orgânico (CO) de um Latossolo Vermelho argiloso após 15 anos de cultivo com a sucessão milho-aveia sob plantio direto e fertilização anual com dejeto líquido de suíno (DLS) nas doses 0 (controle), 25, 50, 100 e $200 \mathrm{~m}^{3} \mathrm{ha}^{-1}$ ano $^{-1}$, DLS na dose de $25 \mathrm{~m}^{3} \mathrm{ha}^{-1}$ combinado com fertilizante mineral

(DLS+FM) e fertilizante mineral solúvel (FM).

\begin{tabular}{|c|c|c|c|c|c|c|c|c|}
\hline Camada & $\mathbf{A M}$ & DLS+AM & DLS0 & DLS25 & DLS50 & DLS100 & DLS200 & $\mathrm{CV}(\%)$ \\
\hline (cm) & & & & $\mathrm{g} \mathrm{kg}$ & & & & \\
\hline 00 a 05 & $53 \mathrm{~b}$ & $58 \mathrm{ab}$ & $48 \mathrm{~d}$ & $52 \mathrm{c}$ & $55 \mathrm{~b}$ & $59 \mathrm{a}$ & $63 \mathrm{a}$ & 14,2 \\
\hline 05 a 10 & $40 \mathrm{bc}$ & $38 \mathrm{bc}$ & $35 \mathrm{~d}$ & $37 \mathrm{~cd}$ & $38 \mathrm{bcd}$ & $44 \mathrm{a}$ & $40 \mathrm{~b}$ & 9,3 \\
\hline 10 a 20 & $32 \mathrm{ab}$ & $31 \mathrm{bcd}$ & $30 \mathrm{~d}$ & $32 a b c$ & $31 \mathrm{~cd}$ & $32 \mathrm{a}$ & $31 \mathrm{~cd}$ & 3,7 \\
\hline 20 a $40^{\mathrm{ns}}$ & 27 & 27 & 25 & 27 & 26 & 27 & 26 & 8,1 \\
\hline 40 a $60^{\mathrm{ns}}$ & 23 & 23 & 22 & 22 & 22 & 22 & 22 & 6,5 \\
\hline
\end{tabular}

Médias seguidas pelas mesmas letras não apresentam diferença significativa entre elas $\mathrm{p} \leq 0.05$.

${ }^{\mathrm{ns}}$ não significativo.

Tabela 2. Densidade de um Latossolo Vermelho argiloso, após 15 anos de cultivo com a sucessão milhoaveia sob plantio direto e fertilização anual com dejeto líquido de suíno (DLS) nas doses 0 (controle), 25, 50, 100 e $200 \mathrm{~m}^{3} \mathrm{ha}^{-1} \mathrm{ano}^{-1}$, DLS na dose de $25 \mathrm{~m}^{3} \mathrm{ha}^{-1}$ combinado com fertilizante mineral (DLS+FM) e fertilizante mineral solúvel (FM).

\begin{tabular}{cccccccc}
\hline $\begin{array}{c}\text { Camadas } \\
(\mathbf{c m})\end{array}$ & FM & DLS+FM & DLS0 & \multicolumn{2}{c}{ Tratamentos } \\
DLS 25 & DLS 50 & DLS 100 & DLS 200 \\
\hline & & \multicolumn{7}{c}{ Densidade do solo $\left(\mathrm{kg} \mathrm{dm}^{-3}\right)$} & & \\
$00-05$ & 1,15 & 1,20 & 1,18 & 1,17 & 1,13 & 1,22 & 1,10 \\
$05-10$ & 1,28 & 1,29 & 1,29 & 1,33 & 1,31 & 1,23 & 1,23 \\
$10-20$ & 1,31 & 1,32 & 1,24 & 1,34 & 1,34 & 1,32 & 1,29 \\
$20-40$ & 1,22 & 1,21 & 1,21 & 1,22 & 1,25 & 1,21 & 1,19 \\
$40-60$ & 1,17 & 1,16 & 1,16 & 1,17 & 1,19 & 1,16 & 1,15 \\
\hline
\end{tabular}

Obs.: não houve diferença entre tratamentos pelo teste de Fischer $(\mathrm{p}<0,05)$. 


\title{
AVALIAÇÃO DE FERTILIZANTES OBTIDOS EM COMPOSTAGEM AUTOMATIZADA DE RESÍDUOS DE FRIGORÍFICO E DE PORTO GRANELEIRO
}

\author{
Cantú, R.R.*1; Schallenberger, E. ${ }^{1}$; Morales, R.G.F. ${ }^{1}$; Visconti, A. ${ }^{1}$; Vale, M.L.C ${ }^{1}$; Ceccon, A.P. ${ }^{2}$ \\ ${ }^{1}$ Pesquisadores da Epagri, Itajaí, SC - Brasil \\ ${ }^{2}$ Estudante da UFPR, PR - Brasil \\ rrcantu@epagri.sc.gov.br
}

\begin{abstract}
RESUMO: O setor agrícola e agroindustrial de Santa Catarina possui elevada importância socioeconômica. Apesar disso, geram elevados volumes de resíduos, que podem ocasionar sérios problemas ambientais. Assim, é fundamental estudos para a transformação desses resíduos em fertilizantes para uso em cultivos agrícolas. Em 2017 foram iniciados projetos de compostagem automatizada de resíduos dos frigoríficos do Vale do Itajaí SC e de grãos residuais de porto graneleiro. A compostagem automatizada de grãos foi realizada na Epagri de Itajaí (EEI) e a de resíduos de frigorífico na unidade de compostagem Lauro Pamplona em Rio do Sul. Embora essas compostagens venham sendo realizadas com sucesso e os compostos de resíduos de frigorífico (CF) e grãos (CG) produzidos apresentem características de fertilidade promissoras, não há estudos sobre o valor agronômico desses fertilizantes. Assim, o objetivo do trabalho foi avaliar o valor agronômico do CF e CG, com diferentes formas de aplicação no cultivo do repolho. O Experimento foi realizado em 2018 na EEI, onde os compostos foram aplicados na linha de plantio sem incorporação (SI), incorporados na linha (CI) e incorporados na área total (TI), todos comparados com a testemunha, sem composto $(\mathrm{C} 0)$. Os tratamentos foram: T1- CF+SI; T2- CG+SI; T3- C0+SI; T4- CF+CI; T5- CG+CI; T6- C0+CI; T7- CF+TI; T8- CG+TI; T9$\mathrm{C} 0+\mathrm{TI}$. Os compostos proporcionaram, independentemente da forma de aplicação, incrementos na produção do repolho, comparado as testemunhas sem fertilizantes. Os compostos proporcionaram elevadas produções de MV e MS, independente da forma de aplicação ou do tipo de composto.
\end{abstract}

Palavras-chave: compostagem automatizada, resíduos de frigorífico, hortaliças

\section{EFECT OF FERTILIZERS OBTAINED IN AUTOMATED COMPOSTING OF WASTE FROM AGROINDUSTRY AND PORT GRAINS}

\begin{abstract}
The agricultural and agroindustrial sector of Santa Catarina has high socioeconomic importance. Despite this, they generate high volumes of waste, which can cause serious environmental problems. Thus, studies for the transformation of these residues into fertilizers for use in agricultural crops are fundamental. In 2017, automated waste composting projects were started for the agroindustry of the Itajaí Valley SC and for residual grain from the bulk grain port. The automated grain composting was carried out in Epagri de Itajaí (EEI) and that of agroindustry residues at the Lauro Pamplona composting unit in Rio do Sul. Although these composting was successfully carried out and the agroindustry compost $(\mathrm{CF})$ and grains compost (CG) produced have promising fertility characteristics, there are no studies on the agronomic value. Thus, the objective of the work was to evaluate the agronomic value of CF and CG, with different forms of application in cabbage cultivation. The experiment was carried out in 2018 at the IEE, where the compost were applied in the planting line without incorporation (SI), incorporated in the line (CI) and incorporated in the total area (TI), all compared to the control, without compost (C0) . The treatments were: T1- CF + SI; T2- CG + SI; T3- C0 + SI; T4-CF + CI; T5-CG + CI; T6-C0 + Cl; T7-CF + TI; T8-CG + TI; T9-CO + TI. The compost provided, regardless of the application form, increases in cabbage production, compared to controls without fertilizers. The composts provided high MV and MS yields, regardless of the application form or the type of compost.
\end{abstract}

Keywords: automated composting, agroindustry waste, vegetable crops

\section{INTRODUÇÃO}

Santa Catarina (SC) possui uma forte presença dos setores agrícola e agroindustrial, que representam uma elevada importância socioeconômica, sendo responsável por aproximadamente $60 \%$ das exportações do Estado e envolvendo mais de 400 mil famílias. Apesar da relevância, os setores geram elevados volumes de resíduos, que quando não tratados, podem ocasionar sérios problemas ambientais. Esses materiais podem ser 
transformados em fertilizantes de elevada qualidade para cultivos como os de hortaliças, que possuem grande relevância para a agricultura de SC (Cantú et al. 2016; Santos et al. 2016).

$\mathrm{Na}$ região do Alto Vale do Itajaí - SC as agroindústrias frigoríficas, vem desenvolvendo trabalhos contundentes com compostagem automatizada de resíduos, produzindo fertilizante orgânico seguros de acordo com as resoluções do MAPA / IN SDA n 7 2016. Já no Litoral Norte de SC, iniciativas de compostagem de grãos residuais de porto graneleiro, igualmente vem sendo desenvolvida com sucesso (Cantú et al., 2018), produzindo um fertilizante promissor.

Embora estas compostagens venham sendo realizadas com sucesso e os fertilizantes produzidos apresentem características químicas de fertilidade promissoras, não há estudos sobre o valor agronômico do composto final. A região de produção do composto se caracteriza pela forte produção e consumo de hortaliças, que demanda elevados volumes de fertilizantes orgânicos, (Santos et al. 2016).

Considerando os aspectos aqui abordados, o objetivo do trabalho foi realizar um experimento com o uso dos compostos de resíduos de frigorífico e do porto graneleiro, em diferentes formas de aplicação, para avaliar o valor agronômico do fertilizante, por meio da sua contribuição no crescimento do repolho.

\section{MATERIAL E MÉTODOS}

O composto de resíduos (CF) de frigorífico foi desenvolvido na unidade de compostagem automatizada Lauro Pamplona localizada no Alto Vale do Itajaí SC, no período de 30 de outubro de 2017 a 30 de janeiro de 2018. Os resíduos eram provenientes dos frigoríficos, de criações de suínos e da fábrica de rações localizada na Região. Os resíduos foram distribuídos e misturados em compartimentos (duas paredes paralelas de alvenaria) de 1,5 $\mathrm{m}$ de altura por 4,0 $\mathrm{m}$ de largura e $95 \mathrm{~m}$ de comprimento. A leira era diariamente revolvida desde seu início, por uma máquina autopropulsionada. Após três meses do início da compostagem, o material foi depositado em um outro compartimento, sem revolvimento e após dois meses, o composto foi considerado pronto.

O composto de resíduos de grãos (CG) foi obtido na unidade da Epagri de Itajaí - EEI, com um sistema automatizado de compostagem, semelhante a utilizada com resíduos de frigorífico, mas de menor dimensão. A máquina se movimentava sobre uma leira (duas paredes paralelas de madeira) de 1,5 $\mathrm{m}$ de altura por $1,1 \mathrm{~m}$ de largura e $10 \mathrm{~m}$ de comprimento. Os resíduos eram constituídos de grãos de soja, predominantemente e de poda urbana de árvores e grama. A compostagem de grãos foi revolvida três vezes por semana e adicionado água sempre que a umidade baixava de 50\%, aproximadamente. Aos 90 dias foi finalizado os revolvimentos e após, o composto foi depositado no local de armazenagem, sem mais revolvimentos, sendo considerado pronto após mais dois meses.

A tomada de decisão para finalização de ambas as compostagens foi devido às características do composto relacionadas a relação $\mathrm{C} / \mathrm{N}$, abaixo de 14 (Tabela 1), além da temperatura do fertilizante estar próxima à do ambiente, que indicam a estabilidade do material.

O Experimento para a avaliação dos compostos foi realizado na EEI no ano de 2018, no cultivo do repolho, com diferentes formas de aplicação dos compostos. Os fertilizantes foram aplicados na linha de plantio sem incorporação (SI), incorporados na linha (CI) e incorporados na área total (TI), todos comparados com a dose 0 , sem composto (C0). As doses utilizadas dos compostos foram com base no $\mathrm{N}$ total, atribuindo uma mineralização de 30\% (Bernal et al., 2009; CQFS-RS/SC, 2016) de acordo com a demanda de nutrientes pela cultura do repolho (CQFS-RS/SC, 2016).

Os tratamentos foram: T1 - composto de resíduos de grãos aplicado na linha de plantio sem incorporação; T2- composto de resíduos de frigorífico aplicado na linha de plantio sem incorporação; T3- sem aplicação de composto e sem revolvimento da linha; T4- composto de resíduos de grãos aplicado na linha de plantio com incorporação; T5- composto de resíduos de frigorífico aplicado na linha de plantio com incorporação; T6- sem aplicação de composto com revolvimento da linha, T7- composto de resíduos de grãos incorporado em área total; T8- composto de resíduos de frigorífico incorporado em área total; T9- sem aplicação de composto com revolvimento da área total. $\mathrm{O}$ delineamento foi em blocos ao acaso com quatro repetições por tratamento, sendo que cada repetição era constituída de oito plantas úteis por parcela. As características do solo e dos compostos estão descritas na Tabela 1.

Ao final do cultivo, as plantas foram coletadas e pesadas para determinar a matéria verde (MV) e após, colocadas em estufa a $60^{\circ} \mathrm{C}$, até atingir peso constante, sendo posteriormente pesadas para determinar a massa seca (MS). Os resultados foram submetidos a análise de variância e ao teste de separação de médias com o programa computacional Sisvar 5.6. 


\section{RESULTADOS E DISCUSSÃO}

Observando a Figura 1 é possível observar, que de maneira geral, os compostos de grãos residuais do porto graneleiro (T1, T4 e T7) e de resíduos de frigorífico (T2, T5 e T8) incrementaram a produção de MV e MS do repolho, quando comparados as testemunhas (T3, T6 e T9) que não receberam os fertilizantes. Esse aspecto, indica que não houve imobilização dos nutrientes quando o composto foi misturado ao solo, conforme abordado por Bernal et al. (2009). Com isso, é possível inferir que os compostos podem ser considerados estabilizados ou maturos, provavelmente por possuir uma relação $\mathrm{C} / \mathrm{N}$ abaixo de 14 , indicando uma decomposição satisfatória durante o processo de compostagem, conforme discutido por outros autores (Bernal et al. 2009; Cantú et al. 2017).

Independentemente do preparo do solo, os tratamentos que não receberam compostos (T1, T4 e T7), não apresentaram diferenças entre si (Figura 1) na produção de MV e MS. Assim, é possível inferir que a mineralização e disponibilidade dos nutrientes inicialmente presentes no solo, não foram afetadas pelo seu preparo. Esse aspecto é bastante discutido na literatura, onde se espera na maioria dos casos que a mobilização do solo contribua com uma maior disponibilidade dos nutrientes, especialmente provenientes da mineralização da matéria orgânica (Dadalto et al., 2015; Cantú et al. 2017). Contudo isso não foi constatado no presente estudo, devendo ser atribuído aos tores elevados dos nutrientes encontrados inicialmente no solo (Tabela 1)

As aplicações dos compostos, independentemente da forma, além de produzir mais do que as testemunhas sem aplicação dos fertilizantes, não apresentaram diferenças entre os tratamentos. Esse aspecto pode sugerir que as doses determinadas com base na literatura (Bernal et al., 2009; CQFS-RS/SC, 2016) estavam de acordo e servem para todas as formas de aplicação, por proporcionarem elevadas produções de repolho, conforme encontrado por outros autores (Correa et al., 2013).

O fato de não haver diferenças significativas entre as formas de aplicação dos compostos, independentemente da sua origem, reforça a possibilidade da produção de hortaliças em sistemas de plantio direto (SPDH). Esse sistema vem sendo preconizado e estudado por universidade e empresas de pesquisa em Santa Catarina, que vem destacando diversas vantagens proporcionadas pelo sistema (Lenz et al., 2018). É importante destacar, que além dos benefícios atribuídos a melhoria do agroecossitema (Lenz et al., 2018), o SPDH notadamente reduz o aporte de mão de obra nos cultivos.

Considerando os resultados obtidos, é possível inferir que nas condições de solo com alta fertilidade como o utilizado no presente experimento, a aplicações dos compostos em dose única no início do cultivo do repolho é o suficiente para se obter produções satisfatórias, independentemente da forma de aplicação e preparo do solo. Embora os resultados tenham demonstrado que os compostos, possuam potencial para promover o crescimento da hortaliça, outros estudos a campo e com outros cultivos devem ser realizados, buscando adequar as recomendações do fertilizante.

\section{CONCLUSÃO}

O composto de resíduos da indústria frigorífica e de grãos residuais de porto graneleiro, apresentam um importante valor agronômico, com potencial de uso em repolho, pois incrementa a produção, independentemente da forma de distribuição e preparo do solo, permitindo o cultivo com uso exclusivo do fertilizante, aplicado em dose única na implantação da lavoura.

\section{REFERÊNCIAS}

BERNAL, M. P.; ALBURQUERQUE, J. A.; MORAL, R. Composting of animal manures and chemical criteria for compost maturity assessment. A review. Bioresource Technology, v. 100, p. 5444-5453, 2009.

CANTU, R. R. et al Dinamica da temperatura na compostagem de residuos da industria do palmito, Revista Brasileira de Agroecologia: In: Cadernos de agroecologia, 2016.

CANTÚ, RR; AITA, C; DONEDA, A, GIACOMINI, DA; DESSBESELL, A; ARENHARDT, M; BASTIANI, GG; PUJOL, SB; ROCHETE, F; CHANTIGNY, MH; GIACOMINI, S. 2017. Alternatives to regular urea for abating $\mathrm{N}$ losses in lettuce production under sub-tropical climate. Biology and Fertility of Soils. 53: 589-599.

CANTÚ, R.R. Compostagem automatizada de grãos residuais do porto de São Francisco do Sul - SC. Anais: XII Reunião Sul Brasileira de Ciência do Solo, Xanxerê, 2018.

CORREA, C.V; CARDOSO, A.I.I; CLAUDIO, M.T.R. Produção de repolho em função de doses e fontes de potássio em cobertura. Ciências Agrárias. 34: 2129-2138. 2013. 
LENZ, G.L.; BORDALLO, S.U.; SANTOS, T.S.; SCHALLENBERGER, E.; CANTÚ, R.R.; COMIN, J.J. Estrutura do solo e matéria orgânica leve em diferentes sistemas de manejo do solo. Anais: XII Reunião Sul Brasileira de Ciência do Solo, xanxerê, 2018.

SANTOS, A. A.; FELICIANO, A. M.; PADRAO, G. A. In: Feliciano, A.M. (Coord.). Números da Agropecuaria Catarinense. Florianopolis: Epagri/Cepa, 2016. 69 p.

Tabela 1. Principais características dos compostos e do solo utilizados no experimento de avaliação de fontes e formas de aplicação dos fertilizantes na cultura do repolho.

\begin{tabular}{|c|c|c|c|c|c|c|}
\hline Material & pH & $\begin{array}{c}\mathbf{P} \\
0\end{array}$ & $\begin{array}{c}\mathbf{K} \\
\mathrm{kg}^{-3} \ldots\end{array}$ & $\mathbf{N}$ & $\begin{array}{c}\text { MO } \\
\%\end{array}$ & Relação C/N \\
\hline Composto CF* & 6,0 & 17,0 & 7,9 & 26,2 & - & 14 \\
\hline Composto CG & 6,2 & 6,2 & 16,0 & 49,0 & - & 11 \\
\hline \multicolumn{7}{|c|}{.................................mg $\mathrm{mg}^{-3}$} \\
\hline Solo & 6,3 & 234 & 432 & - & 2,9 & - \\
\hline
\end{tabular}

* $\overline{\mathrm{CF}}$ - composto de resíduos de frigorífico; $\mathrm{CG}$ - composto de resíduos de grãos de porto graneleiro.

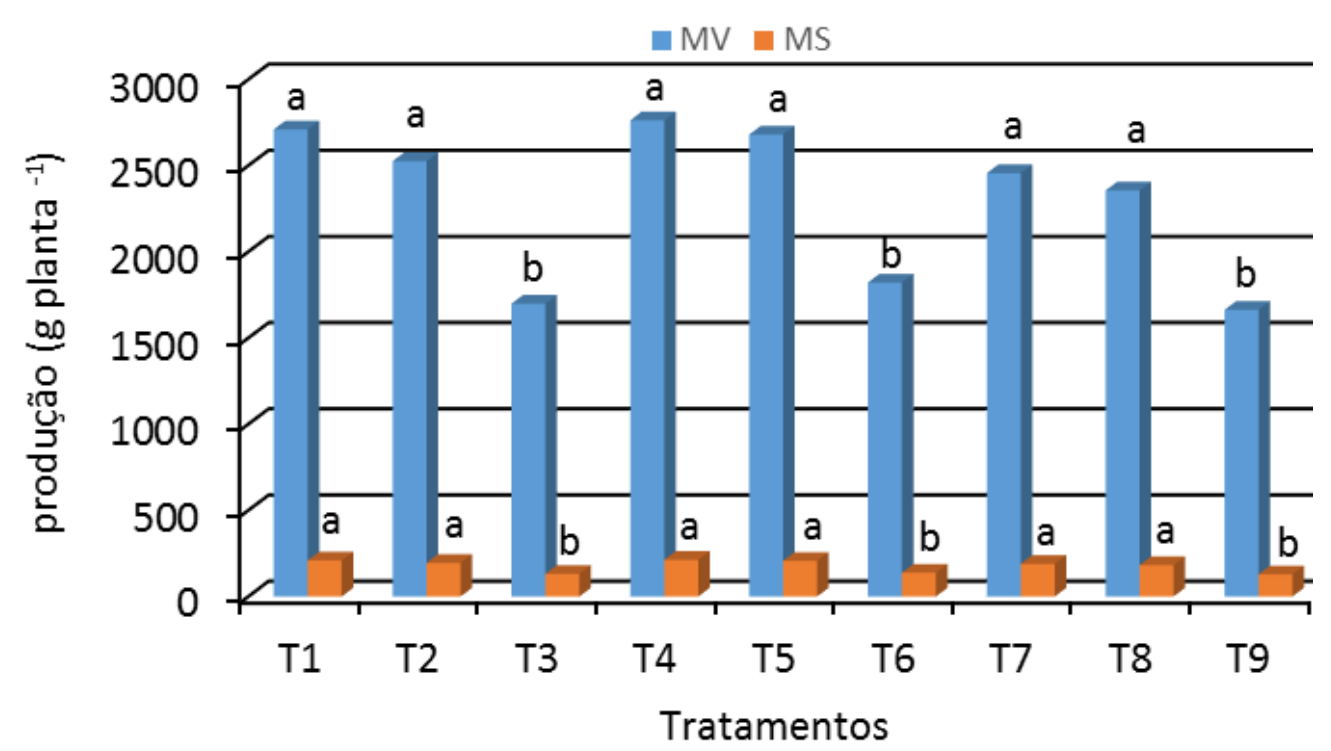

Figura 1. Produção de matéria verde (MV) e matéria seca (MS) do repolho submetidos fontes de compostos orgânicos e formas de aplicação. T1- composto de resíduos de grãos aplicado na linha de plantio sem incorporação; T2- composto de resíduos de frigorífico aplicado na linha de plantio sem incorporação; T3sem aplicação de composto e sem revolvimento da linha; T4- composto de resíduos de grãos aplicado na linha de plantio com incorporação; T5- composto de resíduos de frigorífico aplicado na linha de plantio com incorporação; T6- sem aplicação de composto com revolvimento da linha, T7- composto de resíduos de grãos incorporado em área total; T8- composto de resíduos de frigorífico incorporado em área total; T9- sem aplicação de composto com revolvimento da área total. 


\title{
AVALIAÇÃO DO COMPOSTO DE RESÍDUOS DA AGROINDUSTRIA FRIGORÍFICA NO CULTIVO DE TOMATE EM SISTEMA ORGÂNICO DE PRODUÇÃO
}

\author{
Schallenberger, E.*1; Cantú, R.R. ${ }^{1}$; Morales, R.G.F.'; Visconti, A. ${ }^{\text {; }}$ Guimarães, G.G.F. ${ }^{1}$; Padilha, \\ P.R. ${ }^{2}$
}

${ }^{1}$ Pesquisadores da Epagri, Itajaí, SC - Brasil - schallenberger@epagri.sc.gov.br

${ }^{2}$ Estudante de agronomia - UFP - Curitiba - PR

\begin{abstract}
RESUMO: A produção orgânica de alimentos é uma atividade em crescimento, motivada pela demanda da sociedade por alimentos saudáveis e com sistema de produção ambientalmente correto. O sistema orgânico de produção atende estas demandas. Entre as dificuldades para produzir tomate no sistema orgânico está a nutrição das plantas. O emprego de compostos na produção orgânica é uma prática recomendada oficialmente. Seu grau de eficiência depende do sistema e da forma como se executa o processo de compostagem e das matérias primas utilizadas. O setor agroindustrial de Santa Catarina gera elevados volumes de resíduos, que quando não tratados, ocasionam sérios problemas ambientais. Esses materiais podem ser transformados em compostos para uso em cultivos agrícolas por meio do processo de compostagem. Visando avaliar a eficiência do composto de resíduos da agroindústria frigorífica, foi realizado este trabalho de avaliação de doses deste composto na nutrição orgânica do tomateiro. O composto apresentou a seguinte composição química: N:2,3\%; $\mathrm{P}: 2,0 \%, \mathrm{~K}: 0,75 \%$, Ca: $2,2 \% ; \mathrm{Mg}: 0,7 \%$ e relação $\mathrm{C} / \mathrm{N}$ de 15 . O trabalho constou de quatro tratamentos com cinco repetições, nas doses de 0,$0 ; 2,3 ; 3,45$ e $4,6 \mathrm{Kg}$ de composto por metro linear de solo. $\mathrm{O}$ resultado demonstrou aumento da produtividade do tomateiro em função da dose do composto aplicado $\left(y=0,457 \mathrm{x}^{2}+\right.$ $6,3924 \mathrm{x}+30,884$ e $\mathrm{R}^{2}=0,9926$. Conclui-se que o composto elaborado com resíduos da agroindústria frigorífica é um produto que pode ser utilizado na adubação do tomateiro, viabilizando o sistema orgânico de produção de tomate e o aproveitamento correto dos resíduos da agroindústria frigorífica.
\end{abstract}

Palavras-chave: agroecologia, adubação orgânica, compostagem.

\section{EVALUATION OF THE RESIDUE COMPOUND FROM AGRICULTURAL REFRIGERATION IN THE TOMATO CULTIVATION IN AN ORGANIC PRODUCTION SYSTEM}

\begin{abstract}
The organic production of food is a growing activity, motivated by demand for healthy foods and with an environmentally correct production system. Among the difficulties to produce tomato in the organic system is the nutrition of plants. The use of compounds in organic production is an officially recommended. Its degree of efficiency depends on the system the composting is processig and the raw materials used. The agroindustry sector of Santa Catarina generates high volumes of waste, which, when left untreated, cause serious environmental problems. These materials can be transformed into compounds for use in agricultural crops through the composting process. In order to evaluate the efficiency of the waste compost from the cold agroindustry, this work was carried out to evaluate the doses of this compound in the organic nutrition of the tomato. The compound had the following chemical composition: $\mathrm{N}: 2.3 \% ; \mathrm{P}: 2.0 \%, \mathrm{~K}: 0.75 \%$, Ca: $2.2 \%$; $\mathrm{Mg}: 0.7 \%$ and $\mathrm{C} / \mathrm{N}$ ratio of 15 . The work consisted of four treatments with five replicates at doses of $0.0 ; 2,3 ; 3.45$ and $4.6 \mathrm{~kg}$ of compound per linear meter of soil. The results showed an increase in tomato productivity as a function of the dose of the compound applied $(y=0.457 x 2+6.3924 x+30.884$ and $R 2=$ 0.9926. It is concluded that the compound elaborated with refrigerated agroindustry wastes can be used to fertilize the tomato, enabling the organic system of tomato production and the correct use of the waste from the agroindustry.
\end{abstract}

Keywords: agroecology, organic fertilization, composting

\section{INTRODUÇÃO}

O setor agroindustrial de Santa Catarina gera elevados volumes de resíduos, que quando não tratados, ocasionam sérios problemas ambientais. Esses materiais podem ser transformados em fertilizantes para uso em cultivos agrícolas por meio do processo de compostagem. No alto vale do Itajaí-SC está sendo elaborado composto do resíduo de agroindústria frigorífica na unidade de compostagem automatizada Lauro Pamplona 
localizada no município de Trombudo Central - SC. O total de resíduos transformados em composto orgânico chega a 450 toneladas por mês. O composto elaborado apresenta características promissoras de um fertilizante orgânico de elevada qualidade para o uso em cultivos, estando de acordo com as normas exigidas pelo MAPA.

O emprego de compostos orgânicos na produção agrícola é uma prática adotada no mundo inteiro. Seu grau de eficiência depende do sistema e da forma como se executa o processo de seu preparo e das matérias primas utilizadas, podendo ocorrer elevadas variações de qualidade. A riqueza nutricional e biológica que os compostos orgânicos conferem ao solo e às plantas auxiliam, sobremaneira, no seu cultivo por meio da melhoria das qualidades químicas, físicas e biológicas do solo (Souza \& Prezotti, 2007).

Com a utilização do composto nas adubações produzem-se múltiplos efeitos positivos sobre o solo e nas plantas cultivadas, pelo aumento da permeabilidade, agregação das partículas minerais, fornecimento de macro e micronutrientes, correção da acidez, incremento na população de micro-organismos e elevação na eficiência de absorção de nutrientes pelo aumento da capacidade de troca de cátions do solo. Entretanto, falta informações sobre o uso do composto orgânicos da agroindústria frigorífica na produção de cultivos agrícolas, especialmente nas condições subtropicais do sul do Brasil (Souza, 2008).

Considerando que o composto orgânico elaborado com resíduos da agroindústria frigorífica está estabilizado, justificou-se a realização deste trabalho objetivando estudar doses do composto para nutrição do tomateiro visando a viabilização do sistema orgânico de produção de tomate e o aproveitamento correto dos resíduos da agroindústria frigorífica, atendendo a demanda da sociedade por alimentos saudáveis e a preservação ambiental.

\section{MATERIAL E MÉTODOS}

O composto foi desenvolvido na unidade de compostagem automatizada Lauro Pamplona localizada no município de Trombudo Central - SC, localidade de Pouso da Caixa, no período de 30 de outubro de 2017 a 30 de janeiro de 2018. Os resíduos foram provenientes dos frigoríficos, localizados em Rio do Sul e Presidente Getúlio, das criações de suínos de granjas localizadas em Ituporanga e Rio do Sul e da fábrica de rações localizada em Agronômica.

Os resíduos foram distribuídos e misturados com caminhões e trator com concha, em compartimentos (duas paredes paralelas de alvenaria) de 1,5 m de altura por 4,0 m de largura e $95 \mathrm{~m}$ de comprimento. A leira de compostagem (mistura de materiais) foi montada de uma extremidade à outra, avançando $25 \mathrm{~m}$ por semana, sendo que em 25 dias ocupava todo o compartimento. A leira era continuadamente revolvida desde seu início por uma máquina autopropulsionada que revolve a mistura com helicoides, se deslocando sobre a pilha da compostagem.

Após três meses do início da compostagem, o material foi retirado do compartimento automatizado e depositado em um outro compartimento para depósito, sem revolvimento e após dois meses, o composto foi considerado pronto. A tomada de decisão para finalização do processo foi devido às características do composto relacionadas a relação $\mathrm{C} / \mathrm{N}$, abaixo de 15 (Tabela 1), além da temperatura do fertilizante estar próxima à do ambiente, que indicam a estabilidade do material.

O experimento de avaliação do composto foi realizado na Estação Experimental da Epagri de Itajaí, na área de estudos de cultivo em hortaliças, no município de Itajaí - SC. O experimento foi realizado com o cultivo do tomateiro, em abrigos de cultivo, onde foram avaliadas doses do composto de resíduos da agroindústria frigorífica (CF) constituindo os seguintes tratamentos: T1 - $0 \mathrm{~g} \mathrm{~m}^{-1} \mathrm{de}$ CF; T2 - $1.150 \mathrm{~g} \mathrm{~m}^{-1} \mathrm{de} \mathrm{CF}$; T3 - 2.300 $\mathrm{g} \mathrm{m}^{-1}$ de CF e T4 - $4.600 \mathrm{~g} \mathrm{~m}^{-1}$. As doses do composto foram estabelecidas considerando suas características químicas, tomando como base trabalhos já publicados onde foram estudados outros compostos (Bernal et al. 2009; Cantú et al. 2017) e a recomendação da CQFS- RS/SC (2016) para o cultivo em questão.

Cada tratamento teve quatro repetições, com cinco plantas de tomateiro por parcela, conduzido em delineamento em blocos ao acaso. Foram realizadas duas colheitas semanais quando os frutos iniciavam a coloração vermelha. A irrigação foi realizada manualmente, procurando manter a umidade próximo a capacidade de campo. Os resultados foram submetidos a análise de regressão com auxílio do programa computacional Excel. 


\section{RESULTADOS E DISCUSSÃO}

A aplicação do composto elaborado com resíduos da agroindústria frigorífica na nutrição do tomateiro em sistema orgânico de produção mostrou ser uma recomendação que pode ser adotada, pois os resultados na produtividade do tomateiro (Figura 1) foram crescentes conforme o aumento da dose aplicada. Os valores de produção obtidos com a maior dose são considerados satisfatória conforme Schallenberger et al. (2016).

No estudo sobre a utilização do composto orgânico elaborado com resíduos da agroindústria frigorífica no cultivo de alface, Schallenberger et al. (2018) constataram que a aplicação do fertilizante influenciou positivamente no rendimento da cultura, aumentando a produtividade conforme o aumento da dose do composto, até um limite máximo de dose, sendo detectada a dose ideal para a adubação da alface.

Analisando os resultados encontrados, é possível inferir que na adubação com composto elaborado com resíduos da agroindústria frigorífica, as perdas são poucas, conforme verificado por Cantú (2015). Isso porque, mesmo aplicando o composto com uma expectativa de mineralização que não atenderia a extração e as perdas do nutrientes pelo cultivo, a produtividade foi se elevando proporcional à dose aplicada.

Freitas et.al (2012) utilizando diferentes doses de adubo orgânico na nutrição de sorgo forrageiro não encontraram diferenças entre as doses aplicadas para a área foliar, número de espiguetas e peso da panícula.

Considerando que a produtividade do tomateiro foi crescente e não teve declínio com o aumento da dose aplicada, novos estudos devem ser realizados para determinar a melhor dose do composto elaborado com resíduos da agroindústria frigorífica na adubação do tomateiro em sistema orgânico de produção.

Por fim, é importante destacar que a utilização em dose única do composto elaborado com resíduos da agroindústria frigorífica, aplicado no início cultura, possibilitou a produção satisfatória de tomate, reduzindo despesas com o manejo das adubações.

\section{CONCLUSÃO}

Conclui-se que o composto elaborado com resíduos da agroindústria frigorífica é um produto que pode ser utilizado na adubação do tomateiro, viabilizando o sistema orgânico de produção de tomate e o aproveitamento correto dos resíduos da agroindústria frigorífica.

\section{AGRADECIMENTOS}

A Fundação de Amparo à Pesquisa e Inovação de Santa Catarina - FAPESC e ao Conselho Nacional de Desenvolvimento Científico e Tecnológico - CNPq.

\section{REFERÊNCIAS}

BERNAL, M. P.; ALBURQUERQUE, J. A.; MORAL, R. Composting of animal manures and chemical criteria for compost maturity assessment. A review. Bioresource Technology, v. 100, p. 5444-5453, 2009.

CANTÚ, R. R. Acidificação de dejetos de suínos em compostagem automatizada: emissões gasosas de nitrogênio e resposta da alface à aplicação do composto no solo. Tese de doutorado - Programa de pósgraduação em ciência do solo, área de concentração em biodinâmica e manejo do solo, universidade federal de santa maria (ufsm, rs), 2015, 90 p.

FREITAS, G. A.; SOUSA, C. R.; CAPONE, A.; AFFÉRRI, F. S.; DE MELO, A. V.; DA SILVA, R. R. Adubação orgânica no sulco de plantio e sua influência no desenvolvimento do sorgo. Journal of biotechnology and biodiversity, vol. 3, n. 1: pp. 61-67, february, 2012.

SCHALLENBERGER, E.; CANTÚ, R. R.; MORALES, R. G. F.; SQUERZZATO, N.; MISFELD, A. G. Uso de Composto de Resíduos da Indústria Frigorífica na Nutrição de Alface em Sistema Orgânico de Produção. In: Congresso Brasileiro De Olericultura, 55, 2018, Bonito, MS. Resumos... Campo Grande, MS: UEMS, 2018. P. 9-10.

SCHALLENBERGER, E.; CANTÚ, R. R.; HARO, M. M.; MORALES, R. G. F.; HEINZEN, J. Método e dose de adubação de hortaliças com composto orgânico em sistema orgânico de produção. In: Seminario de Agroecologia da América do Sul, 2, 2016, Dourados, MS. Resumos... Dourados: Associação Brasileira de Agroecologia, 2016. P. 1-10. MS

SOUZA, J. Cultivo orgânico de frutas e hortaliças, XX Congresso Brasileiro de Fruticultura 54th annual meeting of the interamerican society for tropical horticulture, Anais... outubro de 2008 - Centro de Convenções - Vitória/ES 160p.

SOUZA, J.L.; PREZOTTI, L. C. Avaliação técnica e econômica de sistema de compostagem orgânica.2007 disponível em: www.cnph.embrapa.br/novidade/eventos/organica/anexre01.doc. 
Tabela 1. Principais características dos resíduos (RF-Resíduos de frigoríficos; RS-Resíduos de suínos; RAResíduos de ração e RC-Resíduos de cinza de caldeiras) utilizados na compostagem automatizada de resíduos da agroindústria frigorífica. Itajaí-SC, 2018.

\begin{tabular}{|c|c|c|c|c|c|c|c|c|}
\hline Resíduos & pH & $\begin{array}{c}\mathbf{P} \\
\ldots \ldots \ldots . . .\end{array}$ & $\mathbf{K}$ & $\begin{array}{c}\mathrm{N} \\
. . \mathrm{g} \mathrm{kg}^{-3}\end{array}$ & $\begin{array}{c}\mathrm{Ca} \\
\ldots \ldots \ldots . . .\end{array}$ & Mg & $\begin{array}{c}\text { Umidade } \\
\%\end{array}$ & Relação C/N \\
\hline RF & 6,8 & 12,5 & 8,1 & 15,3 & 21,6 & 8,9 & 62,5 & 15,2 \\
\hline $\mathrm{RS}$ & 6,0 & 28,0 & 7,2 & 21,9 & 31,6 & 2,5 & 67,6 & 23,5 \\
\hline RA & 6,1 & 11,8 & 6,1 & 27,2 & 9,6 & 1,7 & 12,7 & 16,2 \\
\hline $\mathrm{RC}$ & 5,8 & 7,5 & 11,9 & 3,9 & 49,0 & 16,6 & 5,7 & 112,8 \\
\hline
\end{tabular}

Tabela 2. Características do composto de resíduos da agroindústria frigorífica utilizado no experimento Itajaí-SC, 2018.

\begin{tabular}{|c|c|c|c|c|c|c|c|c|}
\hline \multirow[t]{2}{*}{ Composto } & \multirow[t]{2}{*}{ pH } & $\mathbf{P}$ & $\mathbf{K}$ & $\mathbf{N}$ & $\mathbf{C a}$ & Mg & \multirow{2}{*}{\multicolumn{2}{|c|}{ Umidade Relação C/N }} \\
\hline & & .......... & $\ldots . .$. & $\mathrm{kg}^{-3}$ & ......... & ............... & & \\
\hline Composto & 7,1 & 20,0 & 7,5 & 23,0 & 22,0 & 7,0 & 25,1 & 14,0 \\
\hline
\end{tabular}

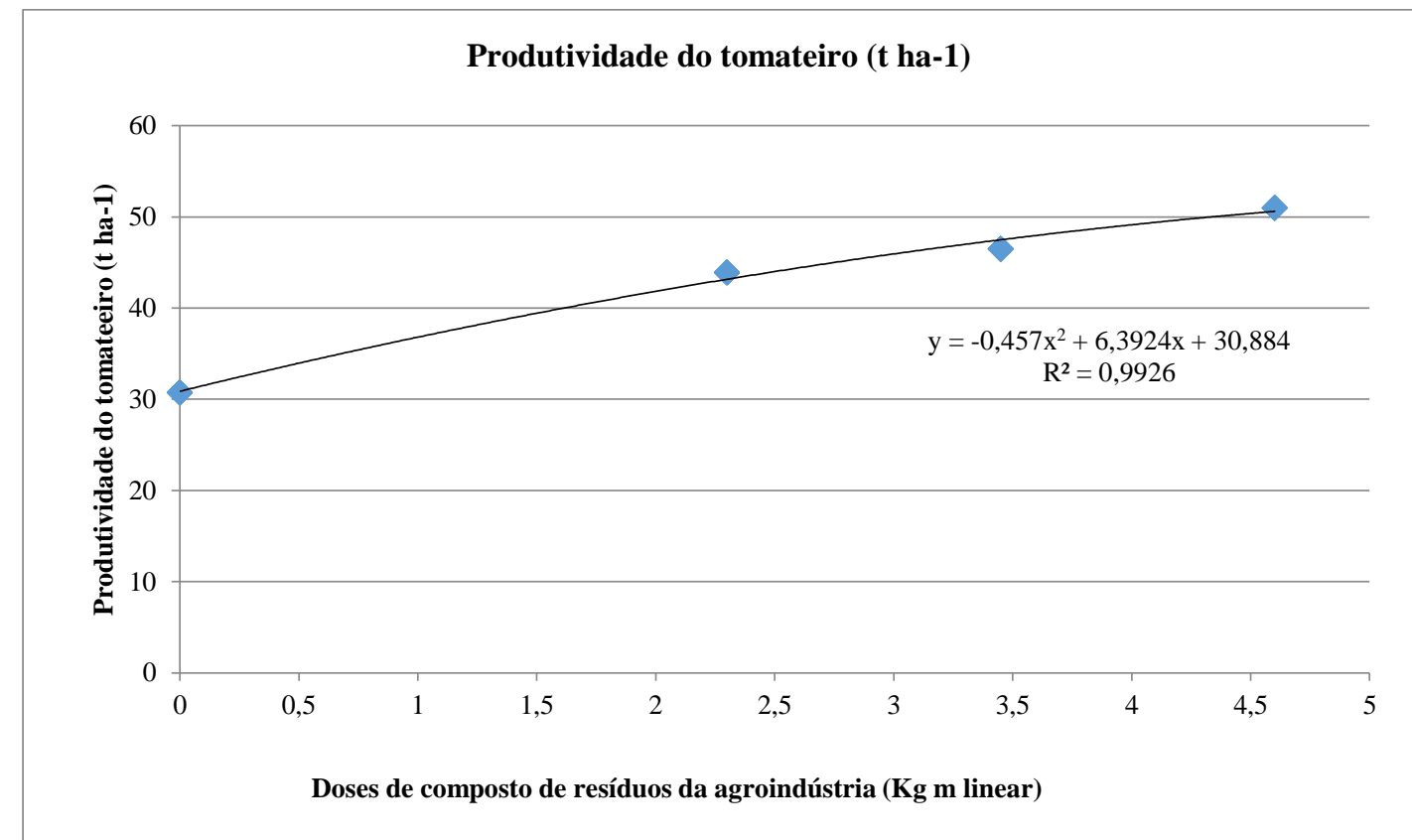

Figura 1. Produtividade do tomateiro $\left(\mathrm{t} \mathrm{ha}^{-1}\right)$ em função de doses de composto de resíduos da agroindústria frigorífica, Itajaí-SC, 2018. 


\title{
EVALUATION OF THE DIGESTATE FROM A REAL-SCALE ANAEROBIC REACTOR AS A BIOFERTILIZER
}

\author{
Ortega, A. ${ }^{1}$; D'avila, L. ${ }^{\text {; }}$ Bastos, J.A. ${ }^{1}$; Schmoeller, L. ${ }^{2}$; Somer, J.G. ${ }^{2}$; Edwiges, T. ${ }^{*}$ \\ ${ }^{1}$ Acadêmicos do Curso de Engenharia Ambiental da Universidade Tecnológica Federal do Paraná, Campus Medianeira, \\ PR-Brasil,a_amandaortega@yahoo.com.br,lucasdvla@outlook.com, jbastos.ea@gmail.com \\ ${ }^{1 *}$ Professor do Departamento de Ciências Biológicas e Ambientais da Universidade Tecnológica Federal do Paraná, Campus \\ Medianeira, PR-Brasil, thiagoe@utfpr.edu.br \\ ${ }^{2}$ Centro Internacional de Energias Renováveis - CIBiogás, Foz.do Iguaçu, PR - Brasil, larissa.s@cibiogas.org, \\ juliana.somer@cibiogas.org
}

\begin{abstract}
The importance of separation of the organic fraction from the urban waste presents the possibility of converting it into energy. The anaerobic digestion is able to decomposes organic matter, resulting in by-products such as biogas and biofertilizer. In this sense, the objective of the study was to monitor the anaerobic digestion performance of a real scale biogas plant, focusing on the evaluation of the digestate to be used as a biofertilizer. The phytotoxicity and germination tests were performed based on the methodology described by Alburquerque (2012). Phytotoxicity test indicated that the undiluted digestate $(213 \%$ ) and $50 \%$ dilution (145\%) from C2 presented the highest values and potential for the germination index and growth of the root plant. In contrast, samples $\mathrm{C} 3$ and $\mathrm{C} 4$ had a high phytotoxicity level, 50\% and 27\%, respectively, when compared to the same dilution. In the case of sample $\mathrm{C} 1$, only the $10 \%$ dilution presented GI value above $100 \%$. In the germination test, it was observed that the sample of $\mathrm{C} 1(10 \%)$ and $\mathrm{C} 2(50 \%)$ presented an increase in shoot size of $42 \%$ and $57 \%$, respectively. Root length was $43 \%$ and $30 \%$, respectively, when compared to control. However, when using the digestate in natura (100\%), the increase of the aerial part, the root length and the stem length present only $34 \%, 21 \%$ and $23 \%$, respectively. Such a factor can be explained by the inhibition of plant growth due to the large amount of nutrients or the presence of inhibitory compounds.
\end{abstract}

Keywords: waste, phytotoxicity, germination.

\section{INTRODUCTION}

In order to minimize the generation of waste, the National Solid Waste Policy (Law 12.305/10) brings with it fundamental guidelines regarding the uncontrolled consumption and final disposition environmentally appropriate waste. In addition, studies reveal the importance of separation of the organic fraction by presenting the possibility of conversion into energy. The treatment of these residues occurs in environments lacking oxygen, being called anaerobic reactors. In this environment, the organic matter decomposes, which generates by-products such as biogas and a liquid that can be used as biofertilizer due to the physico-chemical characteristics (BLEY JR, 2014).

The evaluation and monitoring of environmental contaminants is done through the use of plants that have sensitivity to toxic substances, such as lettuce (Lactuca sativa L. - Asteraceae). These plants have been used in phytotoxicity tests (DING et al., 2009) and genotoxicity (MONTEIRO et al., 2009; EOM et al., 2007) due to its representativeness and cultivation worldwide. According to Campos et al. (2008) the lettuce has stable and well defined cytogenetic characteristics, which favors the evaluation of damages in relation to the chromosomal complement.

Thus, to evaluate the phytotoxicity of a compound is important, since with the results obtained in the analyzes it is possible to determine if the material to be used as fertilizer will inhibit seed germination, root growth or plant development (TRAUTMANN; KRASNY, 1997). In this sense, the objective of this study was to monitor the anaerobic digestion performance of the demonstration unit of the international renewable energy center - CIBiogás, with a focus on the evaluation of the potential of the digestate of a real - scale reactor for use as a biofertilizer.

\section{MATERIAL AND METHODS}

For the accomplishment of the experiments sample of digestate of the demonstration unit from the International Center on Renewable Energy - Biogas (CIBiogas) (Foz do Iguaçu/Parana/Brazil) were collected between the september/2017 and january/2018, except december/2017. The reactor was fed daily with organic waste from restaurants and garden grass from the green areas of Itaipu Hydroelectrical Power Plant. The 
analyzes were carried out in the biofuels laboratory of the Federal University of Technology Paraná (Medianeira/Parana/Brazil).

The phytotoxicity test was performed according to the methodology proposed by alburquerque et al (2012) with seeds of American lettuce (lactuca sativa). The samples of the digester of the months of September $(\mathrm{C} 1)$, October (C2), November (C3) and January (C4) were tested witch three dilutions (1\%, $10 \%$ and 50\%) and undiluted. For comparison purposes, was used distilled water for the control. Petri dishes (autoclavadas) were used for every treatment (months of collection) and incubated in germinating chamber (B.O.D.) with temperature $\left(17^{\circ} \mathrm{c}\right)$ and absence of light for 5 days. For the calculation of the germination index (GI), the number of germinated seeds was measured and the length of the seed measures used for the digital scale (Equation 1) (TIQUIA et al., 1998).

On what:

$$
\mathrm{GI}=\% \mathrm{~g}(\mathrm{~lm} / \mathrm{lc})
$$

(Equation 1)

GI: germination index;

$\% \mathrm{~g}=$ percentage of germination seed in relation to the control;

$\mathrm{Lm}=$ mean root length of the sample $(\mathrm{cm})$;

$\mathrm{Lc}=$ mean root length of the control $(\mathrm{cm})$.

To evaluate the use of the digestate as a biofertilizer, the methodology for the germination test described by Albuquerque et al., (2012) was used. Aluminum trays containing hydrtated perlite and lettuce seeds were used to incubate the digestate samples that presented GI values above $100 \%$. As a control, only seeds and distilled water, were used for comparison purposes for each order sample. The incubation occurred for three

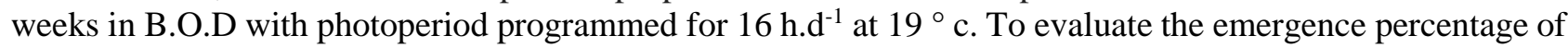
the seedlings were measured the shoot size, stem length and root with the aid of the digital scaler.

\section{RESULTS AND DISCUSSION}

Based on the classification table presented by Belo (2011) (Table 1), only the undiluted digestate of sample C2 presented the highest value (213\%) and potential for the germination index and growth of the root plant, when compared to the other undiluted digestate samples (Table 2). According to Coelho et al., (2018) the management practices of the digestates may be different according to the characteristics. In this case, it has been observed that the use of undiluted digestates without the evaluation of phytotoxicity can be harmful to the soil.

For samples with 50\% dilution, the highest value was obtained by the sample C2 (145\%) and considered as potential material for germination and growth of the plant root. In contrast, samples C3 and C4 had a high phytotoxicity level, $50 \%$ and $27 \%$, respectively, when compared to the same dilution (Table 2). In the case of sample $\mathrm{C} 1$, only the $10 \%$ dilution presented GI value above $100 \%$ (Table 2), being used in the germination test together with the digestates of the sample C2 (undiluted and 50\%) (Table 3).

Analyzing the phytometric parameters, it was observed that the sample $\mathrm{C} 1$ with concentration of $10 \%$ showed increase of $42 \%$ and $43 \%$ in shoot size and root length, respectively, when compared to the control. For the $\mathrm{C} 2$ samples, it also showed an increase for all parameters, and the concentration of the $50 \%$ digestate contributed with $57 \%$ in shoot size, $30 \%$ in root length and $15 \%$ in stem length. However, observed that when using the undiluted, the addition of shoot, root length and stem length present only $34 \%, 21 \%$ and $23 \%$, respectively (Table 3).

Regarding the phytometric parameters of the undiluted digestive and $50 \%$ of the dilution of the $\mathrm{C} 2$ sample, it is observed that the values are close. In this case, the use of undiluted digestate is considered the best option, as it does not require the addition of water for dilution. In contrast, the digest of the $\mathrm{C} 1 \mathrm{sample}$ needs to be diluted 10 times to inhibit the presence of phytotoxic compounds and present potential for germination.

\section{CONCLUSIONS}

The phytotoxicity test and the potential for germination contribute to the monitoring of a reactor and the adequad disposition of the digestate. In the study, only an undiluted (C2) digestate sample did not present phytotoxicity and obtained values in the germination test near the diluted samples, being an alternative to avoid costs and water consumption. In contrast, the other samples require the addition of water to dilute the phytotoxic compounds and ensure safety for application in agriculture. 


\section{VISIGERÂ DEF7 A9 M MAO 2019

ACKNOWLEDGMENTS

We thank the financial support from the CIBiogas through the scientific initiation scholarship and the Federal Technological University of Paraná (UTFPR), Campus Medianeira, which contributed with the infrastructure and scientific support.

\section{REFERENCIAS}

ALBUQUERQUE, J. A et al. Assessment of the fertiliser potential of digestates from farm and agroindustrial residues. Biomass and Bioenergy, Elsevier v. 40, p. 181-189, 2012.

BELO, S. R. S. Evaluation of phytotoxicity through Lepidium sativum in the context of composting processes. 2011. Dissertation (Master in Environmental Engineering) - Department of Mechanical Engineering, University of Coimbra, Coimbra.

BLEY JR, Cicero. Biogas - The invisible energy, 2nd ed. rev. e ampl.; São Paulo: Cibiogás, 2014.

BRAZIL. Law 12,305 of August 2, 2010. Institutes the National Solid Waste Policy; amends Law No. 9,605 of February 12, 1998; and gives other measures, Brasília, 2010.

CAMPOS, J. M. S. et al. Mutagenic effects due to allelopathic action of fern (Gleicheniaceae) extracts. Allelopathy Journal, p.143-152, 2008.

COElHO, J. J., PRIETO, M. L., DOWling, S., HENNESSY, A., CASEY, I., WOODCOCK, T., \& KENNEDY, N. (2018). Physical-chemical traits, phytotoxicity and pathogen detection in liquid anaerobic digestates. Waste Management, 78, 8-15. doi:10.1016/j.wasman.2018.05.017.

DING, L.; JING, H. et al. Regulation of cell division and growth in roots of Lactuca sativa L. seedlings by the ent-kaurene diterpenoid rabdosin B. Journal of Chemical Ecology, v.36, n.5, p.553-563, 2009.

EOM, I. C.; RAST, C.; VEBER, A. M.; VASSEUR, P. Ecotoxicity of a polycyclic aromatic hydrocarbon (PAH)-contaminated soil. Ecotoxicology and Environmental Safety, v.67, n.2, p.190-205, 2007.

MONTEIRO, M. S.; LOPES, T.; MANN, R. M.; PAIVA, C.; SOARES, A. M. V. M.; SANTOS, C. Microsatellite instability in Lactuca sativa chronically exposed to cadmium. Mutation Research: Genetic Toxicology and Environmental, v.672, n.2, p.90-94, 2009.

TRAUTMANN, N. e KRASNY, M. Composting in the Classroom, Scientific Inquiry for High School Students. Ed. Cornell University, 1997.

TIQUIA, S. M.; TAM, N. F. Y \& HODGKISS, I. J. Elimination of phytotoxicity during co-composting of spent pig-manure sawdust litter and pig sludge, ed. Elsevier, 1998.

Table 1. Level of phytotoxicity.

\begin{tabular}{cc}
\hline$\%$ GI & Level of Phytotoxicity \\
\hline$>100$ & The material contributes to the germination and \\
growth of the plant root \\
$80-100$ & No phytotoxic; mature compound \\
$60-80$ & Moderaly phytotoxic \\
$30-60$ & Phytotoxic \\
$<30$ & Very phytotoxic \\
\hline & Font: adaptad of Belo et al.
\end{tabular}


Table 2. Germination index from the digestates.

\begin{tabular}{ccc}
\hline Sample & Dilution $(\boldsymbol{\%})$ & GI $(\boldsymbol{\%})$ \\
\hline \multirow{3}{*}{ C1 } & 1 & 91 \\
& 10 & 105 \\
& 50 & 84 \\
$\mathrm{C} 2$ & - & 31 \\
\hline & 1 & 93 \\
& 10 & 83 \\
& 50 & 145 \\
$\mathrm{C} 3$ & - & 213 \\
\hline & 1 & 75 \\
& 10 & 94 \\
& 50 & 50 \\
& - & 38 \\
\hline & 1 & 92 \\
& 10 & 65 \\
& 50 & 27 \\
& - & 0 \\
\hline
\end{tabular}

Table 3. Germination test results.

\begin{tabular}{cccc}
\hline \multirow{2}{*}{ Sample } & \multicolumn{3}{c}{ Parameters $(\mathbf{m m})$} \\
\cline { 2 - 4 } & Aereal part $(\mathbf{c m})$ & Root length $(\mathbf{c m})$ & Stem length $(\mathbf{c m})$ \\
\hline CON & $25.2 \pm 7$ & $17.8 \pm 11$ & $22.1 \pm 6$ \\
C1 at dilution 10\% & $35.8 \pm 14$ & $25.4 \pm 13$ & $21.6 \pm 4$ \\
C2 at dilution 50\% & $39.5 \pm 0$ & $23.2 \pm 0$ & $25.5 \pm 0$ \\
C2 undiluted & $33.9 \pm 0$ & $21.3 \pm 0$ & $23.2 \pm 0$ \\
\hline
\end{tabular}




\title{
BIOFERTILIZANTES AERÓBIOS FORMULADOS COM RESIDUOS MARINHOS PROMOVEM O CRESCIMENTO DE PLANTAS DE ALFACE E REDUZEM A SEVERIDADE DE SCLEROTIUM ROLFSII
}

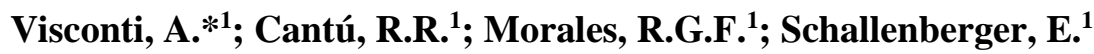 \\ ${ }^{1}$ Pesquisadores da Epagri-Estação Experimental de Itajaí, Itajaí, SC - Brasil \\ visconti@epagri.sc.gov.br
}

\begin{abstract}
RESUMO: O objetivo deste trabalho foi testar o efeito de biofertilizantes aeróbios contendo farinha de peixe (FP) ou casca de camarão (CC) na promoção de crescimento de alface e no controle de S. Rolfsii (Sr). Biofertilizantes foram formulados com $0,5 \mathrm{~L}$ do pó de $\mathrm{FP}$ ou CC e fermentados a $28^{\circ} \mathrm{C}$ com aeração a cada 15 minutos por 8 dias. Em vasos de 2,8L contendo solo areno-argiloso, os biofertilizantes foram incorporados em pre e pós semeadura de 4 escleródios de $S r$ incubados por 6 dias, nas concentrações de 0,25, 50 e $100 \%$ (v/v) da capacidade de campo seguido de nova incubação de 6 dias. Três mudas de alface "Vanda" com 15 dias foram transplantadas em cada vaso. $\mathrm{O}$ tratamento controle foram vasos sem o patógeno. Por 5 semanas foi avaliada a severidade (S) pela escala de notas: 0-sadia; 1-murcha das folhas baixeiras, infecção precoce; 2mais que duas folhas adultas infectadas e murcha severa; 3-planta morta, os valores convertidos em área abaixo da curva de severidade da doença (AACSD). O delineamento experimental foi o inteiramente casualizado em fatorial $(2 \times 4 \times 3)$ para resíduo, concentração e tratamento, com 6 repetições ( 1 rep $=1$ vaso com 3 plantas). As análises das regressões demostraram redução da severidade com resposta quadrática à concentração para FP e $\mathrm{CC}$ nos tratamentos curativos e preventivos, respectivamente. Os tratamentos FP $25 \%$ preventivo e CC $25 \%$ preventivo e curativo elevaram os teores da matéria seca nas plantas de alface. O tratamento FP 100\% de FP foi fitotóxico às plantas.
\end{abstract}

Palavras-chave: controle biológico; casca de camarão; farinha de peixe; supressividade.

\section{AEROBIC BIOFERTILIZERS FORMULATED WITH MARINE RESIDUES PROMOTE THE GROWTH OF LETTUCE PLANTS AND REDUCE THE SEVERITY OF SCLEROTIUM ROLFSII}

\begin{abstract}
The aim of this work was to test the effect of aerobic biofertilizers containing fish meal (FP) or shrimp shell (CC) in the promotion of lettuce growth and control of $S$. rolfsii $(\mathrm{Sr})$. Biofertilizers were formulated with $0.5 \mathrm{~L}$ of $\mathrm{FP}$ or CC powder and fermented at $28^{\circ} \mathrm{C}$ with aeration every 15 minutes for 8 days. In 2,8L pots containing sandy-clay soil, biofertilizers were incorporated in pre and post sowing of $4 \mathrm{Sr}$ sclerotia incubated for 6 days at concentrations of $0,25,50$ and $100 \%(\mathrm{v} / \mathrm{v})$ of the field capacity followed by a new incubation for 6 days. Three seedlings of "Vanda" lettuce with 15 days-old were transplanted in each pot. The control treatment was pots without the pathogen. For 5 weeks the severity $(S)$ were evaluated by the scale of notes: 0-healthy; 1-wilt of the leaflets, early infection; 2-more than two infected adult leaves and severe wilt; 3 -plant dead, values converted into area under below curve of the disease severity (AUCDS). The experimental design was completely randomized in factorial $(2 \times 4 \times 3)$ for residue, concentration and treatment, with 6 replicates ( 1 rep $=1$ pot with 3 plants). Regression analysis showed a reduction in severity with quadratic response to concentration for $\mathrm{FP}$ and $\mathrm{CC}$ in curative and preventive treatments, respectively. The treatments FP 25\% preventive and CC 25\% preventive and curative raised the dry matter contents in the lettuce plants. The treatment FP 100\% was phytotoxic to the plants.
\end{abstract}

Keywords: biological control; shrimp shell; fishmeal; suppressiveness.

\section{INTRODUÇÃO}

Os resíduos gerados na agropecuária são reciclados naturalmente, com ação na melhoria das características físico-químicas de solos, porém parte significativa é descartada como lixo, poluindo os ecossistemas, desprezando seu potencial como inibidor de patógenos de plantas (BAILEY \& LAZAROVITS, 2003). Informações sobre o uso de resíduos no controle de fitopatógenos ainda são escassos, principalmente, em regiões tropicais. 
Os resíduos marinhos seguem eventualmente a mesma tendência de descarte, com destino para lixões ou despejados no mar sem tratamento. Esses resíduos são constituídos de frações significativas de carbono, proteínas, cálcio, vitaminas, macro e micronutrientes, mas possuem também em sua composição elevado teor de água e gorduras insaturadas facilmente oxidadas, constituindo-se de material altamente perecível, capazes de gerar grande impacto poluidor se inadequadamente descartados no ambiente, porém, com evidente utilidade na agricultura, quando convertidos em fertilizantes orgânicos (ABBASI et al., 2004; ABBASI et al.; 2006).

No controle de fitopatógenos, os resíduos de origem marinha apresentam-se promissores e eficientes (ABBASI et al., 2004; ABBASI et al.; 2006; VISCONTI et al., 2010) atuando, como os demais resíduos, por meio dos diversos mecanismos de controle, bióticos e abióticos (BETTIOL et al.; 2009), porém, com resultados variáveis, dependente das características do solo, do patossistema estudado, tipo de resíduo e concentração, forma de aplicação e grau de maturação.

\section{Resíduos da indústria pesqueira}

\section{MATERIAL E MÉTODOS}

Dos resíduos utilizados, a farinha de peixe é um produto comercial da Farinha de Peixe Kenya de Itajaí, SC. A casca de camarão (CC) foi coletada na colônia de pescadores do município de Balneário Camboriú, SC, seco em estufa de ar forçado a $40^{\circ} \mathrm{C}$ para perda da umidade até o ponto de moagem, seguido de trituração, moagem e separação em peneira de 60 Mesh $(0,25 \mathrm{~mm})$.

\section{Produção do biofertilizante aeróbio}

Para o preparo de 100 litros de cada biofertilizante foi adotado a fórmula: 94 litros de água; $1,0 \mathrm{Kg}$ de composto orgânico; $2,0 \mathrm{~kg}$ de farelo de arroz; $1,0 \mathrm{Kg}$ de torta de mamona; $0,5 \mathrm{Kg}$ de açúcar e $0,5 \mathrm{Kg}$ de amido de mandioca e ao final de $0,5 \mathrm{~L}$ da farinha de cada resíduo marinho. O processo de fermentação foi a $28^{\circ} \mathrm{C}$ com aeração a cada 15 min por 8 dias. Os atributos químicos e biológicos de cada biofertilizante encontramse nas Tabelas 1 e 2 , respectivamente.

Efeito dos biofertilizantes com resíduos marinhos adicionados ao solo de cultivo, infestado e não infestado, na promoção de crescimento de alface no controle de $S$. rolfsii

Em vasos de 2,8 L contendo solo areno-argiloso os biofertilizantes foram incorporados em dois tratamentos: a) Preventivo - incorporação do biofertilizante nas concentrações de 0, 25, 50 e $100 \%$ (v/v) da capacidade de campo, com incubação por seis dias, seguido de semeadura de 4 escleródios de $S$. rolfsii e nova incubação por mais 6 dias. b) Curativo: semeadura de 4 escleródios de $S$. rolfsii e incubação por 6 dias seguido de incorporação do biofertilizante e nova incubação por 6 dias. Em seguida, 3 mudas de alface "Vanda" com 15 dias de idade foram transplantadas em cada vaso e mantidos em casa de vegetação com irrigação por gotejamento. $\mathrm{O}$ tratamento controle foram vasos sem o patógeno. Por 5 semanas foi avaliada a severidade (S) da doença pela escala de notas: 0 - sadia; 1 - murcha das folhas baixeiras, infecção precoce; 2 - mais que duas folhas adultas infectadas e murcha severa; 3 - planta morta e os valores convertidos em área abaixo da curva de severidade da doença (AACSD). O delineamento experimental foi o inteiramente casualizado em arranjo fatorial $(2 \times 4 \times 3)$ para resíduo, concentração e tratamento, com 6 repetições ( 1 rep $=1$ vaso com 3 plantas). Os teores de matéria seca foram determinados através de secagem das plantas em estufa de circulação forçada a $60^{\circ} \mathrm{C}$ até a estabilização do peso seguido de pesagem em balança analítica. Os resultados foram submetidos à análise de variância e as médias ao teste de comparação de Scott-Knott a 5\% de probabilidade.

\section{RESULTADOS E DISCUSSÃO}

Os valores de severidade da doença foram submetidos à análise de regressão que registrou significância para os biofertilizantes e tratamentos sobre a área baixo da curva de severidade da doença (AACSD), com resposta quadrática para a farinha de peixe ( $\mathrm{y}_{\text {Prev }}=1,3955-0,0017 \mathrm{x}-0,0001 \mathrm{x}^{2} \mathrm{R}^{2}=0,8956$ e $\mathrm{y}_{\text {Cur }}=1,818-$ $\left.0,0297 x+0,0001 x^{2} R^{2}=0,8061\right)$ e para a casca de camarão $\left(y_{\text {Prev }}=1,4409-0,0104 x-3,8384 x 10^{-5} x^{2} R^{2}=\right.$ 0,9637 e ycur $\left.=1,4485-0,0139 x+5,6566 \times 10^{-5} x^{2} R^{2}=0,9185\right)$ nos tratamentos preventivo e curativo, respectivamente (Figuras $1 \mathrm{~A}$ e B).

Abbasi et al. (2004) reduziram a severidade de Rhizoctonia solani, Pythium aphanidermatum em mudas de rabanete e pepino com a incorporação de $4 \%$ de emulsão de peixe aplicado em solo areno-argiloso e incubado por 28 dias antes da semeadura. 
Bettiol et al. (2009), estudaram o potencial do hidrolisado de peixe, sobre três isolados de Fusarium oxysporum f. sp. lycopersici $(\mathrm{Fol})$ raça $3 \mathrm{em}$ tomateiro. Em substrato contendo $40 \%$ de substrato à base de casca de pinus compostada e $60 \%$ de latossolo, infestado com clamidósporos de $\mathrm{Fol}$ na concentração de $10^{5}$ $\mathrm{UFC} \mathrm{g}^{-1}$ de substrato e incubados por 15 dias, foi incorporado o hidrolisado de peixe e incubado por 10 dias, seguido do plantio de mudas do tomateiro Santa Clara, com 30 dias de idade. Os autores concluíram que todas as concentrações de hidrolisado de peixe foram efetivas na redução da severidade da doença.

Kupper et al. (2006) avaliaram o efeito in vivo de biofertilizante aplicados nas concentrações de $0,5,10$ e $20 \%$ e 0, 20, 30 e 40\% (v/v), respectivamente, em pomares de citros no estado de São Paulo, contendo Guignardia citricarpa nos frutos. O biofertilizante reduziu a severidade da doença proporcionalmente à concentração aplicada.

As aplicações dos biofertilizantes elevaram os teores da matéria seca (MS) nas plantas de alface nas nos tratamentos contendo biofertilizante de farinha de peixe a partir de $25 \%$, em g de MS, de 8,3 13,7, e nos tratamentos com biofertilizante de casca de camarão, preventivo e curativo, de 6,2 g para 14,7 e de 7,2 para 12,7 , respectivamente.

Gagnon \& Berrouard (1994) incorporam farelo de peixe a solo a base de turfa e observaram aumento significativo, de 57 a $83 \%$ no peso seco da parte aérea de plantas de tomate em comparação a testemunha.

Abbasi et al. (2004) avaliaram a eficácia da emulsão de peixes no crescimento de mudas de rabanete ou pepino. A incorporação de $4 \%$ de emulsão de peixe ao substrato de produção de mudas foi suficiente para duplicar e triplicar os teores de matéria seca de mudas de rabanete e pepino, respectivamente, com 14 dias de idade em comparação àquelas que receberam N-P-K equivalente.

A concentração de $100 \%$ do biofertilizante com farinha de peixe foi fitotóxica às plantas (Figura 1A e Tabela 3).

\section{CONCLUSÃO}

Nas condições experimentais, os biofertilizantes, fermentados aerobiamente, contendo resíduos marinhos promoveram o crescimento de plantas de alface e reduziram a severidade da doença causada por Sclerotium rolfsii.

\section{AGRADECIMENTOS}

A Fundação de Amparo à Pesquisa e Inovação de Santa Catarina - FAPESC e ao Conselho Nacional de Desenvolvimento Científico e Tecnológico - CNPq.

\section{REFERÊNCIAS}

ABBASI, P.A.; CONN, K.L.; LAZAROVITS, G. Suppression of Rhizoctonia and Pythium damping-off of radish and cucumber seedlings by addition of fish emulsion to peat mix or soil. Canadian Journal of Plant Pathology, Ottawa, v. 26, p.177-187, 2004.

ABBASI, P.A.; CONN, K.L.; LAZAROVITS, G. Effect of fish emulsion used as a preparing soil amendment on verticillium wilt, scab, and tuber yeld of potato. Canadian Journal of Plant Pathology, Ottawa, v. 28, n.4, p. 509-518, 2006

BAILEY, K.L.; LAZAROVITS, G. Suppressing soil-borne diseases with residue management and organic amendments. Soil \& Tillage Research, Amsterdam BV, v. 72, n. 2. p. 169-180. Aug. 2003.

BETTIOL, W.; GHINI, R.; MARIANO, R.R.L.; MICHEREFF, S.J.; MATTOS, L.P.V.; ALVARADO, I.C.M.; PINTO, Z.V. Supressividade a fitopatógenos habitantes do solo. In: BETTIOL, W.; MORANDI, M.A.B. (Eds.). Biocontrole de doenças de plantas: uso e perspectivas. Jaguariúna-SP: Embrapa Meio Ambiente, 2009. p. 187-208.

GAGNON, B.; BERROUARD, S. Effects of several organic fertilizers on growth of greenhouse tomato transplants. Canadian Journal of Plant Science, Ottawa, v. 74, n. 1, p. 167-168, Jan. 1994.

KUPPER, K.C.; BETTIOL, W.; DE GOES, A.; DE SOUZA, P.S.; BELLOTTE, J.A.M. Biofertilizer for control of Guignardia citricarpa, the causal agent of citrus black spot. Crop Protection, Surrey, v. 25, n. 6 , p. 569-573, Jun. 2006.

VISCONTI, A.; BETTIOL, W. Efeito de hidrolisado de peixe sobre o crescimento micelial e contole de Cylindrocladium spathiphylli em espatifilo. Summa Phytopathologica, Botucatu, v. 36, n. 4, p. 298-308, Dez. 2010. 
Tabela 1. Atributos dos biofertilizantes.

\begin{tabular}{|c|c|c|c|c|c|c|c|c|c|c|c|}
\hline \multirow{2}{*}{ Biofertilizante } & \multirow{2}{*}{ pH } & \multirow{2}{*}{$\begin{array}{c}\mathrm{UR65}^{\circ} \mathrm{C} \\
(\%)\end{array}$} & $\mathbf{P}_{2} \mathbf{O}_{5}{ }^{*}$ & $\mathbf{K}_{2} \mathbf{O} *$ & Ca* & Mg* & $\mathbf{N}^{*}$ & $\mathbf{C u}^{*}$ & $\mathbf{Z n} *$ & $\mathrm{Fe}^{*}$ & Mn* \\
\hline & & & \multicolumn{5}{|c|}{$\left(\mathrm{Kg} / \mathrm{m}^{3}\right)$} & \multicolumn{4}{|c|}{$\left(\mathbf{g} / \mathbf{m}^{3}\right)$} \\
\hline & 5,6 & 98,04 & 2,05 & 1,85 & 0,96 & 1,17 & 0,56 & 0,00 & 5,29 & 0,00 & 8,40 \\
\hline Casca camarão & 6,5 & 98,26 & 0,63 & 2,05 & 1,20 & 0,73 & 0,59 & 14,20 & 5,70 & 14,40 & 8,40 \\
\hline
\end{tabular}

*Teor total no material úmido.

Tabela 2. Diversidade microbiana dos biofertilizantes (UFC $\left.\mathrm{mL}^{-1}\right)$.

\begin{tabular}{lccccc}
\hline Biofertilizante & Bactérias totais & Bacillus sp. & Fungos totais & Trichoderma sp. & Actinobactérias \\
\hline Farinha de peixe & $4,4 \times 10^{5}$ & $1,1 \times 10^{5}$ & $7,5 \times 10^{4}$ & $4,0 \times 10^{3}$ & $3,8 \times 10^{4}$ \\
Casca camarão & $1,0 \times 10^{17}$ & $1,0 \times 10^{16}$ & $1,5 \times 10^{9}$ & $6,6 \times 10^{7}$ & $6,2 \times 10^{12}$ \\
\hline
\end{tabular}

Tabela 3. Teor de matéria seca (g) de plantas de alface nas concentrações de 0, 25, 50 e $100 \%$ (v/v) de biofertilizantes de farinha de peixe e casca de camarão, incorporados ao solo de cultivo nas concentrações de $0,25,50$ e $100 \%$ (v/v) da capacidade de campo.

\begin{tabular}{|c|c|c|c|}
\hline \multirow{3}{*}{$\begin{array}{c}\text { Concentração } \\
(\%)\end{array}$} & \multicolumn{3}{|c|}{ Teor de Matéria Seca (g) } \\
\hline & \multicolumn{2}{|c|}{ Tratamento } & \multirow[b]{2}{*}{ Sem patógeno } \\
\hline & Preventivo & Curativo & \\
\hline \multicolumn{4}{|c|}{ Farinha de peixe } \\
\hline 0 & $8,3 \pm 0,8 \mathrm{aB} *$ & $6,7 \pm 1,5 \mathrm{aB}$ & $7,3 \pm 1,8 \mathrm{aA}$ \\
\hline 25 & $13,7 \pm 0,8 \mathrm{aC}$ & $10,7 \pm 0,8 \mathrm{aB}$ & $10,7 \pm 1,2 \mathrm{aA}$ \\
\hline 50 & $12,7 \pm 2,0 \mathrm{aC}$ & $9,7 \pm 1,7 \mathrm{aB}$ & $11,7 \pm 1,3 \mathrm{aA}$ \\
\hline 100 & $0 \mathrm{aA} * *$ & $0 \mathrm{aA}^{* *}$ & $9,3 \pm 1,2 \mathrm{bA}$ \\
\hline \multicolumn{4}{|c|}{ Casca de camarão } \\
\hline 0 & $6,2 \pm 1,3 \mathrm{aA}$ & $7,2 \pm 1,9 \mathrm{aA}$ & $9,7 \pm 1,2 \mathrm{aA}$ \\
\hline 25 & $14,7 \pm 1,9 \mathrm{aB}$ & $12,7 \pm 12,7 \mathrm{aB}$ & $12,7 \pm 0,8 \mathrm{aA}$ \\
\hline 50 & $14,7 \pm 1,5 \mathrm{aB}$ & $14,3 \pm 1,0 \mathrm{aB}$ & $16 \pm 1,2 \mathrm{aB}$ \\
\hline 100 & $16 \pm 0,7 \mathrm{aB}$ & $13,3 \pm 0,8 \mathrm{aB}$ & $14,7 \pm 1,4 \mathrm{aB}$ \\
\hline
\end{tabular}

$\mathrm{CV}(\%)=29,52$

* Valores seguidos da mesma letra minúscula e maiúscula não diferem entre si na linha e na coluna, respectivamente para o teste de Scott-Knott a 5\%.** Fitotoxicidade.

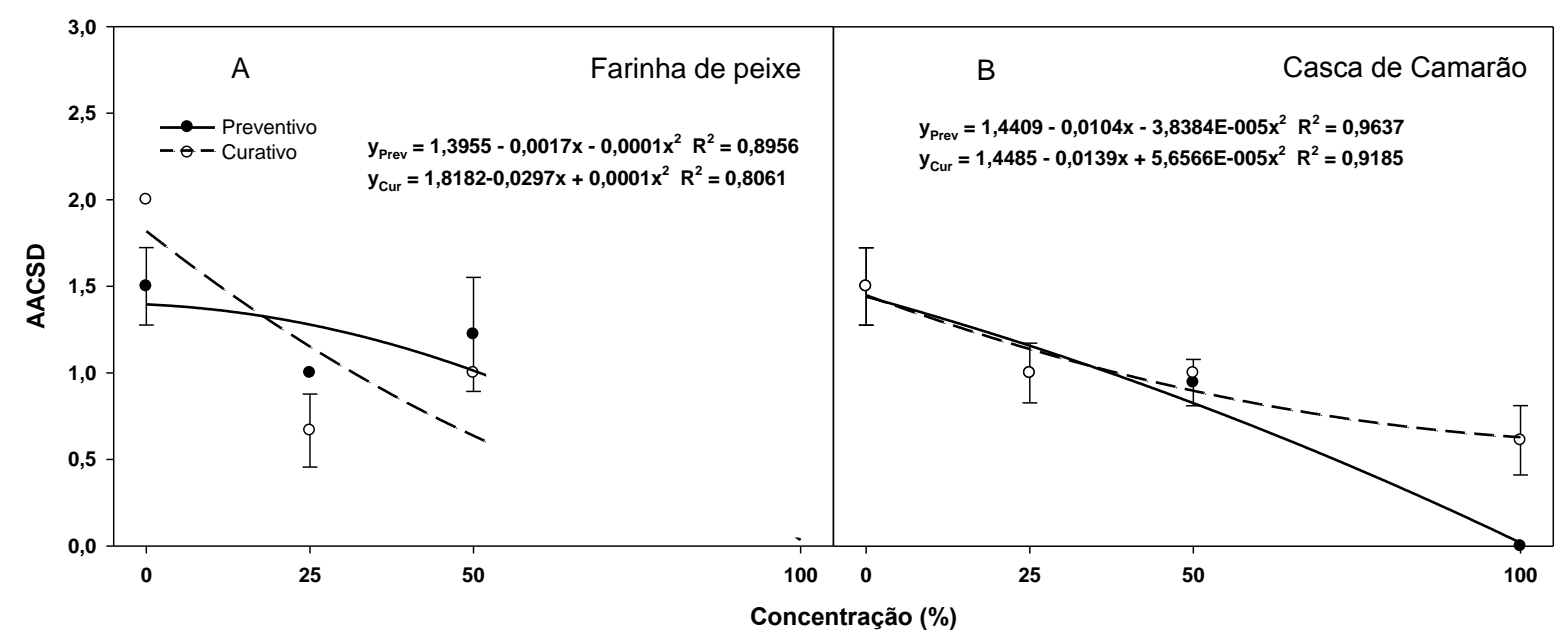

Figura 1. Área abaixo da curva de severidade da doença (AACSD) causada por Sclerotium rolfsii em plantas de alface "Vanda" cultivadas durante 5 semanas com biofertilizantes aeróbios de farinha de peixe e casca de camarão incorporados ao solo de cultivo nas concentrações de $0,25,50$ e $100 \%$ (v/v) da capacidade de campo. 


\title{
EFEITO DO COMPOSTO DE RESÍDUOS DA AGROINDÚSTRIA FRIGORÍFICA E DE PORTO GRANELEIRO NA PRODUÇÃO DE PIMENTÃo
}

\author{
Morales, R.G.F. ${ }^{* 1}$; Cantú, R.R. ${ }^{1}$; Schallenberger, E. ${ }^{1}$; Visconti, A. ${ }^{1}$; Ceccon, A.P. ${ }^{2}$; Squerzzato, N. ${ }^{3}$ \\ ${ }^{1}$ Pesquisadores da Epagri, Itajaí, SC-Brasil \\ ${ }^{2}$ Graduação em Agronomia, UFPR \\ ${ }^{3}$ Engenheiros da Pamplona Alimentos S/A, Rio do Sul, SC - Brasil \\ *rafaelmorales@epagri.sc.gov.br
}

\begin{abstract}
RESUMO: O objetivo do presente trabalho foi o de avaliar o efeito de adubação com composto de resíduos da agroindústria frigorífica (CRAF) e de grão residuais de porto graneleiro (CRG) na produção de quatro cultivares de pimentão no sistema orgânico. O delineamento experimental foi o bloco casualizado, com quatro repetições de cinco plantas cada. Os tratamentos foram distribuídos num esquema fatorial $5 \times 4$, sendo: cinco adubações (zero, CRAF, CRG, composto tradicional e comercial) e quatro cultivares de pimentão (Casca Dura, Verde Luz, Yollo e Otto). Foram avaliadas as seguintes características: peso e total de frutos por planta, massa média de frutos, espessura e firmeza do mesocarpo, comprimento e largura do fruto. Os dados foram submetidos a análise de variância e, quando significativas, as médias comparadas pelo teste de Tukey $(\mathrm{p}<0,05)$. Não houve interação entre os quatro compostos e as quatro cultivares em todas as variáveis analisadas. Plantas de pimentão adubadas com CRAF produziram 44,7 $\mathrm{t} \mathrm{ha}^{-1}$ de frutos, produção equivalente ao obtido com o composto tradicional $\left(43,3 \mathrm{t} \mathrm{ha}^{-1}\right)$ e comercial $\left(43,5 \mathrm{t} \mathrm{ha}^{-1}\right)$, sendo os três tratamentos superiores a testemunha sem composto $\left(27,3 \mathrm{t} \mathrm{ha}^{-1}\right)$. Quanto as cultivares, o híbrido Otto foi o mais produtivo, com 51,6 $\mathrm{t} \mathrm{ha}^{-1}$, mas não diferiu do cultivar OP Casca Dura, com 45,5 $\mathrm{t} \mathrm{ha}^{-1}$. Conclui-se que as adubações com CRAF e com CRG apresentam eficiência agronômica equivalentes a adubação com composto tradicional e composto comercial, podendo, assim, serem utilizados na adubação do pimentão quando cultivado no sistema orgânico.
\end{abstract}

Palavras-chave: Capsicum annuum, resíduo agroindústrial, hortaliças

\section{EFFECT OF AGRIBUSINESS WASTE COMPOST AND PORT GRAINS IN THE PRODUCTION OF SWEET PEPPER}

\begin{abstract}
The aim of the present work was to evaluate the effect of fertilization with agribusiness waste compost (CRAF) in the yield of four sweet pepper cultivars in the organic system. The experimental design was the randomized block, with four replications of five plants each. The vectors were analyzed in $5 \times 4$ factorial, being: five fertilizations (zero, CRAF, CRG, CT and Commercial Compound) and four sweet pepper cultivars (Casca Dura, Luz Verde, Yollo and Otto). Were evaluated the following characteristics: weight and total of fruits per plant, average fruit mass, thickness and firmness of the mesocarp, length and width of the fruit. The data were compared with the analysis of variance and, when they, as means compared by the Tukey test $(\mathrm{p}<0.05)$. There was no interaction between the four compounds and four cultivars in all variables analyzed. Sweet pepper plants fertilized with CRAF yield $44.7 \mathrm{tha}^{-1}$ of fruits, equivalent to that obtained with the traditional $\left(43.3 \mathrm{t} \mathrm{ha}^{-1}\right)$ and commercial $\left(43.5 \mathrm{t} \mathrm{ha}^{-1}\right)$, with the three treatments superior the control without compound $\left(27.3 \mathrm{t} \mathrm{ha}^{-1}\right)$. Regarding the cultivation, the Otto hybrid was more productive, with $51.6 \mathrm{t} \mathrm{ha}^{-1}$, but did not differ from the cultivar OP Casca Dura, with $45.5 \mathrm{t} \mathrm{ha}^{-1}$. It is concluded that the fertilizations with CRAF and with CRG present agronomic efficiency equivalent to fertilization with traditional compound and commercial compound, and can be used in the fertilization of the sweet pepper when grown in the organic system.
\end{abstract}

Keywords: Capsicum annuum, agroindustrial residue, greenery

\section{INTRODUÇÃO}

A busca constante da sociedade pela sustentabilidade tem levado as empresas a investirem na destinação correta dos resíduos produtivos. Empresas que obtém êxito nesse sentido tendem a receber um "feedback" positivo dos seus consumidores e incentivos governamentais que a cada dia estão mais comprometidos a bater metas estabelecidas por tratados internacionais. 
Em Santa Catarina, um dos principais ramos agropecuários e que movimenta a economia do estado é o da agroindústria frigorífica e portuária. Na região do Alto Vale do Itajaí - SC as agroindústrias frigoríficas vêm desenvolvendo trabalhos contundentes com compostagem automatizada de resíduos, produzindo fertilizante orgânico seguros de acordo com as resoluções do MAPA / IN SDA nº 7 2016. Já no Litoral Norte de Santa Catarina, iniciativas de compostagem de grãos residuais de porto graneleiro, igualmente vem sendo desenvolvida com sucesso (Cantú et al., 2018), produzindo um fertilizante promissor.

Resultados preliminares indicam que o CRAF é promissor na produção de hortaliças (Schallenberger et al., 2018), devido a inúmeras vantagens, com destaque para: liberação gradual dos nutrientes pelo processo de mineralização; elevada capacidade de troca de cátions, o que ajuda a reter os nutrientes e diminui a perda por lixiviação; quantidades significativas de macro e micronutrientes; e apresenta uma microbiologia favorável a indução a supressividade à patógenos (CÃMARA, 2001; SANTOS et al., 1994; SILVA et al., 2000; SCHALLENBERGER et al., 2016). Sendo assim, o objetivo do presente trabalho foi o de avaliar o efeito de adubação com CRAF, bem como outros três compostos orgânicos, na produção de quatro cultivares de pimentão no sistema orgânico.

\section{MATERIAL E MÉTODOS}

O experimento foi conduzido na Estação Experimental da Epagri de Itajaí-SC, no setor de olericultura, em abrigos de cultivo, sem o revolvimento total do solo (plantio direto), seguindo-se os conceitos do sistema orgânico. A produção das mudas e instalação do experimento ocorreu entre os meses de março e abril, conduzindo-se as plantas até dezembro de 2018.

O composto de resíduo da agroindústria frigorífica (CRAF) foi desenvolvido na unidade de compostagem automatizada Lauro Pamplona, localizada no município de Trombudo Central - SC, entre os meses de setembro e outubro de 2017. Foi realizada uma combinação de diferentes resíduos, buscando uma relação carbono/nitrogênio inicial de 22/1. A matéria prima para a elaboração do composto foi resíduo dos frigoríficos (aparelhos digestivos do abate de suínos e bovinos), entre outros rejeitos provenientes desse processo (Tabela 1).

O composto de resíduos de grãos (CRG) foi obtido na unidade da Epagri de Itajaí - EEI, com um sistema automatizado de compostagem, semelhante a utilizada com resíduos de frigorífico, mas de menor dimensão. A máquina se movimentava sobre uma leira (duas paredes paralelas de madeira) de 1,5 m de altura por 1,1 m de largura e $10 \mathrm{~m}$ de comprimento. Os resíduos eram constituídos de grãos de soja, predominantemente e de poda urbana de árvores e grama. A compostagem de grãos foi revolvida três vezes por semana e adicionado água sempre que a umidade baixava de 50\%, aproximadamente. Aos 90 dias foi finalizado os revolvimentos e após, o composto foi depositado no local de armazenagem, sem mais revolvimentos, sendo considerado pronto após mais dois meses.

O composto tradicional (CT) foi elaborado em leiras estáticas, com camadas alternadas de capim elefante e cama de aves (5 a 6 lotes), numa proporção de 19,4 kg do primeiro para cada $\mathrm{kg}$ do segundo, em base úmida, conforme análise prévia para obter uma relação C/N inicial de 30/1 e fỉnal 13/1. O composto comercial foi escolhido por ser comumente utilizado na região e o seu nome será velado para evitar conflito de interesses.

O delineamento experimental foi o bloco casualizado, com quatro repetições de cinco plantas cada, sendo as três centrais consideradas como plantas úteis e as duas da extremidade como bordadura. Os tratamentos foram distribuídos num esquema fatorial 5x4, sendo: cinco adubações (zero, CRAF, CRG, CT e Composto Comercial) e quatro cultivares de pimentão (Casca Dura, Verde Luz, Yollo e Otto). Destes cultivares, apenas o Otto é híbrido.

As doses de cada composto foram estabelecidas considerando suas características químicas, tomando como base trabalhos publicados (Bernal et al. 2009; Cantú et al. 2017) e a recomendação da CQFS- RS/SC (2016) para o cultivo em questão. Os compostos foram dispostos superficialmente na linha de cultivo, em dose única, sem o revolvimento do solo. O espaçamento foi de 1,0 m entre linhas e 0,6 m entre plantas. Durante todo o cultivo não foi necessária a intervenção para o controle de pragas e doenças.

Foram realizadas ao total 12 colheitas, quando os frutos estavam maduros, avaliando-se as seguintes características: peso e total de frutos por planta, obtendo-se por meio destes a massa média de frutos. Na quarta colheita os frutos foram separados para análises fitotécnicas de espessura do mesocarpo, comprimento e largura do fruto, com auxílio de paquímetro digital com duas casas decimais de precisão. A firmeza do fruto foi determinada de forma destrutiva, com o auxílio do penetrômetro digital de bancada (Soil Control/USA, modelo 
PDF-200), com ponteira de $8 \mathrm{~mm}$ de diâmetro. Tomou-se cinco pontos de leitura, feitos em "chipes" do mesocarpo obtidos da região central dos frutos, em dez frutos que apresentam maturação fisiológica característica. Os resultados foram expressos em newton $(\mathrm{N})$. Os dados foram submetidos a análise de variância e, quando significativas, as médias comparadas pelo teste de Tukey $(\mathrm{p}<0,05)$.

\section{RESULTADOS E DISCUSSÃO}

Não houve interação entre os quatro compostos e as quatro cultivares em todas as variáveis analisadas. Plantas de pimentão adubadas com CRAF produziram 44,7 $\mathrm{t} \mathrm{ha}^{-1}$ de frutos, produção equivalente ao obtido com o composto tradicional $\left(43,3 \mathrm{t} \mathrm{ha}^{-1}\right)$ e comercial $\left(43,5 \mathrm{t} \mathrm{ha}^{-1}\right)$, sendo os três tratamentos superiores a testemunha sem composto $\left(27,3 \mathrm{t} \mathrm{ha}^{-1}\right)$. O CRG, que apresentou maiores valores médios de produtividade (51,7 $\mathrm{t} \mathrm{ha}^{-1}$ ), e apresentou melhor aspecto visual entre todos os tratamentos, não diferiu dos demais compostos. Na literatura existem relatos de sucesso do uso do CRAF na produção de hortaliças, como é o caso de Schallenberger et al. (2018) que avaliou a produção de alface, mas esse é o primeiro relato do seu uso no cultivo de hortaliça-fruto, que apresentam ciclo longo de cultivo.

O número de frutos por planta apresentou uma tendência muito similar a produtividade, não havendo diferença entre os compostos e, o composto comercial, foi o único igual a testemunha (Tabela 1). A utilização de compostos orgânicos não influenciou significativamente a MMF, a firmeza e a espessura do mesocarpo, bem como o comprimento e a largura de frutos.

Quanto as cultivares, o híbrido Otto foi o mais produtivo, com 51,6 t ha-1 , mas não diferiu do cultivar OP Casca Dura, com 45,5 t ha-1. Os cultivares Yollo e Verde Luz foram os menos produtivos, com 33,9 e 37,4 $\mathrm{t} \mathrm{ha}^{-1}$, respectivamente, e não diferiram estatisticamente do cultivar Casca Dura. O bom desempenho produtivo observado pelo cultivar Casca Dura pode ser atribuído ao maior potencial em emissão de frutos, que apresentou 38,4 frutos $\mathrm{pl}^{-1}$. A maior produtividade do híbrido Otto, por sua vez, pode ser atribuída a maior MMF, que apresentou $113,7 \mathrm{~g}$ fruto $^{-1} \mathrm{e}$ foi superior a todos os demais cultivares.

Quanto a caracterização fitotécnica dos frutos, Otto e Casca Dura apresentaram a maior firmeza de casca (mesocarpo), com 36,3 e 33,9 N, respectivamente. Contudo, a maior espessura do mesocarpo foi apresentada por Yollo e Otto, com $5 \mathrm{~mm}$ cada. Os maiores frutos foram dos cultivares Casca Dura e Verde Luz, com 116,8 e 109,2 mm, respectivamente, e o menor fruto foi o do cultivar Yollo, com $79 \mathrm{~mm}$. A variável largura não variou significativamente entre os cultivares.

Por fim, é importante destacar que os compostos foram aplicados em dose única na implantação do cultivo, proporcionando produções satisfatórias, o que reduz custos com manejo da adubação.

\section{CONCLUSÃO}

Conclui-se que as adubações com CRAF e com CRG apresentam eficiência agronômica equivalentes a adubação com composto tradicional (capim elefante e cama de aves), bem como composto comercial disponível no mercado, podendo, assim, serem utilizados na adubação do pimentão quando cultivado no sistema orgânico.

\section{AGRADECIMENTOS}

À Fundação de Amparo à Pesquisa e Inovação de Santa Catarina - FAPESC.

\section{REFERÊNCIAS}

BERNAL, M. P.; ALBURQUERQUE, J. A.; MORAL, R. Composting of animal manures and chemical criteria for compost maturity assessment. A review. Bioresource Technology, v. 100, p. 5444-5453, 2009.

CÃMARA, M. J. T. Diferentes compostos orgânicos e plantmax como substratos na produção de mudas de alface. 2001. 32f. Monografia (Graduação) - ESAM, Mossoró, 2001.

CANTÚ, R.R; AITA, C; DONEDA, A, GIACOMINI, D.A; DESSBESELL, A; ARENHARDT, M; BASTIANI, G.G; PUJOL, S.B; ROCHETE, F; CHANTIGNY, M.H; GIACOMINI, S. 2017. Alternatives to regular urea for abating $\mathrm{N}$ losses in lettuce production under sub-tropical climate. Biology and Fertility of Soils. 53: 589-599.

CANTÚ, R.R. Compostagem automatizada de grãos residuais do porto de São Francisco do Sul - SC. Anais: XII Reunião Sul Brasileira de Ciência do Solo, Xanxerê, 2018.

SANTOS, R. H. S.; CASALI, V. W.; CONDÉ, A. R.; MIRANDA, L. C. G. Qualidade de alface cultivada com composto orgânico. Horticultura Brasileira, Brasília: v.12, n. 2, p.259-260, 1994. 
SCHALLENBERGER, E.; CANTÚ, R. R.; HARO, M. M.; MORALES, R. G. F.; HEINZEN, J. Método e dose de adubação de hortaliças com composto orgânico em sistema orgânico de produção. In: Seminario de Agroecologia da América do Sul, 2, 2016, Dourados, MS. Resumos... Dourados: Associação Brasileira de Agroecologia, 2016. P. 1-10. MS

SCHALLENBERGER, E.; CANTÚ, R. R.; MORALES, R. G. F.; SQUERZZATO, N.; MISFELD, A. G. Uso de Composto de Resíduos da Indústria Frigorífica na Nutrição de Alface em Sistema Orgânico de Produção. In: Congresso Brasileiro De Olericultura, 55, 2018, Bonito, MS. Resumos... Campo Grande, MS: UEMS, 2018. P. 9-10.

SILVA, A. C. R.; FERNANDES, H. S.; MARTINS, S. R.; SILVA, J. B. SCHIEDECK, G.; ARMAS, E. Produção de mudas de alface com vermicompostos em diferentes tipos de bandeja. Horticultura Brasileira, Brasília: v.18, p. 512-523, jul. 2000.

Tabela 1. Principais características dos resíduos utilizados na compostagem e do composto final de resíduos da agroindústria frigorífica (CRAF).

\begin{tabular}{ccccccccc}
\hline Tratamento & $\mathbf{p H}$ & $\mathbf{P}$ & $\mathbf{K}$ & $\begin{array}{c}\mathbf{N} \\
\mathbf{2}\end{array}$ & $\mathbf{C a}$ & $\mathbf{M g}$ & $\begin{array}{c}\text { Umidade } \\
\mathbf{\%}\end{array}$ & Relação C/N \\
\hline RF & 6,8 & 12,5 & 8,1 & 15,3 & 21,6 & 8,9 & 62,5 & 15,2 \\
RS & 6,0 & 28,0 & 7,2 & 21,9 & 31,6 & 2,5 & 67,6 & 23,5 \\
RA & 6,1 & 11,8 & 6,1 & 27,2 & 9,6 & 1,7 & 12,7 & 16,2 \\
RC & 5,8 & 7,5 & 11,9 & 3,9 & 49,0 & 16,6 & 5,7 & 112,8 \\
RP & - & 2,0 & 37,0 & - & 17,0 & 35,0 & - & - \\
CRAF & 7,1 & 20,0 & 7,5 & 23,0 & 22,0 & 7,0 & 25,1 & 14,0 \\
\hline
\end{tabular}

RF - material proveniente dos aparelhos digestivos do abate de suínos e bovinos; RS- resíduos das granjas de criação de suínos; RAresíduos das fábricas de ração; RC- cinzas de caldeira; RP- resíduo (pó) de mineradoras de ardósia.

Tabela 2. Resposta agronômica e fitotécnica de quatro cultivares de pimentão (Capsicum annuum) adubadas com composto de resíduos da agroindústria frigorífica (CRAF), composto de resíduo de soja (CRG), composto tradicional (Capim elefante + Cama de Aves) e composto comercial.

\begin{tabular}{|c|c|c|c|c|c|c|c|c|c|c|c|c|c|c|}
\hline \multirow{3}{*}{$\begin{array}{l}\text { Compostos } \\
\text { Zero } \\
\text { Composto }\end{array}$} & \multirow{2}{*}{\multicolumn{2}{|c|}{$\begin{array}{c}\text { Produtiv. } \\
\text { t ha }^{-1}\end{array}$}} & \multirow{2}{*}{\multicolumn{2}{|c|}{$\begin{array}{c}\text { NFP } \\
\text { fruto } \mathrm{pl}^{-1} * *\end{array}$}} & \multirow{2}{*}{\multicolumn{2}{|c|}{$\begin{array}{c}\text { MMF } \\
\text { g fruto }^{-1} * * *\end{array}$}} & \multicolumn{4}{|c|}{ Mesocarpo } & \multicolumn{4}{|c|}{ Fruto } \\
\hline & & & & & & & \multicolumn{2}{|c|}{$\operatorname{Firmeza}(\mathbf{N})$} & \multicolumn{2}{|c|}{ Espessura (mm) } & \multicolumn{2}{|c|}{ Comprim. (mm) } & \multicolumn{2}{|c|}{ Largura (mm) } \\
\hline & 27,3 & $b^{*}$ & 20,2 & $\mathrm{~b}$ & 82,5 & ns & 27,9 & ns & 4,5 & ns & 99,3 & $\mathrm{~ns}$ & 65,3 & $\mathrm{~b}$ \\
\hline Tradicional & 43,3 & $\mathrm{a}$ & 30,8 & $\mathrm{a}$ & 84,2 & & 29,5 & & 4,4 & & 96,3 & & 71,1 & $a b$ \\
\hline CRAF & 44,7 & $\mathrm{a}$ & 34,7 & $\mathrm{a}$ & 79,8 & & 32,6 & & 4,2 & & 96,8 & & 72,0 & $a b$ \\
\hline Comercial & 43,5 & $\mathrm{a}$ & 28,5 & $a b$ & 96,7 & & 32,0 & & 4,3 & & 100,7 & & 75,1 & $\mathrm{a}$ \\
\hline $\mathrm{CRG}$ & 51,7 & $\mathrm{a}$ & 36,6 & $\mathrm{a}$ & 86,1 & & 30,3 & & 4,4 & & 104,3 & & 75,7 & $\mathrm{a}$ \\
\hline
\end{tabular}

\section{Cultivares}

\begin{tabular}{lllllllllllllll} 
Casca Dura & 45,5 & ab & 38,4 & a & 71,1 & b & 33,9 & a & 3,8 & b & 116,8 & a & 71,3 & ns \\
Verde Luz & 37,4 & b & 30,2 & ab & 74,5 & b & 26,4 & b & 3,7 & b & 109,2 & a & 71,7 & \\
Yollo & 33,9 & b & 24,9 & b & 84,2 & b & 25,3 & b & 5,0 & a & 79,0 & c & 72,1 & \\
Otto & 51,6 & a & 27,1 & b & 113,7 & a & 36,3 & a & 5,0 & a & 92,9 & b & 72,4 & \\
\hline
\end{tabular}

*Médias seguidas pela mesma letra na coluna, dentro do mesmo fator, não diferem entre si pelo teste de Tukey (p<0,05). **NFP Número de frutos por planta; ***MMF - Massa média de frutos; ns- Não significativo. 


\title{
EFEITO DO COMPOSTO DE RESÍDUOS DA AGROINDÚSTRIA FRIGORÍFICA NA PRODUÇÃO DE MUDAS DE RÚCULA
}

\author{
Morales, R.G.F. ${ }^{* 1}$; Palma, M.S. ${ }^{2}$; Cantú, R.R. ${ }^{1}$; Schallenberger, E. ${ }^{1}$; Visconti, A. ${ }^{1}$; Squerzzato, N. ${ }^{3}$ \\ ${ }^{1}$ Pesquisadores da Epagri, Itajaí, SC-Brasil \\ ${ }^{2}$ Graduação em Agronomia, UFPR \\ ${ }^{3}$ Engenheiros da Pamplona Alimentos S/A, Rio do Sul, SC - Brasil \\ *rafaelmorales@epagri.sc.gov.br
}

\begin{abstract}
RESUMO: O objetivo do presente trabalho foi o de avaliar o efeito de adubação com resíduos da agroindústria frigorífica (CRAF) na produção de mudas de rúcula no sistema orgânico. O delineamento experimental foi o inteiramente casualizado, distribuídos num esquema fatorial $2 \times 3 \times 6$, sendo: duas cultivares (A e B), três formas de adubação de base (zero, dose dimensionada como ideal de CRAF e de composto tradicional-CT) e seis adubações de cobertura (zero; a dose dimensionada como ideal de CT e CRAF; o dobro da dose ideal de CT e CRAF; solução nutritiva). No primeiro cultivo foi avaliada apenas a massa fresca da parte aérea (MFA) das mudas e, no segundo cultivo, além da MFA, foi avaliada a massa seca da parte aérea (MSA). Os dados foram submetidos a análise de variância e, quando significativas, as médias comparadas pelo teste de Scott Knott $(\mathrm{p}<0,05)$. No primeiro cultivo, o CT na base, sem o uso de adubos na cobertura, tanto para a cultivar A, como para B, foi o suficiente para produzir um bom padrão de muda. No segundo cultivo, diferentemente ao observado no primeiro, a adubação com CRAF resultou em aumento da qualidade das mudas quando comparado ao CT. Com base nesses resultados pode-se concluir que a adubação com CRAF aumenta a qualidade de mudas de rúcula, com resultados compatíveis aos obtidos com CT, podendo ser utilizado na mistura do substrato antes do preparo da bandeja, bem como na adubação de cobertura.
\end{abstract}

Palavras-chave: Eruca sativa, resíduos de frigorífico, hortaliças

\section{EFFECT OF AGRIBUSINESS WASTE COMPOST IN THE PRODUCTION OF RÚCULA SEEDLINGS}

\begin{abstract}
The objective of the present work was to evaluate the effect of fertilization with agribusiness waste compost (AWC) on the production of rocket seedlings in the organic system. The experimental design was a completely randomized design, distributed in a 2x3x6 factorial scheme, being: two cultivars (A and B), three forms of base fertilization (zero, ideal dose of AWC and traditional compost-CT) and six coverage fertilization (zero; ideal dose of CT and AWC, twice the ideal dose of CT and AWC, nutrient solution). In the first crop, only the fresh shoot mass (MFA) of the seedlings were evaluated, and in the second crop, besides the MFA, the aerial part dry mass (MSA). Data were submitted to analysis of variance and, when significant, means were compared by the Scott Knott test $(\mathrm{p}<0.05)$. In the first cultivation, CT at the base, without the use of cover fertilizers, for both the A and B cultivars was enough to produce a good seedling pattern. In the second crop, unlike the one observed in the first one, the fertilization with AWC resulted in an increase in the quality of the seedlings when compared to the CT. Based on these results, it can be concluded that the AWC fertilization increases the quality of rocket seedlings, with results compatible with those obtained with CT, and can be used in the substrate mixing before the tray preparation, as well as in the coverage fertilization.
\end{abstract}

Keywords: Eruca sativa, slaughterhouse waste, greenery

\section{INTRODUÇÃO}

As agroindústrias de Santa Catarina possuem elevada importância sócio econômica, gerando direta e indiretamente milhares de empregos e contribuindo significativamente para o PIB do estado. Embora possua tal importância, esse setor gera um elevado volume de resíduos com alto potencial poluente. A compostagem dos resíduos da agroindústria frigorífica (CRAF) vem sendo desenvolvida com eficiência na região do Alto Vale do Itajaí, em SC. O composto produzido é promissor e pode chegar no mercado catarinense em breve. Embora esta compostagem venha sendo realizada com sucesso e o fertilizante produzido apresente características químicas de fertilidade promissoras, não há estudos sobre a sua utilização para a produção de 
mudas de hortaliças. Os compostos orgânicos para serem comercializados devem ser estudados visando verificar a sua eficiência agronômica.

Produtores orgânicos utilizam para adubação a cama de aves e de gado compostada ou estabilizada, torta de mamona, cinzas, terra de mato e inúmeros outros insumos derivados do sistema de produção agrícola, a fim de ciclar os nutrientes e otimizar o sistema de produção agrícola. Dentre os principais adubos que o produtor pode utilizar para a nutrição de mudas de hortaliças está o composto orgânico, que apresenta inúmeras vantagens, com destaque para: liberação gradual dos nutrientes pelo processo de mineralização; elevada capacidade de troca de cátions, o que ajuda a reter os nutrientes e diminui a perda por lixiviação; quantidades significativas de macro e micronutrientes; e apresenta uma microbiologia favorável a indução a supressividade à patógenos (CÃMARA, 2001; SANTOS et al., 1994; SILVA et al., 2000). Sendo assim, o objetivo do presente trabalho foi o de avaliar o efeito de adubação com CRAF na produção de mudas de rúcula no sistema orgânico.

\section{MATERIAL E MÉTODOS}

O experimento com a produção de mudas foi conduzido na Estação Experimental da Epagri de ItajaíSC, entre os meses de setembro e outubro de 2018. O composto de resíduo da agroindústria frigorífica (CRAF) foi desenvolvido na unidade de compostagem automatizada Lauro Pamplona localizada no município de Trombudo Central - SC, entre os meses de setembro e outubro de 2018. Foi realizada uma combinação de diferentes resíduos, buscando uma relação carbono e nitrogênio inicial de 22/1. A matéria prima para a elaboração do composto são resíduos de abate de suínos e bovinos, como carcaça de animais, esterco sólido e resíduo da fábrica de ração, provenientes de frigoríficos localizados em Rio do Sul, Presidente Getúlio, Ituporanga e Agronômica. A tomada de decisão para finalização do processo foi devido às características do composto relacionadas a relação $\mathrm{C} / \mathrm{N}$, próximo a 15 , além da temperatura do fertilizante estar próxima à do ambiente, que indica a estabilidade do composto.

O composto tradicional (CT) foi elaborado em leiras estáticas, com camadas alternadas de capim elefante e cama de aves (5 a 6 lotes), numa proporção de 19,4 $\mathrm{kg}$ do primeiro para cada $\mathrm{kg}$ do segundo, em base úmida, conforme análise prévia para obter uma relação C/N inicial de 30/1 e final 13/1.

O delineamento experimental foi o inteiramente casualizado, com três repetições de 20 mudas cada. A semeadura foi realizada com seis sementes por célula, em bandejas de polipropileno de 200 células, preenchidas com substrato comercial Maxfertil e empilhadas até a emergência. Os tratamentos foram distribuídos num esquema fatorial $2 \times 3 \times 6$, sendo: duas cultivares comerciais $\mathrm{A}$ e $\mathrm{B}$, três formas de adubação de base (zero, dose ideal de CT e CRAF) e seis adubações de cobertura (zero; a dose ideal de CT e CRAF; o dobro da dose ideal de CT e CRAF; solução nutritiva).

A dose dimensionada como ideal de cada composto foi calculada com base em informações literárias da extração de nitrogênio por mudas de rúcula produzidas em bandejas de 200 células, pela taxa de mineralização teórica do $\mathrm{N}$ e pelo percentual de perda por lixiviação. Assim, considerando que cada muda precisa de $0,4 \mathrm{mg}$ de $\mathrm{N}$, e que a eficiência teórica de fornecimento de $\mathrm{N}$ pelos compostos orgânicos é de $10 \%$, o total de $\mathrm{N}$ via composto necessário foi de $4 \mathrm{mg}$. Com isso, a dose ideal calculada de cada composto foi de $0,22 \mathrm{~g}$ de CT e 0,16 g do CRAF por muda, considerando que CT e CRAF possuem 1,8\% e 2,5\% de N, respectivamente, conforme análise química prévia dos compostos. As aplicações em cobertura dos dois compostos orgânicos e do tratamento com solução nutritiva ocorreram aos 5 e 10 dias após a semeadura. A solução nutritiva foi elaborada conforme Furlani et al. (1999), modificada para ferro (60 mg L ${ }^{-1}$ de FeEDDHA$6 \%)$, a $25 \%$ de força.

As avaliações das mudas foram realizadas quando $3 / 4$ das mudas apresentavam quatro folhas definitivas e apresentam-se aptas para o transplantio para o campo, que foi aos 19 e 15 dias após a semeadura para o primeiro e segundo cultivo, respectivamente. No primeiro cultivo foi avaliada apenas a massa fresca da parte aérea (MFA) das mudas e, no segundo cultivo, além da MFA, foi avaliada a massa seca da parte aérea (MSA). Para a MFA foi pesada a parte aérea de todas as mudas da repetição, removidas da bandeja cortando com uma tesoura. As folhas foram levadas para uma estufa de secagem com ar forçado (aproximadamente $65^{\circ} \mathrm{C}$ ), onde ocorreu a desidratação da massa vegetal por 72 horas. Após esse período foi aferida a massa vegetal com balança de precisão, obtendo-se a MSA.

Os dados foram submetidos a análise de variância e, quando significativas, as médias comparadas pelo teste de Scott Knott $(\mathrm{p}<0,05)$. 


\section{RESULTADOS E DISCUSSÃO}

A eficiência dos compostos orgânicos na produção de mudas de rúcula foi diferente entre o primeiro e o segundo cultivo. No primeiro cultivo, o CT na base, sem o uso de adubos na cobertura, tanto para a cultivar A, como para a B, foi o suficiente para produzir um padrão satisfatório de muda (Reghin et al., 2004), com MFA de 510,1 e 492,6 $\mathrm{mg} \mathrm{muda}^{-1}$, respectivamente. Esses valores foram praticamente o dobro do observado quando o adubo de base foi o CRAF, e o quádruplo quando comparado com a testemunha (Tabela 1). A combinação do uso de CT na base e o dobro de CT em cobertura foi a condição que proporcionou melhor desenvolvimento das mudas, com MFA de 835,5 e 809,7 $\mathrm{mg} \mathrm{muda}^{-1}$ para as cultivares A e B, respectivamente. Esses valores foram superiores até mesmo aos obtidos com o uso de solução nutritiva (SN), o que demonstra o grande potencial do uso de CT na produção de mudas orgânicas de rúcula. Os melhores resultados com o uso do CRAF foram com o uso dele na base e o dobro da dose em cobertura, produzindo MFA de 459,2 e $536,0 \mathrm{mg}$ muda $^{-1}$ para as cultivares $\mathrm{A}$ e $\mathrm{B}$, respectivamente, quatro vezes a mais do que observado na testemunha (Tabela 1).

No segundo cultivo houve interação tripla para as variáveis MFA $(\mathrm{P}=0,037)$, MSA $(\mathrm{p}=0,05)$, MFR ( $<<0,01)$ e MSR ( $p=0,024)$ (Tabela 2). Diferentemente ao observado no primeiro cultivo, a adubação com CRAF resultou em aumento da qualidade das mudas quando comparado ao CT. O uso do CRAF na base, sem o uso de fertilização em cobertura, aumentou a MFA de 133,5 para 255,3 mg muda $^{-1}$ para cultivar A, valor superior ao obtido com o CT na base, que produziu 192,4 mg muda-1 e não diferiu da testemunha. Para o cultivar B, CRAF e CT produziram mais que a testemunha sem adubo na base, e não diferiram entre si, com 227,5 e 277,2 $\mathrm{mg} \mathrm{muda}^{-1}$ para CT e CRAF, respectivamente (Tabela 2). Apesar de serem observados valores inferiores de MFA no segundo cultivo, o padrão de mudas é condizente ao observado por Reghin et al. (2003).

Para o cultivar B, as adubações de cobertura com CRAF e CT no dobro da dose ideal produziram mudas com MFA equivalente ao obtido na testemunha com $\mathrm{SN}$, indicando que ambos os compostos podem ser utilizados nessas quantidades para obtenção de mudas com elevado padrão comercial (Tabela 2).

O aumento da MFA proporcionado pelo CRAF não refletiu em aumento da MSA nas mesmas proporções. Com a ausência do uso dos compostos na base, a adubação em cobertura com CRAF em dobro, para ambas as cultivares, não aumentou a MSA em relação a testemunha. Nesse caso, o melhor tratamento foi com CT em dobro em cobertura, que não diferiu do tratamento com $\mathrm{SN}$, mas ambos foram superiores a testemunha. A MSA foi 49,8 e 48,8 $\mathrm{mg} \mathrm{muda}^{-1}$ nos tratamentos CT e SN para a cultivar A, e 53,3 e 59,9 mg muda $^{-1}$ para a cultivar B, respectivamente (Tabela 2). A diferença entre o efeito dos compostos nos dois cultivos pode ser atribuída às taxas de mineralização dos nutrientes dos fertilizantes, ocasionada pelas condições ambientais distintas entre os cultivos. Isso porque, compostos com diferentes composições podem apresentar diferentes taxas de mineralização conforme a variação de temperatura (Cantú, 2015). Nesse caso, mais estudos devem ser realizados ao longo das épocas do ano.

\section{CONCLUSÃO}

A adubação com CRAF aumenta a qualidade de mudas de rúcula, com resultados compatíveis aos obtidos com CT, podendo ser utilizado na mistura do substrato antes do preparo da bandeja, bem como na adubação de cobertura.

\section{AGRADECIMENTOS \\ À Fundação de Amparo à Pesquisa e Inovação de Santa Catarina - FAPESC.}

\section{REFERÊNCIAS}

CÃMARA, M. J. T. Diferentes compostos orgânicos e plantmax como substratos na produção de mudas de alface. 2001. 32f. Monografia (Graduação) - ESAM, Mossoró, 2001.

CANTÚ, R.R. Acidificação de dejetos de suínos em compostagem automatizada: emissões gasosas de nitrogênio e resposta da alface à aplicação do composto no solo. [Tese]. Santa Maria: Universidade Federal de Santa Maria; 2015.

FURLANI, P.R.; SILVEIRA, L.C.P.; BOLONHESI, D.; FAQUIN, V. Cultivo hidropônico de plantas. Campinas: IAC. 52p (Boletim Técnico 180), 1999.

REGHIN, M. Y.; OTTO, R. F.; VAN DER VINNE, J. Efeito da densidade de mudas por célula e do volume da célula na produção de mudas e cultivo da rúcula. Ciência e Agrotecnologia, Lavras, v. 28, n. 2, p. 287295, mar./abr., 2004. 
SANTOS, R. H. S.; CASALI, V. W.; CONDÉ, A. R.; MIRANDA, L. C. G. Qualidade de alface cultivada com composto orgânico. Horticultura Brasileira, Brasília: v.12, n. 2, p.259-260, 1994.

SANTOS, A. A.; FELICIANO, A. M.; PADRAO, G. A. Números da Agropecuária Catarinense. In: Feliciano, A.M. (Coord.). Florianopolis: Epagri/Cepa, 2016. 69p.

SILVA, A. C. R.; FERNANDES, H. S.; MARTINS, S. R.; SILVA, J. B. SCHIEDECK, G.; ARMAS, E. Produção de mudas de alface com vermicompostos em diferentes tipos de bandeja. Horticultura Brasileira, Brasília: v.18, p. 512-523, jul. 2000.

Tabela 1. Massa fresca da parte aérea de mudas de duas cultivares de rúcula produzidas em substrato sem adubação (Zero) e com composto tradicional (CT) e de resíduos da agroindústria frigorífica (CRAF) na base, e CT, CRAF e solução nutritiva (SN) em cobertura. Itajaí, setembro de 2018.

\begin{tabular}{|c|c|c|c|c|c|c|}
\hline \multicolumn{7}{|c|}{ Massa fresca da parte aérea $\left(\mathrm{mg} \mathrm{muda}^{-1}\right)$} \\
\hline \multirow[b]{2}{*}{ Cobertura/Base } & \multicolumn{3}{|c|}{ Cultivar A } & \multicolumn{3}{|c|}{ Cultivar B } \\
\hline & Zero & CT & CRAF & Zero & CT & CRAF \\
\hline Zero & $135,6 \mathrm{eC}$ & $510,1 \mathrm{dA}$ & $276,1 \quad \mathrm{~dB}$ & $132,8 \mathrm{eC}$ & $492,6 \mathrm{dA}$ & $270,0 \mathrm{fB}$ \\
\hline $\mathrm{SN}$ & $461,4 \quad b B$ & $590,7 \mathrm{cA}$ & 519,0 & $578,8 \mathrm{aB}$ & $713,7 \quad b A$ & 633,0 \\
\hline CT Ideal & 363,2 & 756,5 & 528,2 & 324,2 & 707,7 bA & 480,0 \\
\hline CRAF Ideal & 217,3 & 647,3 & 425,0 & 213,2 & $568,1 \mathrm{cA}$ & 368,3 \\
\hline CT Dobro & 538,3 & 835,5 & 670,8 & 472,2 & 809,7 aA & 734,5 \\
\hline CRAF Dobro & $232,9 \mathrm{dC}$ & $749,0 \quad \mathrm{bA}$ & 459,2 & $333,3 \mathrm{cC}$ & $630,8 \mathrm{cA}$ & 536,0 \\
\hline
\end{tabular}

Médias seguidas pela mesma letra na linha minúscula na coluna e maiúscula na linha não diferem entre si pelo teste de Scott Knott $(\mathrm{P}<0,05)$.

Tabela 2. Massa fresca e seca da parte aérea de mudas de duas cultivares de rúcula produzidas com composto tradicional (CT) e de resíduos da agroindústria frigorífica (CRAF) na base, e CT, CRAF e solução nutritiva (SN) em cobertura. Itajaí, outubro de 2018.

\begin{tabular}{|c|c|c|c|c|c|c|c|c|c|c|c|}
\hline \multicolumn{12}{|c|}{ Massa fresca da parte aérea $\left(\mathrm{mg} \mathrm{muda}^{-1}\right)$} \\
\hline \multirow[b]{2}{*}{ Cobertura/Base } & \multicolumn{6}{|c|}{ Cultivar A } & \multicolumn{5}{|c|}{ Cultivar B } \\
\hline & \multicolumn{2}{|c|}{ Zero } & \multicolumn{2}{|c|}{ CT } & \multicolumn{2}{|c|}{ CRAF } & \multicolumn{2}{|c|}{ Zero } & \multicolumn{2}{|c|}{ CT } & CRAF \\
\hline Zero & 133,5 & $\mathrm{cB}$ & 192,4 & $\mathrm{cB}$ & 255,3 & eA & 149,5 & $\mathrm{~dB}$ & 227,5 & $\mathrm{dA}$ & $277,2 \quad \mathrm{cA}$ \\
\hline SN & 283,8 & $\mathrm{bC}$ & 372,4 & $\mathrm{aB}$ & 494,3 & $\mathrm{aA}$ & 309,2 & $\mathrm{aC}$ & 424,1 & $\mathrm{aB}$ & 498,3 \\
\hline CT Ideal & 300,2 & $\mathrm{aC}$ & 221,5 & $\mathrm{cB}$ & 381,5 & $\mathrm{cA}$ & 210,0 & $\mathrm{cB}$ & 302,2 & $\mathrm{cA}$ & 352,3 \\
\hline CRAF Ideal & 244,5 & bB & 307,7 & $\mathrm{bA}$ & 342,5 & $\mathrm{dA}$ & 267,0 & bB & 359,0 & bA & 401,5 \\
\hline CT Dobro & 329,2 & $\mathrm{aC}$ & 387,5 & $\mathrm{aB}$ & 441,2 & bA & 315,3 & $\mathrm{aB}$ & 460,7 & $\mathrm{aA}$ & 457,8 \\
\hline CRAF Dobro & 276,5 & $\mathrm{aB}$ & 405,2 & $\mathrm{aA}$ & 403,7 & $\mathrm{cA}$ & 341,8 & $\mathrm{aB}$ & 472,3 & $\mathrm{aA}$ & 509,0 \\
\hline \multicolumn{12}{|c|}{ Massa seca da parte aérea $\left(\mathrm{mg} \mathrm{muda}^{-1}\right)$} \\
\hline & \multicolumn{6}{|c|}{ Cultivar A } & \multicolumn{5}{|c|}{ Cultivar B } \\
\hline Cobertura/Base & \multicolumn{2}{|c|}{ Zero } & \multicolumn{2}{|c|}{ CT } & \multicolumn{2}{|c|}{ CRAF } & \multicolumn{2}{|c|}{ Zero } & \multicolumn{2}{|c|}{ CT } & CRAF \\
\hline Zero & 33,8 & $\mathrm{bC}$ & 40,1 & bB & 48,6 & $\mathrm{bA}$ & 46,7 & $\mathrm{bB}$ & 50,3 & $\mathrm{bB}$ & $63,7 \quad \mathrm{cA}$ \\
\hline $\mathrm{SN}$ & 48,8 & $\mathrm{aB}$ & 53,0 & $\mathrm{aB}$ & 69,3 & $\mathrm{aA}$ & 59,9 & $\mathrm{aB}$ & 72,3 & $\mathrm{aA}$ & 82,3 \\
\hline CT Ideal & 54,5 & $\mathrm{aA}$ & 41,5 & $b B$ & 61,2 & $\mathrm{aA}$ & 47,5 & bB & 59,7 & bA & 66,8 \\
\hline CRAF Ideal & 37,3 & bA & 48,0 & $\mathrm{aA}$ & 43,5 & $\mathrm{bA}$ & 44,8 & bA & 52,3 & $\mathrm{bA}$ & 56,0 \\
\hline CT Dobro & 49,8 & $\mathrm{aA}$ & 55,7 & $\mathrm{aA}$ & 61,3 & $\mathrm{aA}$ & 53,3 & $\mathrm{aB}$ & 73,5 & $\mathrm{aA}$ & 70,8 \\
\hline CRAF Dobro & 35,3 & $\mathrm{bB}$ & 52,0 & $\mathrm{aA}$ & 56,7 & $\mathrm{aA}$ & 48,5 & bA & 59,8 & bA & 58,8 \\
\hline
\end{tabular}

Médias seguidas pela mesma letra na linha minúscula na coluna e maiúscula na linha não diferem entre si pelo teste de Scott Knott $(\mathrm{P}<0,05)$. 


\title{
QUALIDADE FÍSICA DO SOLO EM ÁREA COM APLICAÇÃO DE DEJETOS SUÍNOS
}

\author{
Paiva Filho, S.V. ${ }^{1}$;Medeiros, S.F. ${ }^{*}$; ;Ferreira, R.V. ${ }^{2}$;Oliveira, C.L. ${ }^{2}$;Guimarães, A.G. ${ }^{1}$;Tavares, \\ R.L.M. ${ }^{3}$

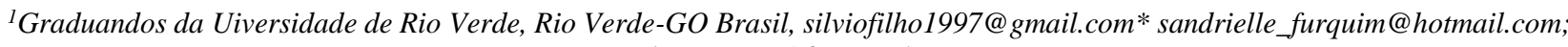 \\ arthurgouveia06@gmail.com \\ ${ }^{2}$ Mestrando da Universidade de Rio Verde, Rio Verde-GO, Brasil, raniervieiraferreira@hotmail.com; cleire.oliveira@gmail.com \\ ${ }^{3}$ Orientadora, Prof. Dr. da Faculdade de Agronomia, Rio Verde - GO, Brasil, roseluiza@ unirv.edu.br
}

\begin{abstract}
RESUMO: Com o uso crescente da utilização de dejetos suínos na agricultura na região sudoeste de Goiás, estima-se uma redução nos custos com adubação e aumento de produtividade das culturas, além disso, é uma forma de descarte adequado e sustentável do dejeto suíno no ambiente. Esse trabalho teve como objetivo avaliar alguns atributos físicos do solo sob sistema de semeadura direta com a adubação de dejetos de suínos em Rio Verde - GO. A área experimental está localizada no município de Rio Verde - GO. O experimento foi conduzido em campo com delineamento experimental de blocos ao acaso (DBC) com 6 tratamentos e 3 blocos, cujos tratamentos consistiram na aplicação de DLS em diferentes doses $\left(0,25,50,75\right.$ e $\left.100 \mathrm{~m}^{3} \mathrm{ha}^{-1}\right)+$ tratamento com NPK na formulação 4-30-16. Em cada parcela, foi aberta uma trincheira para retirada de amostras indeformadas do solo nas profundidades $0,00-0,10,0,10-0,20,0,20-0,40 \mathrm{~m}$, sendo utilizadas para análises de densidade e porosidade do solo. O solo coletado ao redor das trincheiras foi utilizado para análises de textura e umidade gravimétrica. Os resultados mostraram que houve tendência de diminuição da densidade do solo e aumento da macroporosidade em áreas com aplicação de $50 \mathrm{~m}^{3}$ há ${ }^{-1}$ DLS. No geral, a camada superficial do solo 0-10 cm apresentou melhor estrutura física comparada às camadas 10-20 e 20-40 cm do solo, independente da aplicação de dejetos suínos.
\end{abstract}

Palavras chaves: Densidade, macroporosidade, microporosidade, resistência a penetração

\section{SOIL PHYSICAL QUALITY IN AREA WITH SWINE MANURE APPLICATION}

\begin{abstract}
With the increasing use of swine manure in agriculture in the southwestern region of Goiás, it is estimated a reduction in fertilization costs and an increase in crop productivity. In addition, it is a suitable and sustainable disposal method for swine manure in the environment. The objective of this work was to evaluate some physical attributes of the soil under no - tillage system with fertilization of swine manure in. The experimental area is located in the municipality of Rio Verde - GO. The experiment was conducted in a field with a randomized complete block design (DBC) with 6 treatments and 3 blocks, which treatments consisted of the application of DLS in different doses $\left(0,25,50,75\right.$ and $100 \mathrm{~m}^{3}$ há $\left.{ }^{-1}\right)+$ treatment with NPK in formulation 4-30-16. In each plot, a trench was opened for withdrawal of undisturbed soil samples at depths $0.00-0.10,0.10-0.20,0.20-0.40 \mathrm{~m}$, being used for analysis of soil density and porosity. The soil collected around the trenches was used for analysis of texture and gravimetric moisture. The results showed that there was a tendency of soil density decrease and macroporosity increase in areas with application of $50 \mathrm{~m}^{3} \mathrm{ha}^{-1}$ DLS. In general, the superficial layer of the soil $0-10 \mathrm{~cm}$ presented better physical structure compared to the layers $10-20$ and $20-40 \mathrm{~cm}$ of the soil, independent of the application of swine manure
\end{abstract}

Keywords: Density, macroporosity, microporosity, penetration resistance.

\section{INTRODUÇÃO}

O consumo de carne suína é crescente, o que consequentemente intensifica o sistema de suínos confinados, sendo que uma das consequências, é a geração e concentração de um grande volume de dejetos líquidos de suinos (DLS), o que pode apresentar um risco no ponto de vista ambiental. Para minimizar esse risco, o DLS pode ser utilizado como fonte de nutrientes em áreas com lavouras e pastagem (CERETTA et al., 2010; ASSMANN et al., 2009).

O uso de dejetos líquidos suínos no solo pode modificar a estrutura e sua funcionalidade no solo, o que pode ser vista nas modificações na quantidade, continuidade e tamanho dos poros do solo. Pode influenciar também na absorção de água, nutrientes, desenvolvimento de plantas, resistência a penetração da raiz (RIBEIRO et al., 2007). Estudos constatam que a aplicação de dejetos de suíno promove melhorias na 
densidade e na resistência a penetração do solo, emlatossolo vermelho em plantio direto (SEGANFREDO, 2007).

Os resíduos orgânicos no solo, como o DLS, podem funcionar no solo como fertilizantes e condicionadores do solo, sendo assim, têm sido aplicados nas lavouras com o objetivo de melhorar a fertilidade e sua estrutura física. Isso porque os dejetos suínos podemser fontes de nutrientes, como N, P e K, e quando manejado adequadamente, podem suprir os fertilizantes químicos (KONZEN, 2005).Porém, a utilização desses dejetos no campo, não apresentam um padrão específico de recomendação de uso, pois possuem variação na sua composição, cuja aplicação em doses excessivas pode causar alterações químicas, físicas e biológicas que nem sempre resulta na melhoria do solo, podendo acarretar danos ambientais (OLIVEIRA et al, 2016).

Sendo o solo um meio promissor para o descarte de resíduos, a adição de matéria orgânica proveniente do DLS pode proporcionar melhorias na química do solo como aumento de nutrientes (N P K), e também nos atributos físicos do solo no que confere: densidade aparente, estruturação, aeração, agregação, drenagem, retenção de água e consistência (KIEHL,1985).

Segundo Castro filho et al. (2003) o principal atributo físico do solo beneficiado pelo uso de fertilizantes orgânicos é a agregação, cujos autores verificaram melhorias na agregação do solo com aplicação de doses crescentes de DLS até a taxa de $140 \mathrm{~m}^{3} \mathrm{ha}^{-1}$. Segundo Mecabô Júnior (2013), em trabalho realizado sobre o efeito da adição de três doses de DLS, foi observado que o uso do dejeto afetou positivamente as propriedades físicas do solo, com tendência de aumento da macroporosidade, e redução da densidade do solo, bem como de manter em níveis elevados de estabilidade de agregados.

Entretanto, pesquisas apontam que o DLS pode ter o efeito não benéfico ao solo, no que confere a porosidade do solo. A aplicação de dejetos orgânicos no solo pode alterar as condições de estruturação de um solo, evidenciando modificações na quantidade e tamanho dos poros no solo (RIBEIRO et al., 2007). Esse efeito reflete na resistência do solo à penetração das raízes e a absorção de nutrientes (MOSADDEGHI et al., 2009). Baseado nisso, este trabalho teve como objetivo avaliar alguns atributos físicos do solo sob sistema de semeadura direta com a adubação de dejetos de suínos em Rio Verde - GO.

\section{MATERIAL E MÉTODOS}

A área experimental está localizada no município de Rio Verde - GO, nas coordenadas $17^{\circ} 48^{\prime}$ de latitude sul e $55^{\circ} 55^{\prime}$ de longitude oeste, com $760 \mathrm{~m}$ de altitude e $4 \%$ de declividade. É uma área utilizada para pesquisa experimental em parceria entre as instituições: Universidade de Rio Verde, Embrapa Solos e empresa Perdigão Agroindústrias S.A. O clima da região é do tipo Aw, característico de duas estações bem definidas (seco no inverno e úmido no verão) de acordo com classificação de Koppen. O solo da área foi classificado como Latossolo Vermelho distrófico, com textura argilosa (60\% de argila, $15 \%$ de silte e $25 \%$ de areia).

A área recebe aplicação de dejetos líquidos suínos desde a safra 2000/2001 e, vem sendo cultivada no esquema de sucessão soja/milho (safra/safrinha) sob sistema de plantio direto. Na área foram instaladas parcelas experimentais que consistem na aplicação ou não de dejetos suínos com diferentes doses. $\mathrm{O}$ experimento tem sido conduzido em campo com delineamento experimental de blocos ao acaso (DBC) com 5 tratamentos (doses de dejetos suínos nas quantidades 0, 25, 50, 75 e $100 \mathrm{~m}^{3} \mathrm{ha}^{-1}$ ) e 3 blocos. Além disso, foi adicionado um tratamento com uso de adubação mineral com NPK.

O dejeto líquido suíno é proveniente de um Sistema Vertical Terminador (VST) com sistema de lagoa de estabilização anaeróbia com capacidade de $120 \mathrm{~m} 3$. O dejeto suíno foi aplicado em cobertura, por aspersão, anualmente no mês de outubro, enquanto que a adubação com NPK é feita no plantio.

No ano de 2017, após 16 anos de aplicação de dejetos supinos, foram abertas trincheiras onde foram coletadas amostras indeformadas com auxílio de anel volumétrico nas profundidades 0-10, 10-20, 20-40, 4060, 60-80 e 80-100 cm para análise de densidade e porosidade do solo. Ao redor das trincheiras, foram coletadas amostras deformadas com trado manual nas mesmas profundidades de coleta. Estas amostras foram utilizadas para análises de textura do solo.

A determinação da resistência do solo à penetração foi efetuada no mesmo dia de coleta das amostras de solos (Figura 1). Para isto, foi utilizado um penetrômetro digital que realiza medição da resistência à penetração do cone metálico no solo em várias profundidades, e o valor de pressão correspondente à compactação do solo naquela camada.

Os dados de análises de solo foram submetidos ao teste estatístico de normalidade dos dados shapirowilk. Para comparação da adição de dls foi feita análise de regressão e para comparação das diferentes profundidades de solo, foi utilizado teste de tukey a $5 \%$ de probabilidade. 


\section{RESULTADOS E DISCUSSÃO}

Para avaliação dos atributos físicos em profundidade do solo por influência de DLS, os dados foram reunidos na Tabela 1 e mostram que a densidade do solo na profundidade de 10-20 apresentou maiores valores quando comparado com as profundidades $0-10$ e $20-40 \mathrm{~cm}$, com exceção na área com dose $50 \mathrm{~m}^{3} \mathrm{ha}^{-1}$. Isso porque, em sistemas de semeadura direta, ocorre intenso tráfego de máquinas pesadas, cuja tendência é o adensamentodas camadas subsuperficiais do solo (Kiehl, 1985).

No geral, a macroporosidade do solo foi maior na camada de solo $20-40 \mathrm{~cm}$, com exceção nas áreas

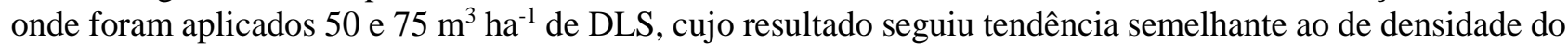
solo. Enquanto que nas camadas mais superficiais, os macroporos foram em menores quantidades, provocado pelo possível adensamento do solo de $0-20 \mathrm{~cm}$. Em trabalho de Barilli (2005), a macroporosidade do solo e a densidade também foram afetadas com a aplicação de dejetos de suínos, onde houve aumento na macroporosidade do solo na camada $40-60 \mathrm{~cm}$.

Os dados de microporosidade foram maiores na camada $20-40 \mathrm{~cm}$, com exceção nas áreas onde foram aplicados 50 e $75 \mathrm{~m}^{3} \mathrm{ha}^{-1}$ de DLS, confirmando o efeito antagônico entre macro e microporosidade, pois no geral, em áreas onde a macroporidade é menor, a microporosidade tende a ser maior devido o aumento da densidade, o que transforma os macroporos em microporos (BARBOSA, 2000).

A resistência do solo à penetração foi menor na camada 0-10 e maior nas camadas $10-20$ e 20-40 cm do solo em todas ás áreas (com e sem aplicação de DLS) (Tabela 1), possivelmente relacionado ao teor de matéria orgânica na camada superficial do solo, a qual melhora o espaço poroso e grau de estruturação do solo, promovendo melhores condições de desenvolvimento da raíz na superfície. Da mesma forma, Barbosa (2000), detectaram menor resistência do solo à penetração somente na superfície do solo quando aplicaram uma fonte orgânica (lodo de esgoto) sobre o solo.

A resistência do solo à penetração aumenta com o nível de adensamento do solo em profundidade e com a diminuição da umidade do solo (BENGHOUGH et al., 2012), sendo que para este trabalho, a umidade do solo manteve-se semelhante em todas as parcelas analisadas. No geral, independente da aplicação de DLS, a resistência do solo à penetração foi menor na camada superficial $(0-10 \mathrm{~cm})$ e maior nas camadas 20-40 e 40$60 \mathrm{~cm}$, não havendo diferença significativa entre as duas últimas.

\section{CONCLUSÃO}

$\checkmark$ Houve tendência de diminuição da densidade do solo e aumento da macroporosidade em áreas com aplicação de $50 \mathrm{~m}^{3}$ ha $^{-1}$ DLS.

$\checkmark$ No geral, a camada superficial do solo 0-10 $\mathrm{cm}$ apresentou melhor estrutura física que comparada às camadas $10-20$ e $20-40 \mathrm{~cm}$ do solo.

$\checkmark$ A resistência do solo à penetração foi menor na camada superficial 0-10 cm e maior nas camadas 2040 e 40-60 cm, independente da aplicação ou não de dejetos suínos.

\section{AGRADECIMENTOS}

À Faculdade de Agronomia da Universidade de Rio Verde e ao Programa de Pós-Graduação em Produção Vegetal

\section{REFERÊNCIAS}

ASSMANN, J. M. et al. Produção de matéria seca de forragem e acúmulo de nutrientes em pastagem anual de inverno tratada com esterco líquido de suínos. Ciência Rural, Santa Maria, v. 39, p. 2408-2416, 2009.

BARBOSA, G.M.C.; TAVARES FILHO, J.; FONSECA, I.C.B. Avaliações de propriedades físicas de um latossolo vermelho eutroférrico tratado com lodo de esgoto por dois anos consecutivos. 2000. Disponível em: www.sanepar.com.br/sanepar/sanare/v17/AVALIACOESDE PROPRIEDADES. htm. Acessado em 22/05/2018.

BARILLI, J. Atributos de um Latossolo Vermelho sob aplicação de resíduos de suínos. 77 p. Tese (Doutorado). Faculdade de Ciências Agronômicas, Universidade Estadual Paulista, Botucatu, 2005.

BENGHOUGH, P. C.; COSTA, A. C.; CIPRANDI, O.; PANDOLFO, C. M.; ERNANI, P. R. Disponibilidade de macronutrientes e rendimento de milho em Latossolo fertilizado com dejeto suíno. Revista Brasileira de Ciência do Solo, v. 36, p. 1911-1923, 2012. 
CERETTA, et al. Nutrienttransferbyrunoffunder no tillage in a soiltreatedwithsuccessiveapplicationsofpigslurry. Agriculture, Ecosystemsand Environment, v. 139, p. 689699, 2010.

KIEHL, J.E. Fertilizantes orgânicos. Piracicaba: Agronômica Ceres, 1985. 492p.

KONZEN, E. A.; ALVARENGA, R. C.Manejo e utilização de dejetos animais: aspectos agronômicos e ambientais. Sete Lagoas: Embrapa-CNPMS, Circular técnica, 2005, 63 p.

MOSADDEGHI, M. R.; MAHBOUBI, A. A.; SAFADOUST, A. Short-termeffectsoftillageandmanureon some soil physicalpropertiesandmaize root growth in a sandyloam soil in western Iran. Soil andTillageResearch, v.104, p.173-179, 2009.

OLIVEIRA, J. G. R.; TAVARES FILHO, J.; BARBOSA, G. M. C.Alterações na Física do Solo com a Aplicação de Dejetos Animais. GeographiaOpportuno Tempore, Especial. v. 2, p. 66-80, 2016.

RIBEIRO, K. D.; MENEZES, S. M.; MESQUITA, M. G. B. F.; SAMPAIO, F. M. T. Propriedades físicas do solo, influenciadas pela distribuição de poros, de seis classes de solos da região de Lavras-MG. Ciência e Agrotecnologia, v.31, p.1167-1175, 2007.

SEGANFREDO, M.A. Uso de dejetos suínos como fertilizantes e seus riscos ambientais. In: Gestão ambiental na suinocultura. Brasília: Embrapa Informação Tecnológica, 2007. p.149-175. Disponível em: http://www.scielo.br/scielo.php?pid=S1413-7054 2010000400002 \& script=sci_abstract\&tlng=pt.

Acesso em: 22 jun. 2017.

Tabela 1. Valores médios de densidade, macroporosidade e microporosidade do solo em área com aplicação de dejetos suínos em Rio Verde/GO.

\begin{tabular}{|c|c|c|c|c|c|c|}
\hline \multicolumn{7}{|c|}{ Dose DLS $\left(\mathbf{m}^{3} \mathbf{h a}^{-1}\right)$} \\
\hline Profundidade & $\mathbf{0}$ & 25 & $\mathbf{5 0}$ & 75 & 100 & Mineral \\
\hline \multicolumn{7}{|c|}{ Densidade do Solo $\left(\mathrm{g} \mathrm{cm}^{-3}\right)$} \\
\hline $0-10$ & $1,30 \mathrm{~b}$ & $1,44 \mathrm{ab}$ & $1,33 \mathrm{a}$ & $1,39 \mathrm{~b}$ & $1,27 \mathrm{~b}$ & $1,17 \mathrm{~b}$ \\
\hline $10-20$ & $1,45 \mathrm{a}$ & $1,52 \mathrm{a}$ & $1,34 \mathrm{a}$ & $1,51 \mathrm{a}$ & $1,42 \mathrm{a}$ & $1,33 \mathrm{a}$ \\
\hline $20-40$ & $1,33 \mathrm{~b}$ & $1,36 \mathrm{~b}$ & $1,28 \mathrm{a}$ & $1,40 \mathrm{ab}$ & $1,29 \mathrm{~b}$ & $1,36 \mathrm{a}$ \\
\hline \multicolumn{7}{|c|}{ Macroporosidade (\%) } \\
\hline $0-10$ & $16,41 \mathrm{ab}$ & $10,21 \mathrm{~b}$ & $14,82 \mathrm{a}$ & $12,81 \mathrm{a}$ & $14,61 \mathrm{~b}$ & $21,38 \mathrm{a}$ \\
\hline $10-20$ & $12,02 \mathrm{~b}$ & $10,13 \mathrm{~b}$ & $14,79 \mathrm{a}$ & $9,68 \mathrm{a}$ & $15,25 \mathrm{ab}$ & $17,33 \mathrm{a}$ \\
\hline $20-40$ & $21,09 \mathrm{a}$ & $16,68 \mathrm{a}$ & $19,63 \mathrm{a}$ & $14,68 \mathrm{a}$ & $20,21 \mathrm{a}$ & $16,86 \mathrm{a}$ \\
\hline \multicolumn{7}{|c|}{ Microporosidade (\%) } \\
\hline $0-10$ & 37,91 a & $37,93 \mathrm{a}$ & $37,76 \mathrm{a}$ & $39,05 \mathrm{a}$ & 39,98 a & 39,15 a \\
\hline $10-20$ & $37,30 \mathrm{a}$ & $38,04 \mathrm{a}$ & $36,93 \mathrm{a}$ & 38,59 a & $38,52 \mathrm{ab}$ & $38,85 \mathrm{a}$ \\
\hline $20-40$ & $34,70 \mathrm{~b}$ & $34,67 \mathrm{~b}$ & $35,60 \mathrm{a}$ & $38,60 \mathrm{a}$ & $36,08 \mathrm{~b}$ & $37,72 \mathrm{a}$ \\
\hline \multicolumn{7}{|c|}{ Resistência à penetracão (RP) } \\
\hline $0-10$ & $0,57 \mathrm{~b}$ & $0,74 \mathrm{~b}$ & $0,56 \mathrm{~b}$ & $0,62 \mathrm{~b}$ & $0,66 \mathrm{~b}$ & $0,62 \mathrm{~b}$ \\
\hline $10-20$ & $3,27 \mathrm{a}$ & $3,07 \mathrm{a}$ & $3,23 \mathrm{a}$ & $2,98 \mathrm{a}$ & $3,15 \mathrm{a}$ & $3,20 \mathrm{a}$ \\
\hline $20-40$ & $3,43 \mathrm{a}$ & $3,32 \mathrm{a}$ & $3,25 \mathrm{a}$ & $3,09 \mathrm{a}$ & $3,25 \mathrm{a}$ & $2,35 \mathrm{a}$ \\
\hline
\end{tabular}




\title{
RESPOSTA INICIAL DO EUCALIPTO APÓS APLICAÇÃO DE DEJETOS LÍQUIDOS DE SUÍNOS NO OESTE DO PARANÁ
}

\author{
Soares, M.T.S. ${ }^{1}$; Maeda, S. ${ }^{1}$; Bellote, A.F.J. ${ }^{1}$; Andrade, G.C. ${ }^{\text {; }}$ Gomes, J.B.V. ${ }^{\text {; }}$ Fassina, S.H. ${ }^{3}$ \\ ${ }^{I}$ Engenheiros Agrônomos, Doutores, Pesquisadores da Embrapa Florestas, PR.marcia.toffani@embrapa.br \\ ${ }^{2}$ Engenheiro Florestal, Doutor, Pesquisador da Embrapa Florestas, PR \\ ${ }^{3}$ Engenheiro Agrícola, Cooperativa Agroindustrial C.Vale, $P R$
}

\begin{abstract}
RESUMO: O presente estudo tem por objetivo avaliar a resposta inicial do eucalipto clone AEC 144 à aplicação de dejetos líquidos de suínos tratados (DLS) na região oeste do estado do Paraná, Brasil. O experimento está sendo conduzido a campo na Fazenda Piquiri, Assis Chateaubriand (PR), em tratamentos sob uso de DLS e sob fertilização mineral. Verificou-se que, aos seis meses de idade, o uso de dejetos líquidos de suínos aumenta o crescimento em altura do eucalipto, sendo sua eficiência como biofertilizante na dose $80 \mathrm{~m}^{3}$ $\mathrm{ha}^{-1} \mathrm{e}$ na dose $10 \mathrm{~m}^{3} \mathrm{ha}^{-1}$ de DLS mais fósforo solúvel (superfosfato triplo) similar àquela obtida com o uso de NPK. Os resultados obtidos até o presente momento devem ser substanciados pelo monitoramento de longo prazo do sistema solo-planta-atmosfera, a fim de delinear recomendações silviculturais voltadas ao estabelecimento de plantios florestais energéticos na região.
\end{abstract}

Palavras-chave: adubação orgânica, Eucalyptus, resíduos animais.

\section{INITIAL RESPONSE OF EUCALYPTUS AFTER PIG SLURRY APPLICATION IN WEST OF PARANÁ STATE, BRAZIL}

\begin{abstract}
The present study aims to evaluate the initial response of eucalyptus clone AEC 144 after the application of treated liquid swine waste (LSW) in the western region of Paraná State, Brazil. The experiment is being conducted at the Piquiri Farm, Assis Chateaubriand (PR), under treatments under LSW and under mineral fertilization. The use of liquid swine manure increases the height growth of six-month-old trees. The efficiency of $80 \mathrm{~m}^{3} \mathrm{ha}^{-1}$ and $10 \mathrm{~m}^{3} \mathrm{ha}^{-1}$ of LSW plus phosphorus (superphosphate triple) was similar to that obtained with the use of NPK. The results obtained so far must be substantiated by the long-term monitoring of the soil-plant-atmosphere system, in order to delineate silvicultural recommendations aimed at the establishment of energetic forest plantations in the region.
\end{abstract}

Keywords: organic fertilization, Eucalyptus, animal wastes.

\section{INTRODUÇÃO}

O Brasil apresenta destaque internacional na exportação de carne suína (Andreazzi et al., 2014), sendo os estados de Santa Catarina, Paraná e Rio Grande do Sul os principais estados em quantidade de abates no país (IBGE, 2018). A região oeste do Paraná, além de importante polo suinícola, agrega também em sua produção agroindustrial outras atividades como a avicultura, produção de laticínios e grãos, como soja e milho (Ilha et al., 2018), que geram elevada demanda por biomassa florestal para uso energético. A necessidade do estabelecimento de florestas plantadas na região para suprir essa demanda, pode contribuir como uma destinação segura do DLS, pela sua para o aumento da oferta de madeira, pode ofertar aos sistemas de produção a possibilidade de receber resíduos de origem animal tratados para aplicação no solo como biofertilizante. Aspectos técnicos de tratamento e uso silvicultural, como doses, formas e épocas de aplicação não são ainda bem definidos para espécies florestais estabelecidas na região. Neste contexto, o presente estudo tem por objetivo avaliar a resposta inicial do eucalipto clone AEC 144 após aplicação de dejetos líquidos de suínos tratados (DLS) na região oeste do estado do Paraná, Brasil.

\section{MATERIAL E MÉTODOS}

$\mathrm{O}$ experimento está sendo conduzido na Fazenda Piquiri, pertencente à Cooperativa Agroindustrial C.Vale, localizada no município de Assis Chateaubriand (PR), Bacia Hidrográfica do Rio Piquiri. Trata-se de uma área de reforma anteriormente cultivada com eucalipto por 12 anos. $\mathrm{O}$ solo da área foi classificado como Latossolo Vermelho Distrófico textura média/argilosa (Typic Hapludox) conforme Santos et al. (2013). A área experimental é de $11.430 \mathrm{~m}^{2}$. O preparo da área envolveu o controle da matocompetição, a aplicação de iscas 
formicidas contra o ataque de formigas e a aplicação de calcário dolomítico na dose de 2 ton ha ${ }^{-1}$, conforme resultados analíticos do solo e recomendação de adubação espécies do gênero Eucalyptus (Bellote, 2001). O preparo do solo envolveu subsolagem na linha de plantio, com o uso de subsolador acoplado ao trator. Foram selecionadas para plantio a campo, no espaçamento 2,5 m entre linhas e 2,4 m entre plantas $\left(6 \mathrm{~m}^{2}\right)$, mudas de Eucalyptus urophylla, clone AEC 144, que está entre os mais utilizados em plantios comerciais no Brasil (Stape et al., 2010), sendo considerado como um dos mais indicados para plantios que visem ao fornecimento de matéria-prima para geração de energia (Santos e Paludzyszyn Filho, 2014). O delineamento experimental utilizado foi o de blocos ao acaso, com dois blocos, sete tratamentos e três repetições dentro do bloco, totalizando 42 parcelas. Os tratamentos foram T1 = Controle, sem adubação e sem aplicação de DLS, T2 = 10 $\mathrm{m}^{3} \mathrm{ha}^{-1}$ de DLS, sem suplementação mineral; T3 = $20 \mathrm{~m}^{3}$ ha $^{-1}$ de DLS, sem suplementação mineral; T4 = 40 $\mathrm{m}^{3} \mathrm{ha}^{-1}$ de DLS, sem suplementação mineral; T5 = $80 \mathrm{~m}^{3} \mathrm{ha}^{-1}$ de DLS, sem suplementação mineral; T6 = 10 $\mathrm{m}^{3}$ ha $^{-1}$ de DLS + suplementação fosfatada; $\mathrm{T} 7$ = fertilização mineral de referência. Os dejetos líquidos de suínos (DLS) foram oriundos de sistemas de lagoas de estabilização em operação na Fazenda Piquiri, cuja granja tem a finalidade de produção de leitões para os cooperados da C.Vale. As doses de DLS foram previamente definidas tendo-se como referência a recomendação de fertilização nitrogenada para a espécie (Gonçalves et al., 1997), bem como na concentração de nitrogênio total no DLS, estimada com base em laudos analíticos obtidos a partir de amostras coletadas em setembro de 2017 (dados não apresentados). Os tratamentos T6 e T7 receberam, no ato do plantio (14-15.nov.17), na projeção da copa e levemente incorporado ao solo, 180 gramas por planta de superfosfato triplo $\left(41 \%\right.$ de $\left.\mathrm{P}_{2} \mathrm{O}_{5}\right)$, o que corresponde à aproximadamente $120 \mathrm{~kg} /$ ha de $\mathrm{P}_{2} \mathrm{O}_{5}$ conforme recomendações de fertilização para florestamentos de eucalipto (Gonçalves et al., 1997; Bellote et al., 2001). No tratamento T7 (fertilização mineral de referência) foram aplicados a aproximadamente 30 dias após o plantio, (12.12.2017), em covetas laterais às mudas, $120 \mathrm{~g}$ planta $^{-1}$ de sulfato de amônio $(21 \% \mathrm{~N})$, o que corresponde a $40 \mathrm{kgha}^{-1}$ de $\mathrm{N}$ conforme recomendações de fertilização da espécie, e 60 gramas por planta de $\mathrm{KCl}(60 \%$ de $\mathrm{K} 2 \mathrm{O})$, o que corresponde a aproximadamente $60 \mathrm{~kg}^{-1} \mathrm{de}_{2} \mathrm{O}$ conforme recomendações de fertilização da espécie (Gonçalves et al., 1997; Bellote et al., 2001. O DLS utilizado no experimento foi obtido da Lagoa 2 com o auxílio de misturador acoplado a um trator e caminhão tanque com capacidade de 6-8 mil litros. A aplicação de DLS nos tratamentos T2 a T6 foi realizada entre os dias 08 e 11 de janeiro de 2018, manualmente, com uso de regadores previamente calibrados. O resíduo foi aplicado na superfície do solo, em cobertura, nas entrelinhas de plantio, em distância mínima aproximada de $50 \mathrm{~cm}$ das mudas estabelecidas à campo. Amostras do líquido aplicado foram reunidas e encaminhadas à Merieux Nutrisciences (Curitiba/PR) para determinação da composição química e obtenção das quantidades de nutrientes aplicadas em cada tratamento. Aos seis meses de idade e quatro meses após aplicação de DLS (15.05.2018) foram mensuradas as nove árvores centrais em cada parcela útil; a altura foi obtida com o auxílio de uma vara telescópica e a circunferência a altura do peito (CAP) por meio de uma fita graduada. Os dados de CAP foram posteriormente convertidos ao diâmetro a altura do peito (DAP) conforme a equação: DAP = CAP/Pi. Os efeitos dos diferentes tipos de fertilização (mineral, orgânica e mineral+orgânica, T1 a T7), de bloco e a interação entre eles no crescimento das árvores foram verificados por meio da análise de variância (ANOVA) seguida do teste de médias (Tukey) a 5\% de probabilidade. Para os tratamentos submetidos a doses crescentes de DLS, sem fertilização mineral (T1 a T5) foi também realizada a análise de regressão com ajuste de modelo quando cabível.

\section{RESULTADOS E DISCUSSÃO}

A concentração de nitrogênio, fósforo e potássio do DLS, bem como respectivas quantidades aplicadas via DLS em cada tratamento estão apresentadas na Tabela 1. Dos tratamentos estabelecidos, somente a dose máxima de DLS (T5) extrapola as quantidades máximas recomendadas de $\mathrm{N}$ para a cultura do eucalipto no estado do Paraná, de 81-90 kg ha-1, considerando-se uma produtividade de toras esperada de $75 \mathrm{~m}^{3} \mathrm{ha}^{-1} \mathrm{ano}^{-1}$ (Pauletti \& Motta, 2017).

Quanto ao desenvolvimento das plantas aos seis meses de idade (quatro meses após aplicação DLS), de acordo com a equação ajustada para as doses T1 a T5, houve efeito linear crescente de DLS aplicado somente sobre a altura eucalipto $(\mathrm{p}<0,05)$, todavia com diferenças pequenas entre tratamentos (Tabela 2). Resultado similar foi obtido por Ribeiro et al. (2014) com o uso de doses crescentes de lodo de efluentes suínos em eucalipto estabelecido em condições de casa de vegetação. Quando incluídos os tratamentos T6 e T7 na análise, verificou-se que o crescimento em altura e DAP sob fertilização mineral (T7) foi superior aos tratamentos sob doses 0 a $40 \mathrm{~m}^{3} \mathrm{ha}^{-1}$ de DLS sem suplementação mineral (T1 a T4, p<0,05). A adubação mineral fosfatada 
somada à aplicação de $10 \mathrm{~m}^{3} \mathrm{ha}^{-1}$ de DLS (T6) também resultou, nesta época, em aumento do crescimento em altura em comparação às doses 0,10 e $20 \mathrm{~m}^{3} \mathrm{ha}^{-1}$ (T1 a T3, p<0,05). Somente a maior dose de DLS (T5) possibilitou crescimento em altura e DAP similar à fertilização mineral $(\mathrm{T} 7, \mathrm{p}<0,05)$. Houve diferença estatística entre blocos para DAP, todavia sem interação entre fatores.

No presente trabalho, os resultados apresentados para T6 e, secundariamente, em T7 para os parâmetros avaliados sugerem, na situação apresentada, que o uso de fósforo mineral como suplemento à fertilização com DLS favoreceu o estabelecimento inicial das plantas a campo. Os benefícios da suplementação fertilização fosfatada com o uso de resíduos orgânicos em povoamentos de eucalipto também foram apontados por Vaz et al. (2002) e Andrade et al. (2003) (biossólido e lodo celulósico, respectivamente). O comportamento registrado nesta fase inicial de estabelecimento do plantio a campo pode ainda sofrer mudanças até o período de corte, sendo que os resultados obtidos até o presente momento devem ser substanciados pelo monitoramento de longo prazo do sistema solo-planta-atmosfera.

\section{CONCLUSÃO}

Aos seis meses de idade, o uso de dejetos líquidos de suínos aumenta o crescimento em altura do eucalipto, sendo sua eficiência como biofertilizante na dose $80 \mathrm{~m}^{3} \mathrm{ha}^{-1}$ e na dose $10 \mathrm{~m}^{3} \mathrm{ha}^{-1}$ de DLS mais fósforo solúvel (superfosfato triplo) similar àquela obtida com o uso de adubos minerais (NPK). Os resultados obtidos até o presente momento devem ser substanciados pelo monitoramento de longo prazo do sistema soloplanta-atmosfera.

\section{AGRADECIMENTOS}

Ao Projeto Bioeste Florestas, uma parceria da Embrapa Florestas, Itaipu Binacional, CIBiogas e Funpar. À C.Vale pela parceria e apoio de campo. Aos técnicos e bolsistas da CIBiogas Larissa Caroline Sbalqueiro, Thiago Gonzáles, e Giordano Corradi, ao gerente da C.Vale Alcemir Chiodelli, e ao técnico da C.Vale Guilherme Daniel. Aos pesquisadores Edilson Batista de Oliveira e Krisle da Silva (Embrapa Florestas) pelas valiosas sugestões e contribuições realizadas.

\section{REFERÊNCIAS}

ANDRADE, G. C., DA SILVA, H. D., BELLOTE, A. F. J., \& FERREIRA, C. A. (2003). Efeitos da adubação fosfatada e da aplicação de resíduo de celulose no crescimento de Eucalyptus dunnii. Embrapa florestas-artigo em periódico indexado (alice). Disponível em: <https://www.alice.cnptia.embrapa.br/alice/bitstream/doc/ 300359/1/pag4354.pdf>. Acesso em 08.11.18

ANDREAZZI, M. A., DOS SANTOS, J. M. G., \& LAZARETTI, R. M. J. Estudo sobre a destinação dos resíduos da suinocultura em granjas do estado do Paraná. Revista Eletrônica em Gestão, Educação e Tecnologia Ambiental, v. 19, n. 3, p.744-751, 2015.

BARROS, N.F.; NEVES, J.C.L.; NOVAIS, R.F. Nutrição e adubação mineral do eucalipto. In: Eucaliptocultura no Brasil: silvicultura, manejo e ambiência. 2014. pp. 188-208

INSTITUTO BRASILEIRO DE GEOGRAFIA E ESTATÍSTICA - IBGE. Sistema IBGE de Recuperação Automática. Pesquisa Trimestral do Abate de Animais - $2^{\circ}$ trimestre 2018 [online]. Brasília, Distrito Federal, 2018. Disponível em: 〈https://sidra.ibge.gov.br/home/abate/brasil〉. Acesso em: 10.nov.18.

PAULETTI V, MOTTA A.C.V. Manual de adubação e calagem para o estado do Paraná. Curitiba: Sociedade Brasileira de Ciência do Solo, Núcleo Estadual Paraná; 2017.

RIBEIRO, E. P., MAGAlHÃES, J. L., RODRIGUES, A. A., RODRIGUES, D. A., FRAZÃO, M. A., \& RODRIGUES, C. L. (2015). Análise inicial do super clone de eucalipto adubado com lodo de efluente suíno. Pesquisa Florestal Brasileira, 35(84), 399-407. DOI: https://doi.org/10.4336/2015.pfb.35.84.913.

VAZ, L. M. S.; GONÇALVES, J. L. M. Uso de biossólidos em povoamento de eucalipto: efeito em atributos químicos do solo, no crescimento e na absorção de nutrientes. Revista Brasileira de Ciência do Solo, v. 26, n. 3, 2002.

BELLOTE, A. F. J.; NEVES, E. J. M. Calagem e adubação em espécies florestais plantadas na propriedade rural. Colombo: Embrapa Florestas, 2001. (Embrapa Florestas. Circular técnica, 54). Disponível em: <https://www.infoteca.cnptia.embrapa.br/bitstream/doc/306311/1/CT0054.pdf>.

GONÇALVES, J. L. M.; RAIJ, B. van; GONÇALVES, J. C. Florestais. In: RAIJ, B. van.; CANTARELLA, H.; QUAGGIO, J. A.; FURLANI, A. M. C. Recomendações de adubação e calagem para o estado de São Paulo. Campinas: IAC, 1997. p. 247-260. 
Tabela 1. Concentrações de nitrogênio, fósforo e potássio de dejetos líquidos de suínos aplicado e respectivas quantidades nas doses utilizadas.

\begin{tabular}{|c|c|c|c|c|c|c|}
\hline \multirow[t]{2}{*}{ Parâmetro } & \multirow[t]{2}{*}{ Concentração } & \multicolumn{5}{|c|}{ Quantidades de $\mathrm{N}, \mathrm{P}_{2} \mathrm{O}_{5}$ e $\mathrm{K}_{2} \mathrm{O}$ aplicadas via DLS } \\
\hline & & T1 (0) & T2 (10) & T3 (20) & T4 (40) & T5 (80) \\
\hline & $\mathrm{g} \mathrm{L}^{-1}$ & \multicolumn{5}{|c|}{ - } \\
\hline $\mathrm{N}$ total & 2,14 & 0 & 21 & 43 & 85 & 171 \\
\hline P total & 0,89 & 0 & 20 & 41 & 82 & 163 \\
\hline K total & 0,49 & 0 & 6 & 12 & 24 & 47 \\
\hline
\end{tabular}

Tabela 2. Altura (A) e diâmetro a altura do peito (DAP) aos seis meses pós-plantio e quatro meses pós aplicação de DLS nos diferentes tratamentos ${ }^{(1)}$.

\begin{tabular}{|c|c|c|c|}
\hline $\begin{array}{c}\text { Dose DLS } \\
\left(\mathbf{m}^{3} \mathbf{h a}^{-1}\right)\end{array}$ & $\begin{array}{c}\text { Altura Média } 6 \text { meses idade } \\
\text { (metros) }\end{array}$ & & $\begin{array}{l}\text { DAP } \\
(\mathbf{c m})\end{array}$ \\
\hline $\mathrm{T} 1(0)$ & $3,44 \quad \mathrm{c}$ & 2,60 & $\mathrm{bc}$ \\
\hline $\mathrm{T} 2(10)$ & $3,37 \mathrm{c}$ & 2,41 & $\mathrm{c}$ \\
\hline T3 (20) & $3,40 \quad \mathrm{c}$ & 2,45 & $\mathrm{c}$ \\
\hline $\mathrm{T} 4(40)$ & 3,51 bc & 2,55 & $\mathrm{c}$ \\
\hline T5 (80) & 3,60 abc & 2,72 & $a b c$ \\
\hline $\mathrm{T} 6(10+\mathrm{P})$ & $3,81 \quad a b$ & 3,04 & $\mathrm{ab}$ \\
\hline T7 (Fert.Min) & $3,87 \quad \mathrm{a}$ & 3,09 & $\mathrm{a}$ \\
\hline Bloco1 & 3,59 n.s. & 2,81 & $\mathrm{a}$ \\
\hline Bloco2 & 3,56 & 2,58 & $\mathrm{~b}$ \\
\hline Equação (T1 a T5): & $y=0,0027+3,38 x$ & n.s. & \\
\hline $\mathrm{R}^{2}$ & 0,16 & & \\
\hline $\mathrm{p}$ & 0,028 & & \\
\hline
\end{tabular}




\title{
SUBSTRATOS ORGÂNICOS PROVENIENTES DE RESÍDUOS AGROINDUSTRIAIS: PRODUÇÃO DE MUDAS DE RÚCULA
}

\author{
Poder, J.S.G. ${ }^{1}$; Santos, F.T. ${ }^{1}$; Hermes, E. ${ }^{1}$; Bautitz, I.R.*1 \\ ${ }^{1}$ Programa de Pós-graduação em Tecnologias de Bioprodutos Agroindustriais, Universidade Federal do \\ Paraná (UFPR), Palotina, PR - Brasil \\ ivonete.rossi@ufpr.br
}

\begin{abstract}
RESUMO: O objetivo do estudo foi avaliar substratos orgânicos provenientes da compostagem de resíduos da cadeia avícola associado a glicerina bruta na produção de mudas de rúcula. Os resíduos orgânicos utlizados foram resíduos de incubatório, cama de frango, lodo de flotador (fontes de nitrogênio) e poda de árvores urbanas, bagaço de cana, glicerina bruta e o carvão remanescente de caldeira (fontes de carbono). Os teores de glicerina bruta adicionados na massa fresca em compostagem foram de 0,$0 ; 1,5 ; 3,0 ; 4,5$ e $6,0 \%$. O experimento foi inteiramente casualizado com cinco tratamentos e quatro repetições.Os parâmetros químicos avaliados nos substratos produzidos foram nitrogênio, fósforo, potássio, condutividade elétrica e $\mathrm{pH}$. As avaliações fitométricas realizadas nas mudas foram altura de parte aérea, diâmetro do coleto, número de folhas, massa fresca da parte aérea, massa seca da parte aérea, massa fresca da raiz e massa seca da raiz. Os resultados das avaliações fitométricas do desenvolvimento das mudas de rúcula demostraram que a adição de glicerina bruta ao processo de compostagem não interferiu de forma negativa na qualidade das mudas.
\end{abstract}

Palavras-chave: Substratos alternativos, resíduos orgânicos, glicerina bruta.

\section{ORGANICS SUBSTRATES FROM AGROINSDUSTRIAL WASTE: PRODUCTION OF ARUGULA SEEDLINGS}

\begin{abstract}
The objective of the study was to evaluate organic substrates from the composting of broiler production chain associated with crude glycerin in the production of arugula seedlings. The organic residues used were hatchery, chicken litter, float sludge (nitrogen sources) and pruning of urban trees, sugarcane bagasse, crude glycerin and coal remaining in the boiler (carbon sources). The crude glycerin contents added in the fresh compost were $0.0 ; 1.5,3.0,4.5$ and $6.0 \%$. The experiment was completely randomized with five treatments and four replicates. The chemical parameters evaluated in the substrates were nitrogen, phosphorus, potassium, electrical conductivity and $\mathrm{pH}$. The phytometric evaluations carried out in the seedlings were shoot height, shoot diameter, leaf number, fresh shoot weight, dry shoot mass, fresh root mass and dry root mass. The results of the phytometric evaluations of the development of the arugula seedlings show that the addition of crude glycerin to the composting process does not negatively interfere in the quality of the seedlings.
\end{abstract}

Keywords: Alternative substrate, organic waste, crude glycerin.

\section{INTRODUÇÃO}

A cadeia produtiva de aves de corte é uma das mais importantes do agronegócio brasileiro. No estado do Paraná, segundo o Instituto Paranaense de Desenvolvimento Econômico e Social, em 2015 foi produzido aproximadamente 4 milhões de toneladas de frango, entretanto, essa grande produção contribui significativamente para a geração de resíduos em toda cadeia produtiva (ABPA, 2018).

Outro setor da agroindústria que tem se destacado é o da produção de biocombustíveis, impulsionado sobretudo, pela busca de energias alternativas renováveis. Nesse seguimento, pode-se citar a produção de etanol e de biodiesel. Assim como outras agroindústrias, essas também geram resíduos, como o bagaço da cana-de-açúcar e a glicerina bruta (GB) resultante do processo de transesterificação do óleo (triglicerídeos) na produção do biodiesel (Rivaldi et al, 2007; Apolinário et al., 2012). Com o intuito de reduzir ou minimizar o impacto ambiental da disposição inadequada desses resíduos surge a oportunidade de incorporar esses materiais ao processo de compostagem e assim originar fertilizantes orgânicos (Nasiru et al., 2013).

Nesse sentido, a compostagem é uma ferramenta eficiente para o gerenciamento de resíduos orgânicos provenientes da cadeia de aves de corte, bem como para o tratamento da glicerina bruta. Esse processo que consiste na degradação da matéria orgânica com a presença de oxigênio tem como objetivo também produzir substratos orgânicos alternativos (Kihel 2010). 
A legislação referente aos substratos orgânicos é do Ministério da Agricultura, Pecuária e Abastecimento - MAPA por meio da Instrução Normativa (IN) n ${ }^{\circ} 25$ de 23 de julho de 2009 a qual estabelece as normas sobre especificações e garantias, registro, embalagem e rotulagem dos fertilizantes orgânicos e biofertilizantes destinados à agricultura.

Assim sendo, o substrato orgânico alternativo pode ser utilizado como fonte de nutrientes e condicionador do solo na produção de culturas, tais como hortaliças, mudas e flores (Santos et al., 2016). Dessa forma, o objetivo do presente estudo foi avaliar a qualidade agronômica de substratos orgânicos alternativos provenientes de resíduos orgânicos agroindustriais na produção de mudas de rúcula.

\section{MATERIAL E MÉTODOS}

Os compostos orgânicos foram obtidos por meio de compostagem de resíduos de agroindústrias de abate de aves e produção de aves de engorda, tais como resíduos de incubatório, cama de frango, lodo de flotador as quais foram utilizadas como fontes de nitrogênio e como fontes de carbono foram utilizadas a poda de árvores urbana, o bagaço de cana, a glicerina bruta e o carvão remanescente de caldeira. As proporções de GB adicionadas ao processo foram 0,$0 ; 1,5 ; 3,0 ; 4,5$ e 6,0\% denominando os tratamentos de T0,0; T1,5; T3,0; T4,5 e T6,0.

O composto orgânico foi peneirado e caracterizado por análises químicas. As análises químicas feitas foram nitrogênio, fósforo e potássio (NPK). A metodologia utilizada para determinação de fósforo e o potássio foi baseada em Lana et al. (2010), em contrapartida, para nitrogênio foi utilizada metodologia baseada em Malavolta et al. (1989). Para as análises do $\mathrm{pH}$ e condutividade foi utilizado método potenciométrico (Lana et al. 2010). O experimento de produção de mudas foi realizado em viveiro, em delineamento inteiramente casualizado com 5 tratamentos e 4 repetições. Utilizou-se semente de rúcula comercial. Após a germinação das sementes, aos 30 dias após a semeadura foram realizadas as determinações fitométricas nas mudas: número de folhas, altura da parte aérea, diâmetro do coleto. Além disso, foi avaliado a massa fresca da parte aérea, massa fresca da raiz, massa seca da parte aérea e massa seca da raiz. Os índices de massa foram aferidos utilizando uma balança analítica (Ferreira et al., 2017). Os dados foram submetidos ao teste de Tukey com 5\% de significância.

\section{RESULTADOS E DISCUSSÃO}

As concentrações de nitrogênio total presentes nos substratos alternativos provenientes da compostagem feita nesse trabalho variaram de 29,10 no T1,5 a 31,60 no T3,0 conforme apresentado na Tabela 1 . A IN $\mathrm{N}^{\circ} 25 / 2009$, estabelece que o teor de nitrogênio deve ser de no mínimo $0,5 \%$ ou $5 \mathrm{~g} \mathrm{~kg}^{-1}$, assim sendo, em todos os tratamentos esse teor mínimo exigido foi ultrapassado. Esse resultado é muito importante pois o nitrogênio é o nutriente que as culturas necessitam em maior quantidade (Raij et al, 1997).

Outro nutriente muito importante para as mudas é o fósforo pois ele apresenta influência nas reações vitais das culturas e a sua ausência impede o ciclo de vida da planta (Almeida et al, 2009). Entretanto, a IN $\mathrm{N}^{\circ}$ 25 estabelece apenas que na rotulagem do produto seja expresso o valor desse nutriente, não norteando um valor mínimo. O teor de fósforo encontrado foi de $0,89,0,93,0,98,1,40$ e $0,85 \mathrm{~g} \mathrm{~kg}^{-1}$ nos tratamentos T0,0; T1,5; T3,0; T4,5 E T6,0, respectivamente.

O Potássio é o segundo nutriente mais extraído pelas plantas o qual é absorvido na forma iônica. A maior concentração desse elemento é requerida durante o período de crescimento vegetativo, pois a falta desse nutriente pode limitar a fotossíntese, e reduzir o seu crescimento (Raij et al, 1991). As concentrações de potássio nos substratos orgânicos alternativos apresentaram-se semelhantes em todos os tratamentos, acima de $9 \mathrm{~g} \mathrm{~kg}^{-1}$.

Os valores de $\mathrm{pH}$ e condutividade elétrica (CE) são parâmetros químicos que devem ser avaliados antes do uso do substrato e devem ser monitorados durante o tempo de cultivo. A CE determina a salinidade do substrato, assim quando os valores forem altos a planta pode estar perdendo água pelas raízes (Takane et al., 2012). Segundo Gávilan (2004), valores de CE abaixo de $0,74 \mathrm{~ms} \mathrm{~cm}^{-1}$ são considerados muito abaixo do ideal para nutrição de mudas já entre 0,75 e 2,0 são considerados valores adequados para a produção de mudas de hortaliças. No entanto, valores acima de $5 \mathrm{~ms} \mathrm{~cm}^{-1}$ podem causar redução de crescimento pela salinidade, ocasionado a queimadura das raízes e provocando a murcha das mudas. Nesse estudo, o menor valor de CE foi no T1,5 $\left(1,90 \mathrm{~ms} \mathrm{~cm}^{-1}\right)$ e em T4,5 foi o maior valor encontrado $\left(2,62 \mathrm{~ms} \mathrm{~cm}^{-1}\right)$, estando de acordo com os valores mencionados por Gávilan (2004).

Segundo a IN N ${ }^{\circ} 25 / 2009$ o valor mínimo de $\mathrm{pH}$ para fertilizantes orgânicos deve ser de 6 . O pH do substrato está relacionado com o crescimento das plantas porque afeta a disponibilidade dos nutrientes e alguns 
processos fisiológicos (Takane et al., 2012). O pH encontrado para os substratos foram 7,40; 7,80; 7,59; 7,50 e 7,15, nos tratamentos T0,0; T1,5; T3,0; T4,5 E T6,0, respectivamente. Em todos os tratamentos o pH do substrato está dentro da faixa de neutralidade preconizada pela IN No 25/2009.

A avaliação da qualidade das mudas foi feita por meio de análises fitométricas, tais como altura de parte aérea (APA), diâmetro do coleto (DC), número de folhas (NF), massa fresca da parte aérea (MFPA), massa seca da parte aérea (MSPA), massa fresca da raiz (MFR) e massa seca da raiz (MSR). Os resultados dos parâmetros fitométricos das mudas estão apresentados na Tabela 2.

O DC das mudas pode variar dependendo das condições do meio, por exemplo fatores como sombreamento pode prejudicar o desenvolvimento do DC, mas normalmente em viveiros as condições são homogêneas (Carpanezzi, 1991). Considerando que esse estudo foi conduzido em viveiro não observou-se diferença significativa entre os tratamentos sendo que o DC variou de 1,24 a 1,44 mm. Da mesma forma, a APA não apresentou diferença estatística entre os tratamentos variando de $6,52 \mathrm{a} 7,46 \mathrm{~cm}$. A altura de parte aérea é influenciada pelo contato da raiz com o solo, assim quanto maior o contato maior a absorção de nutrientes (Beutler e Centurion, 2004). Os substratos orgânicos alternativos produzidos nesse estudo não influenciaram negativamente o desenvolvimento da parte aérea das mudas de rúcula (MFPA), pois são iguais estatisticamente as mudas produzidas no substrato sem a adição de glicerina bruta, resultado semelhante ao parâmetro intimamente ligado, massa seca da parte aérea. A produção de MFPA está associada ao acúmulo de nutrientes pela cultura, dessa forma quanto maior a idade da planta e o teor de matéria seca, consequentemente aumentará a área foliar, o tamanho das raízes e a porcentagem de nitrogênio disponível na cultura (Fageria et al., 2008).

As folhas são responsáveis pelo processo de fotossíntese. O surgimento das folhas influencia no índice de área foliar que absorve a energia solar, assim quanto maior o número de folhas na planta, maior a cobertura vegetal (Fagundes et al., 2009). Nos substratos orgânicos avaliados não houve diferença estatística entre os tratamentos para o parâmetro número de folhas, sendo que a média dos valores ficaram entre 5,16 e 6,66 folhas por muda. O número de folhas está diretamente relacionado com a comercialização da rúcula uma vez que um maço com maior número de folhas atrai mais a atenção do consumidor.

A raiz exerce a função de fixação da planta no solo, absorção da água e sais minerais, armazenamento de carboidratos (amido) e compostos orgânicos, e é o local onde ocorre a biossíntese de moléculas como alcalóides e hormônios vegetais (Vieira et al., 2010). Os valores encontrados na avaliação da MSR não indicaram diferença significativa entre os tratamentos, variando entre 0,01 e 0,02 g. Em contrapartida, para a MFR houve diferença estatística entre os tratamentos, maiores valores foram encontrados nos tratamentos com adição de glicerina bruta $(4,5$ e $6,0 \%)$.

\section{CONCLUSÃO}

Os substratos orgânicos alternativos gerados a partir de resíduos agroindustriais podem ser utilizados para a produção de mudas de rúcula pois atendem aos principais parâmetros da legislação vigente. Além disso, a adição de glicerina bruta apresenta-se como uma destinação final ambientalmente correta, de forma a minimizar e promover o gerenciamento dos resíduos agroindustriais. Ademais, gera o substrato orgânico alternativo que nas proporções testadas não afetou negativamente o desenvolvimento das mudas de rúcula.

\section{AGRADECIMENTOS}

O presente trabalho foi realizado com apoio da Coordenação de Aperfeiçoamento de Pessoal de Nível Superior - BRASIL (CAPES) - código de financiamento 001.

\section{REFERÊNCIAS}

ABPA, 2018. Associação Brasileira de Proteína Animal. Relatório Expedição Avicultura 2015. Disponível em: <http://abpa-br.com.br/setores/avicultura/resumo> Acesso em 26 de junho de 2018.

ALMEIDA JÚNIOR, A. B.; OLIVEIRA, F. A.; MEDEIROS, J. F.; OLIVEIRA, M. K. T.; LINHARES, P. C. A. Efeito de doses de fósforo no desenvolvimento inicial da mamoneira. Revista caatinga, v. 22, p. 206-211, 2009.

APOLINÁRIO, F. D. B.; PEREIRA, G. F.; FERREIRA, J. P. Biodiesel e alternativas para utilização da glicerina resultante do processo de produção de biodiesel. Revista de Divulgação do Projeto Universidade Petrobras e Fluminense, v. 2, n. 1, p. 141-146, 2012.

BRASIL - Ministério da Agricultura, Pecuária e Abastecimento. MAPA Instrução Normativa $\mathrm{N}^{\circ} 25$, de 23 de julho de 2009, Brasília, 2009. 


\section{VISIGERÂ DEF7 109 MA10 2019

BEUTLER, A. N.; CENTURION, J. F. Matéria seca e altura das plantas de soja e arroz em função do grau de compactação e do teor de água de dois latossolos. Revista engenharia agrícola. Jaboticabal, v.24, p.142-149, 2004

CARPANEZZI, A. A. Sociedade de investigações florestais. Universidade Federal de Viçosa, MG, Revista árvore, v. 15, 1991.

FAGUNDES, L. K.; STRECKII, N. A.; LOPES, S. J.; ROSA, H. T.; WALTER, L.; ZANON, A. J. Desenvolvimento vegetativo em diferentes hastes da planta de mandioca em função da época de plantio. Ciência rural, Santa Maria, v.39, p.657-663, 2009.

FERREIRA, D. F. Estatística multivariada. 2ed.Lavras, 2011.

KIEHL, E. J. Fertilizantes Orgânicos. Editora Agronômica Ceres LTDA. 248 p. São Paulo, SP, 2010.

GÁVILAN, M. U. Tratado de cultivo sin suelo. 3. Ed. Almería, es: s.a. Mundi-pensa. 2004.

LANA, M. C.; FEY, R.; FRANCOLOSO, J. F.; RICHART, A.; FONTANIVA, S. Análise química de solo e tecido vegetal: práticas de laboratório. Cascavel, Unioeste, 130 p, 2010.

LUCHESE, E. B.; FAVERO, L. O. B.;LENZI, E. Fundamentos da química do solo. Rio de Janeiro, 2 ed., p.182, 2002.

MALAVOLTA, E. ABC da adubação. 5. Ed. São Paulo: agronômica ceres, 1989.

NASIRU, A.; ISMAIL, N.; IBRAHIM, M. H.; VERMICOMPOSTING: Tool for sustainable ruminant manure management. Journal Waste Management article ID 732759, 7 P, 2013.

RAIJ, B. V. Avaliação da fertilidade do solo. Piracicaba: Instituto da potassa e fosfato, p.142, 1991.

RAIJ, B. V; CANTARELLA, H.; QUAGGIO, J. A.; FURLANI, A. M. C. Recomendações de adubação e calagem para o estado de São Paulo. (Boletim técnico, 100) 2. Ed, campinas: Instituto Agronômico \& fundação IAC, p.285, 1997.

RIVALDI, J. D.; SARROUH, B.; FIORILO, R.; SILVA, S. S. Glicerol de biodiesel: estratégias biotecnológicas para o aproveitamento do glicerol gerado da produção de biodiesel. Biotecnologia Ciência e Desenvolvimento, 37, 44-51, 2007.

SANTOS, F.T.; LUDWIG, F.; COSTA, L. A. M.; COSTA, M. S. S. DE M.; REMOR, M. B.; SILVA, P. E. R. Growth analysis of potted gerbera conducted with mineral fertilization and organic fertigation. Ciencia $\mathbf{e}$ Investigación Agraria, v. 43, p. 111-120, 2016.

TAKANE, R. J.; SIQUEIRA, P. T. V.; KAMPF, A. N. Técnicas de preparo de substratos para aplicação em horticultura (olericultura e fruticultura). 2 ed. Brasília, DF, LK editora, p.100, 2012.

Tabela 1. Caracterização química dos substratos orgânicos alternativos.

\begin{tabular}{cccccc}
\hline Tratamento & $\mathbf{N}$ & $\mathbf{P}$ & $\mathbf{K}$ & $\mathbf{C E}$ & $\mathbf{P H}$ \\
\hline & $\mathrm{g} \mathrm{kg}^{-1}$ & $\mathrm{~g} \mathrm{~kg}^{-1}$ & $\mathrm{~g} \mathrm{~kg}^{-1}$ & $\mathrm{~ms} \mathrm{~cm}^{-1}$ & \\
\hline $\mathrm{T} 0,0$ & 29,20 & 0,89 & 9,05 & 2,32 & 7,40 \\
$\mathrm{~T} 1,5$ & 29,10 & 0,93 & 9,02 & 1,90 & 7,80 \\
$\mathrm{~T} 3,0$ & 31,60 & 0,98 & 9,53 & 2,48 & 7,59 \\
$\mathrm{~T} 4,5$ & 29,50 & 1,40 & 9,71 & 2,62 & 7,50 \\
$\mathrm{~T} 6,0$ & 31,10 & 0,85 & 9,33 & 2,28 & 7,15 \\
\hline
\end{tabular}

N: nitrogênio; K: potássio; P: fósforo; CE: condutividade elétrica.

Tabela 2. Parâmetros fitométricos das mudas de Rúcula com o uso de substrato orgânico.

\begin{tabular}{|c|c|c|c|c|c|c|c|}
\hline Tratamento & $\begin{array}{c}\mathrm{DC} \\
\mathrm{mm}\end{array}$ & $\begin{array}{c}\text { APA } \\
\text { cm }\end{array}$ & $\begin{array}{c}\text { NF } \\
-\end{array}$ & $\begin{array}{c}\text { MFPA } \\
\mathrm{g}\end{array}$ & $\begin{array}{c}\text { MSPA } \\
\mathrm{g}\end{array}$ & $\begin{array}{c}\text { MFR } \\
\mathrm{g}\end{array}$ & $\begin{array}{c}\text { MSR } \\
\text { g }\end{array}$ \\
\hline $\mathrm{T} 0,0$ & $1,24 \mathrm{a}$ & $6,52 \mathrm{a}$ & $5,50 \mathrm{a}$ & $0,34 \mathrm{a}$ & $0,05 \mathrm{a}$ & $0,09 \mathrm{~b}$ & $0,02 \mathrm{a}$ \\
\hline $\mathrm{T} 1,5$ & $1,29 \mathrm{a}$ & $6,52 \mathrm{a}$ & $5,16 \mathrm{a}$ & $0,34 \mathrm{a}$ & $0,05 \mathrm{a}$ & $0,10 \mathrm{ab}$ & $0,01 \mathrm{a}$ \\
\hline $\mathrm{T} 3,0$ & $1,33 \mathrm{a}$ & $6,76 \mathrm{a}$ & $5,33 \mathrm{a}$ & $0,34 \mathrm{a}$ & $0,05 \mathrm{a}$ & $0,10 \mathrm{ab}$ & $0,01 \mathrm{a}$ \\
\hline $\mathrm{T} 4,5$ & $1,39 \mathrm{a}$ & $7,39 \mathrm{a}$ & $6,00 \mathrm{a}$ & $0,37 \mathrm{a}$ & $0,06 \mathrm{a}$ & 0,11 a & $0,02 \mathrm{a}$ \\
\hline T6,0 & $1,44 \mathrm{a}$ & $7,46 \mathrm{a}$ & $6,66 \mathrm{a}$ & $0,38 \mathrm{a}$ & $0,06 \mathrm{a}$ & 0,11 & $0,02 \mathrm{a}$ \\
\hline
\end{tabular}

Teste de Tukey - 5\% de significância; APA: altura de parte aérea; DC: diâmetro do coleto; NF: número de folha; MFPA: massa fresca da parte aérea; MSPA: massa seca da parte aérea; MFR: massa fresca da raiz; MSR: massa seca da raiz. 


\title{
USO DE BIOFERTILIZANTE COM RESÍDUO MARINHO NA PRODUÇÃO DE MUDAS DE RÚCULA
}

\author{
Morales, R.G.F. ${ }^{* 1}$; Visconti, A. ${ }^{1}$; Onaka, K.A. ${ }^{2}$; Cantú, R.R. ${ }^{1}$; Schallenberger, E. ${ }^{1}$; Palma, M.S. ${ }^{2}$ \\ ${ }^{1}$ Pesquisadores da Epagri, Itajaí, SC-Brasil \\ ${ }^{2}$ Graduação em Agronomia, UFPR \\ ${ }^{3}$ Engenheiros da Pamplona Alimentos S/A, Rio do Sul, SC - Brasil \\ *rafaelmorales@epagri.sc.gov.br
}

\begin{abstract}
RESUMO: O objetivo do trabalho foi avaliar o efeito do uso de biofertilizante elaborado com resíduos marinhos na produção de mudas de rúcula no sistema orgânico de cultivo. O delineamento experimental foi o inteiramente casualizado e os tratamentos distribuídos num esquema fatorial $2 \times 2 \times 2 \times 5$, sendo: com e sem o uso de Trichoderma; com e sem o uso de tela de sombreamento; duas cultivares; quatro doses de biofertilizante $(0 \%, 5 \%, 25 \%, 50 \%$ da concentração máxima) e uma de solução nutritiva em cobertura. Foi avaliada a massa fresca (MFA) e seca da parte aérea (MSA). Os dados foram submetidos a análise de variância e as médias comparadas pelo teste de Tukey $(\mathrm{p}<0,05 \%)$ e regressão polinomial. A análise de regressão indicou que não houve efeito significativo do uso de biofertilizante sobre a MFA e MSA. Contudo, a dose de 5\% de biofertilizante, quando comparada a testemunha, aumentou a produção de MFA de 319,41 para 350,40 mg muda $^{-1}$, indicando que, apesar de não ser observado efeito progressivo das doses, o uso de biofertilizante estimulou e crescimento das mudas. O uso de Trichoderma no substrato aumentou a MFA de 378,25 para 395,04 $\mathrm{mg} \mathrm{muda}^{-1}$, mas isso não refletiu em aumento da MSA. O uso de tela de sombreamento aumentou a MFA de 346,65 para 426,64 mg muda ${ }^{-1}$, contudo, houve redução da MSA com o uso da tela. Novos estudos devem ser realizados com variações da formulação do biofertilizante para obter um produto mais eficiente na produção de mudas de rúcula.
\end{abstract}

Palavras-chave: Eruca sativa, farinha de peixe, hortaliças

\section{USE OF BIOFERTILIZER WITH MARINE WASTE IN THE PRODUCTION OF ROCKET SEEDLINGS}

\begin{abstract}
The aim of the present work was to evaluate the effect of the use of biofertilizer prepared with marine residues on the production of rocket seedlings in the organic system. The experimental design was completely randomized and the treatments distributed in a $2 \times 2 \times 2 \times 5$ factorial scheme, being: with and without the use of Trichoderma; with and without the use of shading screen; two cultivars; four doses of biofertilizer $(0 \%, 5 \%, 25 \%, 50 \%$ of the maximum concentration) and a nutrient solution in coverage. Fresh mass (MFA) and shoot dry matter (MSA) were evaluated. The data were submitted to analysis of variance and the means were compared by the Tukey test $(\mathrm{p}<0.05 \%)$ and polynomial regression. Regression analysis indicated that there was no significant effect of the use of biofertilizer on MFA and MSA. However, the 5\% biofertilizer dose, when compared to the control, increased MFA production from 319.41 to $350.40 \mathrm{mg}$ seedling ${ }^{-1}$, indicating that although no progressive dose effect was observed, the use of biofertilizer stimulated and seedling growth. The use of Trichoderma in the substrate increased the MFA from 378.25 to $395.04 \mathrm{mg}$ seedling $^{-1}$, but this did not reflect an increase in MSA. The use of shade mesh increased the MFA from 346.65 to $426.64 \mathrm{mg}$ seedlings ${ }^{-1}$, however, there was reduction of the MSA with the use of the screen. Further studies should be carried out with variations of the formulation of the biofertilizer to obtain a more efficient product in the production of rocket seedlings.
\end{abstract}

Keywords: Eruca sativa, fish flour, greenery.

\section{INTRODUÇÃO}

Biofertilizantes são fermentações oriundas de digestão aeróbica ou anaeróbica de materiais orgânicos de origem animal ou vegetal em meio líquido, contendo nutrientes, estimulantes e alta comunidade microbiana capazes de promover o desenvolvimento das plantas e auxiliar na sua proteção a fitopatógenos (BETTIOL, 2003). A composição química do biofertilizante varia conforme o método de preparo e o material utilizado. O controle de doenças pode ser por meio dos metabólitos produzidos pelos microrganismos presentes no 
biofertilizante ou pela ação direta destes microrganismos sobre o patógeno ou sobre o hospedeiro. Ainda existe a ação direta ou indireta dos nutrientes presentes no biofertilizante sobre os fitopatógenos (BETTIOL \& GHINI, 2004).

No litoral norte de Santa Catarina há uma intensa atividade da indústria pesqueira, que gera resíduos com potencial de danos ambientais se dispensados incorretamente. O aproveitamento de resíduos da agroindústria pesqueira para o preparo de biofertilizantes pode ser uma estratégia interessante de uso para esses resíduos. A Epagri, Estação Experimental de Itajaí, tem desenvolvido trabalhos com o uso de biofertilizantes formulados com casca de camarão ou farinha de peixe. Esses resíduos possuem a capacidade de estimular o processo de fermentação de comunidades microbianas com atividade quitinolítica, que podem ser favoráveis para o controle de fitopatógenos habitantes do solo (VISCONTI et al., 2017). Contudo, o potencial de uso é pouco conhecido, devendo-se estudar a viabilidade de utilização do mesmo na agricultura. Sendo assim, o objetivo do presente trabalho foi o de avaliar o efeito do uso de biofertilizante elaborado com farinha de peixe na produção de duas cultivares de rúcula, submetidas ou não ao sombreamento, com e sem o uso de Trichoderma no substrato, no sistema orgânico de cultivo.

\section{MATERIAL E MÉTODOS}

O experimento foi conduzido na Estação Experimental da Epagri de Itajaí-SC, sob casa de vegetação, entre os meses de setembro e outubro de 2018. A formulação para 100 litros de Biofertilizante foi: 94 litros de água, $1 \mathrm{~kg}$ de farinha de peixe, $1 \mathrm{~kg}$ de esterco ou composto, $2 \mathrm{~kg}$ de farelo de arroz, $1 \mathrm{~kg}$ de farelo de mamona, $0,5 \mathrm{~kg}$ de açúcar e $0,5 \mathrm{~kg}$ de amido de mandioca. Como optou-se por um biofertilizante aeróbico, foi feita a indução de ar por meio de um compressor radial a cada 15 minutos durante oito dias, período o qual o biofertilizante foi considerado pronto.

O delineamento experimental foi o inteiramente casualizado, com três repetições de 20 mudas cada. A semeadura foi realizada com seis sementes por célula, em bandejas de polipropileno de 200 células, preenchidas com substrato comercial Maxfertil e empilhadas até a emergência. Os tratamentos foram distribuídos em um arranjo fatorial $2 \times 2 \times 2 \times 5$, sendo: com e sem uso de Trichoderma (1,3 g por bandeja); com e sem o uso de tela de sombreamento (ráfia preta a 50\%); duas cultivares (cv1 e cv2 - os nomes serão guardados em sigilo para evitar problemas de conflito de interesse); e cinco doses, sendo quatro doses de biofertilizante $(0 \%, 5 \%, 25 \%, 50 \%$ da concentração máxima) e uma adubação com solução nutritiva em cobertura. As aplicações em cobertura de biofertilizante e solução nutritiva ocorreram aos 7 e 12 dias após a semeadura. A solução nutritiva foi elaborada conforme Furlani et al. (1999), modificada para ferro (60 mg L-1 de FeEDDHA$6 \%$ ), a $25 \%$ de força.

As avaliações das mudas foram realizadas quando 3/4 das mudas apresentavam quatro folhas definitivas e prontas para o transplantio para o campo, que foi aos 15 dias após a semeadura. Foi avaliada a massa fresca da parte aérea (MFA) e a massa seca da parte aérea (MSA) das mudas. Para a MFA foi pesada a parte aérea de todas as mudas da repetição, removidas da bandeja cortando com uma tesoura. As folhas foram levadas para uma estufa de secagem com ar forçado (aproximadamente $65^{\circ} \mathrm{C}$ ), por 72 horas. Após esse período foi aferida a massa vegetal com balança de precisão, obtendo-se a MSA.

Os dados foram submetidos a análise de variância e, quando significativas, as médias comparadas pelo teste de Tukey $(\mathrm{p}<0,05 \%)$. Os valores referentes as doses de biofertilizante foram submetidos a análise de regressão polinomial, buscando-se o melhor ajuste $(\mathrm{p}<0,05)$.

\section{RESULTADOS E DISCUSSÃO}

Não houve interações significativas entre os quatro fatores analisados. Analisando cada fator isoladamente, o único que não apresentou diferenças significativas foi a comparação entre cultivares, tanto para MFA, como para MSA.

A análise de regressão indicou que não houve efeito significativo do uso de biofertilizante sobre a MFA $\left(\mathrm{R}^{2}=54,27 \%\right)$ e MSA $\left(\mathrm{R}^{2}=43,05 \%\right)$ na produção de mudas de rúcula. Contudo, a dose de $5 \%$ de biofertilizante quando comparada a testemunha, aumentou a produção de MFA de 319,41 para 350,40 mg muda ${ }^{-1}$, indicando que, apesar de não ser observado efeito progressivo das doses, o uso de biofertilizante estimulou e crescimento vegetativo das mudas. Esses resultados podem estar relacionados a comunidade microbiana presente no biofertilizante, que agrega benefícios para as plantas a partir do momento que estão presentes, mas o aumento em quantidade desses microrganismos por meio do aumento de doses não resulta em aumento proporcional dos seus benefícios. Apesar de refletir em aumento da MFA, as mudas produzidas com biofertilizante ficaram 
menores do que o observado quando utilizada a solução nutritiva (SN), que produziu MFA de 490,44 mg muda-

${ }^{1}$ nas mesmas condições de cultivo. Apesar de ser observado aumento da MFA com o uso de biofertilizante na dose de 5\%, esse aumento não refletiu em aumento da MSA, não diferindo da testemunha e ambos foram inferiores ao observado com o uso de solução nutritiva (Tabela 1).

Semelhante ao observado com o uso do biofertilizante, o uso de Trichoderma no substrato aumentou a MFA de 378,25 para 395,04 $\mathrm{mg} \mathrm{muda}^{-1}$, mas isso não refletiu em aumento da MSA (Tabela 1). O uso de tela de sombreamento aumentou a MFA de 346,65 para 426,64 mg muda ${ }^{-1}$, contudo, houve redução da MSA com o uso da tela, que foi de 111,51 para 97,94 $\mathrm{mg} \mathrm{muda}^{-1}$. Esses resultados ocorreram devido a um possível estiolamento das plantas provocado pela tela de sombreamento, que favoreceu o alongamento celular e diminuiu o acúmulo de massa seca. Em casos como esse, onde ocorre o estiolamento foliar e redução da massa seca, há aumento da suscetibilidade as doenças classificadas como "damping off", como é o caso de Phytium spp., Fusarium e Rhizoctonia (Lopes et al., 2005).

\section{CONSIDERAÇÕES FINAIS}

Novos estudos devem ser realizados com variações da formulação do biofertilizante, para obter um produto eficiente para produção de mudas de rúcula. Devido à ausência de interação entre as doses de biofertilizante e fatores como sombreamento e cultivares, deve-se focar nos próximos estudos em testar diferentes formulações de biofertilizantes a fim de encontrar o mais eficiente para a produção de mudas de rúcula.

\section{AGRADECIMENTOS \\ À Fundação de Amparo à Pesquisa e Inovação de Santa Catarina - FAPESC.}

\section{REFERÊNCIAS}

BETTIOL, W. Controle de doenças de plantas com agentes de controle biológico e outras tecnologias alternativas. In: CAMPANHOLA, C.; BETTIOL, W. (Eds). Métodos alternativos de controle fitossanitário. Jaguariúna, SP: Embrapa Meio Ambiente, 2003. p.191-215.

BETTIOL, W.; GHINI, R. Métodos alternativos usados com sucesso no Brasil para o controle de doenças de plantas. In: STADNICK, M.J.; TALAMINI, V. (Ed.). Manejo ecológico de doenças de plantas. Florianópolis: CCA/UFSC, 2004. p.143- 157.

FURLANI, P.R.; SILVEIRA, L.C.P.; BOLONHESI, D.; FAQUIN, V. Cultivo hidropônico de plantas. Campinas: IAC. 52p (Boletim Técnico 180), 1999.

LOPES, C.A.; REIS, A.; MAKISHIMA, N. Como prevenir o "tombamento" em mudas de hortaliças. Comunicado Técnico, 28. Brasília, 2005. (Embrapa Hortaliças).

VISCONTI, A.; ZAMBONIM, F.M.; MARIGUELE. K.H. LONE, A.B. Métodos alternativos para o controle de fitopatógenos habitantes do solo: Parte II - controle biológico. Agropecuária Catarinense, Florianópolis, v.30, n.3, p.33-36, set./dez. 2017. 
Tabela 1. Massa fresca da parte aérea (MFA) e massa seca da parte aérea (MSA) de mudas de rúcula (Eruca sativa) adubadas com biofertilizante com farinha de peixe a 5\% e solução nutritiva, com e sem o uso de Trichoderma no substrato e com e sem o uso de telas de cobertura.

Massa Fresca da Parte Aérea (mg muda $\left.{ }^{-1}\right)$

Massa Seca da Parte Aérea (mg muda $\left.{ }^{-1}\right)$

\begin{tabular}{ccc}
\hline & Tratamento em cobertura & \\
Testemunha (Água) & $319,41 \mathrm{c}$ & $98,30 \mathrm{~b}$ \\
Biofert a 5\% & $350,40 \mathrm{~b}$ & $102,28 \mathrm{~b}$ \\
Solução Nutritiva & $490,44 \mathrm{a}$ & $113,59 \mathrm{a}$ \\
\hline & Uso de Trichoderma no substrato & $104,38 \mathrm{a}$ \\
Não & $378,25 \mathrm{~b}$ & $105,07 \mathrm{a}$ \\
Sim & $395,05 \mathrm{a}$ & \\
& Uso de telas de sombreamento & $111,51 \mathrm{a}$ \\
Não & $346,66 \mathrm{~b}$ & $97,94 \mathrm{~b}$ \\
\hline Sim & $426,64 \mathrm{a}$ &
\end{tabular}

Médias seguidas pela mesma letra na minúscula na coluna não diferem entre si pelo teste de Tukey $(\mathrm{P}<0,05)$. 


\title{
VALOR AGRONÔMICO DO COMPOSTO DE RESÍDUOS DA AGROINDÚTRIA FRIGORÍFICA EM CULTIVOS SUCESSIVOS DE ALFACE
}

\author{
Cantú, R.R.*1; Schallenberger, E. ${ }^{\text {; }}$ Morales, R.G.F. ${ }^{\text {; }}$ Visconti, A. ${ }^{\text {; }}$ Squerzzato, N. ${ }^{2}$; Misfeld, \\ A.G. 2 \\ ${ }^{1}$ Pesquisadores da Epagri, Itajaí, SC - Brasil \\ ${ }^{2}$ Engenheiros da Pamplona Alimentos S/A, Rio do Sul, SC - Brasil \\ rrcantu@epagri.sc.gov.br
}

\begin{abstract}
RESUMO: Santa Catarina possui diversas agroindústrias com uma elevada importância socioeconômica. Apesar disso, os setores geram elevados volumes de resíduos, que podem ocasionar sérios problemas ambientais. Assim, é fundamental estudos para a transformação dos resíduos em fertilizantes e para seu uso em cultivos agrícolas. Em 2017 foi iniciado um projeto de compostagem de resíduos dos frigoríficos da Região do Vale do Itajaí SC. A unidade de compostagem transforma um volume de aproximadamente $350 \mathrm{Mg}$ mês ${ }^{-1}$ desses resíduos, em composto orgânico (CF). Embora essa compostagem venha sendo realizada com sucesso e o fertilizante produzido apresente características de fertilidade promissoras, não há estudos sobre o valor agronômico do CF. Assim, o objetivo do trabalho foi avaliar o valor agronômico como fertilizante do CF por meio das produções de matéria verde (MV) e seca (MS) da alface. O Experimento foi realizado em 2018 na Epagri de Itajaí - SC, conduzido em vasos de dentro de casa de vegetação, utilizando quatro doses do CF por vaso: T1-0g; T2-500g; T3-1000g e 1500g. Em cada vaso foi plantado uma muda de alface, sendo realizado três cultivos sucessivos somente com a adubação inicial. O CF proporcionou incrementos na produção da alface acima de $400 \mathrm{~g}$ planta $^{-1}$ de e promoveu efeito residual nos cultivos sucessivos de maneira crescente conforme o aumento da dose. É possível concluir que o CF possui um importante valor agronômico, com potencial de uso em alface, pois incrementa a produção, permitindo o cultivo com uso exclusivo do fertilizante, aplicado em dose única na implantação da lavoura.
\end{abstract}

Palavras-chave: compostagem automatizada, resíduos de frigorífico, hortaliças

\section{AGRONOMIC VALUE OF AGRIBUSINESS WASTE COMPOST IN SUCCESSIVE LETUCCE CROPS}

\begin{abstract}
Santa Catarina has several agroindustries with a high socioeconomic importance. Despite this, the sectors generate high volumes of waste, which can cause serious environmental problems. Thus, studies on the transformation of waste into fertilizers and their use in agricultural crops are fundamental. In 2017, a waste composting project was started for the refrigerators in the Vale do Itajaí SC Region. The composting unit transforms a volume of approximately $350 \mathrm{Mg}$ month $^{-1}$ of these residues into organic compost (CF). Although this composting has been successfully performed and the fertilizer produced has promising fertility characteristics, there are no studies on the agronomic value of CF. Thus, the objective of this work was to evaluate the agronomic value as CF fertilizer through lettuce green matter (MV) and dry matter (DM) production. The experiment was carried out in 2018 in Epagri de Itajaí - SC, conducted in pots from within greenhouse, using four doses of FC per vessel: T1-0g; T2-500g; T3-1000g and 1500g. In each vase was planted a seedling of lettuce, being carried out three successive crops only with the initial fertilization. CF provided increases in lettuce yield above $400 \mathrm{~g}$ plant-1 of and promoted a residual effect on successive crops incrementally as the dose increased. It is possible to conclude that CF has an important agronomic value, with potential of use in lettuce, since it increases the production, allowing the cultivation with exclusive use of the fertilizer, applied in a single dose in the implantation of the crop.
\end{abstract}

Keywords: automated composting, slaughterhouse waste, vegetables crops

\section{INTRODUÇÃO}

Os setores agropecuário e agroindustrial de Santa Catarina (SC) possuem elevada importância socioeconômica, sendo responsável por aproximadamente 60\% das exportações do Estado e envolvendo mais de 400 mil famílias. Apesar da relevância, os setores geram elevados volumes de resíduos, que quando não 
tratados, podem ocasionar sérios problemas ambientais. Esses materiais podem ser transformados em fertilizantes de elevada qualidade para cultivos como os de hortaliças, que possuem grande relevância para a agricultura de SC (Cantú et al. 2016; Santos et al. 2016).

Somente dois frigoríficos localizados no Alto Vale do Itajaí -SC, geram um volume em torno de 350 $\mathrm{Mg} \mathrm{mês}^{-1}$. Esses materiais eram destinados a aterros sanitários e aplicados áreas de pastagens e reflorestamento, após estabilização em sistemas de decantação a céu aberto. Considerando os custos de destino desses resíduos e a preocupação com sustentabilidade ambiental, foi firmado no ano de 2017 uma parceria entre a Epagri e os frigoríficos, para viabilizar o tratamento dos materiais por meio da compostagem automatizada. Em novembro de 2017 a usina localizada no município de Pouso Redondo, começou a transformar eficientemente os aproximadamente $350 \mathrm{Mg}$ mês ${ }^{-1}$ de resíduos em fertilizante orgânico seguros de acordo com as resoluções do MAPA / IN SDA no 72016.

Embora esta compostagem venha sendo realizada com sucesso e o fertilizante produzido apresente características químicas de fertilidade promissoras, não há estudos sobre o valor agronômico do composto final. A região de produção do composto se caracteriza pela forte produção e consumo de hortaliças, que demanda elevados volumes de fertilizantes orgânicos, (Santos et al. 2016).

Considerando os aspectos aqui abordados, o objetivo do trabalho foi realizar um experimento com aplicação de doses do composto de resíduos de frigorífico, para avaliar o valor agronômico do fertilizante, por meio da sua contribuição no crescimento da alface em cultivos sucessivos.

\section{MATERIAL E MÉTODOS}

O composto foi desenvolvido na unidade de compostagem automatizada Lauro Pamplona localizada no município de Trombudo Central - SC, localidade de Pouso da Caixa, no período de 30 de outubro de 2017 a 30 de janeiro de 2018. Os resíduos foram provenientes dos frigoríficos, localizados em Rio do Sul e Presidente Getúlio, das criações de suínos de granjas localizadas em Ituporanga e Rio do Sul e da fábrica de rações localizada em Agronômica.

Os resíduos foram distribuídos e misturados com caminhões e trator com concha, em compartimentos (duas paredes paralelas de alvenaria) de 1,5 m de altura por 4,0 m de largura e $95 \mathrm{~m}$ de comprimento. A leira de compostagem (mistura de materiais) foi montada de uma extremidade à outra, avançando $25 \mathrm{~m}$ por semana, sendo que em 25 dias ocupava todo o compartimento. A leira era continuadamente revolvida desde seu início por uma máquina autopropulsionada que revolve a mistura com helicoides, se deslocando sobre a pilha da compostagem.

Após três meses do início da compostagem, o material foi retirado do compartimento automatizado e depositado em um outro compartimento para depósito, sem revolvimento e após dois meses, o composto foi considerado pronto. A tomada de decisão para finalização do processo foi devido às características do composto relacionadas a relação $\mathrm{C} / \mathrm{N}$, abaixo de 15 (Tabela 1), além da temperatura do fertilizante estar próxima à do ambiente, que indicam a estabilidade do material.

O experimento de avaliação do composto foi realizado na Estação Experimental da Epagri de Itajaí, na área de estudos de cultivo em hortaliças, em casa de vegetação, no município de Itajaí - SC. O experimento foi realizado com o cultivo da alface, em vasos de oito litros de solo onde o composto de resíduos de frigorífico (CF) foi misturado. O experimento teve 4 tratamentos de doses de composto, sendo: T1 - 0g de CF por vaso; T2 - 500g de CF por vaso; T3 -1000g de CF por vaso; T4 - 1500g de CF por vaso. As referidas doses, T1, T2, T3 e T4, considerando o volume de solo explorado pela alface e a densidade do plantio, estão próximas a 0; 30; 60 e 90Mg ha-1 do composto (base úmida).

As doses do composto foram estabelecidas considerando suas características químicas, tomando como base trabalhos já publicados onde foram estudados outros compostos (Bernal et al. 2009; Cantú et al. 2017) e a recomendação da CQFS- RS/SC (2016) para o cultivo em questão.

Cada tratamento teve 10 repetições, que foram constituídas por um vaso, com uma planta de alface em cada vaso, conduzido em delineamento inteiramente casualizado. Foram realizados três cultivos sucessivos da alface nos vasos, com adição dos fertilizantes somente no início, para verificar o efeito residual dos compostos. O primeiro cultivo da alface foi conduzido de 02/04/2018 a 17/05/2018, o segundo de 20/05/2018 a 09/07/2018 e o terceiro, de 11/07/2018 a 28/08/2018. A irrigação foi realizada manualmente, procurando manter a umidade próximo a capacidade de campo.

Ao final de cada cultivo, as plantas foram coletadas e pesadas para determinar a matéria verde (MV) e após, colocadas em estufa a $60^{\circ} \mathrm{C}$, até atingir peso constante, sendo posteriormente pesadas para determinar a 
massa seca (MS). Os resultados foram submetidos a análise de regressão com auxílio do programa computacional Sigma plot.

\section{RESULTADOS E DISCUSSÃO}

A Figura 1 demostra, de maneira geral, que o composto de resíduos de frigorífico incrementa a produção de MV e MS da alface, quando comparado a testemunha (T1) que não recebeu o fertilizante. Esse aspecto, indica que não houve imobilização dos nutrientes quando o composto foi misturado ao solo, conforme abordado por Bernal et al. (2009). Com isso, é possível inferir que o composto pode ser considerado estabilizado ou maturo, provavelmente por possuir uma relação $\mathrm{C} / \mathrm{N}$ abaixo de 15 , indicando uma decomposição satisfatória durante o processo de compostagem, conforme discutido por outros autores (Bernal et al. 2009; Cantú et al. 2017).

Observando as Figuras 1A, é possível verificar que a dose calculada pelas equações geradas, para atingir as máximas produtividade de MV e MS da alface foi próximo a $790 \mathrm{~g}$ vaso $^{-1}$ de composto. $\mathrm{O}$ efeito das doses no primeiro cultivo proporcionou resultados de produção que seguiram uma tendência polinomial. Resultados com a mesma tendência foram obtidos por (Nunes et al., 2017), com composto de estercos e bagaço de cana. A dose que propiciou a melhor produção está entre T2 e T3, sendo que a MV e MS decai tanto para T1 quanto T4. Esse indica que as quantidades do composto utilizadas nos tratamentos estavam adequadas, visando obter a dose para a melhor produção.

O aspecto das maiores doses (T3 e T4) ocasionarem o declínio na produção no primeiro cultivo, significa menor eficiência do fertilizante, aumento de custos, desperdício de nutrientes e possíveis problemas ambientais, conforme verificado por Cantú et al. (2017). Esse declínio, pode ser atribuído a desequilíbrios e excesso de nutrientes induzidos pelas maiores doses, bem como pela possível salinização do solo, entre outros aspectos nocivos aos cultivos ocasionados pelo excesso de fertilizantes orgânicos (Cantú et al., 2017; Nunes et al., 2017).

No segundo cultivo (Figuras 1B), realizado sob o efeito residual da adubação do primeiro cultivo, é possível observar um aumento da produção linearmente relacionada com a elevação das doses. Esse aspecto, deve estar relacionado com o esgotamento na disponibilidade dos nutrientes (Bernal et al., 2009) observado especialmente na menor dose (T2), que ocasionou uma drástica redução nas produções de MV e MS, estando próximo aos valores obtidos com a testemunha (T1).

As produções de MS e MV do terceiro cultivo (Figuras 1C), sob o efeito residual da adubação seguiu uma tendência exponencial, foram próximas entre os tratamentos T1, T2 e T3, indicando o esgotamento de nutrientes aportado por essas doses para três cultivos. Por outro lado, os valores de MV e MS proporcionados pela maior dose (T4) manteve a produção elevada, estando próxima aos cultivos anteriores, indicando um elevado efeito residual.

Considerando os resultados obtidos, é possível inferir que nas condições de solo com baixa fertilidade como o utilizado no presente experimento, a aplicações do composto em dose única no início do cultivo da alface é o suficiente para se obter produções satisfatórias. Contudo, é importante utilizar doses menores, conforme àquela verificada no primeiro cultivo e reaplicar novamente nos cultivos sucessivos, visando manter a produção elevada sem comprometimentos com falta ou excesso de nutrientes. Embora os resultados tenham demonstrado que o composto, possui potencial para promover o crescimento da hortaliça deixando um efeito residual significativo, outros estudos a campo e com outros cultivos devem ser realizados, buscando adequar as recomendações do fertilizante.

\section{CONCLUSÃO}

O composto de resíduos da indústria frigorífica apresenta um importante valor agronômico, com potencial de uso em alface, pois incrementa a produção, permitindo o cultivo com uso exclusivo do fertilizante, aplicado em dose única na implantação da lavoura. Além disso, possui um significativo efeito residual para os próximos cultivos.

\section{REFERÊNCIAS}

BERNAL, M.P.; ALBURQUERQUE, J.A.; MORAL, R. Composting of animal manures and chemical criteria for compost maturity assessment. A review. Bioresource Technology, v.100, p.5444-5453. 2009.

CANTU, R.R. et al Dinamica da temperatura na compostagem de residuos da industria do palmito, Revista Brasileira de Agroecologia, v 11, n.2. 2016. 


\section{VISIGERA DE 07 A09 MA10 2019

CANTÚ, R.R; AITA, C; DONEDA, A, GIACOMINI, D.A; DESSBESELL, A; ARENHARDT, M; BASTIANI, G.G; PUJOL, S.B; ROCHETE, F; CHANTIGNY, M.H; GIACOMINI, S. Alternatives to regular urea for abating $\mathrm{N}$ losses in lettuce production under sub-tropical climate. Biology and Fertility of Soils. V. 53: 589-599. 2017.

NUNES, K.N; COSTA, R.N.T; CAVALCANTE, J.A.H; ARAÚJO, D.F. Comportamento da alface-americana sob diferentes doses de composto orgânico e lâminas de irrigação Irriga, Botucatu, v. 22, n. 1, p. 167-176, 2017.

SANTOS, A.A.; FELICIANO, A.M.; PADRAO, G.A. In: Feliciano, A.M. (Coord.). Números da Agropecuaria Catarinense. Florianopolis: Epagri/Cepa, 2016. 69 p.

Tabela 1. Principais características do solo e composto utilizado no experimento de doses.

\begin{tabular}{|c|c|c|c|c|c|c|}
\hline Material & pH & $\mathbf{P}$ & $\mathbf{K}$ & $\mathbf{N}$ & MO & Relação C/N \\
\hline & & ..................... & $\mathrm{dm}^{-3}$ & ............. & $\%$ & \\
\hline Composto CF* & 6 & 1720 & 790 & 2620 & - & 14 \\
\hline Solo & 5 & 90 & 40 & - & 2,2 & - \\
\hline
\end{tabular}

*Composto de resíduos de frigorífico.
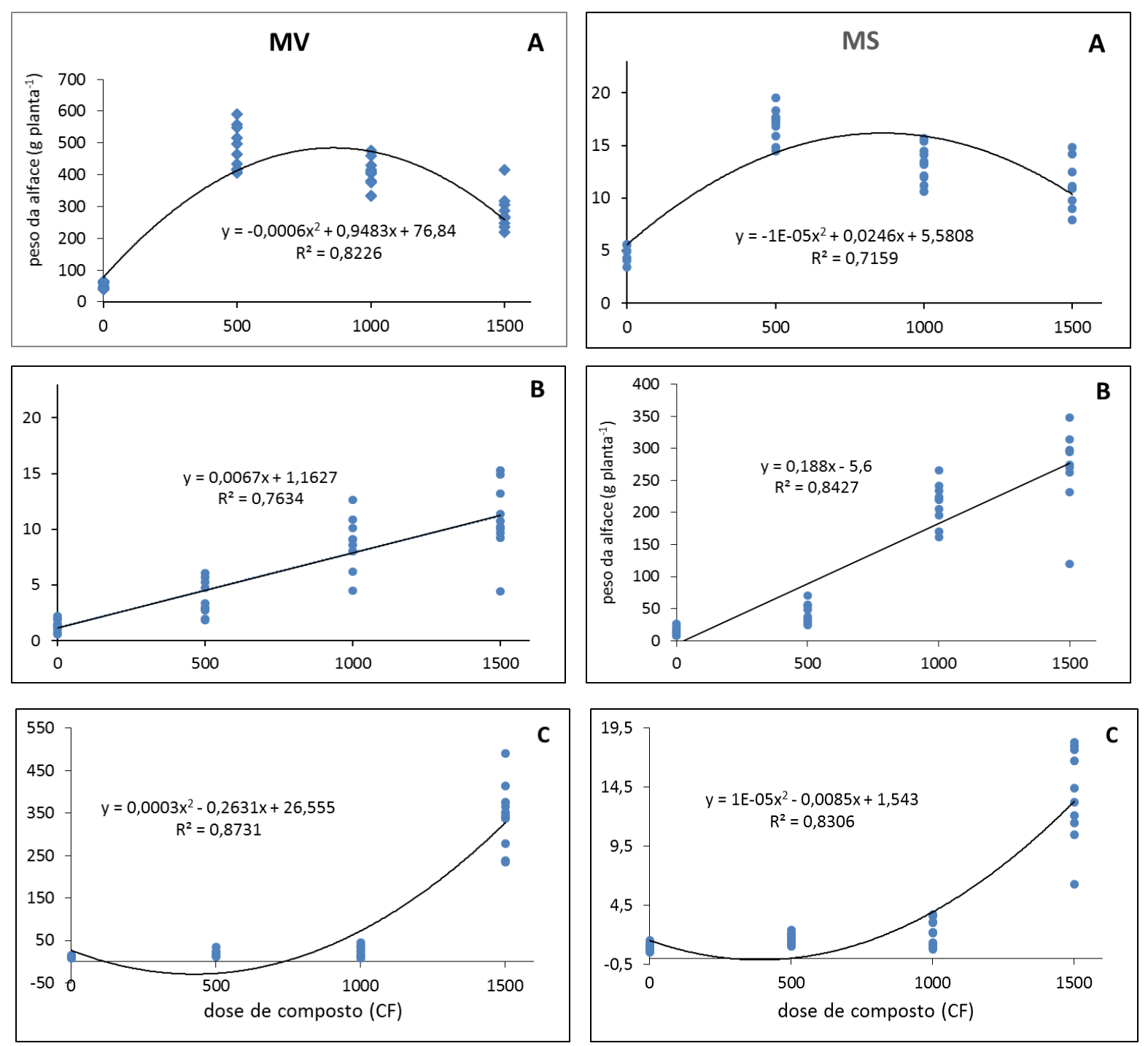

Figura 1. Produção de matéria verde (MV) e matéria seca (MS) durante três cultivos (A - $1^{\circ}$ cultivo; B - 2oㅡㅁ cultivo; C - 3o cultivo) sucessivos da alface submetidas a quatro doses de composto orgânico (CF), produzido a base de resíduos da indústria frigorífico. 


\title{
A ADUBAÇÃo ORGÂNICA É VIÁVEL PARA REDUZIR AS EMISSÕES DE N2O?
}

\author{
Orrico Junior, M.A.P.*1; Reis, S.D.S. ${ }^{1}$; Cardoso, A.S. ${ }^{2}$; Orrico, A.C.A. ${ }^{1}$; Cunha, S.S. ${ }^{1}$ \\ ${ }^{1}$ Pesquisadores da Universidade Federal da Grande Dourados, Dourados, MS - Brasil, marcoorrico@yahoo.com.br \\ ${ }^{2}$ Pesquisador da Universidade Estadual Paulista, Jaboticabal, SP-Brasil
}

\begin{abstract}
RESUMO: As adubações nitrogenadas, as condições do solo e clima afetam diretamente as emissões $\mathrm{N}_{2} \mathrm{O}$ pelo solo. Diante disso, o objetivo deste estudo foi avaliar o efeito de diferentes fontes de fertilizantes (ureia, composto orgânico e biofertilizante) sobre a emissão de óxido nitroso $\left(\mathrm{N}_{2} \mathrm{O}\right)$ de solo cultivado com capim Piatã. Quatro tratamentos foram avaliados (urea, composto orgânico, biofertilizante e controle) em um delineamento blocos o acaso com seis repetições, durante as quatro estações do ano. A emissão de $\mathrm{N}_{2} \mathrm{O}$ foi avaliada utilizando a metodologia de câmaras estáticas com determinação da concentração de $\mathrm{N}_{2} \mathrm{O}$ por cromatografia gasosa. Foram calculados os fluxos diários, produção acumulada e o fator de emissão. $\mathrm{O}$ fluxo médio do tratamento sem adição de $\mathrm{N}$ foi de $0,1 \mathrm{mg} \mathrm{N}-\mathrm{N}_{2} \mathrm{O} \mathrm{m}$ mia $^{-1}$ que aumentou para $0,33,0,61$ e 1,39 $\mathrm{mg}$ $\mathrm{N}-\mathrm{N}_{2} \mathrm{O} \mathrm{m}^{-2}$ dia $^{-1}$ para os tratamentos composto, ureia e biofertilizante, respectivamente. Os maiores fluxos $(\mathrm{P}$ $<0,05)$ de $\mathrm{N}_{2} \mathrm{O}$ foram observados durante o outono e inverno. Os fatores de emissão de $\mathrm{N}_{2} \mathrm{O}$ diferiram $(\mathrm{P}<$ $0,05)$ entre tratamento, sendo $1,16,0,46$ e $0,20 \%$ para biofertilizante, ureia e composto respectivamente. As emissões de $\mathrm{N}_{2} \mathrm{O}$ foram maiores para as fontes líquidas (biofertilizante) do que sólidas (composto) tendo o fertilizante sintético apresentado emissão intermediária, desta forma a utilização de composto apresenta-se como uma alternativa para mitigação da emissão de $\mathrm{N}_{2} \mathrm{O}$.
\end{abstract}

Palavras-chave: Brachiaria brizantha, gases de efeito estufa, meio ambiente.

\section{IS THE ORGANIC FERTILIZATION VIABLE TO REDUCE $\mathrm{N}_{2} \mathrm{O}$ EMISSIONS?}

\begin{abstract}
Nitrogen fertilizations, soil and climate conditions affect $\mathrm{N}_{2} \mathrm{O}$ emissions by soil. Therefore, the aim this study was to evaluate the effect of different sources of fertilizer (urea, organic compost and biofertilizer) on the emission of nitrous oxide $\left(\mathrm{N}_{2} \mathrm{O}\right)$ from soil cultivated with Piatã grass. Four treatments were evaluated (urea, organic compost, biofertilizer and control) in a randomized block design with six repetition, during the four seasons of the year. The emission of $\mathrm{N}_{2} \mathrm{O}$ was evaluated using the static chamber methodology, with determination of $\mathrm{N}_{2} \mathrm{O}$ concentration by gas chromatography. The daily emission, accumulated production and the emission factor were calculated. The mean emission of control was $0.1 \mathrm{mg} \mathrm{N}-\mathrm{N}_{2} \mathrm{O} \mathrm{m}^{-2}$ day ${ }^{-1}$ which increased to $0.33,0.61$ and $1.39 \mathrm{mg} \mathrm{N}^{-\mathrm{N}_{2}} \mathrm{O} \mathrm{m}^{-2}$ day $^{-1}$ for organic compost, urea and biofertilizer, respectively. The highest emission $(\mathrm{P}<0.05)$ of $\mathrm{N}_{2} \mathrm{O}$ were observed during autumn and winter. The $\mathrm{N}_{2} \mathrm{O}$ emission factors differed $(\mathrm{P}<0.05)$ between treatment, being 12, 5 and $2 \mathrm{~kg} \mathrm{ton}^{-1}$ for biofertilizer, urea and compost respectively. The $\mathrm{N}_{2} \mathrm{O}$ emissions were higher for liquid (biofertilizer) than solid (compost) fertilizer and the synthetic fertilizer presented intermediate emission, thus the use of compost is an alternative for mitigation of $\mathrm{N}_{2} \mathrm{O}$ emission.
\end{abstract}

Keywords: Brachiaria brizantha, greenhouse gases, environment.

\section{INTRODUÇÃO}

A produção de bovinos de corte no Brasil é predominantemente realizada em pastagens sendo as Brachiarias as forrageiras mais utilizadas. Embora as Brachiarias possam se desenvolver sobre condições de baixa fertilidade, a falta de reposição de nutrientes, especialmente o nitrogênio, pode levar as pastagens à degradação. Embora o nitrogênio seja essencial para a planta forrageira, seu uso pode levar a emissão do óxido nitroso $\left(\mathrm{N}_{2} \mathrm{O}\right)$ que possui potencial de aquecimento de aproximadamente 300 vezes maior do que o dióxido de carbono (IPCC, 2006). Devido ao alto potencial de aquecimento global do $\mathrm{N}_{2} \mathrm{O}$, alternativas para a mitigação deste gás em função da utilização de fertilizantes nitrogenados devem ser buscadas.

A emissão de $\mathrm{N}_{2} \mathrm{O}$ ocorre principalmente após as adubações nitrogenadas (alta disponibilidade de $\mathrm{N}$ no solo) em condições de umidade e temperatura elevadas (Cardoso et al., 2017). Assim, acreditasse que o parcelamento da adubação nitrogenada e a utilização de fontes de liberação mais lenta de nitrogênio possam auxiliar na mitigação das emissões de $\mathrm{N}_{2} \mathrm{O}$. 
Os adubos orgânicos, entre eles os compostos orgânicos (produto da compostagem) e os biofertilizantes (produto da biodigestão anaeróbia), apresentam parte nitrogênio na forma orgânica (Bowden et al., 2007), o que impede a transformação imediata deste nitrogênio em $\mathrm{N}_{2} \mathrm{O}$ quando aplicados no solo.

Diante do exposto o objetivo deste estudo foi avaliar o efeito de diferentes fontes de fertilizantes (urea, composto e biofertilizante) sobre a emissão de óxido nitroso $\left(\mathrm{N}_{2} \mathrm{O}\right)$ de solo cultivado com capim Piatã.

\section{MATERIAL E MÉTODOS}

O experimento foi conduzido em casa de vegetação da área experimental da Embrapa Agropecuária

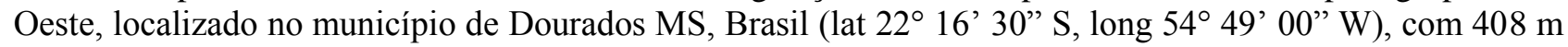
de altitude. Foi utilizado um delineamento em blocos com parcela subdividida no tempo (estações do ano), com quatro tratamentos e seis blocos, sendo eles: controle, adubação com ureia, adubação com composto e adubação com biofertilizante, totalizando 24 unidades experimentais. O capim Piatã foi submetido a uma dose de $400 \mathrm{~kg} \mathrm{~N} \cdot \mathrm{ha}^{-1}$.ano ${ }^{-1}$, parcelada em 10 aplicações de $40 \mathrm{~kg} \cdot \mathrm{ha}^{-1}$ cada uma. O composto orgânico foi proveniente de dejetos de galinhas poedeiras que foram compostados por 70 dias até alcançar a relação C:N constante (em torno de 10:1). O biofertilizante foi proveniente do processo de biodigestão anaeróbia dos dejetos de galinhas poedeiras, manejados com um tempo de retenção hidráulica de 25 dias.

A umidade dos vasos foi controlada constantemente com um sistema de irrigação, sempre mantendo a umidade em torno de $70 \%$ da capacidade de campo. No dia 6 de dezembro de 2016 foi realizada a semeadura do capim Piatã, sendo semeadas trinta sementes do capim Piatã por vaso. Sete dias após a emergência foi realizado um desbaste, deixando as nove melhores plantas de cada vaso. O corte de uniformização ocorreu 50 dias após o plantio a $20 \mathrm{~cm}$ de altura em relação ao solo (início do período experimental). Os cortes foram realizados a cada 35 dias, sendo o capim cortado na altura de $20 \mathrm{~cm}$ em relação ao solo. Após cada corte uma nova adubação era realizada e um novo ciclo de coleta de dados era iniciado. Foram realizados 10 cortes entre os meses de fevereiro de 2017 a fevereiro de 2018.

Os fluxos de $\mathrm{N}_{2} \mathrm{O}$ foram medidos utilizando a técnica de câmara fechada, composta por uma câmara estática circular opaca, com volume de 32,2 L. Uma canaleta foi fixada no vaso, com encaixe para a câmara sobre o vaso, fazendo um sistema fechado, vedado com água na canaleta. As emissões de foram monitoradas $\operatorname{nos} 1^{\circ}, 2^{\circ}, 3^{\circ}, 5^{\circ}, 8^{\circ}, 11^{\circ}, 15^{\circ}, 22^{\circ}, 28^{\circ}$ dia após aplicação da adubação. Quando as emissões continuaram maior que a testemunha após os $28^{\circ}$ dias, as avaliações eram monitoradas por mais 7 dias até que o novo corte fosse realizado (Alves et al., 2012).

As análises para determinar a concentração de $\mathrm{N}_{2} \mathrm{O}$ foram feitas logo após a coleta em cromatógrafo de gás equipado com coluna empacotada de Porapak Q e N e detectores de condução elétrica (ECD) de ionização de chama (FID), com injeção automática. Com a emissão total de $\mathrm{N}_{2} \mathrm{O}$ em cada tratamento e a dose de $\mathrm{N}$ aplicada, foi calculado o fator de emissão de $\mathrm{N}-\mathrm{N}_{2} \mathrm{O}\left(\mathrm{kg} \mathrm{de}_{2} \mathrm{O}\right.$ ton $^{-1}$ de $\mathrm{N}$ aplicado).

Os dados foram submetidos a análise de variância onde foi avaliado o efeito dos tratamentos principais (os tipos de adubação), dos tratamentos secundários (as estações do ano) e a interação (adubação*estação). As médias dos tratamentos foram comparadas pelo teste de Tukey a 5\% de probabilidade. A análise estatística foi realizada pelo software SAS.

\section{RESULTADOS E DISCUSSÃO}

O fluxo médio (Figura 1) do tratamento sem adição de $\mathrm{N}$ foi de $0,1 \mathrm{mg} \mathrm{N}-\mathrm{N}_{2} \mathrm{O} \mathrm{m} \mathrm{m}^{-2}$ dia $^{-1}$ que aumentou para $0,33,0,61 \mathrm{e} 1,39 \mathrm{mg} \mathrm{N}-\mathrm{N}_{2} \mathrm{O} \mathrm{m} \mathrm{m}^{-2} \mathrm{dia}^{-1}$ para os tratamentos composto, ureia e biofertilizante, respectivamente. Este resultado pode ser explicado pela forma líquida e pelos baixos teores de $\mathrm{N}$ do biofertilizante, o qual exigiu doses bem maiores (litros.ha ${ }^{-1}$ ) para atingir o mesmo equivalente de $\mathrm{N}$ dos demais tratamentos. Fertilizantes líquidos e em grande quantidade podem penetrar nas camadas mais profundas do solo e manter um ambiente anaeróbio por mais tempo, favorecendo as emissões de $\mathrm{N}_{2} \mathrm{O}$. Nicholson et al. (2017) ao comparar diferentes adubações orgânicas observaram que as emissões de $\mathrm{N}_{2} \mathrm{O}$ originárias dos fertilizantes líquidos foram superiores as emissões dos fertilizantes sólidos.

Outro fator que merece atenção é a disponibilidade de nitrogênio presentes nos adubos orgânicos. Segundo Bowden et al. (2007) o nitrogênio disponível nos compostos orgânicos pode variar de -1 a $49 \%$ do $\mathrm{N}$-total, o que impede que parte do $\mathrm{N}$ possa ser transformado em $\mathrm{N}_{2} \mathrm{O}$. Esse dado explica a eficiência apresentada pelo composto orgânico na mitigação da emissão de $\mathrm{N}_{2} \mathrm{O}$, quando comparado a adubação com uréia e biofertilizante. 
Os maiores fluxos de $\mathrm{N}_{2} \mathrm{O}$ observados durante o outono e inverno contrastam com os dados observados na literatura (Mazzetto et al., 2014), os quais mostram redução nas emissões de $\mathrm{N}_{2} \mathrm{O}$ nos períodos em que as temperaturas são menores. No entanto, deve-se ressaltar que na maioria das regiões tropicais as épocas mais frias do ano também são acompanhadas de baixa pluviosidade (invernos secos). Assim, os resultados observados por Mazzetto et al. (2014) também tiveram a associação da falta de umidade no solo o que pode ter resultado nas menores emissões observadas pelos autores.

Chen et al. (2018) trabalhando em condições controladas de umidade (irrigação em casa de vegetação) e com elevadas doses de $\mathrm{N}$ (disponível), observaram que os fluxos de $\mathrm{N}_{2} \mathrm{O}$ atingiram o pico (em todos os tratamentos testados ) quando a temperatura do solo atingiu aproximadamente $18^{\circ} \mathrm{C}$, sendo que a partir de $18^{\circ}$ $\mathrm{C}$ houve uma correlação negativa entre as emissões de $\mathrm{N}_{2} \mathrm{O}$ e a temperatura do solo. Com base neste estudo, podemos concluir que as temperaturas médias observadas durante este experimento (média de 19,3 e $17,9{ }^{\circ} \mathrm{C}$ para o outono e inverno) pouco influenciaram nas emissões de $\mathrm{N}_{2} \mathrm{O}$, sendo a forma física do fertilizante (líquido ou sólido) e o $\mathrm{N}$ disponível foram os principais fatores determinantes da emissão de $\mathrm{N}_{2} \mathrm{O}$.

Os fatores de emissão de $\mathrm{N}_{2} \mathrm{O}$ diferiram entre tratamento sendo 12,5 e $2 \mathrm{~kg}^{-1}$ de $\mathrm{N}$ aplicado, para biofertilizante, ureia e composto respectivamente. $\mathrm{O}$ fator de emissão de $\mathrm{N}_{2} \mathrm{O}$ preconizado para fertilizantes pelo (IPCC, 2006) é de $10 \mathrm{~kg}^{-1}$ ton $^{-1}$ do total de $\mathrm{N}$ aplicado. A fração de $\mathrm{N}$ perdido pela aplicação de biofertilizante foi próximo ao guia do IPCC, enquanto que as emissões para ureia foram metade do preconizado pelo guia do IPCC. $\mathrm{O}$ fator de emissão do composto orgânico ( $2 \mathrm{~kg}$ ton $^{-1}$ de $\mathrm{N}$ aplicado) foi praticamente a mesmo encontrado por Cardoso et al. (2019) com uso de composto na adubação de pastagens tropicais. No entanto, Cardoso et al. (2019) não observaram diferenças entre biofertilizantes e composto divergindo dos dados obtidos neste estudo.

\section{CONCLUSÃO}

As emissões de $\mathrm{N}_{2} \mathrm{O}$ são maiores para as fontes líquidas (biofertilizante) do que sólidas (composto) tendo o fertilizante sintético uma emissão intermediária. A utilização de composto apresenta-se como uma alternativa para a mitigação da emissão de $\mathrm{N}_{2} \mathrm{O}$.

\section{AGRADECIMENTOS}

A CAPES, CNPq e FUNDECT por financiarem direta e indiretamente o desenvolvimento desta pesquisa.

\section{REFERÊNCIAS}

Alves, B. J., Smith, K. A., Flores, R. A., Cardoso, A. S., Oliveira, W. R., Jantalia, C. P., Urquiaga, S. \& Boddey, R. M. (2012). Selection of the most suitable sampling time for static chambers for the estimation of daily mean $\mathrm{N}_{2} \mathrm{O}$ flux from soils. Soil Biology and Biochemistry, 46, 129-135.

Bowden, C., J. Spargo, and G. Evanylo. 2007. "Mineralization and N Fertilizer Equivalent Value of Composts as Assessed by Tall Fescue (Festuca arundinacea).” Compost Science \& Utilization 15(2):111-118.

Cardoso, A.S., Junqueira, J.B., Reis, R.A., Ruggieri, A.C, 2019. How do greenhouse gases vary with biofertilizer type, soil temperature, and moisture, in a tropical grassland? Pedosphere 29, A-F

Chen, H., Hou, H., Wang, X., Zhu, Y.,Qaisar, S., Wang, Y., Cai, H. (2018). The effects of aeration and irrigation regimes on soil $\mathrm{CO}_{2}$ and $\mathrm{N}_{2} \mathrm{O}$ emissions in a greenhouse tomato production system. Journal of Integrative Agriculture, 17: 449-460. doi: 10.1016/S2095-3119(17)61761-1

Intergovernmental Panel on Climate Change (IPCC)., 2006. Guidelines for national greenhouse gas inventories. Greenhouse Gas Inventory Reference Manual, 4. Intergovernmental Panel on Climate Change. Available at: http://www.ipccnggip.iges.or.jp/public/2006gl/vol4.html.

Mazzetto, A.M., Barneze, A.S., Feigl, B.J., Cerri, C.P.E., Cerri, C.C., 2016. Nitrogen fertilizer effects on $\mathrm{N}_{2} \mathrm{O}$ emission from Southwest Brazilan Amazon Pastures. Journal of Fertilizers \& Pesticides 7, 1-4.

Nicholson, F., Bhogal, A., Cardenas, L., Chadwick, D., Misselbrook, T., Rollett, A., Taylor, M., Thorman, R., \& Williams, J. (2017). Nitrogen losses to the environment following food-based digestate and compost applications to agricultural land. Environmental Pollution, 228, 504-516. 

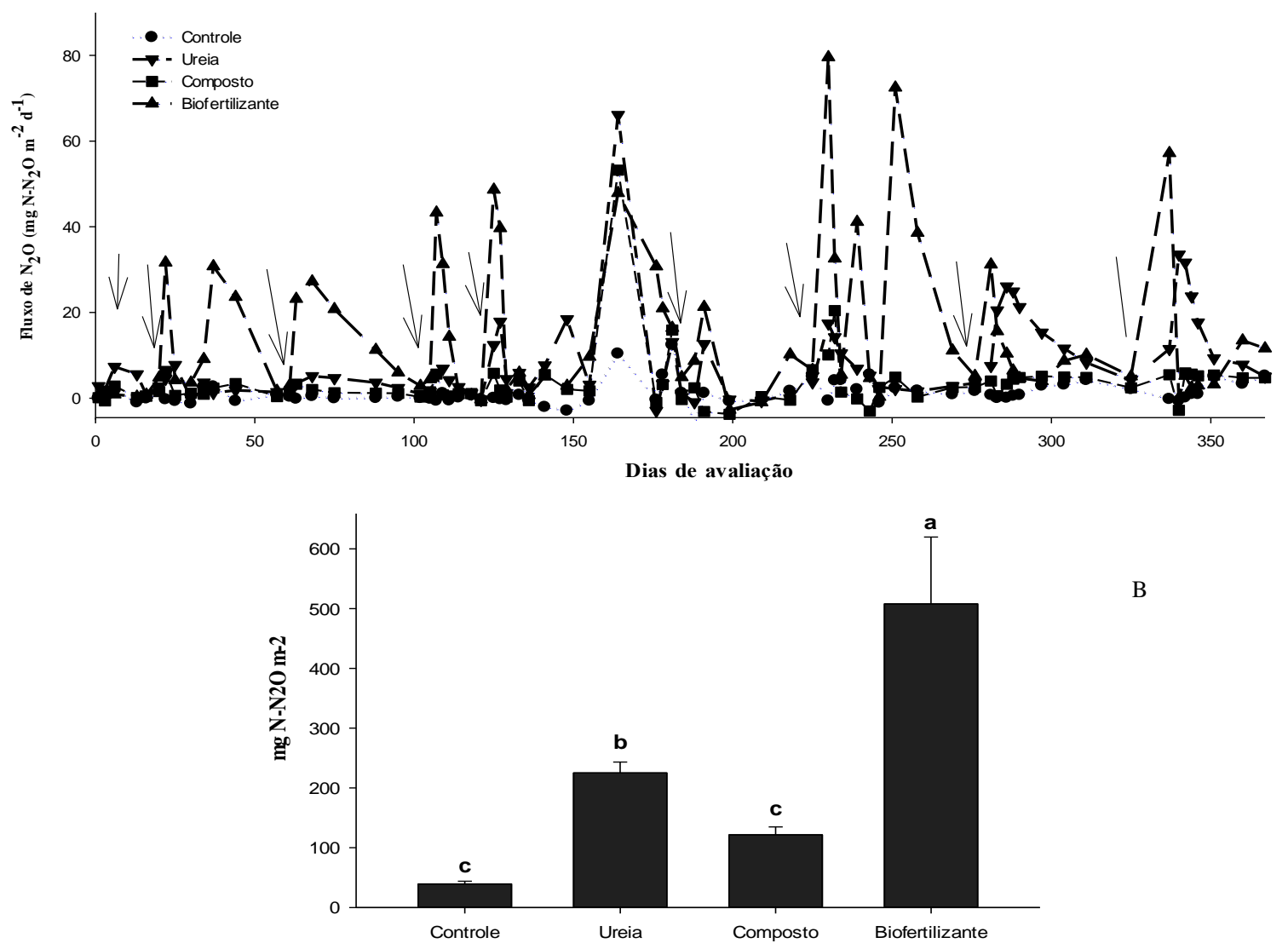

B

Figura 1. Emissões diárias de $\mathrm{N}_{2} \mathrm{O}\left(\mathrm{mg} \mathrm{N}^{-\mathrm{N}_{2}} \mathrm{O} \mathrm{m}^{-2}\right.$ dia $\left.^{-1}\right)$ (a) e emissões acumuladas de $\mathrm{N}_{-} \mathrm{N}_{2} \mathrm{O}\left(\mathrm{mg} \mathrm{N}-\mathrm{N}_{2} \mathrm{O}\right.$ $\mathrm{m}^{-2}$ ) (b) dos diferentes fertilizantes nitrogenados aplicados no solo. Em (a) setas indicam os dias em que foram realizadas as adubações. Em (b) colunas com letras distintas diferem entre si, pelo teste de Tukey a $5 \%$ de probabilidade. 
ch-as. 15

SISTEMAS DE GESTÃO DE E RESÍDUOS

.

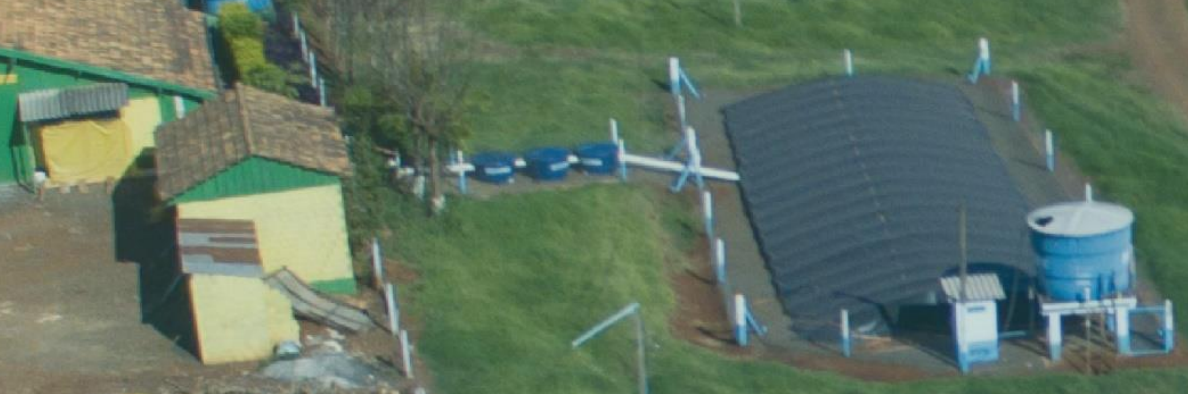

(29)
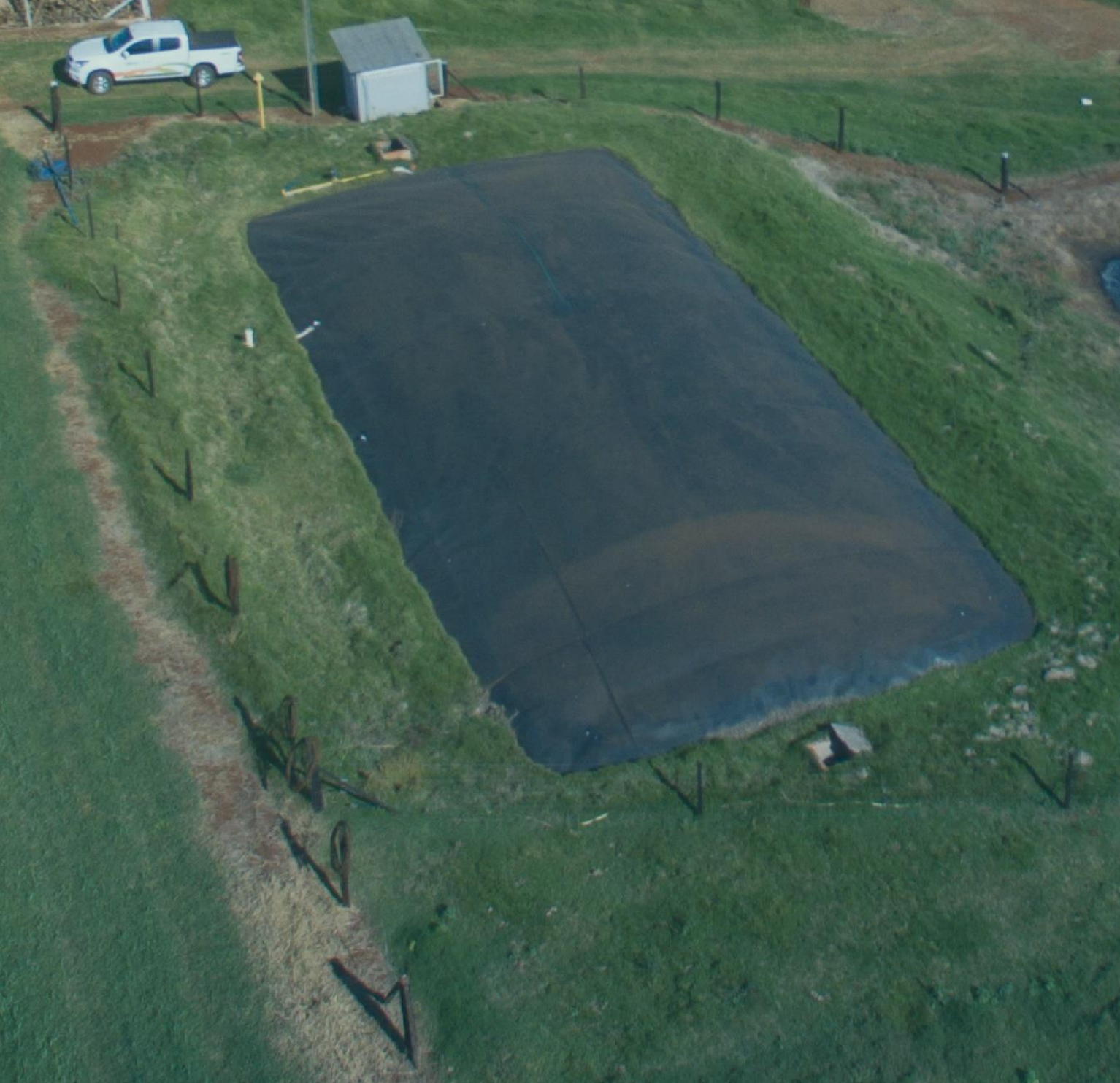


\title{
MANEJO DE EMBALAGENS DE AGROTÓXICOS: UMA ANÁLISE DOS RISCOS AOS AGRICULTORES E AO AMBIENTE
}

\author{
Stedile, N.L.R.*1; Schneider, V.E.S. ${ }^{1}$, Carra, S.H.Z. ${ }^{1}$, Peresin, D. ${ }^{1}$ \\ ${ }^{1}$ Pesquisadores do Instituto de Saneamento Ambiental da Universidade de Caxias do Sul (ISAM-UCS), RS - Brasil \\ nlrstedi@ucs.br; veschnei@ucs.br; shzcarra@ucs.br,dperesin@ucs.br
}

\begin{abstract}
RESUMO: O volume de agrotóxicos utilizados no Brasil tem crescido gradualmente, resultando em um número considerável de embalagens geradas, sendo estas classificadas como resíduos químicos perigosos. Frente ao exposto, este trabalho apresenta uma análise sobre o manejo das embalagens de agrotóxicos realizada por agricultores de uma cidade da região dos Campos de Cima da Serra - Rio Grande do Sul, referência nacional na produção de maçã, com vistas a aumentar a compreensão sobre esta prática e os riscos à saúde humana e ambiental. Os dados sobre a manejo e gestão das embalagens de agroquímicos nas propriedades foram obtidos através da realização de entrevista a produtores rurais, onde observou-se que a tríplice lavagem das embalagens de agrotóxicos é realizada pela maioria dos agricultores. Todavia, apenas $24 \%$ utiliza a calda resultante deste processo, o que aumenta o risco de contaminação ambiental. Apesar de definido na legislação, apenas $51 \%$ dos agricultores afirmam realizar a perfuração das embalagens antes da devolução e após a tríplice lavagem. No que tange ao armazenamento das embalagens de agrotóxico em local próprio, apenas $16 \%$ dos entrevistados afirmam ter depósito externo fechado e específico para este fim. O conjunto de inadequações verificadas expõe os agricultores e suas famílias a situações de risco diretamente. No entanto, a contaminação ambiental pode resultar em risco indireto a toda a sociedade, uma vez que essas substâncias persistem no meio ambiente, podendo interagir e formar outros compostos, atingindo a sociedade como um todo.
\end{abstract}

Palavras-chave: agrotóxicos, manejo de embalagens, resíduos.

\section{AGROCHEMICAL PACKAGING MANAGEMENT: AN ANALYSIS OF RISK TO FARMERS AND THE ENVIRONMENT}

\begin{abstract}
The volume of agrochemicals used in Brazil has gradually increased, resulting in a considerable number of generated packages, which are classified as hazardous chemical residues. In this context, this paper presents an analysis on the management of agrochemical packages carried out by farmers in a city located in the Campos de Cima da Serra Region - Rio Grande do Sul State, a national reference in apple production, in order to increase the understanding of this practice and the risks to human and environmental health. The data on the management of the agrochemical packaging in the properties were obtained through an interview with rural producers, where it was observed that the triple washing of pesticide containers is carried out by the majority of the farmers. However, only $24 \%$ use the resulting syrup, which increases the risk of environmental contamination. Although defined in the legislation, only $51 \%$ of farmers claim to drill the packaging before returning it and after the triple wash. Concerning to the storage of pesticide containers in their own place, only $16 \%$ of farmers state that they have a closed and specific external storage for this purpose. The set of inadequacies verified exposes farmers and their families to risk situations directly. However, environmental contamination can result in an indirect risk to the whole society, since these substances persist in the environment, and can interact and form other compounds, affecting society as a whole.
\end{abstract}

Keywords: agrochemicals, packaging management, waste.

\section{INTRODUÇÃO}

Os efeitos do uso dos agrotóxicos sobre a saúde humana e animal tem sido objeto de preocupação de cientistas do mundo todo. Muitos dos efeitos dessas substâncias sobre a vida estão mapeados e a proibição do uso de vários produtos já é realidade em diferentes países e continentes. No Brasil, recentemente, a Associação Brasileira de Saúde Coletiva (ABRASCO) editou um dossiê que representa um alerta sobre os impactos dos agrotóxicos sobre a saúde (CARNEIRO, 2015), que reúne uma quantidade significativa de evidências dessa relação, demonstrando, por meio de estudos científicos, os efeitos do agrotóxico sobre a saúde humana. 
A utilização de agrotóxicos no Brasil iniciou em meados do século passado e, desde 2008, o país tornouse o maior consumidor mundial desses produtos, com efeitos prejudiciais à saúde e ao ambiente (Londres 2011; Jobim et al., 2010). O mercado brasileiro de agrotóxicos cresceu cerca de $190 \%$ na última década (AUGUSTO et al., 2015), em um ritmo de expansão duas vezes maior do que o apresentado pelo mercado mundial (93\%) no mesmo período (ANVISA, 2012).

A população mais exposta a agrotóxicos é a de agricultores, que podem ser afetados pela manipulação direta (compra e transporte, preparo da calda, aplicação) ou por meio de armazenamento inadequado, reaproveitamento de embalagens, roupas contaminadas ou contaminação da água (PORTELA; TOURINHO, 2015) e os princípios ativos ou atingem o homem ou o meio ambiente.

Cabe destacar que o comportamento dos agrotóxicos no ambiente torna os estudos ainda mais complexos, na medida em que os mesmos, depois de aplicados, sofrem influência dos agentes que atuam provocando seu deslocamento físico e sua transformação química e biológica. Invariavelmente, independente dos caminhos percorridos pelo agrotóxico (lixiviação, infiltração, chuvas, erosão) esses atingem, em última instância, a água e o homem (MINISTÉRIO DO MEIO AMBIENTE, 2012).

O volume de agrotóxicos usado no Brasil tem crescido gradualmente, do que se pode supor um número considerável de embalagens geradas, as quais são classificadas como resíduos químicos perigosos. O manejo dessas embalagens inclui a compra, o transporte, o armazenamento, o manejo para produção da calda, a tríplice lavagem, o acondicionamento temporário na propriedade e o descarte na logística reversa. Em todas essas etapas o agricultor pode intoxicar-se ou contaminar o ambiente e para todas elas há uma legislação que normatiza processos e define padrões técnicos de manejo. Destaca-se a Norma 9843-3 (ABNT, 2013), que estabelece os requisitos para o armazenamento de agrotóxicos de forma a preservar o meio ambiente e o produto e garantir a segurança e a saúde das pessoas e a $N^{\circ} 13968$ (ABNT, 1997) que estabelece como proceder com as embalagens rígidas, incluindo sua lavagem.

Frente ao exposto, este trabalho apresenta uma análise sobre o manejo das embalagens de agrotóxicos realizada por agricultores de uma cidade da região dos Campos de Cima da Serra - Rio Grande do Sul, referência nacional na produção de maçã, com vistas a aumentar a compreensão sobre esta prática e os riscos à saúde humana e ambiental.

\section{MATERIAL E MÉTODOS}

Com vistas a avaliar os problemas relacionados com a utilização e descarte das embalagens de agrotóxicos em um município da região dos Campos de Cima da Serra - Rio Grande do Sul, foi elaborado e aplicado um questionário a uma amostra de agricultores. Para realização das entrevistas, foram usados como critérios de inclusão: a agricultura ser a principal atividade econômica da propriedade, o entrevistado ter trabalhado pelo menos a 1 (um) ano em atividades do ramo da agricultura da maçã, ser maior de 18 anos e estar lúcido para responder a entrevista.

Para a coleta de dados, foram capacitados entrevistadores, bolsistas do Núcleo de Estudos e Pesquisas em Políticas Públicas e Sociais (NEPPPS) e do Instituto de Saneamento Ambiental (ISAM), ambos da Universidade de Caxias do Sul, com apoio do Sindicato dos Trabalhadores Rurais do município. Resultaram 55 participações, das quais quatro foram descartadas porque as propriedades realizavam cultura "orgânica", e outras foram parcialmente respondidas resultando em um número real de participações de 34 agricultores.

\section{RESULTADOS E DISCUSSÃO}

Com a análise do questionário identificou-se que os problemas com o manejo das embalagens de agrotóxicos iniciam precocemente, ou seja, na mistura da calda, uma vez que apenas $10 \%$ dos agricultores usam água sob pressão; a maioria realiza a mistura em recipiente impróprio e usando, para a mistura, artefatos como pedaços de madeira ou cabos de vassoura (18\%).

A síntese de aspectos importantes sobre o processo de manejo das embalagens de agrotóxicos pode ser verificada na Figura 1.

Conforme observado na Figura 1, a maioria dos agricultores afirmam realizar a tríplice lavagem das embalagens de agrotóxicos como definem as normas específicas, no entanto, desses, apenas $24 \%$ utiliza a calda resultante deste processo e $18 \%$ afirmam descartá-la diretamente no solo e $6 \%$ na pia. Assim, o risco de contaminação ambiental é aumentado, uma vez que há uma concentração importante de agrotóxicos nas embalagens, devendo a calda resultante ser novamente aproveitada. 
Outra orientação para evitar o reúso das embalagens, também definida pela legislação, é a perfuração do fundo das embalagens. Apenas $51 \%$ dos agricultores realizam a perfuração antes da devolução e após a tríplice lavagem. Após este processo, as embalagens devem ser armazenadas para serem retornadas ao fabricante. No entanto, apenas $41 \%$ respondeu que retorna a embalagem a empresa especializada (logística reversa), persistindo ainda, mesmo que em baixo percentual (6\%) de agricultores que afirmam queimar ou enterrar as mesmas.

A logística reversa, no caso da agricultura, é definida não apenas pelo Ministério do Meio Ambiente, mas está prevista inclusive na Lei 12.305 (BRASIL, 2010) que institui a Política Nacional de Resíduos Sólidos, que reitera a necessidade de fazer retornar ao fabricante as embalagens de resíduos perigosos, neles incluídos os agrotóxicos.

Outro aspecto importante é que as embalagens devem ser armazenadas em local próprio, exclusivo, longe da residência e em local de acesso controlado. Entre os entrevistados, apenas $16 \%$ afirmam ter depósito externo fechado e específico para este fim. Grande parte improvisa o armazenamento em galpões (37\%), feitos em madeira (31\%), com piso também de madeira (31\%) ou "chão batido". A legislação estabelece que o local de armazenamento das embalagens deve ser construído com material impermeabilizante e com desnível para facilitar a lavagem, o escoamento ou a remoção em caso de acidentes. Em relação ao desnível, $41 \%$ dos agricultores afirmam ter local adequado. Por fim, quanto à sinalização do local, apenas $32 \%$ possuem esta de forma adequada.

\section{CONCLUSÃO}

O uso indiscriminado de agrotóxicos pode ser considerado um problema ambiental, com potencial para produzir efeitos sobre a qualidade de vida e a saúde do homem. Evidenciar a forma como o uso e o manejo das embalagens de agrotóxicos vem sendo feita é uma forma de colaborar na produção dos dados necessários ao entendimento da dimensão do problema e proposição de soluções a esta complexa problemática. Através deste trabalho, observa-se a necessidade de criar uma rede de apoio ao agricultor para que o mesmo possa usar racionalmente e manejar adequadamente os agrotóxicos e suas embalagens, de forma a desenvolver comportamentos protetivos a si próprio e ao ambiente.

O conjunto de inadequações verificadas expõe os agricultores e suas famílias a situações de risco diretamente. No entanto, a contaminação ambiental pode resultar em risco indireto a toda a sociedade, uma vez que essas substâncias persistem no meio ambiente, podendo interagir e formar outros compostos, atingindo a sociedade como um todo.

\section{AGRADECIMENTOS}

Secretaria de Desenvolvimento Econômico, Ciência e Tecnologia do Estado do Rio Grande do Sul (SDECT), Fundação de Amparo à Pesquisa do Estado do Rio Grande do Sul (FAPERGS), Universidade de Caxias do Sul.

\section{REFERÊNCIAS}

ASSOCIAÇÃO BRASILEIRA DE NORMAS TÉCNICAS - ABNT. Norma Brasileira No 3968: Embalagem rígida vazia de agrotóxico - Procedimentos de lavagem. Rio de Janeiro: ABNT, 1997. 8 f. Disponível em: <http://www.abntcatalogo.com.br/norma.aspx?ID=3349>. Acesso em: 18 jul. 2016.

ASSOCIAÇÃO BRASILEIRA DE NORMAS TÉCNICAS - ABNT. Norma Brasileira No 9843-3: Agrotóxicos e afins parte 3: Armazenamento em propriedades rurais. Rio de Janeiro: ABNT, $2013.8 \mathrm{f}$. Disponível em: <http://www.abntcatalogo.com.br/norma.aspx?ID=259879>. Acesso em: 18 ago. 2017.AUGUSTO, L. G. S.; CARNEIRO, F. F.; PIGNATI, W. A.; RIGOTTO, R. M.; FRIEDRICH, K.; FARIA, N. M. X.; BÚRIGO, A. C.; FREITAS, V. M. T. Saúde, ambiente e sustentabilidade. In: CARNEIRO, F. F.; AUGUSTO, L. G. S.; RIGOTTO, R. M.; FRIEDRICH, K.; BÚRIGO, A. C. (Org.). Dossiê ABRASCO: um alerta sobre os impactos dos agrotóxicos na saúde. Rio de Janeiro: Escola Politécnica de Saúde Joaquim Venâncio; São Paulo: Expressão Popular, 2015. cap. 2, p. 89-191. Disponível em: <http://www.abrasco.org.br/dossieagrotoxicos/wp-content/uploads/2013/10/DossieAbrasco_2015_web.pdf>. Acesso em: 10 maio 2017.

AGÊNCIA NACIONAL DE VIGILÂNCIA SANITÁRIA - ANVISA. Expansão da utilização de agrotóxicos. Brasília: [s.n.], 2012. Disponível em: <http://portal.anvisa.gov.br/wps/content/Anvisa+Portal/Anvisa/Inicio/ Agrotoxicos+e+Toxicologia>. Acesso em: 18 jul. 2016. 
CARNEIRO, Fernando Ferreira et al. DOSSIÊ ABRASCO: um alerta sobre os impactos dos agrotóxicos na saúde / Organização de Fernando Ferreira Carneiro, Lia Giraldo da Silva Augusto, Raquel Maria Rigotto, Karen Friedrich e André Campos Búrigo. - Rio de Janeiro: EPSJV; São Paulo: Expressão Popular, 2015.

JOBIM, Paulo Fernandes Costa et al. Existe uma associação entre mortalidade por câncer e uso de agrotóxicos?: Uma contribuição ao debate. Ciênc. saúde coletiva, Rio de Janeiro , v. 15, n. 1, p. 277288, jan. 2010 . Disponível em <http://www.scielo.br/scielo.php?script=sci_arttext\&pid=S1413$81232010000100033 \& \operatorname{lng}=$ pt\&nrm=iso>.

LONDRES, F. Agrotóxicos no Brasil: um guia para ação em defesa da vida. - Rio de Janeiro: AS-PTA Assessoria e Serviços a Projetos em Agricultura Alternativa, 2011.

MINISTÉRIO DO MEIO AMBIENTE - MMA. Agrotóxicos. Brasília: [s.n.], 2012. Disponível em: <http://www.mma.gov.br/seguranca-quimica/agrotoxicos>. Acesso em: 02 mar. 2017.

PORTELA, G.; TOURINHO, R. Artigo relaciona morte de trabalhadores por agrotóxicos e sua subnotificação. 2015. Disponível em: <http://www.icict.fiocruz.br/content/artigo-relaciona-morte-de-trabalhadores-poragrotóxicos-e-sua-subnotificação>. Acesso em: 15 jun. 2017.

SISINNO, Cristina Lúcia Silveira; OLIVEIRA-FILHO, Eduardo Cyrino (Org.). Princípios da Toxicologia Ambiental. Rio de Janeiro: Internacional, 2013. 216 p. Disponível em: <https://ucs.bv3.digitalpages.com.br/users/publications/9788571932630/pages/1>. Acesso em: 14 nov. 2018. SINDICATO NACIONAL DA INDÚSTRIA DE PRODUTOS PARA DEFESA VEGETAL - SINDIVEG. Balanço 2015 - Setor de agroquímicos confirma queda de vendas. 2016. Disponível em: <http://sindiveg.org.br/balanco-2015-setor-de-agroquimicos-confirma-queda-de-vendas/>. Acesso em: 18 jun. 2017.

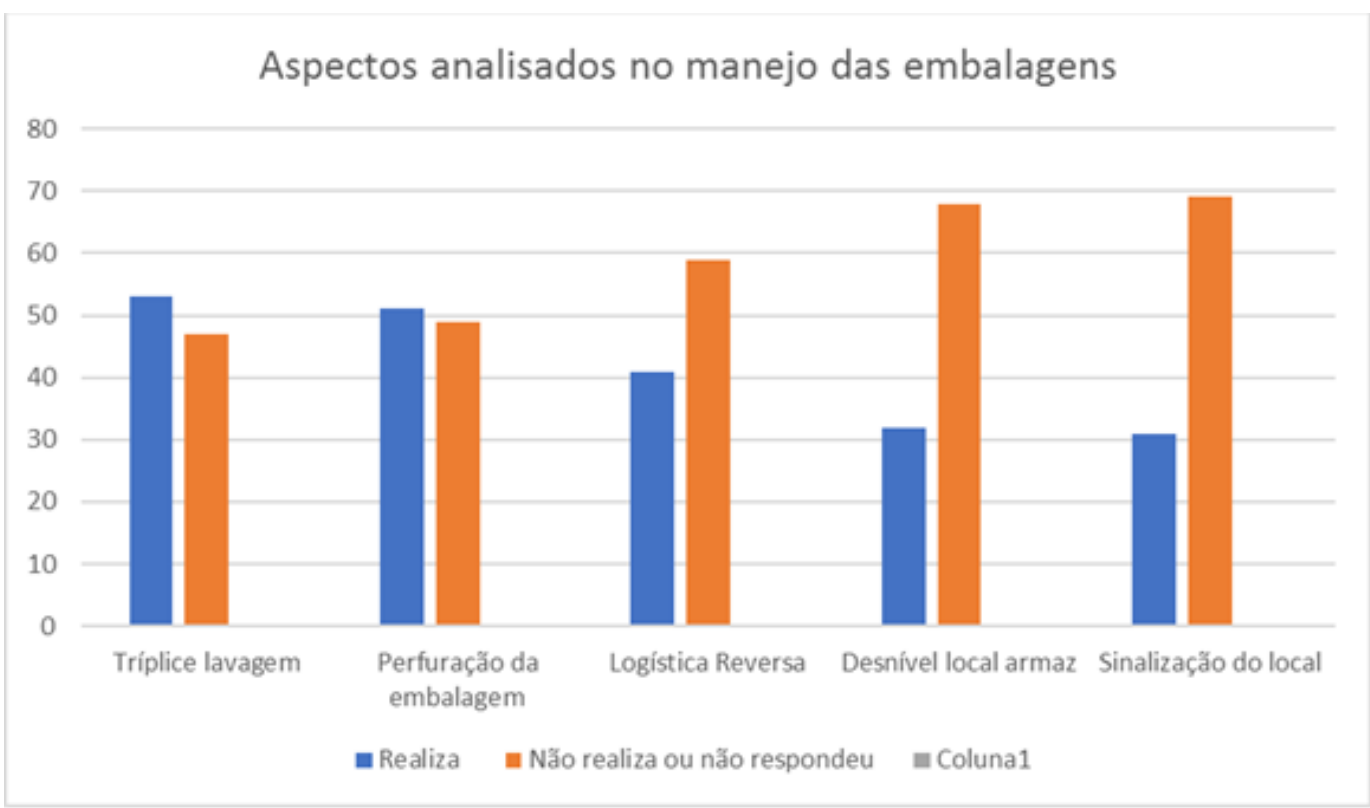

Figura 1. Processo de manejo das embalagens de agrotóxicos segundo os agricultores. 


\title{
AQUACULTURE WASTE MANAGEMENT BY THE BLACK SOLDIER FLY LARVAE (HERMETIA ILLUCENS): PRELIMINARY RESULTS
}

\author{
Lopes, I.G. ${ }^{1}$; Lalander, C. ${ }^{2}$; Vinnerås, B. ${ }^{2}$ \\ ${ }^{1}$ Universidade Estadual Paulista “Júlio de Mesquita Filho”, Centro de Aquicultura da UNESP. Jaboticabal, SP, Brazil \\ ${ }^{2}$ Swedish University of Agricultural Sciences (SLU), Department of Energy and Technology. Uppsala, Sweden \\ ivanguid@gmail.com
}

\begin{abstract}
Aquaculture production is rapidly increasing, coupled with higher waste generation, mostly composed by fish carcasses. Concerning the increased demands for protein sources for animal production and the pressure in natural fish stocks and on land use for soy production, finding new sources of protein is of great interest. Among different waste management methods, using insects to consume the organic fraction of wastes is interesting due to the possibility of generating insect's biomass, which is rich in protein and could close the nutrient cycle. Therefore, the aim of this study was to evaluate the use of fish carcasses as substrate for the growth of black soldier fly larvae (BSFL). Twenty-one different combinations of carcasses and bread waste were tested, which served as substrate for 10,000 larvae. The experiment time was defined as when the time when larvae were sievable from the residue or when $1 \%$ of the larvae reached prepupal stage. From all substrate combinations, it was observed that the larvae were able to efficiently consume the materials from only six treatments (from $100 \%$ bread up to the combination between $75 \%$ bread and $25 \%$ of fish carcasses). In these treatments, waste-to-biomass conversion rates up to $24.9 \%$ were observed and material reduction of more than $60 \%$ in dry basis. From the remaining boxes, several larvae escaped, probably due to high amounts of fish oil that hampered its growth. It was concluded that fish carcasses are feasible for rearing BSFL when cocomposted with bread waste.
\end{abstract}

Keywords: fly larvae, waste, biomass, biotechnology.

\section{INTRODUCTION}

Aquaculture production is rapidly increasing worldwide and is coupled with higher waste generation from fingerling production up to the consumer. The primary waste generated in aquaculture production are fish and shellfish carcasses originated from in-farm mortality events or from fish processing plants. Inadequate disposal of this organic solid waste stands for a significant impending risk for contaminating soil and groundwater (Arvanitoyannis and Kassaveti, 2008) and therefore must be managed properly. On the other hand, this waste has a high content of nutrients and if properly managed can be used to close the nutrient cycle and generate income.

Higher quantities of protein sources (e.g. fishmeal and soybean) are constantly being demanded by the animal production sectors, which implies in environmental challenges regarding the pressure on natural fish stocks and on land use, thus finding alternative sources for use in animal feed is of great interest, both economic and environmentally (Makkar et al., 2014). Among several methods for organic waste management, the use of the black soldier fly larvae (BSFL, Hermetia illucens) has been shown to be highly effective in reducing waste volumes and converting it into insect biomass, which is considered a rich protein source that could be used in animal feeds (Lalander et al., 2019).

The BSFL are able to consume several organic waste streams (e.g. vegetable waste, abattoir waste and bread waste) and present satisfactory growth rates (Lalander et al., 2019). The process involves feeding the larvae with organic waste and before it starts turning into prepupae, harvesting them by separating the larvae from the leftover residue, and for this reason, it is important that by the end of the composting process, the residue is dry and sievable. The aim of this study was to evaluate the feasibility of fish and bread waste to be used as substrate for BSFL growth.

\section{MATERIAL AND METHODS}

BSFL were obtained from a colony located at the Swedish University of Agricultural Sciences (SLU) in Uppsala, Sweden. Bread waste was supplied by a local food distributor in Uppsala and fish carcasses were collected from a Nordic Trout fish farm close to Mora, Sweden (Table 1). Twenty-one combinations of minced fish carcasses and shredded bread waste were tested, ranging from 100\% fish carcasses to $100 \%$ bread waste, with $5 \%$ replacement intervals between each step. 
One treatment box $(40 \times 60 \times 12 \mathrm{~cm})$ covered with a net (mesh size $1 \mathrm{~mm})$ was used in the BSFL composting. Each treatment comprised 10,000 larvae $\left(4.15 \mathrm{larvae} / \mathrm{cm}^{2}\right)$ that were fed an equivalent of $0.2 \mathrm{~g}$ of the substrates' volatile solids (VS) per larva. Larvae were fed three times (days 1,4 and 7) in all treatments while the end of the experiment and thus treatment time was defined as when the time when larvae were sievable from treatment residue or (if that point was not reached) when $1 \%$ of the larvae reached prepupal stage (upon visual inspection) upon treatment.

The process efficiency was evaluated in terms of material reduction, biomass conversion and larvae growth. Regarding growth aspects of larvae, the following zootechnical indexes were calculated: Specific Growth Rate (SGR) (100 x ( $\{$ ln final weight - ln initial weight $\} /$ days $)$ ), Mass Gain (MG) (final weight - initial weight) and survival rate (\%). In relation to process efficiency, material reduction (Mat. Red. DM) and wasteto-biomass bioconversion ratio $\left(\mathrm{BCR}_{\mathrm{DM}}\right)$ as Mat Red.DM $=\left(1-\left(\operatorname{sub}_{\mathrm{in}} \mathrm{DM}_{\mathrm{DM}} / \mathrm{mat} \mathrm{out}_{\mathrm{DM}}\right)\right)^{*} 100$, where sub.in ${ }_{\mathrm{DM}}$ and mat.out $t_{\mathrm{DM}}$ was the dry matter of the substrate fed and of the residue after the experiment, respectively; and the $\mathrm{BCR}_{\mathrm{DM}}=\left(\mathrm{l}_{\mathrm{DM}} / \mathrm{sub} . \mathrm{in}_{\mathrm{DM}}\right)^{*} 100$, where $\operatorname{lv}_{\mathrm{DM}}$ and sub.in $\mathrm{n}_{\mathrm{DM}}$ was the total dry matter in the larvae (lv) and the substrate (sub.in), respectively. Additionally, the $\mathrm{pH}$ and total ammonium nitrogen (TAN) concentrations were measured before each feeding and at the end in the treatment residue.

\section{RESULTS AND DISCUSSION}

From all substrate combinations, it was observed that the larvae were able to efficiently consume the materials from only six treatments (from $100 \%$ bread up to the combination between $75 \%$ bread and $25 \%$ of fish carcasses). In terms of the other treatments, the larvae tended to exit the boxes and consumed only a few of the substrate provided, thus evidencing that it was not feasible. It was visually observed that the treatments with large proportion of fish carcasses, high amounts of the oil existing in the carcasses accumulated in the bottom of the boxes. The oil could have coated the body of the larvae and thus affecting their possibility to breath and thus also their overall activity. Additionally, nitrogen-rich materials may get rancid in quite a short period, hampering its biological degradation due to the generation of toxic substances (Taylor et al., 1989). In contrast, in the treatments with high proportions of bread (>80\%), the larvae did not escape and the material was degraded to a considerably larger degree.

Larvae's growth (mass gain and SGR) differed between treatments, but in general, larvae in treatments with small proportions of carcasses (5-25\%) weighed more and survived to a higher degree (Table 2). It has been suggested that BSFL needs to be fed with adequate carbohydrate: protein ratios in order to optimize their growth and nutritional quality; e.g. Lim et al. (2019) found that an optimum protein nutritional constituent for larvae feed was around $12 \%$, while higher protein contents were found to acidify the environment, which increased the time for larvae rearing and growth. It is likely that the larvae fed with higher proportions of carcasses (>20\%) in comparison to lower, were unable to assimilate large proportion of the substrate and thus did not convert it into biomass, resulting in lower weight gain throughout the experiment.

The SGR calculations revealed that BSFL grew faster in the first four days of feeding $\left(28.0 \pm 8.6 \%\right.$ day $^{-}$ $\left.{ }^{1}\right)$ as compared to the final feeding period, from the seventh to the final days of experiment $\left(10.7 \pm 5.0 \%\right.$ day $^{-}$ ${ }^{1}$ ), especially in treatments containing higher amounts of bread in comparison to fish (Table 2). The same trend was observed for survival rate, whilst weight gain was higher with the $25 \%$ inclusion of carcasses, however, as survival rate in this treatment was very low (18.6\%) it could be considered unfeasible since the biomass production is consequently low. These treatments were sievable, while the remaining ones, the residue was too wet for sieving.

Therefore, sieving was possible only in the treatments containing $0-25 \%$ of fish carcasses and thus survival rates were calculated only up to $25 \%$ fish inclusion. Larvae fed exclusively bread had the highest survival rate, whilst high rates were also verified in treatments with 5\% and $10 \%$ fish carcasses. Several larvae escaped from the treatments with $15-25 \%$ fish carcasses, justifying the observed lower survival rates. Cohen et al. (2004) concluded that the lack of nutrients needed for larval growth in their study resulted in low survival, however it is unlikely that the same trend is true in this study, where it is rather more likely high amounts of toxic substances and oil in the feeding substrates caused the mass escape of larvae.

The material reduction (DM basis) a ranged from $54.2 \%$ to $69.1 \%$ in the treatments that were possible to sieve (Table 3), which is in accordance with the results obtained with other wastes consumed by BSFL (Lalander et al., 2019). The larvae were able to consume bread waste in a short period (12 days), as well as combinations containing from 5 to $15 \%$ of fish carcasses, whilst with other combinations, larvae took more 
time to process the materials (which were visually degraded and reduced in volume), or did not process it at all.

The waste-to-biomass conversion ratio $\left(\mathrm{BCR}_{\mathrm{DM}}\right)$ varied from $5.8 \%$ (high larval escape) to $24.9 \%$ in the $10 \%$ of fish carcasses treatment. Lalander et al. (2019) obtained similar results using abattoir waste (containing stomach contents, blood, meat, viscera and manure), with the first prepupae being registered at day 12 of treatment. In this study, it was verified that the larvae efficiently consumed the substrate (by degrading the material and reducing its mass by more than $60 \%$ on dry basis in the $0-15$ FI treatments) and in the process converting it in large amounts of insect biomass.

When considering large-scale waste management facilities, not only larval growth and survival should be taken into account for decision-making. As an example, Tschirner and Simon (2015) highlighted that fat content relates directly to the processing of the larvae in feed production, and concluded that lower fat contents are desired to easily process the larval biomass for its use in animal feed. One of the most important factors to be considered is the possibility to sieve the residues at the end of substrate consumption, in order to separate it from the larvae, otherwise the process will not be feasible. Therefore, when exploring new substrates for larvae feeding, it is extremely important to decide whether to consider it as adequate to be managed by BSFL or not. In this sense, using fish carcasses as feed substrate might be feasible for BSFL rearing, however in small amounts. In this study, we observed that fish carcasses with high fat contents could be used as substrate for larvae feeding only in small proportions of the total substrate, as it seems that the larvae do not have time to consume/assimilate it fast enough, and the materials starts to degrade in other way and generating possible toxic substances.

\section{CONCLUSIONS}

Black soldier fly larvae are able to consume fish carcasses in combination to bread waste as cocomposting substrate, presenting good results of weight gain, material reduction and waste-to-biomass conversion rate. The presence of high amounts of fat was shown to be undesired in BSFL composting. More studies should be developed using different species of fish with different fat contents.

\section{REFERENCES}

Arvanitoyannis, I.S., Kassaveti, A. Fish industry waste: treatments, environmental impacts, current and potential uses. International Journal of Food Science and Technology 43, 726-745, 2008.

Cohen, A.C. (2004). Insect Diets: Science and Technology. CRC Press, Boca Raton, Fla.

Lalander, C., Diener, S.; Zurbrügg, C., Vinnerås, B. Effects of feedstock on larval development and process efficiency in waste treatment with black soldier fly (Hermetia illucens). Journal of Cleaner Production, 208, 211-219, 2019.

Lim, J.W.; Mohd-Noor, S.N.; Wong, C.Y.; Lam, M.K.; Goh, P.S.; Beniers, J.J.A.; Oh, W.D.; Jumbri, K.; Ghani, N.A. Palatability of black soldier fly larvae in valorizing mixed waste coconut endosperm and soybean curd residue into larval lipid and protein sources. Journal of Environmental Management, 231, 129-136, 2019. Makkar, H.P.S.; Tran, G.; Heuzé, V.; Ankers, P. State-of-the-art on use of insects as animal feed. Animal Feed Science and Technology, 197, 1-33, 2014.

Taylor, S.L.; Stratton, J.E.; Nordlee, J.A. Histamine poisoning (scombroid fish poisoning): an allergy-like intoxication. Journal of Toxicology: Clinical Toxicology, 27, 225-240, 1989.

Tschirner, M.; Simon, A. Influence of different growing substrates and processing on the nutrient composition of black soldier fly larvae destined for animal feed. Journal of Insects as Food and Feed, 1, 249-259, 2015.

Table 1. Physico-chemical characterization of substrates tested as black soldier fly larvae feed. Values are presented as mean \pm standard deviation $(\mathrm{n}=3)$.

\begin{tabular}{lccc}
\hline & Dry Matter (\%) & Total Volatile Solids (\% of DM) & pH \\
\hline Bread & $64.3 \pm 0.9$ & $96.6 \pm 0.1$ & $6.5 \pm 0.1$ \\
Fish Carcasses & $35.0 \pm 3.0$ & $93.8 \pm 0.8$ & $5.2 \pm 0.1$ \\
\hline
\end{tabular}




\section{VISIGERA DE 07 A09 MA10 2019

Table 2. Growth parameters of BSFL fed with different quantities of fish carcasses and bread. The first column refers to the percentage of fish inclusion (FI) in each of the twenty-one tested boxes containing fish and bread waste.

\begin{tabular}{|c|c|c|c|c|c|c|}
\hline & $\begin{array}{c}\text { Larvae Final } \\
\text { Weight (g) }\end{array}$ & $\begin{array}{c}\text { Weight } \\
\text { Gain (g) }\end{array}$ & $\begin{array}{c}\text { SGR Days 1- } \\
4\left(\% \text { day }^{-1}\right)\end{array}$ & $\begin{array}{c}\text { SGR Days 4- } \\
7\left(\% \text { day }^{-1}\right)\end{array}$ & $\begin{array}{l}\text { SGR Days 7- } \\
\text { Final }\left(\% \text { day }^{-1}\right)\end{array}$ & $\begin{array}{c}\text { Survival } \\
(\%)\end{array}$ \\
\hline $100 \% \mathrm{FI}$ & 0.026 & 0.024 & 14.4 & 6.8 & 17.2 & - \\
\hline $95 \% \mathrm{FI}$ & 0.039 & 0.037 & 13.2 & 15.2 & 15.9 & - \\
\hline $90 \%$ FI & 0.063 & 0.061 & 17.7 & 18.0 & 15.3 & - \\
\hline $85 \%$ FI & 0.063 & 0.062 & 18.9 & 14.7 & 17.5 & - \\
\hline $80 \%$ FI & 0.071 & 0.070 & 19.9 & 15.9 & 17.0 & - \\
\hline $75 \%$ FI & 0.093 & 0.091 & 22.3 & 17.7 & 16.5 & - \\
\hline $70 \% \mathrm{FI}$ & 0.098 & 0.096 & 20.3 & 22.9 & 14.1 & - \\
\hline $65 \% \mathrm{FI}$ & 0.096 & 0.095 & 31.2 & 18.4 & 12.7 & - \\
\hline $60 \% \mathrm{FI}$ & 0.123 & 0.122 & 29.0 & 19.2 & 16.5 & - \\
\hline $55 \% \mathrm{FI}$ & 0.149 & 0.148 & 24.9 & 26.9 & 10.2 & - \\
\hline $50 \% \mathrm{FI}$ & 0.114 & 0.113 & 27.3 & 26.4 & 7.3 & - \\
\hline $45 \% \mathrm{FI}$ & 0.118 & 0.117 & 32.4 & 20.4 & 8.0 & - \\
\hline $40 \%$ FI & 0.112 & 0.111 & 34.2 & 26.1 & 3.9 & - \\
\hline $35 \%$ FI & 0.134 & 0.133 & 28.8 & 26.8 & 8.1 & - \\
\hline $30 \%$ FI & 0.120 & 0.119 & 37.4 & 18.1 & 7.2 & - \\
\hline $25 \%$ FI & 0.148 & 0.147 & 32.9 & 28.4 & 6.8 & 18.6 \\
\hline $20 \%$ FI & 0.135 & 0.134 & 30.6 & 30.1 & 6.3 & 38.0 \\
\hline $15 \%$ FI & 0.145 & 0.144 & 42.3 & 22.2 & 10.2 & 67.8 \\
\hline $10 \% \mathrm{FI}$ & 0.130 & 0.129 & 42.9 & 25.6 & 2.3 & 94.8 \\
\hline $5 \% \mathrm{FI}$ & 0.118 & 0.117 & 37.1 & 29.3 & 3.4 & 96.8 \\
\hline $0 \% \mathrm{FI}$ & 0.100 & 0.099 & 31.2 & 28.8 & 8.9 & 101.0 \\
\hline
\end{tabular}

Table 3. Material reduction (Mat.Red.) and waste-to-biomass conversion ratio (BCR) on a dry matter basis, $\mathrm{pH}$, total ammonium nitrogen (TAN) and total consumption process time in the sievable treatments.

\begin{tabular}{lccccc}
\hline & Mat.Red.DM $(\boldsymbol{\%})$ & BCR $_{\mathbf{D M}}(\boldsymbol{\%})$ & pH & TAN & Process Time (days) \\
\hline $25 \%$ FI & 54 & 5.8 & 5.9 & 12.8 & 18 \\
$20 \%$ FI & 59 & 10.5 & 6.5 & 13.2 & 18 \\
$15 \%$ FI & 64 & 20.4 & 6.2 & 11.9 & 12 \\
$10 \%$ FI & 69 & 24.9 & 6.3 & 6.6 & 12 \\
$5 \%$ FI & 66 & 23.4 & 6.5 & 5.1 & 12 \\
$0 \%$ FI & 62 & 23.9 & 6.5 & 4.0 & 12 \\
\hline
\end{tabular}




\title{
AVALIAÇ̃̃O ECONÔMICA DE TECNOLOGIAS PARA TRATAMENTO DOS RESÍDUOS LÍQUIDOS DA SUINOCULTURA E VALORAÇÃO DOS NUTRIENTES RECICLADOS
}

\author{
Souza, M.V.N. de ${ }^{* 1}$; Barros, E.C. ${ }^{2}$; Miranda, C.R. de ${ }^{3}$; Sandi, A.J. ${ }^{4}$ \\ ${ }^{1}$ Administrador/Analista da Embrapa Suínos e Aves, Concórdia, SC - Brasil, marcos.novaes@embrapa.br \\ ${ }^{2}$ Eng. Agrônomo/Analista da Embrapa Suínos e Aves, evandro.barros@embrapa.br \\ ${ }^{3}$ Eng. Agrônomo/Pesquisador da Embrapa Suínos e Aves, claudio.miranda@embrapa.br \\ ${ }^{4}$ Economista/Analista da Embrapa Suínos e Aves, ari-jarbas.sandi@embrapa.br
}

RESUMO: O desenvolvimento da Suinocultura brasileira se deu através da concentração dessa atividade em determinadas regiões, o que trouxe diversos avanços tecnológicos e organizacionais para essa cadeia produtiva. Entretanto, juntamente com isso também veio o problema da concentração dos dejetos líquidos dos suínos nessas regiões. Através da metodologia do excedente econômico, esse trabalho buscou apresentar um comparativo de custos entre as tecnologias que são usadas para tratar esse resíduo líquido da produção, bem como demonstrar que pode haver mitigação dos seus custos variáveis e investimentos, através da substituição do composto orgânico gerado por essas tecnologias, pelos fertilizantes normalmente adquiridos no mercado.

Palavras-chave: Suínos, dejetos, tecnologia, reciclagem, valor.

\section{ECONOMIC EVALUATION OF TECHNOLOGIES FOR TREATMENT OF LIQUID WASTE OF SUINOCULTURE AND VALUATION OF RECYCLED NUTRIENTS.}

\begin{abstract}
The Brazilian swine industry developed through the concentration of this activity in certain regions, which brought several technological and organizational advances to this productive chain. However, along with this also came the problem of the concentration of liquid pig manure in these regions. Through the methodology of the economic surplus, this work sought to present a comparative of costs between the technologies that are used to treat this liquid residue of the production, as well as to demonstrate that there can be mitigation of the variable costs and investments, by replacing the organic compound generated by fertilizers normally purchased on the market.
\end{abstract}

Keywords: Pigs, waste, technology, recycling, value.

\section{INTRODUÇÃO}

Em 2016, o Brasil possuía cerca de 40 milhões de cabeças de suínos, sendo que desses, $50 \%$ concentrados na região sul, distribuídas no Estado do Paraná com 7,13 milhões, Santa Catarina com 6,88 milhões e Rio Grande do Sul com 5,92 milhões de cabeças (IBGE, 2016). Além do crescimento em termos do número de animais nos últimos anos, a suinocultura brasileira tem recebido investimentos substanciais, absorvendo avanços tecnológicos em toda a cadeia produtiva (Gonçalves; Palmeira, 2016).

Ainda no contexto socioeconômico, historicamente a suinocultura brasileira teve grandes saltos de desenvolvimento e organização em consequência da convergência da atividade em determinadas regiões. Contudo, a carga orgânica indesejada gerada durante o processo de criação e terminação dos animais exerce enorme pressão sobre o meio ambiente, especialmente nas situações onde ocorre esse tipo concentração da produção. Esse passivo ambiental, provocado pelos resíduos da suinocultura, dejetos líquidos dos suínos (DLS), pode se configurar como poluição ou, conforme o cenário tecnológico, como fertilizante. Observandose que a Instrução Normativa IN-11 da FATMA define como $50 \mathrm{~m}^{3} / \mathrm{ha}$ o limite de dejetos a ser usado como adubo orgânico.

Os DLS possuem elementos tais como fósforo $(\mathrm{P})$, nitrogênio $(\mathrm{N})$ e potássio $(\mathrm{K})$ que, ao serem manejados de forma adequada podem contribuir com a redução de custos para o suinocultor que tenha lavouras disponíveis, nas quais esse material orgânico serviria como alternativa aos fertilizantes químicos ofertados pelo mercado. Contudo, destaca-se que em Seganfredo et. al., 2016, são apontados casos de poluição difusa causados pelo $\mathrm{P}$, no qual ocorre a saturação desse elemento no solo e transferência para os recursos hídricos.

Diante dessas questões surgiu o presente trabalho, no qual buscamos mostrar que acompanhando o desenvolvimento da suinocultura intensiva, também surgiram soluções tecnológicas para tratar e mitigar o impacto causado pelos resíduos gerados na criação dos animais, sendo que tais tecnologias, quando 
adequadamente utilizadas, podem trazer benefícios com redução de custos para os suinocultores. Para tanto, fizemos uma avaliação econômica e tomamos o elemento fósforo como indicador de referência para valoração desses ganhos (pesquisa vinculada ao Projeto S. A. Suave, da Embrapa Suínos e Aves, em andamento).

\section{Avaliação econômica}

\section{MATERIAL E MÉTODOS}

Para obtermos os resultados econômicos utilizamos o Método do Excedente Econômico, onde tomamos como referência teórica para receita financeira, o valor comercial do superfosfato triplo $\left(\mathrm{P}_{2} \mathrm{O}_{5}\right)$, fonte Epagri/ CEPA, 2018. A metodologia usada para esse trabalho de avaliação econômica segue um enfoque comparativo da adoção de duas ou mais tecnologias para tratamento dos resíduos da atividade suinícola e, busca demonstrar os ganhos e perdas dos investimentos feitos em ambas as situações, bem como os possíveis lucros. O Excedente Econômico (Avila et al., 2008), aponta os benefícios econômicos a partir dos ganhos gerados pela adoção de uma tecnologia, denominada "tecnologia substituta", em comparação com outra tecnologia denominada "tecnologia de referência".

Esses benefícios são calculados a partir dos ganhos gerados pela adoção das tecnologias e, descontados eventuais custos adicionais, entre fixos e variáveis. Sendo que neste caso, o benefício é na redução de custos, onde a principal variável da análise é o volume de dejetos produzido, em metros cúbicos. Acrescentando que os dados e coeficientes técnicos para efetivação da avaliação foram obtidos através de entrevistas com técnicos e pesquisadores da Embrapa Suínos e Aves, segundo estimativas, conclui-se que podemos obter cerca de $1 \mathrm{Kg}$ de $\mathrm{P}$ para cada $\mathrm{m}^{3}$ de DLS. Já para os preços, tomamos como referência as informações divulgadas pela Epagri/CEPA, 2018 e, conforme cálculos, temos o valor de 3,80 por Kg de $\mathrm{P}$.

\section{Tecnologias para tratamento dos resíduos líquidos e coeficientes técnicos}

Para fins comparativos, tomamos a esterqueira como tecnologia de referência, ficando caracterizada por duas escavações próximas à granja, tanque principal e reservatório, além disso, deve possuir um sistema de drenagem e revestimento impermeabilizado para evitar infiltração no solo, mas nesse caso os dejetos ficam expostos a céu aberto. A primeira tecnologia em análise comparativa é o Biodigestor, denominado por Tecnologia Substituta 01 e, toma como base o mesmo modelo e propósito da esterqueira, com finalidade de armazenar e estabilizar os dejetos líquidos provenientes do sistema de produção de carne suína, também caracterizado por duas escavações próximas à granja, tanque principal e lagoa de retenção, sistema de drenagem idem a esterqueira. Entretanto, seu sistema é fechado por lona ou outros materiais, o que permite o melhor controle dos processos anaeróbicos.

A Compostagem Mecânica de Dejetos Líquidos, denominada por Tecnologia Substituta 02, é uma tecnologia que também foi desenvolvida para armazenar e estabilizar os dejetos provenientes da granja e fica caracterizada por máquina revolvedora que mistura maravalha ou serragem aos dejetos líquidos dos suínos, funcionando em edificação adequada, arejada, em sistemas de leiras onde o composto estabiliza e depois fica armazenado, com pé direito alto e muros que comportam trilhos para deslizar o equipamento, deve possuir espaço para instalações elétricas e bombeamento dos dejetos, bem como um sistema de drenagem e revestimento impermeabilizado para evitar infiltração no solo. O dimensionamento das tecnologias deve ser de acordo com o tipo de granja e escala produtiva, mas para fins desse trabalho tomamos como parâmetro a capacidade de armazenamento e processamento de $700 \mathrm{~m}^{3} \mathrm{e}$, o período anual para os cálculos de custos fixos e variáveis.

\section{RESULTADOS E DISCUSSÃO \\ Custos e reciclagem de $P$ - tecnologia de referência $x$ substituta 01}

A tecnologia de referência, esterqueira, é um sistema relativamente simples e requer um menor custo de instalação e operação se comparado com as demais. São aproximadamente 35 mil reais com investimentos iniciais para $700 \mathrm{~m}^{3}$ - dimensões de referência. Essa estrutura permite uma reciclagem anual em torno de 2.400 $\mathrm{Kg}$ de $\mathrm{P}$, conforme nossos cálculos. Contudo, o biodigestor ou tecnologia substituta 01, necessita de um investimento inicial 54\% maior, aproximadamente 54 mil reais, porém, recicla apenas $38 \%$ ou $900 \mathrm{Kg}$ a mais de $\mathrm{P}$ em relação à esterqueira (Tabela 1 , Itens 03 e 07). Quando comparadas a tecnologia de referência e a tecnologia substituta 01, pode-se observar ainda que na substituta, por causa do maior controle do sistema (sistema anaeróbico), temos uma redução no período de maturação e transformação dos elementos $\left(\mathrm{T}_{\mathrm{e}}\right)$, Tabela 1 , Item 02. 
Por fim, temos uma redução de custos com a recuperação do elemento $P$, avaliada em aproximadamente de nove mil reais/ ano para o caso da esterqueira, em outras palavras, a tecnologia de referência pode recuperar seu investimento em cerca de quatro anos, se considerarmos apenas os investimentos iniciais para implementação da tecnologia. Já no caso do biodigestor, temos uma redução de custos com a recuperação do elemento $\mathrm{P}$ de aproximadamente 12,5 mil reais/ ano, com tempo de retorno estimado em cerca de quatro anos e meio.

\section{Custos e reciclagem de $P$ - tecnologia de referência $x$ substituta 02}

Quando comparadas à tecnologia de referência com a substituta 02, compostagem mecânica de dejetos, ocorre então uma discrepância muito maior no que diz respeito aos custos. Nesse caso, a tecnologia substituta exige um investimento inicial consideravelmente mais alto, chegando aos 500 mil reais, entre máquinas, equipamentos e construção civil, contra apenas os 35 mil de investimentos para construção da esterqueira. Lembrando que ambas as tecnologias foram dimensionadas para o processamento de $700 \mathrm{~m}^{3}$, muito embora a tecnologia substituta consiga estabilizar os dejetos mais rapidamente, o que diminui essa desvantagem (Tabela 2 , Item 02). No que diz respeito à quantidade de $\mathrm{P}$ reciclada, temos $2.400 \mathrm{Kg}$ de $\mathrm{P}$ para a tecnologia de referência, contra $6.300 \mathrm{Kg}$ de $\mathrm{P}$ pela substituta 02 , cerca de 2,6 vezes mais $\mathrm{P}$, porém, com os custos anuais totais 16,7 vezes maiores (Tabela 2). Nesse caso, tomando-se como referência apenas os custos do investimento inicial para instalação da tecnologia substituta $02 \mathrm{e}$, com uma redução de custos a partir da recuperação de $\mathrm{P}$ em aproximadamente 23,9 mil reais/ ano, temos então um tempo de retorno estimado em cerca de 20 anos.

\section{CONCLUSÕES}

A esterqueira, o biodigestor, bem como a compostagem mecânica de dejetos foram escolhidas para avaliação nesse trabalho por serem tecnologias que estão atualmente em uso pelos produtores de carne suína, não somente no Estado de Santa Catarina, como também em outras regiões produtoras pelo Brasil afora. Entretanto, fica claro que estamos falando de granjas com necessidades diferentes e, neste caso é importante ressaltar que a tecnologia denominada substituta 02 , compostagem mecânica de dejetos, é uma tecnologia que foi desenvolvida para resolver o problema de granjas com maior escala produtiva e que não possuam área disponível suficiente para manejar os dejetos. Ou seja, essas tecnologias foram desenvolvidas para atender diferentes exigências técnicas ou legais e que, por fim, acabam por demandar diferentes graus de investimento. Entretanto, a partir do estudo de caso apenas do elemento $\mathrm{P}$, utilizado como referência mercadológica para esse trabalho, temos então a constatação de que a reutilização do composto estabilizado proveniente dos dejetos líquidos dos suínos, serve como adubo se manejado de forma adequada e permite ainda uma redução de custos para aquelas propriedades que possuem áreas demandantes de fertilizantes. Desta forma, a reciclagem desses resíduos líquidos da criação dos suínos se mostra como um fator mitigador de custos e que deve ser amplamente estudado e praticado pelos agentes da suinocultura intensiva em busca da sustentabilidade dessa atividade.

\section{REFERÊNCIAS}

AVILA, A. F. D.; RODRIGUES, G. S.; VEDOVOTO, G. L. (Coord.) Avaliação dos impactos de tecnologias geradas pela Embrapa: metodologia de referência. Brasília, DF: Secretaria de Gestão Estratégica, 2008. 189 p. CONAMA. Resolução n. 237, de 19 de dezembro de 1997. Disponível em: http://www.mma.gov.br/port/ conama/res/res97/res23797.html. Acesso em: 03 de dezembro de 2017 às 15h50.

GONÇALVES, R. G.; PALMEIRA, E. M. Mapeamento da Suinocultura Brasileira. [s.l: s.n.].

IBGE. Indicadores IBGE. Instituto Brasileiro de Geografia e Estatística - IBGE, p. 14-49, 2016.

PREÇOS de insumos, serviços e fatores de produção. CEPA, 2018. Disponível em: <https://cepa.epagri.sc.gov.br/index.php/produtos/mercado-agricola/precos-de-insumos-servicos-e-fatoresde-producao/>. Acesso em: 23 de novembro de 2018 às 11 h.

SEGANFREDO, M. A.; BISSANI, C. A.; SÁ, E. L. S. de. Grau de saturação de fósforo do solo e sua relação com o fósforo extraído com água como um índice ambiental. Sociedade Brasileira de Ciência do Solo. XI Reunião Sul-Brasileira de Ciência do Solo. Frederico Westphalen/RS, 2016. 
Tabela 1. Tecnologia de referência x substituta 01 .

\begin{tabular}{|c|c|c|c|c|c|c|}
\hline \multirow{2}{*}{\multicolumn{2}{|c|}{ Item }} & Tecnologia de Referência & Tecnologia Substituta 01 & \multicolumn{2}{|c|}{ Adoção da Substituta 01} & \multirow{3}{*}{$\begin{array}{l}\text { Un. } \\
\mathrm{m} 3\end{array}$} \\
\hline & & Esterqueira & Biodigestor & Benefícios & Ônus & \\
\hline 01 & Cap. Processamento $(\mathrm{Pc})$ & 700 & 700 & - & - & \\
\hline 02 & Tempo p/ Estabilização (Te) & 90 & 70 & -20 & & dias \\
\hline 03 & Cap. Processamento/ Ano $(\mathrm{Pa})$ & 2.400 & 3.300 & +900 & & $\mathrm{~m} 3$ \\
\hline 04 & Custos Fíxos & 2.864 & 4.631 & & 1.767 & $\mathrm{R} \$$ \\
\hline 05 & Custos Variáveis & 307 & 409 & & 102 & $\mathrm{R} \$$ \\
\hline 06 & Custos Totais & 3.171 & 5.040 & & 1.869 & $\mathrm{R} \$$ \\
\hline 07 & Reciclagem de P (RP) & 2.400 & 3.300 & +900 & & $\mathrm{Kg}$ \\
\hline 08 & Redução de Custos com P & 9.121 & 12.540 & +3419 & & $\mathrm{R} \$$ \\
\hline
\end{tabular}

Fonte: Site da Epagri/ CEPA, 2018 e, cálculos dos autores.

Tabela 2. Tecnologia de referência x substituta 02 .

\begin{tabular}{|c|c|c|c|c|c|c|}
\hline \multirow{2}{*}{\multicolumn{2}{|c|}{ Item }} & Tecnologia de Referência & Tecnologia Substituta 02 & \multicolumn{2}{|c|}{ Adoção da Substituta 02} & \multirow{2}{*}{ Un. } \\
\hline & & Esterqueira & Compostagem M. de Dejetos & Benefícios & Ônus & \\
\hline 01 & Cap. Processamento $(\mathrm{Pc})$ & 700 & 700 & - & - & $\mathrm{m} 3$ \\
\hline 02 & Tempo p/ Estabilização (Te) & 90 & 30 & -60 & & dias \\
\hline 03 & Cap. Processamento/ Ano (Pa) & 2.400 & 6.300 & +3900 & & $\mathrm{~m} 3$ \\
\hline 04 & Custos Fíxos & 2.864 & 40.065 & & 37.201 & $\mathrm{R} \$$ \\
\hline 05 & Custos Variáveis & 307 & 13.036 & & 12.729 & $\mathrm{R} \$$ \\
\hline 06 & Custos Totais & 3.171 & 53.101 & & 49.930 & $\mathrm{R} \$$ \\
\hline 07 & Reciclagem de P (RP) & 2.400 & 6.300 & +3900 & & $\mathrm{Kg}$ \\
\hline 08 & Redução de Custos com P & 9.121 & 23.940 & +14819 & & $\mathrm{R} \$$ \\
\hline
\end{tabular}

Fonte: Site da Epagri/ CEPA, 2018 e, cálculos dos autores. 


\title{
NUTRIENT BALANCES IN BEEF PRODUCTION SYSTEMS IN ARGENTINA AND URUGUAY
}

\author{
Gil, S.B. ${ }^{1}$; Tieri, M.P. ${ }^{2}$ ' LaManna, A.F. ${ }^{3}$; Faverín, C. ${ }^{4}$; Herrero, M.A. ${ }^{*}$ \\ ${ }^{1}$ Universidad de Buenos Aires, Facultad de Cs. Veterinarias, Buenos Aires, Argentina; ${ }^{2}$ INTA, EEA Rafaela, Santa Fe, Argentina; \\ ${ }^{3}$ INIA, La Estanzuela, Uruguay; ${ }^{4}$ INTA, EEA Balcarce, Buenos Aires, Argentina \\ *aherrero@fvet.uba.ar
}

\begin{abstract}
Nutrient balances provide information about the potential environmental risks in livestock production systems. This work presents the nitrogen $(\mathrm{N})$ and phosphorus $(\mathrm{P})$ balances and their utilization efficiencies in primary beef production systems, evaluated at farm level (FGB), in Argentina (A) and Uruguay (U). The FGB calculation was made by measurable output-input differences for each mineral in 144 farms (48 in $\mathrm{A} ; 96$ in U), expressed in $\mathrm{kg} \mathrm{ha}^{-1} \mathrm{yr}^{-1}$. The nutrient efficiency was evaluated by the IEI\% indicator that expresses the relation between the N-P surplus (balances) and N-P inputs. Descriptive statistic and multivariate analysis was performed. Median values of N-P FGB were $22.8 \mathrm{~kg} \mathrm{ha}^{-1} \mathrm{yr}^{-1}$ and $0.68 \mathrm{~kg} \mathrm{ha}^{-1} \mathrm{yr}^{-1}$ respectively, for $\mathrm{A}$ and $41.7 \mathrm{~kg} \mathrm{ha}^{-1} \mathrm{yr}^{-1}$ and $5.6 \mathrm{~kg} \mathrm{ha}^{-1} \mathrm{yr}^{-1}$ for $\mathrm{U}$. For both countries inputs of $\mathrm{N}$ by Nfix were the most important and for $\mathrm{P}$ were fertilizers. Principal Component analysis showed for N-P inputs that the greater the farm size is the stocking rate; N-P inputs by fertilizers and feeds, and N by NFix are lesser. Inefficiencies of nutrients utilization were observed in both countries. The greatest ones have occurred in farms with less productivity where the highest input was from fertilizers. Nutrient management differences and similarities in their grazing systems were observed, so in their FGB. In future studies it would be important to incorporate more detail in the components of the production systems in order to better understand the relationships between these components and the nutrients fluxes within farms.
\end{abstract}

Keywords: environmental management indicators, intensification, farm gate nutrient balances, nitrogen, phosphorus

\section{INTRODUÇTION}

Farm gate nutrient balances (FGB) are calculated as the arithmetic difference between the inputs and outputs of a nutrient to a given system (livestock farm, dairy farm, paddock, watershed, etc.). They provide information on the management of the area and the efficiency of nutrient conversion into a product. As it is easy of calculation, is the most used in the determination of environmental policies and regulations (Oenema et al, 2003).

The aspects that most strongly affect the balances are the nutrient contribution in fertilizers and external feeds to the productive system. Another aspect that affects the contribution in temperate pasture regions is the biological fixation of N (NFix). Animal production systems generally have low nutrient use efficiency, which represents a risk for the environment, along with economic losses (Oenema et al, 2003).

The first studies in extensive beef pasture based production systems, held in Great Britain (Watson \& Atkinson, 1999), compared N FGB with (285 $\left.\mathrm{kg} \mathrm{N} \mathrm{ha}^{-1} \mathrm{yr}^{-1}\right)$ and without (17 $\left.\mathrm{kg} \mathrm{N} \mathrm{ha}^{-1} \mathrm{yr}^{-1}\right) \mathrm{N}$ fertilization. In Chile, Alfaro et al. (2009) calculated N and P FGB on implanted pastures with different stocking rate, obtaining values between -309 and $58 \mathrm{~kg} \mathrm{~N} \mathrm{ha}^{-1} \mathrm{yr}^{-1}$ and between -8 and $20 \mathrm{~kg} \mathrm{Pha}^{-1} \mathrm{yr}^{-1}$. In Argentina (A), Viglizzo et al. (2006) calculated N FGB in agricultural livestock systems (average of $21.82 \pm 28.65 \mathrm{~kg} \mathrm{~N} \mathrm{ha}^{-1} \mathrm{yr}^{-1}$ ) and Gil et al. (2009) P FGB of -0.71 and $0.37 \mathrm{~kg} \mathrm{P} \mathrm{ha}^{-1} \mathrm{yr}^{-1}$ for extensive farms without and with low supplementation, respectively. In the case of Uruguay (U), Tieri et al. (2011), in 36 beef cattle systems obtained average values of $\mathrm{N}$ and $\mathrm{P}$ balances of $54 \mathrm{~kg} \mathrm{~N} \mathrm{ha}^{-1} \mathrm{yr}^{-1}$ and $7 \mathrm{~kg} \mathrm{P} \mathrm{ha}^{-1} \mathrm{yr}^{-1}$, respectively.

The objective of this study was to evaluate the N and P FGB through their inputs and outputs, their nutrient utilization efficiency and the association with farm size and stocking rate, in grazing base beef production systems in $\mathrm{A}$ and $\mathrm{U}$.

\section{MATERIALS AND METHODS}

A total of 144 farms dedicated to beef production were studied, 48 in A and 96 in U. In both cases, the surveys to gather the information were carried out over a period of 10 years, during this period the necessary information was accessed through an interview during a visit to the farms and/or accessing farm records. The N-P FGB were calculated for all cases with the corresponding indicators, all on an annual basis. 
In A, the sample consisted of 31 units of extensive systems with breeding livestock (beef production between 56 and $305 \mathrm{~kg} \mathrm{ha}^{-1} \mathrm{yr}^{-1}$ ), of which 15 were with extensive management, 8 with intensified management based on annual crops and forage reserves and eight with semi-intensive management based on rotational grazing. The remaining 17 units were semi-intensive systems with growing-finishing activity (meat production between 536 and $\left.1163 \mathrm{~kg} \mathrm{ha}^{-1} \mathrm{yr}^{-1}\right)$, rotational management based on pastures and annual crops, and supplementation with grains, sunflower expeller and/or silage (corn and sorghum).

In U 96 farm records of mixed crop and cattle farm were accessed. The 96 farms were semi intensified farms as described above but with a lower meat production per ha since crops were planted in part of the farms.

The FGB were calculated by the difference between inputs and outputs for each mineral, expressed in kilos N-P ha- $\mathrm{yr}^{-1}$. The N-P inputs were calculated from external feeds to the farms and from fertilizers. For the $\mathrm{N}$, also was considered the fixation of $\mathrm{N}$ (NFix) by legumes. It was considered in the outputs the N-P exported in the meat produced and the exit of feed (grains and hay). To evaluate nutrient utilization efficiency an indicator was constructed: -Imbalance efficiency indicator (IEI, \%): quotient between the balance (which represents the excess that remains in the farm) and the total nutrient entered to the farm [(balance N-P/input N-P)x100], where lower values indicate greater efficiencies. A descriptive and a multivariate analysis were performed relating inputs and outputs with stocking rate and farm size (ha). The Infostat software (2017) was used.

\section{RESULTS AND DISCUSSION}

Stocking rate was greater in A $\left(2.21 \pm 1.92 \mathrm{hd} \mathrm{ha}^{-1}\right)$ than in $\mathrm{U}\left(1.58 \pm 0.55 \mathrm{hd} \mathrm{ha}^{-1}\right)$ determined by the superior intensified grass finishing level, and with more variability due to the greater farm size and different beef systems.

Results of the different indicators are presented in Table 1. Median FGB-N of U were twice than FGB$\mathrm{N}$ of $\mathrm{A}$ and exceeded the FGB-P in 5 times, possibly related to the amount of extensive systems with breeding activity in A with less use of $\mathrm{P}$ fertilizers and imported feed. Furthermore, both FGB of both countries were in the range of those evaluated in Pampean region of A (-76.62 to $102.87 \mathrm{~kg} \mathrm{~N} \mathrm{ha}^{-1} \mathrm{yr}^{-1}$ and -31.80 to $13.40 \mathrm{~kg} \mathrm{P}$ $\mathrm{ha}^{-1} \mathrm{yr}^{-1}$ by Viglizzo et al. (2006), but resulted lower than the ones obtained in Europe (FGB-N 100 and $42 \mathrm{~kg}$ $\mathrm{N} \mathrm{ha}^{-1} \mathrm{yr}^{-1}$ ) with high quantity of imported manure to the farms (Berry et al., 2003). Otherwise, Watson et al (2002) in an extended review showed higher N FGB (112 kg $\left.\pm 26 \mathrm{~kg} \mathrm{~N} \mathrm{ha}^{-1} \mathrm{yr}^{-1}\right)$ but lower P FGB $(-1.80 \pm$ $1.40 \mathrm{~kg} \mathrm{P} \mathrm{ha}^{-1} \mathrm{yr}^{-1}$ ) than FGB in A and $\mathrm{U}$.

Inputs of $\mathrm{N}$ by Nfix were higher than $63 \%$ for both countries, then by fertilizers $(30 \% \mathrm{~A} ; 18 \% \mathrm{U})$ and by feed $(22 \% \mathrm{~A} ; 12 \% \mathrm{U})$ with a wide range. Inputs of $\mathrm{P}$ by fertilizers were higher than $68 \%$ for both countries, showing the need to restitute $\mathrm{P}$ in soils.

The analysis of Principal Components showed for $\mathrm{N}$ and $\mathrm{P}$ inputs that the greater the farm size is, the stocking rate, N-P inputs of fertilizers and feeds and N by NFix are lesser (Figure 1). Similar behavior was observed for $\mathrm{P}$ inputs (Figure 2).

Farms from U resulted with higher inefficiencies (higher IEI values) (Table 1) for both $\mathrm{N}$ and P. Lower $\mathrm{N}$ IEI values for A were obtained on very extensive farms where no imported nutrients entered the system by fertilizers and feed, with only low inputs by NFix. The greatest inefficiencies have occurred in farms with less productivity where the highest inputs were from fertilizers, being interpreted this situation by the largest number of steps and time in reaching these nutrients to be expressed in plant growth and then in meat production.

\section{CONCLUSIONS}

The FGB of beef production systems in A and $\mathrm{U}$ were studied and presented together for the first time. Nutrient management differences and similarities in their grazing systems were observed. Parameters evaluated showed similar characteristics which allow starting joint studies to monitor these indicators. In future studies it would be important to incorporate more detail of the components of the production systems, in order to better understand the relationships between these components and the nutrients fluxes within farms.

\section{ACKNOWLEDGEMENTS}

To the financial support of the UBACyT 2018-2021 program (University of Buenos Aires, Argentina) project 20020170100226BA, of the INIA, La Estanzuela, Uruguay and of INTA, Argentina 


\section{REFERENCES}

ALFARO, M., SALAZAR, F.S., OENEMA, O. et al. Nutrient balances in beef cattle production systems and their implications for the environment. J. Soil Sci. Plant Nutr 9 (1), 40 - 54, 2009.

BERRY, P.M., STOCKDALE, E.A., SYLVESTER-BRADLEY, R., PHILIPPS, L., SMITH, K.A., LORD, E.I., WATSON, C.A. \& FORTUNE, S. 2003. N, P and K budgets for crop rotations on nine organic farms in the UK. Soil Use and Management 19 (2): $112-118$.

DI RIENZO, J.A., CASANOVES, F., BALZARINI, M.G., et al. InfoStat versión 2017. Grupo InfoStat, FCA, Universidad Nacional de Córdoba, Argentina. URL http://www.infostat.com.ar

GIL, S.B.; HERRERO, M.A.; SAUCEDE, M.C. Intensificación ganadera y valoración del fósforo como factor de presión al ambiente. In "Estrategias Integradas de Mitigación y Adaptación a Cambios Globales". Eds. Fernández Reyes, L. et al. Buenos Aires, CITEP-UBA press Argentina, pp.323-331, 2009.

OENEMA, O., KROS, H., de VRIES, W. Approaches and uncertainties in nutrient budgets: implications for nutrient management and environmental policies. Eur. J. Agric. 20, 3-16, 2003.

TIERI, M.P., LA MANNA, A., MONTOSSI, F. et al. El Balance de Nutrientes en 36 Predios Comerciales del GIPROCAR II (FUCREA/INIA): Una Primera Aproximación al Proceso de Intensificación en Sistemas Agrícola-Ganaderos y su Potencial Impacto en el Ambiente. INIA. 35 p. (Serie Actividades de Difusión Nº. 658).2011.

VIGLIZZO, E.F., FRANK. F., BERNARDOS, J. et al. A Rapid Method for Assessing the Environmental Performance of Commercial Farms in the Pampas of Argentina. Environ. Monit. Assess. 117: 109-134, 2006. WATSON, C.A., BENGTSSON, H., EBBESVIK, M., LOES, A-K., MYRBECK, E., SALOMON, E., SCHRODER, J. \& STOCKDALE, E.A. 2002. A review of farm-scale nutrient budgets for organic farms as a tool for management of soil fertility. Soil Use and Management, 18, Supl: 264-273.

WATSON, C.A. \& ATKINSON, D. Using nitrogen budgets to indicate nitrogen use efficiency and losses from whole farm systems: a comparison of three methodological approaches. Nutr Cycl Agroecosyst 53: 259 - 267, 1999.

Table 1. Farm gate balances (FGB) of nitrogen $(\mathrm{N})$ and phosphorus $(\mathrm{P})$, components and imbalance efficiency indicator (IEI) in beef production systems of Argentina and Uruguay (median values, minimum; maximum).

\begin{tabular}{|c|c|c|}
\hline Parameters & ARGENTINA & URUGUAY \\
\hline $\mathrm{N}$ inputs $\left(\mathrm{kg} \mathrm{ha}^{-1} \mathrm{yr}^{-1}\right)$ & $33.0(5.1 ; 386.2)$ & $48.6(10.7 ; 154.9)$ \\
\hline $\mathrm{N}$ outputs $\left(\mathrm{kg} \mathrm{ha}^{-1} \mathrm{yr}^{-1}\right)$ & $8.3(2.2 ; 96.9)$ & $6.0(2.1 ; 22.2)$ \\
\hline N FGB $\left(\mathrm{kg} \mathrm{ha}^{-1} \mathrm{yr}^{-1}\right)$ & $22.8(-1.4 ; 340.8)$ & $41.7(7.2 ; 138.7)$ \\
\hline $\mathrm{P}$ inputs $\left(\mathrm{kg} \mathrm{ha}^{-1} \mathrm{yr}^{-1}\right)$ & $4.1(0 ; 53.7)$ & $7.4(0 ; 50.7)$ \\
\hline $\mathrm{P}$ outputs $\left(\mathrm{kg} \mathrm{ha}^{-1} \mathrm{yr}^{-1}\right)$ & $2.0(0.6 ; 25.5)$ & $1.6(0.6 ; 5.8)$ \\
\hline P FGB $\left(\mathrm{kg} \mathrm{ha}^{-1} \mathrm{yr}^{-1}\right)$ & $0.7(-9.5 ; 38.7)$ & $5.6(-2.8 ; 47.5)$ \\
\hline N IEI $\%$ & $73(18 ; 88)$ & $86(60 ; 94)$ \\
\hline P IEI \% & $47(2 ; 81)$ & $77(11 ; 96)$ \\
\hline
\end{tabular}




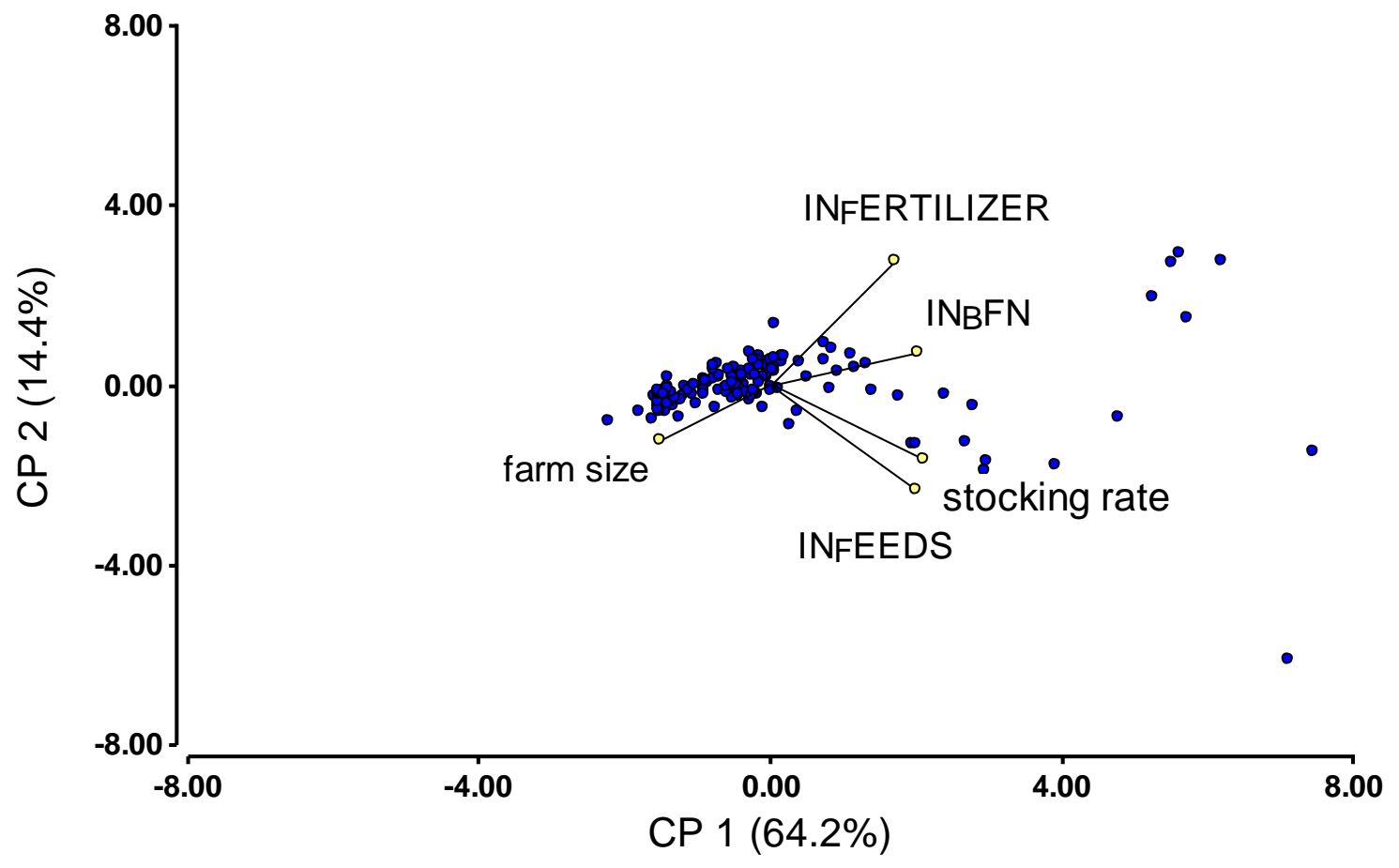

\section{Biplot(1,2) - $\quad$-Biplot(1,2) - Variables}

Figure 1. Analysis of Principal Components among farm size, stocking rate, inputs of $\mathrm{N}$ by NFix, fertilizers and feeds for beef production systems of Argentina and Uruguay $(n=144)$.

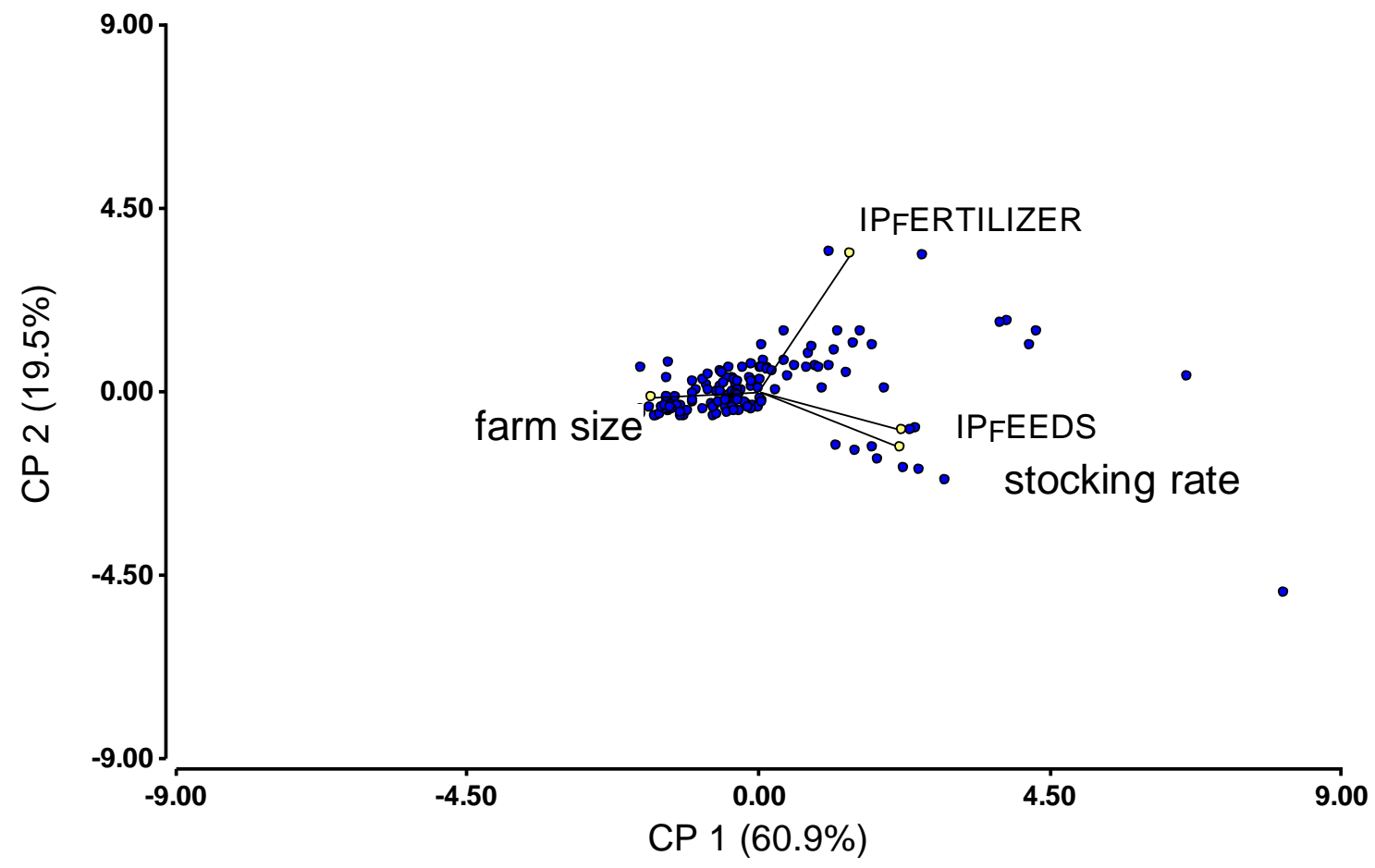

Biplot $(1,2) \quad$-Biplot $(1,2)$ - Variables

Figure 2. Analysis of Principal Components among farm size, stocking rate, inputs of $P$ by fertilizers and feeds for beef production systems of Argentina and Uruguay $(n=144)$. 


\title{
NUTRIENT BALANCES IN MILK PRODUCTION SYSTEMS IN ARGENTINA
}

\author{
Charlón, V. ${ }^{\text {*; }}$ Herrero, M.A. ${ }^{2}$; Cuatrín, A. ${ }^{3}$ \\ ${ }^{I}$ INTA, EEA Rafaela, Santa Fe, Argentina \\ ${ }^{2}$ Universidad de Buenos Aires, Fac. Cs. Veterinarias, Buenos Aires, Argentina \\ ${ }^{3}$ INTA, EEA Parana, Entre Ríos, Argentina \\ *charlon.veronica@inta.gob.ar
}

\begin{abstract}
Nutrient balance is a good indicator to know the potential environmental risk in productive systems. Nitrogen $(\mathrm{N})$ and phosphorus $(\mathrm{P})$ balances and their utilization efficiencies were evaluated, at farm level (FGB), in primary milk production systems in different milk boundaries in Argentina. The balance calculation was made by measurable output-input differences for each mineral in 57 farms, expressed by year as kg.ha- ${ }^{-1}$ and as Kg N-P per ton of fat-and-protein-corrected milk. The nutrient efficiency was evaluated by the IEI\% indicator that expresses the relation between the N-P surplus (balances) and N-P inputs. Descriptive statistic and multivariate analysis was performed. The N FGB were from -26.7 to $329.9 \mathrm{Kg}^{-h^{-1}}{ }^{-1} \mathrm{yr}^{-1}$ or -5.0 to 32.9 Tn $\mathrm{FPCM}^{-1} \cdot \mathrm{yr}^{-1}$ and the P FGB from -4.9 to $131.9 \mathrm{Kg} \mathrm{ha}^{-1} \cdot \mathrm{yr}^{-1}$ or -4.9 to $131.0 \mathrm{Tn} \mathrm{FPCM}^{-1} \cdot \mathrm{yr}^{-1}$. Major N inputs $(70 \%)$ on all dairies farms were concentrates. The principal component analysis showed that a positive association between N-P FGB and the N-P inputs. Four cluster of farms were identified, characterized by different values of balances, outputs and $\mathrm{kg} \mathrm{FPCM} . \mathrm{ha}^{-1}$. Milk was the main source of N-P exported in all cluster $(>86 \% \mathrm{~N} ;>80 \% \mathrm{P})$. A relation was observed between total milk production and the total $\mathrm{N}$ imported to the farm. The IEI found were from 0 to $94 \%$ for $\mathrm{N}$ and $96 \%$ for $\mathrm{P}$. The nutrient management is different between farms. More information about some management practices will be need for future studies, in order to better understand the relationships between these components and the nutrients fluxes within farms.
\end{abstract}

Keywords: environmental management indicators, farm gate balances, nitrogen, phosphorus.

\section{INTRODUCTION}

Nutrient balance approach is one of the most common methods to quantify the environmental impact of nutrient use (Oenema et al., 2003), being key indicators for assessing the sustainability of agro-livestock systems. They are useful to understand nutrient dynamics and to know their potential to be retained and cycled within the system itself, estimating the magnitude of the environmental and economic cost (Gourley et al, 2012; Öborn et al, 2003; Spears et al, 2003 a-b).

The farm gate nutrient balances (FGB) compute the difference in nutrients entering and leaving a system, showing the nutrients surplus (balances) that can be expressed per hectare of on-farm agricultural area or per kilogram of valuable outputs. The balance of $\mathrm{N}$ and $\mathrm{P}$ are mostly studied because they are the major nutrients that can limit crop growth and also their losses can cause environmental problems (Thomassen \& de Boer, 2005). Nutrient balances are of recent diffusion in Argentina. Although the international literature presents a variety of case studies, but they do not represent the reality of Argentina's milk production systems. The objective was to evaluate the nitrogen and phosphorus gate farm balances through their inputs and outputs and their nutrient utilization efficiency, in milk production systems in different productive areas in Argentina.

\section{MATERIALS AND METHODS}

Fifty-seven farms locate in three dairy regions in Argentina were selected and surveyed. The dairies farm surveyed belonged to the basins: Santa Fe (SF): 19, Buenos Aires West (BA_W): 19 and Buenos Aires East (BA_E): 19. Farm gate balances were calculated considering the difference between income and output for each mineral, expressed in kilograms of N-P per hectare and per year and as Kg N-P per ton of fat-andprotein-corrected milk $(\mathrm{FPCM})$ using the formula: [raw milk $(\mathrm{kg}) *(0.337+0.116 *$ Fat content $(\%)+0.06 *$ Protein content (\%)] (FAO, 2010). For N and P incomes were considered those coming from external foods and fertilizers, and in addition, for the $\mathrm{N}$ and the rainfall. $\mathrm{N}$ and $\mathrm{P}$ exported in the milk and meat produced were considered in the outgoings. Also, the following variables were considered total farm land (ha), number of dairy cows, stocking rate (LU.ha ${ }^{-1}$ ), production level (kg of FPCM.cow-1) and dairy efficiency ( $\mathrm{kg}$ of FPCM.ha-1 ${ }^{-1}$. 
To assess nutrient utilization efficiency, the indicators was constructed: Imbalance efficiency indicator (IEI, \%): quotient between the balance (which represents the excess that remains in the establishment) and the total nutrient entered [(balance N-P/income N-P)x100], where lower values indicate greater efficiencies.

In order to establish the association between the studied variables, an analysis of main components (ACP) was carried out. In addition, a cluster analysis using Ward's criterion, based on the Gower distance of the standardized data, was proposed to identify farms with similar management. A Kruskal Wallis analysis was performed with the achieved clusters to determine which variables differ among them, as well as a chisquare test to determine the association between the achieved clusters and the assessed basins. Infostat (2017) was used.

\section{RESULTS AND DISCUSSION}

The N FGB were from -26.7 to $329.9 \mathrm{Kg} \cdot \mathrm{ha}^{-1} \cdot \mathrm{yr}^{-1}$ or -5.0 to $32.9 \mathrm{Tn} \mathrm{FPCM}^{-1}$. $\mathrm{yr}^{-1}$ and the P FGB from 4.9 to $131.9 \mathrm{Kg} \cdot \mathrm{ha}^{-1} \cdot \mathrm{yr}^{-1}$ or -4.9 to $131.0 \mathrm{Tn} \mathrm{FPCM}^{-1} \cdot \mathrm{yr}^{-1}$. Major $\mathrm{N}$ inputs (70\%) on all dairies farms were concentrates.

The results obtained from the ACP explained 54\% of the variability of the data, opposing in the CP1 the dairies farm that have high values in the balance with respect that its have low. The CP2 discriminated the dairy farms that have high outputs and $\mathrm{kg}$ of FPCM per ha, of those with low values.

From the cluster analysis, the 57 dairy farms were classified into 4 clusters (C) of farms discriminated by the selected variables. The distribution of dairy farms according to the basin in each cluster is represented in Figure 1. Table 1 shows the mean and minimum and maximum values of $\mathrm{N}$ y $\mathrm{P}$ input, outputs and balances for each cluster.

The $\mathrm{N}$ inputs from concentrates represented $77 \%$ in $\mathrm{C} 1,62 \%$ in $\mathrm{C} 2,66 \%$ in $\mathrm{C} 3$ and $61 \%$ en $\mathrm{C} 4$. The $\mathrm{N}-$ $\mathrm{P}$ per $\mathrm{kg}$ concentrate was also analyzed, finding in order the magnitude $\mathrm{C} 2<\mathrm{C} 1<\mathrm{C} 3<\mathrm{C} 4$. Milk was the main source of N-P exported in all cluster $(>86 \% \mathrm{~N}$ and $>80 \% \mathrm{P})$. The $\mathrm{N}$ and $\mathrm{P}$ exports in animals, it was very low due to the sale of rejected milking cows.

In all the cases the balances $(\mathrm{N}$ and $\mathrm{P}$ ) were less values than other international studies (Spears et al, 2003; Oenema et al, 2012; Mu et al, 2016). The values found were from 1.88 (C2) to 133.46 (C4) $\mathrm{Kg} \mathrm{N}$ per ha and 0.29 to $15.25 \mathrm{Kg} \mathrm{N}$ per ton FPCM. As for the P, values of 1.36 (C2) to 28.55 (C4) Kg P per ha and 0.2 to $4.05 \mathrm{Kg}$ P per ton FPCM.

There are two clusters ( $\mathrm{C} 2$ and $\mathrm{C} 4)$ that differed statistically in most of the analyzed parameters. The $\mathrm{C} 2$ included 7 farms characterized by a the lowest value of $\mathrm{N}$ and $\mathrm{P}$ input and balances and the highest stockind rate, with a mean of $1.51 \mathrm{LU}^{-h^{-1}}$ and intermediate efficiency (6680 Kg FPCM.ha' $\left.{ }^{-1}\right)$. In this cluster the dairies

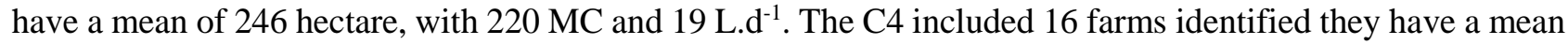
of 410 hectares, $341 \mathrm{MC}$ y $23 \mathrm{~L}^{-\mathrm{d}^{-1}}$ as the highest inputs and outputs and the balances with highest milk production (8464 Kg FPCM.MC ${ }^{-1}$ ). The dairy farms in $\mathrm{C} 2$ had a lower loss of $\mathrm{N}$ compared to those in C4 that rely more on food and fertilizers purchased to produce milk, while the $\mathrm{C} 2$ dairy farms made more intensive use of the pastures. The other cluster were characterized by $\mathrm{C} 1$ had 16 dairy farms with the major P outputs and $\mathrm{C} 3$ with 18 dairy farms had a lowest P outputs.

A relation was observed between total milk production and the total $\mathrm{N}$ imported to the farm (Figure 2). This can be explained by the fact that there is an interdependence between the inputs (concentrate mainly) and the milk productivity (Kg FPCM.ha ${ }^{-1}$ ). Nutrient losses per ha at farm level can reflect the local or regional impacts of dairy farming, whereas nutrient losses per unit of product provide insights into the efficiency of a production system (Halberg et al., 2005). When the efficiency of nutrient utilization was analyzed, C2 was the group with the best IEI_N (5\%) and IEI_P (14\%), given that with the lower income of N-P and with a higher animal load, the highest milk production per hectare.

\section{CONCLUSIONS}

The intensification of the dairy farms in the different basins of Argentina is due, among other aspects, to the greater use of nutrients, specifically $\mathrm{N}$ and $\mathrm{P}$. From the balances it is possible to quantify and compare the losses of nutrients, and provide the necessary information to improve in the use of nutrients at the farm level.The farm gate balances of milk production systems in Argentina boundaries showed that nutrient management is different between farms. More detailed information about fertilization practices, grazing management and nutritional decisions will be need for future studies, in order to better understand the relationships between these components and the nutrients fluxes within farms. 


\section{ACKNOWLEDGEMENTS}

To the financial support of the UBACyT 2018-2021 program (University of Buenos Aires, Argentina) project 20020170100226BA and PNPA 1126043 of INTA, Argentina

\section{REFERENCES}

DI RIENZO, J.A., CASANOVES, F., BALZARINI, M.G., et al. InfoStat versión 2017. Grupo InfoStat, FCA, Universidad Nacional de Córdoba, Argentina. URL http://www.infostat.com.ar

FAO (Food and Agriculture Organization of the United Nations). Greenhouse gas emissions from the dairy sector. A life cycle assessment. FAO, Rome, Italy (2010) Prepared by P. Gerber, T. Vellinga, C. Opio, B. Henderson, and H. Steinfeld. FAO Rome, Italy, 2010

GOURLEY, C.J.P., DOUGHERTY, W., WEAVER, D. et al. . Farm-scale nitrogen, phosphorus, potassium and sulphur balances and use efficiencies on Australian dairy farms. An Prod Sci, 52: 929-944, 2012

HALBERG, N., VAN DER WERF, H., BASSET-MENS, C. et al. Environmental assessment tools for the evaluation and improvement of European livestock production systems. Livest. Prod. Sci. 96, 33e50, 2005.

MU, W.; VAN MIDDELAAR, C.E.; BLOEMHOF, J.M.; OENEMA, J.; DE BOER, I.J.M. Nutrient balance at chain level: a valuable approach to benchmark nutrient losses of milk production systems,

Journal of Cleaner Production, Volume 112, Part 4, 2419-2428, 2016.

OENEMA, O., KROS, H., de VRIES, W. Approaches and uncertainties in nutrient budgets: implications for nutrient management and environmental policies. Eur. J. Agric. 20, 3-16, 2003.

OENEMA, J.; VAN ITTERSUM, M.; VAN KEULEN, H. Improving nitrogen management on grassland on commercial pilot dairy farms in the Netherlands, Agriculture, Ecosystems \& Environment, Volume 162, 116126, 2012.

SPEARS, R. A.; KOHN, R. A.; YOUNG, A. J. Whole-farm Nitrogen Balance on Western Dairy Farms. J. Dairy Sc. 86 (12): 4178-4186, 2003a

SPEARS, R. A.; YOUNG, A. J.; KOHN, R. A. Whole-farm Phosphorus Balance on Western Dairy Farms. J. Dairy Sc. 86 (2): 688-695, 2003b

THOMASSEN, M.A.; DE BOER, I.J.M. Evaluation of indicators to assess the environmental impact of dairy production systems. Agriculture Ecosystems \& Environment 111, 185-199, 2005.

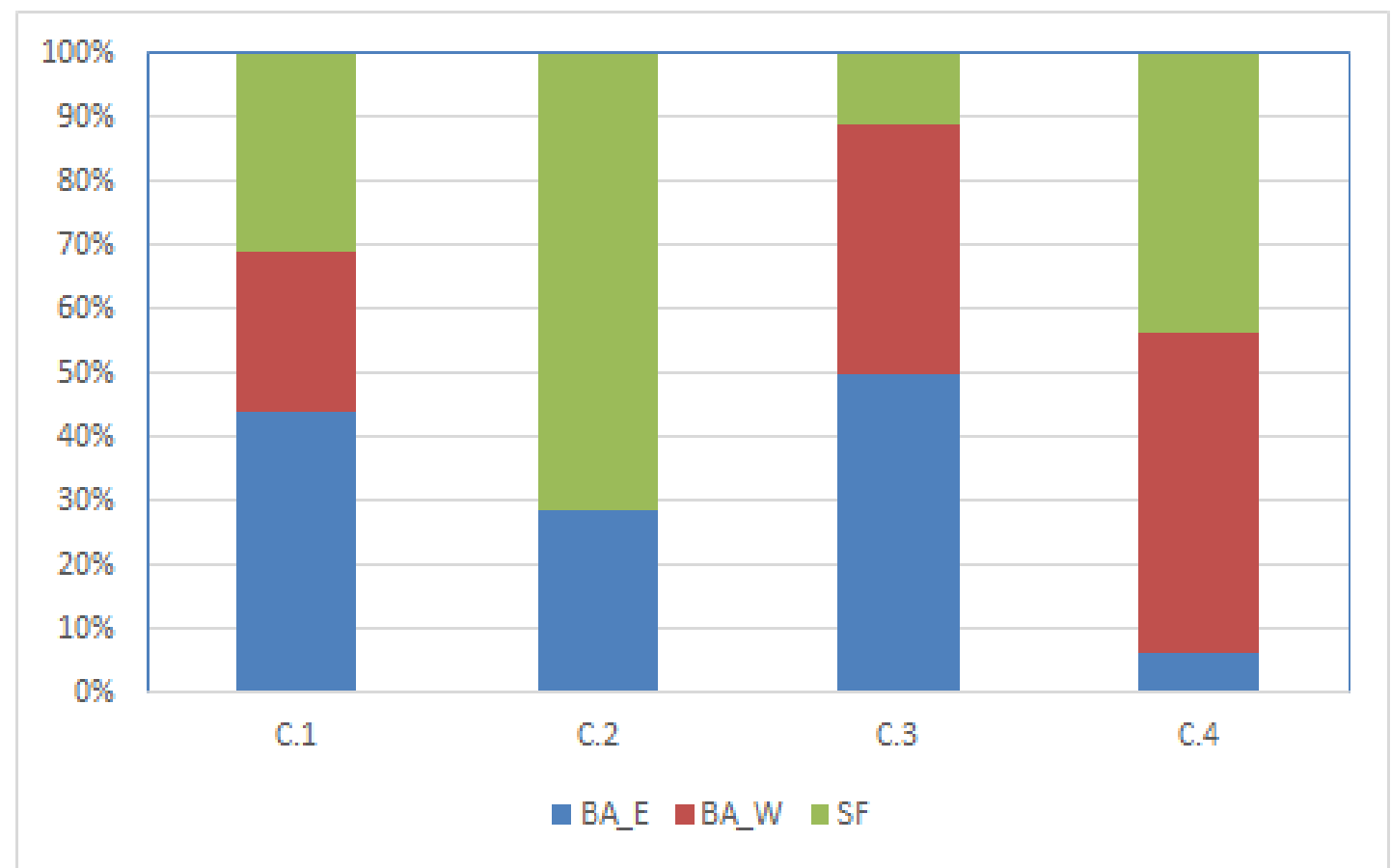

Figure 1. Distribution of dairy farms according to the basin in each cluster. 
Table 1. Nutrient balances and their components in four cluster in Argentina (median values, minimum;

\begin{tabular}{|c|c|c|c|c|}
\hline Parameters & $\begin{array}{c}\text { Cluster 1 (C1) } \\
n=16\end{array}$ & $\begin{array}{c}\text { Cluster 2 (C2) } \\
n=7\end{array}$ & $\begin{array}{c}\text { Cluster } 3(\mathbf{C 3}) \\
\mathrm{n}=18\end{array}$ & $\begin{array}{c}\text { Cluster } 4(\mathbf{C 4}) \\
\mathrm{n}=16\end{array}$ \\
\hline $\begin{array}{l}\mathrm{N} \text { inputs } \\
\left(\mathrm{Kg} \mathrm{ha}^{-1} \cdot \mathrm{yr}^{-1}\right)\end{array}$ & $90.9(37.1 ; 119) \mathrm{b}$ & $40.7(5.9 ; 62.8) \mathrm{a}$ & $79.6(8.6 ; 128 ; 5) b$ & $170.8(51.2 ; 360.4) \mathrm{c}$ \\
\hline $\begin{array}{l}\text { N outputs } \\
\left(\text { Kg.ha-1.yr }{ }^{-1}\right)\end{array}$ & $40,29(18,9 ; 61,9) b$ & $38,79(27,9 ; 59,1) b$ & $22,11(4,0 ; 36,1) \mathrm{a}$ & $38,87(30,4 ; 64,8) b$ \\
\hline $\begin{array}{l}\text { N balance } \\
\left(\text { Kg.ha }^{-1} \cdot \mathbf{y r}^{-1}\right)\end{array}$ & $36.8(18.2 ; 78.4) b$ & $1.9(-26.7 ; 6.4) a$ & $57.2(4.6 ; 120.8) b$ & $133.5(0.8 ; 329.9) c$ \\
\hline $\begin{array}{l}\mathrm{N} \text { balance } \\
\left(\text { Tn } \text { FPCM }^{-1} \cdot \mathbf{y r}^{-1}\right)\end{array}$ & $5.3(2.3 ; 14.5) b$ & $0.3(-5.0 ; 0.7) a$ & $14.2(0.5 ; 20.6) c$ & $15.7(0.1 ; 32.9) c$ \\
\hline $\begin{array}{l}\mathrm{P} \text { inputs } \\
\left(\mathrm{Kg} \cdot \mathrm{ha}^{-1} \cdot \mathrm{yr}^{-1}\right)\end{array}$ & $21.7(16.1 ; 39.7) b c$ & $7.8(1.7 ; 13.7) \mathrm{a}$ & $20.2(0 ; 29.1) b$ & $38.6(13.6 ; 137.5) \mathrm{c}$ \\
\hline $\begin{array}{l}\text { P outputs } \\
\left(\mathrm{Kg} \cdot \mathrm{ha}^{-1} \cdot \mathrm{yr}^{-11}\right)\end{array}$ & $7.3(5.7 ; 10.8) b$ & $7.3(5.2 ; 10.7) b$ & $4.2(1 ; 6.5) \mathrm{a}$ & $6.9(3.4 ; 11.7) b$ \\
\hline $\begin{array}{l}\text { P balance } \\
\left(\text { Kg.ha }^{-1} \cdot \mathbf{y r}^{-1}\right)\end{array}$ & $14.6(9.3 ; 31.5) b$ & $1.4(-4.9 ; 3.7) \mathrm{a}$ & $15.8(-1.06 ; 23.7) b$ & $28.5(4.9 ; 131.9) \mathrm{b}$ \\
\hline $\begin{array}{l}\text { P balance } \\
\left(\text { Tn FPCM }{ }^{-1} \cdot \mathbf{y r}^{-1}\right)\end{array}$ & $2.4(1.1 ; 5.2) b$ & $0.2(-0.8 ; 0.6) a$ & $3.9(-0.12 ; 6.5) b$ & $4.05(0.5 ; 13.2) b$ \\
\hline \% IEI_N & $50(31.6 ; 65.8) b$ & $5(0 ; 10.7) \mathbf{a}$ & $72(33.7 ; 94.5) c$ & $76(1.3 ; 91 ; 5) c$ \\
\hline \% IEI_P & $71(47.3 ; 81.4) b$ & $14(0 ; 35.7) \mathrm{a}$ & $80(0 ; 85.9) c$ & $77(33.3 ; 95.9) b c$ \\
\hline
\end{tabular}

*Medians followed by different letters show significative differences Kruskal Wallis test $(\mathrm{p} \leq 0.05)$.

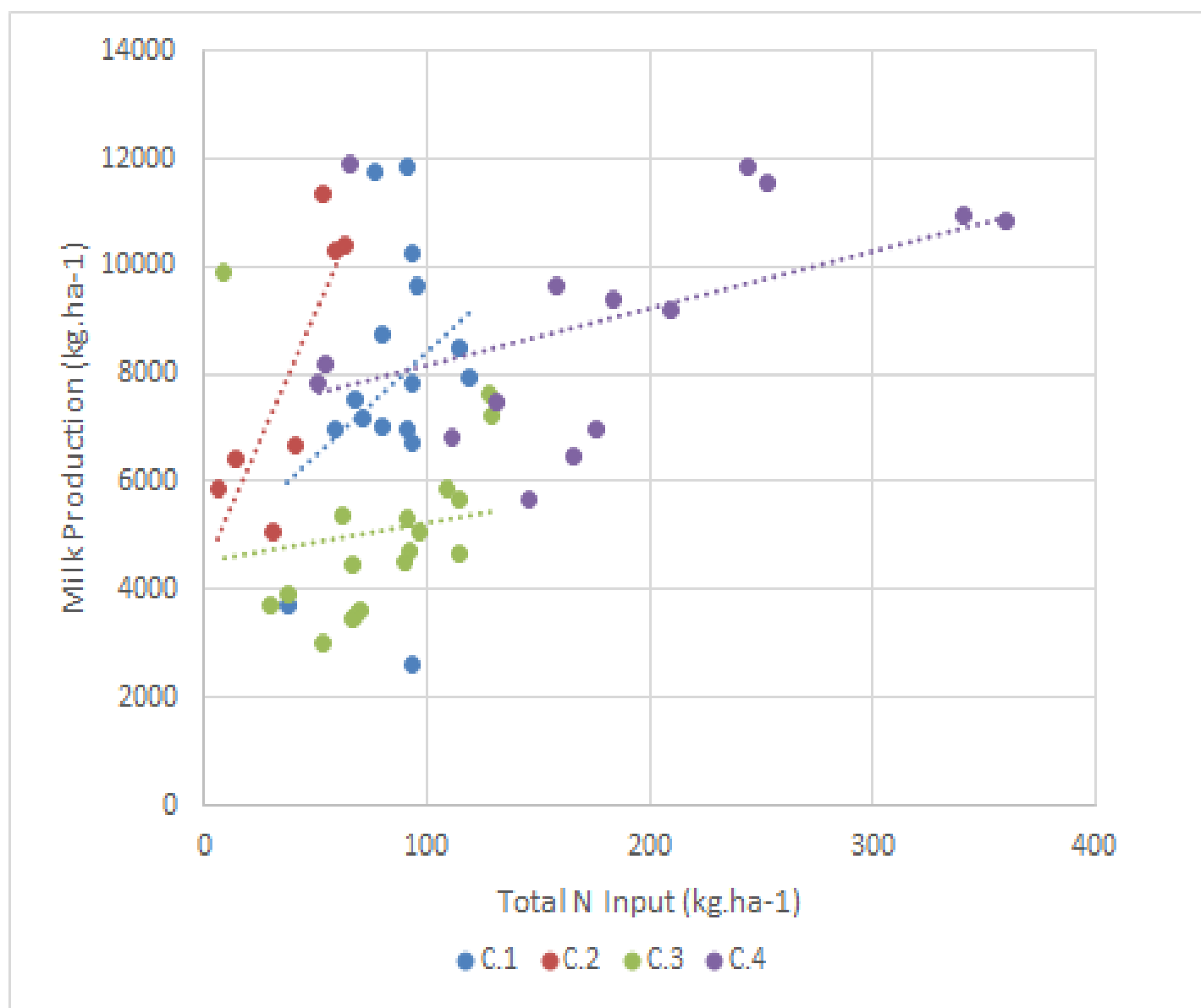

Figure 2. Diagram of dispersion and trend lines of the relationship between total nitrogen input and total milk production for each cluster. 


\title{
CUSTO DO LICENCIAMENTO AMBIENTAL NA SUINOCULTURA
}

\author{
Pietramale, R.T.R. ${ }^{1}$; Leite, B.K.V. ${ }^{1}$; Castro, I.C.C. ${ }^{\text {; }}$ Orrico, A.C.A. ${ }^{2}$; Ruviaro, C.F. ${ }^{2}$ \\ ${ }^{1}$ Pós-graduação no PPGZootecnia - Universidade Federal da Grande Dourados \\ ${ }^{2}$ Docente permanente do PPGZootecnia - Universidade Federal da Grande Dourados \\ rolimpiezoo@gmail.com
}

\begin{abstract}
RESUMO: Objetivou-se neste trabalho levantar os custos financeiros para a adequação de sistemas de produção de suínos, conforme o licenciamento ambiental estadual exige até o ano de 2018, bem como os custos dos produtores ao seguir tais exigências e compará-los as previsões de custos após a implantação da Portaria $\mathrm{n}^{\circ}$ 603, de 17 de maio de 2018. Consultou-se periódicos referentes ao tema proposto e coletou-se informações e dados de campo. As informações e dados foram: - Quais os tipos de Unidades Produtivas (UP) existiam na região e quantas eram em cada modalidade; - Quanto animais compunham cada UP; - Quais eram suas exigências legais contidas em suas licenças ambientais emitidas pelo Instituto do Meio Ambiente de Mato Grosso do Sul (IMASUL). Orçou-se o custo para o Licenciamento Ambiental e a manutenção do mesmo. A região norte do estado do Mato Grosso do Sul é expressiva na atividade suinícola. A quantidade de animais alojados influencia no custo médio por animal ao produtor, gerando uma diferença para animais na fase de engorda de $\mathrm{R} \$ 1,21$ a menos e para matrizes de $\mathrm{R} \$ 3,42$ a menos, isso quando relacionado aos gastos com regularização ambiental. Sendo desta forma mais rentável investir em maiores capacidades de alojamento de animais. Demonstrando a preocupação do Governo do Estado do Mato Grosso do Sul com a atividade, sendo também um dos motivos pelo qual o estado encontra-se entre os que mais crescem na atividade suinícola industrial.
\end{abstract}

Palavras-chave: Suinocultura industrial, legislação ambiental, plano de automonitoramento, resíduos de produção animal.

\section{COST OF ENVIRONMENTAL LICENSING IN PIG FARMING}

\begin{abstract}
The goal of this work was to find the costs for the implantation of pig farms with the state environmental licensing until the year 2018, and the costs to producers to meet these norms and compare them with the cost forecasts after the publication of the Ordinance $n^{\circ}$ 603, of May 17, 2018. Research was done on periodicals related to the proposed theme and information and field data were collected. The information and data were: - What types of productive units (UP) existed in the region and how many were in each modality; How many animals made up each UP; - What were your legal requirements contained in your environmental licenses issued by the Institute of the Environment of Mato Grosso do Sul (IMASUL). The cost for the Environmental Licensing and maintenance of the same was estimated. The northern region of the State of Mato Grosso do Sul is expressive in the swine activity. The number of animals housed influences the average cost per animal to the producer, generating a difference for animals in the fattening phase of $\mathrm{R} \$ 1.21$ less and for sows of $\mathrm{R} \$ 3,42$ less, this when related to environmental regularization expenses. Being this way more profitable to invest in greater capacities of housing of animals. Demonstrating the concern of the Government of the State of Mato Grosso do Sul with the activity, being also one of the reasons why the state is among the ones that grow the most in the swine farming.
\end{abstract}

Keywords: Industrial swine, environmental legislation, self-monitoring plan, waste of animal farming.

\section{INTRODUÇÃO}

A suinocultura vem a ser uma das atividades pecuárias mais importantes para a economia brasileira, gerando empregos e fontes de renda (Cardoso et al., 2015). Foi contabilizado pelo Ministério da Agricultura, Pecuária e Abastecimento (MAPA) que no ano de 2017 o Brasil abateu cerca de 43,185 milhões de cabeças de suínos (IBGE, 2018). Estando o Mato Grosso do Sul entre os estados de maior crescimento da suinocultura industrial.ste artigo descreve o modelo e as normas a serem usados na confecção de trabalhos para publicação nos Anais do V Sigera. Deixar uma linha em branco após a Introdução.

Com essa expressividade dos resultados da atividade busca-se cada vez mais descobrir novas técnicas de produção e otimizar as já existentes. Goehr et al. (2016) afirmam que o avanço tecnológico e a utilização 
de modelos produtivos cada vez mais confinados resultou em um aumento de produção de dejetos por unidade área, sendo imprescindível atenuar a atenção do suinocultor para as questões que envolvem os impactos ambientais causados pela atividade, além do ganho econômico e social. Tornando a suinocultura uma atividade de alta capacidade poluidora, trazendo novas necessidades de adequação ao manejo dos resíduos (ITO et al, 2016).

Os dejetos não tratados são altamente concentrados em matéria orgânica e apresentam nutrientes como nitrogênio, fósforo e potássio além de microrganismos patogênicos, aumentando a capacidade poluente (Souza et al., 2016). Além disso, Cardoso et al. (2015), abordam que os dejetos advindos da suinocultura industrial, quando não há tratamento adequado, podem trazer problemas ambientais impactantes como contaminação de lençóis freáticos, desequilíbrio dos nutrientes encontrados no solo, impermeabilização do solo, proliferação de superbactérias ou bactérias resistentes. Esses fatores atraem a atenção dos orgãos governamentais responsáveis pelas legislações que regulamentam essas atividades. Essas regulamentações são de ordem do Governo Federal, Governo Estadual e Municipal, hierarquicamente, cabendo a cada um exigir e fiscalizar o seguimento das normativas por parte dos produtores de suínos.

As normativas são o Decreto No 12.725 , de 10 de março de 2009, que se complementa com a Resolução SEMADE $n^{\circ}$ 9, de 13 de maio de 2015. Estas determinam em seus detalhes os caminhos a serem seguidos pelos produtores para que instalem e operem regularmente em suas atividades, além da complementação através da Portaria IMASUL n⿳ 603, de 17 de maio de 2018, sendo esta a mais recente e que influencia na periodicidade das análises, que não eram fixas até então, influenciando nos custos das mesmas. Porém o seguimento das normas, até abril de 2018, onerava um custo alto para o suinocultor.

Objetivou-se neste trabalho levantar os custos financeiros para a adequação de sistemas de produção de suínos, conforme o licenciamento ambiental estadual exigido até o ano de 2018, bem como os custos dos produtores ao seguir tais exigências e compará-los as previsões de custos após a implantação da portaria $n^{\circ}$ 603 , de 17 de maio de 2018.

\section{MATERIAL E MÉTODOS}

Foram feitas consultas a periódicos e literaturas referentes ao tema proposto, utilizando as palavraschave "Suinocultura Industrial", "Licenciamento Ambiental", "Legislação e dejetos suínos" e "Custos de licenciamento ambiental" em bases de dados como o Google Scholar, Scientific Periodicals Eletronic Library - SPELL e Scielo e, realizadas consultas com especialistas inseridos no ramo e solicitações de orçamentos para o mesmo seguimento empresarial. Após obter as informações bibliográficas e de campo, foi necessário investigar quais seriam as obrigações dos proprietários de granjas com relação aos regulamentos ambientais. E assim orçar e predizer valores médios para que uma Unidade Produtora (UP) pudesse ser liberada ou manter sua atividade suinícola dentro das exigências legais.

A priori pesquisou-se quais eram as exigências através do auxílio de um gestor ambiental que trabalha com esses regulamentos dando assistência para os suinocultores da região estudada.

Para a coleta de dados de campo utilizou-se de informações fornecidas por uma cooperativa agropecuária do estado do Mato Grosso do Sul, localizada na região norte do mesmo estado. Os dados coletados foram: - Quais os tipos de UP existiam na região e quantas eram de cada modalidade; - Quantos animais compunham cada UP; - Quais eram as exigências legais contidas em suas licenças ambientais emitidas pelo IMASUL.

\section{RESULTADOS E DISCUSSÃO}

Até ano de 2014 não haviam normativas ambientais que regularizassem a obrigatoriedade do uso de tecnologias via biodigestão de dejetos de suínos em sistemas de produção comercial no estado do Mato Grosso do Sul (Civardi et al., 2014). O art. $3^{\circ}$ do CAPÍTULO I da Resolução SEMADE nº 09-2015, que define a atividade como um empreendimento passível de licenciamento ambiental definido pelo IMASUL por ser utilizadora de recursos ambientais e/ou considerada efetiva ou potencial causadora de impacto ambiental.

Segundo Cardoso et al. (2015) o marco no desenvolvimento da legislação foi a formulação e publicação da Lei 6.938/81, que abrange sobre a política nacional do meio ambiente. O objetivo desta lei era a preservação e recuperação da qualidade ambiental e ainda inserir uma penalização pela ação que danifique o meio ambiente, onde a suinocultura se encaixa devido a sua alta produção de dejetos de extrema capacidade poluidora.

Porém, apesar de ser uma atividade representativa na economia nacional, a suinocultura brasileira não apresenta muitos avanços com relação a legislação ambiental federal, salvo as exceções estaduais (Perossi et 
al., 2017). Ito et al. (2016) ressaltam as políticas ambientais dos grandes produtores mundiais, como União Européia, Estados Unidos e China, estando os dois primeiros entre os produtores com normativas e punições mais rígidas para a produções de suínos e o impacto ambiental e a China como a grande máquina de produção de suínos, porém com maior precariedade nas legislações ambientais, que são quase inexistentes para a produção intensiva de suínos.

Abaixo estão representados em quadros as quantidades de propriedades na região norte do estado do Mato Grosso do Sul, inseridas no sistema de cooperativismo da Cooperativa Agropecuária de São Gabriel do Oeste - COOASGO, além de todas as exigências para que se tenha o licenciamento ambiental para a mantença da atividade. E também uma previsão dos custos médios por propriedade, de acordo com a quantidade de animais e fases, e os custos médios por animais para a manutenção do licenciamento ambiental.

A Tabela 1 apresenta cada relatório e exigência para que se tenha o licenciamento ambiental para a atividade suinícola para o período que antecede maio de 2018 e como ficou após a Portaria n ${ }^{\circ} 603$ de 17 de maio de 2018. E a Tabela 2 demonstra o perfil em número de animais da atividade na região onde a cooperativa abrange, totalizando em 38 UT e 4 UPL, sendo uma delas UPLT. Comprovando assim a expressividade numérica da atividade suinícola na região estudada.

Nota-se na Tabela 3 que quanto maior o número de animais alojados mais diluído se torna o custo/animal para as adequações e manutenções das licenças ambientais de acordo com as normas exigidas para a atividade. Também se observa que após a Portaria n ${ }^{\circ} 603$ de 17 de maio de 2018, pode-se prever uma diferença média de aproximadamente $\mathrm{R} \$ 1,21$ por animais em terminação e, aproximadamente $\mathrm{R} \$ 3,42$ por matrizes, a menos no valor das análises exigidas para que a atividade se mantenha dentro dos padrões exigidos pela legislação do Mato Grosso do Sul.

\section{CONCLUSÃO}

É possível concluir que a quantidade de animais alojados influencia no custo médio por animal ao produtor, quando relacionado aos gastos com regularização ambiental. Sendo desta forma mais rentável investir em maiores capacidades de alojamento de animais. E também que a mudança da periodicidade, para as análises de efluentes e de solo e o PAM houve uma diminuição nos custos de produção para os produtores. Isso demonstra a preocupação do Governo do Estado do Mato Grosso do Sul com a atividade, sendo também um dos motivos pelo qual o estado encontra-se entre os que mais crescem na atividade suinícola industrial.

\section{REFERÊNCIAS}

Cardoso, B. F. et al., (2015). Produção, tratamento e uso dos dejetos suínos no Brasil. Desenvolvimento em Questão, v.13(32), p.127-145. CIVARDI, J. F. D. O uso de biodigestores na suinocultura como alternativa de sustentabilidade econômica: uma análise para a região da grande Dourados, MS. 2014. 101f. Dissertação (Agronegócios - Mestrado) - Universidade Federal da Grande Dourados, Dourados, MS. IBGE, (2016). Estatística da Produção Pecuária. Instituto Brasileiro de Geografia e Estatística - IBGE. Brasil, p. 12-15. Ito, M. et al. Impactos ambientais da suinocultura: desafios e oportunidades. Universidade Federal de Goiás, 2016. Catalão-GO. IMASUL - Instituto do Meio Ambiente de Mato grosso do Sul. Portaria n $\mathbf{6}^{\mathbf{6}} \mathbf{6 3}$ de 17 de maio de 2018. Disponível em [http://www.imasul.ms.gov.br/] Acesso em outubro de 2018. Souza, G. E. et al, (2016). Gestão de recursos naturais: sustentabilidade em propriedade produtora de suinos. MIX Sustentável, v.2(2), p. 10-19. Perossi, I.F. et al. Manejo e destinação ambientalmente adequados de resíduos da suinocultura revisão de literatura. Revista Unimar Ciências, v. 26, n. 1-2, 2017. 
Tabela 1. Exigências para licenciamento ambiental e suas periodicidades até maio de 2018 e após maio de 2018.

\begin{tabular}{ccc}
\hline & Licenciamento ambiental até maior de 2018 \\
\hline Atividade & Tipo de relatório & Periodicidade \\
\hline UPL*, UPLT* e UT* $^{*}$. & Pam** & Quadrimestral, semestral ou anual \\
UPL e UPLT & Coleta do solo & Trimestral ou anual \\
UT & Coleta do solo & Anual \\
UPL, UPLT e UT & Coleta de efluentes & Mensal, trimestral ou quadrimestral \\
UPL, UPLT e UT & Pam, Coleta do solo e Coleta de efluentes & Anual $\mathrm{p} / \mathrm{o} 1^{\circ}$ ano e bianual a partir do $2^{\circ}$ ano \\
\hline
\end{tabular}

*UPL: unidade produtora de leitões; UPLT: unidade produtora de leitões e terminadora; UT: unidade terminadora; **PAM: plano de automonitoramento.

Tabela 2. Unidades terminadoras e unidades produtoras de leitões até o ano de 2016.

\begin{tabular}{ccc}
\hline & Unidades Terminadoras & \\
\hline Propriedade em n $\mathbf{~}^{\mathbf{0}}$ de leitões & Quantidade de UT & Total de leitões \\
\hline $1000-2000$ & 4 & 5158 \\
$2001-4000$ & 22 & 55377 \\
$4001-6000$ & 6 & 29821 \\
$6001-8000$ & 3 & 20550 \\
$8001-10000$ & 3 & 26448 \\
Totais & $\mathbf{3 8}$ & $\mathbf{1 3 7 3 5 6}$ \\
\hline Propriedade em no de matrizes & Quantidade de UPL & Total de matrizes \\
$500-2000$ & 4 & 4200 \\
$2001-3500$ & 0 & 0 \\
$3501-5000$ & 1 & 4495 \\
Totais & $\mathbf{5}$ & $\mathbf{8 6 9 5}$ \\
\hline
\end{tabular}

Tabela 3. Recursos financeiros necessários até maio de 2018 e após esta data.

\begin{tabular}{|c|c|c|c|c|c|c|}
\hline $\begin{array}{l}\text { Up em no de } \\
\text { animais (leitões } \\
\text { e matrizes) }\end{array}$ & $\begin{array}{l}\text { Qtde } \\
\text { de UP }\end{array}$ & $\begin{array}{l}\mathrm{R} \$ \text { médio por } \\
\text { propriedade } \\
\text { até Mai/2018 }\end{array}$ & $\begin{array}{l}\text { R\$ médio previsto } \\
\text { por propriedade } \\
\text { após Mai/2018 }\end{array}$ & $\begin{array}{c}\text { R\$ médio } \\
\text { por animal } \\
\text { até Mai/2018 }\end{array}$ & $\begin{array}{l}\text { R\$ médio previsto } \\
\text { por animal após } \\
\text { Mai/2018 }\end{array}$ & $\begin{array}{c}\text { Diferenças } \\
\text { no } \mathbf{R} \$ \text { médio } \\
\text { por animal }\end{array}$ \\
\hline \multicolumn{7}{|c|}{ Valores totais médios UT } \\
\hline $1000-2000$ & 4 & 5823,00 & 2907,00 & 4,52 & 2,25 & 2,27 \\
\hline $2001-4000$ & 22 & 5714,73 & 1900,40 & 2,27 & 0,75 & 1,52 \\
\hline $4001-6000$ & 6 & 6333,33 & 1980,71 & 1,27 & 0,40 & 0,87 \\
\hline $6001-8000$ & 3 & 7312,00 & 1505,83 & 1,07 & 0,22 & 0,85 \\
\hline $8001-10000$ & 3 & 6688,67 & 2087,17 & 0,76 & 0,24 & 0,52 \\
\hline \multicolumn{7}{|c|}{ Valores totais médios UPL } \\
\hline $500-2000 *$ & 4 & $\mathrm{R} \$ 8.576,00$ & 1962,54 & $\mathrm{R} \$ 7,41$ & 1,87 & 5,54 \\
\hline $2001-3500^{*}$ & 0 & 0 & 0 & 0 & 0 & 0 \\
\hline $3501-5000 *$ & 1 & $\mathrm{R} \$ 9.836,00$ & 3983,00 & $\mathrm{R} \$ 2,19$ & 0,88 & 1,31 \\
\hline
\end{tabular}




\title{
DETERMINAÇÃO DA PRESSÃO AMBIENTAL EM BACIA HIDROGRÁFICA COM PRODUÇẪO INTENSIVA DE SUÍNOS POR MEIO DE FERRAMENTAS DE GEOPROCESSAMENTO
}

\author{
Bernardo, E.L.*1; Miranda, C.R. ${ }^{2}$; Matthiensen, A. ${ }^{2}$; Belli-Filho, P. ${ }^{1}$ \\ ${ }^{1}$ Programa de Pós-Graduação em Engenharia Ambiental - PPGEA/UFSC, Florianópolis, SC - Brasil, \\ eduardolbernardo@gmail.com. \\ ${ }^{2}$ Embrapa Suínos e Aves, Concórdia, SC - Brasil
}

RESUMO: O presente trabalho objetivou identificar a pressão ambiental da produção intensiva de suínos na Sub-Bacia Hidrográfica do Lajeado dos Fragosos, Concórdia (SC), utilizando os indicadores: volume de dejetos (mªno) por área (ha) e número de cabeças de suínos (n) por área (ha), em escala de microbacia. Metodologicamente, por meio de ferramentas de geoprocessamento, integraram-se os dados de plantel de suínos, volume de dejetos e os valores de área total de cada microbacia hidrográfica. Os resultados apontaram que as microbacias $\mathrm{n}^{\circ} .: 32,38,20$ e 16, apresentaram os maiores índices de pressão na relação volume de dejetos por área $\left(\mathrm{m}^{3} / \mathrm{ha}\right)$, e, as microbacias $\mathrm{n}^{\circ} .: 32,11,16$ e 20, apresentaram os valores de 90,1, 42,3, 29,0 e 21,0 para o indicador $\mathrm{n}^{\circ}$. de cabeças por área (cabeças/ha). Ainda, este estudo demonstra a importância do emprego da dimensão bacia hidrográfica como unidade espacial de análise, bem como, a validação da utilização de ferramentas de geoprocessamento para avaliação da pressão ambiental.

Palavras-chave: Pressão ambiental, suinocultura, geoprocessamento.

\section{DETERMINATION OF ENVIRONMENTAL PRESSURE IN A HYDROGRAPHIC BASIN WITH INTENSIVE SWINE PRODUCTION BY GEOPROCESSING TOOLS}

\begin{abstract}
The objective of this study was to identify the environmental pressure of the intensive pig production in the Fragosos subbasin, Concordia (SC), using indicators: volume of wastes $\left(\mathrm{m}^{3} /\right.$ year) per area (ha) and number of heads swine (n) by area (ha), in microbasin scale. Methodologically, through geoprocessing tools, the data of swine stock, volume of wastes and total area values of each hydrographic basin were integrated. The results showed that the microbasins $\mathrm{n}^{\circ} .: 32,38,20$ and 16, presented the highest pressure indices in relation to volume of waste per area $\left(\mathrm{m}^{3} / \mathrm{ha}\right)$, and microbasins $\mathrm{n}^{\circ} .: 32,11,16$ and 20 , presented values of 90.1, 42.3, 29.0 and 21.0 for indicator no. of heads per area (heads/ha). Furthermore, this study demonstrates the importance of the use of the watershed dimension as a spatial analysis unit, as well as the validation of the use of geoprocessing tools to assess environmental pressure.
\end{abstract}

Keywords: Environmental pressure, Pig farming, Geoprocessing.

\section{INTRODUÇÃO}

No Brasil, a produção de carne suína ocupa o quarto lugar no ranking mundial, com 3.725 milhões de toneladas, deste montante, exporta 786 mil toneladas anuais, apresentando um consumo de carne suína per capita de 14,1 kg (CIAS, 2018). O plantel brasileiro é de 39,95 milhões de cabeças de suínos, com 49,9\% deste montante, concentrado na região sul, distribuídas no estado do Paraná com 7,13 milhões, Santa Catarina com 6,88 milhões e Rio Grande do Sul com 5,92 milhões de cabeças (IBGE, 2016).

Além do crescimento em termos do número de animais nos últimos anos, a suinocultura tem recebido investimentos substanciais e grande evolução tecnológica em toda a cadeia produtiva (SEBRAE, 2016). Apesar do padrão de excelência da produção industrial de suínos no Brasil, alcançada pelo emprego de tecnologias modernas de manejo e nutrição, têm-se ainda as questões ambientais relacionadas à cadeia, as quais permanecem sendo fonte de muita apreensão em virtude do grande volume de dejetos gerados e pelo potencial impacto e comprometimento dos recursos naturais em regiões onde se concentram as atividades, tais como a eutrofização dos corpos d'água, a proliferação de vetores e o acúmulo de nutrientes no solo (HIGARASHI; OLIVEIRA; MIRANDA, 2010).

Desta forma, o reconhecimento da distribuição espacial da produção de suínos torna-se um fator chave para o planejamento ambiental da atividade, levando em consideração a bacia hidrográfica como unidade 
territorial de gestão, conforme proposto pela Lei no .9 .433 , de 8 de janeiro de 1997 (Institui a Política Nacional de Recursos Hídricos, e, tem a referência da bacia hidrográfica - nas suas mais diversas escalas).

Assim, considerando-se a dimensão bacia hidrográfica como unidade para a gestão ambiental da suinocultura, definiu-se a Sub-Bacia Hidrográfica do lajeado dos Fragosos, situada na porção noroeste do município de Concórdia, Oeste do Estado de Santa Catarina, Brasil, como unidade de análise, objetivando identificar as microbacias hidrográficas que apresentam maior pressão ambiental pela suinocultura, utilizando os indicadores: volume de dejetos ( $\left.\mathrm{m}^{3} / \mathrm{ano}\right)$ por área (ha) e número de cabeças (n) por área (ha), por meio da utilização de ferramentas de geoprocessamento.

\section{MATERIAL E MÉTODOS}

A base de dados cartográfica utilizada foi obtida do Sistema de Informações Geográficas de Santa Catarina (SIGSC). Os dados referentes as unidades de produção de suínos foram obtidos do projeto: Avaliação de indicadores e estratégias para valoração de serviços ambientais em bacias hidrográficas com produção intensiva de animais (SA SUAVE), da linha temática: Serviços ambientais na paisagem rural (arranjo AS), Macroprogama 2, da Empresa Brasileira de Pesquisa Agropecuária - Embrapa, período de 2015/2019. O valor referente a produção média diária de dejeto por animal, de acordo com o sistema de produção, foi extraído da Instrução Normativa $n^{\circ}$. 11 - IN11, do Instituto de Meio Ambiente do Estado de Santa Catarina - IMA (procedimento de licenciamento ambiental da suinocultura). O tratamento, espacialização e o cálculo de grandezas territoriais dos dados foram realizado no software de geoprocessamento QuantumGIS v. 3.2.3-Bonn.

\section{RESULTADOS E DISCUSSÃO}

A sub-bacia hidrográfica do lajeado Fragosos divide-se em 37 microbacias, mais a respectiva bacia de contribuição independente da calha do rio principal. Totalizam 62 unidades de produção industrial de suínos, entre os sistemas produtivos de: Ciclo Completo (03), GRSC (02), UPL (17) e Terminação (40). Em termos do número de animais, o plantel é composto por 38.133 (8.995 matrizes e 29.138 suínos para terminação) cabeças. A produção total de dejetos é de $140.351 \mathrm{~m}$ 3/ano e a forma de manejo nas unidades de produção é, em quase a sua totalidade, como fertilizante de solo em áreas agrícolas.

A espacialização das unidades produtoras se concentra, principalmente, na bacia de contribuição independente, com aproximadamente $30 \%$ das propriedades, em área de 1.286 ha. Área está, onde a topografia é mais favorável, bem como, sua proximidade aos acessos e estradas rurais. Os demais estabelecimentos produtores estão distribuídos em 16 microbacias (43\%), com média de 1.595 cabeças de suínos por bacia.

Com relação aos indicadores de pressão ambiental aplicado, as microbacias $n^{\circ} .: 32,38,20$ e 16, apresentaram os maiores índices de pressão na relação volume de dejetos por área, com: 51,0, 54,0, 75,4 e $128,7 \mathrm{~m}^{3} / \mathrm{ha} /$ ano respectivamente. Já para o indicador número de cabeças por área, as microbacias $\mathrm{n}^{\circ} .: 32,11$, 16 e 20, apresentaram os valores de 90,1, 42,3, 29,0 e 21,0 cabeças/ha (figura 01).

Vale ressaltar que não foram considerados neste estudo os demais sistemas de produção agropecuários, caso das aves e dos bovinos (corte e leite), bem como, o cálculo da grandeza territorial avaliou toda extensão territorial de cada microbacia.

\section{CONCLUSÃO}

Identificaram-se as microbacias $\mathrm{n}^{\circ} .32,20,16$ e 38 com os maiores valores de pressão ambiental analisados, indicando serem as áreas prioritárias para estudos pontuais e de ações e intervenções de gestão do território. Ainda assim, este estudo, mesmo que preliminar, demonstra a importância do emprego da dimensão bacia hidrográfica como unidade espacial de análise, bem como, a validação da utilização de ferramentas de geoprocessamento para avaliação da pressão ambiental.

\section{REFERÊNCIAS}

BRASIL. Política Nacional de Recursos Hídricos - PNRH. Lei nº 9.433 de 08 de janeiro de 1997. Disponível em: https://www.planalto.gov.br. Acesso em: 05 de nov. de 2018.

EMBRAPA. Central de Inteligência de Aves e Suínos - CIAS. Disponível em: https://www.embrapa.br/suinose-aves/cias. Acesso em: 05 de nov. de 2018.

HIGARASHI, M. M.; OLIVEIRA, P. A. V.; MIRANDA, C. R. Meio Ambiente Baliza Atuação da Unidade a Partir dos Anos 90. In: Embrapa Suínos e Aves (Ed.). . Sonho, Desafio e Tecnologia: 35 anos de Contribuições da Embrapa Suínos e Aves. 1. ed. Concórdia, p. 271-289, 2010. 
IBGE. Produção Agropecuária Municipal (PPM 2015). Disponível em: https://www.ibge.gov.br. Acesso em: 05 de jan. 2017.

SEBRAE. Mapeamento da Suinocultura Brasileira (2016). Disponível em: http://www.abcs.org.br/ attachments/-01_Mapeamento_COMPLETO_bloq.pdf. Acesso em 10 de nov. 2018.

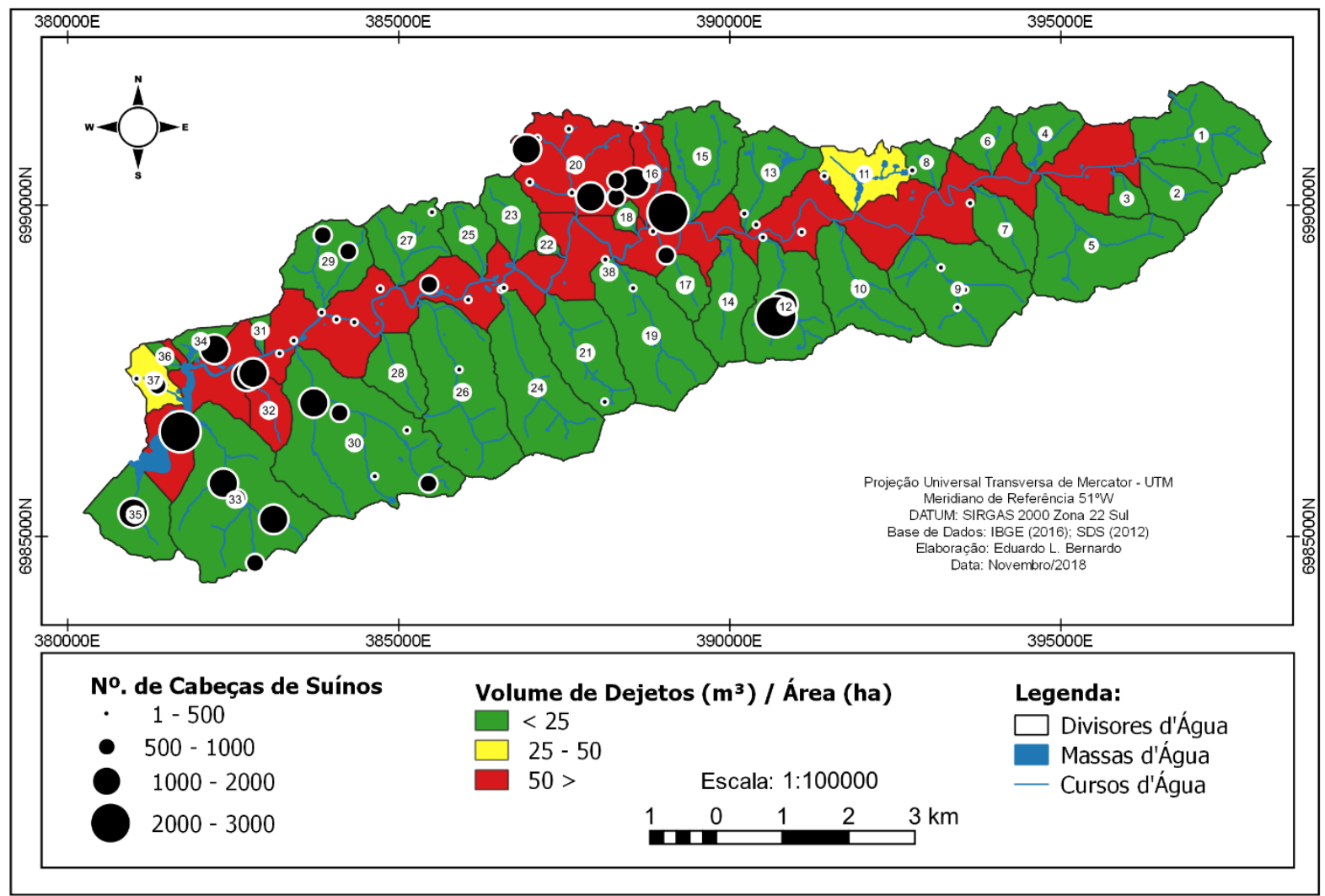

Figura 1. Espacialização das unidades de produção de suínos e seus respectivos indicadores de pressão ambiental, Sub-Bacia Hidrográfica do Lajeado Fragosos, Concórdia, Santa Catarina, Brasil. 


\title{
IMPACTO DA NUTRICÃO NO TEOR DE NUTRIENTES DE FEZES E URINA DE VACAS EM LACTAÇÃO
}

\author{
Novelli, T.I. ${ }^{1}$; Morelli, M. ${ }^{1}$; Palhares, J.C.P. ${ }^{2}$ \\ ${ }^{I}$ Faculdade de Medicina Veterinária e Zootecnia/USP -Brasil \\ ${ }^{2}$ Embrapa Pecuária Sudeste-Brasil \\ julio.palhares@embrapa.br
}

\begin{abstract}
RESUMO: O objetivo do trabalho foi avaliar o impacto do teor de proteína bruta da dieta de vacas em lactação na concentração de nitrogênio, fósforo e potássio das fezes e urina dos animais. Quatorze vacas foram divididas em dois grupos de sete animais. O grupo 1 foi alimentado com uma dieta contendo $20 \%$ de proteína bruta. O ajuste proteico do concentrado do grupo 2 se deu de acordo com a produção de leite média do grupo ao longo do período de lactação. Mensalmente, foram realizadas coletas de fezes e urina de cada animal. As concentrações médias de NPK nas fezes dos animais do grupo 1 foram 20,7, 9,7 e 5,3 $\mathrm{g} \mathrm{kg}^{-1}$, respectivamente. Para o grupo 2 essas médias foram de 20,9,10,9 e 6,1 $\mathrm{g} \mathrm{kg}^{-1}$, respectivamente. Na urina dos animais do grupo 1 as médias foram de 5,9, 4,3 e 150,4 $\mathrm{g} \mathrm{L}^{-1}$, para NPK respectivamente. E no grupo 2, 7,1, 5,5 e 127,9 $\mathrm{g} \mathrm{kg}^{-1}$, para NPK respectivamente. Não foi possível identificar um comportamento de excreção de nutrientes nas fezes e urina ao longo da lactação. A manipulação do teor de proteína bruta da dieta não promoveu impactos significativos na excreção dos elementos. Os sistemas de produção devem ter programas de monitoramento da qualidade dos dejetos e explorar quais manejos produtivos podem reduzir a carga de nutrientes dos resíduos.
\end{abstract}

Palavras-chave: fósforo, nitrogênio, potássio, proteína bruta.

\section{IMPACT OF LACTATION COW NUTRITION ON THE FEZES AND URINE NUTRIENT CONTENT}

\begin{abstract}
The aim of the study was to evaluate the impact of the crude protein content of lactating dairy cows diet on the concentration of nitrogen, phosphorus and potassium in the dung and urine. Fourteen cows were divided into two groups of seven animals. Group 1 was fed a diet containing $20 \%$ of crude protein. The diet crude protein in group 2 was calculated according to the average milk production over the lactation period. Monthly, dung and urine samples were collected from each animal. The average concentrations of NPK in the dung of the group 1animals were 20.7, 9.7 and $5.3 \mathrm{~g} \mathrm{~kg}^{-1}$, respectively. Group 2, had the averages 20.9, 10.9 and $6.1 \mathrm{~g} \mathrm{~kg}^{-1}$, respectively. Urine for group lanimals had the averages $5.9,4.3$ and $150.4 \mathrm{~g} \mathrm{~L}^{-1}$, for NPK respectively. Group 2, the averages were $7.1,5.5$ and $127.9 \mathrm{~g} \mathrm{~kg}^{-1}$, for NPK respectively. It was not possible to identify a nutrient excretion behavior in dung and urine during lactation. The manipulation of the crude protein content did not promote significant impacts on the excretion of the elements. Livestock systems should have programs to monitor the quality of wastes and explore which productive managements can reduce the nutrient loads in them.
\end{abstract}

Keywords: crude protein, nitrogen, phosphorus, potassium.

\section{INTRODUÇÃO}

A bovinocultura de leite, como qualquer outra atividade pecuária, deve internalizar em sua rotina produtiva práticas e tecnologias relacionadas ao manejo de seus resíduos e demonstrar para sociedade que é uma atividade econômica que preza pela conservação dos recursos naturais e eficiente uso dos insumos.

A concentração de nutrientes nas fezes e urina dos animais é resultado de vários fatores produtivos, sendo um dos mais importantes o tipo de dieta oferecida ao animal. Dietas formuladas de acordo com as exigências dos animais irão promover maior eficiência de uso dos nutrientes e, consequentemente, menor excreção destes nas fezes e urina. Manipulando a proteína por meio da redução de seu teor na dieta de vacas em lactação, Sinclair et al. (2013), verificaram melhoria da eficiência de uso do nitrogênio e redução da liberação do elemento para o ambiente.

A consideração de estratégias nutricionais como redutoras da carga de nutrientes disponíveis nos resíduos deve ser explorada em sistemas de produção de leite por significar redução do potencial poluidor da 
atividade. O nitrogênio excedente na dieta significa maiores concentrações do elemento nos dejetos do animal, o que significa maior risco ambiental (Shepherd et al., 2017).

O preciso manejo nutricional irá promover impactos positivos tanto nos aspectos econômicos da produção, pela redução do desperdício de nutrientes, como nos ambientais, pela menor quantidade de nutrientes a serem manejados na forma de resíduos líquidos e sólidos.

O objetivo do trabalho foi avaliar o impacto do teor de proteína bruta da dieta de vacas em lactação na concentração de nitrogênio, fósforo e potássio das fezes e urina dos animais.

\section{MATERIAL E MÉTODOS}

O trabalho foi desenvolvido no Sistema de Produção de Leite (SPL) da Embrapa Pecuária Sudeste. O período experimental foi de maio de 2015 a janeiro de 2016, envolvendo um ciclo completo de lactação. As vacas foram divididas em dois grupos de sete animais. Em cada grupo havia três animais da raça Jersey e quatro da raça Holandesa.

O manejo alimentar dos animais foi baseado em sistema de pastejo de gramíneas tropicais, silagem de milho e concentrado contendo níveis de proteína bruta diferenciados para cada um dos Grupos. O Grupo 1 foi alimentado com uma dieta contendo $20 \%$ de proteína bruta na matéria seca, ao longo de toda a lactação. $\mathrm{O}$ ajuste proteico do concentrado do Grupo 2 se deu de acordo com a produção de leite média do grupo ao longo do período de lactação. Nos meses de maio e junho o teor proteico foi de $23 \%$, de julho a dezembro de $17 \%$ e em janeiro $14,5 \%$

Mensalmente, foram realizadas coletas de fezes e urina de cada animal. Para as coletas houve a imobilização dos animais em tronco de contenção. As fezes foram retiradas diretamente do reto dos animais e armazenadas em bandejas metálicas para posterior secagem em estufa de ventilação forçada $\left(65^{\circ} \mathrm{C}\right)$ por 72 horas e moídas em moinho do tipo Willey com peneira de $2 \mathrm{~mm}$. A urina foi coletada pelo massageamento da parte posterior do animal e armazenada em recipientes de $250 \mathrm{ml}$. As amostras dos resíduos foram analisadas no laboratório de nutrição da Embrapa Pecuária Sudeste para os elementos nitrogênio, fósforo e potássio. A determinação do $\mathrm{N}$ foi feita pelo método semimicro Kjeldhal, segundo a Association of Oficial Analytical Chemists (AOAC, 1995) e o fator de conversão foi de 6,25. Para determinar as concentrações de $\mathrm{P}$ e $\mathrm{K}$ nas fezes foi utilizada a espectrometria de emissão óptica com plasma indutivamente acoplado (ICP-OESInductively Coupled Plasma Optical Emission Spectroscopy).

\section{RESULTADOS E DISCUSSÃO}

Os resultados apresentados nas Tabelas 1 e 2 demostram significativas amplitudes de variação entres as concentrações máximas e mínimas dos nutrientes nas fezes e urina. Sendo a presença dos elementos nos resíduos dos animais condicionada por aspectos produtivos como: idade do animal, estágio do ciclo produtivo e tipo de dieta, as amplitudes de variação são inerentes à caracterização dos dejetos animais. Velthof et al. (2015) existe grande variabilidade nas concentrações de nutrientes dos dejetos de animais.

A variabilidade das concentrações de nutrientes é um complicador para tomada de decisão quanto ao uso dos dejetos como fertilizante, bem como para o planejamento e dimensionamento de sistemas de tratamento dos dejetos. Por isso, é importante se ter como rotina nos sistemas de produção o monitoramento das concentrações de nutrientes nos dejetos dos animais a fim de se tomar decisões mais precisas o que irão determinar menor potencial de impacto ambiental da atividade pecuária.

A manipulação do teor de proteína bruta da dieta não promoveu impactos significativos na excreção dos elementos. No caso do nitrogênio, onde a redução do teor de proteína bruta deveria reduzir a presença do elemento nas fezes e urina isso não foi observado na maioria das coletas. Wilkinson (2011) o excesso de proteína na dieta determina uma maior excreção de nutrientes pelo animal, fazendo com que o sistema de produção seja uma potencial fonte de poluição difusa. As concentrações de nitrogênio na urina foram mais elevadas mesmo nos meses em que a proteína bruta da dieta era mais baixa. Estudos futuros devem explorar dietas com menores teores proteicos e aliar a monitoramento da concentração de nutrientes nos dejetos com o monitoramento de indicadores fisiológicos de vacas em lactação a fim de entender melhor como o estágio produtivo (curva de lactação e confirmação ou não de prenhez) influenciam os fluxos de excreção.

Não foi possível identificar um comportamento de excreção de nutrientes nas fezes e urina ao longo da lactação. Enquanto a concentração de nitrogênio nas fezes aumentou ao longo da lactação para os dois grupos experimentais, na urina esse comportamento foi mais heterogêneo, tendendo a uma redução ao longo da lactação. O fósforo teve uma variabilidade menor para fezes e urina, excetuando-se alguns meses onde se 
observaram elevadas concentrações (julho, fezes e novembro, urina no grupo 2). Estes picos de concentração podem estar relacionados a questões de coleta das amostras. O potássio na urina apresentou um claro comportamento de aumento da concentração ao longo da lactação.

A ingestão de nitrogênio foi identificada como o principal responsável pela presença do elemento nos dejetos de bovinos, especialmente na urina (Dong et al., 2014). Misselbrook et al. (2016) a concentração de N na urina é influenciada pelo tipo de dieta, pelo manejo de pastagem e pela estação do ano. Avaliando a concentração de $\mathrm{N}$ na urina de vacas Holandesas, os autores observaram médias de $13,1 \mathrm{~g} \mathrm{~L}^{-1}$, com maior frequência entre 10-20 g L-1. Neste estudo os valores médios foram de 5,9 e 7,1 g L-1 para os grupos 1 e 2 , respectivamente. Como atestado pelos autores, a concentração de $\mathrm{N}$ é influenciada por vários aspectos produtivos o que justifica as médias do estudo serem diferentes da observada pelos autores.

Ruiz et al. (2016) encontraram concentração de P nas fezes de vacas em lactação com produção de leite de $25,9 \mathrm{~kg} \mathrm{vaca}^{-1} \mathrm{dia}^{-1}$ entre 8,9 e $16,5 \mathrm{~g} \mathrm{~kg}^{-1}$, média de $12,6 \mathrm{~g} \mathrm{~kg}^{-1}$. O grupo 1 apresentou produção média de $23 \mathrm{~kg} \mathrm{vaca}{ }^{-1} \mathrm{dia}^{-1}$ e o $\mathrm{P}$ nas fezes variou de 3,9 e $24,9 \mathrm{~g} \mathrm{~kg}^{-1}$, média de $9,7 \mathrm{~g} \mathrm{~kg}^{-1}$. O grupo 2 apresentou produção média de $25,9 \mathrm{~kg} \mathrm{vaca}^{-1} \mathrm{dia}^{-1}$ e o P nas fezes variou de 2,8 a 24,5 $\mathrm{g} \mathrm{kg}^{-1}$, média de $10,6 \mathrm{~g} \mathrm{~kg}^{-1}$. Essas diferenças podem ser explicadas pela produção de leite e pelo tipo de dieta.

Do nitrogênio total utilizado em uma fazenda leiteira, 55\% é excretado pelas fezes e urina (Powell e Rotz, 2015). Considerando os nove meses de monitoramento e as concentrações mensais de nitrogênio nas fezes e urina, os animais do grupo 1 excretaram um total de $533 \mathrm{~kg}$ de $\mathrm{N}$ e os do grupo $2,586 \mathrm{~kg}$ de $\mathrm{N}$, perfazendo um total de $1.119 \mathrm{~kg}$ de $\mathrm{N}$. As 14 vacas experimentais ocuparam uma área de 1,22 ha que compreendia as áreas de pastejo e oferta de alimento no cocho. Portanto, pode-se inferir que ocorreu um aporte potencial de $917 \mathrm{~kg}$ de $\mathrm{N} \mathrm{ha}^{-1}$. Diz-se potencial porque parte deste nitrogênio será volatizado e parte não foi disposto na área, mas sim no pátio de ordenha.

\section{CONCLUSÃO}

A manipulação do teor de proteína bruta da dieta não promoveu reduções significativas na concentração de nitrogênio, fósforo e potássio das fezes e urina das vacas em lactação, sendo que em algumas coletas as concentrações foram maiores, mesmo os animais recebendo uma dieta com menor teor de proteína bruta. $\mathrm{O}$ manejo nutricional é um dos principais aspectos produtivos que influenciam na concentração de elementos nos dejetos, mas há outros, que no caso de vacas em lactação, podem ser o estágio da curva de lactação e a presença ou ausência de prenhez. Portanto, estudos futuros em monitoramento de nutrientes nos dejetos de vacas em lactação devem relacionar os aspectos nutricionais e de desempenho do animal com a concentração dos elementos nas fezes e urina. O conhecimento das concentrações de nutrientes nos dejetos dos animais é fundamental para tomada de decisão sobre qual o melhor manejo ambiental a se fazer, bem como para o planejamento do uso dos dejetos como fertilizante e para o dimensionamento de sistemas de tratamento. Portanto, os sistemas de produção devem ter programas de monitoramento da qualidade dos dejetos e explorar quais manejos produtivos podem reduzir a carga de nutrientes dos resíduos.

\section{REFERÊNCIAS}

DONG, R.L.; ZHAO, G.Y.; CHAI, L.L.; BEAUCHEMIN, K.A. Prediction of urinary and fecal nitrogen excretion by beef cattle. J. Anim. Sci. v. 92, p. 4669-4681. 2014.

MISSELBROOK, T.; FLEMING, H.; CAM, V. et al. Automated monitoring of urination events from grazing cattle. Agriculture, Ecosystems and Environment v. 230, p. 191-198. 2016.

POWELL, J.M.; ROTZ, C.A. Measures of nitrogen use efficiency in dairy production systems. J. Environ. Qual. V.44, P.336-344. 2015.

RUIZ, T.M.; SOTOMAYOR-RAMÍREZ, D.; TORRES-MELÉNDEZ, C. et al. Phosphorus mass cycling and balance in dairy farms: Case studies in Puerto Rico. Agriculture, Ecosystems and Environment v.220, p.115124. 2016.

SHEPHERD, M.; SHORTEN, P.; COSTALL, D.; MACDONLD, K.A. Evaluation of urine excretion from dairy cows under two farm systems using urine sensors. Agriculture, Ecosystems \& Environment, v. 236, p.285-294, 2017.

SINCLAIR, K. D.; GARNSWORTHY,P.C.; MANN, G.E; SINCLAIR, L.A. Reducing dietary protein in dairy cow diets: implications for nitrogen utilization, milk production, welfare and fertility. Animal, v.8, n.02, p.262$274,2013$. 


\section{VISIGERA DE 07 A A9 MA10 2019

VELTHOF, G.L., HOU, Y., OENEMA, O. Nitrogen excretion factors of livestock in the European Union: a review. J Sci Food Agric. V. 95, P.3004-3014. 2015.

WILKINSON, J.M. Re-defining efficiency of feed use by livestock. Animal v.5, p.1014-1022. 2011.

Tabela 1. Concentrações médias mensais de NPK nas fezes dos animais para cada tipo de dieta.

\begin{tabular}{lrccccc}
\hline & \multicolumn{2}{c}{ Nitrogênio $\left(\mathbf{g ~ k g}^{-\mathbf{1}}\right)$} & \multicolumn{2}{c}{ Fósforo $\left.\mathbf{~ g ~ k g ~}^{-\mathbf{1}}\right)$} & \multicolumn{2}{c}{ Potássio $\mathbf{~ ( \mathbf { ~ k g } ^ { - 1 } )}$} \\
\hline & PB 20\% & PB ajustada & PB 20\% & PB ajustada & PB 20\% & PB ajustada \\
\hline Maio & 19,6 & 20,3 & 10,9 & 12,8 & 6,2 & 7,2 \\
Junho & 19,3 & 20,0 & 11,8 & 14,4 & 8,5 & 8,8 \\
Julho & 17,5 & 16,6 & 24,9 & 24,5 & 2,4 & 1,8 \\
Agosto & 19,0 & 19,1 & 7,3 & 7,7 & 5,3 & 5,7 \\
Setembro & 17,7 & 17,6 & 6,1 & 7,8 & 5,6 & 7,9 \\
Outubro & 19,4 & 20,7 & 4,9 & 7,1 & 7,4 & 10,3 \\
Novembro & 24,0 & 24,0 & 8,6 & 8,5 & 2,5 & 2,2 \\
Dezembro & 25,5 & 25,6 & 3,9 & 2,8 & 3,4 & 3,9 \\
Janeiro & 24,3 & 24,7 & 8,9 & 9,5 & 6,1 & 7,0 \\
\hline Média & 20,7 & 20,9 & 9,7 & 10,6 & 5,3 & 6,1 \\
Valor Máximo & 25,5 & 25,6 & 24,9 & 24,5 & 8,5 & 10,3 \\
Valor Mínimo & 17,5 & 16,6 & 3,9 & 2,8 & 2,4 & 1,8 \\
Desvio Padrão & 3,0 & 3,2 & 6,3 & 6,2 & 2,1 & 2,9 \\
\hline
\end{tabular}

Tabela 2. Concentrações médias mensais de NPK na urina dos animais para cada tipo de dieta.

\begin{tabular}{lcccccc}
\hline & \multicolumn{2}{c}{ Nitrogênio $\left(\mathbf{g ~ L}^{-\mathbf{1}}\right)$} & \multicolumn{2}{c}{ Fósforo $\left(\mathbf{g} \mathbf{L}^{-\mathbf{1}}\right)$} & \multicolumn{2}{c}{ Potássio $\left(\mathbf{g ~ L}^{-\mathbf{1}}\right)$} \\
\hline & PB 20\% & PB ajustada & PB 20\% & PB ajustada & PB 20\% & PB ajustada \\
\hline Maio & 5,8 & 4,2 & 0,2 & 0,2 & 4,5 & 3,4 \\
Junho & 8,4 & 11,3 & 3,8 & 5,1 & 20,9 & 33,3 \\
Julho & 5,2 & 7,9 & 4,1 & 6,6 & 26,0 & 39,7 \\
Agosto & 8,8 & 10,0 & 3,5 & 1,3 & 68,0 & 83,0 \\
Setembro & 4,5 & 8,4 & 1,2 & 0,7 & 88,0 & 90,2 \\
Outubro & 5,0 & 7,2 & 4,5 & 1,0 & 136,1 & 97,6 \\
Novembro & 4,0 & 3,0 & 5,0 & 22,0 & 241,1 & 219,8 \\
Dezembro & 5,6 & 6,0 & 7,5 & 4,9 & 339,5 & 150,3 \\
Janeiro & 5,9 & 5,9 & 9,3 & 7,3 & 429,7 & 433,7 \\
\hline Média & 5,9 & 7,1 & 4,3 & 5,5 & 150,4 & 127,9 \\
Valor Máximo & 8,8 & 11,3 & 9,3 & 22,0 & 429,7 & 433,7 \\
Valor Mínimo & 4,0 & 3,0 & 0,2 & 0,2 & 4,5 & 3,4 \\
Desvio Padrão & 1,6 & 2,6 & 2,8 & 6,8 & 152,6 & 131,8 \\
\hline
\end{tabular}




\title{
PEGADA HÍDRICA MENSAL DE UM SISTEMA LEITEIRO MISTO
}

\author{
Fcamidu, B.V. ${ }^{1}$; Giusti, G. ${ }^{1}$; Novelli, T.I. ${ }^{2}$; Palhares, J.C.P.*3 \\ ${ }^{1}$ Universidade Federal de São Carlos, SP - Brasil \\ ${ }^{2}$ Faculdade de Zootecnia e Engenharia de Alimentos, $s p$ - brasil \\ ${ }^{3}$ Embrapa Pecuária Sudeste, SP - Brasil \\ julio.palhares@embrapa.br
}

\begin{abstract}
RESUMO: O objetivo do estudo foi calcular a pegada hídrica mensal nas dimensões verde, azul e cinza de um sistema leiteiro. O ano produtivo de referência foi o de 2017, os cálculos foram realizados com periodicidade mensal $\mathrm{E}$ considerou-se todas as categorias de animais. $\mathrm{O}$ manejo nutricional era dividido em duas estações: primavera-verão, animais a pasto e outono-inverno, animais em confinamento. Foram calculadas as Pegadas Hídricas ( $\mathrm{PH})$ verde, azul e cinza. A média de produtividade dos animais do sistema analisado foi de 16,7 litros por animal por dia. A PH anual do sistema de produção foi de $831 \mathrm{~L} \mathrm{~kg}^{-1} \mathrm{de}_{\text {leite }}$ corrigido, sendo que a PH verde representou $98,7 \%$ desse valor. A estação a pasto apresentou uma PH média de $610 \mathrm{~L} \mathrm{~kg}^{-1}$ de leite corrigido e no período de confinamento esse valor foi de $986 \mathrm{~L} \mathrm{~kg}^{-1}$ de leite corrigido. A PH no confinamento foi $62 \%$ maior que a $\mathrm{PH}$ a pasto. A dessedentação das vacas em lactação representou $\mathrm{o}$ maior consumo de água azul. Conclui-se que o tipo de sistema de produção, a pasto ou confinado e, consequentemente, o tipo de dieta impactam a eficiência hídrica do produto leite.
\end{abstract}

Palavras-chave: azul, cinza, confinamento, pasto, verde.

\section{MONTHLY WATER FOOTPRINT OF A MIX DAIRY SYSTEM}

\begin{abstract}
The main of this study was to calculate the monthly water footprint in the green, blue and gray dimensions of a dairy system. The productive reference year was 2017 , calculations were performed monthly and all categories of animals were considered. Nutritional management was divided into two seasons: springsummer, grazing, autumn-winter, feedlot. Green, blue and gray Water Footprints (WF) were calculated. The average milk production was 16.7 liters animal ${ }^{-1}$ day $^{-1}$. The annual WF was $831 \mathrm{~L} \mathrm{~kg}^{-1}$ of corrected milk, with the green WF representing $98.7 \%$ of this value. The grazing season had an average WF of $610 \mathrm{~L} \mathrm{~kg}^{-1}$ of corrected milk and during feedlot the value was $986 \mathrm{~L} \mathrm{~kg}^{-1}$ of corrected milk. The feedlot WF was $62 \%$ higher than the pasture WF. The water consumption of lactation cows' was the highest consumption of blue water. The type of production system, grazing or feedlot and, consequently, the type of diet impact the milk water efficiency.
\end{abstract}

Keywords: blue, feedlot, gray, green, pasture.

\section{INTRODUÇÃO}

A Pegada Hídrica $(\mathrm{PH})$ de um produto é um indicador multidimensaional do uso da água, que considera os consumos diretos e indiretos. A abordagem da pegada hídrica possibilita ter como resultados: o conhecer os fluxos hídricos do produto, determinar metas de eficiência hídrica, identificar os pontos críticos de consumo de água e promover a conscientização sobre o uso do recurso natural. (Novelli, 2017) a metodologia da PH mostra-se adequada para compreensão da eficiência hídrica em sistemas de produção animal, uma vez que considera os consumos diretos e indiretos da cadeia de produção.

A bovinocultura de leite é um objeto de estudo importante para abordagem da $\mathrm{PH}$ devido ao seu intensivo consumo de água, pois a atividade enfrenta e enfrentará desafios hídricos relacionados à escassez quantitativa do recurso e/ou a padrões de qualidade que impeçam o uso direto da água, assim, se faz necessário quantificar o consumo através de métricas robustas que se proponham a superar os desafios em questão.

O objetivo do estudo foi calcular a pegada hídrica mensal nas dimensões verde, azul e cinza de um sistema leiteiro que utiliza manejos diferenciados para estação da seca e das águas e também avaliar como o valor da pegada hídrica é impactado pelos diferentes tipos de manejo nestas estações. 


\section{MATERIAL E MÉTODOS}

O estudo foi realizado em uma fazenda produtora de leite do município de Cachoeira Paulista-SP. O ano produtivo de referência foi o de 2017 e os cálculos foram realizados com periodicidade mensal. Considerouse todas as categorias de animais (vacas em lactação, vacas secas, novilhas e bezerros(as)).

O manejo nutricional era dividido em duas estações: primavera-verão, animais a pasto e outono-inverno, animais em confinamento. $\mathrm{O}$ concentrado oferecido aos animais era composto dos seguintes ingredientes: polpa cítrica, caroço de algodão, farelo de soja, fubá de milho e farelo de trigo. O volumoso continha silagem de milho, silagem de cana e pasto. Com exceção da silagem de milho e de cana que eram produzidas na fazenda, todos os outros ingredientes foram adquiridos de fornecedores externos.

Os consumos das águas verde, azul e cinza foram calculados de acordo com a metodologia proposta por Hoekstra (2002) e descrita no "Manual de Avaliação da Pegada Hídrica" (2011). A unidade funcional foi leite corrigido para gordura e proteína $\left(\mathrm{m}^{3}\right.$ ton $^{-1}$ de leite corrigido) (FAO, 2016).

A água verde de um produto agropecuário é a soma da água incorporada ao produto com as águas evapotranspiradas pelas culturas vegetais. Para a realização do cálculo da evapotranspiração de cada cultura vegetal utilizou-se os dados climáticos obtidos na plataforma Agritempo das estações climáticas das regiões de produção dos ingredientes. Nas estações não automáticas, as quais não possuíam dados de ETo, foi utilizado o método de Thornthwaite (1948), descrito por Pereira et al. (2002). Considerou-se o coeficiente de cada cultura (Kc) utilizada como ingrediente das dietas. Os coeficientes de cultura foram obtidos da publicação da FAO (Doorenbos e Kassam, 1994). Quando não foi possível rastrear a localização da produção de um determinado ingrediente da dieta, utilizou-se a base de dados da Companhia Nacional de Abastecimento (Conab), consultando-se a série histórica de produtividade das culturas para determinar o Estado com maior representatividade na produção da cultura em questão. A partir desta informação, calculou-se a média da produtividade do Estado no período de dez anos; em seguida, selecionou-se o munícipio do Estado com o valor de produtividade mais próxima da média decenal estadual.

Para o cálculo da PH azul, utilizou-se dados secundários referentes aos consumos de água de humanos, lavagem do piso e equipamentos da ordenha e de dessedentação animal por categoria (Palhares, 2016).

No cálculo do consumo de água cinza o sistema de produção foi considerado como uma fonte difusa de poluição, pois os efluentes eram direcionados a uma esterqueira e, posteriormente, utilizados como fertilizante. O nitrato foi o elemento utilizado como base de cálculo. As concentrações de nitrato no efluente foram determinadas para o período a pasto e para o período em confinamento, sendo $0,0236 \mathrm{mg} \mathrm{L}^{-1}$ e $0,108 \mathrm{~kg} \mathrm{~m}^{-3}$, respectivamente.

A PH total do sistema foi obtida pela somatória das PH verde, azul e cinza.

\section{RESULTADOS E DISCUSSÃO}

A produção média de leite por vaca foi de $16,7 \mathrm{~L}_{\text {animal }}{ }^{-1}$ dia $^{-1}$, sendo a média da estação de pastejo 15,9 $\mathrm{L}_{\text {animal }}{ }^{-1} \mathrm{dia}^{-1}$ (média de 202 vacas em lactação no mês) e a de confinamento 18,3 $\mathrm{L} \mathrm{animal}^{-1} \mathrm{dia}^{-1}$ (média de 228 vacas em lactação no mês). A produção média mensal de leite foi de 110.886 litros.

A PH anual do sistema de produção foi de $831 \mathrm{~L} \mathrm{~kg}^{-1}$ de leite corrigido, sendo que a PH verde representou 98,7\% desse valor, a azul 0,97\% e a cinza 0,33\%. Avaliando a PH de sistemas mistos (pasto e confinamento), Mekonnen e Hoekstra (2010) calcularam o valor de $956 \mathrm{~L} \mathrm{~kg}^{-1}$ de leite corrigido. Palhares e Pezzopane (2015) calcularam a pegada hídrica de um sistema de leite a pasto com suplementação na seca e obtiveram o valor de $962 \mathrm{~L} \mathrm{~kg} \mathrm{k}^{-1}$ de leite corrigido. Diferenças entre os valores de pegada hídrica para o mesmo produto são esperadas, pois está é influenciada pelo tipo de dieta, pela produtividade das culturas vegetais e pelos usos diretos e indiretos considerados no cálculo.

Dentre as categorias dos animais, as de vacas em lactação são as que mais contribuem para o valor da pegada hídrica, seja a verde, azul ou cinza.

A estação a pasto apresentou uma PH média de $610 \mathrm{~L} \mathrm{~kg}^{-1}$ de leite corrigido e no período de confinamento esse valor foi de $986 \mathrm{~L} \mathrm{~kg}^{-1}$ de leite corrigido. A PH no confinamento foi $62 \%$ maior que a PH a pasto. Os valores mensais das pegadas hídricas são apresentados na Figura 1.

A PH verde é a que melhor representa a diferença entre pasto e confinamento, devido as diferenças de constituição das dietas, demonstrando que a dieta baseada em pasto é hidricamente mais eficiente. A utilização de pastagens de inverno é uma das estratégias que se dispõe para reduzir os custos de alimentação com concentrado e silagens neste período do ano. Esta estratégia exige conhecimentos e planejamento prévio para que seja efetiva, considerando as boas práticas agrícolas e o manejo adequado. 
Os fatores produtivos que mais impactam o valor da pegada hídrica verde são o tipo de dieta do animal, a ingestão de matéria seca e a produtividade agrícola. Hoekstra (2012) enfatiza a necessidade de rever a composição das rações e a origem dos seus ingredientes, para encontrar maneiras de reduzir a pegada hídrica dos produtos de origem animal. Bosire et al. (2015) afirmam que a demanda de água na produção de leite é determinada pela eficiência da conversão alimentar e pela composição da dieta fornecida aos animais.

A dessedentação das vacas em lactação representou o maior percentual da pegada hídrica azul (Figura 2). O consumo de dessedentação de vacas em lactação pode ser mais eficiente oferecendo dietas ajustadas de acordo com as necessidades de proteína e minerais. O segundo maior uso de água azul se deu no manejo da lavagem de piso e equipamentos da ordenha. A água consumida neste manejo é resultado da capacitação do operador, por isso é importante que este esteja capacitado em fazer a lavagem com menor uso de água, e do tipo de equipamento utilizado na lavagem. Uma prática para reduzir o consumo de água neste manejo é se promover a raspagem do piso antes da lavagem e fazer o uso da água com pressão.

Também se observou no consumo de água cinza o impacto do tipo de alimentação no valor da pegada, devido a maior concentração de nitrogênio nos dejetos dos animais. O consumo de água cinza no período em confinamento representou $85,2 \%$ do consumo anual. O valor máximo da pegada cinza $\left(4,2 \mathrm{~L} \mathrm{~kg}^{-1}\right.$ de leite corrigido no mês de maio) é quatro vezes maior que o maior valor da pegada cinza quando os animais estavam a pasto.

\section{CONCLUSÃO}

Os resultados demonstram que o tipo de sistema de produção influencia no valor da pegada hídrica e, consequentemente, na sua variabilidade mensal, sendo que no sistema confinado a pegada hídrica foi maior. Em termos de manejo, a principal diferença entre este sistema é o tipo de alimentação. As dietas do confinamento promoveram maiores consumos de águas verde e cinza e não impactaram no consumo de água azul. Conclui-se que a permanência dos animais a pasto e a dieta baseada no consumo de pastagem contribuiu para eficiência hídrica do produto leite. Estudos futuros devem explorar a relação sistema de leite a pasto e uso da água.

\section{AGRADECIMENTOS}

A equipe da Fazenda São Bento por disponibilizar os dados para a execução da pesquisa.

\section{REFERÊNCIAS}

BOSIRE, C.K.; OGUTU, J. O.; SAID, M.Y.; et al. Trends and spatial variation in water and land footprints of meat and milk production systems in Kenya. Agriculture, Ecosystems \& Environment, v. 205, p.36-47, 2015.

DOORENBOS, J.; KASSAM, A. H. Efeito da água no rendimento das culturas. Campina Grande: UFPB, 1994. 306p. (FAO. Estudos FAO. Irrigação e Drenagem, 33).

FOOD AND AGRICULTURE ORGANIZATION OF THE UNITED NATIONS (FAO). Smallholder dairy methodology. [S.1.]: FAO e ILRI, 2016. 47p.

HOEKSTRA, A. Y. AND HUNG, P. Q. Virtual water trade: A quantification of virtual water flows between nations in relation to international crop trade', Value of Water Research Report Series No 11, UNESCO-IHE, Delft, Netherlands, 2002.

HOEKSTRA, A. Y. The hidden water resource use behind meat and dairy. Animal Frontiers, v.2, n.2, p.38, 20 mar.2012.

HOEKSTRA, A.Y., CHAPAGAIN, A.K., ALDAYA, M.M. et al. Manual de Avaliação da Pegada Hídrica: Estabelecendo o Padrão Global. Earthscan 216. 2011.

MEKONNEN, M. M.; HOEKSTRA, A. Y. The green, blue and grey water footprint of farm animals and animal products. Delft, the Netherlands: UNESCO-IHE, 2010. 43p. (Value of Water Research Report Series, 48).

MEKONNEN, M. M; HOEKSTRA, A, Y. A Global Assessment of the Water Footprint of Farm Animal Products. Department of Water Engineering and Management, University of Twente, 2012.

NOVELLI, T. I. Impacto de intervenções nutricionais no valor da pegada hídrica do produto leite bovino. 2017. 112 p. Dissertação (Mestrado em Ciências) - Faculdade de Medicina Veterinária e Zootecnia, Universidade de São Paulo, Pirassununga, 2017. 
PALHARES, J. C. P. Boas práticas hídricas na produção leiteira (Versão 2). Comunicado técnico, Embrapa. São Carlos - SP. Setembro, 2016.

PALHARES, J.C.P., PEZZOPANE, J.R.M. Water footprint accounting and scarcity indicators of conventional and organic dairy production systems. Journal of Cleaner Production 93, 299-307. 2015.

PEREIRA, A. R.; ANGELOCCI, L. R.; SENTELHAS, P. C. Agrometeorologia: fundamentos e aplicações práticas. Guiabá: Agropecuária, 2002. 487p.

VALADARES FILHO, S.C.; MACHADO, P.A.S; CHIZZOTTI, M.L. et al. CQBAL 3.0. Tabelas brasileiras de composição de alimentos para bovinos. Disponível em: 〈http://www.ufv.br/cqbal>.

WHITE, R. R. Increasing energy and protein use efficiency improves opportunities to decrease land use, water use, and greenhouse gas emissions from dairy production. Agricultural Systems, v.146, p.20-29. 2016.

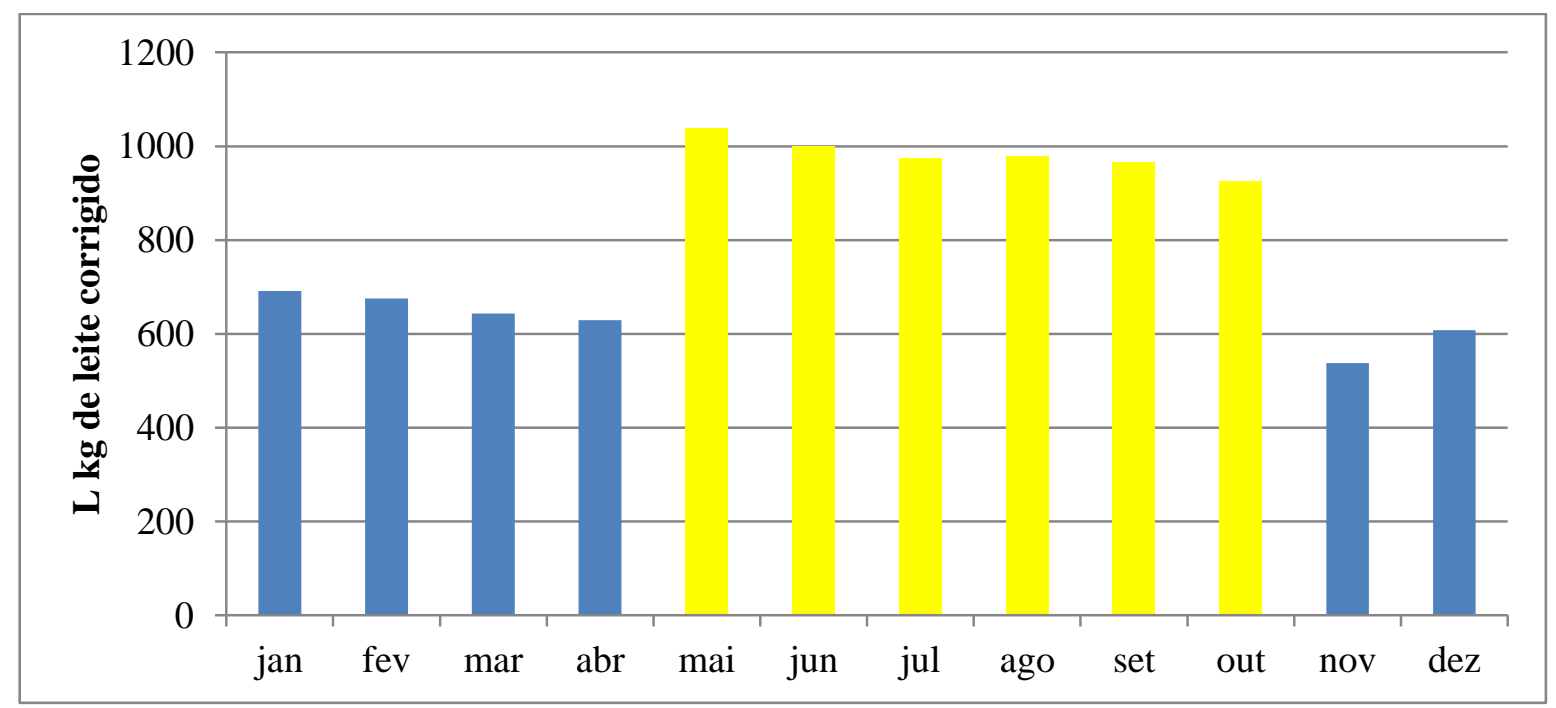

Figura 1. Pegada Hídrica Total da Fazenda São Bento. As barras em azul são referentes aos meses de pastejo e as em amarelo aos meses de confinamento.

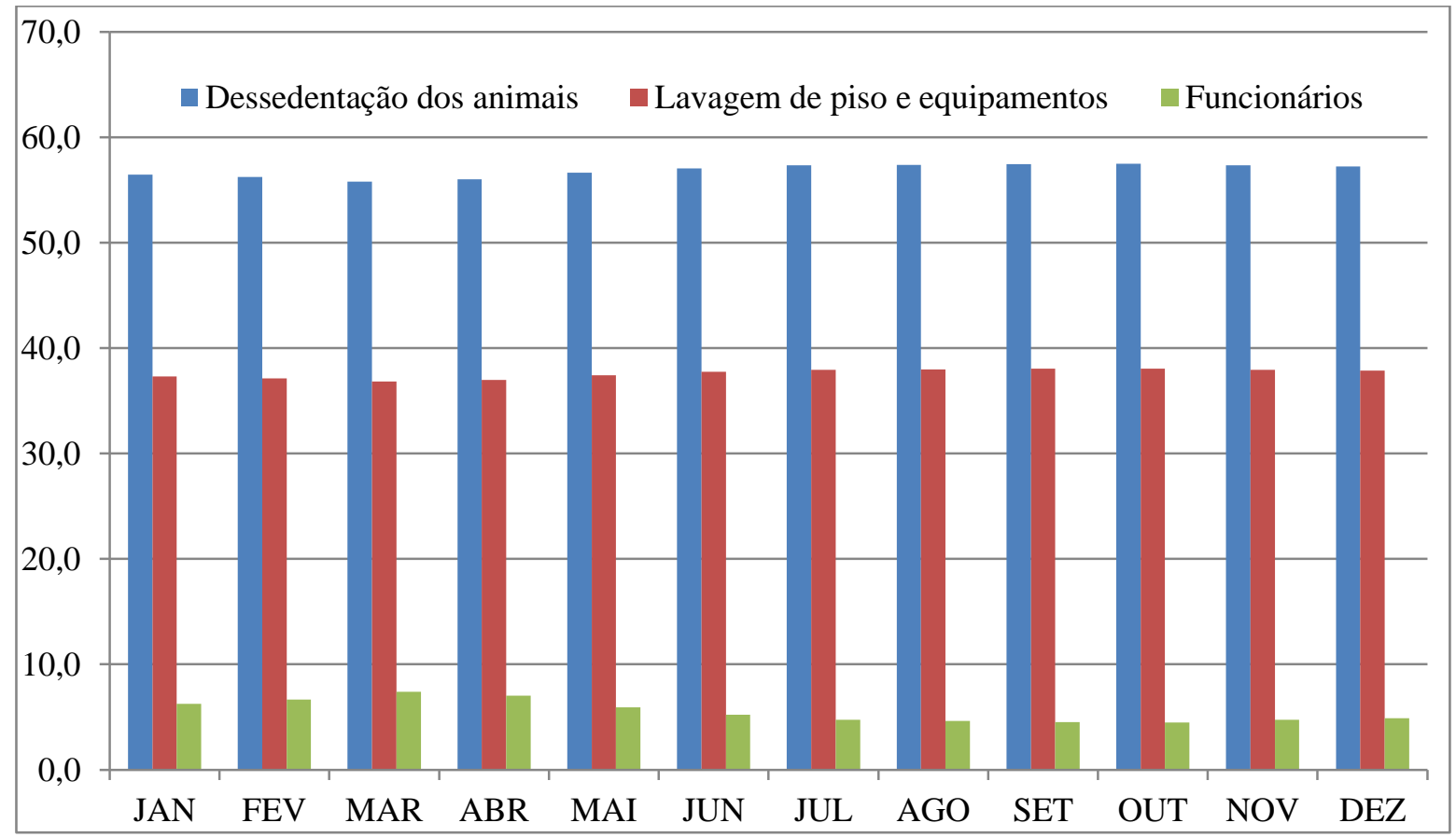

Figura 2. Percentual dos usos da água no valor da pegada hídrica azul da Fazenda São Bento. 


\title{
UTILIZAÇÃO DE PRÁTICAS DE MANEJO DE RESÍDUOS EM PROPRIEDADES LEITEIRAS EM MINAS GERAIS
}

\author{
Palhares, J.C.P. ${ }^{1}$; De Mori, C. ${ }^{\text {; }}$ De Carmago, A.C. ${ }^{1}$; Novo, A.L.M. ${ }^{1}$ \\ ${ }^{1}$ Embrapa Pecuária Sudeste - Brasil \\ julio.palhares@embrapa.br
}

\begin{abstract}
RESUMO: O objetivo do trabalho foi avaliar o uso de sistemas e práticas relacionadas ao manejo de resíduos em propriedades leiteiras do estado de Minas Gerais. Trata-se de um estudo observacional junto a propriedades participantes do Programa Balde Cheio. O período de análise compreende os anos de 2015, 2016 e 2017 . O número de planilhas analisadas para cada ano foi de 63, 215 e 417, respectivamente para os citados anos. Consideraram-se os seguintes indicadores: manejo de efluentes e disposição de carcaças. Ao longo do período avaliado verificou-se que mais de três quartos das propriedades leiteiras não dispunham de sistema de armazenamento ou tratamento de efluentes. Das propriedades que tinham algum sistema, a principal opção foi a esterqueira. Propriedades que dispunham de sistema de tratamento apresentaram representatividade menor do que $3 \%$ ao longo do período. Das propriedades, $50 \%$ não faziam nenhuma prática de disposição de carcaças de animais mortos e quando faziam, o enterramento foi à prática predominante. Os resultados permitem concluir que as práticas e sistemas de armazenamento e tratamento disponíveis para o correto manejo dos resíduos da produção leiteira não estão sendo considerados no cotidiano produtivo das propriedades avaliadas.
\end{abstract}

Palavras-chave: carcaças, dejetos, esterqueira, fertilizante.

\section{WASTE MANAGEMENT PRACTICES IN MINAS GERAIS DAIRY FARMS}

\begin{abstract}
The aim of this study was to evaluate the use of systems and practices related to waste management in dairy farms in the Minas Gerais state. This is an observational study with farmers of Balde Cheio program. The analysis period comprises the years 2015, 2016 and 2017. The number of spreadsheets analyzed for each year was 63, 215 and 417, respectively for those years. The following indicators were considered: effluent management and carcass disposal. Over the period evaluated, it was found that more than three quarters of dairy farms did not have effluent storage or treatment system. Of the farms that had some system, the main option was the deep pit. Farms that had a treatment system represented less than 3\%. Considering all farms, 50\% did not practice carcass disposal and when they did, burial was the predominant practice. The results show that practices and systems of storage and treatment available for the correct management of dairy wastes are not being used in the daily work of the farms.
\end{abstract}

Keywords: carcasses, deep pit, fertilizer, manure.

\section{INTRODUÇÃO}

Dentre os Estados brasileiros, Minas Gerais destaca-se na produção de leite do país. Em 2017, o Estado foi responsável por $25,5 \%$ da produção nacional (8,9 bilhões de litros de leite) e 26,3\% da captação anual dos laticínios registrados (6,5 bilhões de litros), contando com um contingente de 223 mil produtores de leite em atividade (20,3\% do total do Brasil) e um rebanho de 5,8 milhões de vacas (31,2\% do rebanho nacional de vacas) (Embrapa, 2017).

A bovinocultura leiteira insere preocupação ambiental devido ao manejo dado aos dejetos e carcaças gerados pela atividade. Quando esse manejo não é realizado de acordo com os padrões legais e as boas práticas ambientais, a propriedade torna-se uma potencial fonte de poluição pontual e difusa. Os riscos ambientais podem ser potencializados quando os resíduos são usados como fertilizante sem considerar o conceito de balanço de nutrientes. Segundo o Parlamento da Nova Zelândia, os poluentes de origem difusa de maior preocupação para as águas doces são os patógenos, os sedimentos finos e os nutrientes. Esse tipo de poluição está generalizado no território e relacionado com o principal uso das terras (pastagem para produção de leite) e com a produção animal (Parliamentary Commissioner for the Environment, 2015).

Estudos de diagnose da realidade do manejo de resíduos da produção leiteira permitem subsidiar a tomada de decisão por produtores e técnicos e auxiliar na proposição de programas privados e políticas 
públicas, porém ainda são escassos. O objetivo do trabalho foi avaliar o uso de sistemas e práticas relacionadas ao manejo de resíduos em propriedades leiteiras do Estado de Minas Gerais.

\section{MATERIAL E MÉTODOS}

Trata-se de um estudo observacional junto a propriedades participantes do Programa Balde Cheio no Estado de Minas Gerais. O Projeto Balde Cheio, criado pela Embrapa Pecuária Sudeste em 1998, é uma metodologia de transferência de tecnologias, com o objetivo de capacitar profissionais e produtores(as) em técnicas, práticas e processos agropecuários. Em 2017, o Projeto atuou em 229 municípios mineiros, com atendimento a 911 propriedades rurais, envolvendo 97 técnicos e 82 instituições parceiras. O levantamento contempla dados coletados por formulário eletrônico referente ao Índice de Atualização Tecnológica (IAT). A planilha IAT consiste em um instrumental para mensurar a situação do uso de tecnologias da propriedade leiteira por meio do preenchimento de questões específicas de procedimentos/tecnologia ou tipo de equipamento/infraestrutura empregados na atividade. $\mathrm{O}$ formulário abrange dados de perfil da propriedade; de perfil do produtor/família; e de perfil tecnológico. O índice é composto de 237 indicadores de natureza quantitativa e qualitativa. Neste estudo, considerou-se somente a análise dos indicadores relacionados ao manejo de resíduos da propriedade, sendo eles: manejo de efluentes, tratamento e disposição de carcaças e práticas de manejo ambiental.

Cada planilha se refere aos dados de cada produtor assistido por um profissional do Programa Balde Cheio. As planilhas foram preenchidas conjuntamente pelo produtor e pelo técnico responsável pela propriedade. O período de análise compreende os anos de 2015, 2016 e 2017. O número de planilhas analisadas para cada ano foi de 63, 215 e 417, respectivamente para os citados anos. Os resultados são apresentados em percentagem de frequência relativa (quociente entre a frequência absoluta e o número total de observações).

\section{RESULTADOS E DISCUSSÃO}

Ao longo do período avaliado verificou-se que mais de três quartos das propriedades leiteiras não dispunham de sistema de armazenamento ou tratamento de efluentes oriundos da lavagem da instalação de ordenha (Figura 1). Essa realidade insere uma condição de fragilidade ambiental à atividade, pois os efluentes não estão sendo manejados de acordo com as boas práticas ambientais. Por consequência, devem estar sendo dispostos no ambiente de forma incorreta, o que determinará impactos ambientais negativos para as águas, solo e ar.

Herrero et al. (2018) identificaram entre as principais necessidades para que os atores da produção de leite no Brasil promovam o correto manejo dos efluentes a disponibilização de treinamentos e de um manual sobre manejo de efluentes leiteiros. A principal barreira para não praticar o correto manejo dos efluentes para $60 \%$ dos respondentes foi à falta de conhecimento no tema. A baixa utilização de sistemas de armazenamento e/ou tratamento verificadas neste estudo podem ser resultados das necessidades e barreiras elencadas pelos autores. Já existem práticas e tecnologias para o correto manejo dos efluentes leiteiros, se estas não estão sendo utilizadas e/ou compreendidas pelo setor, pode-se inferir que há reduzido conhecimento por parte dos produtores e profissionais agropecuários sobre como fazer esse manejo.

A Deliberação Normativa Copam n ${ }^{\circ} 217$ de 06 de dezembro de 2017 estabelece critérios para definição das modalidades de licenciamento ambiental de atividades utilizadores de recursos ambientais no Estado de Minas Gerais. Considerando os critérios da Deliberação e a estrutura da maioria das propriedades leiteiras do estado, menos de 500 cabeças ou menos de 200 ha, as propriedades teriam que ter uma licença ambiental simplificada que pode ser expedida em uma única fase, mediante cadastro de informações pelo empreendedor, ou em um a única fase pela apresentação do Relatório Ambiental Simplificado (descrição da atividade e das respectivas medidas de controle ambiental). Portanto, a legalização ambiental da atividade leiteira não seria algo complexo, podendo ser feito pelo produtor ou por este com a assistência de um técnico.

Minas Gerais é historicamente a maior bacia leiteira do país. Essa condição de fragilidade no manejo de efluentes pode ser entendida como uma oportunidade para implementação de programas e políticas que promovam a adequação ambiental dos sistemas de produção de leite. Como isso, o estado pode se tornar uma referência para outros estados e bacias leiteiras, demonstrando ser possível produzir de forma ambientalmente correta e economicamente viável.

Das propriedades que dispunham de algum sistema, a maioria optou pelo armazenamento dos efluentes em esterqueiras. O armazenamento insere uma rotina de manejo mais simples, com menor custo de investimento e manutenção e baixa necessidade de capacitação da mão-de-obra. Ao se optar pelo 
armazenamento também está se optando pela disposição do resíduo como fertilizante. A disposição é benéfica para cultura vegetal, pelo efluente ser uma fonte de água e nutrientes; para o solo, pela melhoria da estrutura deste; e para economia da propriedade, pela redução com a aquisição de fertilizantes químicos. Mas a disposição deve ser feita considerando os preceitos do balanço de nutrientes, caso contrário, a disposição representará uma fonte de poluição difusa. Somente no formulário do IAT de 2017, questões relacionadas ao uso dos resíduos como fertilizante foram levantadas. Do total, 33\% declararam que consideravam a fertilidade do solo e as concentrações de nutrientes dos resíduos na disposição e somente 3\% faziam a análise para caracterizar os resíduos quanto à concentração de nutrientes. Esses resultados indicam que o balanço de nutrientes não é considerado na sua integralidade.

Propriedades que dispunham de um sistema de tratamento apresentaram representatividade menor do que $3 \%$ ao longo do período avaliado. Fazer o tratamento dos efluentes tem maior custo e é dependente de mão-de-obra especializada. Por isso, a utilização de sistemas de tratamento para os resíduos da produção animal ainda apresenta baixa frequência de uso, sendo mais comum em realidades que há pressão social e/ou do órgão licenciador ou onde o produtor consegue conciliar o tratamento com mecanismos de agregação de valor ao produto e/ou redução dos custos de produção.

Em média no período avaliado, $50 \%$ das propriedades não faziam nenhuma prática de disposição de carcaças de animais mortos (Figura 2). Isso pode significar que as carcaças estejam sendo deixadas nas áreas da propriedade, o que represente riscos para saúde humana e animal. A queima das carcaças aparece com significativa frequência no ano de 2015 (31,7\%), mas reduz nos anos posteriores. A queima não é um processo de disposição indicado, pois além de colocar em risco a vida e a saúde humana, ela não represente uma forma de tratamento integral o que somente seria alcançado pela incineração.

A frequência de propriedades que praticam o enterramento das carcaças demonstra aumento ao longo dos anos de estudo, representando quase 50\% das propriedades em 2017 . O enterramento pode ser uma forma de disposição deste resíduo, desde que sejam consideradas as recomendações técnicas relacionadas à escolha da área, tipo de solo e drenagem da área, distância de corpos d’água superficiais e subterrâneos e de habitações e instalações de animais.

O tratamento das carcaças por compostagem, sistema mais indicado para disposição deste tipo de resíduo, foi apontado por apenas $1,4 \%$ dos produtores e somente no ano de 2016. Essa realidade demonstra a necessidade de incentivar e transferir os conhecimentos necessários para que os produtores façam a compostagem o que determinará um correto manejo deste resíduo e melhor status sanitário da atividade. Otenio et al (2010) a compostagem de carcaças é economicamente viável, evita a formação de odores, destrói os agentes causadores de doenças, não contamina o lençol freático e pode ser feito em qualquer época do ano.

\section{CONCLUSÃO}

Os resultados permitem concluir que as práticas e sistemas de armazenamento e tratamento disponíveis para o correto manejo dos resíduos da produção leiteira não estão sendo considerados no cotidiano produtivo da maioria das propriedades avaliadas. A iniciativa de cada produtor em fazer a adequação ambiental da atividade e o fomento público e privado para utilização das práticas e sistemas deve fazer parte das agendas do setor leiteiro de Minas Gerais, bem como de outros estados e bacias leiteiras. Produzir leite de forma ambientalmente correta é tecnicamente possível, economicamente viável e socialmente desejável.

\section{AGRADECIMENTOS}

Agradecemos a todos os produtores e técnicos do Projeto Balde Cheio pela colaboração no preenchimento dos formulários.

\section{REFERÊNCIAS}

EMBRAPA. Indicadores: Leite e Derivados. - Ano 8, n. 69 (Agosto/2017) - Juiz de Fora: Embrapa Gado de Leite, 2017.

HERRERO, M. A.; PALHARES, J.C.P.; SALAZAR, F.J.; CHARLÓN, V.; TIERI, M.P.; PEREYRA, A.M. Dairy Manure Management Perceptions and Needs in South American Countries. Frontiers in Sustainable Food Systems, v. 2, p. 1-15, 2018.

MINAS GERAIS. Copam. Deliberação Normativa no 217 de 06 de dezembro de 2017. Estabelece critérios para classificação para definição das modalidades de licenciamento ambiental. Disponível em: <http:// http://www.siam.mg.gov.br/sla/download.pdf?idNorma=45558>. 
OTENIO, M.; DA CUNHA, C.M.; ROCHA, B.B. Compostagem de carcaças de grandes animais. Embrapa Gado de Leite, Juiz de Fora, 2010.

PARLIAMENTARY COMMISSIONER FOR THE ENVIRONMENT. Update report - water quality in New Zealand: land use and nutrient pollution. Wellington: Parliamentary Commissioner for the Environment, 2015. Disponível em: http://www.pce.parliament.nz/media/1008/update-report-water-quality-in-newzealand-web.pdf.

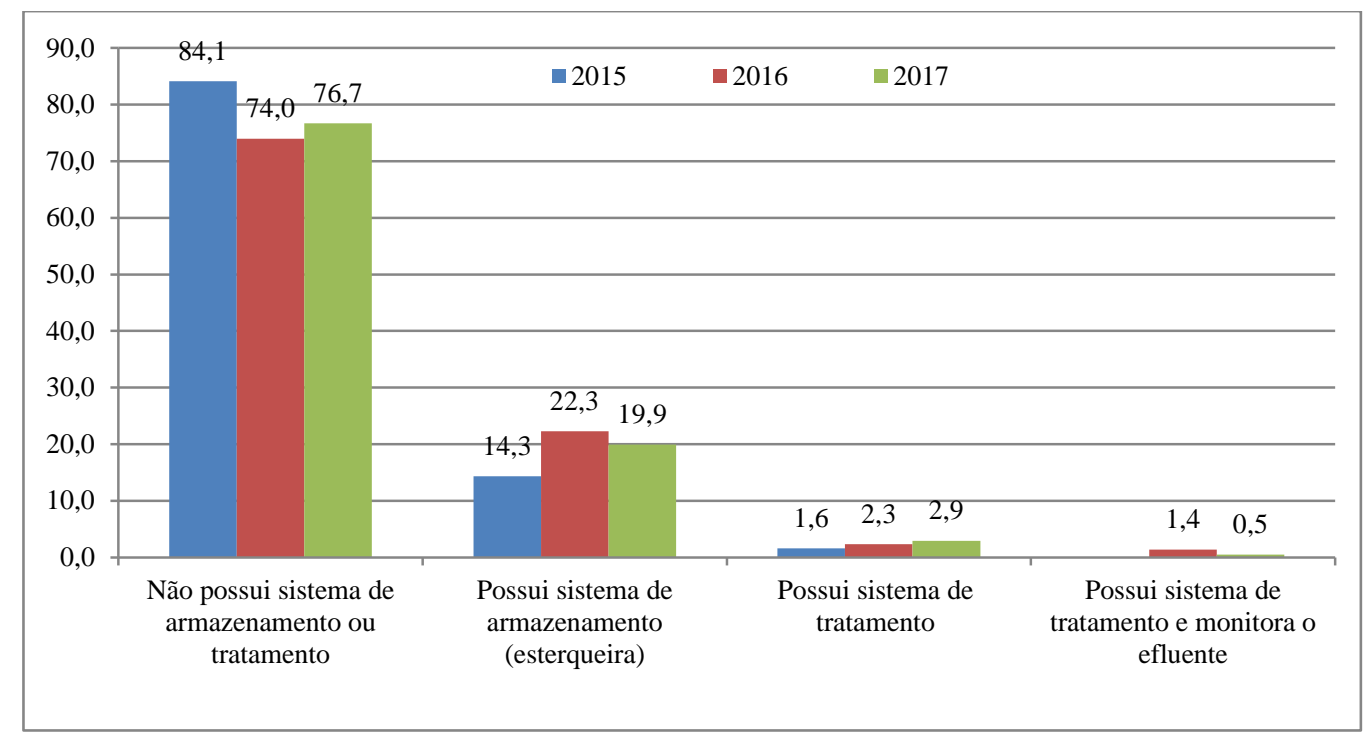

Figura 1. Porcentagem de uso de sistemas de armazenamento e/ou tratamento para o manejo dos efluentes.

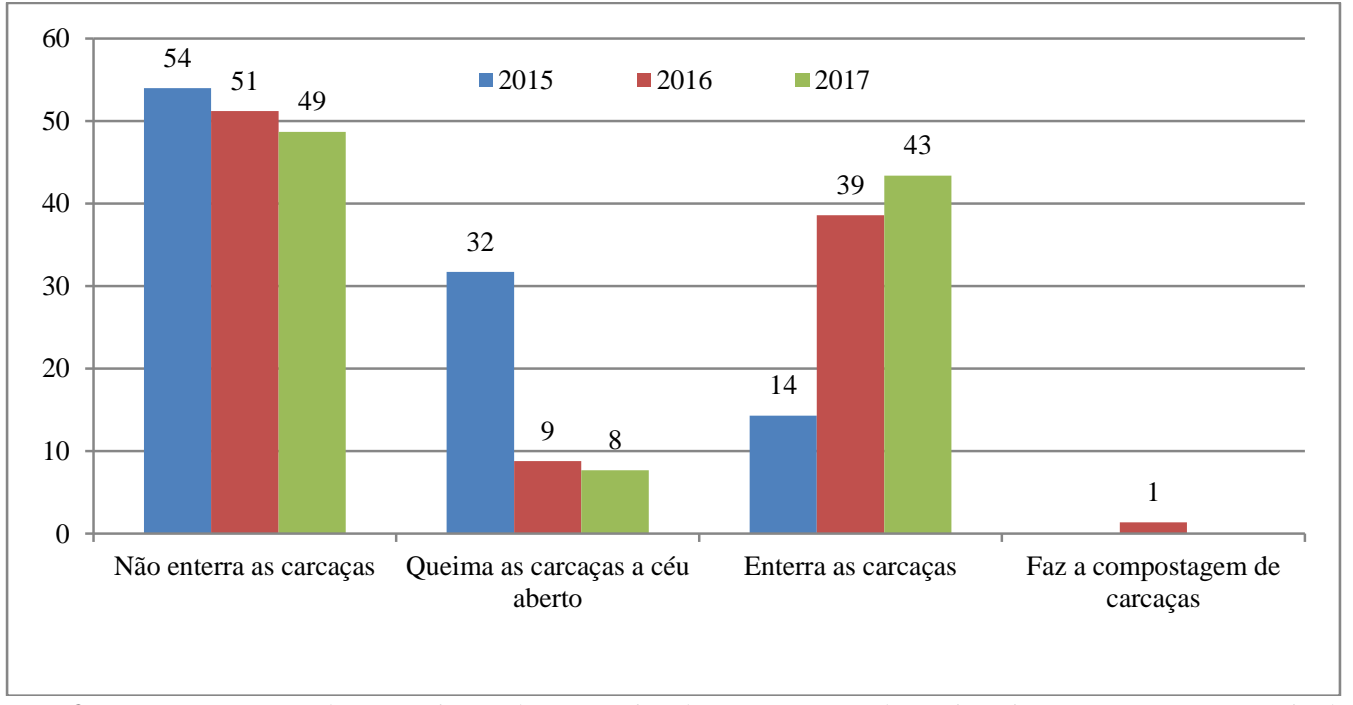

Figura 2. Porcentagem das práticas de manejo das carcaças de animais mortos na propriedade. 


\title{
VALORAÇÃO ECONÔMICA DOS DEJETOS DA FASE DE CONFINAMENTO DE UM SISTEMA DE PRODUÇÃO DE LEITE
}

\author{
Silva, M.F. ${ }^{1}$; Palhares, J.C.P.*1,2; Gameiro, A.H. ${ }^{1}$ \\ ${ }^{1}$ Departamento de Nutrição e Produção Animal, Faculdade de Medicina Veterinária e Zootecnia da Universidade de São Paulo, \\ Pirassununga, SP - Brasil \\ ${ }^{2}$ Embrapa Pecuária Sudeste, São Carlos, SP - Brasil \\ mirian.fabiana@usp.br
}

\begin{abstract}
RESUMO: O balanço de nutrientes é um método utilizado para avaliar o desempenho ambiental das propriedades agropecuárias e outras atividades, por meio de entradas e saídas de nutrientes, como nitrogênio $(\mathrm{N})$, fósforo $(\mathrm{P})$ e potássio $(\mathrm{K})$. Objetivou-se calcular o balanço e a eficiência de uso de nutrientes de um sistema de produção de leite e valorar economicamente os nutrientes que permanecem no sistema na forma de dejetos. $\mathrm{O}$ balanço de nutrientes foi calculado com base em um rebanho leiteiro com 59 vacas em lactação. Para o cálculo se considerou os elementos $\mathrm{N}, \mathrm{P}$ e K, sendo a entrada a dieta e a saída o produto leite. $\mathrm{O}$ valor estimado dos dejetos no período foi calculado com base no preço médio de mercado dos fertilizantes equivalentes, como ureia, superfosfato simples e cloreto de potássio. O balanço foi de 1.906,68 kg de N, 397,49 $\mathrm{kg}$ de $\mathrm{P}$ e $1.271,84 \mathrm{~kg}$ de $\mathrm{K}$. O valor dos dejetos total foi de $\mathrm{R} \$ 18.771,24$, por vaca foi de $\mathrm{R} \$ 318$, 16 e de $\mathrm{R} \$ 0,13$ por kg de leite produzido. Os resultados enfatizam a importância do manejo dos dejetos da produção de leite e sua correta utilização terá impactos positivos na economia da propriedade e para o ambiente.
\end{abstract}

Palavras-chave: balanço de nutrientes, fósforo, nitrogênio, potássio.

\section{ECONOMIC EVALUATION OF THE MANURE ON THE CONFINED STAGE OF A DAIRY SYSTEM}

\begin{abstract}
Nutrient balance is a method used to evaluate the environmental performance of farms and other activities, through nutrients inputs and outputs, such as nitrogen $(\mathrm{N})$, phosphorus $(\mathrm{P})$ and potassium $(\mathrm{K})$. The aim of the study was to calculate the balance and nutrient use efficiency of a milk production system and calculate the economic value of nutrients that remain in the system as manure. Nutrient balance was calculated based on a dairy herd with 59 lactating cows. For the calculation were considered the elements N, P and K. The the inputs were diet ingredients and output the milk. The estimated value of manure in the period was calculated based on of the average market price of equivalent fertilizers, such as urea, simple superphosphate and potassium chloride. The surpplus was $1,906.68 \mathrm{~kg}$ of N, $397.49 \mathrm{~kg}$ of P, and 1,271.84 $\mathrm{kg}$ of $\mathrm{K}$. The total value of manure was $\mathrm{R} \$ 18,771.24, \mathrm{R} \$ 318.16$ per lactation cow and $\mathrm{R} \$ 0.13$ per $\mathrm{kg}$ of milk. The results emphasize the importance of the manure management in dairy systems and that the correct use has positive impacts on the farm economy and to the environment.
\end{abstract}

Keywords: nitrogen, nutrient balance, phosphorus, potassium.

\section{INTRODUÇÃO}

O sistema agroindustrial do leite tem importância significativa para o agronegócio brasileiro, contribuindo economicamente e socialmente com a geração de renda aos produtores, empregos diretos e indiretos, e fornecendo alimentos para a população. Segundo dados da Pesquisa Pecuária Municipal, no ano de 2017 o rebanho brasileiro foi de 17,06 milhões de vacas, que produziram 33,49 bilhões de litros de leite, representando um valor total de $\mathrm{R} \$ 51,57$ bilhões (IBGE, 2018).

A bovinocultura leiteira, como as demais atividades pecuárias, pode causar impactos negativos no ambiente, devido ao incorreto manejo dos resíduos, e, a consequente, disposição inadequada destes, aumentando o risco de contaminação do solo, das águas superficiais e subterrâneas e de emissões de gases e odores.

Portanto, o manejo dos dejetos leiteiros é de extrema relevância e pelo uso de práticas e tecnologias é possível minimizar os impactos ambientais, devendo ser considerado os aspectos zootécnicos, econômicos e sociais do sistema produtivo. 
O balanço de nutrientes é uma ferramenta importante para realizar a estimativa da diferença entre as entradas e saídas de nutrientes de qualquer atividade pecuária. A partir das informações geradas pelo balanço podem ser adotadas medidas de controle dos fluxos de nutrientes, com a finalidade de melhorar a ciclagem de nutrientes e minimizar as perdas para o ambiente. $\mathrm{O}$ balanço também auxilia na gestão dos insumos e aumento da eficiência do uso destes, contribuindo de forma positiva para o retorno econômico da atividade (Rasmussen et al., 2011; Gourley et al., 2012; Mu et al., 2017). Assim, o uso dos dejetos como fertilizante representa uma oportunidade econômica e, consequentemente, reduz a entrada de insumos na forma de fertilizantes químicos o que determinará balanços de nutrientes mais equilibrados.

Nesse sentido, objetivou-se calcular o balanço e a eficiência de uso de nutrientes de um sistema de produção de leite e valorar economicamente os nutrientes que permanecem no sistema na forma de dejetos.

\section{MATERIAL E MÉTODOS}

Para a análise considerou-se um sistema de produção com 59 vacas em lactação, com base nos dados da pesquisa realizada por Pereira et al. (2016) na mesorregião Triângulo Mineiro-Alto Paranaíba, Minas Gerais.

O sistema de produção em análise tinha um manejo das águas, animais a pasto, e de seca, animais em confinamento. A estação de seca foi o período escolhido para realização do balanço pelos animais estarem em confinamento e haver a necessidade de manejo dos dejetos. Na estação chuvosa os animais permaneciam a pasto, sendo a distribuição dos dejetos feita naturalmente.

O período de análise foi de 183 dias (abril a setembro), que de acordo com Santos e Ferreira (2016) e Roldão e Assunção (2014) é a estação seca na região de estudo. A produção total de leite no período foi de $140.361 \mathrm{~kg}$, sendo $13 \mathrm{~kg}$ de leite por vaca por dia. O peso corporal médio dos animais foi de $550 \mathrm{~kg}$ e o consumo médio de $14 \mathrm{~kg} \mathrm{dia}^{-1}$ de matéria seca por animal.

Para o cálculo balanço de nutrientes considerou-se somente as vacas em lactação e sem a aquisição e venda de animais. Os nutrientes analisados foram nitrogênio $(\mathrm{N})$, fósforo $(\mathrm{P})$ e potássio $(\mathrm{K})$, sendo as entradas os ingredientes da dieta e a saída o produto leite. Os cálculos foram feitos com base na matéria seca.

$\mathrm{O}$ balanço foi calculado pela diferença entre a quantidade de N, P e K que entrou por meio dos alimentos e a saída por meio da produção de leite. Os cálculos das entradas de N, P e K foram gerados considerando as médias desses elementos nas análises dos produtos utilizados na dieta.

A dieta das vacas foi composta por: $70 \%$ de silagem de milho, $21 \%$ de milho moído, $7 \%$ de farelo de soja e $2 \%$ de mistura mineral e vitamina na matéria seca. A composição dos alimentos foi obtida por meio da tabela brasileira de composição de alimentos para bovinos (CQBAL, 2018).

A produção de leite total foi calculada pela média de produção por vaca por dia, multiplicando pelo número de vacas em lactação e pelo período analisado (183 dias). A composição do leite foi obtida pela tabela de composição de alimentos da Universidade Estadual de Campinas (NEPA, 2011). As quantidades dos nutrientes presentes no leite foram calculadas multiplicando a produção total pelos teores de N, P e K.

A eficiência do uso dos nutrientes foi calculada pela relação entre a quantidade total de cada nutriente no leite e a quantidade total de cada nutriente nos alimentos.

$\mathrm{O}$ valor econômico dos dejetos foi calculado com base no preço médio de mercado dos fertilizantes equivalentes, como ureia $(45 \% \mathrm{~N})$, superfosfato simples $\left(18 \% \mathrm{P}_{2} \mathrm{O}_{5}\right)$ e cloreto de potássio $\left(60 \% \mathrm{~K}_{2} \mathrm{O}\right)$. Utilizouse os preços médios no ano de 2017 de acordo com o Instituto de Economia Agrícola (IEA-SP, 2018). Para o nitrogênio, considerou-se a perda por volatilização de $28 \%$ segundo Xiccato et al. (2005).

\section{RESULTADOS E DISCUSSÃO}

A Tabela 1 apresenta as entradas, a saída e o balanço de nutrientes do sistema de produção de leite. $\mathrm{O}$ balanço foi positivo para os três nutrientes, as entradas foram maiores que as saídas. A entrada de $\mathrm{N}$ foi de $2.610,69 \mathrm{~kg}$, a de P de $512,59 \mathrm{~kg}$ e a de $\mathrm{K}$ de $1.458,52 \mathrm{~kg}$, sendo que $45 \% 40 \%$ e $71 \%$ desses valores foram constituídos pela silagem de milho, respectivamente. Considerou-se que a diferença entre entradas e a saída ficou no sistema na forma de dejetos que devem ser manejados a fim de reduzir o potencial poluidor do sistema de produção. Sabe-se que parte desta diferença é utilizada na formação dos ossos, tecidos e outros processos fisiológicos dos animais.

A eficiência de uso do N foi de 27\%, do P 22\% e do K 13\%. Segundo o estudo de Gourley et al. (2012) avaliando diferentes sistemas de produção de leite na Austrália a eficiência de uso média do $\mathrm{N}$ foi de $26 \%$, do P $35 \%$ e do K 20\%. Palhares (2013) analisou um sistema de produção de leite a pasto e encontrou eficiência de uso do $\mathrm{N}$ e do $\mathrm{P}$ de $18 \%$ e $20 \%$, respectivamente. 
A eficiência de uso dos nutrientes pode ser melhorada pelo uso de estratégias nutricionais como o fornecimento de proteína bruta ajustada às exigências das vacas em lactação e a redução dos alimentos concentrados na dieta, substituindo-os por alimentos volumosos de alto valor nutricional. As estratégias nutricionais têm demonstrado benefícios ao aproveitamento dos nutrientes pelas vacas em lactação. A redução de proteína bruta da dieta e o balanceamento correto da energia podem aumentar a eficiência de uso do nitrogênio dos alimentos (Powell e Rotz, 2015; Hanigan e Knowlton, 2010; Bahrami-Yekdangi et al., 2016). A redução da ingestão dos minerais pode reduzir as suas excreções (Hanigan e Knowlton, 2010; Kebreab et al., 2010). O aumento da produtividade de leite do sistema também pode contribuir para a maior eficiência de uso de nutrientes. $\mathrm{O}$ bem-estar dos animais também contribui na melhoria do balanço de nutrientes, pois o aumento do estresse determinará alterações fisiológicas que podem afetar a eficiência de absorção de nutrientes pelas vacas.

A quantificação dos nutrientes no dejeto e sua respectiva valoração econômica são apresentados na Tabela 2. No período estudado, estimou-se que o valor do dejeto total, o valor do dejeto por vaca e o valor do dejeto por $\mathrm{kg}$ de leite foi de $\mathrm{R} \$ 18.771,24, \mathrm{R} \$ 318,16$ e de $\mathrm{R} \$ 0,13$, respectivamente. Esses valores demonstram a importância econômica da utilização dos dejetos como fonte de nutrientes para as culturas vegetais na propriedade leiteira. A correta utilização destes terá impactos positivos na economia da propriedade e para o ambiente, desde que a aplicação dos dejetos no solo seja feita considerando as condições climáticas, a fertilidade do solo e a exigência de nutrientes das culturas. Uma opção seria utilizar o dejeto na produção de milho para silagem ou concentrado, reduzindo o custo da produção do milho.

Outra opção seria tratar os dejetos por compostagem e vender o composto. Isso poderia agregar outra fonte de renda à propriedade.

\section{CONCLUSÃO}

O balanço de nutrientes é uma ferramenta útil para avaliar e orientar estratégias para o planejamento, execução, monitoramento e ajustes no manejo do sistema produtivo. O cálculo do balanço de nutrientes demonstrou que a silagem de milho contribuiu com a maior parte das entradas de N, P e K. As entradas foram maiores que a saída na forma de leite. Assim os nutrientes permaneceram no sistema, indicando um potencial de uso como fertilizante orgânico.

Os dejetos representaram um valor econômico de $\mathrm{R} \$ 0,13$ por $\mathrm{kg}$ de leite produzido, assim o seu manejo e uso deve fazer parte da rotina da propriedade leiteira, seja empregando-o na própria fazenda ou vendendo-o como fertilizante orgânico. O conhecimento do valor econômico dos dejetos é importante para a tomada de decisão gerencial da atividade com a finalidade de melhorar a eficiência econômica e ambiental.

\section{REFERÊNCIAS}

BAHRAMI-YEKDANGI, M. et al. Reducing crude protein and rumen degradable protein with a constant concentration of rumen undegradable protein in the diet of dairy cows: Production performance, nutrient digestibility, nitrogen efficiency, and blood metabolites. Journal of Animal Science, v. 94, n. 2, p. 718-725, 2016.

CQBAL. Tabelas brasileiras de composição de alimentos para bovinos. Composição de alimentos. Disponível em: <http://cqbal.agropecuaria.ws/bin/relatorios/filtroAlimentos.php>. Acesso em: 1 out. 2018.

HANIGAN, M. D.; KNOWLTON, K. F. Nutritional approaches to maximize N and P efficiency. In: MidSouth Ruminant Nutrition Conference. 2010. Proceeding... Arlington, Texas. 2010. p.27-38.

IEA-SP. Instituto de Economia Agrícola. Preços médios mensais pagos pela agricultura. Disponível em: <http://ciagri.iea.sp.gov.br/nia1/Precos_Medios.aspx?cod_sis=5>. Acesso em: 26 set. 2018.

IBGE. Pesquisa pecuária municipal. Disponível em: <https://sidra.ibge.gov.br/pesquisa/ppm/quadros/ brasil/2017>. Acesso em: 1 out. 2018.

GOURLEY, C. J. P. et al. Farm-scale nitrogen, phosphorus, potassium and sulfur balances and use efficiencies on Australian dairy farms. Animal Production Science, v. 52, n. 10, p. 929-944, 2012.

KEBREAB, E. et al. Impact of dietary manipulation on nutrient flows and greenhouse gas emissions in cattle. Revista Brasileira de Zootecnia, v. 39, n. suppl spe, p. 458-464, 2010.

MU, W. et al. Benchmarking the environmental performance of specialized milk production systems: selection of a set of indicators. Ecological Indicators, v. 72, p. 91-98, 2017.

NEPA. Tabela Brasileira de Composição de Alimentos. 4. ed. Campinas, SP: Book Editora, 2011. 
PEREIRA, M. N.; RESENDE, J. C.; PEREIRA, R. A. N.; SILVA, H. C. M. Indicadores de desempenho de fazendas leiteiras de Minas Gerais. Arquivo Brasileiro de Medicina Veterinária e Zootecnia, v. 68, n. 4, p. 1033-1042, 2016.

PALHARES, J. C. P. Eficiência de uso do nitrogênio e do fósforo em um sistema de produção de leite. In: 3 Simpósio Internacional sobre Gerenciamento de Resíduos Agropecuários e Agroindustriais. 2013. Anais... São Pedro. 2013. p.1-4.

POWELL, J. M.; ROTZ, C. A. Measures of Nitrogen Use Efficiency and Nitrogen Loss from Dairy Production Systems. Journal of Environmental Quality, v.44, p.336-344, 2015.

RASMUSSEN, C. N.; RISTOW, P.; KETTERINGS, Q. M. Whole Farm Nutrient Balance Calculator: user's manual. Ithaca: Cornell University, 2011. 19p.

ROLDÃO; A. F.; ASSUNÇÃO, W. L. Análise e Caracterização das Secas Sazonais na Mesorregião do Triângulo Mineiro/Alto Paranaíba - MG. OBSERVATORIUM: Revista Eletrônica de Geografia, v.6, n.16, p. 59-84, 2014.

SANTOS, J. G.; FERREIRA, V. O. A variabilidade pluviométrica na Mesorregião do Triângulo Mineiro/Alto Paranaíba-MG. GeoTextos, v. 12, n. 1, p. 233-265, 2016.

XICCATO, G. et al. Nitrogen excretion in dairy cow, beef and veal cattle, pig, and rabbit farms in Northern Italy. Italian Journal of Animal Science, v. 4, n. sup3, p. 103-111, 2005.

Tabela 1. Quantificação das entradas e saída e balanço de nutrientes do sistema do sistema de produção de leite no período de confinamento.

\begin{tabular}{|c|c|c|c|c|c|c|}
\hline Item & & g por período & & & or vac & \\
\hline Entradas (insumos) & $\mathbf{N}$ & $\mathbf{P}$ & $\mathbf{K}$ & $\mathbf{N}$ & $\mathbf{P}$ & $\mathbf{K}$ \\
\hline Silagem de milho & $1.248,44(48 \%)$ & $204,49(40 \%)$ & $1.033,20(71 \%)$ & 21,16 & 3,47 & 17,51 \\
\hline Milho moído & $466,94(18 \%)$ & $80,71(16 \%)$ & $119,45(8 \%)$ & 7,91 & 1,37 & 2,02 \\
\hline Farelo de soja & $895,31(34 \%)$ & $65,44(13 \%)$ & $241,09(17 \%)$ & 15,17 & 1,11 & 4,09 \\
\hline Mistura mineral & - & $161,96(32 \%)$ & $64,78(4 \%)$ & - & 2,75 & 1,10 \\
\hline Total entrada & $2.610,69(100 \%)$ & $512,59(100 \%)$ & $1.458,52(100 \%)$ & 44,25 & 8,69 & 24,72 \\
\hline Saída (produto) & $\mathbf{N}$ & $\mathbf{P}$ & $\mathbf{K}$ & $\mathbf{N}$ & $\mathbf{P}$ & $\mathbf{K}$ \\
\hline Leite & 704,01 & 115,10 & 186,68 & 11,93 & 1,95 & 3,16 \\
\hline Balanço (entradas - saída) & $1.906,68$ & 397,49 & $1.271,84$ & 32,32 & 6,74 & 21,56 \\
\hline
\end{tabular}

Tabela 2. Quantificação do nitrogênio $(\mathrm{N})$, fósforo $(\mathrm{P})$ e potássio $(\mathrm{K})$ e a valoração do dejeto no período de confinamento (183 dias).

\begin{tabular}{lccc}
\hline \multicolumn{1}{c}{ Item } & $\mathbf{N}$ & $\mathbf{P}$ & $\mathbf{K}$ \\
\hline Dejeto $(\mathrm{kg})$ & $1.906,68$ & 397,49 & $1.271,84$ \\
Perdas por volatilização $^{1}(\mathrm{~kg})$ & 533,87 & - & - \\
Quantidade aproveitável $(\mathrm{kg})$ & $1.372,81$ & 397,49 & $1.271,84$ \\
Preço médio de mercado do fertilizante equivalente $^{2}(\mathrm{R} \$ / \mathrm{kg})$ & 1,9 & 1,4 & 1,9 \\
Valor estimado do dejeto no período $^{3}(\mathrm{R} \$)$ & $5.796,31$ & $3.751,97$ & $9.222,96$ \\
\hline
\end{tabular}

${ }^{1}$ Considerou-se perda de $\mathrm{N}$ de $28 \%$, de acordo com Xiccato et al. (2005).

${ }^{2}$ Adubo comercial utilizado para as estimativas: ureia $(45 \% \mathrm{~N})$; superfosfato simples $\left(18 \% \mathrm{P}_{2} \mathrm{O}_{5}\right)$; e cloreto de potássio $\left(60 \% \mathrm{~K} \mathrm{~K}_{2} \mathrm{O}\right)$; preços sugeridos e levantados juntos ao Instituto de Economia Agrícola de São Paulo para o ano de 2017 (IEA-SP, 2018).

${ }^{3}$ Valor total do dejeto produzido $=\mathrm{R} \$ 18.771,24$. 


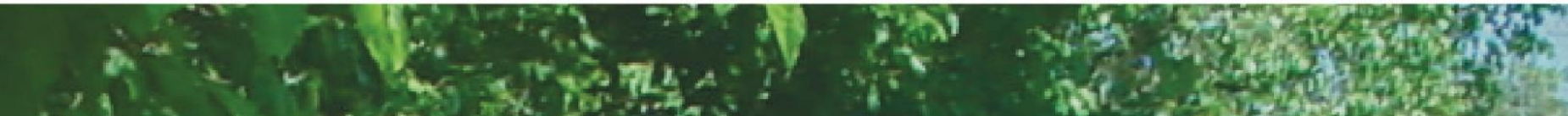

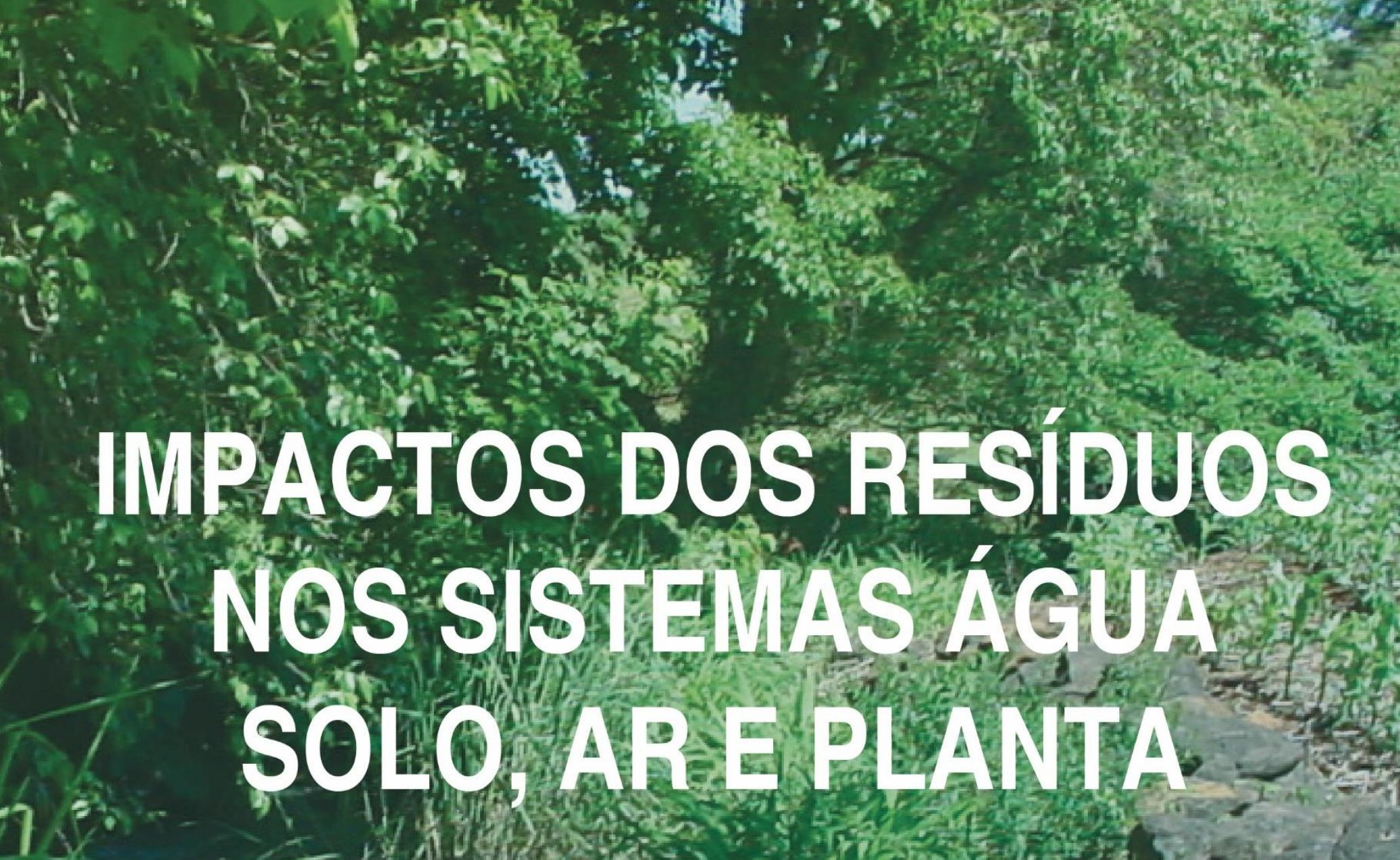

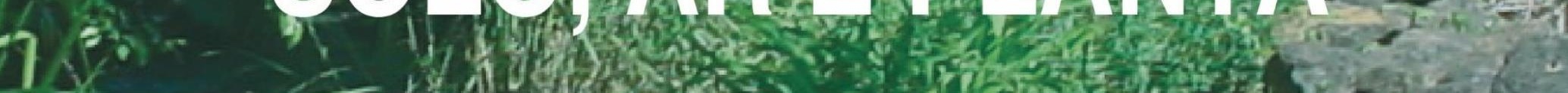

and

(1)
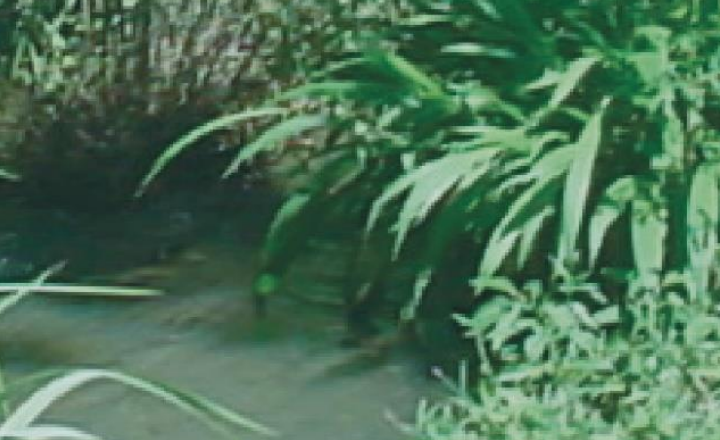

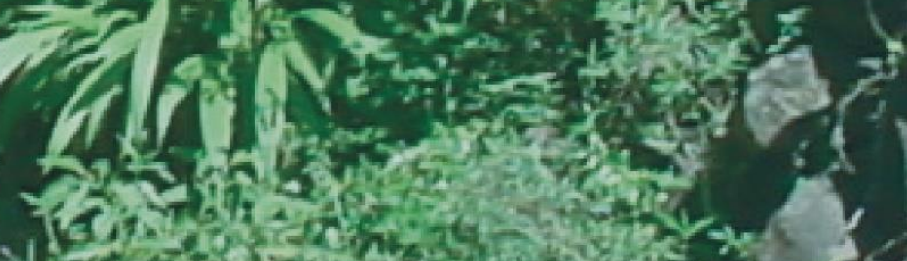

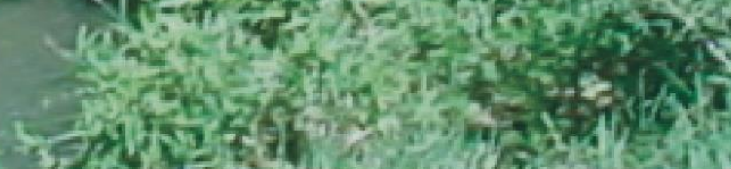

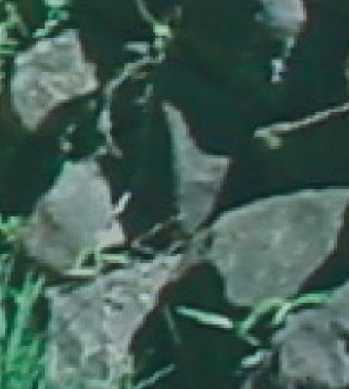
$2-196$ (1) 5

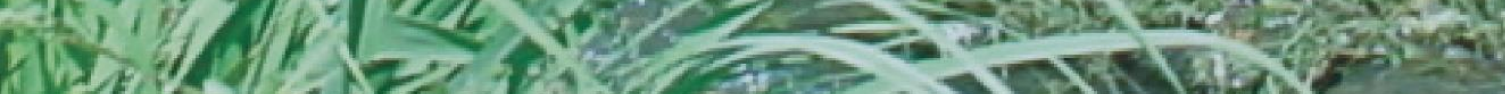
U, $40+3 x$ 


\title{
ANÁLISE DA PRESENÇA DE AGROTÓXICOS EM UMA BACIA DE CAPTAÇÃO DE ÁGUA BRUTA
}

\author{
Schneider, V.E.*1; Menegat, D. ${ }^{2}$, Carra, S.H.Z. ${ }^{3}$, Peresin, D. ${ }^{4}$ \\ 1*Diretora do Instituto de Saneamento Ambiental - Universidade de Caxias do Sul/RS, Brasil - veschnei@ ucs.br \\ ${ }^{2}$ Graduanda em Biologia - Universidade de Caxias do Sul/RS, Brasil - dmenegat@ucs.br \\ ${ }^{3}$ Msc. Eng. Ambiental - Universidade de Caxias do Sul/RS, Brasil - shzcarra@ucs.br \\ ${ }^{4}$ Msc. Bióloga - Universidade de Caxias do Sul/RS, Brasil - dperesin@ucs.br
}

\begin{abstract}
RESUMO: Os agrotóxicos foram amplamente distribuídos e utilizados a partir da $2^{\mathrm{a}}$ Guerra Mundial. Sua utilização se tornou uma estratégia de campo para controle de pragas e doenças em plantas. Devido a essa funcionalidade, seu consumo se tornou indispensável na maioria da produção agrícola atual. Hoje, porém, estudam-se os efeitos que esses compostos podem estar causando ao meio ambiente e a saúde humana, tendo em vista que esses acabam persistindo em solo, água e alimentos, ocasionando problemas tanto ao ecossistema terrestre quando ao aquático. Tendo em vista a problemática acerca da utilização de agrotóxicos, o presente trabalho tem por objetivo identificar a presença de princípios ativos de agrotóxicos relacionados às culturas de milho e soja, nas águas de um reservatório de captação de água bruta, de um município do Estado do Rio Grande do Sul. Esta avaliação se torna necessária uma vez que o reservatório em questão é a única fonte de abastecimento para o município. Serão ainda analisadas as classes de periculosidade ambiental pela qual os princípios ativos detectados são classificados.
\end{abstract}

Palavras-chave: agrotóxicos, meio ambiente, persistência.

\section{ANALYSIS OF THE PRESENCE OF AGROCHEMICALS IN A GROSS WATER CATCHMENT BASIN}

\begin{abstract}
The pesticides were widely distributed and used after World War II. Its use has become a field strategy for pest and disease control in plants. Because of this functionality, its consumption has become indispensable in most current agricultural production. Today, however, we study the effects that these compounds may be causing to the environment and human health, since they end up persisting in soil, water and food, causing problems both terrestrial and aquatic ecosystems. The objective of this study is to identify the presence of active principles of pesticides related to corn and soybean crops in the waters of a raw water catchment reservoir of a municipality in the Rio Grande do Sul state. This assessment becomes necessary since the reservoir in question is the only source of supply for the municipality.
\end{abstract}

Keywords: pesticides, environment, persistence.

\section{INTRODUÇÃO}

Os agrotóxicos foram amplamente distribuídos e utilizados a partir da $2^{a}$ guerra mundial. Sua utilização se tornou uma estratégia de campo para controle de pragas e doenças em plantas. Devido a essa funcionalidade, seu consumo se tornou indispensável na maioria da produção agrícola atual. Hoje, porém, estudam-se os efeitos que esses compostos podem estar causando ao meio ambiente e a saúde humana, tendo em vista que esses acabam persistindo em solo, água e alimentos, ocasionando problemas tanto ao ecossistema terrestre quando ao aquático.

O Brasil é um dos maiores consumidores de pesticidas, com uma forte expansão nos últimos 40 anos, corroborando em um aumento de 700\%. Nos últimos 5 anos, uma média de 300 mil toneladas de agrotóxicos foram comercializadas. O Estado do Rio Grande do Sul possui um destaque neste consumo estando na quarta posição (12\% do total) em 2015 (EMBRAPA, 2016).

O crescimento da produção agrícola Brasileira é acompanhado pelo incremento da utilização de agroquímicos, sem um controle mais efetivo do seu consumo (IBGE, 2011). Isto implica em um aumento dos impactos sobre os ecossistemas aquáticos e biota do solo. De acordo com a Lei Federal n 7.802/89 (BRASIL, 1989), consideram-se agrotóxicos todos os produtos e agentes de processos físicos, biológicos ou químicos, destinados ao uso nos setores de produção, no armazenamento e beneficiamento de produtos agrícolas, nas pastagens, na proteção de florestas, nativas ou implantadas, e de outros ecossistemas e também de ambientes 
urbanos, hídricos e industriais, cuja finalidade seja alterar a composição da flora ou da fauna, a fím de preserválas da ação danosa de seres vivos considerados nocivos ou qualquer produto utilizando como desfolhantes, dessecantes, estimuladores e inibidores de crescimento.

Os agrotóxicos possuem diferentes denominações, sendo essas determinadas para o controle que destina sua utilização. De acordo com Ribas e Matsumura (2009), considera-se fungicida formulações utilizadas para o controle de fungos; herbicidas para o controle de plantas; inseticidas para o controle de insetos; acaricidas para o controle de ácaros. Tem-se, ainda, os desfolhantes, fumigantes, rodenticidas e nematicidas. Todas as culturas, com exceção à orgânica, recebem tratamento com uso de agrotóxicos. Após a aplicação nas culturas, ou ainda se descartados de forma incorreta, podem acabar retidos ao solo e transportados aos recursos hídricos.

O controle de pragas agrícolas através do uso de agrotóxicos é uma estratégia bastante utilizada para a produção de cultivares. Em decorrência dos impactos potenciais que podem gerar, estes foram classificados pela Portaria Normativa IBAMA n 84, de 15 de outubro de 1996, como: Classe I - Produto Altamente Perigoso; Classe II - Produto Muito Perigoso; Classe III - Produto Perigoso; e Classe IV - Produto Pouco Perigos. A classificação quanto ao potencial de periculosidade ambiental apresentada no Art. 3 da referida lei baseia-se nos parâmetros bioacumulação, persistência, transporte, toxicidade a diversos organismos, potencial mutagênico, teratogênico e carcinogênico.

Diante disto, o presente trabalho tem por objetivo identificar a presença de princípios ativos de agrotóxicos relacionados às culturas de milho e soja, nas águas de um reservatório de captação de água bruta, de um município do Estado do Rio Grande do Sul. Esta avaliação se torna necessária uma vez que o reservatório em questão é a única fonte de abastecimento para o município.

\section{MATERIAL E MÉTODOS}

A Bacia Hidrográfica onde o reservatório está localizado na região nordeste do Estado do Rio Grande do Sul, destaca-se pela produção agrícola, onde os cultivos de milho e soja representam grande parcela da área ocupada com lavoura temporária. Foram realizadas três campanhas de amostragem, nos meses de julho, agosto e outubro de 2018, em 8 pontos distribuídos na área de influencia do reservatório, conforme apresentado na Figura 1. As amostras foram analisadas quanto à presença de 55 agrotóxicos, determinados a partir do método desenvolvido por Chiarello et al. (2017). Os agrotóxicos, cuja presença foi identificada, foram comparados aos indicados para serem utilizados nas culturas de milho e soja. O grau de periculosidade ambiental dos agrotóxicos identificados foi realizado a partir da consulta a Ficha de Segurança de Produto Químico (FISPQ) referente a cada produto, que utiliza para a determinação do mesmo a Portaria Normativa do IBAMA $n^{\circ} 84$, de 15 de outubro de 1996.

\section{RESULTADOS E DISCUSSÃO}

Os resultados, bem como as campanhas e pontos em que foram identificados, a classe em que estão inseridos, o grau de periculosidade ambiental e indicação para o uso nos cultivos de milho e soja são apresentados na Tabela 1 .

Os resultados analíticos indicam a presença de 28 princípios ativos, utilizados na formulação de agrotóxicos, do total de 55 que foram analisados. Dentre os princípios ativos detectados, 08 são indicados para o uso em cultura de milho, enquanto 14 estão associados à cultura da soja. Os pontos que apresentaram maior presença dos princípios ativos são os pontos P1, P2, P6 e P8. Esses pontos, conforme observado na Figura 1, encontram-se nos trechos de entrada e saída o reservatório. Os pontos 1 e 2 drenam a maior parte da bacia de captação ocupada com cultivos soja e milho. Os pontos 6 e 8 são representativos da água que sai do reservatório e vai ser captada para posterior tratamento e distribuição para a população.

Os princípios ativos detectados, e que são indicados para uso em culturas de milho e soja apresentam na sua quase totalidade, periculosidade ambiental de classe II, o que caracteriza estes como produtos muito perigosos, conforme determinado pela Portaria do IBAMA n 84, de 15 de outubro de 1996. Para ambos os cultivos, a classe de princípios ativos mais utilizados são os fungicidas. Para a cultura de soja é indicada a maior variedade de princípios ativos se comparado à cultura de milho.

De acordo com o banco de dados Pesticide Properties Database (PPDB, 2018), os agrotóxicos citados apresentam de moderada a alta toxicidade à ambientes aquáticos, podendo contaminar a biota existente e gerar desequilíbrio ecológico. Os agrotóxicos detectados nos pontos analisados e que não estão associados às culturas de milho e soja são, na sua maioria, indicados para uso em lavoura permanente para a cultura da maçã, 
como: diazinona, dimetoato, hexaconazol, imazalil e diuron, e na lavoura temporária para culturas de batata, trigo e feijão, como: etoxazol, fluopicolida, procloraz.

\section{CONSIDERAÇÕES FINAIS}

A partir das análises realizadas nas águas superficiais do reservatório de captação, observa-se a presença de compostos com periculosidade ambiental classificada como muito perigosa, o que pode provocar desequilíbrio ao ecossistema aquático e riscos a saúde da população. Ressalta-se que esta é a única fonte de captação de água do município, o que demanda uma maior atenção sobre a qualidade da água visando o abastecimento da população. Neste contexto, a orientação dos agricultores sobre o manejo dos agrotóxicos, bem como, o planejamento da área de entorno do reservatório de captação, devem fazer parte das prioridades para o poder público municipal.

Os princípios ativos identificados e que não possuem indicação para uso em lavoura temporária, podem sugerir a ocorrência do manejo inadequado destes junto às culturas permanentes, além do potencial de mobilidade e persistência no ambiente dos mesmos.

\section{AGRADECIMENTOS}

Secretaria de Desenvolvimento Econômico, Ciência e Tecnologia do Estado do Rio Grande do Sul (SDECT), Fundação de Amparo a Pesquisa do Estado do Rio Grande do Sul (FAPERGS), Universidade de Caxias do Sul.

\section{REFERÊNCIAS}

Borsoi, A et al. Agrotóxicos: histórico, atualidades e meio ambiente. Acta Iguazu, Cascavel, v. 3, n. 1, p.86100, 2014. Disponível em: <file:///c:/users/user/downloads/9650-34813-1-pb\%20(1).pdf>. Acesso em: 20 setembro. 2018.

Brasil. Lei $\mathbf{n}^{\mathbf{0}} \mathbf{7 . 8 0 2}$, de 11 de julho de 1989. Dispõe sobre a pesquisa, a experimentação, a produção, a embalagem e rotulagem, o transporte, o armazenamento, a comercialização, a propaganda comercial, a utilização, a importação, a exportação, o destino final dos resíduos e embalagens, o registro, a classificação, o controle, a inspeção e a fiscalização de agrotóxicos, seus componentes e afins, e dá outras providências. Disponível em: <http://www.planalto.gov. Br/ccivil_03/leis/l7802.htm>. Acesso em: 23 agosto. 2018.

EMBRAPA - Empresa Brasileira de Pesquisa Agropecuária - Disponível em: https://www.agencia.cnptia. embrapa.br/gestor/agricultura_e_meio_ambiente/arvore/CONTAG01_40_210200792814.html/ Acessada em agosto de 2018.

Chiarello, Marilda et al. Determinação de agrotóxicos na água e sedimentos por HPLC-HRMS e sua relação com o uso e ocupação do solo. Quím. Nova [online]. 2017, vol.40, n.2, pp.158-165. Issn 01004042. Http://dx.doi.org/10.21577/0100-4042.20160180.

IBAMA. Instituto Brasileiro do Meio Ambiente e dos Recursos Naturais Renováveis Vendas de agrotóxicos e afins no brasil no período de 2000 a 2017. Brasil: a, 2018. Disponível em: <http://www.ibama.gov.br/ phocadownload/qualidadeambiental/relatorios/2017/05.vendas_ingredientes_ativos_uf_2017.xlsx>. Acesso em: 15 setembro. 2018.

IBGE. Instituto Brasileiro de Geografia e estatística (IBGE). Produção Agrícola Municipal 2017. Vacaria. Rio de Janeiro, IBGE. 2018.

IBGE. Instituto Brasileiro de Geografia e estatística (IBGE). Atlas do Saneamento: 2011.

PERES, Frederico; MOREIRAa, Josino Costa. É veneno ou é remédio? Agrotóxicos, saúde e ambiente. Rio de Janeiro: Fiocruz, 2003.

PPDB. Pesticide properties database. University of hertfordshire. PPDB, 2018. Disponível em: <http://sitem.herts.ac.uk/aeru/ppdb/en/reports/205.htm>. Acesso em: 20 de novembro 2018.

Ribas, P. P.; Matsumura, A. T. S. A química dos agrotóxicos: impactos sobre a saúde e meio ambiente. Revista Liberato, v. 10, n. 14, p. 149-158, jul./dez., 2009.

IBAMA. Portaria Normativa IBAMA $n^{\circ} 84$, de 15 de outubro de 1996. Disponível em: <https://servicos.ibama.gov.br/ctf/manual/html/Portaria_84.pdf>. Acesso em: 15 setembro 2018. 
Tabela 1. Princípios ativos identificados nos pontos analisados, classe a que pertencem, grau de periculosidade ambiental e indicação para uso nos cultivos de milho e soja.

\begin{tabular}{|c|c|c|c|c|c|c|c|}
\hline \multirow[t]{2}{*}{ Princípio ativo } & \multicolumn{3}{|c|}{ Pontos em que } & \multirow{2}{*}{ Classe } & \multirow{2}{*}{$\begin{array}{c}\text { Periculosida } \\
\text { de } \\
\text { Ambiental }\end{array}$} & \multicolumn{2}{|c|}{$\begin{array}{c}\text { Indicado para } \\
\text { uso nos } \\
\text { cultivos } \\
\end{array}$} \\
\hline & Julho & Agosto & Outubro & & & Milho & Soja \\
\hline Acetamiprido & & & $\mathrm{P} 3, \mathrm{P} 4, \mathrm{P} 5$ & Inseticida & II & Não & Não \\
\hline Benalaxil & & $\begin{array}{c}\text { P1, P2, P6, } \\
\text { P8 }\end{array}$ & $\begin{array}{l}\text { P3, P5, P6, } \\
\text { P7, P8 }\end{array}$ & Fungicida & II & Não & Não \\
\hline Carbendazim & $\begin{array}{c}\mathrm{P} 1, \mathrm{P} 2, \mathrm{P} 6, \\
\text { P8 }\end{array}$ & $\begin{array}{l}\mathrm{P} 2, \mathrm{P} 3, \mathrm{P} 4, \\
\text { P5, P7 }\end{array}$ & $\begin{array}{c}\text { P1, P2, P3, } \\
\text { P4, P5, P6, } \\
\text { P7 }\end{array}$ & Fungicida & II & Não & Sim \\
\hline Ciprodinil & $\begin{array}{c}\text { P1, P2, P6, } \\
\text { P8 }\end{array}$ & & $\mathrm{P} 1, \mathrm{P} 2$ & Fungicida & II & Não & Sim \\
\hline $\begin{array}{l}\text { Cresoxim- } \\
\text { metilico }\end{array}$ & $\mathrm{P} 1$ & & & Fungicida & II & Não & Sim \\
\hline Diazinona & P1, P2 & & & Inseticida & II & Não & Não \\
\hline Difenoconazol & P1, P6, P8 & & $\mathrm{P} 1, \mathrm{P} 2$ & Fungicida & II & Sim & Sim \\
\hline Dimetoato & $\mathrm{P} 2$ & & & Inseticida & II & Não & Não \\
\hline Dimetomorfe & $\begin{array}{c}\text { P1, P2, P6, } \\
\text { P8 }\end{array}$ & & $\mathrm{P} 2$ & Fungicida & II, III & Não & Não \\
\hline Diurom & $\begin{array}{l}\text { P1, P2, P6, } \\
\text { P8 }\end{array}$ & $\mathrm{P} 3, \mathrm{P} 4, \mathrm{P} 7$ & $\mathrm{P} 1, \mathrm{P} 2$ & Herbicida & II & Não & Não \\
\hline Espiromesifeno & P2, P6 & $\mathrm{P} 3$ & & $\begin{array}{l}\text { Inseticida/aca } \\
\text { ricida }\end{array}$ & II & Sim & Sim \\
\hline Etoxazol & P2 & & & Acaricida & III & Não & Não \\
\hline Fluopicolida & $\begin{array}{c}\mathrm{P} 1, \mathrm{P} 2, \mathrm{P} 6, \\
\text { P8 }\end{array}$ & P3, P7 & $\mathrm{P} 1, \mathrm{P} 2$ & Fungicida & II & Não & Não \\
\hline Foxim & $\mathrm{P} 1, \mathrm{P} 2$ & & & Inseticida & II & Sim & Não \\
\hline Hexaconazol & P1 & & & Fungicida & II & Não & Não \\
\hline Imazalil & P1 & & & Fungicida & II & Não & Não \\
\hline Indoxacarbe & $\begin{array}{c}\mathrm{P} 1, \mathrm{P} 2, \mathrm{P} 6, \\
\text { P8 }\end{array}$ & & $\mathrm{P} 1, \mathrm{P} 2$ & Inseticida & III & Sim & Sim \\
\hline Iprovalicarbe & & & P6, P8 & Fungicida & II & Não & Não \\
\hline Metconazol & $\mathrm{P} 1, \mathrm{P} 2$ & & & Fungicida & II & Não & Sim \\
\hline Metribuzin & & $\mathrm{P} 2, \mathrm{P} 8$ & & Herbicida & II & Não & Sim \\
\hline Piraclostrobina & $\begin{array}{c}\text { P1, P2, P6, } \\
\text { P8 }\end{array}$ & & $\mathrm{P} 1, \mathrm{P} 2$ & Fungicida & II & Sim & Sim \\
\hline Procloraz & $\mathrm{P} 1, \mathrm{P} 2, \mathrm{P} 8$ & & P2 & Fungicida & II & Não & Não \\
\hline Propargito & P2, P6, P8 & P3 & $\mathrm{P} 1, \mathrm{P} 2$ & Acaricida & II & Não & Sim \\
\hline Tebuconazol & $\mathrm{P} 1$ & $\mathrm{P} 1$ & & Fungicida & II, III & Sim & Sim \\
\hline Tetraconazol & P1, P2 & & & Fungicida & II & Não & Sim \\
\hline Tiabendazol & $\mathrm{P} 1, \mathrm{P} 2, \mathrm{P} 8$ & P7 & $\mathrm{P} 1$ & Fungicida & II & Sim & Sim \\
\hline Trifloxistrobina & $\begin{array}{c}\mathrm{P} 1, \mathrm{P} 2, \mathrm{P} 6, \\
\mathrm{P} 8\end{array}$ & $\mathrm{P} 1$ & $\mathrm{P} 1, \mathrm{P} 2$ & Fungicida & II & Sim & Sim \\
\hline Zoxamida & P1 & & & Fungicida & II & Não & Não \\
\hline
\end{tabular}




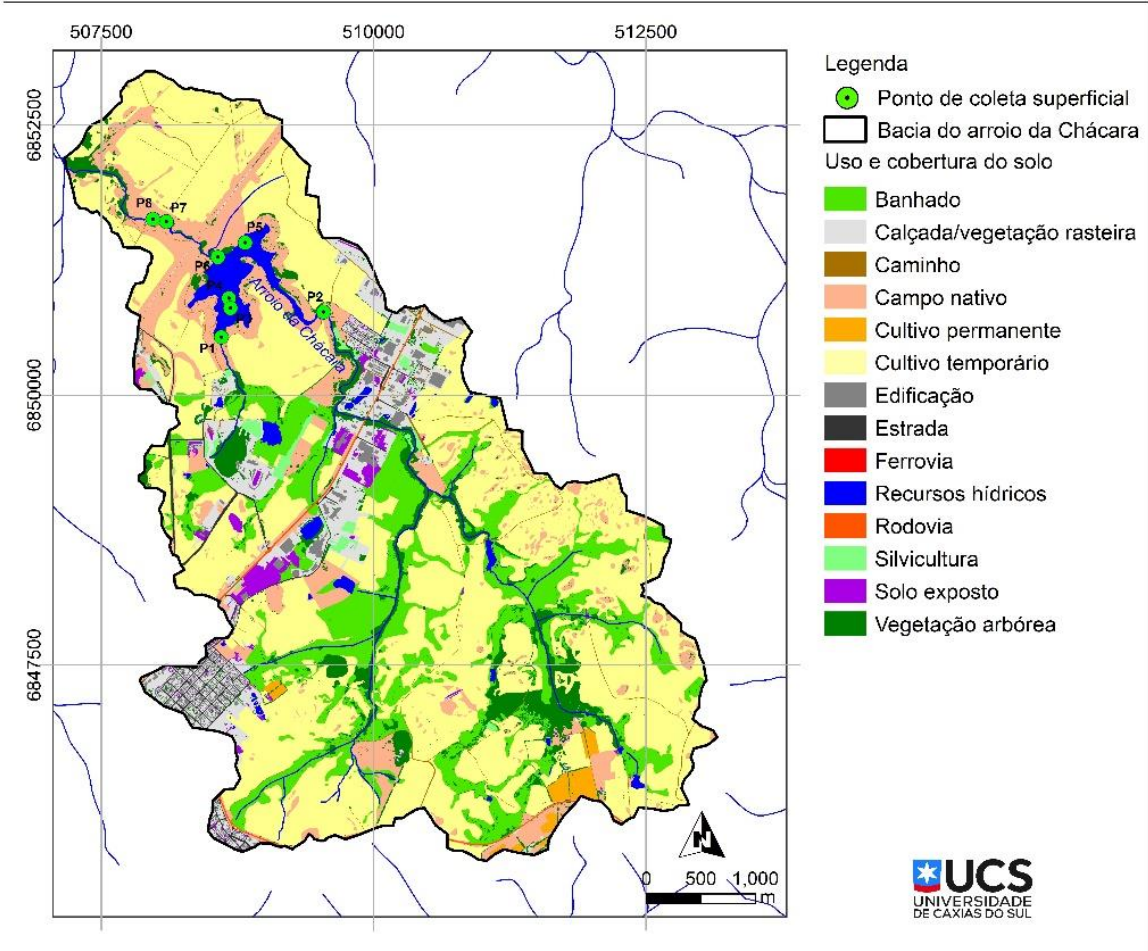

Elaborado por Geise Macedo dos Santo - ISAM (2018).

Figura 1. Mapa de uso e ocupação do solo e pontos de amostragem de água. 


\title{
ARTROPODOFAUNA EM FLORESTAS IRRIGADAS COM EFLUENTE DE ABATEDOURO DE AVES
}

\author{
Vargas, R.J. ${ }^{1 *}$; Araujo, I.R.C. ${ }^{2}$; Morais, J. ${ }^{2}$; Figueiredo, T.A.F.R. ${ }^{3}$; Shutz, F.C.A. ${ }^{1}$ \\ *Mestrando no Programa de Pós-graduação em Tecnologias Computacionais para o Agronegócio-PPGTCA, \\ rodrigovargas@alunos.utfpr.edu.br \\ ${ }^{1}$ Universidade Tecnológica Federal do Paraná, Medianeira, PR, Brasil \\ ${ }^{2}$ Universidade Estadual do Oeste do Paraná, Cascavel, PR, Brasil \\ ${ }^{3}$ Instituto Politécnico de Bragança - Portugal
}

\begin{abstract}
RESUMO: A intensificação no abate de aves resulta na geração de grandes volumes de efluentes. No Brasil, após o tratamento, as águas residuárias costumam ser descartadas no solo, mas pouco se conhece sobre seus efeitos, como contaminação no solo, lençol freático e organismos vivos. Assim, o objetivo deste trabalho foi avaliar o impacto na mesofauna e macrofauna do solo, em área irrigada com efluente industrial de abatedouro de aves. A biologia do solo pode revelar mudanças importantes nessas áreas. Os principais resultados foram obtidos com os índices Simpson, Shanon, Shannon-Wierner, Margalef e Pielou. Os valores médios dos índices de Simpson, Margalef e Shanon-Wierner diferiram estatisticamente entre as comunidades amostradas nas áreas de aplicação do efluente tratado de abatedouro de aves com irrigação de $100 \mathrm{~m}^{3}-1$ dia -1 , das comunidades amostradas em áreas sem irrigação. Concluiu-se com o presente estudo que a maior diversidade de espécies foi encontrada em áreas irrigadas com $200 \mathrm{~m}^{3}$-1dia-1 (índice de Shanon), em relação à dominância (índice de Simpson), o maior índice foi observado em áreas não irrigadas, assim como maior riqueza de espécies (Índice Margalef).
\end{abstract}

Palavras-chave: águas residuárias, solo, índices ecológicos.

\section{ARTROPODO FAUNA IN IRRIGATED FORESTS WITH POULTRY SLAUGHTERHOUSE EFFLUENT}

\begin{abstract}
The intensification in poultry slaughter results in the generation of large volumes of effluents. In Brazil, after treatment, wastewater is usually discarded in the soil, but little is known about its effects, such as contamination in soil, groundwater and living organisms. Thus, the objective of this work was to evaluate the impact on the mesofauna and macrofauna of the soil, in an area irrigated with the industrial effluent from the poultry slaughterhouse. Soil biology can reveal important changes in these areas. The main results were obtained with the Simpson, Shanon, Shannon-Wierner, Margalef and Pielou indices. The mean values of the Simpson, Margalef and Shanon-Wierner indexes differed statistically among the sampled communities in the areas of application of treated effluent from the poultry slaughterhouse with irrigation of $100 \mathrm{~m}^{3}-1$ day -1 , from the communities sampled in areas without irrigation. It was concluded with the present study that the greatest diversity of species was found in irrigated areas with $200 \mathrm{~m}^{3}-1$ dia-1 (Shanon index), in relation to the dominance (Simpson index), the highest index was observed in non-irrigated areas, as well as greater species richness (Margalef Index).
\end{abstract}

Keywords: waste water, soil, ecological indexes.

\section{INTRODUÇÃO}

Com o aumento da demanda por proteína animal no brasil, principalmente em relação à carne de aves, a produção brasileira de carne de frango de corte subiu de 9,34 para 12,90 milhões de toneladas do ano de 2006 até 2016. O consumo per capta no país passou de $37 \mathrm{~kg}$ em 2007 para $41 \mathrm{~kg}$ por habitante neste mesmo período, representando $66 \%$ do total produzido da produção nacional, o restante, $34 \%$ da produção, é destinada à exportação (ABPA, 2017).

O contínuo crescimento no abate de animais em agroindústrias, aumentou também o volume total de água utilizada destinada a este processo. O efluente gerado no abate de aves é carregado de matéria orgânica, sendo que seus principais componentes são sangue, gordura, excrementos, elementos provenientes do trato digestório destes animais, entre outros. Além da alta carga orgânica, estes efluentes podem apresentar potencial 
patogênico por conter organismos contaminantes. Esses efluentes, depois de tratados, em geral são dispostos no solo e podem causar contaminação do solo, das águas superficiais e subterrâneas e do ar.

As modificações na qualidade do solo podem ser avaliadas e mensuradas através de indicadores adequados e compará-los com os valores de referência pretendidos (ODUNZE et al., 2012). Indicadores são atributos que medem ou mostram o perfil ambiental ou a condição de sustentabilidade do ecossistema. Podem ser classificados como indicadores de qualidade do solo os padrões físicos, químicos e biológicos (ARAUJO \& MONTEIRO, 2007).

Os índices ecológicos de biodiversidade podem traduzir em números os indicadores biológicos, permitindo a comparação da fauna epígea em diferentes condições ambientais. Assim, o objetivo deste trabalho foi avaliar, por meio de índices ecológicos, os impactos da irrigação com efluente tratado em áreas de reflorestamento de eucalipto.

\section{MATERIAL E MÉTODOS}

O experimento foi instalado nas áreas de reflorestamento de uma unidade industrial de abate de aves (UIA) no município de Matelândia, no Paraná. Sua geração diária de efluentes é de $7500 \mathrm{~m}^{3}$ de efluentes por dia, cerca de $23 \mathrm{~L}$ de efluente por ave abatida.

Foram instaladas 16 parcelas, com área média de 296,8 $\mathrm{m}^{2}$. Foram aplicadas às parcelas, 4 tratamentos, com 4 repetições cada, sendo um deles T0, testemunha sem aplicação de efluente, T1 com aplicação de 100 $\mathrm{m}^{3}$ ha-1dia-1, T2 com $200 \mathrm{~m}^{3}$ ha-1 dia-1, e T3 com $300 \mathrm{~m}^{3}$ ha-1 dia-1Os tratamentos foram sorteados inteiramente ao acaso, nas 16 parcelas.

Para a captura dos artrópodes terrestres (insetos, aracnídeos, crustáceos, etc) foram utilizadas armadilhas de queda ("pitfall trap"). Utilizou-se copos descartáveis com volume de $500 \mathrm{ml}$ enterrados até a borda, contendo uma solução de álcool $70 \%$ (40\% do volume), água (60\% do volume) e detergente biodegradável (uma gota), para conservação dos animais. Um prato plástico, raso com $26 \mathrm{~cm}$ de diâmetro, foi colocado sobre os copos, apoiado em um tripé de madeira, com o intuito de proteger da chuva.

Os artrópodes coletados foram contados e classificados em nível de Ordem/Família, com auxílio de lupa bi-ocular e chaves taxonômicas específicas para cada grupo.

Os ídices calculados para cada tratamento foram: Îndice de riqueza de Margalef $(\mathrm{I}=[(\mathrm{S}-1)] / \mathrm{lnN}$, em que: $\mathrm{I}$ = diversidade; $\mathrm{S}=$ número de espécies presente; $\mathrm{N}$ = número total de indivíduos encontrados na amostra); Índice de Simpson, forma de dominância $(\mathrm{D}=\Sigma(\mathrm{ni} / \mathrm{N}) 2$, em que: ni = número de indivíduos do grupo "i"; $\mathrm{N}$ = somatório da densidade de todos os grupos); Índice de Diversidade de Shannon (H = $-\Sigma \mathrm{Pi} \operatorname{lnPi}$; em que: Pi = proporção do grupo i no total da amostra) e Índice de equabilidade de Pielou $(\mathrm{J}=\mathrm{H} / \mathrm{ln}$ em que: $\mathrm{H}=$ =índice de Shannon, $\mathrm{S}=$ número total de grupos na comunidade). A riqueza dos grupos taxonômicos foi indicada pelo número (absoluto) de grupos presentes no tratamento.

\section{RESULTADOS E DISCUSSÃO}

Foram capturados, no total, 896 indivíduos, identificados em 11 diferentes ordens, sendo, a maioria (66\%) da classe Insecta, 33\% pertencentes à classe Crustacea, aproximadamente 0,5\% à classe Chilopoda e $0,5 \%$ à classe Arachnida. Dentre os insetos, a maior ocorrência foi de indivíduos da ordem Hymenoptera (22\%). Na Tabela 1 são apresentados os resultados para os índices ecológicos propostos, bem como a comparação de médias para estes índices.

Observa-se que para o índice de Shanon-Wiener, a média do tratamento 1 diferiu significativamente das áreas não irrigadas (tratamento 0), o que pode caracterizar um impacto da introdução do efluente sobre a comunidade epígea. Por outro lado, para as médias dos tratamentos 2 e 3 , que nos quais de dispunham 200 e $300 \mathrm{~m}^{3} \mathrm{ha}^{-1} \mathrm{dia}^{-1}$, não foram observadas diferenças significativas em relação à média do índice para o tratamento testemunha 0. Segundo MAGURRAN (1988), o índice de Shannon-Wiener expressa a uniformidade dos valores através de todas as amostras e raramente ultrapassa 4,5.

O índice de Shannon (base neperiana) indica que a comunidade a comunidade observada nas amostras do tratamento 2 são as mais diversas, já que o índice médio $(4,40)$ é o maior e para a comunidade observada nas amostras do tratamento 1 , foi obtido o menor índice $(3,75)$, indicando, em teoria, menor diversidade. $\mathrm{O}$ índice médio de Simpson para o tratamento 1 também é inferior aos outros tratamentos $(0,59)$, embora não difira estatisticamente a $5 \%$ de significância do tratamento 2 , reforça os resultados de menor diversidade neste tratamento em relação aos outros. Por outro lado, o índice de Simpson observado para a média das comunidades amostradas no tratamento testemunha ( 0$)$ foi o mais alto obtido dentre os tratamentos $(0,76)$, esta 
discrepância entre os índices de Shanon e Simpson acontece, pois, o índice de Shannon dá maior peso a riqueza de espécies do que o índice de Simpson.

O valor da equabilidade de Pielou (J) de 0,87 indica que $87 \%$ da diversidade máxima teórica foram obtidas por meio da amostragem realizada para os tratamentos 0 e 3 , para o tratamento $1,72 \%$ da diversidade máxima foi amostrada e para o tratamento 2, 83\%. De acordo com o teste de Dunnett, as médias dos tratamentos 1,2 e 3 não diferiram significativamente da média do tratamento testemunha 0.

Em relação ao índice de Margalef, observa-se diferença significativa entre o tratamento 1 e testemunha, em amos o teste de média. Margalef (1956) propôs o Índice de Margalef, que demonstra a riqueza específica e referese ao número total de indivíduos. É utilizado para estimar a diversidade com base na distribuição numérica dos indivíduos das diferentes espécies. Quanto maior o valor do índice, maior é a diversidade da comunidade amostrada. O ídice médio variou desde 2,32 (tratamento 1) até 3,25 (Testemunhas).

Pode-se concluir deste trabalho que:

\section{CONCLUSÃO}

1. As médias dos índices de Simpson, Margalef e Shanon-Wierner diferiram estatisticamente entre as comunidades amostradas em áreas de aplicação de efluente tratado de abatedouro de aves, a uma taxa de irrigação de $100 \mathrm{~m}^{3} \mathrm{ha}^{-1} \mathrm{dia}^{-1} \mathrm{e}$ as comunidades amostradas em áreas não irrigadas.

2. A maior diversidade de espécies média foi observada para as amostras coletadas em áreas irrigadas com $200 \mathrm{~m}^{3} \mathrm{ha}^{-1} \mathrm{dia}^{-1}$ (Índice de Shanon), em relação à dominância (Índice de Simpson), observou-se o maior índice nas áreas não irrigadas, assim como a maior riqueza de espécies (Índice de Margalef).

\section{AGRADECIMENTOS}

Agradeço a Universidade Tecnológica Federal do Paraná (UTFPR) e ao Instituto Politécnico de Bragança, Portugal (IPB) pelo apoio a pesquisa, a Cooperativa Agroindustrial Lar em Matelândia por disponibilizar a área do estudo, além do suporte técnico, a Capes e Fundação araucária pelo apoio financeiro.

\section{REFERÊNCIAS}

ABPA - Brazilian Association of Animal Protein. Annual Report. São Paulo, 2017.

ARAÚJO, A. S. F; MONTEIRO, Regina T.R. Indicadores Biológicos de Qualidade do Solo. Bioscience Journal, Uberlândia, v. 23, n. 3, p. 66-75, 2007.

MAGURRAN, A. E. Ecological Diversity and its Measurement. Princeton University Press, 179p, 1988.

ODUNZE, A.C. JINSHUI, W. SHOULONG, L. HANHUA, Z. TIDA, G. YI, W. QIAO, L. Soil Quality Changes and Quality Status: A Case Studyof the Subtropical China Region Ultisol. British Journal of Environment \& Climate Change 2(1): 37-57, 2012.

MARGALEF, R. (1991) Teoría de los Sistemas Ecológicos. Universitat de Barcelona Editora: Barcelona. 
Tabela 1. Médias dos Índice de riqueza de Margalef, Índice de dominância de Simpson, Índice de Diversidade de Shannon, Índice de equabilidade de Pielou para as taxas de irrigação de $0 \mathrm{~m}^{3} \mathrm{ha}^{-1} \mathrm{dia}^{-1}$ (Tratamento 0), $100 \mathrm{~m}^{3} \mathrm{ha}^{-1} \mathrm{dia}^{-1}$ (Tratamento 1), $200 \mathrm{~m}^{3} \mathrm{ha}^{-1} \mathrm{dia}^{-1}$ (Tratamento 2) e $300 \mathrm{~m}^{3} \mathrm{ha}^{-1} \mathrm{dia}^{-1}$ (Tratamento T3) e testes comparativos de médias de Fisher e Dunnett.

\begin{tabular}{|c|c|c|c|c|c|}
\hline Índice & Tratamento & Média & Desvio padrão & Fisher $^{(1)}$ & Dunnett $^{(2)}$ \\
\hline \multirow[t]{4}{*}{ Shannon-Wiener } & 0 & 1,88 & 0,27 & $\mathrm{a}$ & $\mathrm{a}$ \\
\hline & 1 & 1,51 & 0,55 & $\mathrm{~b}$ & $*$ \\
\hline & 2 & 1,81 & 0,26 & $\mathrm{ab}$ & $\mathrm{a}$ \\
\hline & 3 & 1,69 & 0,28 & $\mathrm{ab}$ & $\mathrm{a}$ \\
\hline \multirow[t]{4}{*}{ Simpson } & 0 & 0,76 & 0,11 & $\mathrm{a}$ & $\mathrm{a}$ \\
\hline & 1 & 0,59 & 0,19 & $\mathrm{~b}$ & $*$ \\
\hline & 2 & 0,71 & 0,09 & $\mathrm{ab}$ & $\mathrm{a}$ \\
\hline & 3 & 0,71 & 0,12 & $\mathrm{a}$ & $\mathrm{a}$ \\
\hline \multirow[t]{4}{*}{ Margalef } & 0 & 3,25 & 0,74 & $\mathrm{a}$ & $\mathrm{a}$ \\
\hline & 1 & 2,32 & 0,94 & $\mathrm{~b}$ & $*$ \\
\hline & 2 & 2,93 & 0,63 & $\mathrm{ab}$ & $\mathrm{a}$ \\
\hline & 3 & 2,78 & 0,99 & $\mathrm{ab}$ & $\mathrm{a}$ \\
\hline \multirow[t]{4}{*}{ Pielou } & 0 & 0,87 & 0,07 & $\mathrm{a}$ & $\mathrm{a}$ \\
\hline & 1 & 0,72 & 0,23 & $\mathrm{~b}$ & $\mathrm{a}$ \\
\hline & 2 & 0,83 & 0,11 & $\mathrm{ab}$ & $\mathrm{a}$ \\
\hline & 3 & 0,87 & 0,12 & $\mathrm{a}$ & $\mathrm{a}$ \\
\hline \multirow[t]{4}{*}{ Shanon } & 0 & 3,75 & 1,35 & $\mathrm{a}$ & $\mathrm{a}$ \\
\hline & 1 & 3,18 & 1,39 & $\mathrm{a}$ & $\mathrm{a}$ \\
\hline & 2 & 4,40 & 1,61 & $\mathrm{a}$ & $\mathrm{a}$ \\
\hline & 3 & 4,20 & 1,68 & $\mathrm{a}$ & $\mathrm{a}$ \\
\hline
\end{tabular}

Nota: (1) Teste de comparação de médias de Fisher a 5\% de significância; (2) Teste de comparação de médias de Dunnett a 5\% de significância; *Diferença significativa a 5\% de significância entre a média do tratamento e média da testemunha. 


\title{
BIOINDICADORES DE QUALIDADE DO SOLO EM REFLORESTAMENTO IRRIGADO COM EFLUENTE DE ABATEDOURO DE AVES
}

\author{
Vargas, R.J. ${ }^{1 *}$; Araujo, I.R.C. ${ }^{2}$; Morais, J. ${ }^{2}$; Figueiredo, T.A.F.R. ${ }^{3}$; Shutz, F.C.A. ${ }^{1}$ \\ *Mestrando no Programa de Pós-graduação em Tecnologias Computacionais para o Agronegócio-PPGTCA, \\ rodrigovargas@alunos.utfpr.edu.br \\ ${ }^{1}$ Universidade Tecnológica Federal do Paraná, Medianeira, PR, Brasil \\ ${ }^{2}$ Universidade Estadual do Oeste do Paraná, Cascavel,PR, Brasil \\ ${ }^{3}$ Instituto Politécnico de Bragança - Portugal
}

\begin{abstract}
RESUMO: Com o aumento da demanda e do consumo de proteína de frango, o volume de efluentes gerados nos frigoríficos também está aumentando, especialmente em países como o Brasil, onde a produção de proteína animal tem apresentado crescimento significativo nas últimas décadas. Esses efluentes são tratados e podem ser utilizados como alternativa para irrigação de áreas reflorestadas. O objetivo do presente trabalho é avaliar o impacto do solo através do uso de efluente de um abatedouro de aves aplicado em uma área reflorestada através de bioindicadores da classe dos oligochaetes (minhocas e enquitreídeos) e da ordem isopoda. Devido à sensibilidade destes organismos a pequenas mudanças em seu habitat, é possível utilizá-los como bioindicadores da qualidade do solo. De acordo com os resultados, as médias do número de indivíduos para a ordem isopoda não apresentaram diferenças significativas a 5\% de significância (testes de Tukey e Fisher), nem entre todos os tratamentos e tratamentos irrigados, bem como um controle (tese de Dunnett). Na classe Oligochaeta, tratamentos com aplicação de $300 \mathrm{~m}^{3} \mathrm{ha}^{-1}{ }^{1} \mathrm{dia}^{1}{ }^{1}$ indicaram diferenças significativas para os demais. Para os enquitreídeos, as áreas irrigadas com $200 \mathrm{~m}^{3}-^{1} \mathrm{dia}^{-1}$ apresentaram diferenças significativas para as demais áreas, apresentando maior número de indivíduos por amostra. A análise de correlação de Pearson foi aplicada para estabelecer uma relação entre estes bioindicadores, propriedades do solo e taxas de irrigação, resultando em altas taxas de correlação, mostrando que as propriedades do solo podem influenciar diretamente a ocorrência desses bioindicadores.
\end{abstract}

Palavras-chave: bioindicadores, efluentes, irrigação.

\section{SOIL QUALITY BIOINDICATORS IRRIGATED WITH POUTRY SLOUGHTERHOUSE EFFLUENT}

\begin{abstract}
With increasing demand and consumption of chicken protein, the volume of effluents generated in slaughterhouses is also increasing, especially in countries such as Brazil, where animal protein production has shown significant growth in recent decades. These effluents are treated and can be used as an alternative for irrigation of reforested areas. The objective of the present work is to evaluate the impact of the soil through the use of effluent from a poultry slaughterhouse applied in a reforested area through bioindicators of the class of oligochaetes ("minhocas and tatuzinhos-de-jardim") and the isopoda order. Due to the sensitivity of these organisms to small changes in their habitat, it is possible to use them as bioindicators of soil quality. According to the results, the means of the number of individuals for the order isopoda did not present significant differences at 5\% of significance (Testes de Tukey e Fisher), nor among all treatments and irrigated treatments, as well as a control (Dunnett's thesis) In the Oligochaeta class, treatments with application of $300 \mathrm{~m}^{3} \mathrm{ha}^{-1} \mathrm{dia}^{-1}$ indicated significant differences for the others. For the Enquetreidae, irrigated areas with $200 \mathrm{~m}^{3}-^{1} \mathrm{dia}^{-1}$ presented significant differences for the other areas, presenting a greater number of individuals per sample. Pearson correlation analysis was applied to establish a relationship between these bioindicators, soil properties and irrigation rates, resulting in high correlation rates, showing that soil properties can directly influence the occurrence of these bioindicators.
\end{abstract}

Keywords: bioindicators, effluents, irrigation.

\section{INTRODUÇÃO}

A atividade industrial pode ser apontada como causa de grandes impactos ao meio ambiente, seja na fabricação de produtos ou extração de matéria prima. O volume de efluentes e rejeitos produzidos pelo setor agroindustrial é bastante expressivo, sobretudo no abate de animais. Estes efluentes são carregados de 
compostos orgânicos altamente poluentes, como sangue, gorduras e óleos, vísceras, entre outros. Atualmente, no Brasil, a principal forma de disposição final destes efluentes, depois de tratados, é no solo.

De acordo com Kulay; Vinas; Hespanhol (2015) o impacto ambiental causado pela poluição, geralmente é negativo, pois altera as condições ambientais. Segundo Mechi, Sanches (2010), os efluentes industriais podem provocar decréscimo na cobertura vegetal, exposição do solo aos processos erosivos, além de mudanças na quantidade e qualidade das águas superficiais e subterrâneas.

Uma forma de avaliar estas alterações é monitorando alguns indicadores de qualidade do solo. Devido à sensibilidade dos componentes biológicos e bioquímicos, qualquer índice de qualidade deve incluir estas variáveis (FRIGUETTO; VALARINI, 2000). Por isso, muitos estudos vêm adotando os parâmetros biológicos como forma de avaliar a qualidade do solo e suas alterações (FRIGUETTO; VALARINI, 2000; BARETTA et al., 2008; MENDES et al., 2009; BERTINI, 2010; FREITAS et al., 2012; SANTOS; MAIA, 2013).

Dentre os indicadores de qualidade do solo estão as minhocas, pertencentes a macrofauna, compondo o filo annelida e classe oligochaeta, os enquitreídeos (oligochaeta, enchytraeidae), pertencentes a mesofauna, e tatuzinhos-de-jardim ou tatus-bola (crustáceos da ordem Isopoda), que compõem a macrofauna. Esses animais atuam como decompositores de matéria orgânica, ciclagem de nutrientes, além de auxiliar na infiltração de água através de pequenos túneis escavados no solo (COSTA, ARAUJO, GUERRA, 2015; BROWN, DOMÍNGUEZ, 2010; NIVA, et al, 2015; STEFFEN, et al, 2013). Por outro lado, são animais sensíveis às mudanças ambientais promovidas pela introdução de elementos poluentes, como efluentes, por exemplo. Assim, o presente estudo tem como objetivo avaliar o impacto causado sobre estes bioindicadores de qualidade do solo pelo uso de efluente agroindustrial na irrigação de área reflorestada com Eucalyptus urophylla.

\section{MATERIAL E MÉTODOS}

O experimento foi instalado nas áreas de reflorestamento da unidade industrial de abate de aves (UIA) no município de Matelândia, no Paraná, coordenadas geográficas aproximadas de latitude $25^{\circ} 12,1577 \mathrm{~S}$ e longitude $53^{\circ} 57,1925^{\prime} \mathrm{W}$, no divisor de águas entre a bacia do Paraná III e a bacia do Iguaçu, nas microbacias do rio Sabiá e do rio Xaxim. A altitude é de $585 \mathrm{~m}$.

Atualmente a UIA abate 340 mil aves diariamente, gerando um volume de $7.500 \mathrm{~m}^{3}$ de efluente por dia. Todo esse material é tratado e utilizado na irrigação em áreas reflorestadas com Eucalyptus urophylla, clone 144. Foram instaladas 16 parcelas, com área média de 296,8 m². Aplicou-se às parcelas, 4 tratamentos, com 4 repetições cada, sendo um deles T0, testemunha sem aplicação de efluente, T1 com aplicação de $100 \mathrm{~m}^{3} \mathrm{ha}{ }^{-}$ ${ }^{1} \mathrm{dia}^{-1}$, T2 com $200 \mathrm{~m}^{3} \mathrm{ha}^{-1} \mathrm{dia}^{-1}$, e T3 com $300 \mathrm{~m}^{3} \mathrm{ha}^{-1} \mathrm{dia}^{-1}$. Os tratamentos foram sorteados inteiramente ao acaso, nas 16 parcelas

Para a coleta da classe oligochaeta, a metodologia proposta foi adaptada a partir do TSBF, Tropical Soil Biology and Fertility Method (Anderson \& Ingram, 1993), onde são retirados monolitos de 20 x 20 x $20 \mathrm{~cm}$ de profundidade. Posteriormente o material é peneirado e os animais coletados e levados ao laboratório para identificação.

Para a captura da ordem isópoda, composta pelos "tatuzinhos-de-jardim" foram utilizadas armadilhas de queda do tipo "pitfall trap”. Copos descartáveis foram colocados ao nível da superfície do solo e mantidos no local do experimento por 5 dias. Após esse período os animais foram coletados e levados ao laboratório para classificação com auxílio de lupa bi-ocular.

Nestas amostras, foram avaliados a concentração de matéria orgânica, $\mathrm{pH}$ em $\mathrm{CaCl}_{2} \mathrm{e} \mathrm{H}+\mathrm{Al}$. As análises foram realizadas com base nos métodos descritos por Embrapa (2018).

\section{RESULTADOS E DISCUSSÃO}

Na Tabela 1 são apresentados os resultados médios obtidos por tratamento. Observa-se que, para as médias de número de indivíduos da Ordem Isopoda, não houve diferença significativa a 5\% de significância, nem entre os tratamentos (Testes de Tukey e Fisher) e nem entre os tratamentos irrigados e testemunha (tese de Dunnett), já para as minhocas (classe Oligochaeta), houve diferença significativa entre os tratamentos com aplicação de $300 \mathrm{~m}^{3} \mathrm{ha}^{-1}$ dia $^{-1}$ e os demais. Em relação aos Enquitreídeos o tratamento com aplicação de 200 $\mathrm{m}^{3} \mathrm{ha}^{-1} \mathrm{dia}^{-1}$ foi o que apresentou a maior média de indivíduos por amostra e diferiu estatisticamente dos demais.

Para entender a relação entre estes bioindicadores, as propriedades do solo e as taxas de irrigação aplicadas, procedeu-se a análise de correlação de Pierson, que resultou em altas correlações (BISQUERRA; SARRIERA; MARTÍNEZ, 2004) entre o número de indivíduos de Oligocheatas e as taxas de efluentes aplicadas ao solo $(0,819)$ e a acidez potencial $(0,966)$. A ocorrência de Enquitreídos apresentou correlação 
negativa muito alta com $(-0,856)$ com o $\mathrm{pH}$, o que significa que quanto mais básico o solo, menor a ocorrência deste bioindicador. Além disso, observou-se alta correlação $(0,602)$ entre a taxa de irrigação e o número de Enquitreídeos.

Em relação aos Isópodas, observou-se muito alta correlação com a concentração de fósforo no solo $(0,825)$ e alta correlação com a concentração de matéria orgânica $(0,735)$, indicando que este artrópode tende a viver em áreas de solos mais férteis, corroborando com a avaliação feita por Loureiro et al. (2006), que afirma que os isópodes respondem positivamente à adição de matéria orgânica ao solo.

\section{CONCLUSÃO}

Conclui-se deste trabalho que os bioindicadores avaliados podem ser utilizados na avaliação da qualidade do solo irrigado com efluente de abatedouro de aves. As minhocas e Enquitreídeos (classe Oligocheata) respondem positiva e linearmente às taxas de irrigação.

\section{AGRADECIMENTOS}

Agradecemos à UTFPR - Programa de Pós Graduação em Tecnologias Computacionais para o Agronegócio e ao Instituto Politécnico de Bragança, Portugal (IPB) pelo apoio a pesquisa, à Cooperativa Agroindustrial Lar pelo suporte na pesquisa e à Capes e Fundação Araucária pelo apoio financeiro.

\section{REFERÊNCIAS}

BARETTA, D.; et. al; Colêmbolos (hexapoda: Collembola) como bioindicadores de qualidade do solo em áreas com Araucaria angustifolia. Ciência do Solo, v. 32, n. 1, p. 2693-2699, 2008.

BERTINI, S. B. Indicadores microbiológicos de qualidade do solo em Florestas de Araucária no Estado de São Paulo. Microbiologia, 2010.

BISQUERRA, R.; SARRIERA, J. C.; MARTINEZ, F. Introdução à estatística: enfoque

BROWN, G.G.; DOMÍNGUEZ, J. Uso das minhocas como bioindicadoras ambientais: princípios e práticas o $3^{\circ}$ encontro latino americano de ecologia e taxonomia de oligoquetas (elaetao3). Acta Zoológica Mexicana (n.s.) Número Especial 2, 2010.

COSTA, S.L.N.; ARAUJO, P.B.; GUERRA, T. O tatuzinho-de-jardim como auxiliar na educação ambiental: o papel ecológico dos isópodos terrestres e suas relações com as plantas.

Disponível em: <http://www.journals.ufrpe.br/index.php/apca/article/viewFile/397/349>.

FREITAS, D. A. F. et. al, N. Índices de qualidade do solo sob diferentes sistemas de uso e manejo florestal e cerrado nativo adjacente. Revista Ciencia Agronomica, v. 43, n. 3, p. 417-428, 2012.

FRIGUETTO, R. T. S.; VALARINI, P. J. Indicadores Biológicos e Bioquímicos da Qualidade do Solo,

2000.

informático com o pacote estatístico SPSS. Porto Alegre: Artmed, 2004.

KULAY, L. A. VINAS, R. S. HESPANHOL, I. Avaliação de desempenho ambiental de sistemas para fornecimento de água quente para uso doméstico. Revista Ambiente \& Água - AN Interdisciplinar Journal of Applied Science, v. 10, n.2. Taubaté, 2015.

LOUREIRO, S.; SAMPAIO, A.; BRANDÃO, A.; NOGUEIRA, A.J. A.; SOARES, A. Feeding behaviour of the terrestrial isopod Porcellionides pruinosus Brandt, 1833 (Crustacea, Isopoda) in response to changes in food quality and contamination. Science of Total Environment, v. 369, p. 119-128, 2006.

MECHI, A. SANCHES, D. L. The Environmental Impact of Mining in the State of São Paulo. Estudos avançados, vol. 24, no.68, São Paulo, 2010.

MENDES, I. C.; et. al. Bioindicadores para Avaliação da Qualidade dos Solos Tropicais: utopia ou realidade? Documentos, 246, v. 1, p. 32, 2009.

NIVA, C.C.; CEZAR, R.M.; FONSECA.P.M.; ZANGATTO, M.R.G.; OLIVEIRA, E.M.; BUSH, E.F.; CLASEN, L.A.; BROWN, G.G. Enchytraeid abundance in Araucaria Mixed Forest determined by cold and hot wet extraction. Brazil Journal of Biology. vol.75 no.4 supl.1 Epub Nov 24, 2015, São Carlos, São Paulo. SANTOS, V. M.; MAIA, Leonor C. Bioindicadores De Qualidade Do Solo. Anais da Academia Pernambucana de Ciência Agronômica, v. 10, p. 195-223, 2013.

STEFFEN, G.P.K.; ANTONIOLLI, Z.I.; STEFFEN, R.B.; JACQUES, R.J.S. Importância ecológica e ambiental das minhocas. Revista de Ciências Agrárias, 2013, 36(2): 137-147. Lisboa, Portugal. 


\section{VISIGER AE D 07 A 09 MA10 2019

Tabela 1. Resultados comparativos para bioindicadores de solo e parâmetros físico químicos de áreas irrigadas nos tratamentos com $0 \mathrm{~m}^{3} \mathrm{ha}^{-1} \mathrm{dia}^{-1}, 100 \mathrm{~m}^{3} \mathrm{ha}^{-1} \mathrm{dia}^{-1}, 200 \mathrm{~m}^{3} \mathrm{ha}^{-1} \mathrm{dia}^{-1}$ e $300 \mathrm{~m}^{3} \mathrm{ha}^{-1} \mathrm{dia}^{-1}$ de efluente tratado de abatedouro de aves.

\begin{tabular}{|c|c|c|c|c|c|c|c|}
\hline Variável & Tratamento & Média & $\begin{array}{l}\text { Desvio } \\
\text { padrão }\end{array}$ & $\begin{array}{l}\text { Coeficiente de } \\
\text { variação }(\%)\end{array}$ & Tukey* & Fisher* & Dunnett* \\
\hline \multirow{4}{*}{ Isópodo } & 0 & 3,58 & 4,27 & 119,27 & $\mathrm{a}$ & $\mathrm{a}$ & $\mathrm{a}$ \\
\hline & 100 & 8,33 & 8,4 & 100,83 & $\mathrm{a}$ & $\mathrm{a}$ & $\mathrm{a}$ \\
\hline & 200 & 7,58 & 7,6 & 100,18 & $\mathrm{a}$ & $\mathrm{a}$ & $\mathrm{a}$ \\
\hline & 300 & 5,33 & 6,21 & 116,5 & $\mathrm{a}$ & $\mathrm{a}$ & $\mathrm{a}$ \\
\hline \multirow[t]{4}{*}{ Oligochaeta } & 0 & 4,75 & 3,194 & 67,25 & $\mathrm{a}$ & $\mathrm{a}$ & $\mathrm{a}$ \\
\hline & 100 & 4,08 & 4,48 & 109,75 & $\mathrm{a}$ & $\mathrm{a}$ & $\mathrm{a}$ \\
\hline & 200 & 7,5 & 4,17 & 55,56 & $\mathrm{a}$ & $\mathrm{a}$ & $\mathrm{a}$ \\
\hline & 300 & 34,58 & 18,46 & 53,38 & $\mathrm{~b}$ & $\mathrm{~b}$ & $\mathrm{~b}$ \\
\hline \multirow[t]{4}{*}{ Enquitreídeos } & 0 & 27,83 & 5,95 & 21,38 & a & $\mathrm{a}$ & $\mathrm{a}$ \\
\hline & 100 & 36,5 & 18,92 & 51,84 & $\mathrm{a}$ & $\mathrm{a}$ & $\mathrm{a}$ \\
\hline & 200 & 61,58 & 33,8 & 54,89 & $\mathrm{~b}$ & $\mathrm{~b}$ & $\mathrm{~b}$ \\
\hline & 300 & 41,75 & 21,71 & 52,01 & $\mathrm{ab}$ & $\mathrm{a}$ & $\mathrm{a}$ \\
\hline \multirow[t]{4}{*}{ Fósforo (mg.dm³) } & 0 & 14,43 & 11,23 & 77,83 & $\mathrm{a}$ & $\mathrm{a}$ & $\mathrm{a}$ \\
\hline & 100 & 60,67 & 30,66 & 50,53 & $\mathrm{~b}$ & $\mathrm{~b}$ & $\mathrm{~b}$ \\
\hline & 200 & 36,77 & 30,36 & 82,57 & $a b$ & $a b$ & $\mathrm{a}$ \\
\hline & 300 & 44,2 & 41,7 & 94,52 & $\mathrm{ab}$ & $\mathrm{b}$ & $\mathrm{a}$ \\
\hline \multirow[t]{4}{*}{$\begin{array}{l}\text { Matéria Orgânica } \\
\left(\mathrm{g} \cdot \mathrm{dm}^{-3}\right)\end{array}$} & 0 & 38,96 & 4,39 & 11,27 & a & $\mathrm{a}$ & $\mathrm{a}$ \\
\hline & 100 & 46,25 & 4,51 & 9,75 & $\mathrm{~b}$ & $\mathrm{~b}$ & $\mathrm{~b}$ \\
\hline & 200 & 41,01 & 4,9 & 11,95 & $\mathrm{ab}$ & $\mathrm{a}$ & $\mathrm{a}$ \\
\hline & 300 & 42,95 & 7,3 & 16,99 & $\mathrm{ab}$ & $a b$ & $\mathrm{a}$ \\
\hline \multirow[t]{4}{*}{$\mathrm{pH}$} & 0 & 5,353 & 0,432 & 8,07 & a & $\mathrm{a}$ & $\mathrm{a}$ \\
\hline & 100 & 5,448 & 0,424 & 7,78 & $\mathrm{a}$ & $\mathrm{a}$ & $\mathrm{a}$ \\
\hline & 200 & 5,101 & 0,54 & 10,58 & $\mathrm{a}$ & $\mathrm{a}$ & $\mathrm{a}$ \\
\hline & 300 & 5,2533 & 0,3031 & 5,77 & a & $\mathrm{a}$ & $\mathrm{a}$ \\
\hline \multicolumn{8}{|l|}{ Acidez potencial } \\
\hline \multirow{4}{*}{$\mathrm{H}+\mathrm{Al}\left(\mathrm{cmol}_{\mathrm{c}} \cdot \mathrm{dm}^{-3}\right)$} & 0 & 4,95 & 1,452 & 29,33 & $\mathrm{ab}$ & $\mathrm{a}$ & $\mathrm{a}$ \\
\hline & 100 & 4,704 & 0,85 & 18,06 & $\mathrm{~b}$ & $\mathrm{a}$ & $\mathrm{a}$ \\
\hline & 200 & 4,668 & 0,94 & 20,14 & $\mathrm{~b}$ & $\mathrm{a}$ & $\mathrm{a}$ \\
\hline & 300 & 6,015 & 1,335 & 22,2 & $\mathrm{a}$ & b & $\mathrm{a}$ \\
\hline
\end{tabular}

Nota: *Testes de comparação de médias a 5\% de significância.

Tabela 2. Análise de correlação de Pierson para avaliação de correlação entre os bioindicadores, taxa de aplicação de efluente e propriedade do solo.

\begin{tabular}{|c|c|c|c|c|c|c|c|c|}
\hline & Taxa de apli. & Isópodo & Oligocheata & Enquitreídeos & Fósforo & $\begin{array}{c}\text { Matéria } \\
\text { orgânica }\end{array}$ & pH & $\begin{array}{c}\text { Acidez } \\
\text { Potencial }\end{array}$ \\
\hline Taxa de apli. & 1,000 & & & & & & & \\
\hline Isópodo & 0,268 & 1,000 & & & & & & \\
\hline Oligocheata & 0,819 & $-0,249$ & 1,000 & & & & & \\
\hline Enquitreídeos & 0,602 & 0,566 & 0,084 & 1,000 & & & & \\
\hline Fósforo & 0,439 & 0,825 & 0,158 & 0,223 & 1,000 & & & \\
\hline Matéria orgânica & 0,280 & 0,735 & 0,098 & 0,001 & 0,974 & 1,000 & & \\
\hline $\mathrm{pH}$ & $-0,562$ & $-0,059$ & $-0,258$ & $-0,856$ & 0,246 & 0,459 & 1,000 & \\
\hline Acidez potencial & 0,644 & $-0,448$ & 0,966 & $-0,161$ & 0,022 & 0,01 & $-0,08$ & 1,000 \\
\hline
\end{tabular}




\title{
CONTROLE ESTATÍSTICO DE QUALIDADE NO MONITORAMENTO BIOLÓGICO DO SOLO IRRIGADO COM EFLUENTE AGROINDUSTRIAL
}

\author{
Vargas, R.J. ${ }^{1 *}$; Araujo, I.R.C. ${ }^{2}$; Morais, J. ${ }^{2}$; Figueiredo, T.A.F.R. ${ }^{3}$; Shutz, F.C.A. ${ }^{1}$ \\ *Mestrando no Programa de Pós-graduação em Tecnologias Computacionais para o Agronegócio-PPGTCA, \\ rodrigovargas@alunos.utfpr.edu.br \\ ${ }^{1}$ Universidade Tecnológica Federal do Paraná, Medianeira, PR, Brasil \\ ${ }^{2}$ Universidade Estadual do Oeste do Paraná, Cascavel,PR, Brasil \\ ${ }^{3}$ Instituto Politécnico de Bragança - Portugal
}

\begin{abstract}
RESUMO: Ferramentas de controle estatístico de processo (CEP) buscam implementar e desenvolver processos estatísticos que ajudam a evitar defeitos nos processos de fabricação, custos de fabricação e qualidade do produto. Os gráficos de Shewhart são uma das principais técnicas do CEP, mostrando a média de uma medida das características de qualidade em amostras do processo de verificação em relação ao tempo ou número de amostras. Embora sejam utilizados para monitorar a qualidade dos mais variados processos, o uso desses parâmetros para a avaliação de indicadores biológicos ainda é uma questão inexplorada. Assim, o presente trabalho pretende apresentar técnicas de controle de qualidade para avaliação de indicadores biológicos de solos submetidos a diferentes regimes de irrigação com efluente tratado de abatedouro de aves. Os índices biológicos foram correlacionados de acordo com o controle estatístico do processo, utilizando gráficos de Shewhart. Calculou-se os limites superior e inferior, bem como a média de todas as variáveis, apresentando um ponto fora dos limites estabelecidos para os índices de Shannon, Simpson e Pielou no tratamento 2. Para a ordem Isopoda, os resultados indicaram uma diminuição dos valores observados. para os 4 tratamentos Para a classe oligochaeta (minhocas e enquitreídeos) observa-se a relação entre o aumento da média e também a dispersão dos dados no tratamento 3 para minhocas. Para os enquitreídeos, a maior média e dispersão de dados são observadas no tratamento 2 .
\end{abstract}

Palavras-chave: efluente, indicadores biológicos, processos estatísticos.

\section{STATISTICAL CONTROL OF QUALITY IN THE BIOLOGICAL MONITORING OF THE SOIL IRRIGATED WITH AGROINDUSTRIAL EFFLUENT}

\begin{abstract}
Statistical process control (CEP) tools seek to implement and develop statistical processes that help prevent defects in manufacturing processes, manufacturing costs and product quality. The Shewhart charts are one of the main techniques of the CEP, showing the average of a measure of the quality characteristics in samples of the verification process in relation to the time or number of samples. Although they are used to monitor the quality of the most varied processes, the use of these parameters for the evaluation of biological indicators is still an unexplored issue. Thus, the present work intends to submit quality control techniques for the evaluation of biological indicators of soils submitted to different irrigation regimes with treated effluent from poultry slaughterhouse. The biological indexes were correlated according to the statistical control of the process, using Shewhart charts. It was calculated the upper and lower limits as well as the mean of all variables, presenting a point outside the limits established for the Shannon, Simpson and Pielou indices in treatment 2. For the order Isopoda, the results indicated a decrease observed values for the 4 treatments For the class oligochaeta (earthworms and enquitreídeos) it is observed the relation between the increase of average and also the dispersion of the data in the treatment 3 for earthworms. For the enquitreídeos, the highest mean and dispersion of data are observed in the treatment 2.
\end{abstract}

Keywords: effluent, biological indicators, statistical processes.

\section{INTRODUÇÃO}

A biologia do solo pode trazer repostas importantes sobre impactos causados em áreas antropizadas, usadas para fins agrícolas e de reflorestamento. Esses organismos são muito sensíveis a pequenas mudanças no ambiente, tornando-se ótimos indicadores de qualidade (MATSUMOTO, MARQUES, 2015; SANTOS; MAIA, 2013). O controle estatístico de qualidade é uma das formas de interpretação que podem ser aplicadas em dados referentes aos bioindicadores de qualidade do solo. Trata-se de um conjunto de ferramentas para 
monitoramento da qualidade a fim de que se possa observar o comportamento de determinado processo em relação à um padrão de qualidade obtido a partir de cálculos estatísticos (MONTGOMERY, 2016). Dentre as ferramentas do controle estatístico de qualidade, destacam-se os gráficos de controle, que foram propostos por Walter Shewhart em 1920, com a finalidade de avaliação de processos industriais, aplicado ao monitoramento de operários com pouca instrução (MONTGOMERY, 2016).

Além dos gráficos de controle, a análise da capacidade de um processo é um estudo de engenharia da qualidade cujas técnicas de controle estatístico foram desenvolvidas para avaliar a variabilidade ao longo do tempo do processo. A análise da capacidade de um processo é uma parte vital de um programa de melhoria da qualidade (FRIGO, 2012).

Os solos irrigados com efluentes industriais podem ser monitorados por vários parâmetros, indicadores e ferramentas estatísticas. O controle estatístico de qualidade pode ser uma forma prática e simples de interpretar os dados obtidos em análise, principalmente por ser um formato conhecido de acompanhamento de indicadores de qualidade, bastante difundido e consolidado nas indústrias. Algumas ferramentas do controle estatístico de qualidade já vêm sento utilizadas para avaliar importantes parâmetros agrícolas, tais como uniformidade na irrigação (JUCHEN et al., 2013; HERMES et al.,2015), qualidade nas operações mecanizadas (SILVA et al., 2013; MELO et al., 2016; ZERBATO et al., 2017 ) e parâmetros de qualidade do solo (MOAMENI, 2013), de modo que, estas técnicas, desenvolvidas para servirem como apoio de tomada de decisões dentro das indústrias, já se expandem para o campo das ciências agrárias e ambientais.

O objetivo do presente estudo é a introdução do uso de ferramentas de controle estatístico de qualidade na avaliação de alguns bioindicadores do solo.

\section{MATERIAL E MÉTODOS}

O experimento foi instalado nas áreas de reflorestamento da unidade industrial de abate de aves (UIA) no município de Matelândia, no Paraná, coordenadas geográficas aproximadas de latitude $25^{\circ} 12,1577 \mathrm{~S}$ e longitude $53^{\circ} 57,1925^{\prime} \mathrm{W}$, no divisor de águas entre a bacia do Paraná III e a bacia do Iguaçu, nas microbacias do rio Sabiá e do rio Xaxim. A altitude é de $585 \mathrm{~m}$.

Atualmente a UIA abate 340 mil aves diariamente, gerando um volume de $7.500 \mathrm{~m}^{3}$ de efluente por dia. Todo esse material é tratado e utilizado na irrigação em áreas reflorestadas com Eucalyptus urophylla, clone 144. Foram instaladas 16 parcelas, com área média de 296,8 m². Aplicou-se às parcelas, 4 tratamentos, com 4 repetições cada, sendo um deles T0, testemunha sem aplicação de efluente, T1 com aplicação de $100 \mathrm{~m}^{3}$ ha ${ }^{-}$ ${ }^{1} \mathrm{dia}^{-1}$, T2 com $200 \mathrm{~m}^{3} \mathrm{ha}^{-1} \mathrm{dia}^{-1}$, e T3 com $300 \mathrm{~m}^{3} \mathrm{ha}^{-1} \mathrm{dia}^{-1}$. Os tratamentos foram sorteados inteiramente ao acaso, nas 16 parcelas

Para a coleta da classe oligochaeta, a metodologia proposta foi adaptada a partir do TSBF, Tropical Soil Biology and Fertility Method (Anderson \& Ingram, 1993), onde são retirados monolitos de 20 x 20 x $20 \mathrm{~cm}$ de profundidade. Posteriormente o material é peneirado e os animais coletados e levados ao laboratório para identificação.

Para a captura da ordem isópoda, composta pelos "tatuzinhos-de-jardim" foram utilizadas armadilhas de queda do tipo "pitfall trap”. Copos descartáveis foram colocados ao nível da superfície do solo e mantidos no local do experimento por 5 dias. Após esse período os animais foram coletados e levados ao laboratório para classificação com auxílio de lupa bi-ocular.

Os ídices calculados para cada tratamento foram: Índice de riqueza de Margalef $(\mathrm{I}=[(\mathrm{S}-1)] / \mathrm{lnN}$; em que: I=diversidade; $\mathrm{S}=$ número de espécies presente; $\mathrm{N}=$ número total de indivíduos encontrados na amostra; ); Índice de Simpson, forma de dominância $(\mathrm{D}=\Sigma(\mathrm{ni} / \mathrm{N}) 2$, em que: $n i$ = número de indivíduos do grupo "i”"; $\mathrm{N}=$ somatório da densidade de todos os grupos); Índice de Diversidade de Shannon $(\mathrm{H}=-\Sigma \mathrm{Pi} \operatorname{lnPi}$; em que: $\mathrm{Pi}=$ proporção do grupo i no total da amostra) e Índice de equabilidade de Pielou $(\mathrm{J}=\mathrm{H} / \mathrm{ln}$; em que: $\mathrm{H}=1$ índice de Shannon, $\mathrm{S}=$ número total de grupos na comunidade).

Os bioindicadores e atributos de solo serão avaliados utilizando-se o controle estatístico de qualidade, mais especificamente as ferramentas "Gráficos de qualidade de Shewhart" baseado em valores de referência e "Índice de capacidade de processo", dado por: $\mathrm{Cp}=(\mathrm{LSC}-\mathrm{LIC}) / 6 \sigma$ ( em que: $\mathrm{C}_{\mathrm{p}}=$ índice de capacidade do processo. 


\section{RESULTADOS E DISCUSSÃO}

São apresentados na Figura 1, os gráficos de Shewhart para valores individuais, para os índices ecológicos obtidos (a até e) e para alguns bioindicadores avaliados (f até h). Pode-se observar nestes gráficos, que linhas verticais separam os tratamentos. Para cada tratamento, calculou-se os limites superior e inferior e a média para todas as variáveis. Foram observados um ponto fora dos limites estabelecidos de controle $( \pm 3 \sigma$ em relação à média) para os índices de Shannon-Wierner, Simpson e Pielou no tratamento 2. Considerando que não há uma tendência em relação ao comportamento das curvas de ambos os tratamentos, pode-se deduzir que esta variação se deve a uma causa especial, ou seja, não é inerente, nem às variações aleatórias do processo de coleta e nem à uma tendência no tratamento. Esta causa especial pode estar relacionada com fatores ambientais, como um vazamento do sistema de irrigação da parcela na qual de observou o desvio, ou até mesmo, à própria localização da armadilha. Neste caso, esta observação serve como um alerta ao monitoramento mais detalhado e investigação do histórico de operação nesta parcela.

Em relação à ocorrência de Isópodas (f), observa-se que há uma certa tendência, para os 4 tratamentos, de decréscimo nos valores individuais observados (número total de indivíduos) em função das observações. Esta tendência, revela uma ocorrência destes artrópodes relacionada com o local da coleta, mais concentrados nas parcelas de 1 até 10 do que nas parcelas de 11 a 16 . Esta tendência pode estar associada a maior disponibilidade de água ou de matéria orgânica no solo nesta região, muito embora, a homogeneidade do comportamento da distribuição dos indivíduos corrobore a aleatoriedade dos dados (comportamentos semelhantes das curvas).

Para a ocorrência das, observa-se uma relação entre o aumento da média e também da dispersão dos dados no tratamento $3\left(300 \mathrm{~m}^{3} \mathrm{ha}^{-1} \mathrm{dia}^{-1}\right)$. Este fato pode estar associado ao condicionamento do solo para esta classe de animais em função da introdução de água e matéria orgânica no solo. Já para os Enquitreídeos, as observações com maior média e dispersão dos dados ocorreram para o tratamento $2\left(200 \mathrm{~m}^{3} \mathrm{ha}^{-1} \mathrm{dia}^{-1}\right)$, o que pode estar associado, além dos níveis ótimos para a ocorrência da espécie neste tratamento, com o aumento da acidez potencial, sobretudo no tratamento 3 , o que explicaria médias menores deste tratamento do que no tratamento 2 .

\section{CONCLUSÃO}

Conclui-se deste trabalho que o controle estatístico de qualidade pode ser utilizado como ferramenta para a observação do desvio de processos em sistemas de irrigação com efluente de abatedouro de aves, utilizando para tanto os índices ecológicos e indicadores biológicos. Além disso, conclui-se que os gráficos de controle de Shewhart podem fornecer um panorama geral do experimento ou da operação destes sistemas, indicando comportamentos tendenciosos dos dados relacionados à irrigação e pontos fora de controle, que podem consistir falhas de operação ou causas especiais de variação, como variações na qualidade do efluente ou na taxa de irrigação.

\section{AGRADECIMENTOS}

Agradeço à UTFPR - Programa de Pós-Graduação em Tecnologias Computacionais para o Agronegócio e ao Instituto Politécnico de Bragança, Portugal (IPB) pelo apoio a pesquisa, à Cooperativa Agroindustrial Lar pelo suporte e apoio técnico na pesquisa e à Capes e Fundação Araucária pelo apoio financeiro.

\section{REFERÊNCIAS}

FRIGO, J. P. Controle do processo da irrigação no sistema de aspersão convencional em Palotina - PR. Dissertação de Mestrado (Mestrado em Engenharia Agrícola) - Universidade Estadual do Oeste do Paraná, Cascavel - PR, 2012.

HERMES, E.; ANTONIO, M.; BOAS, V.; RODRIGUES, L. N.; MELO, E. L. De. Process capacity index in drip irrigation with cassava wastewater processing. African Journal of Agricultural Research, v. 10, n. 12, p. 1427-1433, 2015.

JUCHEN, C. R.; SUSZEK, F. L.; BOAS, M. A. V. Irrigação por gotejamento para produção de alface fertirrigada com águas residuárias agroindustriais. Irriga, Botucatu - SP, v. 18, n. 2, p. 243-256, 2013.

MATSUMOTO, L.S.; MARQUES, R.D. Bioindicadores de Qualidade do Solo. IV Reunião Paranaense de Ciência de Solo, 2015, Cascavel, PR. 
MELO, R. P.; ALBIERO, D.; PRACIANO, A. C.; CAVALCANTE, E. S.; FERNANDES, F. R. B. Análise do controle de qualidade de um terraceador trabalhando em um argissolo vermelho amarelo. Brazilian Journal of Biosystems Engineering, v. 10, n. 2, p. 210-216, 2016.

MOAMENI A, ZINCK JA. Application of statistical quality control charts and geostatistics to soil quality assessment in a semi-arid environment of south-central Iran. International Institute for Aerospace Survey and Earth Sciences (ITC), Enscnede, p. 1-26., The Netherlands. 2013.

MONTGOMERY, D. C. Introdução ao controle estatístico da qualidade. 7.ed. Rio de Janeiro: LTC, 2016. $528 \mathrm{p}$.

SANTOS, V. M.; MAIA, Leonor C. Bioindicadores De Qualidade Do Solo. Anais da Academia Pernambucana de Ciência Agronômica, v. 10, p. 195-223, 2013.

Disponível em: <http://www.journals.ufrpe.br/index.php/apca/article/viewFile/397/349>.

SILVA, K.; SILVE JÚNIOR, B.; BATISTA, M.J.; OLIVEIRA, R.; SANTOS, D. B., BARBOSA FILHO, S. Desempenho de gotejadores operando com efluente da castanha de caju sob distintas pressões de serviço.

Revista Ceres, Viçosa - MG, v. 60, n. 3. P. 339-346, 2013.

ZERBATO, C.; FURLANI, C. E. A.; DA SILVA, R. P.; VOlTARElli, M. A.; SANTOS, A. F. Dos. Statistical Control of Processes Aplied for Peanut Mechanical Digging in Soil Textural Classes. Journal of the Brazilian Association of Agricultural Engineering Universidade Estadual Paulista Agríc, v. 37, n. 2, p. 315322, 2017.
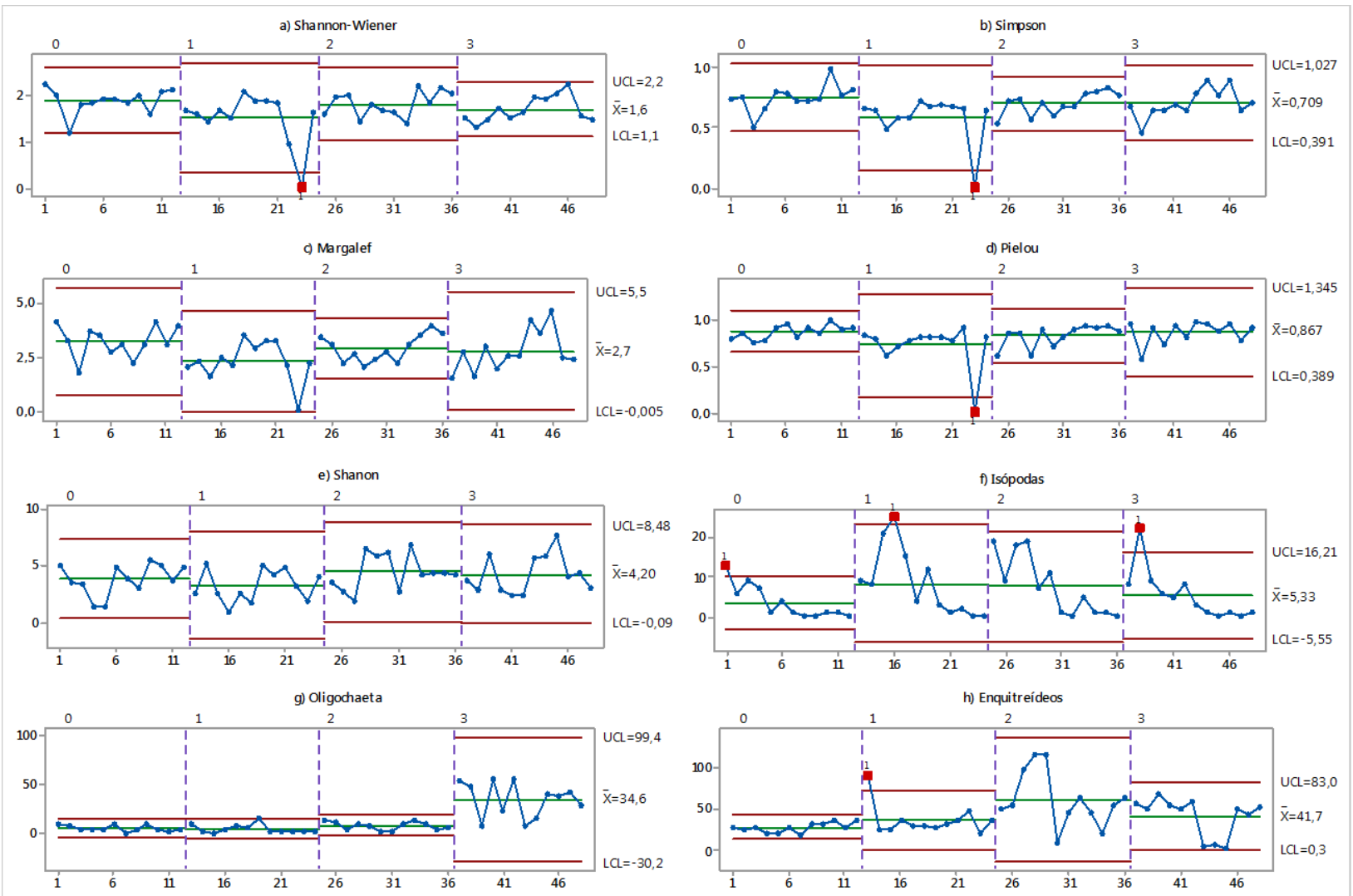

Figura 1. Gráficos de controle de Shewhart para valores individuais dos índices ecológicos de (a) Shannon-

Wierner, (b) Simpson, (c) Margalef, (d) Pielou, (e) Shannon e para os números de indivíduos dos bioindicadores (f) Isópodas, (g) Oligochaetas e (h) Enquitreídeos, considerando os 4 tratamentos aplicados: taxas de aplicação de efluentes de (0) $0 \mathrm{~m}^{3} \mathrm{ha}^{-1} \mathrm{dia}^{-1}$, (1) $100 \mathrm{~m}^{3} \mathrm{ha}^{-1} \mathrm{dia}^{-1}$, (2) $200 \mathrm{~m}^{3} \mathrm{ha}^{-1} \mathrm{dia}^{-1} \mathrm{e} \mathrm{(3)} 300 \mathrm{~m}^{3} \mathrm{ha}^{-}$ ${ }^{1} \mathrm{dia}^{-1}$. 


\title{
ESTIMATIVA DE NITROGÊNIO, FÓSFORO E POTÁSSIO EM DEJETO LÍQUIDO DE SUÍNOS VIA DENSIDADE E MATÉRIA SECA
}

\author{
Vedovato, M. ${ }^{1}$; Soares, M.T.S. ${ }^{2}$; Maeda, S. $^{2}$ \\ ${ }^{I}$ Graduando em Engenharia Florestal, Universidade Federal do Paraná \\ ${ }^{2}$ Engenheiros Agrônomos, Doutores, Pesquisadores da Embrapa Florestas, PR \\ mariovdias96@gmail.com
}

\begin{abstract}
RESUMO: O conhecimento da composição química de dejetos tratados é condição fundamental para a definição de doses, formas e épocas de sua aplicação como biofertilizantes, evitando-se desequilíbrios nutricionais no sistema solo-planta e transferências dos nutrientes em excesso para cursos d'água e, ou atmosfera. Este trabalho teve por objetivo caracterizar a variabilidade de dejeto líquido de suíno tratado (DLS) aplicado a campo em quanto aos teores de nitrogênio $(\mathrm{N})$, fósforo $(\mathrm{P})$ e potássio $(\mathrm{K})$ por meio de métodos de determinação indireta via matéria seca a $60^{\circ} \mathrm{C}$ ("MS60") e pela densidade obtida pelo densímetro de Bouyoucos ("Dbouyoucos"). Amostras de DLS foram obtidas do sistema de lagoas de estabilização que atende a granjas suinícolas de cria (creche) da Fazenda Piquiri, pertencente à Cooperativa Agroindustrial C.Vale, localizada no município de Assis Chateaubriand (PR). Os teores de N, P e K foram estimados por meio de modelos matemáticos a partir dos valores de MS60 e Dbouyoucos. Embora o DLS tenha apresentado pequenas variações quanto aos teores de MS60, este parâmetro possibilitou uma boa aproximação das concentrações de $\mathrm{N}$ e $\mathrm{P}$ obtidos por determinação analítica. As estimativas dos nutrientes pelo densímetro "Bouyoucos" foram muito inferiores àquelas obtidas via MS60, indicando que seu uso requer certa cautela para fins de ajustes de adubação a campo.
\end{abstract}

Palavras-chave: manejo de resíduos, adubação orgânica, suinocultura.

\section{ESTIMATION OF NITROGEN, PHOSPHORUS AND POTASSIUM IN TREATED PIG SLURRY BY DENSITY AND DRY MATTER}

\begin{abstract}
The knowledge of the chemical composition of treated wastes is a fundamental condition for the definition of doses, forms and times of their application as biofertilizers, avoiding nutritional imbalances in the soil-plant system and transfers of excess nutrients to water courses and, or atmosphere. The objective of this work was to characterize the variability of treated pig slurry (PS) in terms of nitrogen (N), phosphorus (P) and potassium $(\mathrm{K})$ levels through indirect dry matter determination method ("DM60") and by the Bouyoucos densimeter (("Dbouyoucos"). PS samples were obtained from the stabilization ponds system at Piquiri Farm, belonging to the Cooperativa Agroindustrial C.Vale, located in the municipality of Assis Chateaubriand (PR). The N, P and K contents were estimated using mathematical models from DM60 and Dbouyoucos values. Although the PS showed small variations in the DM60 content, this parameter allowed a good approximation of the concentrations of $\mathrm{N}$ and $\mathrm{P}$ obtained by analytical determination. The estimates of nutrients by the "Bouyoucos" densimeter were much lower than those obtained via DM60, indicating that their use requires some caution for field fertilization adjustments.
\end{abstract}

Keywords: waste management, organic fertilization, swine production

\section{INTRODUÇÃO}

Os dejetos líquidos de suínos (DLS) brutos e tratados são constituídos basicamente por fezes, urina e restos de ração contido nas esterqueiras (Miyazawa e Barbosa, 2015), podendo apresentar grande heterogeneidade em sua composição por fatores diversos, tais como o tipo de criação (creche, engorda, terminação, etc), o tipo de tratamento adotado (esterqueiras, biodigestores, lagoas de estabilização) e as condições ambientais aos quais foram submetidos. O conhecimento da composição química do dejeto é condição fundamental para a definição de doses, formas e épocas de aplicação de biofertilizantes, evitando-se desequilíbrios nutricionais no sistema solo-planta e transferências dos nutrientes em excesso para cursos d'água e, ou via emissões atmosféricas. A fim de tornar mais prático o monitoramento da qualidade de dejetos líquidos suínos para uso como biofertilizante, são utilizados métodos de determinação simples e rápido para a obtenção da qualidade fertilizante do esterco líquido de suínos (Scherer et al., 1995; Miyazawa; Barbosa, 2015; 
Pauletti \& Motta, 2017). Este trabalho teve por objetivo caracterizar a variabilidade do DLS aplicado a campo em condições experimentais quanto aos teores de nitrogênio, fósforo e potássio por meio de métodos de determinação indireta via matéria seca a $600 \mathrm{C}$ e pela determinação da densidade pelo densímetro de Bouyoucos.

\section{MATERIAL E MÉTODOS}

O dejeto líquido de suíno tratado (DLS) foi obtido do sistema de lagoas de estabilização em série que atende a granjas suinícolas de cria (creche) da Fazenda Piquiri, pertencente à Cooperativa Agroindustrial C.Vale, localizada no município de Assis Chateaubriand (PR), Bacia Hidrográfica do Rio Piquiri. Entre os dias 14 e 15 de agosto de 2018 foram obtidas, diretamente do tanque de transporte, antes da aplicação no solo, seis amostras de DLS em horários distintos. Uma parte foi reunida em uma amostra composta, que foi encaminhada ao Laboratório AQ3 em Cascavel (PR), para determinação dos teores de sólidos totais conforme APHA (2012) e dos teores de nitrogênio, fósforo e potássio totais conforme APHA (2017). Uma outra parte foi identificada, armazenada em gelo, conduzida e mantida no Núcleo de Solos e Ciclos Biogeoquímicos da Embrapa Florestas até análises. Em laboratório cada uma das amostras, após retornar à temperatura ambiente, foi transferida para provetas de $1000 \mathrm{ml}$ para determinação da densidade utilizando o densímetro de vidro "BOUYOUCOS" ("DBouyoucos"), escala 0 a $60 \mathrm{~g} / \mathrm{L}$ (BOUYOUCOS, 1962). A leitura da densidade foi realizada após estabilização do líquido, conforme indicado em Miyazawa; Barbosa (2015). Para a determinação da matéria seca a $60^{\circ} \mathrm{C}$, cada amostra foi dividida em três sub-amostras de $200 \mathrm{ml}$ em Becker de $500 \mathrm{ml}$, que foram pesadas em balança de precisão e levadas à estufa a $60^{\circ} \mathrm{C}$ até peso constante. As estimativas de nitrogênio, fósforo e potássio a partir de "DBouyoucos" foram realizadas conforme Pauletti \& Motta (2017). Os mesmos nutrientes foram também estimados a partir de MS60 conforme as equações propostas por Scherer et al. (1995) e Miyazawa; Barbosa (2015), apresentadas na Tabela 1. Os dados obtidos e os parâmetros estimados foram submetidos à análise descritiva; a variação de MS60 nos diferentes horários de amostragem foi verificada pela análise de variância (ANOVA) seguida do teste de médias (Tukey) a 5\% de probabilidade. Os parâmetros estimados foram comparados com os resultados analíticos emitidos pelo Laboratório AQ3.

\section{RESULTADOS E DISCUSSÃO}

Pode ser verificado pelo teste de médias pequena variação na composição do DLS amostrado, com teores médios de matéria seca do DLS a $60^{\circ} \mathrm{C}$ (MS60) entre 39,47 e 54,67 g L L A obtenção da maior concentração de MS60 no meio da tarde (Am.4, Tabela 2), pode estar relacionada ao processo de fermentação verificado no interior do tanque de armazenamento, estimulado pelo ambiente anaeróbico dentro do reservatório, bem como em reflexo as elevadas temperaturas entre o final da manhã e meio da tarde. O valor médio de MS60 foi um pouco superior ao teor de sólidos totais (ST), que também corresponde ao material remanescente após a remoção da água do dejeto por evaporação (Tabela 2). A densidade média pelo hidrômetro de Bouyoucos foi de 14,68 g L-1 (entre 11,50 e 21,00 $\mathrm{g} \mathrm{L}^{-1}$ ), que corresponderia a valores médios de $\mathrm{N}_{2} \mathrm{P}_{2} \mathrm{O}_{5}$ e $\mathrm{K}_{2} \mathrm{O}$ totais de $1,53,1,16 \mathrm{e} 0,65 \mathrm{~g} \mathrm{~L}^{-1}$, muito inferiores àqueles determinados por via analítica (Tabela 2). Miyazawa \& Barbosa (2015) estimam que o método pode resultar em erros na obtenção da concentração de nutrientes entre $10 \%$ e $40 \%$ dos valores reais, conforme o tempo de estabilização do DLS e alteração de qualidade devido a entrada de água da chuva.

As estimativas dos teores de $\mathrm{N}, \mathrm{P}_{2} \mathrm{O} 5$ e $\mathrm{K}_{2} \mathrm{O}$ a partir dos valores de MS60 estão apresentadas na Tabela 2. Os teores médios de $\mathrm{N}$ obtidos pelas equações propostas por Scherer et al. (1995) e Miyazawa; Barbosa (2015) estão muito próximos do $\mathrm{N}$ total determinado por via analítica $(95 \%$ e $97 \%$, respectivamente do $\mathrm{N}$ obtido via análise química). O teor médio de $\mathrm{P}_{2} \mathrm{O}_{5}$ obtido conforme a equação proposta por Scherer et al. (1995) esteve mais próximo do obtido pelo resultado analítico, correspondendo a $89 \%$ deste último. O teor médio de $\mathrm{K}_{2} \mathrm{O}$ estimado, por outro lado, apresentou valores $55 \%$ superiores aos obtidos por determinação analítica. Diferentemente do $\mathrm{N}$ e P, o K é encontrado quase todo na forma iônica no DLS, oriundo da urina animal e estando pouco relacionado, portanto, à fração particulada do resíduo (Scherer et al., 1995).

\section{CONCLUSÃO}

Embora o DLS aplicado a campo tenha apresentado pequenas variações quanto aos teores de matéria seca a $60^{\circ} \mathrm{C}$, este parâmetro possibilitou uma boa aproximação das concentrações de nitrogênio e fósforo obtidas por determinação analítica. As estimativas dos nutrientes pelo densímetro "Bouyoucos" foram muito 


\section{VISIGERÂ DEF7A A9 MA1 2019

inferiores àquelas obtidas via MS60, indicando que seu uso requer certa cautela para fins de ajustes de adubação a campo.

\section{AGRADECIMENTOS}

Ao Projeto Bioeste Florestas, uma parceria da Embrapa Florestas, Itaipu Binacional, CIBiogas e Funpar. À CVale pela parceria e apoio de campo. Ao CNPq pela concessão da bolsa.

\section{REFERÊNCIAS}

American Public Health Association (APHA), American Water Works Association (AWWA), Water Environment Federation (WEF) Standard Methods for the Examination of Water and Wastewater (23 Ed.), APHA, AWWA, WEF, United States, 2017.

American Public Health Association (APHA), American Water Works Association (AWWA), Water Environment Federation (WEF) Method 2540 B. In: Standard Methods for the Examination of Water and Wastewater (22 Ed.), APHA, AWWA, WEF, United States, 2012.

BOUYOUCOS, G.J. Hydrometer Method Improved for Making Particle Size Analysis of Soils. Agronomy Journal, 54, 464-465, 1962.

MIYAZAWA, M.; BARBOSA, G. M. Dejeto líquido de suíno como fertilizante orgânico: método simplificado. Londrina: Iapar, 2015. Disponível em: <http://www.iapar.br/arquivos/File/banner\%20pequeno/ dejeto_suinoa.pdf>. Acesso em: 13.nov.2018.

SCHERER, E. E., BALDISSERA, I. T., \& DIAS, L. X. (1995). Potencial fertilizante do esterco líquido de suínos da região oeste catarinense. Agropecuária Catarinense, v.8, p. 35-39.

Tabela 1. Funções utilizadas para estimativa dos teores de nitrogênio, fósforo e potássio a partir dos teores de matéria

\begin{tabular}{|c|c|c|c|c|c|c|c|}
\hline \multirow{2}{*}{$\begin{array}{l}\text { Teores totais } \\
\left(\mathrm{g} \mathrm{L}^{-1}\right)\end{array}$} & \multicolumn{4}{|c|}{ Fatores } & \multirow{2}{*}{ Cálculo $\left(\mathrm{g} \mathrm{l}^{-1}\right)$} & \multirow{2}{*}{ Autores } & \multirow{2}{*}{ Obs. } \\
\hline & $F_{1}$ & $\mathbf{F}_{2}$ & $F_{3}$ & $\mathbf{F}_{4}$ & & & \\
\hline $\mathrm{N}$ & MS $60^{\circ} \mathrm{C}$ & 0,668 & 0,670 & - & {$\left[\left(F_{1} / 10\right) \times F_{2}\right]+F_{3}$} & Scherer et & $\operatorname{Pg} 38$ \\
\hline $\mathrm{P}_{2} \mathrm{O}_{5}$ & " & 0,709 & 0,220 & - & {$\left[\left(\mathrm{F}_{1} / 10\right) \times \mathrm{F}_{2}\right]+\mathrm{F}_{3}$} & al. (1995) & $\operatorname{Pg} 39$ \\
\hline $\mathrm{N}$ & $\operatorname{MS} 60^{\circ} \mathrm{C}$ & 0,086 & $-0,078$ & - & $\left(F_{1} \times F_{2}\right)+F_{3}$ & Miyazawa; & Pg 17 \\
\hline $\mathrm{P}_{2} \mathrm{O}_{5}$ & “ & 0,029 & $-0,040$ & 2,29136 & {$\left[\left(F_{1} \times F_{2}\right)+F_{3}\right] \times F_{4}$} & Barbosa & $\operatorname{Pg} 20$ \\
\hline $\mathrm{K}_{2} \mathrm{O}$ & “ & 0.027 & 0,043 & 1,20458 & {$\left[\left(\mathrm{~F}_{1} \times \mathrm{F}_{2}\right)+\mathrm{F}_{3}\right] \times \mathrm{F}_{4}$} & (2015) & Pg. 21 \\
\hline
\end{tabular}

Tabela 2. Matéria seca a $60^{\circ} \mathrm{C}$, densidade e estimativas dos teores totais de nitrogênio, fósforo e potássio $\left(\mathrm{g} \mathrm{L}^{-1}\right)$ nos dejetos líquidos de suínos tratados.

\begin{tabular}{|c|c|c|c|c|c|c|c|c|}
\hline \multirow[t]{3}{*}{ Am. } & \multirow[t]{3}{*}{ Data e hora } & \multicolumn{2}{|c|}{$\operatorname{MS} 60^{\circ} \mathbf{C}^{(1)}$} & \multicolumn{2}{|c|}{---- $\mathbf{N}^{(2)}$} & \multicolumn{2}{|c|}{ 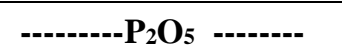 } & \multirow[t]{2}{*}{$\mathbf{K}_{2} \mathbf{O}$} \\
\hline & & & & \multicolumn{4}{|c|}{ - } & \\
\hline & & & & (3) & (4) & (3) & (4) & (4) \\
\hline 1 & $14 / 08,08: 45$ & 46,75 & $\mathrm{~b}$ & 3,79 & 3,94 & 3,53 & 3,01 & 1,57 \\
\hline 2 & 14/08, 09:55 & 40,65 & $\mathrm{~b}$ & 3,38 & 3,42 & 3,10 & 2,61 & 1,37 \\
\hline 3 & $14 / 08,13: 20$ & 47,30 & $a b$ & 3,82 & 3,99 & 3,57 & 3,05 & 1,59 \\
\hline 4 & $14,08,15: 30$ & 54,65 & a & 4,31 & 4,62 & 4,09 & 3,54 & 1,83 \\
\hline 5 & $14 / 08,16: 10$ & 39,45 & $\mathrm{~b}$ & 3,30 & 3,32 & 3,02 & 2,53 & 1,33 \\
\hline 6 & $15 / 08,10-11: 00$ & 47,85 & $a b$ & 3,86 & 4,04 & 3,61 & 3,08 & 1,61 \\
\hline Média & & 46,12 & & 3,75 & 3,89 & 3,49 & 2,97 & 1,55 \\
\hline AQ3 & & - & & 4,03 & & 3,90 & & 1,01 \\
\hline
\end{tabular}

(1) Médias seguidas pelas mesmas letras não apresentam diferença segundo teste de Tukey a 5\%.

(2) Parâmetros obtidos pela relação entre matéria seca e teores de nutrientes conforme equações propostas por (3) Scherer et al. (1995) e (4) Miyazawa; Barbosa (2015). 


\title{
REDUÇÃO DA EMISSÃO DE GEE ATRAVÉS DA COMPOSTAGEM EM UMA FÁBRICA DE PROCESSAMENTO MÍNIMO DE HORTALIÇAS
}

\author{
Paiva, V.M.*1; Inácio, C.T. ${ }^{2}$ \\ ${ }^{1}$ Mestrando Universidade Federal do Rio de Janeiro - PEA/UFRJ \\ ${ }^{2}$ Pesquisador da Embrapa Solos, Rio de Janeiro, RJ, Brasil. \\ vinicius_paiva@poli.ufrj.br
}

\begin{abstract}
RESUMO: Uma preocupação que a agroindústria de processamento mínimo de vegetais enfrenta é a grande quantidade de resíduos orgânicos gerados, uma vez que grandes geradores são responsáveispela destinação final dos mesmos conforme exigências ambientais e legais. A compostagem é um processo aeróbico para tratamento de resíduos orgânicos com baixa emissão de metano, o que demonstra um alto potencial na mitigação de emissões de gases de efeito estufa (GEE). No Brasil, o método mais utilizado para destinação final de resíduos sólidos é o descarte em aterros sanitários, no qual ocorre alta emissão de metano. O objetivo deste estudo é estimar e comparar emissões de GEE em diferentes cenários de gerenciamento de resíduos de uma fábrica de processamento mínimo de hortaliças. A metodologia aprovada pela UNFCCC AMS-III.F foi usada para calcular emissões das diferentes destinações finais dos resíduos, incluindo as emissões pelo transporte. Três cenários foram comparados: Aterros sanitários sem e com captura e queima de biogás (cenários linha de base 1 e 2, respectivamente) e Compostagem (cenário de projeto). Foram considerados a geração média diária de resíduos da fábrica, período de 10 anos de geração de resíduos e 20 anos de horizonte de emissões. A compostagem reduziu as emissões em mais de sete vezes se comparada ao aterro sem captura de gás e 3,8 vezes considerando um aterro sanitário com sistema de captura e queima de gás. Nos cenários linha de base, as emissões de CO2 devido ao transporte dos resíduos foram 15,7 vezes maiores em relação ao cenário de projeto.
\end{abstract}

Palavras-chave: Aterro sanitário, compostagem, emissão, GEE, resíduo sólido orgânico.

\section{GHG EMISSION REDUCTION BY COMPOSTING AT A VEGETABLES MINIMAL PROCESSING FACTORY}

\begin{abstract}
A concern that vegetable processing industry has been facing is the large amount of organic waste generated, since large quantity generators of solid wastes are responsible to treat and/or dispose their waste in face to environmental and legal requests. Composting is an aerobic process for organic waste treatment with low methane emission, which shows a high potential of this practice for greenhouse gas (GHG) emission mitigation. In Brazil, the most commonly used method for final destination of solid waste is the disposal in landfills, which emits large amounts of methane. The aim of this study is to estimate and compare the emission of GHG from different final destinations of organic solid waste, composting and landfill disposal, from a vegetable processing factory in Teresopolis, RJ, Brazil. The UNFCCC approved methodology AMSIII.F was used to calculate emissions from the different waste final destinations, including fossil fuel combustion emissions. Three scenarios were compared: Landfill without gas capture; landfill with gas capture (baseline scenarios 1 and 2) and Composting (project scenario). The factory average waste generation is 2.5 tonnes per day. It was used a 10 years period of waste generation and 20 years horizon of emissions. Composting reduced emissions up to more than 7 times if compared to disposal in a landfill without gas capturing and 3.8 times considering a landfill site with gas capturing and flaring system. In Baseline Scenarios $\mathrm{CO} 2$ emissions by fossil fuel combustion was 15.7 times higher in relation to Project Scenario due to waste transportation.
\end{abstract}

Keywords: Composting, GHG Emission, Landfill, Methane, Organic Solid Waste.

\section{INTRODUÇÃO}

Um dos segmentos agroindustriais que vem apresentando crescimento significativo nos últimos anos é o de alimentos minimamente processados. Esses podem ser classificados como frutas e hortaliças em estado fresco que foram descascados, cortados, higienizados e embalados para serem comercializados prontos para o consumo (SILVA et al., 2011). Um dos problemas enfrentados pela indústria de processamento mínimo de 
hortifrutícolas está relacionado à grande quantidade de resíduos orgânicos gerados durante o processo, uma vez que aproximadamente $50 \%$ da matéria prima utilizada é descartada como resíduo. Os estabelecimentos classificados como grandes geradores de resíduos, aqueles que possuem geração diária de 120 litros ou mais, são responsáveis pelo tratamento e/ou disposição final dos mesmos de acordo com exigências legais e ambientais (Prefeitura da Cidade do Rio de Janeiro, 2016).

A compostagem é uma tecnologia utilizada no tratamento de resíduos orgânicos que consiste na degradação da matéria orgânica por meio de um processo biológico, aeróbio e termofílico (Huag, 1993), tendo como resultado final um produto estável, rico em substâncias húmicas e nutrientes, denominado composto orgânico (Inácio; Miller, 2009). Esta técnica, por ser um processo de tratamento aeróbio, emite pequenas quantidades de metano por massa de resíduo tratado quando comparada a processos anaeróbios, como a disposição em aterros, principalmente quando realizada de forma correta e bem manejada (Inácio et al, 2010; Amlinger et al., 2008). Essa prática apresenta um grande potencial de mitigação de emissão de metano e é uma atividade enquadrada dentro do Mecanismo de Desenvolvimento Limpo (MDL) pela Convenção Quadro das Nações Unidas para as Mudanças Climáticas (United Nations Framework Convention on Climate Change UNFCCC).

No Brasil, o método mais utilizado para destinação final de resíduos sólidos é a disposição em aterros sanitários ou em locais sem estrutura adequada (ABRELPE, 2015), que está associado a elevadas taxas de emissão de metano durante o processo de degradação da matéria orgânica.

O objetivo deste estudo é estimar e comparar emissões de GEE em diferentes cenários de gerenciamento de resíduos de uma fábrica de processamento mínimo de hortaliças localizada em Teresópolis, RJ, Brasil.

\section{MATERIAL E MÉTODOS}

Foi realizado estudo de caso em uma empresa de beneficiamento, comercialização e distribuição de hortaliças e legumes minimamente processados. Sua fábrica está localizada no município de Teresópolis, RJ e seus principais clientes são redes de restaurantes e hotéis na cidade do Rio de Janeiro, RJ. Atualmente a empresa realiza a compostagem de seus resíduos orgânicos através da técnica de leiras estáticas com aeração passiva em um pátio localizado no mesmo terreno que a fábrica e utiliza o composto produzido em suas lavouras.

A metodologia de cálculo AMS-III.F (Avoidance of methane emissions through composting) aprovada pela UNFCCC foi utilizada para calcular emissões provenientes de diferentes alternativas de gerenciamento dos resíduos, considerando também a emissão de $\mathrm{CO}_{2}$ pelo transporte dos mesmos em cada caso.

Três cenários foram comparados (Figura 1): Cenário linha de base 1: Disposição dos resíduos orgânicos em aterro sanitário desprovido de sistema de coleta e queima do biogás. Cenário linha de base 2: Disposição dos resíduos orgânicos em aterro sanitário provido de sistema de coleta parcial e queima do biogás (50\% do biogás total produzido); Cenário de projeto: Compostagem dos resíduos orgânicos realizada na unidade de compostagem localizada no terreno da fábrica.

Nos cenários linha de base, para calcular as emissões provenientes do transporte dos resíduos, foram considerados um caminhão movido à diesel e o aterro sanitário da cidade de Nova Friburgo, RJ, uma vez que esse é o aterro mais próximo da fábrica, localizado a 54,2 $\mathrm{km}$ de distância. Para o cenário linha de base 2 , foi considerada eficiencia de coleta de $50 \%$ para o sistema de captura de gases do aterro, tendo como base o valor apresentado em estudo de viabilidade e projeto MDL registrado do aterro sanitário CTR Santa Rosa, em Seropédica, RJ.

De acordo com dados do gerenciamento de resíduos da fábrica, a média diária registrada de geração de resíduos orgânicos é de 2,5 t. Foi utilizado período de 10 anos de geração de resíduos e horizonte de emissões de até 20 anos para aterros sanitários. Todos os dados utilizados para cálculo das emissões foram escolhidos de acordo com as caracteristicas específicas dos resíduos, do aterro sanitário e da compostagem, com base em levantamentos em campo e ferramentas metodológicas disponibilizadas pela UNFCCC.

\section{RESULTADOS E DISCUSSÃO}

As emissões de GEE, expressas em equivalentes de dióxido de carbono (CO2-eq), oriundas da disposição dos resíduos em aterros sanitários é significantemente maior do que as da compostagem. Em 10 anos de geração de resíduos, a compostagem teve uma emissão de GEE total de 963 t $\mathrm{CO}_{2}$-eq, incluindo emissões pela queima de combustível fóssil associado ao processo, e caiu para zero imediatamente após a interrupção da geração de resíduos (Figura 1). 
As emissões de $\mathrm{CO}_{2}$ pela queima de combustível fóssil no processo de compostagem foram de 13,9 t $\mathrm{CO}_{2}$-eq durante todo o período e representou $1 \%$ da emissão total (Tabela 1). Essas emissões ocorrem devido à utilização de equipamentos movidos a óleo diesel, como por exemplo, o trator agrícola utilizado para transportar os resíduos da fábrica até o pátio de compostagem por uma distância de aproximadamente 500 metros e preparar a mistura de restos de hortaliças com cama de cavalo (esterco + serragem) utilizada para alimentar as leiras.

A disposição em aterro sanitário apresentou aumento anual das emissões durante os 10 anos de geração de resíduos e continuou a emitir metano para a atmosfera em uma taxa decrescente após ser encerrada a disposição de resíduos (Figura 1). O cenário linha de base 1 teve uma emissão total de 7.091 t $\mathrm{CO}_{2}$-eq, na qual $5.739 \mathrm{t} \mathrm{CO}_{2}$-eq foram emitidos durante os primeiros 10 anos e mais $1.352 \mathrm{t} \mathrm{CO}_{2}$-eq do ano 11 até o ano 20 , após interrompida a disposição de resíduos (Tabela 1).

No cenário linha de base 2, com a captura e queima do biogás, as emissões representaram aproximadamente metade do cenário linha de base 1 . Isso significa um total de $3.654 \mathrm{t} \mathrm{CO}_{2}$-eq durante 20 anos, com 2.979 t CO 2 -eq sendo emitidos durante anos de geração de resíduos e 676 t $\mathrm{CO}_{2}$-eq após esse período (Tabela 1).

As emissões de $\mathrm{CO}_{2}$ pela combustão do diesel devido ao transporte de resíduos da fábrica para o aterro sanitário de Nova Friburgo foram de 217,9 t CO 2 -eq em 10 anos de geração de resíduos. Esse valor corresponde a 3\% do total de emissões de GEE no cenário linha de base 1 e $6 \%$ no cenário linha de base 2 (Figura 2).

Nos 10 primeiros anos as emissões evitadas pela implementação da compostagem no lugar da disposição em aterros sanitários chegam a 4.776 e 2.016 t $\mathrm{CO}_{2}$-eq, considerando os cenários linha de base 1 e 2 , respectivamente. Se considerarmos as emissões acumuladas de metano no aterro sanitário ao longo do horizonte de 20 anos esses números aumentam para 6.128 t CO2-eq no cenário linha de base 1 e 2.691 t CO2eq no cenário linha de base 2 .

\section{CONCLUSÃO}

A compostagem reduziu as emissões até mais de sete vezes se comparada com a disposição em aterro sanitário sem captura de biogás e 3,8 vezes considerando um aterro sanitário com sistema de captura e queima de gás. Em cenários linha de base, as emissões de $\mathrm{CO}_{2}$ oriundas da combustão de combustíveis fósseis foram 15,7 vezes maiores em relação ao cenário de projeto devido ao transporte de resíduos. Além disso, a compostagem é uma tecnologia de tratamento de resíduos orgânicos bem conhecida e de relativamente baixo custo que tem como produto final o fertilizante orgânico, o que aumenta o potencial de sua aplicação para mitigar as emissões de GEE em sistemas de gerenciamento de resíduos.

\section{REFERÊNCIAS}

ABRELPE (2015). Associação Brasileira de Empresas de Limpeza Pública e Resíduos Especiais. Panorama dos Resíduos Sólidos no Brasil. Disponível em: www.abrelpe.org.br. Acesso em 10/09/2018.

AMLINGER, F., PEYR, S., CUHLS, C. (2008). Greenhouse gas emissions from composting and mechanical biological treatment. Waste Management \& Research 26, 47-60.

HAUG, R.T. (1993). Practical Handbook of Compost Engineering. 2a. Ed. Taylor \& Francis Inc. Boca Raton, Florida.

INÁCIO, C. T., BETTIO, D. B., MILLER, P. R. M. (2010). O Papel Da Compostagem De Resíduos Orgânicos Urbanos Na Mitigação De Emissão De Metano. Rio de Janeiro: Embrapa Solos. 22 p. - Documentos / Embrapa Solos, ISSN 1517-2627; 127

INÁCIO C. T.; MILLER, P. R. M. (2009). Compostagem Ciência e prática para a gestão de resíduos orgânicos. Rio de Janeiro: Embrapa Solos. 156 p.

Prefeitura da Cidade do Rio de Janeiro (2016). Plano Municipal de Gestão Integrada de Resíduos Sólidos da Cidade do Rio de Janeiro. Disponível em:< http://www.rio.rj.gov.br/dlstatic/10112/3035089/DLFE247507. pdf/Plano_Gestao_Integrada_Residuos.pdf >. Acesso em: 10/05/2018.

SILVA, E.O., PINTO, P.M., JACOMINO, A.P., SILVA, L.T. (2011). Processamento Mínimo de Produtos Hortifrutícolas. Fortaleza: Embrapa Agroindústria Tropical. 72p

UNFCCC - United Nations Framework Convention On Climate Change. AMS-III.F.: Avoidance of Methane Emissions through Composting - version 12.0. Disponível em: http://unfccc.int/2860.php. Acesso em: $10 / 05 / 2018$ 
Tabela 4. Emissões por período e fonte.

\begin{tabular}{lccccc}
\hline \multirow{2}{*}{ Cenário } & \multicolumn{4}{c}{ Emissões (t CO2-eq) } & \multirow{2}{*}{ Ano 11 ao 20 } \\
\cline { 2 - 5 } & \multicolumn{2}{c}{ Ano 1 ao 10 (Geração) } & \multicolumn{2}{c}{ Anotal } \\
\cline { 2 - 5 } & Destinação final & Transporte & Destinação final & Transporte & \\
\hline Linha de base 1 & 5.739 & 217,9 & 1.352 & 0 & 7.309 \\
Linha de base 2 & 2.979 & 217,9 & 676 & 0 & 3.872 \\
Projeto & 949 & 13,9 & 0 & 0 & 963 \\
\hline
\end{tabular}

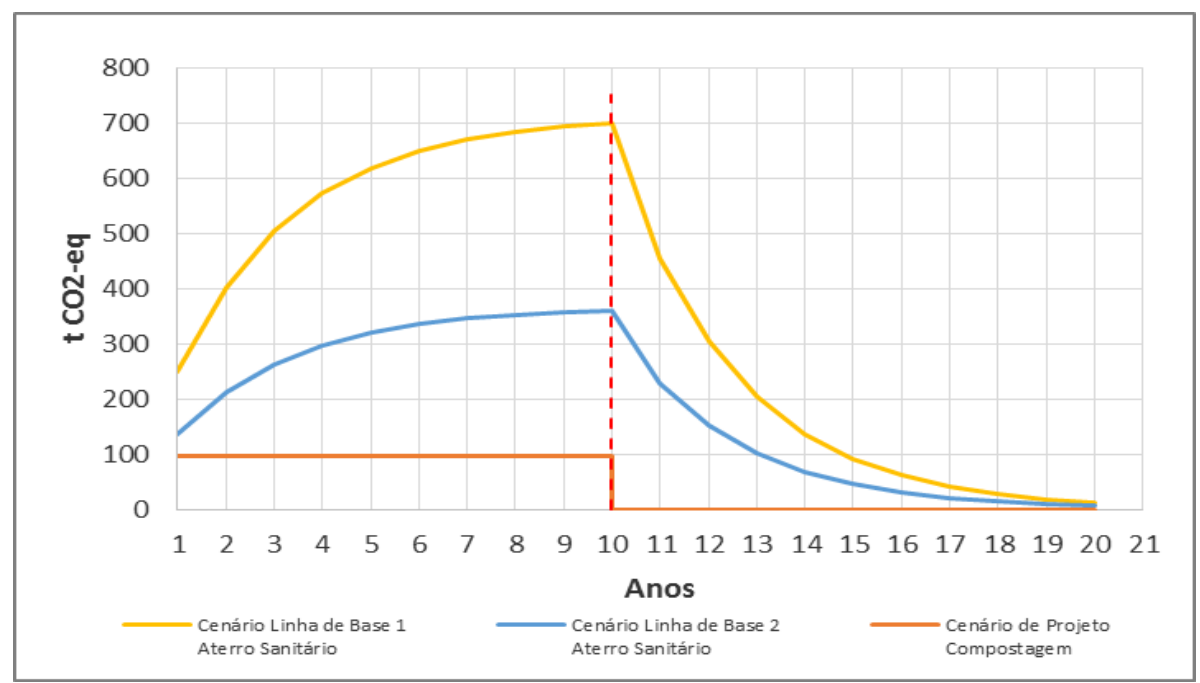

Figura 1. Evolução anual das emissões durante 20 anos para tratamento / disposição anual de 912,5 toneladas de resíduos orgânicos durante 10 anos em três diferentes cenários. Metodologia de cálculo:

AMS.III.F,UNFCCC.

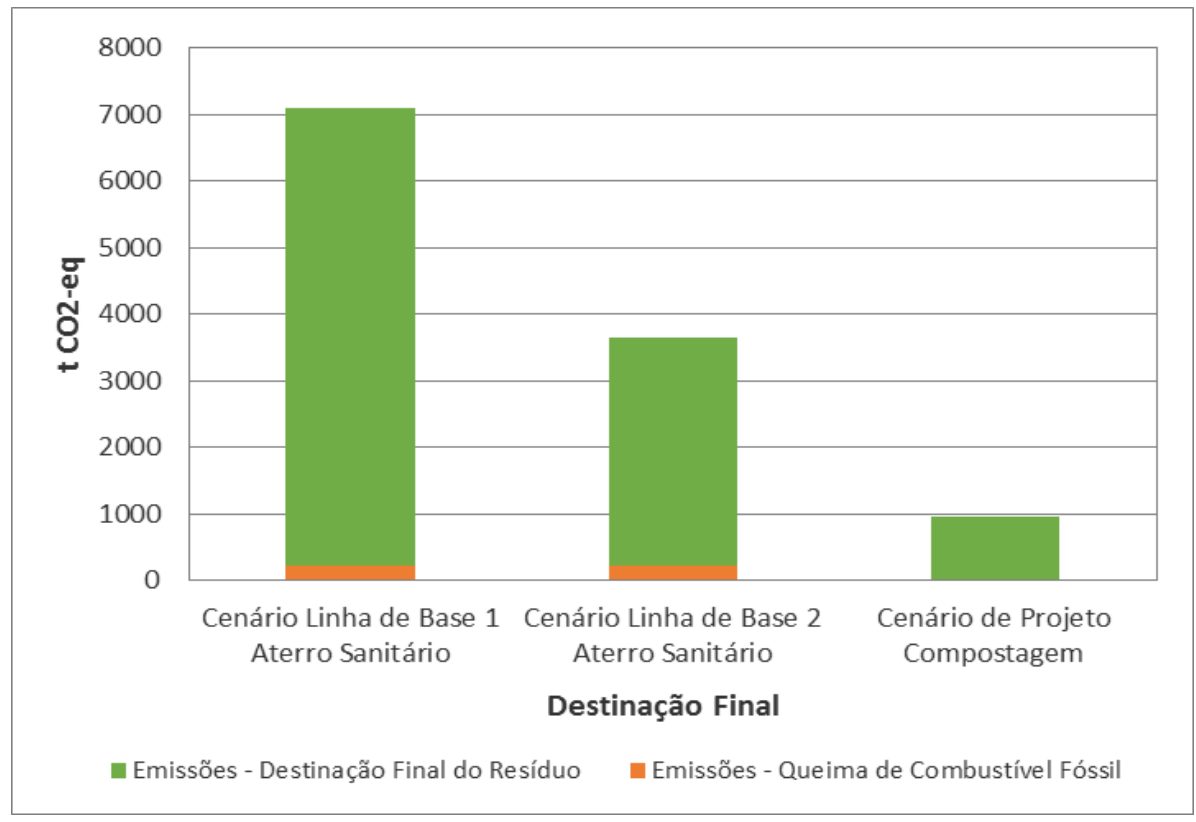

Figura 2. Emissões totais após 20 anos para tratamento / disposição anual de 912,5 toneladas de resíduos orgânicos durante 10 anos em três diferentes cenários, incluindo emissões provenientes da combustão de combustíveis fósseis associadas a cada cenário. 


\title{
Promoção
}

\section{dis}

Sociedade Brasileira dos Especialistas em Residuos

das Produções Agropecuária e Agroindustrial

\section{Co-promoção}

\author{
Embrapa
}

\section{Apoio Institucional}
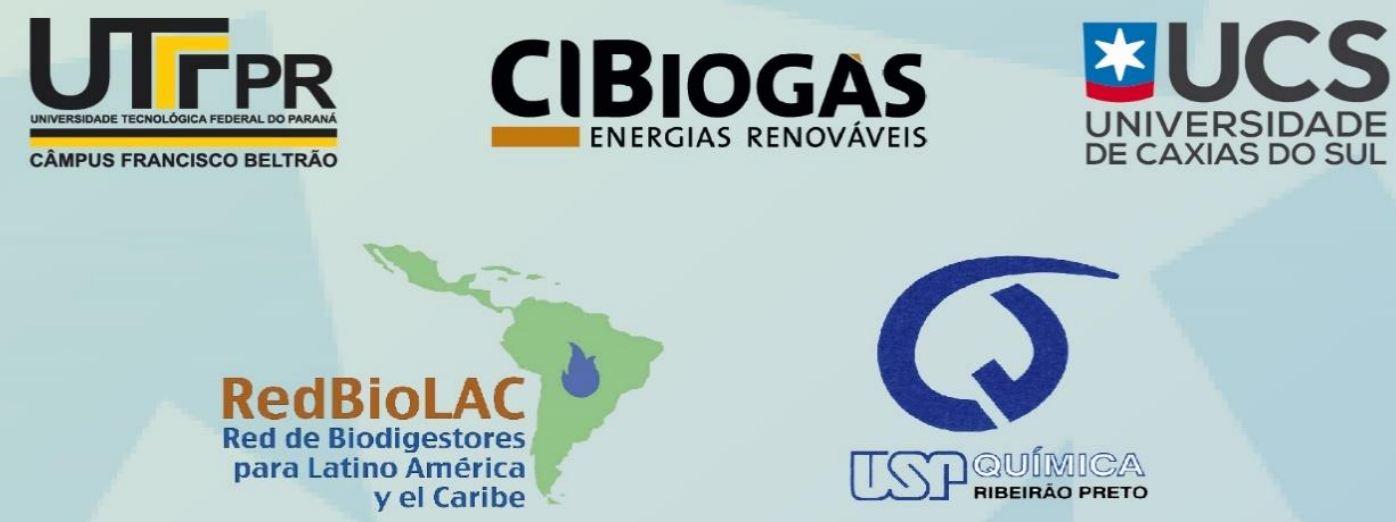

\section{Patrocinadores Ouro}
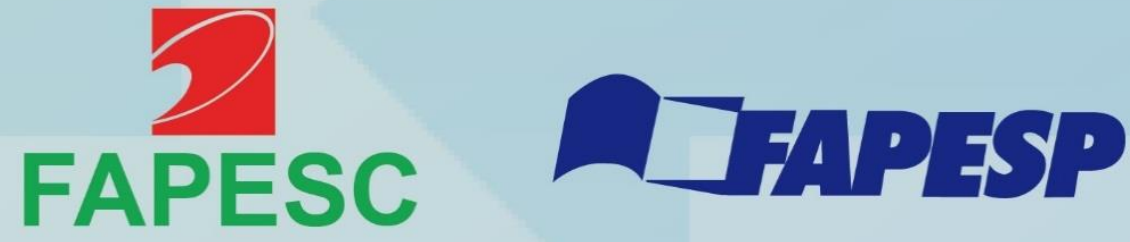

\section{Patrocinadores Bronze}

